Tesis Doctoral:

\title{
MODELO DE DISEÑO DE EDIFICIOS EN ALTURA ENERGÉTICAMENTE EFICIENTES PARA CENTROS URBANOS DE ALTA DENSIDAD
}
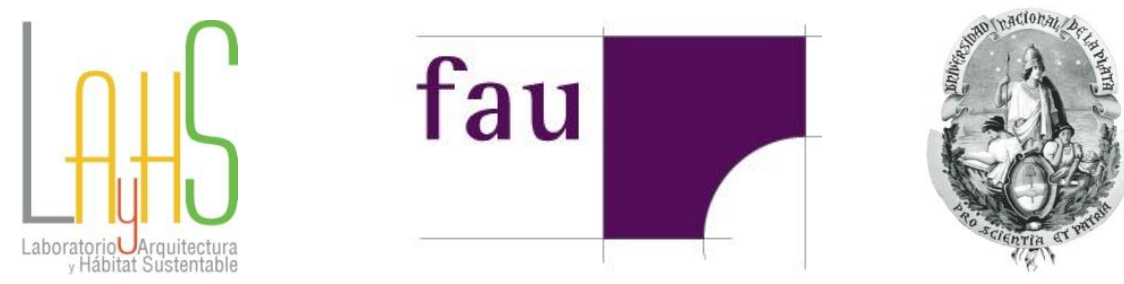

Universidad Nacional de La Plata - Facultad de Arquitectura y Urbanismo

Para la obtención del grado de Doctora en Arquitectura y Urbanismo

Por Arq. María Belén Salvetti

Dr. Ing Jorge D. Czajkowski, director de Tesis.

Arq. Analía Gómez, co-directora de Tesis.

La Plata, Septiembre de 2015. 


\section{AGRADECIMIENTOS}

Quisiera agradecer principalmente a mi familia. A mis padres Antonio y Catalina que me han brindado su confianza y apoyo en cada una de las decisiones que he tomado, y que me han dado su ejemplo de vida. A mi he rmano Luciano, a mi c uñada A na y a s us hijos Silvano, Carmelo y Vicente que son y serán siempre mi cable a tierra.

Agradezco también a mis directores el Dr. Jorge Czajkowski y la Arq. Analía Gómez por poner su confianza en mí, y a cada uno de los integrantes del LAyHS, especialmente a mis queridas amigas Paz Diulio, Mariela M arcilese, Cristina García Toral y Carolina Vagge por los buenos momentos compartidos dentro y fuera del LAyHS. Agradezco al Dr. Juan Etulain, director del Doctorado. A todo el grupo de docentes del Taller de Arquitectura BBC de la FAU - UNLP por darme un espacio en su Cátedra y especialmente al Profesor Alejandro Casas por b rindarme siempre su apoyo y su confianza. Agrade zco al Dr. Julio D urán y al Arq. Is amel Eyras con quienes tu ve la posibilidad de compartir un trabajo muy enriquecedor en lo personal y en lo profesional, en el Marco del Proyecto PICTO 2010-0087.

Agradezco a las Autoridades de la ANPCyT, del CONICET y de la Fundación Erasmus Mundus por otorgarme las becas que me permitieron cumplir con esta meta.

Agradezco a Cecilia Lorenz etti de la Uni dad d e R elaciones In ternacionales de la UN LP, a Geraldine Bustamante Reyes y a Begoña Lluzar de la O ficina de Acción Internacional de la UPV por ayudarme antes, durante y después de mi estancia en Valencia, en lo que fue para mí una experiencia muy enriquecedora tanto en lo personal como en lo académico.

Agradezco a todos los profesores de los diversos cursos de posgrado a los que asistí durante los años ded icados al av ance de esta Te sis y a cada u no de los compañeros con los que compartí importantes horas de mi vida, en e special a aquellos compañeros y amigos de la Maestría en Energías Renovables de la UNSa - Salta, del Curso USE Efficiency en La Ciudad Politécnica de la Innovación de la UPV y de los Másteres en Arquitectura Avanzada, Paisaje, Urbanismo y Diseño, y en Tecnología para el Desarrollo Sostenible de la UPV - Valencia, con quienes además compartí muy gratos momentos fuera de las horas de clase.

Quisiera agradecer muy es pecialmente al Prof. $J$ osé Miguel C orberán por s u apoy o y dedicación dura nte mi es tancia en Valenc ia y a todo el grup o de tr abajo del In stituto de Ingeniería Energética, especialmente al Prof. Man uel Alcazar Ortega por su colaboración con las asignaturas Mercados Energéticos y Auditoría Energética. 
También quisiera agradecer a la $\mathrm{P}$ rof. $\mathrm{S}$ onja $\mathrm{S}$ chelbach por i nteresarse en mi trabaj o e invitarme a participar d el RE AP Workshop "S ustainability and Urban Regeneration Transformation of an old factory site in Guimarães" en la Universidad de Hamburgo.

Agradezco tamb ién al gr upo de becarios e in vestigadores que conocí du rante lo s div ersos congresos a los que asistí, especialmente los de ASADES, y a los integrantes del Subcomité de Acondicionamiento Térmico de IRAM por darme un lugar en sus debates.

Finalmente también quisiera agradecer a mis amigos, esos que es tán siempre y con los que compartí grandes momentos de mi vida mucho antes de empezar esta Tesis, y los tantos otros que supe hacer en medio de tantas idas y venidas que significaron estos años de experiencia. Lamento $\mathrm{n}$ o poder $\mathrm{m}$ encionarlos a $\mathrm{t}$ odos pero para ellos también $\mathrm{v}$ a es te agra decimiento porque son una parte importante de mi vida, como mi familia. 


\section{ÍNDICE}

TíTULO

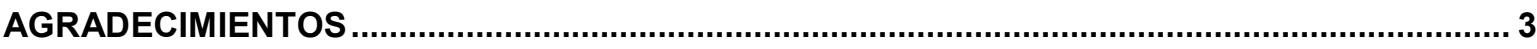

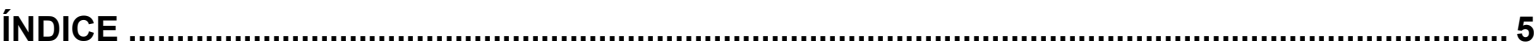

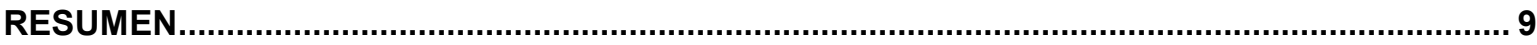

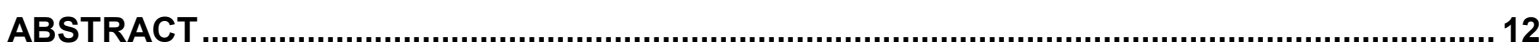

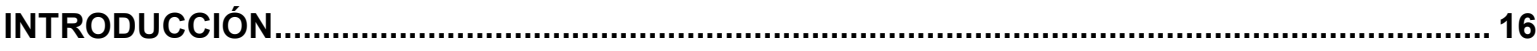

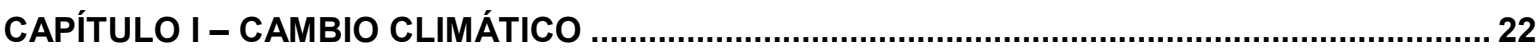

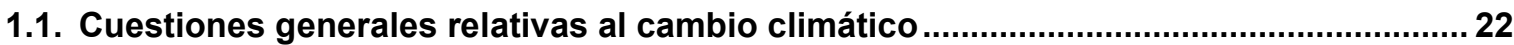

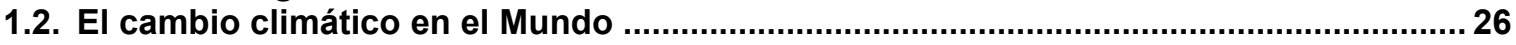

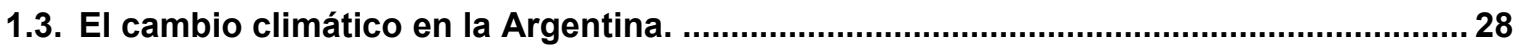

1.4. Los centros urbanos y su influencia en el cambio climático...........................................32

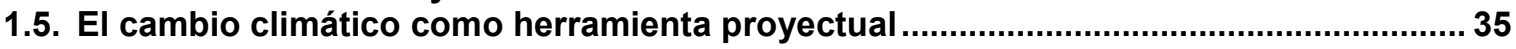

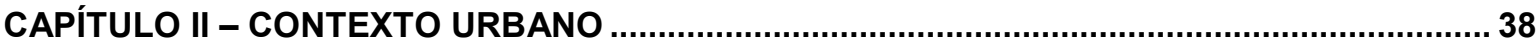

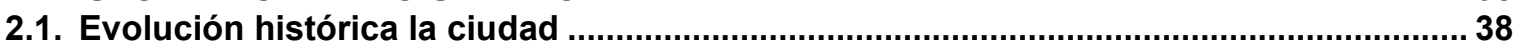

2.2. El desarrollo del Área Metropolitana de Buenos Aires ..................................................... 47

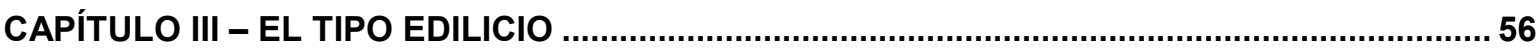

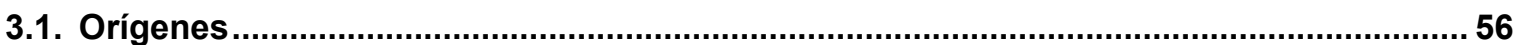

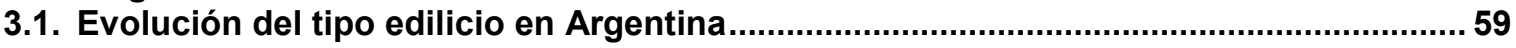

CAPÍTULO IV - NORMATIVA Y LEGISLACIÓN APLICADA A EDIFICIOS ....................................65

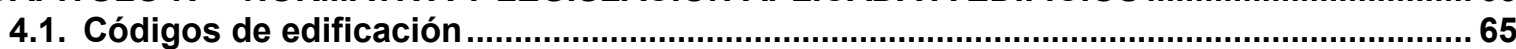

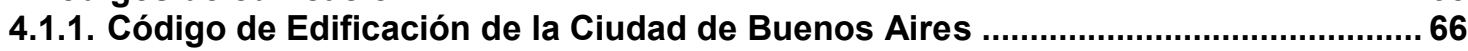

4.1.2. Código de Edificación de la Ciudad de La Plata ....................................................68

4.1.3. Código de Técnico de la Edificación de España.....................................................68

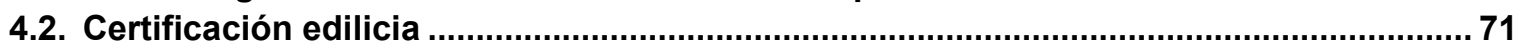

4.2.1. LEED

4.2.2. BREAM

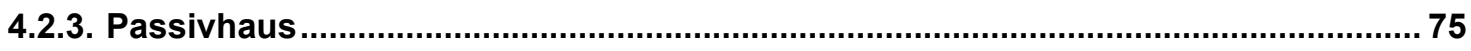




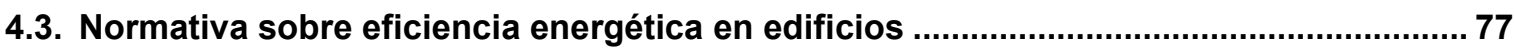

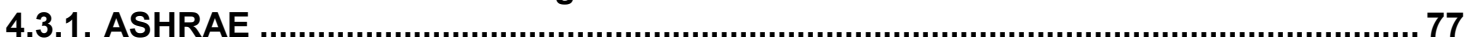

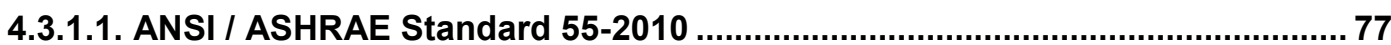

4.3.1.2. ANSI / ASHRAE / USGBC /IES - Standar 189.1-2009 ................................... 79

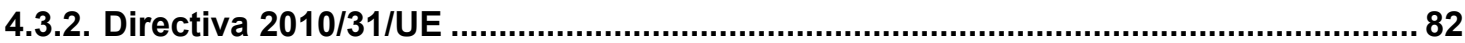

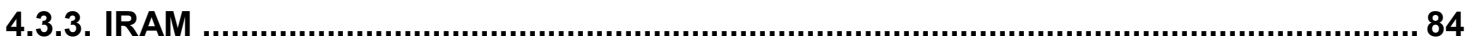

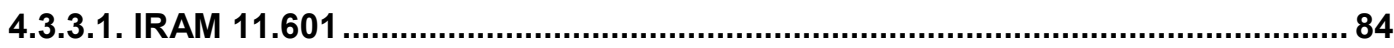

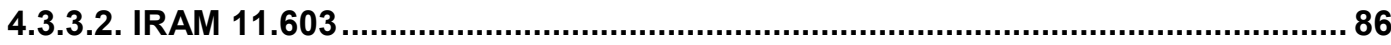

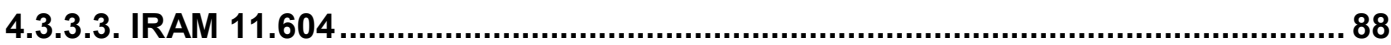

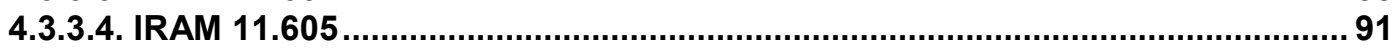

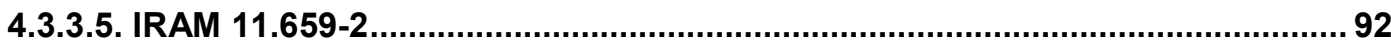

4.3.3.6. IRAM 11.900

CAPÍTULO V - ESTUDIO DE CASOS

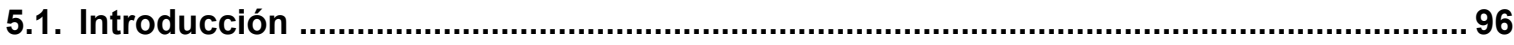

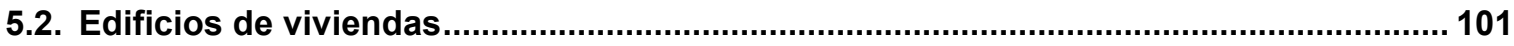

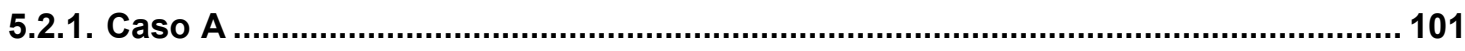

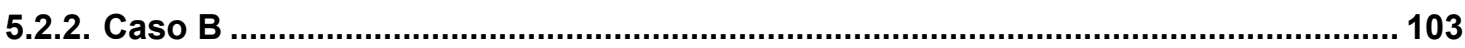

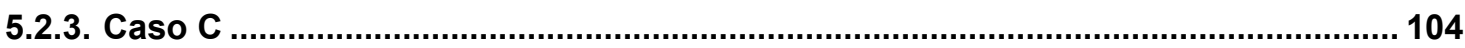

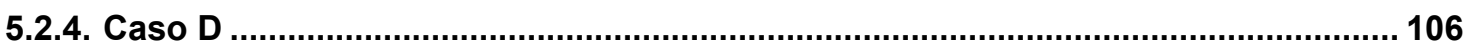

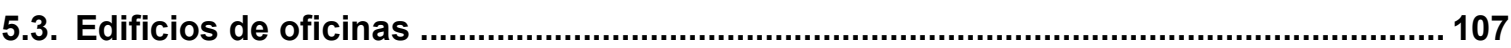

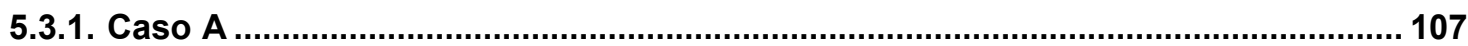

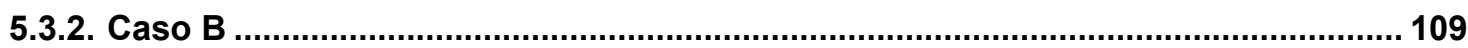

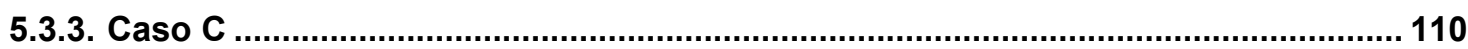

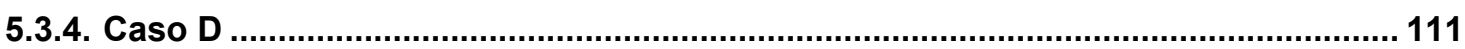

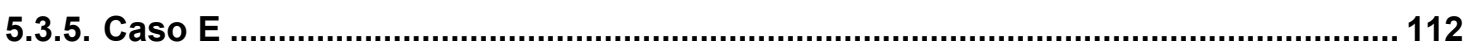

CAPÍTULO VI - AUDITORÍA ENERGÉTICA ........................................................................... 114

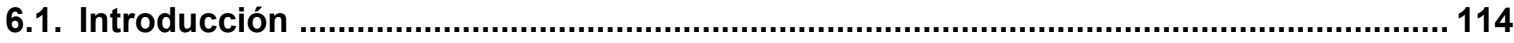

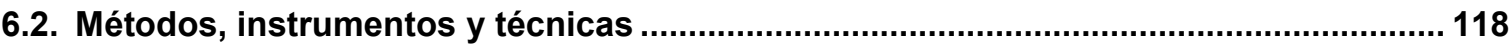

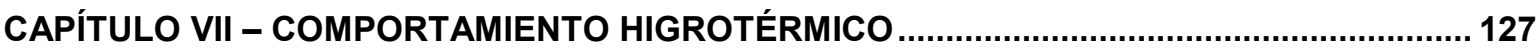

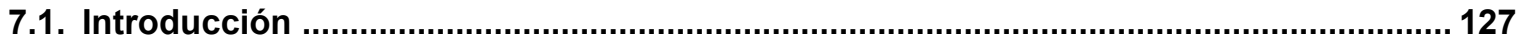

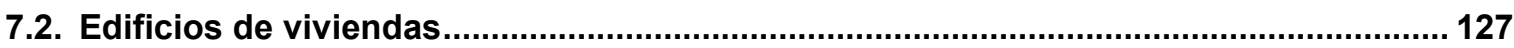

7.2.1. Comportamiento higrotérmico de verano ................................................................. 128

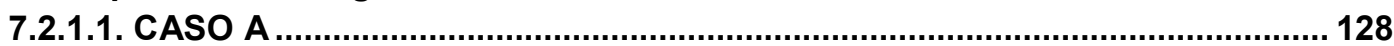

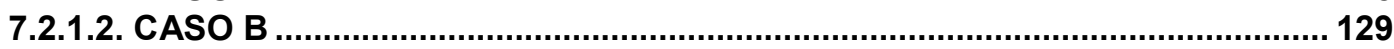

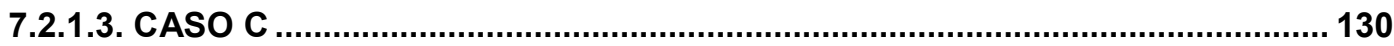

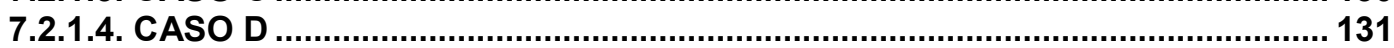

7.2.2. Comportamiento higrotérmico de invierno .............................................................. 133

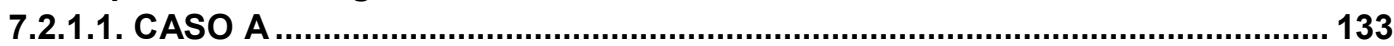

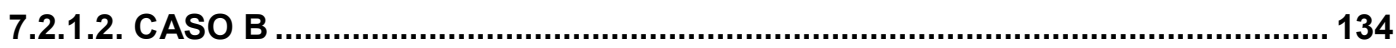

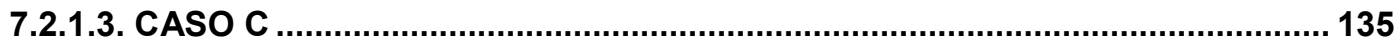

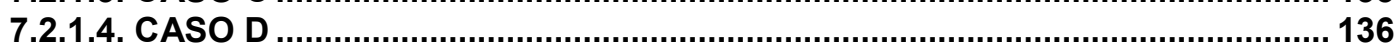

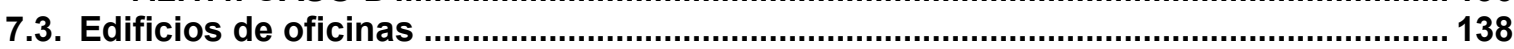

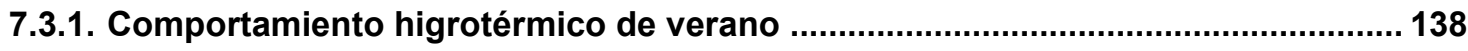

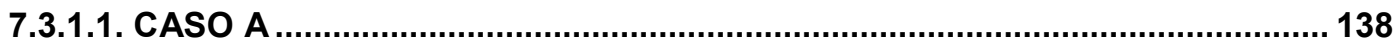

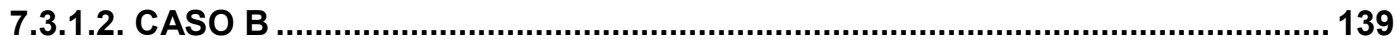

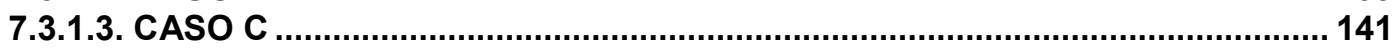

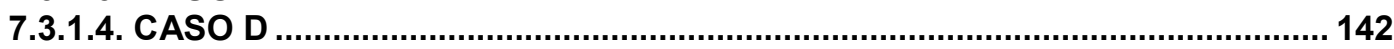

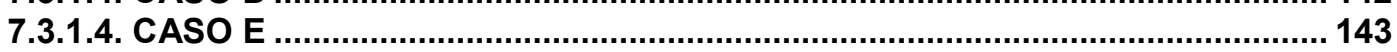

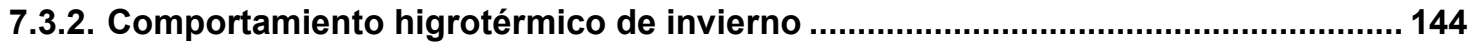

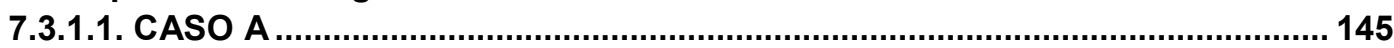

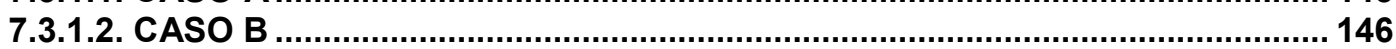

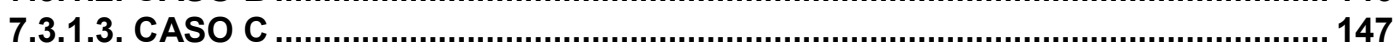

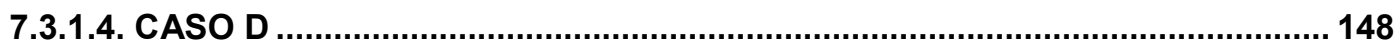

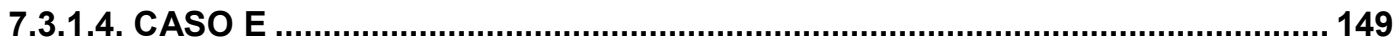




\section{CAPÍTULO VIII - DEMANDA DE ENERGÍA PARA CALEFACCIÓN - ETIQUETADO DE}

EFICIENCIA ENERGÉTICA EN CALEFACCIÓN ..................................................................... 151

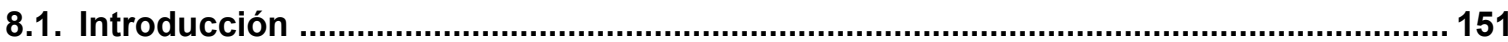

8.2. Demanda de Energía para calefacción .............................................................................. 151

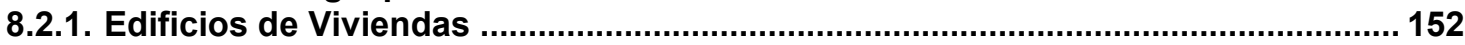

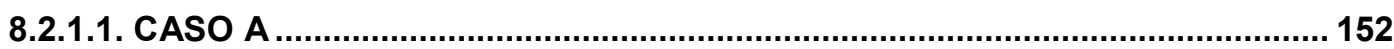

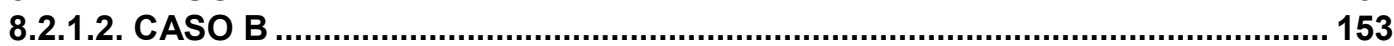

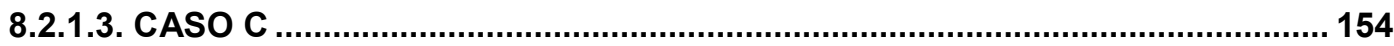

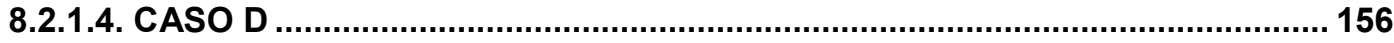

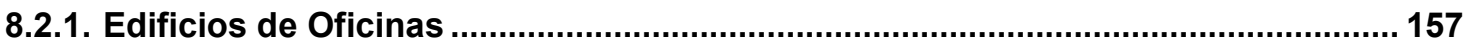

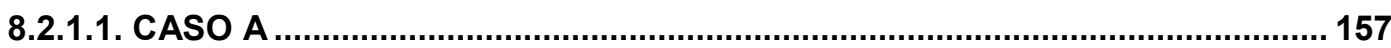

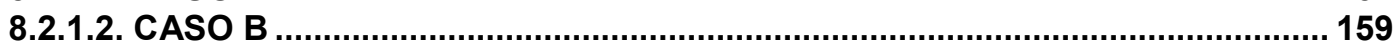

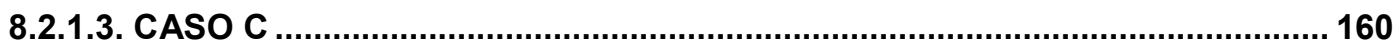

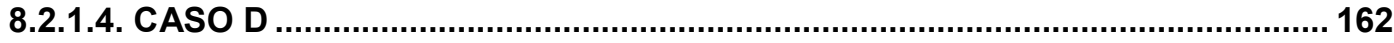

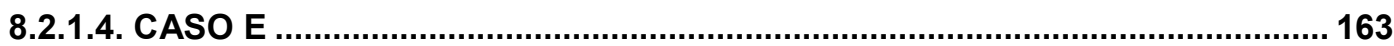

8.3. Etiquetado de Eficiencia Energética en Calefacción (IRAM 11900)............................... 165

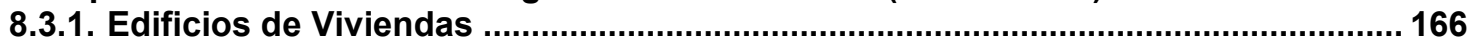

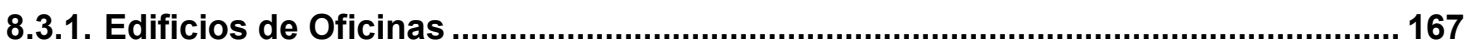

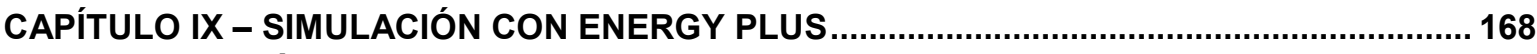

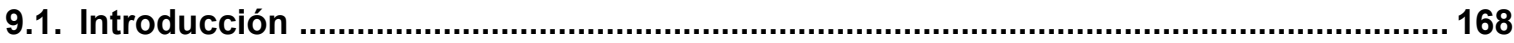

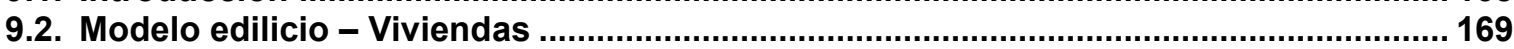

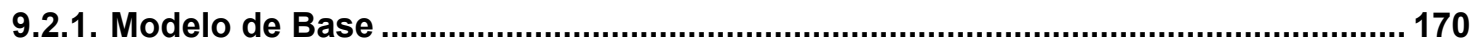

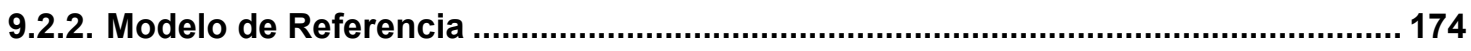

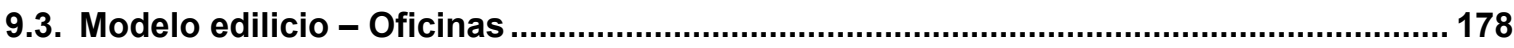

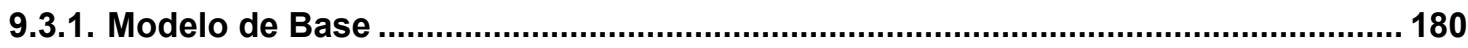

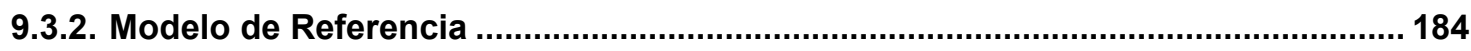

CAPÍTULO X - MODELOS DE AHORRO DE ENERGÍA ….................................................... 188

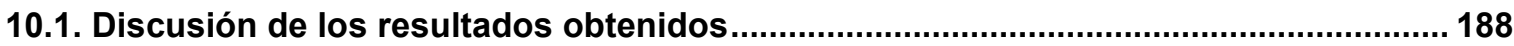

10.2. Modelo de ahorro de energía para edificios de viviendas ......................................... 195

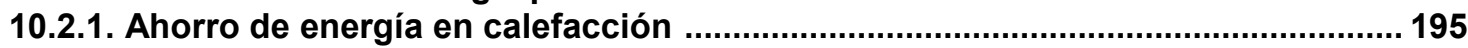

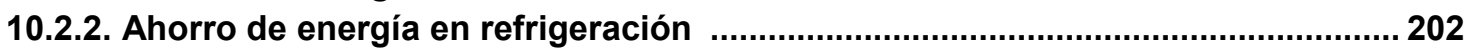

10.3. Modelo de ahorro de energía para edificios de oficinas ............................................209

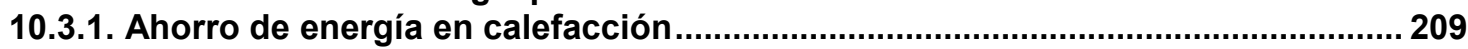

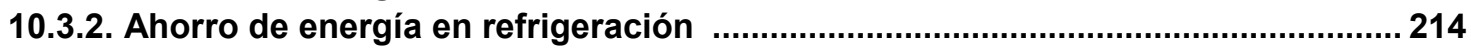

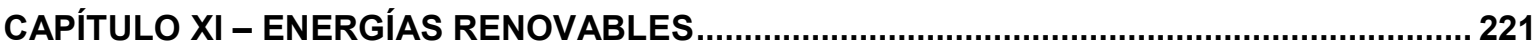

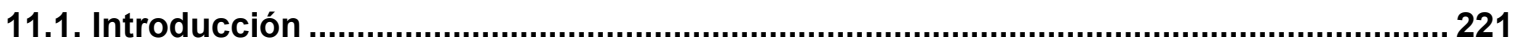

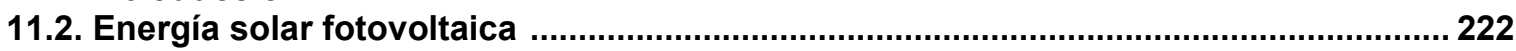

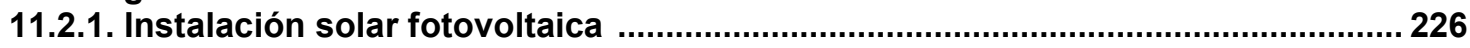

11.2.1.1. Instalación solar fotovoltaica en edificios de viviendas ....................... 226

11.2.1.2. Instalación solar fotovoltaica en edificios de oficinas ........................... 231

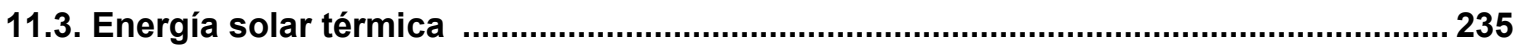

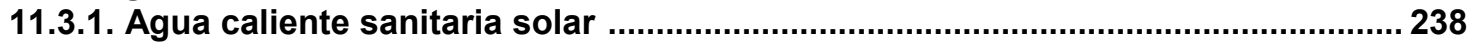

11.3.1.1. Agua caliente sanitaria solar en edificios de viviendas ........................ 238

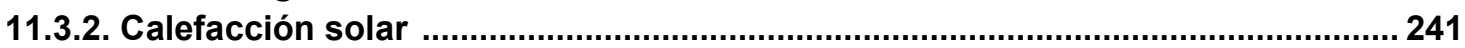

11.3.2.1. Calefacción solar en edificios de viviendas ....................................... 241

11.3.2.2. Calefacción solar en edificios de oficinas ............................................ 245

CONCLUSIONES

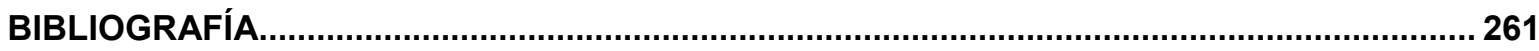




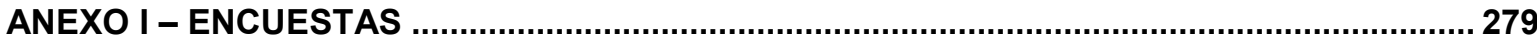

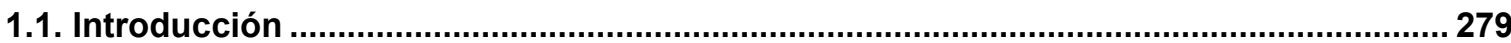

1.2. Modelo de encuesta para edificios de viviendas .................................................... 280

1.3. Modelo de encuesta para edificios de oficinas ............................................................. 289

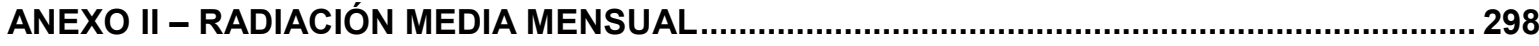

2.1. Resultados de irradiación media mensual para La Plata ...........................................298

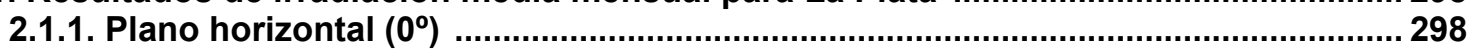

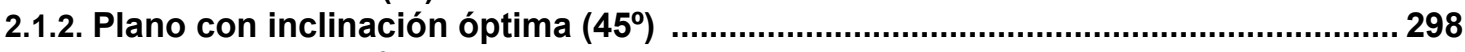

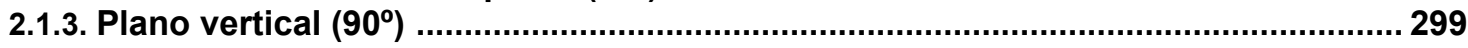

2.2. Verificación con el programa SIMUSOL (Hernández, A.; 2003) ..................................... 299

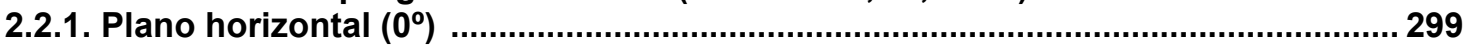

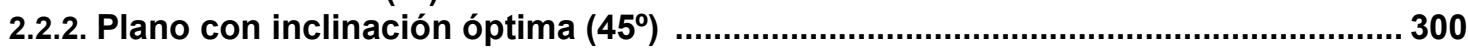

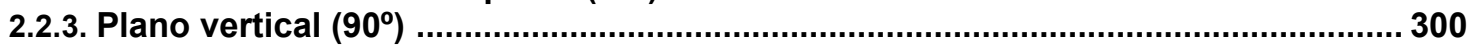

ANEXO III - TECNOLOGÍAS DE ENERGÍAS RENOVABLES ............................................... 301

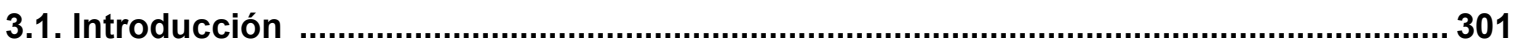

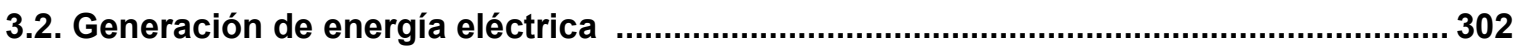

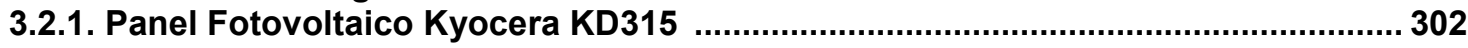

3.2.2. Inversor de Corriente PV Powered PV5200SD ...................................................... 304

3.3. Generación de energía fototérmica ......................................................................... 306

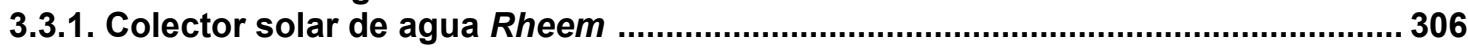

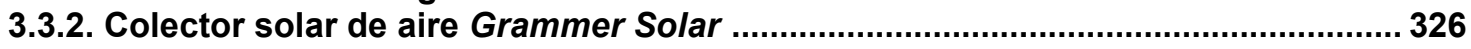

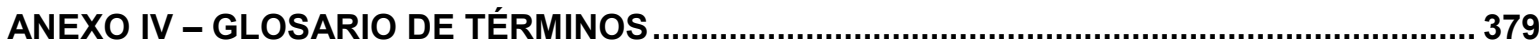

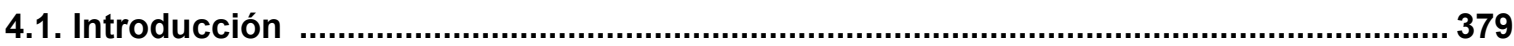

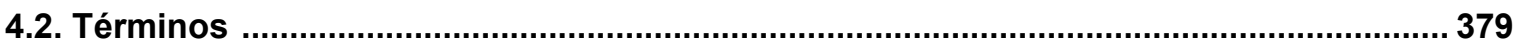

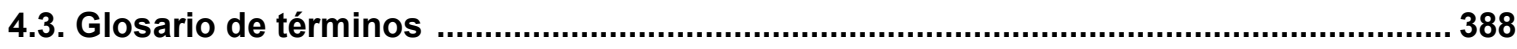




\section{RESUMEN}

La siguiente Tesis Doctoral se encuentra enmarcada dentro de una de las líneas de investigación que se desarrollan en el Laboratorio de Arquitectura y Hábitat Sustentable LAyHS - FAU - UNLP, orientada hacia la eficiencia energética edilicia en áreas urbanas.

El interés por el tema surge en la carrera de grado, durante los años como estudiante en la Facultad de Arquitectura y Urbanismo de la Universidad Nacional de La Plata, y en la particular admiración por las obras de arquitectos con una marcada tendencia tecnológica y con un vuelco hacia la preocupación por el medio ambiente como Richard Rogers, Renzo Piano, Norman Foster, Alvar Aalto, etc.

La siguiente Tesis se ve respaldada por un exhaustivo trabajo que involucra la lectura y análisis de publicaciones técnicas y científicas sobre el tema, el estudio de Normativa argentina e internacional y las consecuentes propuestas de mejora sobre la Normativa argentina en cuanto a eficiencia energética en el ámbito construido, la participación en el Subcomité de Acondicionamiento Térmico de IRAM, la experiencia ganada durante la estancia de investigación en el Instituto de Ingeniería Energética de la UPV, la participación como colaboradora en el Proyecto PICTO 2010-0087 "Interconexión de sistemas fotovoltaicos a la red eléctrica en ambientes urbanos", la experiencia profesional adquirida en el último tiempo, como así también la activa participación en conferencias, reuniones científicas, cursos de postgrado especializados, etc.

\section{Objetivos}

El objetivo principal de la Tesis es evaluar los aspectos primordiales que debe reunir un modelo de integración con Diseño Ambientalmente Consciente (DAC) para edificios de propiedad horizontal en altura, que permita tender a un desarrollo urbano-edilicio sustentable. Para alcanzar este objetivo principal fue necesario seguir los siguientes objetivos específicos:

- Identificar las necesidades y requerimientos energético-ambientales de los principales tipos edilicios en altura, distinguiendo los casos según la función que alberguen (viviendas u oficinas).

- Determinar los parámetros del DAC factibles de ser aplicados al tipo edilicio según la función (viviendas u oficinas).

- Contrastar los resultados de las simulaciones para los modelos de viviendas y oficinas según dos situaciones; una de base que siga los criterios con los que se construye en nuestro país en la actualidad, y otra de referencia, que siga los criterios del DAC. 


\section{Metodología}

Durante los años dedicados a esta investigación se realizó una intensa búsqueda bibliográfica a fin de conocer cuáles son las tecnologías maduras de generación de energía más adecuadas a nuestra realidad económico-productiva. Asimismo se realizó un relevamiento de sistemas de energías renovables existentes en el mundo para luego evaluar su adaptabilidad y adecuación a las posibilidades de nuestro país.

Por otra parte se realizó un estudio de tipos edilicios en altura destinados a oficinas y viviendas. Para ello fue muy importante realizar trabajo de campo enfocándose principalmente en la realización de auditorías ambientales edilicias, para conocer el comportamiento energético del tipo estudiado. También se analizó la normativa existente respecto de la eficiencia energética en el ámbito construido tanto a nivel nacional como internacional y una vez reunida toda la información y experiencia adquirida en el campo de la eficiencia energética en edificios en altura, se plantearon los modelos de integración DAC a fin de sintetizar las características energéticas - ambientales del tipo edilicio estudiado, distinguiendo según el destino (viviendas u oficinas).

Posteriormente fue necesario evaluar la fiabilidad de los resultados obtenidos de modo de poder realizar las modificaciones y correcciones necesarias y, con el modelo de integración DAC propuesto, realizar simulaciones energéticas. Finalmente, con esta información se pudieron elaborar propuestas de adaptación y mitigación del cambio climático a nivel edilicio.

\section{Hipótesis}

- La baja calidad higrotérmica de la envolvente de los edificios que componen el espacio urbano de las principales ciudades del país ocasiona un importante derroche de energía principalmente de fuentes no renovables- para alcanzar el confort de los espacios interiores.

- Producto de la constante búsqueda por reducir los costos de construcción los nuevos edificios demuestran una menor preocupación por el ahorro energético, lo cual puede verse en la calidad de la envolvente higrotérmica. La situación es aún más grave en los edificios de menor volumen, en los cuales los sistemas de acondicionamiento térmico no son pensados en forma conjunta con el diseño del edificio sino que se dejan a criterio de los usuarios.

- Una solución viable para contribuir al ahorro energético en la construcción del espacio urbano es la obligatoriedad de aplicación de las normas nacionales (IRAM) que avalan la habitabilidad higrotérmica y la racionalidad energética en la edificación. Sin embargo, actualmente estas normas sólo son obligatorias en la Ciudad de Rosario y en la Provincia de Buenos Aires (Ley 13.059/03).

- La aplicación de subsidios al consumo de energía provenientes de fuentes no renovables que lleva actualmente el Estado Argentino contribuye al derroche energético. Para llevar a cabo una política energética sustentable y contribuir a la disminución del consumo de energía de combustibles fósiles el Estado debería promocionar y otorgar incentivos para la incorporación de sistemas de energía renovables.

\section{Desarrollo del trabajo}

Introducción

Capítulo I - Cambio Climático

Capítulo II - Contexto Urbano

Capítulo III - El Tipo Edilicio

Capítulo IV - Normativa y Legislación Aplicada a Edificios

Capítulo V - Estudio de Casos

Capítulo VI - Auditoría Energética

Capítulo VII - Comportamiento Higrotérmico

Capítulo VIII - Demanda de Energía para Calefacción - Etiquetado de Eficiencia Energética en Calefacción 
Capítulo IX - Simulación con Energy PLUS

Capítulo X - Modelos de Ahorro de Energía

Capítulo XI - Energías renovables

Anexos

\section{Conclusiones}

Los edificios de propiedad horizontal en altura son los actores predominantes de cualquier ciudad del mundo. En la configuración de los mismos entran en juego una serie de elementos que están directamente relacionados con el contexto histórico, sociocultural, económico y político del país en el cual se desarrollan. En nuestro país, la especulación en el uso del suelo y la incesante búsqueda por reducir los costos de construcción han contribuido al detrimento de la calidad higrotérmica de la envolvente edilicia en los últimos años, priorizando la rentabilidad por sobre el confort interior de los edificios.

La baja calidad higrotérmica de la envolvente edilicia hace que sea necesario un gran consumo de energía, proveniente principalmente de fuentes no renovables, para que la temperatura de los espacios interiores alcance valores razonables. Sin embargo, en la mayoría de los casos, pese al derroche energético, los ambientes no alcanzan las condiciones de confort.

Las Normas IRAM en su serie 11.6XX y la Norma IRAM 11.900 tratan sobre habitabilidad higrotérmica y eficiencia energética. Sin embargo actualmente sólo en la Ciudad de Rosario y en la Provincia de Buenos Aires, con la implementación de la Ley 13.059/03 y su Decreto Reglamentario 1.030, se exige su cumplimiento obligatorio. El mayor problema radica en que, pese a haber sido concebidas para viviendas de interés social, estos valores de referencia se han extrapolado a todo edificio de ocupación humana, lo cual constituye un grave error.

Si se toman como referencia los sistemas de certificación edilicia reconocidos a nivel mundial (LEED, BREEAM, Passivhaus) puede observarse que cada uno cuenta con un sistema de evaluación diferente de acuerdo a la complejidad y al uso del edificio a certificar, e incluso también del clima en el cual se inserta. Esta cuestión está directamente relacionada con el concepto de Benchmarking, por el cual se mide el rendimiento de un sistema, en este caso de un edificio, en comparación con otro de referencia.

Esta Tesis busca subsanar este error, generando un antecedente que continúe con la metodología utilizada en las Normas IRAM pero que pueda aplicarse a edificios de propiedad horizontal en altura, que permita tender a un desarrollo urbano-edilicio sustentable en el contexto de Argentina. Luego deberían buscarse valores de referencia para los distintos tipos edilicios.

Palabras Clave: modelo de diseño - edificios en altura - eficiencia energética. 


\section{ABSTRACT}

The following Doctoral Thesis is framed within one of the research lines developed at Laboratorio de Arquitectura y Hábitat Sustentable LAyHS - FAU - UNLP; buildings energy efficiency in urban areas.

The Interest in the topic arises during the years as a student at Facultad de Arquitectura y Urbanismo - Uninversidad Nacional de La Plata, and in the admiration for the works of architects with a strong technological trend and concern for the environment as Richard Rogers, Renzo Piano, Norman Foster, Alvar Aalto, etc.

The following Thesis is supported by an intensive work that involves reading and analysis of technical and scientific publications on the subject, the study of Argentine and international regulations, and the proposals to improve Argentine Regulations regarding energy efficiency in buildings, the participation at the Subcomité de Acondicionamiento Térmico of IRAM, as well as the participation at conferences, scientific meetings, specialized postgraduate courses, etc.

\section{Objectives}

The main objective of this Thesis is to evaluate the main aspects that an integration model with Environmentally Conscious Design (ECD) for high-rise buildings must meet. So that it allows reaching a sustainable urban development.

To achieve this main objective was necessary to follow these specific objectives:

- To identify the energy - environmental needs and requirements of high-rise buildings, distinguishing cases according to the function (residential or office).

- Determine the ECD parameters feasible to be applied to building type, according to function (residential or office).

- To compare the results of simulations for residential and office models according with two situations; the way in which buildings are build in Argentina nowadays and other that follows ECD criteria.

\section{Methodology}

During the years dedicated to this Thesis it was made an intensive research in order to recognize which are the renewable energy technologies most suitable to the economicproductive situation of Argentina. Also it was carried out a study of the existing renewable 
energy systems in the world to assess their possibility of getting adapted to our economicproductive situation.

Furthermore, there were carried out energetic-environmental audits in both office and residential buildings. There were also analyzed the existing Standards related to energy efficiency in buildings, both Argentinean as international. Then whit this information it was possible to build the ECD model. This model allowed to synthesize the energetic-environmental characteristics of the studied buildings.

Afterward it was necessary to evaluate the reliability of the results in order to make the necessary adjustments to run the simulation of the ECD model proposed. Finally, with all this information it was possible to develop design proposals of adaptation and mitigation of climate change.

\section{Hypothesis}

- The low quality of buildings hygrothermal envelope in Argentinian main cities causes significant waste of energy, mainly from non-renewable sources, to meet the comfort of the interior spaces.

- The constant quest to reduce construction costs causes that new buildings show less concern for energy savings. It can be seen in the poor quality of buildings hygrothermal envelope. The situation is even more serious in smaller buildings where air conditioning systems are not designed in conjunction with the building but are left to owners criteria.

- A viable solution to save energy in the construction of urban space is the mandatory implementation of national standards (IRAM) that support the hygrothermal habitability and energy rationality in buildings. However, these rules are currently only mandatory at Rosario City and at Buenos Aires Province (Law 13.059/03).

- The subsidies to energy consumption from non-renewable sources that Argentine State applies, contributes to energy waste primarily from non-renewable sources. To implement a sustainable energy policy and help to reduce energy consumption of fossil fuels the State should provide incentives to promote the incorporation of renewable energy systems.

\section{Development work}

Introduction

Chapter I - Climate change

Chapter II - Urban context

Chapter III - The building type

Chapter IV - Regulations and Legislation applied to buildings

Chapter V - Case studies

Chapter VI - Energetic-environmental audit

Chapter VII - Hygrothermal behavior

Chapter VIII - Heating energy demand - Heating energy efficiency labeling

Chapter IX - Energy PLUS simulation

Chapter $\mathrm{X}$ - Energy saving models

Chapter XI - Renewable energy

Annexes

\section{Conclusions}

The high-rise buildings are the dominant actors of any city in the world. In its configuration come into play a series of elements that are directly related to the historical, socio-cultural, economic and political context in which they are developed. In our country, speculation in land use and the pursuit to reduce construction costs have contributed to the detriment of buildings hygrothermal envelope quality, prioritizing profitability over buildings interior comfort. 
The low quality of buildings hygrothermal envelope makes it necesary a great energy consumption, primarily from non-renewable sources, so that interior spaces temperature reaches fair values. However, in most cases, although the energy wastes, the interior spaces do not reach comfort conditions.

IRAM Standards in its series 11.6XX and IRAM 11.900 discuss about hygrothermal habitability and energy efficiency. However only at Rosario City and at Buenos Aires Province, with the implementation of Law 13.059/03, it is mandatory its compliance. The biggest problem is that, despite having been designed for social housing, these reference values have been extrapolated to all kind of building for human occupation, which constitute a serious mistake

If we take as reference certification edilicia systems globally recognized (LEED, BREEAM, Passivhaus) it can be seen that each one has a different evaluation system according to the complexity and use of the building to be certified. This issue is directly related to the concept of Benchmarking, whereby the performance of a system is measured as compared with another reference (in this case between two buildings with the same destiny).

This Thesis seeks to correct this mistake, creating a precedent that continues with the methodology used at IRAM Standards but that could be applied to high-rise buildings (residential or office). It is supposed that the implementation of these new values for new buildings will allow sustainable urban development in the context of Argentina. However it will be necessary to find new values for the others kinds of buildings.

Keywords: design model - high-rise buildings - energy efficiency. 
"Entre creer y no creer, más vale creer. Entre actuar y disolver, más vale actuar. Ser juvenil y lleno de salud es poder producir mucho, pero serán necesarios años de experiencia para producir bien. Estar nutrido de las civilizaciones anteriores permite disipar la oscuridad y atraer sobre las cosas un juicio claro. Es ser derrotista pensar que, pasada la época de estudiante, uno no es más que un residuo."

Le Corbusier, diciembre de 1924. 


\section{INTRODUCCIÓN}

La siguiente Tesis Doctoral se encuentra enmarcada dentro de una de las líneas de investigación que se desarrollan en el Laboratorio de Arquitectura y Hábitat Sustentable LAyHS - FAU - UNLP, orientada hacia la eficiencia energética edilicia en áreas urbanas. El trabajo realizado durante los años dedicados al desarrollo de esta Tesis fue financiado por los siguientes proyectos de Investigación:

- Proyecto acreditado U079: "Edificios para habitación humana en climas húmedos. Evaluación y propuesta de medias para la mitigación del cambio climático" (UNLP; 2006 2009).

- Proyecto PICT 06 N 956: "Eficiencia energética edilicia en áreas metropolitanas. Evaluación mediante auditoria y propuesta de estándares" (ANPCyT; 2007-2010).

- Proyecto acreditado U102: "Eficiencia energética y sustentabilidad para la materialización de edificios en un contexto de adaptación al cambio climático" (UNLP; 2010 - 2014).

Asimismo las siguientes Becas de Investigación también permitieron el financiamiento de las actividades relacionadas con el desarrollo de esta Tesis Doctoral:

Beca Inicial, ANPCyT (Octubre 2008 - Marzo 2011).

Beca Doctoral Tipo II, CONICET (Abril 2011 - Marzo 2013).

Beca Doctoral Tipo Sándwich, Erasmus Mundus (Junio 2011 - Diciembre 2011).

La Comisión para el Medio Ambiente de la ONU definió al desarrollo sustentable como aquel que satisface las necesidades del presente sin comprometer la capacidad de las generaciones futuras de satisfacer sus propias necesidades (Brundtland, G.; 1987). La escasez de recursos y el calentamiento global son responsables del deterioro ambiental que viene sufriendo el mundo hace un tiempo, en los cuales la construcción arquitectónica y urbana tiene un grado de incidencia indiscutible.

Durante mucho tiempo se consideró a los recursos naturales como fuentes inagotables. Se creía que el desarrollo de tecnologías adecuadas para su manejo a gran escala haría posible satisfacer las necesidades de la población mundial. Sin embargo la actualidad demuestra que esto no es así; que los recursos se agotan y que el riesgo que esto acarrea para la vida de millones de personas así como para el ambiente, es cada vez mayor (Vegara, A.; De Las Rivas, J.; 2004).

La industria de la construcción es una de las más importantes consumidoras de energía. Este consumo es uno de los principales indicadores del tipo de impacto ambiental que esta involucra no sólo durante los procesos de extracción y elaboración de las materias primas, sino también durante la construcción de edificios, su utilización y aún después, cuando el edificio es demolido. En la Actualidad el ochenta por ciento de los residuos de la construcción no son 
reutilizados, lo que indica un alto porcentaje de contaminación. Por su parte el hormigón, importante material empleado en la construcción de edificios, está compuesto principalmente por cemento, acero y diferentes áridos, todos estos materiales consumen recursos no renovables y suponen un importante consumo de energía y de emisiones tóxicas en el proceso de fabricación (Edwards, B.; 2008).

Los combustibles fósiles por su parte constituyen la principal fuente de energía empleada en el hábitat construido. En Argentina por ejemplo el gas es un insumo fundamental para la generación de energía eléctrica y la calefacción (Secretaría de Energía; 2008). La escasez y el riesgo potencial que representan las emisiones de carbono que el empleo de los mismos genera, hace que sea necesaria la discusión de un empleo tan intensivo.

La práctica arquitectónica no está ajena al problema, sin embargo queda mucho por hacer. En los últimos años han surgido, bajo el marco del paradigma ambiental, una serie de propuestas que sugieren algunos caminos a seguir; arquitectura ecológica, arquitectura verde, arquitectura bioclimática, bio-arquitectura, arquitectura geomórfica o arquitectura sustentable, por mencionar algunas. Todas incorporan instrumentos para evaluar, controlar y minimizar el impacto físico del proyecto y su posterior construcción en el contexto en el que se inserta. Estas posturas parecerían alineadas alrededor de una filosofía que podríamos denominar cientificista o ambientalista, las cuales rigen el proceso de diseño a partir de considerar la creación de arquitectura subordinada o dominada por factores naturales, estableciendo ciertos parámetros ya sea mediante formas preestablecidas, asignando de antemano un coeficiente de contaminación máxima a cumplir, o de los flujos de entrada y salida de energía, etc., que sin duda son de suma importancia para conseguir una efectiva labor de conservación de nuestro entorno natural en un futuro inmediato (Soria López, F.; 2004).

Estos casos de estudio, que han surgido principalmente en países del primer mundo, sirven como antecedentes conceptuales. Sin embargo es necesario hacer un análisis criterioso que contemple las pautas culturales y las posibilidades tecnológicas propias de Argentina en cuanto a la construcción y uso de edificios, y de sectores urbanos.

Como arquitectos, responsables de la creación de espacios habitables, deberíamos entender la importancia de tomar conciencia acerca de los efectos que la industria de la construcción tiene sobre el entorno en el que vivimos. La posibilidad de dejar un mundo sano, económicamente sustentable, con recursos posibles de ser aprovechados por generaciones futuras depende de nuestro trabajo. El diseño ambientalmente consciente debe ser afrontado con responsabilidad, por medio de un abordaje integral de los diferentes procesos que la obra arquitectónica involucra.

En Argentina la construcción del espacio urbano, en particular de los edificios que lo forman, se ha desarrollado sin incorporar métodos que garanticen la habitabilidad higrotérmica y la racionalidad energética. Las normativas existentes (Normas IRAM) no son de cumplimiento obligatorio a nivel nacional; el cumplimiento de las mismas se ha vuelto obligatorio sólo en la provincia de Buenos Aires en el año 2010, con la implementación de la Ley 13.059 y su Decreto Reglamentario 1.030. Por otra parte cabe destacar que si bien estas normas son actualizadas constantemente, la práctica de la construcción pareciera buscar sólo la creciente reducción de los costos iniciales del edificio, mostrando en la mayoría de los casos, un gran desinterés por la calidad energética de la envolvente edilicia. Esta búsqueda incesante por reducir los costos iniciales llevó a un detrimento del hábitat construido en todos los aspectos que atañen a la calidad del ambiente interior. La situación es cada vez más grave y son los usuarios quienes deben resolver las deficiencias producto de esta falta de interés, solventando ellos mismos los costos operativos para mantener el interior del ambiente confortable.

Numerosos estudios realizados en Argentina muestran que la calidad térmica de la envolvente de los edificios en nuestro país ha disminuido en los últimos años (Czajkowski, 1990 a 2006; Evans, 1990 a 2004; Filippin, 1992 a 2005; Gonzalo, 1996; Rosenfeld, 1988 a 2003; etc.). Estos estudios muestran que las deficiencias edilicias en Argentina se deben a múltiples factores, entre los cuales podemos mencionar:

- Marcado desinterés del sector político en la problemática. 
- Importante desconocimiento y resistencia por parte de los sectores profesionales responsables de la producción del hábitat.

- Inadecuado uso de materiales de construcción y/o sistemas constructivos.

- Deficiente conocimiento, manejo y aplicación de estrategias de acondicionamiento natural en diseño pasivo tales como medidas de ventilación natural y protección de viento, adecuado asoleamiento, captación y protección solar e iluminación natural de locales según requerimientos regionales y locales.

- Falta de evaluación post-ocupación de la apropiación, operación y mantenimiento del edificio.

- Falencias en la instrumentación por parte de los Institutos Provinciales de Vivienda y en el desarrollo de criterios de sustentabilidad y eficiencia energética en la evaluación de proyectos.

- Imposibilidad de incluir en los Códigos de Edificación de muchos municipios del país el cumplimiento de las Normas IRAM 11.6XX.

- Mala ventilación, iluminación y asoleamiento de locales que no responden al modo de uso de los habitantes.

- Falta de vigilancia y control de obra, etc.

Muchos de estos problemas podrían ser corregidos con el cumplimiento obligatorio de las Normas IRAM a nivel nacional. Una rápida revisión de la legislación vigente muestra un vacío legal y reglamentario respecto de contemplar la calidad térmica, la eficiencia energética, la reducción de emisiones, el confort higrotérmico, entre otros. La necesidad de construir más unidades habitacionales y de responder a la creciente demanda de infraestructura y equipamiento de los sectores de Educación y Salud cada vez con menos dinero, ha implicado una importante reducción de la calidad constructiva y, en consecuencia, de las prestaciones ambientales y energéticas de las construcciones de todos los sectores, tanto de la gestión pública como de la actividad económica generada por iniciativa privada.

En el diseño de un edificio energéticamente eficiente están involucrados diferentes aspectos orientados todos a la reducción del impacto ambiental del mismo no sólo durante los procesos de extracción y elaboración de las materias primas, sino también durante la construcción, su utilización y aún después, cuando el edificio es demolido y reciclados sus restos. Algunos aspectos que deben considerarse son:

- Envolvente del edificio como el medio entre la arquitectura y el clima exterior.

- Masa de la envolvente como elemento mediante el que se puede proporcionar inercia térmica.

- Técnicas de climatización. Por ejemplo se puede ampliar el área de confort mediante ventilación cruzada, enfriamiento evaporativo, humidificación, etc.

- Diseño solar pasivo. Por ejemplo se puede aprovechar la inercia térmica de los materiales para acumular calor.

- Diseño solar activo. Por ejemplo mediante el uso de dispositivos electromecánicos como paneles fotovoltaicos se puede generar energía eléctrica.

- Protección solar utilizando parasoles, doble vidriado hermético (DVH), fachadas dobles, etc.

- Aprovechamiento de los vientos favorables como así también protección de aquellos desfavorables.

- Elección de materiales teniendo en cuenta el consumo de energía y las emisiones de gases tóxicos durante los procesos de elaboración, transporte, etc.

Todos estos aspectos han sido desarrollados e incorporados en el diseño de muchos de los edificios que conforman el hábitat urbano en distintas ciudades de los países más desarrollados. Para poder comprender el modo en que deberían insertarse en Argentina, fue necesario hacer una evaluación de la inserción de estos conceptos en la configuración de dichos centros urbanos.

Es importante destacar el hecho de que tanto el medio ambiente como el ahorro energético y la innovación tecnológica son todos aspectos que deben tenerse en cuenta como material básico para el proyecto arquitectónico. Obviar la importancia de estos, como así también de los buenos resultados a los que pueden llevar, dificultará la obtención de resultados seductores para que otros arquitectos adopten estos materiales como asuntos básicos para hacer una 
buena arquitectura. Al respecto no cabe más que nombrar la obra de profesionales de reconocida trayectoria tales como Renzo Piano, Richard Rogers o Norman Foster que en los últimos años han dado un vuelco a su carrera, realizando obras que mantienen una estrecha relación con el ambiente. Se trata de una arquitectura contemporánea y situada pero por sobre todo original, que encuentra en la problemática actual el leit motiv para hacer obras de arquitectura (Sarquis, J.; 2009).

\section{Motivaciones}

El interés por el tema surge en la carrera de grado. Durante los años como estudiante de grado en la Facultad de Arquitectura y Urbanismo de la Universidad Nacional de La Plata, en los diversos talleres de Arquitectura, y en otras asignaturas relacionadas con la materialización de la obra y su entorno los docentes a cargo de los cursos estimulaban a los alumnos en la búsqueda por responder al medio, en el cual la obra de arquitectura interviene como actor principal.

Lo que en un principio motivó la búsqueda espacial favoreciendo, con recursos de diseño, el confort higrotérmico de los ambientes principales fue el inicio de lo que años más tarde se constituyó en el incentivo para desarrollar esta Tesis Doctoral.

Durante la carrera de grado, y aún después de concluida esta etapa de formación, la preocupación por responder al entorno físico volcó el interés particular hacia el estudio de arquitectos con una marcada tendencia tecnológica y preocupación por el medio ambiente; Richard Rogers, Renzo Piano, Norman Foster, Alvar Aalto, Wladimiro Acosta, Le Corbusier, Frank Lloyd Wright, Eduardo Sacriste, entre otros sirvieron de fuente de inspiración de la labor arquitectónica. Entender que la dificultad del tema no podía ser afrontada solamente desde el diseño arquitectónico, comprender que por detrás existía un trasfondo científico y tecnológico muy importante, que no podía ser dejado de lado, me llevo a acercarme como colaboradora en la Unidad No8 del IDEHAB - FAU - UNLP primero, y presentarme como becaria de ANPCyT en el LAyHS FAU - UNLP, luego.

Durante los años dedicados a la investigación en el ámbito de la FAU y los meses en los que pude realizar el intercambio científico - tecnológico en el Instituto de Ingeniería Energética de la Universidad Politécnica de Valencia, en España, profundicé los estudios sobre eficiencia energética en edificios en altura para reunir los conocimientos necesarios que hoy me llevan a escribir este documento.

Es por eso que la siguiente Tesis se ve respaldada por un largo camino que involucra la lectura y análisis de publicaciones técnicas y científicas, Normativa argentina e internacional y las consecuentes propuestas de mejora sobre la Normativa argentina a través de publicaciones en congresos y revistas especializadas, la participación en el Subcomité de Acondicionamiento Térmico de IRAM, la activa participación en conferencias, reuniones científicas, cursos de postgrado especializados, etc. Todas estas actividades realizadas tanto en Argentina como en el exterior y relacionadas con el tema de la eficiencia energética en el ámbito construido.

\section{Objetivos}

Luego de varios años de trabajo en el campo de la investigación, ahondando el tema de la eficiencia energética en el ámbito construido, encuentran su punto cúlmine en esta Tesis cuyo objetivo principal es evaluar los aspectos primordiales que debe reunir un modelo de integración con Diseño Ambientalmente Consciente (DAC) para edificios de propiedad horizontal en altura, que permita tender a un desarrollo urbano-edilicio sustentable. Para alcanzar este objetivo principal fue necesario seguir los siguientes objetivos específicos:

- Identificar las necesidades y requerimientos energético-ambientales de los principales tipos edilicios en altura, distinguiendo los casos según la función que alberguen (viviendas u oficinas).

- Determinar los parámetros del DAC factibles de ser aplicados al tipo edilicio según la función (viviendas u oficinas). 
- Contrastar los resultados de las simulaciones para los modelos de viviendas y oficinas según dos situaciones; una de base que siga los criterios con los que se construye en nuestro país en la actualidad, y otra de referencia, que siga los criterios del DAC.

\section{Metodología}

Durante los años dedicados a esta investigación se realizó una intensa búsqueda bibliográfica a fin de conocer cuáles son las tecnologías maduras de generación de energía más adecuadas a nuestra realidad económico-productiva. Asimismo se realizó un relevamiento de sistemas de energías renovables existentes en el mundo para luego evaluar su adaptabilidad y adecuación a las posibilidades de nuestro país.

Por otra parte se realizó un estudio de tipos edilicios en altura destinados a oficinas y viviendas. Para ello fue muy importante realizar una reseña histórica del tipo edilicio y de las particularidades de su evolución en el contexto de la Argentina. Luego se prosiguió con trabajo de campo en donde fue muy importante la realización de auditorías ambientales edilicias, para conocer el comportamiento del tipo estudiado.

También se analizó la normativa existente respecto de la eficiencia energética en el ámbito construido tanto a nivel nacional como internacional, de modo de proponer mejoras a la normativa existente en el país, en la actualidad.

Asimismo la estancia en el IIE - UPV, España permitió profundizar el estudio de la normativa española y europea en cuanto a eficiencia energética en la edificación, experimentar con el software especializado en simulación energética de edificios poniendo especial atención a los promovidos por el gobierno español, evaluar y seguir el protocolo de auditoría energética utilizado en el IIE - UPV. Entre otras actividades se realizaron visitas a edificios energéticamente eficientes y que incorporaban criterios de Diseño Ambientalmente Consciente. También se trabajó con estudiantes de postgrado de diferentes países de la Unión Europea en la elaboración de propuestas de mejora a edificios de distintas universidades de Europa. Todas estas actividades y la activa participación en conferencias relacionadas con el tema de la eficiencia energética en el ámbito construido sirvieron de base para la elaboración de esta Tesis Doctoral.

Una vez reunida toda la información y experiencia adquirida en el campo de la eficiencia energética en edificios en altura, se plantearon los modelos de base y de referencia para el tipo edilicio estudiado, diferenciando los modelos según el destino (viviendas u oficinas). Esto permitió verificar la disminución de la demanda energética a partir de la implementación de las mejoras de la envolvente edilicia. Posteriormente se plantearon los modelos de integración DAC (de viviendas y oficinas) a fin de sintetizar las características energéticas - ambientales del tipo edilicio estudiado.

\section{Hipótesis}

- La baja calidad higrotérmica de la envolvente de los edificios que componen el espacio urbano de las principales ciudades del país ocasiona un importante derroche de energía principalmente de fuentes no renovables- para alcanzar el confort de los espacios interiores.

- Producto de la constante búsqueda por reducir los costos de construcción los nuevos edificios demuestran una menor preocupación por el ahorro energético, lo cual puede verse en la calidad de la envolvente higrotérmica. La situación es aún más grave en los edificios de menor volumen, en los cuales los sistemas de acondicionamiento térmico no son pensados en forma conjunta con el diseño del edificio sino que se dejan a criterio de los usuarios.

- Una solución viable para contribuir al ahorro energético en la construcción del espacio urbano es la obligatoriedad de aplicación de las normas nacionales (IRAM) que avalan la habitabilidad higrotérmica y la racionalidad energética en la edificación. Sin embargo, 
actualmente estas normas sólo son obligatorias en la Ciudad de Rosario y en la Provincia de Buenos Aires (Ley 13.059/03).

- La aplicación de subsidios al consumo de energía provenientes de fuentes no renovables que lleva actualmente el Estado Argentino contribuye al derroche de energía proveniente principalmente de fuentes no renovables. Para llevar a cabo una política energética sustentable y contribuir a la disminución del consumo de energía de combustibles fósiles el Estado debería promocionar y otorgar incentivos para la incorporación de sistemas de energía renovables. 


\section{CAPÍTULO I \\ CAMBIO CLIMÁTICO}

\subsection{Cuestiones generales relativas al cambio climático}

La posibilidad de que exista un cambio climático se pensó por primera vez en 1960. Sin embargo desde 1950 se tienen registros de las emisiones globales de $\mathrm{CO}_{2}$; estos registros mostraron un aumento del $18 \%$ en las concentraciones medias anuales en el año 2002 con respecto a las primeras mediciones en 1950. Los registros aumentaron de las 315,98 partes por millón por volumen (ppmv) de aire seco en 1959 a 372,95 ppmv en el año 2002 (Gráfico I 1). A pesar de ello recién en 1970 una serie de problemas atmosféricos como la lluvia ácida o la polución del aire llamaron la atención del público general. Finalmente la Crisis Energética de 1973 constituyó el primer "shock medioambiental" que ponía de manifiesto que el sueño del Siglo XX de energía económica y recursos ilimitados no era real. Hacia mediados de 1980 las predicciones simuladas por los científicos acerca del cambio climático se aproximaban a la realidad. El aumento de la temperatura y la frecuencia e intensidad de los eventos climáticos extremos se hizo evidente; el clima estaba cambiando más de lo que admitía su variación habitual (Roaf, S.; 2005).

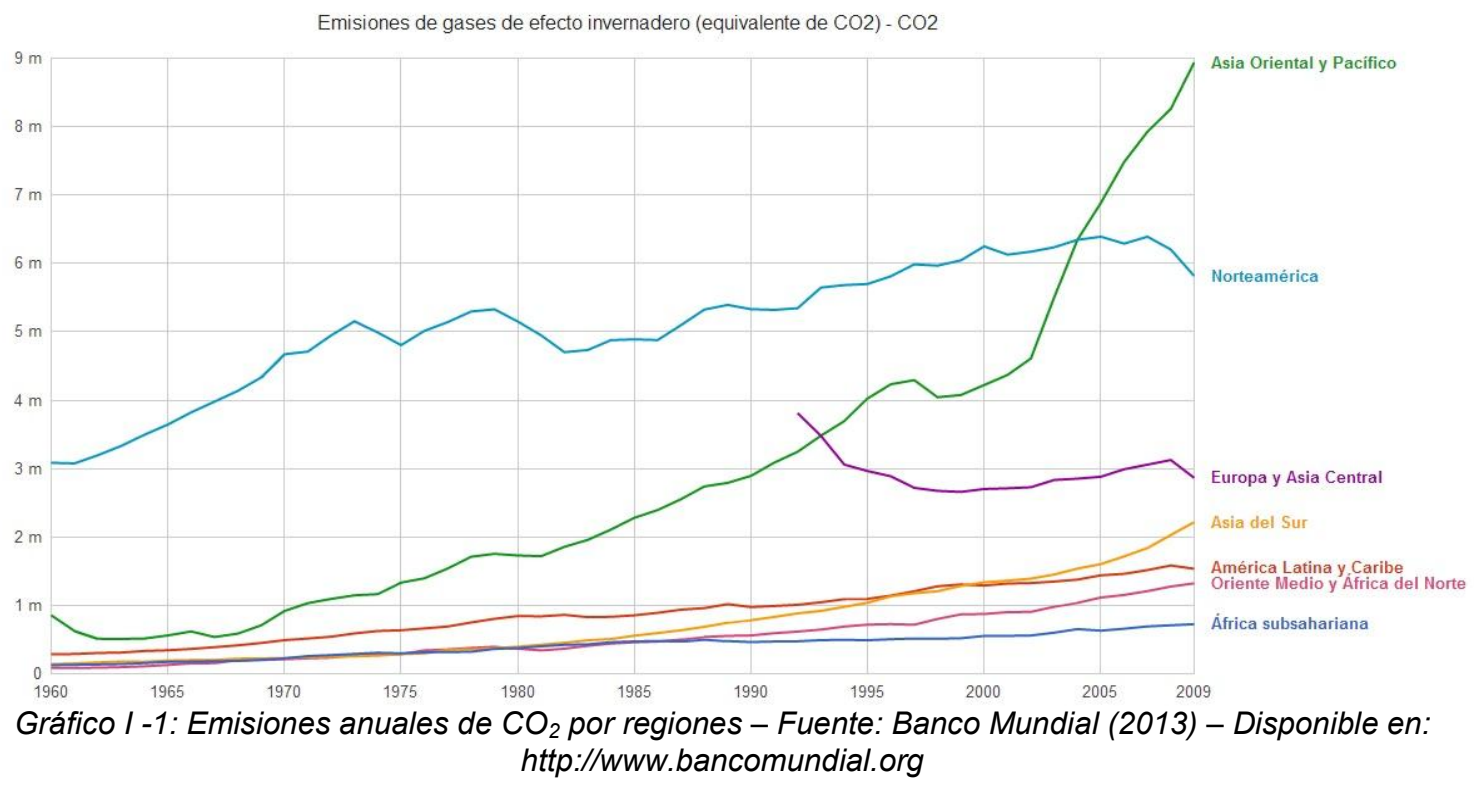

Desde la revolución industrial hasta hoy, el planeta ha aumentado su temperatura en $0,74^{\circ} \mathrm{C}$. Muchos de los impactos que se observan en la actualidad se han manifestado antes de lo que 
se había pronosticado. Las consecuencias del cambio climático se vuelven más alarmantes cada año. Aumenta la intensidad de las tormentas, las precipitaciones y los vientos son más fuertes, y resulta más difícil predecir su aparición en función de las estaciones en los países cercanos a los grandes océanos. Por su parte, la sequía hace que la agricultura sea insostenible en zonas que antes eran productivas y, como resultado, las naciones comienzan a depender de ayudas para obtener alimentos, lo que amenaza su salud y prosperidad (Intergovernmental Panel on Climate Change; 2001).

Entre las consecuencias que puede producir el cambio climático, de continuar la tendencia de emisiones, se destacan las siguientes:

- Elevación del nivel del mar debido al deshielo de los glaciares y a la expansión térmica de los océanos como consecuencia del aumento de las temperaturas.

- Liberaciones de gases de efecto invernadero, provocadas por el deshielo del permafrost y la desaparición de bosques.

- Aumento de eventos climáticos extremos como olas de calor, sequías e inundaciones.

- Amenazas a sistemas naturales como glaciares, arrecifes de coral, bosques, humedales y praderas.

- Riesgos de extinción de especies y pérdida de biodiversidad.

Los mayores impactos los sufrirán los países más pobres de África, Sureste asiático y Sudamérica, así como las pequeñas islas con menor capacidad de protección ante el aumento de sequías y la subida del nivel del mar, el aumento de enfermedades y la caída de la producción agrícola. Argentina no está exenta al problema, en los últimos años hemos sido testigos de fenómenos climáticos como sequías, inundaciones, tormentas destructivas, etc. que cada vez son más frecuentes en nuestro país (Figuras I -1 y 2).
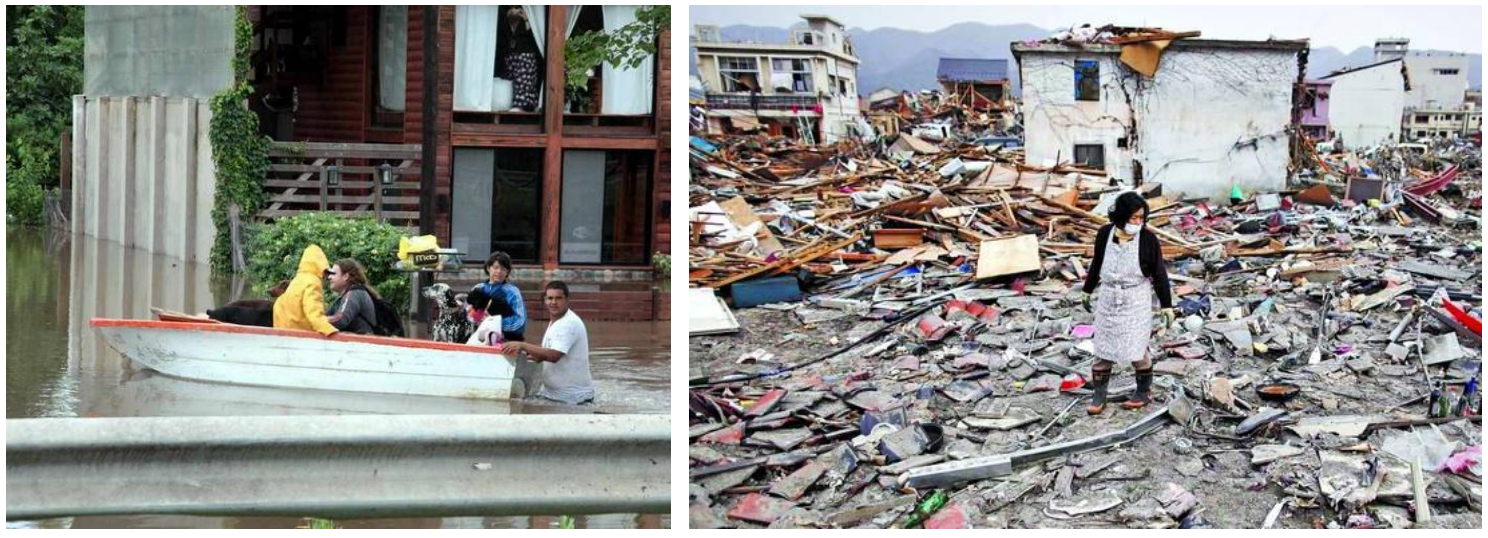

Figuras I - 1 y 2: Inundación en Santa Fe, Argentina (Año 2012). Tsunami en Japón (Año 2011) - Fuente: Diario Clarín, Argentina - Disponible en: http://www.clarin.com

Si no se adoptan medidas políticas inmediatas contra el cambio climático las temperaturas promedio globales se elevarán más de $2^{\circ} \mathrm{C}$ y las consecuencias serán drásticas. El objetivo de las políticas climáticas se orienta a mantener la temperatura media mundial por debajo de los $2^{\circ} \mathrm{C}$, con un objetivo final de no más de $0,5^{\circ} \mathrm{C}$ por encima de los niveles pre-industriales (Teske et al., 2009).

El aumento de la temperatura de los mares que provoca el calentamiento global contribuye al deshielo de los polos. Como consecuencia, el nivel del mar asciende, alterando las corrientes marinas y generando aún más cambios en los patrones climáticos. Asimismo el ascenso del nivel del mar supone una amenaza directa para las ciudades. El hecho de que la mayoría de las grandes ciudades del mundo estén a nivel del mar compromete su propia supervivencia. No se trata solamente del anegamiento de calles y rutas sino también de los servicios subterráneos de los que dependen como abastecimiento de agua, saneamiento, transporte subterráneo, electricidad, etc. Se verán afectados incluso aquellos que no viven ni trabajan en las ciudades ya que la mayor parte de la producción de alimentos proviene de las tierras agrícolas fértiles situadas en llanuras de inundación y, con el ascenso del nivel del mar, gran parte de estos terrenos se perderán (Roaf, S.; 2005). 
La producción de $\mathrm{CO}_{2}$ es un fenómeno esencialmente urbano, pero el grado de emisión depende de varios factores como el clima, los modelos de uso del suelo, la densidad de población y el estilo de vida. En la actualidad las emisiones de $\mathrm{CO}_{2}$ aumentan a pesar de los acuerdos internacionales y de las mejoras en la eficiencia energética de los edificios que se están llevando a cabo en distintas partes del mundo, especialmente en los países más desarrollados. Este aumento de las emisiones de $\mathrm{CO}_{2}$ se debe principalmente a tres factores:

- Aumento de la población mundial (se espera que llegue a los diez mil millones para el año 2050).

- Subsistencia de edificios obsoletos en materia energética, poco eficientes.

- Aumento de las expectativas de confort interior, relacionado de forma directa con el aumento del consumo energético.

Aproximadamente el $40 \%$ de las emisiones que contribuyen al calentamiento global son resultado del empleo de combustibles fósiles para lograr el confort interior en edificios mientras que otra gran parte de las emisiones se debe al transporte de personas y mercancías relacionadas con esos edificios. Las ciudades son, por lo tanto, responsables de entre el $75 \%$ y el $80 \%$ del total de emisiones de $\mathrm{CO}_{2}$ que produce el hombre, y constituyen la principal causa del cambio climático (Gráfico I - 2).

\section{Emisiones de $\mathrm{CO}_{2}$ mundiales por sector}

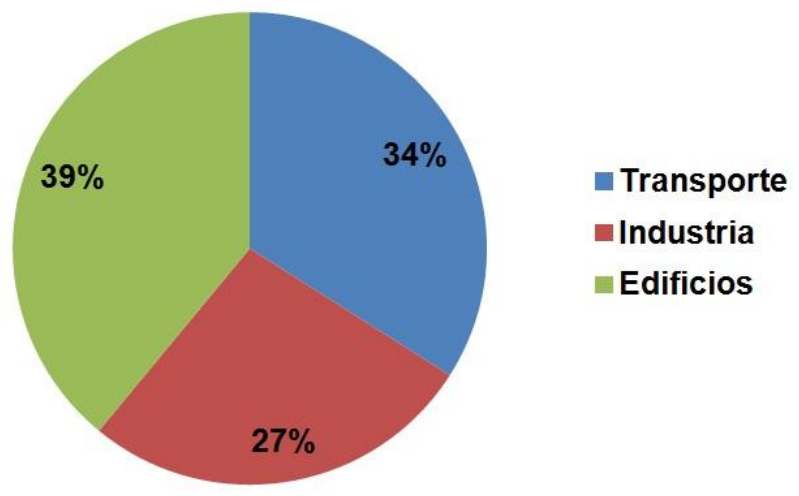

Gráfico I - 2: Emisiones de $\mathrm{CO}_{2}$ mundiales por sector - Fuente: U.S. Department of Energy, Estados Unidos (2009) - Disponible en: http://energy.gov

La mayoría de los aumentos observados en la temperatura media de la Tierra desde la mitad del Siglo XX son debido al aumento de las concentraciones de gases de efecto invernadero. Si bien los gases de efecto invernadero más importantes están presentes en la atmósfera de forma natural, su concentración puede verse modificada por el hombre. Asimismo existen algunos gases artificiales que son producto de la actividad industrial y que también contribuyen de manera notable al calentamiento global (Roaf, S.; 2005).

Si las emisiones de gases de efecto invernadero continúan creciendo, el calentamiento global también continuará. Para los próximos 100 años se estima un aumento de la temperatura de entre 1,1 a $6,4^{\circ} \mathrm{C}$. Considerando que la vida útil de un edificio es de entre 50 y 150 años aproximadamente, resulta evidente pensar que el problema que deberán afrontar muchos de los edificios que se diseñan en la actualidad es muy grave, ya que tendrán que soportar condiciones de temperatura muy distintas en el futuro. Sin embargo existe otro problema mayor en relación a los edificios que conforman las ciudades actuales y es que la mayoría de ellos fueron proyectados cuando la escasez de las fuentes de energía convencionales no era un inconveniente, y se desconocían los riesgos del cambio climático (Edwards, B.; 2005). En los países más desarrollados se están implementando fuertes medidas al respecto. Tal es el caso de la Unión Europea, que a través de la Directiva 2010/31/UE sobre eficiencia energética en edificios exige a los Estados miembros que tomen las medidas necesarias para garantizar el cumplimiento de los requisitos mínimos fijados en los acuerdos internacionales. 
Por su parte, en la Cumbre de la Tierra celebrada en 1992, en Río de Janeiro, se establecieron 27 principios sobre el desarrollo sustentable de los cuales podrían destacarse los siguientes puntos:

- Los seres humanos constituyen el centro de las preocupaciones relacionadas con el desarrollo sustentable. Tienen derecho a una vida saludable y productiva en armonía con la naturaleza.

- El derecho al desarrollo debe ejercerse en forma tal que responda equitativamente a las necesidades de desarrollo y ambientales de las generaciones presentes y futuras.

- A fin de alcanzar el desarrollo sustentable, la protección del medio ambiente debe constituir parte integrante del proceso de desarrollo y no podrá considerarse en forma aislada.

- Para alcanzar el desarrollo sustentable y una mejor calidad de vida para todas las personas, los Estados deben reducir y eliminar las modalidades de producción y consumo insustentables y fomentar políticas demográficas apropiadas.

- Los Estados deben cooperar efectivamente para desalentar o evitar la reubicación y la transferencia a otros Estados de actividades y sustancias que causen degradación ambiental grave o se consideren nocivas para la salud humana.

- Debe movilizarse la creatividad, los ideales y el valor de los jóvenes del mundo para forjar una alianza mundial orientada a lograr el desarrollo sustentable y asegurar un mejor futuro para todos.

Estos principios fomentan la creación de nuevos patrones de producción y promueven el uso de energías alternativas para reemplazar el uso de combustibles fósiles, los cuales están directamente relacionados con el cambio climático.

En el ámbito urbano es sumamente importante mejorar los sistemas de transporte público, de modo de reducir las emisiones debidas a vehículos, la congestión del tránsito en las ciudades y los problemas de salud, relacionados con la contaminación del aire y el smog. Sin embargo no se puede evadir la responsabilidad de los edificios sobre esta problemática. Estos constituyen la principal tipología del ámbito urbano y son los mayores consumidores de energía primaria. Se estima que aproximadamente entre un 35 y un $40 \%$ de la energía primaria del mundo es utilizada para acondicionamiento interior de edificios destinados a viviendas y oficinas (Hernández, A.; 2010).

La energía está en el centro del problema, ya que no sólo es el sector de mayores emisiones de gases de efecto invernadero sino el que genera el crecimiento más rápido de estas emisiones. Reducir los daños del cambio climático requiere de un cambio importante en las fuentes y modos de consumo energético. La mayor eficiencia y el uso de energías limpias y renovables abren posibilidades que deben afianzarse con nuevas y mejores tecnologías. Entendido de este modo el cambio climático representa una gran oportunidad. Es importante destacar que todavía es posible impedir el cambio descontrolado y generar una revolución en la forma en que se aprovechan y utilizan los recursos. Es posible crear una sociedad sustentable, con nuevas tecnologías y comportamientos que contribuyan a la reducción de las emisiones de carbono (Teske et al.; 2009).

El informe realizado por Greenpeace International y por el European Renewable Energy Council para Argentina en el año 2009 señala que la urgencia del cambio climático exige en nuestro país una revolución energética inmediata. Este informe marca la necesidad de transformar de forma total el modo en que se produce, consume y distribuye la energía, sin afectar al desarrollo económico del país. La generación actual de electricidad en Argentina se basa principalmente en la quema de combustibles fósiles en centrales eléctricas de gran tamaño que derrochan la mayor parte de la energía primaria de origen. Es necesario aprender a respetar los límites naturales y aprovechar la energía en forma eficiente, utilizando las tecnologías existentes (Barros, V.; 2009).

Hoy en día las fuentes de energía renovable abarcan solamente el $13 \%$ de la demanda de energía primaria en el mundo. La biomasa, utilizada mayoritariamente para la generación de calor, es la principal fuente de energía renovable. La contribución de las energías renovables a la generación de electricidad es del $18 \%$, y su contribución a la demanda de energía primaria como suministro térmico es del orden del $24 \%$, mientras que la mayor parte del suministro de 
energía primaria, aproximadamente el $80 \%$, proviene de los combustibles fósiles y el $6 \%$ restante de la energía nuclear (International Energy Agency; 2011).

\subsection{El cambio climático en el mundo}

Los impactos que el cambio climático genera en los ecosistemas, la población y la economía presentan nuevos desafíos para los países, fundamentalmente para los menos desarrollados, que son más vulnerables debido a que tienen una menor capacidad para absorber, amortiguar o mitigar los efectos de dichos cambios.

Las emisiones de gases de efecto invernadero se calculan sobre la base de los datos de consumo de combustibles, las emisiones provocadas por escapes de combustible, los procesos industriales, el uso de disolventes, la agricultura, los cambios en el uso de la tierra y la silvicultura, los desechos, etc. Sin embargo existen grandes diferencias en el consumo de combustibles fósiles $y$, por consiguiente, en las emisiones de gases de efecto invernadero, entre los diferentes países del mundo (Gráfico I - 3). En Estados Unidos por ejemplo, estos gases son producidos fundamentalmente por el consumo de petróleo para el transporte de gas para calefacción de viviendas. En gran parte de Europa del Este y China, el principal problema es el carbón, no sólo por las emisiones de gases de efecto invernadero, sino también de otros contaminantes, como el $\mathrm{SO}_{2}$ y los $\mathrm{SO}_{x}$ que provocan enfermedades respiratorias y lluvia ácida. El carbón es la base del $70 \%$ de la energía producida en China, lo que convierte a este país en el segundo productor mundial de gases de efecto invernadero, después de Estados Unidos (Edwards, B.; 2005).

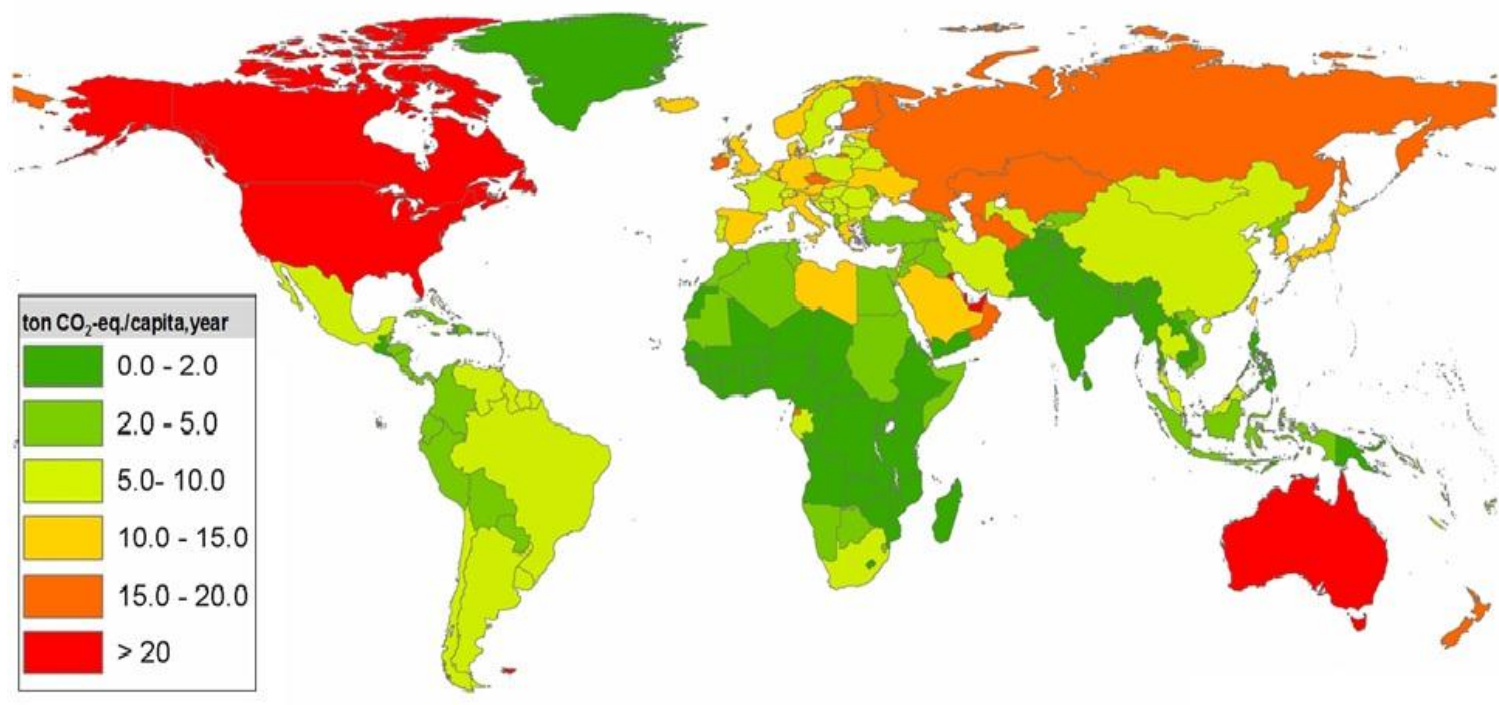

Gráfico I - 3: Emisiones mundiales de $\mathrm{CO}_{2}$ per cápita - Fuente: EDGAR (Emission Database for Global Atmospheric Research, 2009) - Disponible en: http://edgar.jrc.ec.europa.eu/faq.php

La generación de energía eléctrica es un tema fundamental para el desarrollo de una región. En la medida que el bienestar socioeconómico de un país crece, debe aumentar la capacidad de satisfacer unos requerimientos de energía eléctrica cada vez mayores. El Gráfico I - 4 muestra la relación entre el Producto Bruto Interno (PBI) y la Intensidad Eléctrica de diferentes países. Puede verse claramente que los países en vías de desarrollo, que presentan un menor $\mathrm{PBI}$, son los que disponen de una menor Intensidad Eléctrica mientras que los países desarrollados, con un mayor $\mathrm{PBI}$, son los que poseen una mayor Intensidad Eléctrica (Cardinali, L.; 2012).

El crecimiento económico es un conductor de la demanda energética. Desde el año 1970, cada $1 \%$ de aumento del Producto Bruto Interno ha estado acompañado por un aumento del $0,6 \%$ en el consumo de energía primaria. Sin embargo existe una diferencia significativa entre los niveles de consumo de los Estados Unidos, con 11,4 kW por persona y los de Japón y Alemania, con $6 \mathrm{~kW}$ por persona. La población de Estados Unidos representa el $5 \%$ del total del mundo y consume el $25 \%$ de la energía mundial. No obstante, durante los últimos 
años el consumo de electricidad per cápita en Estados Unidos ha decrecido 1\% por año. Este descenso en el consumo de electricidad se debe principalmente a los aumentos de la eficiencia y al uso de lámparas de bajo consumo o LED (Cardinali, L.M.; 2012).

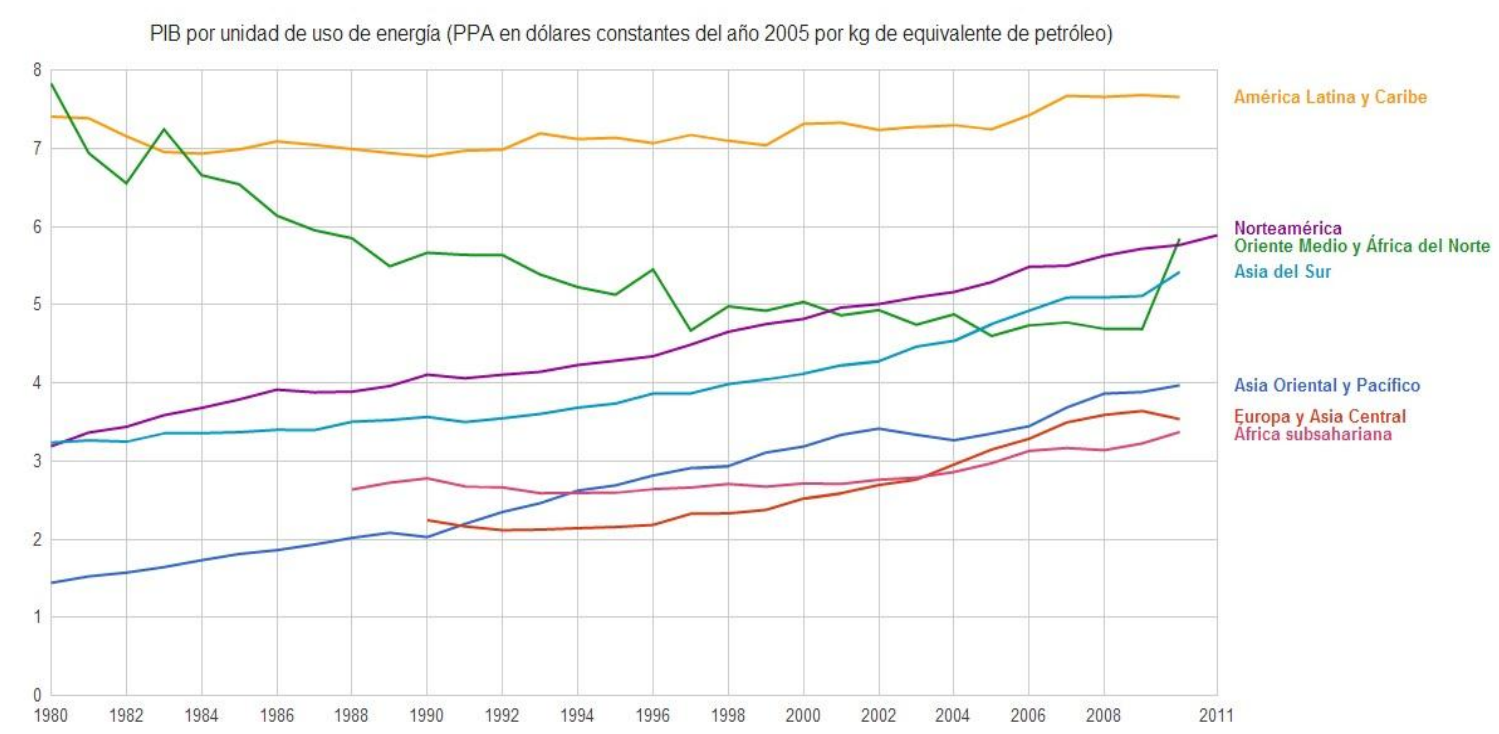

Gráfico I - 4: Relación entre el Producto Bruto Interno (PBI) y la Intensidad Eléctrica por regiones Fuente: Banco Mundial (2013) - Disponible en: http://www.bancomundial.org/

A partir de 1970 China se ha convertido en el país con más rápido crecimiento económico y poblacional del mundo, y es el segundo mayor productor y consumidor de energía primaria. Durante el período 1980-2006 el consumo de energía en China se ha incrementado un 5,6\% anual, impulsando un crecimiento económico anual del 9,8\%. Aproximadamente la mitad de los nuevos edificios construidos en el mundo se hallan en China; se trata de aproximadamente dos billones de metros cuadrados de nuevos edificios por año. Asimismo más del $90 \%$ de estos nuevos edificios son considerados grandes consumidores de energía. El consumo de energía en edificación ha crecido de $10 \%$ del total de energía primaria nacional hacia finales de 1970, a más del $25 \%$ en el 2006 , y se espera que sea del $35 \%$ para el 2020 . Los edificios son responsables de aproximadamente el $18 \%$ de las emisiones de $\mathrm{CO}_{2}$ relacionadas con el consumo energético en China. Cabe aclarar que en el año 2001 la intensidad energética de este país era tres veces mayor a la de Estados Unidos y siete veces mayor a la de Japón (Zhou, N.; Lin, J.; 2008).

En los países de la Organización para la Cooperación y el Desarrollo Económicos (OCDE) a pesar de que la eficiencia en el uso de energía es alta, se están desarrollando nuevas propuestas con el fin de obtener un mejor provecho. En muchos lugares se ha alcanzado una eficiencia superior al $80 \%$, sin embargo se están estudiando nuevas mejoras. A pesar de que aproximadamente a un $90 \%$ del nivel de eficiencia térmica, las modificaciones que se producen no implican un ahorro económico significativo, éstas se llevan a cabo debido a otras razones como ser el cumplimiento de códigos de edificación, acuerdos internacionales sobre las emisiones de gases de efecto invernadero y problemas relacionados con la energía, mayormente en países que dependen de la importación de combustibles (OCDE; 2011).

En la Unión Europea (UE) por su parte, los edificios utilizan el $40 \%$ del total de la energía final consumida y son responsables de aproximadamente el $40 \%$ del total de las emisiones de $\mathrm{CO}_{2}$ de los países miembros de la UE. La dependencia energética media de la Unión Europea se ha incrementado hasta alcanzar el $56 \%$ en el 2006 con un incremento de 4,5\% entre el 2004 y el 2005. Como consecuencia la política energética en Europa tiene una orientación explícita hacia la preservación y el uso eficiente de la energía en edificios (Directiva 2002/91/EC; 2002).

El mundo desarrollado es líder en las energías alternativas con más del $70 \%$ de la capacidad instalada mundial. Sin embargo también cuenta con un $75 \%$ de la capacidad instalada mundial 
en energía nuclear. Por ejemplo en el Reino Unido y en Francia este impulso hacia las tecnologías alternativas y la búsqueda de la eficiencia energética se debe a que para el año 1999 tenían desarrollados el $100 \%$ de sus recursos hídricos técnica y económicamente explotables. Alemania por su parte los tenía en un $85 \%$. Es por ello que la cuestión principal que impulsó en estos países el desarrollo de tecnologías alternativas era la necesidad de cubrir la demanda energética creciente. Actualmente el recurso hídrico ya ha sido explotado, dado lo cual deben apelar necesariamente a otras fuentes para poder cubrir la creciente demanda sin tener que recurrir a las importaciones y sin que caiga su Intensidad Eléctrica y, por lo tanto, sin renunciar al bienestar socioeconómico (Cardinali, L.; 2012).

La situación difiere bastante en los países en vías de desarrollo como la Argentina donde el crecimiento rápido implica la creación de edificios de vivienda y servicios que son construidos según surgen las necesidades. En las últimas décadas, muchos países en vías de desarrollo han experimentado un rápido crecimiento que no ha sido acompañado con mejoras en las técnicas utilizadas en la construcción de edificios ni en los códigos de edificación, esto requiere de mucho tiempo de investigación y discusiones políticas de los que, en la mayoría de los casos, no se dispone. Por otra parte, en estos países los precios de la energía suelen ser bajos y entonces la calidad deficiente de la envolvente edilicia debe ser solventada con un alto consumo energético (Juanicó, L.; Gonzalez, A.; 2008).

Sudamérica es la contracara de Europa. Por ejemplo, para el año 1999 Brasil, líder en el continente en la utilización de los recursos hídricos para la generación de energía eléctrica, tenía desarrollado solamente el $19 \%$ de sus recursos técnica y económicamente explotables. Sin embargo, es importante destacar que si bien la capacidad instalada en hidroelectricidad en los países en vías de desarrollo es baja, ésta representa el $55 \%$ del total mundial frente al $30 \%$ de los países más desarrollados (Cardinali, L.; 2012). Esto es así porque los países de Sudamérica son ricos en recursos naturales y no llegan a hacer un uso intensivo de los mismos, a diferencia de lo que ocurre con los países más desarrollados donde los recursos son escasos y donde el uso que se hace los mismos es intensivo.

\subsection{El cambio climático en la Argentina}

Según el informe realizado por Greenpeace International y por el European Renewable Energy Council para Argentina, la matriz energética argentina posee una altísima dependencia de los combustibles fósiles; un $90 \%$ de la energía primaria que se consume proviene básicamente del petróleo y del gas natural. Para el año 2009, la alta dependencia de los combustibles fósiles de la Argentina determinaba que la situación energética de nuestro país era complicada y que más allá de los esfuerzos exploratorios de gas, petróleo y carbón, existía un consenso generalizado en el sector acerca de que era muy improbable la aparición de nuevos yacimientos importantes (Barros, V.; 2009). Sin embargo en el año 2011 la empresa YPF anunció el descubrimiento de un yacimiento de petróleo y gas no convencionales de una extensión de $30.000 \mathrm{~km}^{2}$ (Figuras I 3 y 4$)$.

Mediante el desarrollo de los recursos probables de shale gas y tight sand gas (gas de esquistos y de arenas compactas), y de shale oil (petróleo en roca madre) la Argentina podría comenzar a revertir el déficit que tiene el sector energético a partir de la caída de las reservas de gas y petróleo desde 2004. Un informe de la Administración de Información Energética del Departamento de Energía de Estados Unidos sobre las perspectivas mundiales del shale gas asegura que Argentina sería el tercer país del mundo con mayor dotación de este recurso, con un $11 \%$ del total estimado a nivel global, detrás de China y Estados Unidos. Sin embargo se trata de un trabajo a largo plazo que implica la utilización de tecnologías muy costosas para extraer el gas y petróleo entrampados en las rocas. Asimismo una vez confirmadas las reservas, se necesitan hacer los estudios de factibilidad técnica, económica y ambiental, para evaluar si es comercialmente explotable, y sólo después de ello poder hablar de reservas probadas (Boyadjián, C.; 2011). 

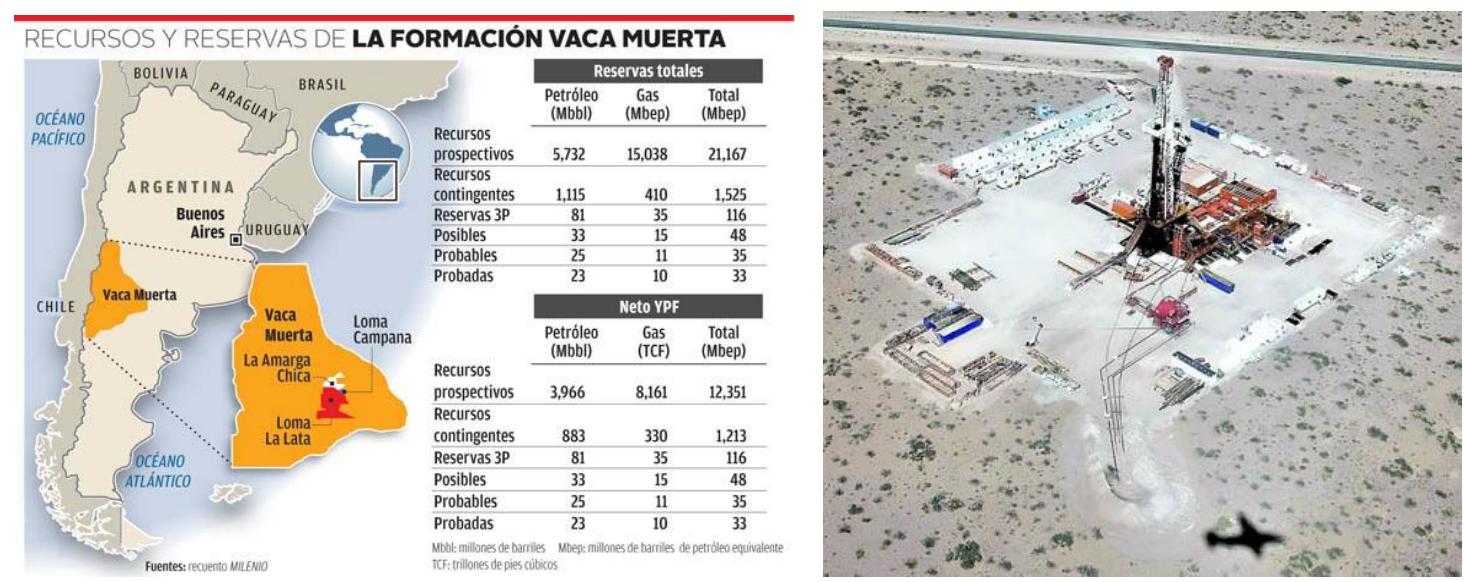

Figuras I - 3 y 4: Ubicación del Yacimiento Vaca Muerta, Neuquén (Argentina) y vista aérea de la explotación - Fuente: Diario Comunicación Popular, Argentina (2012) - Disponible en:

http://comunicacionpopular.com.ar

La mayoría de los expertos coincide en que la pelea entre el gobierno argentino y los ex socios españoles de YPF surgió por cómo se repartirían las ganancias cuando la explotación de la cuenca comenzara a rendir utilidades y quién se haría cargo de las inversiones que se necesitan para extraer las riquezas. A diferencia del gas y el petróleo convencional, que conforman mantos horizontales de fácil acceso, el shale gas y el shale oil se encuentran encapsulados entre las vetas de la roca madre. Para explorar esas cápsulas y luego extraer su contenido se utiliza la técnica del fraking que consiste en perforar la roca en diagonal, con equipamiento de alta tecnología y muy costoso. Para comenzar a extraer los combustibles contenidos en el suelo harían falta 40.000 millones de dólares mientras que las extracciones que se han hecho hasta el momento no alcanzan a cubrir los gastos de mantenimiento de los equipos que se utilizan. (Wurgaft, R.; 2012)

Hasta el descubrimiento del yacimiento Vaca Muerta, en Neuquén, la extracción de gas se mantenía estable pero la relación entre las reservas comprobadas y la extracción anual se declinaba de manera constante (Gráfico I - 5). Sabiendo que los hallazgos de Vaca Muerta son recursos potenciales para los cuales se requiere de una fuerte inversión inicial, y dada la escasa disponibilidad de recursos fósiles comprobados de los que dispone actualmente Argentina, en los próximos años nuestro país debería producir un cambio radical en su matriz energética, de modo de reducir su fuerte dependencia del petróleo y gas, y ampliar la participación de fuentes energéticas limpias y renovables. Actualmente Argentina importa gas natural, gas licuado (GNL) y fuel oil para paliar la escasez de gas natural destinado al uso residencial durante la temporada invernal, situación que se ha agravado en los últimos años y que si bien podría revertirse con la explotación del yacimiento Vaca Muerta, esto requiere de una gran inversión como ya se ha mencionado anteriormente.
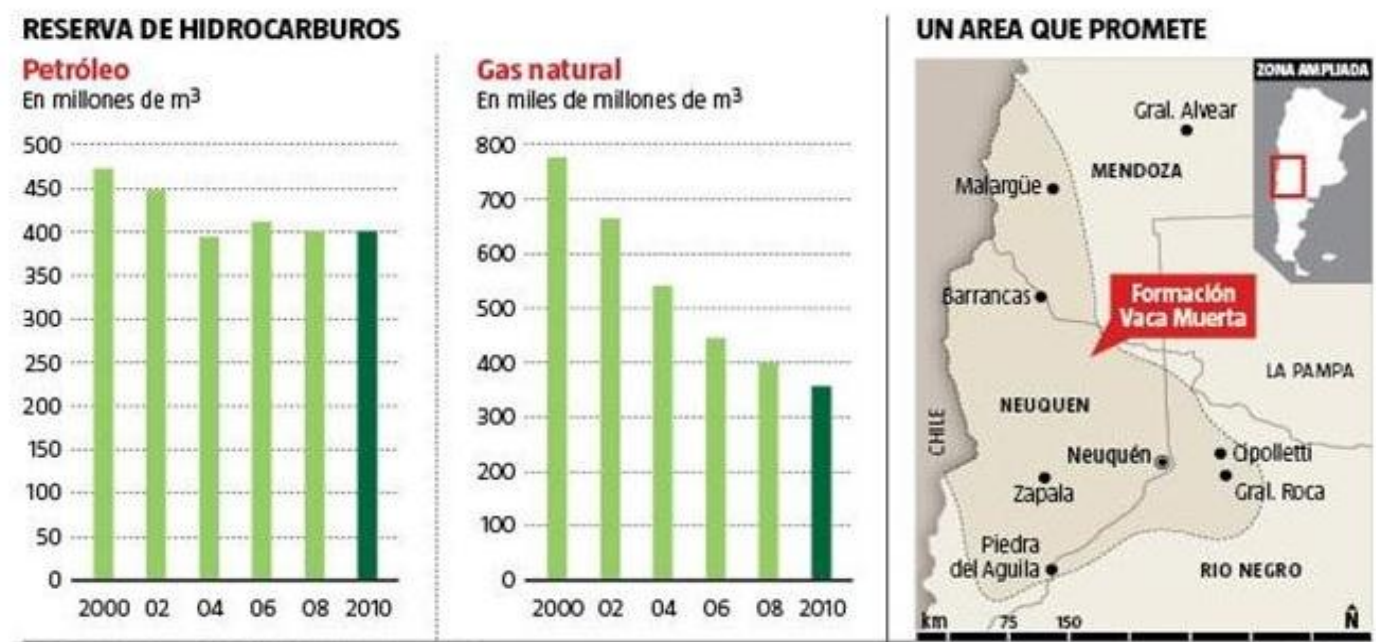

Gráfico I - 5: Reservas de hidrocarburos en Argentina - Ubicación del yacimiento Vaca Muerta, Neuquén

(Argentina) - Fuente: Diario La Nación, Argentina (2012) - Disponible en: http://www.lanacion.com.ar 
El sistema eléctrico de nuestro país también enfrenta dificultades para satisfacer la demanda creciente, mientras que la oferta se ha mantenido constante en los últimos años. La falta de gas ha hecho que las inversiones realizadas años atrás en centrales térmicas de ciclo combinado en base a gas natural hayan tenido que recurrir a combustibles líquidos incrementando así sus costos operativos. Otro indicio de la situación crítica que afronta nuestro país en la actualidad es la compra de electricidad a Brasil, a costos muy por encima de los que se pagan internamente (Teske et al.; 2009).

El consumo de energía primaria en Argentina se distribuye principalmente entre los edificios (residenciales, oficinas y públicos), que consumen aproximadamente el $30 \%$ de la energía primaria disponible en el país; la industria, que consume el $27 \%$, y el transporte, que consume otro $30 \%$. Aproximadamente el $50 \%$ de la matriz energética del país depende del Gas Natural. El 30\% del consumo de este recurso está destinado a la generación de energía eléctrica y a la climatización de edificios destinados a viviendas, oficinas y edificios públicos. La industria, por su parte, consume aproximadamente otro $30 \%$ de este recurso (Hernández, A.; 2010).

En los primeros años posteriores a la crisis del 2001 el sector productivo creció como consecuencia de la demanda externa. Este crecimiento de la actividad industrial se vio acompañado por un incremento en la utilización de la capacidad energética instalada y la consecuente mejora de la eficiencia energética. En estos primeros años posteriores a la crisis del 2001 el bajo costo laboral permitió al país posicionarse internacionalmente en actividades que requerían de mano de obra intensiva. En aquel entonces el consumo de energía en manos del sector productivo aumentó debido no sólo al crecimiento de la actividad productiva con respecto a la crisis del 2001 sino también por el predominio de industrias energo-intensivas. Actualmente los problemas energéticos son una restricción en la actividad económica de Argentina. La debilidad del sistema eléctrico y la ausencia de suministro de combustibles líquidos o de gas natural repercuten tanto en el sector residencial como en el productivo, que sufre restricciones y recortes en la disponibilidad de energía, especialmente en las temporadas de mayor consumo (Teske et al.; 2009).

Sin embargo, los consumos energéticos del sector residencial y comercial se han visto menos afectados por los vaivenes económicos que el consumo energético final total del país. Dentro del sistema eléctrico existe una parálisis de nuevas inversiones privadas y las inversiones que se desarrollan desde el Estado no alcanzan a cubrir la brecha que se está produciendo entre oferta y demanda. Asimismo, por lo general, se trata de inversiones en opciones energéticas ineficientes, costosas y que profundizan una matriz energética que aleja al país de un modelo sustentable (Teske et al., 2009).

En lo que respecta al transporte, en los últimos años se ha experimentado un incremento en la cantidad de vehículos por habitante y al uso que se hace de los mismos especialmente en las principales ciudades del país y entre ellas, principalmente en aquellas que conforman el Área Metropolitana de Buenos Aires, en donde adquieren un rol protagónico las redes viales que comunican la Capital del país con las localidades próximas que funcionan como "ciudades dormitorio". Pese a políticas impulsadas desde el gobierno de la Ciudad de Buenos Aires aún son muchos los habitantes que prefieren el vehículo propio al transporte público para desplazarse desde su casa al trabajo. Sin embargo cabe destacar que los consumos de combustibles se ven amortiguados por la incorporación de vehículos energéticamente más eficientes, y por las sustituciones de nafta por diesel y GNC. Actualmente el consumo de gasoil representa el $52 \%$ del consumo total del sector, y el GNC el 23\% (Teske et al.; 2009).

En la actual política energética el actor preponderante es el Estado Nacional, ya sea por medio de inversiones de empresas públicas, como por medio de subsidios a empresas privadas. Actualmente no existe una valoración ambiental y económica de largo plazo en las prioridades de inversión. La mayor parte de estas inversiones estatales incrementan la dependencia en los combustibles fósiles o incluso en la energía nuclear (Gráfico I - 6). Las energías renovables se ubican en un rol marginal desconociendo el potencial existente en el país y las tecnologías disponibles en la actualidad. En los últimos años el Estado Nacional ha venido utilizando cada vez más subsidios para sostener precios y tarifas en el sector que no reflejan la realidad económica y ambiental de la actividad energética. Si bien en el período post-crisis económica del 2001 fue necesario sostener las tarifas para evitar un grave impacto social y económico, 
este modelo de emergencia debió ser reemplazado progresivamente por uno nuevo, que permita alcanzar un punto de equilibrio tal que lo haga económicamente sustentable. Al no reflejarse en las tarifas los costos reales para la operación del sistema y la necesaria ampliación del mismo, la oferta energética no ha podido seguir la evolución de una demanda creciente. De igual manera, la aplicación de subsidios en las tarifas ha tenido un efecto doblemente perjudicial; por un lado ha estado beneficiando a los sectores de mayor consumo mientras que por otro, ha incentivado el sobreconsumo, exacerbando el problema de escasez de oferta (Barrios, V.; 2009).

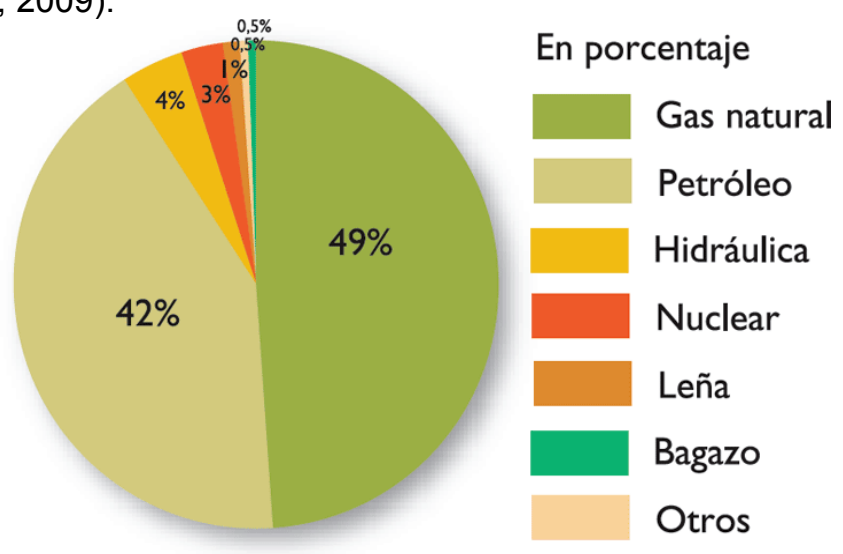

Gráfico I - 6: Consumo de energía primaria en Argentina (año 2009) - Fuente: Secretaría de Energía de la Nación - Disponible en: http://www.energia.gov.ar

En lo que respecta al sistema eléctrico de nuestro país es importante mencionar que se han ampliado las redes de alta tensión. Ya en el año 1999 la Secretaría de la Energía de la Nación, por medio de la Resolución R.S.E. No657 dispuso la constitución de un fondo fiduciario con objeto único. En el año 2000 éste fue modificado por la R.S.E. №174, ampliando la aplicación del fondo. De este modo la Secretaría de Energía de la Nación identificó un listado de líneas eléctricas, como ampliaciones del sistema de transporte, destinadas al abastecimiento de la demanda o a la interconexión de regiones eléctricas para mejoras de calidad y/o seguridad. El conjunto de estas líneas integró el denominado Plan Federal de Transporte Eléctrico en 500kV (Figura I - 5), el que comprende la interconexión Comahue-Cuyo, la interconexión NOA-NEA, la interconexión Cuyo-NOA, la interconexión del MEM con el MEMSP y la interconexión de la región atlántica de la Provincia de Buenos Aires (Secretaría de Energía; 2000).

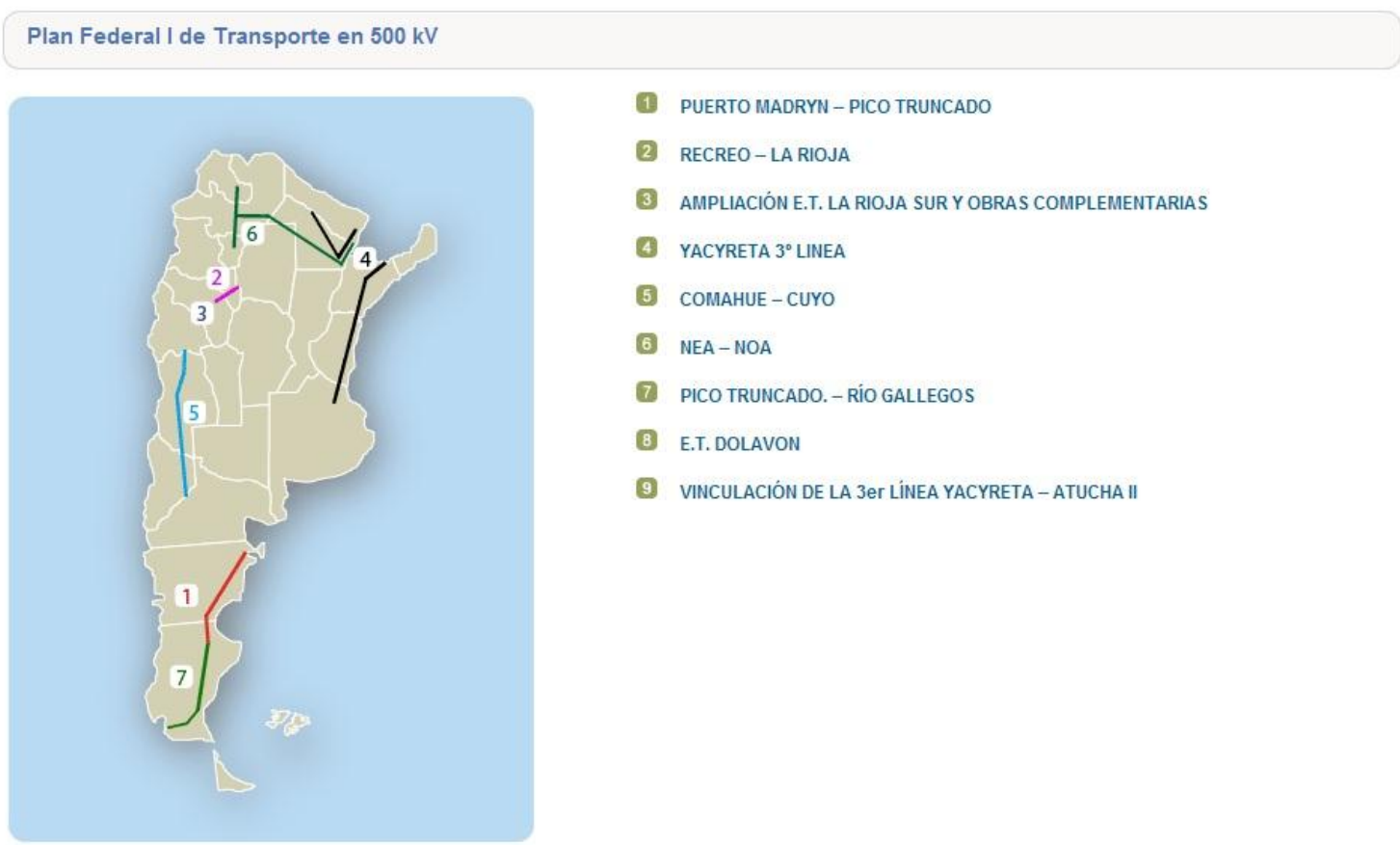

Figura I - 5: Plan Federal de Transporte Eléctrico en 500kV (año 2000) - Fuente: Secretaría de Energía de la Nación - Disponible en: http://www.energia.gov.ar 
Este plan representa un importante potencial para el país en materia de energías renovables ya que facilita la conexión de distintas regiones de la Argentina con gran potencial energético renovable, permitiendo el máximo aprovechamiento de los recursos disponibles (solar, eólico, geotermia, etc.).

Los programas de eficiencia energética son relativamente nuevos en la Argentina; comenzaron a desarrollarse en respuesta a la crisis energética actual pero sin planificación previa. Tal es el caso del "Programa Nacional de Uso Eficiente y Racional de la Energía Eléctrica" (PRONUREE), implementado por el Decreto 140/2007 del Poder Ejecutivo Nacional, el cual tiene previstos ahorros en períodos de corto, mediano y largo plazo del orden del $7 \%$ de la potencia máxima registrada en el 2007. Entre los objetivos del Programa se encuentran favorecer la optimización en el uso de energía eléctrica en los edificios de la administración pública nacional, sustituir lámparas y otras luminarias por instrumentos más eficientes e implementar ahorros de energía en edificios públicos (Secretaría de la Energía; 2007).

También desde la Secretaría de Energía de la Nación se han impulsado leyes que promueven el uso racional de la energía y la utilización de fuentes de energías renovables. Tal es el caso de la Ley Nacional 26.190 "Régimen de Fomento Nacional para el uso de fuentes renovables de energía destinada a la producción de energía eléctrica" aprobada en el año 2006 y su Decreto Reglamentario 562 del año 2009. Según esta Ley para el año 2016 la Argentina debería alcanzar la meta de $8 \%$ de la generación de electricidad proveniente de fuentes de energía renovable, excluyendo a las hidroeléctricas de más de 30MW (MECON; 2006).

Sin embargo pese a los intentos desde la Secretaría de Energía de la Nación aún no ha generado una política eficaz para introducir masivamente las energías renovables en el país. Algunas de las medidas estructurales más importantes que se han llevado a cabo en los últimos años son el etiquetado energético de electrodomésticos, la reciente Norma IRAM 11.900 sobre etiquetado de eficiencia energética en calefacción para edificios y la prohibición, a partir del año 2011, de la comercialización de lámparas incandescentes. Estas son medidas iniciales, correctas, que comienzan a formar parte de una política de eficiencia energética que debe ampliar sus horizontes.

\subsection{Los centros urbanos y su influencia en el cambio climático}

Hacia 1890 sólo una décima parte de la población vivía en ciudades. En la actualidad aproximadamente la mitad de la población mundial se radica en centros urbanos; en todo el mundo se están produciendo flujos migratorios masivos del campo a las ciudades. Este crecimiento planetario de la población urbana y la precariedad de los modelos de habitabilidad están acelerando el grado de erosión y contaminación del mundo en general. Las ciudades generan la mayoría de los gases que producen el efecto invernadero. En Estados Unidos la polución procedente de las ciudades ya ha mermado un $10 \%$ las cosechas. En Japón, los residuos producidos por la ciudad de Tokio se acercan a los veinte millones de toneladas al año. Ciudad de México ha conseguido secar prácticamente sus dos ríos, y el tráfico de Londres contamina más el aire de lo que lo hacía el combustible de carbón antes de las medidas tomadas en 1956 para controlar la polución. La arquitectura y la planificación urbana deben evolucionar y aportar las herramientas para proteger el futuro del planeta, creando ciudades que produzcan entornos sustentables (Rogers, R.; 2000).

La velocidad de los cambios tecnológicos otorga a la sociedad moderna un potencial enorme que permite a las ciudades albergar cada vez mayor población. A pesar del incremento global de la riqueza, la pobreza empeora y sigue creciendo, y son los centros urbanos los que deben absorber una proporción cada vez mayor de esta población pobre, que queda fuera del ciclo de consumo. La pobreza, el desempleo, el deficiente sistema sanitario y educativo, y los conflictos dificultan la capacidad de las ciudades para ser medioambientalmente sustentables. Según la Organización de las Naciones Unidas Tokio, Delhi, San Pablo, Bombay y Ciudad de México son las cinco aglomeraciones urbanas más pobladas del mundo, con más de 20 millones de habitantes cada una, en general en ellas se produce un gran contraste entre la población rica y los pobres (Organización de las Naciones Unidas; 2009). 
Las ciudades actuales consumen tres cuartas partes de la energía mundial y provocan al menos tres cuartas partes de la contaminación total. Ciudad de México ejemplifica esta doble amenaza, es en la actualidad una de las ciudades más pobladas y contaminadas del mundo. En 1890 su población era de trescientos cuarenta mil habitantes; hoy sobrepasa los veinte millones, con cuatro millones de autos. El nivel de ozono excede el nivel de riesgo permitido durante más de trescientos días al año. Sin embargo la inmigración rural continúa, lo que plantea un gran problema de vivienda ya que se trata de setenta mil nuevos residentes mensuales. En la actualidad Ciudad de México es una de las ciudades del mundo más complejas por las calidades de su asentamiento, la distribución de su población y las características de crecimiento por adición que presenta (Rogers, R.; 2000).

La ciudad es una matriz compleja y cambiante; planificar una ciudad sustentable requiere una amplia comprensión de las relaciones entre ciudadanos, servicios, política de transporte y generación de energía, así como su impacto total sobre el entorno inmediato.

Actualmente, el modelo dominante instaurado en las principales ciudades del mundo es el tomado de Estados Unidos; la ciudad zonificada por sus funciones con áreas de oficinas en el centro, centros comerciales y de ocio en las afueras, y barrios residenciales conectados por autopistas. Sin embargo a diferencia de este modelo, la ciudad compacta puede aportar muchas ventajas ecológicas; las ciudades densas pueden diseñarse mediante una planificación integradora con el fin de aumentar el rendimiento energético, consumir menos recursos, producir menos polución y evitar expandirse sobre el paisaje rural. Las ciudades de forma compacta tienen menos autopistas y más zonas verdes; los parques, jardines, etc. aportan la vegetación que proporciona sombra y refresca las calles, patios y edificios en verano. Las ciudades suelen registrar una temperatura entre dos y cuatro grados más que sus alrededores, efecto que se conoce como "isla de calor", pero al incrementar en número y superficie las zonas verdes, se reduce el calor adicional, racionalizando el uso del aire acondicionado. Las plantas amortiguan también el ruido ambiental y mitigan la contaminación, absorbiendo el dióxido de carbono y produciendo oxígeno. Asimismo las zonas verdes absorben la lluvia y reducen el impacto de las tormentas (Rogers, R.; 2000).

Se estima que existen cerca de quinientos millones de vehículos privados en el mundo (Figuras I - 6 y 7); éstos erosionan la calidad de los espacios públicos y fomentan la expansión metropolitana. El auto permitió a los ciudadanos vivir alejados del centro de las ciudades y facilitar la división de las actividades; separando las oficinas de los comercios y de las viviendas. Cuánto más se expanden las ciudades, menos rentable resulta la expansión de sus sistemas de transporte público y, por lo tanto, los ciudadanos son más dependientes del vehículo privado (Rogers, R.; 2000).
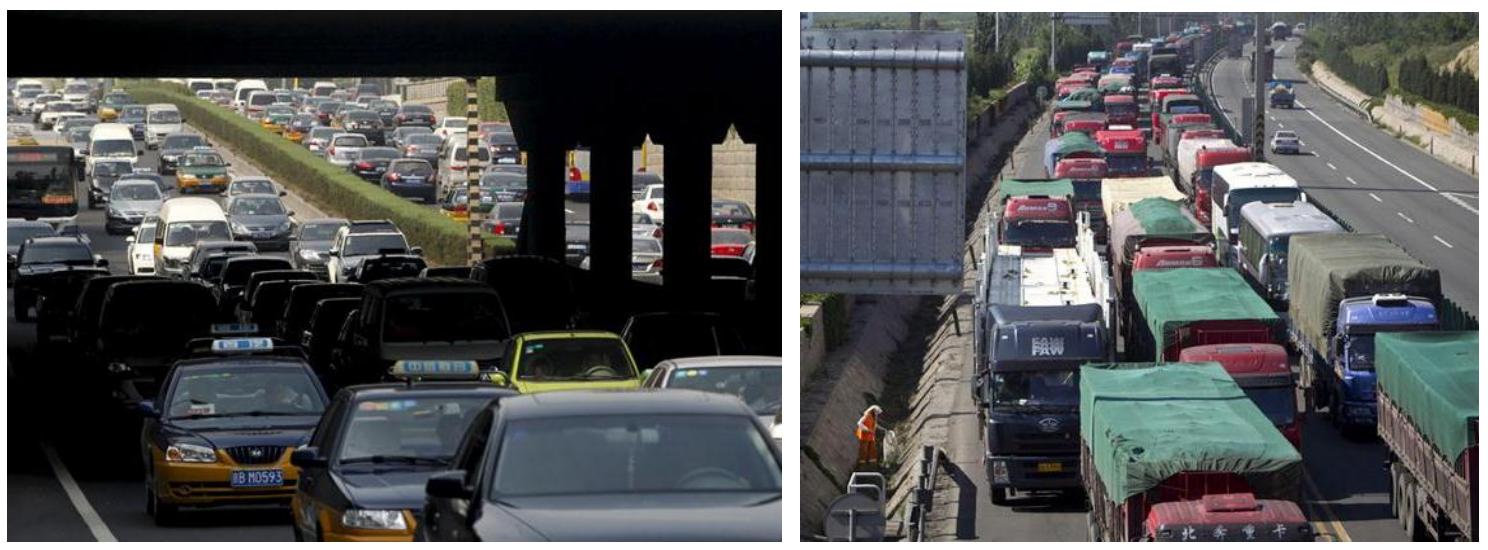

Figuras I - 6 y 7: Embotellamiento de tránsito en China - Fuente: Diario La Nación, Argentina (2010) Disponible en: http://www.lanacion.com.ar

China cuenta aproximadamente con mil quinientos millones de habitantes, que suponen un cuarto de la población mundial. El país está experimentando la mayor migración de su historia desde el campo a las ciudades; en menos de una generación ochenta millones de habitantes se están desplazando a asentamientos informales que rodean las principales ciudades del 
país. Si bien en la actualidad el área metropolitana de Shangai es prácticamente autosuficiente en lo relativo al suministro de vegetales y cereales, la rápida industrialización y urbanización está afectando gravemente la ecología del sistema. Cinco de las diez ciudades con la mayor polución de aire del mundo se encuentran en China, cuatro de los siete sistemas fluviales más importantes del país están contaminados y la lluvia ácida afecta a casi un tercio del territorio nacional. Ciudades como Shenzhen, Dongguan y Zhuhai están arrasando con el campo para suministrar terrenos a la construcción. Las nuevas ciudades chinas se están articulando alrededor de grandes nudos viarios en lugar de confiar en el transporte público (Zhou, N.; Lin, J.; 2008).

También en los países en vías de desarrollo las ciudades se expanden a una gran velocidad, dando como resultado la aparición de asentamientos precarios. Se estima que entre el $30 \%$ y el $60 \%$ de los residentes de las mayores ciudades del tercer mundo habitan en estos asentamientos informales. Estos carecen de los servicios más elementales, tales como desagües cloacales, electricidad y agua corriente. La inestabilidad política, la persecución, el hambre, la deforestación y otras causas graves siguen desplazando a las comunidades rurales hacia las principales ciudades, aunque éstas no estén preparadas para absorberlas ni asegurar su sostén económico. En Bombay cinco millones de personas viven en asentamientos precarios. El informe de la ONU sobre Asentamientos Humanos afirma que en San Pablo el $32 \%$ de la población vive en este tipo de asentamientos, el $40 \%$ en Ciudad de México, el $47 \%$ en Manila y el $59 \%$ en Bogotá. En Argentina las villas miserias suelen asentarse sobre emplazamientos de alto riesgo como cauces fluviales o pendientes inestables (Figuras I - 8 y 9). Es necesario que se disponga de fuentes de energía seguras para calefacción y cocción, de modo de reducir el riesgo de incendio y contaminación, depuradoras de agua que protejan las reservas y reduzcan el riesgo de enfermedades, sistemas de drenaje que impidan las inundaciones y transporte público que mejore los accesos (Organización de las Naciones Unidas; 2009).
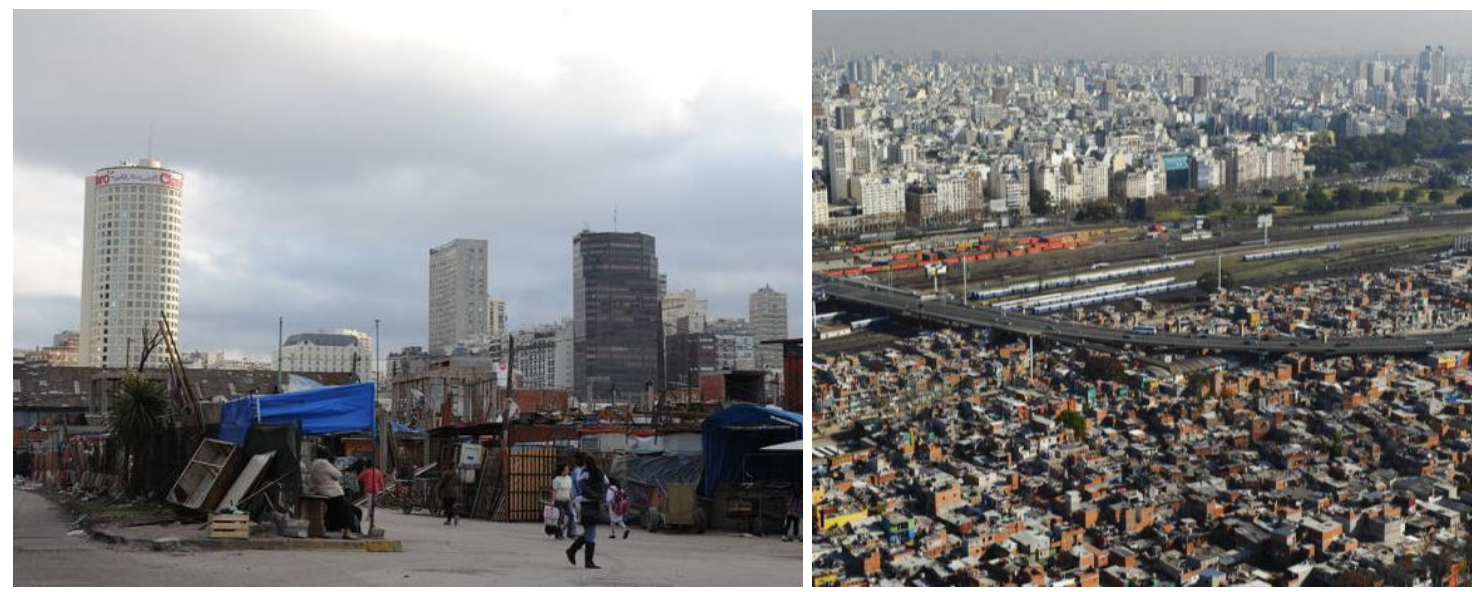

Figuras I - 8 y 9: Villa 31, Buenos Aires - Fuente: Revista Ñ - Diario Clarín, Argentina (2011) - Disponible en: http://www.revistaenie.clarin.com

En América Latina las capitales concentran el poder socio-económico del territorio, el control de las economías nacionales y la concentración de población. Los crecimientos de la periferia de Ciudad de México y Buenos Aires por ejemplo son mucho mayores y dinámicos que los de las áreas centrales, y las pautas de control ambiental y urbano de estas zonas son mínimas. El crecimiento de las ciudades capitales latinoamericanas ha demostrado que hay una reciprocidad entre la realidad regional y la nacional; el crecimiento demográfico y la expansión de estas ciudades responden a los fenómenos sociales y económicos que se originaron fuera de las mismas. Por lo tanto, la planificación de alternativas para estas ciudades no puede prescindir de la misma planificación que para las áreas rurales ya que su dinámica está interrelacionada (Roca, M.A.; 2003).

En Brasil, Curitiba representa un modelo de planificación urbana que comprende y propone una solución a las problemáticas actuales de las ciudades (Figura I - 10). A finales del Siglo XX esta 
ciudad empezó a sufrir los problemas relacionados con el rápido crecimiento poblacional y la acelerada urbanización que éste conlleva. Las consecuencias fueron la congestión del tránsito, problemas de contaminación del aire, hacinamiento residencial, gran acumulación de desperdicios y una resultante crisis ecológica, seguida por la disminución de la calidad de vida de sus habitantes. Sin embargo la ciudad ha logrado resolver los problemas de crecimiento y mantenimiento gracias a la participación ciudadana, y a una buena gestión política. Los proyectos de planificación urbana ponen énfasis tanto a la población como al territorio, enfocándose en la mejora de la calidad de vida de las personas. La transformación de la ciudad comenzó a partir de a mediados de 1960, con las primeras iniciativas para el ordenamiento territorial a través de un proyecto urbano, llamado Plan Maestro o plan preliminar de urbanismo, en el que se planteó el desarrollo de vías estructurales, transporte público de carril exclusivo, peatonalización de calles, el trabajo, la recreación, la promoción social y la vivienda, todos dentro de una visión integrada de la ciudad. Al éxito del Plan contribuyeron la creación del Instituto de Pesquisa y Planeamiento Urbano de Curitiba (IPPUC), que es la institución encargada de llevar a cabo los lineamientos del Plan, y la colaboración de profesionales que tomaron las decisiones técnicas y políticas para llevarlo a cabo (Lerner, J.; 1965).

El contraste entre Curitiba y San Pablo es muy grande. San Pablo es la tercera ciudad en tamaño y contaminación de la Tierra, se trata de un continuo urbano de edificios y rascacielos, donde los niveles de crecimiento, la congestión y la contaminación son alarmantes, y donde la ciudad parece no tener centro, ni diversidad, ni coherencia urbana. Curitiba está zonificada de manera que sus torres residenciales y de oficinas conforman cinco ejes principales de transporte público, basados en trayectos de autobús rápido y de gran capacidad. En el centro de la ciudad las principales calles y plazas son peatonales, y todo el transporte público concurre al mismo, reduciendo la necesidad del uso del automóvil (Rogers, R.; 2000).
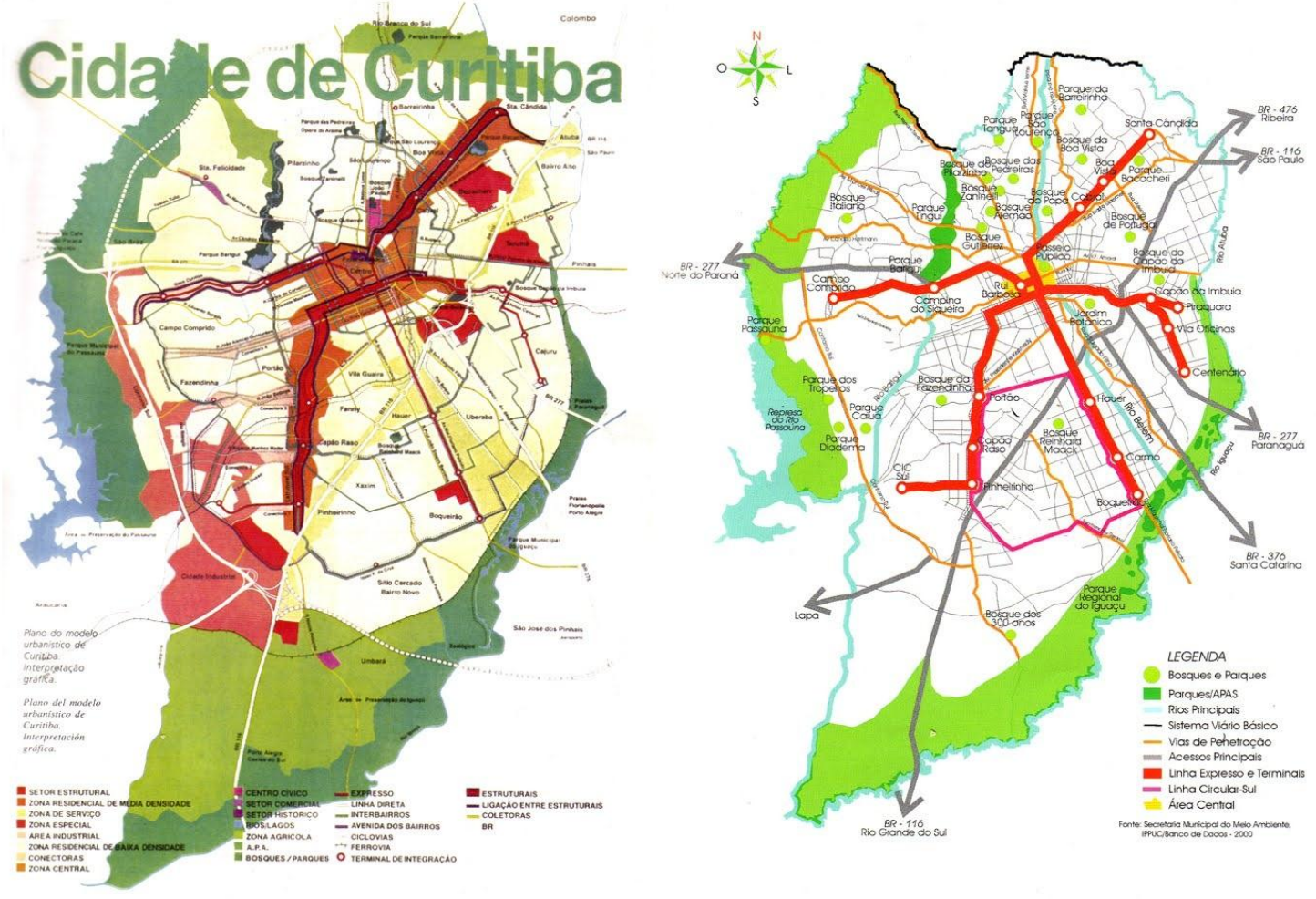

Figura I - 10: Plan Maestro de Curitiba y Plan de áreas verdes (1960) - Fuente: Instituto de Pesquisa y Planejamento Urbano de Curitiba, Brasil (IPPUC) - Disponible en: http://www.ippuc.org.br

\subsection{El cambio climático como herramienta proyectual}

Los maestros del movimiento moderno se basaron en las técnicas industriales y las nuevas formas que éstas permitían porque ofrecían libertad creativa y una perspectiva de mejoras 
sociales. En la actualidad, en general, los responsables de la construcción trabajan para entregar un mayor volumen de construcción en el menor tiempo y al menor precio posible. Sin embargo es necesario responder desde la arquitectura a las necesidades cambiantes de la época en la que estamos viviendo y explotar las nuevas tecnologías sustentables. La necesidad actual de construir de un modo sustentable brinda la posibilidad de instaurar una nueva ambición y nuevos órdenes estéticos capaces de dar un empuje revitalizante a la profesión. Es necesario ofrecer flexibilidad e investigar sobre nuevas formas capaces de expresar belleza dentro de su funcionalidad.

Los edificios consumen la mitad de la energía derivada de los combustibles fósiles, es por ello que el principal desafío para los responsables de la construcción del espacio urbano consiste en desarrollar edificios que incorporen tecnologías sustentables para reducir la contaminación y los costes de mantenimiento que la utilización de estos combustibles genera. Actualmente tres cuartas partes de la energía diaria consumida en los edificios se deben principalmente a la luz eléctrica, calefacción y ventilación. La innovación en esos campos puede reducir radicalmente los costes de mantenimiento a largo plazo, así como la contaminación que estos generan (Edwards, B.; 2008).

Desde el inicio de la industrialización se ha hecho hincapié en la extracción y el consumo, y durante los últimos doscientos años, se han creado técnicas altamente eficientes pero orientadas a un gasto y un consumo lineal. El típico bloque de oficinas, producto de una época en la que el uso abusivo de combustibles fósiles era el modelo aceptado, se caracterizaba por un medio interior estanco que no operaba en conjunto con el medio ambiente (Figuras I - 11, 12 y 13). Este enfoque generó unos edificios de secciones con mucha profundidad y espacios interiores artificiales. Las plantas de grandes dimensiones y alta ocupación, el uso intensivo de computadoras, etc. generan grandes cantidades de calor y requiere de equipos potentes para extraerlo, renovar el aire y aportar aire fresco, filtrado y humedecido. Además, las ventanas suelen estar tan alejadas de los escritorios que hacen necesario el uso de iluminación artificial durante todo el día. El resultado es un ambiente derrochador de energía (Rogers, R.; 2000).
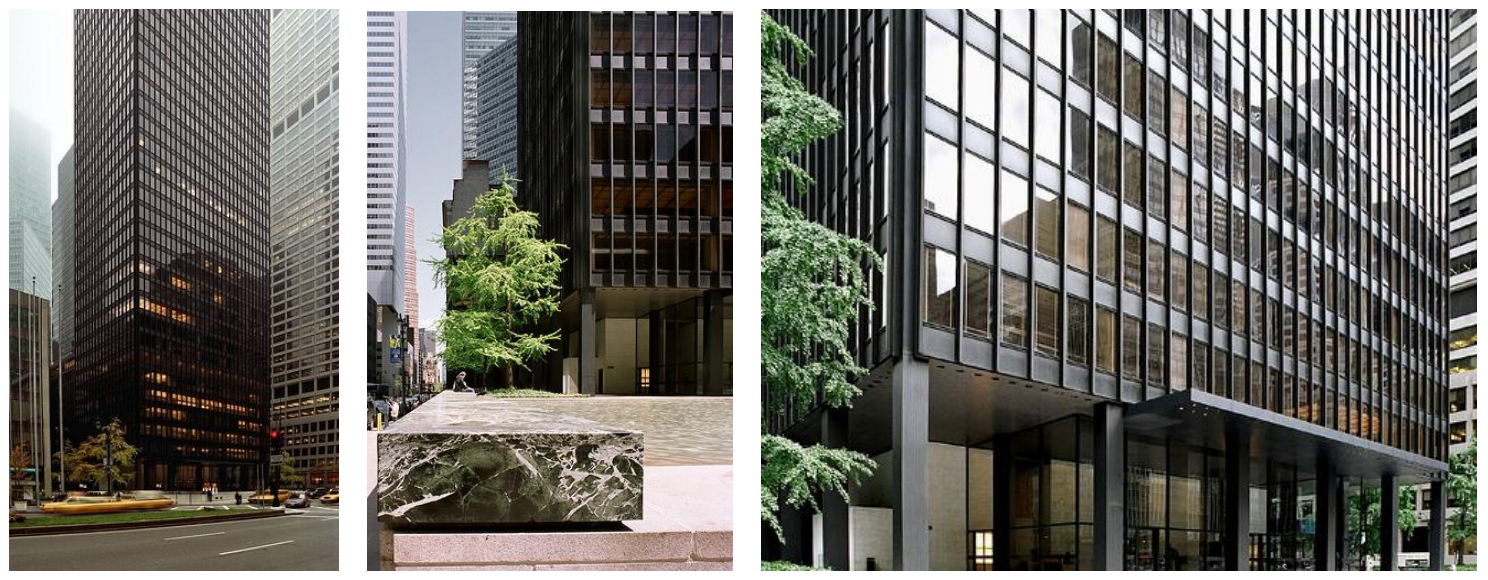

Figuras I - 11, 12 y 13: Edificio Seagram, Mies Van der Rohe - Fuente: Hagen Stier (2013) - Disponible en: http://hagenstier.polychroma.de

En el mundo desarrollado, principalmente, la arquitectura está cambiando en respuesta a las demandas medioambientales y al desarrollo de nuevos materiales ecológicos y altamente rentables. Está consolidándose una nueva visión de la arquitectura que se centra en ser más "amigable con el ambiente". Un análisis de los casos muestra una variación de la "arquitectura bioclimática" a la que se adicionan variables como: ciclo de vida del edificio y sus materiales, reconstrucción, re-uso de materiales, minimización de uso de agua potable, minimización de efluentes cloacales, aprovechamiento del agua de lluvia, entre otros (Goulding et al.; 1996).

La arquitectura ambientalmente consciente es un modo de concebir el diseño arquitectónico aprovechando los recursos naturales para minimizar el impacto en el entorno, dándole mayor importancia a la eficiencia y la moderación en el uso de materiales y consumo de energía. 
La producción del hábitat construido para un futuro sustentable implica un doble desafío a la creatividad profesional y a la responsabilidad institucional. Queda delegada la responsabilidad en los creadores del espacio urbano, profesionales e instituciones, y en las distintas escalas de intervención, como proyectistas o como administradores de la producción edilicia. Las opciones más importantes que contribuyen al ahorro energético son la mejora en el aislamiento térmico y el diseño de la envolvente, el uso de sistemas energéticamente eficientes, el reemplazo de los sistemas de calefacción convencionales por la generación de calor mediante fuentes renovables, la reducción del consumo energético de vehículos utilizados para el transporte público de mercaderías y personas, entre otros (Teske et al.; 2009).

La producción creativa y responsable de la arquitectura responde a procedimientos particulares en todas las escalas de proyecto, desde la elección del sitio y plan de prevención de polución, restauración y cuidado del paisaje, selección y especificación de materiales, uso racional de agua, y reducción de la dependencia energética del edificio en operación hasta el momento en que es demolido.

La creatividad juega un papel fundamental en el proceso de alcanzar el confort interior y la eficiencia energética, optimizando los recursos disponibles, a escala de la unidad, el conjunto y el entorno. La puesta en práctica de criterios sustentables en los proyectos de arquitectura plantea nuevos desafíos en el desarrollo de procedimientos novedosos que alienten un desarrollo social, económico y ambiental responsable, capaz de atender los requerimientos locales y sostener la producción de una arquitectura para un futuro sustentable (De Schiller, S.; 2009). 


\section{CAPÍTULO II \\ CONTEXTO URBANO}

\subsection{Evolución histórica la ciudad}

El desarrollo de esta Tesis se basa en el estudio particularizado de los edificios de propiedad horizontal en altura, actores principales de los centros urbanos. Este tipo edilicio surge como consecuencia de los avances tecnológicos en la industria del acero, la implementación del ascensor y la especulación del uso del suelo que cobra importancia con el desarrollo del urbanismo como técnica de proyectación urbana (Tafuri, M.; 1972).

Por su parte el urbanismo como técnica de proyectación urbana tiene su origen hacia finales del Siglo XVIII frente a la necesidad de dar respuesta al caos en el ordenamiento territorial causado por la Revolución Industrial y que posteriormente se vio condicionado por diferentes factores como las Guerras Mundiales, la expansión del capitalismo y la globalización, entre otros (Roca, M.A.; 2003).

El análisis del desarrollo de una ciudad puede hacerse desde diversos aspectos que van más allá de cuestiones puramente arquitectónicas. Influyen en el desarrollo de una ciudad cuestiones económicas, políticas, legislativas, sociológicas, simbólicas, filosóficas, etc. Sin embargo la conformación tridimensional del ambiente construido representa un dato de evaluación que no puede ser dejado de lado; en la forma de la ciudad se encuentran las respuestas a todas aquellas cuestiones que pueden analizarse en forma independiente, y que confluyen en ese todo que es el ámbito urbano. Para comprender la configuración de la ciudad tal y como se vive en la actualidad es necesario hacer un análisis del desarrollo urbano de los últimos siglos.

Desde los origines se puede clasificar a las ciudades en dos categorías; las planificadas, surgidas y desarrolladas sobre la base de un diseño predeterminado, y las espontaneas, derivadas de aldeas y evolucionadas de manera casual. Sin embargo los orígenes del urbanismo moderno se remontan a la Revolución Industrial de finales del Siglo XVIII y principios del Siglo XIX, como consecuencia de la innovación en los ciclos de producción que tuvieron lugar en aquellos años. La revisión de los instrumentos, técnicas y métodos del urbanismo se vio influenciada entre otros factores por las investigaciones higiénicas sobre la salubridad de los espacios construidos hacia finales del Siglo XVIII (Gravagnuolo, B.; 1998).

En el siglo XIX se experimenta una notable aceleración en el crecimiento de las grandes ciudades. Existen diversos factores como el gran incremento demográfico gracias a la mejora de las condiciones higiénicas y alimentarias, al derribo de las murallas como consecuencia de los cambios de defensa bélica, la industrialización del modo de producción y la consiguiente concentración de la mano de obra en zonas aledañas a las fábricas, etc. Si bien en los primeros años del siglo XIX sólo Londres, París, Nápoles, Amsterdam y Lisboa eran las 
ciudades con un alto porcentaje de población, luego de cien años de marcado urbanismo las demás ciudades europeas quintuplicaron su nivel demográfico. El gran crecimiento de los centros urbanos llevó a que los problemas sociales debieran ser afrontados desde la planificación urbana. La demanda de viviendas se transformó en uno de los problemas más difíciles de afrontar del Siglo XIX. (Benévolo, L.; 2000)

En casi todas las grandes ciudades europeas se realizaron obras de embellecimiento urbano con parques y monumentos, y se llevaron a cabo programas de racionalización de los centros, los cuales fueron refuncionalizados. La transformación de París realizada por Haussmann (Figuras II - 1 y 2) contribuye a comprender el sentido de las innovaciones introducidas en la segunda mitad del siglo XIX; fue la manera misma de pensar la ciudad la que cambió. La lógica de los "embellecimientos", dirigida a intervenciones puntuales de los tejidos urbanos, y la estrategia de la ciudad-servicio fueron sustituidas por la idea de metrópoli, entendida como máquina urbana en donde la red de infraestructura era jerarquizada por sobre todo lo demás. La arquitectura quedó subordinada al dominio del trazado viario y el paisaje metropolitano se vio renovado de forma radical (Gravagnuolo, B.; 1998).

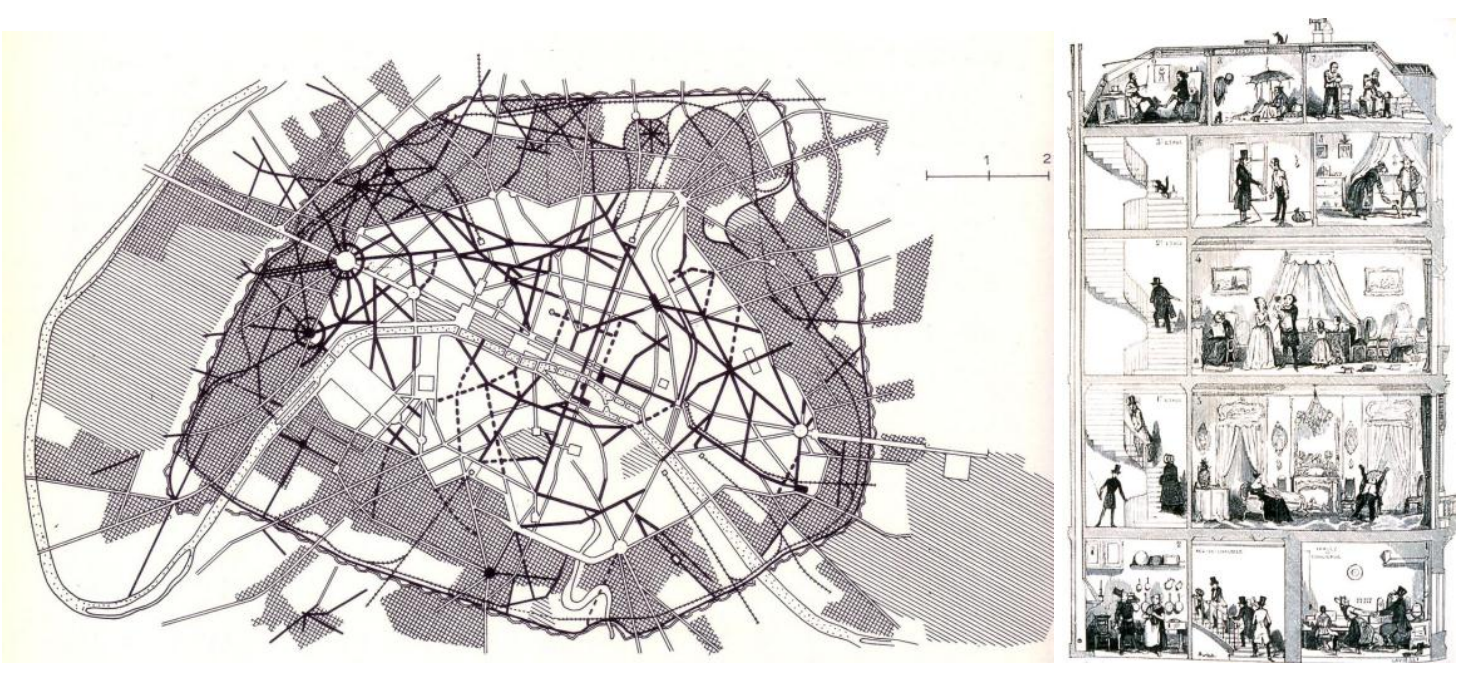

Figuras II - 1 y 2 : Imágenes del París de Haussmann - Fuente: Benévolo, L. "Historia de la arquitectura moderna”. Editorial Gustavo Gili Barcelona, España (Edición año 2000).

En aquel momento se argumentó que tales decisiones proyectuales buscaban paliar cuestiones relacionadas con la seguridad y la higiene. Algunas de las justificaciones utilizadas para llevar a cabo las intervenciones propuestas fueron que por ejemplo la amplitud de las calles ofrecía rapidez y eficiencia en las intervenciones policiales o que la demolición de algunos sectores favorecía a eliminar posibles focos de epidemias. Sin embargo en la práctica el objetivo de estos planes era la potenciación de la renta del suelo como mecanismo de expansión urbana. Las nuevas infraestructuras viarias no sólo revalorizaban la renta de las áreas centrales sino que además abrían nuevas zonas edificables. La homologación de los elementos constitutivos de las fachadas se transformó en un factor clave que se debió en parte al cambio en el destino social de las viviendas, que condujo a una nueva definición tipológica del edificio de viviendas. Se trataba de una intervención en la cual tenía lugar una doble sustitución, edilicia y social, donde podía verse claramente una tendencia a expulsar a las capas sociales menos favorecidas de las áreas centrales de alta renta (Gravagnuolo, B.; 1998).

Entre las intervenciones a escala urbana que se desarrollaron en esos años se destaca también el plan de ampliación de Barcelona elaborado por Ildefonso Cerdá y Suñer en 1859 (Figura II - 3), en el cual se propuso una innovación tipológica del edificio urbano. La idea del asentamiento derivaba del trazado ortogonal de la antigua polis griega. Sin embargo en este plan la retícula fue reinterpretada; las calles se ensancharon adoptando los veinte metros de ancho las vías secundarias, las avenidas principales por su parte adoptaron sesenta o incluso ochenta metros de ancho, los ángulos de las manzanas se cortaron en chanfle para favorecer el desarrollo del tráfico y mejorar la estética de las uniones. La ordenación del damero siguió criterios heliotérmicos para la defensa contra los vientos dominantes, y las diagonales que 
cruzaban la ciudad coincidían con la línea de los meridianos y los paralelos terrestres. En muchos aspectos el plan de Cerdá mostraba similitudes con los criterios "modernos" de planificación de las grandes ciudades de nueva fundación de América más que con los ejemplos europeos (Benévolo, L.; 2000).

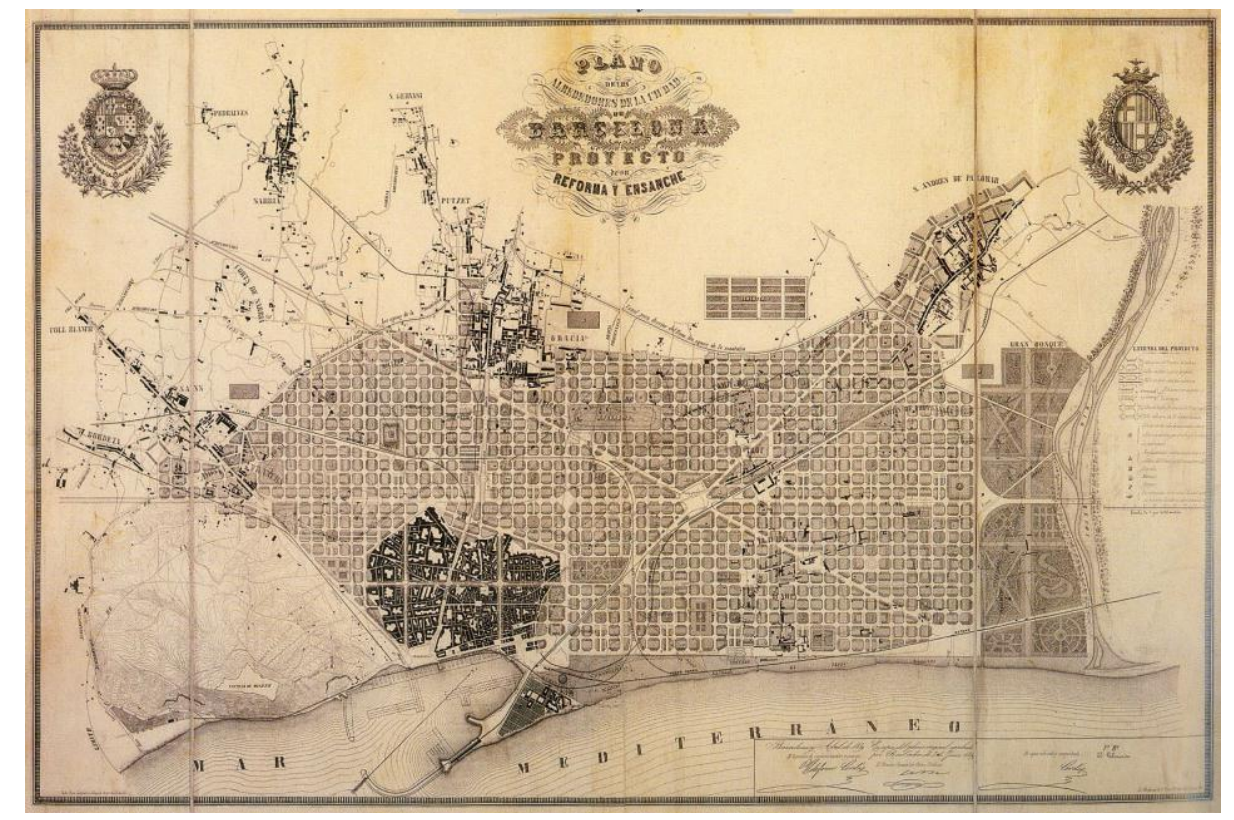

Figura II - 3: Plan de Cerdá para Barcelona (1859) - Fuente: Museo de Historia de Barcelona, España Disponible en: $h t t p: / / w w w . b c n . c a t$

También por aquellos años, como alternativa al crecimiento compacto y radio-céntrico de la ciudad del Siglo XIX, surgieron distintos modelos de organización urbana entre los que se destaca la ciudad lineal de Soria y Mata (Figura II - 4) y la ciudad-jardín de Howard (Figura II 5). El primer modelo se proponía la construcción de una calle única de quinientos metros de ancho y de longitud necesaria. En medio circulaban los trenes y tranvías, los conductos para el agua, el gas y la electricidad, depósitos, jardines y, distanciados entre sí, los edificios para los diversos servicios municipales. De este modo se pretendía resolver todos los problemas causados por el gran crecimiento demográfico, uniendo las condiciones higiénicas del campo con las grandes metrópolis. Por su parte la ciudad-jardín consistía en la realización de otro tipo de mediación entre la ciudad y el campo. La ciudad era representada como un conjunto de anillos concéntricos cortados por seis ejes radiales; en el centro tenía lugar un gran vacío que conformaba el parque de la ciudad, rodeado por el primer círculo formado por los edificios públicos, luego un anillo verde preparado para actividades deportivas con un lugar de intercambios sociales y comerciales; avenidas circundadas de casas bajas, y en el círculo medio la Grand Avenue, enmarcada a ambos lados por edificios de seis a ocho niveles; $y$ en el exterior, la línea ferroviaria de circunvalación y las fábricas. En ambos casos se trataba de crear un tercer elemento capaz de asumir los requisitos positivos de ambas condiciones; las ventajas higiénicas del hábitat rural y la red de intercambios sociales del hábitat urbano (Gravagnuolo, B.; 1998).
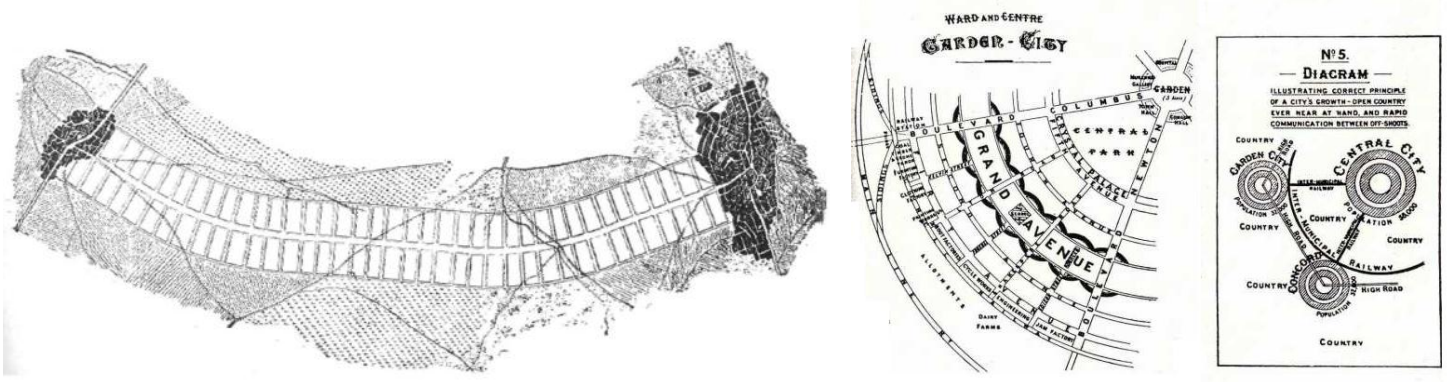
Figuras II - 4 y 5: Plano de la Ciudad Lineal (Soria y Mata) y de la Ciudad Jardín (Howard) - Fuente: Benévolo, L. "Historia de la arquitectura moderna". Editorial Gustavo Gili Barcelona, España (Edición año 2000)

En la segunda mitad del siglo XIX se inicia un proceso de "mecanización" del mundo productivo, que adquiere un alcance innovador en todos los campos; desde el transporte, las tecnologías constructivas, los medios de representación, los sistemas de comunicación, etc. De este modo surge la idea de la metrópoli tecnológica, que vincula el progreso técnico con el progreso social. En ese entorno nacen las Exposiciones Universales que dan inicio a un proceso de atracción de los visitantes, un modo de mostrar los avances tecnológicos y económicos de los diferentes países partícipes (Figuras II - 6 y 7). Se realizaban visiones futurísticas que eran proyectadas sobre el paisaje urbano, primero efímeras y después cada vez más fundidas en la estructura de la ciudad hasta el punto de modificar permanentemente su estructura, algunas de estas grandes obras realizadas para las Exposiciones Universales permanecen aún en pie, convertidas en íconos. Tal es el caso de la Torre Eiffel en París que, en la exposición de 1889, fue la representación paradigmática de la modernidad tecnológica; resuelta con superficies curvas y estructuras espaciales, marcó una ruptura con el París histórico y si bien en un principio generó cierto rechazo, luego adquirió un valor simbólico (Gravagnuolo, B.; 1998).
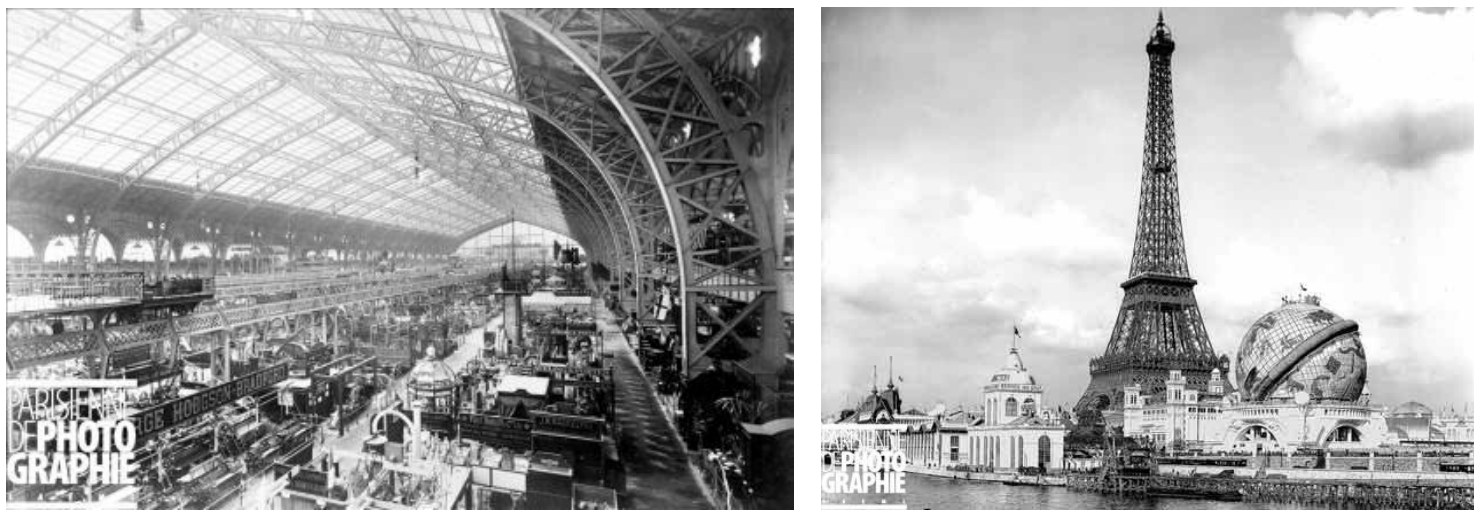

Figuras II - 6 y 7: Exposición Universal de París, 1889 - Fuente: Parisienne de Photographie - Disponible en: $h t t p: / / w w w . p a r i s e n i m a g e s . f r$

La primera mitad del Siglo XX se vio marcada por muchos eventos, entre los cuales no puede soslayarse el gran impacto que tuvieron las Guerras Mundiales. Más allá de las graves consecuencias sociales y políticas que significaron para el mundo en general, las Guerras Mundiales representaron un importante cambio en la concepción del urbanismo y de la arquitectura tal y como se entendía hasta ese momento. La necesidad de vivienda que ya constituía un problema real como consecuencia del crecimiento demográfico que venía cobrando importancia desde la Revolución Industrial, se vio colapsada por la destrucción que significaron estos eventos.

A comienzos de 1900, como consecuencia del caos provocado por la I Guerra Mundial, comienza a cobrar fuerza la idea de "tabula rasa" como absoluto rechazo a la tradición. En aquel momento el funcionalismo se presentó como la posición cultural más avanzada y progresista, relacionado con el culto a la estandarización donde "todos los hombres tienen las mismas necesidades" con el deseo de alcanzar una forzada homologación internacional. Los partidarios del funcionalismo eran partidarios de la negación de un pasado que consideraban nefasto. Según esta orientación proyectual, que idealizaba la técnica para lograr una absoluta perfección funcional de la máquina urbana, toda clase de sentimiento colectivo ligado a la memoria común, a la identidad de los lugares y a los caracteres de la ciudad histórica debía ser estigmatizado como una debilidad humana que debía ser reprimida en cuanto que se trataba de una resistencia "irracional" al cambio. El símbolo de la "ciudad nueva" planteaba también la hipótesis de un "hombre nuevo" absolutamente racional, libre de lazos sentimentales con el pasado y feliz de vivir en el "nuevo universo" del triunfo de la mecanización y en la "nueva era" proyectada hacia una armonía tecnológica futura, y hacia una igualdad social ficticia (Benévolo. L; 2000). 
Para los funcionalistas la industria representaba el ideal a emular. En aquel entonces el taylorismo y el fordismo ejercieron una fuerte persuasión sobre las vanguardias intelectuales europeas (Figuras II - 8 y 9). Se trataba de una exaltación de la belleza de las máquinas y de la eficiencia tecnológica de la cadena de montaje, utilizado como argumento en la teoría arquitectónica de los años veinte del purismo, del constructivismo, de la nueva objetividad y de la Bauhaus. Los partidarios de esta orientación proyectual se preocuparon por racionalizar las tipologías edilicias, separar las manzanas residenciales de la red viaria, enfatizar la higiene de los bloques de viviendas lineales a lo largo de ejes heliotérmicos, distinguir la red del tráfico de vehículos de la de los recorridos peatonales, las zonas de negocio de las de vivienda, etc. De este modo, animados por la fascinación por "lo nuevo", los arquitectos radicales terminaron anulando la ciudad histórica (Gravagnuolo, B.; 1998).
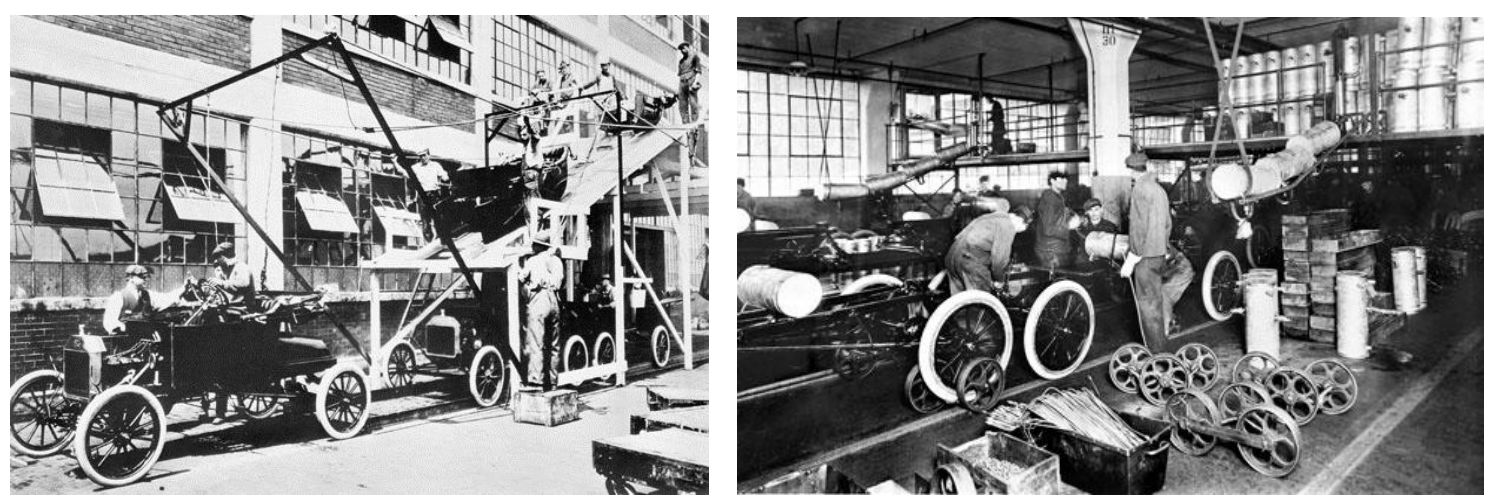

Figuras II - 8 y 9: Producción industrializada a finales del Siglo XIX en una planta Ford - Fuente: U.S. National Archives - Disponible en: http:// www.archives.gov

Esta nueva orientación inclinada por la industrialización del ciclo edilicio, la tipificación de las viviendas y la estandarización de la planificación urbanística encontró su espacio de pruebas en la construcción de los barrios de edificación económica y popular realizados en Europa en los años veinte. La demanda de viviendas, consecuencia de la destrucción provocada por las guerras, y la mayor conciencia civil acerca de buscar soluciones técnicas al problema causado en el desarrollo urbano, consecuencia de la Revolución Industrial de finales del Siglo XIX, contribuyó a la experimentación proyectual en el sector residencial (Gravagnuolo, B.; 1998).

Le Corbusier ha sido el más claro referente de esta ideología. Para él la industria irrumpía trayendo instrumentos nuevos adecuados para aquella época animada por un espíritu nuevo. La gran industria debía ocuparse de la construcción y producción de los elementos de la vivienda (Figuras II - 10 y 11). Era necesario crear el espíritu de la producción en serie, de construir casas en serie, de habitar casas en serie, de concebir casas en serie (Le Corbusier; 1998).
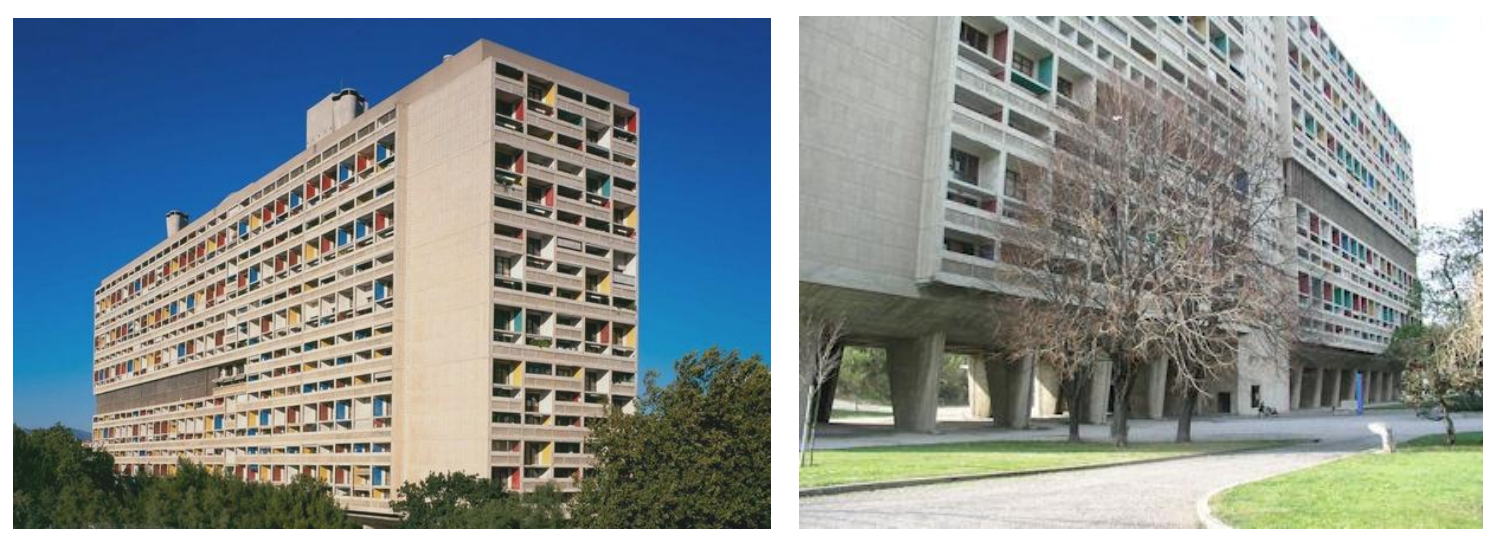

Figuras II - 10 y 11: Unidad de Habitación de Marsella - Fuente: Foundation Le Corbusier - Disponible en: http://www.fondationlecorbusier.fr 
Entre las múltiples propuestas de Le Corbusier se destacó la ciudad de tres millones de habitantes. El objetivo no consistía en someter las situaciones preexistentes sino alcanzar, con la construcción de un edificio teórico riguroso, a formular principios fundamentales del urbanismo moderno. Dichos principios, que debían constituir la base de todo sistema de urbanización moderna, eran los siguientes:

- Terreno: el terreno llano era el ideal ya que en todas las partes donde la circulación se intensificaba, el terreno llano proporcionaba las soluciones normales y donde la circulación disminuía, los accidentes del terreno estorbaban menos.

- La población: la urbana, la suburbana, la mixta. La urbana; que trabajaba y residía en la capital. La suburbana; que trabajaban en la periferia y no iban a la ciudad. La mixta; que trabajaba en el centro y residía en la periferia.

- Pulmón: la ciudad moderna debía aumentar su densidad pero al mismo tiempo debía aumentar las superficies verdes y disminuir el trayecto a recorrer.

- La calle: la calle moderna era un organismo nuevo que debía ser accesible de todas partes.

- La circulación: era necesario clasificarla en pesos pesados, vehículos con recorridos cortos en cualquier sentido y vehículos rápidos que atravesaban la ciudad.

- La estación: sólo podía estar en el centro de la ciudad.

- El centro: estaba compuesto por veinticuatro rascacielos destinados a hoteles, negocios, vivienda, etc.

En este contexto marcado por los cambios sociales, culturales y tecnológicos surgen los Congresos Internacionales de Arquitectura Moderna (CIAM), los cuales sirvieron de guía para la confrontación entre las diversas teorías arquitectónicas (Figuras II - 12 y 13). En el I CIAM se habló de la relación de la Nueva Arquitectura con la economía y con la producción industrial, la planificación territorial a escala regional, la opinión pública, y el Estado como centro del poder de decisión. En el II y III CIAM se analizaron las interrelaciones entre los esquemas de vivienda óptimos y los tipos edilicios así como de las relaciones proporcionales deseables de volumen y de distancia entre los bloques, y entre éstos y los trazados viarios, la vegetación y los servicios. En el IV CIAM se puso en discusión el tema del Urbanismo Funcional, reafirmando la idea de que el urbanismo, como disciplina que se ocupaba de ordenar el conjunto de las actividades de la vida colectiva, no debía prestar atención únicamente a exigencias estéticas. Surgió entonces la necesidad de que el arquitecto se asociase con especialistas de otras ciencias; técnicos, economistas, sociólogos, médicos, estadistas, etc. Se fijaron de este modo las cuatro funciones primarias que debía tener en cuenta la planificación urbana: habitar, trabajar, recrearse y circular (Gravagnuolo, B.; 1998).
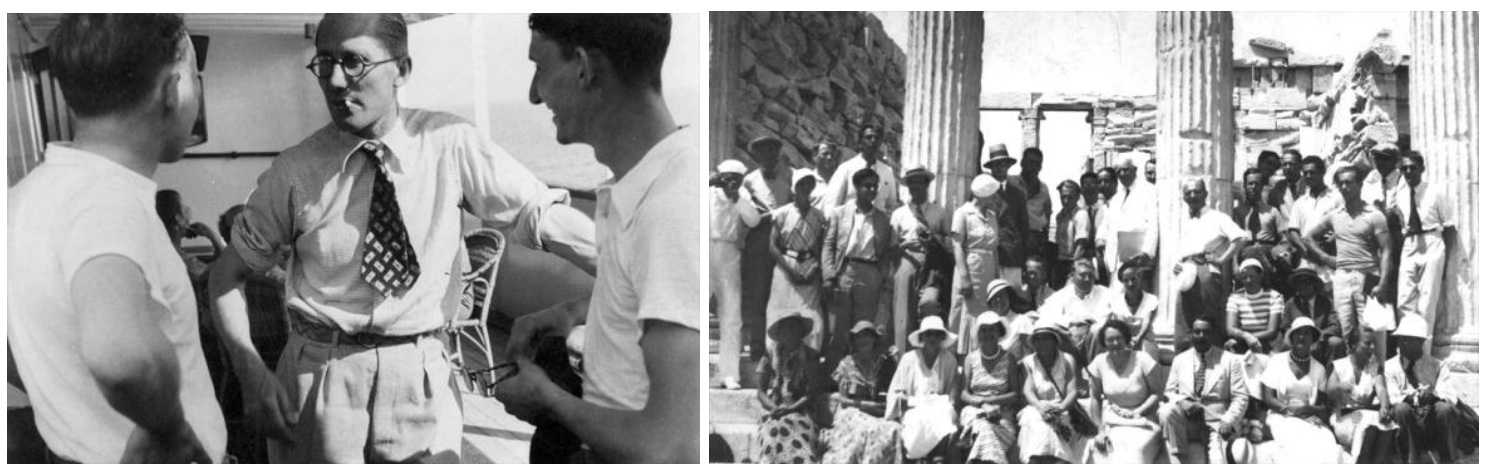

Figuras II - 12 y 13: Reunión del IV CIAM en Atenas, Grecia - Fuente: Foundation Le Corbusier Disponible en: http://www.fondationlecorbusier.fr

Entre los hechos que acontecieron en aquellos años es importante destacar el papel que tuvo el éxodo provocado por las Guerras Mundiales y especialmente por el Nazismo en la expansión del movimiento moderno hacia el resto del mundo. Luego de la II Guerra Mundial muchos de los arquitectos y pensadores de la "modernidad" alemana de los años veinte emigraron a otros países, mayoritariamente a Estados Unidos. Este país se presentó, en ese contexto, como el lugar adecuado para implantar los conceptos de la modernidad y desarrollar sus presupuestos. Con la inmigración masiva de los pensadores de la modernidad, las miradas se volcaron sobre las obras del MOMA o del Art Institute de Chicago donde los objetos eran simplificados con la intención de generar un orden geométrico -en apariencia emergente de la nueva civilización 
industrial maquinista- que evolucionó hasta la estandarización y la precisión determinadas por la función en los sistemas constructivos, los materiales y su interacción como bases de la generación de formas según podía verse en el rigor geométrico de la urbanidad Norteamericana (Gravagnuolo, B.; 1998).

No obstante, si bien Estados Unidos fue el principal receptor de muchos de los pensadores y arquitectos modernos, América Latina también fue un foco importante hacia donde se expandieron sus ideas. Esta parte del continente se convirtió en el campo de prueba de las ideas vanguardistas del pensamiento europeo. Sin embargo, a diferencia de lo que ocurrió en Europa y en Estados Unidos, en América Latina la urbanización no acompañó a la industrialización sino que la precedió; el acelerado proceso de urbanización superó las potencialidades de la planificación. Las dificultades del planeamiento urbano y regional de América se debieron principalmente a la falta de continuidad y sistematización en la toma de medidas, a las tensiones provocadas por la urgencia, la escasez de recursos y la ineficacia (Gutiérrez, R.; 1983).

La figura de Le Corbusier también alcanzó renombre fuera del continente europeo, sus ideas y principios llegaron también a América Latina donde sus conferencias y proyectos urbanísticos para Montevideo, San Pablo, Río de Janeiro y Buenos Aires impulsaron el debate. Enviado para el plan de algunas grandes obras en Río de Janeiro en 1936, Le Corbusier estableció una sólida relación con Lucio Costa, dando lugar a la tendencia local al "modernismo de manera".

La obra de Oscar Niemeyer, seguidor de las ideas de Le Corbusier, constituye el eje de referencia troncal de la arquitectura moderna brasileña. La inserción de la arquitectura en la ciudad, los problemas originados por el estacionamiento y circulación de vehículos fueron temas que desarrolló en la teoría y la docencia. Entre las ideas que se plantearon la más importante fue la ruptura del esquematismo geométrico que pretendía controlar la naturaleza, para potenciar las calidades y libertades formales de la técnica como dato a valorar. La arquitectura moderna brasilera buscaba la coherencia entre la naturaleza y la arquitectura, dotándola de gran libertad formal. El plan para Brasilia (Figuras II - 14 y 15) -el cual puede considerarse la concreción de la utopía de los CIAM- fue llevado a cabo junto a Lucio Costa entre los años 1956 y 1963, y constituye la imagen más clara de la producción de Niemeyer y de la arquitectura moderna brasileña (Gutiérrez, R.; 2005).
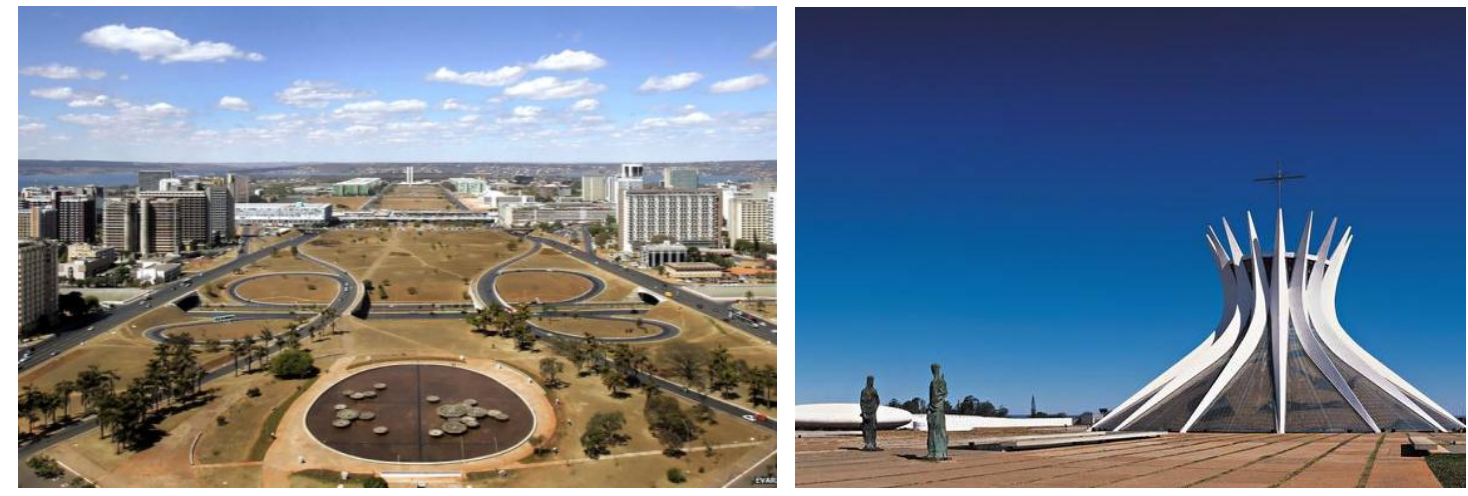

Figuras II - 14 y 15: Imágenes de la ciudad de Brasilia (Eje Monumental y Catedral) - Fuente: Diario O Globo, Brasil - Disponible en: http://oglobo.globo.com

Pero además de favorecer la expansión de las ideas del Movimiento Moderno, las Guerras Mundiales también contribuyeron a cambiar el marco de referencia del proyecto moderno dentro del continente europeo. La destrucción de los centros históricos ofreció a los teóricos funcionalistas el marco de verificación proyectual propicia. La tabula rasa de los manifiestos de arquitectura moderna se volvió un hecho real en el gran vacío generado por la Guerra. Los arquitectos debían trabajar en el centro de la ciudad y no en la periferia como lo habían hecho hasta ese entonces, con todo el peso de los valores simbólicos en los que el pueblo se identificaba y a cuya propiedad no querían renunciar. Como resultado surge la primera crisis de las convicciones teóricas previas a las Guerras, que abre divergencias de opinión entre los miembros de los CIAM. Se diferenciaban dos partes; los defensores de la estética maquinista y otros partidarios de una profunda revisión teórica de los principios del funcionalismo. Los 
críticos más sensibles remarcaban la necesidad de una profunda reflexión sobre la herencia cultural del pasado. La cuestión a afrontar era la ausencia del sentido histórico causado por la destrucción de la Guerra, se trataba de reconstruir la identidad perdida. De estas tensiones surgió el Team X, que terminó por decretar la disolución de los CIAM (Benévolo, L.; 2000).

Simultáneamente a esta crisis del Movimiento Moderno y a esta reivindicación de la herencia cultural del pasado que se inicia en Europa con el Team X, surge en Estados Unidos la ciudad post industrial en una sociedad que seguía un modelo de acumulación capitalista con crisis económica, tecnológica, social y cultural. Comenzó hacia 1950 junto a un proceso de desindustrialización y globalización; descentralización de las actividades, con desplazamiento según tecnologías informáticas y automáticas, y al auge de las telecomunicaciones. En aquel entonces comenzó a cobrar importancia la especialización laboral y la concentración de capitales, lo que hizo crecer también el trabajo sin formación cualificada, el desempleo, la marginalidad, etc. Los grandes cambios sociales que estas cuestiones implicaban se tradujeron en nuevos requerimientos tipológicos e institucionales. Aparecieron en ese entorno las megalópolis, como fenómeno no urbano, mezcla de áreas urbanizadas y rurales; una pérdida del sentido del lugar de la ciudad en el territorio y de los lugares de la ciudad que la identificaban, y una multiplicación de los no lugares como autopistas, shoppings, etc. (Roca, M.A.; 2003).

La ciudad contemporánea emerge como un conjunto heterogéneo constituido por un área central administrativa y comercial que se extiende con intensidad decreciente, y con un gran tejido que se despliega como conurbano, formado por áreas residenciales, distritos de desarrollo estatal o privado, periferias de autoconstrucción, suburbios y hasta villas miseria, a lo que se suman áreas comerciales e industriales. Se trata de continuos urbanos de veinte millones de habitantes, aéreas metropolitanas y grandes ejes como Chicago-Filadelfia; Boston-Washington; Tokio-Yokohama, etc. (Figura II - 16). Este modelo que surgió en Estados Unidos donde el hiper-shopping que reúne trabajo, cultura, entretenimiento, alimentación y comercios, apareció como un modelo de vida nuevo, con formas de socialización nuevas, y carece de la cualificación y la estructura propia de la ciudad (Roca, M.A.; 2003).

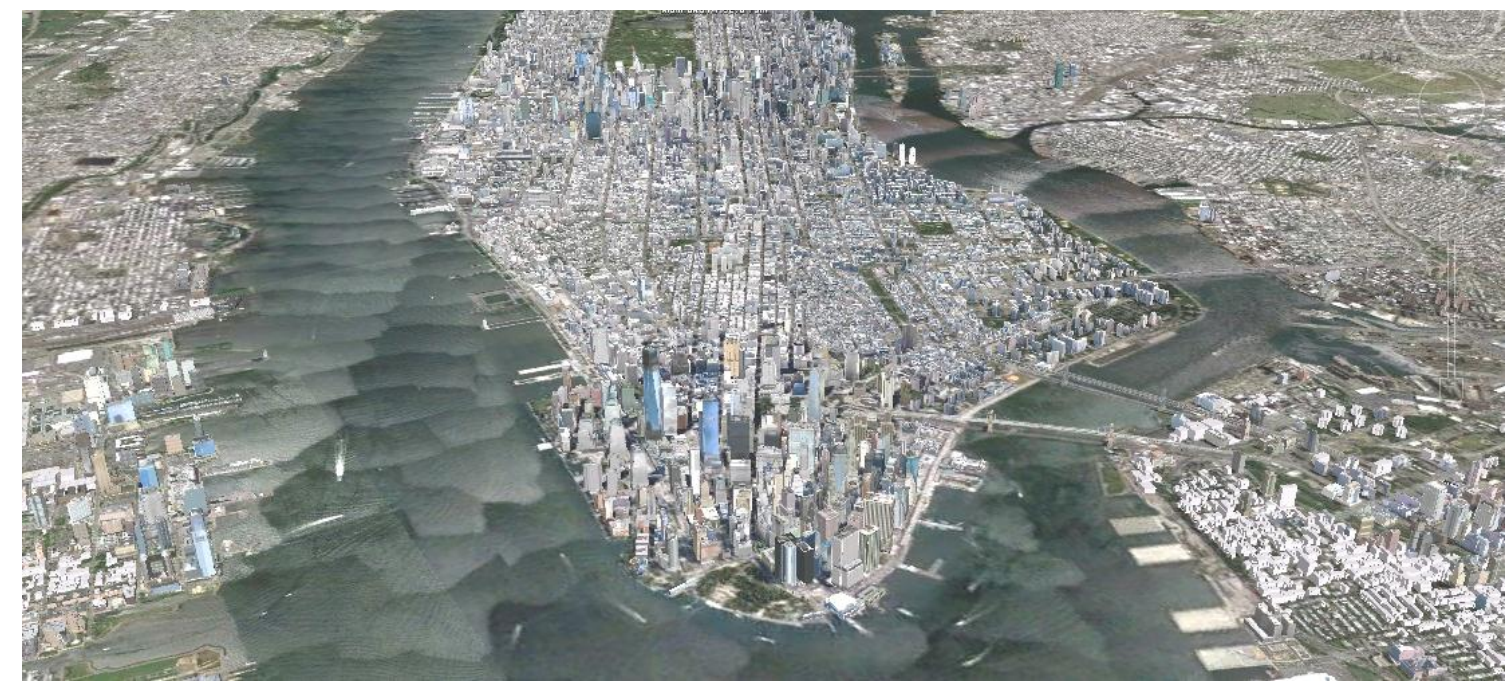

Figura II - 16: Imagen aérea de la Isla de Manhattan, Nueva York (Estados Unidos) - Fuente: Google Earth. Terrametrics, 2013 - Disponible en: http://www.google.com/earth/index.html

Actualmente toda ciudad está conformada por elementos irreductibles de su imagen existencial hecha de trayectos-calles, edificios-monumentos que alojan lugares de encuentro y expresión, que conforman la espacialidad urbana, lugares que identifican a sus habitantes y que permiten a los visitantes reconocer y recordar la ciudad, pero también por no lugares. En los lugares tiene lugar la coexistencia y la simultaneidad de intereses y clases de la ciudad histórica mientras que en el no lugar se impone en la cultura de masas; shoppings, aeropuertos y demás espacios que carecen de identidad (Calvino, l.; 1998).

Los nuevos sistemas de transporte y producción hicieron crecer desmedidamente a las ciudades, generando centralidades alternativas. Con la expansión del modelo capitalista y la 
globalización las áreas comerciales se desplazaron y multiplicaron, en el área central se favoreció la generación de actividades recreativas (teatros, centros culturales, gastronomía, museos, etc.). La relocalización de las actividades industriales en la periferia y el incremento del costo de los lotes urbanos favorecieron la emigración de los habitantes de menos recursos hacia esta zona, contribuyendo a que aquellos habitantes de mayores recursos quisieran volver al centro histórico. En los países desarrollados se promovieron políticas de demolición, renovación y sustitución para revitalizar los centros; entre estos nuevos intentos de recuperación de la ciudad se destacan el caso de Berlín y Barcelona. (Roca, M.A.; 2003).

Entre 1979 y 1987 Berlín preparó el IBA `87 (Figura II - 17). Para esta exposición se realizaron dos operaciones; la primera fue la renovación urbana del barrio de Kreuzberg, central antes de la Guerra y luego marginado por su alto deterioro edilicio y el hacinamiento de población de escasos recursos. La renovación se basó en el trabajo común de los técnicos con los usuarios. Se repararon, ampliaron y mejoraron instalaciones, se crearon escuelas, guarderías y otros centros comunitarios, con lo que se mejoró la calidad de vida, reforzando la identificación y confianza de los habitantes. La otra operación se desarrolló sobre cuatro sectores, contiguos al Friedrichstadt sud, Tiergartenviert sud, Tegel y Prager Platz. Los múltiples emprendimientos fueron realizados por concursos cerrados por invitación de diferentes equipos de trabajo para el planteo de la renovación urbana. La exposición del IBA '87 contribuyó a unificar la ciudad fragmentada como consecuencia del Nazismo y de la Guerra Fría. Al tomar la vivienda como tema dominante se reinterpretó la acción urbano-arquitectónica de 1920, reivindicando el valor de los trazados preexistentes con tipos edilicios modernos (Roca, M.A.; 2003).

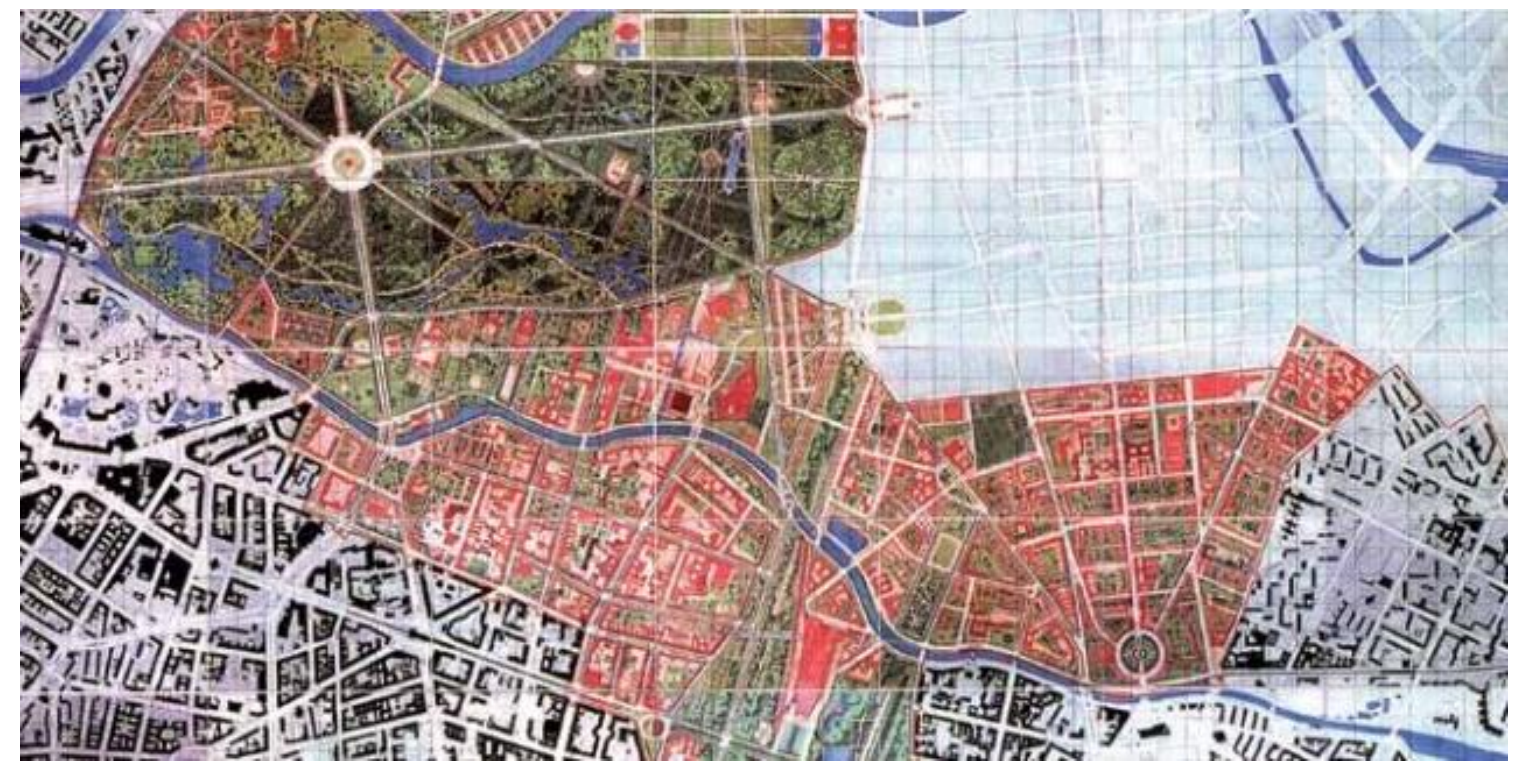

Figura II - 17: Plan para IBA Berlin - Fuente: Dr. Dagmar Tille. "Learning from IBA. Die IBA 1987 in Berlin". Studio Nelke. Berlín, Alemania (2010).

Barcelona es otra ciudad que muestra una experiencia de gestión urbana ejemplar desarrollada en los últimos años. La ciudad estaba marcada por la Guerra Civil Española y por el Régimen Franquista. Sin embargo, tras la muerte de Franco en 1975 se produjo una apertura paulatina de España al mundo acompañada por una rápida industrialización e inversión de capitales extranjeros, junto con una evolución cultural, social y política (Roca, M.A.; 2003).

Oriol Bohigas, delegado del área de Urbanismo del Ayuntamiento de Barcelona en 1980 se mostró contrario al planeamiento zonificatorio; defendiendo la idea de que dentro del marco del Plan General Metropolitano la acción urbana tiene su eje en la proyectación arquitectónica. De este modo se decidió intervenir puntualmente recualificando, definiendo, ordenando y vitalizando plazas, calles, parques pequeños y equipamientos. En esos años surgió la posibilidad de realizar los Juegos Olímpicos en Barcelona, en 1992, lo que sirvió de pretexto para realizar varias intervenciones (Figuras II - 18 y 19). Se construyó el Montjuic, como parque de la ciudad donde se hallaba el estadio de 1932. La ampliación del Plan de Cerdá sobre cuarenta hectáreas pobladas de vías y de establecimientos industriales se convirtió en la 
Villa Olímpica. El Plan dotó a la ciudad de un frente marítimo con la incorporación de un puerto, un parque frontal y nuevas manzanas con dos mil quinientas viviendas. De la manzana tradicional surgieron tipologías con corazones de manzana de viviendas en diagonal, o torres alineadas y escalonadas. Se trató de construir una ciudad nueva con el precedente histórico de Cerdá y una reinterpretación moderna de la manzana tomada como unidad de proyecto en donde el espacio público fue el primer objetivo (Bohigas, O. et Al; 1990).

Actualmente los rasgos de las diferentes ciudades del mundo son muy distintos; en los países desarrollados las redes de comunicaciones y los nodos monofuncionales entremezclados con el tejido disperso de las residencias convierten a la metrópolis en megalópolis. Por su parte en los países en vías de desarrollo, a excepción de las grandes ciudades como Buenos Aires, San Pablo, México D.F, etc. tiene lugar el conurbano, un tejido yuxtapuesto a la ciudad, que es absorbido por ella, generando una periferia débil, con lotes de autoconstrucción (Roca, M.A.; 2003).
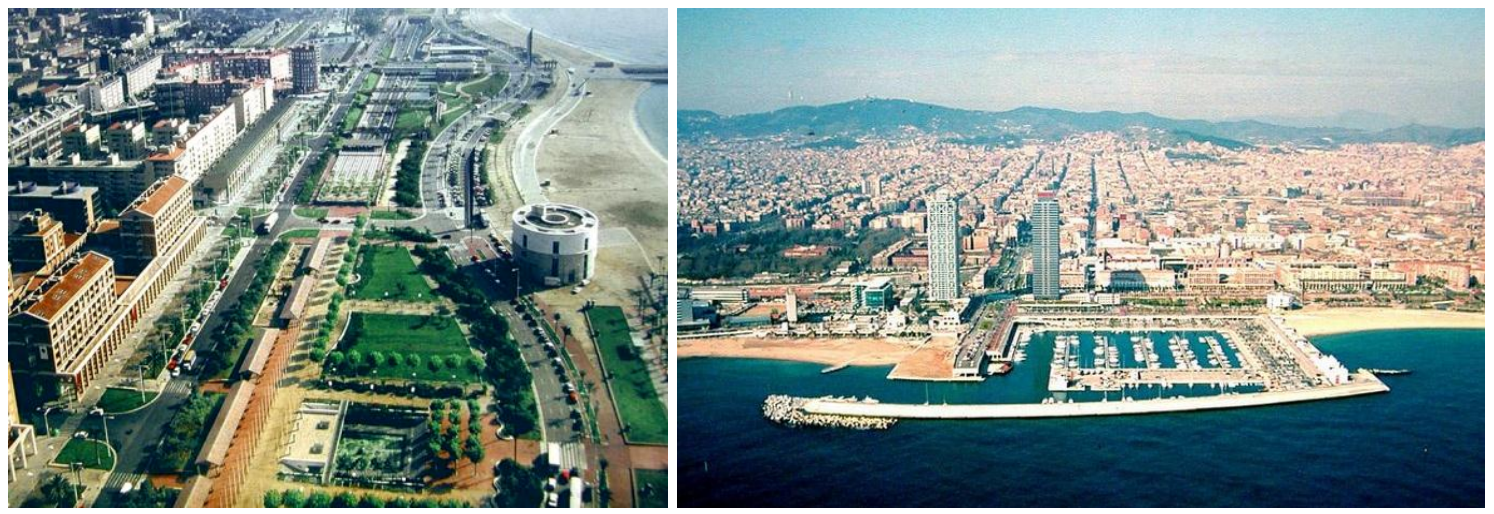

Figuras II - 18 y 19: Imágenes del Plan de Barcelona de Bohigas - Fuente: MBM arquitectes - Disponible en: http://www.mbmarquitectes.cat

\subsection{El desarrollo del Área Metropolitana de Buenos Aires}

Hacia 1880 Argentina se incorporó a la economía mundial, acelerándose el reemplazo del sistema de ocupación del territorio que se venía llevando a cabo hasta ese entonces, con ocupación parcial y pequeños núcleos urbanos, por un sistema civil de base industrial creciente, expandido y con aglomeraciones de escala metropolitana (Gutiérrez, R.; 1983).

La expansión urbana que tuvo lugar en aquellos años en Argentina tuvo un doble impacto; por un lado se construyeron nuevos pueblos y ciudades en varias regiones del país, y por otro varios de los viejos centros se transformaron en ciudades modernas. Por su parte Buenos Aires, Córdoba y Rosario sufrieron una metropolización radical. El crecimiento de Buenos Aires como centro de concentración de servicios y comercio, en función de ser el puerto privilegiado y capital de la Argentina se manifestó claramente en 1887, tras definir su perímetro federal abarcando los antiguos poblados de Belgrano y Flores. Con la organización Estatal creció la necesidad de espacios para la administración pública, pero también para la actividad privada (Liernur, J.F.; 2008).

En este período, que en su libro "La grilla y el parque" Adrián Gorelik denomina Primer ciclo metropolitano, y que abarca desde la ampliación administrativa del municipio de Buenos Aires hasta su casi completa urbanización, se promovió una nueva forma de renta urbana, que rompió con la ciudad tradicional. La figura del Estado quedó profundamente ligada al proceso de modernización, y debió dar respuesta a la masividad que representaban los nuevos sectores populares. La noción de espacio público fue abordada en este período como un estímulo para solucionar los nuevos problemas que la masividad representaba (Gorelik, A.; 2010).

Frente a la nueva problemática de la expansión urbana, hacia finales de 1880 se iniciaron varias acciones públicas las cuales buscaban entre otras cuestiones controlar la expansión, construir un mercado racional y definir las modalidades de la sociedad para los nuevos 
habitantes. La demarcación de los nuevos límites de la Capital Federal, el desarrollo de un plano público de la extensión y la disposición de parques perimetrales fueron las principales acciones que se desarrollaron en ese entonces. El nuevo límite de la ciudad que incluía los barrios de Flores y Belgrano, no constituía la sumatoria exacta de estos poblados sino que con su forma buscaba preservar la centralidad y la simetría de la ciudad tradicional, diferenciando de este modo la ciudad del territorio no urbanizado. Por su parte el plano publicado en 1904 determinó el trazado viario que se consolidaría luego, se trataba de una grilla homogénea con la cual el Estado pretendía incorporar las nuevas tierras al mercado. Asimismo, con la disposición de los parques se buscaba formar un cinturón verde que rodeara la ciudad concentrada, ya consolidada, limitando de este modo la expansión urbana (Gorelik, A.; 2010).

Durante la intendencia de Alvear se apuntó a dotar a Buenos Aires de obras públicas y símbolos, y a crear recintos urbanos centrales que permitieran definir la imagen de la ciudad. Las intervenciones urbanas que se llevaron a cabo durante este período para adecuar Buenos Aires a la imagen de la gran metrópoli cosmopolita que se pretendía mostrar al resto del mundo marcaron la primera ruptura de la traza con la apertura de la Avenida de Mayo (Figuras II - 20 y 21). En la zona se instalaron hoteles, comercios, oficinas y otras actividades burocráticas, incluida la Municipalidad, que determinaron el traslado de la función residencial privilegiada a la Avenida Alvear en pleno barrio norte, donde se construyeron mansiones increíbles (Liernur, J.F.; 2008).
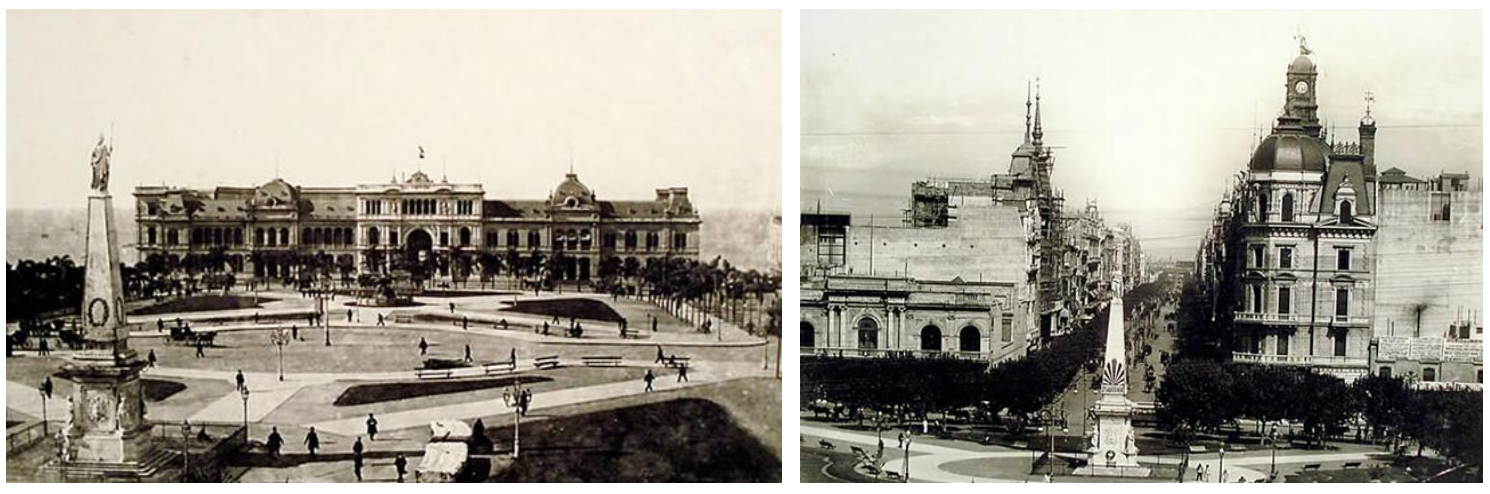

Figuras II - 20 y 21: Imágenes de la Ciudad de Buenos Aires a finales del Siglo XIX (Casa de Gobierno y Avenida de Mayo) -Fuente: Archivo General de La Nación, Ministerio del Interior y Transporte -

Disponible en: http://www.mininterior.gov.ar/archivo/archivo.php

A diferencia de lo que ocurrió en otras ciudades latinoamericanas, en Buenos Aires el territorio anexado en 1887 no fue ocupado según el designio de la especulación inmobiliaria o de la modernización técnica. Existía una regulación por parte del gobierno que pretendía dar una imagen global de la ciudad que se estaba conformando. Sin embargo en casi todas las grandes ciudades latinoamericanas los accidentes de la naturaleza favorecieron a construir barreras entre los distintos sectores sociales. En Buenos Aires, en cambio, la imposibilidad de fijar una frontera estable entre la ciudad y la llanura pampeana constituyó uno de los principales incentivos para creer que la expansión ilimitada era la forma de resolver las condiciones de hacinamiento del centro (Gorelik, A.; 2010).

En la periferia, la zona de fábricas y talleres de Barracas, Avellaneda, Lanús y Quilmes creció en usos residenciales mediante la ocupación de tierras bajas y áreas carentes de condiciones higiénicas y de servicios. Hacia el oeste se desarrolló una creciente actividad de loteos, fomentada por los altos precios de la propiedad y los alquileres que el mismo proceso de consolidación urbana provocaron en el centro histórico. En los primeros años del siglo XX las acciones urbanas contaban con un gran número de participantes que pugnaban cada uno por consolidar sus propios intereses. Tanto en Buenos Aires como en Rosario el crecimiento en este período se caracterizó por la creación de grandes porciones del territorio que un propietario organizaba en torno de un proyecto unitario, dominado por una plaza central, loteando los terrenos circundantes. Los propietarios negociaban con las empresas de transporte para que se realizaran desvíos de los ramales, estaciones, o tranvías que conectaran las nuevas zonas, consolidando nuevos barrios para los sectores medios (Liernur, J.F.; 2008). 
La función de los parques fue cambiando y si bien las epidemias acentuaron el carácter higiénico, los mismos constituyeron también el escenario elegido por las masas para pasar el tiempo libre (Figuras II - 22 y 23). El parque se ha entendido siempre como el instrumento privilegiado de reforma social, cultural y urbana, frente a la grilla, representativa de los intereses económicos especulativos. Esto explica porque la acción privada se volcó a la construcción de los nuevos barrios mientras que la acción pública se inclinó por la construcción de espacios verdes. Esta idea del parque como instrumento de reforma surgió con el proceso de formación del Central Park en Manhattan a mediados del Siglo XIX. Su construcción indujo el interés público por sobre el beneficio de los propietarios de tierras, especuladores y políticos. A partir de ese entonces el parque quedó instaurado como un instrumento de la reforma (Gorelik, A.; 2010).
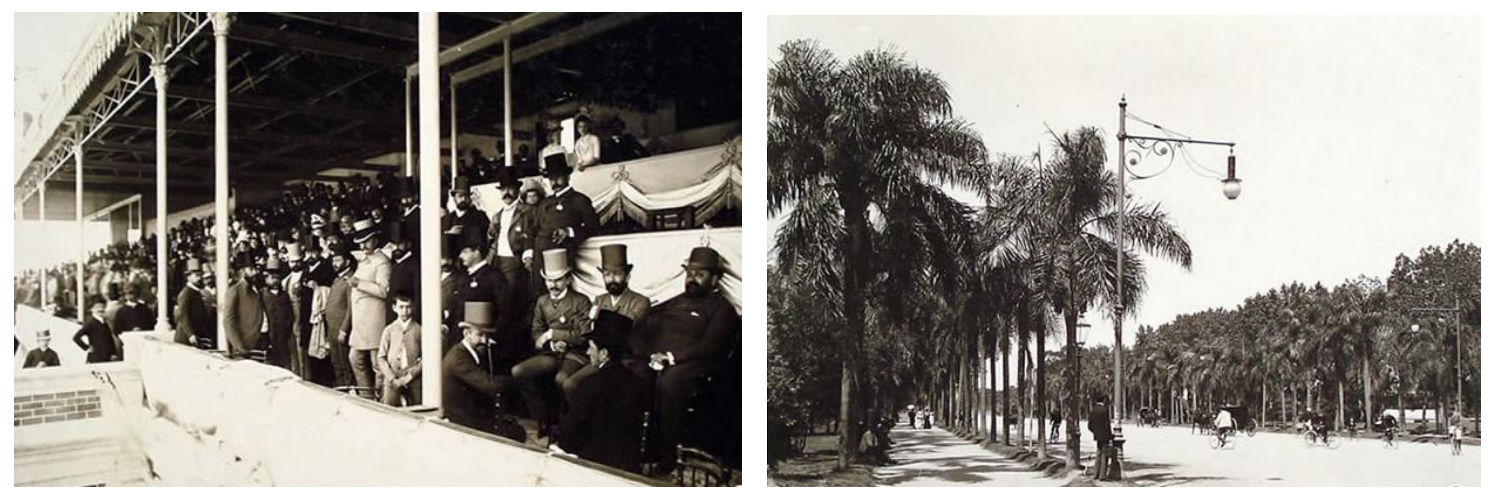

Figuras II - 22 y 23: Imágenes de la ciudad de Buenos Aires de Principios de Siglo XX (Hipódromo de Palermo y Bosques de Palermo) - Fuente: Archivo General de La Nación, Ministerio del Interior y Transporte - Disponible en: http://www.mininterior.gov.ar/archivo/archivo.php

En las primeras décadas del Siglo XX la ciudad se encontraba en plena expansión. La explotación intensiva de las áreas centrales se había extendido al suburbio. La acumulación de mano de obra, de fuentes de trabajo y la ausencia de infraestructura adecuada favoreció la concentración y el hacinamiento de las viviendas en el área central. Esto se tradujo en un deterioro acelerado del hábitat que terminó con la formación del conventillo, como tipología de alquiler en la cual se instalaban los inmigrantes que llegaban principalmente de Europa. Sin embargo, las mejoras urbanas que se consolidaron en las primeras décadas del Siglo XX y el aumento de los impuestos en los alquileres en las áreas centrales produjeron la expulsión de los sectores bajos hacia el suburbio. Asimismo, el aumento del valor del suelo en las áreas centrales contribuyó a la disminución de vacantes de lotes de grandes dimensiones. Dejaron de realizarse intervenciones para la construcción de grandes unidades de viviendas colectivas y comenzó a explotarse el crecimiento vertical en lotes de dimensiones mínimas de $8,66 \mathrm{~m}$. de frente, adaptando el sistema funcional de la vivienda. Este modelo se constituyó en el antecedente directo del modelo de vivienda de "propiedad horizontal" (Brito, G.A.; Maur, I.; 1993).

En 1929 Le Corbusier visitó Buenos Aires, sin embargo su paso por Argentina no dejó la misma impronta que en Brasil. En 1941 terminó su Plan Urbano para Buenos Aires (Figuras II - 24) junto a Kurchan y Ferrari Hardoy, el cual finalmente no se concretó. De este Plan se destacaron cinco características principales; la primera fue su total desentendimiento de la expansión de la ciudad por fuera de los límites de la Capital Federal, la segunda fue la reiteración de la idea de "ciudad concentrada" con altas densidades, la tercera fue la dispersión de las actividades directivas en centros ubicados en distintas zonas del casco, la cuarta fue el desarrollo de la "ciudad de los negocios" mediante cinco super-rascacielos planteados en el río y la quinta fue el plan de reemplazo paulatino de la trama existente mediante una grilla de supermanzanas (Liernur, J.F.; 2008).

En 1940 la Guerra interrumpió de manera definitiva las comunicaciones con Europa y en los años posteriores América Latina y principalmente las ciudades más importantes como Buenos Aires recibieron la influencia del "american way of life". El cine y las revistas difundían las ideas neoyorquinas, los primeros rascacielos y la hiper-equipada vivienda de los suburbios 
norteamericanos fueron las nuevas tipologías que se expandían en toda América Latina al ritmo del crecimiento de la industria automotriz. Los primeros rascacielos que surgieron en Buenos Aires fueron el Comega, el Safico y el Kavanagh, que se convirtieron en los hitos más relevantes de este tipo de arquitectura en Latino América. (Gutiérrez, R.; 1983).

Se conformó en ese entonces una nueva arquitectura determinada por la emergencia de los códigos expresivos y una morfología urbana estructurada por el parcelamiento preexistente que condujo a la verticalización de la imagen urbana. La utilización de la tecnología del hormigón armado, los ascensores, la modulación y la estandarización hicieron posible la materialización de esta nueva arquitectura que fue transformando el tejido urbano. Como consecuencia de la mayor altura de los edificios se produjeron modificaciones en la estructura urbana, en el perfil de las calles, en el anchor de las mismas, etc. (Brito, G.A.; Maur, I.; 1993).

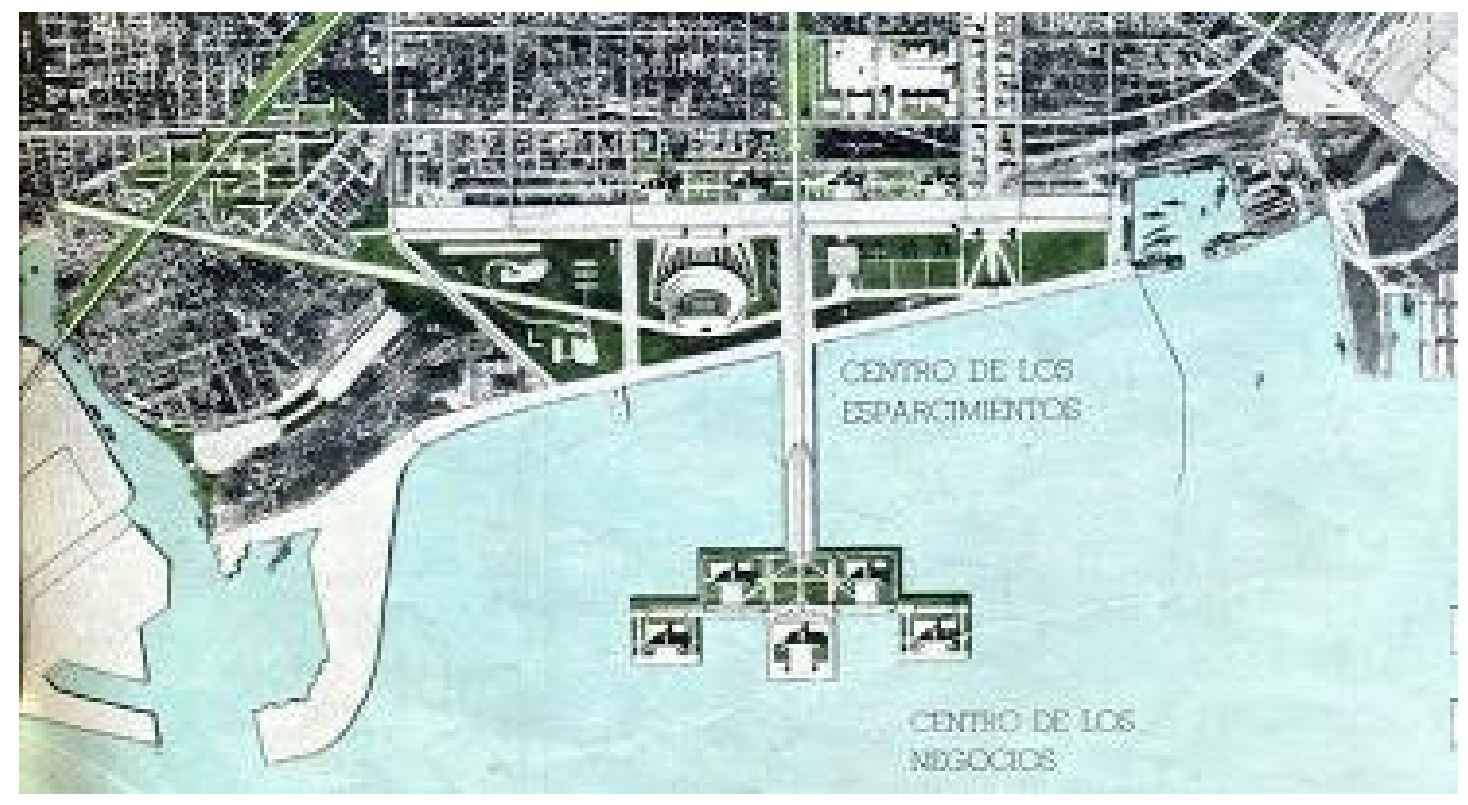

Figura II - 24: Planta del Plan de Le Corbusier para Buenos Aires - Fuente: Liernur, J.F.; Aliata, F. Diccionario de arquitectura en la Argentina. Voz: CIAM, Equipos Argentinos. Buenos Aires, Argentina. 2004

Entre 1940 y 1950 se realizaron muchos planes urbanísticos. En esos años los arquitectos modernistas participaron en concursos o fueron articulándose con el Estado. El principal emprendimiento urbano llevado a cabo en este período fue la construcción del Aeropuerto Internacional de Ezeiza, a cincuenta kilómetros de la Capital Federal. La zona afectada por las instalaciones era un enorme territorio que la construcción de la autopista Ricchieri comunicó con el sudoeste de Buenos Aires. Las obras incluyeron la creación de zonas verdes públicas, centros de recreación y barrios de viviendas que determinaron la apertura de un nuevo frente de la ciudad (Liernur, J.F.; 2008).

Las zonas fabriles y el cinturón industrial del gran Buenos Aires crecieron aceleradamente debido al impulso de una importante migración de población rural; llegando en 1950 a ser una ciudad de cuatro millones de habitantes, incluidos los habitantes del área metropolitana. La expansión urbana fue llenando las áreas intersticiales con viviendas de sectores de bajos ingresos, marginales (Liernur, J.F.; 2008).

En ese contexto se reiniciaron los aportes para la redacción de un Plan para Buenos Aires en 1953, como parte de las tareas de la División de Urbanismo; uno de los principales resultados fue el estudio de la evolución histórica de la ciudad. Este estudio sirvió de base para la puesta en marcha de la Dirección del Plan Regulador en 1956 y para la constitución de la Organización del Plan Regulador de Buenos Aires en 1958. Si bien el Plan fue aprobado en 1957 los capitales que comenzaban a construir la ciudad eran muy poderosos. Los debates y modelos tipológicos ideados hasta entonces a través de acciones privadas, de las administraciones provinciales o municipales y de la Comisión Nacional de Casas Baratas se 
articularon en una línea de acción que se caracterizó por tres factores; la consideración de la vivienda como derecho, la construcción masiva de unidades compactas y dispersas, y el surgimiento de las primeras grandes inversiones de media y alta densidad (Liernur, J.F.; 2008).

Los programas de vivienda que se produjeron en el marco de los planes quinquenales constituyeron los ejes del crecimiento urbano en ese período. Se multiplicó la cantidad de créditos destinados a las familias de recursos escasos, lo que significó el acceso a la vivienda digna de gran parte de la población. La ciudad continuó creciendo como una mancha de aceite en torno a las vías del ferrocarril. Sin embargo la dispersión y la falta de coordinación supuso un enorme gasto de recursos y un gran aumento de los costos sociales a cargo de las generaciones posteriores, que debieron cubrir los costos de la extensión de las redes de transporte, energía, cloacas y agua, y de los servicios de todo tipo, inexistentes al momento de la expansión (Liernur, J.F.; 2008).

Entre 1940 y 1950 se produjo un importante flujo migratorio desde el interior del país. Sin embargo recién a partir de 1950 se produjo un proceso creciente de incorporación de esos inmigrantes a la estructura industrial, que a partir de ese momento comenzó a ser insuficiente como fuente de trabajo. La reapertura de la economía a los grandes capitales internacionales en los rubros de la energía y las nuevas industrias había comenzado en 1950, no obstante las condiciones para su avance acelerado se generaron entre 1960 y 1980. En ese contexto cobra importancia el fenómeno de las villas miseria, que ya había comenzado con la crisis de 1929 (Liernur, J.F.; 2008).

En 1953 la promulgación de la Ley 14.222, de radicación de capitales extranjeros, dio impulso a un proceso de transformación por el que el país abrió sus puertas a la entrada de grandes empresas de origen multinacional. El resultado fue el comienzo de un acelerado proceso de concentración de capitales. La arquitectura argentina y los centros urbanos se vieron afectados por la instalación de nuevas plantas industriales, la construcción de sedes administrativas, la declinación del sistema ferroviario a favor del automotriz, la importancia del capital financiero privado, etc. Los programas complementarios a los grandes establecimientos fabriles fueron las sedes de esas mismas empresas, lo que significó la aparición de un nuevo tipo, el edificio en torre, y su adopción como emblema empresarial. Esta tipología constituyó la más clara expresión de la modernización de la Argentina (Liernur, J.F.; 2008).

En pocos años Buenos Aires y otras ciudades argentinas contaron con edificios vidriados, emblemas de las primeras apariciones de las corporaciones internacionales. La concentración en altura a partir de la unificación de predios, premiada en general por el nuevo Código, significó un gran beneficio para los inversionistas inmobiliarios ya que permitía multiplicar la superficie a construir. Los sectores de la ciudad destinados a este tipo de construcciones habían sido fijados por el Código sin embargo los nuevos edificios fueron surgiendo, haciendo caso omiso a esta normativa. El predio Catalinas Norte se convirtió en un campo de ensayo para estas grandes construcciones. La idea de concentrar en ese lugar un conjunto de edificios de oficinas de gran envergadura en relación con los edificios existentes hacía referencia a la vieja propuesta de la ciudad de los negocios de Le Corbusier. Asimismo reproducía la experiencia norteamericana de revitalización de los viejos centros urbanos mediante concentración de grandes inversiones en funciones terciarias superiores (Liernur, J.F.; 2008).

Durante el Proceso de Reorganización Nacional el Estado funcionó como promotor de grandes obras y planes. Durante el período que duró el Proceso se establecieron modificaciones importantes en los modos de gestión, en las características de la organización industrial y en los encargos de arquitectura. La Ley de Entidades Financieras implantada por el ministro José Alfredo Martínez de Hoz impulsó el crecimiento de las actividades terciarias superiores en el área central norte de la ciudad de Buenos Aires y la expansión de esta zona hasta Retiro. Las tasas de interés provocaron una disminución del mercado de vivienda, contribuyendo a que los edificios de oficinas concentraran una gran porción de las industrias edilicias urbanas en esos años. En 1975 éste área concentraba el $28 \%$ de las oficinas construidas en la Capital Federal, que pasaron a constituir el 44\% del total en 1976 (Liernur, J.F.; 2008).

Si bien la Guerra de Malvinas constituyó el fin de la Dictadura Militar, el país que emergió del Proceso debió reconstruir una economía devastada, con empresas estatales empobrecidas y 
con una abultada deuda externa. Por otra parte con la Dictadura Militar se dejó de lado también la realización de programas de alcance social y envergadura colectiva. Las transformaciones que experimentó el país a lo largo de las dos últimas décadas del siglo XX fueron resultado de una reestructuración general del capitalismo en todo el mundo. A partir de 1980 se produjo en el sistema capitalista un pasaje del modo de desarrollo industrial al modo de desarrollo informacional. Este cambio que se identifica con la idea de globalización requirió de estructuras de extrema flexibilidad desde los puntos de vista legal, cultural, económico, político y geográfico (Roca, M.A.; 2003).

En las últimas dos décadas del siglo XX se produjo una fuerte concentración de las riquezas en Argentina por parte de los sectores de mayores ingresos. Por su parte los sectores más bajos de la clase media fueron arrastrados hacia la clase baja. Un alto porcentaje de los hogares tenían necesidades básicas insatisfechas y otro tanto estaba bajo el índice de pobreza. La situación que ya era grave en el conurbano bonaerense, se hacía más grave en el interior del país. Hacia finales del Siglo XX muchas de las viviendas no contaban con servicio de agua potable ni desagües cloacales conectados a la red pública. Existía un gran déficit de viviendas en las áreas rurales y, aunque menor, también en las urbanas. La crisis del Estado Nacional como unidad principal de decisiones contribuyó a la apertura del mercado. De este modo el Estado abandonó el papel de regulador que había tenido en épocas anteriores, provocando grandes consecuencias en la ordenación del territorio en dos aspectos; por la privatización de empresas y servicios, y por la descentralización de una importante cantidad de funciones en las provincias y municipios (Liernur, J.F.; 2008).

La primera manifestación generalizada de la concepción de la ciudad por partes se produjo en 1986 con el concurso "20 ideas para Buenos Aires", organizado entre la Municipalidad de la Ciudad de Buenos Aires y la Comunidad de Madrid (Figuras II - 25 y 26). El interés local por la transformación española excede a los técnicos y profesionales que se ocupaban de la ciudad, y se relacionaba con las alternativas de la transición democrática. En esos años se intensificaron las afinidades políticas e ideológicas entre los gobiernos de Raúl Alfonsín y de Felipe González, y se multiplicaron la cantidad de acuerdos bilaterales entre Argentina y España. Sin un plan detrás del concurso, las bases sostenían la inconveniencia de aguardar su elaboración para intervenir sobre la ciudad, y señalaban la falta de efectividad de los planes previos. Los organizadores indicaron una serie de áreas situadas mayormente en la periferia de la ciudad, un conjunto de 'vacíos urbanos', y solicitaron propuestas realistas y realizables, en las que los arquitectos proyectistas proponían al proyecto como instrumento, tal como lo había planteado Bohigas en la transformación de Barcelona (Jajamovich, G.; 2012).
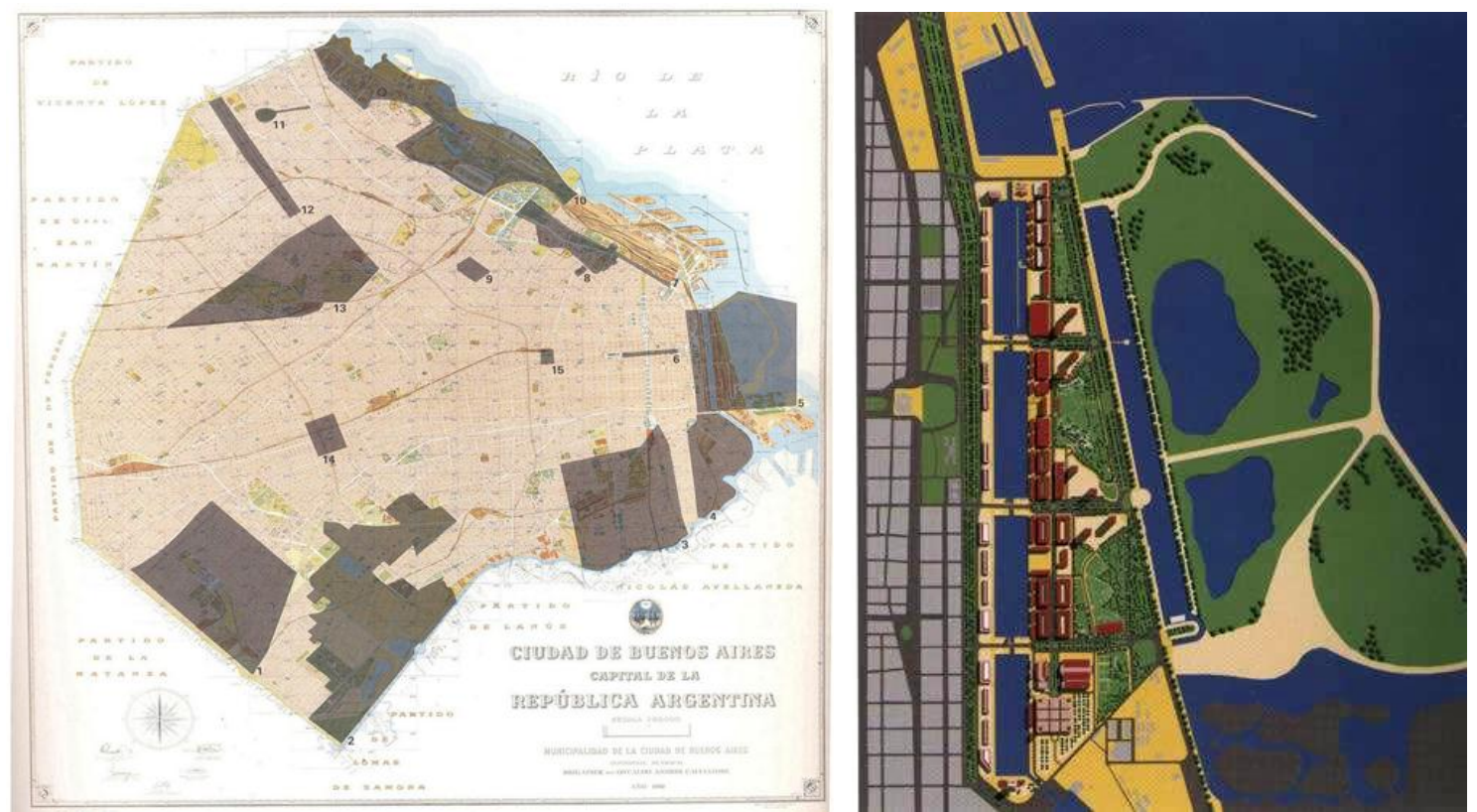

Figura II - 25 y 26: Plano del concurso "20 ideas para Buenos Aires" y Sector Puerto Madero - Fuente: Consejo Profesional de Arquitectura y Urbanismo (CPAU) - Disponible en:

http://www.observatorioamba.org 
En el Concurso para el plan maestro de los terrenos de Puerto Madero confluyeron distintos tipos y modelos de acciones que se deducían de las nuevas actitudes frente al fenómeno urbano. Ciudad por partes, creación de una zona privilegiada con una máxima renta, de posición histórica, paisajística y con el máximo valor absoluto de los predios, por su ubicación junto a los terrenos centrales de la ciudad. También en Retiro se llevó a cabo un concurso con el objeto de determinar una reforma general para el área, y que finalmente provocó el aumento de densidad y una nueva oferta de espacios terciarios. Sin embargo, el Proyecto Retiro constituyó un proceso de privatización de la propiedad estatal, sin otro beneficio para los ciudadanos que el proveniente de la venta de los terrenos (Liernur, J.F.; 2008).

En 1991 el Ministerio de Economía pone en práctica un nuevo proyecto, orientado a la apertura de la economía, la desregulación de los mercados, la privatización de las empresas públicas y el cambio del régimen fiscal existente hasta ese momento. Estos cambios terminaron con la industria de sustitución de importaciones, sentando las bases de un sistema centrado en la acción del capital financiero extranjero y nacional. Estos cambios fueron acompañados por un proceso de alta concentración económica empresaria, cierre de fábricas, cambios sustanciales en la estructura del comercio y los servicios, cambios en el mercado del trabajo, precarización del empleo y aumento del desempleo, transformaciones en la estructura sindical, descenso en el nivel de vida de los sectores medios y bajos, deterioro de las prestaciones sociales, crisis del sistema previsional y de la educación pública (Liernur, J.F.; 2008).

Una de las consecuencias más importantes de la privatización de servicios antes controlados por el Estado fue la sesión de las obras de transporte; la construcción de aeropuertos, la gestión y construcción privada de autopistas en relación con los centros urbanos más grandes que actuaron como los motores principales de los nuevos procesos de reestructuración territorial y urbana. El mejoramiento de las autopistas posibilitó el acceso rápido a amplias áreas de suelo vacante que aumentaron rápidamente su valor ya que en ellas podían realizarse inversiones inmobiliarias muy importantes. Aparecieron en el mercado nacional capitales de nuevos fondos que no existían en períodos anteriores lo que posibilitó un cambio en la magnitud en que se realizaba la construcción del territorio. El Estado comenzó a delegar las funciones de ordenamiento territorial al capital privado. La localización de los proyectos inmobiliarios se daba en los lugares elegidos por los inversores, modificando la zonificación establecida. El mercado se transformó en el punto principal donde se establecen las relaciones y articulaciones entre actores que accionan en la conformación del espacio urbano (Roca, M.A.; 2003).

Como consecuencia de estas decisiones en Buenos Aires se destacaron dos tipos de efectos; los producidos en el área metropolitana y los referidos a las dos principales aglomeraciones articuladas con ella por las nuevas vías de circulación, Rosario y La Plata. Ambas ciudades han experimentado una considerable reducción de la distancia-tiempo que las separa de la Capital Federal, pero han reaccionado de manera distinta. Rosario ha impulsado su papel como nudo intermodal de transporte del Mercosur, punto de cruce de los más importantes corredores vial, ferroviario y fluvial de la región. Se ha caracterizado en los últimos años como el polo más activo de la cultura arquitectónica en la Argentina. Las autoridades han apostado a las intervenciones en infraestructura más que a las piezas arquitectónicas. En La Plata las políticas económicas a escala del gobierno provincial pusieron en marcha intentos de revitalización mediante la creación de un polo tecnológico y una zona franca en el área del viejo puerto correspondiente a las localidades de Berisso y Ensenada. La ciudad asumió un rol complementario con Buenos Aires, sin embargo en los últimos años se han concretados algunos proyectos que fueron concebidos en distintos momentos del pasado; se completó la construcción de la Catedral, el Teatro Argentino y el Estadio Único, y la remodelación del Pasaje Dardo Rocha (Roca, M.A.; 2003).

Como ocurre entre Rosario y Buenos Aires, la mayor accesibilidad hacia las zonas de actividades terciarias superiores estimuló el aumento de la construcción de bloques de administración y servicios. La reducción de la distancia-tiempo entre el centro y los cinturones periurbanos determinó la aparición del nuevo fenómeno de los barrios cerrados. Por su parte la creciente inseguridad urbana sumada a la incapacidad de la administración para reorganizar de manera atractiva zonas comerciales existentes favoreció la aparición de los centros de compras 
que en la mayoría de los casos se instalaron en la periferia, conectados a vías importantes de circulación (Roca, M.A.; 2003).

Por otra parte la crisis de las economías regionales continuó estimulando la llegada de inmigrantes y acentuó la formación de asentamientos precarios. La caída del empleo y las condiciones de vida de los habitantes de los sectores más carenciados y la libertad de ocupación del espacio público urbano llevaron a una creciente presión sobre la Ciudad de Buenos Aires, como centro del país. La caída de la inversión pública contribuyó al deterioro de la ciudad, provocando la expulsión de los sectores medios del centro y el crecimiento de la tugurización en las afueras, o en los vacíos urbanos, como ocurrió con la Villa 31, el Elefante Blanco y otros asentamientos precarios insertos en el centro mismo de la trama urbana (Roca, M.A.; 2003).

En 1999 se presentó a la Legislatura de la Ciudad de Buenos Aires el diagnóstico y los objetivos de lo que sería el primer Plan Urbano Ambiental para la ciudad (Figura II - 27). Este Plan constituyó un marco de referencia tanto para la gestión pública como para la sociedad. Inicialmente, fue definido desde sus dimensiones urbanas y ambientales; refiriéndose con lo "urbano" al territorio de Buenos Aires en su dimensión regional, como objeto de estudio y acción, y con "ambiental" a los resultados de los estudios-diagnóstico hasta la puesta en marcha de las acciones. Se manifestó la necesidad de implementar un proceso integral de desarrollo que contemplara el mejoramiento de la calidad de vida desde una distribución equitativa de los recursos presentes y futuros, creando escenarios de consenso, a los efectos de contribuir a la constitución de un proyecto de ciudad compartido y en el largo plazo (Ministerio de Planeamiento y Obras Públicas, Gobierno de la Ciudad de Buenos Aires; 2006).

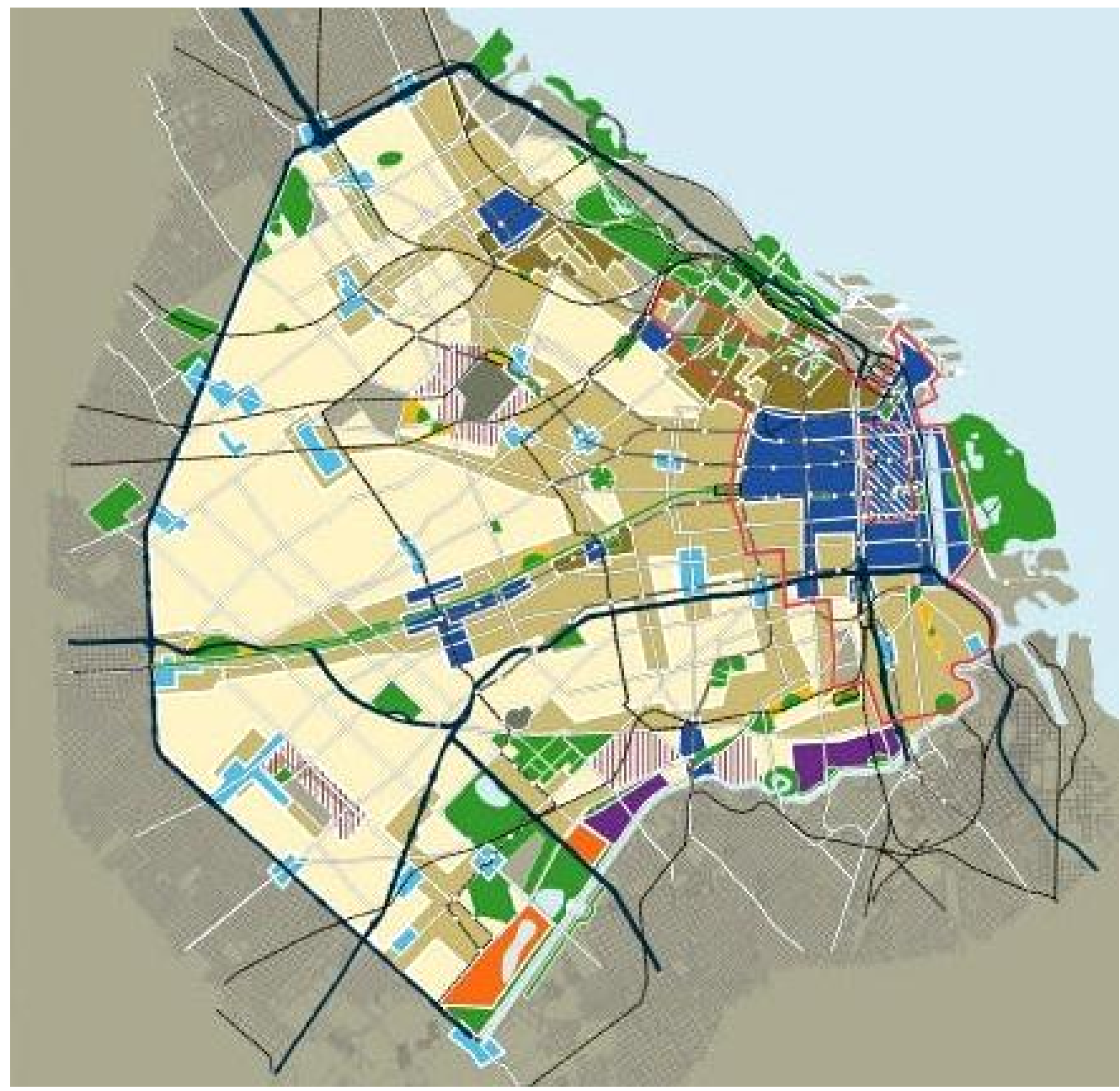

Figura II - 28: Plan Urbano Ambiental para la ciudad de Buenos Aires - Fuente: Gobierno de la Ciudad de Buenos Aires - Disponible en: http://www.buenosaires.gob.ar 
Sin embargo, las acciones que se han realizado a escala urbana en los últimos años consistieron fundamentalmente en operaciones para los sectores de mayores ingresos, en emprendimientos privados puntuales de gran escala generalmente vinculados al comercio, a la recreación y a los asentamientos en zonas destacadas de la ciudad. Los capitales concentrados se convirtieron en los nuevos actores de la construcción de la ciudad. Debido a la escasez de fondos públicos y a la gran demanda de vivienda, estas inversiones fueron recibidas por las autoridades sin realizar los estudios adecuados de impacto ambiental, contribuyendo al crecimiento de la segregación social dentro de la ciudad (Liernur, J.F.; 2008).

Por su parte el espacio público se privatizó de dos maneras; por un lado se acentuó la tendencia a la privatización de predios pertenecientes a la ciudad, por otro, numerosos lugares de esparcimiento de propiedad pública pasaron a ser accesibles exclusivamente para quienes estaban en condiciones de pagar por ello. La costanera y los balnearios fueron reemplazados por pabellones destinados a exposiciones, centros culturales, gastronomía, hoteles, vivienda, etc. En Capital Federal las cifras de las superficies que en estos años han dejado de pertenecer plenamente al Estado son significativas; Puerto Madero, La Rural, Tandanor, Santa María del Buen Ayre, Warnes, etc. suman aproximadamente doscientos cincuenta hectáreas de las tierras más valiosas del país que han pasado a manos privadas (Liernur, J.F.; 2008). 


\section{CAPÍTULO III \\ EL TIPO EDILICIO}

\subsection{Orígenes}

La construcción en altura se relaciona de manera directa con el poder económico. No es casual que las primeras edificaciones en altura se hayan construido en Estados Unidos, en los años en los que este país comenzaba a posicionarse como potencia mundial. Los rascacielos, máximos exponentes de la construcción en altura, son el resultado del empuje y la iniciativa del auge del sistema capitalista que ganó espacio en Estados Unidos hacia finales del Siglo XIX y principios del Siglo XX. La agrupación de edificios de gran altura representa una época cultural que busca fama y reconocimiento (Johnson, P.; 1999).

En la actualidad los rascacielos dominan el escenario urbano, son símbolos de las ciudades y del poder empresarial. Si bien desde sus inicios se argumentó su construcción en el máximo aprovechamiento económico del suelo, dado el alto valor de los lotes en las áreas centrales, la motivación económica no es tan real ya que el crecimiento en altura significó siempre costos muy elevados. La motivación real de los edificios en altura es puramente publicitaria ya que otorgan una imagen de poder y bienestar económico a la empresa que representan y a la ciudad en la que se instalan (Dupré, J.; 1999).

Los rascacielos son una forma de arte genuinamente de Estados Unidos, sus inicios estructurales se remontan al 1880 en Chicago. En el año 1871 esta ciudad había sido destruida por un gran incendio, sus construcciones hasta ese momento eran de madera y de baja altura. Los daños provocados por el incendio se evaluaron en aquel entonces en más de doscientos millones de dólares, sin embargo esta destrucción otorgó a las nuevas generaciones de arquitectos la posibilidad de reconstruir la ciudad desde el inicio (Dupré, J.; 1999).

Alrededor de 1869 ya se disponía de las tecnologías fundamentales necesarias para construir este tipo de edificios sin embargo no se explotaron hasta el año 1885, con la construcción del edificio de la Home Insurance en Chicago. La construcción en altura planteaba nuevas problemáticas que debían resolverse:

- Estructura

- Seguridad

- Transporte

- Habitabilidad

Todos estos requerimientos se fueron desarrollando simultáneamente y contribuyeron al avance de la tecnología de los rascacielos. Los avances en la técnica del hormigón armado, el acero y el desarrollo del ascensor hicieron posible el crecimiento en altura. La construcción con acabados de acero dio paso a estructuras de acero soldado, contribuyendo a que los edificios prescindieran de los muros exteriores para mantener la estructura. El hormigón armado por su 
parte otorgó a los arquitectos libertad formal y, junto con los avances en el uso del acero estructural, permitió la conformación del curtain wall. Las fachadas de los edificios se conformaron de grandes paños vidriados que favorecieron la iluminación interior de las plantas. Este nuevo elemento, clave del repertorio formal utilizado por el Estilo Internacional, hizo necesario el uso del aire acondicionado para mantener los ambientes interiores en los límites de confort. Por otra parte, el ascensor de seguridad desarrollado por la empresa Otis en el año 1850 hizo posible el acceso a los pisos superiores. Hasta ese entonces las construcciones no superaban los seis pisos de alto porque el acceso a los últimos pisos, de menor valor, era dificultoso. Con el desarrollo del ascensor los pisos altos se revalorizaron, en detrimento de los más bajos, por la exclusividad de las vistas que ofrecían (Dupré, J.; 1999).

En 1885 William Le Baron Jenney construyó el edificio de la Home Insurance en Chicago (Figuras III -1 y 2). Se trató del primer edificio de gran altura soportado por una estructura metálica e ignífuga. Esta estructura de hierro liberaba a las fachadas de las funciones estructurales, reduciendo el espesor de los muros de cerramiento, al tiempo que aumentaba la superficie de suelo útil, aligeraba el peso total del edificio y permitía el crecimiento en altura. Se trataba de un edificio de diez plantas y $42 \mathrm{~m}$. de altura cuya fachada imitaba las estructuras tradicionales (Dupré, J.; 1999).
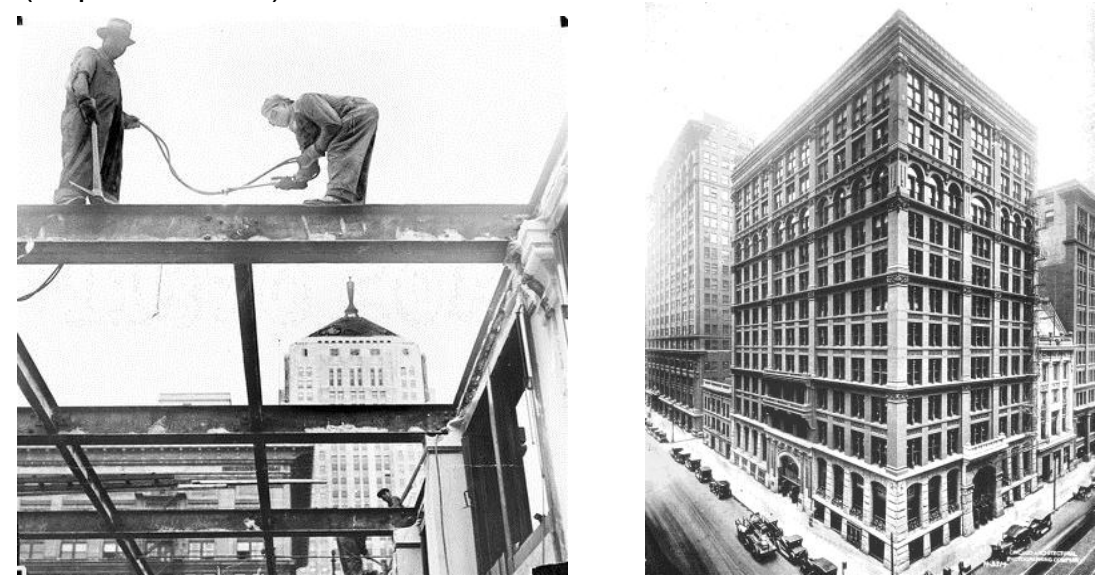

Figuras III- 1 y 2: Edificio de la Home Insurance, Chicago (1885) - Fuente: United States Library of Congress's National Digital Library Program - Disponible en: http://memory.loc.gov

Una vez resuelta la técnica que hacía posible la construcción en altura, quedaba por resolver la cuestión estética. Esta discusión fue abordada por los arquitectos de la Escuela de Chicago, aspecto que se refleja en el ensayo escrito por Louis Sullivan en el año 1896 "The tall office building artistically considered". En este artículo Louis Sullivan trataba cuestiones relacionadas con las fachadas del tipo edilicio; la conformación de las líneas principales y la configuración del basamento, el desarrollo y el remate, como elementos compositores (Dupré, J.; 1999).

Sin embargo, y pese a que Chicago ha sido el gestor de este tipo edilicio, no cabe dudas de que Nueva York ha sido el máximo exponente de este tipo de arquitectura. Debido al crecimiento demográfico que experimentó esta ciudad hacia finales del Siglo XIX, y que aún hoy continúa experimentando especialmente en el área de Manhattan, se vio obligada a crecer en altura. El edificio Barclay Vesey fue el primer edificio que cumplió con los requerimientos de las leyes urbanísticas que en 1920 fueron creadas en Nueva York para reducir la congestión del tránsito, la falta de luz y los riesgos de seguridad generados por los rascacielos. Las leyes obligaban a recurrir a una reducción de la superficie de las plantas en los niveles más altos para alejar los edificios de las veredas, y controlar su altura y su volumen. En aquel contexto se realizó un estudio sobre la relación costo - altura para determinar cuál era la altura óptima que debían tener las torres. Estaba claro que a mayor altura, el costo de superficie del lote disminuía pero sin embargo el precio de superficie construida era mayor. Finalmente se determinó que la altura óptima era de treinta y dos pisos (Dupré, J.; 1999).

A medida que las compañías que promovían la construcción exigían a los arquitectos alcanzar cada vez mayor altura y destacarse en el "skyline"1 de las ciudades, éstas se convertirían en el

\footnotetext{
${ }^{1}$ Silueta, o visión total o parcial, de las estructuras y edificios más altos de una ciudad.
} 
laboratorio para experimentar con nuevas tecnologías. Los primeros edificios con ascensores de Manhattan supusieron una auténtica reacción en cadena en el mercado inmobiliario. La introducción sistemática del ascensor equilibró el precio de alquiler de todos los pisos en los espacios comerciales, acabó con las inversiones económicas seguras, y creó nuevas y extraordinarias rentas inmobiliarias (Tafuri, M.; 1975).

Hacia 1930 el Edificio Chrysler (Figura III - 3) competía por ser el más alto del mundo con el edificio del Banco de Manhattan, de $278 \mathrm{~m}$. de altura. La competencia llegó a tal extremo que Van Alen, el arquitecto encargado del proyecto, construyó en secreto una aguja dentro del edificio, la cual fue colocada en la cima una vez finalizado el mismo, convirtiendo al Chrysler en el edificio más alto del mundo con $315 \mathrm{~m}$. de altura. Sin embargo, menos de un año más tarde, con la construcción del Empire State (Figura III - 4), el Chrysler perdió esa categoría. El rascacielos situado en la intersección de la Quinta Avenida y West 34th Street, con 443m. de altura, fue el edificio más alto del mundo durante más de cuarenta años desde su finalización en 1931 hasta 1972, año en que se completó la construcción de la torre norte del World Trade Center (Dupré, J.; 1999).
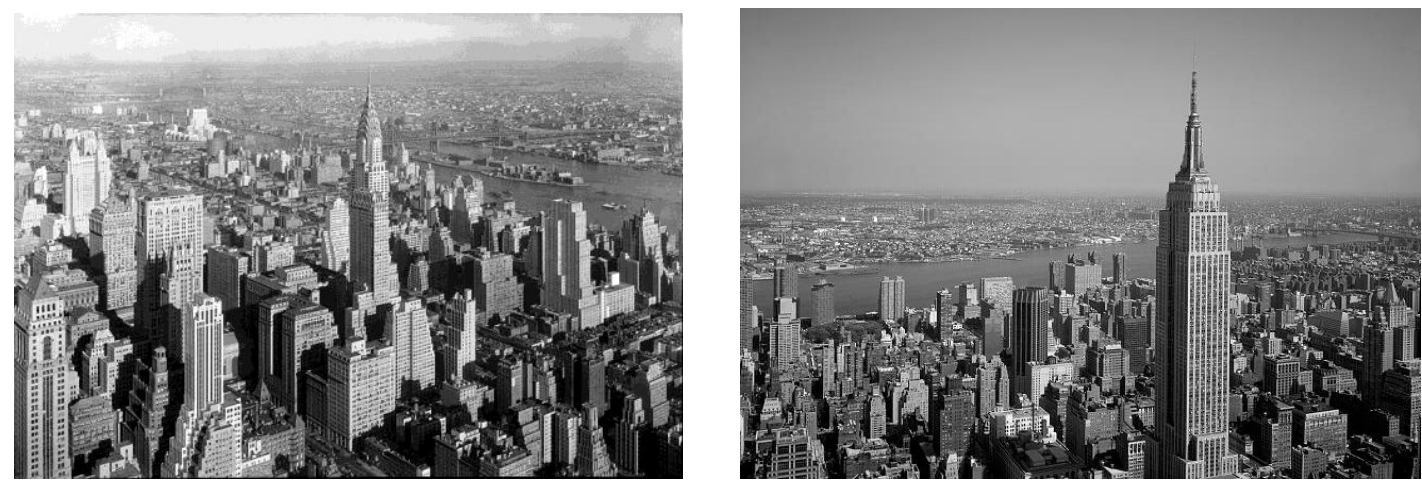

Figuras III - 3 y 4: Edificio de Chrysler, Nueva York (1930) y edificio Empire State, Nueva York (1931) Fuente: United States Library of Congress's National Digital Library Program - Disponible en: http://memory.loc.gov

Construido en el año 1957, el edificio Seagram de Mies Van der Rohe (Figuras III - 5, 6 y 7) conjugó los ideales del movimiento moderno, representando la culminación de la búsqueda de la arquitectura contemporánea. Su diseño y la relación que planteaba con el entorno en el cual se insertaba provocaron la aparición en 1961 de una normativa urbanística que obligaba a ampliar los espacios abiertos alrededor de los edificios altos. Dejando a un lado los criterios económicos, Mies Van der Rohe decidió liberar un espacio próximo al edificio, cediendo a los habitantes de la ciudad una plaza pública. Con ello no sólo creó una distancia necesaria con respecto a la calle para poner de relieve el edificio, sino que se distanció de la tendencia a llevar al límite la construcción de rascacielos, en favor del crecimiento urbano (Zimmerman, C.; 2006).
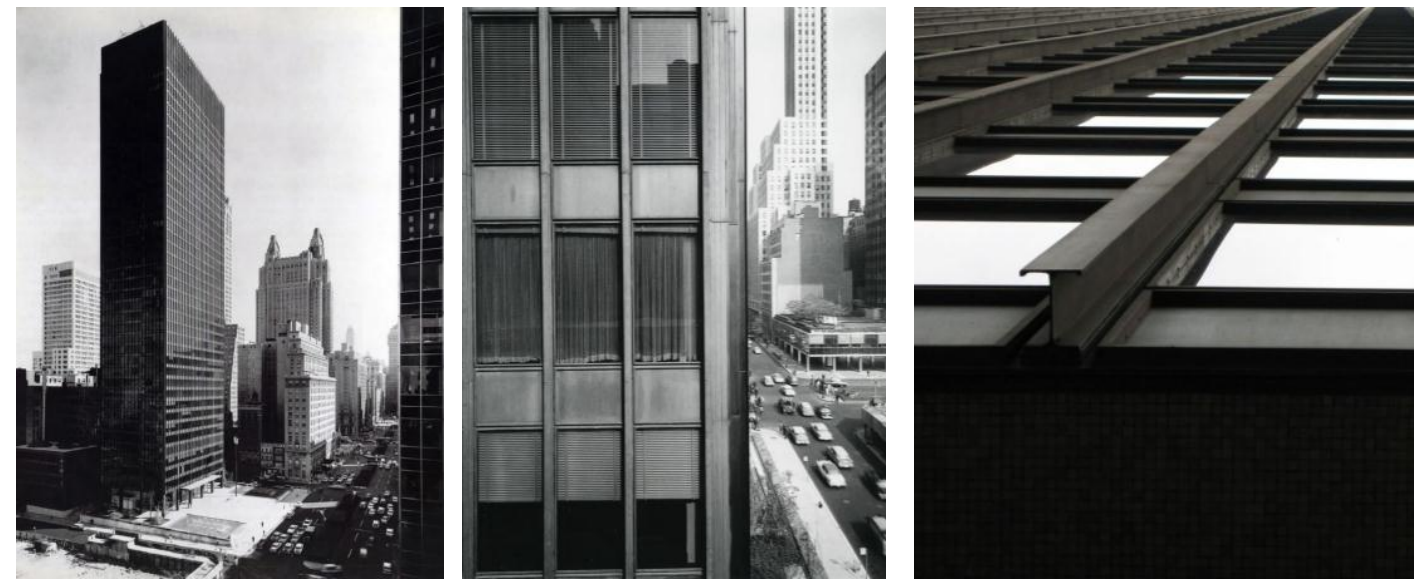

Figuras III - 5, 6 y 7: Edificio Seagram, Nueva York (1957) Mies Van der Rohe - Fuente: 375 Park Avenue Seagram Building - Disponible en: http://www.375parkavenue.com 


\subsection{Evolución del tipo edilicio en Argentina}

Tal como en otras ciudades de Latinoamérica, en Buenos Aires la vivienda en altura constituyó la forma de agrupamiento más emblemática de la especulación inmobiliaria moderna. La construcción de edificios en altura en las principales ciudades latinoamericanas se vio acelerada hacia finales del Siglo XIX por el proceso de modernización que convirtió a las ciudades en un motor de valoración del capital. Sin embargo, la agrupación en altura no significó resoluciones distributivas para las unidades distintas a las de vivienda individual hasta las primeras décadas del Siglo XX, con la difusión del tipo a todo el país (Cutruneo, J.P.; 2012).

El crecimiento que experimentaron las principales ciudades latinoamericanas en aquellos años favoreció el incremento del valor del suelo en las áreas centrales al tiempo que se experimentaba una reducción de los lotes de grandes dimensiones vacantes. En Buenos Aires esto favoreció la explotación de lotes de dimensiones mínimas de 8,66m. de frente, adaptando el sistema funcional de vivienda que venía utilizándose hasta ese entonces. Las dimensiones, proporciones, posición, orientación, contorno y demás aspectos que marcaban la configuración de los edificios quedaban determinados por la estructura parcelaria de la ciudad (Figuras III - 8 y 9). Estos factores y los derivados de los modos de habitar, de la modernización de las técnicas de confort y de las tecnologías constructivas, y la inserción de las leyes del mercado, entre otros, fueron determinando distintas tipologías (Liernur, J.F.; Aliata, F.; 2004).

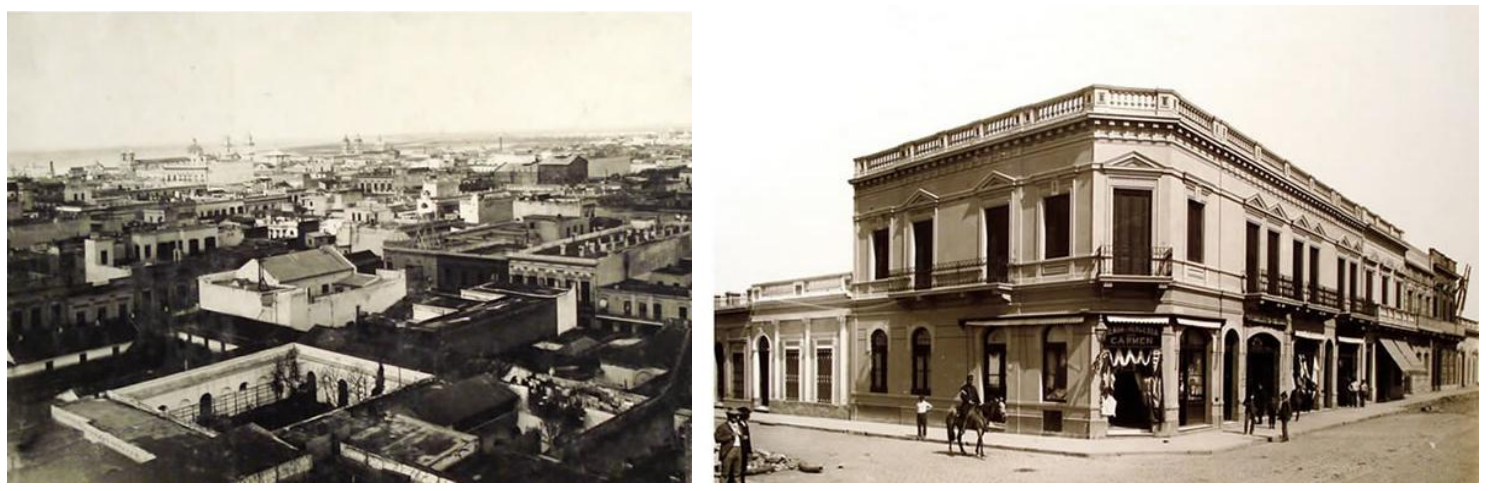

Figuras III - 8 y 9: Panorama de la Ciudad de Buenos Aires hacia finales del Siglo XIX - Fuente: Archivo General de La Nación, Ministerio del Interior y Transporte - Disponible en: http://www.mininterior.gov.ar/archivo/archivo.php

En 1885 la introducción del esqueleto de acero en la edilicia doméstica permitió el desarrollo de la edificación en altura. También la implementación de distintos mecanismos posibilitados por la energía eléctrica tales como los ascensores, llamadores, etc. y el desarrollo de las instalaciones de higiene (inodoros con sifón, duchas, desagües cloacales, etc.) hicieron posible la construcción de este tipo de edificios. Sin embargo, en los primeros años estos nuevos elementos implicaban un costo muy elevado ya que se trataba de insumos importados. Por este motivo las primeras casas de renta en altura se destinaron a un público de altos ingresos. El primer antecedente que se produce es la repetición en altura de la casa chorizo (Cutruneo, J.P.; 2012).

A finales del Siglo XIX el desarrollo de este tipo edilicio se dio casi en forma exclusiva en Buenos Aires. Hacia 1887 con la apertura de la Avenida de Mayo, la construcción de edificios de renta en altura excedió los límites del área central en Buenos Aires (Figuras III - 10 y 11). Los mismos alcanzaban una altura máxima de $20 \mathrm{~m}$. (cinco niveles), que era el máximo permitido por el Reglamento de Construcciones. Por su parte, las condiciones de habitabilidad dependían de la orientación de los locales; los que daban al frente contaban con buenas condiciones de iluminación natural y ventilación mientras que en los locales que daban a los patios de aire y luz las condiciones de iluminación y ventilación eran muy malas. La industria de la construcción, los bancos e incluso los municipios apoyaban el desarrollo de estas tipologías ya que constituían la alternativa a la construcción de conventillos (Liernur, J.F.; Aliata, F.; 2004). 

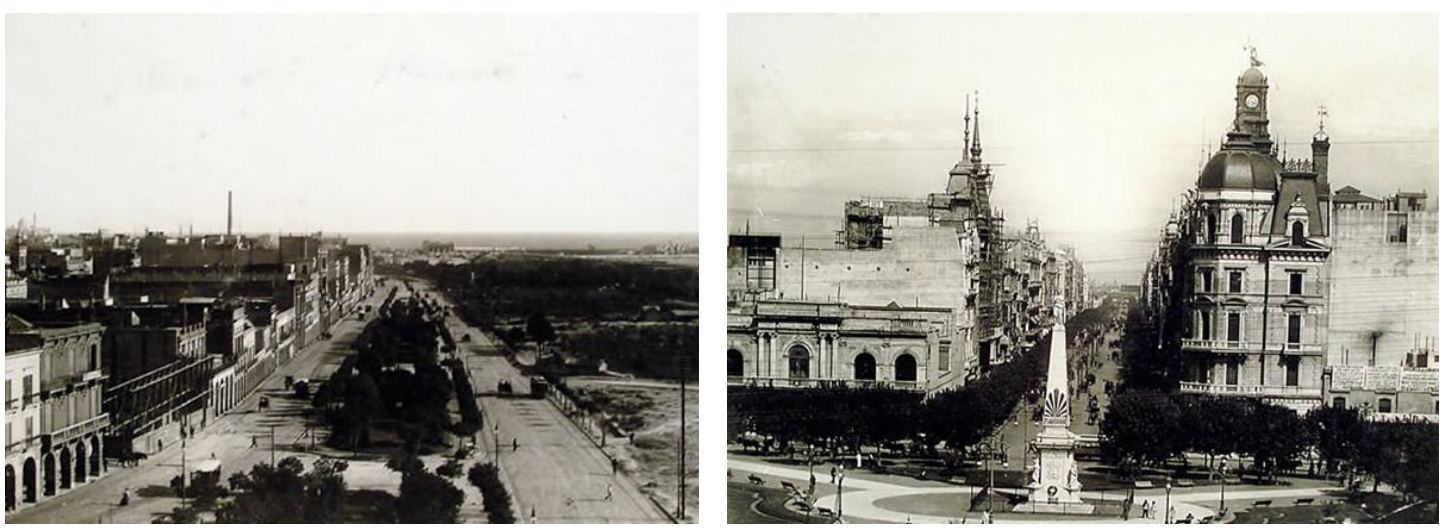

Figuras III - 10 y 11: Paseo Julio del Puerto y Avenida de Mayo, Buenos Aires (1890) - Fuente: Archivo General de La Nación, Ministerio del Interior y Transporte - Disponible en: http://www.mininterior.gov.ar/archivo/archivo.php

En las primeras décadas del Siglo XX se produjo la difusión del tipo al resto del país. Este hecho fue acompañado por una modificación de la planta, la cual se dividió en lugares de recepción (hall, comedor, escritorio), lugares privados (dormitorios, vestidores, baños) y locales de servicio (cocina, lavadero, office, habitaciones de servicio). En 1909 se modificó el Reglamento de Construcciones de la ciudad de Buenos Aires, sin embargo pese a que se reglamentaron las dimensiones mínimas de los patios de aire y luz, las condiciones de habitabilidad no mejoraron. Por otra parte, se introdujeron cambios en la altura máxima permitida sobre la Línea Municipal, la cual llegó a ser de 40m e incluso se permitió la sobreelevación de la edificación dentro del nivel dado, dando origen a los primeros rascacielos. La tipología adoptada para estos edificios fue similar a la que se venía desarrollando, se introdujeron lugares de acceso común a las unidades y las plantas se hicieron más compactas, aunque seguían manteniendo los patios de aire y luz (Liernur, J.F.; Aliata, F.; 2004).

Una de las consecuencias del proceso de modernización de la tipología fue la extensión de su alcance a las clases medias. Esto produjo la necesidad de reducir las superficies, realizar algunas transformaciones técnicas y de confort, etc. Se trataba de eliminar de la planta toda traba que el saber profesional podría ofrecer para producir masivamente la tipología y reducir de este modo los costos de construcción. Sin embargo con estas modificaciones aparecieron también nuevos valores vinculados con el mejoramiento de las técnicas de los servicios, la mejor vinculación interior - exterior, la calidad del diseño técnico y de las terminaciones, etc. (Liernur, J.F.; Aliata, F.; 2004).

El Kavanagh (Figuras III - 12 y 13) se consolidó como el paradigma del cambio. Se trataba de una lujosa torre de $120 \mathrm{~m}$. de altura cuya imagen se había consolidado por ser el edificio más alto del mundo construido en hormigón armado de la época. El Edificio Comega fue otro de los edificios emblemáticos del desarrollo de este tipo de construcciones en la Argentina de aquellos años. Construido en plena crisis de 1930, con su estructura de hormigón armado presentaba una adelantada solución tecnológica para la época por la situación particular del lote en que se construyó (González Montaner, B.; 2010).

En julio de 1948 se sancionó la Ley 13.512/48 de Propiedad Horizontal. Hasta la promulgación de esa Ley, según lo establecido en el artículo 2.617 del Código Civil, los propietarios de los edificios no podían vender las distintas unidades funcionales que los componían. La Ley de Propiedad Horizontal, aún vigente en nuestro país, establece que los distintos pisos de un edificio o los distintos departamentos de un piso o departamentos de un edificio en una sola planta con salida directa o pasaje común a vía pública pueden pertenecer a distintos propietarios (Bodio, I.; Bartolini, E.; 2010).

En otros países esta situación ya estaba reglamentada. Sin embargo en Argentina el hecho de que no haya sido reglamentada antes se debió principalmente a que hasta ese entonces no existía superpoblación y a que se suponía que el condominio traía aparejados muchos inconvenientes de convivencia. Con la propiedad horizontal se admitía sobre un lote la vivienda 
de muchas familias, abaratando costos de tierras y compartiendo gastos (Bodio, I.; Bartolini, E.; 2010).
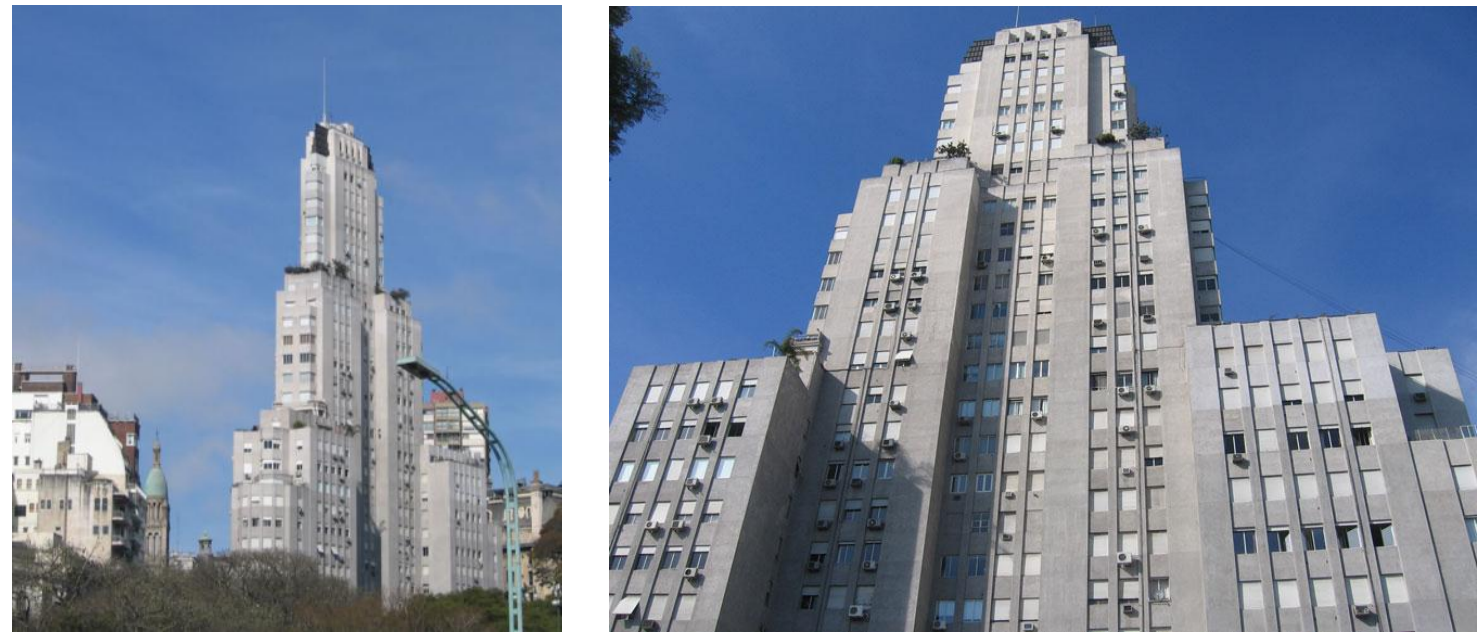

Figuras III - 12 y 13: Edificio Kavanagh, Buenos Aires (1936) - Fuente: 1:1 Buenos Aires - Disponible en: http://1en1ba.com.ar/edificio-kavanagh

El concepto de propiedad horizontal se funda en que el edificio está construido por partes propias de cada propietario (unidades funcionales) y partes comunes. Las partes comunes son accesorias de la principal y su finalidad es facilitar su funcionalidad. Aparece entonces una nueva figura jurídica, el copropietario, como la unión de condominio y propiedad exclusiva. Cada propietario tiene dominio exclusivo (es dueño de su unidad funcional) y condominio (es copropietario del terreno, los cimientos, los muros, techos, galerías, escaleras, ascensores, patios y jardines comunes, etc.) (Bodio, I.; Bartolini, E.; 2010).

La Ley 13.512 fue propuesta por el gobierno peronista e integraba el Primer Plan Quinquenal. Formaba parte de las políticas de democratización del acceso a la propiedad inmobiliaria y de ampliación del parque habitacional propuesto por el peronismo. Se suponía que el nuevo régimen paralizaría la circulación de las propiedades como consecuencia de la desaparición de la renta proveniente de los alquileres, sin embargo se constituyó en uno de los móviles principales de las transformaciones edilicias de sectores fuertemente urbanizados. Estas y otras razones generaban el rechazo de algunos sectores de la sociedad. El peronismo proponía esta Ley al mismo tiempo que mantenía congelados los alquileres desde 1943, se trataba de una nueva forma de invertir en la ciudad (Liernur, J.F.; Aliata, F.; 2004).

A través de créditos otorgados por el Banco Hipotecario Nacional para la construcción de edificios de propiedad horizontal el Estado estimuló el desarrollo del nuevo emprendimiento. En los primeros años después de la sanción de la Ley 13.512 también mediante estos créditos se permitió la adquisición de los departamentos ya construidos. Durante el gobierno peronista la venta de edificios existentes incorporados a la propiedad horizontal fue mayor que la construcción de nuevos edificios. Esto se debió principalmente a que en aquel entonces la industria de la construcción estaba volcada a la obra pública y los empresarios demandaban mayores créditos estatales para la construcción de edificios de propiedad horizontal (Liernur, J.F.; Aliata, F.; 2004).

La existencia del nuevo régimen jurídico comenzó a introducir cambios en los diseños de las antiguas casas de renta, antecedentes directos de los edificios de propiedad horizontal. EI sistema de alquiler exigía edificios con bajo costo de mantenimiento lo que produjo una pérdida de calidad en los materiales y de los métodos constructivos utilizados. Los edificios de propiedad horizontal constituyeron un mercado muy activo, sobre todo a partir de 1960. Las inmobiliarias crearon argumentos de venta que definían lo que debía considerarse una buena vivienda. Detalles de terminación, servicios, etc. se convirtieron en clichés que poco tenían que ver con la cualidad del espacio y con las condiciones de habitabilidad de la vivienda. Las superficies y equipamientos comunes tendieron a reducirse porque dejaron de ser superficies 
rentables. Los diseños buscaron el máximo aprovechamiento de las posibilidades constructivas de los predios (Liernur, J.F.; Aliata, F.; 2004).

En los últimos años de la década de 1950 se produjeron nuevas formas de gestión que permitieron a la clase media acceder a esta nueva tipología de vivienda. Se desarrollaron en esos años planes de ahorro y préstamos, y se permitió la venta en cuotas de las unidades, mediante el pago de anticipos antes de la construcción. En general los edificios de propiedad horizontal se construyeron en lotes de esquinas o entre medianeras, con anchos de entre $8,66 \mathrm{~m}$. y $10 \mathrm{~m}$. Como consecuencia del nuevo régimen jurídico se aumentó el número de unidades funcionales por piso y se privatizó el fondo libre del lote, como expansión de la unidad de la planta baja. Por su parte las condiciones de ventilación e iluminación siguieron siendo muy malas para los locales que se orientaban hacia los patios de aire y luz (Liernur, J.F.; Aliata, F.; 2004).

Con el fin de erradicar estos patios, en 1957 se impuso la reglamentación de edificios de perímetro libre o torres (Figuras III - 14 y 15). Surgieron de este modo edificios destinados a viviendas con el área de servicios en el centro de la planta, con cuatro caras de iluminación y ventilación. Sin embargo, las ventajas de iluminación y ventilación que significaba la implementación de esta tipología se vieron limitadas por las dimensiones de los lotes. Los nuevos edificios produjeron discontinuidad en el tejido urbano sin mejorar las condiciones de habitabilidad de los locales. Para mejorar estas condiciones en mayo de 1957 se sancionó el Decreto Municipal 4.110/57, el cual tenía como propósito favorecer el englobamiento parcelario de los lotes urbanos de pequeñas dimensiones para lograr el reparcelamiento que permitiera una posible urbanización futura. La nueva reglamentación generó nuevas formas de ocupación del suelo urbano, contribuyendo a la desintegración de la manzana (Liernur, J.F.; Aliata, F.; 2004).
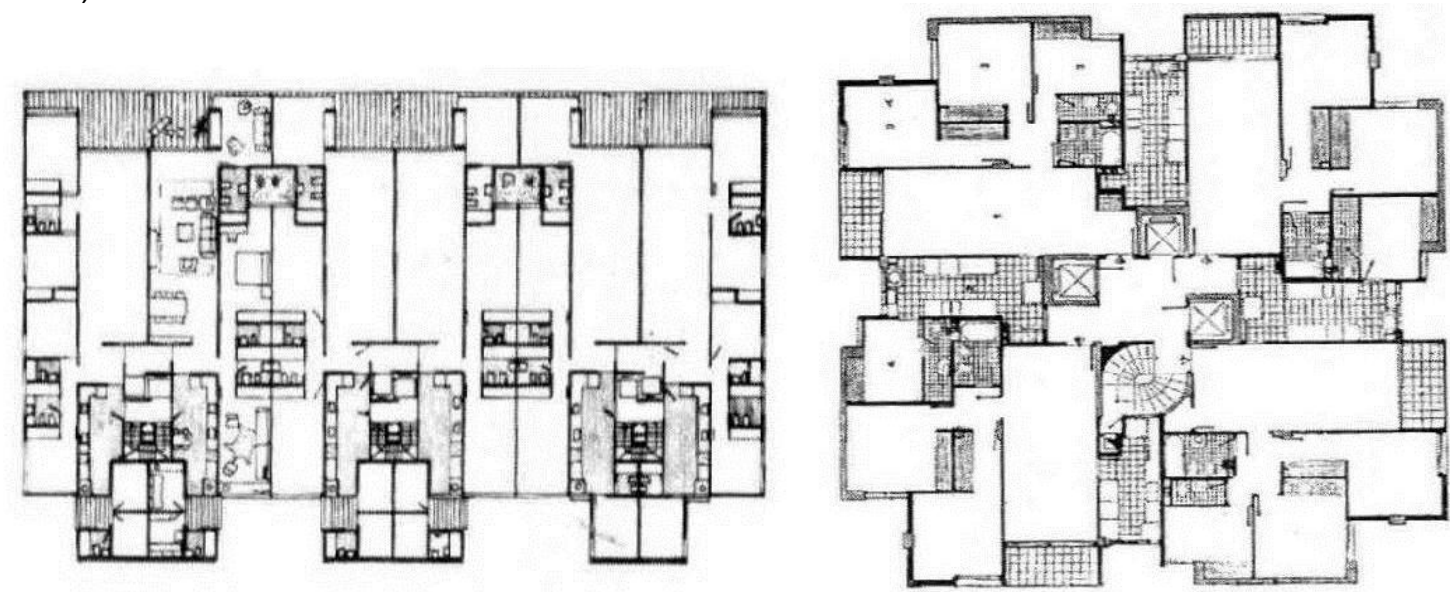

Figuras III - 14 y 15: Planta tipo del edificio Terraza Palace (A. Bonet) y de edificio de viviendas en La Boca (E. Katznestein) - Fuente: Liernur, J.F.; Aliata, F. Diccionario de arquitectura en la Argentina. Voz: CIAM, Equipos Argentinos. Buenos Aires, Argentina. 2004

Con la promulgación de la Ley 14.222, de radicación de capitales extranjeros, se dio impulso a un proceso de transformación por el que el país abrió sus puertas a la entrada de grandes empresas de origen multinacional. El resultado fue el comienzo de un acelerado proceso de concentración de capitales. La arquitectura argentina y los centros urbanos se vieron afectados por la instalación de nuevas plantas industriales, la construcción de sedes administrativas, la declinación del sistema ferroviario a favor del automotriz, la importancia del capital financiero privado, etc. Los programas complementarios a los grandes establecimientos fabriles fueron las sedes de esas mismas empresas, lo que significó la aparición del edificio de oficinas y su adopción como emblema empresarial. Esta tipología constituyó la más clara expresión de la modernización de la Argentina (Liernur, J.F.; 2008).

En pocos años Buenos Aires y otras ciudades argentinas contaron con edificios vidriados, emblemas de las primeras apariciones de las corporaciones internacionales. La concentración en altura a partir de la unificación de predios, premiada en general por el nuevo Código, significó un gran beneficio para los inversionistas inmobiliarios ya que permitía multiplicar la 
superficie a construir. Para evitar la propagación de edificios de oficinas en el casco de la ciudad la oficina del Plan Regulador propuso la construcción de un polo de actividades terciarias en la zona de Retiro. El predio Catalinas Norte (Figuras III - 16 y 17) se convirtió en un campo de ensayo para estas grandes construcciones. La idea de concentrar en ese lugar un conjunto de edificios de oficinas de gran envergadura en relación con los edificios existentes hacía referencia a la vieja propuesta de la ciudad de los negocios de Le Corbusier. Asimismo reproducía la experiencia norteamericana de revitalización de los viejos centros urbanos mediante concentración de grandes inversiones en funciones terciarias superiores. El predio contaba con óptimas condiciones urbanas para concentrar estas funciones; estaba próximo al puerto, al aeroparque metropolitano, a la central ferroviaria de Retiro y a la autopista costera. Sin embargo la fuerte presión de las empresas contribuyó a que las torres aprovecharan al máximo la reglamentación, quebrando la voluntad de los proyectistas del Plan Catalinas (Liernur, J.F.; 2008).
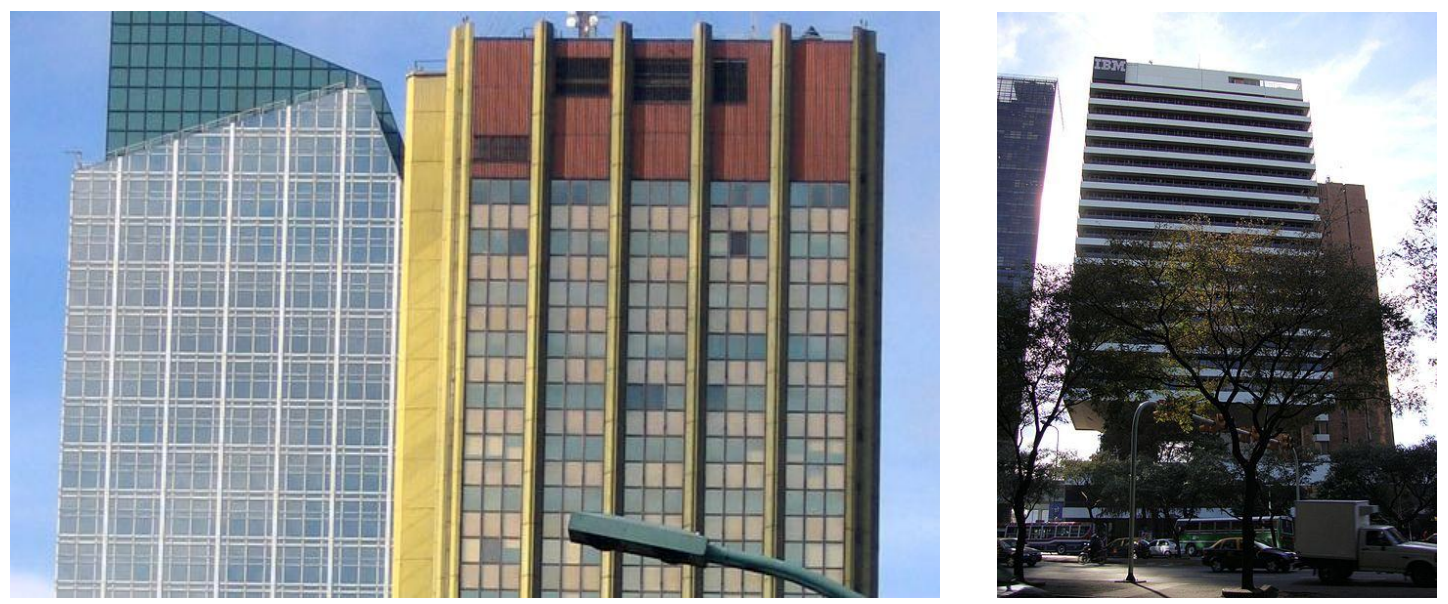

Figuras III - 16 y 17: Edificio de la UIA (1974) y Torre IBM (1983), Catalinas Norte - Fuente: 1:1 Buenos Aires - Disponible en: http://1en1ba.com.ar/edificio-kavanagh

El crecimiento del mercado de los edificios en altura llamó a la reflexión del debate arquitectónico. Se favoreció la experimentación, la búsqueda de nuevas tipologías, la racionalización de la planta de las distintas unidades y del conjunto, las mejoras en la relación con el espacio libre, el tratamiento de las fachadas, la utilización de nuevos materiales, las mejoras de la técnica, etc. También se redujeron las medidas mínimas y, en el caso de la vivienda, se simplificó el sector destinado al personal doméstico, se redujeron los espacios circulatorios, se racionalizaron los diseños de baños, cocinas y lavaderos, etc. (Liernur, J.F.; Aliata, F.; 2004).

El impulso de las actividades productivas se convirtió en una de las líneas centrales durante la dictadura militar. En 1970 se sancionó el nuevo Código de Planeamiento Urbano de la Ciudad de Buenos Aires. Esta normativa además de estimular la concentración de predios impuso restricciones al uso del suelo urbano a través de los indicadores de FOS y FOT, al tiempo que otorgaba premios a los edificios tipo torre. Se fijaron mayores fondos libres y se establecieron los distintos indicadores urbanísticos según la caracterización de las diferentes áreas urbanas (Liernur, J.F.; Aliata, F.; 2004).

Paralelamente se produjeron transformaciones en el mercado de los edificios de propiedad horizontal debido a que la falta de créditos oficiales produjo su restricción a los sectores medios - altos. Se refinaron los diseños y los patios de aire y luz quedaron subordinados a la ventilación de ambientes de servicios (baños y cocinas). Las experimentaciones se centraron en la conformación de las fachadas, la morfología y la relación con el entorno (Liernur, J.F.; Aliata, F.; 2004).

Por otra parte, como consecuencia de la Ley de Actividades Financieras sancionada en 1977 surgieron nuevas torres de oficinas que se extendieron desde Catalinas Norte hasta la zona de Retiro. Las mismas se articulaban con la trama urbana y con el predio de Catalinas. Como 
extensión de este impulso hacia finales de 1970 se construyeron nuevas torres destinadas a oficinas sobre la Avenida 9 de Julio (Liernur, J.F.; Aliata, F.; 2004).

En los últimos años la expansión de los empleos terciarios superiores se orientó principalmente en dos direcciones; hacia la periferia y hacia el Este de la ciudad. El desplazamiento hacia la periferia se debió principalmente a la renovación de la red de accesos a la Capital Federal, al aumento de los precios y a la limitación de los predios disponibles en el centro tradicional, la creciente inseguridad y el deterioro de las áreas más antiguas. El desplazamiento hacia el Este de la ciudad se produjo debido a la atracción ejercida por el proyecto de Puerto Madero (Figura III - 18). Dentro del área del nuevo barrio estaba prevista la construcción de dos torres de oficinas en los diques de los extremos. Sin embargo también se construyeron torres de mayor altura dentro del barrio, y en su expansión hacia el predio de Catalinas Norte (Liernur, J.F.; Aliata, F.; 2004).

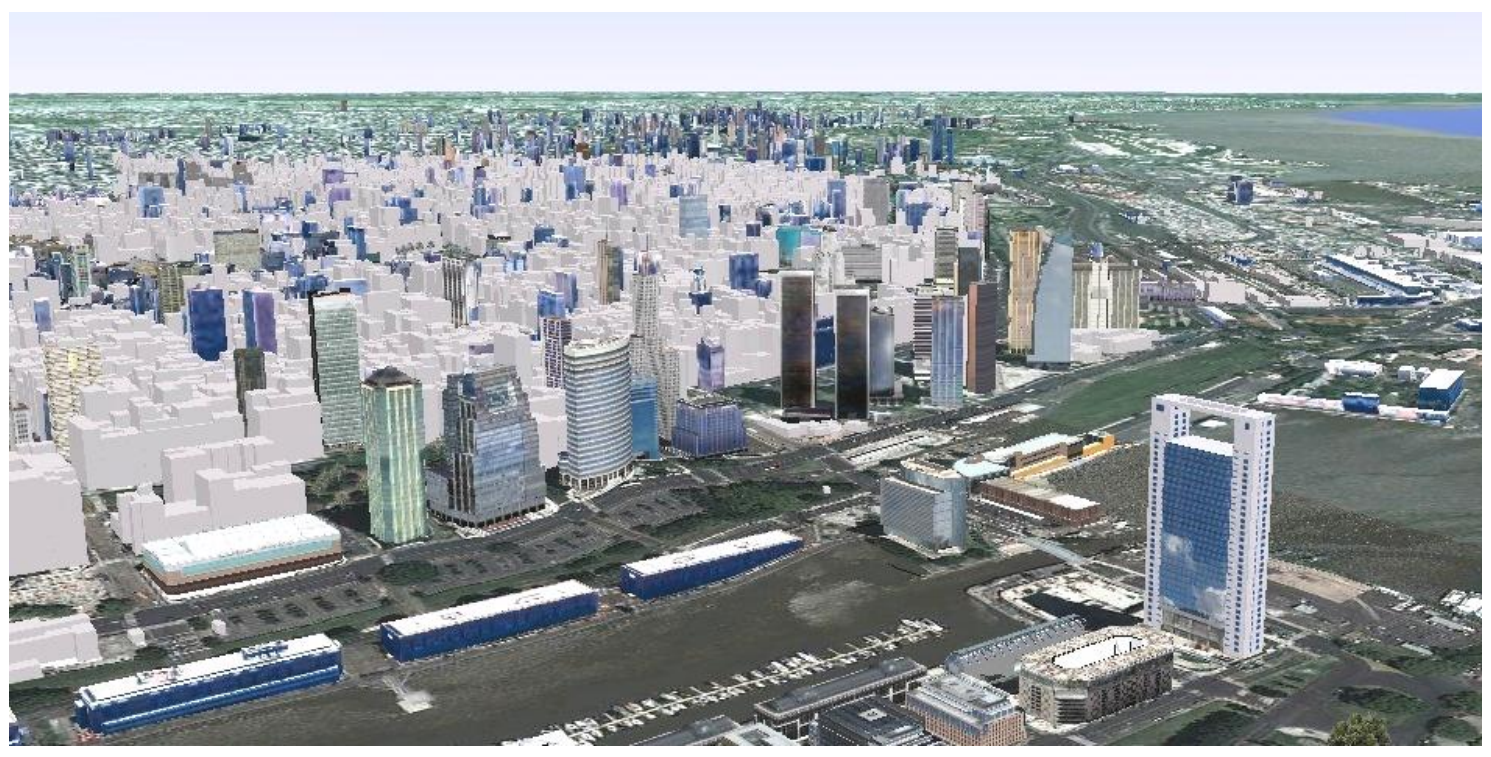

Figura III - 18: Imagen predio Catalinas Norte y su expansión hacia el Norte y hacia Puerto Madero Fuente: Google Earth. Terrametrics, 2013 - Disponible en: http://www.google.com/earth/index.html

En nuestro país la construcción de torres no se ha inclinado hacia la competencia por alcanzar las mayores alturas posibles, a diferencia de lo que ocurrió en otros países del mundo. El menor tamaño de las torres en Argentina está directamente relacionado con la importancia de las compañías que albergan y con los montos de las inversiones en el sector (Liernur, J.F.; Aliata, F.; 2004). 


\section{CAPÍTULO IV}

NORMATIVA Y LEGISLACIÓN APLICADA A EDIFICIOS

\subsection{Códigos de Edificación}

El Código de Edificación de una ciudad o región constituye el marco normativo que establece las exigencias que deben cumplir los edificios construidos en el ámbito que dicho código regula. Si bien estos documentos establecen los requisitos básicos de seguridad, accesibilidad y habitabilidad, también hacen referencia a cuestiones administrativas como pueden ser las necesarias para realizar tramitaciones previas a la construcción del edificio o requisitos para obtener el permiso de obra.

La siguiente Tesis Doctoral involucra el estudio particularizado de los códigos de Edificación de la Ciudad de Buenos Aires y La Plata. La Ciudad Autónoma de Buenos Aires es la segunda ciudad más importante de Sudamérica y uno de los mayores centros urbanos del mundo, además es el centro cultural más importante de Argentina y uno de los principales de América Latina. Su extensión sobre la provincia de Buenos Aires ha configurado una gran conurbación en la que se concentra casi el $32 \%$ de la población del país (Czajkowski, J.; 2009). El Área Metropolitana de Buenos Aires -así se denomina a esta gran conurbación- ha avanzado sobre distintas localidades con un tejido prácticamente continuo desde Pilar, en el noroeste, hasta La Plata en el sureste, a lo largo de cien kilómetros de longitud. La Plata, por su parte, es la ciudad capital de la provincia de Buenos Aires; fue fundada en 1882 como paradigma de planificación urbanística de avanzada del Siglo XIX y cuenta aproximadamente con seiscientos noventa mil habitantes, según el censo del 2001.

Asimismo, en el siguiente trabajo se plantea el estudio del Código Técnico de la Edificación de España. Esta decisión se fundamenta en el hecho que la tradición constructiva de nuestro país tiene sus raíces en la época de la colonia española, la cual se vio consolidada posteriormente con la gran inmigración de españoles e italianos que llegaron al país como consecuencia de la crisis provocada por las Guerras Mundiales; muchos de estos inmigrantes se volcaron a la construcción de viviendas que, en la mayoría de los casos, eran las propias. Además dicho código constituye un marco normativo homologable al existente en los países más avanzados y ajusta la reglamentación española existente en la edificación con las disposiciones de la Unión Europea vigentes en esta materia. Al respecto se profundiza en el estudio del Documento Básico HE - Ahorro de Energía del CTE, el cual tiene como objetivo principal cumplir con las exigencias de la Directiva 2002/91/CE del Parlamento Europeo y del Consejo, relativa a la eficiencia energética de los edificios. 


\subsubsection{Código de Edificación de la Ciudad de Buenos Aires}

El Código de la Edificación de la Ciudad Autónoma de Buenos Aires es el marco normativo que dispone las exigencias básicas de calidad de estructuras, edificios, instalaciones y materiales y sistemas constructivos en la Ciudad Autónoma de Buenos Aires. Este Código regula los aspectos técnico-constructivos y técnico-administrativos del proceso de la edificación y de las actividades relacionadas. El mismo se estructura bajo la tipología de "Código por Objetivos", las disposiciones establecidas en él rigen en la Ciudad Autónoma de Buenos Aires, y establecen el marco legal dentro del cual su Gobierno ejerce el poder de policía y los comitentes o propietarios, profesionales y empresas ejercen sus derechos y obligaciones (Gobierno de la Ciudad de Buenos Aires; 2012).

Dicho Código se aplica a las edificaciones públicas y privadas cuyas obras requieran aviso, permiso y control por la Autoridad de Aplicación y no estén regidas por una ley especial. Para determinar las acciones posibles la Autoridad de Aplicación debe tener en cuenta la zonificación dispuesta en el Código de Planeamiento Urbano.

El Código reconoce la supremacía de la Constitución Nacional, de la Constitución de la Ciudad Autónoma de Buenos Aires y del Código de Planeamiento Urbano, y se construye como derivación de sus normas. Por su parte los Reglamentos Obligatorios admiten excepciones en técnicas constructivas sólo en casos en que la normativa de aplicación sea equivalente o de mayor exigencia. Estas excepciones deben estar documentadas y justificadas ante la Autoridad de Aplicación que debe otorgar el permiso.

El Código entra en vigencia a partir de su publicación en el Boletín Oficial de la Ciudad de Buenos Aires mientras que los Reglamentos Técnicos entran en vigencia a partir de la publicación o en la fecha que en cada caso determinan. Los Reglamentos Técnicos de Referencia, incorporados como recomendaciones, solo tienen ese carácter y se basan en los usos recomendados por organismos nacionales e internacionales de avalada trayectoria y con experiencia probada en la materia.

En términos generales el Código de Edificación de la Ciudad Autónoma de Buenos Aires se compone de dos partes:

\section{Parte 1:}

Esta parte se compone de nueve títulos que abarcan cuestiones relacionadas a la higiene y seguridad en el trabajo, proyecto de obra, gestión y ejecución de la obra, profesionales y empresas, prescripciones para cada uno, autoridad de aplicación, régimen de penalidades, etc. También se establecen las generalidades relativas al Código de Edificación de la Ciudad Autónoma de Buenos Aires y los objetivos del mismo, entre los cuales se destacan los siguientes:

- Requisitos básicos de la Edificación: Aborda el tema de la edificación en sus aspectos técnicos y administrativos. El Código de la Edificación es el marco normativo que dispone las exigencias básicas de calidad de estructuras, edificios, instalaciones y materiales y sistemas constructivos en la Ciudad Autónoma de Buenos Aires. Regula los aspectos técnico-constructivos y técnico-administrativos del proceso de la edificación y actividades conexas.

- Relativos a la habitabilidad: Higiene, salud y protección del habitante de tal manera que se cumplan condiciones aceptables de salubridad y estanqueidad en el ambiente interior del edificio sin que se produzca un deterioro del medio ambiente en su entorno inmediato. Adecuada gestión de los residuos. Protección contra el ruido. Ahorro de energía y aislamiento térmico. Consideración de nuevos aspectos funcionales de los elementos constructivos o de las instalaciones que permitan un uso satisfactorio del edificio.

- Relativos a la seguridad: Seguridad estructural. Seguridad en caso de incendio. Seguridad de utilización. 
- Relativos a la funcionalidad: Utilización, de tal forma que la disposición y las dimensiones de los espacios y la dotación de las instalaciones faciliten la adecuada realización de las funciones previstas en el edificio. Accesibilidad. Acceso a los servicios de telecomunicación, audiovisuales y de información.

- Relativos a la durabilidad: Los materiales, productos y sistemas que se incorporan a la obra deben certificar la durabilidad entendida como ciclo de uso.

- Exigencias referidas a la Habitabilidad: El objetivo en materia de habitabilidad es obtener una mejor calidad de vida para los habitantes, estableciéndose los servicios vinculados a los sistemas de higiene y salud en armonía con el medio ambiente.

- Protección frente a la humedad

- Protección frente a la producción y necesidad de eliminación de residuos

- Renovación y pureza del aire interior:

- Suministro de agua potable para usos variados

- Evacuación de aguas residuales

- Protección frente al ruido

- Uso racional de la energía: Consiste en conseguir un uso racional de la energía necesaria en los edificios, reduciendo a límites sustentables su consumo. Se debe lograr que una parte de este consumo proceda de fuentes de energía renovable, como consecuencia de las características del proyecto, construcción, uso y mantenimiento.

El Gobierno de la Ciudad Autónoma de Buenos Aires debe disponer de parámetros, objetivos, procedimientos y programas para cumplir con el ahorro de energía en relación con los planes nacionales de sustentabilidad energética. Integran el cumplimiento de este objetivo los siguientes aspectos:

- Limitación de la demanda energética: Los edificios deben disponer de una envolvente que limite adecuadamente la demanda energética necesaria para alcanzar el bienestar térmico en función del clima, del uso del edificio y del régimen de verano y de invierno.

- Rendimiento de instalaciones térmicas: Los edificios deben poseer instalaciones térmicas apropiadas, destinadas a proporcionar el bienestar térmico de sus ocupantes. Debe poder regularse el rendimiento de las mismas y de sus equipos, y su aplicación debe definirse en el proyecto del edificio.

- Eficiencia energética de las instalaciones de iluminación: Los edificios deben tener instalaciones de iluminación energéticamente eficientes, adecuadas a las necesidades de sus usuarios que por medio de un sistema de control permita ajustar el encendido a la ocupación real de la zona, así como contar con un sistema de regulación que optimice el aprovechamiento de la luz natural. Se debe promover el "inmueble eficiente".

- Contribución solar mínima de agua caliente sanitaria: En los edificios con provisión de demanda de agua caliente sanitaria o de climatización de piscina cubierta, una parte de las necesidades energéticas térmicas derivadas de esa demanda debe cubrirse mediante la incorporación de sistemas de captación, almacenamiento y utilización de energía solar de baja temperatura, adecuada a la radiación solar global de su emplazamiento y a la demanda de agua caliente del edificio.

- Contribución fotovoltaica mínima de energía eléctrica: El Gobierno de la Ciudad Autónoma de Buenos Aires debe promover la incorporación de sistemas de captación y transformación de energía solar en energía eléctrica por procedimientos fotovoltaicos para uso propio o suministro a la red.

- Uso de sistemas inteligentes: Se debe promover la instalación de sistemas inteligentes, de automatización y control electrónico. Estos sistemas contribuyen al ahorro energético.

Parte 2:

Esta parte establece la relación del Código de Edificación de la Ciudad Autónoma de Buenos Aires con sus Anexos y Normas Finales. 


\subsubsection{Código de Edificación de la Ciudad de La Plata}

Las disposiciones del Código de Edificación de la Ciudad de La Plata alcanzan a los asuntos que se relacionan con la gestión, construcción, ampliación, reforma, refacción, demolición, registro, inspección, ocupación, uso y mantenimiento de predios, estructuras y edificios, cualquiera sea su destino y sus instalaciones complementarias (Municipalidad de La Plata; 2010).

En este Código se especifican cuestiones relacionadas con la prevención contra incendio, aplicada a usos administrativos y de vivienda multifamiliar, la seguridad edilicia, las responsabilidades de particulares, profesionales o empresas en las distintas etapas de tramitación y ejecución de obras.

Las disposiciones establecidas en este Código se aplican por igual tanto a las propiedades gubernamentales como a las particulares que se construyen en el partido de La Plata. El Código de Edificación de la Ciudad de La Plata se compone de seis títulos que se organizan en distintas secciones, las cuales contienen los distintos artículos que definen los temas abordados.

Es importante destacar que en ningún momento se hace alusión a la incorporación de materiales que contribuyan a mejorar la calidad térmica de la envolvente. Sólo en el caso de las cubiertas se menciona esta cuestión, en caso de que el proyectista responsable o constructor opte por una cubierta de chapa, por ser un material con muy baja resistencia al paso del calor y de espesor muy pequeño. Del mismo modo tampoco se menciona la necesidad de incorporar en el diseño del edificio algún sistema de fuentes de energía renovables para reducir el consumo de energía utilizada ya sea para climatización o iluminación interior, o para el reciclado de aguas grises o pluviales.

Por último, cabe mencionar que en el Código de Edificación de la Ciudad de La Plata se establecen disposiciones administrativas vinculadas con el estímulo a la edificación privada, y disposiciones reglamentarias relacionadas con la interpretación del Código, la aplicación de las disposiciones del Código Civil y Leyes Provinciales vigentes. Entre las cuales se destaca la Ley 13.059 de la Provincia de Buenos Aires por la cual se establecen las condiciones de acondicionamiento térmico exigibles en la construcción de edificios para contribuir a la disminución del impacto ambiental a través del uso racional de la energía.

\subsubsection{Código Técnico de la Edificación de España}

El Código Técnico de la Edificación de España (CTE) es el marco normativo que establece las exigencias que deben cumplir los edificios en relación con los requisitos básicos de seguridad y habitabilidad establecidos en la Ley 38/1999, de Ordenación de la Edificación (Gobierno de España; 1999).

Las Exigencias Básicas de calidad que deben cumplir los edificios se refieren a materias de seguridad estructural, contra incendios, de utilización, y habitabilidad (salubridad, protección frente al ruido y ahorro de energía). También se ocupa de la accesibilidad como consecuencia de la Ley 51/2003, de igualdad de oportunidades, no discriminación y accesibilidad universal de las personas con discapacidad. Su aplicación es tanto para edificios de nueva construcción, como para obras de ampliación, modificación, reforma o rehabilitación y a determinadas construcciones protegidas desde el punto de vista ambiental, histórico o artístico.

Hasta la aprobación del CTE en 2006, la regulación de la edificación en España había sido de carácter prescriptivo en donde se establecían los procedimientos aceptados o las guías técnicas que debían seguirse a la hora de construir un edificio. Esto suponía una barrera técnica que en la práctica obstaculizaba la aplicación de innovaciones tecnológicas al proceso de edificación. Si bien en la actualidad el CTE se encarga de enunciar los criterios que deben cumplir los edificios, deja abierta la forma en que deben cumplirse estas reglas, permitiendo la configuración de un entorno normativo más flexible. De esta forma, el CTE favorece el 
desarrollo de tareas de investigación, desarrollo e innovación $(1+D+i)$, al integrar de forma más directa los avances logrados gracias a estas actividades.

Asimismo contribuye al desarrollo de las políticas del Gobierno de España en materia de sustentabilidad, en particular del Plan de Acción de la Estrategia de Ahorro y Eficiencia Energética. Además favorece el cumplimiento de compromisos de largo alcance del Gobierno español en materia medioambiental, como son el Protocolo de Kyoto o la Estrategia de Göteborg.

El Código Técnico de la Edificación da cumplimiento a los requisitos básicos de la edificación establecidos en la Ley 38/1999, de Ordenación de la Edificación, con el fin de garantizar la seguridad de las personas, el bienestar de la sociedad, la sustentabilidad de la edificación y la protección del medio ambiente.

Por un lado, la aprobación del Código Técnico de la Edificación supone la superación y modernización del marco normativo de la edificación vigente en España, regulado por el Real Decreto 1650/1977, sobre normativa de la edificación, que estableció las Normas Básicas de la Edificación. Por otro, el Código Técnico de la Edificación crea un marco normativo homologable al existente en los países más avanzados y ajusta la reglamentación nacional existente en la edificación con las disposiciones de la Unión Europea vigentes.

EI CTE se divide en dos partes, ambas de carácter reglamentario. En la primera se contienen las disposiciones de carácter general (ámbito de aplicación, estructura, clasificación de usos, etc.) y las exigencias que deben cumplir los edificios para satisfacer los requisitos de seguridad y habitabilidad de la edificación.

La segunda parte está constituida por los Documentos Básicos cuya adecuada utilización garantiza el cumplimiento de las exigencias básicas. En los mismos se contienen procedimientos, reglas técnicas y ejemplos de soluciones que permiten determinar si el edificio cumple con los niveles de prestación establecidos. Dichos Documentos no tienen carácter excluyente. Como complemento para la aplicación del Código se crearon los Documentos Reconocidos cuya utilización facilita el cumplimiento de determinadas exigencias y contribuyen al fomento de la calidad de la edificación.

Los Documentos Básicos establecen las reglas y procedimientos para cumplir con las siguientes exigencias básicas:

- Seguridad Estructural.

- Seguridad Caso de Incendio.

- Seguridad de Utilización y Accesibilidad.

- Salubridad.

- Protección frente al Ruido.

- Ahorro de Energía.

El Documento Básico HE - Ahorro de Energía del Código Técnico de la Edificación de España, está ampliamente relacionado con el desarrollo de esta Tesis. Este DB tiene por objeto establecer reglas y procedimientos que permitan cumplir con las exigencias básicas de ahorro de energía. Por su parte, el objetivo de las exigencias básicas de ahorro de energía es conseguir un uso racional de la energía necesaria para la utilización de los edificios, reduciendo a límites sustentables su consumo y conseguir que una parte de este consumo proceda de fuentes de energía renovable. Las exigencias básicas que se establecen en el CTE, orientadas a cumplir con la Directiva 2002/91/CE relativa a la eficiencia energética de edificios, son las siguientes:

- Limitación de demanda energética: Los edificios deben disponer de una envolvente que limite la demanda energética necesaria para alcanzar el bienestar térmico en función del clima de la localidad, el uso del edificio, las estaciones del año, la utilización de aislamiento e inercia térmica, permeabilidad al aire y exposición a la radiación solar, reduciendo el 
riesgo de condensación superficial e intersticial, y tratando adecuadamente los puentes térmicos para limitar las pérdidas o ganancias de calor y evitar problemas higrotérmicos. Se aplica a edificios de nueva construcción; modificaciones, reformas o rehabilitaciones de edificios existentes con una superficie útil superior a $1.000 \mathrm{~m}^{2}$ donde se renueve más del $25 \%$ del total de sus cerramientos. Entre otras cuestiones este DB establece que:

- La demanda energética de los edificios debe limitarse en función del clima de la localidad en la que se ubican, según la carga interna en sus espacios.

- Las particiones interiores de edificios de vivienda que separan espacios calefaccionados con otros no calefaccionados deben tener una transmitancia inferior a $1,2 \mathrm{~W} / \mathrm{m}^{2} \mathrm{~K}$.

- Las condensaciones intersticiales en los cerramientos y particiones interiores que componen la envolvente del edificio no deben modificar las prestaciones térmicas de los materiales.

- La permeabilidad de los huecos debe limitarse en función del clima de la localidad en la que se implanta el edificio.

- A efectos del cálculo de la demanda energética, los espacios habitables se clasifican en función de la cantidad de calor disipada en su interior, debido a la actividad realizada y al periodo de utilización de cada espacio.

- Rendimiento de las instalaciones térmicas: Los edificios deben disponer de instalaciones térmicas apropiadas que proporcionen el bienestar térmico de sus ocupantes.

- Eficiencia energética de las instalaciones de iluminación: Los edificios deben disponer de instalaciones de iluminación adecuadas a las necesidades de sus usuarios y a la vez eficaces energéticamente disponiendo de un sistema de control que permita ajustar el encendido a la ocupación real de la zona, así como de un sistema de regulación que optimice el aprovechamiento de la luz natural. Se aplica a instalaciones de iluminación interior en edificios nuevos, rehabilitación de edificios existentes con una superficie útil superior a $1.000 \mathrm{~m}^{2}$ (donde se renueve más del $25 \%$ de la superficie iluminada), reformas de locales comerciales y de edificios de uso administrativo en los que se renueve la instalación de iluminación. La eficiencia energética de una instalación de iluminación, se determinará mediante el valor de eficiencia energética de la instalación VEEI $\left(\mathrm{W} / \mathrm{m}^{2}\right)$ por cada 100 lux mediante la siguiente expresión:

Donde:

$$
V E E I=\frac{P \times 100}{S \times E_{m}}
$$

[Ecuación IV - 1]

P: la potencia de la lámpara más el equipo auxiliar [W];

$\mathrm{S}$ : la superficie iluminada $\left[\mathrm{m}^{2}\right]$;

$\mathrm{E}_{\mathrm{m}}$ : la iluminancia media mantenida [lux]

- Contribución solar mínima de agua caliente sanitaria: En los edificios, con previsión de demanda de agua caliente sanitaria una parte de las necesidades energéticas derivadas de esa demanda debe cubrirse mediante la incorporación en los mismos de sistemas de captación, almacenamiento y utilización de energía solar de baja temperatura, adecuada a la radiación solar global de su emplazamiento y a la demanda de agua caliente del edificio. Se aplica a edificios nuevos y rehabilitados en los que exista una demanda de agua caliente sanitaria. En el caso de que en algún mes del año la contribución solar real sobrepase el $110 \%$ de la demanda energética la instalación debe poder disipar dichos excedentes a través de equipos específicos o mediante la circulación nocturna del circuito primario; otra solución es tapar parcialmente el campo de los captadores o vaciar parcialmente el campo de captadores, bien desviar los excedentes energéticos a otras aplicaciones existentes.

- Contribución fotovoltaica mínima de energía eléctrica: Los siguientes edificios deben incorporar sistemas de captación y transformación de energía solar por procedimientos fotovoltaicos cuando superen los límites de aplicación establecidos: 
- Hipermercado: $5.000 \mathrm{~m}^{2}$ construidos

- Centros de recreación: $3.000 \mathrm{~m}^{2}$ construidos

- Almacenamiento: $10.000 \mathrm{~m}^{2}$ construidos

- Administrativos: $4.000 \mathrm{~m}^{2}$ construidos

- Hoteles: 100 plazas

- Hospitales: 100 camas

- Pabellones de recintos feriales: $10.000 \mathrm{~m}^{2}$ construidos.

La potencia pico a instalar se calculará mediante la siguiente fórmula:

$\mathrm{P}=\mathrm{C} \times(\mathrm{A} \times \mathrm{S}+\mathrm{B}) \quad$ [Ecuación IV - 2]

Donde:

$\mathrm{P}$ : potencia pico a instalar [kWp];

A y $B$ : coeficientes definidos en función del uso del edificio;

C: coeficiente definido en función de la zona climática establecida;

$\mathrm{S}$ : superficie construida del edificio $\left[\mathrm{m}^{2}\right]$.

La disposición de los módulos se hará de tal manera que las pérdidas debidas a la orientación e inclinación del sistema y a las sombras sobre el mismo sean mínimas. Se deben evaluar las pérdidas por orientación e inclinación y sombras del sistema generador. Cuando, por razones arquitectónicas no se pueda instalar toda la potencia exigida se justificará esta imposibilidad analizando las distintas alternativas de configuración del edificio y de ubicación de la instalación, debiéndose optar por la solución que más se aproxime a las condiciones de máxima producción.

\subsection{Certificación edilicia}

Existen en el mundo diversos sistemas de certificación edilicia. Estos constituyen una herramienta para medir, evaluar y ponderar el nivel de sustentabilidad de un edificio y su entorno, tanto en la fase de diseño como en las fases de ejecución, uso y mantenimiento, y aún después cuando el edificio es demolido; contemplando cuestiones relacionadas con el tratamiento de los desechos de la construcción y el reciclado de materiales.

Si bien estos sistemas varían en las herramientas que proponen para el análisis de los edificios y del entorno, todos apuntan a conseguir una reducción en las emisiones de $\mathrm{CO}_{2}$ causadas por los edificios en sus distintas fases, contemplando las particularidades propias de cada una de las principales tipologías de uso existentes (vivienda, oficinas, edificación industrial, centros de salud, escuelas, etc.).

En este trabajo se ha desarrollado un análisis particularizado del sistema Británico "Building Research Establishment Environmental Assessment Methodology" (BREEAM), del sistema estadounidense "Leadership in Energy \& Environmental Design" (LEED) y del sistema alemán Passivhaus, y su adaptación a climas menos rigurosos, por ser los sistemas de mayor implementación a nivel mundial.

\subsubsection{LEED}

LEED (Leadership in Energy \& Environmental Design) es un sistema de certificación de edificios sustentables desarrollado por el U.S. Green Building Council. Si bien LEED fue creado en Estados Unidos, actualmente existen edificios con certificado LEED en más de 30 países en todo el mundo. La expansión de este sistema de certificación por fuera de los límites de los Estados Unidos ha generado un debate a nivel mundial ya que este sistema se basa en la implementación de las normas ASHRAE principalmente, las cuales muchas veces resultan de difícil aplicación fuera del ámbito de los Estados Unidos (Haselbach, L.; 2008). 
Este sistema, el cual debe ser considerado como una herramienta de diseño, tiene su fundamento en la incorporación de aspectos relacionados con la eficiencia energética, el uso de energías renovables, la mejora de la calidad ambiental interior, la eficiencia del consumo de agua, el desarrollo sustentable de los espacios libres y la selección de materiales. Al respecto, existen cuatro niveles de certificación:

- LEED Certificate

- LEED Silver

- LEED Gold

- LEED Platinum

Si bien este sistema no es de cumplimiento obligatorio, el U.S. Green Building Council se encarga del análisis y validación de los distintos aspectos del proyecto. El objetivo principal de la certificación es contribuir a la utilización de estrategias que permitan una mejora global en el impacto medioambiental de la industria de la construcción. Existen diversos sistemas de evaluación, dependiendo del uso y complejidad de los edificios, y si bien en un principio este sistema podía aplicarse únicamente a edificios de nueva planta, luego se desarrollaron pautas para la evaluación de obras de acondicionamiento interior (LEED for Commercial Interiors) o para edificios en funcionamiento (LEED Operations and Maintenance). Actualmente pueden encontrarse los siguientes sistemas de certificación LEED:

- Green Building Design \& Construction

- LEED for New Construction and Major Renovations

- LEED for Core \& Shell Development

- LEED for Schools

- LEED for Retail: New Construction and Major Renovations

- LEED for Healthcare

- Green Interior Design \& Construction

- LEED for Commercial Interiors

- LEED for Retail: Commercial Interiors

- Green Building Operations \& Maintenance

- LEED for Existing Buildings: Operations \& Maintenance

- Green Neighborhood Development

- LEED for Neighborhood Development

- Green Home Design and Construction

- LEED for Homes

La metodología de evaluación LEED es la misma para todos los sistemas nombrados anteriormente. Al respecto se determinan 100 puntos a analizar en los edificios que se distribuyen en las siguientes categorías:

- Sustainable Sites (parcelas sustentables).

- Water Efficiency (ahorro de agua).

- Energy and Atmosphere (eficiencia energética).

- Materials and Resources (materiales).

- Indoor Environmental Quality (calidad de aire interior).

Además el sistema de certificación LEED propone un adicional por Innovación en el proceso de diseño (Innovation in design) y un adicional por Prioridades regionales (Regional priorities). Dentro de cada una de estas categorías se incluye una serie de requisitos que son de cumplimiento obligatorio (prerequisites) y otros que son de cumplimiento voluntario (credits). La justificación del cumplimiento de dichos parámetros otorga una serie de puntos, en función de los cuales se otorga el grado de la certificación: 
- LEED Certified: $40-49$ puntos.

- LEED Silver: 50 - 59 puntos.

- LEED Gold: 60 - 79 puntos.

- LEED Platinum: más de 80 puntos.

Para poder solicitar un certificado LEED el edificio debe cumplir con ciertos pre-requisitos como ser el cumplimiento de leyes y normativa relacionada con el medioambiente, la vida útil del edificio, los bordes del área de implantación y la obligatoriedad de suministrar por cinco años toda la información referida a la utilización de agua y energía desde el momento en que el edificios es ocupado o, en caso de edificios existentes, desde el momento en que adquiere el certificado. Para el caso de viviendas unifamiliares existen además otras categorías que tienen que ver con la relación de la vivienda con el entorno (acceso al transporte, cercanía a espacios abiertos, posibilidad de realizar actividades físicas al exterior, etc.) y con la educación (posibilidad de acceso a la educación de los ocupantes).

En el año 2003 un análisis sobre el ahorro de energía en edificios verdes mostró que en una muestra de sesenta edificios LEED estos resultaban entre un $20-30 \%$ más eficientes energéticamente que un edificio convencional. En parte estos beneficios se atribuyeron al incremento de la productividad como consecuencia de las mejoras en la ventilación, el control de la temperatura y de la iluminación, y la reducción de la contaminación interior y exterior. El sistema de certificación LEED se centra en el diseño integral del edificio, con esto se busca conseguir un uso más eficiente de los recursos naturales que en los edificios convencionales, construidos según lo establecido en los códigos de edificación. Los edificios con certificado LEED proveen espacios interiores más saludables, lo que contribuye a que los ocupantes tengan un mejor confort.

Si bien el costo inicial de diseño y construcción es más elevado en un edificio con certificado LEED que en un edificio convencional, este sobrecosto es amortizado durante la vida útil del edificio, por el ahorro generado durante en el funcionamiento del mismo. El costo del ciclo de vida de un edificio se evalúa teniendo en cuenta todas las etapas por las que atraviesa el mismo desde el momento en que el propietario lo adquiere hasta que el edificio es demolido. Además se logra un costo adicional debido a la mejora en la salud y en la productividad de los ocupantes, especialmente en el caso de edificios de oficinas. Algunos estudios sugieren que el incremento de un $2 \%$ del costo inicial que puede llegar a tener un edificio de este tipo, produce un ahorro diez veces mayor, hacia el final del ciclo de vida del mismo.

\subsubsection{BREEAM}

BREEAM (Building Research Establishment Environmental Assessment Methodology) es un sistema de certificación que, al igual que la certificación LEED, permite evaluar la sustentabilidad en edificios. Si bien se desarrolló en 1990, en Inglaterra, actualmente es utilizado en distintos países del mundo, especialmente de Europa.

Este sistema comprende un conjunto de herramientas avanzadas y procedimientos encaminados a medir, evaluar y ponderar los niveles de sustentabilidad de un edificio, tanto en fase de diseño como en fases de ejecución y mantenimiento, contemplando las particularidades propias de cada una de las principales tipologías de uso existentes (vivienda, oficinas, edificación industrial, centros de salud, escuelas, etc.). BREEAM evalúa impactos en 10 categorías, a saber:

- Gestión.

- Salud y Bienestar.

- Energía.

- Transporte.

- Agua.

- Materiales.

- Residuos.

- Uso ecológico del suelo. 
- Contaminación.

- Innovación.

Las evaluaciones de los edificios son realizadas por Asesores capacitados y autorizados por BREEAM. Se recomienda que el Asesor BREEAM se elija desde el momento en que se decide intervenir sobre un terreno para construir un edificio, de modo que acompañe todo el proceso. El Asesor toma registro durante el proyecto, realiza una pre-evaluación y define la estrategia a seguir. Con la pre-evaluación, acompañada por las evidencias de proyecto recogidas en un informe del Asesor, se puede conseguir el Certificado de Diseño BREEAM. Sin embargo la emisión del Certificado con la puntuación definitiva se emite con la evaluación, al final de la construcción, cuando el informe del Asesor se presenta a BREEAM con los resultados, evidencias del proyecto en cada uno de los requisitos y la clasificación provisional.

A continuación se detallan los esquemas que tratan cuestiones de interés al desarrollo de esta Tesis; estos son BREEAM Vivienda, BREEAM Comercial y BREEAM en Uso.

- BREEAM Vivienda: Es el esquema de evaluación y certificación de la sustentabilidad aplicable a edificios de vivienda unifamiliares y en bloque. La metodología BREEAM Vivienda es aplicable tanto a nueva edificación como a obras de rehabilitación de edificios ya construidos, y tanto en la fase de proyecto como en la de post-construcción. Como todos los esquemas BREEAM en la evaluación de las edificaciones se consideran todas las áreas de la sostenibilidad; aspectos económicos, ambientales y también sociales. La aplicación del esquema BREEAM Vivienda responde a la necesidad de limitar el impacto sobre el medio ambiente; permite reducir las emisiones de gases de efecto invernadero y una mejor adaptación al cambio climático. Según la experiencia del Code for Sustainable Homes, la aplicación del certificado reduce los costes de mantenimiento de las viviendas, mejorando además los niveles de bienestar y confort. Una vivienda con certificado BREEAM Vivienda reducirá como mínimo un $7 \%$ de las emisiones de $\mathrm{CO}_{2}$, pudiendo alcanzar una reducción del $56 \%$ en aquellas que alcancen la mejor calificación. En cuanto al consumo de agua, se podrá ahorrar entre un $20 \%$ y un $35 \%$.

- BREEAM Comercial: Es el esquema de evaluación y certificación de sustentabilidad aplicable a oficinas, establecimientos comerciales y edificios industriales. La metodología propuesta es aplicable tanto a edificios de nueva planta como a obras de rehabilitación para edificios ya construidos, tanto en la fase de proyecto como en la edificación ya terminada. Según estudios realizados los edificios con certificado BREEAM reducen el impacto medioambiental de la construcción y promueven la eficiencia energética con ahorros de consumo entre un $30 \%$ y un $70 \%$, con la consiguiente reducción de las emisiones de $\mathrm{CO}_{2}$. Asimismo pueden producir una reducción del consumo de agua de hasta un $40 \%$ y una reducción en los gastos de funcionamiento y mantenimiento de hasta un $30 \%$.

- BREEAM en Uso: Es el esquema de certificación pensado para proporcionar información sobre el comportamiento ambiental de los edificios existentes de uso no doméstico y que estén en funcionamiento. Es aplicable a edificios de cualquier uso no doméstico como oficinas, comercio, etc. Es imprescindible que estos edificios lleven un mínimo de dos años en funcionamiento, de modo que se pueda evaluar su comportamiento real a través de la información sobre las prestaciones ambientales, las facturas y otros registros de consumos del bien. BREEAM en Uso permite obtener una visión detallada y significativa del comportamiento ambiental del edificio a lo largo de toda su vida útil. El uso de la herramienta constituye la base para abastecer objetivos, el desarrollo de un plan de acción y de su implementación y revisión periódica. Como todos los esquemas BREEAM en la evaluación de las edificaciones se consideran todas las áreas de la sustentabilidad; aspectos económicos, ambientales y también sociales. BREEAM en Uso está principalmente dirigido a propietarios, inquilinos, o consultores para que puedan pre-evaluar ellos mismos el edificio y las prácticas de gestión, y desarrollar planes de acción para mejorar su comportamiento ambiental, reduciendo el consumo de energía. BREEAM en uso permite obtener dos certificados; 
- Certificado Parte 1 - El edificio: certifica los aspectos constructivos, de instalaciones, etc.

- Certificado Parte 2 - Gestión del edificio: certifica las prácticas de facility management.

La aplicación del esquema BREEAM en Uso ayuda a establecer planes de acción con el objetivo de reducir los costes de funcionamiento y a mejorar la sustentabilidad ambiental. Su aplicación sirve de marco o guía para la implementación de medidas enfocadas a la mejora del comportamiento ambiental del edificio. La reducción de los costes de funcionamiento de los edificios gestionados de forma sustentable se establece entre un 8 y un $9 \%$.

\subsubsection{Passivhaus}

Passivhaus es un conjunto de normas para la construcción de edificios energéticamente eficientes, que garantizan el confort interior de los espacios habitables. Mediante la implementación de los conceptos de Passivhaus a la construcción de edificios puede alcanzarse un ahorro en el consumo de energía de alrededor del $90 \%$ en comparación con edificios tradicionales y de un $75 \%$ si se compara con edificios de nueva construcción según las normas europeas. Para calentar un metro cuadrado de superficie habitable, las viviendas construidas bajo estos conceptos consumen menos de $1.5 \mathrm{~m}^{3}$ de gas natural por año. En climas donde los edificios pueden abastecerse de sistemas de calefacción pasivos, los ahorros pueden ser mayores (Passivhaus Institut; 1996).

Passivhaus propone hacer un uso eficiente del sol, de las fuentes internas de generación de calor y de sistemas de recuperación para reducir el consumo de energía para calefacción, incluso en los meses más fríos. Por su parte, durante los meses más cálidos se proponen técnicas de enfriamiento pasivo.

El confort interior alcanzado en las construcciones que siguen los principios de Passivhaus es muy grande. En ellas la temperatura interior de las superficies en contacto con el exterior no varía demasiado con respecto a la temperatura media interior de los locales habitables. Asimismo mediante un sistema de ventilación mecánico de bajo consumo energético, se garantiza que las condiciones de habitabilidad sean óptimas.

$\mathrm{Si}$ bien este sistema fue desarrollado en Alemania para climas extremadamente fríos, actualmente se han desarrollado adaptaciones del mismo a climas menos rigurosos, como el mediterráneo. A los efectos de que el estudio de este sistema constituya un aporte a esta Tesis, que plantea el desarrollo de un modelo edilicio energéticamente eficiente para el Área Metropolitana de Buenos Aires, en donde el clima es templado húmedo (clima Cfa - Köppen), se profundiza en el análisis de esta adaptación.

La certificación Passivhaus se puede obtener a través del Passivhaus Institut, u otro organismo de certificación homologado por dicho instituto. Esta certificación contribuye en el proceso de diseño, al tiempo que verifica la calidad de los edificios construidos. Actualmente se entregan certificados Passivhaus a edificios residenciales, no residenciales y a edificios que hayan sido remodelados.

Para obtener la certificación según Passivhaus Institut en climas templados es necesario cumplir con los siguientes requisitos:

- Demanda máxima para calefacción: $15 \mathrm{kWh} / \mathrm{m}^{2} /$ año.

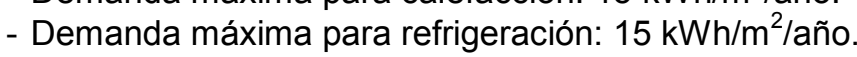

- Para edificios con calefacción y refrigeración por aire, se acepta como alternativa una carga

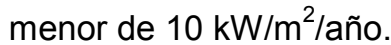

- Valor de Renovaciones de aire inferior a 0,6/h RA (obtenido mediante el test de presurización "Blower Door").

- Consumo de energía primaria para todos los sistemas (calefacción, refrigeración, ACS, electricidad, auxiliar, etc.) inferior a $120 \mathrm{kWh} / \mathrm{m}^{2}$

- Temperaturas superficiales interiores de la envolvente térmica durante invierno mayor a $17^{\circ} \mathrm{C}$. 
Los requisitos deben ser calculados mediante el programa Passivhaus Planning Package (PHPP), un software para la simulación de edificios Passivhaus. Para calcular la energía necesaria para calefacción, se puede utilizar el método anual o mensual. Si la demanda para calefacción está por debajo de los $8 \mathrm{kWh} / \mathrm{m}^{2}$, o si la relación entre las ganancias y las pérdidas de calor es superior a 0.70 , debe utilizarse el método mensual.

El método de cálculo determinado por el Passivhaus Planning Package (PHPP) se basa en los siguientes parámetros:

- Datos climáticos regionales.

- Datos climáticos propios; su uso debe ser aprobado por el certificador.

- Temperatura interior de invierno; $20^{\circ} \mathrm{C}$ sin variaciones nocturnas.

- Aportaciones internas; $2,1 \mathrm{~W} / \mathrm{m}^{2}$.

- Ocupación; $35 \mathrm{~m}^{2} /$ persona (si se utilizan valores diferentes deben justificarse).

- Requisitos de agua caliente solar; 25 litros/persona/día (temperatura $60^{\circ} \mathrm{C}$ ). Agua de ingreso al sistema, $10^{\circ} \mathrm{C}$.

- Caudal de aire; $20-30 \mathrm{~m}^{3} /$ hora/persona. Renovaciones de aire, 0.3/hora en relación con la superficie calefaccionada y con la altura del local.

- Envolvente térmica; se utilizan las medidas exteriores.

- Coeficiente $U$ de los elementos opacos de la envolvente; valores determinados por el PHPP de acuerdo con la UNE EN ISO 6946 y en relación a las tablas de conductividad térmica del mercado de la Comunidad Europea.

- Coeficiente $U$ de los elementos transparentes; valores determinados por el PHPP y los valores calculados de acuerdo con la norma EN 10077.

- Vidrios; valor de la transmitancia del vidrio $(U g)$ según Norma EN 673. Factor solar $(g)$ según Norma EN 410.

- Sistema de recuperación de calor y ventilación; valor del rendimiento según pruebas de ensayo del Passivhaus Institut (PHI).

- Rendimiento de la generación de calor; mediante el método PHPP o justificaciones específicas.

- Factores de energía primaria; datos del PHPP.

Para el proceso de evaluación es necesario entregar la siguiente documentación del proyecto al PassivHaus Institut:

- Plano de sitio con indicación del Norte, los edificios vecinos y los principales elementos que arrojen sombra sobre el edificio.

- Planos en escala 1:100 y 1:50; deben contener todas las medidas y especificaciones necesarias para comprender la morfología del edificio.

- Planilla de carpinterías (identificación y posición en el edificio).

- Detalles constructivos para identificar posibles puentes térmicos. Debe indicarse en forma detallada los puntos de conexión de la envolvente térmica con los cerramientos interiores, tipos de pisos, espesores de materiales, detalle de carpinterías, etc. Los detalles deben estar acotados y deben incluir las especificaciones suficientes como para determinar las conductividades térmicas de la envolvente.

- Cálculo de la superficie de referencia.

- Planos técnicos o esquemas donde se indiquen los sistemas de abastecimiento y distribución de la calefacción y refrigeración, y de ventilación. Deben indicarse las medidas, el aislamiento acústico, los filtros, válvulas de escape, potencia de consumo de la ventilación y renovación, caudales de los difusores, etc.

Para el caso de certificación de productos se solicita la siguiente información técnica:

- Información sobre carpinterías en contacto con el exterior: determinar marca y valores de U.

- Información respecto a los vidrios: marca, tipo, valor de $U$, factor solar (g), tipo de espaciador.

- Breve descripción del sistema de instalaciones activas. 
- Indicar fabricante, tipo y especificaciones de todos los componentes activos: ventilación, calefacción y refrigeración, producción de agua caliente solar, etc.

- Para el caso de intercambiador de calor tierra-aire (tubo canadiense) debe determinarse la profundidad del sistema, el método de colocación, material, diámetro de los conductos, y cálculo de la eficiencia térmica.

- Para agua caliente solar, calefacción y refrigeración indicar la longitud aproximada y el nivel de aislamiento de los conductos de distribución y de los conductos de ventilación entre el intercambiador de calor y la envolvente térmica.

- Utilización eficiente de los aparatos eléctricos; indicar las medidas previstas para reducir el consumo de los electrodoméstico.

La declaración del director de obra consiste en la conformidad de la obra ejecutada con los valores indicados en el Passivhaus Planning Package (PHPP). Por su parte los cambios en la ejecución respecto al proyecto ejecutivo deben estar documentados y especificados, siendo acompañados de los certificados correspondientes. La obra debe ser documentada con fotografías.

Además, dependiendo de las circunstancias, el proyecto puede necesitar de evaluaciones adicionales de los componentes o datos utilizados en la construcción. En caso de trabajar con valores menos estrictos que los valores estándares del Pasivhaus Institut, esos deben ser documentados mediante las pruebas adecuadas.

El certificado corrobora la coherencia de la documentación suministrada con los requisitos de la norma, sin embargo no certifica la ejecución correcta de la obra, ni el buen uso del edificio que realicen los usuarios. La responsabilidad para alcanzar los estándares de las Normas Passivhaus depende del proyectista y de la calidad de la ejecución a cargo del director de obra. Asimismo se aconseja que una vez finalizada la obra se haga un seguimiento del funcionamiento del edificio.

\subsection{Normativa sobre eficiencia energética en edificios}

En los últimos años, en distintas partes del mundo se están llevando a cabo políticas de Estado orientadas a cumplir con el Protocolo de Kyoto de la Convención Marco de las Naciones Unidas sobre el Cambio Climático (CMNUCC).

Esta tesis se centra en el estudio particularizado de las normas ANSI/ASHRAE/USGBC/IES189.1-2009 y ANSI/ASHRAE 55-2010 que tratan sobre el diseño de edificios verdes de alto rendimiento y las condiciones higrotérmicas para la ocupación humana respectivamente. En el siguiente trabajo también estudia la Directiva 2010/31/UE del Parlamento Europeo y del Consejo, relativa a la eficiencia energética de los edificios. Resultado de este análisis y del estudio particularizado de las Normas IRAM 11.6XX y 11.900, son las propuestas de mejora de la Normativa argentina que se han presentado en distintos congresos e incluso en el Subcomité de Acondicionamiento Térmico de Edificios de IRAM.

\subsubsection{ASHRAE}

La American Society of Heating, Refrigerating and Air Conditioning Engineers (ASHRAE) es una sociedad que realiza investigaciones, publicaciones, promueve la formación de profesionales especializados y estable normas. Todas estas actividades que realiza ASHRAE están relacionadas con la utilización de sistemas en edificios, la eficiencia energética, la calidad del aire interior, la refrigeración y climatización de espacios interiores, entre otras cuestiones. ASHRAE fue fundada en 1894 y actualmente cuenta con más de cincuenta mil miembros en todo el mundo.

\subsubsection{ANSI/ASHRAE Standard 55-2010}

El propósito de la Norma 55-2010 ANSI/ASHRAE "Thermal Environmental Conditions for Human Occupancy (Condiciones ambientales térmicas para la ocupación del hombre)" es 
especificar los factores del ambiente térmico interior y los relacionados con los ocupantes que contribuyen a la generación de condiciones térmicas ambientales aceptables.

Los factores ambientales registrados en esta norma son: temperatura, radiación térmica, humedad y velocidad del viento. Por su parte los factores relacionados con las personas son la actividad y la vestimenta. El confort interior responde a la interacción de todos estos factores. Se define al confort térmico como la condición de la mente que expresa satisfacción con el ambiente térmico. Si bien existen variaciones fisiológicas y psicológicas entre las personas, esta norma determina seis factores principales que deben ser considerados cuando se definen las condiciones de confort térmico:

- Nivel metabólico.

- Vestimenta.

- Temperatura del aire.

- Temperatura radiante.

- Velocidad del viento.

- Humedad.

Estos factores pueden variar con el tiempo, sin embargo esta norma considera el confort térmico en estado estacionario y para una situación similar a la del trabajo de oficina. Si bien puede utilizarse esta norma para determinar las condiciones de confort de espacios en los que el nivel de actividad sea más elevado, no es aplicable para lugares de descanso.

Esta Norma establece un método para determinar las condiciones térmicas aceptables en espacios ocupados, el cual se basa en los siguientes parámetros:

- Temperatura operativa: para valores de humedad, velocidad del viento, nivel de vestimenta determinados se establece una zona termal. La zona de confort se define en función del rango de temperatura operativa, que determina un ambiente térmico aceptable, o en términos de la combinación de temperatura del aire y temperatura radiante media que los ocupantes encuentran térmicamente aceptable.

- Velocidad del aire: esta norma permite elevar la velocidad del aire a ser utilizado de modo de incrementar la máxima temperatura operativa. Los límites impuestos dependen de factores ambientales y en relación con las personas, y de que los ocupantes tengan control sobre la velocidad del aire.

- Disconfort térmico local: es causado por la diferencia de temperatura del aire a la altura del suelo y de la cabeza como consecuencia del enfriamiento convectivo, por la asimetría del campo radiante o por contacto con un piso frío o cálido. Las personas son más propensas a sentir disconfort cuando el cuerpo tiene la sensación de frío o calor, que cuando esta sensación es neutra.

Esta Norma también plantea un método opcional para determinar condiciones térmicas aceptables en espacios acondicionados naturalmente. Los espacios acondicionados naturalmente controlados por los ocupantes son aquellos espacios en los cuales las condiciones térmicas del espacio son regulados a partir de la apertura o el cierre de ventanas (u otros dispositivos). La experiencia demuestra que las respuestas de los ocupantes a las condiciones térmicas en estos espacios depende del clima exterior y difiere de las respuestas térmicas que se dan en edificios acondicionados mecánicamente como consecuencia de distintas experiencias térmicas, cambios en la vestimenta, disponibilidad de control, etc. Esta opción no puede utilizarse en caso de que la temperatura media mensual exterior sea menor a $10^{\circ} \mathrm{C}$ o superior a $33,5^{\circ} \mathrm{C}$.

En la etapa de diseño es posible evaluar el ambiente térmico mediante cálculos o con modelos de simulación pero una vez que se haya concluido la obra, y el edificio se encuentre ocupado deben realizarse mediciones en los locales donde los ocupantes pasan la mayor parte del tiempo. Las mediciones deben ser una muestra representativa de los lugares ocupados del 
espacio general. En locales no ocupados el evaluador debe estimar cuál es el lugar más significativo donde podrán ubicarse los futuros ocupantes. En cualquier caso las mediciones deben ser tomadas donde se observan los valores más extremos de los parámetros térmicos (cerca de ventanas, salidas de difusores, esquinas, entradas).

La temperatura y la velocidad del aire debe ser medida a una altura de $0,6 \mathrm{~m}-1,0 \mathrm{~m}$ y $1,1 \mathrm{~m}$ para nivel de actividad bajo. La asimetría radiante debe ser medida a $0,6 \mathrm{~m}$ si las personas están sentadas y a $1,1 \mathrm{~m}$ si las personas están paradas. Por su parte las temperaturas a nivel de suelo deben ser medidas con el piso terminado. La humedad debe ser medida a cualquier nivel en la zona ocupada.

Luego de la etapa de medición y para determinar si el ambiente térmico cumple finalmente con los criterios definidos en esta norma existen dos métodos. El primer método se trata de determinar estadísticamente la satisfacción de los ocupantes a través de la evaluación de los resultados de las encuestas. El segundo se trata de establecer técnicamente las condiciones de confort a través del análisis de las variables medioambientales, para el cual es necesario verificar la temperatura del suelo, la estratificación del aire y la asimetría de la temperatura radiante.

\subsubsection{ANSI/ASHRAE/USGBC/IES - Standar 189.1-2009}

El propósito de la Norma 189.1-2009 ANSI/ASHRAE/USGBC/IES "Diseño de Edificios Verdes de Alto Rendimiento (Excepto Edificios Residenciales Bajos)" es proporcionar los requisitos mínimos para el emplazamiento, diseño, construcción, y el plan para la operación de edificios verdes de alto rendimiento.

Esta Norma proporciona criterios mínimos que se aplican a edificios nuevos, nuevas partes de edificios, y nuevos sistemas y equipos en edificios existentes. Intenta promover cuestiones relacionadas con la sustentabilidad del lugar, la eficiencia en el uso del agua, la eficiencia energética, la calidad ambiental interior y el impacto del edificio sobre la atmósfera, materiales y recursos.

En cuanto a cuestiones relacionadas con la sustentabilidad del lugar, la Norma busca mitigar el efecto de isla de calor, y la reducción de la contaminación ligera.

En cuanto a cuestiones de Eficiencia Energética la Norma especifica los requerimientos de edificios y equipos electrodomésticos, para los sistemas de energía renovable in situ y para la medición de energía. Los dispositivos de medición deben proporcionar datos diarios y registrarán los perfiles de energía horarios, los cuales deben ser utilizados para evaluar el desempeño de la edificación, al menos mensualmente.

El proyecto de construcción deberá contener sistemas de energía renovables locales que proporcionen la producción de energía anual equivalente de no menos de $20 \mathrm{kWh} / \mathrm{m}^{2}$ al espacio acondicionado. La producción de energía anual será la suma combinada de todos los sistemas de energía renovables del sitio.

La envolvente del edificio debe cumplir con la Sección 5 de la norma ANSI/ASHRAE/IENSA 90.1, con las siguientes modificaciones:

- Área de abertura vertical:

El área total de abertura vertical debe ser menor del $40 \%$ del área total de la pared.

- Proyecciones permanentes:

Para las zonas climáticas 1 a 5 , las aberturas verticales en el oeste, sur y este deberán ser sombreadas por proyecciones permanentes que tenga un área promedio no menor a $0,50 \mathrm{~m}^{2}$.

- Cámara de aire continua: 
La envolvente del edifico debe contar con una cámara de aire continua para controlar las fugas de aire de entrada o salida del espacio acondicionado. Todos los componentes de la envolvente deben estar claramente identificados en los documentos de construcción.

La calefacción, ventilación y el aire acondicionado deberán cumplir con la norma ANSI/ASHRAE/IESNA 90.1, con las siguientes modificaciones:

- Los productos deben cumplir con la mínima eficiencia abordada en la Nacional Appliance Energy Conservation Act (NAECA), Energy Policy Act (EPAct) y la Energy Independence and Security Act (EISA).

- Los productos deben cumplir con los requisitos de ENERGY STAR.

- Los sistemas de energía renovables locales requeridos deben proporcionar una producción de energía anual de al menos $13 \mathrm{kWh} / \mathrm{m}^{2}$.

- Los sistemas de reducción de la carga pico requeridos serán capaces de reducir la demanda pico eléctrica por lo menos en el $5 \%$ de la demanda pico proyectada.

En las zonas donde el aire es mezclado, el volumen de este no debe ser mayor al porcentaje de caudal de aire exterior de diseño para la zona o al 15\% del porcentaje de suministro del pico de diseño para la zona.

Cada sistema de ventilación debe tener un sistema de recuperación de energía que se active cuando el porcentaje de caudal de aire del sistema de alimentación supere a los valores propuestos, basados en las zonas climáticas o en el porcentaje de aire exterior. Los sistemas de recuperación de energía requeridos por esta sección tendrán al menos el $60 \%$ de efectividad de recuperación de energía.

El agua caliente para calefacción debe cumplir con la norma ANSI/ASHRAE/IENSA 90.1, con las siguientes modificaciones:

- Los proyectos de construcción deben contener sistemas automáticos para la limitar la demanda del edificio por lo menos en el $10 \%$ de la demanda proyectada.

- Las oficinas de $25 \mathrm{~m}^{2}$ o más pequeñas, aulas de cualquier tamaño, salas profesionales de menos de $100 \mathrm{~m}^{2}$, salones de usos múltiples de menos de $100 \mathrm{~m}^{2}$, y centros de reunión deben contar con sensores de ocupación para que se apaguen las luces si en un lapso de treinta minutos el espacio queda vacío, además deben permitir el control manual.

La iluminación en pasillos de edificios multifamiliares, dormitorios, hoteles, áreas de almacenamiento y bibliotecas debe ser controlada por un sensor de ocupación, con sistema de atenuación que reduzca la iluminación a un mínimo de 50\% cuando los espacios estén vacíos. Asimismo la iluminación en cualquier área dentro de un edificio que requiera estar continuamente iluminada por razones de seguridad no superará $1 \mathrm{~W} / \mathrm{m}^{2}$. Se permite iluminación adicional de salida y de seguridad siempre que esté controlada por un dispositivo de control automático.

Las zonas mayores a los $25 \mathrm{~m}^{2}$ con iluminación natural deben contar con controles que reduzcan el poder de iluminación en respuesta a la luz natural disponible mediante oscurecimiento o controles automáticos. Para la iluminación de las fachadas de los edificios, estacionamientos, garajes y todas las áreas exteriores deben instalarse controles automáticos para apagar la iluminación exterior pasados treinta minutos del amanecer.

El resto de los equipos eléctricos deben cumplir con la norma ANSI/ASHRAE/IESNA 90.1. EI equipamiento que se haya instalado antes de la emisión del certificado de ocupación deberá cumplir con los criterios equivalentes requeridos para lograr la etiqueta ENERGY STAR. Los proyectos de construcción deben tener un costo anual de energía menor o igual al obtenido mediante el cumplimiento de las secciones relacionadas con la gestión del uso de energía, y la sustentabilidad en la construcción. El proyecto de construcción debe tener unas emisiones de $\mathrm{CO}_{2}$ anual menores o iguales a las obtenidas mediante el cumplimiento de las secciones relacionadas con el uso de la energía, la sustentabilidad de la construcción y la calidad 
ambiental interior. Para determinar el valor de $\mathrm{CO}_{2}$ para cada fuente de energía suministrada al proyecto de construcción, debe multiplicarse el consumo de energía por el factor de emisión.

La Norma también especifica cuestiones relacionadas con la calidad ambiental interior, incluyendo control del tabaco, inyección de aire exterior, confort térmico, entradas del edificio, control acústico, iluminación natural y materiales de baja emisión

En cuanto a la calidad del aire interior, los porcentajes de ventilación mínima deben ser calculados según el procedimiento de la norma ANSI/ASHRAE 62.1.

En lo que se refiere a iluminación cenital, la Norma establece que los espacios cerrados de gran tamaño deben tener un mínimo de superficie vidriada para proveer iluminación natural en forma cenital. Los edificios de tres pisos (o menos), de más de $2.000 \mathrm{~m}^{2}$ de superficie de techo, y que tengan una asignación del poder de iluminación igual o mayor a $5,5 \mathrm{w} / \mathrm{m}^{2}$, deben contar con un mínimo del $50 \%$ de la superficie con un poder de iluminación natural superior a $5 \mathrm{~W} / \mathrm{m}^{2}$. Las áreas con iluminación natural deben tener un área mínima de iluminación cenital en relación a esa área. Las claraboyas deben tener un valor de transparencia del $90 \%$.

En lo que respecta a iluminación lateral tanto oficinas como aulas deberán tener aberturas en las fachadas con orientación norte, sur y este. Asimismo las superficies interiores opacas en las zonas de iluminación natural deberán ser tener un nivel de reflectancia igual o mayor al $80 \%$ para techos y $70 \%$ para muros. Cada fachada con orientación oeste, sur y este debe ser diseñada con un factor de proyección mayor o igual a 0,5.

El edificio debe tener una iluminación mínima de 300 lux en un plano de $1 \mathrm{~m}$ por encima del suelo, en el $75 \%$ de la superficie de la zona de iluminación natural. Además debe demostrarse que el sol directo no impacta sobre cualquier parte de la superficie de trabajo de algún espacio con iluminación natural por más del $20 \%$ de las horas de ocupación.

La Norma también abarca cuestiones relacionadas al impacto del edificio sobre la atmósfera, materiales y recursos, incluyendo el manejo de los residuos de la construcción, refrigerantes, almacenamiento y colección de materiales reciclables, y materiales de impacto reducidos.

Un mínimo del $50 \%$ de material de residuos de la construcción y demolición no peligroso deben ser desviados de la disposición en vertederos e incineradores para su reciclado y o reutilización. Para nuevos proyectos de construcción en sitios con menos de $5 \%$ de superficie construida, los residuos de construcción generados por el proyecto no pueden exceder los $6 \mathrm{~kg} / \mathrm{m}^{2}$ de superficie construida.

Los materiales deben ser extraídos y fabricados según las leyes de regulación del país de origen. Un porcentaje de los materiales utilizados en el proyecto deben ser reciclados y otro porcentaje deben ser regionales. Un mínimo del $15 \%$ de materiales de construcción o productos utilizados deben ser extraídos de la región donde se emplazará el edificio, en un radio de $800 \mathrm{~km}$. Un mínimo de $5 \%$ de los materiales de construcción utilizados serán productos de base biológica. Además se debe realizar una evaluación del ciclo de vida según lo especificado en la norma ISO 14.044.

Esta Norma también establece los requerimientos para la construcción y operación de edificios, incluyendo el proceso de puesta en marcha, pruebas de aceptación, la construcción, medición y verificación, informes del uso de energía, durabilidad, gestión del transporte, erosión y control de sedimentos, construcción y calidad del aire interior durante la construcción.

Los sistemas de aire acondicionado, calefacción, refrigeración y controles asociados a estos sistemas, los sistemas de iluminación, los sistemas de energías renovables, los dispositivos de medición de agua y de energía deberán contar con prueba de aceptación. Para edificios que superen los $500 \mathrm{~m}^{2}$ se debe desarrollar un plan funcionamiento del edificio que debe incorporarse en las distintas etapas (prediseño, diseño, construcción y primer año de ocupación) del edificio. 
Debe garantizarse el seguimiento y buen funcionamiento de los equipos de calefacción, ventilación, aire acondicionado, refrigeración, sistemas de la envolvente del edificio, presurización, controles de iluminación y sombreado, irrigación, agua caliente y bombeo de agua entre otros. Además debe realizarse un monitoreo del funcionamiento del edificio antes de la ocupación del edificio y con todos los acabados interiores instalados.

Esta Norma también hace mención al diseño integrado del edificio, en el cual se requiere la colaboración de quien encarga el proyecto desde el primer momento para permitir un diseño equilibrado en todos los aspectos, mediante el intercambio de experiencias con los miembros del equipo. Este proceso contrasta el método tradicional de diseño, donde existe una limitación de los conocimientos de los diferentes responsables que trabajan en la configuración del proyecto. Un proceso de diseño integrado permite la construcción de edificios verdes de alto rendimiento que consumen menos energía al tiempo que logran un mayor confort y funcionalidad. Facilita una mayor performance de construcción; contribuye a determinar la forma del edificio en conjunto con la envolvente, el tendido mecánico, eléctrico y otros sistemas del edificio. En la medida en que estos sistemas sean introducidos en el proceso de diseño serán más rentables, que si se incorporan luego de construido el edificio.

\subsubsection{Directiva 2010/31/UE}

El objetivo principal de la Directiva 2010/31/UE relativa a la eficiencia energética de los edificios es lograr que la Unión Europea pueda cumplir con Protocolo de Kyoto de la Convención Marco de las Naciones Unidas sobre el Cambio Climático (CMNUCC), así como con el compromiso a largo plazo de mantener el aumento de la temperatura global por debajo de $2^{\circ} \mathrm{C}$ y de reducir, para el año 2020 , las emisiones totales de gases de efecto invernadero en un $20 \%$ como mínimo con respecto a los niveles de 1990.

Esta Directiva fomenta la eficiencia energética en los edificios de la Unión Europea, teniendo en cuenta las condiciones climáticas exteriores y las particularidades locales, así como las exigencias ambientales interiores y la rentabilidad en términos coste-eficacia. Establece requisitos en relación con una metodología de cálculo de la eficiencia energética integrada; planes nacionales destinados a aumentar el número de edificios de consumo de energía casi nulo; la certificación energética de los edificios; la inspección periódica de las instalaciones, y la aplicación de requisitos mínimos de eficiencia energética a edificios nuevos, edificios existentes con reformas importantes, elementos de construcción que formen parte de la envolvente del edificio e instalaciones técnicas.

La Directiva compromete a los Estados miembros a tomar las medidas necesarias para garantizar que los edificios nuevos cumplan los requisitos mínimos de eficiencia energética. En los edificios nuevos es importante que se considere la viabilidad técnica, medioambiental y económica de instalaciones alternativas de alta eficiencia (instalaciones descentralizadas de abastecimiento de energía basadas en energía procedente de fuentes renovables, cogeneración, calefacción o refrigeración, bombas de calor, etc.). Por su parte en edificios existentes, siempre que sea técnica, funcional y económicamente viable, debe mejorarse la eficiencia energética, cuando estos sean ampliados o remodelados.

La Directiva compromete a los Estados miembros para que a fines de 2020, todos los edificios nuevos sean edificios de consumo de energía casi nulo, y a fines de 2018, los edificios nuevos de autoridades públicas sean edificios de consumo de energía casi nulo. Para ello los Estados miembros deberán elaborar planes nacionales destinados a aumentar el número de edificios de consumo de energía casi nulo. Los planes nacionales incluirán:

- la aplicación en la práctica de la definición de edificios de consumo de energía casi nulo, que refleje sus condiciones nacionales, regionales o locales e incluya un indicador numérico

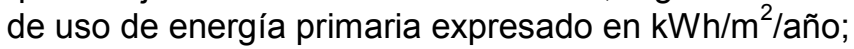

- objetivos intermedios para mejorar la eficiencia energética de los edificios nuevos en 2015; 
- información sobre las políticas y medidas financieras para promover los edificios de consumo de energía casi nulo.

Además la Directiva compromete a los Estados a establecer un sistema de certificación de la eficiencia energética de los edificios. El certificado de eficiencia energética deberá incluir la eficiencia energética del edificio y valores de referencia tales como requisitos mínimos de eficiencia energética; podrá incluir información adicional, como el consumo anual de energía para edificios no residenciales y el porcentaje que la energía procedente de fuentes renovables representa en el consumo total de energía. Asimismo deberá incluir recomendaciones para la mejora de los niveles óptimos de eficiencia energética de un edificio; medidas relacionadas con la envolvente o con las instalaciones técnicas del edificio.

Por otra parte los Estados miembros deben garantizar que se brinde orientación y formación a los encargados de aplicar esta Directiva, remarcando la importancia de mejorar la eficiencia energética. Considerando al mismo tiempo cuál es la combinación óptima de las mejoras de la eficiencia energética, de la utilización de energía de fuentes renovables y del empleo de sistemas urbanos de calefacción y refrigeración al planificar, diseñar, construir y reformar zonas industriales o residenciales.

La eficiencia energética de un edificio se determina partiendo de la cantidad de energía consumida anualmente para satisfacer las distintas necesidades ligadas a su utilización normal, de modo que refleje la energía necesaria para la calefacción y refrigeración a fin de mantener las condiciones de temperatura previstas para el edificio y sus necesidades de agua caliente sanitaria.

La metodología de cálculo de la eficiencia energética de los edificios debe tener en cuenta las normas europeas y ajustarse a la legislación correspondiente de la Unión, incluida la Directiva 2009/28/CE. Debe establecerse teniendo en cuenta los siguientes aspectos:

- características térmicas del edificio: capacidad térmica, aislamiento, calefacción pasiva, elementos de refrigeración, y puentes térmicos;

- instalación de calefacción y de agua caliente, y sus características de aislamiento;

- instalaciones de aire acondicionado;

- ventilación natural y mecánica;

- instalación de iluminación incorporada;

- diseño, emplazamiento y orientación del edificio, incluidas las condiciones climáticas exteriores;

- instalaciones solares pasivas y protección solar;

- condiciones ambientales interiores, incluidas las condiciones ambientales interiores proyectadas;

- cargas internas.

En el cálculo debe tenerse en cuenta la incidencia positiva de los siguientes aspectos:

- condiciones locales de exposición al sol, sistemas solares de calefacción o producción de electricidad basados en energía procedente de fuentes renovables;

- electricidad producida por cogeneración;

- sistemas urbanos o centrales de calefacción y refrigeración;

- iluminación natural.

A efectos del cálculo, los edificios deben clasificarse adecuadamente en las siguientes categorías:

- viviendas unifamiliares de distintos tipos;

- edificios en bloque;

- oficinas;

- centros de enseñanza;

- hospitales; 
- hoteles y restaurantes;

- instalaciones deportivas;

- edificios comerciales;

\subsubsection{IRAM}

El Instituto Argentino de Normalización y Certificación (IRAM) es una asociación civil sin fines de lucro cuya finalidad es establecer normas técnicas, y pugnar por el conocimiento y la aplicación de las mismas, promoviendo actividades de certificación de productos y de sistemas de calidad para brindar seguridad al consumidor. Las normas IRAM son el resultado del consenso técnico entre los diversos sectores involucrados.

IRAM es el representante de la Argentina en la International Organization for Standardization (ISO), en la Comisión Panamericana de Normas Técnicas (COPANT) y en la Asociación MERCOSUR de Normalización (AMN).

Si bien IRAM estudia y publica normas argentinas en todos los campos de actividad, las normas que se detallan a continuación tratan específicamente el tema de la eficiencia energética en edificios, de total incumbencia al tema desarrollado en esta Tesis. Resultado del estudio de estas normas han sido las propuestas de mejora que se han presentado en distintos congresos.

\subsubsection{IRAM 11.601}

El objeto de la Norma IRAM 11.601 "Aislamiento térmico de edificios. Métodos de cálculo. (Propiedades térmicas de los componentes y elementos de construcción en régimen estacionario)" es, como su nombre lo indica, establecer los valores y los métodos fundamentales para el cálculo de las propiedades térmicas de los componentes y elementos de construcción en régimen estacionario. Esta norma contiene métodos simplificados para el cálculo de elementos planos no homogéneos. Los métodos de cálculo no tienen en cuenta ni las infiltraciones de aire a través de los elementos, ni la radiación solar sobre las superficies o a través de elementos transparentes.

Según lo establece esta Norma la resistencia térmica de una capa homogénea de material sólido, $\mathrm{R}$, en metro cuadrado kelvin por watt, se calcula con la siguiente fórmula:

Donde:

$$
\mathrm{R}=\mathrm{e} / \lambda \quad \text { [Ecuación IV - 3] }
$$

- e: espesor de la capa, $(\mathrm{m})$.

- $\lambda$ : conductividad térmica del material, $\left(\mathrm{W} / \mathrm{m}^{2} \mathrm{~K}\right)$.

También se determinan los valores de las resistencias térmicas superficiales, las cuales varían en función de la dirección del flujo de calor y de la situación (interior - exterior), y los valores de las resistencias térmicas de las cámaras de aire.

Por su parte se establece el criterio para el cálculo de la transmitancia térmica de un elemento constructivo, que se define como la inversa de la resistencia térmica total $\left(K=1 / R_{t}\right)$.

Esta norma también establece el método de cálculo de la resistencia térmica para un componente plano formado por diversas capas homogéneas perpendiculares al flujo de calor, el cual se calcula con las fórmulas siguientes:

- entre ambas caras, $R_{T}$ :

- de aire a aire, $R_{T}$ :

$$
R_{T}=R_{1}+R_{2}+R_{n} \quad \text { [Ecuación IV - 4] }
$$

$$
R_{T}=R_{s i}+R_{t}+R_{s e} \quad \text { [Ecuación IV - 5] }
$$

Donde: 
- $R_{1}, R_{2}, R_{n}$ : resistencias térmicas de capas homogéneas.

- $R_{c 1}, R_{c 2}, R_{c n}$ : resistencias térmicas de cámaras de aire, $\left(\mathrm{m}^{2} \mathrm{~K} / \mathrm{W}\right)$.

- $R_{s i}, R_{s e}$ : resistencias térmicas superficiales, $\left(\mathrm{m}^{2} \mathrm{~K} / \mathrm{W}\right)$.

Esta Norma también establece el método de cálculo de la resistencia térmica total del techo $\left(R_{T}\right)$, según la siguiente fórmula:

Donde:

$$
R_{T}=R_{f}+\frac{A_{f}}{\sum \frac{A_{i}}{R_{i}}} \quad[\text { Ecuación IV - 6] }
$$

- $R_{f}$ : resistencia térmica total del forjado, $\left(\mathrm{m}^{2} \mathrm{~K} / \mathrm{W}\right)$.

- $R_{i}$ : resistencia térmica total de los componentes que delimitan el espacio de aire, $\left(\mathrm{m}^{2} \mathrm{~K} / \mathrm{W}\right)$.

- $A_{i}$ : área de los componentes exteriores que delimitan el espacio de aire, $\left(\mathrm{m}^{2}\right)$.

- $A_{f:}$ el área del forjado, $\left(\mathrm{m}^{2}\right)$.

Por su parte la resistencia térmica de componentes con cámara de aire medianamente ventilada se calcula mediante la siguiente fórmula:

Donde:

$$
\frac{1}{R_{T}}=K=K_{1}+\alpha\left(K_{2}-K_{1}\right) \quad \text { [Ecuación IV - 7] }
$$

- $K$ : transmitancia térmica del componente, $\left(\mathrm{m}^{2} \mathrm{~K} / \mathrm{W}\right)$;

- $K_{1}$ : transmitancia térmica de la capa interior, $\left(\mathrm{m}^{2} \mathrm{~K} / \mathrm{W}\right)$;

- $K_{2}$ : transmitancia térmica de la capa exterior, $\left(\mathrm{m}^{2} \mathrm{~K} / \mathrm{W}\right)$;

- $\alpha$ : coeficiente de ventilación de la cámara.

La resistencia térmica total de un ático se calcula con la siguiente fórmula:

$$
R_{T}=R_{f}+\frac{1}{\alpha+\frac{\sum A_{i} / R_{i}}{A_{f}}}
$$

Donde:

$$
\text { [Ecuación IV - 8] }
$$

- $\alpha$ : coeficiente $\left(5 \mathrm{~W} / \mathrm{m}^{2} \mathrm{~K}\right)$.

- $R_{f}$ : resistencia térmica total del forjado, $\left(\mathrm{m}^{2} \mathrm{~K} / \mathrm{W}\right)$.

- $R_{i}$ : resistencia térmica total de los componentes que delimitan el espacio de aire, $\left(\mathrm{m}^{2} \mathrm{~K} / \mathrm{W}\right)$.

- $A_{i}$ : área de los componentes exteriores que delimitan el espacio de aire, $\left(\mathrm{m}^{2}\right)$.

- $A_{f}:$ el área del forjado, $\left(\mathrm{m}^{2}\right)$.

Por su parte la resistencia térmica total de componentes con cámara de aire muy ventilada se calcula sin considerar a la hoja exterior, suponiendo que el aire exterior se encuentra quieto, es decir que no hay flujos de aire. Se utiliza la siguiente fórmula:

Donde:

$$
\mathrm{RT}=2 \mathrm{R}_{\mathrm{si}}+\mathrm{R}_{\mathrm{i}} \quad \text { [Ecuación IV - 9] }
$$

- $R_{s i}$ : resistencia superficial interna del componente, $\left(\mathrm{m}^{2} \mathrm{~K} / \mathrm{W}\right)$.

- $R_{i}$ : resistencia térmica de la hoja interior del componente, $\left(\mathrm{m}^{2} \mathrm{~K} / \mathrm{W}\right)$.

Si la hoja exterior del componente consiste en una pantalla o protección situada a cierta distancia, se considera al espacio de aire abierto, existen flujos de aire en contacto con la cara exterior. En ese caso la resistencia térmica total del componente se calcula con la siguiente fórmula: 
Donde:

$$
\mathrm{R}_{\mathrm{t}}=\mathrm{R}_{\mathrm{si}}+\mathrm{R}_{\mathrm{i}}+\mathrm{R}_{\mathrm{se}} \quad \text { [Ecuación IV - 10] }
$$

- $R_{s e}:$ resistencia superficial externa, $\left(\mathrm{m}^{2} \mathrm{~K} / \mathrm{W}\right)$.

- $R_{s i}$ : resistencia superficial interna del componente, $\left(\mathrm{m}^{2} \mathrm{~K} / \mathrm{W}\right)$.

- $R_{i}$ : resistencia térmica de la hoja interior del componente, $\left(\mathrm{m}^{2} \mathrm{~K} / \mathrm{W}\right)$.

\subsubsection{IRAM 11.603}

La Norma IRAM 11.603 "Acondicionamiento térmico de edificios. Clasificación bioambiental de la República Argentina" establece la zonificación de la República Argentina de acuerdo con un criterio bioambiental, indicando las características climáticas de cada zona.

Para cada una de las zonas establecidas se dan pautas generales para el diseño, la evaluación de las orientaciones favorables y el cumplimiento del asoleamiento mínimo de los edificios destinados a vivienda. Se establece la caracterización de los microclimas y su evaluación desde el punto de vista del acondicionamiento térmico de edificios. En el Anexo A de la Norma IRAM 11.603 se incluye un listado con datos climáticos correspondientes a 165 estaciones meteorológicas de todo el país. Las zonas bioambientales se definen conforme lo muestra el mapa de la figura 56. Esta clasificación se ha desarrollado teniendo en cuenta los índices de confort de la temperatura efectiva corregida (TEC), correlacionada con el voto medio predecible (VMP) y el índice de Beldin y Hatch (IBH), desarrollados para zonas cálidas. Por su parte la evaluación de las zonas frías se realizó con los Grados Días para las necesidades de calefacción.

- Zona I - Muy cálida: comprende la región donde los valores de TEC media en un día típicamente cálido, son superiores a $26,3^{\circ} \mathrm{C}$. Se extiende en la región Centro-Este del extremo Norte del país. Durante la época caliente presenta valores de temperatura máxima superiores a los $34^{\circ} \mathrm{C}$ y valores medios superiores a los $25^{\circ} \mathrm{C}$, con amplitudes térmicas inferiores a los $15^{\circ} \mathrm{C}$. El período invernal es poco significativo con temperaturas medias, durante el mes más frío, superiores a los $12^{\circ} \mathrm{C}$. Esta zona se subdivide en función de las amplitudes térmicas (Subzona la, amplitudes térmicas mayores a $14^{\circ} \mathrm{C}$; Subzona $\mathrm{lb}$, amplitudes térmicas menores a $14^{\circ} \mathrm{C}$ ).

- Zona II - Cálida: Limitada por las isolíneas de TEC $26,3^{\circ} \mathrm{C}$ y $24,6^{\circ} \mathrm{C}$, comprende dos fajas del territorio argentino, una de extensión Este-Oeste centrada alrededor del paralelo $30^{\circ} \mathrm{y}$ otro, de extensión Norte-Sur recortada sobre el este de la Cordillera de los Andes. En esta zona el verano es la estación crítica, con valores de temperatura media superiores a los $24^{\circ} \mathrm{C}$ y máxima superiores a los $30^{\circ} \mathrm{C}$. Las mayores amplitudes térmicas se dan en esta época del año, con valores que no superan los $16^{\circ} \mathrm{C}$. El invierno es más seco, con bajas amplitudes térmicas y temperaturas medias que oscilan entre $8^{\circ} \mathrm{C}$ y $12^{\circ} \mathrm{C}$, sin embargo la aislación de verano resulta suficiente para esta situación. Esta zona se subdivide en función de las amplitudes térmicas (Subzona lla, amplitudes térmicas mayores a $14^{\circ} \mathrm{C}$; Subzona $\mathrm{Ilb}$, amplitudes térmicas menores a $14^{\circ} \mathrm{C}$ ).

- Zona III - Templada - Cálida: Limitada por las isolíneas de TEC $24,6^{\circ} \mathrm{C}$ y $22,9^{\circ} \mathrm{C}$, esta zona tiene igual distribución que la zona II, con la faja de extensión Este-Oeste centrada alrededor del paralelo $35^{\circ}$ y la de extensión Norte - Sur, ubicada en las primeras ramificaciones montañosas al Noroeste de Argentina, sobre la Cordillera de los Andes. Los veranos son relativamente calurosos y presentan temperaturas medias que oscilan entre $20^{\circ} \mathrm{C}$ y $26^{\circ} \mathrm{C}$, con máximas medias que superan los $30^{\circ} \mathrm{C}$. El invierno no es muy frío y presenta valores medios de temperatura entre $8^{\circ} \mathrm{C}$ y $12^{\circ} \mathrm{C}$, y valores mínimos que rara vez son menores que $0^{\circ} \mathrm{C}$. En general esta zona tiene inviernos relativamente benignos, con veranos no muy calurosos. Esta zona se subdivide en función de las amplitudes térmicas (Subzona IIla, amplitudes térmicas mayores a $14^{\circ} \mathrm{C}$; Subzona $\mathrm{Illb}$, amplitudes térmicas menores a $\left.14^{\circ} \mathrm{C}\right)$. 
- Zona IV - Templada - fría: Esta zona está limitada por las isolíneas de 1.170 y 1.950 Grados Días. Presenta una faja meridional paralela a la correspondiente la Zona III, ubicada a mayor altura de la Cordillera de los Andes y la región plana del centro y Sur del territorio, que alcanza la costa atlántica de la Provincia de Buenos Aires y Río Negro. Los veranos no son rigurosos y presentan máximas promedio que rara vez superan los $30^{\circ} \mathrm{C}$. Los inviernos son fríos con valores medios entre 4 y $8^{\circ} \mathrm{C}$, y las medias mínimas anuales muchas veces alcanzan valores por debajo de los $0^{\circ} \mathrm{C}$. Esta zona se subdivide en cuatro subzonas mediante las líneas de amplitud térmica de 14 y $18^{\circ} \mathrm{C}$ (Subzona IVa, de montaña; Subzona $\mathrm{IVb}$, de máxima irradiancia; Subzona IVc, de transición; Subzona IVd, marítima).

- Zona V - Fría: Limitada entre las isolíneas de 1.950 y 2.730 Grados Días, comprende una extensa faja de extensión Norte-Sur a lo largo de la Cordillera y la región central de la Patagonia. Los inviernos son rigurosos, con temperaturas medias del orden de $4^{\circ} \mathrm{C}$ y mínimas menores que $0^{\circ} \mathrm{C}$. Los veranos son frescos, con temperaturas medias inferiores a los $16^{\circ} \mathrm{C}$.

- Zona VI - Muy fría: Ubicada en la región donde los valores en Grados Días son mayores que 2.730, comprende toda la extensión de las altas cumbres de la Cordillera de los Andes y el extremo Sur de la Patagonia, Tierra del Fuego, Islas Malvinas y Antártida. En verano las temperaturas medias son inferiores a $12^{\circ} \mathrm{C}$ y en invierno estos valores no superan los $4^{\circ} \mathrm{C}$. La faja que se extiende al norte del paralelo $37^{\circ}$ presenta la rigurosidad propia de la altura y una alta intensidad de radiación solar.

Asimismo la Norma establece las siguientes condiciones de diseño, de acuerdo a las características antes descritas para cada zona:

- Zona I - Muy cálida y Zona II - Cálida: se recomienda utilizar colores claros en paredes exteriores y techos, gran aislación térmica en techos y en las paredes orientadas al este y al oeste. Todas las superficies deben protegerse de la radiación solar, minimizar la superficie de ventanas y evitar la orientación Este u Oeste para las mismas. El eje mayor de la vivienda preferentemente es el Este-Oeste. La ventilación cruzada de la vivienda es fundamental. Deben aprovecharse los vientos dominantes y crear zonas de alta y baja presión que aumenten la circulación de aire.

- Zona III - Templada cálida: debe evitarse la orientación Oeste. Las aberturas deben tener sistemas de protección a la radiación solar. Se recomienda utilizar colores claros en las superficies exteriores. La Subzona Illa se caracteriza por grandes amplitudes térmicas por lo que es aconsejable el uso de viviendas agrupadas y de todos los recursos que tiendan al mejoramiento de la inercia térmica.

- Zona IV - Templada fría: En las Subzonas IVa y IVb se presentan grandes amplitudes térmicas, motivo por el cual es importante agrupar las viviendas y proveer los recursos necesarios para el mejoramiento de la inercia térmica. En la Subzona IVd las amplitudes térmicas son pequeñas durante todo el año, sin embargo se recomienda la protección solar eficiente en el verano. La Subzona IVc es una zona de transición entre la zona de mayores amplitudes térmicas hacia la de menores, por lo tanto es necesario evaluar cuáles son las condiciones más desfavorables.

- Zona V - Fría: La aislación térmica de paredes, pisos y techos será un factor primordial y las ventanas, salvo la orientación norte, serán lo más reducidas posible. Evaluar los riesgos de condensación superficial e intersticial y evitar los puentes térmicos.

- Zona IV - Muy fría: Las recomendaciones de diseño para la Zona $V$ tienen validez para esta zona pero en forma más acentuada. Por su parte en las viviendas al sur del paralelo $38^{\circ}$ es primordial el diseño urbano que posibilite el correcto asoleamiento de las viviendas y una adecuada protección del viento en los espacios comunes, zonas abiertas de recreación y circulaciones peatonales. La rigurosidad del clima determina la conveniencia de agrupamientos que permitan minimizar las superficies expuestas al exterior. Por otra parte 
las viviendas al norte del paralelo $38^{\circ}$ se encuentran en zonas con altos valores de amplitud térmica durante gran parte del año por lo que deberán preverse las medidas necesarias para conferir una mayor inercia térmica.

En cuanto a la radiación solar para cada una de las zonas bioambientales se detallan las orientaciones térmicas óptimas, regulares y desfavorables. En general, para las orientaciones cálidas las orientaciones térmicamente favorables coinciden con las de mínimo asoleamiento, mientras que para las regiones templadas y frías, las orientaciones con máximo asoleamiento son las más favorables. El asoleamiento directo que penetra a través de las ventanas proporciona beneficios psico-higiénicos, mejora la calidad de la iluminación natural y disminuye la demanda de energía convencional para calefacción. En edificios que aprovechan la radiación solar a través de sistemas solares pasivos, es necesario obtener por lo menos seis horas de asoleamiento para optimizar la captación de energía. Se recomienda utilizar protecciones solares para las zonas bioambientales I a IV, para las orientaciones SO-O-NO-N-NE-E-SE.

Por su parte la Norma también hace referencia a los distintos microclimas que se producen en todo el país:

- Microclima de ciudad.

- Microclima costero.

- Microclima de montaña.

- Microclima de valles.

- Microclima de bosques.

\subsubsection{IRAM 11.604}

La Norma IRAM 11.604 "Aislamiento térmico de edificios. (Verificación de sus condiciones higrotérmicas. Ahorro de energía en calefacción. Coeficiente volumétrico $G$ de pérdidas de calor. Cálculo y valores límites)" establece el método de cálculo del coeficiente volumétrico de pérdida de calor $\left(G_{c a l}\right)$; el cual permite evaluar el ahorro de energía en calefacción de edificios, que según esta Norma, estén destinados a vivienda.

El control de los efectos del clima en el interior de una vivienda depende en gran parte de los materiales empleados en la construcción, su combinación y del diseño de los espacios, los vanos y las distintas orientaciones. El cumplimiento de las transmitancias térmicas máximas admisibles de los elementos que componen la envolvente térmica no es un parámetro suficiente para controlar las pérdidas de calor totales del conjunto.

El coeficiente volumétrico de pérdida de calor $\left(G_{c a l}\right)$, es un parámetro global que pondera todos los elementos que intervienen en el proceso. El concepto de aislamiento térmico -desde el punto de vista de condiciones de habitabilidad y consumo de energía- incluye no sólo la obtención de una mejor calidad de aislación térmica de la envolvente, sino también la adecuada selección de la orientación y de la forma.

Esta norma fija los parámetros de ahorro de energía para calefaccionar edificios destinados a vivienda, a través de los valores máximos admisibles del coeficiente volumétrico de pérdidas de calor $\left(\mathrm{G}_{\mathrm{adm}}\right)$. Está pensada para ser aplicada en las zonas bioambientales III, IV, V y VI de la República Argentina, establecidas en la norma IRAM 11.603 así como en todas aquellas localidades de otras zonas donde se superan los 900 Grados Días de calefacción. La norma IRAM 11.603 indica los Grados Días para distintas localidades del país, correspondientes a las temperaturas base de calefacción de $18^{\circ} \mathrm{C}, 20^{\circ} \mathrm{C}$ y $22^{\circ} \mathrm{C}$.

La evaluación de una vivienda, a los efectos del ahorro energético, se realiza en función del coeficiente volumétrico de pérdida de calor $\left(G_{c a l}\right)$. Esta evaluación comprende una doble verificación:

- de la vivienda calefaccionada.

- del edificio calefaccionado en conjunto, del cual forma parte la vivienda calefaccionada. 
El coeficiente $G_{c a l}$ tiene en cuenta las pérdidas de calor a través de los cerramientos que componen la envolvente y las pérdidas por renovación de aire de los locales. Para cumplir con el ahorro energético requerido, el valor del $G_{\text {cal }}$ no debe exceder el valor máximo admisible $\left(G_{\text {adm }}\right)$ fijado.

En el período invernal, la temperatura base de calefacción adoptada es aquella que el sistema de calefacción es capaz de mantener en forma constante, medida en el centro del recinto a 1,50 m de altura. El proyectista de la vivienda, debe determinar la temperatura base de calefacción para realizar la verificación del $\mathrm{G}_{\mathrm{cal}}$, adoptando un valor mínimo de $18^{\circ} \mathrm{C}$.

Según lo establece la Norma, la envolvente del edificio calefaccionado no incluye a los locales de subsuelo y puede incluir o no a los locales no calefaccionados externos, de acuerdo con el criterio del proyectista. Sin embargo, en todos los casos el volumen a utilizar en el cálculo es el encerrado por la envolvente. Por su parte los locales contiguos a la envolvente, serán considerados en todos los casos como locales no calefaccionados. Además, en las zonas $\mathrm{V}$ y VI (fría y muy fría) no se admite el uso de carpinterías con vidrios simples.

Los valores máximos admisibles $\left(G_{a d m}\right)$ establecidos para el coeficiente $G_{\text {cal }}$ limitan las pérdidas de calor por unidad de volumen de la vivienda calefaccionada para mantener un determinado nivel de ahorro energético. Por lo tanto, para cumplir con este nivel de ahorro el $G_{c a l}$ del proyecto de la debe ser menor al $G_{a d m}$.

El coeficiente volumétrico $\mathrm{G}_{\mathrm{cal}}$ del edificio vivienda, se calcula con la siguiente fórmula:

$$
\mathrm{G}_{\text {cal }}=\frac{\sum \mathrm{K}_{\mathrm{m}} \mathrm{S}_{\mathrm{m}}+\sum \mathrm{K}_{\mathrm{v}} \mathrm{S}_{\mathrm{v}}+\sum \gamma \mathrm{K}_{\mathrm{r}} \mathrm{S}_{\mathrm{r}}+\operatorname{Per}_{\mathrm{p}}}{\mathrm{V}}+0,35 \mathrm{n}
$$

Donde:

[Ecuación IV - 11]

- $G_{\text {cal: }}$ coeficiente volumétrico del edificio vivienda calefaccionado, $\left(\mathrm{W} / \mathrm{m}^{3} \mathrm{~K}\right)$.

- $\mathrm{K}_{\mathrm{m}}$ : transmitancia térmica de cada uno de los elementos que componen los cerramientos opacos en contacto con el exterior, $\left(\mathrm{W} / \mathrm{m}^{2} \mathrm{~K}\right)$

- $\mathrm{S}_{\mathrm{m}}$ : área interior de los cerramientos opacos, $\left(\mathrm{m}^{2}\right)$.

- $\mathrm{K}_{\mathrm{v}}$ : transmitancia térmica de cada uno de los elementos que componen los cerramientos no opacos en contacto con el exterior, $\left(\mathrm{W} / \mathrm{m}^{2} \mathrm{~K}\right)$.

- $\mathrm{S}_{\mathrm{v}}$ : área interior de los cerramientos no opacos, $\left(\mathrm{m}^{2}\right)$.

- $\gamma \mathrm{K}_{\mathrm{r}}$ : transmitancia térmica corregida de cada uno de los elementos que componen los cerramientos opacos y no opacos, en contacto con locales no calefaccionados, $\left(\mathrm{W} / \mathrm{m}^{2} \mathrm{~K}\right)$.

- $\mathrm{S}_{\mathrm{r}}$ : área interior de los cerramientos opacos y no opacos, $\left(\mathrm{m}^{2}\right)$.

- $P_{\mathrm{er}}$ : perímetro del piso en contacto con el aire exterior, $(\mathrm{m})$.

- $P_{p}$ : pérdidas por piso en contacto con el terreno, $(\mathrm{W} / \mathrm{m})$.

- V: volumen interior del edificio vivienda, $\left(\mathrm{m}^{3}\right)$.

- 0,35: capacidad específica del aire del aire, $\left(\mathrm{Wh} / \mathrm{m}^{3} \mathrm{~K}\right)$.

- n: número de renovaciones de aire promedio por hora.

Los locales no calefaccionados en contacto con el exterior podrán incluirse o no dentro de la envolvente a criterio del proyectista. Sin embargo a la transmitancia térmica $\mathrm{K}_{\mathrm{r}}$ de los cerramientos de estos locales se les aplica un factor de corrección, según la siguiente fórmula:

$$
\gamma=\frac{\sum \mathrm{K}_{\mathrm{i}} \mathrm{S}_{\mathrm{i}}}{\sum \mathrm{K}_{\mathrm{i}} \mathrm{S}_{\mathrm{i}}+\sum \mathrm{K}_{\mathrm{r}} \mathrm{S}_{\mathrm{r}}}
$$

Donde:

- $\gamma$ : factor de corrección de la transmitancia térmica Kr. 
- $\mathrm{K}_{\mathrm{i}}$ : transmitancia térmica de los cerramientos del local no calefaccionado que no pertenecen a la envolvente, $\left(\mathrm{W} / \mathrm{m}^{2} \mathrm{~K}\right)$.

- $\mathrm{S}_{\mathrm{i}}$ : área interior de los cerramientos anteriores, $\left(\mathrm{m}^{2}\right)$.

- $\mathrm{K}_{\mathrm{r}}$ : transmitancia térmica de los cerramientos del local no calefaccionado que pertenecen a la envolvente, $\left(\mathrm{W} / \mathrm{m}^{2} \mathrm{~K}\right)$.

- $S_{r}$ : área interior de los cerramientos anteriores, $\left(\mathrm{m}^{2}\right)$.

O pueden adoptarse los siguientes valores:

$-\gamma=0,5$ (cerramientos que lindan con locales calefaccionados).

$-\gamma=1,0$ (cualquier otro caso).

Para el cálculo de las pérdidas por piso solamente se calculan las pérdidas por el piso en contacto con el suelo contiguo a la envolvente vertical, corresponden a la suma de las pérdidas desde el aire interior en contacto con el piso hacia el suelo y hacia el aire exterior. En el caso de locales calefaccionados en planta baja, adyacentes a locales no calefaccionados, las pérdidas por el piso corresponden al $50 \%$ de los valores establecidos por la Norma, para las zonas bioambientales III, IV, V y VI.

Los valores indicados en la Norma son promedios de flujos térmicos correspondientes a soluciones constructivas usuales en Argentina (natural, suelo de relleno, contrapiso de hormigón pobre y terminaciones varias).

La aislación perimetral corresponde a una capa de material aislante térmico con un $R=0,7$ $\mathrm{m}^{2} \mathrm{~K} / \mathrm{W}$, un ancho mínimo de $0,50 \mathrm{~m}$ y una densidad comprendida entre $25 \mathrm{~kg} / \mathrm{m}^{3}$ y $120 \mathrm{~kg} / \mathrm{m}^{3}$. Por su parte la aislación total corresponde a una capa de material aislante térmico con un $R=0,7$ $\mathrm{m}^{2} \mathrm{~K} / \mathrm{W}$ y una densidad comprendida entre $25 \mathrm{~kg} / \mathrm{m}^{3}$ y $120 \mathrm{~kg} / \mathrm{m}^{3}$, sobre toda la superficie del piso, colocada en forma horizontal. En localidades con suelos muy densos y alta transmitancia térmica, o con suelos muy húmedos o nivel de la napa freática muy cercano a la superficie, las pérdidas por el piso son mayores que las indicadas en la Norma. En estos casos se recomienda el uso de aislación perimetral en las zonas III y IV, y aislación en todo el piso en las zonas V y VI.

El número de renovaciones de aire requerido para el cálculo de $G_{\text {cal }}$ es 2 . Sin embargo si se dispone de los valores de infiltración de las carpinterías utilizadas, puede calcularse el valor de $n$, no obstante la ventilación natural y controlada de los locales de la vivienda debe cumplir con los requisitos mínimos de salubridad y confort $(n=0,7)$.

Por su parte la carga térmica de calefacción anual del edificio se determina con la siguiente fórmula:

Donde:

$$
\mathrm{Q}=\frac{24^{\circ} \mathrm{D} \mathrm{G}_{\text {cal }} \mathrm{V}}{1.000} \quad \text { [Ecuación IV - 13] }
$$

- Q: carga térmica de calefacción, (kWh).

- 24: tiempo de calefacción por día, (h).

- 'D: Grados Días de calefacción anual, $\left({ }^{\circ} \mathrm{C}\right)$.

- $G_{\text {cal }}$ : coeficiente volumétrico de pérdida de calor del edificio vivienda calefaccionado, $\left(\mathrm{W} / \mathrm{m}^{3} \mathrm{~K}\right)$.

- V: volumen interior del edificio, $\left(\mathrm{m}^{3}\right)$.

En el anexo normativo de esta Norma se mencionan ciertos aspectos que no son considerados en el cálculo del coeficiente $G_{\text {cal }}$ pero que sin embargo están directamente relacionados con el proceso de intercambio térmico entre un edificio y el exterior. Entre estos factores se destacan los siguientes:

- Humedad relativa.

- Producción de condensación superficial o intersticial.

- Inercia térmica de paredes y techos. 
- Ganancias térmicas por asoleamiento e iluminación artificial.

- Modalidades de uso, calor generado por procesos, variación del número de personas, etc.

- Efectos de "isla caliente".

- Parquización.

- Pérdidas por formas de ventilación no tenidas en cuenta.

Además se recomienda que el largo máximo de cañerías para agua caliente, sin aislación, sea de tres metros, entre el calefactor de agua y el grifo o válvula. Del mismo modo se recomienda aislar las instalaciones que contengan fluidos a más de $40^{\circ} \mathrm{C}$.

También se recomienda mejorar la calidad de las carpinterías de modo de controlar las pérdidas de calor por infiltración. En las zonas bioambientales $\mathrm{V}$ y VI, se recomienda el uso de vidrios dobles en las carpinterías.

En cuanto a la configuración del edificio, en aquellos con geometría compacta la reducción de la superficie de la envolvente en relación con la superficie de la planta contribuye a la disminución las pérdidas de calor a través de la envolvente.

También el aporte de calor de la energía solar puede reducir la demanda de combustibles convencionales. El diseño de las viviendas debe respetar las recomendaciones de asoleamiento y orientación establecidas en la Norma IRAM 11.603.

Los sistemas solares, mediante recursos de diseño o instalaciones de acondicionamiento térmico, permiten lograr un aporte de energía solar térmica mayor que el $25 \%$ de la demanda total de energía, de forma pasiva o activa. Los proyectos que implementan estos sistemas deben ser complementados con un detalle del cálculo del consumo energético y de las temperaturas internas de la vivienda. En todos los casos, los sistemas de captación deben tener orientación Norte $( \pm$ $20^{\circ}$ ), con una exposición mínima de cinco horas de sol en el solsticio de invierno.

Adicionalmente se recomienda que los edificios con sistemas solares deben incorporar niveles óptimos de aislación térmica (nivel A de la norma IRAM 11.605), y recursos de diseño para almacenar calor, evitar sobrecalentamiento y controlar la amplitud térmica interior, tales como:

- Materiales con gran capacidad térmica en el interior del edificio, especialmente en las superficies expuestas al sol;

- Ventilación natural o forzada para evacuar aire caliente;

- Sistemas de protección solar según latitud y condiciones meteorológicas.

\subsubsection{IRAM 11.605}

La Norma IRAM 11.605 "Acondicionamiento térmico de edificios. Condiciones de habitabilidad en edificios. (Valores máximos de transmitancia térmica en cerramientos opacos)" propone como su nombre lo indica, valores máximos de transmitancia térmica para los elementos de cerramiento de edificios. En esta Norma se introducen exigencias relativas a la protección que debe ser lograda a fin de garantizar ciertas condiciones ambientales de bienestar, así como también evitar la aparición de condensación de vapor de agua en las superficies interiores de la envolvente en todo el recinto habitable.

Sin embargo esta norma indica que para garantizar condiciones mínimas de habitabilidad junto con un razonable consumo de energía para climatización, además del cumplimiento de esta norma, se debe cumplir con lo establecido por las normas IRAM 11.603, IRAM 11.604 e IRAM 11.625 .

Esta norma establece tres niveles, los cuales corresponden a diferentes condiciones de confort higrotérmico (Nivel A, recomendado; Nivel B, medio; Nivel C, mínimo). Para los tres niveles de confort se establecen valores máximos de transmitancia térmica para las condiciones de invierno y verano. La verificación debe realizarse para ambas condiciones, excepto para las zonas bioambientales $\mathrm{V}$ y VI (IRAM 11.603) donde sólo se exige la verificación para la 
condición de invierno. Los valores máximos admisibles de transmitancia térmica que deben cumplir los muros y techos para los niveles establecidos, fueron determinados en función de la temperatura exterior de diseño de la localidad en la que se encuentra emplazada la vivienda (IRAM 11.603).

Por su parte para la condición de verano, los valores máximos admisibles de transmitancia térmica para los niveles establecidos están dados en función de la zona bioambiental correspondiente a la localidad en la que se encuentre la vivienda.

Para definir los niveles de confort higrotérmico se adoptaron los siguientes criterios:

- Invierno: verificar que no se produzca condensación superficial en función de la temperatura de diseño (Nivel $A=22^{\circ} \mathrm{C}$, Nivel $B=20^{\circ} \mathrm{C}$, Nivel $\mathrm{C}=18^{\circ} \mathrm{C}$ ). Verificar que se cumplan las condiciones de confort, en función de la diferencia entre la temperatura interior de diseño y la temperatura superficial del cerramiento (Nivel $A=1^{\circ} \mathrm{C}$; Nivel $B=2,5^{\circ} \mathrm{C}$; Nivel $\mathrm{C}=4^{\circ} \mathrm{C}$ ).

- Verano: verificar que se cumplan las condiciones de confort, en función de la diferencia entre la temperatura interior de diseño y la temperatura superficial del cerramiento (Nivel $A=1^{\circ} \mathrm{C}$; Nivel $B=2,5^{\circ} \mathrm{C}$; Nivel $\mathrm{C}=4^{\circ} \mathrm{C}$ ).

En todos los casos, la transmitancia térmica correspondiente a un puente térmico no debe ser mayor que el $50 \%$ de la transmitancia térmica del muro opaco. Asimismo existe un aumento en el riesgo de condensación en las aristas de los muros y en determinados locales de la vivienda; para evitar esto la norma establece que es necesario aumentar el nivel de aislamiento térmico en estos puntos. Se recomienda que la aislación térmica utilizada para compensar los puentes térmicos se ubiquen en el interior del cerramiento. Por su parte, para compensar puentes térmicos ocasionados por la presencia de una columna, la faja de aislación debe ser del doble del ancho de la columna.

\subsubsection{IRAM 11.659-2}

La Norma IRAM 11.659-2 "Acondicionamiento térmico de edificios. Verificación de sus condiciones higrotérmicas. Ahorro de energía en refrigeración (Parte 2: Edificios para viviendas)" establece el procedimiento para determinar la carga térmica total en refrigeración $\left(Q_{R}[W]\right) ;$ el método de cálculo del coeficiente volumétrico de refrigeración $\left(G_{R}\left[W / \mathrm{m}^{3}\right]\right)$, para evaluar el ahorro de energía en refrigeración de edificios; el método de cálculo de la carga térmica por unidad de superficie $\left(S_{R}\left[\mathrm{~W} / \mathrm{m}^{2}\right]\right)$, para evaluar el ahorro de energía en refrigeración de edificios; y los valores admisibles de $Q_{R}, G_{R}$ y $S_{R}$ para edificios de vivienda.

Esta norma es aplicable a edificios de vivienda para las zonas bioambientales I, II, III y IV (IRAM 11.603). También es aplicable para todas aquellas localidades donde se superen los $30^{\circ} \mathrm{C}$ de temperatura máxima de diseño (TDMX), o donde esté prevista la instalación de un acondicionador de aire.

La evaluación de un edificio o local a los efectos del ahorro energético, se realiza en función del denominado coeficiente volumétrico de refrigeración $\left(G_{R}\right)$. Esta evaluación comprende una triple verificación; del local o unidad habitacional refrigerada, del edificio refrigerado en conjunto, de la $\mathrm{G}_{\text {Radm }}$ de refrigeración, por tipo de edificio.

Los coeficientes $Q_{R}, G_{R}$ y $S_{R}$, tienen en cuenta las ganancias de calor a través de los cerramientos que componen la envolvente, las ganancias por renovación de aire de los locales, las ganancias debidas al sol, y las ganancias por fuentes internas del local o edificio.

Los valores máximos admisibles establecidos para $\mathrm{G}_{\text {Radm, }}$ limitan las ganancias de calor por unidad de volumen para mantener un determinado nivel de ahorro y uso racional de energía. Esta Norma establece valores máximos admisibles de $Q_{R}, G_{R}$ y $S_{R}$ para viviendas, para la TDMX correspondiente a la localidad de emplazamiento del edificio proyectado, o la más próxima con similar altura sobre el nivel del mar.

Se definen los distintos tipos de vivienda: 
- edificio tipo casa: volumen refrigerado entre $30 \mathrm{~m}^{3}$ y $1.000 \mathrm{~m}^{3}$.

- edificio tipo bloque: volumen refrigerado entre $1.000 \mathrm{~m}^{3}$ y $10.000 \mathrm{~m}^{3}$, la altura del edificio debe ser de tres pisos como máximo.

- edificio tipo torre: volumen refrigerado entre $1.000 \mathrm{~m}^{3}$ y $10.000 \mathrm{~m}^{3}$, la altura del edificio debe estar comprendida entre los cuatro y los treinta y cuatro pisos.

Según el valor del proyecto de la vivienda refrigerada, de acuerdo al tipo edilicio correspondiente, y por medio de la curva de TDMX, se obtiene el valor máximo admisible con los coeficientes admisibles de refrigeración $Q_{R}, G_{R}$ y $S_{R}$.

La carga térmica de un edificio de viviendas refrigerado, se calcula con la siguiente expresión:

$$
Q_{R}=Q_{c}+Q_{a}+Q_{s}+Q_{0}
$$

[Ecuación IV - 14]

Donde:

- $Q_{R}$ : carga térmica total en refrigeración, (W).

- $Q_{c}$ : carga térmica por conducción a través de la envolvente, (W).

- $Q_{a}$ : carga térmica por ventilación, (W).

- Qs: carga térmica solar, (W).

- $Q_{0}$ : carga térmica por fuentes internas, $(W)$.

Por su parte la carga térmica por conducción a través de la envolvente se calcula con la siguiente expresión:

$$
\mathrm{Q}_{\mathrm{C}}=\mathrm{K}_{\mathrm{i}} \cdot \mathrm{A}_{\mathrm{i}} \cdot\left(\mathrm{t}_{\mathrm{e}}-\mathrm{t}_{\mathrm{i}}\right) \text { [Ecuación IV - 15] }
$$

Donde:

- $Q_{C}$ : carga térmica por conducción, (W).

- K: transmitancia térmica del cerramiento, $\left(\mathrm{W} / \mathrm{m}^{2} \mathrm{~K}\right)$.

- A: superficie del cerramiento, $\left(\mathrm{m}^{2}\right)$.

- $\mathrm{t}_{\mathrm{e}}$ : temperatura exterior de diseño, $\left({ }^{\circ} \mathrm{C}\right)$.

- $\mathrm{t}_{\mathrm{i}}$ : temperatura de confort interior, $\left({ }^{\circ} \mathrm{C}\right)$.

Para la determinación de la carga térmica por ventilación se supone al edificio cerrado herméticamente. Sin embargo es necesario ventilar una parte del aire interior, por lo que debe introducirse al ambiente interior una cantidad de aire nuevo que el equipo de aire debe acondicionar. La carga térmica por ventilación se calcula con la siguiente expresión:

Donde:

$$
\left.\mathrm{Q}_{\mathrm{a}}=\mathrm{C}_{A R} \cdot(0,25 \cdot \Delta \mathrm{t}+0,61 \cdot \Delta \mathrm{w}) \quad \text { [Ecuación IV }-16\right]
$$

- $Q_{\mathrm{a}}$ : carga térmica por ventilación, (W).

- $\mathrm{C}_{\mathrm{AR}}$ : caudal de aire a renovar, $\left(\mathrm{m}^{3} / \mathrm{h}\right)$.

- 0,25: constante, $\left(\mathrm{W} / \mathrm{m}^{3}{ }^{\circ} \mathrm{C}\right)$;

- $\Delta$ t: diferencia entre la temperatura exterior y la temperatura interior, $\left({ }^{\circ} \mathrm{C}\right)$.

- 0,61: constante, $\left(\mathrm{W} / \mathrm{m}^{3} \mathrm{gr}\right)$.

- $\Delta$ w: diferencia entre la humedad específica del aire exterior y la humedad específica del aire interior, $(\mathrm{gr} / \mathrm{Kg})$.

Cuando existen superficies vidriadas en el local una parte de los aportes se debe a la radiación del sol que al atravesar el vidrio ingresa al mismo calentándolo. La radiación del sol varía con cada hora del día solar y también a lo largo de los meses del año. La carga térmica solar se calcula con la siguiente expresión:

$$
\left.\mathrm{Q}_{\mathrm{S}}=\sum_{\mathrm{i}=1}^{\mathrm{n}} \mathrm{A}_{\mathrm{i}} \cdot \mathrm{I}_{\mathrm{S}_{\mathrm{i}}} \cdot \mathrm{F}_{\mathrm{eS}} \quad \text { [Ecuación IV }-17\right]
$$

Donde: 
- Qs: carga térmica solar, (W).

- A: superficie vidriada, $\left(m^{2}\right)$.

- Is: intensidad de la radiación solar, $\left(\mathrm{W} / \mathrm{m}^{2}\right)$.

- $F_{\text {es: }}$ factor de exposición solar del vidrio.

En verano el aporte interno puede llegar a representar un aporte significativo respecto de la carga total. La carga térmica por fuentes internas se calcula con la siguiente expresión:

$$
\mathrm{Q}_{\mathrm{o}}=\mathrm{Q}_{\text {pers }}+\mathrm{Q}_{\text {ilum }}+\mathrm{Q}_{\text {equip }} \quad \text { [Ecuación IV - 18] }
$$

Donde:

- $Q_{0}$ : carga térmica por fuentes internas, (W).

- Q Q ocupan el local por el coeficiente de calor metabólico emitido por persona, (W).

- Qilum: carga térmica de debida a la iluminación. Determinada por la sumatoria de las fuentes internas de la iluminación artificial por la superficie a iluminar del local correspondiente a cada tipo de artefacto y por el coeficiente térmico según el tipo de iluminación utilizado, (W).

- Qequip: carga térmica debida al equipamiento, determinada por la sumatoria del calor emitido por los artefactos por la cantidad de artefactos, (W).

Luego, el valor del coeficiente volumétrico de refrigeración de la vivienda, se calcula con la siguiente expresión:

$$
G_{R}=\frac{Q_{R}}{V}
$$

[Ecuación IV - 19]

Donde:

- $G_{R}$ : coeficiente volumétrico de refrigeración, $\left(W / m^{3}\right)$.

- $Q_{R}$ : carga térmica total en refrigeración, (W).

- V: volumen de la vivienda refrigerada, $\left(\mathrm{m}^{3}\right)$.

Por su parte el valor del coeficiente de refrigeración por unidad de superficie de la vivienda o del edificio de viviendas, se calcula con la siguiente expresión:

Donde:

$$
S_{R}=\frac{Q_{R}}{A}
$$

[Ecuación IV - 20]

- $S_{R}$ : carga térmica por unidad de superficie, $\left(W / m^{2}\right)$.

- $Q_{R}$ : carga térmica total en refrigeración, (W).

- A: superficie de la vivienda o del edificio de viviendas, $\left(\mathrm{m}^{2}\right)$.

\subsubsection{IRAM 11.900}

La Norma IRAM 11.900 "Etiqueta de eficiencia energética de calefacción para edificios. Clasificación según la transmitancia térmica de la envolvente" propone, como su nombre lo indica, el etiquetado de eficiencia energética de calefacción para edificios, estableciendo la clasificación según la transmitancia térmica de la envolvente. La etiqueta de eficiencia energética tiene por objeto informar al consumidor sobre la eficiencia térmica de la envolvente de los edificios, de acuerdo con los parámetros y valores especificados.

Mediante la etiqueta se califica la eficiencia a través de un sistema comparativo, compuesto por ocho clases de eficiencia energética identificadas por las letras $A, B, C, D, E, F, G$ y H. La letra A corresponde a la envolvente más eficiente y la $\mathrm{H}$, a la menos eficiente.

La temperatura interior de diseño para todas las clases de eficiencia energética debe ser $20^{\circ} \mathrm{C}$. En el caso de edificios con varias unidades funcionales debe realizarse la verificación de manera individual. En ese caso, para los muros y entrepisos divisorios se adopta un salto térmico del $50 \%$ respecto de los cerramientos exteriores. 
El valor de la variación media ponderada de la temperatura $\left(\tau_{m}\right)$ se determina mediante la siguiente expresión:

$$
\tau_{m}=\frac{\sum\left(\tau_{i} \cdot S_{i}\right)}{\sum S_{i}}
$$

Donde:

$$
\tau_{i}=0,13 \frac{m^{2} \cdot K}{W} \cdot K_{i} \cdot \Delta t
$$

[Ecuación IV - 22]

$K_{i}$ : transmitancia térmica, según IRAM $11601 K_{i}=1 / R_{t}\left(\mathrm{~W} / \mathrm{m}^{2} \mathrm{~K}\right)$.

$\Delta t$ : diferencia de Temperatura de Diseño Interior y Exterior $\left({ }^{\circ} \mathrm{C}\right)$. En el caso de techos, $\Delta t=T_{\text {int }}-$ TDMN $+8^{\circ} \mathrm{C}\left({ }^{\circ} \mathrm{C}\right)$. La temperatura interior $\left(T_{\text {int }}\right)$ es $20^{\circ} \mathrm{C}$ y la temperatura exterior (TDMN) se obtiene de la IRAM 11.603, para condiciones de invierno.

$S_{i}$ : superficie de cada uno de los componentes de la envolvente $\left(\mathrm{m}^{2}\right)$.

Por su parte la transmitancia térmica media ponderada $\left(K_{m}^{\prime}\right)$ en $\mathrm{W} / \mathrm{m}^{2} \mathrm{~K}$, se determina con la siguiente expresión:

$$
K_{m}^{\prime}=\frac{\sum_{1}^{n}\left(K_{i} \cdot S_{i}\right)}{\sum_{1}^{n} S_{i}}
$$

\section{[Ecuación IV - 23]}

Donde:

$K_{i}$ : transmitancia térmica, según IRAM $11.601 K_{i}=1 / R_{t},\left(\mathrm{~W} / \mathrm{m}^{2} \mathrm{~K}\right)$.

$S_{i}$ : superficie de cada uno de los componentes de la envolvente, $\left(\mathrm{m}^{2}\right)$.

Luego, de acuerdo a los resultados obtenidos, se clasifica el edificio teniendo en cuenta los valores propuestos en la siguiente tabla:

\begin{tabular}{|c|c|}
\hline $\begin{array}{c}\text { Clases de } \\
\text { eficiencia } \\
\text { energética }\end{array}$ & Condición $^{1)}$ \\
\hline $\mathrm{A}$ & $\tau_{m} \leq 1{ }^{\circ} \mathrm{C}$ \\
\hline $\mathrm{B}$ & $1{ }^{\circ} \mathrm{C}<\tau_{m} \leq 1,5^{\circ} \mathrm{C}$ \\
\hline $\mathrm{C}$ & $1,5^{\circ} \mathrm{C}<\tau_{m} \leq 2^{\circ} \mathrm{C}$ \\
\hline $\mathrm{D}$ & $2{ }^{\circ} \mathrm{C}<\tau_{m} \leq 2,5^{\circ} \mathrm{C}$ \\
\hline $\mathrm{E}$ & $2,5^{\circ} \mathrm{C}<\tau_{m} \leq 3^{\circ} \mathrm{C}$ \\
\hline $\mathrm{F}$ & $3{ }^{\circ} \mathrm{C}<\tau_{m} \leq 3,5^{\circ} \mathrm{C}$ \\
\hline $\mathrm{G}$ & $3,5^{\circ} \mathrm{C}<\tau_{m} \leq 4{ }^{\circ} \mathrm{C}$ \\
\hline $\mathrm{H}$ & $\tau_{m}>4{ }^{\circ} \mathrm{C}$ \\
\hline
\end{tabular}

Tabla IV - 1: Valores de $\tau_{m}$ para las clases de eficiencia energética en calefacción de edificios propuestos por la Norma IRAM 11.900 - Fuente: Norma IRAM 11.900. Instituto Argentino de Normalización y

Certificación. Buenos Aires, Argentina. 2010. 


\section{CAPÍTULO $V$ \\ ESTUDIO DE CASOS}

\subsection{Introducción}

La siguiente Tesis Doctoral se centra en el desarrollo de auditorías energéticas realizadas a edificios de propiedad horizontal en altura del Área Metropolitana de Buenos Aires, incluyendo en este conglomerado urbano a la ciudad de La Plata.

En esta región se concentra casi el $32 \%$ de la población del país. La aglomeración que tiene lugar en las áreas metropolitanas favorece la generación del efecto de "Isla de calor", el cual implica una suba de entre $3^{\circ} \mathrm{C}$ y $4^{\circ} \mathrm{C}$ por sobre las zonas circundantes (Czajkowski, J.; 2009).

El área analizada se encuentra en la Zona Bioclimática IIlb de la República Argentina, clima templado - cálido húmedo. A pesar de sus características particulares el clima templado en nuestro país se distingue por veranos e inviernos marcados pero no rigurosos. Su característica principal es el alto nivel de humedad durante todo el año, con amplitudes térmicas menores a $14^{\circ} \mathrm{C}$. En verano las temperaturas medias varían entre los 20 y los $26^{\circ} \mathrm{C}$, con máximas que superan los $30^{\circ} \mathrm{C}$. En invierno las temperaturas medias varían entre los 8 y los $12^{\circ} \mathrm{C}$, con mínimas entre los 5 y los $8^{\circ} \mathrm{C}$. Por su parte, la humedad relativa media varía entre el 70 y el $85 \%$ (IRAM; 2011).

Para esta zona la Norma IRAM 11.603 recomienda utilizar colores claros y doble aislamiento térmico en techos con respecto a los muros, fachadas ventiladas en grandes edificios, ventanas con DVH y protección solar móvil. Asimismo se recomienda aprovechar los vientos predominantes y proteger las carpinterías que dan al S-SE por las fuertes tormentas. La orientación óptima es la NNO-N-NNE porque facilita la protección solar en verano y el asoleamiento en invierno. Además, según el climograma de Givoni durante gran parte del año debe tenerse en cuenta el uso de sistemas solares pasivos (Gráfico V - 1).

Siguiendo el protocolo de auditorías energéticas utilizado en el Laboratorio de Arquitectura y Hábitat Sustentable (LAyHS) pudo estudiarse el comportamiento higrotérmico de distintas unidades funcionales de los edificios analizados en dos períodos; invierno y verano. Para complementar los datos obtenidos con las mediciones fue necesario realizar una encuesta sobre el confort térmico de las distintas unidades analizadas en los edificios. 


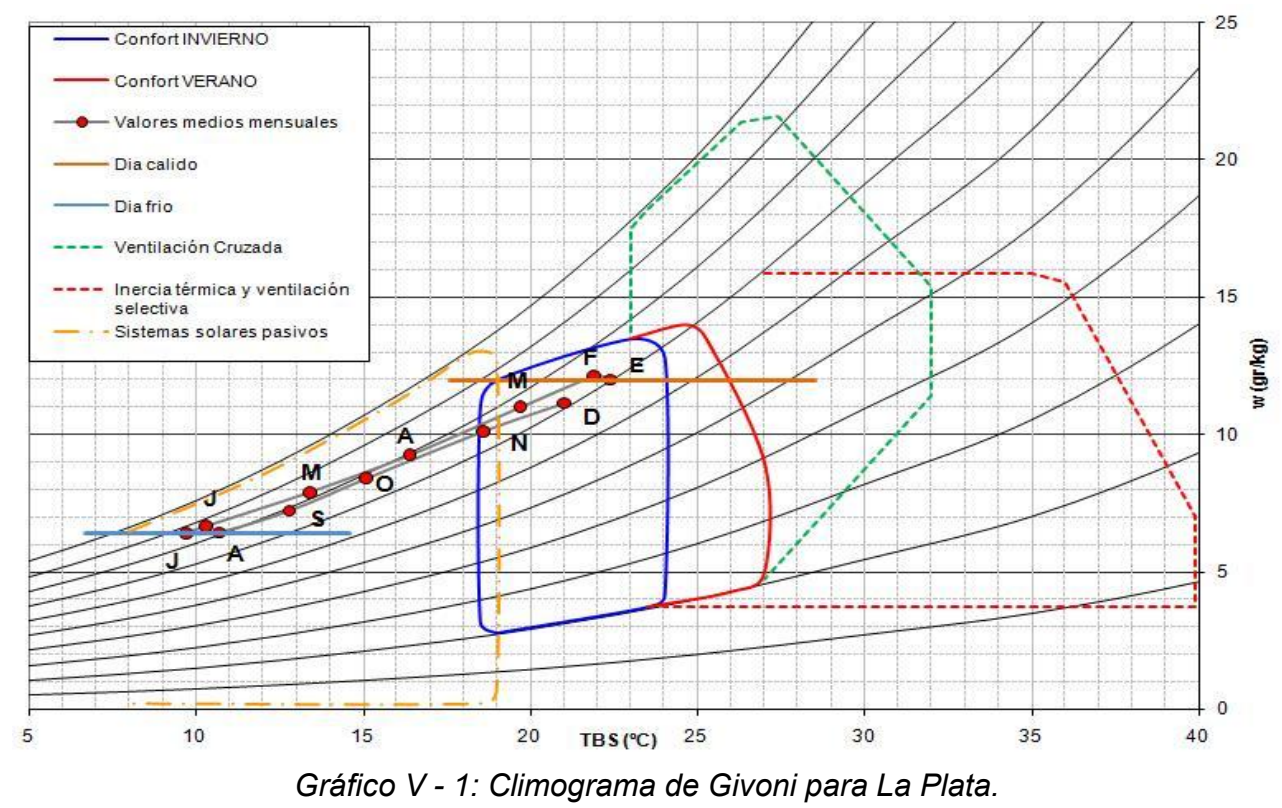

Previo a la realización de las auditorías energéticas se realizó un estudio acerca de la evolución del tipo edilicio en nuestro país; se estudiaron cuestiones relacionadas con la envolvente del edificio, el consumo de energía para acondicionamiento interior y con el comportamiento térmico - energético, poniendo especial atención a la actual respuesta a estas cuestiones. Para ello se estudiaron distintos edificios en altura cuya información se extrajo de revistas técnicas, luego estos ejemplos fueron comparados con una muestra tomada de un trabajo previo desarrollado en lo que en aquel entonces era la Cátedra de Instalaciones $\mathrm{N}^{\circ} 2$ de la FAU - UNLP (Corredera, C.; 2003).

El objetivo de este trabajo fue realizar un análisis comparativo del comportamiento energético de diferentes casos de edificios en altura, de viviendas y de oficinas, teniendo en cuenta las diversas variables que intervienen en su materialización. Se buscó generar un antecedente que permitiera analizar y comprender cuales son las características principales del tipo edilicio.

Inicialmente se tomó una muestra de seis edificios -tres de vivienda y tres de oficina- con características constructivas diversas. La elección de los ejemplos se hizo al azar entre diversos medios gráficos especializados en arquitectura. Se buscó que los distintos ejemplos elegidos presentaran diversidad en las formas de aventanamiento y de materialización de la envolvente, diversidad en la relación de superficies acristaladas y opacas, y en los sistemas de protección solar entre otras cuestiones. Al mismo tiempo se realizó un análisis comparativo con la muestra tomada del trabajo mencionado con anterioridad (Tabla $\mathrm{V}-1$ ).

\begin{tabular}{|l|c|c|c|c|c|c|c|}
\hline Edificio & Area env. $\left(\mathbf{m}^{2}\right)$ & Superficie $\left(\mathbf{m}^{2}\right)$ & Volumen $\left(\mathbf{m}^{3}\right)$ & F. forma (adim) & $\mathbf{G}\left(\mathbf{W} /{ }^{\circ} \mathbf{C}\right)$ & $Q_{\text {cal }}(\mathbf{K W h} /$ año) & $Q_{\text {s cal }}\left(\mathbf{K W h} / \mathbf{m}^{2} /\right.$ año) \\
\hline Comega & 19045 & 13357 & 40072 & 0,48 & 4,00 & 909212 & 68 \\
\hline Chacofi & 16975 & 10736 & 32208 & 0,52 & 4,23 & 972647 & 91 \\
\hline Conurban & 22776 & 15118 & 45354 & 0,50 & 4,14 & 1377589 & 91 \\
\hline Esmeralda 116 & 9358 & 26555 & 79666 & 0,12 & 4,14 & 1966292 & 74 \\
\hline IBM & 32642 & 18067 & 54201 & 0,60 & 6,48 & 1799576 & 100 \\
\hline Libertad 565 & 3848 & 1323 & 3970 & 0,97 & 3,64 & 213527 & 161 \\
\hline Madero & 24153 & 25142 & 75426 & 0,32 & 4,77 & 1815493 & 72 \\
\hline Malecom & 8761 & 5045 & 15136 & 0,58 & 4,16 & 532326 & 106 \\
\hline Corrientes 1427 & 7451 & 4219 & 12656 & 0,59 & 4,48 & 403810 & 96 \\
\hline Libertad 731 & 7582 & 5619 & 16858 & 0,45 & 2,52 & 544560 & 97 \\
\hline La Plata & 14479 & 12681 & 38043 & 0,38 & 4,20 & 1018820 & 80 \\
\hline
\end{tabular}

Tabla V - 1: Cuadro síntesis muestra previa. Fuente: Corredera, C.; Czajkowski, J. (2003) 
Reunida la muestra; se determinaron las características de la envolvente a partir de la documentación gráfica y de las memorias técnicas de los edificios, extraídas de medios gráficos especializados. Al mismo tiempo se profundizó en el análisis del diseño formal de los distintos ejemplos, su relación con la calidad térmica edilicia y el uso racional de la energía (Figuras $\mathrm{V}$ - 1 a 6). Para el análisis energético de los casos seleccionados se utilizó el programa AuditCAD (Czajkowski, J.; 1999). Dicho programa permite analizar el comportamiento térmico y energético del edificio mensualmente en estado estacionario, al tiempo que determina indicadores formales basados en las Normas IRAM. Posteriormente los resultados fueron exportados a Excel para su análisis estadístico.

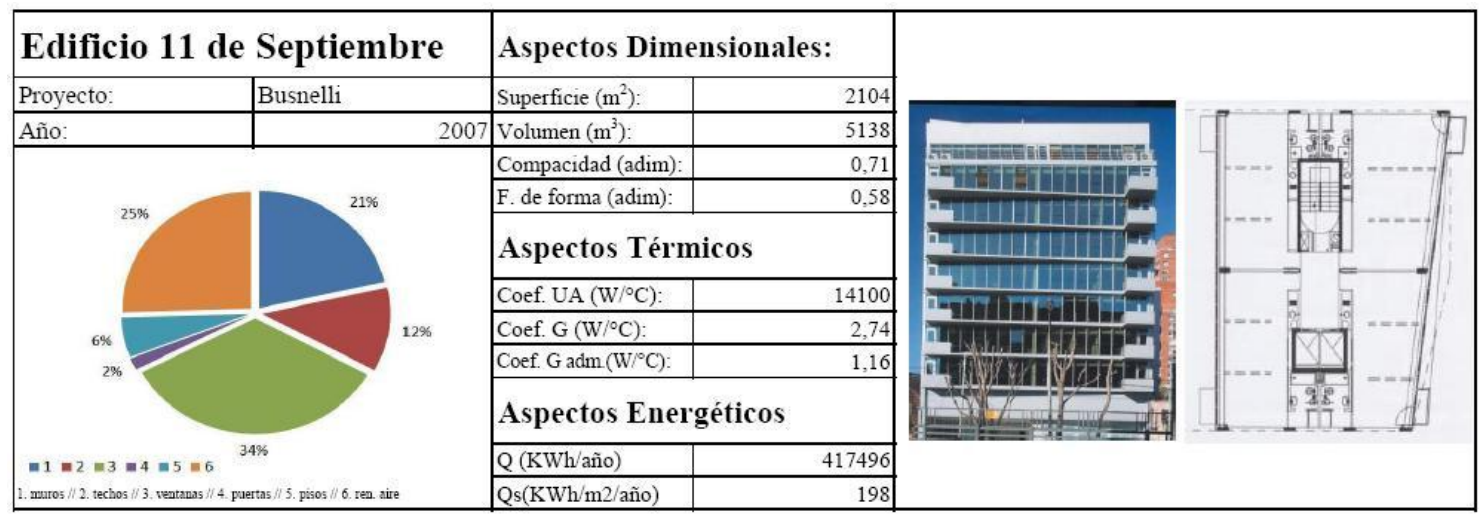

Figura V-1: Descripción básica del edificio.

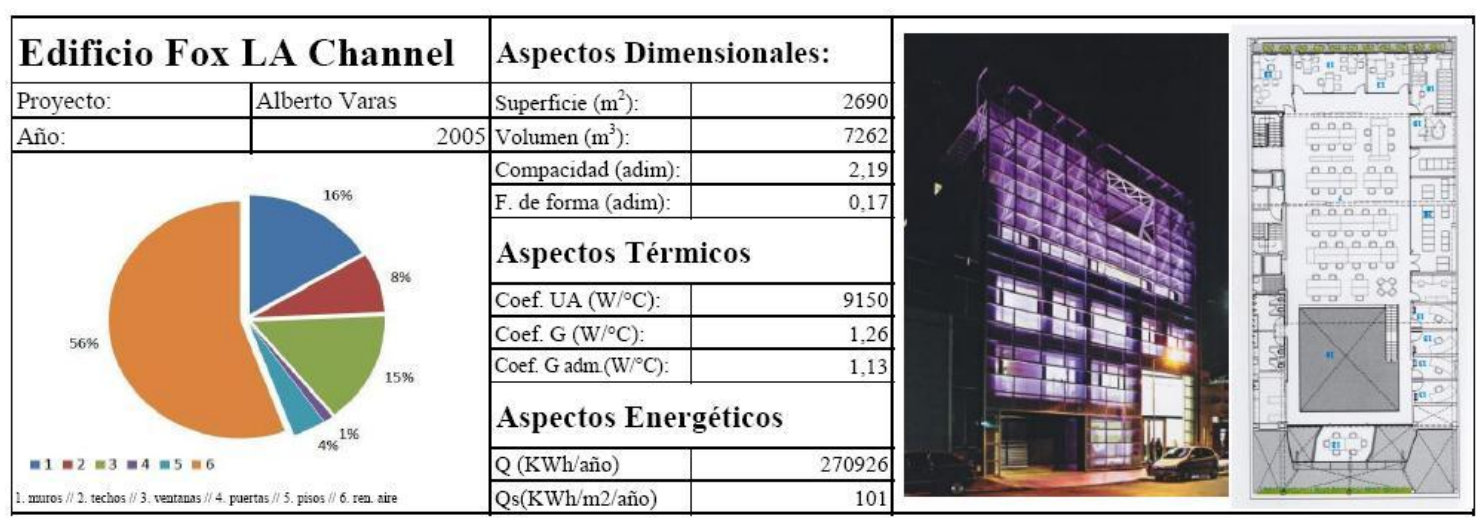

Figura V - 2: Descripción básica del edificio.

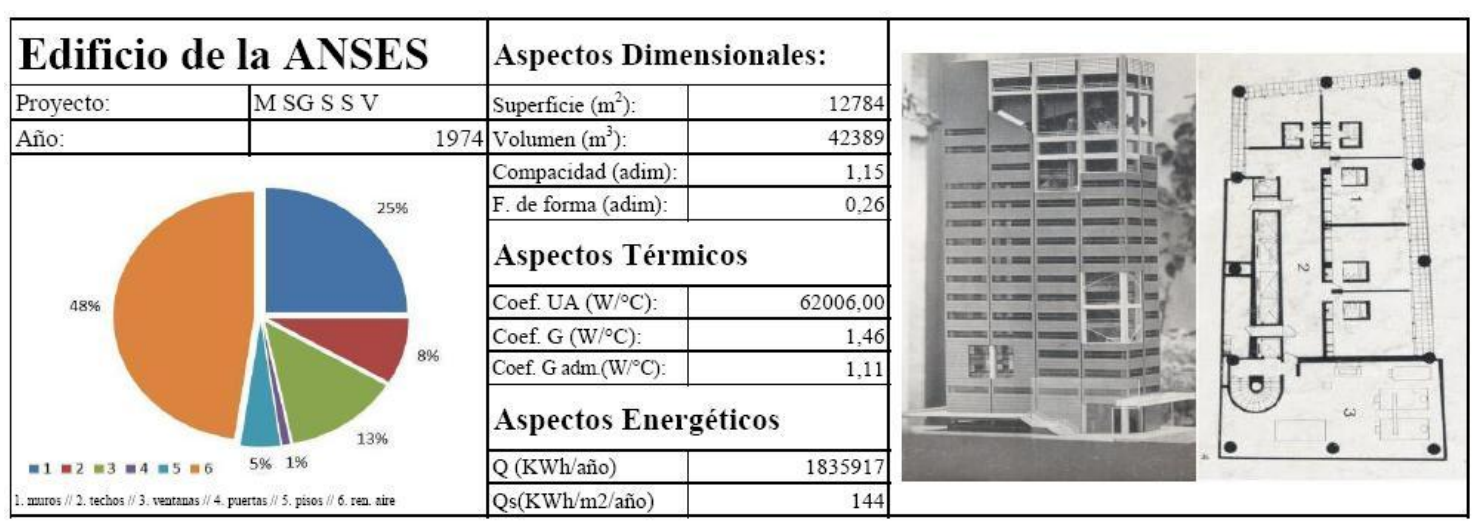

Figura V - 3: Descripción básica del edificio. 


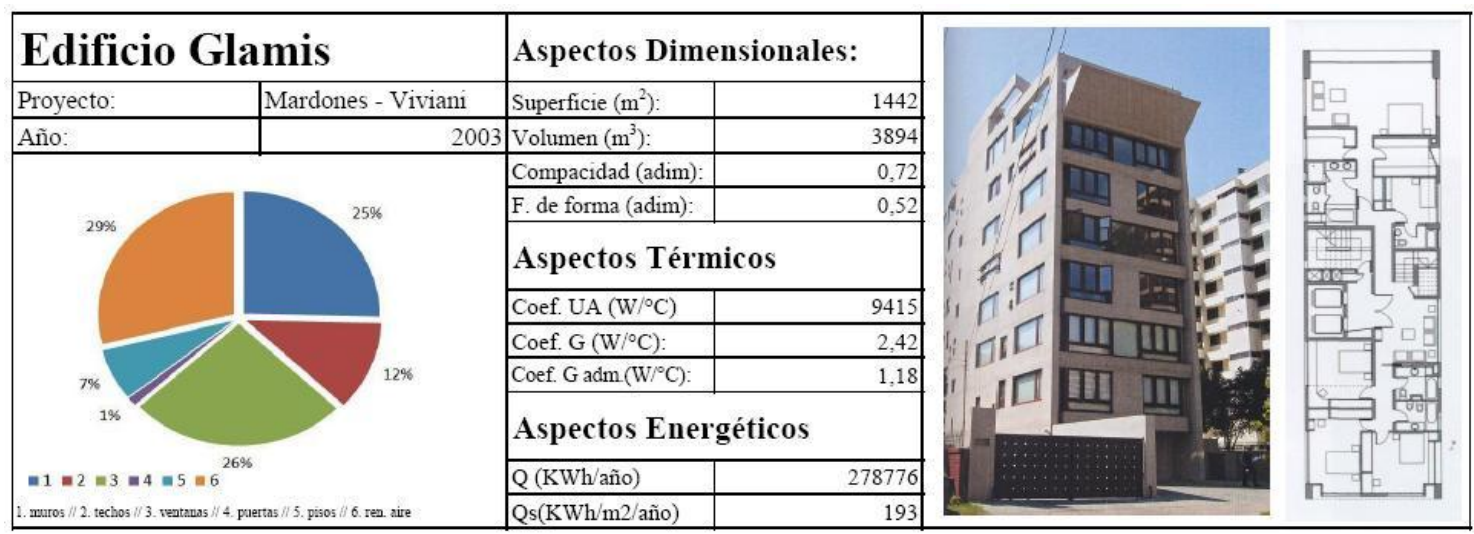

Figura V - 4: Descripción básica del edificio.

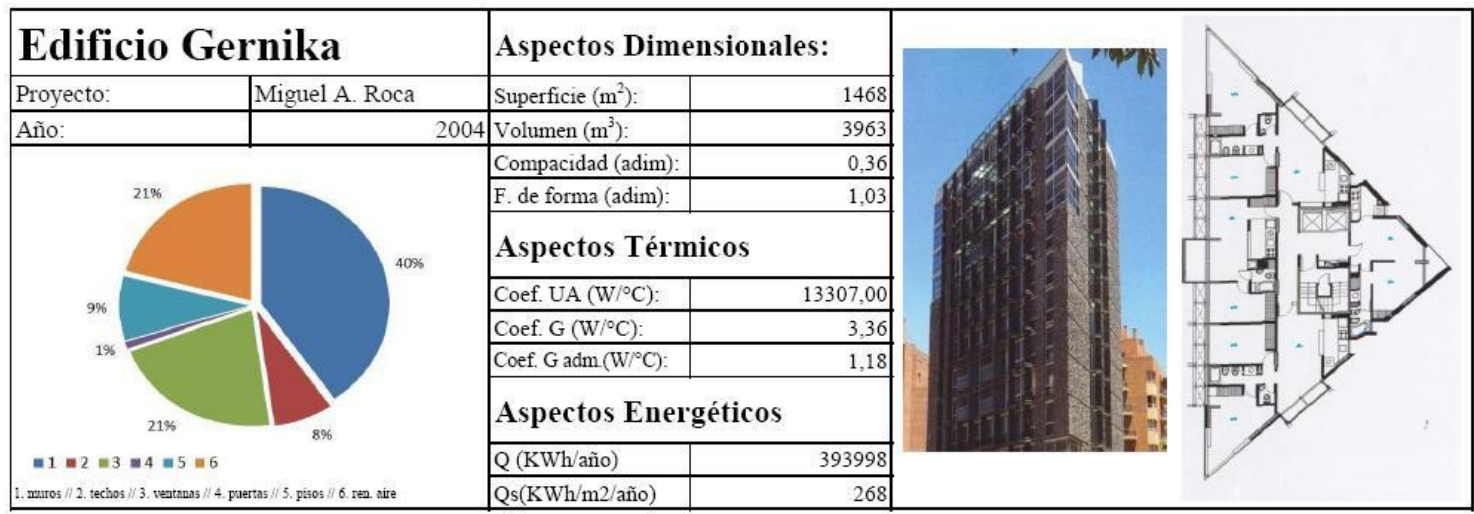

Figura V - 5: Descripción básica del edificio.

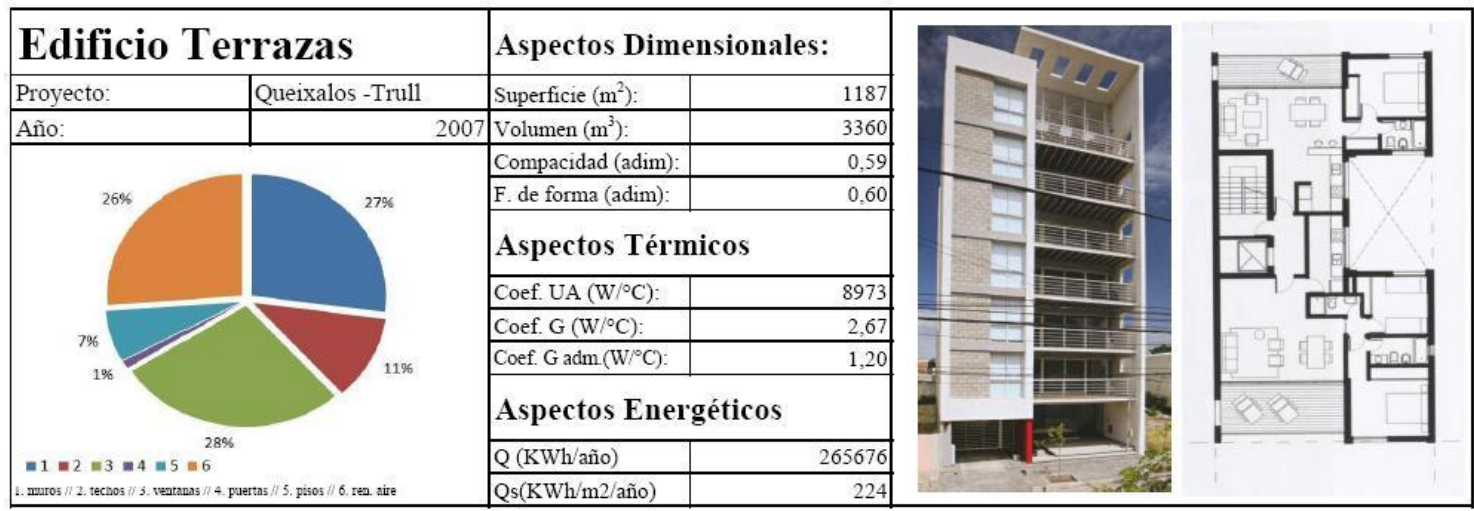

Figura V - 6: Descripción básica del edificio.

El gráfico V - 2 muestra la relación entre el volumen a calefaccionar y la carga térmica de los edificios analizados, y los compara con la muestra del trabajo previo. Las líneas de tendencia de cada uno de los trabajos son similares y las expresiones resultantes permiten conocer la demanda anual de energía en calefacción a partir del volumen calefaccionado con un $R^{2}=0,98$ para la muestra seleccionada y $\mathrm{R}^{2}=0,94$ para la muestra previa.

$$
\begin{aligned}
& Q_{\text {cal }}=39,749 \times \text { volumen }+139.849(\mathrm{kWh} / \mathrm{año}) \text { [Ecuación } \mathrm{V}-1 \text { ] } \\
& \mathrm{Q}_{\text {cal }}^{\prime}=23,788 \times \text { volumen }+155.940(\mathrm{kWh} / \mathrm{año}) \text { [Ecuación } \mathrm{V}-2 \text { ] }
\end{aligned}
$$




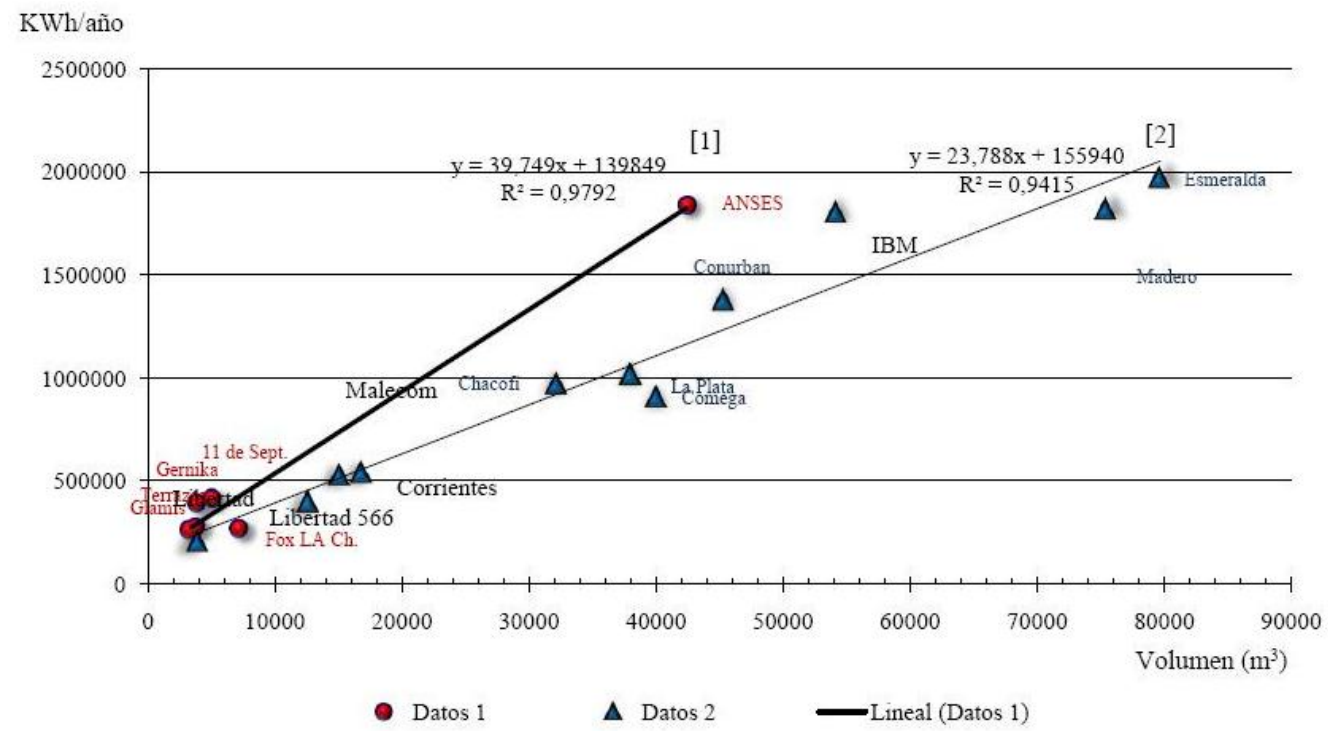

Gráfico V - 2: Relación entre volumen a calefaccionado y carga térmica anual en calefacción. Comparación con un trabajo previo.

La mayor pendiente de la expresión [1], que se corresponde con casos de construcción reciente, muestra un crecimiento en la demanda de energía en calefacción. Esto podría deberse al aumento de la ineficiencia energética en los últimos años.

El gráfico $V$ - 3 relaciona el volumen de los diferentes edificios con el coeficiente $G_{\text {cal }}$ $\left[\mathrm{W} / \mathrm{m}^{3}{ }^{3} \mathrm{~K}\right]$ de los mismos (IRAM 11.604). Puede verse como en todos los casos el $\mathrm{G}_{\text {cal }}$ de los edificios es superior al $G_{a d m}$, con lo cual ningún caso -incluso los de la muestra previa- cumple con las Normas IRAM, que de hecho sólo son de cumplimiento obligatorio la Ciudad de Rosario y en la Provincia de Buenos Aires, en donde la Ley 13.059/03 y su decreto reglamentario 1.030 establecen las exigencias mínimas de eficiencia energética y confort higrotérmico que debe cumplir toda obra de arquitectura. La correlación entre el volumen calefaccionado y el $G_{\text {cal }}$ es baja para ambas muestras $\left(R^{2}=0,352\right.$ y $\left.R^{2}=0,195\right)$. Esto demuestra la ausencia de regulación acerca de la calidad energética edilicia en los Códigos de Edificación. Cabe destacar que la relación vidriado-opaco de la muestra seleccionada es menor a las del trabajo de previo; esto llevaría a que los $\mathrm{G}_{\mathrm{cal}}$ sean sensiblemente más bajos y cercanos a los valores admisibles de la Norma IRAM.

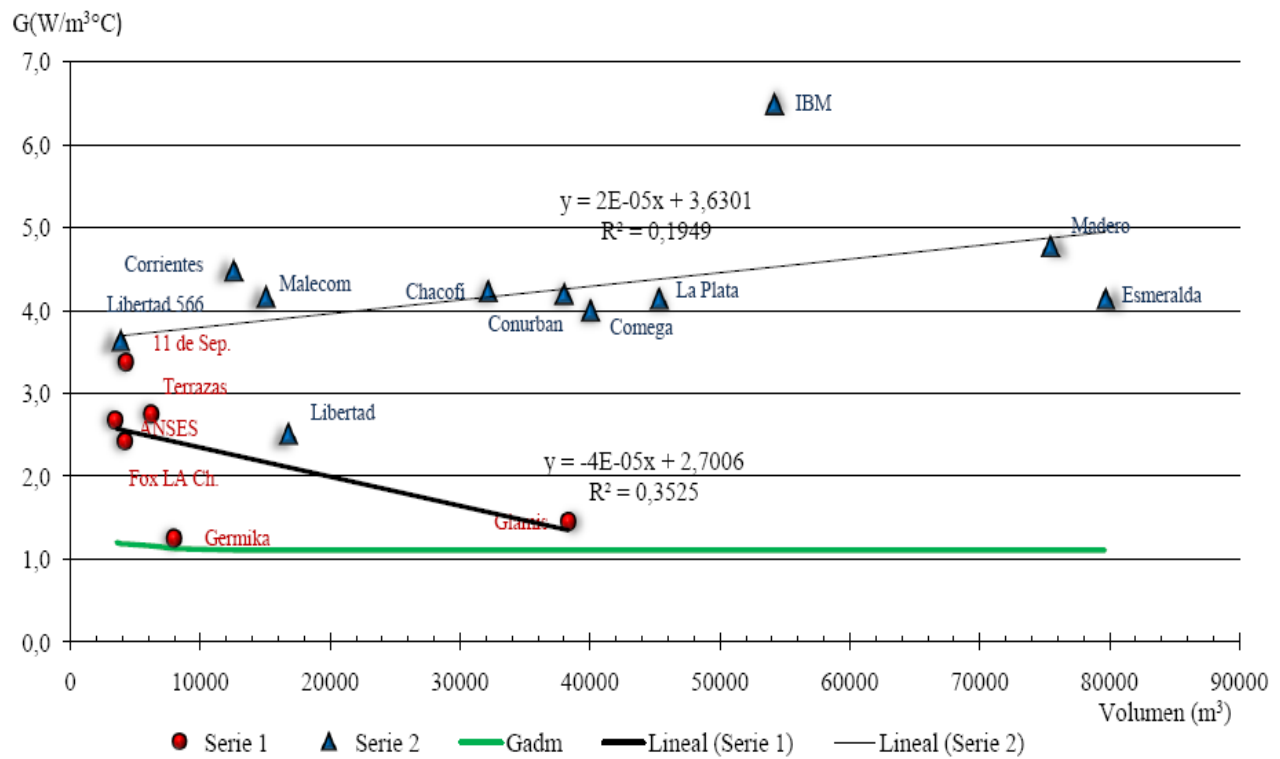

Gráfico V - 3: Relación entre volumen climatizado y Coeficiente $G_{c a l}$ - Comparación con trabajo previo. 
Este trabajo permitió tener una lectura aproximada acerca del comportamiento higrotérmico y energético del tipo edilicio, distinguiendo entre edificios destinados a oficinas o viviendas. La decisión de agrupar a los edificios según el destino (viviendas u oficinas) se debió principalmente a que si bien pertenecen a un mismo tipo y comparten características generales, presentan diferencias morfológicas (disposición del núcleo vertical, relación superficie vidriado - opaco, espacios semicubiertos, etc.), tecnológicas (tipo de aventanamiento, protecciones solares, etc.), y principalmente en lo que respecta al funcionamiento (número de ocupantes y régimen horario, uso de energía eléctrica para iluminación, equipamiento eléctrico, acondicionamiento térmico, etc.).

Al respecto cabe destacar que las cuestiones relativas al funcionamiento de un edificio son determinantes al momento de evaluar el comportamiento energético del mismo. Esta cuestión está directamente relacionada con la técnica del Benchmarking, por la cual se mide el rendimiento de un sistema, en este caso de un edificio, en comparación con otro de referencia. Siendo que para un mismo tipo edilicio, la variable función impacta en la intensidad de uso en lo que respecta al grado de ocupación, potencia de iluminación, potencia de equipamiento eléctrico, etc., es claro que para un mejor análisis deben distinguirse los casos según el destino.

Uno de los principales inconvenientes que se encontraron en la normativa argentina es que actualmente se utilizan los mismos parámetros para medir edificios con diversas morfologías y lo que es aún más grave, con diferentes destinos (escuelas, oficinas, viviendas, hospitales, etc.). La propuesta de mejora para la Norma IRAM 11.604 elaborada en el LAyHS en el año 2012, y que aún se encuentra en discusión, plantea la necesidad de determinar distintas curvas para el coeficiente $G_{\text {cal }}$, la carga térmica de calefacción $\left(Q_{\text {cal }}\right)$ y la carga térmica de calefacción por unidad de superficie $\left(S_{\text {cal }}\right)$, para los diferentes tipos edilicios (placa, torre, etc.) pero también para los distintos usos (viviendas, oficinas, escuelas, hospitales, etc.).

Esta misma propuesta también se pensó para la Norma IRAM 11.659-2 en la que se determinan los valores de Carga térmica total de verano $\left(Q_{R}\right)$, de la cual se derivan el Coeficiente de refrigeración por unidad de superficie $\left(S_{R}\right)$ y el Coeficiente volumétrico de refrigeración $\left(G_{R}\right)$. Estos valores fueron calculados teniendo en cuenta factores de ocupación, equipamiento e iluminación aplicables a viviendas pero se aplican a todo edificio de ocupación humana. Para el caso de edificios de oficinas, donde hay una mayor concentración de personas y donde el uso de artefactos eléctricos y de iluminación es mucho más intensivo, deberían considerarse valores diferenciados.

\subsection{Edificios de viviendas}

El trabajo de campo abordó el estudio particularizado de cuatro edificios de propiedad horizontal en altura destinados a viviendas, ubicados en la ciudad de La Plata. La elección de los casos se basó en la búsqueda de ejemplos que fueran representativos de la realidad constructiva actual en el AMBA (Rosenfeld, E. et Al.; 1986, 1988, 1989; Veigas, G. et Al.; 2007; Evans, J. M.; 2012) e incluso en el país (Gonzalo, G.; 1999 - Baso, M. et Al.; 2001). No obstante un condicionante importante al momento de elegir los casos fue la posibilidad de tener acceso a toda la información. Tal como se comentará en el capítulo siguiente para la realización de las auditorias energéticas fue necesario no sólo tomar los consumos de gas natural y energía eléctrica de todas las unidades que conformaban el edificio sino que además debió medirse el comportamiento higrotérmico de las unidades a las que se podía acceder. En estas unidades además se realizaron encuestas socio-energéticas. Al respecto cabe destacar que algunos casos debieron ser descartados ya que no fue posible completar la etapa de análisis por diferentes motivos.

\subsubsection{Caso A}

El edificio fue construido en el año 1999, sobre un lote de 10x60m. Se compone de planta baja y diez plantas tipo. En la planta baja se encuentran los espacios destinados a los 
medidores de energía eléctrica y gas natural, un depósito, el hall de acceso, una oficina y espacio libre destinado a cocheras. Las plantas del primer al noveno piso se dividen en dos departamentos de uno y dos dormitorios, de 40 y $60 \mathrm{~m}^{2}$ respectivamente. Por su parte en el último nivel se encuentra un único departamento de tres dormitorios, de $100 \mathrm{~m}^{2}$ (Figuras $\mathrm{V}-7$ y 8).

Su tecnología constructiva es convencional con estructura de hormigón armado y muros de cerramiento exterior de ladrillos huecos de $18 \times 18 \times 33 \mathrm{~cm}$, sin aislamiento higrotérmico adicional. Por su parte los cerramientos interiores se han materializado con ladrillos huecos de $12 \times 18 \times 33 \mathrm{~cm}$, los que separan a los departamentos entre sí y con las áreas comunes, y con ladrillos de $8 \times 18 \times 33 \mathrm{~cm}$ aquellos que dividen los ambientes interiores de cada departamento. Las carpinterías son de simple vidriado con perfilería de aluminio, sin protección solar las que se disponen sobre la fachada principal y con cortinas de enrollar de pvc, aquellas dispuestas sobre el contrafrente.

Como sistema de calefacción los departamentos de $60 \mathrm{~m}^{2}$ cuentan con una estufa de tiro balanceado de $4.000 \mathrm{Kcal}$ de potencia y aquellos de $40 \mathrm{~m}^{2}$ cuentan con una estufa de tiro balanceado de $3.000 \mathrm{Kcal}$. Por su parte el sistema de refrigeración de los distintos departamentos se dejó a criterio de cada uno de los habitantes. De los departamentos analizados uno $\left(1^{\circ} \mathrm{B}\right)$ ha optado por un equipo de aire acondicionado tipo Split de $1.200 \mathrm{~W}$ de potencia en la zona del estar-comedor y ventiladores de techo en la zona de dormitorios, mientras que el otro $\left(3^{\circ} \mathrm{B}\right)$ ha optado por colocar ventiladores de techos en todos los locales de primera clase.

La fachada principal del edificio, sobre la que se ubican las salas de estar y los comedores de las distintas unidades funcionales, presenta orientación noroeste. Las áreas de servicios (cocinas y baños) se ubican en el centro del edificio, junto al núcleo vertical compuesto por un ascensor y una escalera de incendios. Sobre el contrafrente del edificio, de orientación sureste, se ubican los dormitorios. Esta orientación es la más desfavorable para esta zona del país. Sobre el cuadrante Sur-Sureste la región recibe la influencia de la Sudestada; este fenómeno meteorológico consiste en una rápida rotación de vientos fríos que produce un descenso de temperaturas y fuertes lluvias durante gran parte del año (IRAM 11.603). La Figura V - 9 muestra la descripción básica del edificio, en ella puede verse que los mayores porcentajes de pérdidas de calor se dan a través de muros, ventanas y renovaciones de aire.
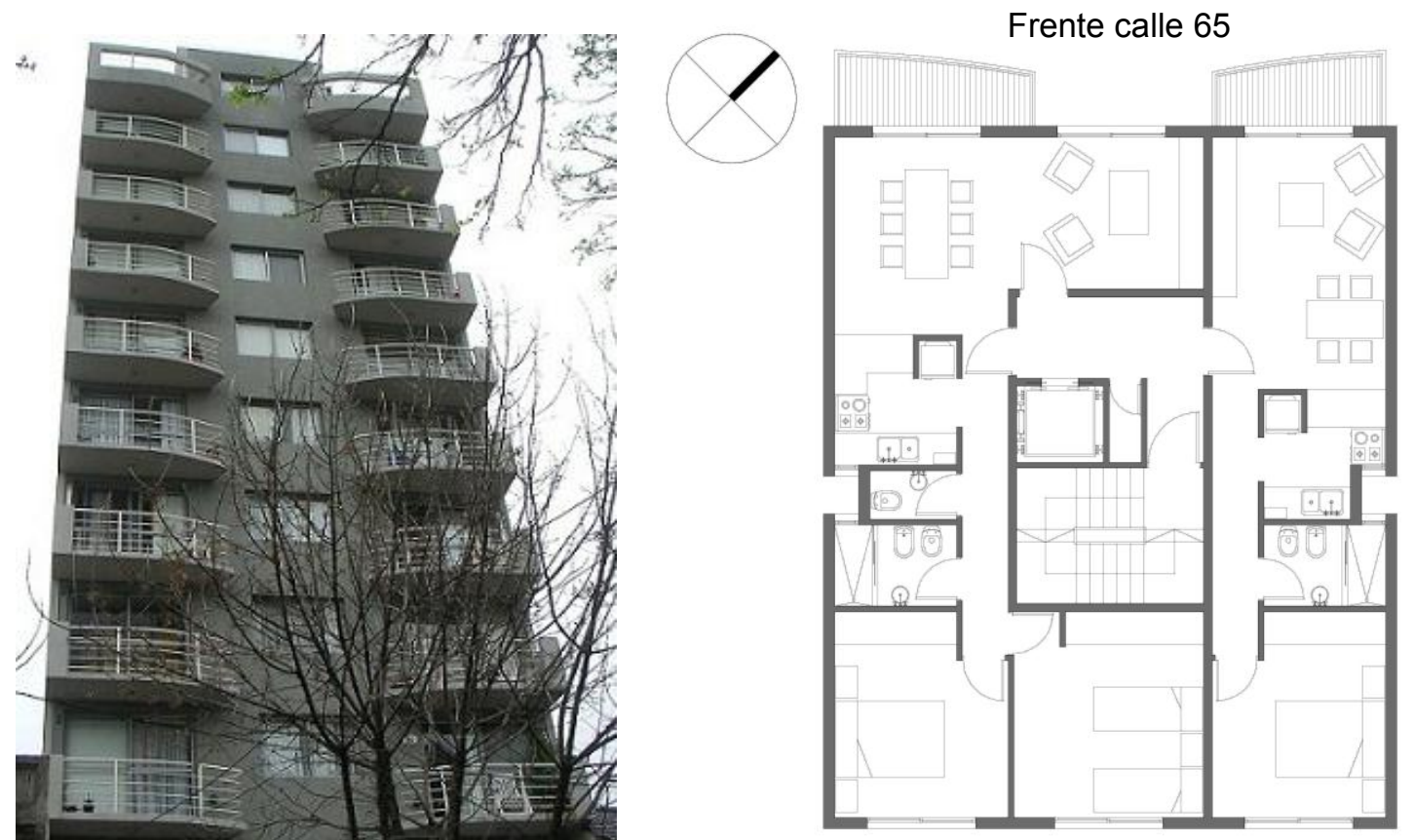

Figuras $V-7$ y 8: Vista del frente y planta tipo del edificio de viviendas analizado (Caso A). 


\begin{tabular}{|c|c|c|c|c|c|}
\hline \multicolumn{2}{|c|}{ Caso A - Viviendas } & \multicolumn{2}{|c|}{ Aspectos Dimensionales } & \multicolumn{2}{|c|}{ Aspectos Tecnológicos } \\
\hline Ubicación: & Calle $65 \mathrm{~N}^{0} 830$ - LP & Superficie (m2) & 1315,00 & \multicolumn{2}{|l|}{ Muros: } \\
\hline Año: & 1.999 & Volumen (m3): & 3550,00 & Exteriores: & Lad. Hueco 18 \\
\hline \multirow{2}{*}{\multicolumn{2}{|c|}{ Pérdidas a través de: }} & Compacidad (adim.): & 0,43 & Interiores: & LH 12 - LH 08 \\
\hline & & F. Forma (adim.): & 0,88 & Aisl. Termica adicional: & No \\
\hline & & \multicolumn{2}{|l|}{ Aspectos Térmicos } & \multicolumn{2}{|l|}{ Estructura: } \\
\hline & & Coef. UA $\left(W /{ }^{\circ} \mathrm{C}\right)$ : & 5300,00 & Columnas / Vigas: & $\mathrm{H}^{0} \mathrm{~A}^{\circ}$ \\
\hline & & Coef. G $\left(\mathrm{W} /{ }^{\circ} \mathrm{C}\right)$ : & 1,49 & Cubierta / Entrepiso: & Losa $\mathrm{H}^{\circ} \mathrm{A}^{0}$ \\
\hline & & Coef. G Adm. $\left(\mathrm{W} /{ }^{\circ} \mathrm{C}\right)$ : & 1,17 & Aisl. Termica adicional: & No \\
\hline & & Aspectos Energéti & & Carpinterias: & \\
\hline \multirow{2}{*}{\multicolumn{2}{|c|}{ - Muros $\|$ Techos $\|$ Ventanas $\|$ Puertas $\|$ Pisos $\|$ RA }} & Q (kWh/año): & 203884,00 & Ventanas: & Aluminio (vidrio simple) \\
\hline & & Qs (kWh/m2/año): & 155,045 & Prot. Solar: & Cortina Enrollar PVC \\
\hline
\end{tabular}

Figura V - 9: Descripción básica del edificio de viviendas analizado (Caso A).

\subsubsection{Caso B}

El edificio fue construido en el año 1974, sobre un lote de 10x20m. Se compone de un subsuelo, planta baja y once plantas tipo. En el subsuelo se ubican las salas de medidores de energía eléctrica y gas natural, y la sala de máquinas del edificio. En planta baja se dispone el hall del edificio y tres locales comerciales. Las plantas del primer al décimo piso se dividen en cuatro departamentos de entre 35 y $50 \mathrm{~m}^{2}$, de uno y de dos dormitorios respectivamente. La última planta cuenta con un departamento de $90 \mathrm{~m}^{2}$, de tres dormitorios (Figuras V - 10 y 11).

Su tecnología constructiva es convencional con estructura de hormigón armado y muros de cerramiento exterior de ladrillos huecos de $18 \times 18 \times 33 \mathrm{~cm}$, sin aislamiento higrotérmico adicional. Por su parte los cerramientos interiores se han materializado con ladrillos huecos de $12 \times 18 \times 33 \mathrm{~cm}$, los que separan a los departamentos entre sí y con las áreas comunes, y con ladrillos de $8 \times 18 \times 33 \mathrm{~cm}$ aquellos que dividen los ambientes interiores de cada departamento. Las carpinterías son de simple vidriado con perfilería de chapa doblada, con cortinas de enrollar de pvc.
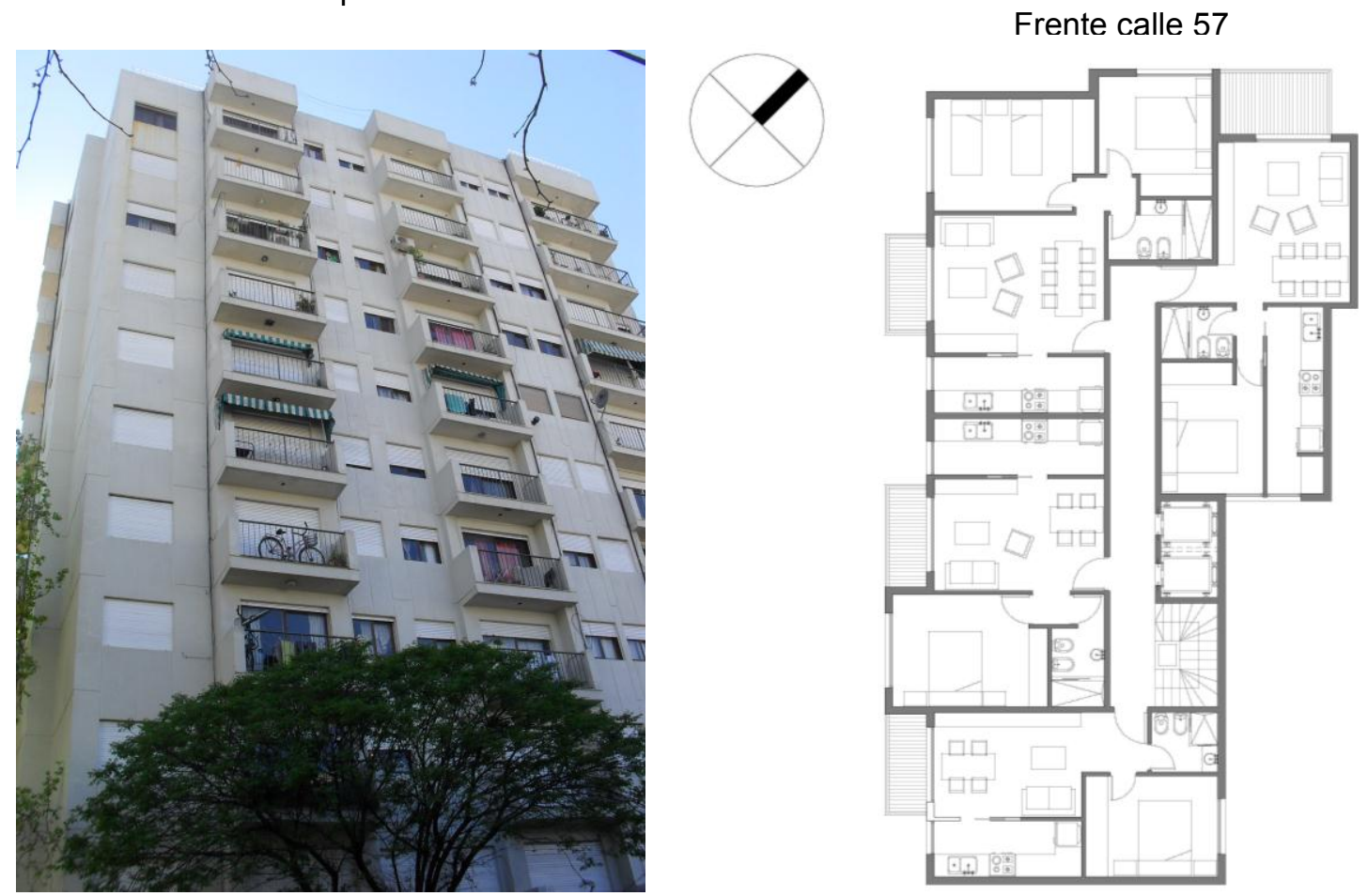

Figuras V-10 y 11: Vista del frente y planta tipo del edificio de viviendas analizado (Caso B). 
Como sistema de calefacción cada departamento cuenta con una estufa de tiro balanceado de $2.500 \mathrm{Kcal}$ de potencia. Por su parte el sistema de refrigeración de los distintos departamentos se ha dejado a criterio de cada uno de los habitantes. De los departamentos analizados uno $\left(6^{\circ} \mathrm{B}\right)$ ha optado por un equipo de aire acondicionado tipo Split de $1.200 \mathrm{~W}$ de potencia en la zona del estar-comedor y un ventilador en el dormitorio, mientras que los otros departamentos $\left(6^{\circ} \mathrm{A}\right.$ y $\left.6^{\circ} \mathrm{C}\right)$ han optado por colocar ventiladores en todos los ambientes principales.

Sobre la fachada principal del edificio, de orientación suroeste, se ubican indistintamente salas de estar, comedores, habitaciones y cocinas de las distintas unidades funcionales. Sobre el contrafrente del edificio, que recibe la orientación noreste, se ubican algunos dormitorios y el núcleo de servicio del edificio. Cabe destacar que ambas fachadas se materializan del mismo modo y no reciben ningún tratamiento especial respecto de la protección solar y de otros agentes meteorológicos, sólo cortinas de enrollar de pvc sobre las superficies vidriadas. La Figura V - 12 muestra la descripción básica del edificio, en ella puede verse que los mayores porcentajes de pérdidas de calor se dan a través de ventanas, renovaciones de aire y muros.

\begin{tabular}{|c|c|c|c|c|c|}
\hline \multicolumn{2}{|c|}{ Caso B - Viviendas } & \multicolumn{2}{|c|}{ Aspectos Dimensionales } & \multicolumn{2}{|c|}{ Aspectos Tecnológicos } \\
\hline Ubicación: & Calle $3 \mathrm{~N}^{0} 1206$ - LP & Superficie (m2) & 2040,00 & \multicolumn{2}{|l|}{ Muros: } \\
\hline Año: & 1.974 & Volumen (m3): & 5510,00 & Exteriores: & Lad. Hueco 18 \\
\hline \multicolumn{2}{|c|}{ Pérdidas a través de: } & Compacidad (adim.): & 0,45 & Interiores: & LH 12 - LH 08 \\
\hline & - & F. Forma (adim.): & 0,83 & Aisl. Termica adicional: & No \\
\hline & & \multicolumn{2}{|l|}{ Aspectos Térmicos } & \multicolumn{2}{|l|}{ Estructura: } \\
\hline & & Coef. UA $\left(\mathrm{W} /{ }^{\circ} \mathrm{C}\right)$ : & 7232,00 & Columnas / Vigas: & $\mathrm{H}^{\circ} \mathrm{A}^{\circ}$ \\
\hline & & Coef. G $\left(\mathrm{W} /{ }^{\circ} \mathrm{C}\right)$ : & 1,31 & Cubierta / Entrepiso: & Losa $\mathrm{H}^{0} \mathrm{~A}^{0}$ \\
\hline & & Coef. G Adm. $\left(\mathrm{W} /{ }^{\circ} \mathrm{C}\right)$ : & 1,14 & Aisl. Termica adicional: & No \\
\hline & 0 & Aspectos Energéti & & Carpinterias: & \\
\hline \multirow{2}{*}{\multicolumn{2}{|c|}{ $=$ Muros $\|$ Techos $\approx$ Ventanas $\|$ Puertas $\|$ Pisos $\|$ RA }} & Q (kWh/año): & 278181,00 & Ventanas: & Aluminio (vidrio simple) \\
\hline & & Qs (kWh/m2/año): & 136,36 & Prot. Solar: & Cortina Enrollar PVC \\
\hline
\end{tabular}

Figura V - 12: Descripción básica del edificio de viviendas analizado (Caso B).

\subsubsection{Caso C}

No pudieron conseguirse los datos exactos del año de construcción del edificio, sin embargo por el tipo de construcción puede afirmarse que se trata de un edificio principios de 1980, ubicado sobre un lote de $30 \times 30 \mathrm{~m}$. Se compone de un subsuelo, planta baja y veinte plantas tipo. En el subsuelo se ubican las salas de medidores de energía eléctrica y gas natural, la sala de máquinas y las cocheras del edificio. En planta baja se dispone el hall del edificio y once locales comerciales. Las plantas del primer al décimo piso se dividen en cinco departamentos de entre 50 y $95 \mathrm{~m}^{2}$, de dos y tres dormitorios (Figuras $V-13$ y 14).

Su tecnología constructiva es convencional con estructura de hormigón armado y muros de cerramiento exterior de ladrillos huecos de $18 \times 18 \times 33 \mathrm{~cm}$., sin aislamiento higrotérmico adicional. Por su parte los cerramientos interiores se han materializado con ladrillos huecos de $12 \times 18 \times 33 \mathrm{~cm}$, los que separan a los departamentos entre sí y con las áreas comunes, y con ladrillos de $8 \times 18 \times 33 \mathrm{~cm}$ aquellos que dividen los ambientes interiores de cada departamento. Las carpinterías son de simple vidriado con perfilería de aluminio, con cortinas de enrollar de pvc.

El sistema de acondicionamiento de aire interior de los distintos departamentos se ha dejado a criterio de cada uno de los habitantes. De los departamentos analizados uno $\left(17^{\circ} \mathrm{D}\right)$ ha optado por un equipo de aire acondicionado frío calor en la zona del estar-comedor y en el dormitorio principal, de $2.400 \mathrm{~W}$ y $1.200 \mathrm{~W}$ de potencia respectivamente, y ventiladores en los otros dormitorios; el otro departamento $\left(17^{\circ} \mathrm{B}\right)$ ha optado por colocar un equipo de aire acondicionado en el estar-comedor de $1.200 \mathrm{~W}$ de potencia y ventiladores en los dormitorios 
para la refrigeración de los distintos ambientes. Por su parte para la calefacción del aire interior cada uno de los departamentos cuenta con una estufa de tiro balanceado de $2.500 \mathrm{Kcal}$ en la zona del estar. La climatización de los dormitorios se ha dejado a criterio de los ocupantes; de los departamentos analizados uno $\left(17^{\circ} \mathrm{B}\right)$ ha optado por un equipo de acondicionado frío-calor en el dormitorio principal y estufas eléctricas en los otros dormitorios, mientras que el otro departamento $\left(17^{\circ} \mathrm{D}\right)$ ha optado por colocar estufas eléctricas en ambos dormitorios.

El edificio se encuentra implantado en una esquina de la Ciudad de La Plata. Sobre las fachadas principales del edificio, de orientación noreste y noroeste, se ubican indistintamente salas de estar, comedores, habitaciones y cocinas de las distintas unidades funcionales. Sobre las fachadas que conforman el contrafrente del edificio, que reciben las orientaciones sureste y suroeste, se ubican algunos dormitorios y zonas de servicios de las distintas unidades funcionales. Hacia el centro del edificio se encuentra el núcleo de circulación vertical del edificio, las circulaciones hacia las distintas unidades funcionales y algunos servicios. La Figura V - 15 muestra la descripción básica del edificio, en ella puede verse que los mayores porcentajes de pérdidas de calor se dan a través de renovaciones de aire, ventanas y muros.
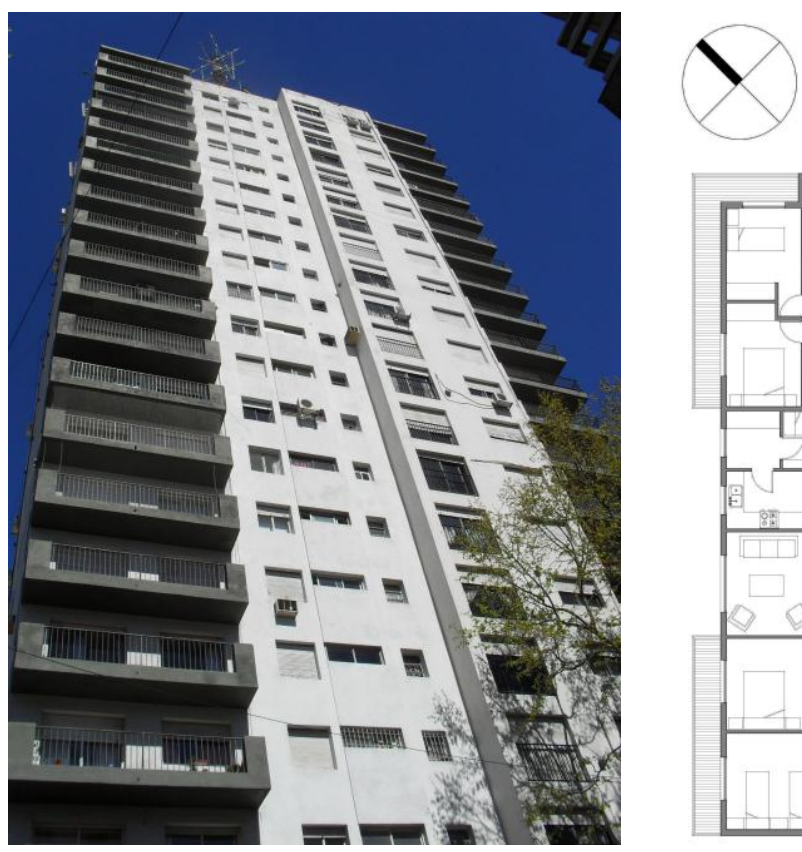

Frente calle 10

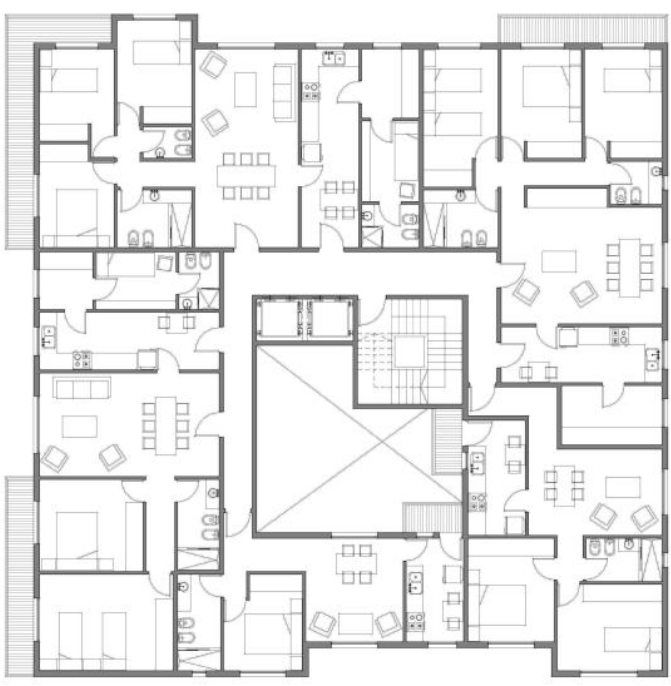

Figuras V-13 y 14: Vista del frente y planta tipo del edificio de viviendas analizado (Caso C).

\begin{tabular}{|c|c|c|c|c|c|}
\hline \multicolumn{2}{|c|}{ Caso C - Viviendas } & \multicolumn{2}{|c|}{ Aspectos Dimensionales } & \multicolumn{2}{|c|}{ Aspectos Tecnológicos } \\
\hline Ubicación: & Calle $10 \mathrm{~N}^{0} 857$ - LP & Superficie (m2) & 9113,00 & Muros: & \\
\hline Año: & 1980 (aprox.) & Volumen (m3): & 24606,00 & Exteriores: & Lad. Hueco 18 \\
\hline \multicolumn{2}{|c|}{ Pérdidas a través de: } & Compacidad (adim.): & 0,52 & Interiores: & LH 12 - LH 08 \\
\hline & & F. Forma (adim.): & 0,72 & Aisl. Termica adicional: & No \\
\hline & & \multicolumn{2}{|l|}{ Aspectos Térmicos } & \multicolumn{2}{|l|}{ Estructura: } \\
\hline & & Coef. UA $\left(\mathrm{W} /{ }^{\circ} \mathrm{C}\right)$ : & 13120,00 & Columnas / Vigas: & $\mathrm{H}^{\circ} \mathrm{A}^{\circ}$ \\
\hline & & Coef. G $\left(\mathrm{W} /{ }^{\circ} \mathrm{C}\right)$ : & 1,07 & Cubierta / Entrepiso: & Losa $\mathrm{H}^{\circ} \mathrm{A}^{\circ}$ \\
\hline & & Coef. G Adm. (W/PC): & 1,06 & Aisl. Termica adicional: & No \\
\hline & & Aspectos Energét & & Carpinterias: & \\
\hline \multirow{2}{*}{\multicolumn{2}{|c|}{ 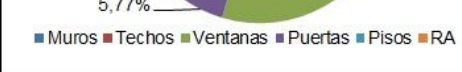 }} & Q (kWh/año): & 1009380,00 & Ventanas: & Aluminio (vidrio simple) \\
\hline & & Qs (kWh/m2/año): & 110,76 & Prot. Solar: & Cortina Enrollar PVC \\
\hline
\end{tabular}

Figura V - 15: Descripción básica del edificio de viviendas analizado (Caso C). 


\subsubsection{Caso D}

No pudieron conseguirse los datos exactos del año de construcción del edificio, sin embargo por el tipo de construcción puede afirmarse que se trata de un edificio de finales de 1980. Ocupa un lote de $40 \times 40 \mathrm{~m}$. La planta total del edificio adopta la forma de "C" con la mayor superficie de la envolvente vertical sobre el frente del lote $(40 \mathrm{~m})$ y los dos brazos -cada uno de $35 \mathrm{~m}$ de longitud- sobre los laterales, dejando un patio central entre el volumen que conforma el edificio. El conjunto se compone de un subsuelo, planta baja y dieciséis plantas tipo. En el subsuelo se ubican las salas de medidores de energía eléctrica y de gas natural, las salas de máquinas (agrupadas en las cuatro esquinas del volumen que conforma el edificio), y las cocheras. En la planta baja se ubican ocho locales comerciales y diez departamentos. Las plantas tipo del volumen funcionan como si se tratasen de cuatro edificios independientes, que no tienen comunicación si no a través de la planta baja y la planta de cocheras, pero que volumétricamente se encuentran unidas. En total la planta del conjunto se compone de doce departamentos por planta, de entre 40 y $80 \mathrm{~m}^{2}$ cada uno; de dos y tres dormitorios (Figuras V - 16 y 17).

Su tecnología constructiva es convencional con estructura de hormigón armado y muros de cerramiento exterior de ladrillos huecos de $18 \times 18 \times 33 \mathrm{~cm}$ con revestimiento de tejuelas de ladrillo cerámico visto, sin aislamiento higrotérmico adicional. Por su parte los cerramientos interiores se han materializado con ladrillos huecos de $12 \times 18 \times 33 \mathrm{~cm}$, los que separan a los departamentos entre sí y con las áreas comunes, y con ladrillos de $8 \times 18 \times 33 \mathrm{~cm}$ aquellos que dividen los ambientes interiores de cada departamento. Las carpinterías son de simple vidriado con perfilería de chapa doblada, con cortinas de enrollar de pvc.
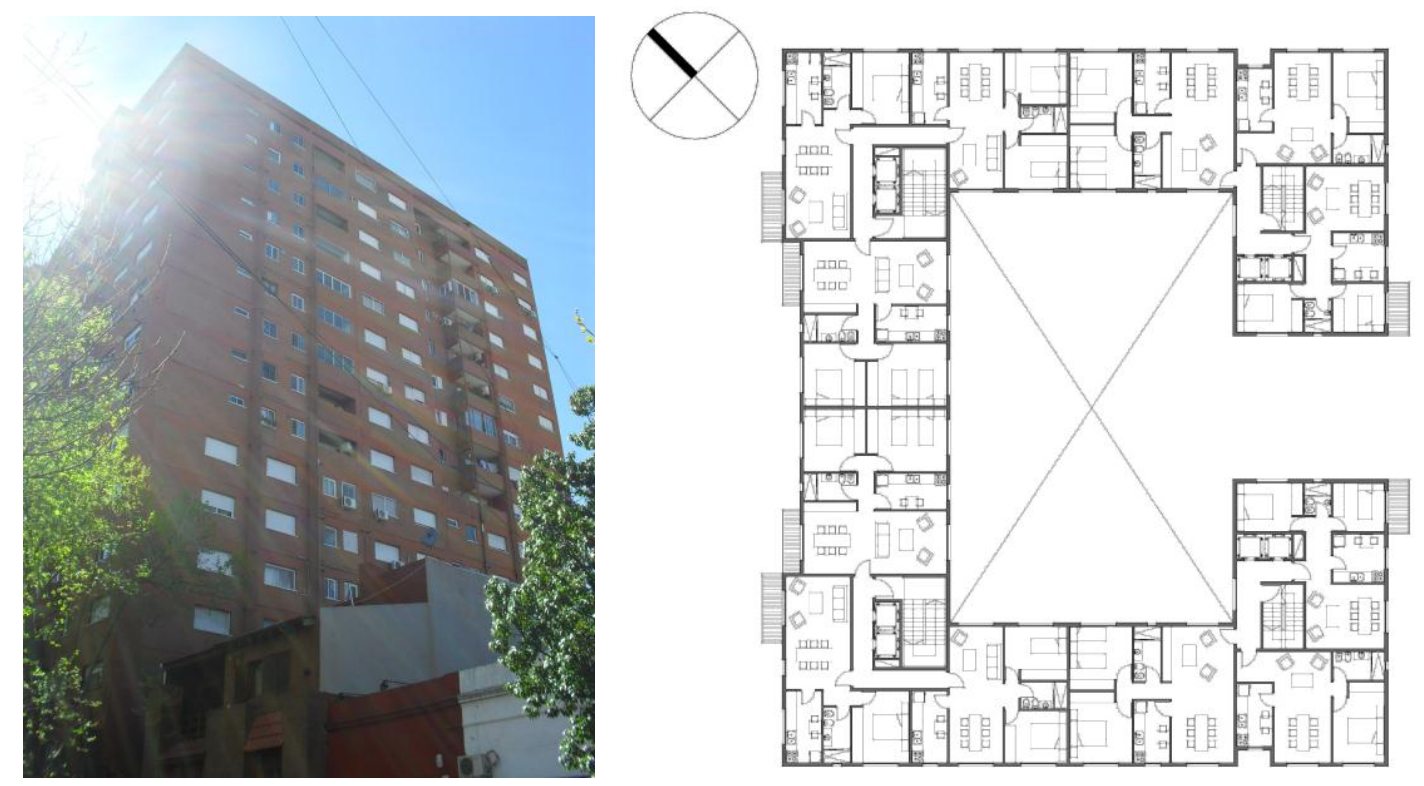

Figuras $V-16$ y 17: Vista del frente y planta tipo del edificio de viviendas analizado (Caso D).

Como sistema de calefacción cada departamento cuenta con una estufa de tiro balanceado de distinta potencia según la superficie de cada departamento, aunque cabe aclarar que por lo que pudo observarse en las fachadas del edificio muchos han optado por retirarlos y colocar equipos de aire acondicionado. De los departamentos analizados uno $\left(4^{\circ} \mathrm{H}\right)$ cuenta con una estufa de tiro balanceado de $3.500 \mathrm{Kcal}$ de potencia en la zona de estar, mientras que el otro cuenta con una estufa de tiro balanceado de $5.000 \mathrm{Kcal}$ de potencia en la zona de estar y estufas eléctricas en los dormitorios. Por su parte el sistema de refrigeración de los distintos departamentos se ha dejado a criterio de cada uno de los ocupantes. Los departamentos analizados han optado por equipos de aire acondicionado tipo Split de $2.250 \mathrm{~W}$ y $1.200 \mathrm{~W}$ de potencia en la zona del estar-comedor, y ventiladores en los dormitorios. 
Los núcleos de circulación vertical se ubican en los vértices internos del conjunto. Sobre la fachada principal del edificio, de orientación noroeste, se ubican indistintamente salas de estar, comedores, habitaciones y cocinas de las distintas unidades funcionales. La misma situación se repite en los laterales, de orientación noreste y noroeste, y en el contrafrente del edificio, de orientación sureste. Durante gran parte del día las distintas fachadas sobre el patio central reciben la sombra arrojada por el propio edificio. Asimismo cabe aclarar que si bien todas las fachadas presentan condiciones distintas de relación con el exterior, todas reciben el mismo tratamiento en cuanto a protección de las condiciones meteorológicas. La Figura V - 18 muestra la descripción básica del edificio, en ella puede verse que los mayores porcentajes de pérdidas de calor se dan a través de renovaciones de aire, ventanas y muros.

\begin{tabular}{|c|c|c|c|c|c|}
\hline \multicolumn{2}{|c|}{ Caso D - Viviendas } & \multicolumn{2}{|c|}{ Aspectos Dimensionales } & \multicolumn{2}{|c|}{ Aspectos Tecnológicos } \\
\hline Ubicación: & Calle $56 \mathrm{~N}^{0} 720$ - LP & Superficie (m2) & 14856,00 & \multicolumn{2}{|l|}{ Muros: } \\
\hline Año: & 1980 (aprox.) & Volumen (m3): & 40112,00 & Exteriores: & LH 18 + Rev. Lad. visto \\
\hline \multicolumn{2}{|c|}{ Pérdidas a través de: } & Compacidad (adim.): & 0,50 & Interiores: & LH 12 - LH 08 \\
\hline & now & F. Forma (adim.): & 0,75 & Aisl. Termica adicional: & No \\
\hline & & \multicolumn{2}{|l|}{ Aspectos Térmicos } & \multicolumn{2}{|l|}{ Estructura: } \\
\hline & & Coef. UA $\left(\mathrm{W} /{ }^{\circ} \mathrm{C}\right)$ : & 21902,00 & Columnas / Vigas: & $\mathrm{H}^{\circ} \mathrm{A}^{0}$ \\
\hline & & Coef. G $\left(\mathrm{W} /{ }^{\circ} \mathrm{C}\right)$ : & 1,09 & Cubierta / Entrepiso: & Losa $\mathrm{H}^{\circ} \mathrm{A}^{0}$ \\
\hline & & Coef. G Adm. $\left(\mathrm{W} /{ }^{\circ} \mathrm{C}\right)$ : & 1,04 & Aisl. Termica adicional: & No \\
\hline & 28,81 & Aspectos Energéti & & Carpinterias: & \\
\hline \multirow{2}{*}{\multicolumn{2}{|c|}{$\|$ Muros $\|$ Techos $\|$ Ventanas $\|$ Puertas $\|$ Pisos $\|$ RA }} & Q (kWh/año): & 1685012,00 & Ventanas: & Aluminio (vidrio simple) \\
\hline & & Qs (kWh/m2/año): & 113,42 & Prot. Solar: & Cortina Enrollar PVC \\
\hline
\end{tabular}

Figura V - 18: Descripción básica del edificio de viviendas analizado (Caso D).

\subsection{Edificios de oficinas}

El trabajo de campo abordó el estudio particularizado de cinco edificios de propiedad horizontal en altura destinados a oficinas, ubicados en la Ciudad Autónoma de Buenos Aires y en la Ciudad de La Plata. Al igual que para el caso de los edificios de viviendas, la elección de los casos se basó en la búsqueda de ejemplos que fueran representativos de la realidad constructiva actual en el AMBA (Rosenfeld, E. et Al.; 1986, 1988, 1989; Veigas, G. et Al.; 2007; Evans, J. M.; 2012 ) e incluso en el país (Gonzalo, G.; 1999 - Baso, M. et Al.; 2001).

No obstante un condicionante importante al momento de elegir los casos fue la posibilidad de tener acceso a toda la información. Tal como se comentará en el capítulo siguiente para la realización de las auditorias energéticas fue necesario no sólo tomar los consumos de gas natural y energía eléctrica de todas las unidades que conformaban el edificio sino que además debió medirse el comportamiento higrotérmico de las unidades a las que se podía acceder. En estas unidades además se realizaron encuestas socio-energéticas. Sin embargo algunos casos que habían sido seleccionados debieron ser descartados ya que no fue posible completar la etapa de análisis.

\subsubsection{Caso A}

El edificio fue construido aproximadamente en el año 1930, sobre un lote de $20 \times 20 \mathrm{~m}$, en la ciudad de La Plata. Se compone de un subsuelo, planta baja y seis plantas tipo. En el subsuelo se encuentran los espacios destinados a los medidores de energía eléctrica y gas natural, en planta baja se encuentra la portería, el hall de acceso y algunos locales comerciales. Las plantas del primer al sexto piso se dividen en tres oficinas de aproximadamente $120 \mathrm{~m}^{2}$ cada una (Figuras $\mathrm{V}-19$ y 20 ).

Su tecnología constructiva es convencional con estructura de hormigón armado y muros de cerramiento exterior de ladrillos comunes que conforman un muro de $22 \mathrm{~cm}$ de espesor final, sin aislamiento higrotérmico adicional. Por su parte los cerramientos interiores se han 
materializado con muros de $15 \mathrm{~cm}$ de espesor final de ladrillos comunes, los que separan los ambientes interiores de las oficinas, a las oficinas entre sí y con las áreas comunes, y con sistema de construcción en seco (placas de yeso) aquellos que dividen los ambientes interiores de cada oficina, que son el resultado de la adaptación de la planta a las necesidades actuales. Las carpinterías originales son de simple vidriado con perfilería de hierro y cortinas de enrollar de madera aunque en las zonas refaccionadas tiene también carpinterías de aluminio de simple vidriado sin protección.

El sistema de acondicionamiento de aire interior de las distintas oficinas se ha dejado a criterio de los ocupantes. Las oficinas analizadas han optado por colocar equipos de aire acondicionado frío-calor en los ambientes principales tanto para el acondicionamiento del aire en invierno como en verano.

El edificio se encuentra implantado en una esquina de la Ciudad de La Plata. Sobre las fachadas principales del edificio, de orientación noreste y sureste, se ubican los espacios principales de las oficinas (oficinas principales, salas de reunión, etc.) dejando sobre el centro del edificio, en torno de un patio de aire y luz, los servicios, las zonas de archivos y las oficinas secundarias. La Figura V - 21 muestra la descripción básica del edificio.
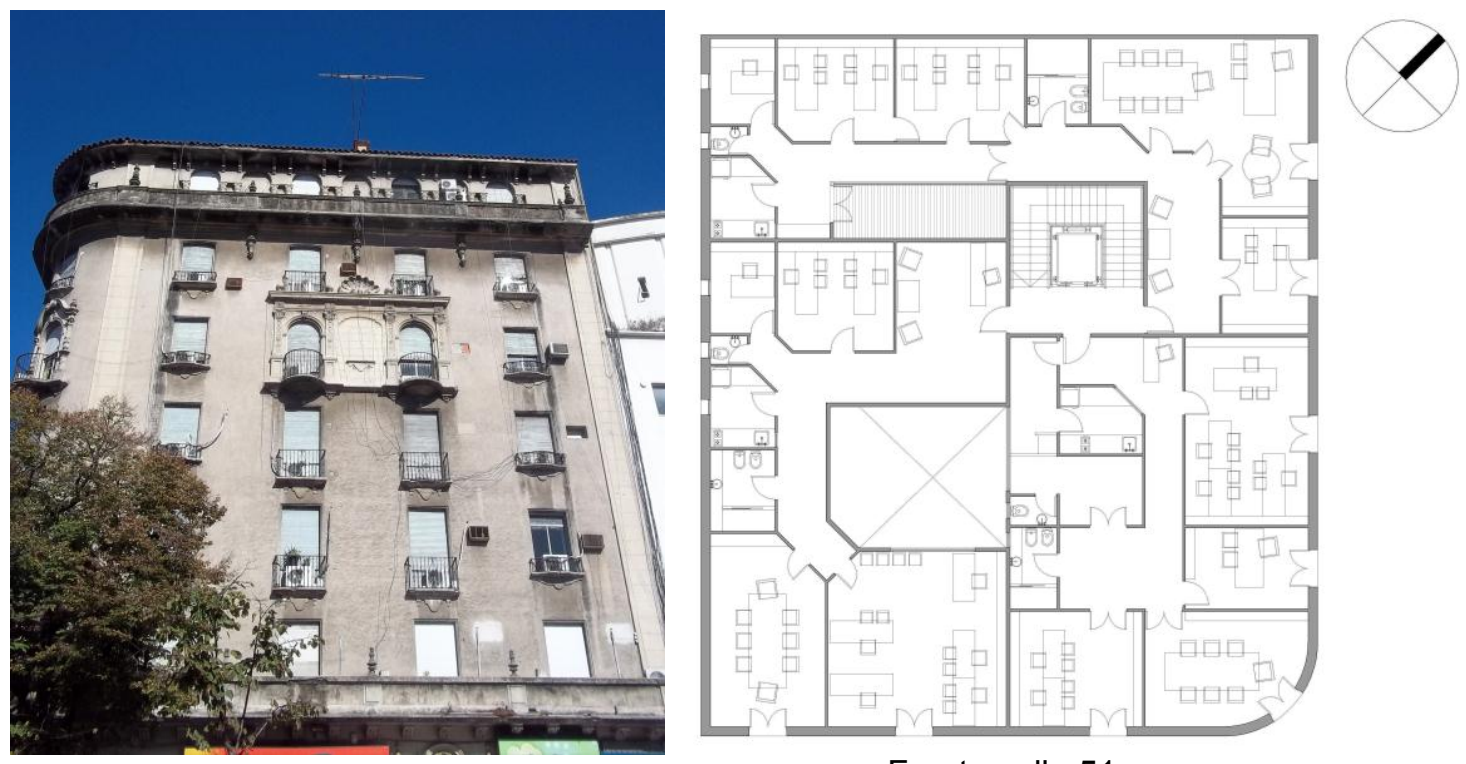

Frente calle 51

Figuras V-19 y 20: Vista del frente y planta tipo del edificio de oficinas analizado (Caso A).

\begin{tabular}{|c|c|c|c|c|c|}
\hline \multicolumn{2}{|c|}{ Caso A - Oficinas } & \multicolumn{2}{|c|}{ Aspectos Dimensionales } & \multicolumn{2}{|c|}{ Aspectos Tecnológicos } \\
\hline \multirow{2}{*}{\begin{tabular}{|l|} 
Ubicación: \\
Año: \\
\end{tabular}} & \multirow{2}{*}{\begin{tabular}{|l|} 
Calle $7 \mathrm{~N}^{\circ} 953-\mathrm{LP}$ \\
1930 (aprox.) \\
\end{tabular}} & Superficie $(\mathrm{m} 2)$ & 2702,00 & \multicolumn{2}{|l|}{ Muros: } \\
\hline & & Volumen (m3): & 7298,00 & Exteriores: & Lad. Común $(22 \mathrm{~cm}$.) \\
\hline \multirow{2}{*}{\multicolumn{2}{|c|}{ Pérdidas a través de: }} & Compacidad (adim.): & 0,56 & Interiores: & L.C. $15 \mathrm{~cm}$. / Durlock \\
\hline & & F. Forma (adim.): & 0,70 & Aisl. Termica adicional: & No \\
\hline & & \multicolumn{2}{|l|}{ Aspectos Térmicos } & \multicolumn{2}{|l|}{ Estructura: } \\
\hline & & Coef. UA $\left(\mathrm{W} /{ }^{\circ} \mathrm{C}\right)$ : & 10105,00 & Columnas / Vigas: & $H^{\circ} A^{\circ}$ \\
\hline & & Coef. G $\left(\mathrm{W} /{ }^{\circ} \mathrm{C}\right)$ : & 1,38 & Cubierta / Entrepiso: & Losa $\mathrm{H}^{\circ} \mathrm{A}^{\circ}$ \\
\hline & & Coef. G Adm. (W/PC): & 1,12 & Aisl. Termica adicional: & No \\
\hline & & Aspectos Energét & & Carpinterias: & \\
\hline \multirow{2}{*}{\multicolumn{2}{|c|}{ - Muros $\|$ Techos $\|$ Ventanas $\boldsymbol{\|}$ Puertas $\boldsymbol{\|}$ Pisos $\|$ RA }} & Q (kWh/año): & 388716,00 & Ventanas: & Hierro (vidrio simple) \\
\hline & & Qs (kWh/m2/año): & 143,86 & Prot. Solar: & Cortina Enrollar Madera \\
\hline
\end{tabular}

Figura V - 21: Descripción básica del edificio de oficinas analizado (Caso A). 


\subsubsection{Caso B}

El edificio fue construido aproximadamente en el año 1960, sobre un lote triangular de $20 \times 30 \mathrm{~m}$, en la ciudad de La Plata. Se compone de un subsuelo, planta baja y diez plantas tipo. En el subsuelo se encuentran los espacios destinados a los medidores de energía eléctrica y gas natural, y la sala de máquinas; en planta baja se encuentra la portería, el hall de acceso y once locales comerciales. Las plantas del primer al décimo piso se dividen en ocho oficinas de aproximadamente $30 \mathrm{~m}^{2}$ cada una (Figuras $V-22$ y 23 ).

Su tecnología constructiva es convencional con estructura de hormigón armado y muros de cerramiento exterior de ladrillos huecos de $18 \times 18 \times 33 \mathrm{~cm}$, sin aislamiento higrotérmico adicional. Por su parte los cerramientos interiores se han materializado con ladrillos huecos de $12 \times 18 \times 33 \mathrm{~cm}$, los que separan a las oficinas entre sí y con las áreas comunes, y con ladrillos huecos de $8 \times 18 \times 33 \mathrm{~cm}$, aquellos que dividen los ambientes interiores de cada oficina. Las carpinterías son de simple vidriado con perfilería de chapa doblada y cortinas de enrollar de madera.

El sistema de acondicionamiento de aire interior de las distintas oficinas se ha dejado a criterio de los ocupantes. De las oficinas analizadas, una (68) ha optado por colocar un equipo de aire acondicionado frío-calor de $2.400 \mathrm{~W}$ en la oficina principal tanto para el acondicionamiento del aire en invierno como en verano. La otra (95) ha optado por colocar un equipo de aire acondicionado de $2.400 \mathrm{~W}$ para el acondicionamiento en verano y dos estufas de tiro balanceado de $3.500 \mathrm{Kcal}$ para calefacción.

El edificio se encuentra implantado en una esquina de la Ciudad de La Plata, en la que cruza uno de los diagonales principales de la ciudad, motivo por el cual presenta condiciones de borde singulares en lo que respecta a forma y orientación. Sobre las fachadas principales del edificio, de orientación noreste y oeste, se ubican los espacios principales de las oficinas (oficinas principales, salas de reunión, etc.) dejando sobre el centro del edificio en torno al núcleo central los espacios de servicios, las zonas de archivos y las circulaciones principales del edificio. La Figura V - 24 muestra la descripción básica del edificio, en ella puede verse que los mayores porcentajes de pérdidas de calor se dan a través de renovaciones de aire, muros y ventanas.
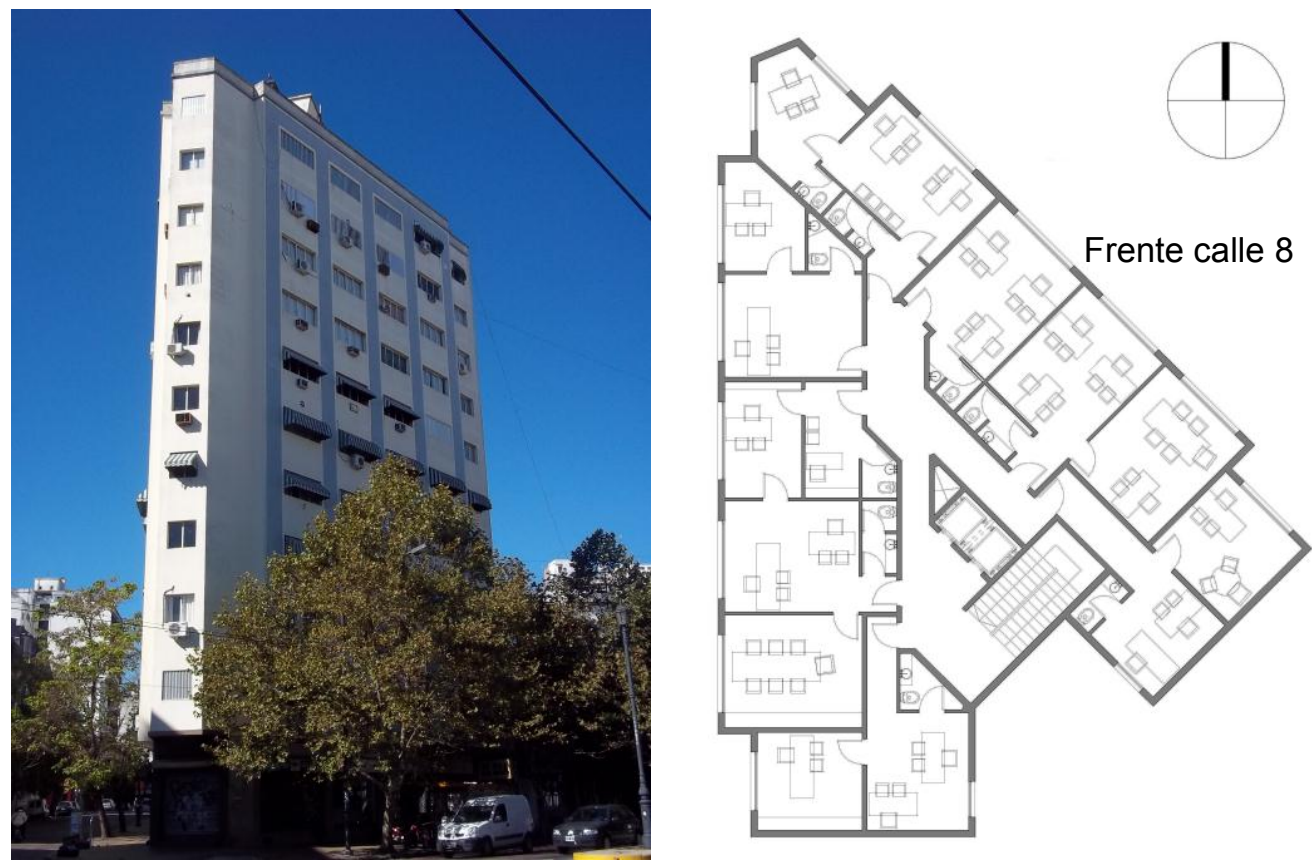

Figuras V-22 y 23: Vista del frente y planta tipo del edificio de oficinas analizado (Caso B). 


\begin{tabular}{|c|c|c|c|c|c|}
\hline \multicolumn{2}{|c|}{ Caso B - Oficinas } & \multicolumn{2}{|c|}{ Aspectos Dimensionales } & \multicolumn{2}{|c|}{ Aspectos Tecnológicos } \\
\hline Ubicación: & Diag. 74 - LP & Superficie (m2) & 2738,00 & \multicolumn{2}{|l|}{ Muros: } \\
\hline Año: & 1960 (aprox.) & Volumen (m3): & 7394,00 & Exteriores: & LH 18 \\
\hline \multicolumn{2}{|c|}{ Pérdidas a través de: } & Compacidad (adim.): & 0,50 & Interiores: & LH 12 - LH 08 \\
\hline & प the & F. Forma (adim.): & 0,81 & Aisl. Termica adicional: & No \\
\hline & & \multicolumn{2}{|l|}{ Aspectos Térmicos } & \multicolumn{2}{|l|}{ Estructura: } \\
\hline & & Coef. UA $\left(W /{ }^{\circ} \mathrm{C}\right)$ : & 8916,00 & Columnas / Vigas: & $\mathrm{H}^{\circ} \mathrm{A}^{\circ}$ \\
\hline & & Coef. G $\left(\mathrm{W} /{ }^{\circ} \mathrm{C}\right)$ : & 1,21 & Cubierta / Entrepiso: & Losa $\mathrm{H}^{\circ} \mathrm{A}^{0}$ \\
\hline & & Coef. G Adm. $\left(\mathrm{W} /{ }^{\circ} \mathrm{C}\right)$ : & 1,12 & Aisl. Termica adicional: & No \\
\hline & & Aspectos Energét & & Carpinterias: & \\
\hline \multirow{2}{*}{\multicolumn{2}{|c|}{$\|$ Muros $\|$ Techos $\|$ Ventanas $\|$ Puertas $\|$ Pisos $\| R A$}} & Q (kWh/año): & 342963,00 & Ventanas: & Aluminio (vidrio simple) \\
\hline & & Qs (kWh/m2/año): & 125,26 & Prot. Solar: & Toldo (algunos casos) \\
\hline
\end{tabular}

Figura V - 24: Descripción básica del edificio de oficinas analizado (Caso B).

\subsubsection{Caso C}

Si bien no se tienen datos exactos acerca de la fecha de construcción del edificio, por sus características constructivas puede afirmarse que se trata de un edificio de mediados de 1980, ubicado sobre un lote de $10 \times 60 \mathrm{~m}$ en la ciudad de La Plata. Se compone de un subsuelo, planta baja y catorce plantas tipo. En el subsuelo se encuentran los espacios destinados a los medidores de energía eléctrica y gas natural, la sala de máquinas y parte de las cocheras. En planta baja se encuentra la portería, el hall de acceso, cuatro oficinas, dos locales comerciales y el resto de las cocheras. Las plantas del primer al catorceavo piso se dividen en seis oficinas de $33 \mathrm{~m}^{2}$ cada una, algunas de las cuales se hallan unidas, formando espacios de hasta $100 \mathrm{~m}^{2}$ (Figuras $\vee-25$ y 26 ).

Su tecnología constructiva es convencional con estructura de hormigón armado y curtain wall con estructura metálica y simple vidriado coloreado sobre las fachadas. Por su parte los muros medianeros se han materializado con ladrillos huecos de $18 \times 18 \times 33 \mathrm{~cm}$. Los cerramientos interiores se han materializado con ladrillos huecos de $12 \times 18 \times 33 \mathrm{~cm}$, los que separan a las oficinas entre sí y con las áreas comunes, y con ladrillos huecos de $8 \times 18 \times 33 \mathrm{~cm}$, aquellos que dividen los ambientes interiores de cada oficina.
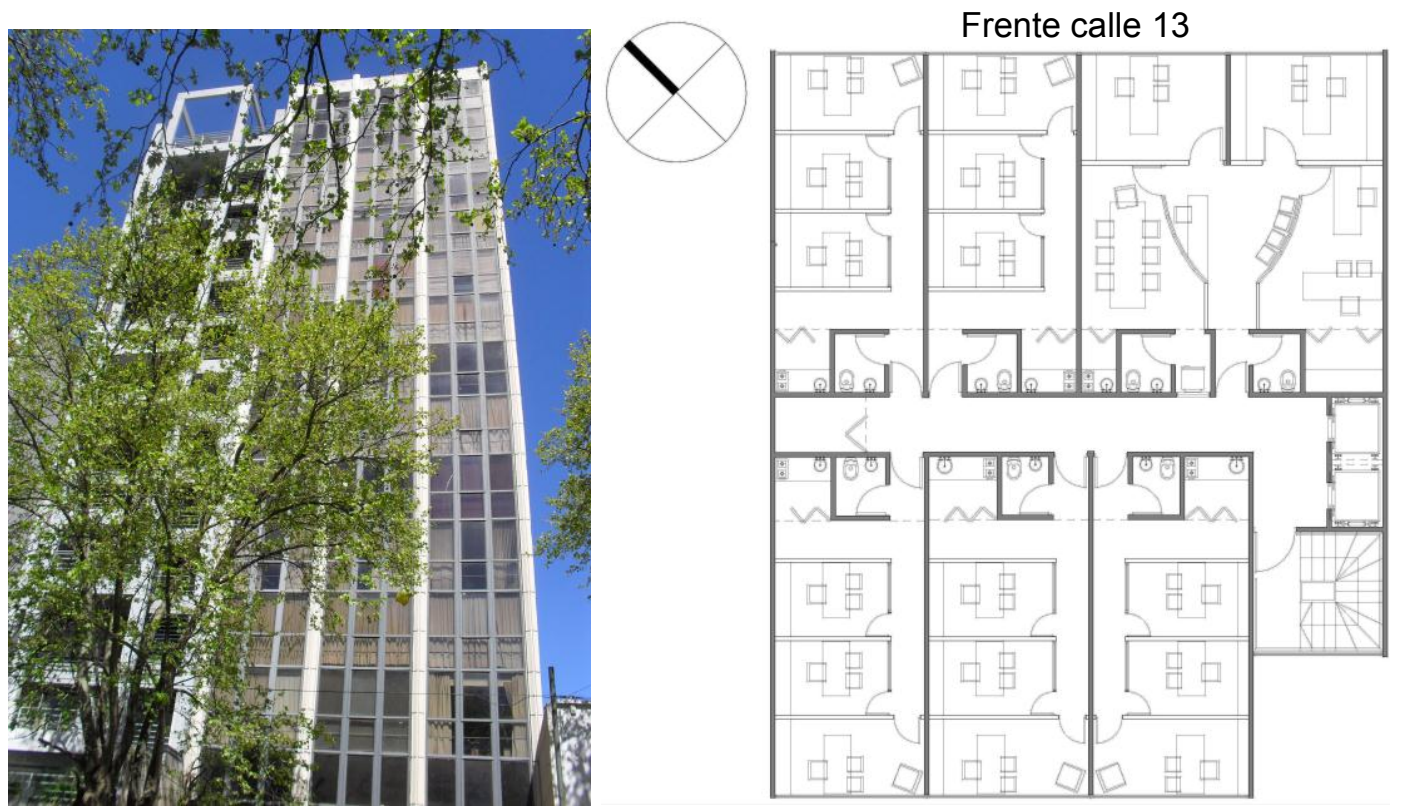

Figuras V-24 y 25: Vista del frente y planta tipo del edificio de oficinas analizado (Caso C). 
Para la calefacción de las distintas unidades se dispone de un sistema de calefacción central alimentado por gas natural, por planta. Por su parte el sistema de acondicionamiento de aire interior de las distintas oficinas se ha dejado a criterio de los ocupantes. Las oficinas analizadas han optado por colocar equipos de aire acondicionado tipo split en los locales de primera que componen las oficinas.

Por otra parte, los espacios destinados a oficinas se disponen indistintamente al frente y al contrafrente, de orientación noreste y suroeste respectivamente. Los ambientes principales que conforman el espacio interior de las distintas unidades funcionales se disponen sobre las fachadas, dejando el centro de la planta para la localización de los accesos, los servicios y la circulación general de acceso a las distintas unidades. A pesar de tener diferentes orientaciones, ambas fachadas se materializaron, como ya se mencionó anteriormente, con curtain wall de vidrio simple coloreado, sin ningún dispositivo de protección solar. La Figura V - 27 muestra la descripción básica del edificio, en ella puede verse que los mayores porcentajes de pérdidas de calor se dan a través de ventanas, renovaciones de aire y muros.

\begin{tabular}{|c|c|c|c|c|c|}
\hline \multicolumn{2}{|c|}{ Caso C - Oficinas } & \multicolumn{2}{|c|}{ Aspectos Dimensionales } & \multicolumn{2}{|c|}{ Aspectos Tecnológicos } \\
\hline Ubicación: & Calle $13 \mathrm{~N}^{\circ} 723$ - LP & Superficie (m2) & 2992,00 & Muros: & \\
\hline Año: & 1980 (aprox.) & Volumen (m3): & 8080,00 & Exteriores: & LH 18 \\
\hline \multicolumn{2}{|c|}{ Pérdidas a través de: } & Compacidad (adim.): & 0,45 & Interiores: & LH 12 - LH 08 - Durlock \\
\hline & & F. Forma (adim.): & 0,83 & Aisl. Termica adicional: & No \\
\hline & & \multicolumn{2}{|l|}{ Aspectos Térmicos } & \multicolumn{2}{|l|}{ Estructura: } \\
\hline & & Coef. UA $\left(\mathrm{W}^{\circ}{ }^{\circ} \mathrm{C}\right)$ : & 12332,00 & Columnas / Vigas: & $H^{0} A^{0}$ \\
\hline & $3,94 \%$ & Coef. G $\left(\mathrm{W} /{ }^{\circ} \mathrm{C}\right)$ : & 1,53 & Cubierta / Entrepiso: & Losa $\mathrm{H}^{\circ} \mathrm{A}^{\circ}$ \\
\hline & & Coef. G Adm. (W/PC): & 1,11 & Aisl. Termica adicional: & No \\
\hline & & Aspectos Energét & & Carpinterias: & \\
\hline \multirow{2}{*}{\multicolumn{2}{|c|}{ nas $\boldsymbol{\|}$ Puertas $\|$ Pisos $=$ RA }} & Q (kWh/año): & 474380,00 & Ventanas: & Curtain Wall \\
\hline & & Qs (kWh/m2/año): & 158,55 & Prot. Solar: & No \\
\hline
\end{tabular}

Figura V - 27: Descripción básica del edificio de oficinas analizado (Caso C).

\subsubsection{Caso $D$}

Se trata de un edificio construido en la Ciudad Autónoma de Buenos Aires sobre un lote de $15 \times 40 \mathrm{~m}$. Si bien no se tienen datos exactos de la fecha de edificación, por el tipo de construcción, puede afirmarse que se trata de un edificio alrededor de 1930. Se compone de un subsuelo, planta baja y diez plantas tipos. En planta baja se encuentra la portería, el hall de acceso y tres locales comerciales. Las plantas del primer al décimo piso se dividen en dos oficinas de $75 \mathrm{~m}^{2}$ cada una (Figuras $V-28$ y 29 ).
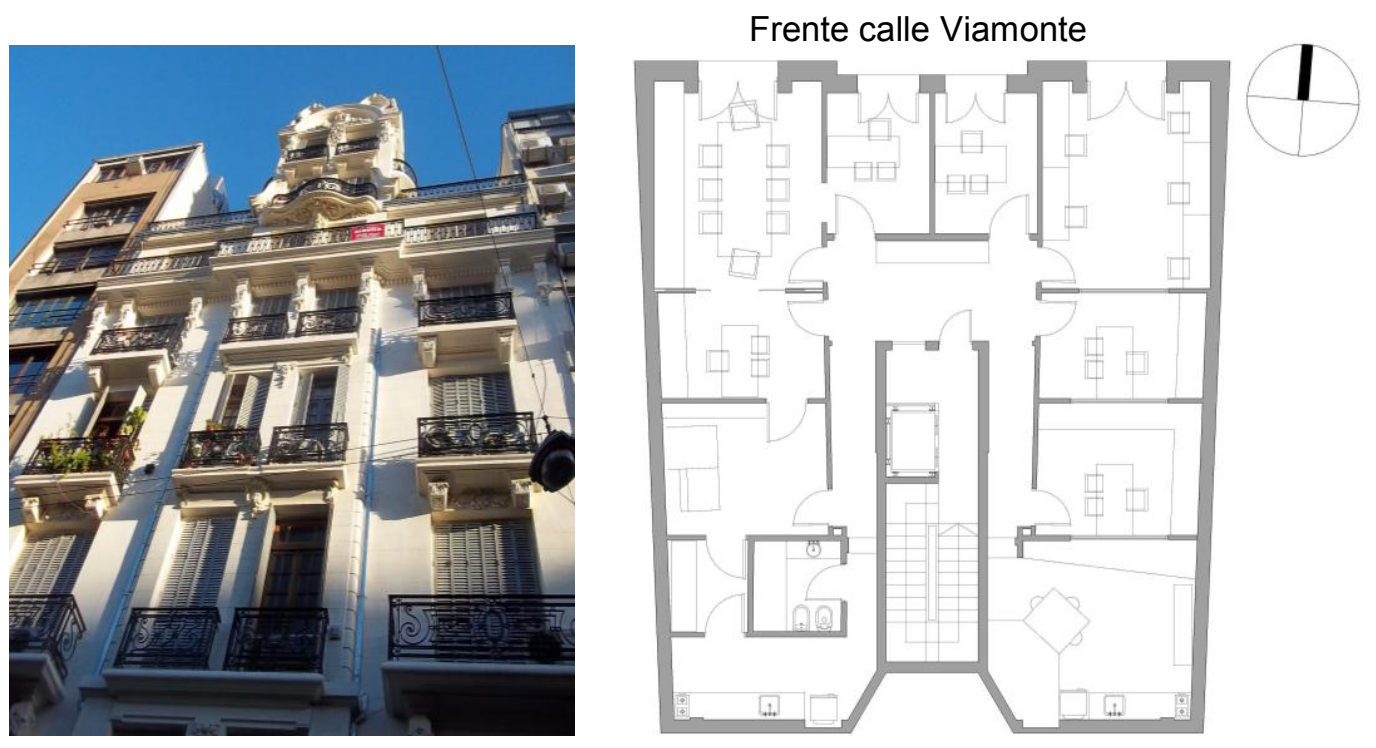

Figuras V-28 y 29: Vista del frente y planta tipo del edificio de oficinas analizado (Caso D). 
Su tecnología constructiva es convencional con estructura de hormigón armado y muros de cerramiento exterior de ladrillos comunes, conformando un muro de $22 \mathrm{~cm}$ de espesor final, sin aislamiento higrotérmico adicional. Por su parte los cerramientos interiores se han materializado con muros de $15 \mathrm{~cm}$ de espesor final de ladrillos comunes, los que separan los ambientes interiores de las oficinas, a las oficinas entre sí y con las áreas comunes, y con sistema de construcción en seco (placas de yeso) aquellos que dividen los ambientes interiores de cada oficina, que son el resultado de la adaptación de la planta a las necesidades actuales. Las carpinterías son de simple vidriado con perfilería de hierro y cortinas de enrollar de madera.

El sistema de acondicionamiento de aire interior de las distintas oficinas se ha dejado a criterio de los ocupantes. La oficina analizada ha optado por colocar equipos de aire acondicionado frío-calor de $2.400 \mathrm{~W}$ de potencia en los espacios principales para el acondicionamiento del aire en verano. Por su parte para el acondicionamiento del aire en invierno la oficina analizada cuenta con tres estufas de tiro balanceado de $2.500 \mathrm{Kcal}$ y dos estufas eléctricas de $1.200 \mathrm{~W}$.

Los espacios principales de las oficinas se disponen sobre el frente del edificio, de orientación noreste. En el centro del edificio, rodeando el núcleo vertical, se localizan las áreas de servicios y la circulación general de acceso a las oficinas, sin acceso a iluminación ni a ventilación natural. La Figura $V-30$ muestra la descripción básica del edificio, en ella puede verse que los mayores porcentajes de pérdidas de calor se dan a través de renovaciones de aire, muros y ventanas.

\begin{tabular}{|c|c|c|c|c|c|}
\hline \multicolumn{2}{|c|}{ Caso D - Oficinas } & \multicolumn{2}{|c|}{ Aspectos Dimensionales } & \multicolumn{2}{|c|}{ Aspectos Tecnológicos } \\
\hline Ubicación: & Viamonte № 454 - BA & Superficie (m2) & 1994,00 & Muros: & \\
\hline Año: & 1930 (aprox.) & Volumen (m3): & 5384,00 & Exteriores: & Lad. Común $(22 \mathrm{~cm}$.) \\
\hline \multirow{2}{*}{\multicolumn{2}{|c|}{ Pérdidas a través de: }} & Compacidad (adim.): & 0,48 & Interiores: & L.C. $15 \mathrm{~cm}$. / Durlock \\
\hline & & F. Forma (adim.): & 0,79 & Aisl. Termica adicional: & No \\
\hline & & \multicolumn{2}{|l|}{ Aspectos Térmicos } & \multicolumn{2}{|l|}{ Estructura: } \\
\hline & & Coef. UA $\left(\mathrm{W}^{\circ} \mathrm{C} \mathrm{C}\right)$ : & 6199,00 & Columnas / Vigas: & $H^{\circ} A^{\circ}$ \\
\hline & & Coef. G $\left(\mathrm{W} /{ }^{\circ} \mathrm{C}\right)$ : & 1,15 & Cubierta / Entrepiso: & Losa $\mathrm{H}^{\circ} \mathrm{A}^{0}$ \\
\hline & & Coef. G Adm. $\left(\mathrm{W} /{ }^{\circ} \mathrm{C}\right)$ : & 1,14 & Aisl. Termica adicional: & No \\
\hline & & Aspectos Energéti & & Carpinterias: & \\
\hline \multirow{2}{*}{\multicolumn{2}{|c|}{ 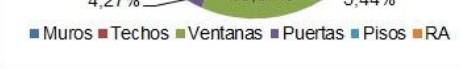 }} & Q (kWh/año): & 238444,00 & Ventanas: & Hierro (vidrio simple) \\
\hline & & Qs (kWh/m2/año): & 119,58 & Prot. Solar: & Cortina Enrollar Madera \\
\hline
\end{tabular}

Figura V - 30: Descripción básica del edificio de oficinas analizado (Caso D).

\subsubsection{Caso E}

Se trata de un edificio construido en la Ciudad Autónoma de Buenos Aires sobre un lote de $15 \times 40 \mathrm{~m}$. No se tienen datos exactos de la fecha de edificación, sin embargo por el tipo de construcción, puede afirmarse que se trata de un edificio de fines de 1970. Se compone de un subsuelo, planta baja y nueve plantas tipo. En planta baja se encuentra la portería, el hall de acceso y un local comercial. Las plantas del primer al noveno piso se dividen en cinco oficinas de dimensiones variables, las cuales rondan los $70 \mathrm{~m}^{2}$ (Figuras $\mathrm{V}-31$ y 32 ).

Su tecnología constructiva es convencional con estructura de hormigón armado y curtain wall con estructura metálica y vidrio simple coloreado. Por su parte los muros medianeros se han materializado con ladrillos huecos de $18 \times 18 \times 33 \mathrm{~cm}$, los cerramientos interiores se han materializado con ladrillos huecos de $12 \times 18 \times 33 \mathrm{~cm}$, los que separan a las oficinas entre sí y con las áreas comunes, y con ladrillos huecos de $8 \times 18 \times 33 \mathrm{~cm}$, aquellos que dividen los ambientes interiores de cada oficina. 
Para la calefacción de las distintas unidades del edificio se dispone de un sistema del tipo central, alimentado por gas natural. Por su parte el sistema de acondicionamiento de aire interior de las distintas oficinas se ha dejado a criterio de los ocupantes; las unidades analizadas han optado por colocar equipos de aire acondicionado en los distintos ambientes que componen las oficinas.

Las unidades funcionales se agrupan en forma de peine a lo largo del eje mayor del lote (40 $\mathrm{m}$ ), dejando dos patios de aire y luz con orientación este. Los ambientes principales que conforman el espacio interior de las distintas unidades funcionales se disponen sobre la fachada principal (orientación sur) y sobre los patios internos (orientación norte y sur). Sobre el lateral (orientación este) se disponen las áreas de circulación para el acceso a las distintas unidades funcionales, los sanitarios y el núcleo de circulación vertical. La fachada principal del edificio se compone de un curtain wall con perfilería de aluminio y simple vidriado coloreado. Por su parte, las fachadas de las oficinas sobre los patios interiores (orientación norte y sur), en cambio, se han materializado con muros de ladrillo cerámico hueco de $18 \times 18 \times 33 \mathrm{~cm}$ y cuentan con carpinterías de aluminio de simple vidriado sin protección solar. La Figura $\mathrm{V}-33$ muestra la descripción básica del edificio, en ella puede verse que los mayores porcentajes de pérdidas de calor se dan a través de ventanas, muros y renovaciones de aire.
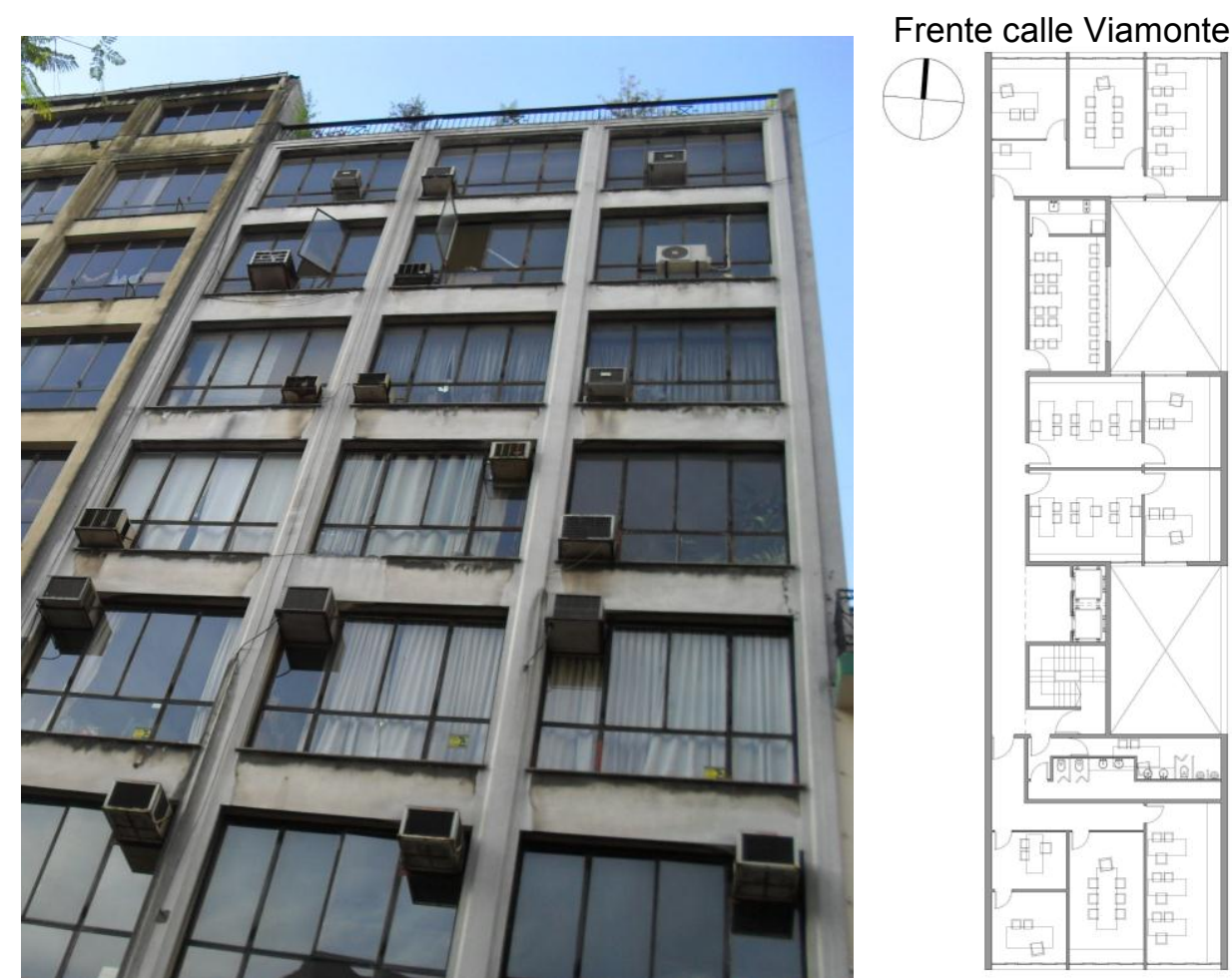

Figuras V-31 y 32: Vista del frente y planta tipo del edificio de oficinas analizado (Caso E).

\begin{tabular}{|c|c|c|c|c|c|}
\hline \multicolumn{2}{|c|}{ Caso E - Oficinas } & \multicolumn{2}{|c|}{ Aspectos Dimensionales } & \multicolumn{2}{|c|}{ Aspectos Tecnológicos } \\
\hline \multirow{2}{*}{\begin{tabular}{|l|} 
Ubicación: \\
Año:
\end{tabular}} & Viamonte № 867 - BA & Superficie $(\mathrm{m} 2)$ & 2907,00 & \multicolumn{2}{|l|}{ Muros: } \\
\hline & 1970 (aprox.) & Volumen (m3): & 7849,00 & Exteriores: & LH 18 \\
\hline \multirow{2}{*}{\multicolumn{2}{|c|}{ Pérdidas a través de: }} & Compacidad (adim.): & 0,45 & Interiores: & LH 12 - LH 08 - Durlock \\
\hline & & F. Forma (adim.): & 0,83 & Aisl. Termica adicional: & No \\
\hline & & \multicolumn{2}{|c|}{ Aspectos Térmicos } & \multicolumn{2}{|l|}{ Estructura: } \\
\hline & & Coef. UA $\left(\mathrm{W} /{ }^{\circ} \mathrm{C}\right)$ : & 11541,00 & Columnas / Vigas: & $H^{\circ} A^{\circ}$ \\
\hline & & Coef. G $\left(\mathrm{W} /{ }^{\circ} \mathrm{C}\right)$ : & 1,47 & Cubierta / Entrepiso: & Losa $\mathrm{H}^{\circ} \mathrm{A}^{\circ}$ \\
\hline & & Coef. G Adm. $\left(\mathrm{W} /{ }^{\circ} \mathrm{C}\right):$ & 1,11 & Aisl. Termica adicional: & No \\
\hline & & Aspectos Energét & & Carpinterias: & \\
\hline \multirow{2}{*}{\multicolumn{2}{|c|}{ 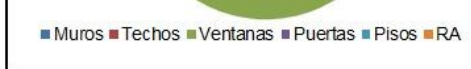 }} & $\mathrm{Q}$ (kWh/año): & 443961,00 & Ventanas: & Curtain Wall \\
\hline & & Qs (kWh/m2/año): & 152,72 & Prot. Solar: & No \\
\hline
\end{tabular}

Figura V - 33: Descripción básica del edificio de oficinas analizado (Caso E). 


\section{CAPÍTULO VI}

AUDITORÍA ENERGÉTICA

\subsection{Introducción}

Una auditoría energética es el estudio, inspección y análisis del consumo energético de un sistema para comprender su dinámica y buscar oportunidades de mejora del rendimiento energético. Los objetivos de una auditoría energética son analizar los flujos energéticos de la instalación auditada, establecer las estrategias de ahorro y eficiencia energética más adecuadas, evaluar y valorar los ahorros potenciales desde el punto de vista técnico, económico y medioambiental.

La elaboración de una auditoría energética proporciona ciertos beneficios para quien la solicita. Algunos de ellos son la evaluación del uso de la energía por parte de la instalación, la identificación de puntos a través de los cuales se producen los derroches de energía, y la consecuente reducción de costes y emisiones en caso de que se implementen las medidas propuestas.

Si la auditoría energética se realiza según el enfoque tradicional, por el que se evalúan cuestiones relacionadas únicamente con la eficiencia energética del sistema, la implementación de las medidas propuestas garantizará el consumo eficiente de energía de la instalación, entendiendo por eficiencia energética al conjunto de acciones que garantizan el ahorro energético. Esto significa poder realizar el mismo trabajo con un menor gasto de recursos energéticos y la consecuente reducción de los costos del suministro.

En los países más desarrollados donde la energía es considerada un bien de consumo y no un servicio como sucede en nuestro país, el desarrollo de una auditoría energética se realiza según otro enfoque, distinto del tradicional. Según este enfoque, al cual podría denominarse de "eficiencia + gestión", por el que se evalúan cuestiones relacionadas con la eficiencia energética y la gestión del consumo energético; el estudio además establece propuestas para un consumo inteligente en el que se lleva a cabo la gestión de los procesos. El término gestión implica, en un principio, consumir la misma cantidad de energía y realizar el mismo trabajo pero a un menor costo económico, el cual puede lograrse a partir del ajuste del perfil de carga del sistema a las señales económicas que intervienen. Se trata, en este caso, de dar una respuesta al precio de la energía. Sin embargo este enfoque también involucra cuestiones relacionadas a la eficiencia energética, motivo por el cual igualmente debe poder realizarse el mismo trabajo con un menor consumo energético. 
Cuando el objeto estudiado es un edificio, el resultado de la auditoría tiende a buscar el modo de reducir el consumo de energía, manteniendo y, en caso de ser posible, mejorando el confort higrotérmico, la salubridad y la seguridad del ambiente interior.

En los países más avanzados los contenidos mínimos que debe tener una auditoría energética están fijados por el Gobierno. En España, por ejemplo, el Instituto para la Diversificación y el Ahorro de Energía (IDAE) y las Agencias Regionales de la Energía de cada comunidad son los encargados de fijar estos requisitos mínimos. En este país, además, es posible la financiación pública de hasta el $75 \%$ del coste total de la auditoría y existen también ayudas adicionales para realizar las inversiones necesarias según el resultado de la auditoría.

En la elaboración de una auditoría energética se distinguen distintas etapas, a saber:

- Diagnóstico de la situación inicial.

- Balance energético.

- Benchmarking.

- Evaluación de mejoras aplicables.

- Presentación de resultados.

En la etapa del diagnóstico inicial se recogen los datos necesarios para la pre-evaluación del edificio. De ser posible debe accederse a esta información antes de la primera visita, de modo que se pueda elaborar la encuesta antes de ir al edificio por primera vez. Entre la información que debe recolectarse es muy importante tener datos de los consumos y costes mensuales de electricidad y gas natural, la estructura de esos costes, y los planos de planta de las unidades a auditar.

Previo a la visita deben detectarse las carencias de información sobre las que es necesario incidir. Debe evaluarse el tamaño del edificio y de las unidades funcionales a auditar, los consumos específicos de energía eléctrica y gas natural (en $\mathrm{kWh} / \mathrm{m}^{2}$ y m $3 / \mathrm{m}^{2}$ respectivamente) y los costes respectivos, y comparar con consumidores del mismo sector. Asimismo es necesario evaluar los perfiles de utilización de energía eléctrica y gas natural; determinar la estacionalidad, discriminación horaria, etc.

La encuesta no es más que un esquema formalizado para recopilar la información requerida; es la traducción de los objetivos informativos de la investigación en preguntas específicas. Si bien el diseño del cuestionario es una técnica aprendida por el investigador a través de su experiencia, existen pautas para ayudar en su diseño. Existen distintos tipos de preguntas (abiertas, cerradas o semi-abiertas) entre las cuales puede hacerse una combinación para que el cuestionario resulte ameno para el entrevistado y eficiente para el entrevistador.

Asimismo resulta muy importante realizar un control del trabajo de campo; la base de toda investigación descansa en la veracidad de la información recogida. Es necesario realizar una verificación de los patrones de consumo y valores indicados durante la entrevista con las mediciones realizadas.

Luego de la primera visita al edificio es necesario plantearse qué variables deben medirse, qué equipos de medición y registro de datos son necesarios en función de la disponibilidad que se tenga de los mismos, y dónde se van a tomar las mediciones. Para el desarrollo de la auditoría energética de un edificio es necesario mínimamente tomar mediciones de los consumos de energía eléctrica y gas natural, de la temperatura y humedad relativa (interior y exterior), y del nivel de iluminación. No obstante, también pueden tomarse mediciones de la temperatura superficial de la envolvente para controlar, por ejemplo, el nivel de aislamiento térmico de las superficies en contacto con el exterior o con otros ambientes no calefaccionados.

Una vez reunida toda la información debe procederse a realizar una valoración de las instalaciones para lo cual es necesario evaluar la información disponible; si es o no suficiente y la consistencia de la misma. Luego se procede con un pre-diagnóstico energético del edificio, 
para ello es necesario realizar el balance energético del mismo. El balance energético consiste en realizar un análisis detallado de los consumos energéticos del edificio y el consecuente cálculo de los consumos energéticos y costes específicos de la energía utilizada por unidad de superficie.

El Benchmarking (punto de referencia) es una técnica utilizada para medir el rendimiento de un sistema, en este caso de un edificio, en comparación con otro de referencia. Se trata de indicar en qué situación se encuentra el consumidor dentro de su entorno de actividad. Esto constituye un factor determinante por el cual se decide analizar los casos de estudio y los modelos propuestos según el destino; viviendas u oficinas. Si bien todos los casos responden a un mismo tipo edilicio en lo formal (el edificio de propiedad horizontal en altura), existen diferencias en cuanto a lo funcional (destino). La variable función impacta en la intensidad de uso del edificio o modelo propuesto en lo que respecta al grado de ocupación, potencia de iluminación, potencia de equipamiento eléctrico, etc.

Para la evaluación de las mejoras aplicables deben analizarse las potenciales mejoras energéticas posibles de ser realizadas en las instalaciones. Se trata de hacer una valoración técnica, económica, medioambiental y calcular la inversión necesaria para llevar a cabo las mejoras a implementar.

La valoración técnica no es otra cosa que conocer cuánta energía se ahorra al año (en kWh ó $\mathrm{m}^{3}$ ), para ello es necesario identificar los componentes en los que se implantarán las medidas, identificar los días típicos en los que se pueden aplicar las medidas, identificar a qué períodos afectan estas medidas, o si afectan a todos por igual, calcular el consumo por período de la unidad sobre la que se va a implementar la medida antes de aplicar la mejora, calcular el consumo por período de la unidad sobre la que se va a implementar la medida después de aplicar la mejora y, por último, calcular el ahorro por período.

La valoración económica, por su parte, se trata de calcular el coste por período de los procesos sobre los que se van a implementar las medidas antes de llevar a cabo las mejoras, calcular el coste por período de los procesos sobre los que van a implementarse las medidas después de llevar a cabo las mejoras y luego calcular el ahorro por período como la diferencia entre los costes calculados.

La valoración medioambiental comprende el cálculo de las emisiones por período de los procesos sobre los que se van a implementar las medidas antes de llevar a cabo las mejoras sugeridas, luego el cálculo de las emisiones por período de los procesos sobre los que se van a implementar las medidas después de llevar a cabo las mejoras sugeridas y, finalmente el ahorro de emisiones por período como la diferencia entre las cantidades obtenidas en dichos cálculos.

Por su parte, el cálculo de la inversión a realizar está dado por el coste de los elementos a incorporar al edificio para conseguir las mejoras propuestas más el coste de instalación y de la puesta en obra de esos elementos (materiales y mano de obra). El período de retorno está dado por el tiempo necesario para que los ahorros compensen la inversión; se puede calcular según la siguiente expresión:

$$
\text { Período de Retorno }=\frac{\text { Costo de Inversión }}{\text { Ahorro anual }}
$$$$
\text { [Ecuación VI - 1] }
$$

Una vez reunida toda la información necesaria, y luego de analizar las posibles acciones que garanticen el ahorro energético, se procede a la redacción del informe final para ser presentado ante quien lo haya solicitado. El informe resultante de la auditoría energética constituye una herramienta fundamental para la toma de decisiones por parte de los responsables de la instalación, además debe resultar básico para la obtención de ayuda sobre futuras inversiones para medidas de eficiencia energética. 
El informe final es la última fase en la realización de una auditoria, en la cual debe hacerse una exposición clara y concisa de los principales resultados de la auditoria (descripción de las instalaciones, balances energéticos y de producción, principales medidas detectadas y valoración y, benchmarking -posición del edificio auditado en su sector-).

En correspondencia con lo expresado anteriormente, los contenidos mínimos de una auditoría energética para un edificio son los siguientes:

- Datos generales del establecimiento:

- Provincia, localidad, dirección.

- Descripción de las actividades realizadas.

- Antigüedad de las instalaciones.

- Características constructivas.

- Número de ocupantes.

- Factor de ocupación y régimen de actividades (días hábiles, fines de semana, feriados, vacaciones).

- Fuentes de suministro energético:

- Consumo anual de electricidad (kWh/año).

- Consumo anual de gas natural $\left(\mathrm{m}^{3} / a n ̃ o\right)$.

- Instalaciones:

- Descripción de las instalaciones de servicios generales.

- Descripción de las instalaciones de producción y distribución de frío.

- Descripción de las instalaciones de producción y distribución de calor.

- Descripción del equipamiento eléctrico.

- Descripción de las instalaciones de alumbrado exterior (número, tipo y características de luminarias de alumbrado exterior).

- Descripción de las instalaciones de alumbrado interior (número, tipo y características de luminarias por local).

- Análisis energético:

- Consumo anual de electricidad para iluminación, acondicionamiento de aire y equipamiento eléctrico ( $\mathrm{kWh} / \mathrm{año}$ ).

- Consumo anual de gas natural para calefacción, agua caliente y cocción ( $\left.\mathrm{m}^{3} / a n ̃ o\right)$.

- Consumos y costes específicos:

- Consumos mensuales de electricidad y energía térmica por unidad de superficie.

- Costes mensuales de electricidad y energía térmica por unidad de superficie.

- Benchmarking:

- Benchmark= punto de referencia (comparación de consumos del edificio con otros de su misma función).

- Propuestas de mejoras que pueden realizarse en el edificio:

- Actuaciones de eficiencia energética (para cada mejora: descripción, ventajas, áreas de aplicación).

- Ahorro energético (en kWh/año).

- Ahorro en costes energéticos (en \$/año).

- Mejora medioambiental (ahorro en emisiones de $\mathrm{CO}_{2}$, en tonCO $\mathrm{CO}_{2} / \mathrm{año}$ ).

- Inversiones y rentabilidad económica (inversión y periodo de retorno).

- Tabla resumen de las medidas propuestas.

- Anexos

- Facturas energéticas (uno o dos últimos años).

- Mediciones realizadas (equipos utilizados, datos obtenidos, duración de las campañas, etc.). 
- Planos.

- Encuestas.

\subsection{Métodos, Instrumentos y Técnicas}

Tal como se menciona en el capítulo anterior, durante los años dedicados al desarrollo del siguiente trabajo como Becaria de Investigación en el LAyHS - FAU - UNLP se desarrollaron auditorías energéticas en edificios de propiedad horizontal en altura destinados a viviendas y oficinas, tanto en la Ciudad Autónoma de Buenos Aires como en la Ciudad de La Plata. El desarrollo de tales auditorías se realizó según el enfoque tradicional, el cual se definió anteriormente. Sin embargo durante la estancia en el IIE - UPV, se realizó la auditoría energética de un polideportivo municipal según el enfoque denominado "eficiencia + gestión", en el marco del Máster en Tecnología para el Desarrollo Sostenible de la UPV; estudiando de este modo el protocolo utilizado en países más avanzados.

El hecho de que en nuestro país la energía sea considerada hoy en día como un servicio ha sido la causa determinante para optar por el enfoque tradicional al momento de llevar a cabo las auditorías energéticas. Mediante este enfoque, como se expresa en párrafos anteriores, la implementación de las medidas propuestas asegura el consumo eficiente de energía, entendiendo por eficiencia energética al conjunto de acciones que garantizan el ahorro energético. Por otra parte se asume que la reducción de la demanda de energía para el acondicionamiento interior del edificio se ve reflejada en la reducción del costo necesario para mantener al interior en confort higrotérmico.

El proceso de auditorías abarcó los años 2009, 2010 y 2011. Durante este tiempo se tomaron mediciones de las condiciones de confort higrotérmico de los ambientes interiores y de las condiciones exteriores en dos períodos; invierno y verano, durante un lapso de entre siete y diez días. Durante este tiempo también se tomaron mediciones de los consumos de gas natural y electricidad en todas las unidades funcionales de los edificios analizados, de modo de poder determinar un índice de consumo de gas natural y energía eléctrica por unidad de superficie para las condiciones de invierno y verano, tanto para viviendas como para oficinas (Figuras VI -1 y 2$)$.
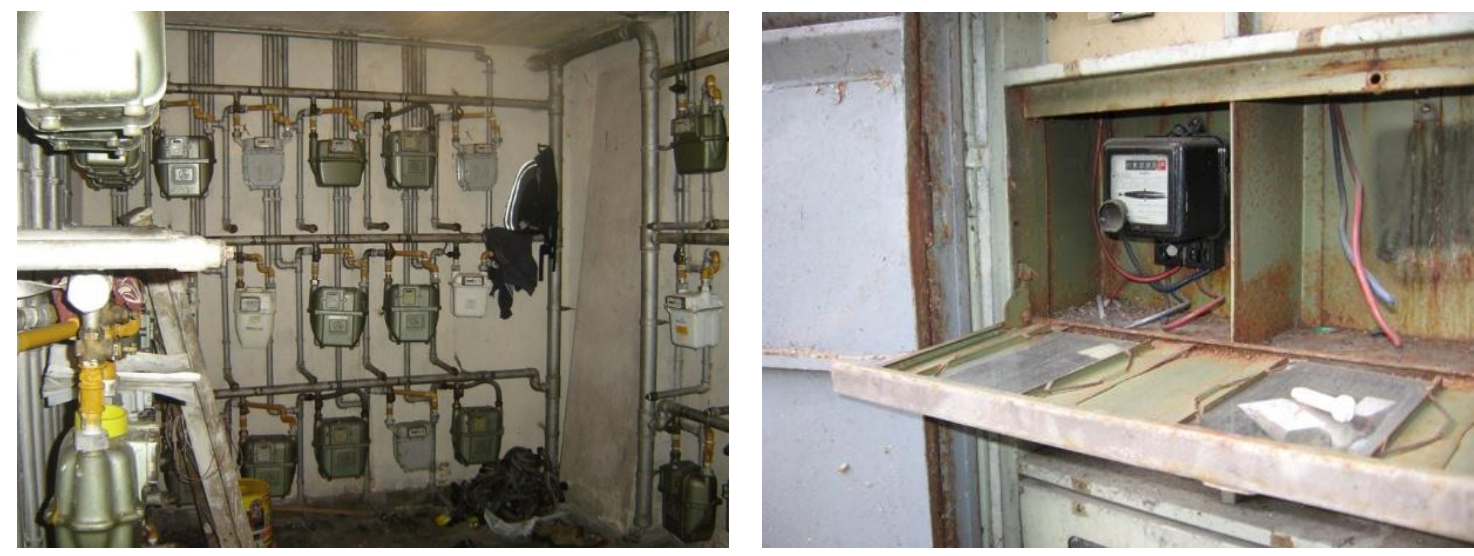

Figuras VI- 1 y 2: Sala de medidores de gas natural y de energía eléctrica de uno de los edificios auditados.

En un principio se auditaron los edificios destinados a viviendas y luego los edificios destinados a oficinas. Para la elección de los casos se buscó principalmente que la muestra fuera representativa de la realidad construida en nuestro país (Rosenfeld, E. et Al.; 1986, 1988, 1989; Gonzalo, G.; 1999 - Baso, M. et Al.; 2001; Veigas, G. et Al.; 2007; Evans, J. M.; 2012;). No obstante un condicionante importante al momento de elegir los casos fue la posibilidad de tener acceso a toda la información. Al respecto cabe destacar que algunos casos que habían sido pre-seleccionados debieron ser descartados ya que no fue posible 
completar la etapa de análisis por falta de información. Para la realización de las auditorias energéticas fue necesario no sólo tomar los consumos de gas natural y energía eléctrica de todas las unidades que conformaban cada edificio sino que además debió medirse el comportamiento higrotérmico de las unidades a las que se podía acceder. En estas unidades además se realizaron encuestas socio-energéticas.

Para llevar a cabo la campaña de medición se utilizaron micro-adquisidores de datos HOBO U10-003 para medir la temperatura y humedad en los ambientes interiores, micro-adquisidores de datos HOBO U12-012 para medir temperatura, humedad e iluminación en los ambientes interiores y una Estación Meteorológica HOBO ProV2 para medir la temperatura y humedad en el exterior. La radiación solar fue registrada por la estación meteorológica fija Davis "Vantage Pro2" y para el procesamiento de los datos generados por los HOBOS se utilizó el "HOBOwarePro" y el "BoxCarPro" (Figuras VI - 3, 4 y 5).

Previo a la colocación de los micro-adquisidores de datos debieron estudiarse las unidades funcionales que iban a auditarse. Fue necesario realizar una visita previa al edificio en la que se tomaron las medidas de los locales para poder desarrollar un plano orientativo de la planta del departamento o la oficina que iba a ser auditada. Del mismo modo se tomaron notas que describían las condiciones particulares de los locales, de modo que contribuyeran a elegir los sitios más apropiados donde disponer los HOBOS.
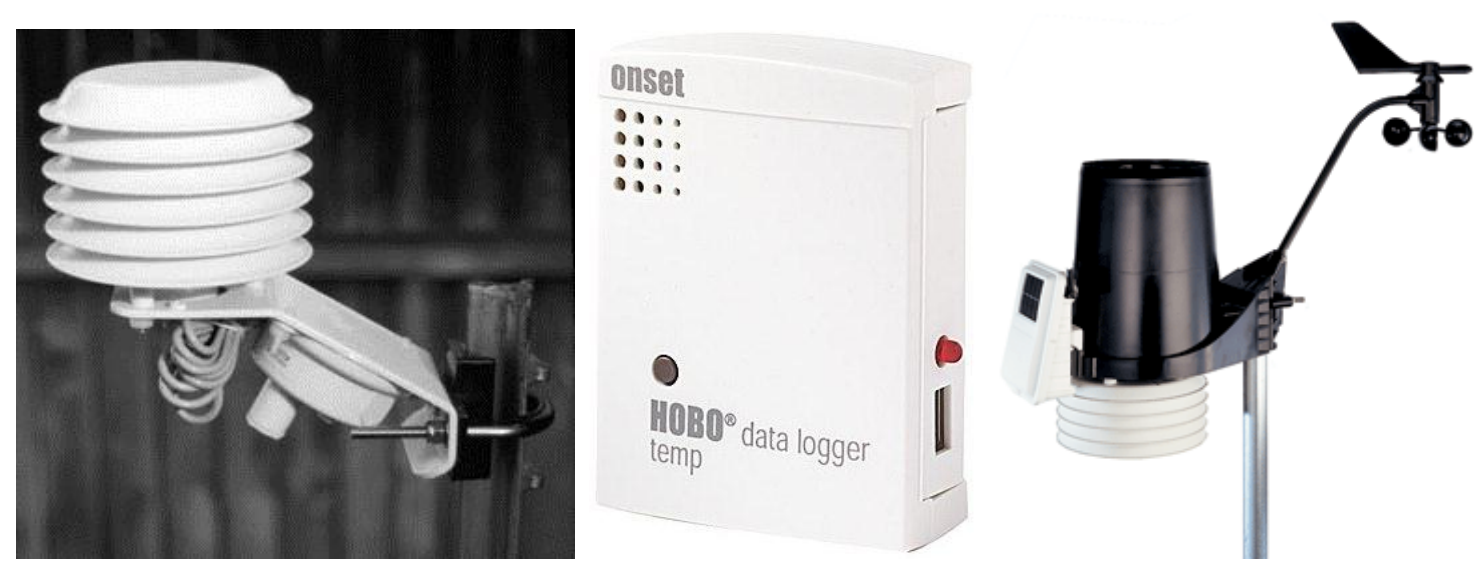

Figuras VI - 3, 4 y 5: Estación meteorológica HOBO ProV2, micro-adquisidores de datos HOBO U10-003 y estación meteorológica fija Davis Vantage Pro2 - Fuente: Onset HOBO Data Loggers - Disponible en: http://www.onsetcomp.com

En el caso de los edificios de viviendas los HOBOS se distribuyeron de la siguiente manera; uno en el dormitorio principal, otro en el estar-comedor, y los otros dos en el calefón y sobre el horno para poder discriminar el consumo de gas natural para agua caliente sanitaria y cocción respectivamente (Figura $\mathrm{VI}-6$ ). El intervalo de tiempo en la toma de datos se fijó en quince minutos para los HOBOS ubicados en los ambientes principales y en la Estación Meteorológica, y un minuto para los HOBOS ubicados sobre el calefón y sobre el horno. Luego, los datos obtenidos fueron exportados a Excel para su análisis particularizado.

En el caso de los edificios de oficinas los HOBOS se distribuyeron en los ambientes principales, variando la cantidad en función de la superficie de cada unidad funcional, se utilizaron entre dos y cuatro micro-adquisidores por unidad (Figura IV - 7). El intervalo de tiempo en la toma de datos se fijó en quince minutos tanto para los HOBOS ubicados en los ambientes principales como para la Estación Meteorológica. Al igual que en el caso de los edificios de viviendas, los datos obtenidos fueron exportados a Excel para su análisis particularizado. 


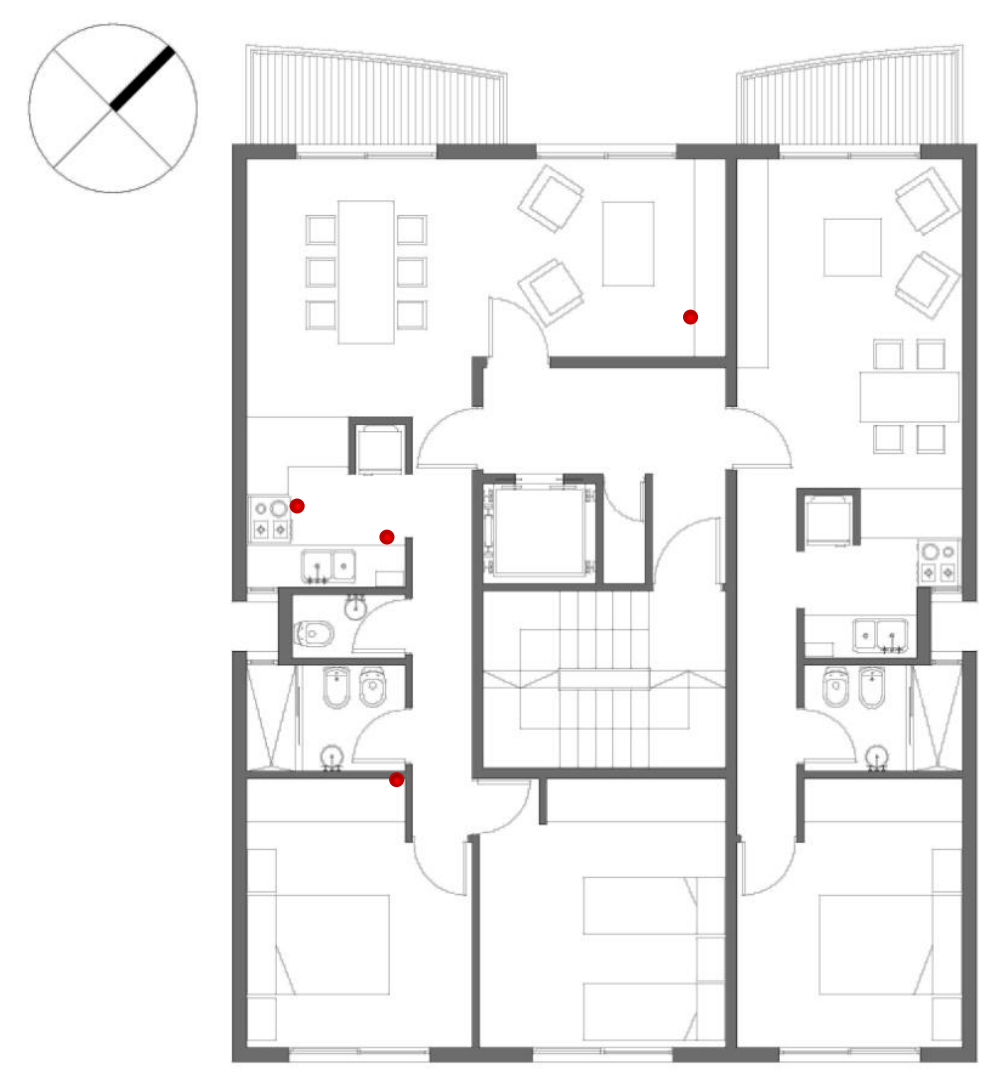

Figura VI - 6: distribución de los HOBOS en uno de los edificios de viviendas auditado.

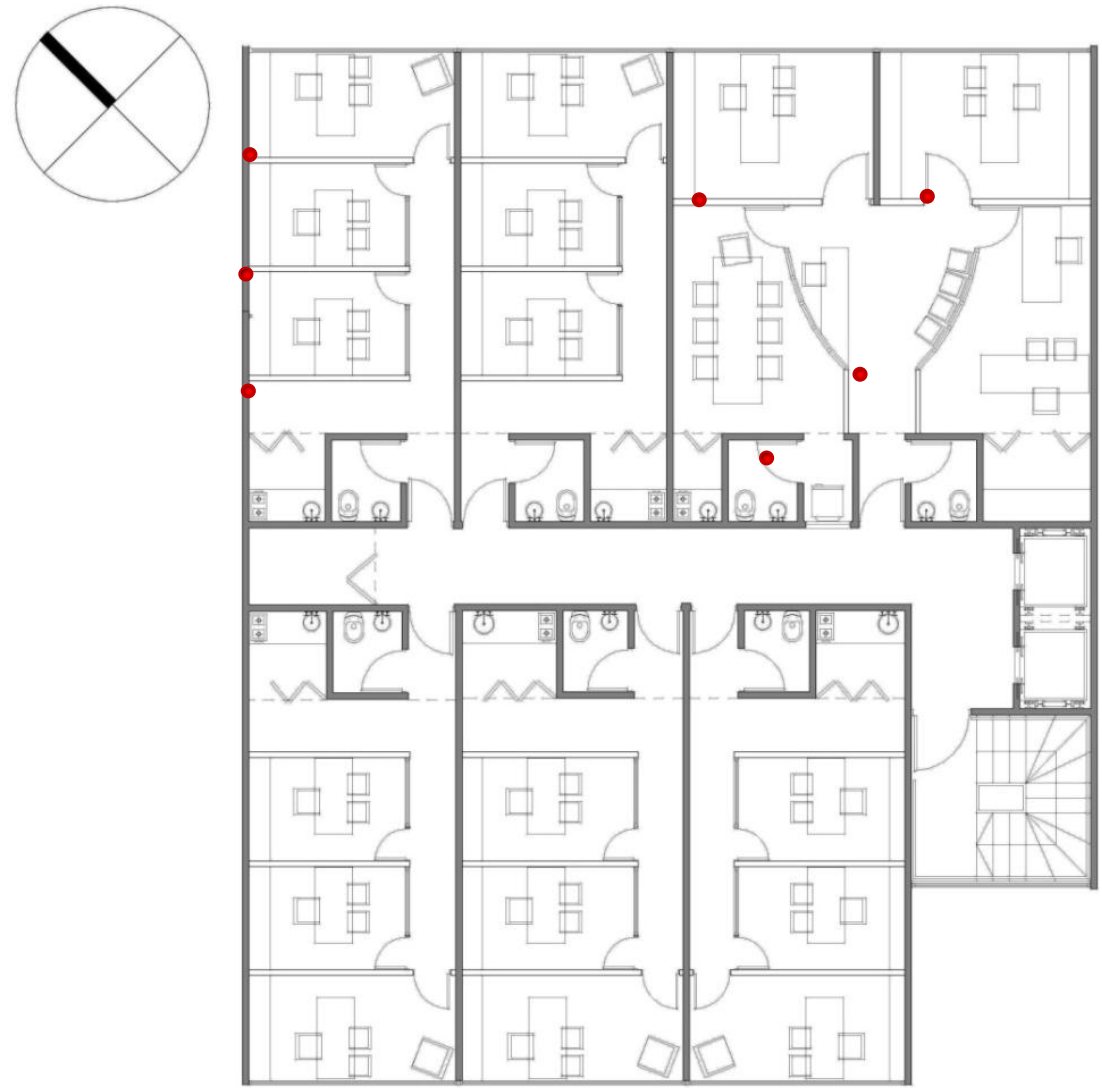

Figura IV - 7: distribución de los HOBOS en uno de los edificios de oficinas auditado. 
Los HOBOS deben colocarse fuera del alcance de la radiación solar directa y de fuentes de calor cercanas que modifiquen las lecturas de temperatura y humedad que se desean obtener, y en el caso de aquellos que miden intensidad lumínica, fuera de todo elemento que interrumpa su lectura. De modo que, como ya se mencionó anteriormente, antes de colocar el instrumental debieron evaluarse las condiciones interiores de las distintas unidades funcionales que iban a auditarse (Figuras $\mathrm{VI}-8,9$ y 10 ).

Teniendo en cuenta la estratificación del aire que se produce en los ambientes interiores, los HOBOS deben colocarse a una altura media, para que las lecturas se aproximen a las percibidas por los ocupantes. En este sentido para el caso de edificios de vivienda se tomó la altura media del local (aproximadamente $1,50 \mathrm{~m}$ ) pero para el caso de edificios de oficinas los micro-adquisidores de datos se colocaron a la altura del plano de trabajo (aproximadamente $0,80 \mathrm{~m}$ ), que es la altura a la que los ocupantes se encuentran la mayor parte del tiempo.
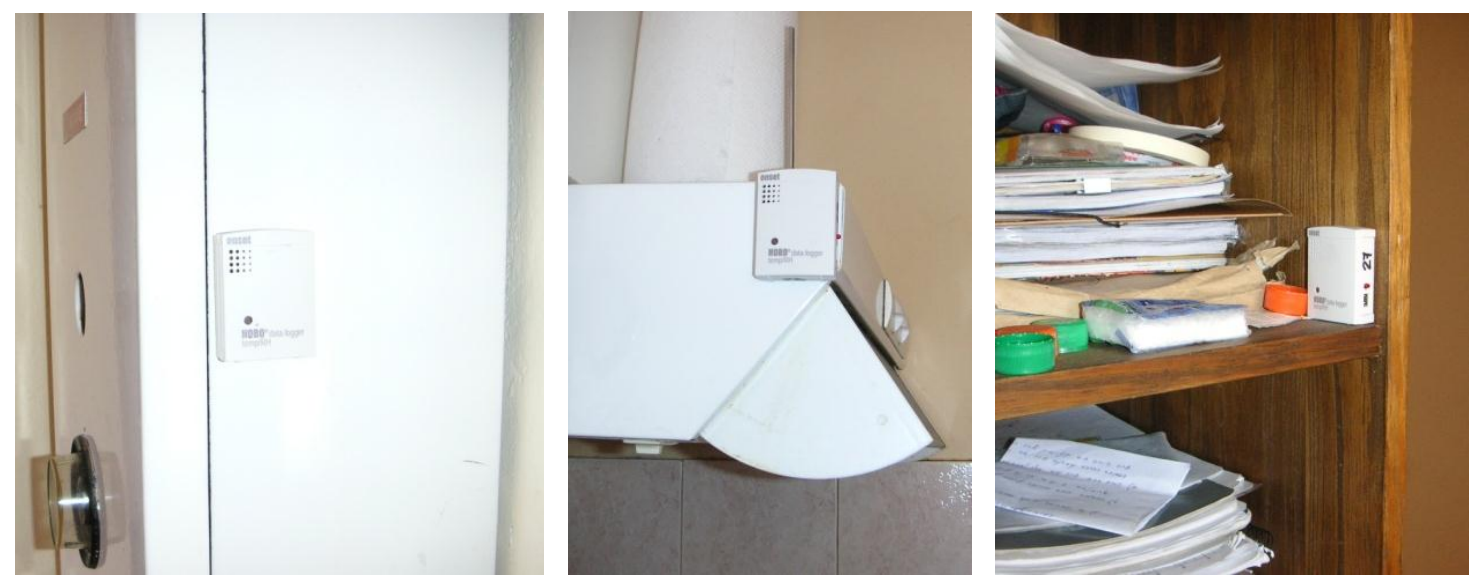

Figuras VI- 8, 9 y 10: colocación de los HOBOS en una de las viviendas auditadas (mediciones de agua caliente, cocción y confort higrotérmico).

La información recolectada de los HOBOS y de los medidores de energía eléctrica y gas natural no brindaba toda información necesaria para poder llevar a cabo la auditoría, por lo cual fue necesario realizar una encuesta socio-energética a los usuarios de las distintas unidades funcionales analizadas. Cabe aclarar que las encuestas destinadas a los usuarios de edificios de viviendas (Anexo I - 1.1) no eran las mismas que las encuestas destinadas a los usuarios de edificios de oficinas (Anexo I-1.2).

Con las encuestas pudieron obtenerse datos precisos acerca del edificio (año de construcción, ubicación, características constructivas, etc.), pero también datos relevantes de los ocupantes y de la percepción que estos tenían respecto del confort de las unidades funcionales. Se obtuvieron datos acerca de la composición del grupo que ocupaba la unidad funcional auditada, factor de ocupación según bandas horarias (distinguiendo días hábiles y fines de semana), equipamiento de calefacción, acondicionamiento térmico, equipamiento eléctrico y de iluminación artificial, movilidad de los ocupantes, hábitos de calefacción, ventilación, iluminación, uso de agua caliente, etc. Del mismo modo se obtuvieron datos relacionados con la opinión de los usuarios respecto del comportamiento de la unidad funcional en invierno y verano, de la luminosidad, y del consumo anual de energía eléctrica y de gas natural, para lo cual se tomaron lecturas de las boletas de gas natural y energía eléctrica de cada una de las unidades auditadas (Figuras $\mathrm{VI}-11$ y 12). 

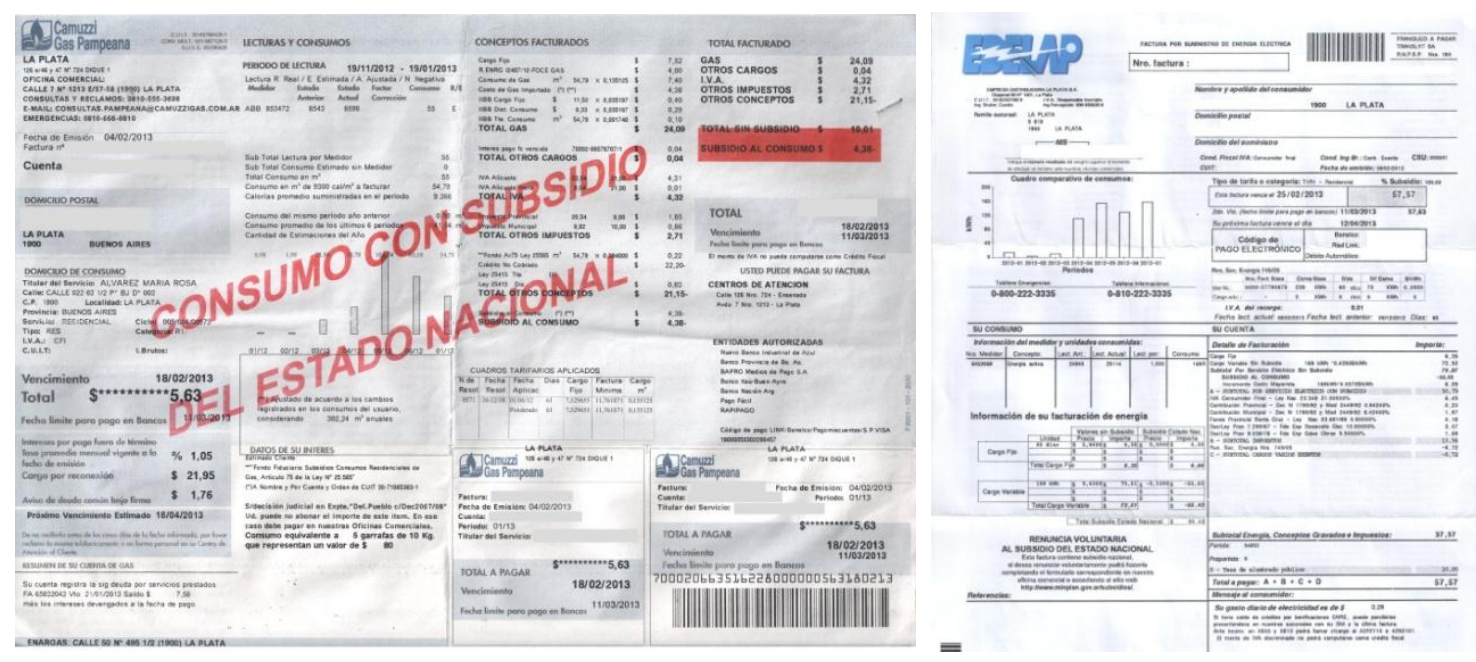

Figuras VI - 11 y 12: Boletas de gas natural y energía eléctrica de una de las unidades de viviendas auditadas.

Junto con la elaboración de los planos y la encuesta socio-energética, se tomaron notas acerca de las características de la envolvente edilicia; estructura de sostén, composición de cerramientos opacos verticales y horizontales, carpinterías y cerramientos vidriados, elementos de protección solar, altura de locales, etc. Se prestó especial atención a la materialización de los elementos de la envolvente edilicia en contacto con el exterior como así también de aquellos que separan a las distintas unidades funcionales entre sí y con los espacios comunes, no acondicionados térmicamente. Con estas notas y los datos extraídos de la encuesta se procedió a realizar un análisis global de los distintos edificios.

Con ayuda del Google Earth, fotografías peatonales exteriores e interiores, y las anotaciones realizadas durante las visitas realizadas pudieron obtenerse datos precisos de cada planta tipo de los edificios analizados. Estos datos facilitaron el estudio particularizado de las distintas unidades de análisis. En todos los casos, para el estudio del comportamiento energéticoambiental de los edificios analizados se partió del estudio particularizado de las unidades funcionales a las que pudo accederse. Luego los resultados obtenidos fueron extrapolados al total del edificio estudiado para su análisis global.

Se estudió particularmente la planta tipo de cada edificio analizado, por considerarse la más representativa en este tipo de construcción. Cada una de estas plantas se analizó por medio del AuditCAD (Figura VI - 13). Dicho programa permite analizar mensualmente el comportamiento térmico y energético de un edificio, mediante el ingreso de los datos auditados al tiempo que determina indicadores formales y energéticos. A partir de las características del edificio y grado de ocupación (iluminación, personas, equipamiento) determina cuanta energía será requerida para mantener al edificio en temperatura de termostato. Los resultados devueltos son la demanda de energía eléctrica y gas natural, distinguiendo la demanda con sol y sin sol (días nublados). 


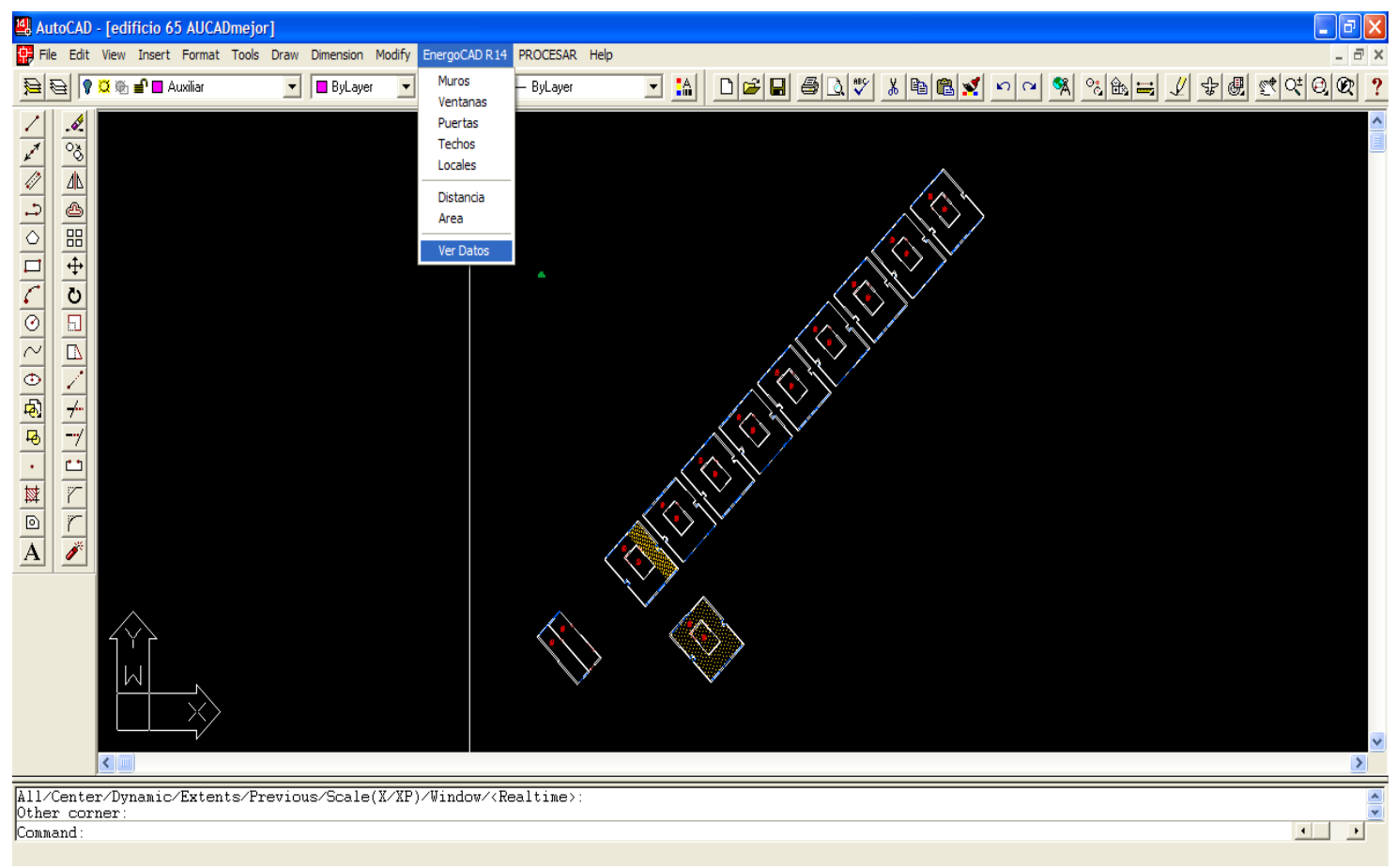

Figura VI - 13: Interfaz gráfica del AuditCAD.

Para el análisis del comportamiento higrotérmico de los edificios, y de las variaciones de temperatura y humedad en las distintas unidades funcionales se eligieron cinco horarios que relacionan las horas de mayor y menor ocupación con la incidencia del sol sobre la envolvente del edificio. El criterio de elección de esas bandas horarias para el caso de edificios de viviendas fue el siguiente:

- 07.00hs: horario de salida del sol - comienzo de actividad dentro de la vivienda.

- 10.00hs: media mañana - los departamentos se encuentran vacíos.

- 13.00hs: primera hora de la tarde - los departamentos vuelven a ocuparse parcialmente.

- 17.00hs: últimas horas de la tarde - ocupación parcial de las viviendas.

- 20.00hs: ausencia de sol - ocupación definitiva hasta el día siguiente.

Para el caso de los edificios de oficinas, el criterio de elección de las bandas horarias fue el siguiente:

- 07.00hs: horario de salida del sol - las oficinas se encuentran vacías.

- 10.00hs: media mañana - máxima ocupación.

- 13.00hs: primera hora de la tarde - horario de almuerzo, ocupación parcial.

- 17.00hs: últimas horas de la tarde - máxima ocupación.

- 20.00hs: ausencia de sol - las oficinas se encuentran vacías.

Como ya se mencionó anteriormente la campaña de medición para cada edificio comprendió entre siete y diez días. Los datos reunidos durante ese período fueron volcados a Excel para su análisis gráfico (Gráfico VI - 1), permitiendo de este modo evaluar el comportamiento interior de las unidades funcionales en relación a las condiciones meteorológicas del ambiente exterior. 


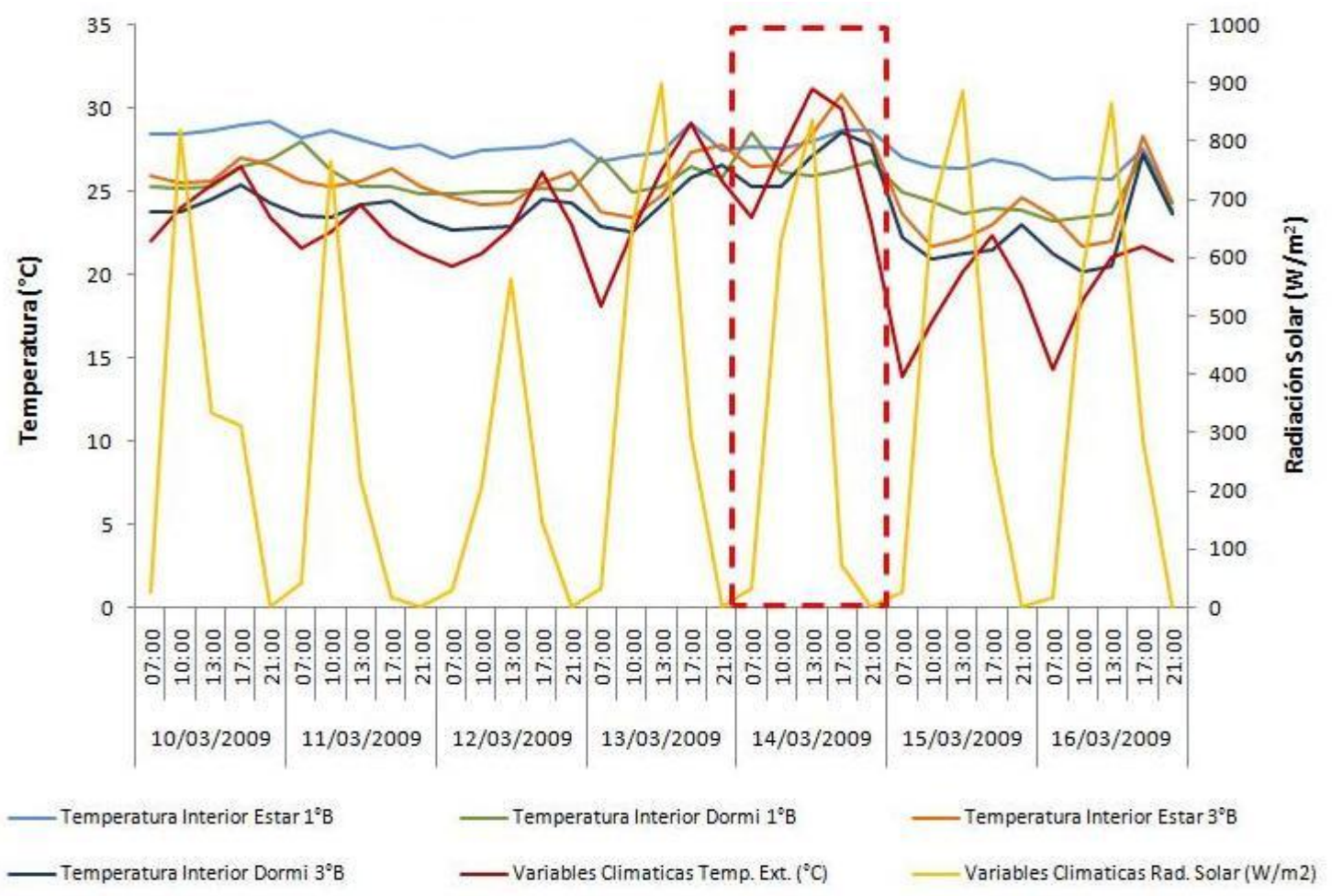

Gráfico VI - 1: Análisis gráfico de los datos extraídos de los Data Loggers HOBOS para una de las unidades de viviendas auditadas (verano).

Luego, para cada unidad funcional, se eligió el día crítico (el más frío en invierno y el más cálido en verano) y se analizó con el PsiConf 1.4 (Gráfico VI - 2), el cual permite ingresar los datos extraídos de los HOBOS y automatizar su graficado en climogramas de B. Givoni. A partir de estos gráficos pudo evaluarse cuáles eran las recomendaciones de diseño que debían llevarse a cabo en el edificio para que los ambientes interiores alcanzaran los niveles de confort indicados en el climograma, para las condiciones de invierno y verano.

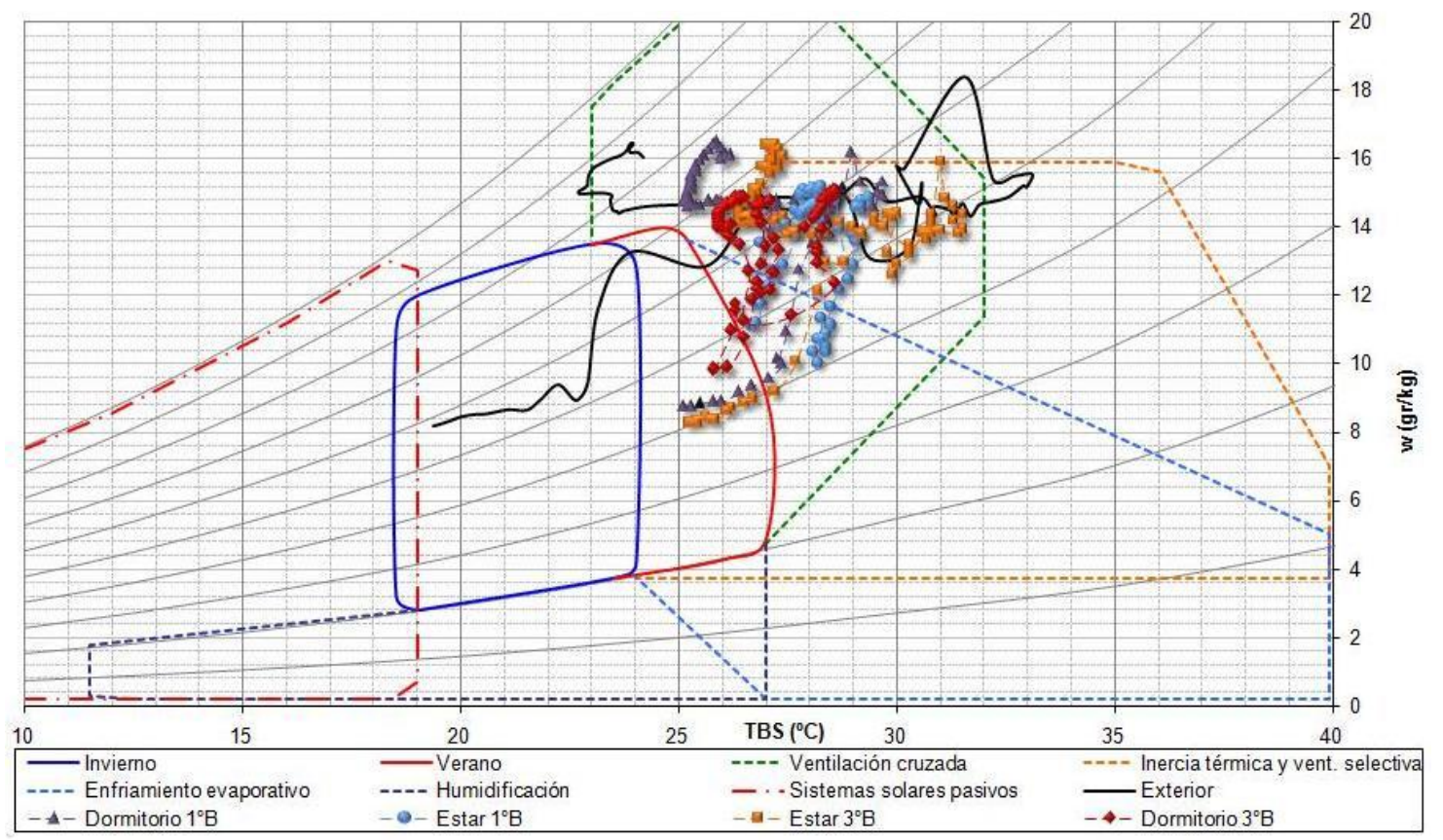

Gráfico VI - 2: Climograma de B. Givoni de un día de verano crítico para una de las unidades de viviendas auditadas. 
Luego, para todos los casos analizados se realizó la verificación de la Norma IRAM 11.900 por la cual se establece la etiqueta de eficiencia energética de calefacción para edificios y la clasificación según la transmitancia térmica de la envolvente.

La etiqueta de eficiencia energética especificada en dicha norma tiene por objeto informar al consumidor sobre la eficiencia térmica de la envolvente de los edificios. Mediante la etiqueta se califica la eficiencia a través de un sistema comparativo, compuesto por ocho clases de eficiencia energética identificadas por las letras $A, B, C, D, E, F, G$ y H, donde la letra $A$ se adjudica a las envolventes de los edificios más eficientes y la $\mathrm{H}$ a las menos eficientes.

Para la determinación de la clase de eficiencia energética del edificio debe obtenerse el valor de la variación media ponderada entre la temperatura de la superficie interior y la temperatura interior de diseño $\left(\tau_{m}\right)$, en grados Celsius, mediante la siguiente expresión:

Donde:

$$
\tau_{m}=\frac{\sum\left(\tau_{i} \cdot S_{i}\right)}{\sum S_{i}}
$$

[Ecuación VI - 2]

$$
\left.\tau_{i}=0,13 \frac{\mathrm{m}^{2} \cdot K}{W} \cdot K_{i} \cdot \Delta t \quad \text { [Ecuación } \mathrm{VI}-3\right]
$$

$K_{i}$ : transmitancia térmica cada uno de los componentes de la envolvente $\left[\mathrm{W} / \mathrm{m}^{2} \cdot \mathrm{K}\right]$.

$\Delta_{t}$ : diferencia de temperatura de diseño interior y exterior $\left[{ }^{\circ} \mathrm{C}\right]$.

La etiqueta también debe mostrar el valor de la transmitancia térmica media ponderada $\left(K_{m}^{\prime}\right)$ en watt por metro cuadrado kelvin, la cual se determina con la siguiente expresión:

$$
K_{m}^{\prime}=\frac{\sum_{1}^{n}\left(K_{i} \cdot S_{i}\right)}{\sum_{1}^{n} S_{i}}
$$

Donde:

$$
\text { [Ecuación VI - 4] }
$$

$K_{i}$ : transmitancia térmica cada uno de los componentes de la envolvente $\left[\mathrm{W} / \mathrm{m}^{2} \cdot \mathrm{K}\right]$.

$S_{i}$ : superficie de cada uno de los componentes de la envolvente $\left[\mathrm{m}^{2}\right]$.

Si bien la norma establece que en el caso de edificios con varias unidades funcionales la verificación debe realizarse de manera individual, a los efectos de estudiar el tipo edilicio de interés a la siguiente Tesis Doctoral, se analizaron primero las plantas tipos de los distintos edificios auditados en forma conjunta, interpretando a cada planta tipo como una unidad de análisis, y luego de forma particular las unidades funcionales a las que pudo accederse.

Finalmente, siguiendo las recomendaciones del Apéndice G de la Norma ASHRAE 90.1 y con el fin de simplificar la simulación, se construyeron dos modelos edilicios de base, uno de viviendas y otro de oficinas. Para la construcción de estos modelos se tomaron las principales características de los edificios auditados: constructivas, relación de superficies vidriadas opacas, factor de forma, factor de ocupación, nivel de iluminación y de equipamiento eléctrico, horarios de ocupación y uso de los sistemas de acondicionamiento de aire, equipamiento eléctrico, iluminación, etc. Luego sobre estos modelos de base se construyeron los modelos de referencia, a los cuales se aplicaron las propuestas de mejora que seguían los criterios del DAC.

El EnergyPlus es un software gratuito de simulación energética de edificios creado por el U.S. DOE (Departamento de Energía de Estados Unidos) para el modelado y cálculo de calefacción, 
refrigeración, iluminación, ventilación y otros flujos energéticos. Este software se construye sobre las características de BLAST y DOE-2, e incorpora otras funcionalidades de simulación como intervalos de simulación inferiores a una hora, integración en un cálculo simultáneo del balance zonal y la instalación, flujo multizona, confort térmico y sistemas fotovoltaicos. Se trata de una aplicación aislada, sin un interfaz gráfico "amigable". El DesignBuilder integra EnergyPlus, y permite realizar la simulación simplemente definiendo el modelo del edificio, solicitando los resultados y dejando el resto al motor de simulación EnergyPlus. El DesignBuilder se ha desarrollado de manera específica alrededor del EnergyPlus, incorporando bases de datos de materiales, cerramientos, vidrios y dispositivos de sombreado. Sin embargo el DesignBuilder no es de distribución gratuita como el EnergyPlus, motivo por el cual en el LAyHS se utiliza como interfaz gráfica un Plug-in para el Google SketchUp.

El Plug-in OpenStudio permite utilizar las herramientas del SketchUp para crear y editar zonas y superficies en EnergyPlus, mediante el modelado del edificio en 3D. De esta manera pueden explorarse los archivos de entrada de EnergyPlus mediante la posibilidad de ver la geometría del edificio desde cualquier punto de vista, aplicar diferentes estilos de renderizado y realizar estudios de sombreado del edificio. Además este Plug-in permite mezclar el contenido de simulación del EnergyPlus con contenidos decorativos tales como la aplicación de imágenes de fondo, la localización en Google Earth y la definición de detalles constructivos.

En resumen, el Plug-in OpenStudio permite crear y editar zonas y superficies de EnergyPlus, correr el EnergyPlus y ver los resultados sin salir del SketchUp, relacionar las condiciones de borde de las superficies interzonales, buscar superficies y objetos de superficies (ventanas, puertas, etc.) por el nombre del objeto, agregar cargas internas y archivos de clima para el cálculo de las cargas térmicas, agregar sistemas de acondicionamiento térmico del aire, establecer y modificar las construcciones (muros, techos, pisos, carpinterías, etc.), agregar controles de iluminación natural y obtener ayuda de tutoriales, entre otras cosas. Sin embargo este Plug-in no permite ingresar todos los datos, motivo por el cual para ingresar otros datos debe utilizarse el IDF Editor, que es como se trabajó en el LAyHS. 


\section{CAPÍTULO VII COMPORTAMIENTO HIGROTÉRMICO}

\subsection{Introducción}

A continuación se presentan los datos obtenidos en las campañas de medición realizadas entre los años 2009 y 2011, tanto para los edificios de viviendas como los edificios de oficinas que se describen en el Capítulo V. Siguiendo el protocolo de auditorías utilizado en el LAyHS -el cual se comenta en el Capítulo VI- pudieron obtenerse datos acerca del confort higrotérmico del interior de las unidades funcionales a las cuales pudo accederse. Para todos los casos analizados se tomaron mediciones en dos períodos, para poder estudiar el comportamiento tanto en verano como en invierno. Los resultados obtenidos fueron volcados al PsiConf 1.4 y al Excel para su análisis estadístico.

\subsection{Edificios de viviendas}

Como se explica en el Capítulo VI, para el caso de los edificios de viviendas la distribución de los micro-adquisidores de datos HOBOS fue la siguiente; uno en el dormitorio principal, otro en el estar-comedor, y los otros dos en el calefón y sobre el horno para poder discriminar el consumo de gas natural para agua caliente sanitaria y cocción respectivamente. El intervalo de tiempo en la toma de datos se fijó en quince minutos para los HOBOS ubicados en los ambientes principales y en la Estación Meteorológica, y un minuto para los HOBOS ubicados sobre el calefón y sobre el horno. Luego, los datos obtenidos fueron exportados a Excel para su análisis particularizado.

Con el fin de tener una lectura más clara de los gráficos resultantes, para el análisis de las variaciones de temperatura y humedad en los distintos ambientes se eligieron cinco horarios que relacionaran las horas de mayor y menor ocupación de las viviendas con la incidencia del sol sobre los diferentes ambientes que las conformaban. El criterio de elección de esas bandas horarias fue el siguiente:

- 07.00hs: horario de salida del sol - comienzo de actividad dentro de las viviendas.

- 10.00hs: media mañana - las unidades se encuentran vacías.

- 13.00hs: primera hora de la tarde - las unidades vuelven a ocuparse.

- 17.00hs: hora crítica de la tarde - ocupación parcial de las viviendas.

- 20.00hs: ausencia de sol - ocupación definitiva hasta el día siguiente. 
La campaña de medición para cada edificio comprendió entre siete y diez días. Los datos reunidos durante ese período fueron volcados al Excel para su análisis gráfico, permitiendo evaluar el comportamiento interior de las unidades funcionales en relación a las condiciones meteorológicas exteriores.

Luego, para cada caso, se eligió el día crítico (el más frío en invierno y el más cálido en verano) y se analizó con el PsiConf 1.4, el cual permite ingresar los datos extraídos de los HOBOS y automatizar su graficado en climogramas de Givoni. A partir de estos gráficos pudo evaluarse cuáles eran las recomendaciones de diseño que debían llevarse a cabo en los edificios para que los ambientes interiores alcanzaran los niveles de confort indicados para las condiciones de invierno y verano.

\subsubsection{Comportamiento higrotérmico de verano}

A continuación se muestran los resultados de la campaña de medición de verano para los edificios de vivienda. La misma comprendió los meses de febrero y marzo del 2009. Tal como puede verse en los gráficos durante este período se presentaron días con temperaturas extremas y otros no.

\subsubsection{Caso A}

Tal como puede verse en el Gráfico VII - 1 en general las temperaturas interiores de cada una de las unidades analizadas permanecieron por encima de los límites de confort para verano con máximas que rondaron los $30^{\circ} \mathrm{C}$ y mínimas que se aproximaron a los $20^{\circ} \mathrm{C}$. Durante este período las variaciones de las temperaturas interiores mantuvieron cierta correlación con las variaciones de la temperatura exterior, y sólo los períodos en los que las viviendas eran climatizadas, las temperaturas se mantuvieron constantes. Esto demuestra la ineficiencia energética de la envolvente edilicia, carente de masa térmica y de otros elementos de control sobre las condiciones exteriores.

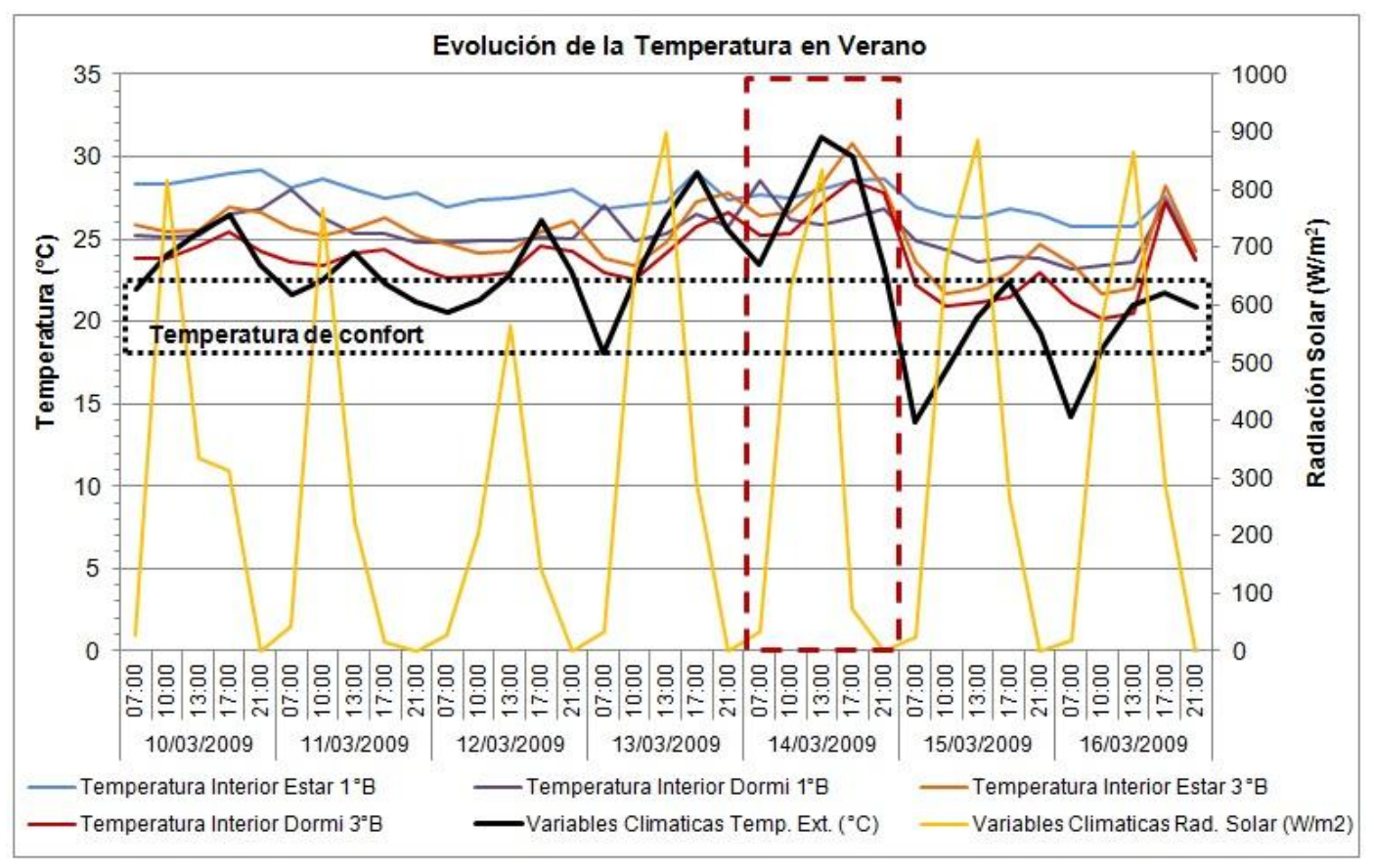

Gráfico VII - 1: Evolución de la temperatura en verano - Caso A (viviendas)

Luego se analizó el día crítico con el PsiConf 1.4. Tal como puede observarse en el Gráfico VII - 2 la mayor parte del día analizado, gran parte de los ambientes de las unidades analizadas permanecieron fuera de los límites de confort. Según el Climograma de Givoni, para alcanzar el 
confort, el edificio en general debería incorporar a su diseño ventilación cruzada, enfriamiento evaporativo e inercia térmica y ventilación selectiva.

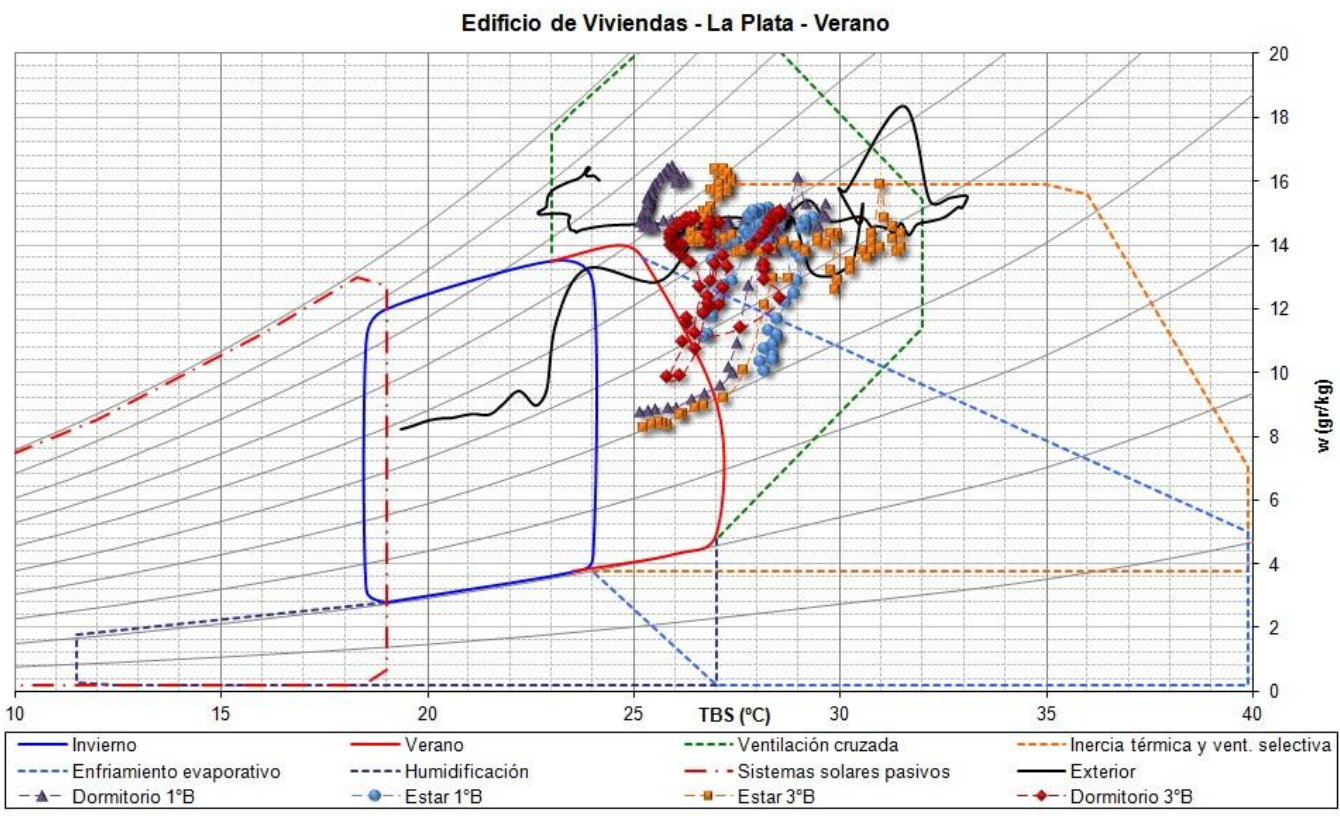

Gráfico VII - 2: Análisis del día crítico de verano con el PsiConf-Caso A (viviendas)

\subsubsection{Caso B}

Tal como puede verse en el Gráfico VII - 3 las temperaturas interiores de cada una de las unidades analizadas permanecieron por encima de los límites de confort para verano en todo momento con máximas que rondaron los $28^{\circ} \mathrm{C}$ y mínimas que se aproximaron a los $22^{\circ} \mathrm{C}$. Si se lo compara con el caso anterior puede verse que la variación de las temperaturas máximas y las mínimas interiores resultó mucho menor pero esto se debió a que la variación de la temperatura exterior también lo fue. Durante este período las temperaturas exteriores se mantuvieron bajas, con máximas que rondaron los $20^{\circ} \mathrm{C}$ y mínimas cercanas a los $15^{\circ} \mathrm{C}$. Las mayores temperaturas interiores ponen de manifiesto el sobrecalentamiento que sufrió el edificio debido a las cargas internas y a la incidencia de la radiación solar.

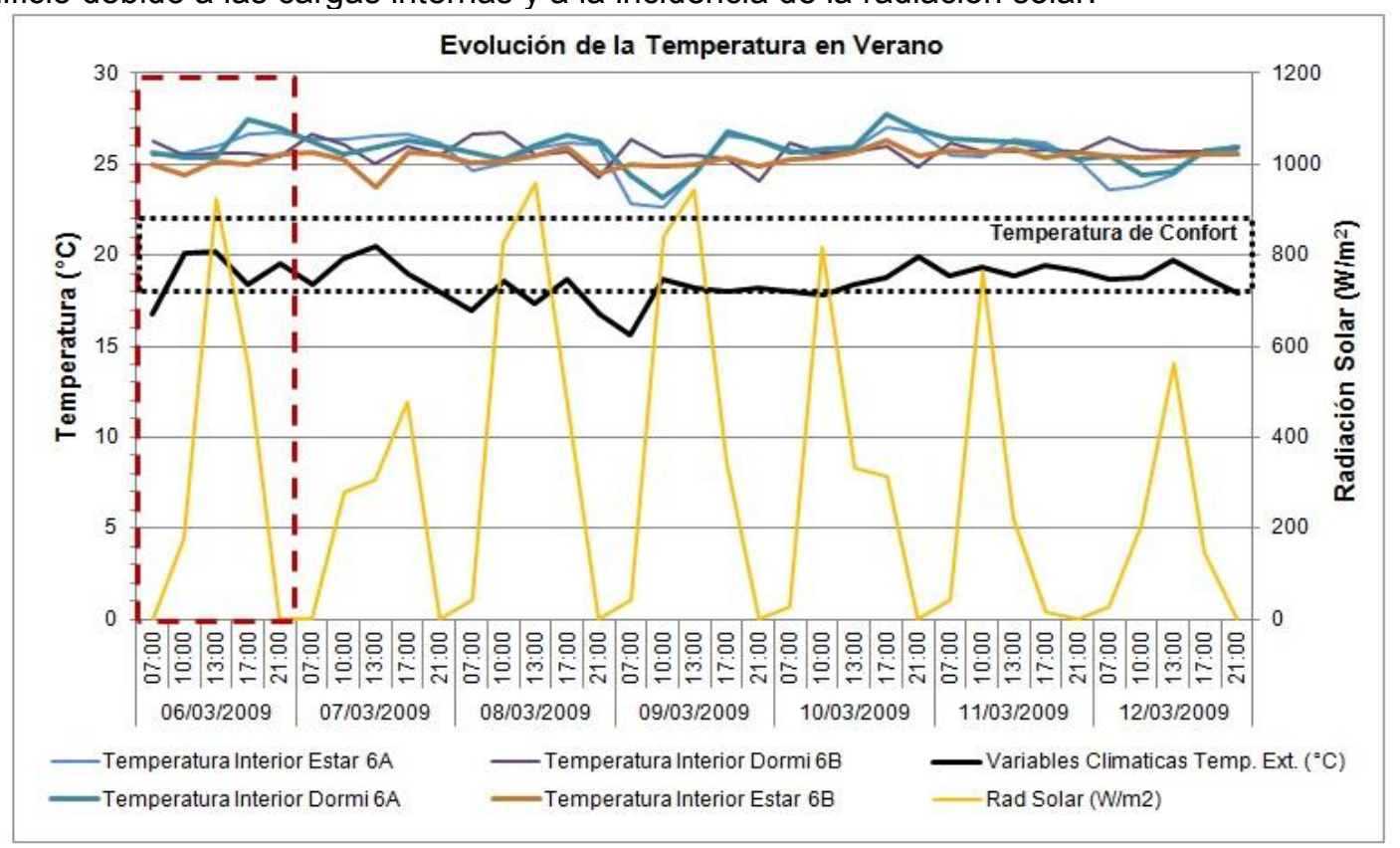

Gráfico VII - 3: Evolución de la temperatura en verano - Caso B (viviendas) 
Al igual que para el caso anterior, se analizó el día crítico con el PsiConf 1.4. Tal como puede observarse en el Gráfico VII - 4 la dispersión de los puntos es mucho menor a la del Caso A, resultado de una variación mucho más pequeña de las temperaturas interiores y exteriores. Sin embargo se observa que en este caso también durante gran parte del día, los ambientes interiores permanecieron fuera de los límites de confort para verano. Según el Climograma de Givoni para alcanzar dichos límites el edificio debería incorporar en su diseño ventilación cruzada, enfriamiento evaporativo e inercia térmica y ventilación selectiva.

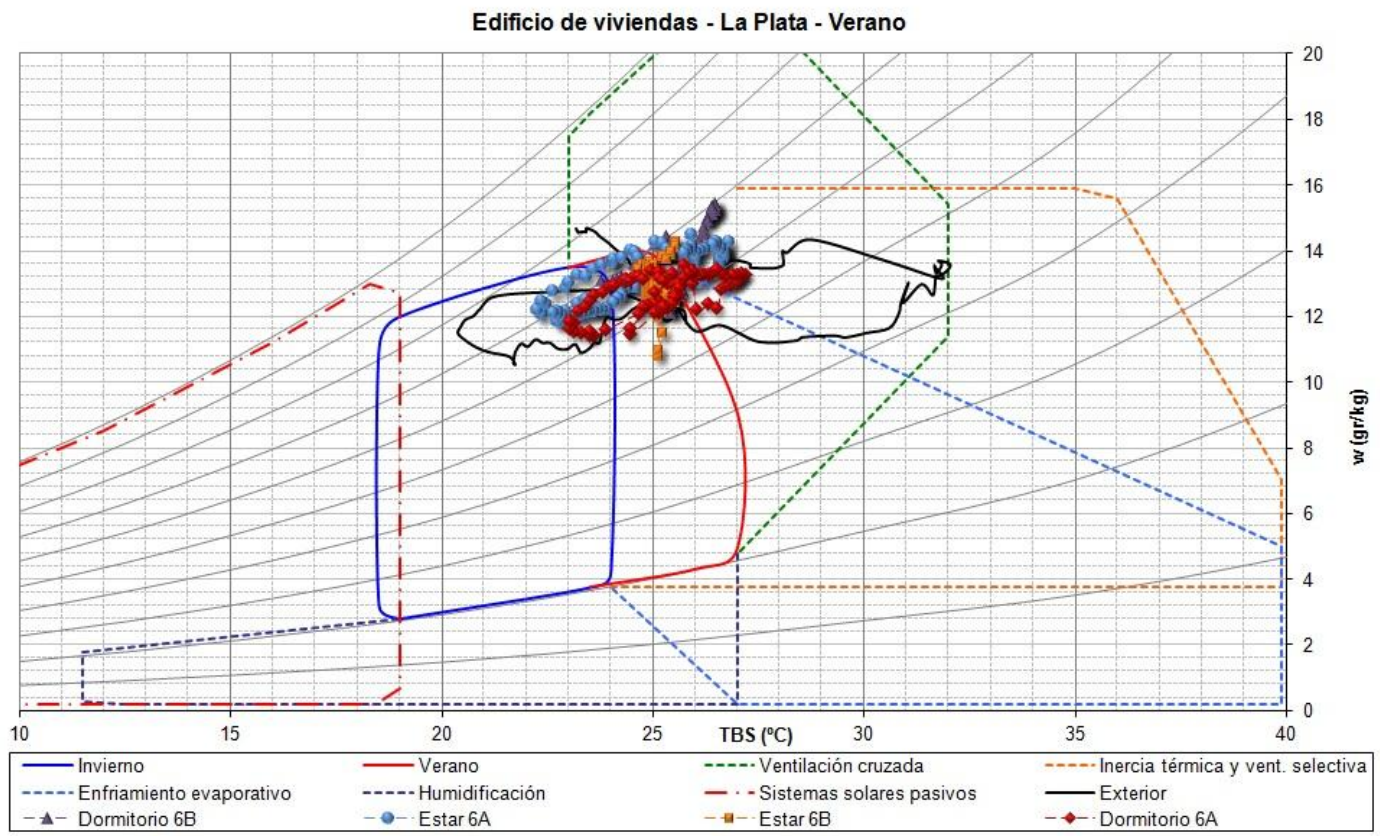

Gráfico VII - 4: Análisis del día crítico de verano con el PsiConf - Caso B (viviendas)

\subsubsection{Caso C}

Tal como puede verse en el Gráfico VII - 5 en general las temperaturas interiores de cada una de las unidades analizadas permanecieron por encima de los límites de confort para verano con máximas que rondaron los $30^{\circ} \mathrm{C}$ y mínimas que se aproximaron a los $21^{\circ} \mathrm{C}$. La variación de las temperaturas interiores máximas y las mínimas resultó mayor a la del caso anterior e incluso se pueden observan diferencias de comportamiento entre las distintas unidades analizadas, producto de la climatización. Durante este período las temperaturas exteriores fueron muy variables, con días de bajas temperaturas (mínima $15^{\circ} \mathrm{C}$ y máxima $21^{\circ} \mathrm{C}$ ) y días en los que se alcanzó una temperatura máxima de $35^{\circ} \mathrm{C}$. La diferencia en el comportamiento de las distintas unidades funcionales así como la correlación entre las temperaturas interiores y las exteriores pone de manifiesto la baja calidad higrotérmica de la envolvente edilicia para afrontar las condiciones exteriores.

Luego se analizó el día crítico con el PsiConf 1.4. Tal como puede observarse en el Gráfico VII - 6 la dispersión de los puntos es mayor a la del Caso B, resultado de una variación mucho más grande de las temperaturas interiores y exteriores. Se observa que sólo algunos puntos de una de las unidades auditadas se aproximaron a la zona de confort de verano, producto de la diferencia de climatización. El resto del día gran parte de los ambientes de esa unidad y la totalidad de los ambientes de la otra unidad permanecieron fuera de la zona de confort para verano. Según el Climograma de Givoni para alcanzar dichos límites el edificio debería incorporar en su diseño ventilación cruzada, enfriamiento evaporativo e inercia térmica y ventilación selectiva. 


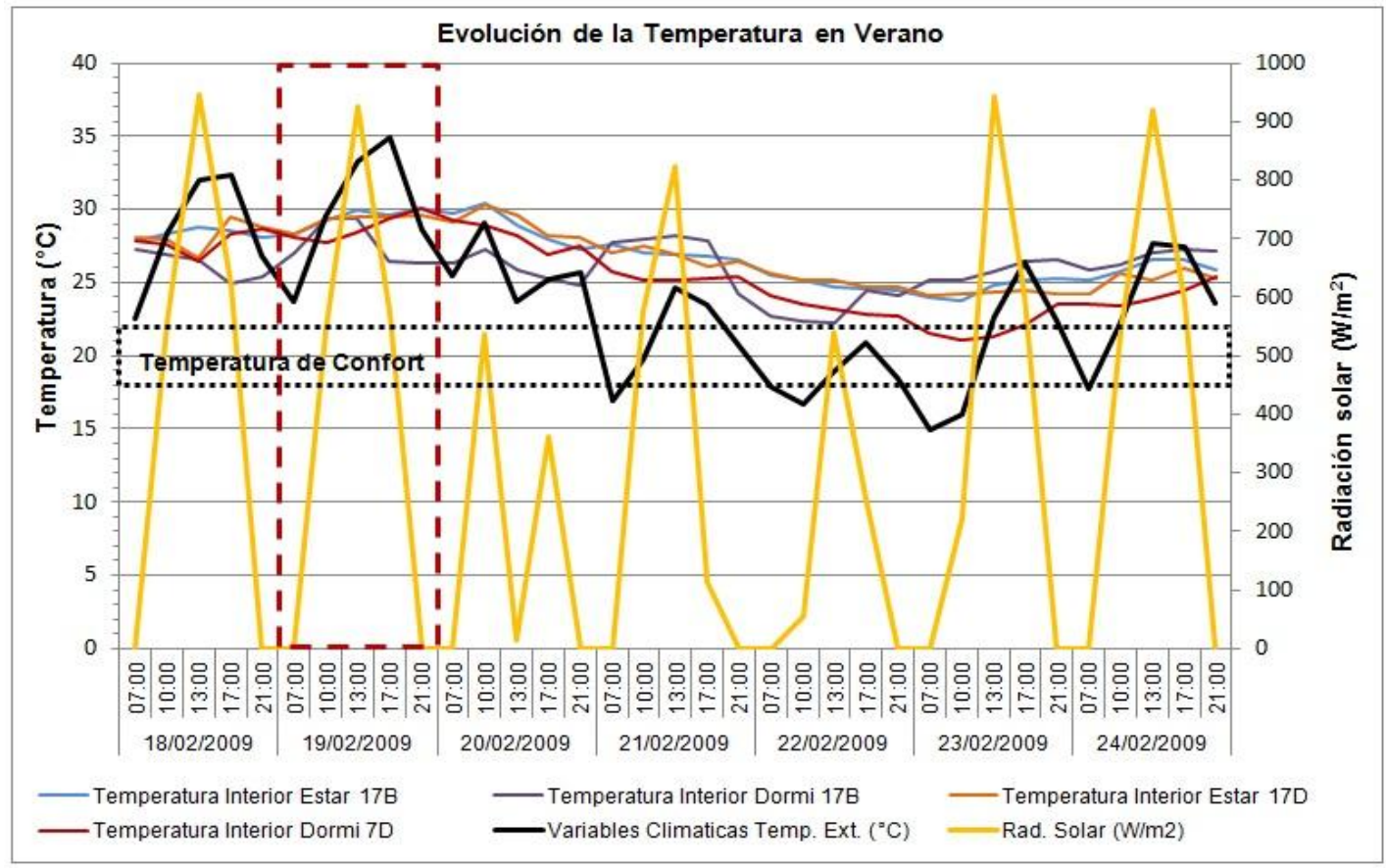

Gráfico VII - 5: Evolución de la temperatura en verano - Caso C (viviendas)

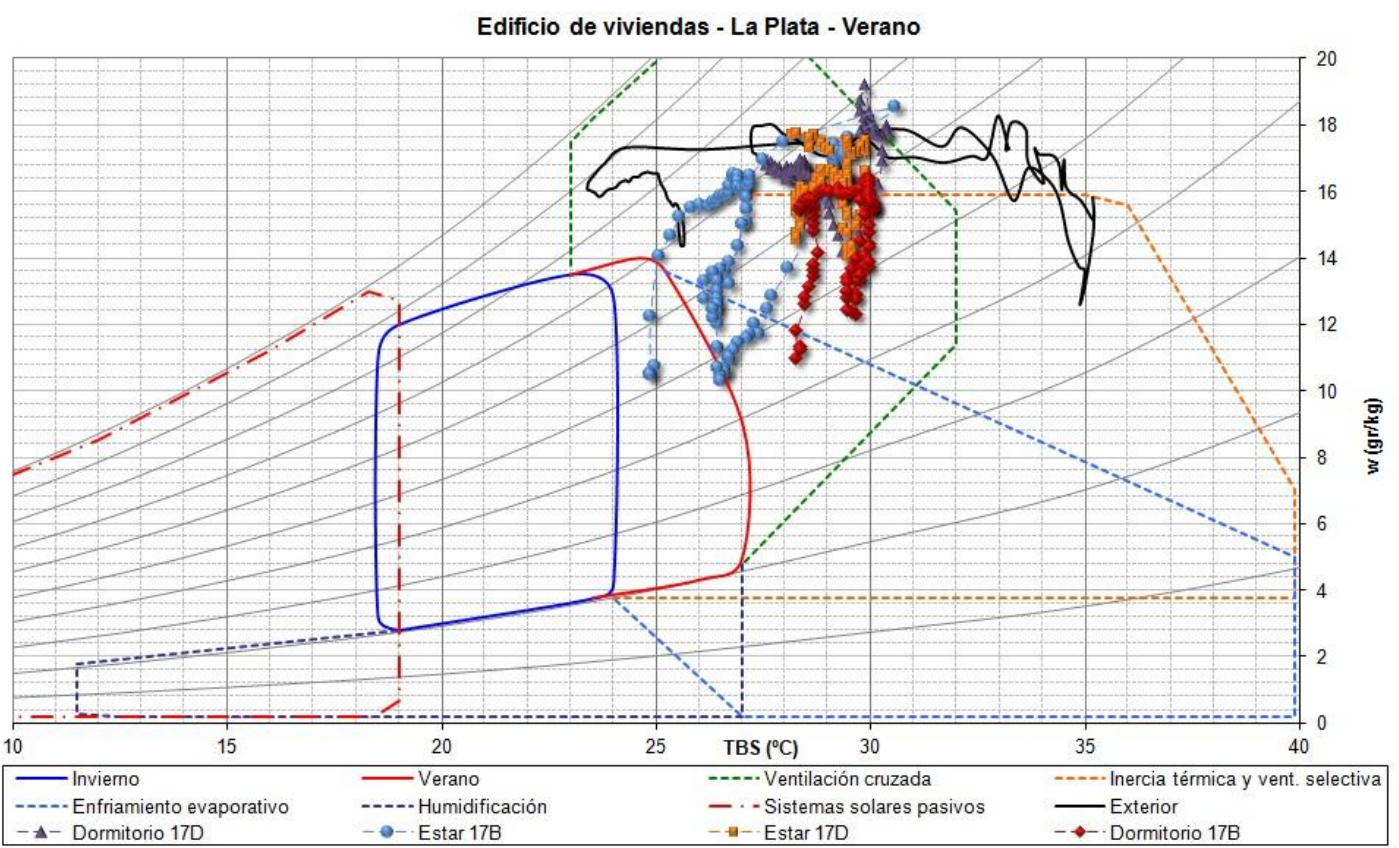

Gráfico VII - 6: Análisis del día crítico de verano con el PsiConf - Caso C (viviendas)

\subsubsection{Caso D}

Tal como puede verse en el Gráfico VII - 7 las temperaturas interiores de cada una de las unidades analizadas permanecieron muy por encima de los límites de confort para verano con máximas que rondaron los $30^{\circ} \mathrm{C}$ y mínimas que se aproximaron a los $23^{\circ} \mathrm{C}$. En este caso también se observa cierta correlación entre las variaciones de las temperaturas interiores y las exteriores y, a diferencia del caso anterior, las unidades se comportan de forma similar. Tal como en los casos anteriores, la correlación entre las temperaturas interiores y las exteriores, y las altas temperaturas interiores pusieron de manifiesto la baja calidad higrotérmica de la envolvente edilicia para afrontar las condiciones exteriores. 


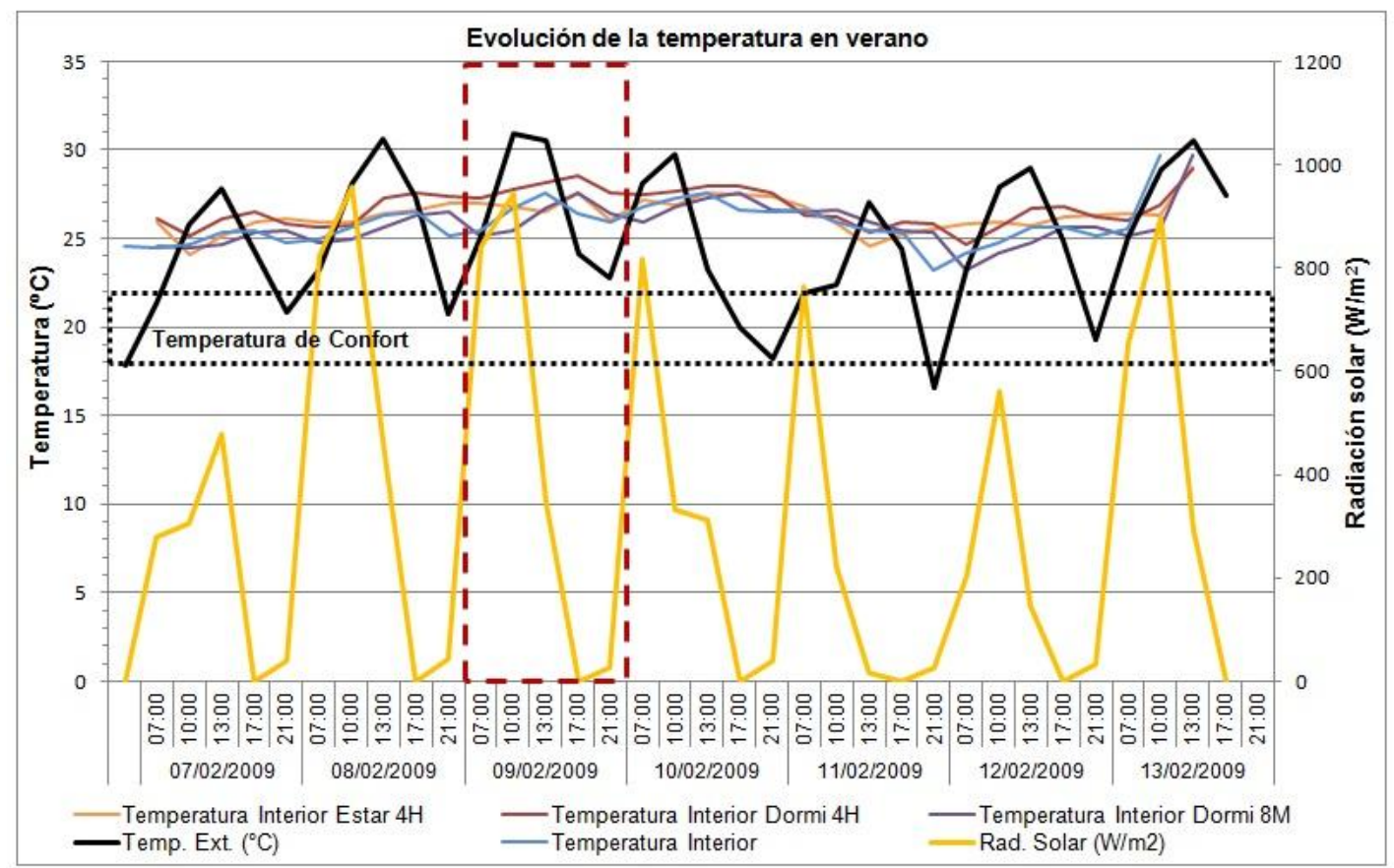

Gráfico VII - 7: Evolución de la temperatura en verano - Caso D (viviendas)

Luego se analizó el día crítico con el PsiConf 1.4. Tal como puede observarse en el Gráfico VII - 8 la dispersión de los puntos es menor a la del caso anterior, resultado de una variación mucho más pequeña de las temperaturas interiores y exteriores. Se observa que sólo algunos puntos de una de las unidades auditadas permanecieron dentro de la zona de confort. El resto del día gran parte de los ambientes de esa unidad y la totalidad de los ambientes de la otra unidad permanecieron fuera de la zona de confort para verano. Según el Climograma de Givoni para alcanzar dichos límites el edificio debería incorporar en su diseño ventilación cruzada, enfriamiento evaporativo e inercia térmica y ventilación selectiva.

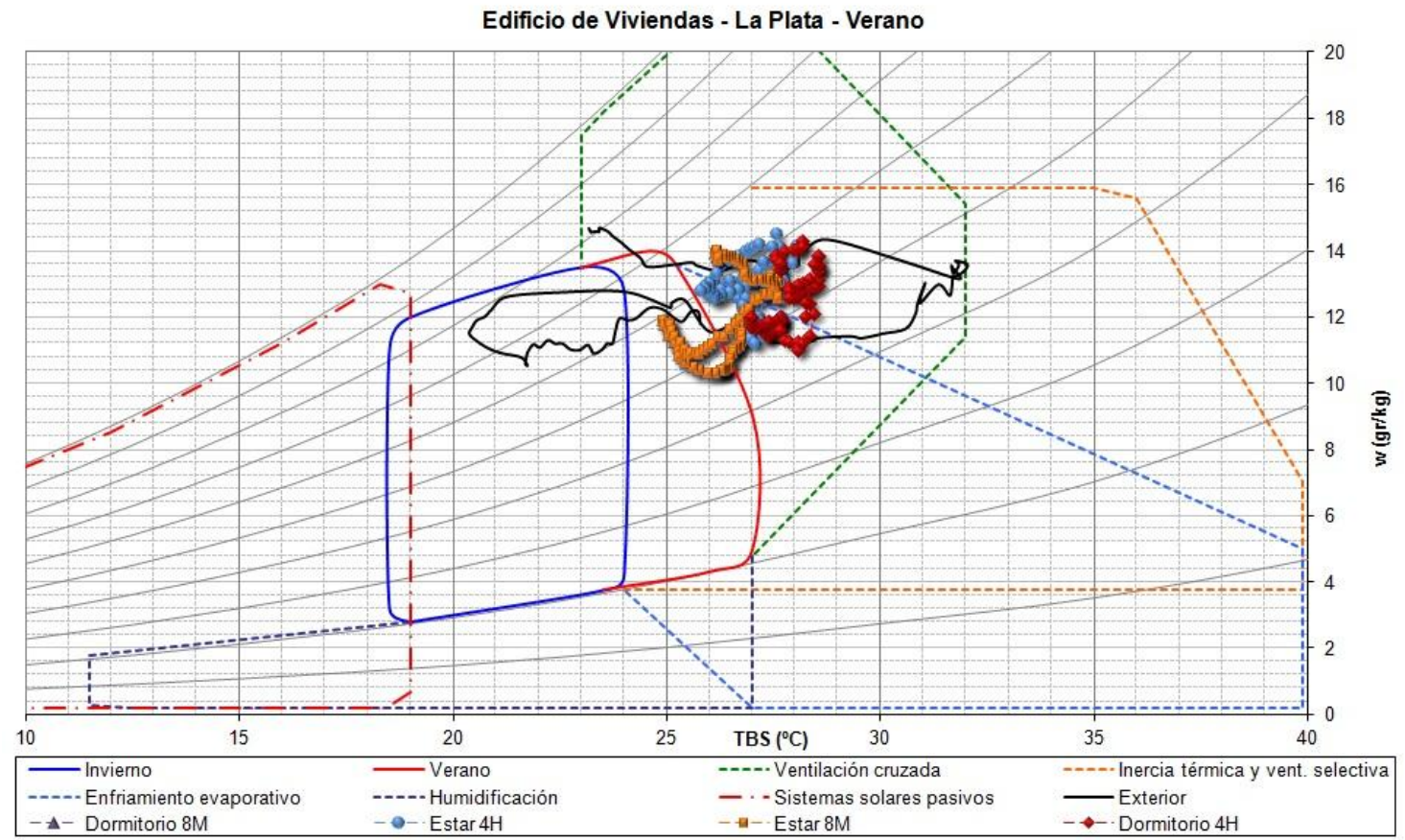

Gráfico VII - 8: Análisis del día crítico de verano con el PsiConf - Caso D (viviendas) 


\subsubsection{Comportamiento higrotérmico de invierno}

A continuación se muestran los resultados de la campaña de medición de invierno para los edificios de vivienda. La misma comprendió los meses de junio y julio del 2009. Tal como puede verse en los gráficos durante este período se presentaron días con temperaturas extremas y otros no.

\subsubsection{Caso A}

Tal como puede verse en el Gráfico VII - 9 en general las temperaturas interiores de cada una de las unidades analizadas permanecieron por fuera de los límites de confort para invierno, ya sea por sobrecalentamiento o por falta de calefacción, dependiendo de la unidad analizada. Al igual que en el período estival, durante este período las variaciones de las temperaturas interiores mantuvieron cierta correlación con las variaciones de la temperatura exterior, en especial la unidad que presenta temperaturas interiores más bajas. Esta correlación entre las temperaturas interiores y las exteriores, especialmente en los casos en los que existe un menor grado de climatización demuestra la ineficiencia energética de la envolvente edilicia, carente de elementos de control sobre las condiciones exteriores.

Luego se analizó el día crítico con el PsiConf 1.4. Tal como puede observarse en el Gráfico VII - 10 sólo los ambientes de una de las unidades funcionales permanecieron dentro de los límites de confort. Los ambientes de la otra unidad analizada, la cual presentaba un menor consumo de gas natural para calefacción permanecieron la mayor parte del día siempre fuera de los límites de confort para invierno. Según el Climograma de Givoni, para alcanzar el confort, el edificio en general debería incorporar a su diseño sistemas solares pasivos.

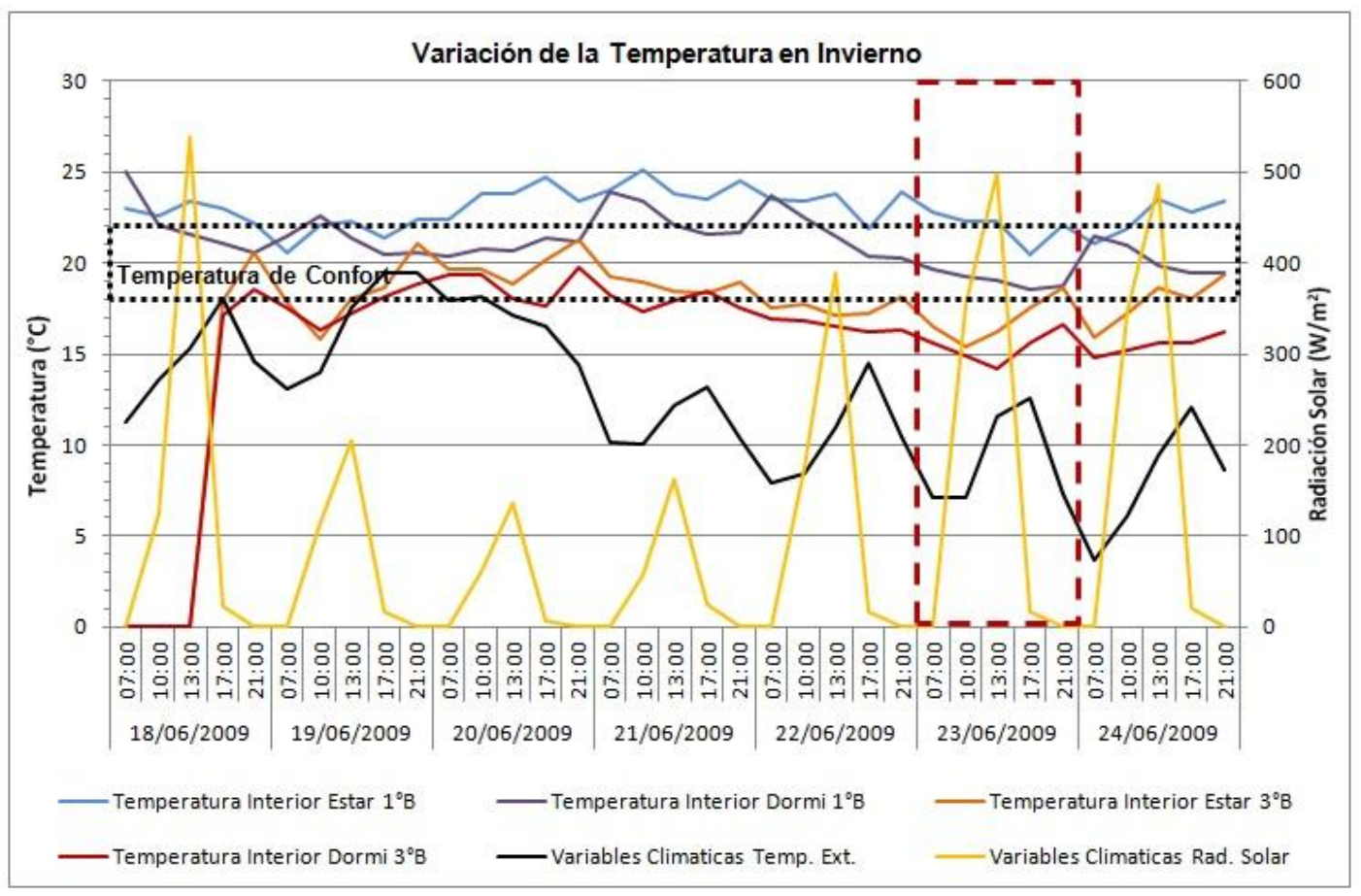

Gráfico VII - 9: Evolución de la temperatura en invierno - Caso A (viviendas) 


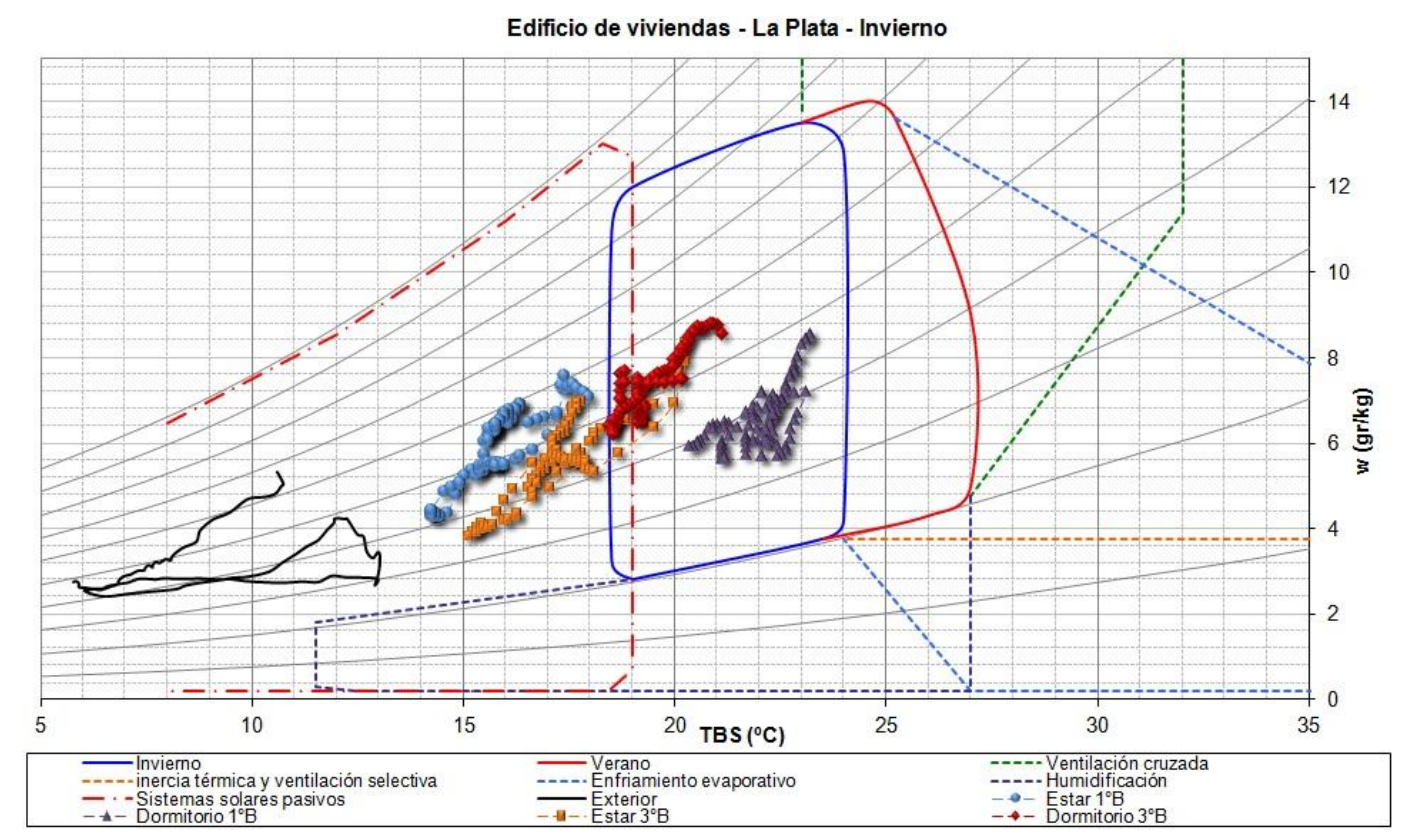

Gráfico VII - 10: Análisis del día crítico de invierno con el PsiConf - Caso A (viviendas)

\subsubsection{Caso B}

Tal como puede verse en el Gráfico VII - 11 en general las temperaturas interiores de cada una de las unidades analizadas permanecieron dentro de los límites de confort para invierno, se observan algunos puntos por debajo y algunos otros por encima, producto del sobrecalentamiento por calefacción y de la influencia de la radiación solar y las mayores temperaturas exteriores. Al igual que en el período estival, durante este período las variaciones de las temperaturas interiores mantuvieron cierta correlación con las variaciones de la temperatura exterior. Esta correlación entre las temperaturas interiores y las exteriores, especialmente en los extremos (sobrecalentamiento o bajas temperaturas) demuestra la ineficiencia energética de la envolvente edilicia, carente de elementos de control sobre las condiciones exteriores.

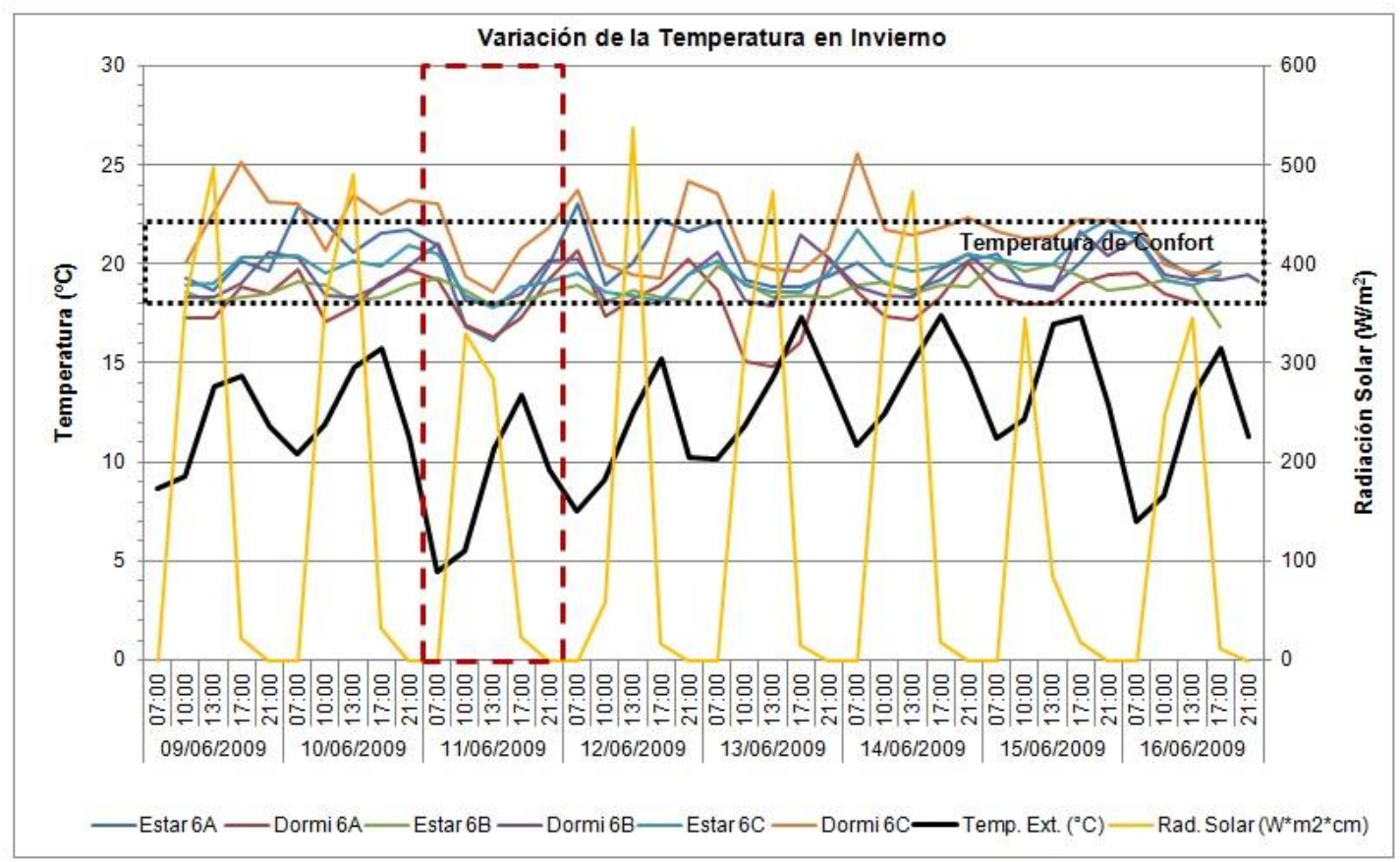

Gráfico VII - 11: Evolución de la temperatura en invierno - Caso B (viviendas) 
Luego se analizó el día crítico con el PsiConf 1.4. Tal como puede observarse en el Gráfico VII - 12 gran parte del día los distintos ambientes que conforman las unidades analizadas permanecieron dentro de los límites de confort. Sin embargo existen algunos puntos fuera de esta zona de confort. Según el Climograma de Givoni, para alcanzar el confort, el edificio en general debería incorporar a su diseño sistemas solares pasivos.

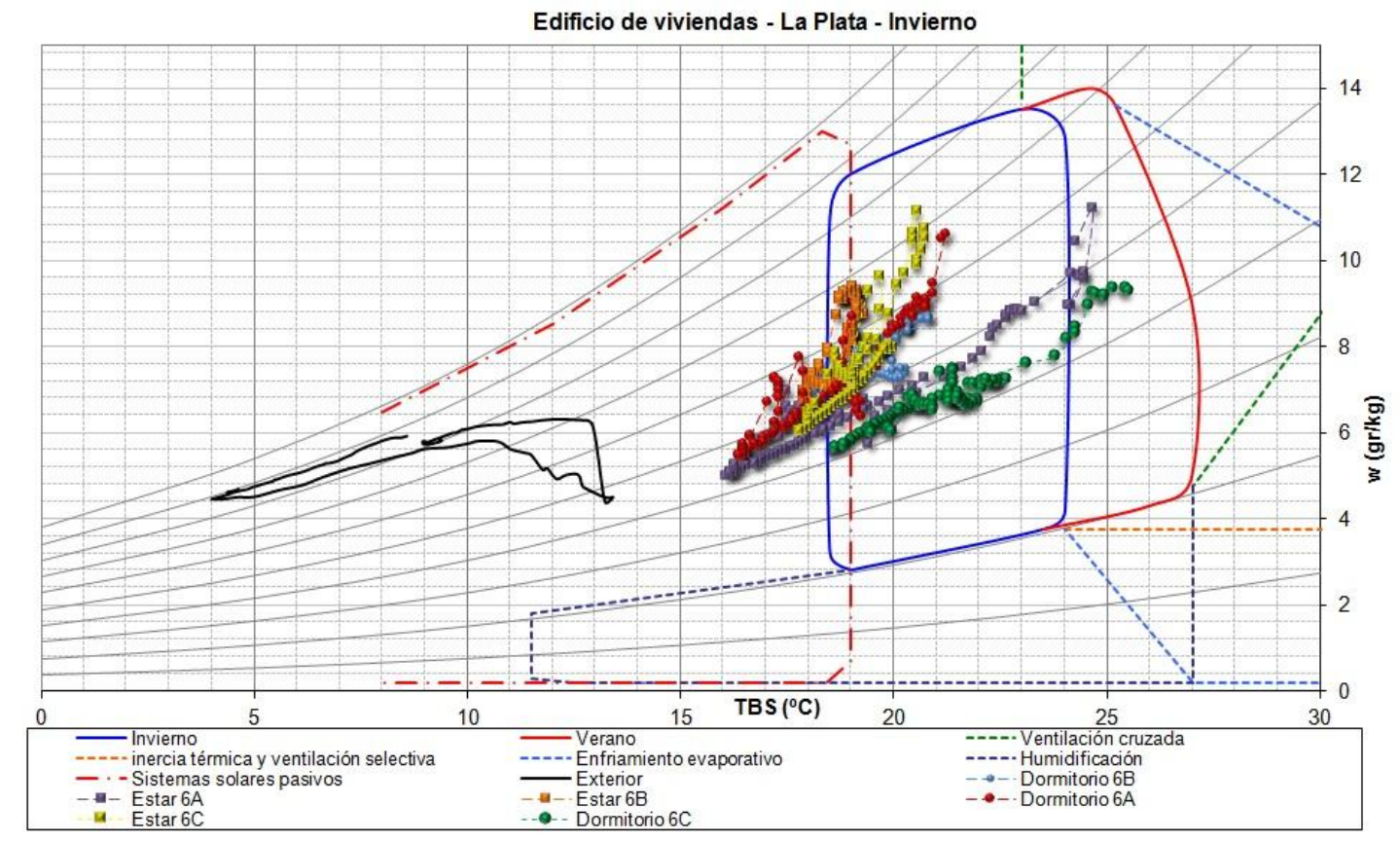

Gráfico VII - 12: Análisis del día crítico de invierno con el PsiConf - Caso B (viviendas)

\subsubsection{Caso C}

Tal como puede verse en el Gráfico VII - 13 las unidades analizadas presentaron situaciones bien diferentes. En la unidad con menor consumo de gas natural se observan dos situaciones; mientras que el dormitorio se encontraba siempre por debajo de la zona de confort, el estar se encontraba mayoritariamente dentro de la zona de confort, e incluso pudieron observarse algunos puntos con sobrecalentamiento. Esto se debe a que la climatización se concentra en la zona del estar. Por su parte la otra vivienda analizada presenta una situación más homogénea entre los espacios interiores que la conforman, en esta vivienda se puede observar que los espacios permanecieron mayoritariamente por encima de la temperatura de confort. Esto puede deberse a la baja calidad de la envolvente térmica, la cual no puede hacer frente a las condiciones exteriores. Frente a las temperaturas exteriores bajas, la mala calidad de la envolvente higrotérmica dificulta su calentamiento, aún cuando en el centro de los locales las temperaturas superan los límites de confort. Estas diferencias entre la temperatura del centro del local y la temperatura de los cerramientos generan zonas de disconfort en el interior de las viviendas.

Luego se analizó el día crítico con el PsiConf 1.4. En el Gráfico VII - 12 se observa con mayor claridad lo que se comentaba en el gráfico anterior. Por un lado el dormitorio de la vivienda que presenta menor consumo de gas natural se encontraba fuera de los límites de confort. Según el Climograma de Givoni para alcanzar estos límites el edificio debería incorporar en su diseño sistemas solares pasivos. Por el otro, puede observarse como las zonas calefaccionadas se encontraban dentro de los límites de confort e incluso en el caso de la vivienda que presenta mayores consumos de gas natural se observa que en algunas partes del día los locales superaron los valores límites para la condición de invierno. 


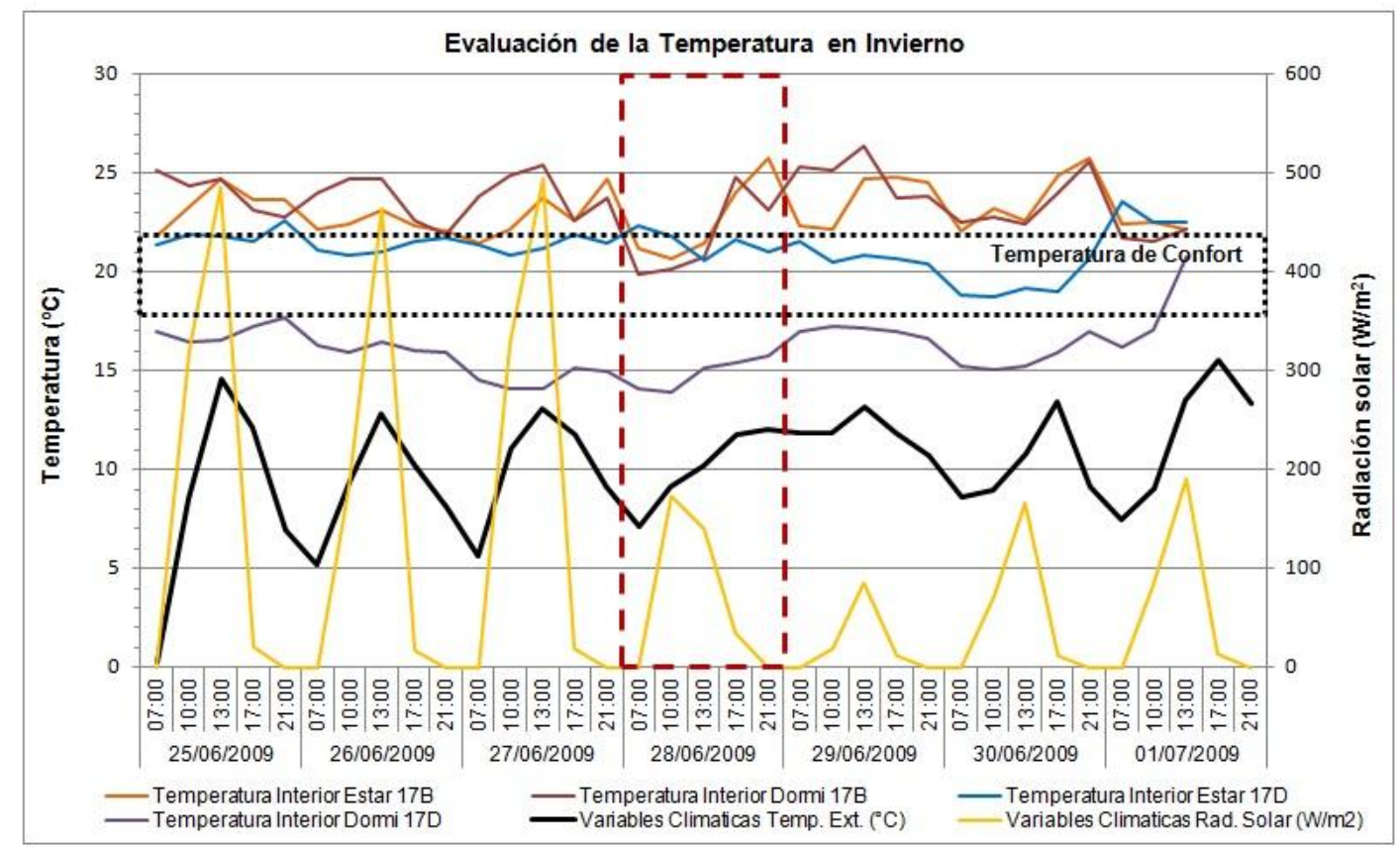

Gráfico VII - 13: Evolución de la temperatura en invierno - Caso C (viviendas)

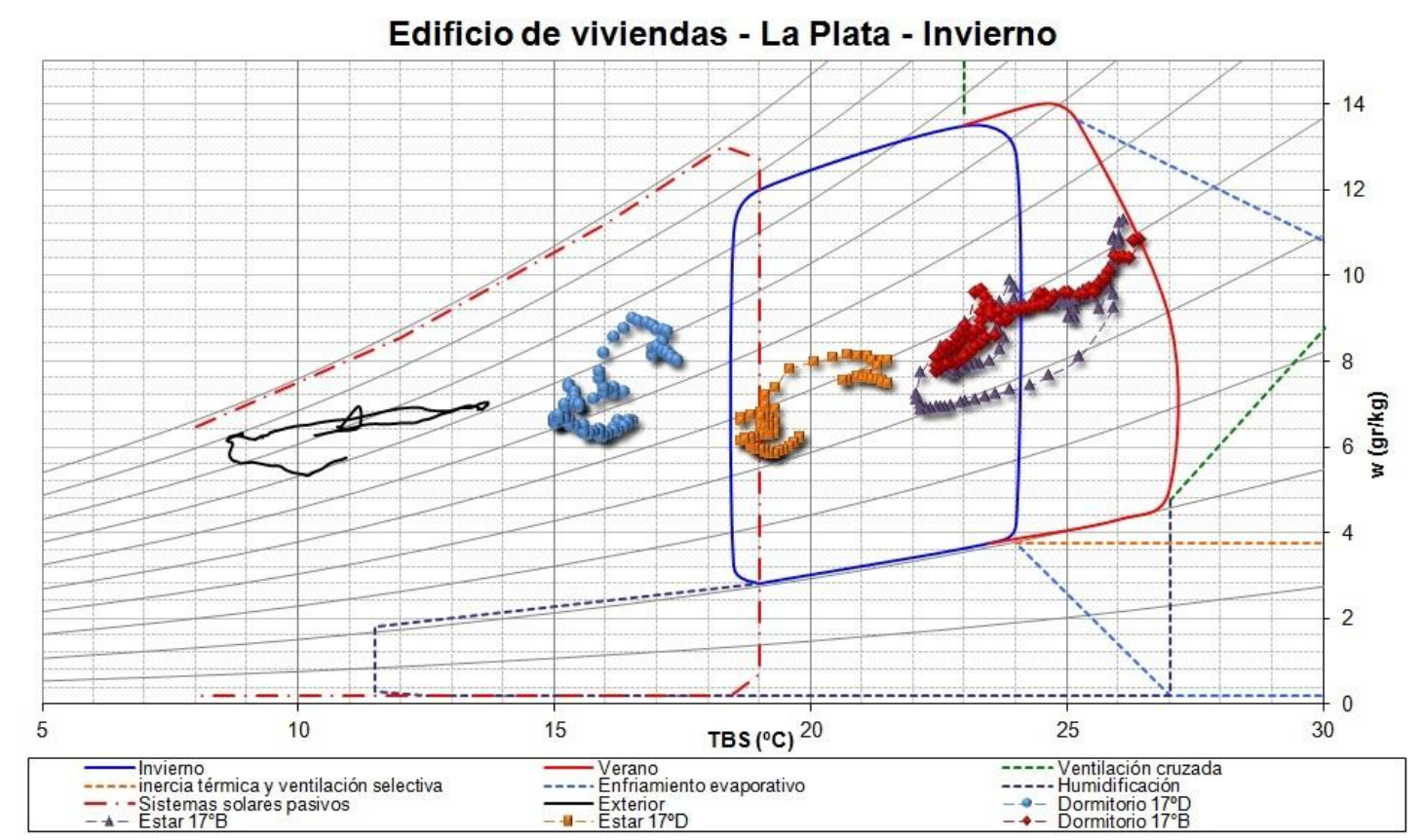

Gráfico VII - 14: Análisis del día crítico de invierno con el PsiConf - Caso C (viviendas)

\subsubsection{Caso D}

Tal como puede verse en el Gráfico VII - 15 las unidades analizadas presentaron situaciones bien diferentes. En la unidad que presentó un mayor consumo de gas natural pudo observarse una marcada diferencia entre los días hábiles y los fines de semana. Durante los días hábiles la zona del estar se encontraba sobre-calefaccionada mientras que la zona del dormitorio mayoritariamente se encontraba dentro de los límites de confort. Por su parte la otra unidad analizada presentó una situación más homogénea durante todos los días, incluso durante el fin de semana, que coincide con las mayores temperaturas exteriores. La calefacción de los espacios interiores lleva a que no pueda hacerse una lectura clara del comportamiento de la envolvente edilicia, sin embargo tal como en el caso anterior el sobre-calentamiento de los 
espacios interiores puede estar relacionado a la baja temperatura de los cerramientos, producto de la baja calidad de la envolvente higrotérmica.

Al hacer el análisis del día crítico pudo observarse claramente esta situación. Tal como puede verse en el Gráfico VII - 16 en general todos los ambientes permanecieron dentro de la zona de confort para invierno, a excepción de la zona del estar del departamento que presentó mayor consumo de gas natural, el cual superó los límites de la zona de confort para invierno. Por su parte algunos puntos de la vivienda que presentó menor consumo de gas natural permanecieron por debajo de los límites de confort para invierno. Según el Climograma de Givoni para alcanzar estos límites el edificio debería incorporar en su diseño sistemas solares pasivos.

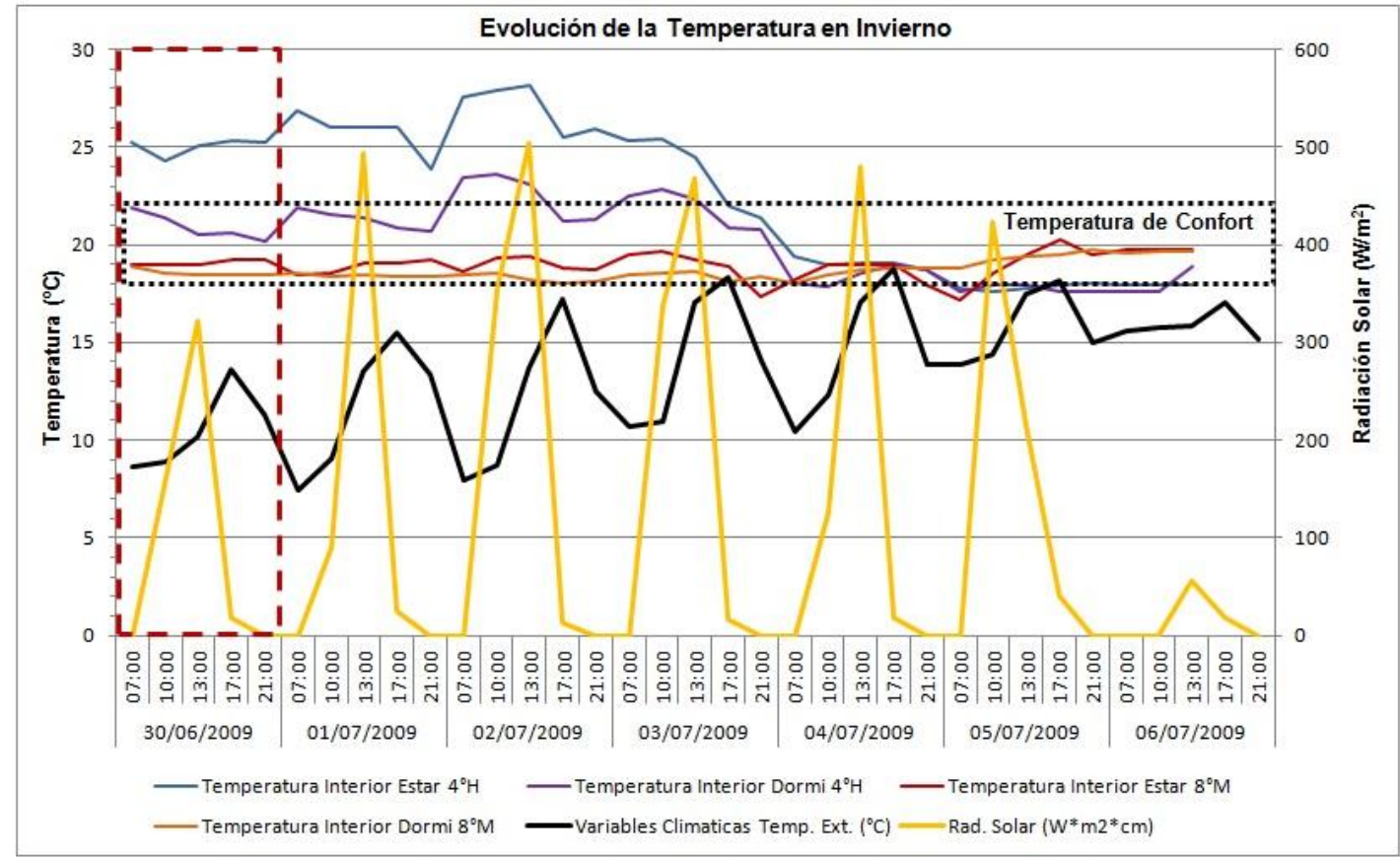

Gráfico VII - 15: Evolución de la temperatura en invierno - Caso D (viviendas)

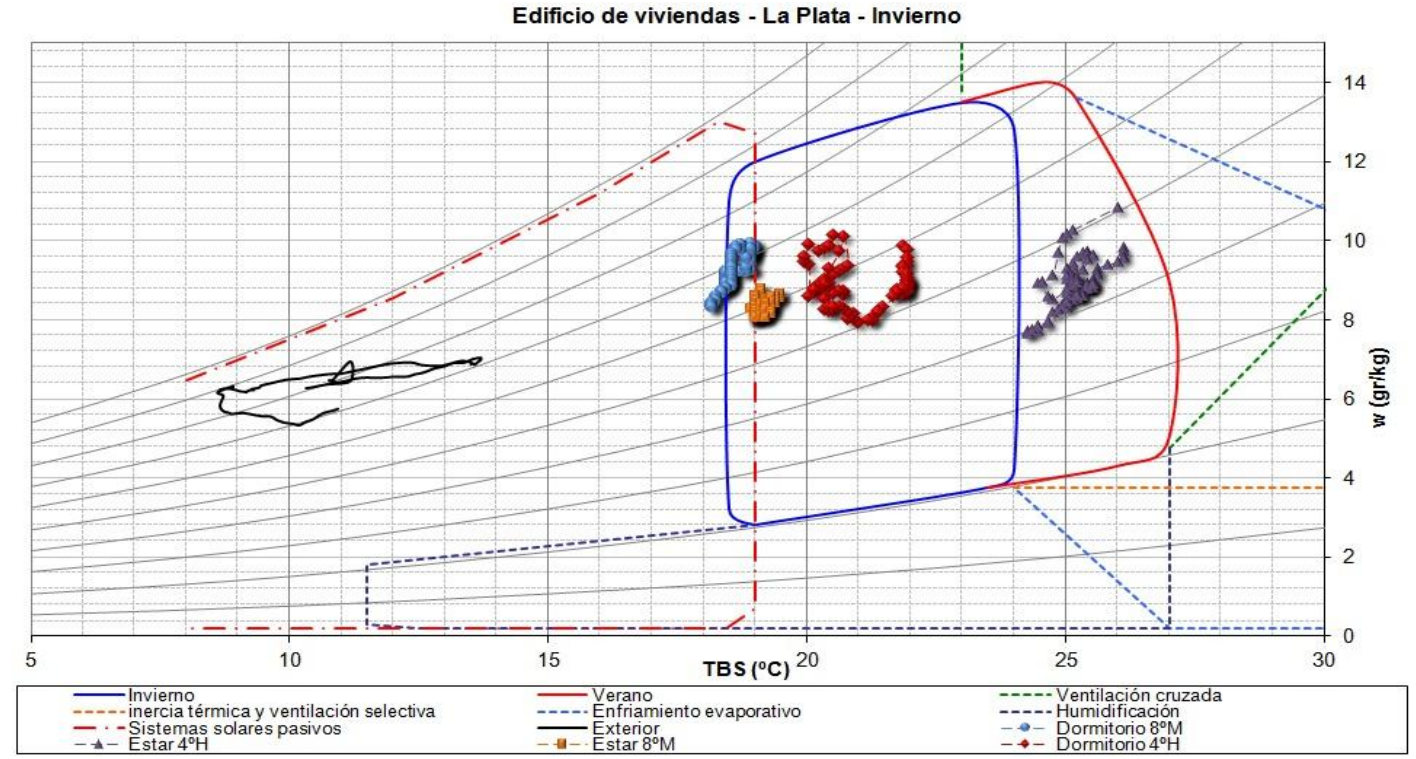

Gráfico VII - 16: Análisis del día crítico de invierno con el PsiConf - Caso D (viviendas) 


\subsection{Edificios de oficinas}

Como se explica en el Capítulo $\mathrm{VI}$, para el caso de los edificios de oficinas los microadquisidores de datos HOBOS se distribuyeron en los ambientes principales de las unidades funcionales, variando la cantidad en función de la superficie de las mismas (se utilizaron entre dos y cuatro micro-adquisidores por unidad funcional). El intervalo de tiempo en la toma de datos se fijó en quince minutos tanto para los HOBOS ubicados en el interior de las unidades funcionales como para los datos registrados por la Estación Meteorológica.

Con el fin de tener una lectura más clara de los gráficos resultantes, para el análisis de las variaciones de temperatura y humedad en los distintos ambientes se eligieron cinco horarios que relacionaran las horas de mayor y menor ocupación de las oficinas con la incidencia del sol sobre los diferentes ambientes que las conformaban. El criterio de elección de esas bandas horarias fue el siguiente:

- 07.00hs: horario de salida del sol - las oficinas se encuentran vacías.

- 10.00hs: media mañana - máxima ocupación.

- 13.00hs: primera hora de la tarde - horario de almuerzo, ocupación parcial.

- 17.00hs: últimas horas de la tarde - máxima ocupación.

- 20.00hs: ausencia de sol - las oficinas se encuentran vacías.

La campaña de medición para cada edificio comprendió entre siete y diez días. Los datos reunidos durante ese período fueron volcados a Excel para su análisis gráfico, permitiendo evaluar el comportamiento interior de las unidades funcionales en relación a las condiciones meteorológicas exteriores.

Luego, para cada caso, se eligió el día crítico (el más frío en invierno y el más cálido en verano) y se analizó con el PsiConf 1.4, el cual permite ingresar los datos extraídos de los HOBOS y automatizar su graficado en climogramas de Givoni. A partir de estos gráficos pudo evaluarse cuáles eran las recomendaciones de diseño que debían llevarse a cabo en los edificios para que los ambientes interiores alcanzaran los niveles de confort indicados para las condiciones de invierno y verano.

\subsubsection{Comportamiento higrotérmico de verano}

A continuación se muestran los resultados de la campaña de medición de verano para los edificios de oficinas. La misma comprendió los meses de febrero y marzo del 2011. Tal como puede verse en los gráficos durante este período se presentaron días con temperaturas extremas y otros no.

\subsubsection{Caso A}

Tal como puede verse en el Gráfico VII - 17, pese a contar con sistemas de aire acondicionado, todos los espacios de las unidades analizadas permanecieron fuera de los límites de confort. Para este período las temperaturas mínimas exteriores rondaron los $18^{\circ} \mathrm{C} \mathrm{y}$ las máximas se aproximaron a los $33^{\circ} \mathrm{C}$, es decir que si bien fueron altas, no fueron extremas. Por su parte las temperaturas interiores se mantuvieron siempre por encima de los $25^{\circ} \mathrm{C}$ y en algunos casos rondaron los $28^{\circ} \mathrm{C}$, las variaciones fueron leves pero siempre por encima de la zona de confort.

Al hacer el análisis del día crítico pudo observarse claramente esta situación. Tal como puede verse en el Gráfico VII - 18 en general todos los ambientes permanecieron fuera de la zona de confort para verano, a excepción de algunos puntos de una de las oficinas, los cuales permanecieron dentro de la zona de confort para verano. Según el Climograma de Givoni para alcanzar el confort el edificio debería incorporar en su diseño enfriamiento evaporativo, ventilación selectiva e inercia térmica y ventilación cruzada. 


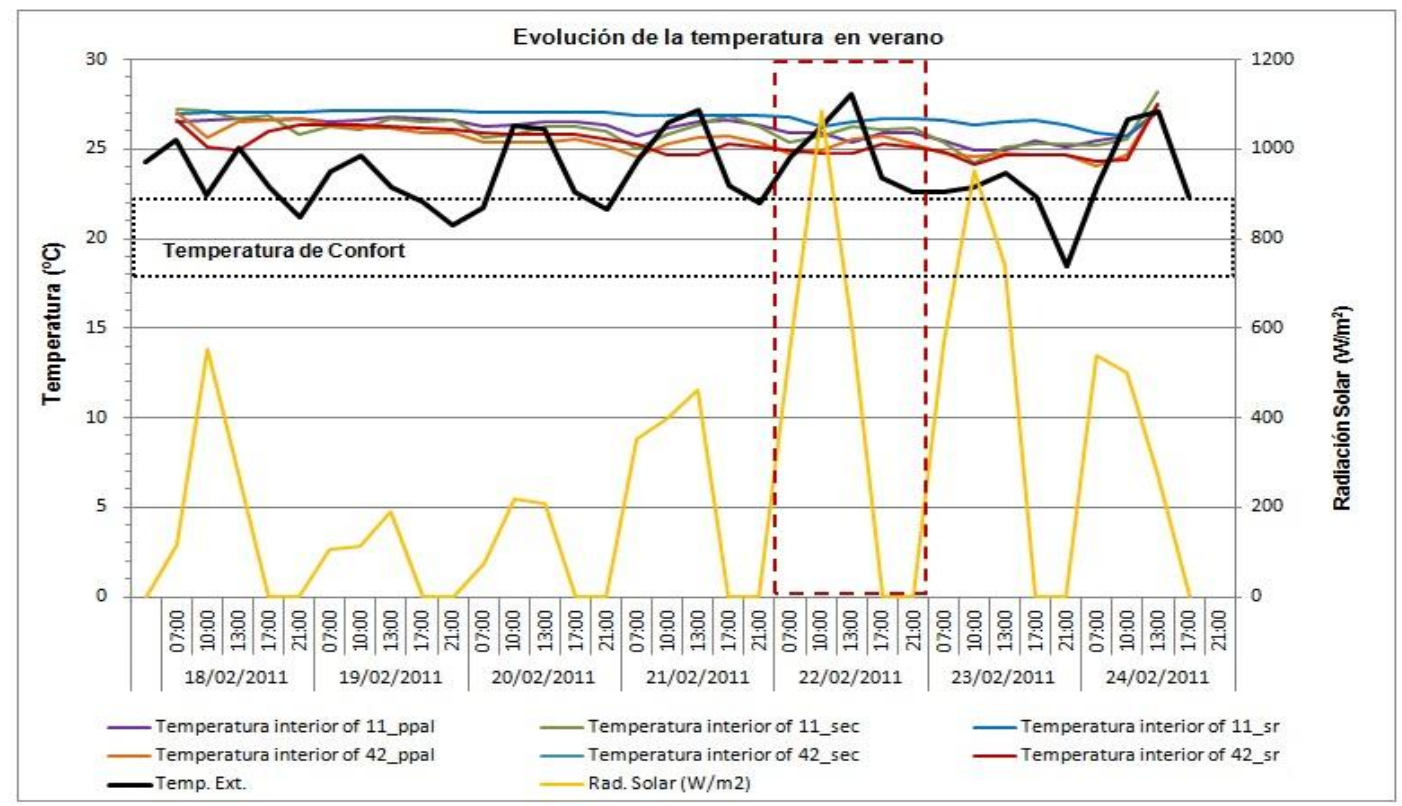

Gráfico VII - 17: Evolución de la temperatura en verano - Caso A (oficinas)

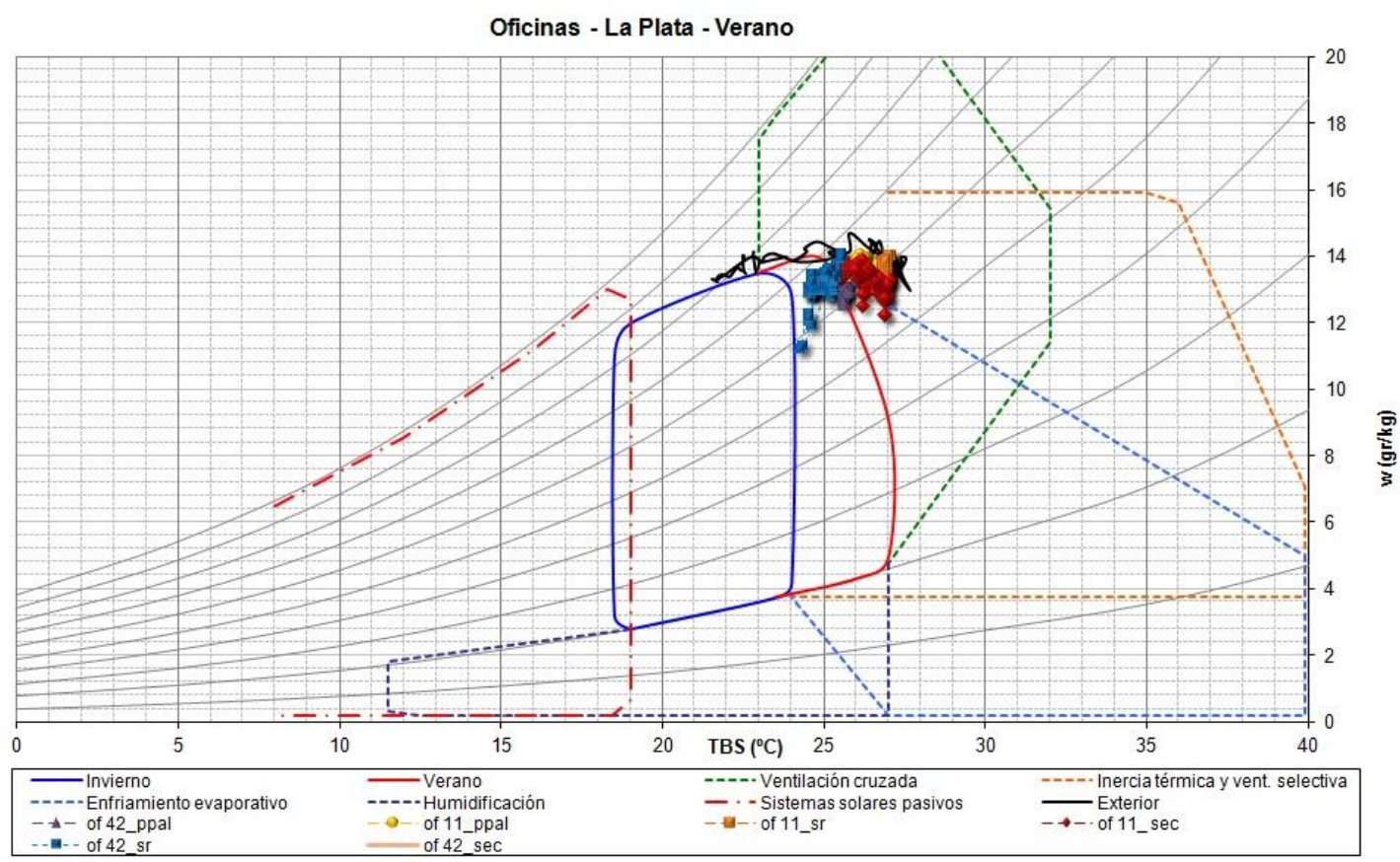

Gráfico VII - 18: Análisis del día crítico de verano con el PsiConf - Caso A (oficinas)

\subsubsection{Caso B}

Tal como puede verse en el Gráfico VII - 19 pese a contar con sistemas de aire acondicionado todos los espacios de las unidades analizadas permanecieron fuera de los límites de confort. Se observa además, a diferencia del caso anterior, un notable aumento de la temperatura interior en concordancia con los aumentos de la temperatura exterior, sumado a las cargas internas. En este caso también se ve claramente el contraste entre los días laborables y los fines de semana, durante los cuales las temperaturas interiores se mantuvieron casi constantes. Para este período las temperaturas mínimas exteriores rondaron los $21^{\circ} \mathrm{C}$ y las máximas se aproximaron a los $33^{\circ} \mathrm{C}$. Por su parte las temperaturas interiores se mantuvieron entre los $24^{\circ} \mathrm{C}$ y los $32^{\circ} \mathrm{C}$, las variaciones fueron más marcadas que en el caso anterior y 
generalmente coincidían con el aumento de la radiación solar y de la temperatura exterior, así como por el calor acumulado por las cargas internas.

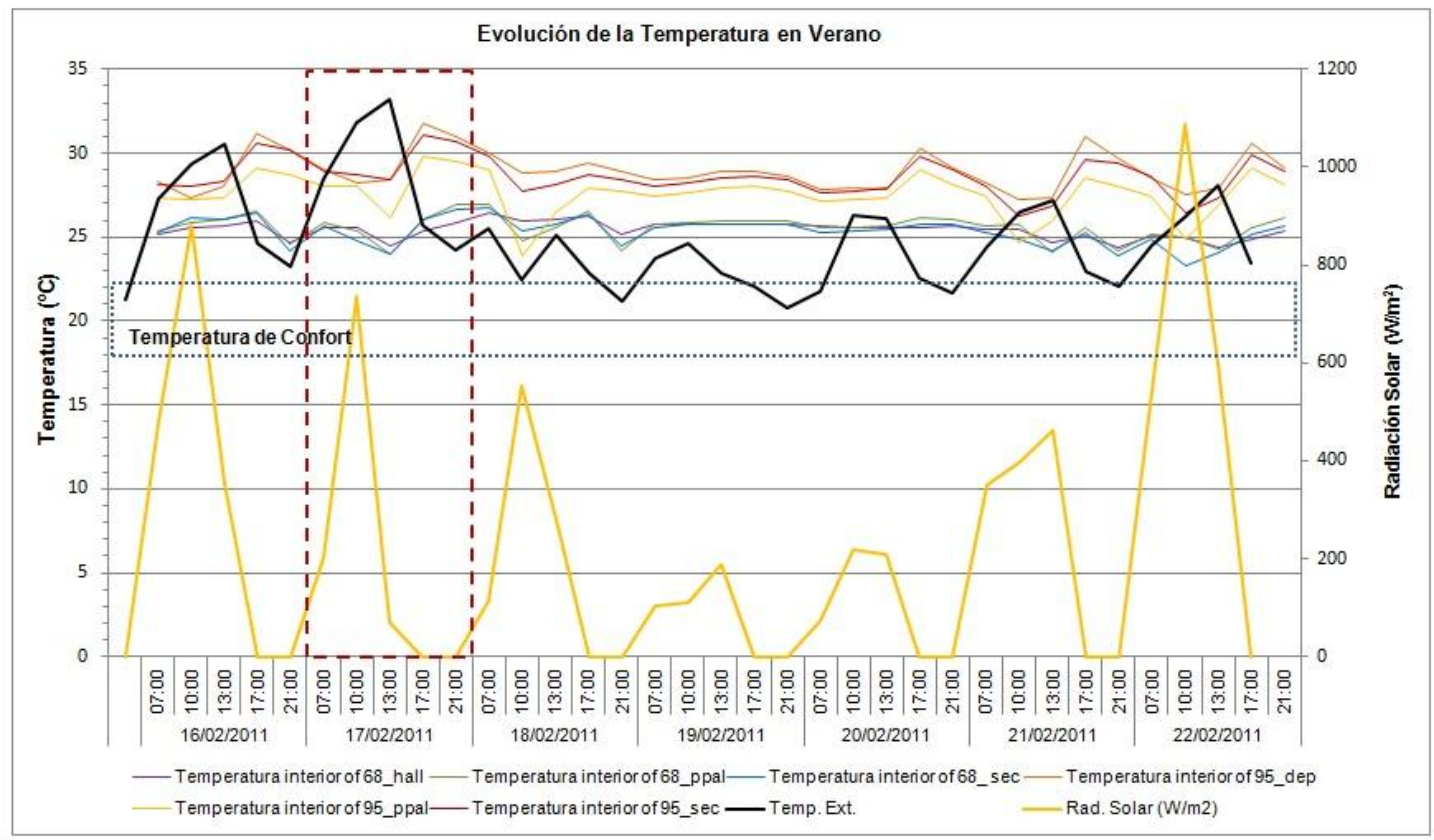

Gráfico VII - 19: Evolución de la temperatura en verano - Caso B (oficinas)

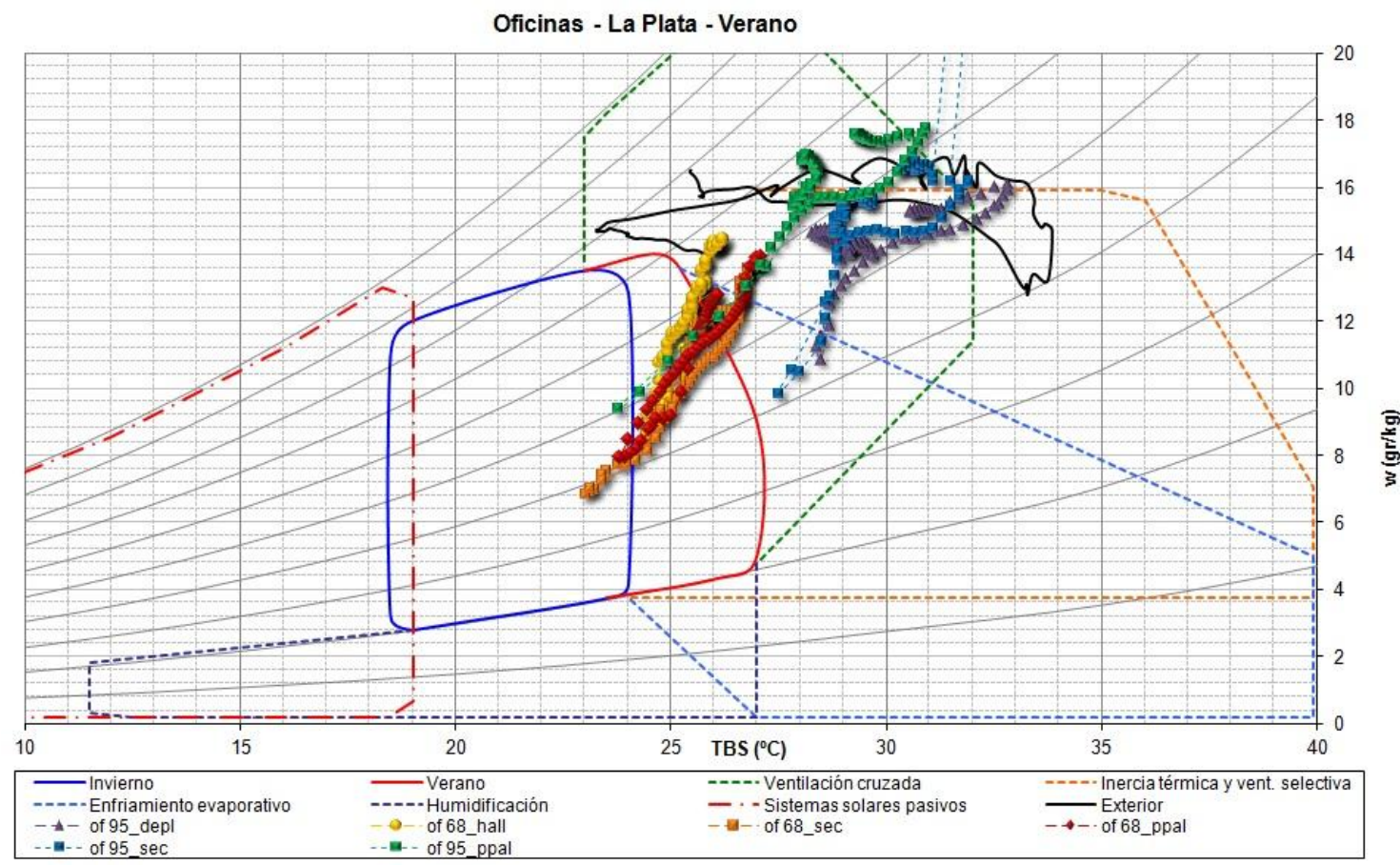

Gráfico VII - 20: Análisis del día crítico de verano con el PsiConf - Caso B (oficinas)

Tal como lo muestra el Gráfico VII - 20, al analizar el día crítico con el PsiConf 1.4 pudo verse una situación, bastante diferente a la del caso anterior. Los puntos presentan una mayor dispersión producto de que las temperaturas interiores mostraron una mayor variación, correlativa a la variación de la temperatura exterior y al aumento producido por las cargas internas. Sólo algunos puntos permanecieron dentro de los límites de confort. Los mismos corresponden mayoritariamente a la oficina que presenta un mayor consumo de energía eléctrica para acondicionamiento térmico. Según el Climograma de Givoni para alcanzar el 
confort de verano el edificio debería incorporar en su diseño enfriamiento evaporativo, ventilación selectiva e inercia térmica y ventilación cruzada.

\subsubsection{Caso C}

Tal como puede verse en el Gráfico VII - 21 pese a contar con sistemas de aire acondicionado todos los espacios analizados permanecieron fuera de los límites de confort. Según se observa, en uno de los ambientes de la oficina analizada tuvieron lugar temperaturas muy superiores a la del resto de los locales. Esto se debe a que se trataba de un local ubicado sobre el frente del edificio, en el cual el cerramiento exterior estaba materializado por un curtain wall de vidrio simple. El resto de los locales se ubicaron sobre el interior del edificio, protegidos de la incidencia directa de la radiación solar, en ellos las temperaturas resultaron inferiores pero igualmente se encontraronn muy por encima de la zona de confort. Para este período las temperaturas mínimas exteriores rondaron los $15^{\circ} \mathrm{C}$ y las máximas se aproximaron a los $20^{\circ} \mathrm{C}$. Por su parte las temperaturas interiores se mantuvieron entre los $23^{\circ} \mathrm{C}$ y los $37^{\circ} \mathrm{C}$, denotando la incidencia de la radiación solar sobre los espacios en contacto directo con el exterior y el sobrecalentamiento por las fuentes internas

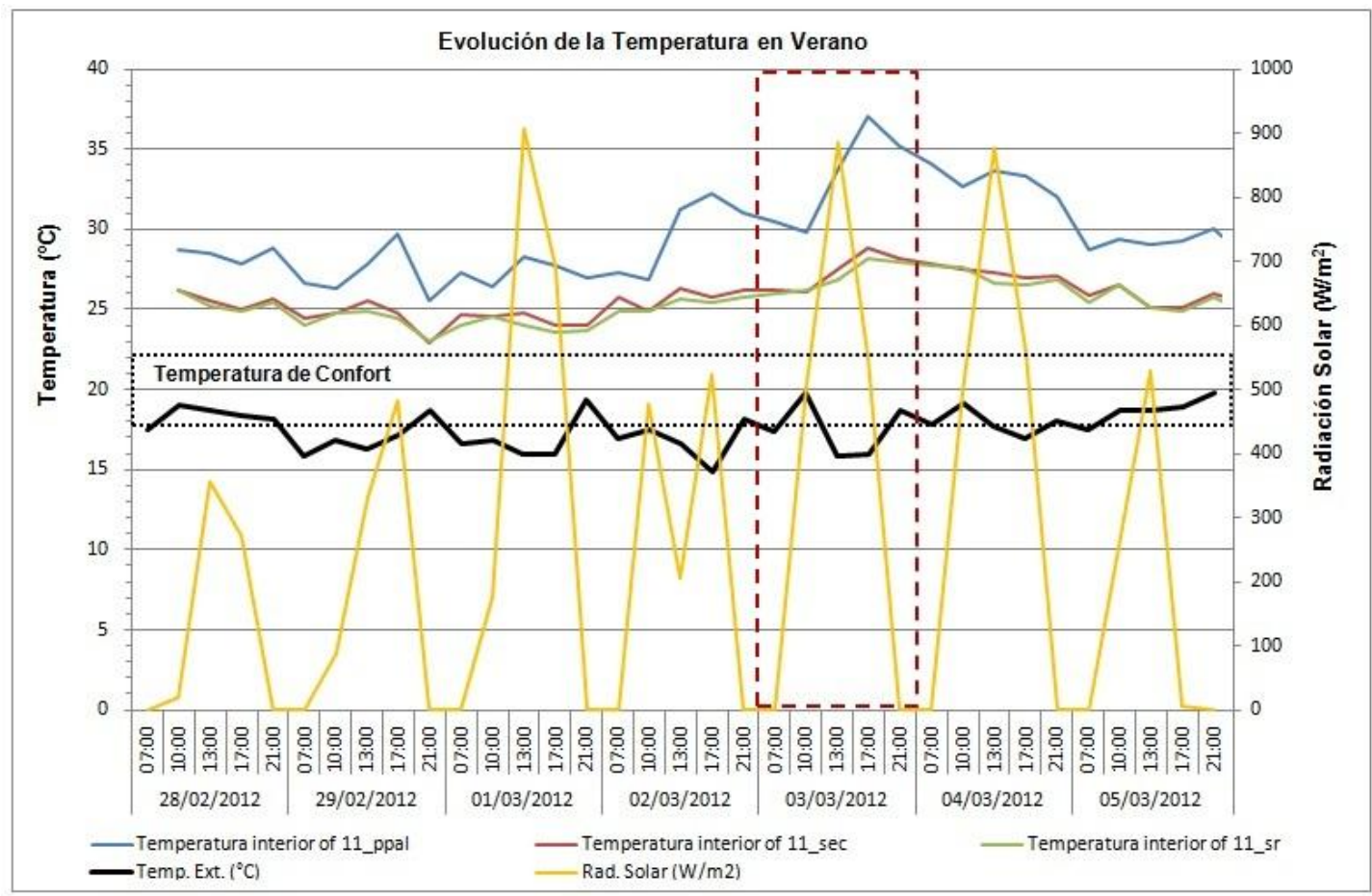

Gráfico VII - 21: Evolución de la temperatura en verano - Caso C (oficinas)

Al realizar el análisis del día crítico con el PsiConf 1.4 pudo verse esta situación con mayor claridad. Los puntos que dentro de la zona de confort son muy pocos y corresponden a los ambientes que se hallaban más alejados del exterior, sin contacto directo con el curtain wall. Por su parte la oficina principal, sobre el frente del edificio presenta todos sus puntos fuera de la zona de confort. Según el Climograma de Givoni para alcanzar el confort el edificio debería incorporar ventilación cruzada, enfriamiento evaporativo e inercia térmica y ventilación selectiva. 


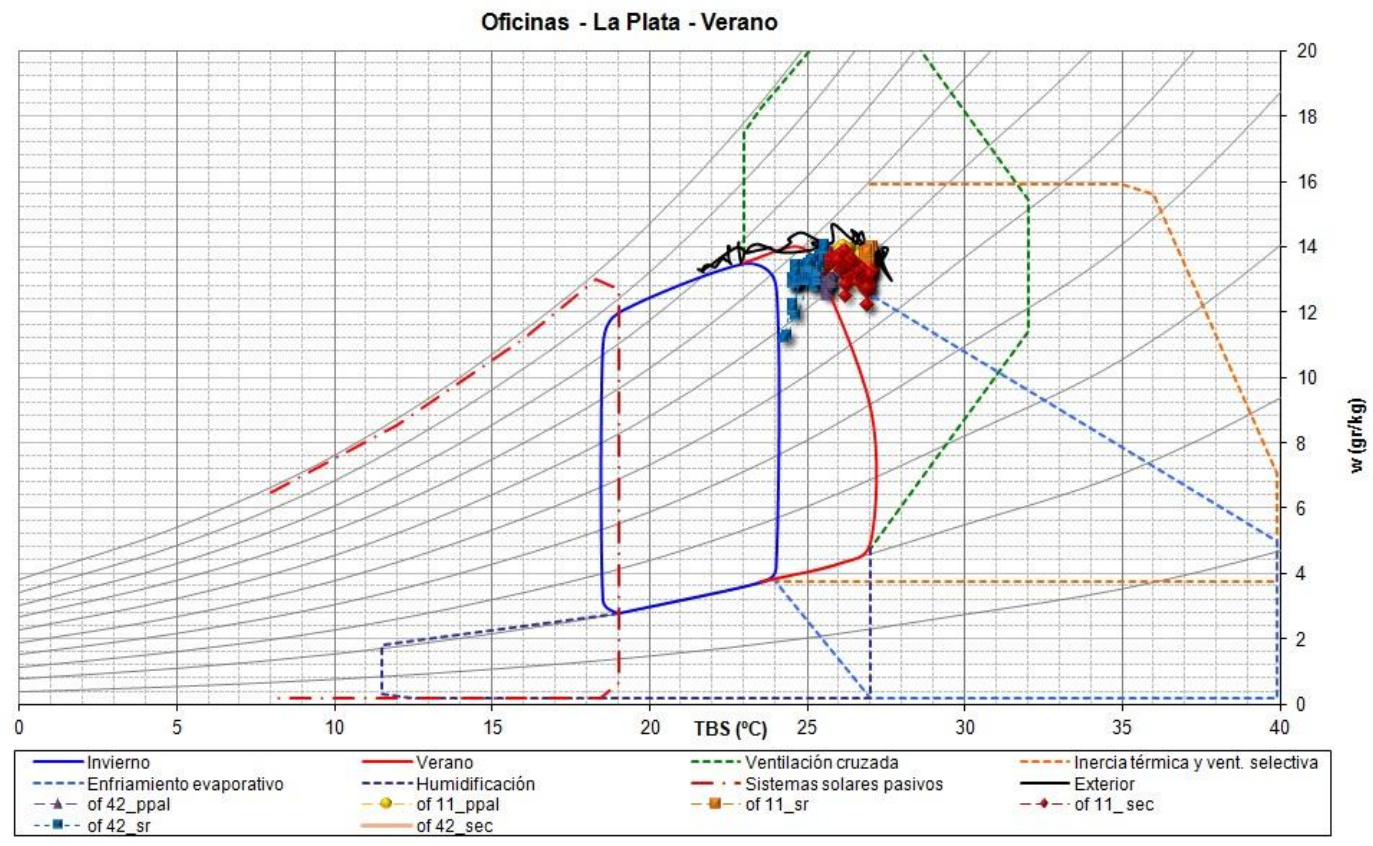

Gráfico VII - 22: Análisis del día crítico de verano con el PsiConf-Caso C (oficinas)

\subsubsection{Caso D}

Tal como puede verse en el Gráfico VII - 23 en general las temperaturas interiores de cada una de las unidades analizadas permanecieron por encima de los límites de confort para verano con máximas que rondaron los $27^{\circ} \mathrm{C}$ y mínimas que se aproximaron a los $19^{\circ} \mathrm{C}$. Para este período las temperaturas mínimas exteriores rondaron los $21^{\circ} \mathrm{C}$ y las máximas se aproximaron a los $33^{\circ} \mathrm{C}$. Pese a la utilización de sistemas de aire acondicionado pudo observarse cierta correspondencia con la variación de la temperatura exterior y con el uso de las oficinas, pudiendo distinguir los días hábiles de los fines de semana, que es cuando las temperaturas se mantuvieron constantes.

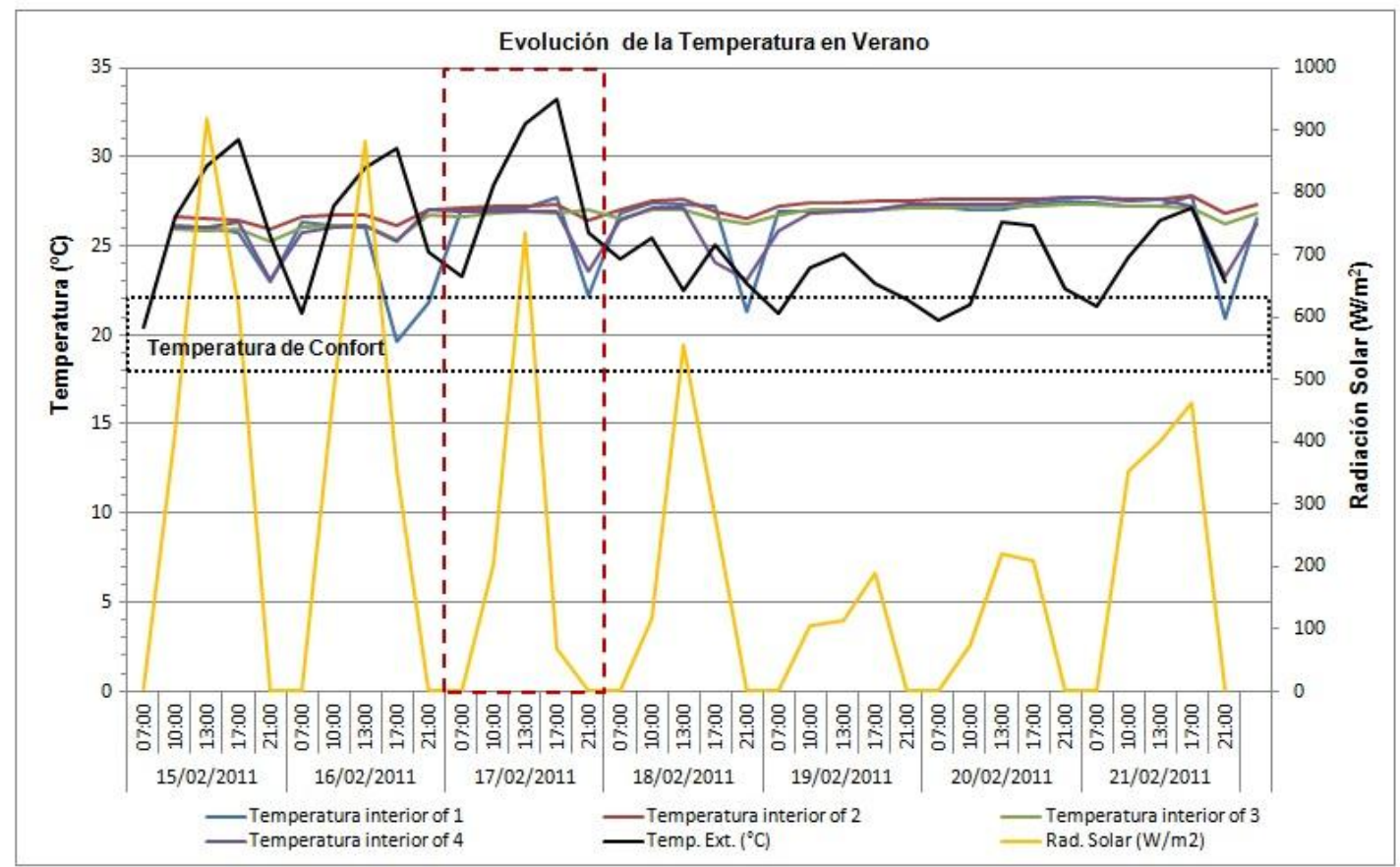

Gráfico VII - 23: Evolución de la temperatura en verano - Caso D (oficinas) 
Luego se analizó el día crítico con el PsiConf 1.4. Tal como puede observarse en el Gráfico VII - 24 algunos puntos permanecieron dentro de la zona de confort para verano pero son los que coincidían con las temperaturas más bajas. Pese a la utilización de sistemas de aire acondicionado, en general, la mayor parte del tiempo todos los espacios analizados se encuentraban fuera de los límites de confort. Según el Climograma de Givoni, para alcanzar el confort, el edificio en general debería incorporar a su diseño ventilación cruzada, enfriamiento evaporativo e inercia térmica y ventilación selectiva.

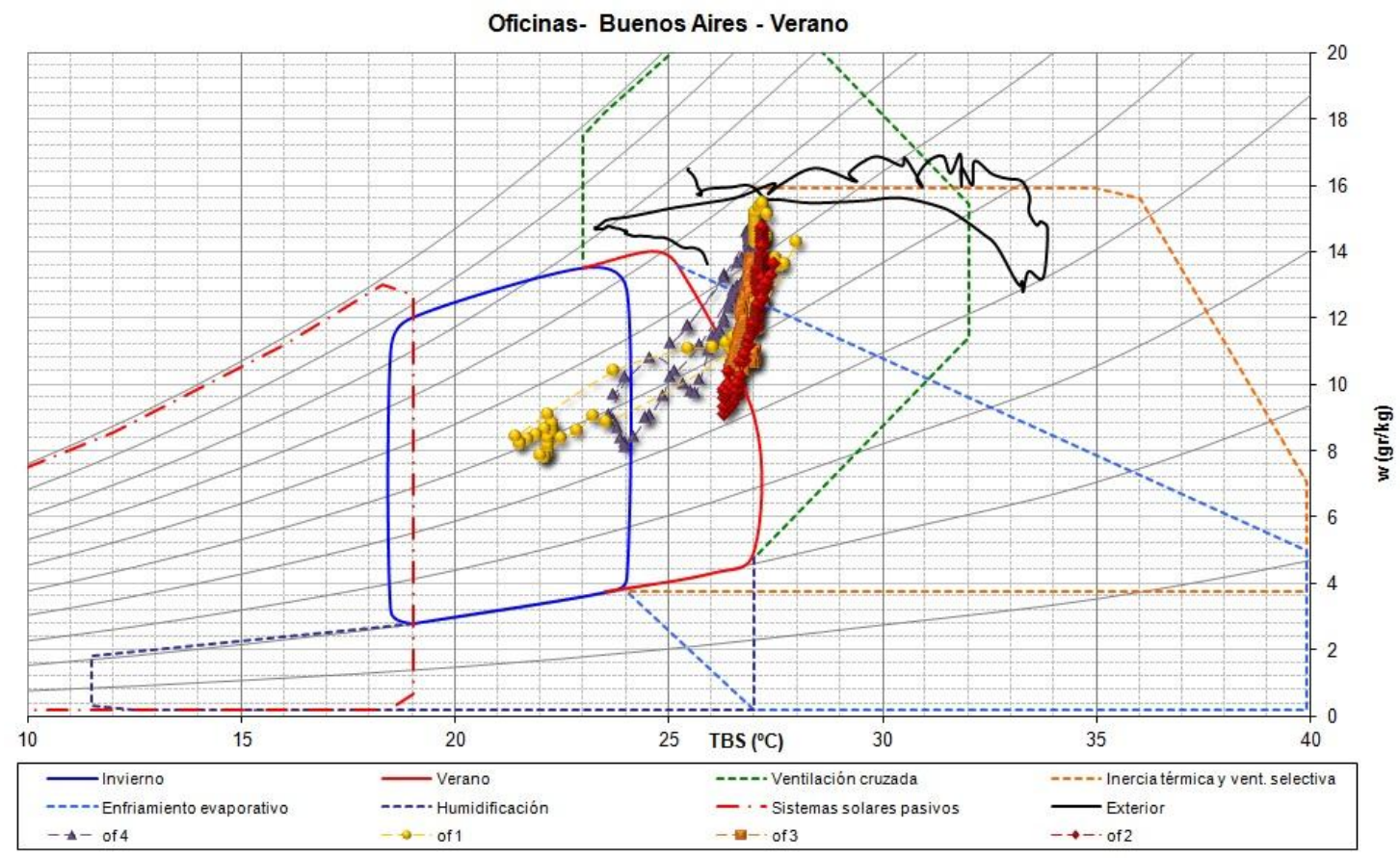

Gráfico VII - 24: Análisis del día crítico de verano con el PsiConf - Caso D (oficinas)

\subsubsection{Caso E}

Tal como puede verse en el Gráfico VII - 25 en general las temperaturas interiores de cada una de las unidades analizadas permanecieron por encima de los límites de confort para verano con máximas que rondaron los $27^{\circ} \mathrm{C}$ y mínimas que se aproximaron a los $23^{\circ} \mathrm{C}$. Para este período las temperaturas mínimas exteriores rondaron los $21^{\circ} \mathrm{C}$ y las máximas se aproximaron a los $33^{\circ} \mathrm{C}$. Pese a la utilización de sistemas de aire acondicionado pudo observarse cierta correspondencia con la variación de la temperatura exterior y con el uso de las oficinas, pudiendo distinguir los días hábiles de los fines de semana, que es cuando las temperaturas se mantuvieron constantes. Asimismo pudieron distinguirse los usos que albergan los distintos espacios analizados. Por ejemplo, en uno de ellos la temperatura interior permaneció constante en $24^{\circ} \mathrm{C}$, esto se debió a que dicho espacio albergaba el servidor que abastece a todas las oficinas del piso, el cual debía permanecer en un espacio refrigerado en forma continua.

Luego se analizó el día crítico con el PsiConf 1.4. Tal como puede observarse en el Gráfico VII - 26 la mayor parte del tiempo los distintos ambientes analizados permanecieron dentro de la zona de confort para verano. También pudo distinguirse la oficina que alberga el servidor, que es donde los puntos presentan una menor dispersión ya que dicho ambiente se mantuvo a una temperatura casi constante de $24^{\circ} \mathrm{C}$. Sin embargo, pese a la utilización de sistemas de refrigeración se observan algunos puntos fuera de los límites de confort. Según el Climograma de Givoni, para alcanzar el confort, el edificio en general debería incorporar a su diseño ventilación cruzada, enfriamiento evaporativo e inercia térmica y ventilación selectiva. 


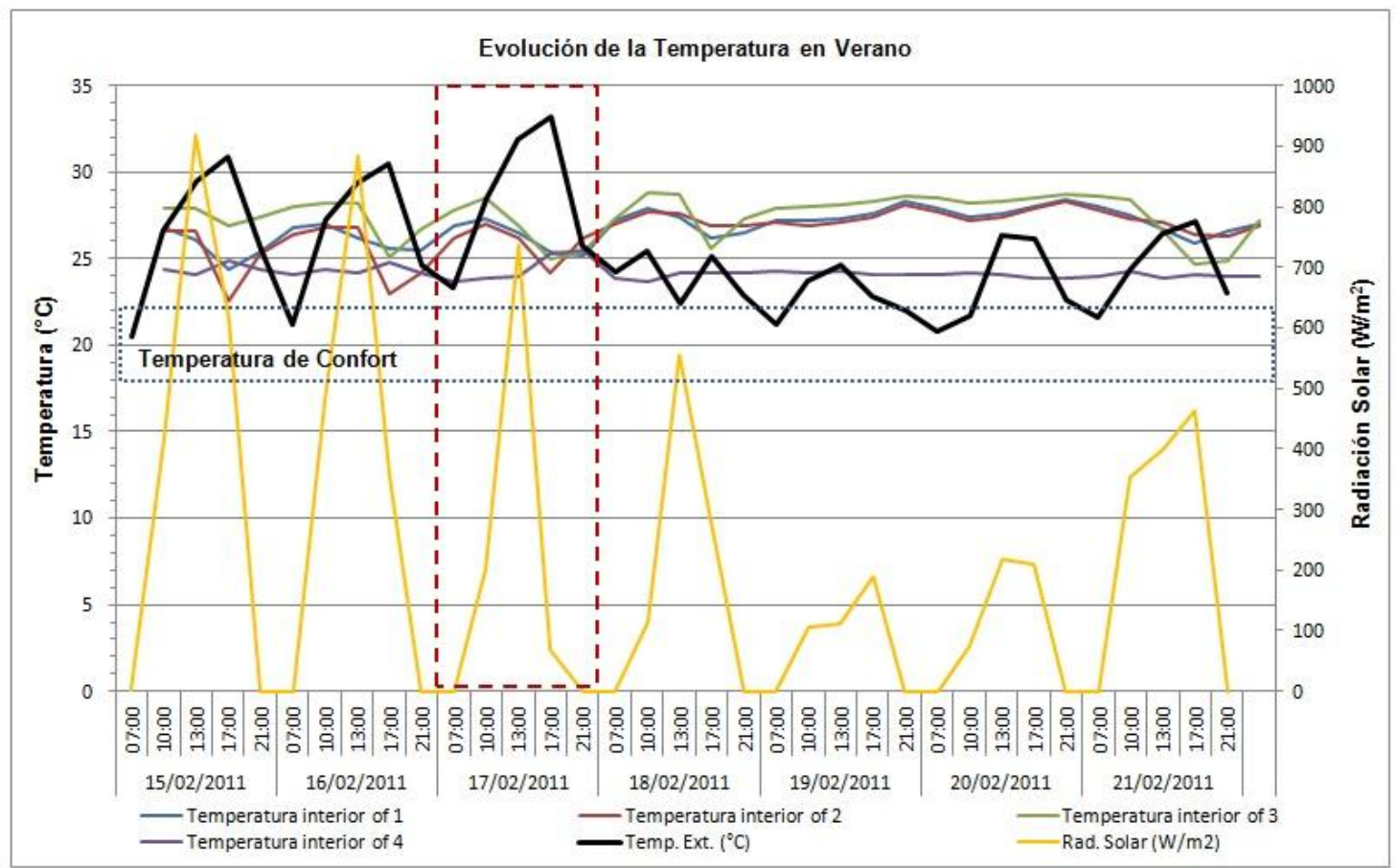

Gráfico VII - 25: Evolución de la temperatura en verano - Caso E (oficinas)

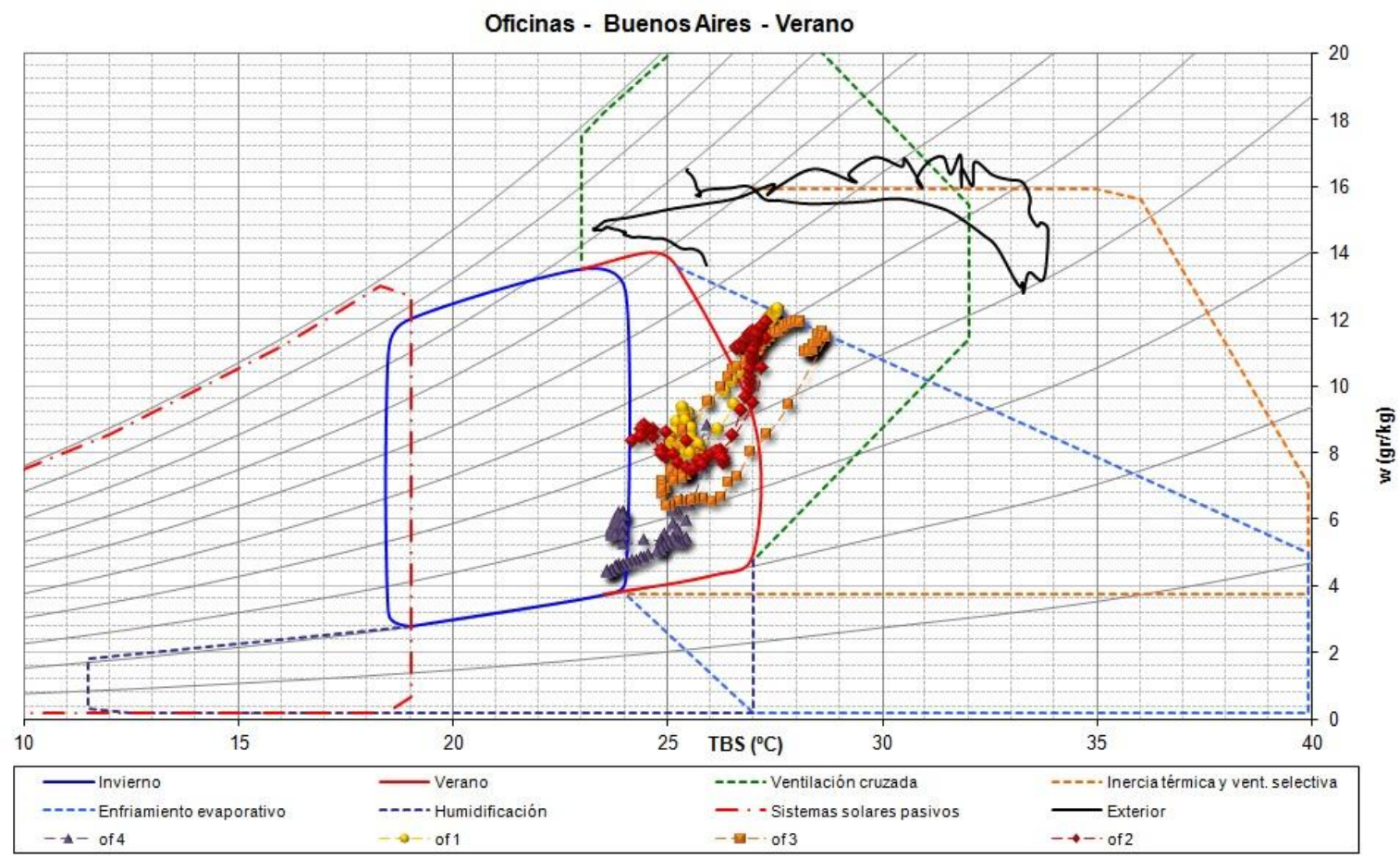

Gráfico VII - 26: Análisis del día crítico de verano con el PsiConf - Caso E (oficinas)

\subsubsection{Comportamiento higrotérmico de invierno}

A continuación se muestran los resultados de la campaña de medición de verano para los edificios de oficinas. La misma comprendió los meses de junio, julio y agosto del 2010. Tal como puede verse en los gráficos durante este período se presentaron días con temperaturas extremas y otros no. 


\subsubsection{Caso A}

Tal como puede verse en el Gráfico VII - 27 en general las temperaturas interiores de cada una de las unidades analizadas permanecieron dentro de los límites de confort para invierno con máximas que rondaron los $24^{\circ} \mathrm{C}$ y mínimas que se aproximaron a los $18^{\circ} \mathrm{C}$, se observan algunos puntos con sobrecalentamiento, sin embargo los valores se mantuvieron próximos a la zona de confort. Para este período las temperaturas mínimas exteriores rondaron los $9^{\circ} \mathrm{C}$ y las máximas se aproximaron a los $23^{\circ} \mathrm{C}$. La utilización de sistemas de calefacción y el uso de las oficinas permitió distinguir los días hábiles de los fines de semana, que es cuando las temperaturas se mantuvieron constantes.

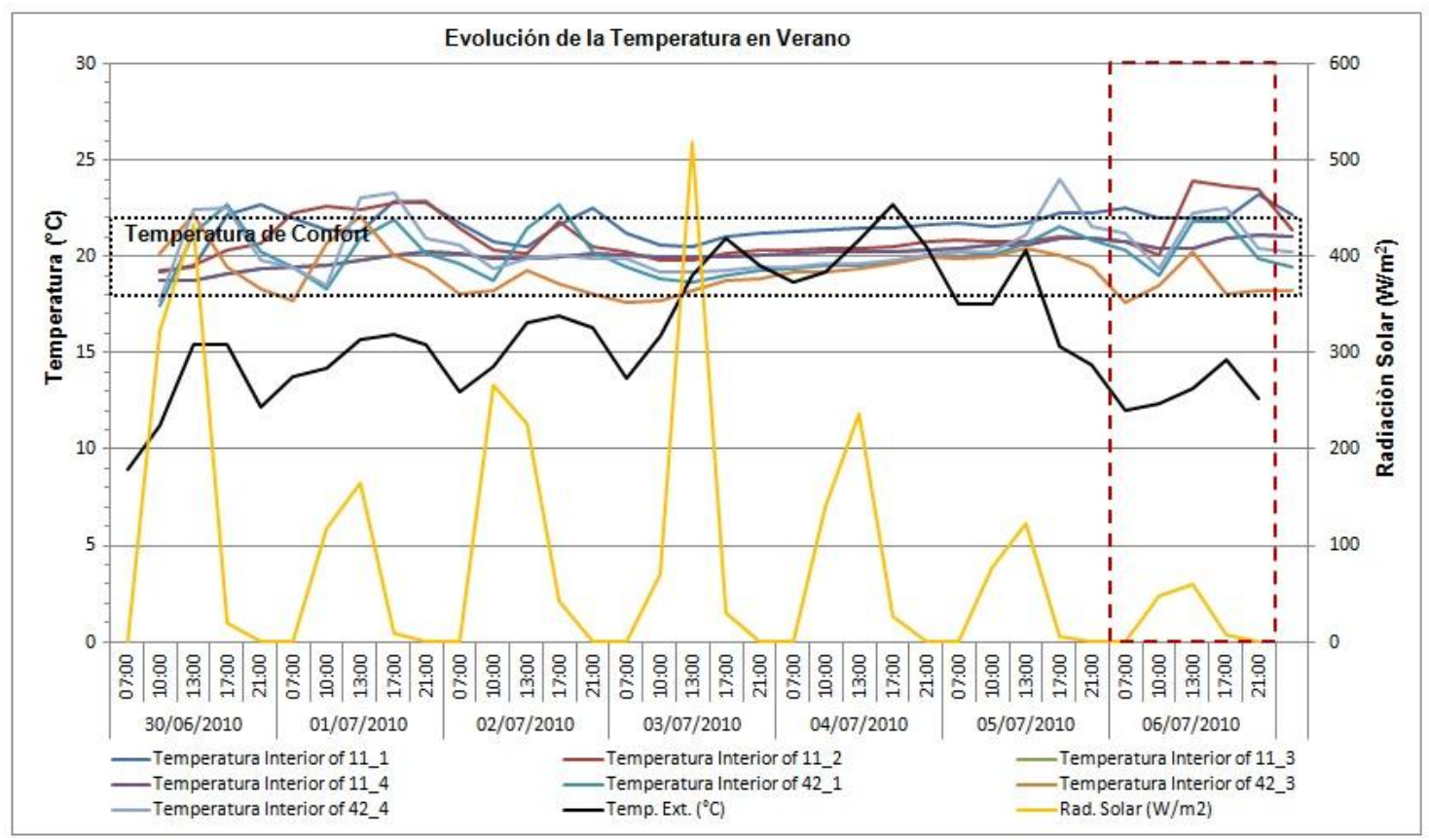

Gráfico VII - 27: Evolución de la temperatura en invierno - Caso A (oficinas)

Oficinas - La Plata - Invierno

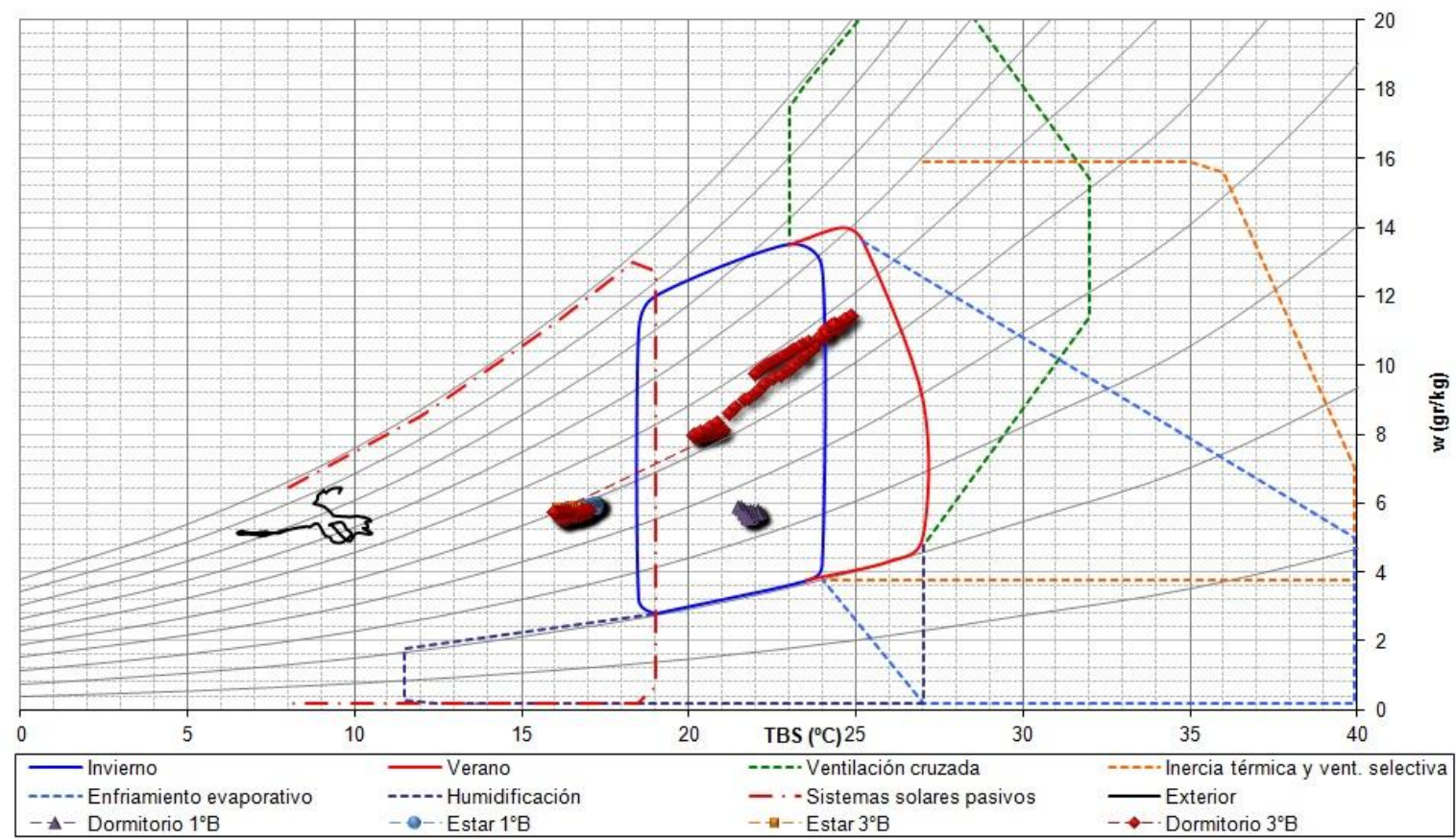

Gráfico VII - 28: Análisis del día crítico de invierno con el PsiConf - Caso A (oficinas) 
Luego se analizó el día crítico con el PsiConf 1.4. Tal como puede observarse en el Gráfico VII - 28 la mayor parte del tiempo los distintos ambientes analizados permanecieron dentro de la zona de confort para invierno, esto debido al uso de sistemas de calefacción. Sin embargo pudieron obserse algunos puntos fuera de los límites de confort. Según el Climograma de Givoni, para alcanzar el confort, el edificio en general debería incorporar a su diseño sistemas solares pasivos.

\subsubsection{Caso B}

Tal como puede verse en el Gráfico VII - 29 en general las temperaturas interiores de cada una de las unidades analizadas permanecieron fuera de los límites de confort para invierno con máximas que rondaron los $22^{\circ} \mathrm{C}$ y mínimas que se aproximaron a los $13^{\circ} \mathrm{C}$. Si bien pueden observarse algunos puntos dentro de la zona de confort, pero estos coinciden con las máximas temperaturas exteriores. Tal como en caso anterior la utilización de sistemas de calefacción y el uso de las oficinas permitieron distinguir los días hábiles de los fines de semana, que es cuando las temperaturas se mantienen constantes.

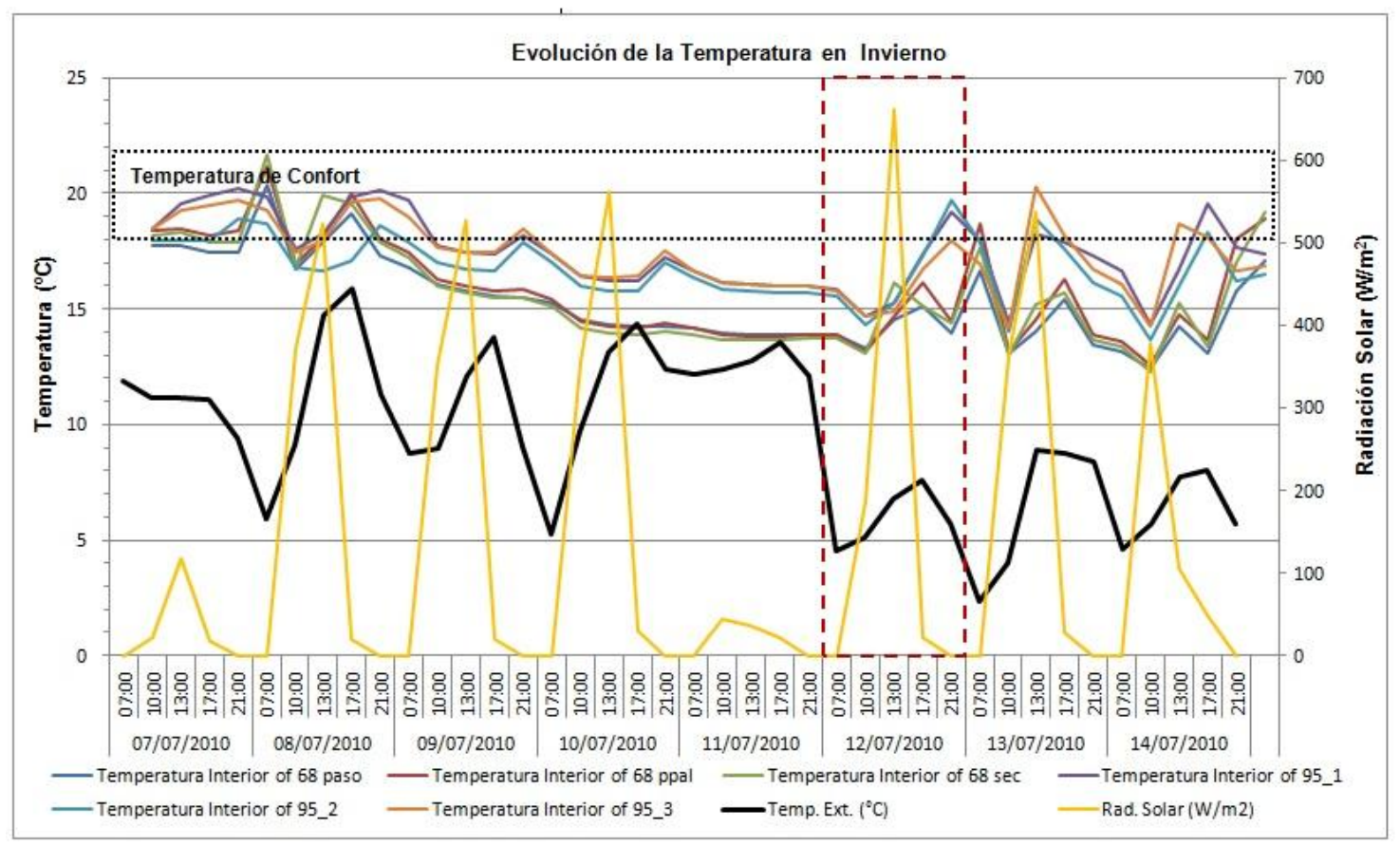

Gráfico VII - 29: Evolución de la temperatura en invierno - Caso B (oficinas)

Luego se analizó el día crítico con el PsiConf 1.4. Tal como puede observarse en el Gráfico VII - 30 la mayor parte del tiempo los distintos ambientes analizados permanecieron fuera de la zona de confort para invierno. Se observan algunos puntos dentro de los límites de confort pero los mismos se correspondían con las mayores temperaturas exteriores. Según el Climograma de Givoni, para alcanzar el confort, el edificio en general debería incorporar a su diseño sistemas solares pasivos. 


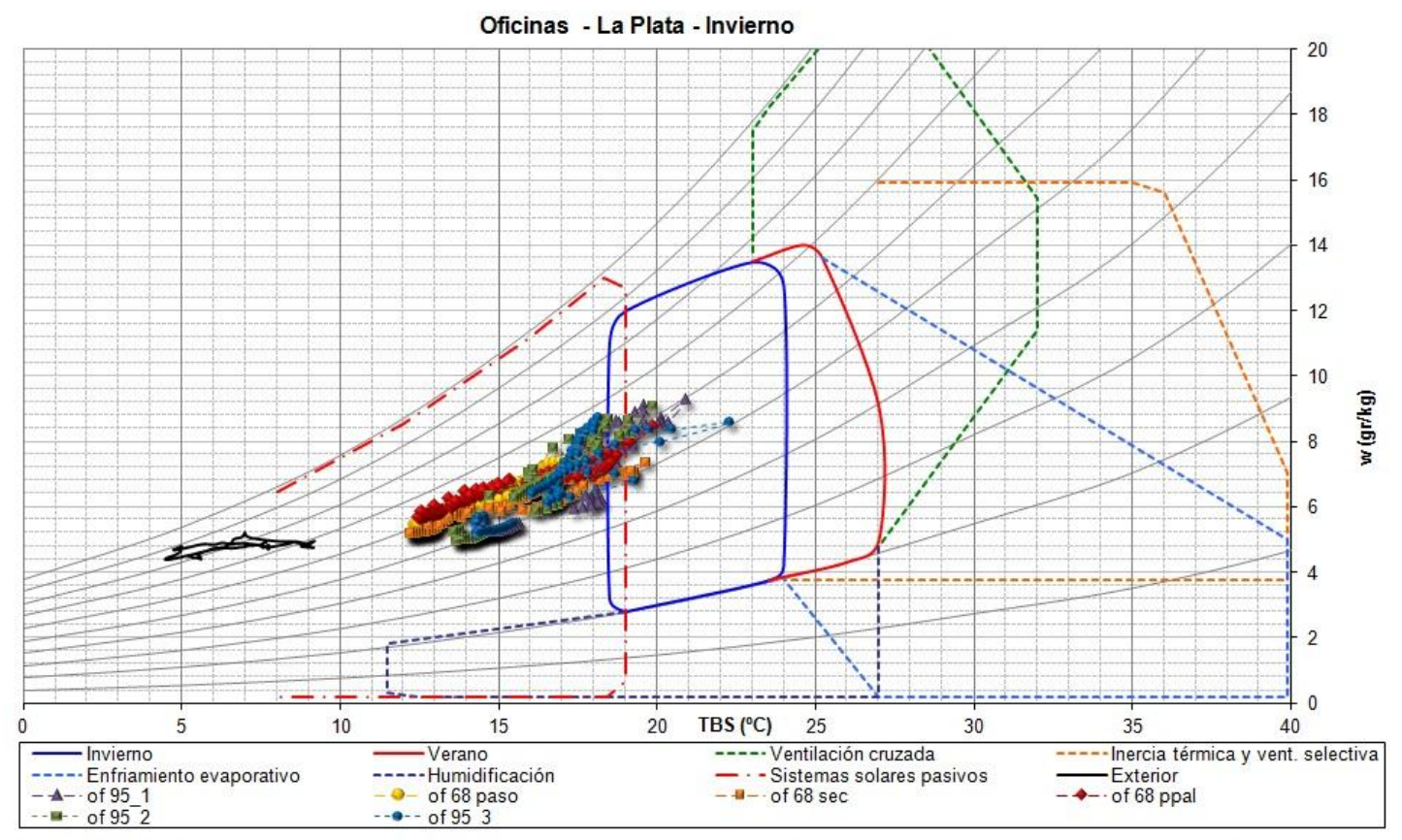

Gráfico VII - 30: Análisis del día crítico de invierno con el PsiConf - Caso B (oficinas)

\subsubsection{Caso C}

Tal como puede verse en el Gráfico VII - 31 en general las temperaturas interiores de cada una de las unidades analizadas permanecieron fuera de los límites de confort para invierno. Pueden observarse algunos puntos en los que se produjo sobrecalentamiento y otros que permanecieron muy por debajo de los valores admisibles. Las máximas temperaturas interiores rondaron los $25^{\circ} \mathrm{C}$ y las mínimas se aproximaron a los $12^{\circ} \mathrm{C}$. Pudieron observarse también diferencias de comportamiento entre las dos unidades analizadas y entre los distintos ambientes que las conformaban, donde las temperaturas máximas coincidían con las zonas más próximas a la fachada principal conformada por un curtain wall de vidrio simple coloreado. Tal como en caso anterior la utilización de sistemas de calefacción y el uso de las oficinas permitió distinguir los días hábiles de los fines de semana, que es cuando las temperaturas se mantuvieron constantes.

Luego se analizó el día crítico con el PsiConf 1.4. Tal como puede observarse en el Gráfico VII - 32 la situación fue diferente para las dos unidades. Los ambientes de la unidad que presentaba mayor consumo de gas natural para calefacción se encontraba en confort la mayor parte del día mientras que los locales de la unidad que presentaba menor consumo se encontraba mayoritariamente fuera de los límites de confort para invierno. Según el Climograma de Givoni, para alcanzar el confort, el edificio en general debería incorporar a su diseño sistemas solares pasivos. 


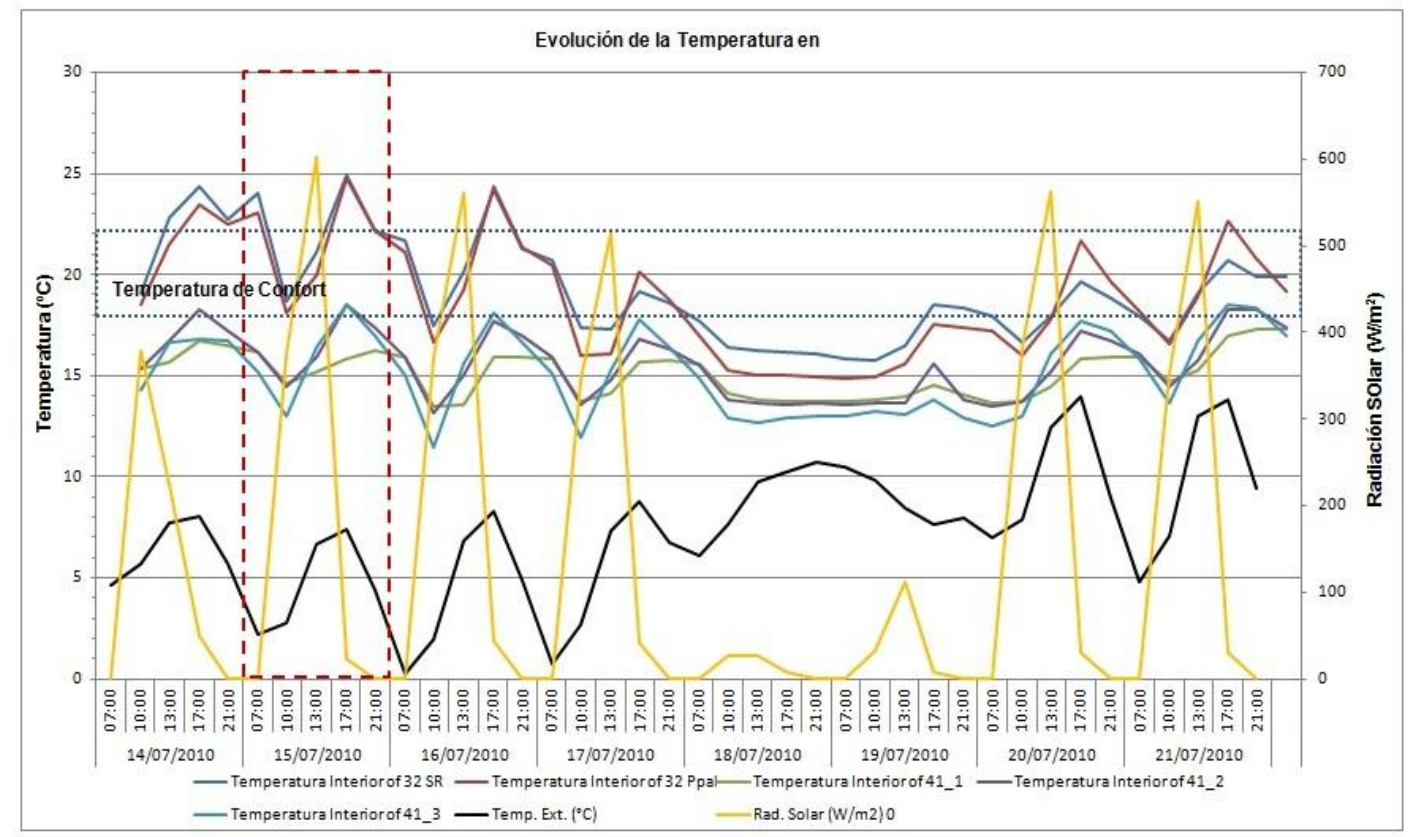

Gráfico VII - 31: Evolución de la temperatura en invierno - Caso C (oficinas)

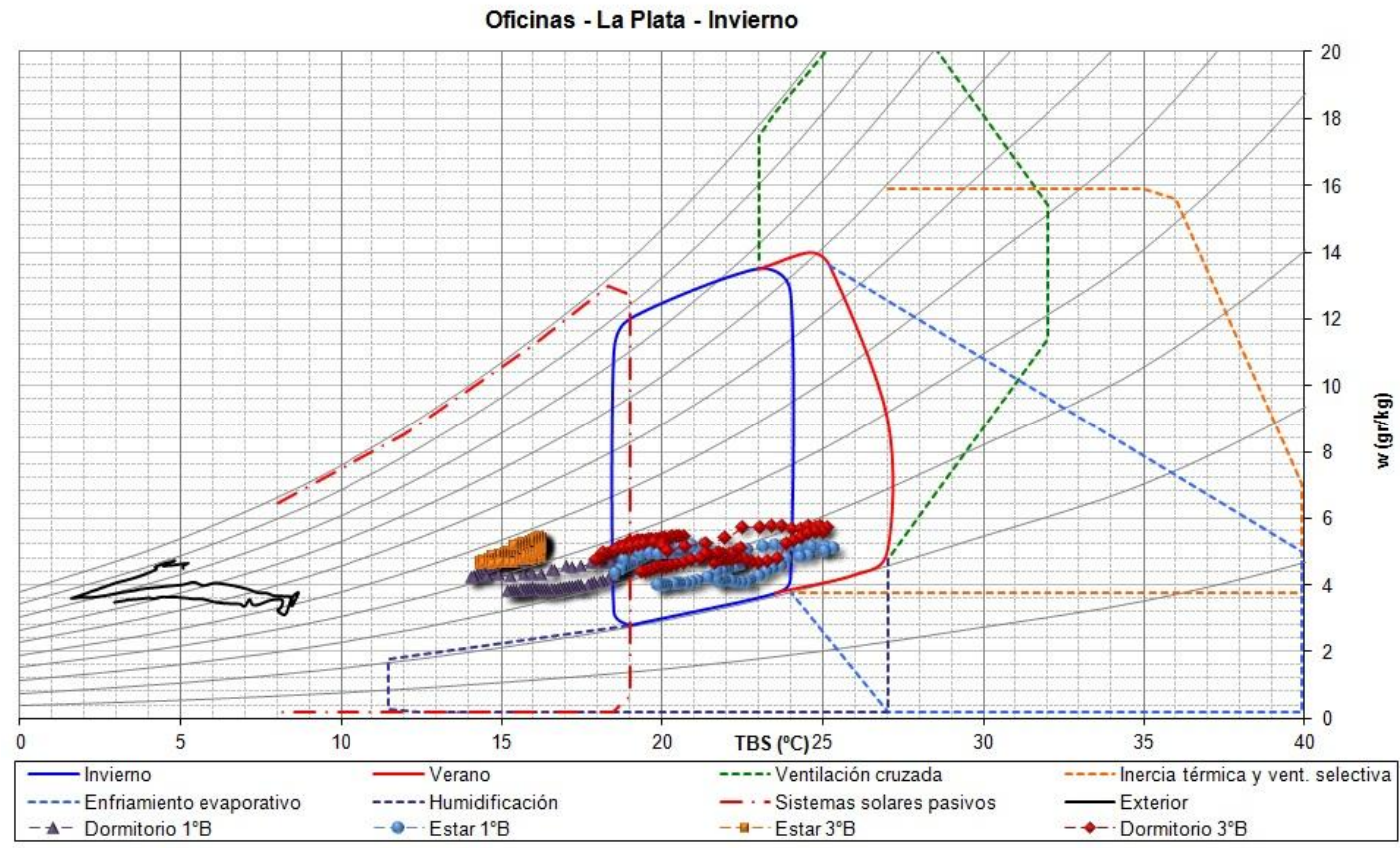

Gráfico VII - 32: Análisis del día crítico de invierno con el PsiConf-Caso C (oficinas)

\subsubsection{Caso D}

Tal como puede verse en el Gráfico VII - 33 en general las temperaturas interiores de cada una de las unidades analizadas permanecieron dentro de los límites de confort para invierno. Se observaron algunos puntos con sobrecalentamiento que se correspondian con las horas de ocupación y de mayor influencia de la radiación solar. Las máximas temperaturas interiores rondaron los $25^{\circ} \mathrm{C}$ y las mínimas se aproximaron a los $21^{\circ} \mathrm{C}$. Tal como en los casos anteriores la utilización de sistemas de calefacción y el uso de las oficinas permitió distinguir los días hábiles de los fines de semana, que es cuando las temperaturas se mantuvieron constantes. 


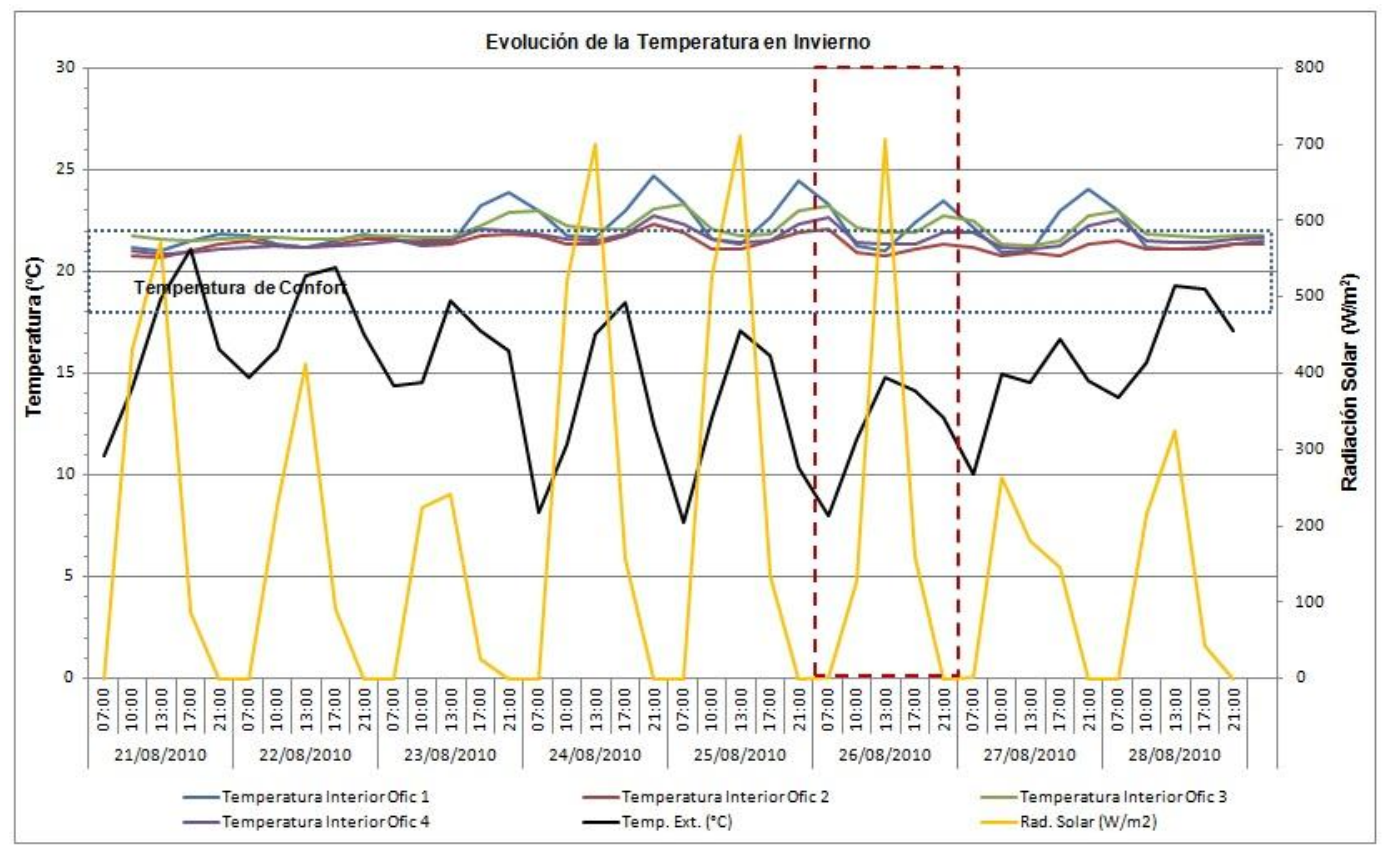

Gráfico VII - 33: Evolución de la temperatura en invierno - Caso D (oficinas)

Luego se analizó el día crítico con el PsiConf 1.4. Tal como pudo observarse en el Gráfico VII 34 todos los ambientes permanecieron dentro de los límites de confort para invierno. Las temperaturas exteriores se ubicaron en el cuadrante inferior izquierdo. Según el Climograma de Givoni, para alcanzar el confort sin tener que recurrir a climatización con gas natural o energía eléctrica, el edificio en general debería incorporar a su diseño sistemas solares pasivos.

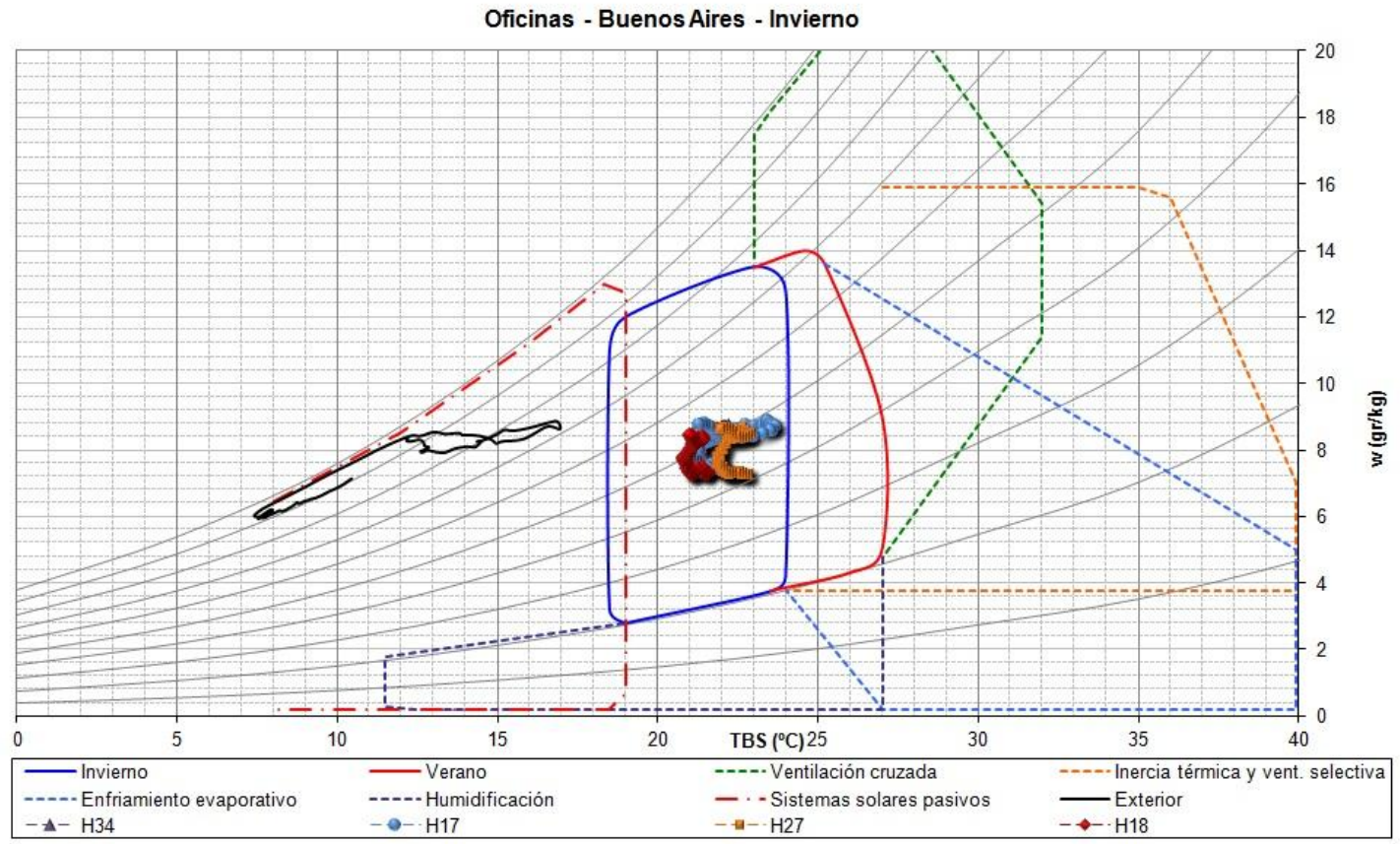

Gráfico VII - 34: Análisis del día crítico de invierno con el PsiConf - Caso D (oficinas)

\subsubsection{Caso E}

Tal como puede verse en el Gráfico VII - 35 en general las temperaturas interiores de cada una de las unidades analizadas permanecieron dentro de los límites de confort para invierno. Se observaron algunos puntos con sobrecalentamiento que se correspondían con las horas de ocupación y de mayor influencia de la radiación solar. La línea que se distingue del resto, que 
marca una temperatura casi constante de $24^{\circ} \mathrm{C}$ corresponde a la sala donde se ubicaba el servidor que abastecía al resto de las oficinas, el cual debía permanecer a una temperatura constante de $24^{\mathrm{a}} \mathrm{C}$. En general las máximas temperaturas interiores rondaron los $25^{\circ} \mathrm{C}$ y las mínimas se aproximaron a los $2^{\circ} \mathrm{C}$. Tal como en los casos anteriores la utilización de sistemas de calefacción y el uso de las oficinas permitió distinguir los días hábiles de los fines de semana, que es cuando las temperaturas se mantuvieron constantes.

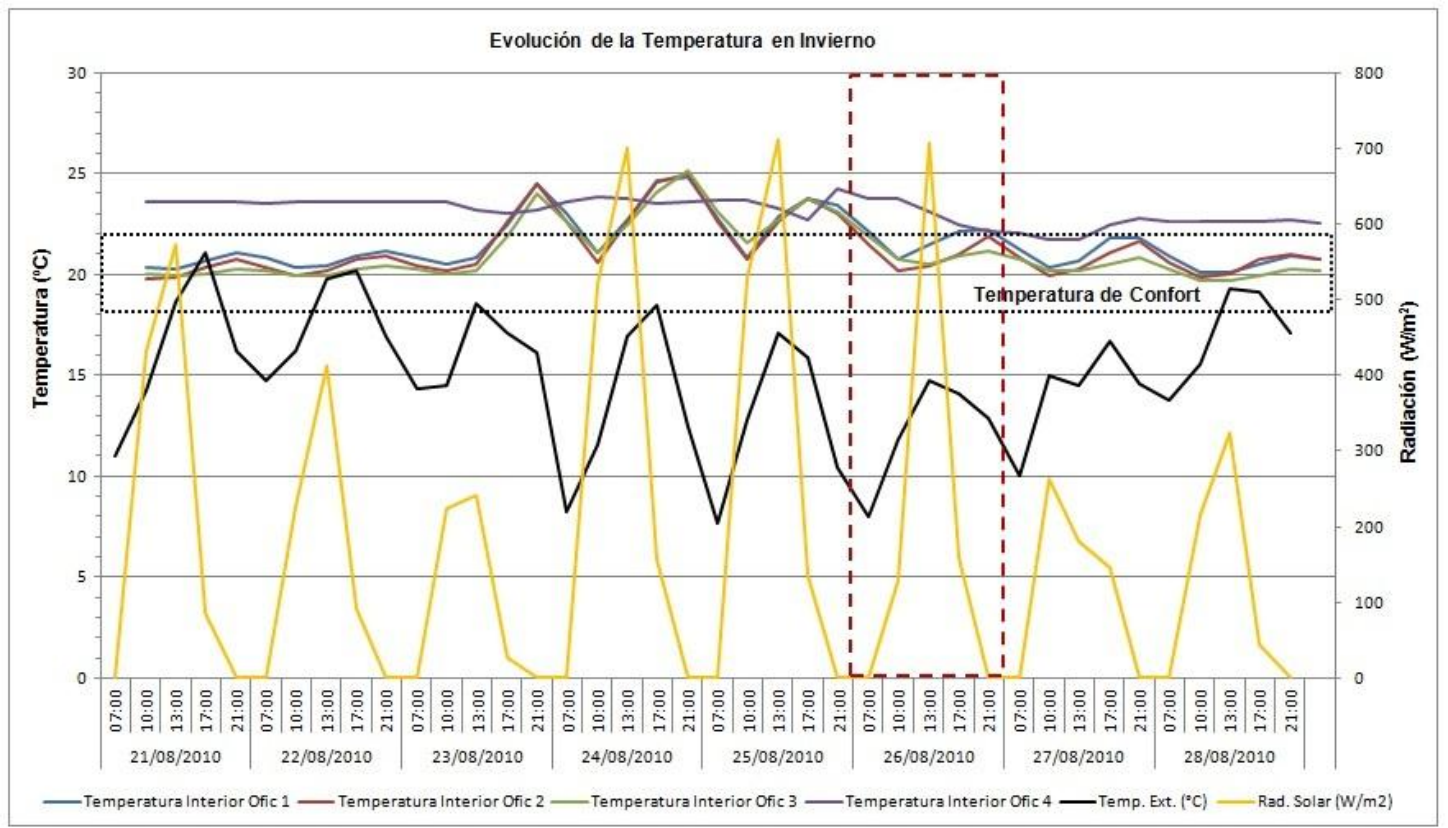

Gráfico VII - 35: Evolución de la temperatura en invierno - Caso E (oficinas)

Luego se analizó el día crítico con el PsiConf 1.4. Tal como puede observarse en el Gráfico VII - 36 a excepción de la sala donde se alojaba el servidor, todos los ambientes permanecieron fuera de los límites de confort para invierno. Según el Climograma de Givoni, para alcanzar el confort sin tener que recurrir a climatización con gas natural o energía eléctrica, el edificio debería incorporar a su diseño sistemas solares pasivos.

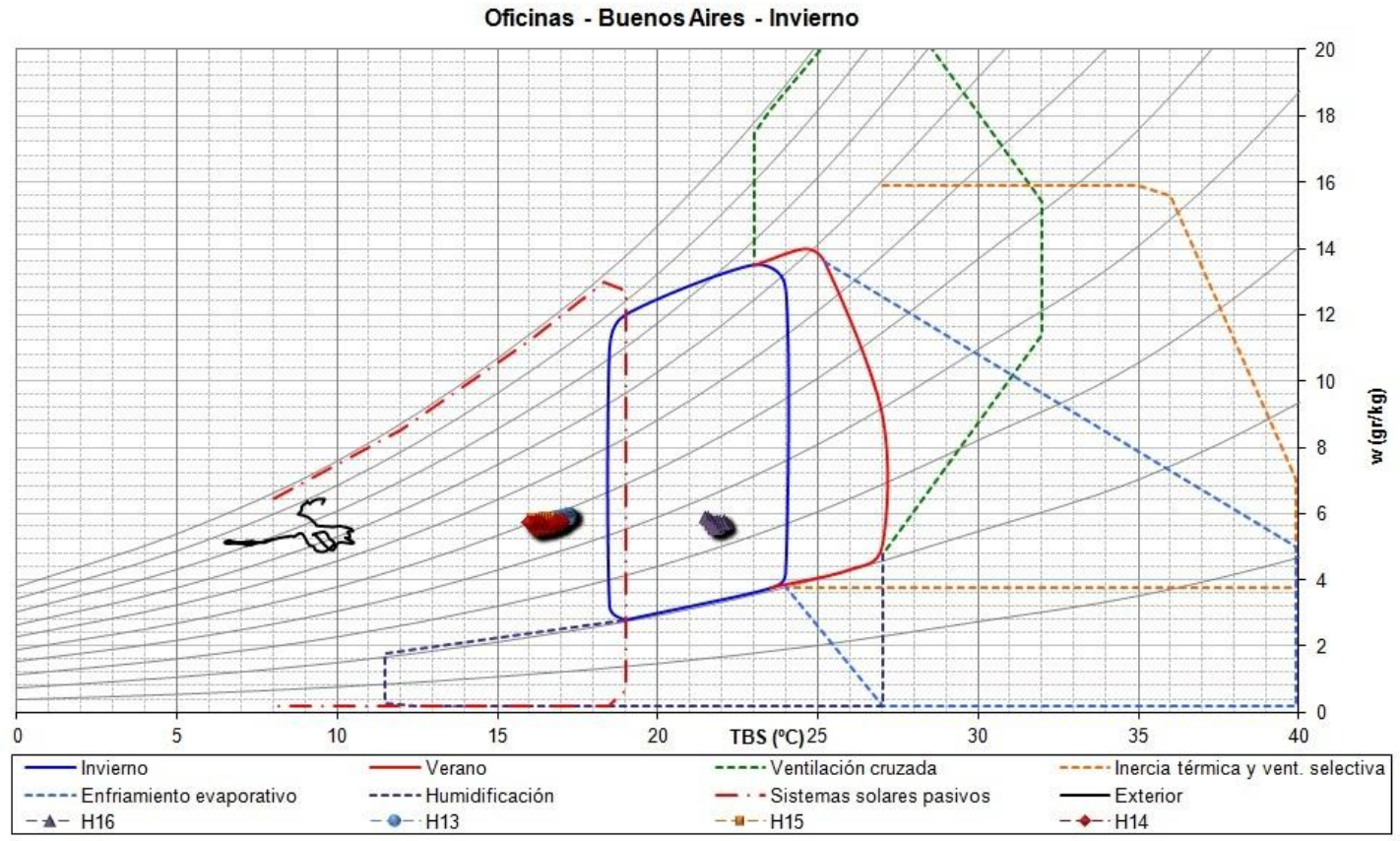

Gráfico VII - 36: Análisis del día crítico de invierno con el PsiConf - Caso E (oficinas) 


\section{CAPÍTULO VIII \\ DEMANDA DE ENERGÍA PARA CALEFACCIÓN - ETIQUETADO DE EFICIENCIA ENERGÉTICA EN CALEFACCIÓN}

\subsection{Introducción}

En el siguiente Capítulo se presentan los resultados del balance térmico de cada uno de los edificios auditados contemplando dos situaciones; una que sigue el modo en que están construidos en la actualidad y la otra según las propuestas de mejoras que siguen los criterios del Diseño Ambientalmente Consciente. Tal como se comenta en el Capítulo VI - Auditoría energética, con los datos obtenidos en las auditorías energéticas pudo realizarse el cálculo del balance térmico de la planta tipo mediante el AuditCAD (Czajkowski, J.; 1999). También se muestran los resultados del Etiquetado Energético según la Norma IRAM 11.900, para los edificios tal como están construidos en la actualidad y para las propuestas de mejoras que siguen los criterios del Diseño Ambientalmente Consciente.

\subsection{Demanda de Energía para calefacción}

Para el análisis de la demanda de energía en calefacción se estudió la planta tipo de cada edificio auditado. Cada planta se analizó por medio del AuditCAD; dicho programa permite analizar mensualmente el comportamiento térmico y energético de un edificio, mediante el ingreso de los datos auditados al tiempo que determina indicadores formales y energéticos. A partir de las características del edificio y grado de ocupación (iluminación, personas, equipamiento), determina cuanta energía será requerida para mantener al edificio en temperatura de termostato. Los resultados devueltos son la demanda de energía eléctrica y gas natural, distinguiendo la demanda con sol y sin sol (días nublados). En todos los casos el análisis se realizó para un período de 168hs (7 días).

Cabe aclarar que sólo se consideraron los elementos de la envolvente en contacto con el exterior y con ambientes no acondicionados térmicamente. Del mismo modo es importante mencionar que en el caso de los muros medianeros, así como en todos los elementos en contacto con ambientes interiores no calefaccionados, se utilizó un factor de protección del $50 \%{ }^{1}$.

\footnotetext{
${ }^{1}$ Este factor de protección es un coeficiente que se aplica a las pérdidas de las distintas superficies de la envolvente consideradas en el cálculo que no están en contacto directo con el aire exterior. De este modo las pérdidas a través de estos elementos se consideran a la mitad.
} 


\subsubsection{Edificios de Viviendas}

\subsubsection{Caso A}

La Figura VIII - 1 muestra un resumen de los datos obtenidos con el AuditCAD para el edificio tal como está construido en la actualidad, es decir según la información que pudo recolectarse durante la auditoría energética. Tal como se comenta en el Capítulo V - Estudio de Casos su tecnología constructiva es convencional con estructura de hormigón armado y muros de cerramiento exterior de ladrillos huecos de $18 \times 18 \times 33 \mathrm{~cm}$, sin aislamiento higrotérmico adicional. Por su parte los cerramientos interiores se han materializado con ladrillos huecos de $12 \times 18 \times 33 \mathrm{~cm}$, los que separan a los departamentos entre sí y con las áreas comunes, y con ladrillos de $8 \times 18 \times 33 \mathrm{~cm}$ aquellos que dividen los ambientes interiores de cada departamento. Las carpinterías son de simple vidriado con perfilería de aluminio, sin protección solar las que se disponen sobre la fachada principal y con cortinas de enrollar de pvc, aquellas dispuestas sobre el contrafrente.

Según estos datos, los valores de transmitancia térmica de los diferentes elementos que componen la envolvente de este edificio rondan los siguientes valores:

- Pisos / Techos: $\mathrm{K}=2,34 \mathrm{~W} / \mathrm{m}^{2} \cdot \mathrm{K}$ (factor de protección $50 \%$ )

- Muros exteriores: $\mathrm{K}=1,82 \mathrm{~W} / \mathrm{m}^{2} \cdot \mathrm{K}$

- Muros medianeros: $\mathrm{K}=1,82 \mathrm{~W} / \mathrm{m}^{2} \cdot \mathrm{K}$ (factor de protección $50 \%$ )

- Muros interiores: $\mathrm{K}=2,18 \mathrm{~W} / \mathrm{m}^{2} \cdot \mathrm{K}$ (factor de protección $50 \%$ )

- Superficies vidriadas: $\mathrm{K}=5,80 \mathrm{~W} / \mathrm{m}^{2} \cdot \mathrm{K}$

- Puertas interiores: $\mathrm{K}=3,50 \mathrm{~W} / \mathrm{m}^{2} \cdot \mathrm{K}$ (factor de protección $50 \%$ )

En la Figura VIII - 1 puede verse claramente que los mayores aportes de energía para calefacción provienen del gas natural, con más del $80 \%$. La incidencia de la ocupación, la energía eléctrica e insolación suman un total de menos del 19\%. Puede verse también que los mayores porcentajes de pérdidas se dan a través de techos $(30 \%)$, muros $(24 \%)$, ventanas $(19 \%)$ y renovaciones de aire $(18 \%)$, esto principalmente debido a la falta de aislación térmica. La planta tipo del edificio tal como está construido en la actualidad requiere de un consumo de $0,15 \mathrm{~m}^{3} / \mathrm{m}^{2} /$ día de gas natural para alcanzar una temperatura interior de $20^{\circ} \mathrm{C}$. La carga térmica

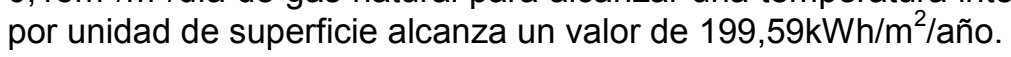

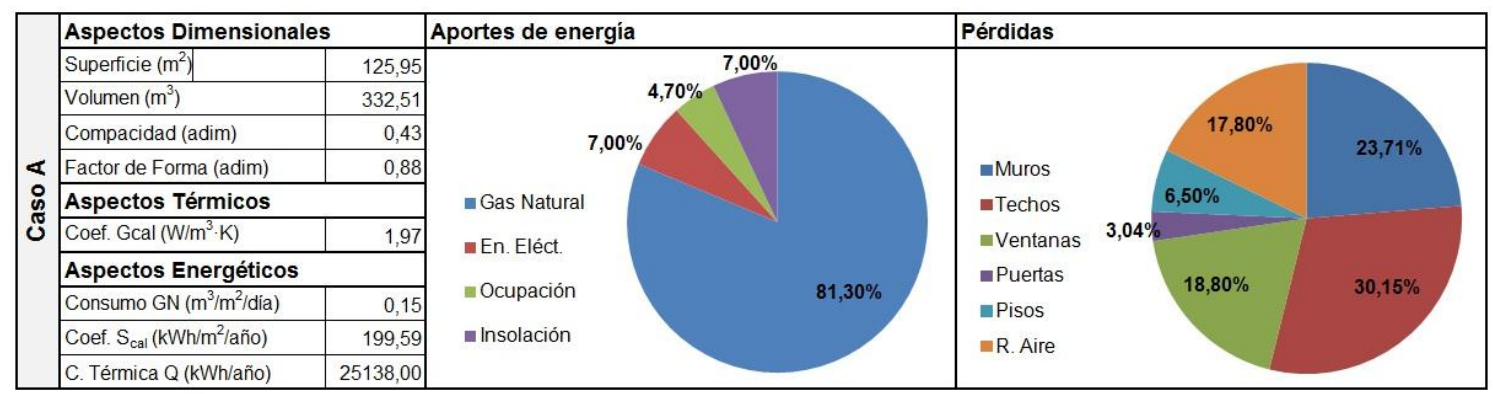

Figura VIII - 1: Resumen de los datos obtenidos con el AuditCAD - Caso A viviendas sin DAC.

Al aplicar los criterios del Diseño Ambientalmente Consciente a la envolvente del edificio, los coeficientes de transmitancia térmica rondaron los siguientes valores:

- Pisos / Techos: $\mathrm{K}=0,49 \mathrm{~W} / \mathrm{m}^{2} \cdot \mathrm{K}$ (factor de protección $50 \%$ )

- Muros exteriores: $\mathrm{K}=0,66 \mathrm{~W} / \mathrm{m}^{2} \cdot \mathrm{K}$

- Muros medianeros: $\mathrm{K}=0,66 \mathrm{~W} / \mathrm{m}^{2} \cdot \mathrm{K}$ (factor de protección $50 \%$ )

- Muros interiores: $\mathrm{K}=0,83 \mathrm{~W} / \mathrm{m}^{2} \cdot \mathrm{K}$ (factor de protección $50 \%$ )

- Superficies vidriadas: $\mathrm{K}=2,86 \mathrm{~W} / \mathrm{m}^{2} \cdot \mathrm{K}$

- Puertas interiores: $\mathrm{K}=3,50 \mathrm{~W} / \mathrm{m}^{2} \cdot \mathrm{K}$ (factor de protección $50 \%$ ) 
Para alcanzar estos valores se agregaron $5 \mathrm{~cm}$ de lana de vidrio en la cámara de aire entre el cielorraso suspendido y la losa de hormigón en pisos y techos $(10 \mathrm{~cm}$ en la cara exterior de la última planta, en contacto directo con el aire exterior), $2,5 \mathrm{~cm}$ de poliuretano proyectado en la cara exterior de los muros de cerramiento exterior, medianeros e interiores (aquellos que separan los ambientes calefaccionados de aquellos no acondicionados térmicamente), y carpinterías con DVH.

Tal como puede verse en la Figura VIII - 2 el porcentaje de aporte del gas natural para calefacción se redujo a $68 \%$, aumentando el porcentaje de incidencia de la energía eléctrica, la insolación y la ocupación, las cuales en total sumaron aproximadamente un $32 \%$. El consumo de gas natural se redujo a la mitad $\left(0,07 \mathrm{~m}^{3} / \mathrm{m}^{2} /\right.$ día) y la carga térmica por unidad de superficie se redujo en un $42 \%$, alcanzando un valor de $115,18 \mathrm{kWh} / \mathrm{m}^{2} /$ año. Como consecuencia del mayor aislamiento de las superficies exteriores, las mayores pérdidas se dan por las renovaciones de aire $(31 \%)$, reduciéndose de manera notable las pérdidas por techos $(19 \%)$, muros $(18 \%)$ y ventanas $(16 \%)$.

\begin{tabular}{|c|c|c|c|c|c|c|c|}
\hline & Aspectos Dimensione & & Aportes de ene & & Pérdidas & & \\
\hline & Superficie $\left(\mathrm{m}^{2}\right)$ & 125,95 & & & & & \\
\hline & Volumen $\left(\mathrm{m}^{3}\right)$ & 332,51 & & & & & \\
\hline & Compacidad (adim) & 0,43 & & & & & 76 \\
\hline$\ll$ & Factor de Forma (adim) & 0,88 & & & Muros & $30,82 \%$ & \\
\hline \& & Aspectos Térmicos & & ॥as Natural & & -Techos & & \\
\hline 0 & Coef. Gcal $\left(\mathrm{W} / \mathrm{m}^{3} \cdot \mathrm{K}\right)$ & 1,13 & En. Eléct. & $12,10 \%$ & =Ventanas & & \\
\hline & Aspectos Energéticos & & & $67,60 \%$ & =Puertas & & \\
\hline & Consumo $\mathrm{GN}\left(\mathrm{m}^{3} / \mathrm{m}^{2} / \mathrm{dia}\right)$ & 0,07 & =cupación & & $=$ Pisos & & \\
\hline & Coef. $\mathrm{S}_{\text {cal }}\left(\mathrm{kWh} / \mathrm{m}^{2} / a n ̃ o\right)$ & 115,18 & - Insolación & & & & \\
\hline & C. Térmica Q (kWh/año) & 14507,00 & & & & & \\
\hline
\end{tabular}

Figura VIII - 2: Resumen de los datos obtenidos con el AuditCAD - Caso A viviendas con DAC.

\subsubsection{Caso B}

La Figura VIII - 3 muestra un resumen de los datos obtenidos con el AuditCAD para el edificio tal como está construido en la actualidad, es decir según la información que pudo recolectarse durante la auditoría energética. Tal como se comenta en el Capítulo V - Estudio de Casos su tecnología constructiva es convencional con estructura de hormigón armado y muros de cerramiento exterior de ladrillos huecos de $18 \times 18 \times 33 \mathrm{~cm}$, sin aislamiento higrotérmico adicional. Por su parte los cerramientos interiores se han materializado con ladrillos huecos de $12 \times 18 \times 33 \mathrm{~cm}$, los que separan a los departamentos entre sí y con las áreas comunes, y con ladrillos de $8 \times 18 \times 33 \mathrm{~cm}$ aquellos que dividen los ambientes interiores de cada departamento. Las carpinterías son de simple vidriado con perfilería de chapa doblada, con cortinas de enrollar de pvc.

Según estos datos, los valores de transmitancia térmica de los diferentes elementos que componen la envolvente de este edificio rondan los siguientes valores:

- Pisos / Techos: $\mathrm{K}=2,34 \mathrm{~W} / \mathrm{m}^{2} \cdot \mathrm{K}$ (factor de protección $50 \%$ )

- Muros exteriores: $\mathrm{K}=1,82 \mathrm{~W} / \mathrm{m}^{2} \cdot \mathrm{K}$

- Muros medianeros: $\mathrm{K}=1,82 \mathrm{~W} / \mathrm{m}^{2} \cdot \mathrm{K}$ (factor de protección $50 \%$ )

- Muros interiores: $\mathrm{K}=2,18 \mathrm{~W} / \mathrm{m}^{2} \cdot \mathrm{K}$ (factor de protección $50 \%$ )

- Superficies vidriadas: $\mathrm{K}=5,80 \mathrm{~W} / \mathrm{m}^{2} \cdot \mathrm{K}$

- Puertas interiores: $\mathrm{K}=3,50 \mathrm{~W} / \mathrm{m}^{2} \cdot \mathrm{K}$ (factor de protección $50 \%$ )

En la Figura VIII - 3 puede verse claramente que los mayores aportes de energía para calefacción provienen del gas natural, con el $86 \%$. La incidencia de la ocupación, la energía eléctrica e insolación suman en total un $14 \%$. Puede verse también que los mayores porcentajes de pérdidas se dan a través de techos (47\%), muros (15\%), ventanas $(15 \%)$ y renovaciones de aire $(15 \%)$, esto principalmente debido a la falta de aislación térmica. La 
planta tipo del edificio tal como está construido en la actualidad requiere de un consumo de $0,19 \mathrm{~m}^{3} / \mathrm{m}^{2} /$ día de gas natural para alcanzar una temperatura interior de $20^{\circ} \mathrm{C}$. La carga térmica

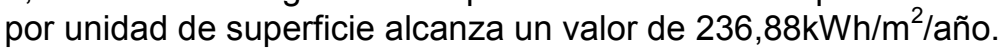

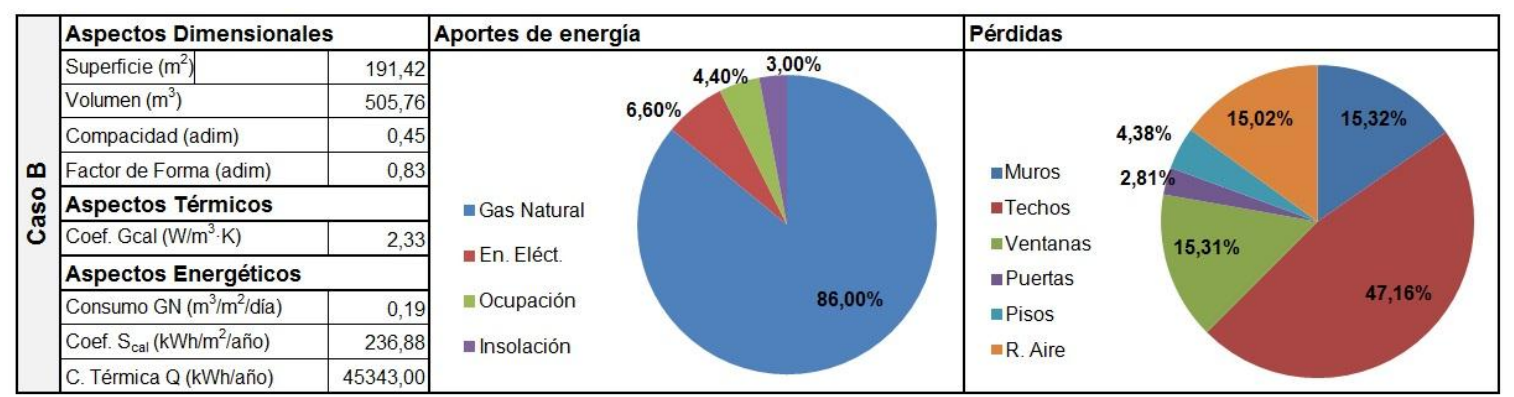

Figura VIII - 3: Resumen de los datos obtenidos con el AuditCAD - Caso B viviendas sin DAC.

Al aplicar los criterios del Diseño Ambientalmente Consciente a la envolvente del edificio, los coeficientes de transmitancia térmica rondaron los siguientes valores:

- Pisos / Techos: $\mathrm{K}=0,49 \mathrm{~W} / \mathrm{m}^{2} \cdot \mathrm{K}$ (factor de protección $50 \%$ )

- Muros exteriores: $\mathrm{K}=0,66 \mathrm{~W} / \mathrm{m}^{2} \cdot \mathrm{K}$

- Muros medianeros: $\mathrm{K}=0,66 \mathrm{~W} / \mathrm{m}^{2} \cdot \mathrm{K}$ (factor de protección $50 \%$ )

- Muros interiores: $\mathrm{K}=0,83 \mathrm{~W} / \mathrm{m}^{2} \cdot \mathrm{K}$ (factor de protección $50 \%$ )

- Superficies vidriadas: $\mathrm{K}=2,86 \mathrm{~W} / \mathrm{m}^{2} \cdot \mathrm{K}$

- Puertas interiores: $\mathrm{K}=3,50 \mathrm{~W} / \mathrm{m}^{2} \cdot \mathrm{K}$ (factor de protección $50 \%$ )

Para alcanzar estos valores se agregaron $5 \mathrm{~cm}$ de lana de vidrio en la cámara de aire entre el cielorraso suspendido y la losa de hormigón en pisos y techos $(10 \mathrm{~cm}$ en la cara exterior de la última planta, en contacto directo con el aire exterior), $2,5 \mathrm{~cm}$ de poliuretano proyectado en la cara exterior de los muros de cerramiento exterior, medianeros e interiores (aquellos que separan los ambientes calefaccionados de aquellos no acondicionados térmicamente), y carpinterías con DVH.

Tal como puede verse en la Figura VIII - 4 el porcentaje de aporte del gas natural para calefacción se redujo a 70\%, aumentando el porcentaje de incidencia de la energía eléctrica, la insolación y la ocupación, las cuales en total sumaron aproximadamente un $30 \%$. El consumo de gas natural se redujo un $63 \%\left(0,07 \mathrm{~m}^{3} / \mathrm{m}^{2} /\right.$ día $)$ y la carga térmica por unidad de superficie se redujo en un $55 \%$, alcanzando un valor de $105,22 \mathrm{kWh} / \mathrm{m}^{2} / a n ̃ o$. Como consecuencia del mayor aislamiento de las superficies exteriores, las mayores pérdidas se dan por las renovaciones de aire $(34 \%)$, reduciéndose de manera notable las pérdidas por techos $(21 \%)$, muros $(13 \%)$ y ventanas $(17 \%)$.

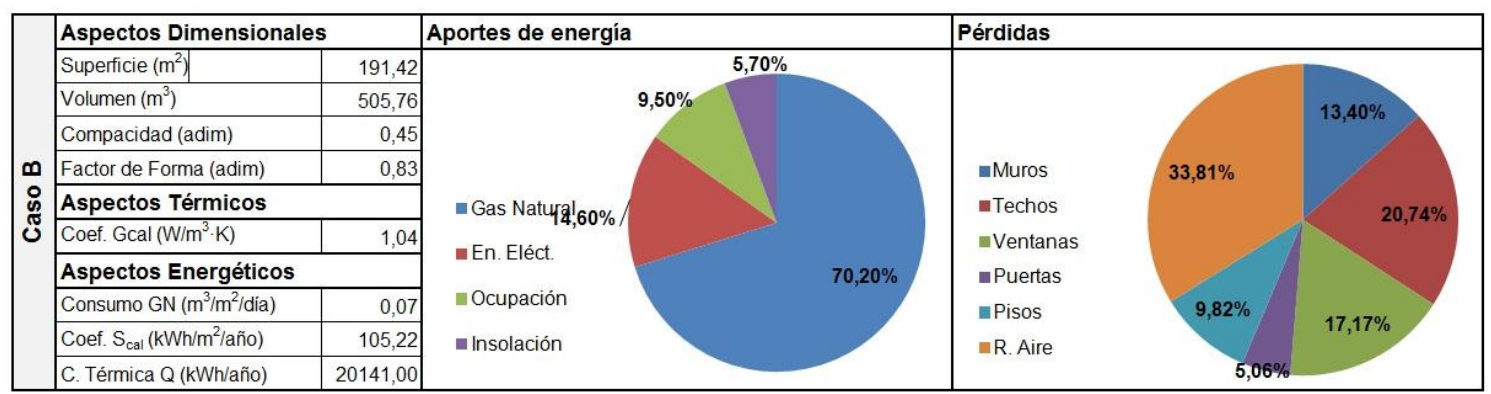

Figura VIII - 4: Resumen de los datos obtenidos con el AuditCAD - Caso B viviendas con DAC.

\subsubsection{Caso C}

La Figura VIII - 5 muestra un resumen de los datos obtenidos con el AuditCAD para el edificio tal como está construido en la actualidad, es decir según la información que pudo 
recolectarse durante la auditoría energética. Tal como se comenta en el Capítulo $V$ - Estudio de Casos su tecnología constructiva es convencional con estructura de hormigón armado y muros de cerramiento exterior de ladrillos huecos de $18 \times 18 \times 33 \mathrm{~cm}$., sin aislamiento higrotérmico adicional. Por su parte los cerramientos interiores se han materializado con ladrillos huecos de $12 \times 18 \times 33 \mathrm{~cm}$, los que separan a los departamentos entre sí y con las áreas comunes, y con ladrillos de $8 \times 18 \times 33 \mathrm{~cm}$ aquellos que dividen los ambientes interiores de cada departamento. Las carpinterías son de simple vidriado con perfilería de aluminio, con cortinas de enrollar de pvc.

Según estos datos, los valores de transmitancia térmica de los diferentes elementos que componen la envolvente de este edificio rondan los siguientes valores:

- Pisos / Techos: $\mathrm{K}=2,34 \mathrm{~W} / \mathrm{m}^{2} \cdot \mathrm{K}$ (factor de protección $50 \%$ )

- Muros exteriores: $\mathrm{K}=1,82 \mathrm{~W} / \mathrm{m}^{2} \cdot \mathrm{K}$

- Muros medianeros: $\mathrm{K}=1,82 \mathrm{~W} / \mathrm{m}^{2} \cdot \mathrm{K}$ (factor de protección $50 \%$ )

- Muros interiores: $\mathrm{K}=2,18 \mathrm{~W} / \mathrm{m}^{2} \cdot \mathrm{K}$ (factor de protección $50 \%$ )

- Superficies vidriadas: $\mathrm{K}=5,80 \mathrm{~W} / \mathrm{m}^{2} \cdot \mathrm{K}$

- Puertas interiores: $\mathrm{K}=3,50 \mathrm{~W} / \mathrm{m}^{2} \cdot \mathrm{K}$ (factor de protección $50 \%$ )

En la Figura VIII - 5 puede verse claramente que los mayores aportes de energía para calefacción provienen del gas natural, con el $77 \%$. La incidencia de la ocupación, la energía eléctrica e insolación suman en total un $23 \%$. Puede verse también que los mayores porcentajes de pérdidas se dan a través de techos (37\%), muros (16\%), ventanas $(17 \%)$ y renovaciones de aire $(15 \%)$, esto principalmente debido a la falta de aislación térmica. La planta tipo del edificio tal como está construido en la actualidad requiere de un consumo de $0,12 \mathrm{~m}^{3} / \mathrm{m}^{2} /$ día de gas natural para alcanzar una temperatura interior de $20^{\circ} \mathrm{C}$. La carga térmica

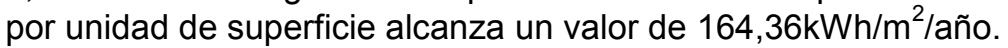

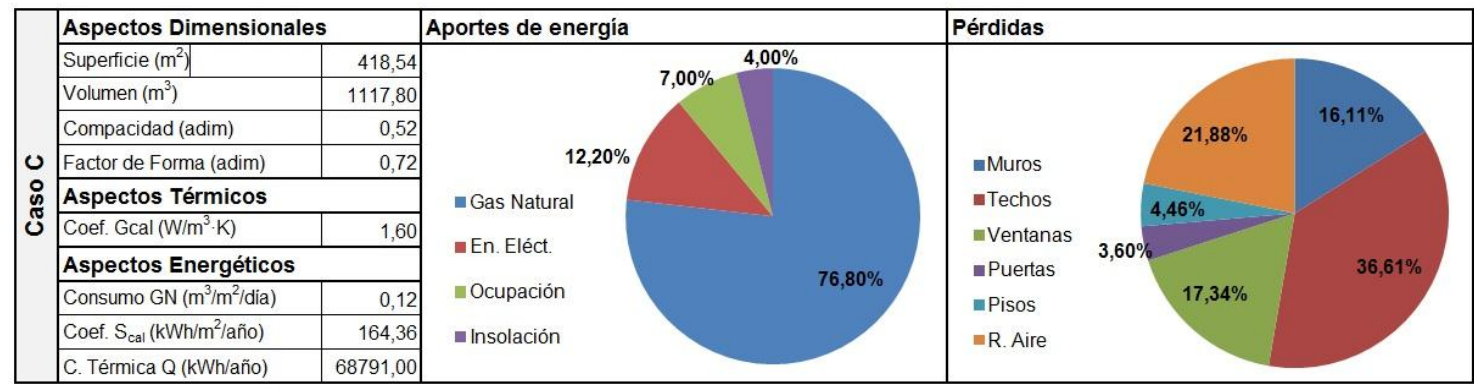

Figura VIII - 5: Resumen de los datos obtenidos con el AuditCAD - Caso C viviendas sin DAC.

Al aplicar los criterios del Diseño Ambientalmente Consciente a la envolvente del edificio, los coeficientes de transmitancia térmica rondaron los siguientes valores:

- Pisos / Techos: $\mathrm{K}=0,49 \mathrm{~W} / \mathrm{m}^{2} \cdot \mathrm{K}$ (factor de protección $50 \%$ )

- Muros exteriores: $\mathrm{K}=0,66 \mathrm{~W} / \mathrm{m}^{2} \cdot \mathrm{K}$

- Muros medianeros: $\mathrm{K}=0,66 \mathrm{~W} / \mathrm{m}^{2} \cdot \mathrm{K}$ (factor de protección $50 \%$ )

- Muros interiores: $\mathrm{K}=0,83 \mathrm{~W} / \mathrm{m}^{2} \cdot \mathrm{K}$ (factor de protección $50 \%$ )

- Superficies vidriadas: $\mathrm{K}=2,86 \mathrm{~W} / \mathrm{m}^{2} \cdot \mathrm{K}$

- Puertas interiores: $\mathrm{K}=3,50 \mathrm{~W} / \mathrm{m}^{2} \cdot \mathrm{K}$ (factor de protección $50 \%$ )

Para alcanzar estos valores se agregaron $5 \mathrm{~cm}$ de lana de vidrio en la cámara de aire entre el cielorraso suspendido y la losa de hormigón en pisos y techos $(10 \mathrm{~cm}$ en la cara exterior de la última planta, en contacto directo con el aire exterior), $2,5 \mathrm{~cm}$ de poliuretano proyectado en la cara exterior de los muros de cerramiento exterior, medianeros e interiores (aquellos que separan los ambientes calefaccionados de aquellos no acondicionados térmicamente), y carpinterías con DVH. 
Tal como puede verse en la Figura VIII - 6 el porcentaje de aporte del gas natural para calefacción se redujo a $60 \%$, aumentando el porcentaje de incidencia de la energía eléctrica, la insolación y la ocupación, las cuales en total sumaron aproximadamente un $40 \%$. El consumo de gas natural se redujo un $58 \%\left(0,05 \mathrm{~m}^{3} / \mathrm{m}^{2} /\right.$ día $)$ y la carga térmica por unidad de superficie se redujo en un $42 \%$, alcanzando un valor de $95,26 \mathrm{kWh} / \mathrm{m}^{2} / a n ̃ o$. Como consecuencia del mayor aislamiento de las superficies exteriores, las mayores pérdidas se dan por las renovaciones de aire $(38 \%)$, reduciéndose de manera notable las pérdidas por techos $(23 \%)$, muros $(11 \%)$ y ventanas $(15 \%)$.

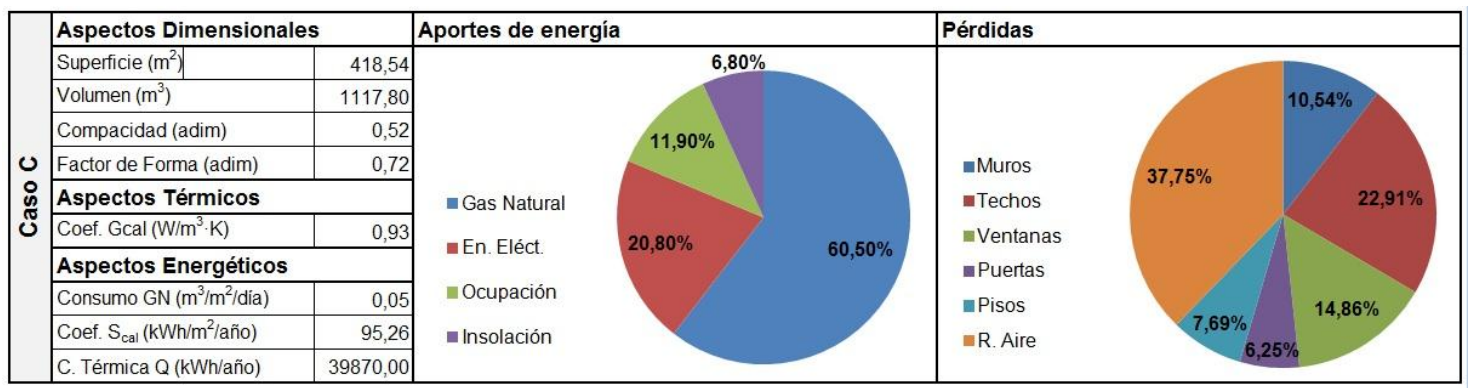

Figura VIII - 6: Resumen de los datos obtenidos con el AuditCAD - Caso C viviendas con DAC.

\subsubsection{Caso D}

La Figura VIII - 7 muestra un resumen de los datos obtenidos con el AuditCAD para el edificio tal como está construido en la actualidad, es decir según la información que pudo recolectarse durante la auditoría energética. Tal como se comenta en el Capítulo V - Estudio de Casos su tecnología constructiva es convencional con estructura de hormigón armado y muros de cerramiento exterior de ladrillos huecos de $18 \times 18 \times 33 \mathrm{~cm}$ con revestimiento de ladrillo cerámico visto, sin aislamiento higrotérmico adicional. Por su parte los cerramientos interiores se han materializado con ladrillos huecos de $12 \times 18 \times 33 \mathrm{~cm}$, los que separan a los departamentos entre sí y con las áreas comunes, y con ladrillos de $8 \times 18 \times 33 \mathrm{~cm}$ aquellos que dividen los ambientes interiores de cada departamento. Las carpinterías son de simple vidriado con perfilería de chapa doblada, con cortinas de enrollar de pvc.

Según estos datos, los valores de transmitancia térmica de los diferentes elementos que componen la envolvente de este edificio rondan los siguientes valores:

- Pisos / Techos: $\mathrm{K}=2,34 \mathrm{~W} / \mathrm{m}^{2} \cdot \mathrm{K}$ (factor de protección $50 \%$ )

- Muros exteriores: $\mathrm{K}=1,74 \mathrm{~W} / \mathrm{m}^{2} \cdot \mathrm{K}$

- Muros medianeros: $\mathrm{K}=1,82 \mathrm{~W} / \mathrm{m}^{2} \cdot \mathrm{K}$ (factor de protección $50 \%$ )

- Muros interiores: $\mathrm{K}=2,18 \mathrm{~W} / \mathrm{m}^{2} \cdot \mathrm{K}$ (factor de protección $50 \%$ )

- Superficies vidriadas: $\mathrm{K}=5,80 \mathrm{~W} / \mathrm{m}^{2} \cdot \mathrm{K}$

- Puertas interiores: $\mathrm{K}=3,50 \mathrm{~W} / \mathrm{m}^{2} \cdot \mathrm{K}$ (factor de protección $50 \%$ )

En la Figura VIII - 7 puede verse claramente que los mayores aportes de energía para calefacción provienen del gas natural, con el $78 \%$. La incidencia de la ocupación, la energía eléctrica e insolación suman en total un $22 \%$. Puede verse también que los mayores porcentajes de pérdidas se dan a través de techos $(36 \%)$, muros $(18 \%)$, ventanas $(18 \%)$ y renovaciones de aire $(21 \%)$, esto principalmente debido a la falta de aislación térmica. La planta tipo del edificio tal como está construido en la actualidad requiere de un consumo de $0,12 \mathrm{~m}^{3} / \mathrm{m}^{2} /$ día de gas natural para alcanzar una temperatura interior de $20^{\circ} \mathrm{C}$. La carga térmica por unidad de superficie alcanza un valor de 167,52kWh/año. 


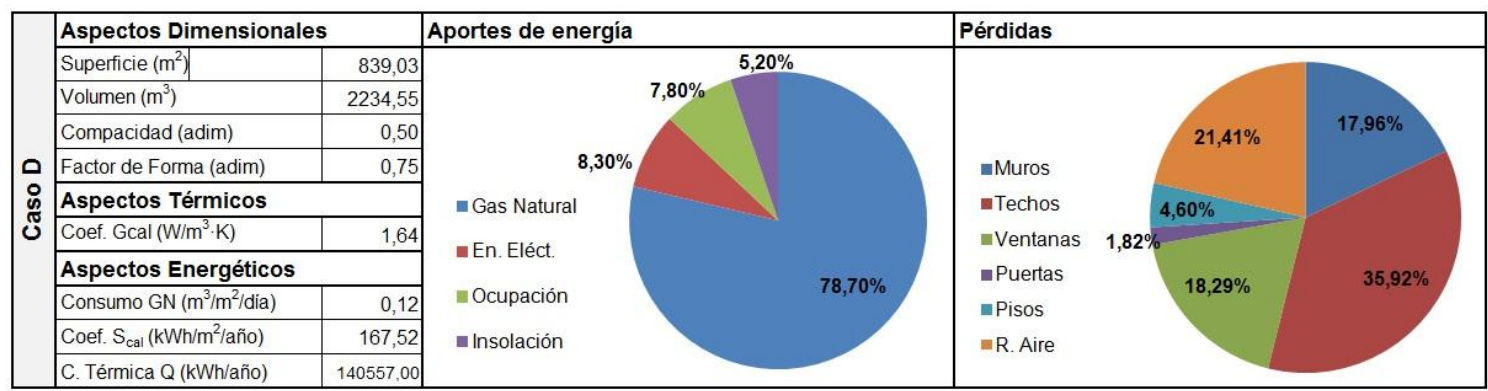

Figura VIII - 7: Resumen de los datos obtenidos con el AuditCAD - Caso D viviendas sin DAC.

Al aplicar los criterios del Diseño Ambientalmente Consciente a la envolvente del edificio, los coeficientes de transmitancia térmica rondaron los siguientes valores:

- Pisos / Techos: $\mathrm{K}=0,49 \mathrm{~W} / \mathrm{m}^{2} \cdot \mathrm{K}$ (factor de protección $50 \%$ )

- Muros exteriores: $\mathrm{K}=0,65 \mathrm{~W} / \mathrm{m}^{2} \cdot \mathrm{K}$

- Muros medianeros: $\mathrm{K}=0,66 \mathrm{~W} / \mathrm{m}^{2} \cdot \mathrm{K}$ (factor de protección $50 \%$ )

- Muros interiores: $\mathrm{K}=0,83 \mathrm{~W} / \mathrm{m}^{2} \cdot \mathrm{K}$ (factor de protección $50 \%$ )

- Superficies vidriadas: $\mathrm{K}=2,86 \mathrm{~W} / \mathrm{m}^{2} \cdot \mathrm{K}$

- Puertas interiores: $\mathrm{K}=3,50 \mathrm{~W} / \mathrm{m}^{2} \cdot \mathrm{K}$ (factor de protección $50 \%$ )

Para alcanzar estos valores se agregaron $5 \mathrm{~cm}$ de lana de vidrio en la cámara de aire entre el cielorraso suspendido y la losa de hormigón en pisos y techos $(10 \mathrm{~cm}$ en la cara exterior de la última planta, en contacto directo con el aire exterior), $2,5 \mathrm{~cm}$ de poliuretano proyectado en la cara exterior de los muros de cerramiento exterior, medianeros e interiores (aquellos que separan los ambientes calefaccionados de aquellos no acondicionados térmicamente), y carpinterías con DVH.

Tal como puede verse en la Figura VIII - 8 el porcentaje de aporte del gas natural para calefacción se redujo a $61 \%$, aumentando el porcentaje de incidencia de la energía eléctrica, la insolación y la ocupación, las cuales en total sumaron aproximadamente un $39 \%$. El consumo de gas natural se redujo un $58 \%\left(0,05 \mathrm{~m}^{3} / \mathrm{m}^{2} /\right.$ día $)$ y la carga térmica por unidad de superficie se redujo en un $43 \%$, alcanzando un valor de $94,98 \mathrm{kWh} / \mathrm{m}^{2} /$ año. Como consecuencia del mayor aislamiento de las superficies exteriores, las mayores pérdidas se dan por las renovaciones de aire $(38 \%)$, reduciéndose de manera notable las pérdidas por techos $(23 \%)$, muros $(13 \%)$ y ventanas $(15 \%)$.

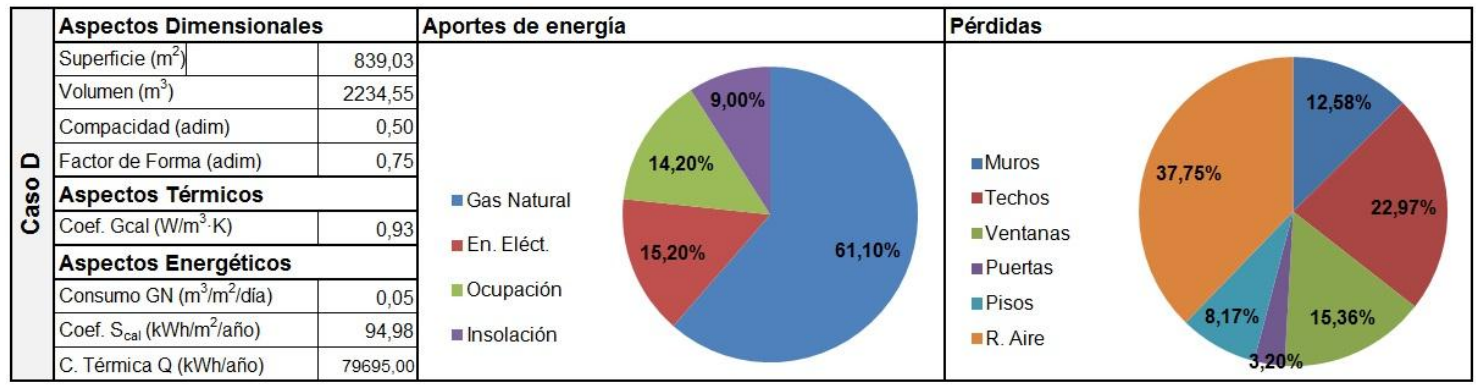

Figura VIII - 8: Resumen de los datos obtenidos con el AuditCAD - Caso D viviendas con DAC.

\subsubsection{Edificios de Oficinas}

\subsubsection{Caso A}

La Figura VIII - 9 muestra un resumen de los datos obtenidos con el AuditCAD para el edificio tal como está construido en la actualidad, es decir según la información que pudo recolectarse durante la auditoría energética. Tal como se comenta en el Capítulo V - Estudio de Casos su tecnología constructiva es convencional con estructura de hormigón armado y 
muros de cerramiento exterior de ladrillos comunes que conforman un muro de $22 \mathrm{~cm}$ de espesor final, sin aislamiento higrotérmico adicional. Por su parte los cerramientos interiores se han materializado con muros de $15 \mathrm{~cm}$ de espesor final de ladrillos comunes, los que separan los ambientes interiores de las oficinas, a las oficinas entre sí y con las áreas comunes, y con sistema de construcción en seco (placas de yeso) aquellos que dividen los ambientes interiores de cada oficina, que son el resultado de la adaptación de la planta a las necesidades actuales. Las carpinterías originales son de simple vidriado con perfilería de hierro y cortinas de enrollar de madera aunque también cuenta con carpinterías de aluminio en las zonas refaccionadas.

Según estos datos, los valores de transmitancia térmica de los diferentes elementos que componen la envolvente de este edificio rondan los siguientes valores:

- Pisos / Techos: $\mathrm{K}=2,34 \mathrm{~W} / \mathrm{m}^{2} \cdot \mathrm{K}$ (factor de protección $50 \%$ )

- Muros exteriores: $\mathrm{K}=2,57 \mathrm{~W} / \mathrm{m}^{2} \cdot \mathrm{K}$

- Muros medianeros: $\mathrm{K}=2,57 \mathrm{~W} / \mathrm{m}^{2} \cdot \mathrm{K}$ (factor de protección $50 \%$ )

- Muros interiores: $\mathrm{K}=3,35 \mathrm{~W} / \mathrm{m}^{2} \cdot \mathrm{K}$ (factor de protección $50 \%$ )

- Superficies vidriadas: $\mathrm{K}=5,80 \mathrm{~W} / \mathrm{m}^{2} \cdot \mathrm{K}$

- Puertas interiores: $\mathrm{K}=3,50 \mathrm{~W} / \mathrm{m}^{2} \cdot \mathrm{K}$ (factor de protección $50 \%$ )

En la Figura VIII - 9 puede verse claramente que los mayores aportes de energía para calefacción provienen del gas natural, con el $82 \%$. La incidencia de la ocupación, la energía eléctrica e insolación suman en total un $18 \%$. Puede verse también que los mayores porcentajes de pérdidas se dan a través de techos (37\%), muros (19\%), ventanas $(15 \%)$ y renovaciones de aire $(22 \%)$, esto principalmente debido a la falta de aislación térmica. La planta tipo del edificio tal como está construido en la actualidad requiere de un consumo de $0,13 \mathrm{~m}^{3} / \mathrm{m}^{2} /$ día de gas natural para alcanzar una temperatura interior de $20^{\circ} \mathrm{C}$. La carga térmica por unidad de superficie alcanza un valor de 160,59kWh/año.

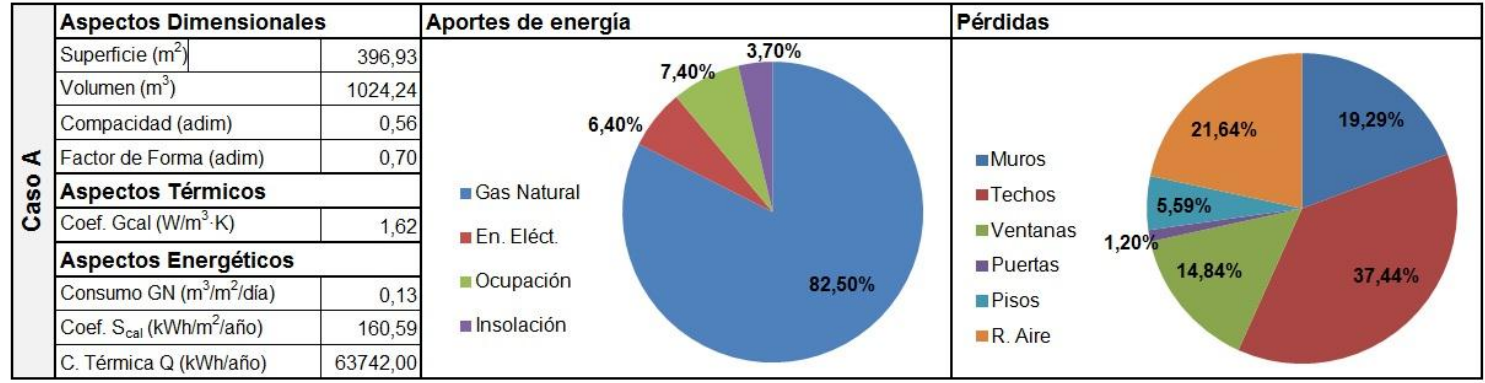

Figura VIII - 9: Resumen de los datos obtenidos con el AuditCAD - Caso A oficinas sin DAC.

Al aplicar los criterios del Diseño Ambientalmente Consciente a la envolvente del edificio, los coeficientes de transmitancia térmica rondaron los siguientes valores:

- Pisos / Techos: $\mathrm{K}=0,49 \mathrm{~W} / \mathrm{m}^{2} \cdot \mathrm{K}$ (factor de protección $50 \%$ )

- Muros exteriores: $\mathrm{K}=0,87 \mathrm{~W} / \mathrm{m}^{2} \cdot \mathrm{K}$

- Muros medianeros: $\mathrm{K}=0,87 \mathrm{~W} / \mathrm{m}^{2} \cdot \mathrm{K}$ (factor de protección $50 \%$ )

- Muros interiores: $\mathrm{K}=0,93 \mathrm{~W} / \mathrm{m}^{2} \cdot \mathrm{K}$ (factor de protección $50 \%$ )

- Superficies vidriadas: $\mathrm{K}=2,86 \mathrm{~W} / \mathrm{m}^{2} \cdot \mathrm{K}$

- Puertas interiores: $\mathrm{K}=3,50 \mathrm{~W} / \mathrm{m}^{2} \cdot \mathrm{K}$ (factor de protección $50 \%$ )

Para alcanzar estos valores se agregaron $5 \mathrm{~cm}$ de lana de vidrio en la cámara de aire entre el cielorraso suspendido y la losa de hormigón en pisos y techos $(10 \mathrm{~cm}$ en la cara exterior de la última planta, en contacto directo con el aire exterior), $2,5 \mathrm{~cm}$ de poliuretano proyectado en la cara exterior de los muros de cerramiento exterior, medianeros e interiores (aquellos que separan los ambientes calefaccionados de aquellos no acondicionados térmicamente), y carpinterías con DVH. 
Tal como puede verse en la Figura VIII - 10 el porcentaje de aporte del gas natural para calefacción se redujo a $69 \%$, aumentando el porcentaje de incidencia de la energía eléctrica, la insolación y la ocupación, las cuales en total sumaron aproximadamente un $31 \%$. El consumo de gas natural se redujo un $53 \%\left(0,06 \mathrm{~m}^{3} / \mathrm{m}^{2} /\right.$ día) y la carga térmica por unidad de superficie se redujo en un $43 \%$, alcanzando un valor de $91,23 \mathrm{kWh} / \mathrm{m}^{2} / a n ̃ o$. Como consecuencia del mayor aislamiento de las superficies exteriores, las mayores pérdidas se dan por las renovaciones de aire $(38 \%)$, reduciéndose de manera notable las pérdidas por techos $(26 \%)$, muros $(12 \%)$ y ventanas $(13 \%)$.

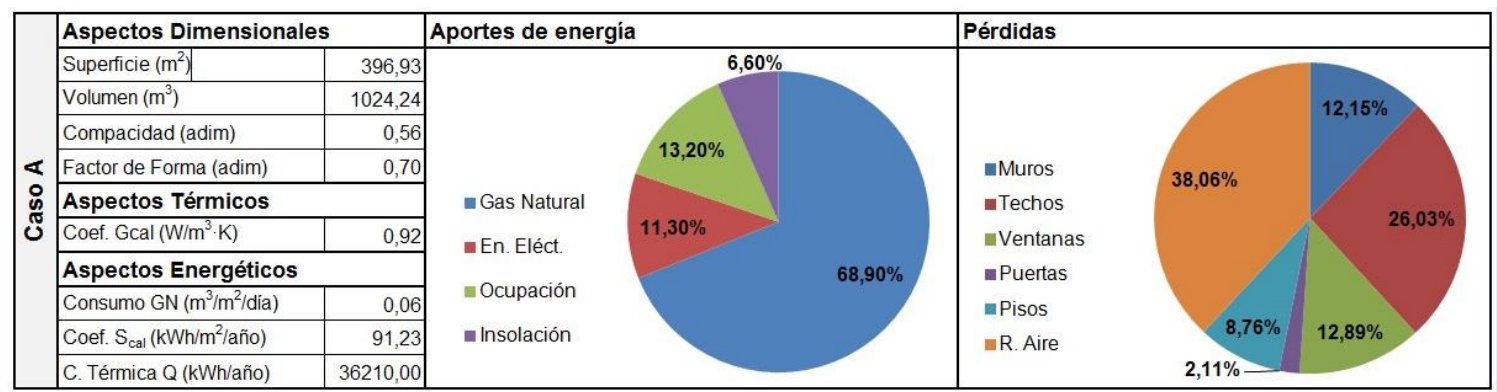

Figura VIII - 10: Resumen de los datos obtenidos con el AuditCAD - Caso A oficinas con DAC.

\subsubsection{Caso B}

La Figura VIII - 11 muestra un resumen de los datos obtenidos con el AuditCAD para el edificio tal como está construido en la actualidad, es decir según la información que pudo recolectarse durante la auditoría energética. Tal como se comenta en el Capítulo V - Estudio de Casos su tecnología constructiva es convencional con estructura de hormigón armado y muros de cerramiento exterior de ladrillos huecos de $18 \times 18 \times 33 \mathrm{~cm}$, sin aislamiento higrotérmico adicional. Por su parte los cerramientos interiores se han materializado con ladrillos huecos de $12 \times 18 \times 33 \mathrm{~cm}$, los que separan a las oficinas entre sí y con las áreas comunes, y con ladrillos huecos de $8 \times 18 \times 33 \mathrm{~cm}$, aquellos que dividen los ambientes interiores de cada oficina. Las carpinterías son de simple vidriado con perfilería de chapa doblada y cortinas de enrollar de madera.

Según estos datos, los valores de transmitancia térmica de los diferentes elementos que componen la envolvente de este edificio rondan los siguientes valores:

- Pisos / Techos: $\mathrm{K}=2,34 \mathrm{~W} / \mathrm{m}^{2} \cdot \mathrm{K}$ (factor de protección $50 \%$ )

- Muros exteriores: $\mathrm{K}=1,74 \mathrm{~W} / \mathrm{m}^{2} \cdot \mathrm{K}$

- Muros medianeros: $\mathrm{K}=1,82 \mathrm{~W} / \mathrm{m}^{2} \cdot \mathrm{K}$ (factor de protección $50 \%$ )

- Muros interiores: $\mathrm{K}=2,18 \mathrm{~W} / \mathrm{m}^{2} \cdot \mathrm{K}$ (factor de protección $50 \%$ )

- Superficies vidriadas: $\mathrm{K}=5,80 \mathrm{~W} / \mathrm{m}^{2} \cdot \mathrm{K}$

- Puertas interiores: $\mathrm{K}=3,50 \mathrm{~W} / \mathrm{m}^{2} \cdot \mathrm{K}$ (factor de protección $50 \%$ )

En la Figura VIII - 11 puede verse claramente que los mayores aportes de energía para calefacción provienen del gas natural, con el $64 \%$. La incidencia de la ocupación, la energía eléctrica e insolación suman en total un $36 \%$. Puede verse también que los mayores porcentajes de pérdidas se dan a través de techos (17\%), muros $(25 \%)$, ventanas $(19 \%)$ y renovaciones de aire $(26 \%)$, esto principalmente debido a la falta de aislación térmica. La planta tipo del edificio tal como está construido en la actualidad requiere de un consumo de $0,08 \mathrm{~m}^{3} / \mathrm{m}^{2} /$ día de gas natural para alcanzar una temperatura interior de $20^{\circ} \mathrm{C}$. La carga térmica

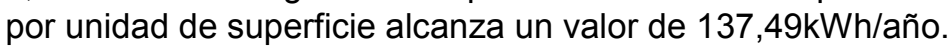




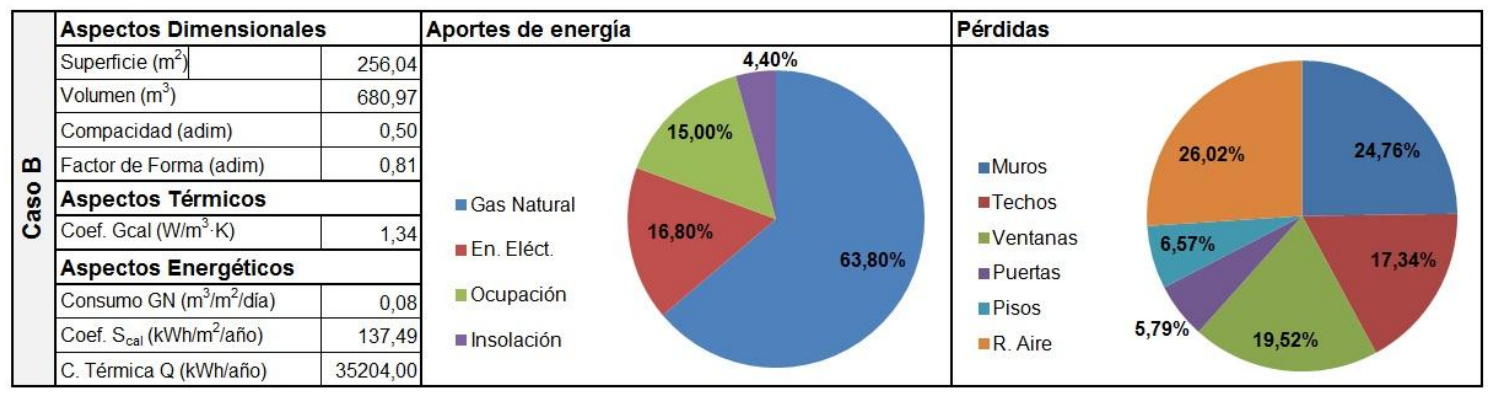

Figura VIII - 11: Resumen de los datos obtenidos con el AuditCAD - Caso B oficinas sin DAC.

Al aplicar los criterios del Diseño Ambientalmente Consciente a la envolvente del edificio, los coeficientes de transmitancia térmica rondaron los siguientes valores:

- Pisos / Techos: $\mathrm{K}=0,49 \mathrm{~W} / \mathrm{m}^{2} \cdot \mathrm{K}$ (factor de protección $50 \%$ )

- Muros exteriores: $\mathrm{K}=0,65 \mathrm{~W} / \mathrm{m}^{2} \cdot \mathrm{K}$

- Muros medianeros: $\mathrm{K}=0,66 \mathrm{~W} / \mathrm{m}^{2} \cdot \mathrm{K}$ (factor de protección $50 \%$ )

- Muros interiores: $\mathrm{K}=0,83 \mathrm{~W} / \mathrm{m}^{2} \cdot \mathrm{K}$ (factor de protección $50 \%$ )

- Superficies vidriadas: $\mathrm{K}=2,86 \mathrm{~W} / \mathrm{m}^{2} \cdot \mathrm{K}$

- Puertas interiores: $\mathrm{K}=3,50 \mathrm{~W} / \mathrm{m}^{2} \cdot \mathrm{K}$ (factor de protección $50 \%$ )

Para alcanzar estos valores se agregaron $5 \mathrm{~cm}$ de lana de vidrio en la cámara de aire entre el cielorraso suspendido y la losa de hormigón en pisos y techos $(10 \mathrm{~cm}$ en la cámara de aire del cielorraso de la última planta, en contacto directo con el aire exterior) $2,5 \mathrm{~cm}$ de poliuretano proyectado en la cara exterior de los muros de cerramiento exterior, medianeros e interiores (aquellos que separan los ambientes calefaccionados de aquellos no acondicionados térmicamente), y carpinterías con DVH.

Tal como puede verse en la Figura VIII - 12 el porcentaje de aporte del gas natural para calefacción se redujo a 53\%, aumentando el porcentaje de incidencia de la energía eléctrica, la insolación y la ocupación, las cuales en total sumaron aproximadamente un $47 \%$. El consumo de gas natural se redujo un $37 \%\left(0,05 \mathrm{~m}^{3} / \mathrm{m}^{2} /\right.$ día $)$ y la carga térmica por unidad de superficie se redujo en un $23 \%$, alcanzando un valor de $104,98 \mathrm{kWh} / \mathrm{m}^{2} /$ año. Como consecuencia del mayor aislamiento de las superficies exteriores, las mayores pérdidas se dan por las renovaciones de aire $(34 \%)$, reduciéndose de manera notable las pérdidas por techos $(24 \%)$, muros $(13 \%)$ y ventanas $(13 \%)$.

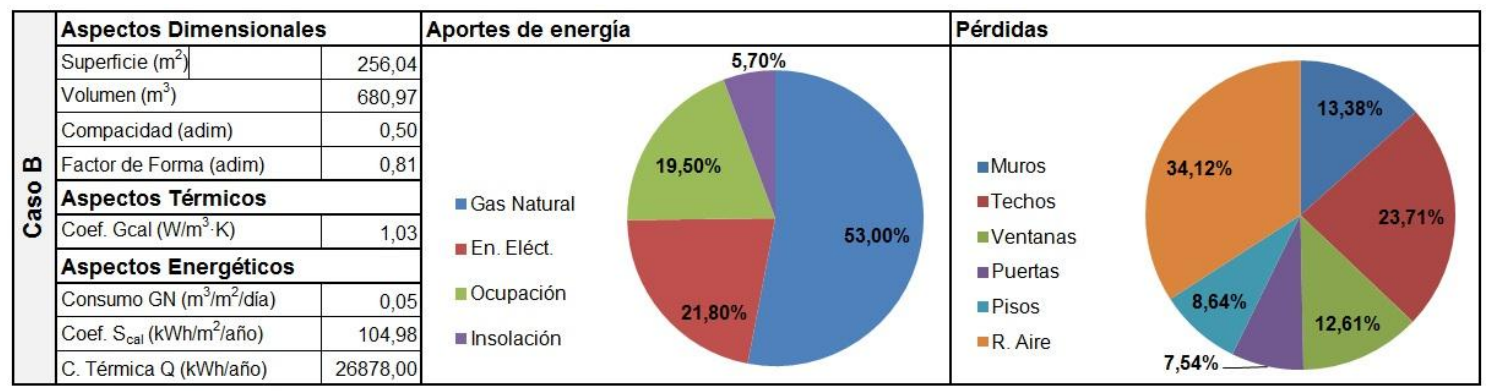

Figura VIII - 12: Resumen de los datos obtenidos con el AuditCAD - Caso B oficinas con DAC.

\subsubsection{Caso C}

La Figura VIII - 13 muestra un resumen de los datos obtenidos con el AuditCAD para el edificio tal como está construido en la actualidad, es decir según la información que pudo recolectarse durante la auditoría energética. Tal como se comenta en el Capítulo V - Estudio de Casos su tecnología constructiva es convencional con estructura de hormigón armado y curtain wall con estructura metálica y simple vidriado coloreado sobre las fachadas. Por su parte los muros medianeros se han materializado con ladrillos huecos de $18 \times 18 \times 33 \mathrm{~cm}$. Los 
cerramientos interiores se han materializado con ladrillos huecos de $12 \times 18 \times 33 \mathrm{~cm}$, los que separan a las oficinas entre sí y con las áreas comunes, y con ladrillos huecos de $8 \times 18 \times 33 \mathrm{~cm}$, aquellos que dividen los ambientes interiores de cada oficina.

Según estos datos, los valores de transmitancia térmica de los diferentes elementos que componen la envolvente de este edificio rondan los siguientes valores:

- Pisos / Techos: $\mathrm{K}=2,34 \mathrm{~W} / \mathrm{m}^{2} \cdot \mathrm{K}$ (factor de protección $50 \%$ )

- Muros exteriores: $\mathrm{K}=1,74 \mathrm{~W} / \mathrm{m}^{2} \cdot \mathrm{K}$

- Muros medianeros: $\mathrm{K}=1,82 \mathrm{~W} / \mathrm{m}^{2} \cdot \mathrm{K}$ (factor de protección $50 \%$ )

- Muros interiores: $\mathrm{K}=2,18 \mathrm{~W} / \mathrm{m}^{2} \cdot \mathrm{K}$ (factor de protección $50 \%$ )

- Superficies vidriadas: $\mathrm{K}=5,80 \mathrm{~W} / \mathrm{m}^{2} \cdot \mathrm{K}$

- Puertas interiores: $\mathrm{K}=3,50 \mathrm{~W} / \mathrm{m}^{2} \cdot \mathrm{K}$ (factor de protección $50 \%$ )

En la Figura VIII - 13 puede verse claramente que los mayores aportes de energía para calefacción provienen del gas natural, con el $77 \%$. La incidencia de la ocupación, la energía eléctrica e insolación suman en total un $23 \%$. Puede verse también que los mayores porcentajes de pérdidas se dan a través de techos (37\%), muros (16\%), ventanas $(17 \%)$ y renovaciones de aire $(22 \%)$, esto principalmente debido a la falta de aislación térmica. La planta tipo del edificio tal como está construido en la actualidad requiere de un consumo de $0,15 \mathrm{~m}^{3} / \mathrm{m}^{2} /$ día de gas natural para alcanzar una temperatura interior de $20^{\circ} \mathrm{C}$. La carga térmica

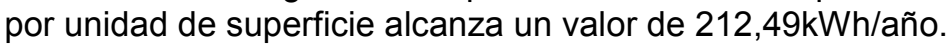

\begin{tabular}{|c|c|c|c|c|c|c|}
\hline & \multicolumn{2}{|c|}{ Aspectos Dimensionales } & Aportes de energía & \multicolumn{3}{|l|}{ Pérdidas } \\
\hline \multirow{10}{*}{ 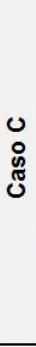 } & Superficie $\left(\mathrm{m}^{2}\right)$ & 279,74 & \multirow{10}{*}{$\begin{array}{l}\text { - Gas Natural } \\
\text { - En. Eléct. } \\
\text { - Ocupación } \\
\text { - Insolación }\end{array}$} & \multirow{10}{*}{$\begin{array}{l}\text {-Muros } \\
\text {-Techos } \\
\text {-Ventanas } \\
\text {-Puertas } \\
\text { =Pisos } \\
\text { "R. Aire }\end{array}$} & & \\
\hline & Volumen $\left(\mathrm{m}^{3}\right)$ & 742,37 & & & & \\
\hline & Compacidad (adim) & 0,45 & & & $21,88 \%$ & \\
\hline & Factor de Forma (adim) & 0,83 & & & & \\
\hline & \multicolumn{2}{|l|}{ Aspectos Térmicos } & & & & \\
\hline & \begin{tabular}{|l} 
Coef. Gcal $\left(\mathrm{W} / \mathrm{m}^{3} \cdot \mathrm{K}\right)$ \\
\end{tabular} & 2,08 & & & & \\
\hline & \multicolumn{2}{|l|}{ Aspectos Energéticos } & & & & 36 \\
\hline & Consumo $\mathrm{GN}\left(\mathrm{m}^{3} / \mathrm{m}^{2} / \mathrm{dia}\right)$ & 0,15 & & & & \\
\hline & Coef. $\mathrm{S}_{\text {cal }}\left(\mathrm{kWh} / \mathrm{m}^{2} /\right.$ /año) & 212,49 & & & & \\
\hline & C. Térmica Q (kWh/año) & 59442,00 & & & & \\
\hline
\end{tabular}

Figura VIII - 13: Resumen de los datos obtenidos con el AuditCAD - Caso C oficinas $\sin$ DAC.

Al aplicar los criterios del Diseño Ambientalmente Consciente a la envolvente del edificio, los coeficientes de transmitancia térmica rondaron los siguientes valores:

- Pisos / Techos: $\mathrm{K}=0,49 \mathrm{~W} / \mathrm{m}^{2} \cdot \mathrm{K}$ (factor de protección $50 \%$ )

- Muros exteriores: $\mathrm{K}=0,65 \mathrm{~W} / \mathrm{m}^{2} \cdot \mathrm{K}$

- Muros medianeros: $\mathrm{K}=0,66 \mathrm{~W} / \mathrm{m}^{2} \cdot \mathrm{K}$ (factor de protección $50 \%$ )

- Muros interiores: $\mathrm{K}=0,83 \mathrm{~W} / \mathrm{m}^{2} \cdot \mathrm{K}$ (factor de protección $50 \%$ )

- Superficies vidriadas: $\mathrm{K}=2,86 \mathrm{~W} / \mathrm{m}^{2} \cdot \mathrm{K}$

- Puertas interiores: $\mathrm{K}=3,50 \mathrm{~W} / \mathrm{m}^{2} \cdot \mathrm{K}$ (factor de protección $50 \%$ )

Para alcanzar estos valores se agregaron $5 \mathrm{~cm}$ de lana de vidrio en la cámara de aire entre el cielorraso suspendido y la losa de hormigón en pisos y techos $(10 \mathrm{~cm}$ en la cara exterior de la última planta, en contacto directo con el aire exterior), $2,5 \mathrm{~cm}$ de poliuretano proyectado en la cara exterior de los muros de cerramiento exterior, medianeros e interiores (aquellos que separan los ambientes calefaccionados de aquellos no acondicionados térmicamente), y carpinterías con DVH.

Tal como puede verse en la Figura VIII - 14 el porcentaje de aporte del gas natural para calefacción se redujo a 59\%, aumentando el porcentaje de incidencia de la energía eléctrica, la insolación y la ocupación, las cuales en total sumaron aproximadamente un $41 \%$. El consumo de gas natural se redujo un $53 \%\left(0,07 \mathrm{~m}^{3} / \mathrm{m}^{2} /\right.$ día) y la carga térmica por unidad de superficie se redujo en un $43 \%$, alcanzando un valor de $119,85 \mathrm{kWh} / \mathrm{m}^{2} /$ año. Como consecuencia del mayor 
aislamiento de las superficies exteriores, las mayores pérdidas se dan por las renovaciones de aire $(30 \%)$, reduciéndose de manera notable las pérdidas por techos $(18 \%)$, muros $(13 \%)$ y ventanas $(26 \%)$.

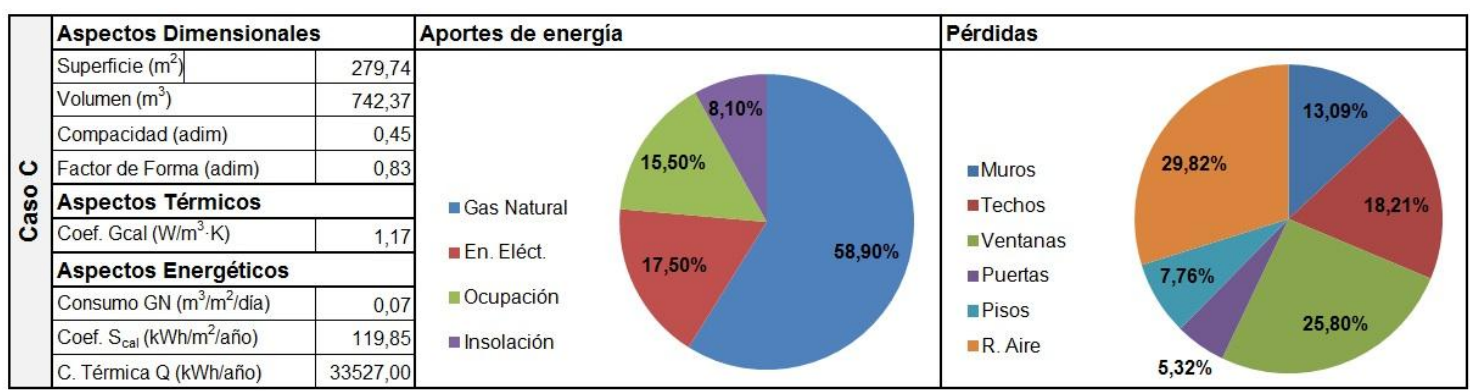

Figura VIII - 14: Resumen de los datos obtenidos con el AuditCAD - Caso C oficinas con DAC.

\subsubsection{Caso D}

La Figura VIII - 15 muestra un resumen de los datos obtenidos con el AuditCAD para el edificio tal como está construido en la actualidad, es decir según la información que pudo recolectarse durante la auditoría energética. Tal como se comenta en el Capítulo V - Estudio de Casos su tecnología constructiva es convencional con estructura de hormigón armado y muros de cerramiento exterior de ladrillos comunes, conformando un muro de $22 \mathrm{~cm}$ de espesor final, sin aislamiento higrotérmico adicional. Por su parte los cerramientos interiores se han materializado con muros de $15 \mathrm{~cm}$ de espesor final de ladrillos comunes, los que separan los ambientes interiores de las oficinas, a las oficinas entre sí y con las áreas comunes, y con sistema de construcción en seco (placas de yeso) aquellos que dividen los ambientes interiores de cada oficina, que son el resultado de la adaptación de la planta a las necesidades actuales. Las carpinterías son de simple vidriado con perfilería de hierro y cortinas de enrollar de madera.

Según estos datos, los valores de transmitancia térmica de los diferentes elementos que componen la envolvente de este edificio rondan los siguientes valores:

- Pisos / Techos: $\mathrm{K}=2,34 \mathrm{~W} / \mathrm{m}^{2} \cdot \mathrm{K}$ (factor de protección $50 \%$ )

- Muros exteriores: $\mathrm{K}=2,57 \mathrm{~W} / \mathrm{m}^{2} \cdot \mathrm{K}$

- Muros medianeros: $\mathrm{K}=2,57 \mathrm{~W} / \mathrm{m}^{2} \cdot \mathrm{K}$ (factor de protección $50 \%$ )

- Muros interiores: $\mathrm{K}=3,35 \mathrm{~W} / \mathrm{m}^{2} \cdot \mathrm{K}$ (factor de protección $50 \%$ )

- Superficies vidriadas: $\mathrm{K}=5,80 \mathrm{~W} / \mathrm{m}^{2} \cdot \mathrm{K}$

- Puertas interiores: $\mathrm{K}=3,50 \mathrm{~W} / \mathrm{m}^{2} \cdot \mathrm{K}$ (factor de protección $50 \%$ )

En la Figura VIII - 15 puede verse claramente que los mayores aportes de energía para calefacción provienen del gas natural, con el $76 \%$. La incidencia de la ocupación, la energía eléctrica e insolación suman en total un $24 \%$. Puede verse también que los mayores porcentajes de pérdidas se dan a través de techos $(36 \%)$, muros $(24 \%)$, ventanas $(9 \%)$ y renovaciones de aire $(21 \%)$, esto principalmente debido a la falta de aislación térmica. La planta tipo del edificio tal como está construido en la actualidad requiere de un consumo de $0,13 \mathrm{~m}^{3} / \mathrm{m}^{2} /$ día de gas natural para alcanzar una temperatura interior de $20^{\circ} \mathrm{C}$. La carga térmica por unidad de superficie alcanza un valor de 136,37kWh/año. 


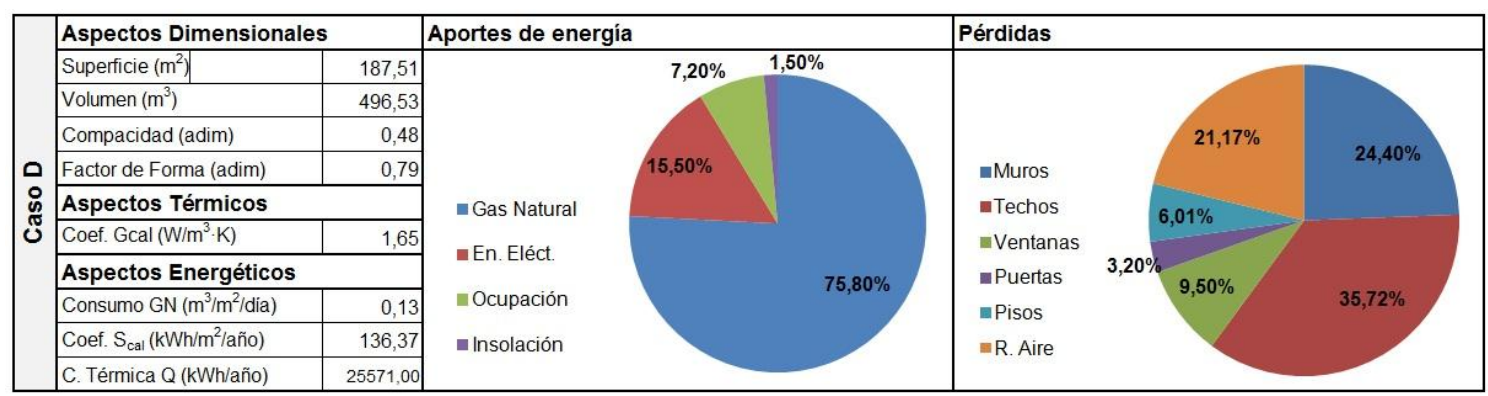

Figura VIII - 15: Resumen de los datos obtenidos con el AuditCAD - Caso D oficinas sin DAC.

Al aplicar los criterios del Diseño Ambientalmente Consciente a la envolvente del edificio, los coeficientes de transmitancia térmica rondaron los siguientes valores:

- Pisos / Techos: $\mathrm{K}=0,49 \mathrm{~W} / \mathrm{m}^{2} \cdot \mathrm{K}$ (factor de protección $50 \%$ )

- Muros exteriores: $\mathrm{K}=0,87 \mathrm{~W} / \mathrm{m}^{2} \cdot \mathrm{K}$

- Muros medianeros: $\mathrm{K}=0,87 \mathrm{~W} / \mathrm{m}^{2} \cdot \mathrm{K}$ (factor de protección $50 \%$ )

- Muros interiores: $\mathrm{K}=0,93 \mathrm{~W} / \mathrm{m}^{2} \cdot \mathrm{K}$ (factor de protección $50 \%$ )

- Superficies vidriadas: $\mathrm{K}=2,86 \mathrm{~W} / \mathrm{m}^{2} \cdot \mathrm{K}$

- Puertas interiores: $\mathrm{K}=3,50 \mathrm{~W} / \mathrm{m}^{2} \cdot \mathrm{K}$ (factor de protección $50 \%$ )

Para alcanzar estos valores se agregaron $5 \mathrm{~cm}$ de lana de vidrio en la cámara de aire entre el cielorraso suspendido y la losa de hormigón en pisos y techos $(10 \mathrm{~cm}$ en la cara exterior de la última planta, en contacto directo con el aire exterior), $2,5 \mathrm{~cm}$ de poliuretano proyectado en la cara exterior de los muros de cerramiento exterior, medianeros e interiores (aquellos que separan los ambientes calefaccionados de aquellos no acondicionados térmicamente), y carpinterías con DVH.

Tal como puede verse en la Figura VIII - 16 el porcentaje de aporte del gas natural para calefacción se redujo a $57 \%$, aumentando el porcentaje de incidencia de la energía eléctrica, la insolación y la ocupación, las cuales en total sumaron aproximadamente un $43 \%$. El consumo de gas natural se redujo un $46 \%\left(0,07 \mathrm{~m}^{3} / \mathrm{m}^{2} /\right.$ día) y la carga térmica por unidad de superficie se redujo en un $42 \%$, alcanzando un valor de $79,15 \mathrm{kWh} / \mathrm{m}^{2} / a n ̃ o$. Como consecuencia del mayor aislamiento de las superficies exteriores, las mayores pérdidas se dan por las renovaciones de aire $(36 \%)$, reduciéndose de manera notable las pérdidas por techos $(22 \%)$, muros $(17 \%)$ y ventanas $(8 \%)$.

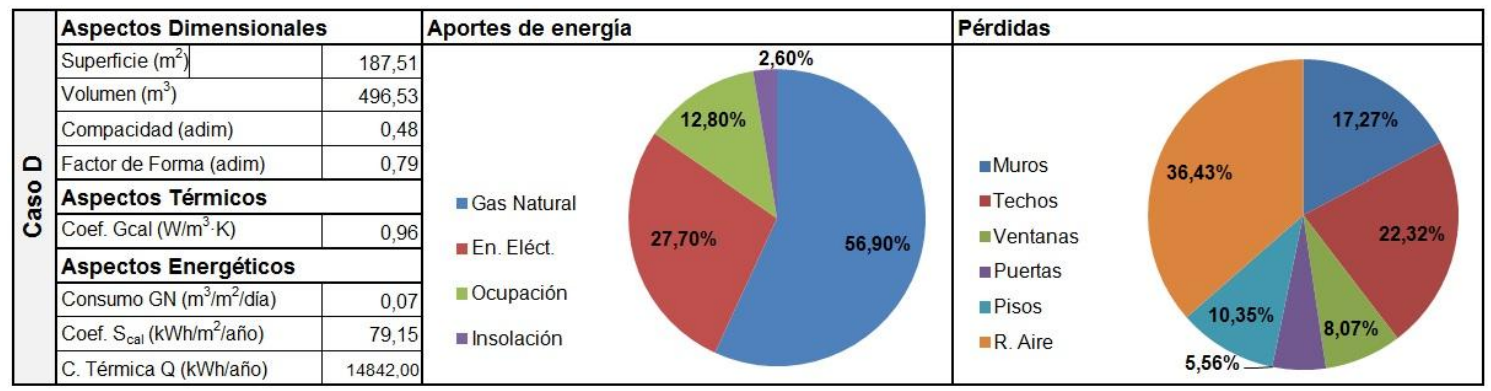

Figura VIII - 16: Resumen de los datos obtenidos con el AuditCAD - Caso D oficinas con DAC.

\subsubsection{Caso E}

La Figura VIII - 17 muestra un resumen de los datos obtenidos con el AuditCAD para el edificio tal como está construido en la actualidad, es decir según la información que pudo recolectarse durante la auditoría energética. Tal como se comenta en el Capítulo V - Estudio de Casos su tecnología constructiva es convencional con estructura de hormigón armado y curtain wall con estructura metálica y vidrio simple coloreado. Por su parte los muros medianeros se han materializado con ladrillos huecos de $18 \times 18 \times 33 \mathrm{~cm}$, los cerramientos 
interiores se han materializado con ladrillos huecos de $12 \times 18 \times 33 \mathrm{~cm}$, los que separan a las oficinas entre sí y con las áreas comunes, y con ladrillos huecos de $8 \times 18 \times 33 \mathrm{~cm}$, aquellos que dividen los ambientes interiores de cada oficina.

Según estos datos, los valores de transmitancia térmica de los diferentes elementos que componen la envolvente de este edificio rondan los siguientes valores:

- Pisos / Techos: $\mathrm{K}=2,34 \mathrm{~W} / \mathrm{m}^{2} \cdot \mathrm{K}$ (factor de protección $50 \%$ )

- Muros exteriores: $\mathrm{K}=1,74 \mathrm{~W} / \mathrm{m}^{2} \cdot \mathrm{K}$

- Muros medianeros: $\mathrm{K}=1,82 \mathrm{~W} / \mathrm{m}^{2} \cdot \mathrm{K}$ (factor de protección $50 \%$ )

- Muros interiores: $\mathrm{K}=2,18 \mathrm{~W} / \mathrm{m}^{2} \cdot \mathrm{K}$ (factor de protección $50 \%$ )

- Superficies vidriadas: $\mathrm{K}=5,80 \mathrm{~W} / \mathrm{m}^{2} \cdot \mathrm{K}$

- Puertas interiores: $\mathrm{K}=3,50 \mathrm{~W} / \mathrm{m}^{2} \cdot \mathrm{K}$ (factor de protección $50 \%$ )

En la Figura VIII - 17 puede verse claramente que los mayores aportes de energía para calefacción provienen del gas natural, con el $76 \%$. La incidencia de la ocupación, la energía eléctrica e insolación suman en total un $24 \%$. Puede verse también que los mayores porcentajes de pérdidas se dan a través de techos (30\%), muros $(21 \%)$, ventanas $(23 \%)$ y renovaciones de aire $(18 \%)$, esto principalmente debido a la falta de aislación térmica. La planta tipo del edificio tal como está construido en la actualidad requiere de un consumo de $0,15 \mathrm{~m}^{3} / \mathrm{m}^{2} /$ día de gas natural para alcanzar una temperatura interior de $20^{\circ} \mathrm{C}$. La carga térmica

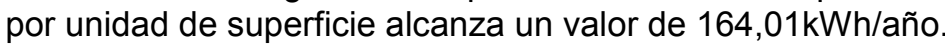

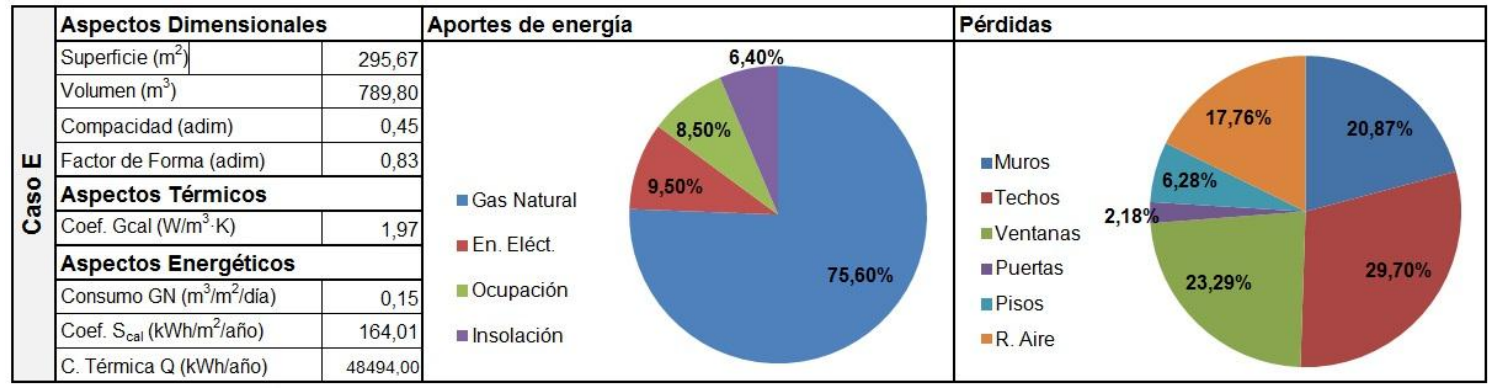

Figura VIII - 17: Resumen de los datos obtenidos con el AuditCAD - Caso E oficinas sin DAC.

Al aplicar los criterios del Diseño Ambientalmente Consciente a la envolvente del edificio, los coeficientes de transmitancia térmica rondaron los siguientes valores:

- Pisos / Techos: $\mathrm{K}=0,49 \mathrm{~W} / \mathrm{m}^{2} \cdot \mathrm{K}$ (factor de protección $50 \%$ )

- Muros exteriores: $\mathrm{K}=0,87 \mathrm{~W} / \mathrm{m}^{2} \cdot \mathrm{K}$

- Muros medianeros: $\mathrm{K}=0,87 \mathrm{~W} / \mathrm{m}^{2} \cdot \mathrm{K}$ (factor de protección $50 \%$ )

- Muros interiores: $\mathrm{K}=0,93 \mathrm{~W} / \mathrm{m}^{2} \cdot \mathrm{K}$ (factor de protección $50 \%$ )

- Superficies vidriadas: $\mathrm{K}=2,86 \mathrm{~W} / \mathrm{m}^{2} \cdot \mathrm{K}$

- Puertas interiores: $\mathrm{K}=3,50 \mathrm{~W} / \mathrm{m}^{2} \cdot \mathrm{K}$ (factor de protección $50 \%$ )

Para alcanzar estos valores se agregaron $5 \mathrm{~cm}$ de lana de vidrio en la cámara de aire entre el cielorraso suspendido y la losa de hormigón en pisos y techos $(10 \mathrm{~cm}$ en la cara exterior de la última planta, en contacto directo con el aire exterior), $2,5 \mathrm{~cm}$ de poliuretano proyectado en la cara exterior de los muros de cerramiento exterior, medianeros e interiores (aquellos que separan los ambientes calefaccionados de aquellos no acondicionados térmicamente), y carpinterías con DVH.

Tal como puede verse en la Figura VIII - 18 el porcentaje de aporte del gas natural para calefacción se redujo a 57\%, aumentando el porcentaje de incidencia de la energía eléctrica, la insolación y la ocupación, las cuales en total sumaron aproximadamente un $43 \%$. El consumo de gas natural se redujo un $53 \%\left(0,07 \mathrm{~m}^{3} / \mathrm{m}^{2} /\right.$ día $)$ y la carga térmica por unidad de superficie se redujo en un $43 \%$, alcanzando un valor de $93,55 \mathrm{kWh} / \mathrm{m}^{2} / a n ̃ o$. Como consecuencia del mayor 
aislamiento de las superficies exteriores, las mayores pérdidas se dan por las renovaciones de aire $(31 \%)$, reduciéndose de manera notable las pérdidas por techos $(19 \%)$, muros $(15 \%)$ y ventanas $(20 \%)$.

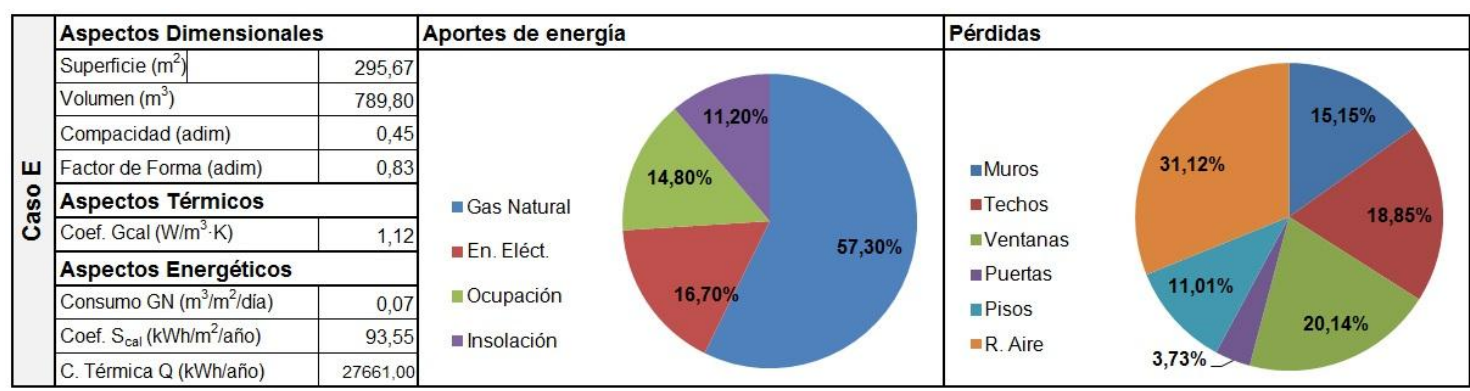

Figura VIII - 18: Resumen de los datos obtenidos con el AuditCAD - Caso D oficinas con DAC.

\subsection{Etiquetado de Eficiencia Energética en Calefacción (IRAM 11900)}

Para todos los casos analizados se realizó la verificación de la Norma IRAM 11.900 por la cual se establece la etiqueta de eficiencia energética de calefacción para edificios y la clasificación según la transmitancia térmica de la envolvente.

La etiqueta de eficiencia energética especificada en dicha norma tiene por objeto informar al consumidor sobre la eficiencia térmica de la envolvente de los edificios. Mediante la etiqueta se califica la eficiencia a través de un sistema comparativo, compuesto por ocho clases de eficiencia energética identificadas por las letras $A, B, C, D, E, F, G$ y H, donde la letra $A$ se adjudica a las envolventes de los edificios más eficientes y la $\mathrm{H}$ a las menos eficientes.

Para la determinación de la clase de eficiencia energética del edificio debe obtenerse el valor de la variación media ponderada entre la temperatura de la superficie interior y la temperatura interior de diseño $\left(\tau_{m}\right)$, en grados Celsius, mediante la siguiente expresión:

$$
\tau_{m}=\frac{\sum\left(\tau_{i} \cdot S_{i}\right)}{\sum S_{i}}
$$

Donde:

$$
\text { [Ecuación VIII - 1] }
$$

$$
\tau_{i}=0,13 \frac{m^{2} \cdot K}{W} \cdot K_{i} \cdot \Delta t \quad \text { [Ecuación VIII - 2] }
$$

$K_{i}$ : transmitancia térmica de cada uno de los componentes de la envolvente $\left[\mathrm{W} / \mathrm{m}^{2} \cdot \mathrm{K}\right]$. $\Delta_{t}$ : diferencia de temperatura de diseño interior y exterior $\left[{ }^{\circ} \mathrm{C}\right]$.

La etiqueta también debe mostrar el valor de la transmitancia térmica media ponderada $\left(K_{m}^{\prime}\right)$ en watt por metro cuadrado kelvin, la cual se determina con la siguiente expresión:

$$
K_{m}^{\prime}=\frac{\sum_{1}^{n}\left(K_{i} \cdot S_{i}\right)}{\sum_{1}^{n} S_{i}}
$$

[Ecuación VIII - 3]

Donde:

$K_{i}$ : transmitancia térmica cada uno de los componentes de la envolvente $\left[\mathrm{W} / \mathrm{m}^{2} \cdot \mathrm{K}\right]$.

$S_{i}$ : superficie de cada uno de los componentes de la envolvente $\left[\mathrm{m}^{2}\right]$.

Luego, de acuerdo a los resultados obtenidos, se clasifica el edificio teniendo en cuenta los valores propuestos en la siguiente tabla: 


\begin{tabular}{|c|c|}
\hline $\begin{array}{l}\text { Clases de } \\
\text { eficiencia } \\
\text { energética }\end{array}$ & Condiciónn ${ }^{1)}$ \\
\hline A & $\tau_{m} \leq 1{ }^{\circ} \mathrm{C}$ \\
\hline B & $1^{\circ} \mathrm{C}<\tau_{m} \leq 1,5^{\circ} \mathrm{C}$ \\
\hline C & $1,5^{\circ} \mathrm{C}<\tau_{m} \leq 2{ }^{\circ} \mathrm{C}$ \\
\hline D & $2^{\circ} \mathrm{C}<\tau_{m} \leq 2,5^{\circ} \mathrm{C}$ \\
\hline$E$ & $2,5^{\circ} \mathrm{C}<\tau_{m} \leq 3^{\circ} \mathrm{C}$ \\
\hline $\mathrm{F}$ & $3^{\circ} \mathrm{C}<\tau_{m} \leq 3,5^{\circ} \mathrm{C}$ \\
\hline G & $3,5^{\circ} \mathrm{C}<\tau_{m} \leq 4{ }^{\circ} \mathrm{C}$ \\
\hline $\mathrm{H}$ & $\tau_{m}>4^{\circ} \mathrm{C}$ \\
\hline \multicolumn{2}{|c|}{$\begin{array}{l}\text { 1) } \tau_{m} \text { es ia variacion media ponderada de la temporatu- } \\
\text { ra, entre la suporricio interior do la onvolvente y la } \\
\text { temperatura interior de disono, on grados Colsilus. }\end{array}$} \\
\hline
\end{tabular}

Tabla VIII - 1: Valores de $\tau_{m}$ para las clases de eficiencia energética en calefacción de edificios propuestos por la Norma IRAM 11.900 - Fuente: Norma IRAM 11.900. Instituto Argentino de Normalización y Certificación. Buenos Aires, Argentina. 2010.

Si bien la Norma establece que en el caso de edificios con varias unidades funcionales la verificación debe realizarse de manera individual, a los efectos de estudiar el tipo edilicio de interés a la siguiente Tesis Doctoral, se analizaron las plantas tipos de los distintos edificios auditados, interpretando a cada planta tipo como una unidad de análisis, de modo de continuar con la misma metodología.

Las auditorías energéticas realizadas en los distintos edificios permitieron obtener los datos para realizar los cálculos necesarios. Como se menciona en el Capítulo $\mathrm{V}$ ninguno de los edificios responde a los criterios del Diseño Ambientalmente Consciente, y si bien varían entre ellos en algunos aspectos como ser la superficie total de la planta tipo, la relación vidriadoopaco del total de la envolvente o incluso los sistemas de aventanamiento y de protección solar utilizados, en líneas generales se trata de edificios con una baja calidad en lo que respecta a la envolvente térmica.

\subsubsection{Edificios de Viviendas}

En la Tabla VIII - 2 se muestra un resumen del etiquetado de eficiencia energética en calefacción para los edificios de viviendas auditados para el modo en que están construidos en la actualidad y para la propuesta de mejora, aplicando los criterios del Diseño Ambientalmente Consciente, según se especificó en el punto anterior.

Como puede verse en esta tabla, de acuerdo al modo en que están construidos en la actualidad, todos los edificios auditados alcanzan la etiqueta $\mathrm{H}$. La situación es bastante grave ya que los valores de la variación media ponderada entre la temperatura de la superficie interior y la temperatura interior de diseño $\left(\tau_{m}\right)$ se encuentran muy por encima del valor mínimo que plantea la clase más baja $\left(\mathrm{H}: \tau_{\mathrm{m}}>4^{\circ} \mathrm{C}\right)$. Por su parte la transmitancia térmica media ponderada de los elementos que componen la envolvente edilicia supera los $2 \mathrm{~W} / \mathrm{m}^{2} \cdot \mathrm{K} / \mathrm{m}^{2}$.

Al aplicar los conceptos del Diseño Ambientalmente Consciente, según como se especificó en el punto anterior los casos $B, C$ y $D$ alcanzaron la clase $D$, con variación media ponderada entre la temperatura de la superficie interior y la temperatura interior de diseño $\left(\tau_{m}\right)$ superior a los $2^{\circ} \mathrm{C}$ y una transmitancia térmica media ponderada de los elementos que componen la envolvente edilicia superior a $0,7 \mathrm{~W} / \mathrm{m}^{2} \cdot \mathrm{K} / \mathrm{m}^{2}$. El caso A por su parte alcanzó la clase $\mathrm{C}$, con variación media ponderada entre la temperatura de la superficie interior y la temperatura interior de diseño $\left(\tau_{m}\right)$ inferior a los $2^{\circ} \mathrm{C}$ y una transmitancia térmica media ponderada de los elementos que componen la envolvente edilicia próxima a los $0,7 \mathrm{~W} / \mathrm{m}^{2} \cdot \mathrm{K} / \mathrm{m}^{2}$. 


\begin{tabular}{|c|c|c|c|c|c|c|c|c|}
\hline Caso & $\begin{array}{c}\text { Sup. } \\
\text { envolvente }\end{array}$ & $\begin{array}{c}\text { Sup. } \\
\text { cubierta }\end{array}$ & $\begin{array}{c}\mathrm{T} \text { medio } \\
\text { ponderado }\end{array}$ & $\begin{array}{l}\text { k medio } \\
\text { ponderado }\end{array}$ & Etiqueta & $\begin{array}{c}\mathrm{T} \text { medio } \\
\text { ponderado }\end{array}$ & $\begin{array}{l}\text { k medio } \\
\text { ponderado }\end{array}$ & Etiqueta \\
\hline A & 334,98 & 126,00 & 6,84 & 2,25 & $\mathrm{H}$ & 1,93 & 0,69 & C \\
\hline B & 436,65 & 190,00 & 7,44 & 2,33 & H & 2,22 & 0,73 & D \\
\hline C & 1676,73 & 840,00 & 7,76 & 2,36 & H & 2,24 & 0,72 & D \\
\hline D & 788,07 & 394,00 & 7,90 & 2,38 & H & 2,33 & 0,74 & D \\
\hline
\end{tabular}

Tabla VIII - 2: Resumen de Etiquetado de Eficiencia Energética en Calefacción (Edificios de viviendas)

\subsubsection{Edificios de Oficinas}

En la Tabla VIII - 3 se muestra un resumen del etiquetado de eficiencia energética en calefacción para los edificios de oficinas auditados para el modo en que están construidos en la actualidad y para la propuesta de mejora, aplicando los criterios del Diseño Ambientalmente Consciente, según se especificó en el punto anterior.

Como puede verse en esta tabla, de acuerdo al modo en que están construidos en la actualidad, todos los edificios auditados alcanzan la etiqueta $\mathrm{H}$. Al igual que para los edificios de viviendas, la situación es bastante grave ya que los valores de la variación media ponderada entre la temperatura de la superficie interior y la temperatura interior de diseño $\left(\tau_{m}\right)$ se encuentran muy por encima del valor mínimo que plantea la clase más baja $\left(\mathrm{H}: \tau_{\mathrm{m}}>4^{\circ} \mathrm{C}\right)$. Por su parte la transmitancia térmica media ponderada de los elementos que componen la envolvente edilicia supera los $2 \mathrm{~W} / \mathrm{m}^{2} \cdot \mathrm{K} / \mathrm{m}^{2}$.

Al aplicar los conceptos del Diseño Ambientalmente Consciente, según como se especificó en el punto anterior, todos los casos alcanzaron la clase $D$, con variación media ponderada entre la temperatura de la superficie interior y la temperatura interior de diseño $\left(\tau_{m}\right)$ superior a los $2^{\mathrm{a}} \mathrm{C}$ y una transmitancia térmica media ponderada de los elementos que componen la envolvente edilicia próxima a $0,7 \mathrm{~W} / \mathrm{m}^{2} \cdot \mathrm{K} / \mathrm{m}^{2}$.

\begin{tabular}{|c|c|c|c|c|c|c|c|c|}
\hline Caso & $\begin{array}{c}\text { Sup. } \\
\text { envolvente }\end{array}$ & $\begin{array}{c}\text { Sup. } \\
\text { cubierta }\end{array}$ & $\begin{array}{c}\mathrm{T} \text { medio } \\
\text { ponderado }\end{array}$ & $\begin{array}{l}\text { k medio } \\
\text { ponderado }\end{array}$ & Etiqueta & $\begin{array}{c}\mathrm{T} \text { medio } \\
\text { ponderado }\end{array}$ & $\begin{array}{l}\text { k medio } \\
\text { ponderado }\end{array}$ & Etiqueta \\
\hline A & 820,50 & 397,00 & 8,52 & 2,61 & $\mathrm{H}$ & 2,24 & 0,73 & D \\
\hline B & 544,59 & 270,00 & 7,60 & 2,32 & $\mathrm{H}$ & 2,14 & 0,69 & D \\
\hline C & 535,00 & 290,00 & 9,02 & 2,73 & H & 2,84 & 0,91 & D \\
\hline D & 442,00 & 186,50 & 8,13 & 2,60 & H & 2,33 & 0,78 & D \\
\hline$E$ & 772,50 & 354,00 & 7,85 & 2,42 & $\mathrm{H}$ & 2,40 & 0,78 & D \\
\hline & & & \multicolumn{3}{|c|}{ Situación actual (sin DAC) } & \multicolumn{3}{|c|}{ Propuesta de mejora (con DAC) } \\
\hline
\end{tabular}

Tabla VIII - 3: Resumen de Etiquetado de Eficiencia Energética en Calefacción (Edificios de viviendas) 


\section{CAPÍTULO IX \\ SIMULACIÓN CON ENERGY PLUS}

\subsection{Introducción}

En el siguiente Capítulo se presentan los resultados de las simulaciones con el Energy PLUS para los modelos de edificios propuestos. Tal como se comentó en el Capítulo 6 - Auditoría Energética, el Energy PLUS es un software gratuito de simulación energética de edificios creado por el U.S. DOE (Departamento de Energía de Estados Unidos) para el modelado y cálculo de calefacción, refrigeración, iluminación, ventilación y otros flujos energéticos.

Con el fin de simplificar la simulación, se construyeron dos modelos edilicios de base, uno de viviendas y otro de oficinas. Para la construcción de estos modelos se tomaron las principales características de los edificios auditados: características constructivas, relación de superficies vidriadas - opacas, factor de forma, factor de ocupación, nivel de iluminación y de equipamiento eléctrico, horarios de ocupación y uso de los sistemas de acondicionamiento de aire, equipamiento eléctrico, iluminación, etc. Luego sobre estos modelos de base se construyeron los modelos de referencia, a los cuales se aplicaron las propuestas de mejora que se comentaron en el Capítulo 8.

Esta decisión de construir dos modelos -uno de base y otro de referencia- se fundamenta en lo establecido en el Apéndice G de la Norma ASHRAE 90.1, en donde se destaca que para ningún caso la simulación energética arroja resultados reales de consumo y costo. Según lo establecido en dicha Norma, esto se debe a que la experiencia real difiere de los cálculos en lo que respecta a la ocupación, la operación y mantenimiento del edificio, el clima, etc. y también a la precisión de las herramientas de medición. Por lo tanto la comparación de los casos reales con otros de referencia no llevaría a resultados confiables.

Para la construcción de los modelos y la posterior simulación se siguieron las recomendaciones establecidas en el Apéndice G de la Norma ASHRAE 90.1. Se determinó que el intercambio de calor de los modelos con el exterior se haría a través de las fachadas de frente y contrafrente, el techo de la última planta, el piso en contacto con el suelo de fundación, y el piso de la primera planta en contacto con el aire exterior (suponiendo que existe una pasante para acceso vehicular). Las medianeras, por su parte, se consideraron superficies adiabáticas; esto último porque se supone al modelo inserto en un medio urbano, rodeado de edificios de características similares, en donde los ambientes próximos a las medianeras se encuentran en contacto con los ambientes calefaccionados de los edificios vecinos.

En cuanto al interior de los modelos, el Apéndice G de la Norma ASHRAE 90.1 especifica que las distintas zonas térmicas deben ser definidas en base a similares usos, cargas internas, 
ocupación, niveles de iluminación y temperaturas, y horarios de acondicionamiento de los espacios. Si bien establece que cada espacio con un equipo de aire acondicionado debe ser modelado como una zona térmica diferente, también menciona que pueden unificarse zonas para facilitar la simulación cuando la clasificación del uso del espacio es igual para dos zonas. Lo mismo sucede con aquellas zonas con igual sistema de aire acondicionado que tengan la misma orientación y relación interior - exterior. Además sugiere que en espacios residenciales se utilice una zona térmica por unidad de vivienda, e incluso que aquellas unidades con iguales condiciones exteriores, puedan unirse y conformar una única zona térmica.

Establecido esto, y a los efectos de simplificar la simulación, tanto en el modelo de viviendas como en el de oficinas se consideró a las distintas unidades funcionales de cada planta como una única zona climatizada en la que el intercambio de calor se haría únicamente con el núcleo de circulación vertical y hall de acceso, no climatizados, y con las plantas superior e inferior, a través de las superficies en contacto de ambas zonas.

Por otra parte, en lo que respecta a los sistemas de acondicionamiento de aire cabe destacar que tanto para el modelo de edificio de viviendas como para el de oficinas se utilizó el sistema "Ideal Loads" por el cual el programa determina las cargas necesarias para mantener a las zonas a temperatura de termostato, durante el tiempo establecido según los horarios de uso y considerando los parámetros cargados (características constructivas, régimen de actividad, factor de ocupación, equipamiento eléctrico, iluminación, etc.).

\subsection{Modelo edilicio - Viviendas}

Para la construcción de los modelos de base y de referencia se tomaron las características formales extraídas de las auditorías energéticas. El modelo edilicio que resultó de este análisis se compone de planta baja y diez pisos destinados a viviendas. La superficie de la planta baja se distribuyó entre el hall de acceso al edificio, el núcleo de circulación vertical, un espacio destinado a oficinas y una pasante para el acceso vehicular a la zona de cocheras exterior. Las plantas tipo, por su parte, se componen de dos unidades funcionales con orientación Norte-Sur, y un espacio destinado al núcleo de circulación vertical y al hall de acceso a las viviendas.

Se trata de un modelo de $10 \mathrm{~m}$ de frente y $14 \mathrm{~m}$ de largo, con una superficie total de $1.650 \mathrm{~m}^{2}$, de los cuales $1.405 \mathrm{~m}^{2}$ son climatizados y $245 \mathrm{~m}^{2}$ no. El $30 \%$ de la superficie total de la envolvente es vidriada, la cual se distribuye entre el frente y el contrafrente del edificio. Sobre el frente del modelo, de orientación Norte, se ubicaron las carpinterías con mayor superficie (tres unidades de 2,00 × 2,10m) protegidas por un alero longitudinal de 1,20m de ancho (a modo de balcón). Sobre esta cara se ubicaron las salas de estar y comedores de las distintas unidades funcionales. En la fachada Sur, por su parte, se dispusieron las aberturas de menor tamaño (tres unidades de $2,00 \times 1,10 \mathrm{~m}$ ). Sobre esta cara se ubicaron los dormitorios de las distintas unidades funcionales. Sobre las medianeras del edificio, de orientación Este y Oeste, se ubicaron las áreas de servicios de las distintas unidades, dejando el centro de la planta para la localización del núcleo de circulación vertical (Figuras IX - 1 y 2 ).

Con los datos extraídos de las auditorías energéticas se determinaron las ganancias internas debidas a ocupación, iluminación y equipamiento eléctrico. Se adoptó un factor de ocupación de $12 \mathrm{~m}^{2} /$ persona para las unidades de vivienda y $8 \mathrm{~m}^{2} /$ persona para el sector de la planta baja destinado a oficinas. Los espacios destinados al núcleo de circulación vertical, al hall de planta baja y a la sala de medidores del edificio se consideraron como no ocupados.

En lo que respecta al equipamiento eléctrico se determinó un factor de $16 \mathrm{~W} / \mathrm{m}^{2}$ para las unidades de vivienda y $28 \mathrm{~W} / \mathrm{m}^{2}$ para el área destinada a oficinas. El nivel de iluminación artificial adoptado fue de $12 \mathrm{~W} / \mathrm{m}^{2}$ para las unidades de viviendas y los espacios comunes (hall de acceso, palier de ascensores, escalera y sala de medidores), y $16 \mathrm{~W} / \mathrm{m}^{2}$ para el sector de oficinas. En ambos casos se consideró únicamente iluminación artificial de bajo consumo. 

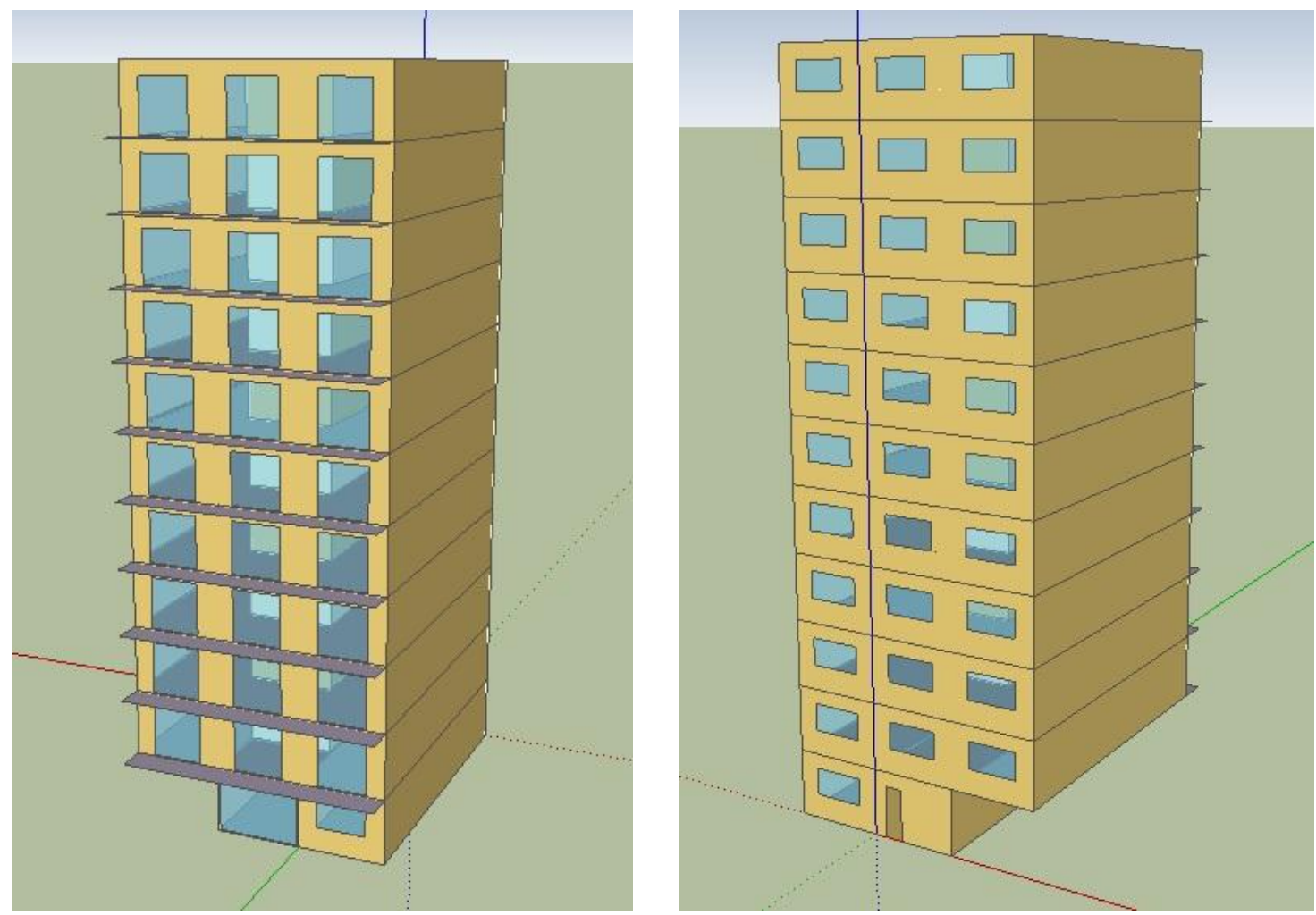

Figuras IX - 1 y 2: Modelo Edilicio construido con Plug-in OpenStudio para SketchUp

En función de los datos extraídos de las auditorías energéticas pudieron armarse los "schedules" para ocupación, iluminación, uso de equipamiento eléctrico y de los equipos de aire acondicionado. El Gráfico IX-1 muestra un resumen de la ocupación de las viviendas por zona, distinguiendo días hábiles de fines de semana. Tal como se mencionó anteriormente, para en cada planta se incorporó un sistema de aire acondicionado que regulaba la temperatura interior de las unidades de vivienda, dejando al núcleo de circulación vertical y al hall de acceso a las viviendas sin climatizar. Se utilizó el sistema "Ideal Loads" por el cual el programa determina las cargas necesarias para mantener a las zonas a temperatura de termostato durante el tiempo establecido según los horarios de uso y considerando los parámetros cargados (régimen de actividad, factor de ocupación, equipamiento eléctrico, iluminación, etc.). La temperatura base de calefacción se fijó en $22^{\circ} \mathrm{C}$ y la temperatura base de refrigeración se fijó en $24^{\circ} \mathrm{C}$. Por su parte, en lo que respecta a las renovaciones de aire, se adoptó un valor de RA= 1 .

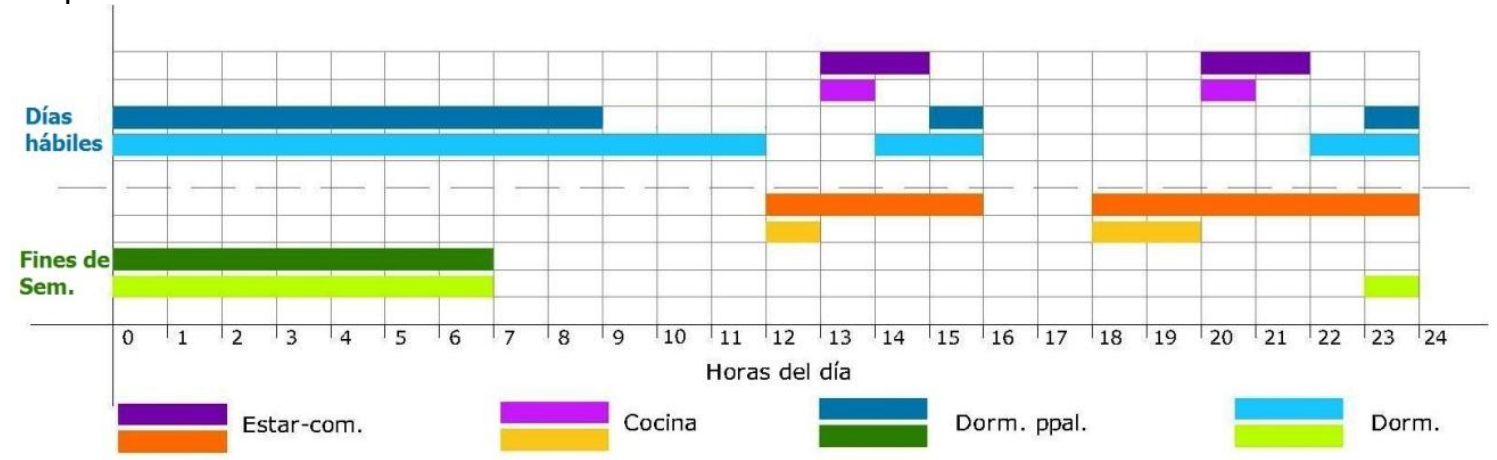

Gráfico IX-1: Bandas horarias de ocupación de las viviendas por zona.

\subsubsection{Modelo de Base}

Para determinar las características de la envolvente del modelo base se utilizaron los datos extraídos de las auditorías energéticas. La tecnología constructiva del modelo es convencional 
con estructura de hormigón armado y muros de cerramiento exterior de ladrillos huecos de $18 \times 18 \times 33 \mathrm{~cm}\left(\mathrm{~K}=1,82 \mathrm{~W} / \mathrm{m}^{2} \cdot \mathrm{K}\right)$, sin aislamiento higrotérmico adicional. Por su parte los cerramientos interiores son de ladrillos huecos de $12 \times 18 \times 33 \mathrm{~cm}\left(\mathrm{~K}=2,10 \mathrm{~W} / \mathrm{m}^{2} \cdot \mathrm{K}\right)$, los que separan a los departamentos entre sí y con las áreas comunes, y con ladrillos de $8 \times 18 \times 33 \mathrm{~cm}$ $\left(\mathrm{K}=2,18 \mathrm{~W} / \mathrm{m}^{2} \cdot \mathrm{K}\right)$ aquellos que dividen los ambientes interiores de cada departamento. La cubierta y las losas de entrepiso son de $\mathrm{H}^{\circ} \mathrm{A}^{\circ}$ sin aislamiento higrotérmico adicional $(\mathrm{K}=2,34$ $\mathrm{W} / \mathrm{m}^{2} \cdot \mathrm{K}$ ). Las carpinterías son de simple vidriado con perfilería de aluminio, sin protección solar las que se disponen sobre la fachada principal $\left(\mathrm{K}=5,80 \mathrm{~W} / \mathrm{m}^{2} \cdot \mathrm{K}\right)$ y con cortinas de enrollar de pvc, aquellas dispuestas sobre el contrafrente (Figura IX - 3).

\begin{tabular}{|c|c|c|c|}
\hline \multicolumn{4}{|c|}{ Modelo Base - Viviendas } \\
\hline \multicolumn{2}{|c|}{ Aspectos Dimensionales } & \multicolumn{2}{|c|}{ Detalle constructivo } \\
\hline Sup. Total & \begin{tabular}{l|l}
1650 & $\mathrm{~m}^{2}$
\end{tabular} & \multirow{3}{*}{ 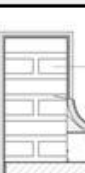 } & \multirow{2}{*}{ Carga de ladrillo común } \\
\hline Sup. Habitable & $1405 \mathrm{~m}^{2}$ & & \\
\hline Sup. Nucleo & \begin{tabular}{|l|l|}
245 & $\mathrm{~m}^{2}$ \\
\end{tabular} & & 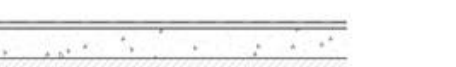 \\
\hline F. Forma & 0,60 & \multirow{6}{*}{\begin{tabular}{|l} 
\\
\\
\end{tabular}} & \multirow{7}{*}{$\begin{array}{l}\text { Membrana asfáltica } \\
\text { Carpeta cementicia } \\
\text { Contrapiso con pendiente } \\
\text { Estructura } \mathrm{H}^{\circ} \mathrm{A}^{\circ} \\
\text { Revoque interior: grueso + fino } \\
\text { Ladrillo hueco } 18 \times 18 \times 33 \mathrm{~cm} \text {. } \\
\text { Revoque exterior: grueso } \\
\text { fratasado + hidrófugo }\end{array}$} \\
\hline \multicolumn{2}{|c|}{ Características de la Envolvente } & & \\
\hline k muros ext. & \begin{tabular}{l|l}
1,82 & $\mathrm{~W} / \mathrm{m}^{2} \cdot \mathrm{K}$
\end{tabular} & & \\
\hline k muros int. & \begin{tabular}{l|l|}
2,18 & $\mathrm{~W} / \mathrm{m}^{2} \cdot \mathrm{K}$
\end{tabular} & & \\
\hline $\mathrm{k}$ techos & \begin{tabular}{l|l}
2,34 & $\mathrm{~W} / \mathrm{m}^{2} \cdot \mathrm{K}$
\end{tabular} & & \\
\hline $\mathrm{k}$ ventanas & \begin{tabular}{l|l}
5,80 & $\mathrm{~W} / \mathrm{m}^{2} \cdot \mathrm{K}$ \\
\end{tabular} & & \\
\hline k puertas & \begin{tabular}{ll|l}
3,50 & $\mathrm{~W} / \mathrm{m}^{2} \cdot \mathrm{K}$ \\
\end{tabular} & & \\
\hline \multicolumn{2}{|c|}{ Aspectos Térmicos } & & \multirow{2}{*}{$\begin{array}{l}\text { Carpintería de aluminio } \\
\text { s/protección. }\end{array}$} \\
\hline Gcal & \begin{tabular}{l|l|l}
1,50 & $\mathrm{~W} / \mathrm{m}^{3} \cdot \mathrm{K}$ \\
\end{tabular} & & \\
\hline
\end{tabular}

Figura IX - 3: Resumen de las características del Modelo Base - Viviendas

Una vez cargados todos los datos mencionados se procedió a realizar la simulación completa para un período 8.760 horas (un año), tal como lo recomienda el Apéndice $G$ de la Norma ASHRAE 90.1. El gráfico que sigue a continuación muestra la superficie total del modelo, distinguiendo el área climatizada del área no climatizada. El núcleo de circulación vertical representa aproximadamente el $15 \%$ del total de la superficie total del modelo (Gráfico IX - 2).

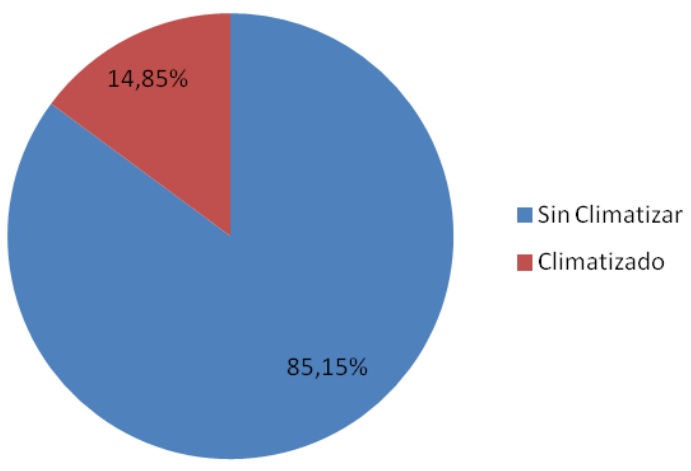

Gráfico IX - 2: Superficie climatizada y no climatizada.

La Tabla IX - 1 distingue los usos finales de la energía para calefacción, refrigeración, iluminación y equipamiento eléctrico. Tal como puede verse en esta tabla las mayores demandas se deben a refrigeración (435,22GJ/año), equipamiento eléctrico (197GJ/año), iluminación (149,25GJ/año) y luego a calefacción (17,91GJ/año). El Gráfico IX - 3 muestra un resumen de esta situación. En él puede verse que la demanda de energía para refrigeración representa más del $50 \%$ del total de la demanda de energía del modelo. 


\begin{tabular}{|r|r|r|r|r|r|r|}
\hline & Electricity [G] & Natural Gas [G] & Other Fuel [GJ] & District Cooling [G] & District Heating [GJ] & Water [m3] \\
\hline Heating & 0.00 & 0.00 & 0.00 & 0.00 & 17.91 & 0.00 \\
\hline Cooling & 0.00 & 0.00 & 0.00 & 435.22 & 0.00 & 0.00 \\
\hline Interior Lighting & 149.25 & 0.00 & 0.00 & 0.00 & 0.00 & 0.00 \\
\hline Exterior Lighting & 0.00 & 0.00 & 0.00 & 0.00 & 0.00 & 0.00 \\
\hline Interior Equipment & 197.00 & 0.00 & 0.00 & 0.00 & 0.00 & 0.00 \\
\hline Exterior Equipment & 0.00 & 0.00 & 0.00 & 0.00 & 0.00 & 0.00 \\
\hline Fans & 0.00 & 0.00 & 0.00 & 0.00 & 0.00 & 0.00 \\
\hline Pumps & 0.00 & 0.00 & 0.00 & 0.00 & 0.00 & 0.00 \\
\hline Heat Rejection & 0.00 & 0.00 & 0.00 & 0.00 & 0.00 & 0.00 \\
\hline Humidification & 0.00 & 0.00 & 0.00 & 0.00 & 0.00 & 0.00 \\
\hline Heat Recovery & 0.00 & 0.00 & 0.00 & 0.00 & 0.00 & 0.00 \\
\hline Water Systems & 0.00 & 0.00 & 0.00 & 0.00 & 0.00 & 0.00 \\
\hline Refrigeration & 0.00 & 0.00 & 0.00 & 0.00 & 0.00 & 0.00 \\
\hline Generators & 0.00 & 0.00 & 0.00 & 0.00 & 0.00 & 0.00 \\
\hline & & & & & & 17.91 \\
\hline Total End Uses & 346.25 & 0.00 & 0.00 & 435.22 & 0.00 \\
\hline
\end{tabular}

Note: District heat appears to be the principal heating source based on energy usage.

Tabla IX - 1: Usos finales de la energía para el Modelo de Base - Viviendas

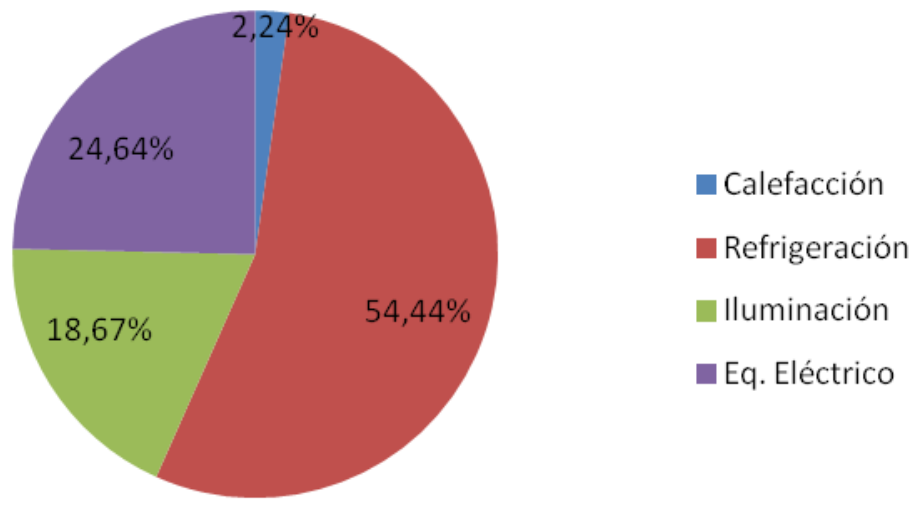

Gráfico IX - 3: Usos finales de la energía. Modelo de Base - Viviendas.

El informe suministrado por el Energy PLUS también muestra la energía utilizada por unidad de superficie climatizada. En este caso, tal como lo muestra la Tabla IX - 2, se distingue el uso de los equipos de aire acondicionado, iluminación y otros (equipamiento eléctrico).

Utility Use Per Total Floor Area

\begin{tabular}{|r|r|r|r|r|r|r|}
\hline & Electricity Intensity [MJ/m2] & Natural Gas Intensity [MJ/m2] & Other Fuel Intensity [MJ/m2] & District Cooling Intensity [MJ/m2] & District Heating Intensity [MJ/m2] & Water Intensity [m3/m2] \\
\hline Lighting & 90.50 & 0.00 & 0.00 & 0.00 & 0.00 & \\
\hline HVAC & 0.00 & 0.00 & 0.00 & 263.90 & 0.00 \\
\hline Other & 119.45 & 0.00 & 0.00 & 0.00 & 0.00 & 0.86 \\
\hline Total & 209.95 & 0.00 & 0.00 & 263.90 & 0.00 & 0.00 \\
\hline
\end{tabular}

Tabla IX - 2: Energía utilizada por unidad de superficie acondicionada para el Modelo Base - Viviendas.

Como se muestra en el Gráfico IX - 4 el mayor porcentaje se debe al funcionamiento de los equipos de Aire Acondicionado (56,69\%). Luego le sigue en importancia la energía destinada al 
equipamiento eléctrico $(24,64 \%)$ y finalmente el porcentaje menor se debe a iluminación $(18,67 \%)$.

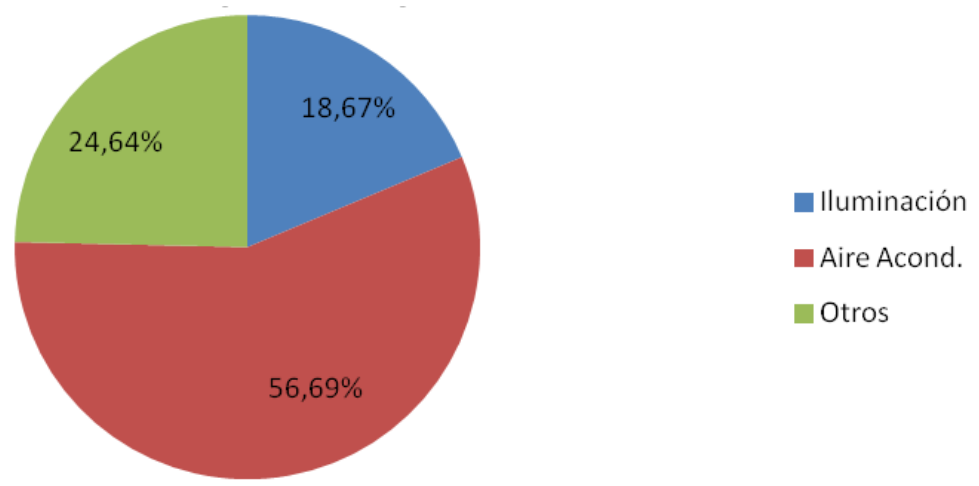

Gráfico IX - 4: Energía utilizada por unidad de superficie acondicionada para el Modelo Base - Viviendas.

El informe suministrado por el Energy PLUS también muestra un resumen de las horas en las que no se alcanzó el confort o la temperatura base de calefacción y refrigeración. Según puede verse en la siguiente tabla en todo momento durante el período de ocupación se alcanzó la temperatura base de calefacción y de refrigeración que propone el Apéndice $G$ de la Norma ASHRAE 90.1. Por otra parte no se cumplieron con los niveles de confort propuestos por ASHRAE 55 -2004 durante aproximadamente 1.370,25 horas (Tabla IX - 3).

Comfort and Setpoint Not Met Summary
\begin{tabular}{|l|r|r|r|}
\hline & & Facility [Hours] \\
\hline Tolerance for Time Heating Setpoint Not Met & 0.20 \\
\cline { 3 - 4 } \cline { 3 - 4 } & Degrees [deltaC] & Time Set Point Not Met During Occupied Heating & 0.00 \\
\cline { 3 - 4 } & & Time Set Point Not Met During Occupied Cooling & 0.00 \\
\cline { 3 - 4 } & Time Not Comfortable Based on Simple ASHRAE 55-2004 & 1370.25 \\
\hline
\end{tabular}

Note 1 : An asterisk $\left(^{*}\right)$ indicates that the feature is not yet implemented.

Tabla IX - 3: Resumen confort, temperatura base de calefacción, temperatura base refrigeración.

El Energy PLUS también brinda un resumen mensual de refrigeración para cada zona. En el puede verse la cantidad de energía necesaria para refrigerar la zona mes a mes, las temperaturas exteriores de bulbo seco y bulbo húmedo, y las ganancias internas de calor latente.

El Gráfico IX - 5 muestra la cantidad de energía total (sensible + latente) necesaria para mantener la zona refrigerada a la temperatura de $24^{\circ} \mathrm{C}$ en relación a la temperatura exterior de bulbo seco. Como puede verse los meses de enero, febrero, marzo y diciembre son los de mayor demanda de energía eléctrica para refrigeración, superando los $2.000 \mathrm{kWh} / \mathrm{mes}$ (en enero se aproxima los $2.500 \mathrm{kWh} / \mathrm{mes}$ ). Durante los meses de abril y noviembre la demanda se aproxima a los $1.000 \mathrm{kWh} / \mathrm{mes}$. En octubre por su parte la demanda de energía eléctrica para refrigeración ronda los $500 \mathrm{kWh} / \mathrm{mes}$. Asimismo se puede observar que hay un pequeño consumo de refrigeración incluso en los meses más fríos (mayo a septiembre). Esto se debe a que en las horas centrales del día, cuando la radiación solar es máxima y las viviendas se encuentran sobrecalentadas, se alcanzan temperaturas superiores a $24^{\circ} \mathrm{C}$ y el EnergyPlus activa el sistema de refrigeración. Sin embargo, en la realidad este problema podría resolverse con ventilación natural, en caso de que las fachadas lo permitan, y por lo tanto este consumo puede considerarse despreciable. 


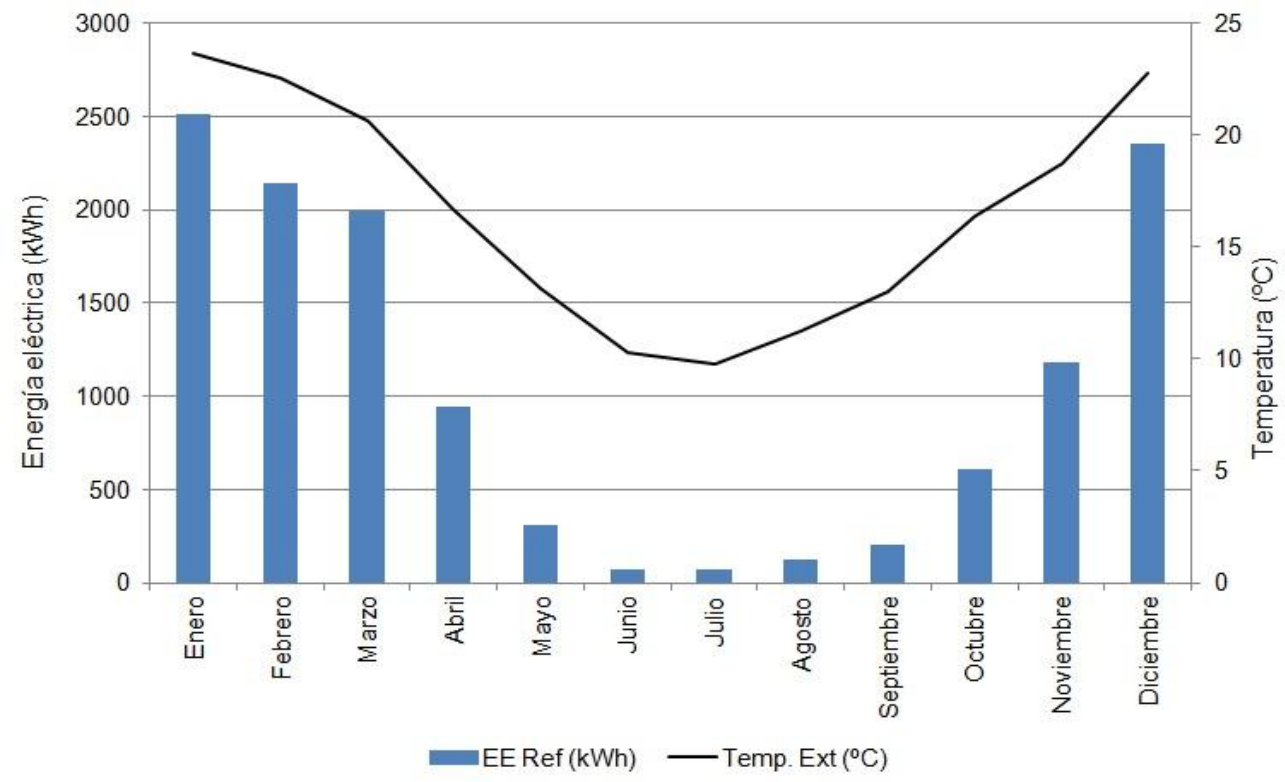

Gráfico IX - 5: Requerimientos mensuales de energía eléctrica para refrigeración (Planta tipo).

Así como para refrigeración, el Energy PLUS también brinda un resumen mensual de calefacción para cada zona. En él puede verse la cantidad de energía necesaria para calefaccionar la zona mes a mes y las temperaturas exteriores de bulbo seco.

El Gráfico IX - 6 muestra la energía total (sensible + latente) necesaria para mantener la zona en condiciones de confort a $22^{\circ} \mathrm{C}$ durante los periodos de ocupación. Como puede verse los meses de junio, julio y agosto son los de mayor demanda, requiriendo alrededor de $3 \mathrm{~m}^{3} / \mathrm{mes}$ para calefaccionar la zona. En septiembre la demanda de gas natural ronda los $2 \mathrm{~m}^{3} / \mathrm{mes}$ mientras que en mayo y octubre la demanda de gas natural para calefacción ronda el metro cúbico. En marzo, abril y noviembre la demanda cae por debajo de la unidad y finalmente es nula durante los meses de enero, febrero y diciembre.

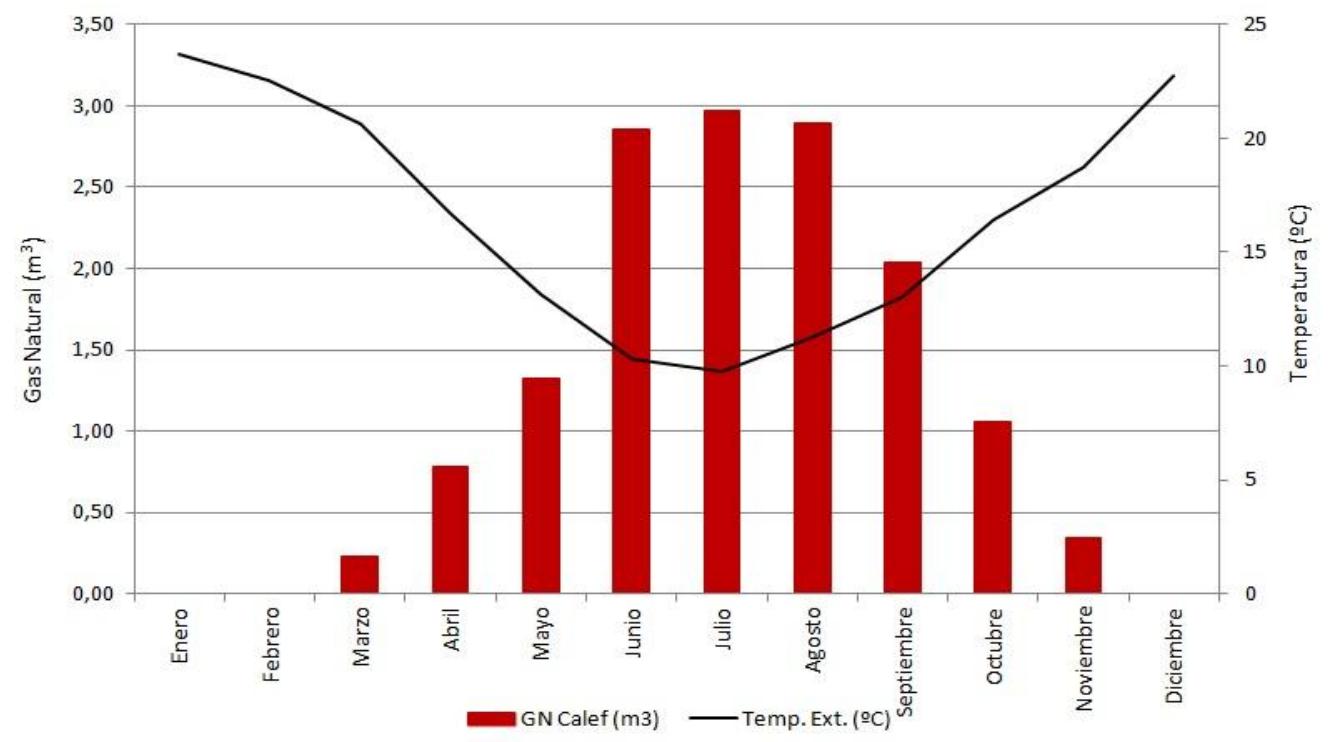

Gráfico IX - 6: Requerimientos mensuales de gas natural para calefacción (Planta tipo).

\subsubsection{Modelo de Referencia}

Para determinar las características de la envolvente del modelo de referencia se utilizaron los mismos datos que para las propuestas de mejora que permitieron verificar el cumplimiento de 
la Norma IRAM 11.900. La envolvente del modelo de base fue mejorada mediante la incorporación de aislamiento térmico en los muros exteriores, así como también en la cubierta del último piso y de las losas de entrepiso (Figura IX - 4) Se agregaron $5 \mathrm{~cm}$. de lana de vidrio en la cámara de aire entre el cielorraso suspendido y la losa de hormigón en pisos y techos, y $10 \mathrm{~cm}$ en la cara exterior de la última planta $\left(\mathrm{K}=0,49 \mathrm{~W} / \mathrm{m}^{2} \cdot \mathrm{K}\right)$, en contacto directo con el aire exterior; $2,5 \mathrm{~cm}$ de poliuretano proyectado en la cara exterior de los muros de cerramiento exterior, medianeros $\left(\mathrm{K}=0,66 \mathrm{~W} / \mathrm{m}^{2} \cdot \mathrm{K}\right)$ e interiores $\left(\mathrm{K}=0,83 \mathrm{~W} / \mathrm{m}^{2} \cdot \mathrm{K}\right)$. Los sistemas de aventamientos fueron reemplazados por otros con $\mathrm{DVH}\left(\mathrm{K}=2,86 \mathrm{~W} / \mathrm{m}^{2} \cdot \mathrm{K}\right)$.

\begin{tabular}{|c|c|c|c|c|}
\hline \multicolumn{3}{|c|}{ Aspectos Dimensionales } & \multicolumn{2}{|c|}{ Detalle constructivo } \\
\hline Sup. Total & $1650 \mathrm{r}$ & $\mathrm{m}^{2}$ & \multirow{3}{*}{\multicolumn{2}{|c|}{$\underbrace{\substack{\text { Carga de ladrillo común } \\
\text { Grava }}}$}} \\
\hline Sup. Habitable & $1405 \mathrm{r}$ & $\mathrm{m}^{2}$ & & \\
\hline Sup. Nucleo & $245 \mathrm{r}$ & $\mathrm{m}^{2}$ & & \\
\hline F. Forma & 0,60 & & \multirow{4}{*}{ 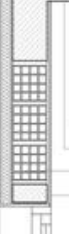 } & \multirow{4}{*}{$\begin{array}{l}\text { Fieltro geotextil } \\
\text { Aislación térmica } \\
\text { Membrana asfáltica } \\
\text { Carpeta cementicia } \\
\text { Contrapiso con pendiente } \\
\text { Estructura } \mathrm{H}^{\circ} \AA^{\circ} \\
\text { Ladrillo hueco } 18 \times 18 \times 33 \mathrm{~cm} \text {. } \\
\text { Revoque interior: grueso + fino }\end{array}$} \\
\hline \multicolumn{3}{|c|}{ Características de la Envolvente } & & \\
\hline k muros ext. & 0,83 & $\mathrm{~W} / \mathrm{m}^{2} \cdot \mathrm{K}$ & & \\
\hline k muros int. & 0,66 & $\mathrm{~W} / \mathrm{m}^{2} \cdot \mathrm{K}$ & & \\
\hline $\mathrm{k}$ techos & 0,49 & $\mathrm{~W} / \mathrm{m}^{2} \cdot \mathrm{K}$ & & $\begin{array}{l}\text { Carpintería de aluminio } \\
\text { s/protección. }\end{array}$ \\
\hline k ventanas & 2,86 & $\mathrm{~W} / \mathrm{m}^{2} \cdot \mathrm{K}$ & & \\
\hline k puertas & 3,501 & $\mathrm{~W} / \mathrm{m}^{2} \cdot \mathrm{K}$ & & \\
\hline \multicolumn{3}{|c|}{ Aspectos Térmicos } & \multirow{2}{*}{ 匧 } & Revoque exterior \\
\hline Gcal & 0,99 & $\mathrm{~W} / \mathrm{m}^{3} \cdot \mathrm{K}$ & & $\begin{array}{l}\text { proyectado c/ hidrófugo } \\
\text { Aislación térmica proyectada }\end{array}$ \\
\hline
\end{tabular}

Figura IX - 4: Resumen de las características del Modelo de Referencia - Viviendas

Al igual que para el Caso Base se procedió a realizar la simulación completa para un período 8.760 horas (un año), tal como recomienda el Apéndice G de la Norma ASHRAE 90.1.

El Energy Plus brinda un informe en el cual distingue los usos finales de la energía para calefacción, refrigeración, iluminación y equipamiento eléctrico. Tal como puede verse en la Tabla IX - 4 las mayores demandas se deben a refrigeración (494,31GJ/año), equipamiento eléctrico (197GJ/año), iluminación (151,66GJ/año) y luego a calefacción (4,16GJ/año). Las mejoras de la envolvente térmica tuvieron un efecto contraproducente en lo que respecta a la demanda de energía eléctrica para refrigeración. El modelo de referencia experimentó una aumento de aproximadamente el 14\%. Este aumento de la demanda de energía eléctrica para refrigeración como consecuencia de la mejora de la envolvente térmica podría deberse a que las ganancias de calor por fuentes internas y la radiación solar encuentran una mayor resistencia para disiparse hacia el exterior, contribuyendo al sobrecalentamiento de los espacios interiores.

Una alternativa viable sería colocar vidrios de baja emisividad en las carpinterías con DVH (K= $\left.1,80 \mathrm{~W} / \mathrm{m}^{2} \cdot \mathrm{K}\right)$, esto permitiría reducir el impacto de la radiación solar sobre el interior de los ambientes. La Tabla IX - 5 muestra los resultados para el modelo de referencia al aplicar estos cambios. Tal como puede verse en dicha tabla, la demanda de energía eléctrica para refrigeración se redujo aproximadamente un $19 \%$.

Por su parte, en lo que respecta a la demanda de energía para calefacción el modelo de referencia con DVH muestra una reducción del $77 \%$ mientras que para el Modelo de Referencia al que se incorporó el sistema de carpinterías con vidrios de baja emisividad, la reducción fue del $54 \%$. 


\begin{tabular}{|r|r|r|r|r|r|r|}
\hline & Electricity [GJ] & Natural Gas [GJ] & Other Fuel [GJ] & District Cooling [G] & District Heating [GJ] & Water [m3] \\
\hline Heating & 0.00 & 0.00 & 0.00 & 0.00 & 4.16 & 0.00 \\
\hline Cooling & 0.00 & 0.00 & 0.00 & 494.31 & 0.00 & 0.00 \\
\hline Interior Lighting & 151.66 & 0.00 & 0.00 & 0.00 & 0.00 & 0.00 \\
\hline Exterior Lighting & 0.00 & 0.00 & 0.00 & 0.00 & 0.00 & 0.00 \\
\hline Interior Equipment & 197.00 & 0.00 & 0.00 & 0.00 & 0.00 & 0.00 \\
\hline Exterior Equipment & 0.00 & 0.00 & 0.00 & 0.00 & 0.00 & 0.00 \\
\hline Fans & 0.00 & 0.00 & 0.00 & 0.00 & 0.00 & 0.00 \\
\hline Pumps & 0.00 & 0.00 & 0.00 & 0.00 & 0.00 & 0.00 \\
\hline Heat Rejection & 0.00 & 0.00 & 0.00 & 0.00 & 0.00 & 0.00 \\
\hline Humidification & 0.00 & 0.00 & 0.00 & 0.00 & 0.00 & 0.00 \\
\hline Heat Recovery & 0.00 & 0.00 & 0.00 & 0.00 & 0.00 & 0.00 \\
\hline Water Systems & 0.00 & 0.00 & 0.00 & 0.00 & 0.00 & 0.00 \\
\hline Refrigeration & 0.00 & 0.00 & 0.00 & 0.00 & 0.00 & 0.00 \\
\hline Generators & 0.00 & 0.00 & 0.00 & 0.00 & 0.00 & 0.00 \\
\hline & & & & & & \\
\hline Total End Uses & 348.67 & 0.00 & 0.00 & 494.31 & 4.16 & 0.00 \\
\hline
\end{tabular}

Note: District heat appears to be the principal heating source based on energy usage.

Tabla IX - 4: Usos finales de la energía para el Modelo de Referencia - Viviendas.

End Uses

\begin{tabular}{|r|r|r|r|r|r|r|}
\hline & Electricity [GJ] & Natural Gas [GJ] & Other Fuel [GJ] & District Cooling [GJ] & District Heating [GJ] & Water [m3] \\
\hline Heating & 0.00 & 0.00 & 0.00 & 0.00 & 8.28 & 0.00 \\
\hline Cooling & 0.00 & 0.00 & 0.00 & 353.94 & 0.00 & 0.00 \\
\hline Interior Lighting & 151.66 & 0.00 & 0.00 & 0.00 & 0.00 & 0.00 \\
\hline Exterior Lighting & 0.00 & 0.00 & 0.00 & 0.00 & 0.00 & 0.00 \\
\hline Interior Equipment & 197.00 & 0.00 & 0.00 & 0.00 & 0.00 & 0.00 \\
\hline Exterior Equipment & 0.00 & 0.00 & 0.00 & 0.00 & 0.00 & 0.00 \\
\hline Fans & 0.00 & 0.00 & 0.00 & 0.00 & 0.00 & 0.00 \\
\hline Pumps & 0.00 & 0.00 & 0.00 & 0.00 & 0.00 & 0.00 \\
\hline Heat Rejection & 0.00 & 0.00 & 0.00 & 0.00 & 0.00 & 0.00 \\
\hline Humidification & 0.00 & 0.00 & 0.00 & 0.00 & 0.00 & 0.00 \\
\hline Heat Recovery & 0.00 & 0.00 & 0.00 & 0.00 & 0.00 & 0.00 \\
\hline Water Systems & 0.00 & 0.00 & 0.00 & 0.00 & 0.00 & 0.00 \\
\hline Refrigeration & 0.00 & 0.00 & 0.00 & 0.00 & 0.00 & 0.00 \\
\hline Generators & 0.00 & 0.00 & 0.00 & 0.00 & 0.00 & 0.00 \\
\hline & & & & & & \\
\hline Total End Uses & 348.67 & 0.00 & 0.00 & 353.94 & & 0.00 \\
\hline
\end{tabular}

Note: District heat appears to be the principal heating source based on energy usage.

Tabla IX - 5: Usos finales de la energía para el Modelo de Referencia (DVH + Low-e) - Viviendas.

En el Gráfico IX - 7 se comparan las demandas de energía para refrigeración para el Modelo de Base y los Modelos de Referencia (con DVH y con DVH + Low-e). Se observa que mientras el Modelo de Referencia al cual se incorporaron carpinterías con DVH experimenta un aumento de la demanda de energía eléctrica para refrigeración con respecto al Modelo de Base, en el 
Modelo de Referencia en el que se implementaron los sistemas de aventanamiento con DVH + Low-e se produce una disminución de la demanda. En todos los casos se observa una pequeña demanda de energía eléctrica para refrigeración incluso en los meses más fríos pero, como se mencionó anteriormente, es despreciable. Para todos los casos, las mayores demandas se dan los meses de diciembre, enero, febrero y marzo. Para el Modelo de Base estas demandas varían entre $2.000 \mathrm{kWh} /$ mes y $2.500 \mathrm{kWh} / \mathrm{mes}$; para el Modelo de Referencia con DVH estas demandas varían entre los $2.250 \mathrm{kWh} / \mathrm{mes}$ y los $3.000 \mathrm{kWh} / \mathrm{mes}$, y finalmente para el Modelo de Referencia con DVH + Low-e las demandas para los meses más rigurosos varían entre los $1.500 \mathrm{kWh} / \mathrm{mes}$ y los $2.000 \mathrm{kWh} / \mathrm{mes}$.

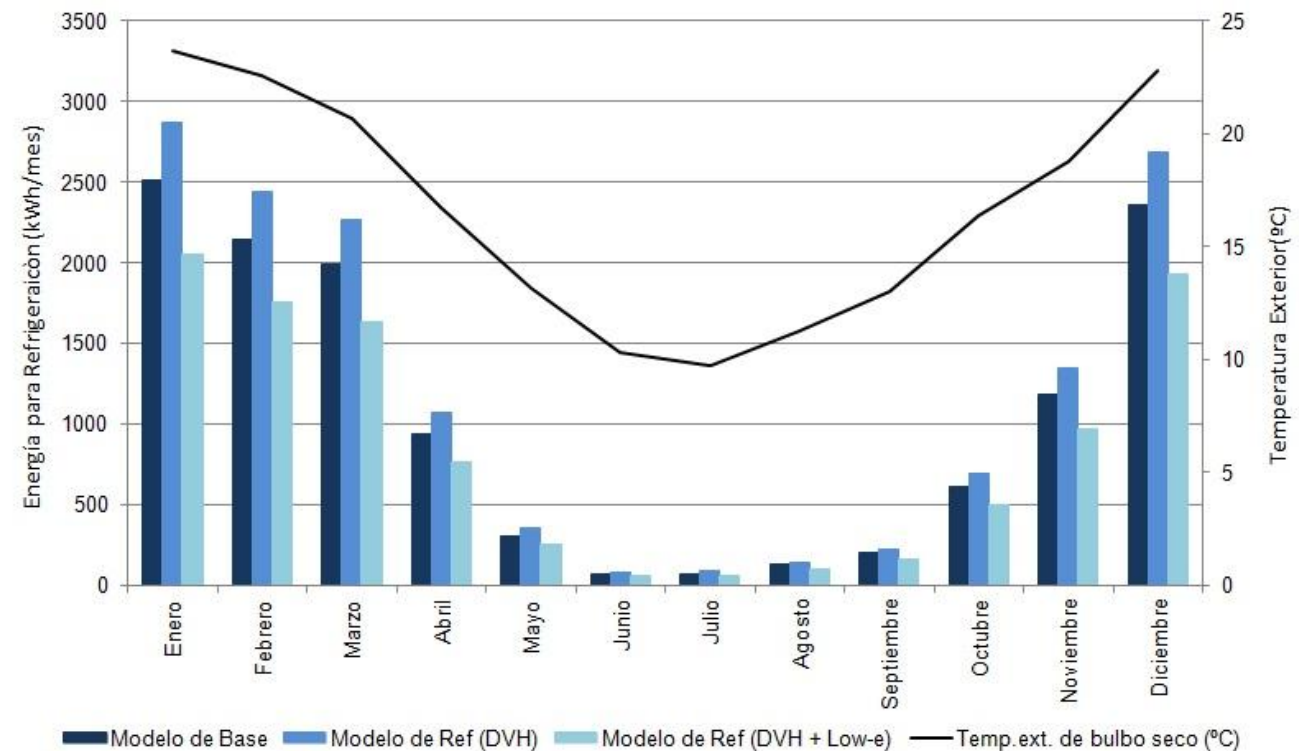

Gráfico IX - 7: Requerimientos mensuales de energía eléctrica para refrigeración (Planta tipo). Comparación del Modelo de Base con los Modelos de Referencia.

El Gráfico IX - 8 por su parte compara las demandas de energía para calefacción para el Modelo de Base y los Modelos de Referencia (con DVH y con DVH + Low-e), se puede observar que en este caso ambos Modelos de Referencian experimentan una reducción de la demanda con respecto al Modelo de Base. Para el Modelo de Referencia con DVH las mayores demandas rondan los $0,50 \mathrm{~m}^{3} / \mathrm{mes}$, mientras que para el Modelo de Referencia con DVH + Low-e para los meses de mayor consumo la demanda de gas natural para calefacción supera el $1 \mathrm{~m}^{3} /$ mes.

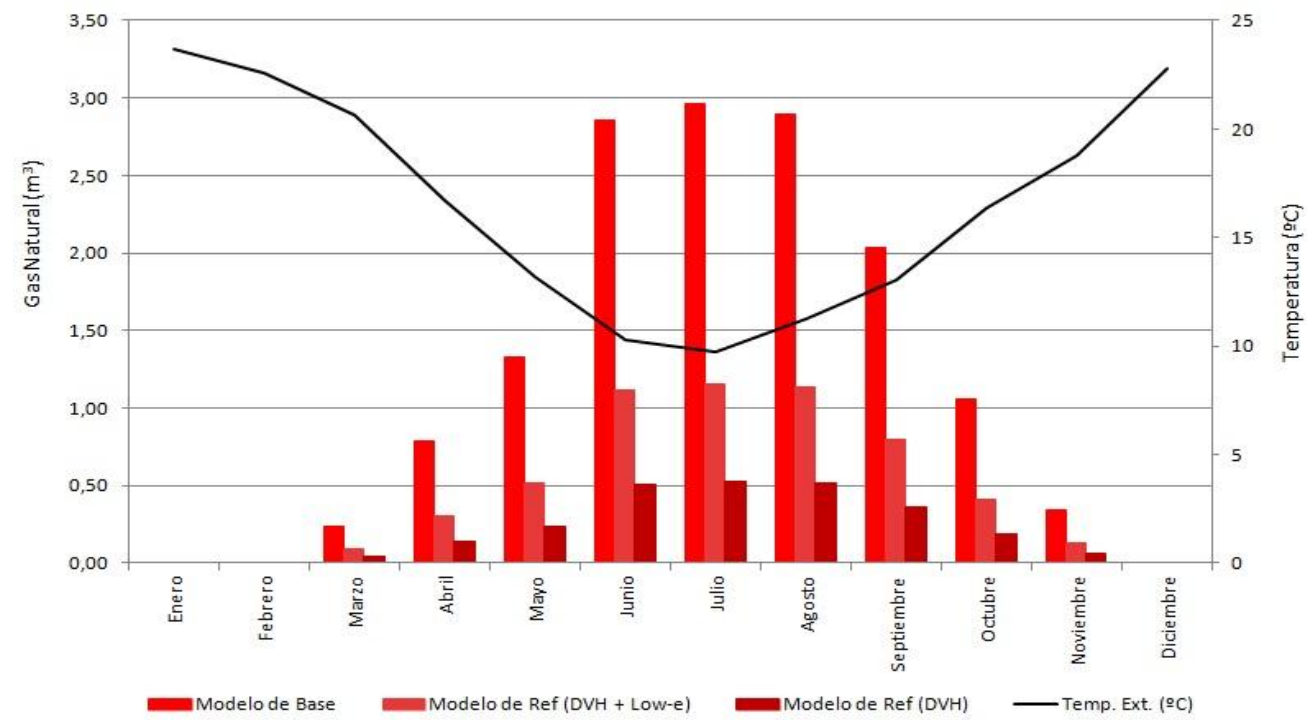

Gráfico IX - 8: Requerimientos mensuales de gas natural para calefacción (Planta tipo). Comparación del Modelo de Base con los Modelos de Referencia. 
La Tabla IX - 6 muestra la energía utilizada por unidad de superficie climatizada para el Modelo de Referencia al cual se aplicaron los sistemas de aventanamiento con DVH + Low-e. Se distingue el uso de los equipos de aire acondicionado, iluminación y otros (equipamiento eléctrico).

Utility Use Per Conditioned Floor Area

\begin{tabular}{|r|r|r|r|r|r|r|}
\hline & Electricity Intensity [MJ/m2] & Natural Gas Intensity [MJ/m2] & Other Fuel Intensity [MJ/m2] & District Cooling Intensity [MJ/m2] & District Heating Intensity [MJ/m2] & Water Intensity [m3/m2] \\
\hline Lighting & 108.01 & 0.00 & 0.00 & 0.00 & & 0.00 \\
\hline HVAC & 0.00 & 0.00 & 0.00 & 252.06 & 0.00 \\
\hline Other & 140.30 & 0.00 & 0.00 & 0.00 & 5.90 & 0.00 \\
\hline Total & 248.30 & 0.00 & 0.00 & 252.06 & 0.00 & 5.90 \\
\hline
\end{tabular}

Tabla IX - 6: Energía utilizada por unidad de superficie acondicionada para el Modelo de Referencia (DVH + Low-e) - Viviendas.

Como se muestra en el Gráfico IX - 9 el mayor porcentaje se debe al funcionamiento de los equipos de Aire Acondicionado (53,22\%). Luego le sigue en importancia la energía destinada al equipamiento eléctrico $(28,95 \%)$ y finalmente el porcentaje menor se debe a iluminación $(22,28 \%)$. Si se lo compara con el mismo gráfico para el Modelo de Base se observa que hay una notable reducción porcentual de la demanda de energía para el acondicionamiento del aire, lo cual contribuye a que se incrementen los valores porcentuales de los demás parámetros analizados.

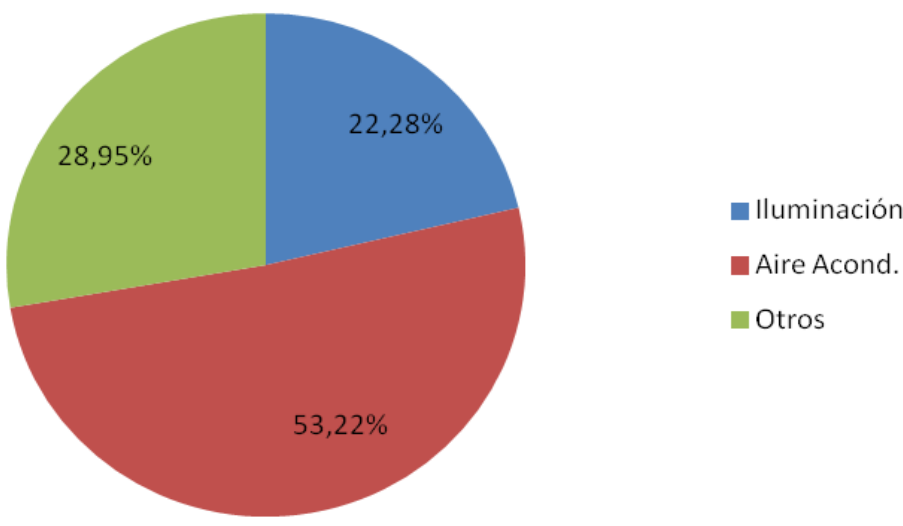

Gráfico IX - 9: Energía utilizada por unidad de superficie acondicionada para el Modelo de Referencia $(D V H+$ Low-e $)$ - Viviendas.

\subsection{Modelo edilicio - Oficinas}

Para la construcción de los modelos de base y de referencia se tomaron las características formales extraídas de las auditorías energéticas. El modelo edilicio que resultó de este análisis se compone de planta baja y diez pisos destinados a oficinas. La superficie de la planta baja se distribuye entre el hall de acceso al edificio, el núcleo de circulación vertical y servicios, y un espacio destinado a oficinas. Las plantas tipo, por su parte, se componen de un espacio central destinado a oficinas, el cual admite un armado flexible, y un espacio destinado al núcleo de circulación y servicios.

Se trata de un modelo de $10 \mathrm{~m}$ de frente y $17 \mathrm{~m}$ de largo, con una superficie total de $1.955 \mathrm{~m}^{2}$, de los cuales $1.660 \mathrm{~m}^{2}$ son climatizados y $295 \mathrm{~m}^{2}$ no. El $60 \%$ de la superficie total de la envolvente es vidriada, la cual se distribuye entre el frente y el contrafrente del edificio, en forma de un curtain wall sin protección solar (Figuras IX -5 y 6 ). 

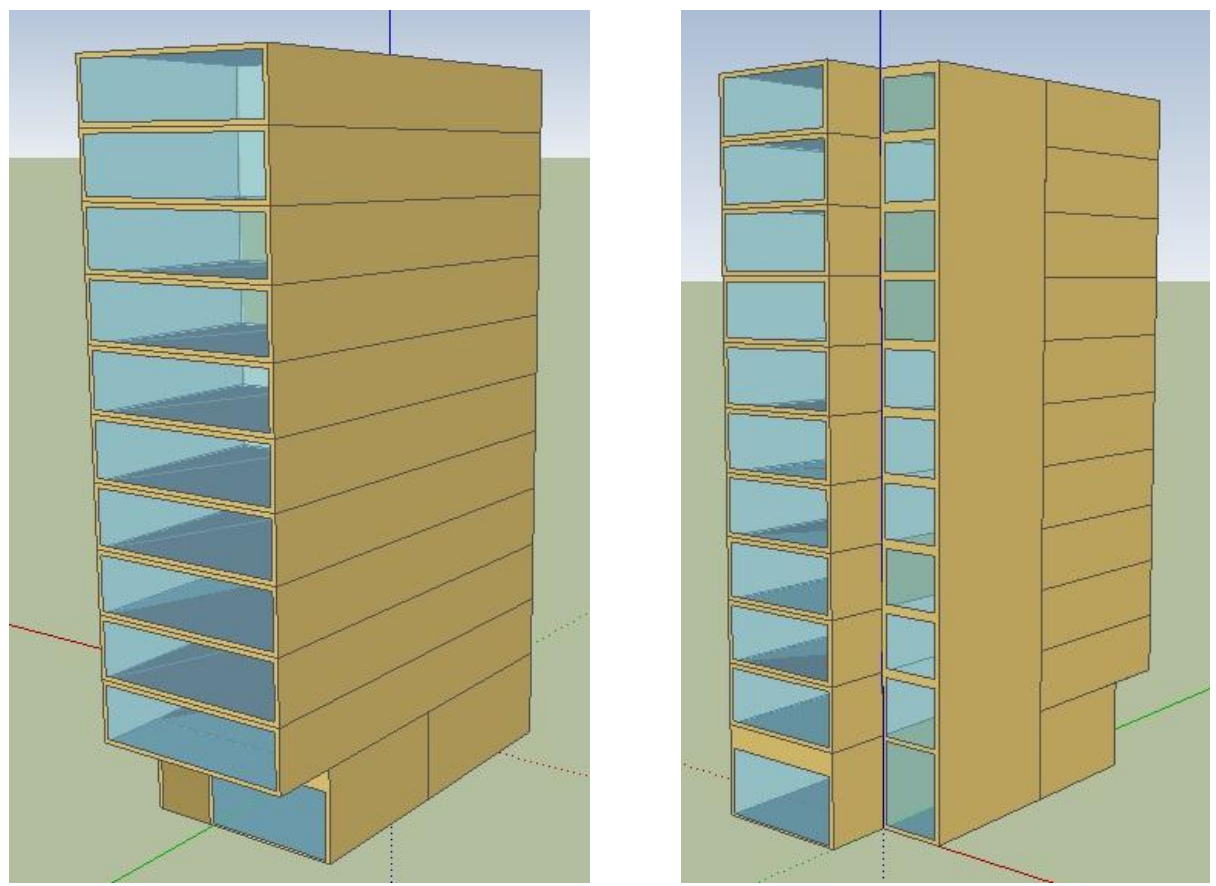

Figuras IX - 5 y 6: Modelo Edilicio construido con Plug-in OpenStudio para SketchUp

Con los datos extraídos de las auditorías energéticas se determinaron las ganancias internas debidas a ocupación, iluminación y equipamiento eléctrico. Se adoptó un factor de ocupación de $8 \mathrm{~m}^{2} /$ persona para los espacios destinados a oficinas. Por su parte, los espacios destinados al núcleo de circulación vertical, al hall de planta baja y a la sala de medidores del modelo se consideraron como no ocupados.

En lo que respecta al equipamiento eléctrico se determinó un factor de $28 \mathrm{~W} / \mathrm{m}^{2}$ para el área destinada a oficinas. El nivel de iluminación artificial adoptado fue de $12 \mathrm{~W} / \mathrm{m}^{2}$ para los espacios comunes (hall de acceso, palier de ascensores, escalera y sala de medidores), y $16 \mathrm{~W} / \mathrm{m}^{2}$ para el sector de oficinas. En ambos casos se consideró únicamente iluminación artificial de bajo consumo.

En función de los datos extraídos de las auditorías energéticas pudieron armarse los "schedules" para ocupación, iluminación, uso de equipamiento eléctrico y de los equipos de aire acondicionado. El Gráfico IX-10 muestra un resumen de la ocupación de las oficinas, distinguiendo días hábiles de fines de semana.

Para cada planta se incorporó un sistema de aire acondicionado que regulara la temperatura interior de las unidades funcionales, dejando al núcleo de circulación vertical y servicios sin climatizar. Se utilizó el sistema "Ideal Loads" por el cual el programa determina las cargas necesarias para mantener a las zonas a temperatura de termostato durante el tiempo establecido según los horarios de uso y considerando los parámetros cargados (régimen de actividad, factor de ocupación, equipamiento eléctrico, iluminación, etc.). La temperatura base de calefacción se fijó en $22^{\circ} \mathrm{C}$ y la temperatura base de refrigeración se fijó en $24^{\circ} \mathrm{C}$. Por su parte, en lo que respecta a las renovaciones de aire, se adoptó un valor de RA= 1 .

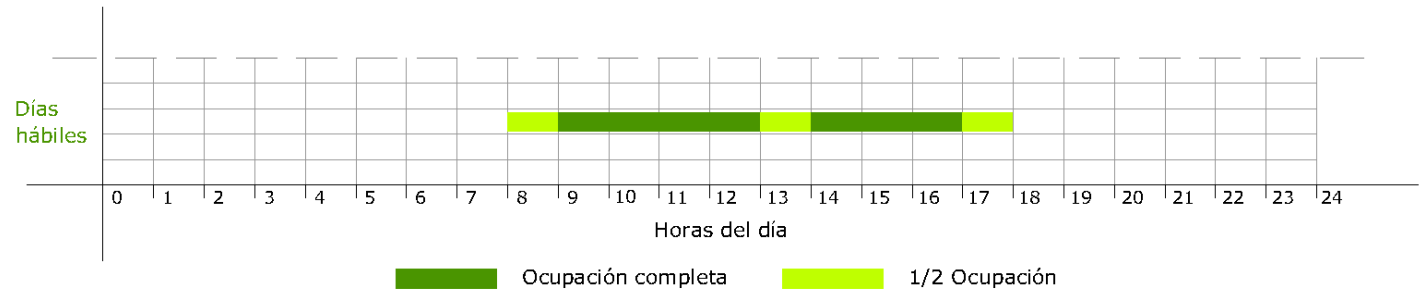

Gráfico IX-10: Bandas horarias de ocupación de las oficinas. 


\subsubsection{Modelo de Base}

Para determinar las características de la envolvente del modelo base se utilizaron los datos extraídos de las auditorías energéticas. La tecnología constructiva del modelo es convencional con estructura de hormigón armado y muros de cerramiento exterior de ladrillos huecos de $18 \times 18 \times 33 \mathrm{~cm}\left(\mathrm{~K}=1,82 \mathrm{~W} / \mathrm{m}^{2} \cdot \mathrm{K}\right)$, sin aislamiento higrotérmico adicional. Por su parte los cerramientos interiores son de ladrillos huecos de $12 \times 18 \times 33 \mathrm{~cm}\left(\mathrm{~K}=2,10 \mathrm{~W} / \mathrm{m}^{2} \cdot \mathrm{K}\right)$, los que separan las oficinas de las áreas comunes, y con tabiquería de Durlock $\left(\mathrm{K}=2,18 \mathrm{~W} / \mathrm{m}^{2} \cdot \mathrm{K}\right)$ aquellos que dividen los ambientes interiores de cada oficina. La cubierta y las losas de entrepiso son de $\mathrm{H}^{\circ} \mathrm{A}^{\circ}$ sin aislamiento higrotérmico adicional $\left(\mathrm{K}=2,34 \mathrm{~W} / \mathrm{m}^{2} \cdot \mathrm{K}\right)$. El curtain wall es de simple vidriado con perfilería de aluminio, sin protección solar $\left(\mathrm{K}=5,80 \mathrm{~W} / \mathrm{m}^{2} \cdot \mathrm{K}\right)$. La Figura IX - 7 muestra un resumen de esta situación.

\begin{tabular}{|c|c|c|c|c|}
\hline \multicolumn{5}{|c|}{ Modelo Base - Oficinas } \\
\hline \multicolumn{3}{|c|}{ Aspectos Dimensionales } & \multicolumn{2}{|c|}{ Detalle constructivo } \\
\hline Sup. Total & 1955 & $\mathrm{~m}^{2}$ & \multirow{3}{*}{ 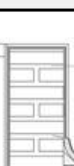 } & \multirow{3}{*}{ Carga de ladrillo común } \\
\hline Sup. Habitable & 1660 & $\mathrm{~m}^{2}$ & & \\
\hline Sup. Nucleo & 295 & $\mathrm{~m}^{2}$ & & \\
\hline F. Forma & 0,45 & & & \multirow{7}{*}{$\begin{array}{l}\text { Membrana asfáltica } \\
\text { Carpeta cementicia } \\
\text { Contrapiso con pendiente } \\
\text { Estructura } \mathrm{H}^{\circ} \mathrm{A}^{\circ}\end{array}$} \\
\hline \multicolumn{3}{|c|}{ Características de la Envolvente } & & \\
\hline k muros ext. & 1,82 & $\mathrm{~W} / \mathrm{m}^{2} \cdot \mathrm{K}$ & & \\
\hline k muros int. & 2,18 & $\mathrm{~W} / \mathrm{m}^{2} \cdot \mathrm{K}$ & & \\
\hline k techos & 2,34 & $\mathrm{~W} / \mathrm{m}^{2} \cdot \mathrm{K}$ & & \\
\hline k curtain wall & 5,80 & $\mathrm{~W} / \mathrm{m}^{2} \cdot \mathrm{K}$ & & \\
\hline k puertas & 3,50 & $\mathrm{~W} / \mathrm{m}^{2} \cdot \mathrm{K}$ & & \\
\hline \multicolumn{3}{|c|}{ Aspectos Térmicos } & & \multirow{2}{*}{$\begin{array}{l}\text { Curtain Wall vidrio simple } \\
\text { s/protección. }\end{array}$} \\
\hline Gcal & 1,53 & $\mathrm{~W} / \mathrm{m}^{3} \cdot \mathrm{K}$ & & \\
\hline
\end{tabular}

Figura IX - 7: Resumen de las características del Modelo Base - Oficinas.

Una vez cargados todos los datos mencionados se procedió a realizar la simulación completa para un período 8.760 horas (un año), tal como recomienda el Apéndice $\mathrm{G}$ de la Norma ASHRAE 90.1. El gráfico que sigue a continuación muestra la superficie total del modelo, distinguiendo el área climatizada del área no climatizada. El núcleo de circulación vertical representa aproximadamente el $15 \%$ del total de la superficie total del modelo (Gráfico IX - 11).

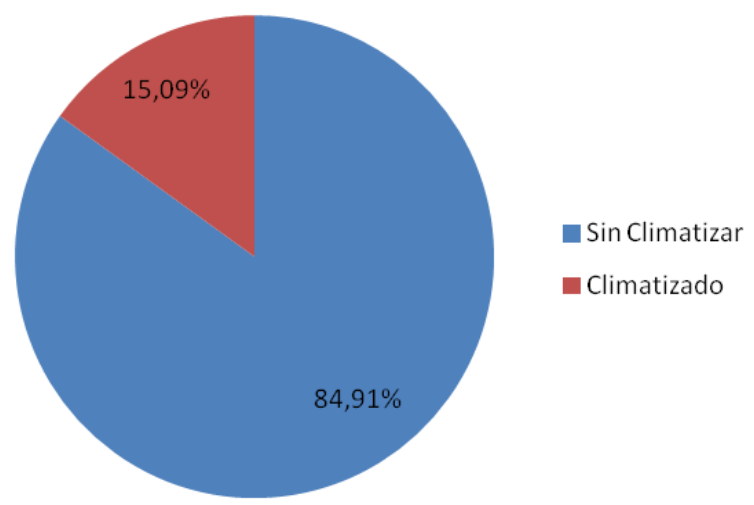

Gráfico IX - 11: Superficie climatizada y no climatizada.

La Tabla IX - 7 distingue los usos finales de la energía para calefacción, refrigeración, iluminación y equipamiento eléctrico. Tal como puede verse en esta tabla las mayores demandas se deben a refrigeración (496,98GJ/año), equipamiento eléctrico (222,76GJ/año), iluminación (133,93GJ/año) y luego a calefacción (11,32GJ/año). 


\begin{tabular}{|r|r|r|r|r|r|r|}
\hline & Electricity [GJ] & Natural Gas [GJ] & Other Fuel [GJ] & District Cooling [GJ] & District Heating [GJ] & Water [m3] \\
\hline Heating & 0.00 & 0.00 & 0.00 & 0.00 & 11.32 & 0.00 \\
\hline Cooling & 0.00 & 0.00 & 0.00 & 496.98 & 0.00 & 0.00 \\
\hline Interior Lighting & 133.93 & 0.00 & 0.00 & 0.00 & 0.00 & 0.00 \\
\hline Exterior Lighting & 0.00 & 0.00 & 0.00 & 0.00 & 0.00 & 0.00 \\
\hline Interior Equipment & 222.76 & 0.00 & 0.00 & 0.00 & 0.00 & 0.00 \\
\hline Exterior Equipment & 0.00 & 0.00 & 0.00 & 0.00 & 0.00 & 0.00 \\
\hline Fans & 0.00 & 0.00 & 0.00 & 0.00 & 0.00 & 0.00 \\
\hline Pumps & 0.00 & 0.00 & 0.00 & 0.00 & 0.00 & 0.00 \\
\hline Heat Rejection & 0.00 & 0.00 & 0.00 & 0.00 & 0.00 & 0.00 \\
\hline Humidification & 0.00 & 0.00 & 0.00 & 0.00 & 0.00 & 0.00 \\
\hline Heat Recovery & 0.00 & 0.00 & 0.00 & 0.00 & 0.00 & 0.00 \\
\hline Water Systems & 0.00 & 0.00 & 0.00 & 0.00 & 0.00 & 0.00 \\
\hline Refrigeration & 0.00 & 0.00 & 0.00 & 0.00 & 0.00 & 0.00 \\
\hline Generators & 0.00 & 0.00 & 0.00 & 0.00 & 0.00 & 0.00 \\
\hline & & & & & 11.32 & 0.00 \\
\hline Total End Uses & 356.69 & 0.00 & 0.00 & 496.98 & &
\end{tabular}

Note: District heat appears to be the principal heating source based on energy usage.

Tabla IX - 7: Usos finales de la energía para el Modelo de Base - Oficinas.

El Gráfico IX - 12 muestra un resumen de esta situación. En él puede verse que la demanda de energía para refrigeración representa más del $50 \%$ del total de la demanda de energía del modelo.

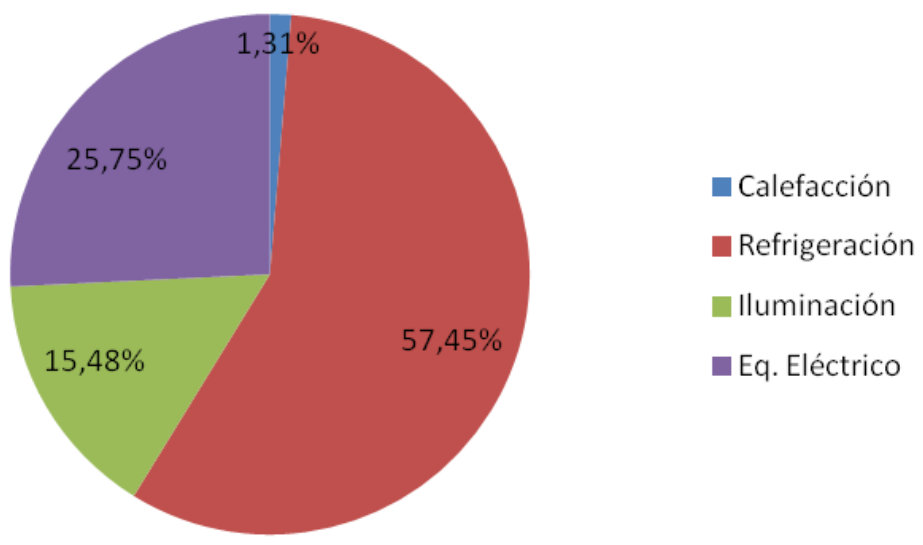

Gráfico IX - 12: Usos finales de la energía. Modelo de Base - Oficinas.

El informe suministrado por el Energy PLUS también muestra la energía utilizada por unidad de superficie climatizada. En este caso, tal como lo muestra la Tabla IX - 8, se distingue el uso de los equipos de aire acondicionado, iluminación y otros (equipamiento eléctrico). 
Utility Use Per Conditioned Floor Area

\begin{tabular}{|r|r|r|r|r|r|r|}
\hline & Electricity Intensity [MJ/m2] & Natural Gas Intensity [MJ/m2] & Other Fuel Intensity [MJ/m2] & District Cooling Intensity [MJ/m2] & District Heating Intensity [MJ/m2] & Water Intensity [m3/m2] \\
\hline Lighting & 91.48 & 0.00 & 0.00 & 0.00 & 0.00 & \\
\hline HVAC & 0.00 & 0.00 & 0.00 & 339.47 & 0.00 \\
\hline Other & 152.16 & 0.00 & 0.00 & 0.00 & 0.00 & 7.74 \\
\hline Total & 243.64 & 0.00 & 0.00 & 339.47 & 0.00 & 0.00 \\
\hline
\end{tabular}

Tabla IX - 8: Energía utilizada por unidad de superficie acondicionada para el Modelo Base - Oficinas

Como se muestra en el Gráfico IX - 13 el mayor porcentaje se debe al funcionamiento de los equipos de Aire Acondicionado (58,77\%). Luego le sigue en importancia la energía destinada al equipamiento eléctrico $(25,75 \%)$ y finalmente el porcentaje menor se debe a iluminación $(15,48 \%)$.

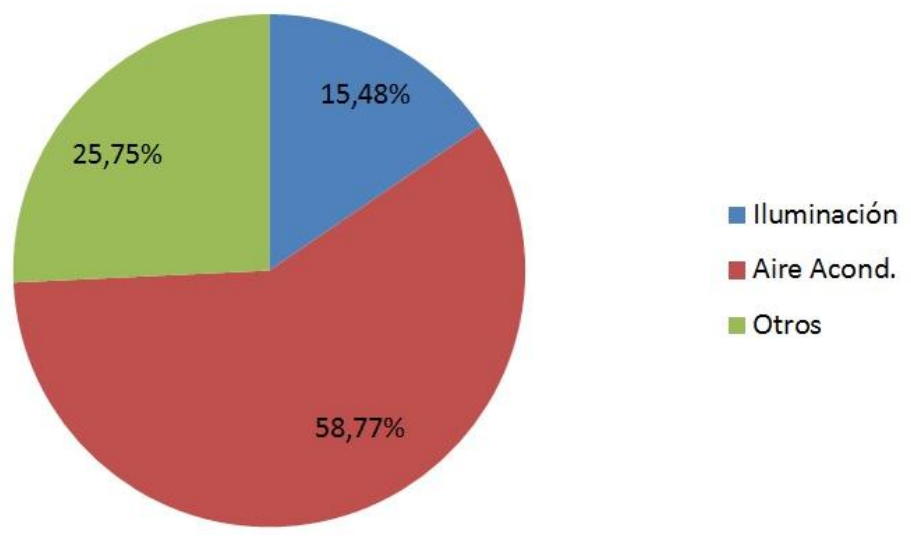

Gráfico IX - 13: Energía utilizada por unidad de superficie acondicionada para el Modelo Base - Oficinas.

El informe suministrado por el Energy PLUS también muestra un resumen de las horas en las que no se alcanzó el confort o la temperatura base de calefacción y refrigeración. Según puede verse en la siguiente tabla en todo momento durante el período de ocupación se alcanzó la temperatura base de calefacción y de refrigeración que propone el Apéndice $G$ de la Norma ASHRAE 90.1. Por otra parte no se cumplieron con los niveles de confort propuestos por ASHRAE 55 -2004 durante aproximadamente 575,75 horas (Tabla IX - 9).

Comfort and Setpoint Not Met Summary

\begin{tabular}{|l|r|}
\hline & Degrees [deltaC] \\
\hline Tolerance for Time Heating Setpoint Not Met & 0.20 \\
\hline Tolerance for Time Cooling Setpoint Not Met & 0.20 \\
\hline
\end{tabular}

\begin{tabular}{|r|r|}
\hline & Facility [Hours] \\
\hline Time Set Point Not Met During Occupied Heating & 0.00 \\
\hline Time Set Point Not Met During Occupied Cooling & 0.00 \\
\hline Time Not Comfortable Based on Simple ASHRAE 55-2004 & 575.75 \\
\hline
\end{tabular}

Note $1:$ An asterisk $\left({ }^{*}\right)$ indicates that the feature is not yet implemented.

Tabla IX - 9: Resumen confort, temperatura base de calefacción, temperatura base refrigeración.

El Energy PLUS también brinda un resumen mensual de refrigeración para cada zona. En el puede verse la cantidad de energía necesaria para refrigerar la zona mes a mes, las temperaturas exteriores de bulbo seco y bulbo húmedo, y las ganancias internas de calor latente.

El Gráfico IX - 14 muestra la cantidad de energía total (sensible + latente) necesaria para mantener la zona refrigerada a la temperatura de $24^{\circ} \mathrm{C}$ en relación a la temperatura exterior de bulbo seco. Como puede verse los meses de enero, febrero, marzo y diciembre son los de mayor demanda de energía eléctrica para refrigeración, superando ampliamente los $2.000 \mathrm{kWh} / \mathrm{mes}$ (en enero se aproxima los $3.000 \mathrm{kWh} / \mathrm{mes}$ ). Durante los meses de abril y noviembre la demanda se mantiene entre los $1.000 \mathrm{kWh} / \mathrm{mes}$ y los $1.500 \mathrm{kWh} / \mathrm{mes}$. En octubre por su parte la demanda de energía eléctrica para refrigeración ronda los $750 \mathrm{kWh} / \mathrm{mes}$, en mayo y septiembre por su parte la demanda no alcanza los $500 \mathrm{kWh} / \mathrm{mes}$. Asimismo se puede 
observar que hay un pequeño consumo de refrigeración incluso en los meses más fríos (junio, julio y agosto). Esto se debe a que en las horas centrales del día, cuando la radiación solar es máxima y las viviendas se encuentran sobrecalentadas, se alcanzan temperaturas superiores a $24^{\circ} \mathrm{C}$ y el EnergyPlus activa el sistema de refrigeración. Sin embargo, en la realidad este problema se resuelve con ventilación natural y por lo tanto esta demanda puede considerarse despreciable.

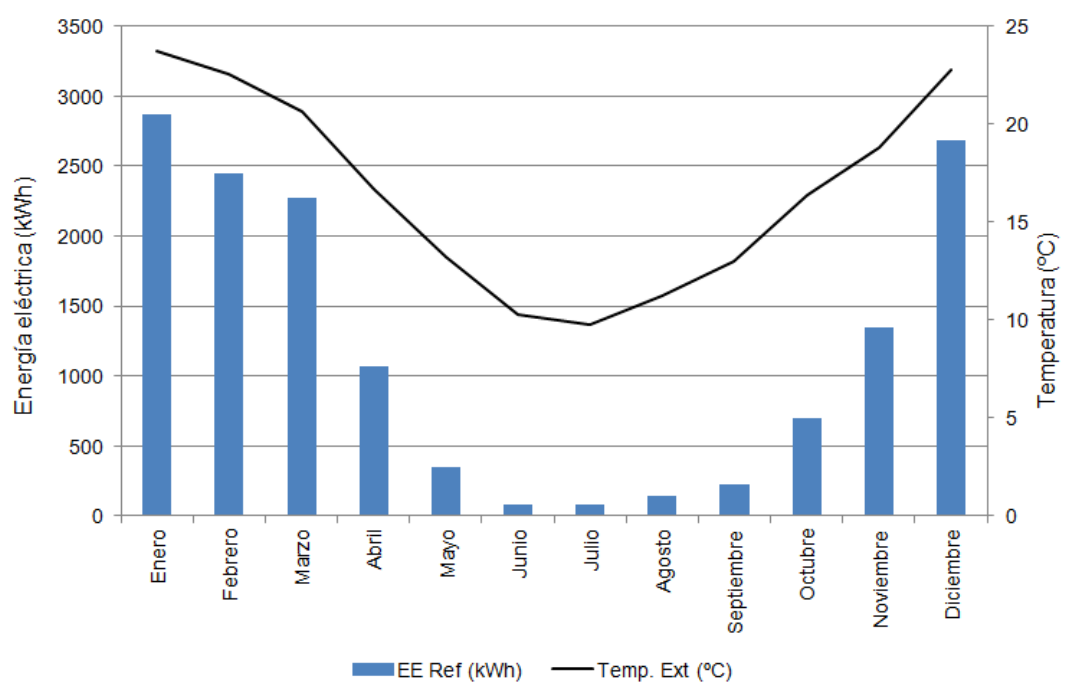

Gráfico IX - 14: Requerimientos mensuales de energía eléctrica para refrigeración (Planta tipo).

Así como para refrigeración, el Energy PLUS también brinda un resumen mensual de calefacción para cada zona. En él puede verse la cantidad de energía necesaria para calefaccionar la zona mes a mes y las temperaturas exteriores de bulbo seco.

El Gráfico IX - 15 muestra la energía total (sensible + latente) necesaria para mantener la zona en condiciones de confort a $22^{\circ} \mathrm{C}$ durante los periodos de ocupación. Como puede verse los meses de junio, julio y agosto son los de mayor demanda, requiriendo alrededor de $3,50 \mathrm{~m}^{3} / \mathrm{mes}$ para calefaccionar la zona. En septiembre la demanda de gas natural ronda los $2,50 \mathrm{~m}^{3} / \mathrm{mes}$ mientras que en mayo y octubre la demanda de gas natural para calefacción ronda los $1,50 \mathrm{~m}^{3} / \mathrm{mes}$. En abril la demanda de gas natural no alcanza el metro cúbico. En marzo y noviembre la demanda permanece por debajo de la unidad y finalmente es nula durante los meses de enero, febrero y diciembre.

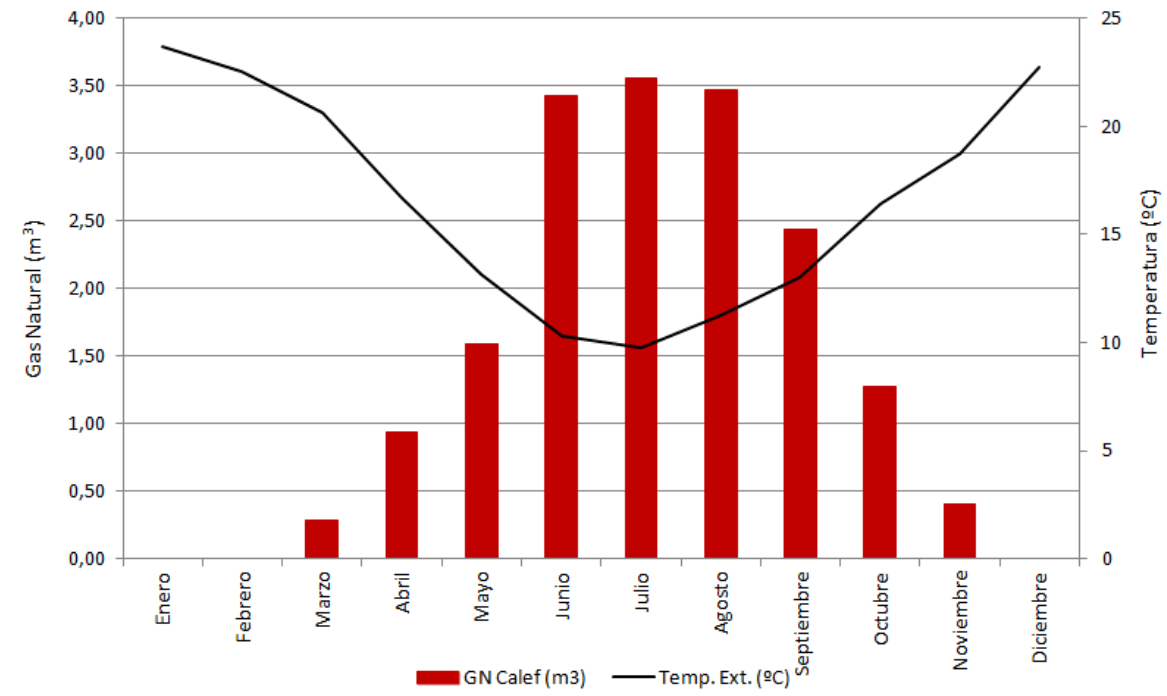

Gráfico IX - 15: Requerimientos mensuales de gas natural para calefacción (Planta tipo). 


\subsubsection{Modelo de Referencia}

Para determinar las características de la envolvente del modelo de referencia se utilizaron los mismos datos que para las propuestas de mejora que permitieron verificar el cumplimiento de la Norma IRAM 11.900. La envolvente del modelo de base fue mejorada mediante la incorporación de aislamiento térmico en los muros exteriores, así como también en la cubierta del último piso y de las losas de entrepiso (Figura IX - 8) Se agregaron $5 \mathrm{~cm}$ de lana de vidrio en la cámara de aire entre el cielorraso suspendido y la losa de hormigón en pisos y techos, y $10 \mathrm{~cm}$ en la cara exterior de la última planta $\left(\mathrm{K}=0,49 \mathrm{~W} / \mathrm{m}^{2} \cdot \mathrm{K}\right)$, en contacto directo con el aire exterior; $2,5 \mathrm{~cm}$ de poliuretano proyectado en la cara exterior de los muros de cerramiento exterior, medianeros $\left(\mathrm{K}=0,66 \mathrm{~W} / \mathrm{m}^{2} \cdot \mathrm{K}\right)$ e interiores $\left(\mathrm{K}=0,83 \mathrm{~W} / \mathrm{m}^{2} \cdot \mathrm{K}\right)$. Los sistemas de aventamientos fueron reemplazados por otros con DVH + Low-e $\left(K=1,80 \mathrm{~W} / \mathrm{m}^{2} \cdot \mathrm{K}\right)$.

Al igual que para el Caso Base se procedió a realizar la simulación completa para un período 8.760 horas (un año), tal como recomienda el Apéndice G de la Norma ASHRAE 90.1.

Como se mencionó anteriormente, el Energy Plus brinda un informe en el cual distingue los usos finales de la energía para calefacción, refrigeración, iluminación y equipamiento eléctrico. Tal como puede verse en la Tabla IX - 10 las mayores demandas se deben a refrigeración $(380,16 \mathrm{GJ} / a n ̃ o)$, equipamiento eléctrico (222,76GJ/año), iluminación (133,93GJ/año) y luego a calefacción (4,39GJ/año). Las mejoras de la envolvente térmica favorecieron una reducción del $23,5 \%$ de la demanda de energía eléctrica para refrigeración y una reducción del $61,2 \%$ para calefacción.

\begin{tabular}{|c|c|c|c|c|}
\hline \multicolumn{5}{|c|}{ Modelo Base - Oficinas } \\
\hline \multicolumn{3}{|c|}{ Aspectos Dimensionales } & \multicolumn{2}{|c|}{ Detalle constructivo } \\
\hline Sup. Total & 1955 & $\mathrm{~m}^{2}$ & \multirow{3}{*}{\multicolumn{2}{|c|}{$\begin{array}{l}\text { Carga de ladrillo común } \\
\text { Grava }\end{array}$}} \\
\hline Sup. Habitable & 1660 & $\mathrm{~m}^{2}$ & & \\
\hline Sup. Nucleo & 295 & $m^{2}$ & & \\
\hline F. Forma & 0,45 & & \multicolumn{2}{|c|}{ ( } \\
\hline \multicolumn{3}{|c|}{ Características de la Envolvente } & & \\
\hline k muros ext. & 0,66 & $\mathrm{~W} / \mathrm{m}^{2} \cdot \mathrm{K}$ & \multirow{7}{*}{\multicolumn{2}{|c|}{$\begin{array}{l}\text { Fieltro geotextil } \\
\text { Aislación térmica } \\
\text { Membrana asfáltica } \\
\text { Carpeta cementicia } \\
\text { Contrapiso con pendiente } \\
\text { Estructura } \mathrm{H}^{\circ} \mathrm{A}^{\circ} \\
\text { Curtain Wall } \\
\text { (DVH + Low-e) }\end{array}$}} \\
\hline k muros int. & 0,83 & $\mathrm{~W} / \mathrm{m}^{2} \cdot \mathrm{K}$ & & \\
\hline $\mathrm{k}$ techos & 0,49 & $\mathrm{~W} / \mathrm{m}^{2} \cdot \mathrm{K}$ & & \\
\hline k curtain wall & 1,80 & $\mathrm{~W} / \mathrm{m}^{2} \cdot \mathrm{K}$ & & \\
\hline k puertas & 3,50 & $\mathrm{~W} / \mathrm{m}^{2} \cdot \mathrm{K}$ & & \\
\hline \multicolumn{3}{|c|}{ Aspectos Térmicos } & & \\
\hline Gcal & 0,99 & $\mathrm{~W} / \mathrm{m}^{3} \cdot \mathrm{K}$ & & \\
\hline
\end{tabular}

Figura IX - 8: Resumen de las características del Modelo de Referencia - Oficinas. 
End Uses

\begin{tabular}{|r|r|r|r|r|r|r|}
\hline & Electricity [GJ] & Natural Gas [GJ] & Other Fuel [GJ] & District Cooling [GJ] & District Heating [GJ] & Water [m3] \\
\hline Heating & 0.00 & 0.00 & 0.00 & 0.00 & 4.39 & 0.00 \\
\hline Cooling & 0.00 & 0.00 & 0.00 & 380.16 & 0.00 & 0.00 \\
\hline Interior Lighting & 133.93 & 0.00 & 0.00 & 0.00 & 0.00 & 0.00 \\
\hline Exterior Lighting & 0.00 & 0.00 & 0.00 & 0.00 & 0.00 & 0.00 \\
\hline Interior Equipment & 222.76 & 0.00 & 0.00 & 0.00 & 0.00 & 0.00 \\
\hline Exterior Equipment & 0.00 & 0.00 & 0.00 & 0.00 & 0.00 & 0.00 \\
\hline Fans & 0.00 & 0.00 & 0.00 & 0.00 & 0.00 & 0.00 \\
\hline Pumps & 0.00 & 0.00 & 0.00 & 0.00 & 0.00 & 0.00 \\
\hline Heat Rejection & 0.00 & 0.00 & 0.00 & 0.00 & 0.00 & 0.00 \\
\hline Humidification & 0.00 & 0.00 & 0.00 & 0.00 & 0.00 & 0.00 \\
\hline Heat Recovery & 0.00 & 0.00 & 0.00 & 0.00 & 0.00 & 0.00 \\
\hline Water Systems & 0.00 & 0.00 & 0.00 & 0.00 & 0.00 & 0.00 \\
\hline Refrigeration & 0.00 & 0.00 & 0.00 & 0.00 & 0.00 & 0.00 \\
\hline Generators & 0.00 & 0.00 & 0.00 & 0.00 & 0.00 & 0.00 \\
\hline Total End Uses & 356.69 & 0.00 & 0.00 & 380.16 & 9.53 & 0.00 \\
\hline
\end{tabular}

Note: District heat appears to be the principal heating source based on energy usage.

Tabla IX - 10: Usos finales de la energía para el Modelo de Referencia - Oficinas.

En el Gráfico IX - 16 se comparan las demandas de energía para refrigeración para el Modelo de Base y el Modelo de Referencia. Se observa la notable reducción de la demanda de energía para refrigeración en el Modelo de Referencia. Cabe destacar que si bien en ambos casos se observa un pequeño consumo de energía eléctrica para refrigeración incluso en los meses más fríos, este puede considerarse despreciable. Para ambos casos, las mayores demandas se dan los meses de diciembre, enero, febrero y marzo. Para el Modelo de Base estas demandas varían entre $2.250 \mathrm{kWh} / \mathrm{mes}$ y $3.000 \mathrm{kWh} / \mathrm{mes}$ mientras que para el Modelo de Referencia las demandas varían entre los $1.750 \mathrm{kWh} / \mathrm{mes}$ y los $2.200 \mathrm{kWh} / \mathrm{mes}$.

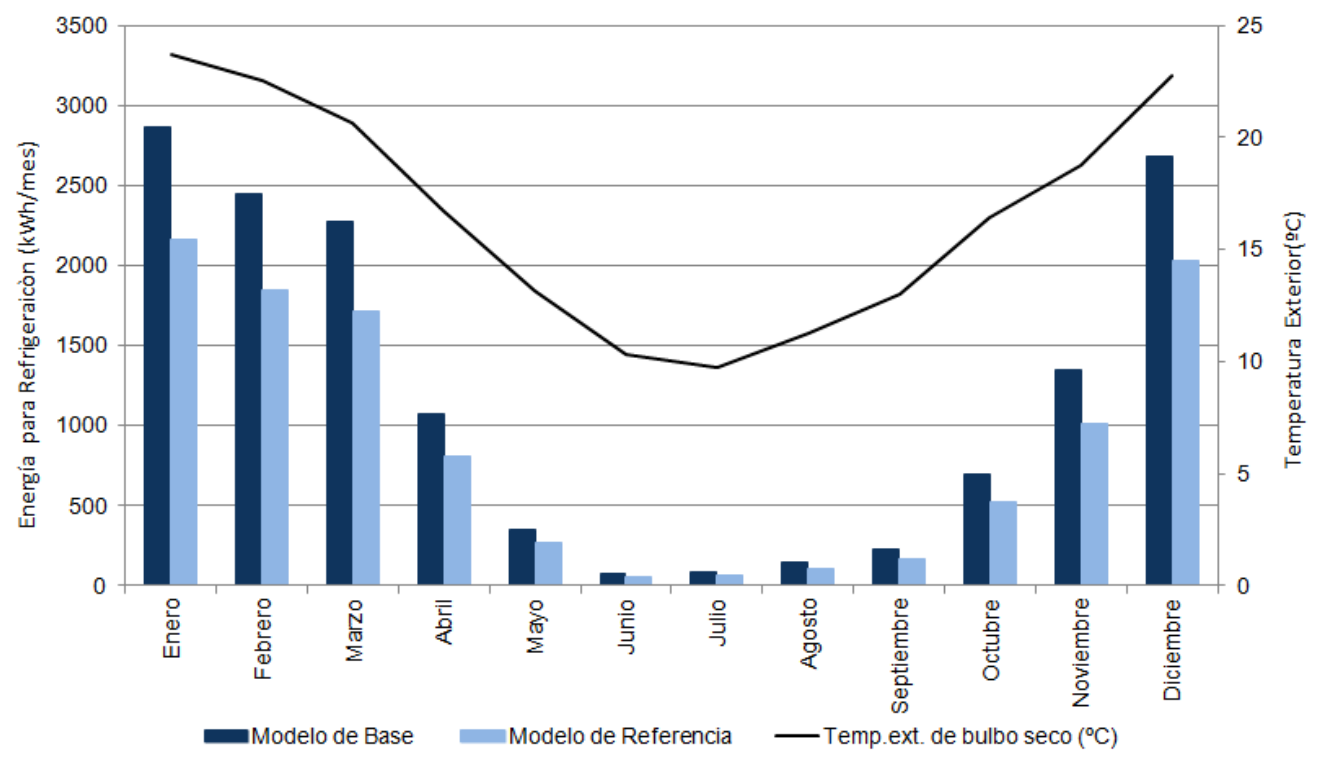

Gráfico IX - 16: Requerimientos mensuales de energía eléctrica para refrigeración (Planta tipo). Comparación del Modelo de Base con el Modelo de Referencia. 
El Gráfico IX - 17 por su parte compara las demandas de energía para calefacción para el Modelo de Base y el Modelo de Referencia. Para el Modelo de Base las mayores demandas (junio, julio y agosto) rondan los $3,50 \mathrm{~m}^{3} / \mathrm{mes}$, mientras que para el Modelo de Referencia las estos valores rondan los $1,50 \mathrm{~m}^{3} / \mathrm{mes}$.

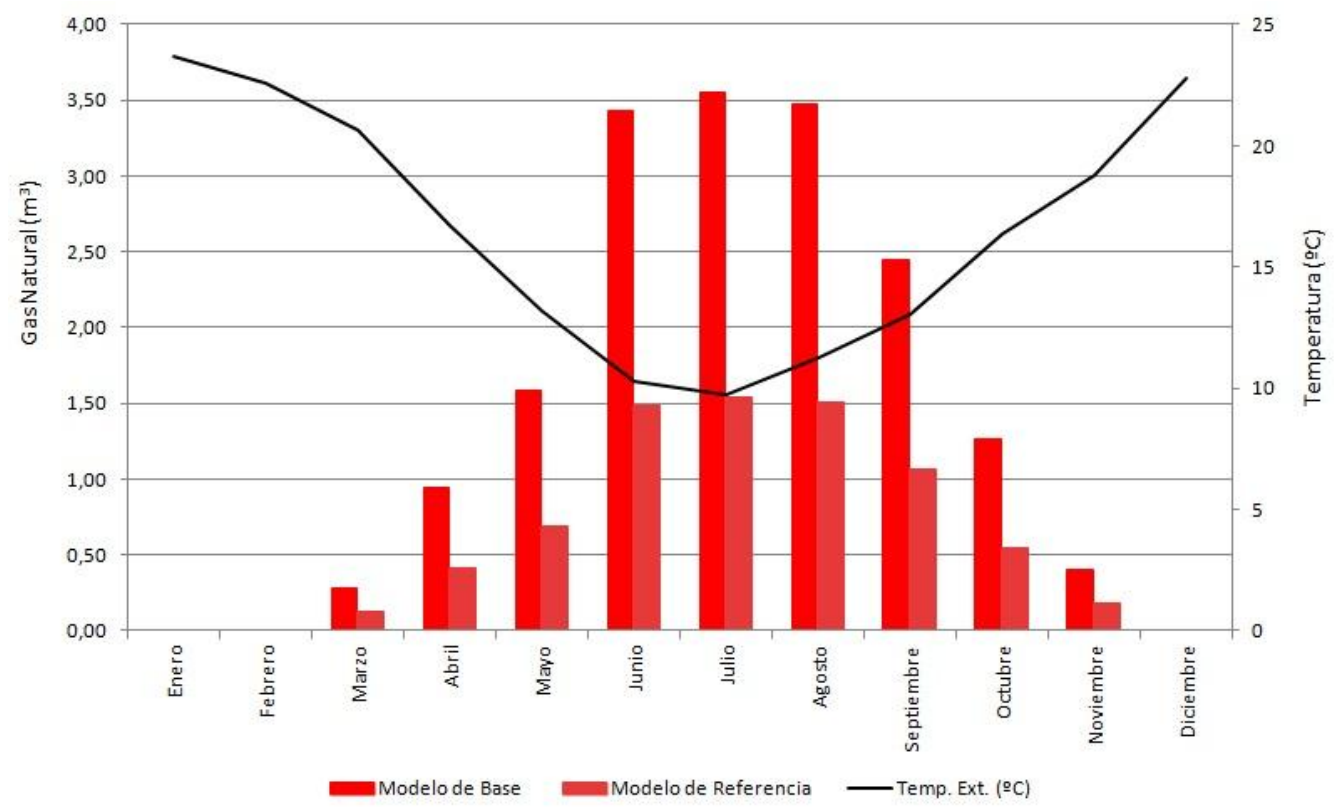

Gráfico IX - 17: Requerimientos mensuales de gas natural para calefacción (Planta tipo). Comparación del Modelo de Base con el Modelo de Referencia.

La Tabla IX - 11 muestra la energía utilizada por unidad de superficie climatizada para el Modelo de Referencia. Se distingue el uso de los equipos de aire acondicionado, iluminación y otros (equipamiento eléctrico).

Utility Use Per Conditioned Floor Area

\begin{tabular}{|r|r|r|r|r|r|r|}
\hline & Electricity Intensity [MJ/m2] & Natural Gas Intensity [MJ/m2] & Other Fuel Intensity [MJ/m2] & District Cooling Intensity [MJ/m2] & District Heating Intensity [MJ/m2] & Water Intensity [m3/m2] \\
\hline Lighting & 91.48 & 0.00 & 0.00 & 0.00 & 259.67 & 0.00 \\
\hline HVAC & 0.00 & 0.00 & 0.00 & 0.00 & 0.00 \\
\hline Other & 152.16 & 0.00 & 0.00 & 259.67 & 3.00 & 0.00 \\
\hline Total & 243.64 & 0.00 & 0.00 & 0.00 & 3.00 \\
\hline
\end{tabular}

Tabla IX - 11: Energía utilizada por unidad de superficie acondicionada para el Modelo de Referencia Oficinas.

Como se muestra en el Gráfico IX - 18 el mayor porcentaje se debe al funcionamiento de los equipos de Aire Acondicionado (54,19\%). Luego le sigue en importancia la energía destinada al equipamiento eléctrico $(31,39 \%)$ y finalmente el porcentaje menor se debe a iluminación $(18,87 \%)$. Si se lo compara con el mismo gráfico para el Modelo de Base se observa que hay una notable reducción porcentual de la demanda de energía para el acondicionamiento del aire, lo cual contribuye a que se incrementen los valores porcentuales de los demás parámetros analizados. 


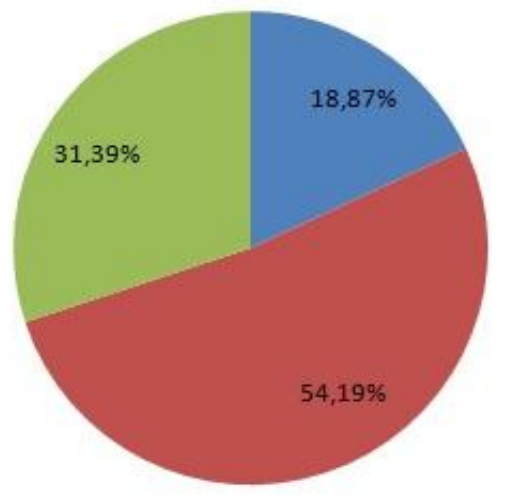

- lluminación

aire Acond

otros

Gráfico IX - 18: Energía utilizada por unidad de superficie acondicionada para el Modelo de Referencia Oficinas. 


\section{CAPÍTULO X \\ MODELOS DE AHORRO DE ENERGÍA}

\subsection{Discusión de los resultados obtenidos}

La información reunida durante las auditorías energéticas y el consiguiente procesamiento de los datos mediante el AuditCAD, el Psiconf, el Excel y el EnergyPlus permitieron conocer el comportamiento higrotérmico interior de las unidades auditadas, y determinar indicadores de consumo de gas natural para calefacción y de energía eléctrica para refrigeración, para el tipo edilicio estudiado.

Los resultados de estos estudios fueron presentados para su discusión en distintos congresos y en el Subcomité de Acondicionamiento Térmico del Instituto Argentino de Normalización y Certificación, donde actualmente se está discutiendo la propuesta llevada por el LAyHS para la modificación de la Norma IRAM 11.604 "Aislamiento térmico de edificios. Verificación de sus condiciones higrotérmicas. Coeficiente volumétrico $\mathrm{G}$ de pérdidas de calor. Cálculo y valores límites".

Los datos que se muestran a continuación derivan de la discusión de los avances presentados en los distintos congresos e incluso en el Subcomité de Acondicionamiento Térmico de IRAM, en los cuales el intercambio con profesionales e investigadores de otras disciplinas ha contribuido a enriquecer esta investigación.

El Gráfico X - 1 muestra la correlación entre el volumen y la carga térmica anual obtenida mediante el AuditCAD para los edificios auditados tal como están construidos en la actualidad, y para las propuestas de mejoras que siguen los criterios del diseño ambientalmente consciente (DAC). Como puede verse en dicho gráfico al aplicar estos conceptos a la envolvente edilicia, la disminución de la carga térmica se vuelve más importante a medida que se incrementa el volumen del edificio calefaccionado.

Las líneas de tendencia difieren según si la envolvente contempla los criterios del diseño ambientalmente consciente o no. Por su parte las expresiones resultantes permiten conocer la demanda anual de energía en calefacción a partir del volumen calefaccionado con un $R^{2}=0,99$ para los edificios tal como están construidos en la actualidad [Ecuación $X-1$ ] y $R^{2}=0,89$ para la opción que sigue los criterios del DAC [Ecuación X - 2].

$$
\begin{aligned}
& \mathrm{Q}_{\text {cal }}=39,655 \times \text { volumen }+79.056(\mathrm{KWh} / \mathrm{año})[\text { [Ecuación } X-1] \\
& \left.\mathrm{Q}_{\text {cal }}=10,035 \times \text { volumen }+149.776(\mathrm{KWh} / \mathrm{año}) \text { [Ecuación } X-2\right]
\end{aligned}
$$




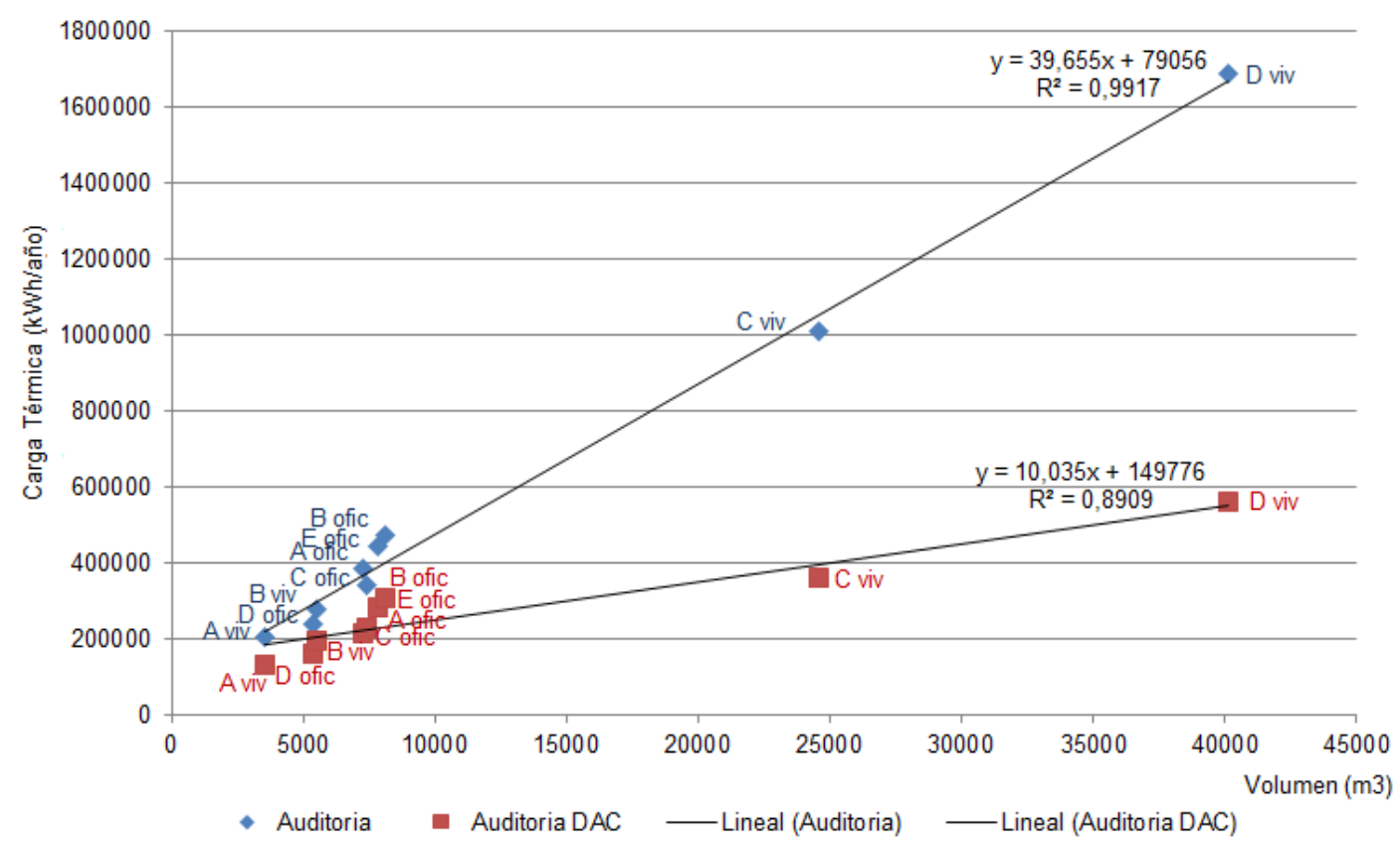

Gráfico X - 1: Correlación entre el volumen calefaccionado y la Carga Térmica anual.

Por su parte, el Gráfico X - 2 muestra los valores del coeficiente $G_{\text {cal }}\left[\mathrm{W} / \mathrm{m}^{3 \circ} \mathrm{K}\right]$ para los edificios analizados (IRAM 11.604). Puede verse como en todos los casos el valor del coeficiente $G_{\text {cal }}$ de los edificios auditados supera los valores admisibles, con lo cual se verifica que ningún caso cumple con las Normas IRAM, que de hecho sólo son de cumplimiento obligatorio la Ciudad de Rosario y en la Provincia de Buenos Aires, en donde la Ley 13.059/03 y su decreto reglamentario 1.030 establecen las exigencias mínimas de eficiencia energética y confort higrotérmico que debe cumplir toda obra de arquitectura.

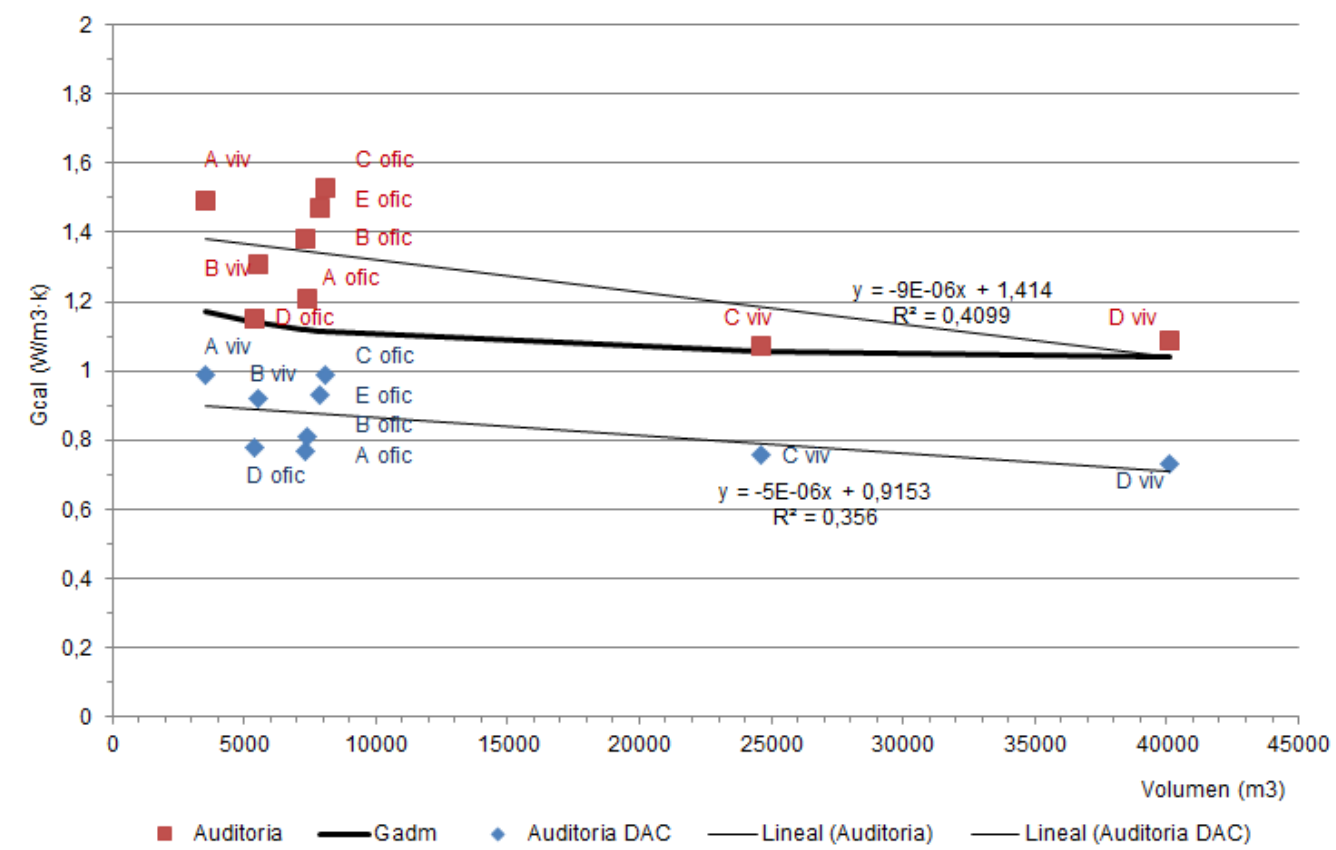

Gráfico $X-2$ : Valores de coeficiente volumétrico de calefacción $G_{c a l}$ para los edificios auditados según el modo en que están construidos y para las propuestas de mejoras (DAC).

Asimismo, las auditorías energéticas permitieron realizar la discriminación del consumo de gas natural para consumo base (agua caliente y cocción) y para calefacción. Cabe aclarar que esta discriminación sólo se realizó para el caso de edificios de viviendas ya que los edificios de 
oficinas auditados no hacían uso del gas natural para agua caliente ni cocción e incluso algunos, como se describe en el Capítulo V, contaban con un sistema de calefacción central para todo el edificio o discriminado por planta.

Según el estudio presentado por ENARGAS en 2008 para el caso de edificios de vivienda aproximadamente el $60 \%$ del consumo anual de gas natural corresponde a calefacción y el $40 \%$ restante corresponde al consumo base. Se trata de consumos promedio para todo el país.

El Gráfico X - 3 muestra el consumo discriminado (consumo base y calefacción) de gas natural por unidad de superficie, promedio por día para los distintos meses del año. Los datos con los que se elaboró este gráfico fueron extraídos de las auditorías energéticas para los edificios de vivienda en los que, como se menciona anteriormente, puede hacerse esta discriminación del consumo de gas natural.

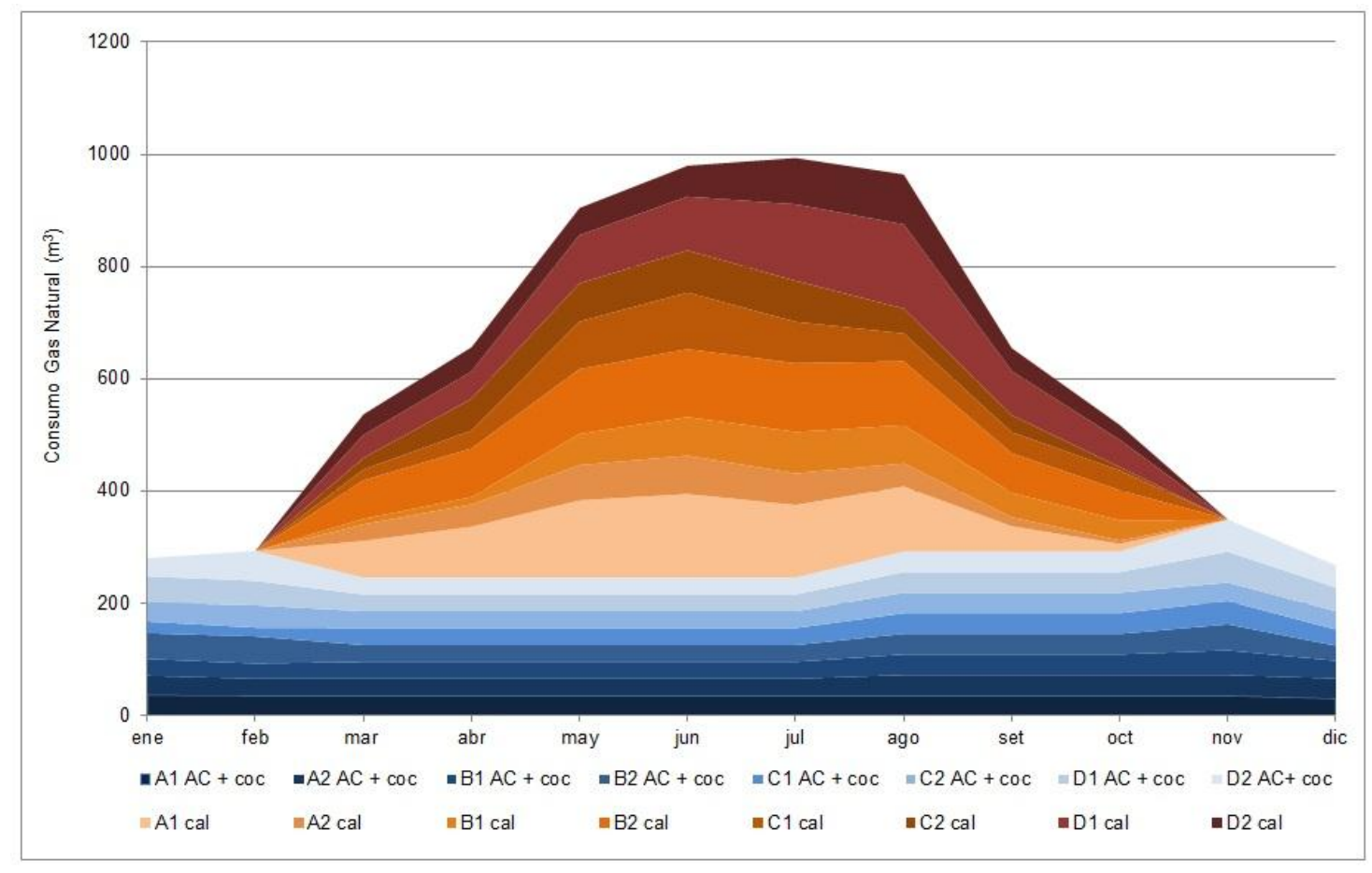

Gráfico X-3: Discriminación del consumo medido de gas natural por unidad de superficie $\left(\mathrm{m}^{3} / \mathrm{m}^{2} / \mathrm{día}\right)$.

Para la obtención de estos resultados se partió de los registros bimensuales de consumo de gas natural de las unidades auditadas. Luego, para obtener el consumo mensual de gas natural para cada unidad, se aplicó el criterio de conversión que utilizó Czajkowski en su Tesis Doctoral, en el año 2009. Las expresiones utilizadas para la conversión de consumos facturados bimestrales en mensuales fueron las siguientes:

\begin{tabular}{|c|c|c|c|c|c|}
\hline Enero & Febrero & Marzo & Abril & Mayo & Junio \\
\hline$=0,3667 \times B 2+0,15 \times B 1$ & $=0,4667 \times \mathrm{B} 2$ & $=0,1667 \times \mathrm{B} 2+0,35 \times \mathrm{B} 3$ & $=0,5 \times \mathrm{B} 3$ & $=0,15 \times B 3+0,3492 \times B 4$ & $=0,4762 \times B 4$ \\
\hline Julio & Agosto & Septiembre & Octubre & Noviembre & Diciembre \\
\hline$=0,1746 \times B 4+0,3279 \times$ B5 & $=0,5082 \times B 5$ & $=0,1639 \times \mathrm{B} 5+0,3279 \times \mathrm{B} 6$ & $=0,50821 \times B 6$ & $=0,1639 \times \mathrm{B} 6+0,3333 \times \mathrm{B} 1$ & $=0,5167 \times B 1$ \\
\hline
\end{tabular}

Tabla X - 1: Expresiones para la conversión de consumos facturados bimestrales en mensuales.

Finalmente se procedió a realizar la discriminación del consumo de gas natural para agua caliente y cocción, y calefacción. Para ello a los cinco meses con grados día de calefacción igual a cero se descontó el consumo de gas natural de forma directa; a los meses de abril a 
julio se descontaron los consumos de marzo y a los meses de agosto a octubre se descontaron los consumos de noviembre (Czajkowski, J.; 2009).

De los resultados obtenidos surge que para el caso de viviendas el $53 \%$ del consumo de gas natural anual corresponde a calefacción y el $47 \%$ restante corresponde al consumo base para agua caliente y cocción. Cabe aclarar que se trata de consumos promedio para la región del AMBA. Esto da un indicador de consumo de gas natural promedio por unidad de superficie y por día de $0,538 \mathrm{~m}^{3} / \mathrm{m}^{2} /$ día para calefacción y $0,228 \mathrm{~m}^{3} / \mathrm{m}^{2} /$ día para agua caliente y cocción.

Los datos extraídos de las auditorías energéticas fueron corroborados con los resultados del AuditCAD para los distintos casos analizados. El Gráfico X - 4 muestra los resultados arrojados por el AuditCAD para todos los casos analizados, incluidos los edificios de oficinas. En este gráfico se incluyen además los resultados arrojados por el AuditCAD para las propuestas de mejora que siguen los criterios del diseño ambientalmente consciente (DAC).

De este modo pudo estimarse la demanda de gas natural para calefacción por unidad de superficie, por día para los edificios de vivienda y de oficinas en sus dos versiones; tal como están construidos en la actualidad y según los criterios del diseño ambientalmente consciente. Para la primera opción el AuditCAD arrojó un valor de $0,531 \mathrm{~m}^{3} / \mathrm{m}^{2} /$ día de gas natural para calefacción de edificios de viviendas (muy aproximado al valor medido) y $0,420 \mathrm{~m}^{3} / \mathrm{m}^{2} /$ día para edificios de oficinas. Para la segunda opción (según los criterios del DAC) el AuditCAD arrojó un valor de $0,112 \mathrm{~m}^{3} / \mathrm{m}^{2} /$ día de gas natural para calefacción de edificios de viviendas y 0,204 $\mathrm{m}^{3} / \mathrm{m}^{2} /$ día para edificios de oficinas. Como puede verse en estas cifras la reducción de la demanda de gas natural para calefacción al aplicar los criterios del DAC se vuelve más importante para los casos de vivienda que para los casos de oficinas; se trata de una reducción del $78,90 \%$ contra una del $51,43 \%$.

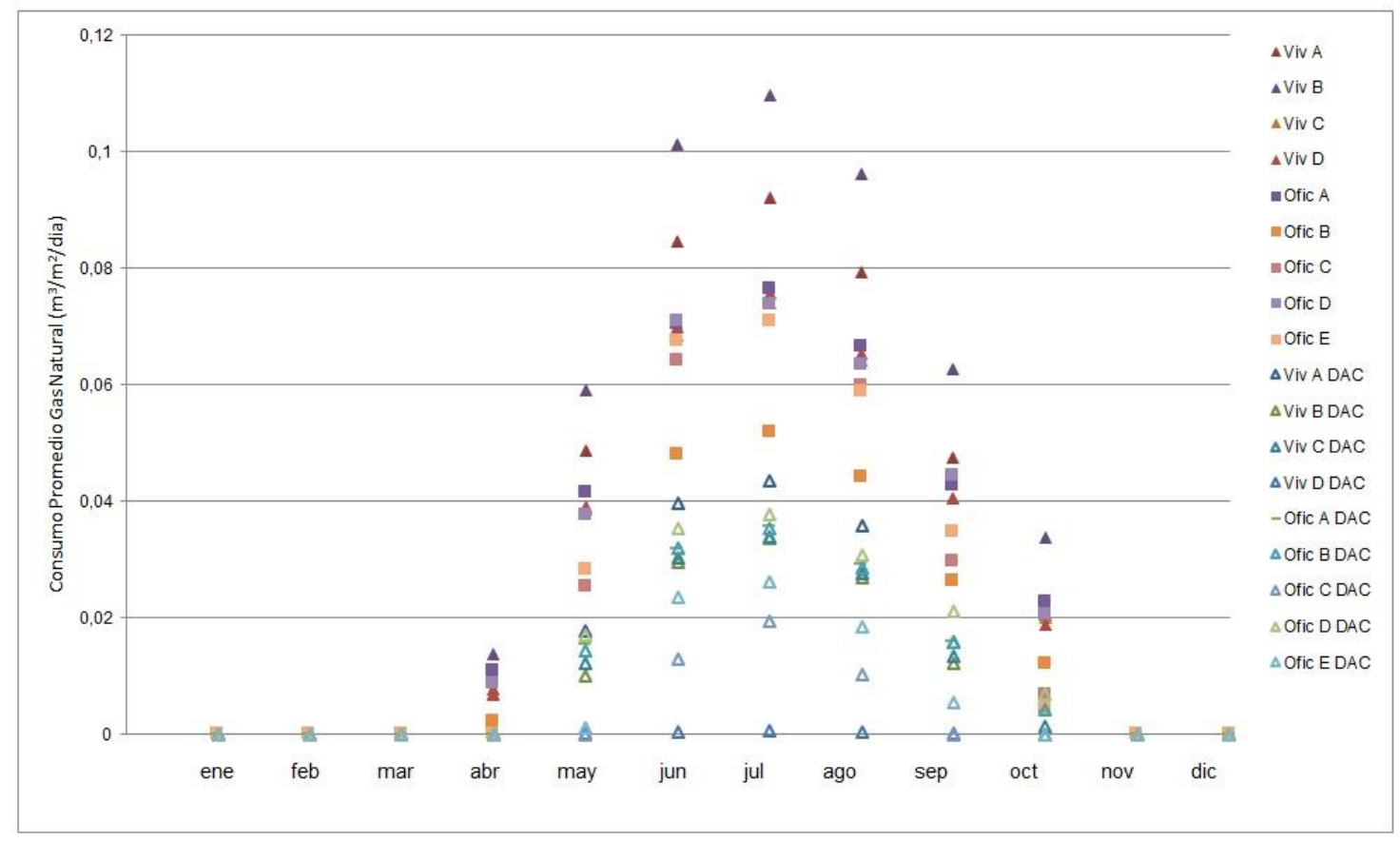

Gráfico X - 4: Consumo promedio de gas natural por unidad de superficie $\left(\mathrm{m}^{3} / \mathrm{m}^{2} /\right.$ día $)$ - AuditCAD

Del mismo modo que para la condición de invierno se realizó el balance térmico de verano para cada uno de los edificios auditados. De este modo fue posible determinar el coeficiente volumétrico de refrigeración $\left(G_{R}\right)$ y la carga térmica total de verano para cada edificio analizado en sus dos versiones; tal como están construidos en la actualidad y según los criterios del DAC.

La Carga térmica total de verano $\left(Q_{R}\right)$ de la cual se derivan el Coeficiente de refrigeración por unidad de superficie $\left(S_{R}\right)$ y el Coeficiente volumétrico de refrigeración $\left(G_{R}\right)$ propuestos en la 
Norma IRAM 11.659-2 fueron calculados teniendo en cuenta factores de ocupación, equipamiento e iluminación aplicables a viviendas. Sin embargo para el caso de edificios de oficinas, donde hay una mayor concentración de personas y donde el uso de artefactos eléctricos y de iluminación es mucho más intensivo, deberían considerarse valores diferenciados.

En el año 2010 se presentó un trabajo que dio continuidad al modelo de ahorro de energía en refrigeración presentado al Instituto Argentino de Normalización y Certificación, el cual se convirtió en la parte 2 de la Norma IRAM 11.659 en 2007. De la parte 1 de dicha Norma (Czajkowski, J.; Corredera, C.; 2006) se tomaron los datos para determinar la carga térmica de refrigeración, teniendo en cuenta el destino de los locales habitables. Los resultados de este trabajo se muestran en el Capítulo X, en el modelo de ahorro de energía en refrigeración para edificios de oficinas.

Como puede verse en el Gráfico $X$ - 5, en la mayoría de los casos el $G_{R}$ de los edificios estudiados es superior al $G_{\text {Radm }}$-a excepción de los casos $C$ y $D$ de vivienda- que corresponden a los de mayor volumen. Al aplicar los conceptos del diseño ambientalmente consciente al total de la envolvente de estos edificios el $G_{R}$ de los mismos disminuye por debajo de la línea de $G_{\text {Radm. }}$. En este gráfico también puede verse que, incluso al incorporar los criterios del DAC al total de la envolvente, en la mayoría de los casos para los edificios de oficinas el $G_{R}$ es superior al $G_{\text {Radm. }}$. Esta situación tiene lugar pese a que se han incorporado valores de transmitancia térmica mucho más exigentes en los sistemas de carpinterías que para el caso de los edificios de vivienda $\left(K_{c a r p}=1,86\right.$; DVH con Low-e). Esto se debe a que en el caso de edificios de oficinas la relación de superficie vidriado - opaco es mucho mayor a la de edificios de viviendas y a que, como ya se mencionó anteriormente, en este tipo de edificios hay una mayor concentración de personas y el uso de artefactos eléctricos y de iluminación es mucho más intensivo. De este modo se confirma que deberían considerarse valores diferenciados de $G_{R}$ adm para el caso de edificios de oficinas.

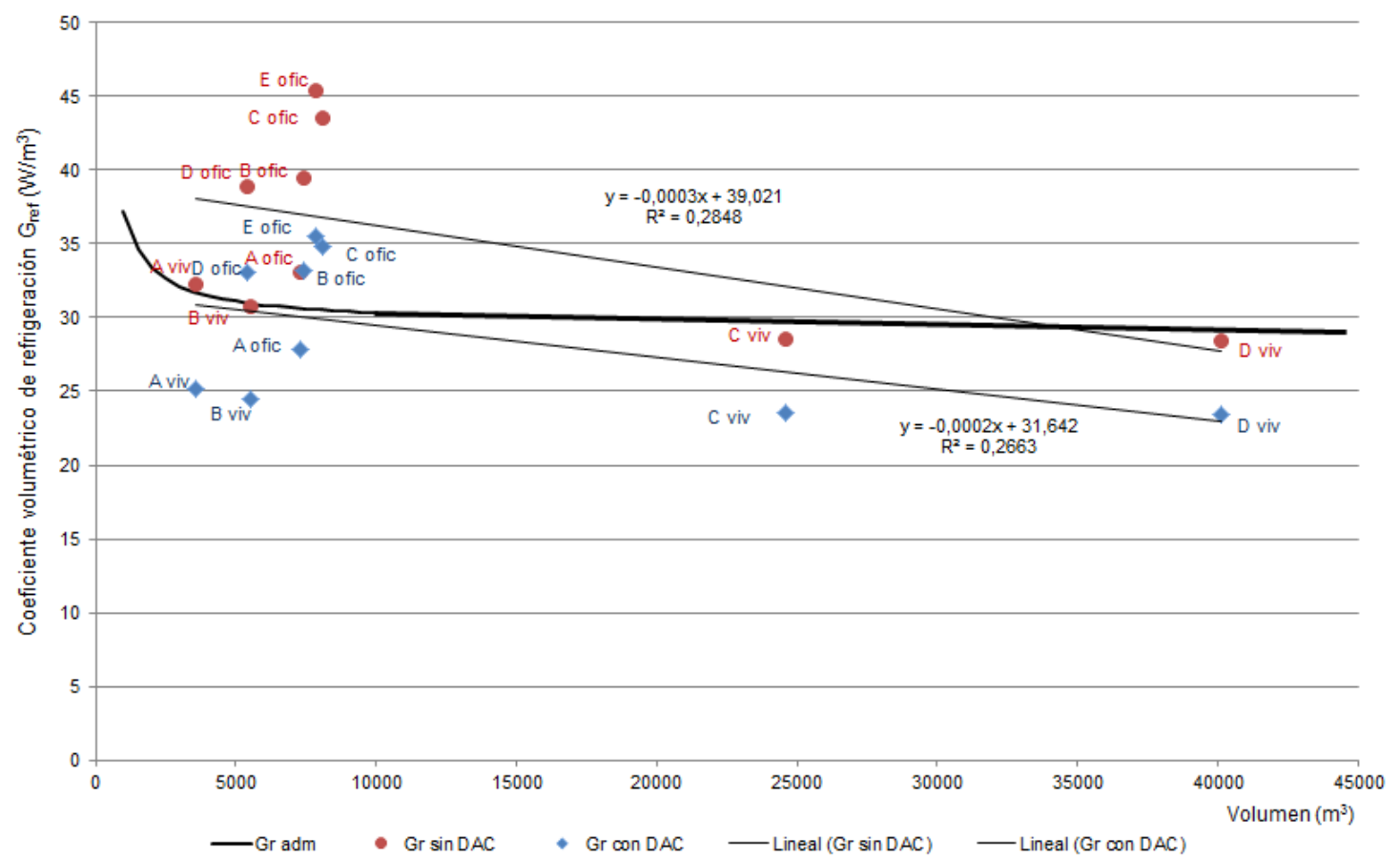

Gráfico $X$ - 5: Valores de coeficiente volumétrico de refrigeración $G_{R}$ para los edificios auditados según el modo en que están construidos y para las propuestas de mejoras (DAC).

Por su parte, el Gráfico X - 6 muestra la correlación entre el volumen y la carga térmica de verano para los edificios auditados tal como están construidos en la actualidad, y para las propuestas de mejoras que siguen los criterios del diseño ambientalmente consciente. Como puede verse en este gráfico, al aplicar estos conceptos a la envolvente edilicia, la disminución 
de la carga térmica de verano se vuelve más importante a medida que se incrementa el volumen del edificio refrigerado tal como ocurría con la carga térmica de calefacción, aunque en menor grado.

Las líneas de tendencia difieren según si la envolvente contempla los criterios del Diseño Ambientalmente Consciente o no. Las expresiones resultantes permiten conocer la demanda anual de energía para refrigeración a partir del volumen acondicionado térmicamente con un $R^{2}=0,9803$ para los edificios tal como están construidos en la actualidad [Ecuación $X-3$ ] y $\mathrm{R}^{2}=0,9831$ para la opción que sigue los criterios del DAC [Ecuación $\mathrm{X}-4$ ].

$$
\begin{aligned}
& \left.\mathrm{Q}_{\mathrm{R}}=0,0265 \times \text { volumen }+73,753(\mathrm{~kW}) \text { [Ecuación } X-3\right] \\
& \mathrm{Q}_{\mathrm{R}}=0,022 \times \text { volumen }+57,507(\mathrm{~kW})[\text { Ecuación } X-4]
\end{aligned}
$$

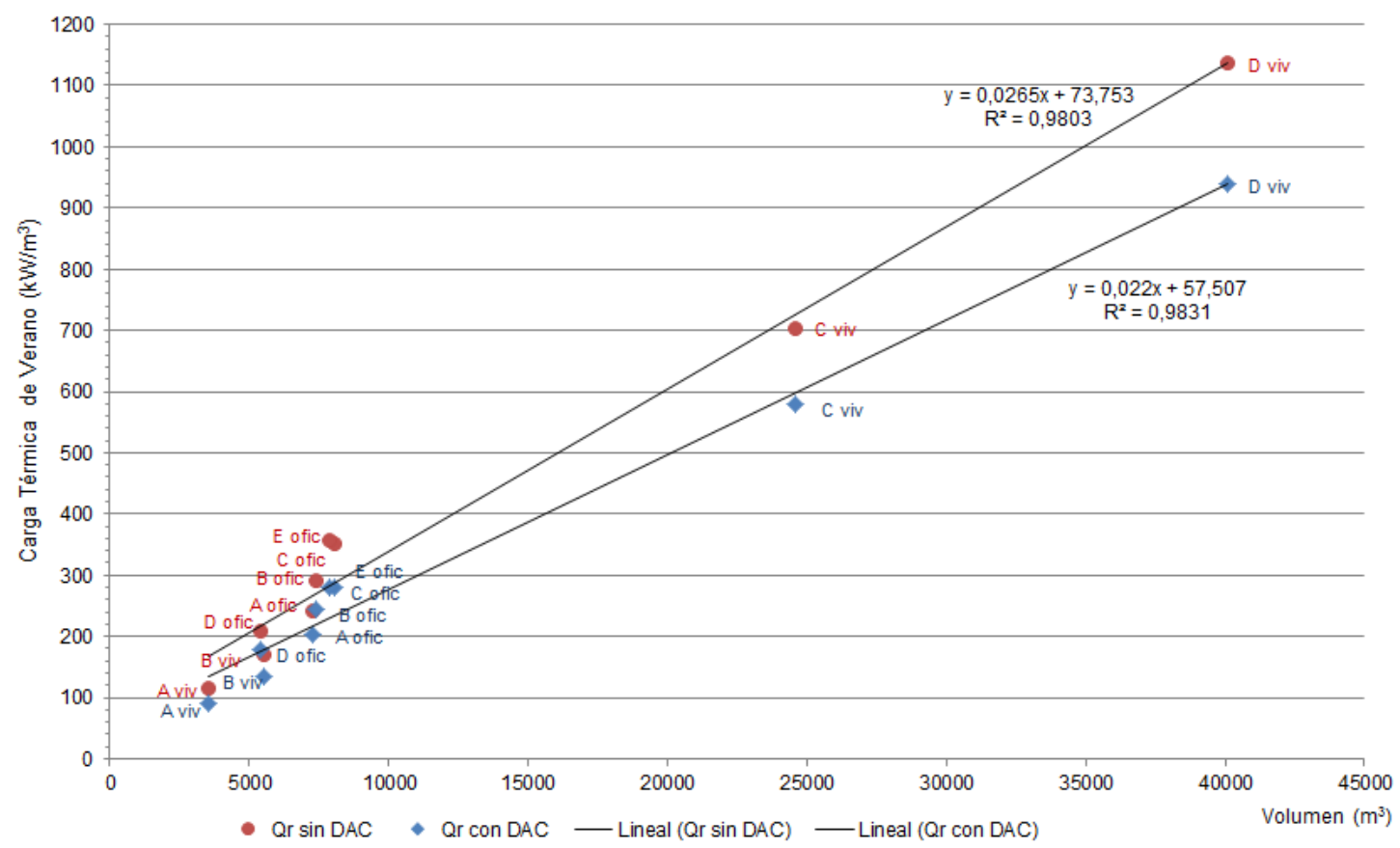

Gráfico X - 6: Correlación entre el volumen refrigerado y la Carga Térmica anual de refrigeración $\left(\mathrm{kW} / \mathrm{m}^{3}\right)$.

Por otra parte, cabe destacar que al momento de realizar la discriminación del consumo de energía eléctrica de todas las unidades fue muy difícil poder discriminar los usos. Esto se debió principalmente a la gran variación entre los consumos de energía eléctrica de cada una de las unidades, incluso en el período invernal. Durante las auditorías energéticas se tomaron los consumos de energía eléctrica de todas las unidades y se pudo conocer detalladamente el equipamiento eléctrico, de iluminación y de acondicionamiento térmico de cada una de las unidades a las que pudo accederse. Se tomó nota de las potencias de los equipos de las unidades a las que se tuvo acceso, sin embargo fue muy difícil poder obtener una respuesta certera acerca de las horas de funcionamiento del equipamiento a partir de las encuestas realizadas y de las opiniones de los ocupantes.

El Gráfico X - 7 muestra el consumo diario ${ }^{1}$ de energía eléctrica por unidad de superficie para cada una de las unidades funcionales de los edificios de vivienda analizados. Para el periodo invernal el consumo diario promedio de energía eléctrica por unidad de superficie fue de $0,102 \mathrm{kWh} / \mathrm{m}^{2} /$ día mientras que para el periodo estival fue de $0,089 \mathrm{kWh} / \mathrm{m}^{2} / \mathrm{día}$. Si bien, como se menciona anteriormente, fue muy difícil realizar la discriminación de dicho consumo; de la

\footnotetext{
${ }^{1}$ El consumo diario se obtuvo dividiendo el consumo del período analizado por la cantidad de días para la unidad funcional del edificio auditado.
} 
lectura de esta figura puede inferirse el uso de equipos de aire acondicionado para refrigeración e incluso también para calefacción. Para edificios de vivienda podría hablarse de un consumo base (iluminación artificial y equipamiento eléctrico) que ronda los $0,075 \mathrm{kWh} / \mathrm{m}^{2} /$ día y un consumo destinado al funcionamiento de los equipos de aire acondicionado que ronda los $0,20 \mathrm{kWh} / \mathrm{m}^{2} / \mathrm{d}$ ía. Sin embargo cabe aclarar que esto es sólo un valor aproximado ya que la variación en el uso de energía eléctrica para el acondicionamiento del aire interior depende del equipo utilizado y del uso que se haga del mismo.

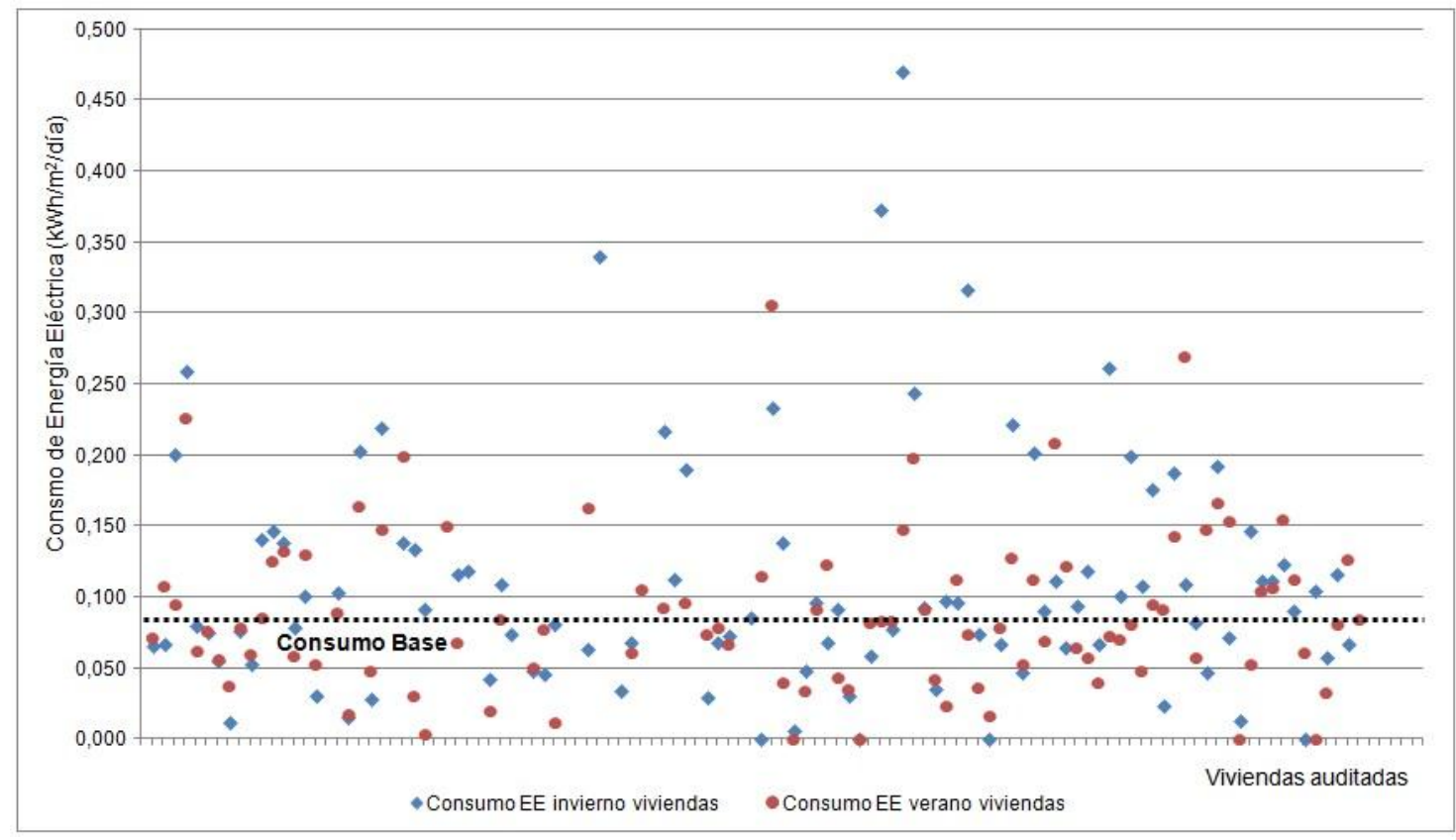

Gráfico x - 7: Consumo de energía eléctrica por unidad de superficie por día - edificios de vivienda.

Por su parte el Gráfico X - 8 muestra el consumo diario ${ }^{1}$ de energía eléctrica por unidad de superficie para cada una de las unidades funcionales de los edificios de oficinas analizados. Para el periodo invernal el consumo diario promedio de energía eléctrica por unidad de superficie fue de $0,119 \mathrm{kWh} / \mathrm{m}^{2} /$ día mientras que para el periodo estival fue de $0,123 \mathrm{kWh} / \mathrm{m}^{2} /$ día. Al igual que en el caso anterior, de la lectura de esta figura se puede inferir el uso de equipos de aire acondicionado para refrigeración e incluso también para calefacción. Podría hablarse de un consumo base (iluminación artificial y equipamiento eléctrico) que ronda los $0,05 \mathrm{kWh} / \mathrm{m}^{2} /$ día para las oficinas que no cumplen jornada completa de trabajo -lo que se deduce de las encuestas realizadas- y $0,15 \mathrm{kWh} / \mathrm{m}^{2} /$ día para aquellas que sí lo hacen, y un consumo destinado al funcionamiento de los equipos de aire acondicionado que ronda los $0,25 \mathrm{kWh} / \mathrm{m}^{2} /$ día.

Para comprobar estos datos se realizó la simulación energética de un modelo edilicio que reuniera las características de los casos analizados mediante el EnergyPlus. Tal como se comenta en el Capítulo IX - Simulación con Energy PLUS, se realizó un modelo de edificio de oficinas y otro de viviendas, de modo de obtener resultados diferenciados.

Como se menciona en el Capítulo IX para la condición de verano el modelo de edificio de viviendas que reúne las características de los edificios que se construyen en la actualidad requiere de 435,22GJ/año (120.894,40kWh/año) para refrigerar el área climatizada. Al dividir esta cifra por la superficie climatizada del modelo $\left(1.405 \mathrm{~m}^{2}\right)$ y por el número de días de medición (365 días) puede hablarse de un indicador de consumo de energía eléctrica para el funcionamiento de los equipos de aire acondicionado de $0,23 \mathrm{kWh} / \mathrm{m}^{2} /$ día, bastante aproximado al $0,20 \mathrm{kWh} / \mathrm{m}^{2} /$ día que deriva del análisis del gráfico de los edificios de viviendas.

Por su parte el modelo de edificio de oficinas que reúne las características de los edificios que

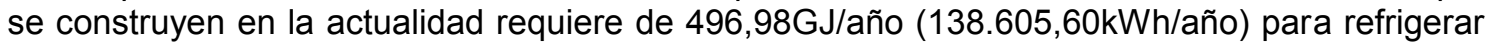


el área climatizada. Al dividir esta cifra por la superficie climatizada del modelo $\left(1.660 \mathrm{~m}^{2}\right)$ y por el número de días de medición (365 días) puede hablarse de un indicador de consumo de energía eléctrica para el funcionamiento de los equipos de aire acondicionado de $0,229 \mathrm{kWh} / \mathrm{m}^{2} /$ día, bastante aproximado al $0,25 \mathrm{kWh} / \mathrm{m}^{2} /$ día que deriva del análisis del gráfico de los edificios de oficinas.

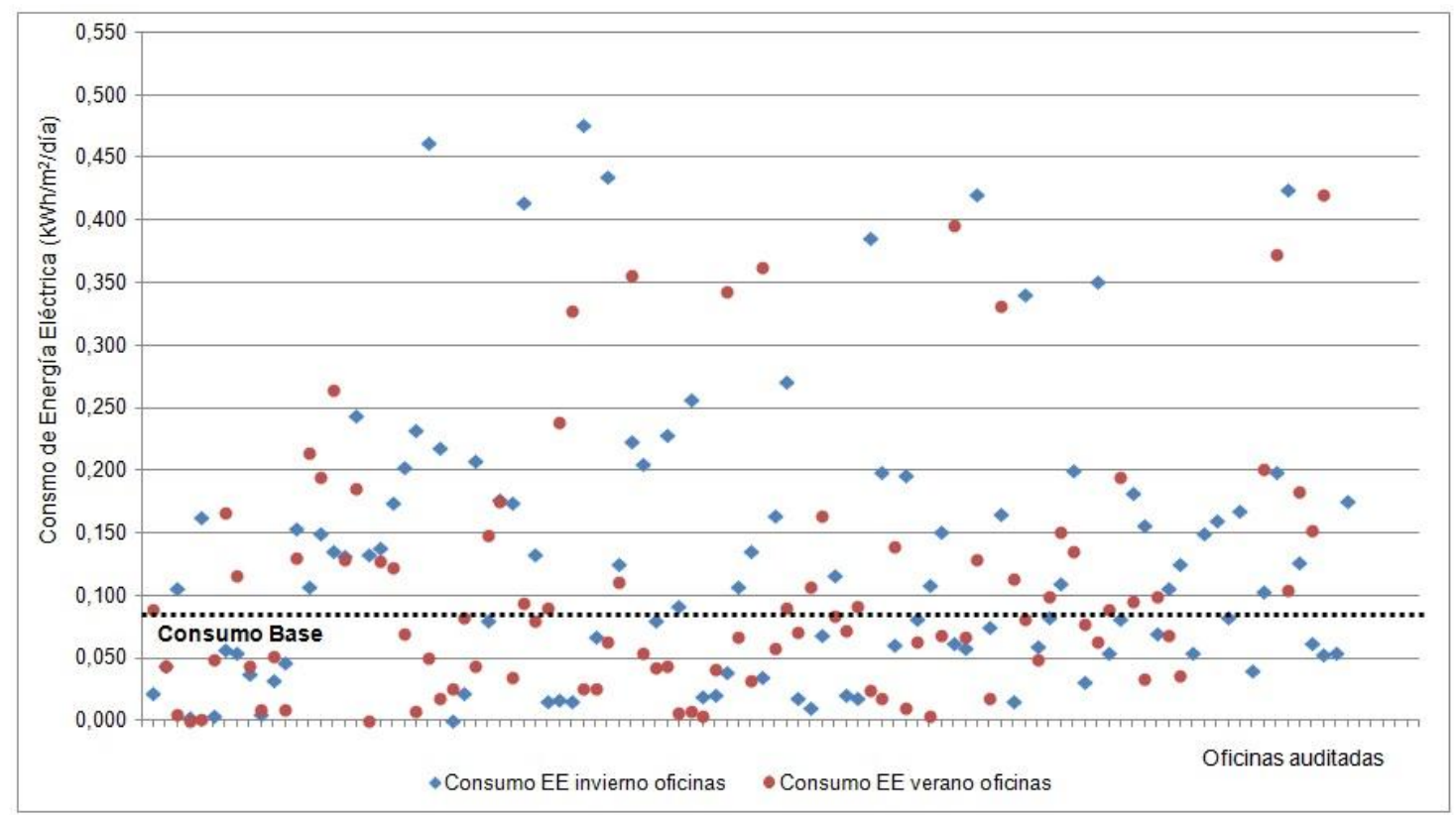

Gráfico X - 8: Consumo de energía eléctrica por unidad de superficie por día - edificios de oficinas.

\subsection{Modelo de ahorro de energía para edificios de viviendas}

A continuación se muestran los resultados del modelo de ahorro de energía en calefacción y refrigeración aplicable a edificios de viviendas para centros urbanos de alta densidad de toda Argentina. Los datos que se muestran a continuación son el resultado de la discusión con profesionales e investigadores de distintas áreas, de los avances presentados en distintos congresos y en el Subcomité de Acondicionamiento Térmico de Edificios de IRAM.

\subsubsection{Ahorro de energía en calefacción}

Como se mencionó anteriormente en agosto de 2010 se comenzó a participar en las reuniones del Subcomité Acondicionamiento Térmico de Edificios del Instituto Argentino de Normalización y Certificación como representante del LAyHS - FAU - UNLP / CONICET. Se llevó a estas reuniones una propuesta de mejora para la Norma IRAM 11.604 "Aislamiento térmico de edificios. Verificación de sus condiciones higrotérmicas. Coeficiente volumétrico $\mathrm{G}$ de pérdidas de calor. Cálculo y valores límites". Dicha propuesta sigue los lineamientos de cálculo y da continuidad al modelo de ahorro de energía en calefacción propuesto por la actual Norma IRAM 11.604 pero plantea mejoras en la construcción del modelo edilicio de referencia.

Según esta Norma el Coeficiente Volumétrico de Pérdidas de Calor $\left(G_{\text {cal }}\right)$ se calcula con la siguiente ecuación:

$$
G_{c a l}=\frac{\sum K m * S m+\sum K v * S v+\sum \gamma K r * S r+P e r P p}{v}+0,35 n
$$

[Ecuación X - 5]

Donde:

$\boldsymbol{G}_{\text {cal: }}$ : coeficiente volumétrico de pérdidas de calor del edificio $\left[\mathrm{W} / \mathrm{m}^{3} \cdot \mathrm{K}\right]$.

$K_{m}$ : transmitancia térmica de cerramientos opacos (muros, techos y pisos en contacto con el exterior) $\left[\mathrm{W} / \mathrm{m}^{2} \cdot \mathrm{K}\right]$. 
$\boldsymbol{S}_{\boldsymbol{m}}$ : área de los cerramientos opacos en contacto con el exterior $\left[\mathrm{m}^{2}\right]$.

$\boldsymbol{K}_{v}$ : transmitancia térmica de los cerramientos no opacos que lindan con el exterior $\left[\mathrm{W} / \mathrm{m}^{2} \cdot \mathrm{K}\right]$.

$S_{v}$ : área de los cerramientos no opacos en contacto con el exterior $\left[\mathrm{m}^{2}\right]$.

$y K_{r}$ : transmitancia térmica corregida de los cerramientos opacos y no opacos que lindan con locales no calefaccionados $\left[\mathrm{W} / \mathrm{m}^{2} \cdot \mathrm{K}\right]$.

$S_{r}$ : área de los cerramientos opacos que lindan con locales no calefaccionados $\left[\mathrm{m}^{2}\right]$.

$\boldsymbol{P}_{\text {er: }}$ : perímetro del piso en contacto con el aire exterior $\left[\mathrm{m}^{2}\right]$.

$\boldsymbol{P}_{p}$ : pérdidas por piso en contacto con el terreno.

$V:$ volumen interior del edificio calefaccionado $\left[\mathrm{m}^{3}\right]$.

0,35: capacidad específica del aire $\left[\mathrm{Wh} / \mathrm{m}^{3} \cdot \mathrm{K}\right]$.

$n$ : número de renovaciones de aire promedio por hora del edificio calefaccionado.

Por su parte, según la Norma IRAM 11.604, el cálculo de la Carga Térmica Anual (Q) del edificio calefaccionado se determina con la siguiente ecuación:

$$
\left.Q=\frac{24^{* 0} D^{*} \mathrm{Gcal}^{*} V}{1.000} \quad \text { [Ecuación } \mathrm{X}-6\right]
$$

Donde:

Q: carga térmica anual de calefacción $[\mathrm{kWh}]$.

24: Tiempo de calefacción por día.

${ }^{\circ} \mathrm{D}$ : Grados día de calefacción anual (obtenidos de la Norma IRAM 11.603 ) [ $\left.{ }^{\circ} \mathrm{C}\right]$.

$\boldsymbol{G}_{\text {cal: }}$ : coeficiente volumétrico de pérdidas de calor del edificio $\left[\mathrm{W} / \mathrm{m}^{3} \cdot \mathrm{K}\right]$.

$V:$ volumen interior del edificio calefaccionado $\left[\mathrm{m}^{3}\right]$.

Asimismo, como parte de la propuesta presentada al Subcomité de Acondicionamiento Térmico de Edificios de IRAM se propuso determinar el Coeficiente de Calefacción por unidad de superficie - $S_{\text {cal }}$, el cual puede ser calculado con la siguiente ecuación:

$$
S_{\text {cal }}=Q_{C} / A_{C} \quad \text { [Ecuación X -7] }
$$

Donde:

$\boldsymbol{S}_{\text {cal: }}$ : Coeficiente de Calefacción por Unidad de Superficie en $\left[\mathrm{kWh} / \mathrm{m}^{2}\right]$

$Q_{c}:$ Carga térmica total de invierno en [kWh]

$\boldsymbol{A}_{C}$ : Superficie calefaccionada $\left[\mathrm{m}^{2}\right]$

El modelo edilicio de referencia de la actual Norma IRAM 11.604 parte de un cubo que crece a altura constante de $2,70 \mathrm{~m}$, y que va desde los $50 \mathrm{~m}^{3}$ a $10.000 \mathrm{~m}^{3}$. A partir del estudio de dicha Norma se concluyó que este modelo edilicio de referencia devenía en un aumento en las pérdidas a través de las superficies horizontales (pisos y techos) que se apartaba de la realidad a medida que el volumen del edificio crecía. Si bien actualmente la Norma plantea que la premisa básica es dar libertad al diseñador al momento de materializar el edificio, a partir del estudio de casos de la realidad se concluyó que el modelo propuesto por la actual Norma IRAM 11.604 no es representativo de los edificios construidos en la actualidad.

La propuesta presentada al Subcomité de Acondicionamiento Térmico de Edificios de IRAM plantea el desarrollo de curvas distintas para los modelos edilicios de referencia para viviendas tipo casa, tipo bloque y edificio en altura. La determinación de estos tres tipos parte de la observación de la realidad construida y del estudio del modelo de ahorro de energía en refrigeración que el Grupo Eficiencia Energética Edilicia (GEEE) de la Cátedra de Instalaciones de la FAU - UNLP presentó en el año 2006 al Instituto Argentino de Normalización y Certificación, el cual se convirtió en la parte 2 de la Norma IRAM 11.659 en 2007.

Al mismo tiempo la propuesta presentada al Subcomité de Acondicionamiento Térmico de Edificios de IRAM plantea la mejora de la envolvente térmica del modelo edilicio de referencia de la actual Norma IRAM 11.604, la cual plantea la utilización del Nivel C de la Norma IRAM 11.605 en cuanto a la transmitancia térmica de muros y techos. Cabe destacar que los valores 
de transmitancia térmica propuestos por el Nivel C son ineficientes en cuanto al ahorro de energía ya que dicho nivel fue elaborado para ser implementado en viviendas de interés social y solamente previene el riesgo de condensación superficial.

A continuación se explica el procedimiento para la elaboración de las curvas para el modelo de referencia para edificios de viviendas en altura, eje del desarrollo de esta Tesis.

\section{El modelo edilicio:}

El modelo propuesto para este tipo edilicio parte de la repetición en altura de una planta tipo de $185 \mathrm{~m}^{2}$, con altura de local mínima media según Códigos de Edificación de $2,70 \mathrm{~m}$, y con un volumen variable entre $1.000 \mathrm{~m}^{3}$ (dos niveles) y $10.000 \mathrm{~m}^{3}$ (veinte niveles). Esto implica un volumen creciente a superficie de planta constante (Figura $X-1$ ), a partir del cual se obtienen las superficies de la envolvente discriminadas; muros, techos y superficies vidriadas.

El hecho de adoptar una planta de $185 \mathrm{~m}^{2}$ que se desarrolla en altura está relacionado con el relevamiento de casos de la realidad donde puede apreciarse cómo el avance de este tipo edilicio en las limitaciones de los solares urbanos es incentivado por la especulación inmobiliaria.

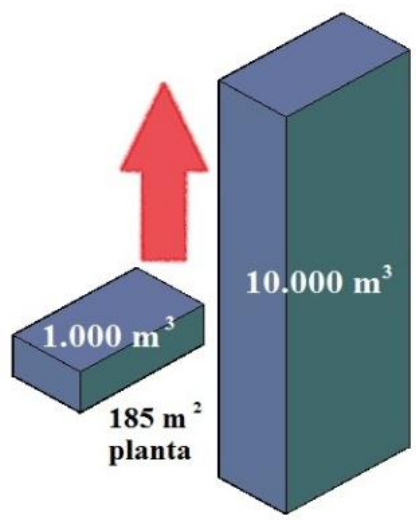

Figura $X$ - 1: Modelo adoptado de volumen edilicio creciente.

Por otra parte en lo que respecta a la relación vidriado - opaco se prevé un máximo del $20 \%$ de superficie vidriada sobre el total de la envolvente vertical, el cual se distribuye según un criterio bioclimático (Czajkowski, J.; Corredera, C.; 2006) de la siguiente forma:

- No se admiten vidriados en techos.

- $40 \%$ del área vidriada se ubica al norte.

- $25 \%$ del área vidriada se ubica al este.

- 25\% del área vidriada se ubica al oeste.

- 10\% del área vidriada se ubica al sur.

En cuanto a las Renovaciones de Aire el apartado 6.6.1 de la actual Norma IRAM 11.604 plantea que el número de renovaciones de aire del edificio de vivienda calefaccionado requerido para el cálculo de $\mathrm{G}_{\text {cal }}$ es 2 , salvo que se realice la verificación de acuerdo con el apartado 6.6.2. Esto es cuando se disponga de valores de infiltración de las carpinterías, puede calcularse el valor de las renovaciones de aire mediante el método indicado en el apartado B.1.2 del Anexo B, debiendo tener en cuenta que la ventilación natural y controlada de los locales de la vivienda debe cumplir con los requisitos mínimos de salubridad y confort. Se utilizó el método de cálculo propuesto por el Anexo B de la actual Norma IRAM 11.604 pero los resultados obtenidos fueron valores muy bajos $(0,11<\mathrm{RA}<0,28)$. Por este motivo decidió adoptarse un valor de 0,7RA, que cumple con los requisitos mínimos de salubridad y confort (Ley 13.059/03 - Provincia de Buenos Aires). 


\section{Calidad térmica de la envolvente:}

La Norma IRAM 11.605 sugiere tres niveles de calidad térmica para muros y techos -A, B y C-. Debido a que los valores de transmitancia térmica propuestos por el Nivel $C$ son ineficientes en cuanto al ahorro de energía, dicho nivel fue descartado.

El modelo propuesto utiliza un valor intermedio entre el Nivel A y el Nivel B de la Norma IRAM 11.605 para muros y techos (Czajkowski, J.; Gómez, A.; 2009). Siguiendo este criterio se adoptaron valores de $\mathrm{K}_{\max }$ admisibles para la condición de invierno, para muros y techos, los cuales varían en función de los valores de Temperatura Mínima Exterior de Diseño (TDMN) [ ${ }^{\circ} \mathrm{C}$ ] en un rango que va desde $-15^{\circ} \mathrm{C}$ a $0^{\circ} \mathrm{C}$ (Gráfico $\left.X-9\right)$.

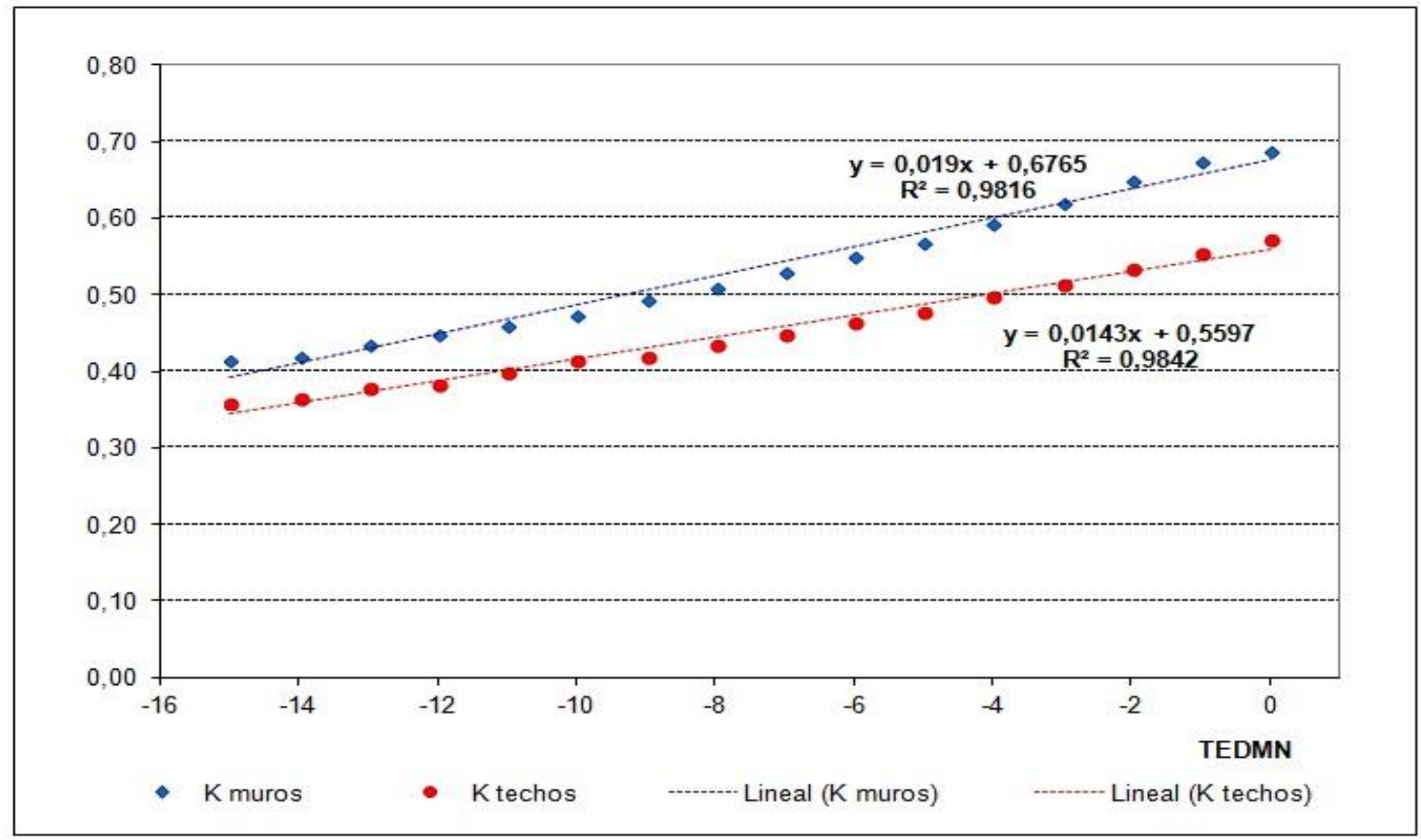

Gráfico X-9: Valores de $K_{\max }$ admisibles para muros y techos variables en función de TDMN.

$$
\begin{array}{ll}
K_{m}=0,019 * T D M N+0,6765 & \text { [Ecuación } X-8] \\
K_{t}=0,0143 * T D M N+0,5597 & \text { [Ecuación } X-9]
\end{array}
$$

Para poder realizar las curvas del Coeficiente Volumétrico de Pérdidas $\left(G_{\text {cal }}\right)$ en función de los Grados Día de Calefacción en base $18^{\circ} \mathrm{C}$ debió determinarse la correlación entre las Temperaturas Exteriores Mínimas de Diseño (TDMN) y los Grados Día de Calefacción en base $18^{\circ} \mathrm{C}\left({ }^{\circ} \mathrm{D}_{\text {cal }} 18^{\circ} \mathrm{C}\right)$. Para ello se tomaron los valores de la Tabla de Datos Climáticos de Invierno de la Norma IRAM 11.603, donde figuran estos parámetros para distintas ciudades del territorio argentino. Luego, mediante el Gráfico X - 10 pudo determinarse la ecuación para calcular los $\mathrm{GD}_{\text {cal } 18^{\circ} \mathrm{C}}$ en función de las TDMN.

Asimismo la propuesta presentada al Subcomité de Acondicionamiento Térmico de Edificios plantea un nuevo límite inferior de $500^{\circ} \mathrm{D}_{\text {cal }} 18^{\circ} \mathrm{C}$ para las curvas del Coeficiente Volumétrico de Pérdidas $\left(\mathrm{G}_{\text {cal }}\right)$, por debajo de los $900^{\circ} \mathrm{D}_{\text {cal }} 18^{\circ} \mathrm{C}$ que propone la Norma actual. Esto permite la inclusión de zonas Templadas - Cálidas que no son contempladas en la actual Norma IRAM 11.604 , y que también requieren de calefacción en el periodo invernal. 


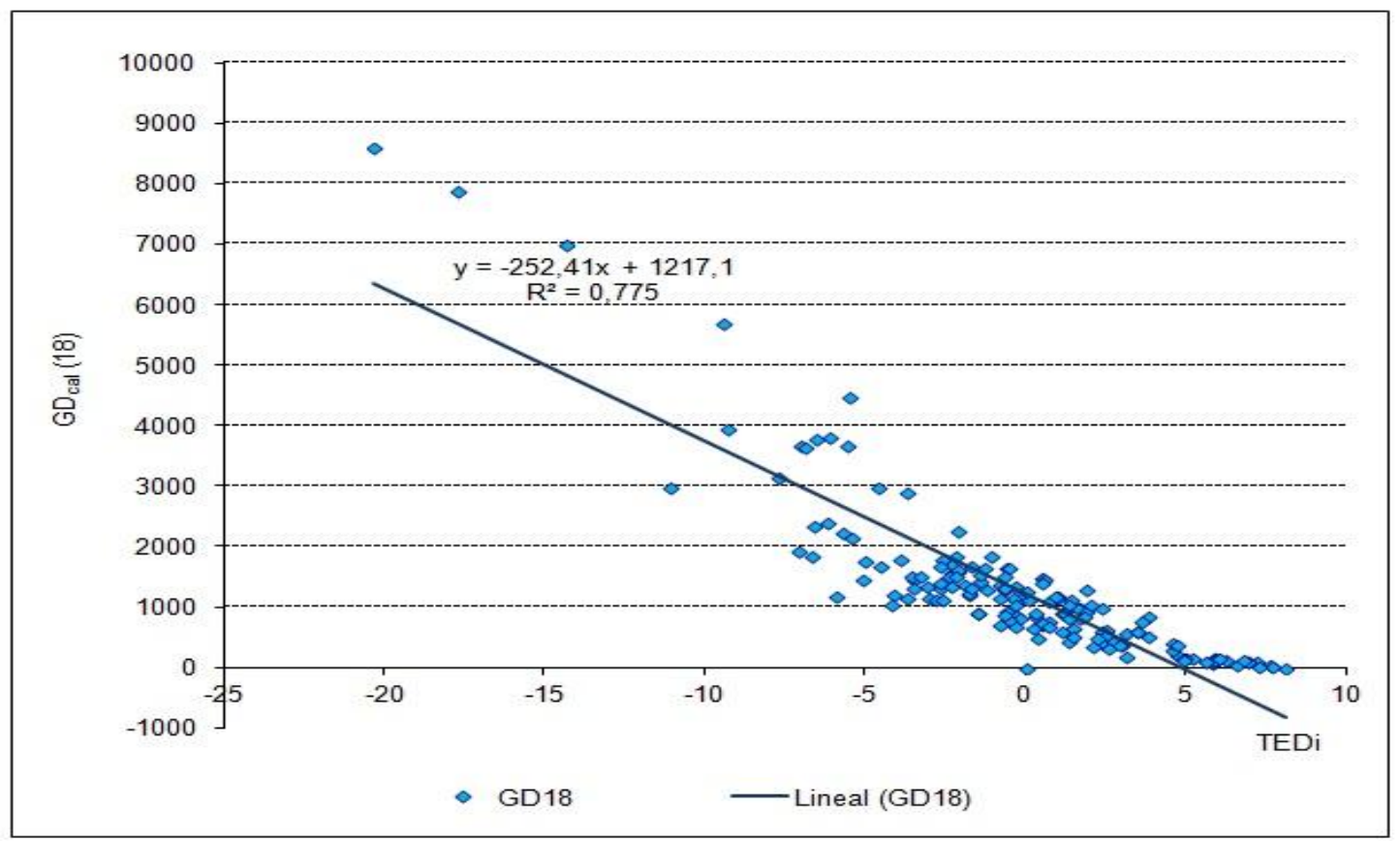

Gráfico X-10: Gráfico de dispersión para calcular los $G D_{c a l} 18^{\circ} \mathrm{C}$ en función de las $T D M N$.

$$
G D_{\text {cal }\left(18^{\circ} \mathrm{C}\right)}=-252,41 * T D M N+1.217,1 \quad \text { [Ecuación } X \text { - 10] }
$$

Posteriormente, como muestra el Gráfico X - 11, se realizó una verificación mediante el Excel. Para ello los valores de los $G D_{\text {cal }} 18^{\circ} \mathrm{C}$ fueron considerados negativos, de modo que pudieran compararse las pendientes de las curvas.

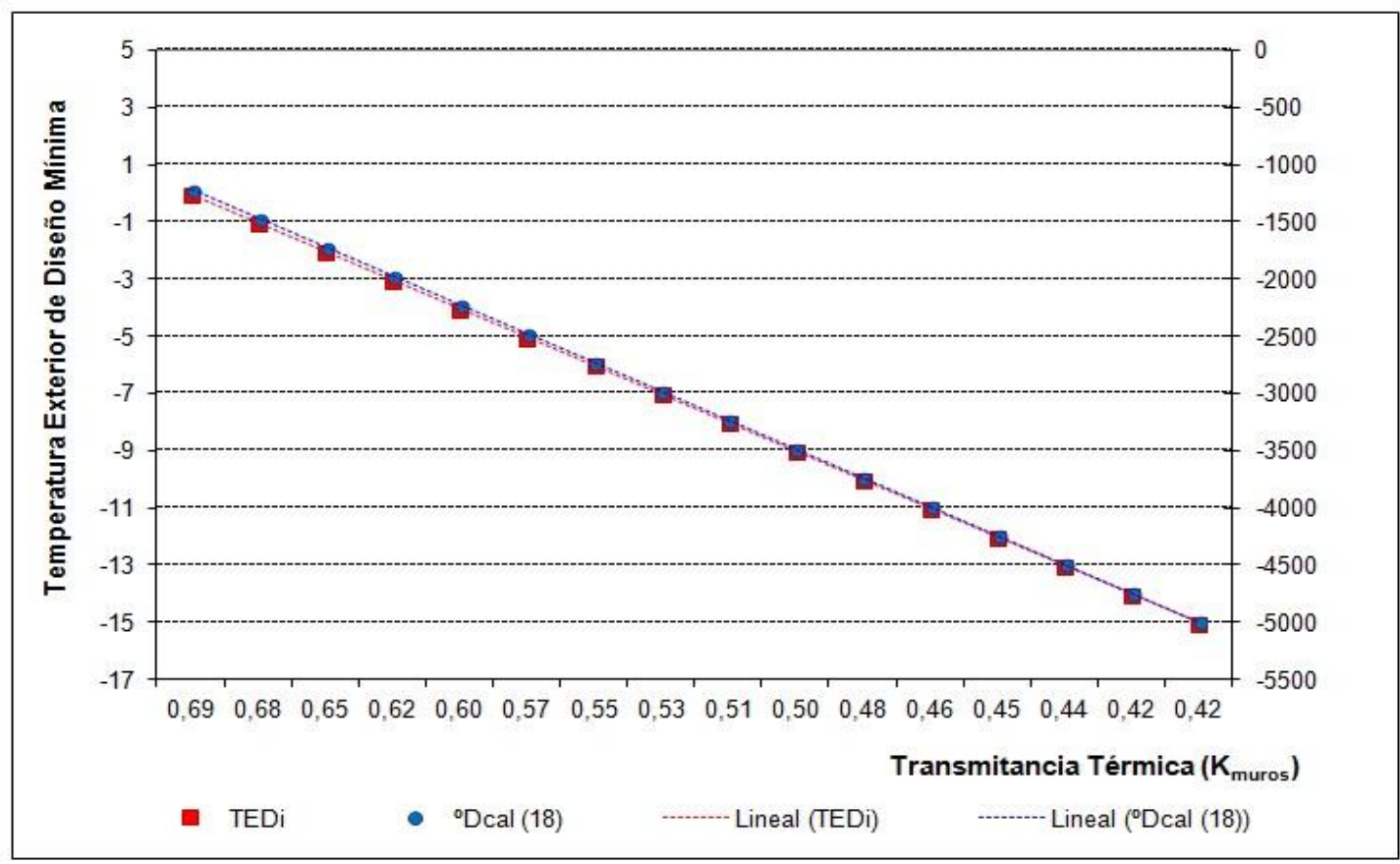

Gráfico $X-11$ : Verificación.

Luego, como lo muestra el Gráfico $X-12$, fue posible calcular las Transmitancias Térmicas $(K)$ de muros y techos en función de los $\mathrm{GD}_{\text {cal } 18^{\circ} \mathrm{C}}$. 


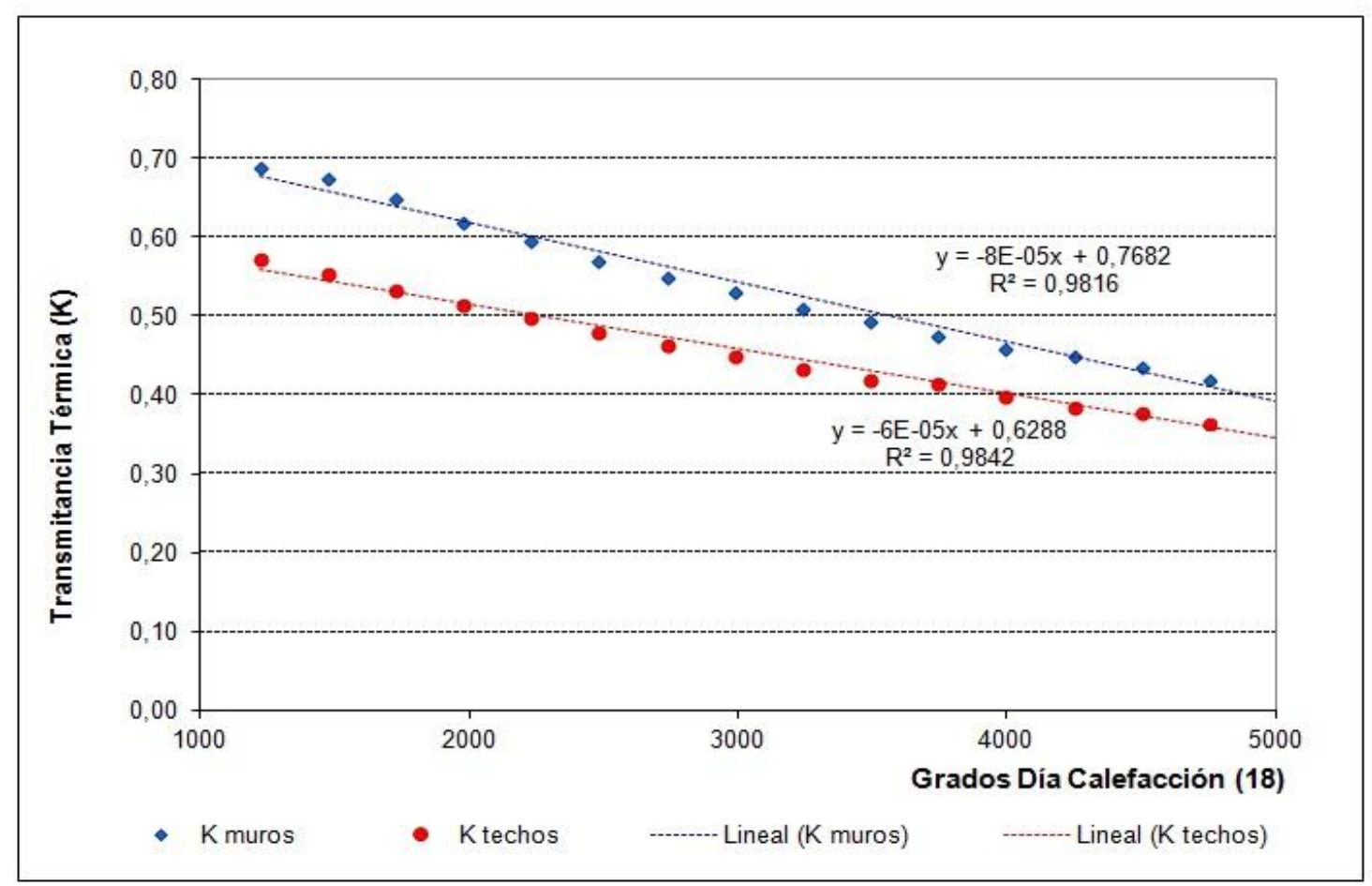

Gráfico X - 12: Valores de $K_{\max }$ admisibles para muros y techos variables en función de $G D_{\text {cal }} 18$.

$$
\begin{array}{cc}
K_{m}=-0,00008 * G D_{\text {cal }\left(18^{\circ} \mathrm{C}\right)}+0,7682 & \text { [Ecuación } X-11] \\
K_{t}=-0,00006 * G D_{\text {cal }\left(18^{\circ} \mathrm{C}\right)}+0,6288 & \text { [Ecuación } X-12]
\end{array}
$$

En cuanto al sistema de carpinterías se planteó la utilización de sistemas con DVH. De la Tabla A.1 del Anexo A de la Norma IRAM $11.507-4$ se obtuvo el valor de $\mathrm{k}=2,86 \mathrm{~W} / \mathrm{m}^{2} \mathrm{~K}$ para ventanas simples con perfilería de aluminio y ruptor de puente térmico. La elección de este tipo de carpinterías busca reducir las pérdidas de calor a través de las superficies vidriadas.

La Tabla X - 2 muestra los valores admisibles del Coeficiente Volumétrico de Pérdidas de Calor $\left(G_{\text {cal }}\right)$ para el modelo edilicio de referencia para edificios de viviendas en altura. El Gráfico $\mathrm{X}-14$ por su parte muestra estos valores y los compara con los valores propuestos por la

\begin{tabular}{|c|c|c|c|c|c|c|c|c|c|c|c|c|c|c|c|c|}
\hline \multirow{2}{*}{$\begin{array}{c}\text { Volumen } \\
\left(\mathrm{m}^{3}\right)\end{array}$} & \multicolumn{16}{|c|}{ Grados Día de Calefacción $\left(18^{\circ} \mathrm{C}\right)$} \\
\hline & $\overline{000^{\circ} \mathrm{D}}$ & $4000^{\circ} \mathrm{D}$ & $3000^{\circ} \mathrm{D}$ & $2500^{\circ} \mathrm{D}$ & $2000^{\circ} \mathrm{D}$ & $1500^{\circ} \mathrm{D}$ & $1400^{\circ} \mathrm{D}$ & $1300^{\circ} \mathrm{D}$ & $1200^{\circ} \mathrm{D}$ & $1100^{\circ} \mathrm{D}$ & $1000^{\circ} \mathrm{D}$ & $900^{\circ} \mathrm{D}$ & $800^{\circ} \mathrm{D}$ & $700^{\circ} \mathrm{D}$ & $600^{\circ} \mathrm{D}$ & $500^{\circ} \mathrm{D}$ \\
\hline 1000 & 0,732 & 0,759 & 0,787 & 0,801 & 0,815 & 0,829 & 0,832 & 0,835 & 0,837 & 0,840 & 0,843 & 0,846 & 0,849 & 0,851 & 0,854 & 0,857 \\
\hline 1500 & 0,658 & 0,683 & 0,709 & 0,721 & 0,734 & 0,746 & 0,749 & 0,751 & 0,754 & 0,756 & 0,759 & 0,761 & 0,764 & 0,766 & 0,769 & 0,771 \\
\hline 2000 & 0,622 & 0,645 & 0,669 & 0,681 & 0,693 & 0,705 & 0,707 & 0,710 & 0,712 & 0,714 & 0,717 & 0,719 & 0,722 & 0,724 & 0,726 & 0,729 \\
\hline 2500 & 0,600 & 0,623 & 646 & 0,657 & 0,669 & 0,680 & 0,682 & 0,685 & 0,687 & 0,689 & 0,692 & 0,694 & 0,696 & 0,698 & 0,701 & 1,703 \\
\hline 3000 & 0,585 & 607 & 630 & 0,641 & 0,652 & 0,663 & 1,666 & 668 & 0,670 & 0,672 & 0,675 & 0,677 & 0,679 & 0,681 & 0,684 & 686 \\
\hline 3500 & 0,575 & 0,597 & 619 & 0,630 & 0,641 & 0,652 & 0,654 & 0,656 & 0,658 & 0,660 & 0,663 & 0,665 & 0,667 & 0,669 & 0,671 & 0,674 \\
\hline 4000 & 0,567 & 0,588 & 0,610 & 0,621 & 0,632 & 0,643 & 0,645 & 0,647 & 0,649 & 0,651 & 0,654 & 0,656 & 0,658 & 0,660 & 0,662 & 0,665 \\
\hline 4500 & 0,561 & 0,582 & 604 & 0,614 & 0,625 & 0,636 & 1,638 & 0,640 & 0,642 & 0,644 & 0,647 & 0,649 & 0,651 & 0,653 & 0,655 & 0,657 \\
\hline 5000 & 0,556 & 0,577 & 598 & 0,609 & 0,620 & 0,630 & 0,632 & 0,635 & 0,637 & 0,639 & 0,641 & 0,643 & 0,645 & 0,647 & 0,650 & 0,652 \\
\hline 5500 & 0,552 & 0,573 & 0,594 & 0,605 & 0,615 & 0,626 & \begin{tabular}{l|l}
0,628 \\
\end{tabular} & 0,630 & 0,632 & 0,634 & 0,636 & 0,639 & 0,641 & 0,643 & 0,645 & 0,647 \\
\hline 6000 & 0,548 & 569 & & 0,601 & 0,612 & 0,622 & 624 & & & 0,630 & 0,633 & 0,635 & 0,637 & 0,639 & 0,641 & 0,643 \\
\hline 6500 & 0,546 & 567 & 87 & 0,598 & 0,608 & 619 & 621 & 0623 & 0,625 & 0,627 & 0,629 & 0,631 &, 634 & 0,636 & 0,638 & 0,640 \\
\hline 7000 & 0,543 & 0,564 & 585 & 0,595 & 0,606 & 0,616 & 618 & 0,620 & 0,622 & 0,625 & 0,627 & 0,629 & 0,631 & 0,633 & 0,635 & 0,637 \\
\hline 7500 & 0,541 & 0,562 & 0,583 & 0,593 & 0,603 & 0,614 & 0,616 & 0,618 & 0,620 & 0,622 & 0,624 & 0,626 & \begin{tabular}{|c|}
0,628 \\
\end{tabular} & 0,630 & 0,632 & 0,635 \\
\hline 8000 & 0,539 & 0,560 & 581 & 0,591 & 0,601 & 0,612 & 0,614 & 0,616 & 0,618 & 0,620 & 0,622 & 0,624 & 0,626 & 0,628 & 0,630 & 0,632 \\
\hline 8500 & 0,538 & 558 & & 0,589 & 0,600 & 610 & 612 & 14 & 0,616 & 0,618 & 0,620 & 0,622 & 0,624 & 0,626 & 0,628 & 0,631 \\
\hline 9000 & 0,536 & 0,557 & 577 & 0,588 & 0,598 & 0,608 & 610 & 12 & 0,614 & 0,617 & 0,619 & 0,621 & 0,623 & 0,625 & 0,627 & 0,629 \\
\hline 9500 & 0,535 & 0,555 & 0,576 & 0,586 & 0,597 & 0,607 & 0,609 & 0,611 & 0,613 & 0,615 & 0,617 & 0,619 & 0,621 & 0,623 & 0,625 & 0,627 \\
\hline 10000 & 0,534 & 0,554 & 0,575 & 0,585 & 0,595 & 0,606 & 0,608 & 0,610 & 0,612 & 0,614 & 0,616 & 0,618 & 0,620 & 0,622 & 0,624 & 0,626 \\
\hline
\end{tabular}
actual Norma IRAM 11.604.

Tabla X - 2: Valores admisibles del Coeficiente Volumétrico de Pérdidas de Calor $\left(G_{c a l}\right)$ propuestos.

Como puede verse en el Gráfico $X-13$, los valores de $G_{\text {cal }}$ admisibles para el modelo propuesto son inferiores a los valores planteados por la Norma IRAM 11.604; se trata de una reducción de aproximadamente un $45 \%$. Esta reducción en los valores admisibles del $\mathrm{G}_{\text {cal }}$ se 
debe en parte a la mayor exigencia en cuanto a la calidad de la envolvente térmica del edificio y a la reducción del número de renovaciones de aire. Por ejemplo para el caso de la Ciudad de La Plata $\left(1.200^{\circ} \mathrm{D}_{\text {cal }} 18^{\circ} \mathrm{C}\right)$ el $\mathrm{G}_{\text {cal }}$ admisible varía de $0,837 \mathrm{~W} / \mathrm{m}^{3} \cdot \mathrm{K}$ para un edificio de $1.000 \mathrm{~m}^{3} \mathrm{a}$ $0,612 \mathrm{~W} / \mathrm{m}^{3} \cdot \mathrm{K}$ para un edificio de $10.000 \mathrm{~m}^{3}$.

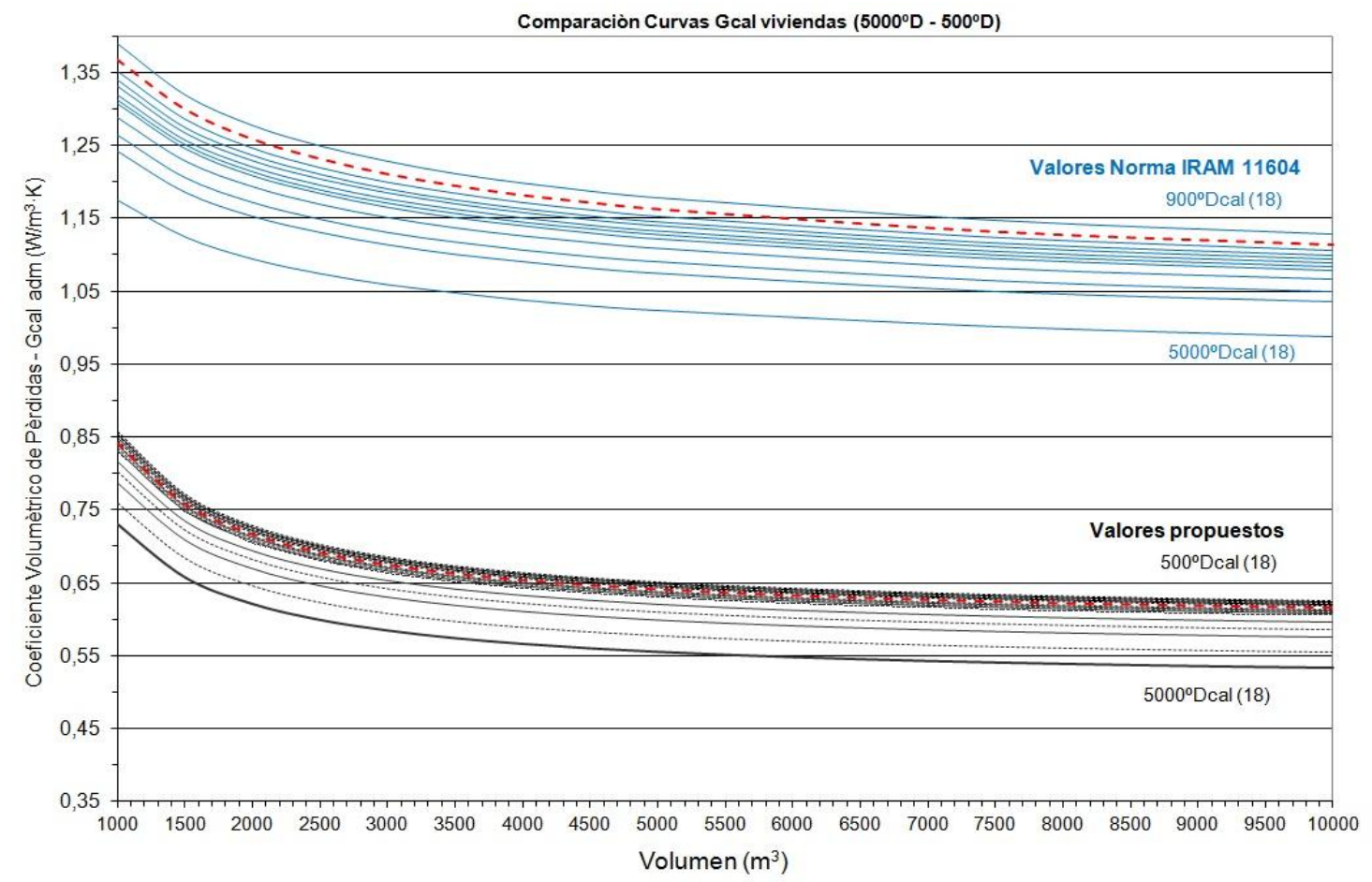

Gráfico X-13: Valores admisibles del $G_{c a l}$ - Comparación de valores actuales y propuestos.

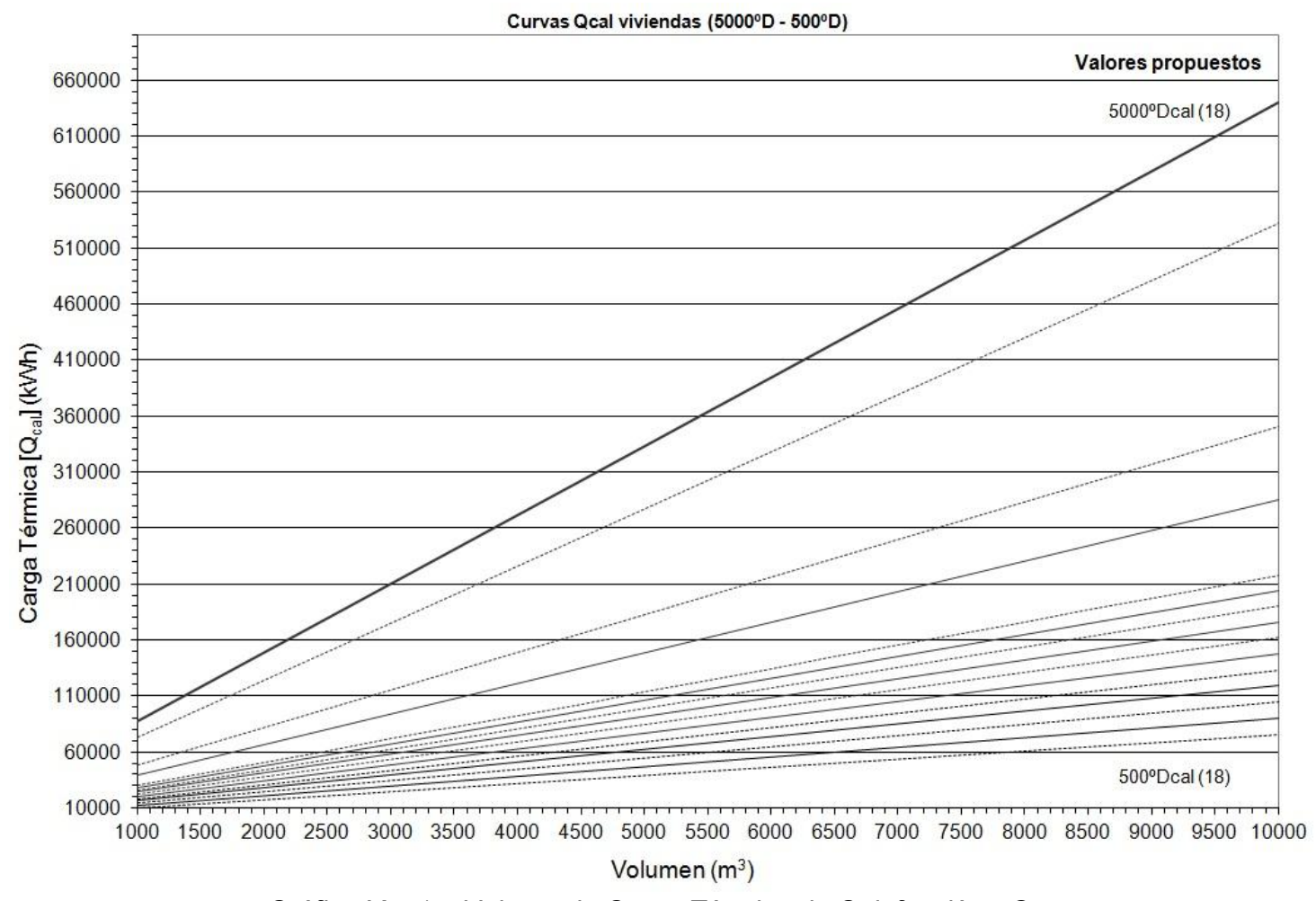

Gráfico X-14: Valores de Carga Térmica de Calefacción - $Q_{c a l}$.

Por su parte el Gráfico X - 14 muestra los valores de Carga Térmica en Calefacción $\left(Q_{c a l}\right)$ para el modelo propuesto; con él se pretende determinar valores máximos admisibles. Por ejemplo, 
para un edificio de $10.000 \mathrm{~m}^{3}$ implantado en la Ciudad de La Plata $\left(1.200^{\circ} \mathrm{D}_{\text {cal }} 18^{\circ} \mathrm{C}\right)$, el valor máximo de la Carga Térmica en Calefacción sería de $176.160 \mathrm{~W}$, mientras que para un edificio de $1.000 \mathrm{~m}^{3}$, para la misma localización, el valor máximo admisible sería de $241.18 \mathrm{~W}$.

Por último el Gráfico X - 15 muestra los valores del Coeficiente de Calefacción por unidad de superficie $\left(\mathrm{S}_{\mathrm{cal}}\right)$ para el modelo propuesto; con él se pretende determinar valores máximos admisibles. Por ejemplo, para un edificio de $10.000 \mathrm{~m}^{3}$ implantado en la Ciudad de La Plata $\left(1.200^{\circ} \mathrm{D}_{\text {cal }} 18^{\circ} \mathrm{C}\right)$ el valor máximo de la Carga Térmica en Calefacción sería de $47,56 \mathrm{~W} / \mathrm{m}^{2}$ mientras que para un edificio de $1.000 \mathrm{~m}^{3}$ para esa misma localización sería de $65,12 \mathrm{~W} / \mathrm{m}^{2}$.

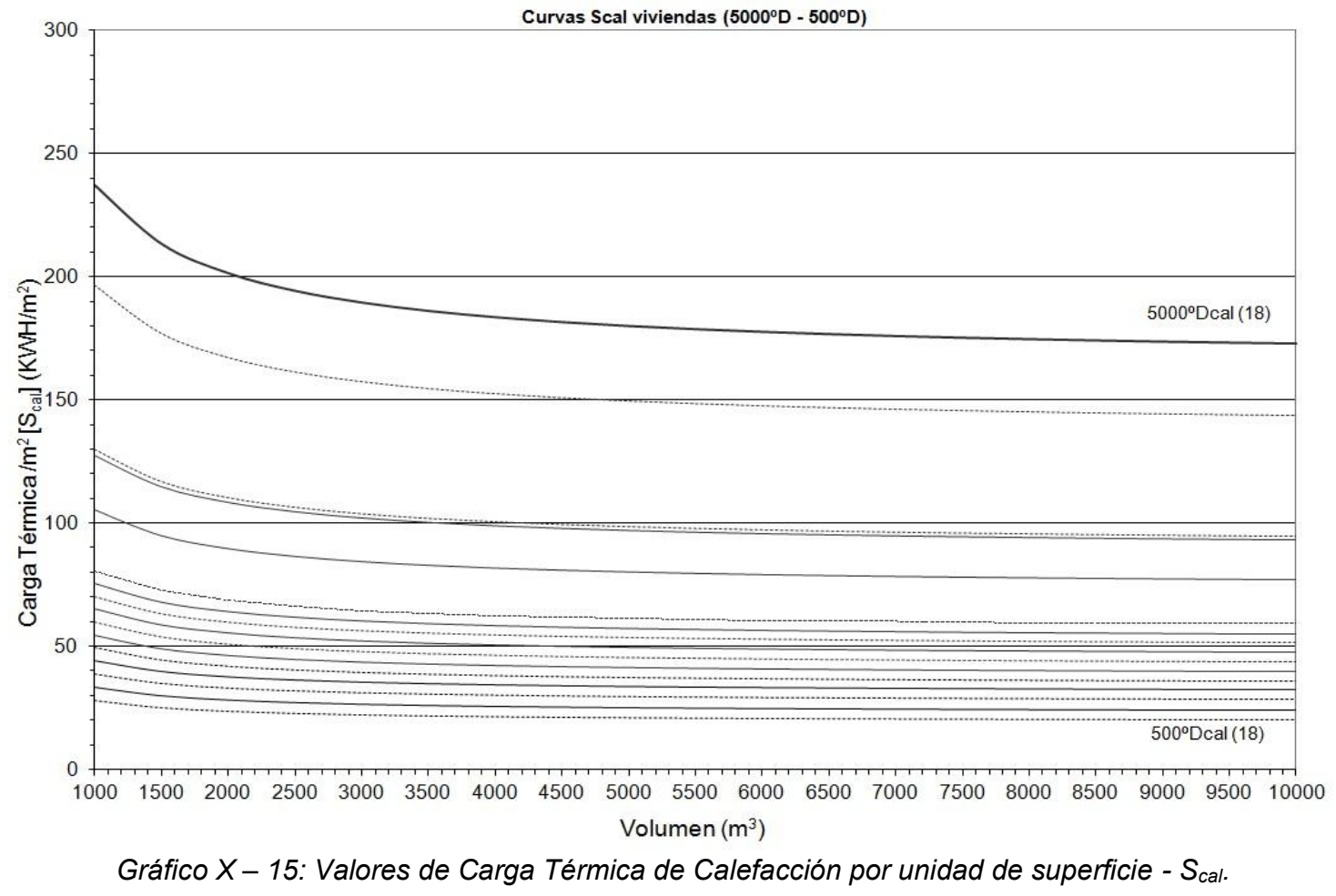

\subsubsection{Ahorro de energía en refrigeración}

El modelo de ahorro de energía en refrigeración para edificios de vivienda en altura adopta la metodología utilizada por el Grupo Eficiencia Energética Edilicia (GEEE) de la Cátedra de Instalaciones de la FAU - UNLP en el año 2006, el cual se convirtió en la parte 2 de la Norma IRAM 11.659 en 2007. De la parte 1 de dicha Norma se tomaron los datos para determinar la carga térmica de refrigeración del edificio.

En aquel entonces, luego de analizar los datos normativos de los que se disponía y ante la inexistencia de Grados Día de Refrigeración propuestos, se planteó la necesidad de adoptar como indicador climático la Temperatura Exterior de Diseño en el período de verano (TDMX). Luego de analizar las características de las distintas zonas bioambientales que conforman la Argentina (Norma IRAM 11.603) se decidió adoptar un rango entre los $30^{\circ} \mathrm{C}$ y los $40^{\circ} \mathrm{C}$ de TDMX.

Se resolvió que la verificación se haría para el día 15 de enero a las $13 \mathrm{hs}$. Como a nivel normativo no se contaba con datos ni procedimientos de cálculo de radiación solar Is horaria para las diferentes latitudes, orientaciones y pendientes de los planos posibles de ser analizados, se propuso un anexo normativo en el cual se analizó la ls horaria en las capitales provinciales respecto de su pertenencia a las zonas bioambientales I a IV, que son las que requerirían de la utilización de refrigeración mecánica durante el período estival. El resultado obtenido fueron 8 tablas con datos de $/ s$ horarios (en $\mathrm{W} / \mathrm{m}^{2}$ y MJ $/ \mathrm{m}^{2}$ ) para nueve orientaciones, para las zonas bioambientales la, Ib, Ila, Ilb, IIla, IIlc, IVa, IVb, IVc y IVd. En la determinación 
de la ls se utilizó el procedimiento de Liu \& Jordan aplicando el $K t$ provisto por la Comisión Nacional de Investigaciones Espaciales (CNIE) de Argentina con el programa Radiac2.

Luego se propusieron tres indicadores de eficiencia energética edilicia en refrigeración para diferentes tipos de edificios para vivienda, complementarios entre sí; la Carga térmica total de verano $\left(Q_{R}\right)$ de la cual se derivan el Coeficiente de refrigeración por unidad de superficie $\left(S_{R}\right)$ y el Coeficiente volumétrico de refrigeración $\left(G_{R}\right)$. Los tipos de vivienda fueron "casa", "placa" y "torre".

\section{Carga térmica total de verano $\left(Q_{R}\right)$ :}

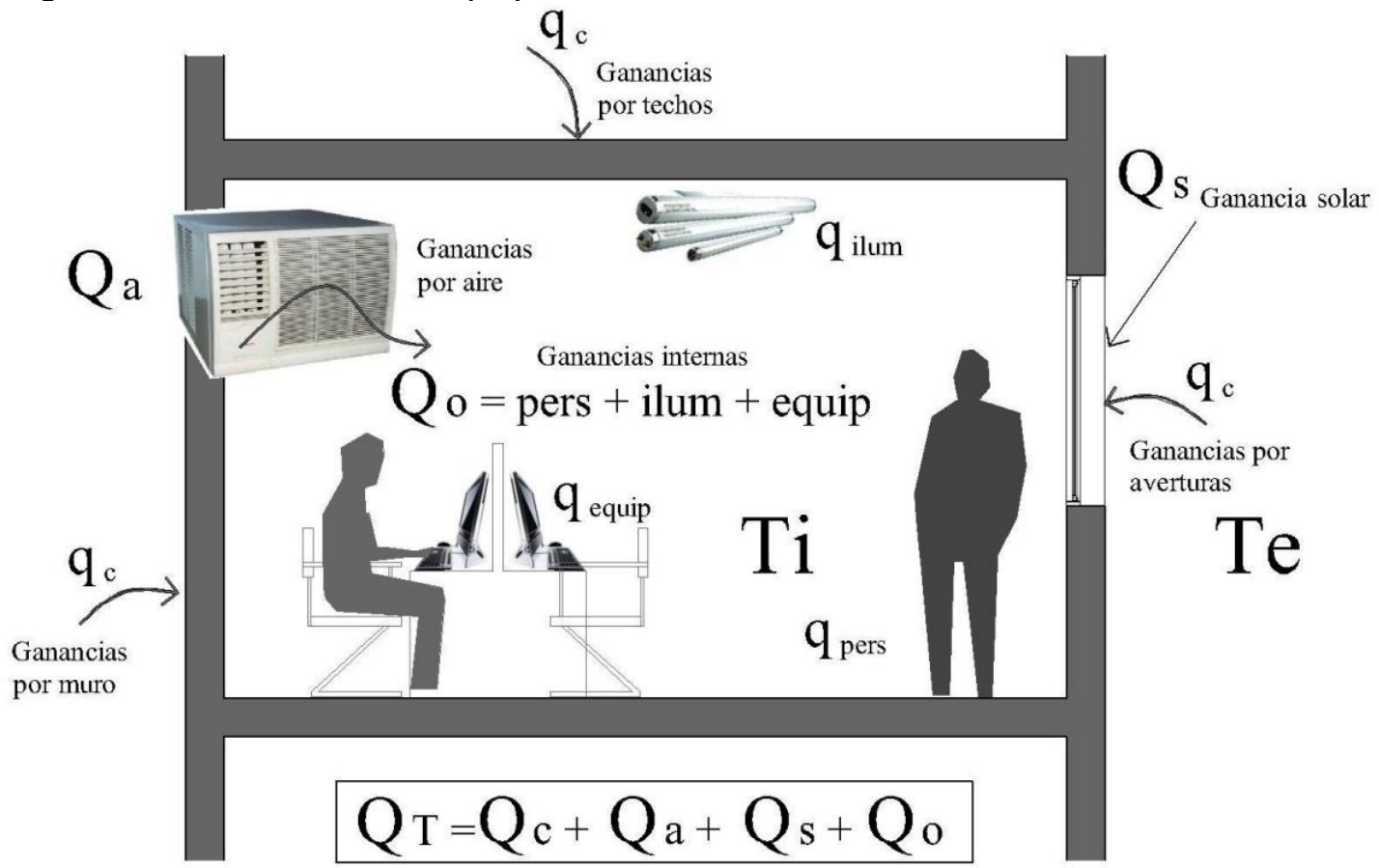

Figura X - 2: Ganancias de calor de un local en verano.

El valor de la carga térmica del edificio o local refrigerado, en estado estacionario, se calcula con la siguiente ecuación general.

Donde:

$$
Q_{R}=Q_{c}+Q_{a}+Q_{s}+Q_{o} \quad[[\text { Ecuación X-13] }
$$

$Q_{R}=$ Carga térmica total $[\mathrm{W}]$.

$Q c=$ Carga térmica por conducción a través de la envolvente $[\mathrm{W}]$.

$Q a=$ Carga térmica por ventilación aportado por el aire exterior [W].

$Q s=$ Carga térmica solar [W].

Qo = Carga térmica por fuentes internas (personas + equipamiento + iluminación) [W].

Carga térmica por conducción a través de la envolvente $\left(Q_{c}\right)$ : La ganancia de calor por conducción parcial $q c$ a través de la envolvente del local se determina con la siguiente ecuación:

$$
\left.Q_{C}=\sum q_{c} \quad \text { [Ecuación } X-14\right]
$$

La sumatoria de todas las pérdidas parciales $q c$ por conducción a través de la envolvente dan como resultado las pérdidas totales por conducción $Q_{C}$, según la siguiente ecuación:

$$
\left.q_{C}=K \cdot A\left(T_{D M X}-T_{i}\right) \quad \text { [Ecuación } X-15\right]
$$


Donde:

$\mathrm{K}=$ Transmitancia térmica del cerramiento (muro, techo, piso, ventana, etc.) $\left[\mathrm{W} / \mathrm{m}^{2} \cdot \mathrm{K}\right]$.

$A=$ Superficie del cerramiento $\left[\mathrm{m}^{2}\right]$.

$T_{D M X}=$ Temperatura exterior de diseño $\left[{ }^{\circ} \mathrm{C}\right]$.

$T_{\mathrm{i}}=$ Temperatura interior $\left[{ }^{\circ} \mathrm{C}\right]$

Carga térmica por ventilación aportada por el aire exterior $\left(Q_{a}\right)$ : En verano se supone al edificio cerrado para reducir pérdidas y ahorrar energía. Esto implica que es necesario ventilar una parte o la totalidad del aire interior, por lo que se supone que debería introducirse en el ambiente interior una importante masa de aire caliente y húmedo que el equipo de aire deberá acondicionar. Este aire de renovación y recirculado contiene humos, partículas en suspensión y olores que son necesarios eliminar.

Donde:

$$
Q_{A}=C A R \times(0,29 \times \Delta t+0,72 \times \Delta w) \text { [Ecuación X - 16] }
$$

CAR: Cantidad de aire a renovar $\left[\mathrm{m}^{3} / \mathrm{h} \cdot \mathrm{pers}\right]$.

$\Delta \mathrm{t}$ : diferencia entre temperatura exterior y temperatura interior $\left[{ }^{\circ} \mathrm{C}\right]$.

$\Delta \mathrm{w}$ : diferencia entre la humedad específica exterior e interior $[\mathrm{g} / \mathrm{kg}]$.

Carga térmica solar $\left(Q_{s}\right)$ : Debido a las superficies vidriadas del local a analizar una parte de los aportes se deberá a la radiación del sol que al atravesar el cristal ingresa al local calentándolo. La radiación del sol varía con cada hora del día solar y también a lo largo de los meses del año. La expresión general para el cálculo de la carga debida al sol es:

Donde:

$$
\left.Q_{S}=S . I_{S} \cdot F_{e s} \quad \text { [Ecuación } X-17\right]
$$

$Q_{S}$ : ganancia solar [W].

$S:$ superficie vidriada $\left[\mathrm{m}^{2}\right]$.

$I_{\mathrm{S}}$ : Intensidad de la radiación solar $\left[\mathrm{W} / \mathrm{m}^{2}\right]$.

$\mathrm{F}_{\mathrm{es}}$ : Factor de exposición solar del vidrio o aventanamiento (adimensional 0 a 1)

Carga térmica por fuentes internas $\left(Q_{0}\right)$ : Es la suma del calor total por personas, más el calor sensible de la iluminación artificial, más el calor sensible de artefactos. La expresión general para el cálculo de la carga debida a fuentes internas es:

Donde:

$$
Q_{O}=Q_{\text {pers }}+Q_{\text {ilum }}+Q_{\text {equip }} \quad[\text { Ecuación X - 18] }
$$

$Q_{0}$ : carga térmica por fuentes internas [W].

$Q_{\text {PERS: }}$ aporte de calor interno por personas; sensible + latente [W].

$Q_{\text {ILUM: }}$ aporte de calor interno por iluminación; sensible [W].

QEQUIP: aporte de calor interno por equipamiento; sensible + latente [W]

Otras ganancias internas de calor sensible: Existen otros aportes internos debidos a los conductos de inyección y retorno de aire acondicionado. Es usual que estos se establezcan como un valor estimado porcentual. Existe otra penalización a agregar debida a la calidad en la construcción de los conductos de distribución y retorno, y que en general se establece entre un $4 \%$ y un $10 \%$ de la suma de calor sensible debida a conducción y efecto solar.

\section{El Coeficiente de refrigeración por unidad de superficie $\left(S_{R}\right)$ :}

El valor del Coeficiente de refrigeración por unidad de superficie del edificio o local refrigerado, se calcula con la fórmula siguiente: 


\section{Donde:}

$$
S_{R}=Q_{R} / A_{R} \quad \text { [Ecuación X - 19] }
$$

$Q_{R}$ : Carga térmica total de verano $[\mathrm{W}]$.

$A_{R}$ : Superficie refrigerada $\left[\mathrm{m}^{2}\right]$.

\section{El coeficiente volumétrico de refrigeración $\left(G_{R}\right)$ :}

El valor del coeficiente volumétrico de refrigeración del edificio o local refrigerado, se calcula con la fórmula siguiente:

$$
\left.G_{R}=Q_{R} / V_{R} \quad \text { [Ecuación } X-20\right]
$$

Donde:

$Q_{R}$ : Carga térmica total de verano [W].

$V_{R}$ : Volumen refrigerado $\left[\mathrm{m}^{3}\right]$.

\section{El modelo edilicio:}

El modelo de ahorro de energía en refrigeración para edificios de vivienda en altura es el mismo que para el caso de calefacción. El mismo parte de la repetición en altura de una planta tipo de $185 \mathrm{~m}^{2}$, con altura de local mínima media según Códigos de Edificación de $2,70 \mathrm{~m}$, y con un volumen variable entre $1.000 \mathrm{~m}^{3}$ (dos niveles) y $10.000 \mathrm{~m}^{3}$ (veinte niveles). Esto implica un volumen creciente a superficie de planta constante (Figura $X-3$ ), a partir del cual se obtienen las superficies de la envolvente discriminadas; muros, techos y superficies vidriadas.

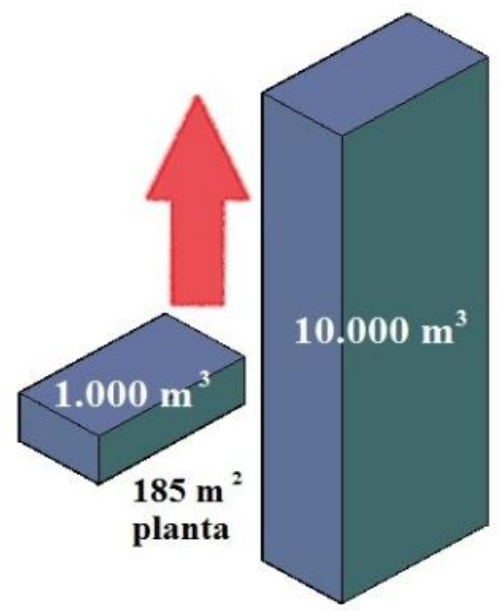

Figura X - 3: Modelo adoptado de volumen edilicio creciente.

El hecho de adoptar una planta de $185 \mathrm{~m}^{2}$ que se desarrolla en altura está relacionado con el relevamiento de casos de la realidad donde puede apreciarse cómo el avance de este tipo edilicio en las limitaciones de los solares urbanos es incentivado por la especulación inmobiliaria, tal como se menciona anteriormente.

Por otra parte en lo que respecta a la relación vidriado - opaco se prevé un máximo del $20 \%$ de superficie vidriada sobre el total de la envolvente vertical, el cual se distribuye según un criterio bioclimático (Czajkowski, J.; Corredera, C.; 2006) de la siguiente forma:

- No se admiten vidriados en techos.

- 40\% del área vidriada se ubica al norte. 
- 25\% del área vidriada se ubica al este.

- $25 \%$ del área vidriada se ubica al oeste.

- $10 \%$ del área vidriada se ubica al sur.

En cuanto a las Renovaciones de Aire, igual que para el caso de calefacción, se adopta un valor de 0,7RA, que cumple con los requisitos mínimos de salubridad y confort.

\section{Calidad térmica de la envolvente:}

Como se mencionó anteriormente la Norma IRAM 11.605 sugiere tres niveles de calidad térmica para muros y techos -A, B y C-. Debido a que los valores de transmitancia térmica propuestos por el Nivel C son ineficientes en cuanto al ahorro de energía, dicho nivel fue descartado. Por consiguiente se tomó como nivel de calidad térmica para muros y techos un nivel intermedio entre los niveles A y B propuestos por la Norma IRAM 11.605.

Asimismo se propuso el uso de una transmitancia térmica "K" variable en función de la variación de la Temperatura Exterior de Diseño "TDMX" de verano (IRAM 11.603). Esto implica una variación desde $\mathrm{K}_{\text {techos }}=0,335 \mathrm{~W} / \mathrm{m}^{2} \cdot \mathrm{K}$ y $\mathrm{K}_{\text {muros }}=0,875 \mathrm{~W} / \mathrm{m}^{2} \cdot \mathrm{K}$ para una $\mathrm{T}_{\mathrm{DMX}}=30^{\circ} \mathrm{C}$ hasta un $\mathrm{K}_{\text {techos }}=0,315 \mathrm{~W} / \mathrm{m}^{2} \cdot \mathrm{K}$ y K muros $=0,775 \mathrm{~W} / \mathrm{m}^{2} . \mathrm{K}$ para una $\mathrm{T}_{\mathrm{DMX}}=40^{\circ} \mathrm{C}$.

En cuanto al sistema de carpinterías se plantea la utilización de sistemas con DVH + Low-e. De la Tabla A.1 del Anexo A de la Norma IRAM $11.507-4$ se obtuvo el valor de $\mathrm{k}=1,80 \mathrm{~W} / \mathrm{m}^{2} \cdot \mathrm{K}$ para ventanas simples con perfilería de aluminio y ruptor de puente térmico. La elección de este tipo de carpinterías busca reducir las ganancias de calor a través de las superficies vidriadas.

Como se mencionó anteriormente la verificación del modelo se hizo para el rango entre los $30^{\circ} \mathrm{C}$ y los $40^{\circ} \mathrm{C}$ de TDMX, para el día 15 de enero a las $13 \mathrm{hs}$.

\section{Sobre referencia climática:}

Las Normas IRAM 11.601/3/4/5 utilizan diferentes criterios para adoptar un valor de referencia climática del sitio donde se implantará el edificio. Para la situación de verano puede utilizarse la temperatura de diseño máxima de la IRAM 11.603 o los grados día de enfriamiento, que están en los antecedentes de dicha norma.

Sin embargo, como se mencionó anteriormente, se utilizó el criterio adoptado en el trabajo realizado por el Grupo Eficiencia Energética Edilicia (GEEE) de la Cátedra de Instalaciones de la FAU - UNLP, en el cual se hizo un análisis comparativo del antecedente respecto de las necesidades de refrigeración en el territorio nacional. En aquel trabajo se concluyó que hay un rango que va de los 100 Grados Día de Refrigeración $\left(G_{R}\right)$ en el norte de la Patagonia (latitud $=40^{\circ}$ Sur) a los 1.000 Grados Día de Refrigeración $\left(G_{R}\right)$ en la zona chaqueñoformoseña (latitud $=25^{\circ}$ Sur). Esto implica un rango de Temperaturas de Diseño Máximas que va desde los $30^{\circ} \mathrm{C}$ a los $40^{\circ} \mathrm{C}$.

Cabe destacar que mientras los Grados Día de Refrigeración $\left(G_{R}\right)$ funcionan como un indicador muy útil en la determinación de la Carga Térmica Anual en Refrigeración con fines de economía y gestión ambiental de la energía, no lo son tanto en cuanto a verificar la Calidad Térmica y el Diseño Ambiental de la envolvente; aunque estén relacionados. Razón por la cual se optó por utilizar la Temperatura de Diseño Exterior.

\section{Radiación solar:}

Como se concluyó en el antecedente, la radiación solar es un componente significativo en la carga térmica de un local o edificio y no es sencillo encontrar una correlación de fácil implementación ya que en la Argentina existen variaciones por latitud, altitud o amplitud térmica según el sitio. Motivo por el cual fue necesario adoptar un criterio que permita tratarla como un valor preestablecido, de manera que se pondere su influencia según las diferentes orientaciones del edificio, al tiempo que se contemple la variación en latitud y longitud. 
Para este modelo se adoptaron los valores propuestos en el trabajo desarrollado por el Grupo Eficiencia Energética Edilicia (GEEE) de la Cátedra de Instalaciones de la FAU - UNLP, para las $13 \mathrm{hs}$. del día 15 de enero: Plano horizontal $736 \mathrm{~W} / \mathrm{m}^{2}$; Norte $370 \mathrm{~W} / \mathrm{m}^{2}$; Sur $268 \mathrm{~W} / \mathrm{m}^{2}$; Este $268 \mathrm{~W} / \mathrm{m}^{2} ;$ y 360 Oeste $\mathrm{W} / \mathrm{m}^{2}$. Se adoptó un factor de exposición solar $\mathrm{F}_{\mathrm{ES}}$ de 0,5 que implica la utilización de algún sistema o mecanismo que permita reducir la carga solar sobre las áreas vidriadas. Es un valor que puede alcanzarse con cortinas de enrollar, toldos o parasoles; todos de uso muy frecuente en el país.

El modelo propuesto no tiene en cuenta el aporte de calor solar por conducción en la envolvente opaca puesto que la verificación se realiza en estado estacionario y supone la incorporación de aislamiento térmico a esta parte de la envolvente edilicia.

\section{Carga térmica por iluminación artificial:}

En cuanto a las fuentes internas de energía debidas a la iluminación artificial se adoptó un nivel de iluminación de 250 lux propuestos por la Norma IRAM 11.659-1 para viviendas, que equivale a un factor de $10 \mathrm{~W} / \mathrm{m}^{2}$ para lámparas del tipo bajo consumo. Al respecto se prevé que las necesidades de iluminación se cubran en un 100\% con lámparas de bajo consumo, despreciándose el uso de lámparas incandescentes o halógenas para satisfacer esta demanda.

\section{Carga térmica por fuentes internas:}

En el caso de la carga térmica por personas se adoptó una densidad de $12 \mathrm{~m}^{2} /$ persona y 99 W/persona de calor total (sensible + latente). En cuanto al equipamiento se utilizó un coeficiente de $16,4 \mathrm{~W} / \mathrm{m}^{2}$ de calor sensible y $2,12 \mathrm{~W} / \mathrm{m}^{2}$ de calor latente.

Para la carga de calor total por renovaciones de aire se utilizó una tasa de ventilación sanitaria de $15 \mathrm{~m}^{3} / \mathrm{h} /$ persona (Norma IRAM 11.659-1).

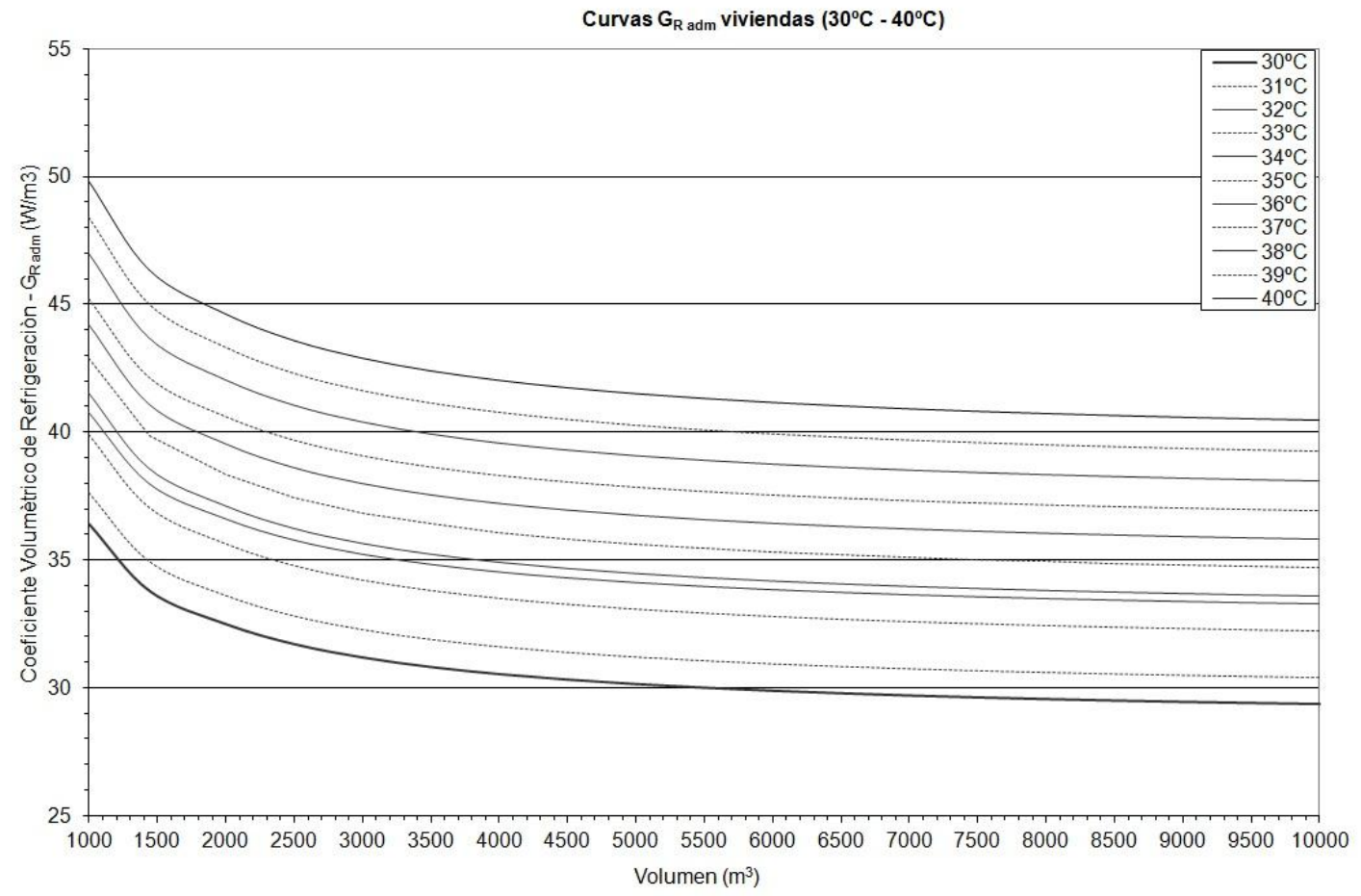

Gráfico X-16: Valores admisibles para el Coeficiente Volumétrico de Refrigeración $-G_{R}$.

El Gráfico X - 16 muestra los valores de $G_{R}$ admisibles para el modelo propuesto; para el caso de la Ciudad de La Plata $\left(35^{\circ} \mathrm{C}\right)$ el $G_{R}$ admisible varía de $42,89 \mathrm{~W} / \mathrm{m}^{3}$ para un edificio de $1.000 \mathrm{~m}^{3}$ a $34,71 \mathrm{~W} / \mathrm{m}^{3}$ para un edificio de $10.000 \mathrm{~m}^{3}$. Por su parte el Gráfico X - 17 muestra los 
valores de Carga Térmica de Refrigeración $\left(Q_{R}\right)$ para el modelo propuesto; con él se pretende determinar valores máximos admisibles. Por ejemplo, para un edificio de $10.000 \mathrm{~m}^{3}$ implantado en la Ciudad de La Plata $\left(35^{\circ} \mathrm{C}\right)$, el valor máximo de la Carga Térmica de Refrigeración sería de $347.142 \mathrm{~W}$, mientras que para un edificio de $1.000 \mathrm{~m}^{3}$, para la misma localización, el valor máximo admisible sería de 42.889W.

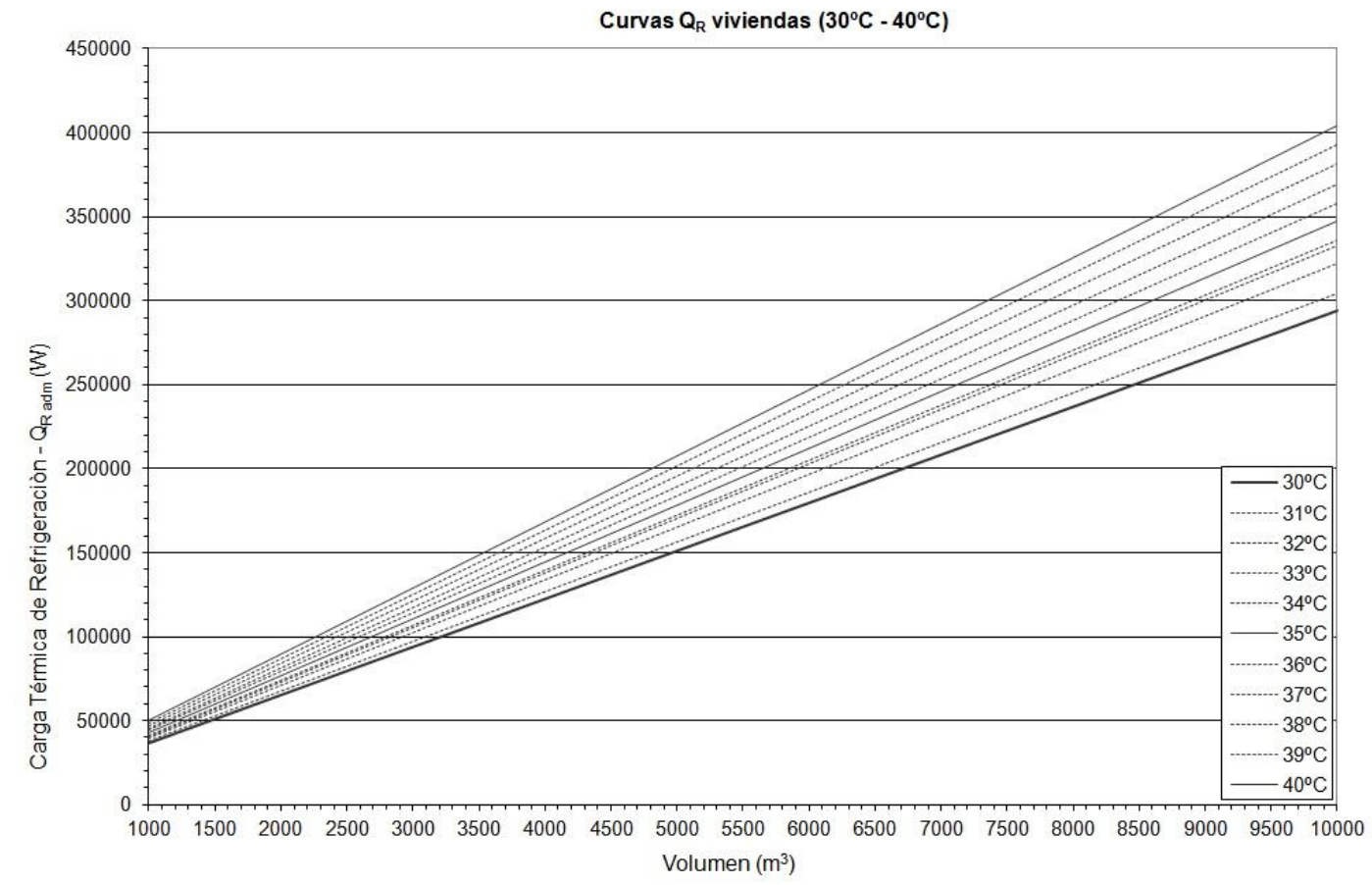

Gráfico X-17: Valores de Carga Térmica en Refrigeración $-Q_{R}$.

Por último el Gráfico X - 18 muestra los valores del Coeficiente de Refrigeración por unidad de superficie $\left(S_{R}\right)$ para el modelo propuesto; con él se pretende determinar valores máximos admisibles. Por ejemplo, para un edificio de $10.000 \mathrm{~m}^{3}$ implantado en la Ciudad de La Plata $\left(35^{\circ} \mathrm{C}\right)$ el valor máximo de la Carga Térmica de Refrigeración sería de $93,73 \mathrm{~W} / \mathrm{m}^{2}$ mientras que para un edificio de $1.000 \mathrm{~m}^{3}$ para esa misma localización sería de $115,80 \mathrm{~W} / \mathrm{m}^{2}$.

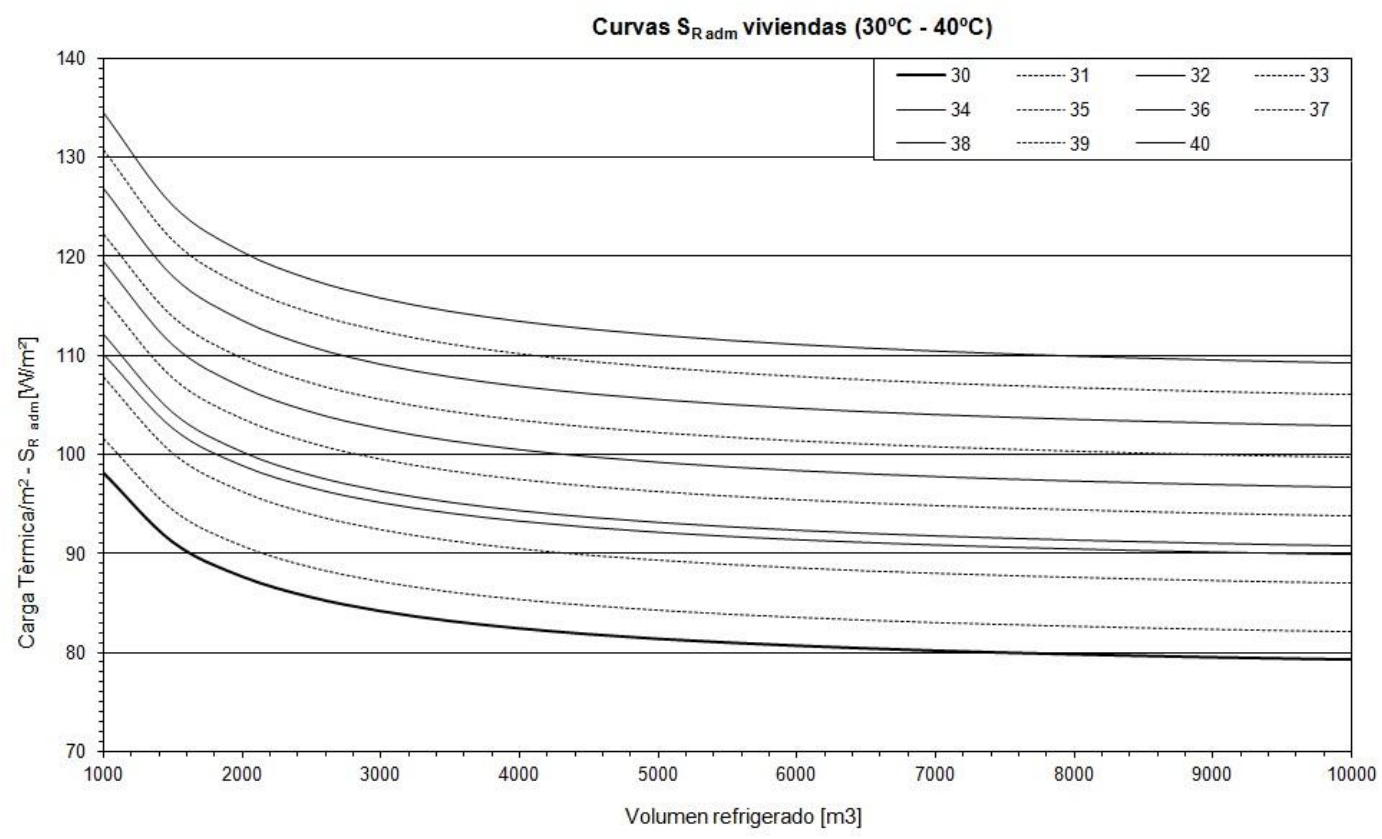

Gráfico X-18: Valores de Carga Térmica en Refrigeración por unidad de superficie - $S_{R}$. 


\subsection{Modelo de ahorro de energía para edificios de oficinas}

A continuación se muestran los resultados del modelo de ahorro de energía en calefacción y refrigeración para edificios de oficinas para centros urbanos de alta densidad de toda Argentina. Los datos que se muestran a continuación son, como se menciona anteriormente, el resultado de la discusión con profesionales e investigadores de distintas áreas de los avances presentados en distintos congresos y en el Subcomité de Acondicionamiento Térmico de Edificios de IRAM.

\subsubsection{Ahorro de energía en calefacción}

La actual Norma IRAM 11.604 establece el método de cálculo del Coeficiente Volumétrico de Pérdidas de Calor $\left(G_{\text {cal }}\right)$, el cual permite evaluar el ahorro de energía en calefacción para edificios destinados a vivienda, oficina, comercio, industria, salud, educación, etc. Esta Norma determina además, los parámetros de ahorro de energía para calefaccionar este tipo de edificios a través de los valores máximos admisibles del coeficiente volumétrico de pérdidas de calor $\left(\mathrm{G}_{\text {cal adm }}\right)$.

Sin embargo las curvas que determinan los valores máximos admisibles para el $\mathrm{G}_{\text {cal }}$ establecidas en la actual Norma IRAM 11.604 fueron calculadas teniendo en cuenta parámetros aplicables a edificios de viviendas.

Entre las propuestas de mejora para la Norma IRAM 11.604 llevadas a las reuniones del Subcomité de Acondicionamiento Térmico de Edificios de IRAM se planteó la necesidad de elaborar curvas que determinen los valores máximos admisibles para el Coeficiente Volumétrico de Pérdidas de Calor $\left(G_{c a l}\right)$ para edificios de oficinas, que difieran de los valores planteados para edificios de viviendas.

Esta propuesta, que se muestra a continuación, sigue los lineamientos de cálculo y da continuidad al modelo de ahorro de energía en calefacción propuesto por la actual Norma IRAM 11.604 pero tiene en cuenta parámetros relacionados con la forma y la envolvente edilicia, aplicables a edificios de oficinas.

Como se menciona anteriormente, según esta Norma el Coeficiente Volumétrico de Pérdidas de Calor $\left(G_{\text {cal }}\right)$ se calcula con la siguiente ecuación:

$$
G_{c a l}=\frac{\sum K m * S m+\sum K v * S v+\sum \gamma K r * S r+P e r P p}{v}+0.35 n
$$

[Ecuación X -21]

Donde:

$\boldsymbol{G}_{\text {cal: }}$ coeficiente volumétrico de pérdidas de calor del edificio $\left[\mathrm{W} / \mathrm{m}^{3} \cdot \mathrm{K}\right]$.

$K_{m}$ : transmitancia térmica de cerramientos opacos (muros, techos y pisos en contacto con el exterior) $\left[\mathrm{W} / \mathrm{m}^{2} \cdot \mathrm{K}\right]$.

$\boldsymbol{S}_{\boldsymbol{m}}$ : área de los cerramientos opacos en contacto con el exterior $\left[\mathrm{m}^{2}\right]$.

$K_{v}$ : transmitancia térmica de los cerramientos no opacos que lindan con el exterior $\left[\mathrm{W} / \mathrm{m}^{2} \cdot \mathrm{K}\right]$.

$\boldsymbol{S}_{v}$ : área de los cerramientos no opacos en contacto con el exterior $\left[\mathrm{m}^{2}\right]$.

$\boldsymbol{y} \boldsymbol{K}_{r}$ : transmitancia térmica corregida de los cerramientos opacos y no opacos que lindan con locales no calefaccionados $\left[\mathrm{W} / \mathrm{m}^{2} \cdot \mathrm{K}\right]$.

$S_{r}$ : área de los cerramientos opacos que lindan con locales no calefaccionados $\left[\mathrm{m}^{2}\right]$.

$\boldsymbol{P}_{\text {er: }}$ : perímetro del piso en contacto con el aire exterior $\left[\mathrm{m}^{2}\right]$.

$\boldsymbol{P}_{\boldsymbol{p}}$ : pérdidas por piso en contacto con el terreno.

$V:$ volumen interior del edificio calefaccionado $\left[\mathrm{m}^{3}\right]$.

0,35: capacidad específica del aire $\left[\mathrm{Wh} / \mathrm{m}^{3} \cdot \mathrm{K}\right]$.

n: número de renovaciones de aire promedio por hora del edificio calefaccionado.

Por su parte, según la Norma IRAM 11.604, el cálculo de la Carga Térmica Anual (Q) del edificio calefaccionado se determina con la siguiente ecuación: 


$$
Q=\frac{24^{* \mathrm{o}} D^{*} G c a l * V}{1.000}
$$

[Ecuación X - 22]

Donde:

Q: carga térmica anual de calefacción [kWh].

24: Tiempo de calefacción por día.

${ }^{\circ} D$ : Grados día de calefacción anual (obtenidos de la Norma IRAM 11.603) [ $\left.{ }^{\circ} \mathrm{C}\right]$.

$\boldsymbol{G}_{\text {cal: }}$ : coeficiente volumétrico de pérdidas de calor del edificio $\left[\mathrm{W} / \mathrm{m}^{3} \cdot \mathrm{K}\right]$.

$V:$ volumen interior del edificio calefaccionado $\left[\mathrm{m}^{3}\right]$.

Asimismo, como parte de la propuesta presentada al Subcomité de Acondicionamiento Térmico de Edificios de IRAM se propone determinar el Coeficiente de Calefacción por unidad de superficie - $S_{\text {cal }}$, el cual puede ser calculado con la siguiente ecuación:

Donde:

$$
\left.S_{\text {cal }}=Q_{C} / A_{C} \quad \text { [Ecuación } X-23\right]
$$

$\boldsymbol{S}_{\text {cal: }}$ : Coeficiente de Calefacción por Unidad de Superficie $\left[\mathrm{kWh} / \mathrm{m}^{2}\right]$

$Q_{C}$ : Carga térmica total de invierno $[\mathrm{kWh}]$

$\boldsymbol{A}_{\boldsymbol{C}}$ : Superficie calefaccionada $\left[\mathrm{m}^{2}\right]$

El modelo edilicio de referencia de la actual Norma IRAM 11.604 parte de un cubo que crece a altura constante de $2,70 \mathrm{~m}$, y que va desde los $50 \mathrm{~m}^{3}$ a $10.000 \mathrm{~m}^{3}$. Este modelo que también sirve de referencia a edificios de vivienda no es comparable con los casos de edificios de oficinas que se construyen en la actualidad; los cuales se desarrollan mayormente en altura, en los solares urbanos.

Al mismo tiempo la propuesta presentada al Subcomité de Acondicionamiento Térmico de Edificios de IRAM plantea la mejora de la envolvente térmica del modelo edilicio de referencia de la actual Norma IRAM 11.604, la cual propone la utilización del Nivel C de la Norma IRAM 11.605 en cuanto a la transmitancia térmica de muros y techos. Cabe destacar que los valores de transmitancia térmica propuestos por el Nivel C son ineficientes en cuanto al ahorro de energía.

A continuación se explica el procedimiento para la elaboración de las curvas para el modelo de referencia para edificios de oficinas en altura, eje del desarrollo de esta Tesis.

\section{El modelo edilicio:}

El modelo propuesto para este tipo edilicio, al igual que para el caso de viviendas en altura, parte de la repetición en altura de una planta tipo de $185 \mathrm{~m}^{2}$, con altura de local mínima media según Códigos de Edificación de $2,70 \mathrm{~m}$, y con un volumen variable entre $1.000 \mathrm{~m}^{3}$ (dos niveles) y $10.000 \mathrm{~m}^{3}$ (veinte niveles). Esto implica un volumen creciente a superficie de planta constante (Figura $X-4$ ), a partir del cual se obtienen las superficies de la envolvente discriminadas; muros, techos y superficies vidriadas.

El hecho de adoptar una planta de $185 \mathrm{~m}^{2}$ que se desarrolla en altura está relacionado con el relevamiento de casos de la realidad donde puede apreciarse cómo el avance de este tipo edilicio en las limitaciones de los solares urbanos es incentivado por la especulación inmobiliaria. 


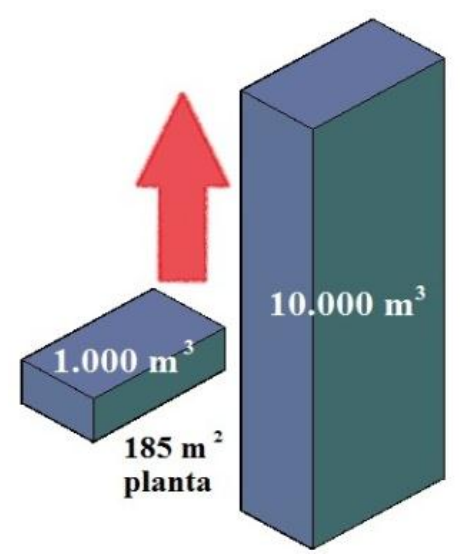

Figura X - 4: Modelo adoptado de volumen edilicio creciente.

Por otra parte en lo que respecta a la relación vidriado - opaco se prevé un máximo del $50 \%$ de superficie vidriada sobre el total de la envolvente vertical, la cual se distribuye según un criterio bioclimático (Czajkowski, J.; Corredera, C.; 2006) de la siguiente forma:

- No se admiten vidriados en techos.

- $40 \%$ del área vidriada se ubica al norte.

- $25 \%$ del área vidriada se ubica al este.

- $25 \%$ del área vidriada se ubica al oeste.

- 10\% del área vidriada se ubica al sur.

En cuanto a las Renovaciones de Aire el apartado 6.6.1 de la actual Norma IRAM 11.604 plantea que el número de renovaciones de aire del edificio de vivienda calefaccionado requerido para el cálculo de $\mathrm{G}_{\text {cal }}$ es 2 , salvo que se realice la verificación de acuerdo con el apartado 6.6.2. Esto es cuando se disponga de valores de infiltración de las carpinterías, puede calcularse el valor de las renovaciones de aire mediante el método indicado en el apartado B.1.2 del Anexo B, debiendo tener en cuenta que la ventilación natural y controlada de los locales de la vivienda debe cumplir con los requisitos mínimos de salubridad y confort. Se utilizó el método de cálculo propuesto por el Anexo B de la actual Norma IRAM 11.604 pero los resultados obtenidos fueron valores muy bajos $(0,11<\mathrm{RA}<0,28)$. Por este motivo se decidió adoptar un valor de 0,7RA, que cumple con los requisitos mínimos de salubridad y confort (Ley 13.059 - Provincia de Buenos Aires).

\section{Calidad térmica de la envolvente:}

La Norma IRAM 11.605 sugiere tres niveles de calidad térmica para muros y techos -A, B y C-. Debido a que los valores de transmitancia térmica propuestos por el Nivel $C$ son ineficientes en cuanto al ahorro de energía, dicho nivel fue descartado.

Para el modelo propuesto se utilizó un valor intermedio entre el Nivel A y el Nivel B de la Norma IRAM 11.605 para muros y techos (Czajkowski, J.; Gómez, A.; 2009). Siguiendo este criterio se adoptaron valores de $\mathrm{K}_{\max }$ admisibles para la condición de invierno, para muros y techos, los cuales varían en función de los valores de Temperatura Mínima Exterior de Diseño (TDMN) [ ${ }^{\circ} \mathrm{C}$ ] en un rango que va desde $-15^{\circ} \mathrm{C}$ a $0^{\circ} \mathrm{C}$, tal como en el caso de viviendas.

Asimismo la propuesta presentada al Subcomité de Acondicionamiento Térmico de Edificios plantea un nuevo límite inferior de $500^{\circ} \mathrm{D}_{\text {cal }} 18^{\circ} \mathrm{C}$ para las curvas del Coeficiente Volumétrico de Pérdidas $\left(\mathrm{G}_{\text {cal }}\right)$, por debajo de los $900^{\circ} \mathrm{D}_{\text {cal }} 18^{\circ} \mathrm{C}$ que propone la Norma actual. Esto permite la inclusión de zonas Templadas - Cálidas que no son contempladas en la actual Norma IRAM 11.604, y que también requieren de calefacción en el periodo invernal.

En cuanto al sistema de carpinterías se plantea la utilización de sistemas con DVH y Low-e. De la Tabla A.1 del Anexo A de la Norma IRAM 11.507-4 se obtuvo el valor de $\mathrm{K}=1,80 \mathrm{~W} / \mathrm{m}^{2} \mathrm{~K}$. La 
elección de este tipo de carpinterías busca reducir las pérdidas de calor a través de las superficies vidriadas, que son mayores que para el caso de edificios de viviendas.

La Tabla X - 3 muestra los valores admisibles del Coeficiente Volumétrico de Pérdidas de Calor $\left(G_{c a l}\right)$ para el modelo edilicio de referencia para edificios de oficinas en altura. El Gráfico X - 21 por su parte muestra estos valores y los compara con los valores propuestos por la actual Norma IRAM 11.604.

\begin{tabular}{|c|c|c|c|c|c|c|c|c|c|c|c|c|c|c|c|c|}
\hline \multirow{2}{*}{$\begin{array}{c}\begin{array}{c}\text { Volumen } \\
\left(\mathrm{m}^{3}\right)\end{array} \\
\end{array}$} & \multicolumn{16}{|c|}{ Grados Día de Calefacción $\left(18^{\circ} \mathrm{C}\right)$} \\
\hline & $000^{\circ} \mathrm{D}$ & $4000^{\circ} \mathrm{D}$ & $3000^{\circ} \mathrm{D}$ & $2500^{\circ} \mathrm{D}$ & $2000^{\circ} \mathrm{D}$ & $1500^{\circ} \mathrm{D}$ & $1400^{\circ} \mathrm{D}$ & $1300^{\circ} \mathrm{D}$ & $1200^{\circ} \mathrm{D}$ & $1100^{\circ} \mathrm{D}$ & $1000^{\circ} \mathrm{D}$ & $900^{\circ} \mathrm{D}$ & $800^{\circ} \mathrm{D}$ & $700^{\circ} \mathrm{D}$ & $600^{\circ} \mathrm{D}$ & $500^{\circ} \mathrm{D}$ \\
\hline 1000 & 0,839 & 0,855 & 0,871 & 0,879 & 0,887 & 0,895 & 0,896 & 0,898 & 0,900 & 0,901 & 0,903 & 0,905 & 0,906 & 0,908 & 0,909 & ,911 \\
\hline 1500 & 752 & 767 & 782 & 0,789 & 0,796 & 0,804 & 05 & 0,807 & 0,808 & 0,810 & 0,811 & 0,813 & 814 & 0,816 & 0,817 & 819 \\
\hline 2000 & 709 & 723 & 737 & 0,744 & 0,751 & 0,758 & & 0,761 & 0,763 & 0,764 & 0,765 & 0,767 & 0,768 & 0,770 & 0,771 & 0,772 \\
\hline 2500 & 583 & 697 & 710 & 717 & 0.724 & 0731 & & & & 737 & 0.738 & & & 742 & 743 & 745 \\
\hline at & & & & & 0,100 & & & & & & 20 & 21 & 22 & 24 & 25 & 20 \\
\hline 00 & 653 & 666 & 680 & 686 & 0,693 & 00 & & & & & 706 & 08 & 09 & 711 & 712 & 713 \\
\hline ant & 44 & 57 & 70 & 677 & 583 & & & & & & 697 & 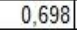 & & 701 & 702 & 703 \\
\hline 00 & 36 & 50 & 63 & 669 & 0,676 & 0,682 & 84 & 685 & 86 & 588 & 0,689 & 0,690 & 692 & 0,693 & 694 & ,696 \\
\hline 00 & 331 & 644 & 657 & 663 & 0,670 & 0,676 & 78 & 679 & 680 & 682 & 0,683 & 0,684 & 0,686 & 0,687 & 0,688 &, 689 \\
\hline 500 & 626 & 639 & 652 & 0,658 & 0,665 & 0,671 & 0,673 & 0,674 & 0,675 & 0,677 & 0,678 & 0,679 & 0,681 & 0,682 & 0,683 & 0,684 \\
\hline 6000 & 622 & 635 & 648 & 0,654 & 0,661 & 0,667 & 0,669 & 0,670 & 0,671 & 0,672 & 0,674 & 0,675 & 0,676 & 0,678 & 0,679 & 0,680 \\
\hline 500 & 619 & 632 & 644 & 0,651 & 0,657 & 0,664 & 0,665 & 0,666 & & 669 & 0,670 & 0,672 & 0,673 & 0,674 & 0,675 & 0,677 \\
\hline 00 & 16 & 629 & 642 & 648 & 0,654 & 0,661 & & & 65 & 66 & 0,667 & 0,668 & 670 & 671 & 672 & 674 \\
\hline 7500 & 613 & 626 & 639 & 645 & 0,652 & 0,658 & 59 & 661 & 62 & 63 & 0,665 & 0,666 & 0,667 & 0,668 & 670 & 671 \\
\hline 100 & 11 & 624 & 637 & 643 & 650 & 656 & & 58 & & & 0,662 & 0,664 & 0,665 & 0,666 & 667 & 669 \\
\hline 8500 & 609 & 622 & 635 & 641 & 0,648 & 0,654 & 655 & 0,656 & 58 & 659 & 0,660 & 0,662 & 0,663 & 0,664 & 0,665 & 0,667 \\
\hline 9000 & 0,608 & 620 & 0,633 & 0,639 & 0,646 & 0,652 & 0,653 & 0,655 & 0,656 & 0,657 & 0,658 & 0,660 & 0,661 & 0,662 & 0,664 & 0,665 \\
\hline 9500 & 606 & 0,619 & 0,631 & 0,638 & 0,644 & 0,651 & 0,652 & 0,653 & 0,654 & 656 & 0,657 & 0,658 & 0,659 & 0,661 & 0,662 & 0,663 \\
\hline 10000 & 0,605 & 0,617 & 0,630 & 0,636 & 0,643 & 0,649 & 0,650 & 0,652 & 653 & 654 & 0.655 & 0,657 & 0.658 & 0,659 & 0,661 & 0,662 \\
\hline
\end{tabular}

Tabla X - 3: Valores admisibles del Coeficiente Volumétrico de Pérdidas de Calor ( $\left.G_{c a l}\right)$ propuestos.

Como puede verse en el Gráfico X - 19, los valores de $G_{\text {cal }}$ admisibles para el modelo propuesto son inferiores a los propuestos por la Norma IRAM 11.604. Se trata de una reducción de aproximadamente un $35 \%$ sobre los valores propuestos por la actual Norma IRAM 11.604. Esta reducción en los valores admisibles del $\mathrm{G}_{\mathrm{cal}}$ se debe en parte a la mayor exigencia en cuanto a la calidad de la envolvente térmica del edificio y a la reducción del número de renovaciones de aire. Por ejemplo para el caso de la Ciudad de La Plata $\left(1.200^{\circ} D_{\text {cal }} 18^{\circ} \mathrm{C}\right)$ el $\mathrm{G}_{\text {cal }}$ admisible varía de $0,90 \mathrm{~W} / \mathrm{m}^{3}$ para un edificio de $1.000 \mathrm{~m}^{3}$ a $0,65 \mathrm{~W} / \mathrm{m}^{3}$ para un edificio de $10.000 \mathrm{~m}^{3}$.

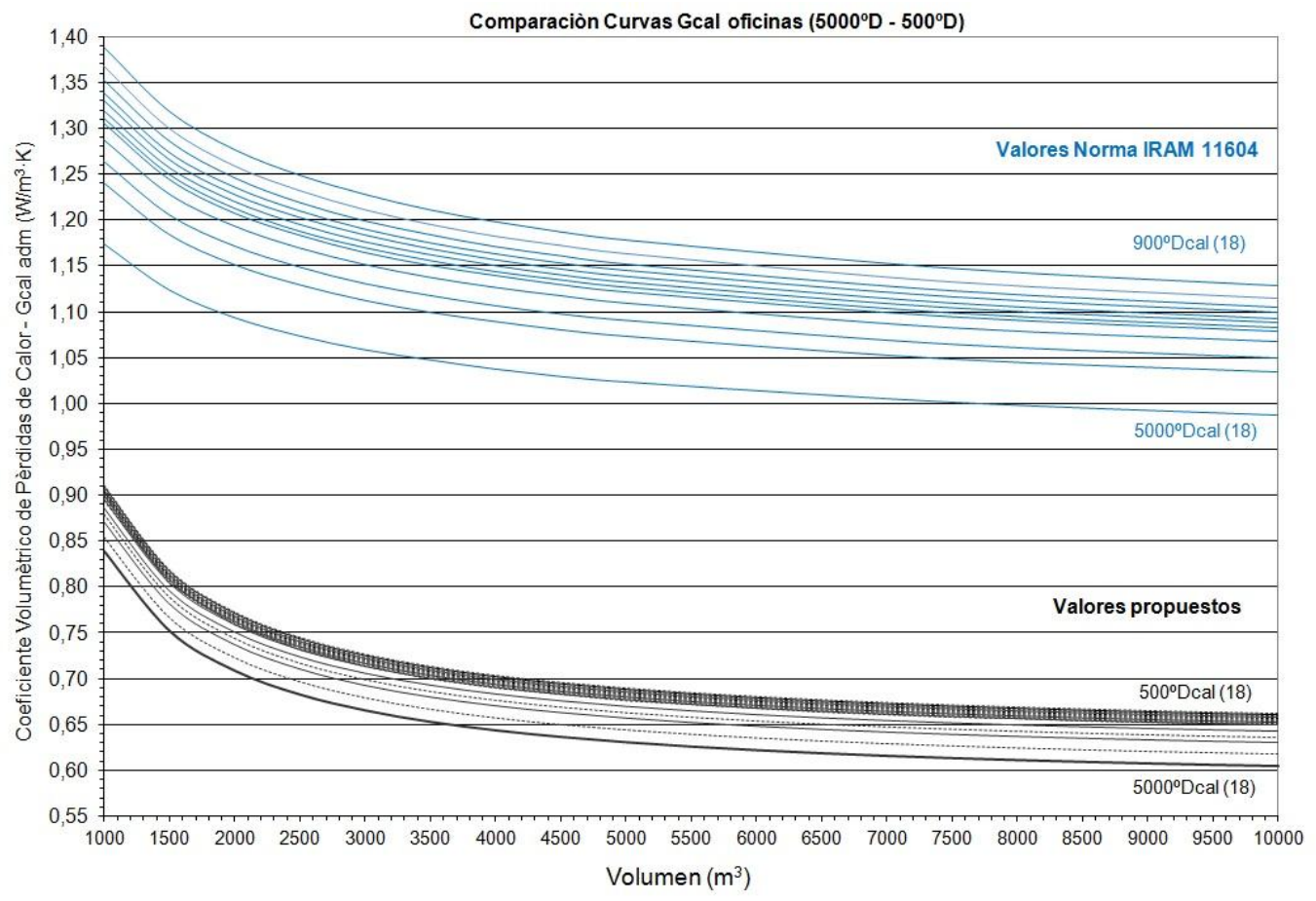

Gráfico X - 19: Valores admisibles del $G_{c a l}$ - Comparación valores actuales y propuestos. 
Por su parte el Gráfico X - 20 muestra los valores de Carga Térmica en Calefacción $\left(Q_{\text {cal }}\right)$ para el modelo propuesto; con él se pretende determinar valores máximos admisibles. Por ejemplo, para un edificio de $10.000 \mathrm{~m}^{3}$ implantado en la Ciudad de La Plata $\left(1.200^{\circ} \mathrm{D}_{\text {cal }} 18^{\circ} \mathrm{C}\right)$, el valor máximo de la Carga Térmica en Calefacción sería de $188.034 \mathrm{~W}$, mientras que para un edificio de $1.000 \mathrm{~m}^{3}$, para la misma localización, el valor máximo admisible sería de $25.911 \mathrm{~W}$. Por último el Gráfico X - 21 muestra los valores del Coeficiente de Calefacción por unidad de superficie $\left(\mathrm{S}_{\mathrm{cal}}\right)$ para el modelo propuesto; con él se pretende determinar valores máximos admisibles. Por ejemplo, para un edificio de $10.000 \mathrm{~m}^{3}$ implantado en la Ciudad de La Plata $\left(1.200^{\circ} D_{\text {cal }} 18^{\circ} \mathrm{C}\right)$ el valor máximo de la Carga Térmica en Calefacción sería de $50,77 \mathrm{~W} / \mathrm{m}^{2}$ mientras que para un edificio de $1.000 \mathrm{~m}^{3}$ para esa misma localización sería de $69,96 \mathrm{~W} / \mathrm{m}^{2}$.

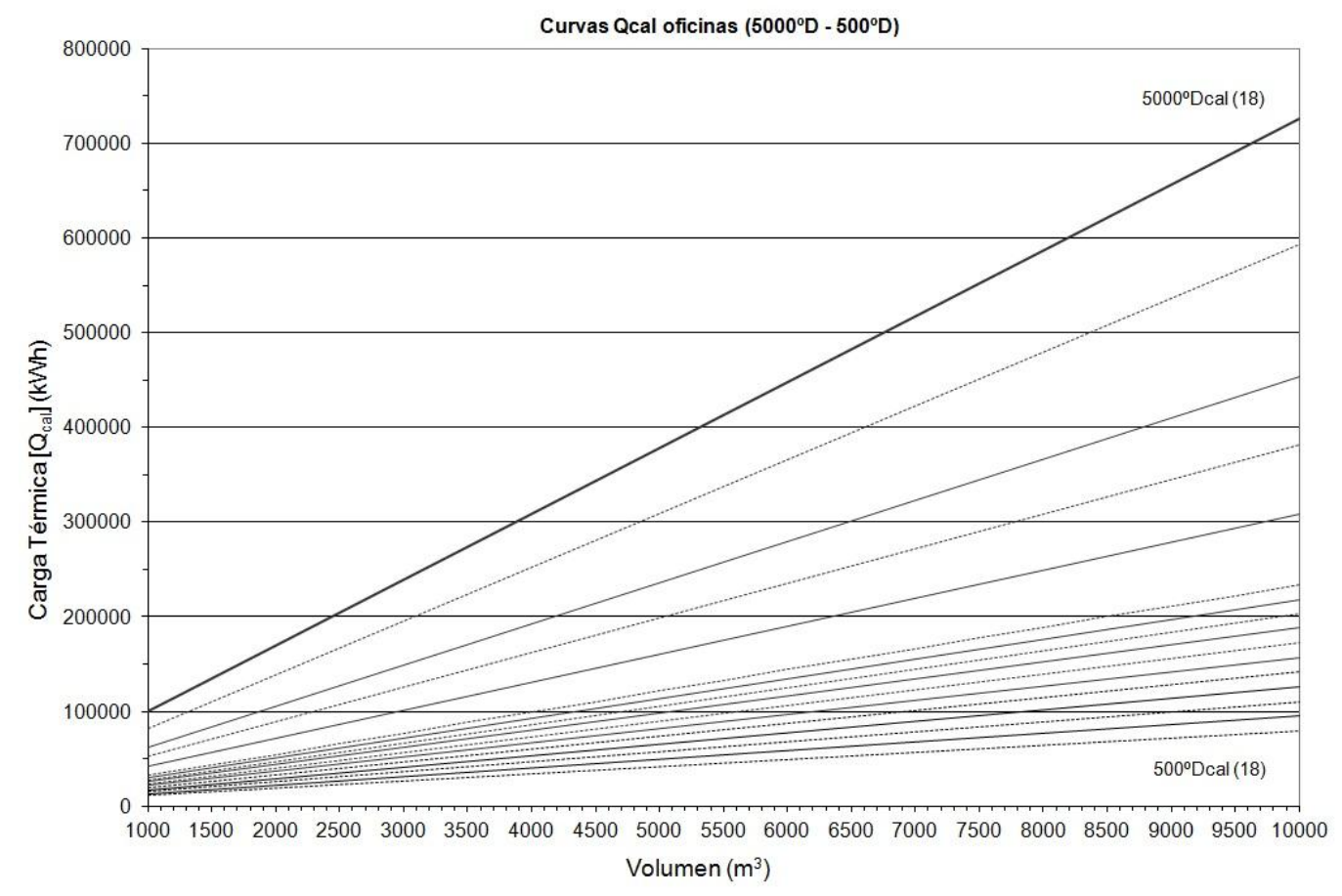

Gráfico X - 20: Valores de Carga Térmica de Calefacción - $Q_{c a l}$.

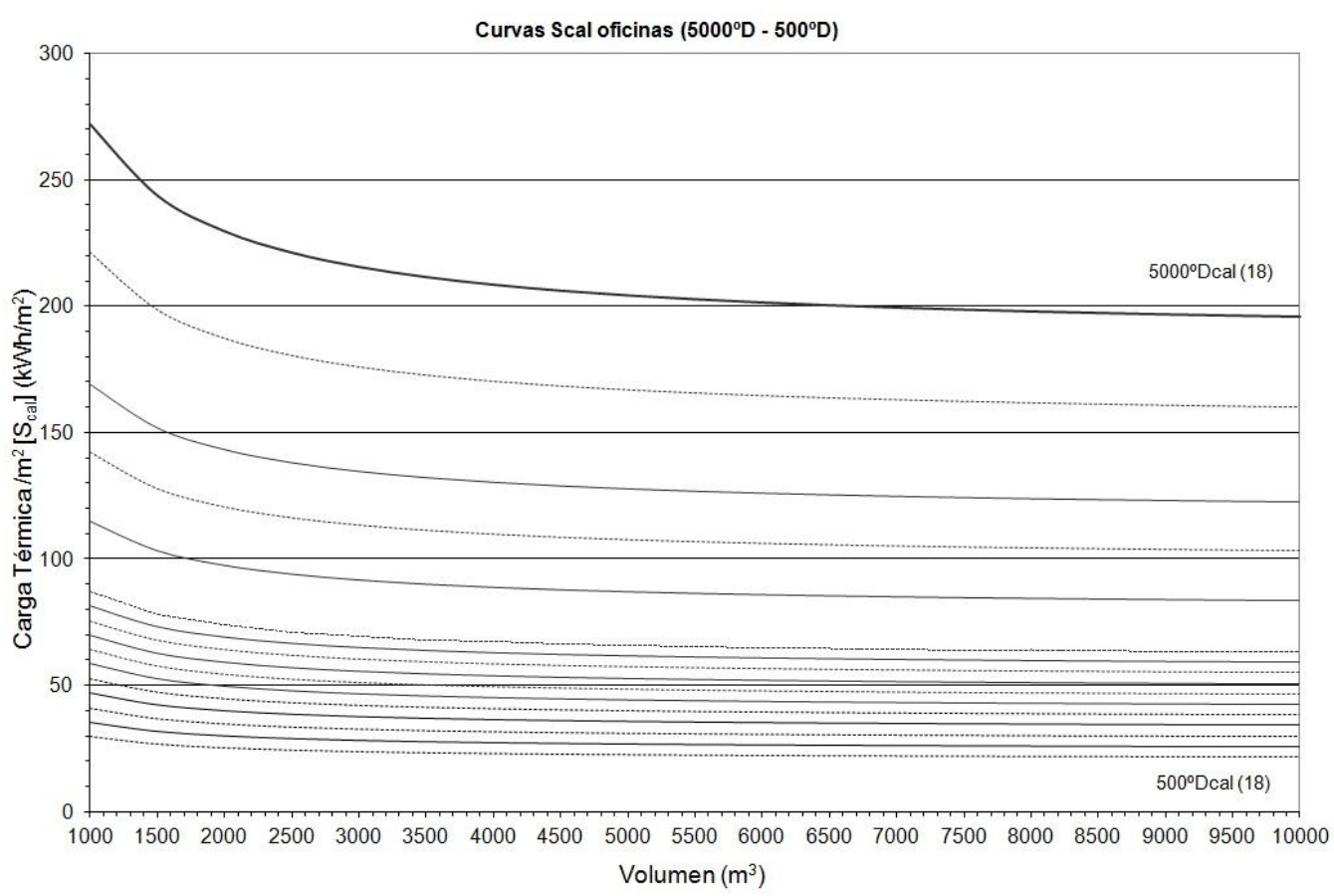

Gráfico X - 21: Valores de Carga Térmica de Calefacción por unidad de superficie - $S_{\text {cal. }}$ 


\subsubsection{Ahorro de energía en refrigeración}

Tal como en el modelo de ahorro de energía en refrigeración para edificios de viviendas, en el modelo de ahorro de energía en refrigeración para edificios de oficinas en altura se adoptó la metodología utilizada por el Grupo Eficiencia Energética Edilicia (GEEE) de la Cátedra de Instalaciones de la FAU - UNLP en el año 2006, el cual se convirtió en la parte 2 de la Norma IRAM 11.659 en 2007. De la parte 1 de dicha Norma se tomaron los datos para determinar la carga térmica de refrigeración del edificio (Czajkowski, J.; 2004).

Como ya se ha mencionado anteriormente, en aquel entonces luego de analizar los datos normativos de los que se disponía y ante la inexistencia de Grados Día de Refrigeración propuestos, se planteó la necesidad de adoptar como indicador climático la Temperatura Exterior de Diseño en el período de verano (TDMX). Luego de analizar las características de las distintas zonas bioambientales que conforman la Argentina (Norma IRAM 11.603), se decidió adoptar un rango entre los $30^{\circ} \mathrm{C}$ y los $40^{\circ} \mathrm{C}$ de TDMX.

Se resolvió que la verificación se haría para el día 15 de enero a las $13 \mathrm{hs}$. Como a nivel normativo no se contaba con datos ni procedimientos de cálculo de radiación solar Is horaria para las diferentes latitudes, orientaciones y pendientes de los planos posibles de ser analizados, se propuso un anexo normativo en el cual se analizó la ls horaria en las capitales provinciales respecto de su pertenencia a las zonas bioambientales I a IV, que son las que requerirían de la utilización de refrigeración mecánica durante el período estival. El resultado obtenido fueron 8 tablas con datos de $/ s$ horarios (en $\mathrm{W} / \mathrm{m}^{2}$ y MJ/m²) para nueve orientaciones, para las zonas bioambientales Ia, Ib, Ila, IIb, IIla, IIlc, IVa, IVb, IVc y IVd. En la determinación de la Is se utilizó el procedimiento de Liu \& Jordan aplicando el Kt provisto por la Comisión Nacional de Investigaciones Espaciales (CNIE) de Argentina con el programa Radiac2.

Luego se propusieron tres indicadores de eficiencia energética edilicia en refrigeración para diferentes tipos de edificios para vivienda, complementarios entre sí; la Carga térmica total de verano $\left(Q_{R}\right)$ de la cual se derivan el Coeficiente de refrigeración por unidad de superficie $\left(S_{R}\right)$ y el Coeficiente volumétrico de refrigeración $\left(G_{R}\right)$. Los tipos de vivienda fueron "casa", "bloque" y "torre".

El trabajo desarrollado en el LAyHS plantea la necesidad de determinar nuevos valores para estos indicadores de modo que tengan en cuenta las diferentes condiciones de ocupación, iluminación y consumo eléctrico que tiene un edificio de oficinas con respecto a uno de vivienda. De este modo se busca evitar caer en la confusión de verificar la carga térmica de refrigeración de un edificio de oficinas según parámetros utilizados para edificios de vivienda.

\section{Carga térmica total de verano $\left(Q_{R}\right)$ :}

El valor de la carga térmica del edificio o local refrigerado, en estado estacionario, se calcula con la siguiente ecuación general.

Donde:

$$
Q_{R}=Q_{c}+Q_{a}+Q_{s}+Q_{o} \quad \text { [Ecuación X - 24] }
$$

$Q_{R}=$ Carga térmica total [W].

$Q c=$ Carga térmica por conducción a través de la envolvente $[\mathrm{W}]$.

$Q a=$ Carga térmica por ventilación aportado por el aire exterior [W].

$\mathrm{Qs}=$ Carga térmica solar [W].

Qo = Carga térmica por fuentes internas (personas + equipamiento + iluminación) [W]. 


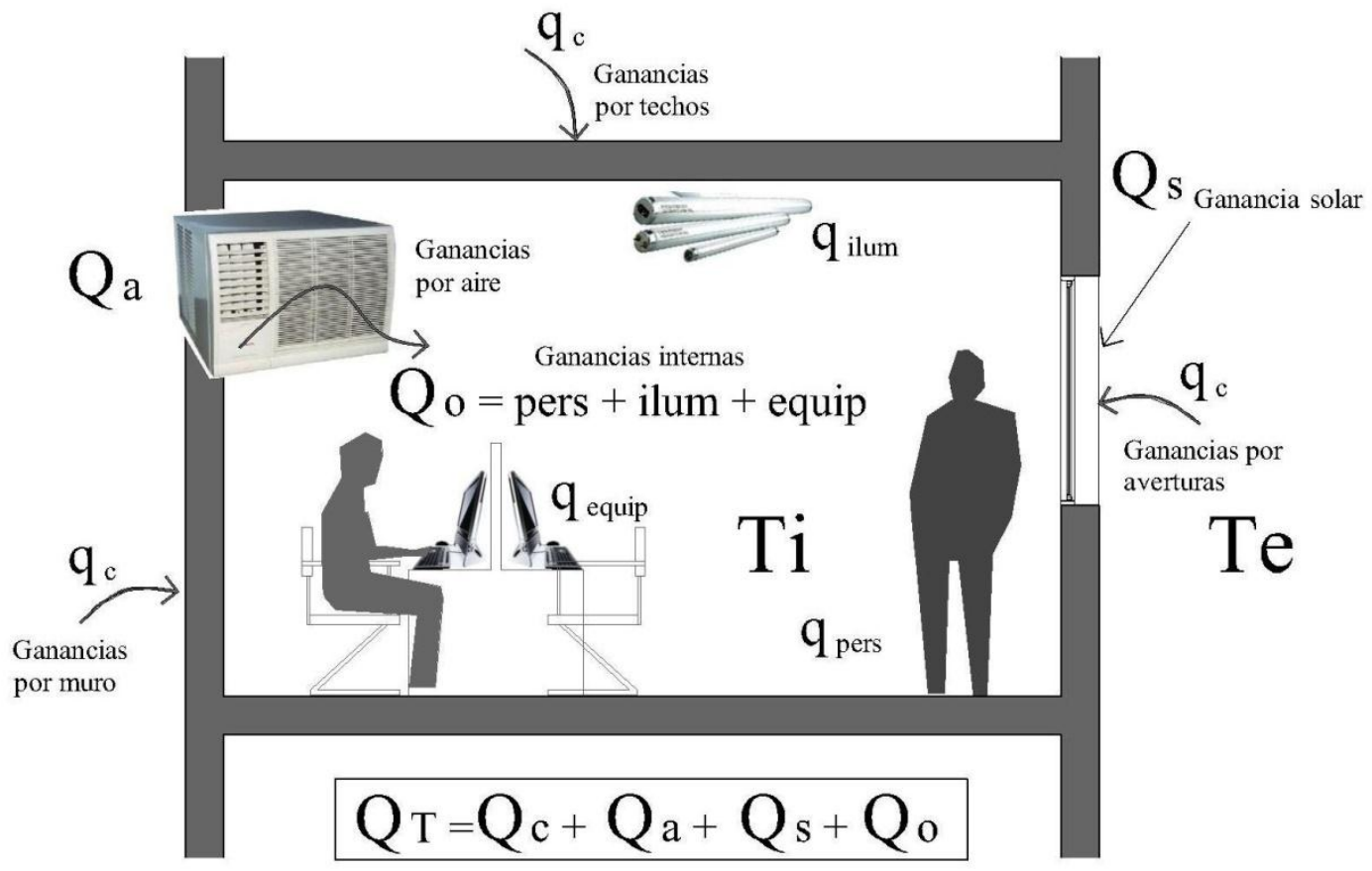

Figura X - 5: Ganancias de calor de un local en verano.

Carga térmica por conducción a través de la envolvente $\left(Q_{c}\right)$ : La ganancia de calor por conducción parcial qc a través de la envolvente del local será:

$$
\left.Q_{C}=\sum q_{c} \text { [Ecuación } X-25\right]
$$

La sumatoria de todas las pérdidas parciales qc por conducción a través de la envolvente dará como resultado las pérdidas totales por conducción $Q_{C}$, según la siguiente ecuación:

Donde:

$$
\left.q_{C}=K \cdot A\left(T_{D M X}-T_{i}\right) \quad \text { [Ecuación } X-26\right]
$$

$\mathrm{K}=$ Transmitancia térmica del cerramiento (muro, techo, piso, ventana, etc.) $\left[\mathrm{W} / \mathrm{m}^{2} \cdot \mathrm{K}\right]$.

$A=$ Superficie del cerramiento $\left[\mathrm{m}^{2}\right]$.

$T_{D M X}=$ Temperatura exterior de diseño $\left[{ }^{\circ} \mathrm{C}\right]$.

$T_{\mathrm{i}}=$ Temperatura interior $\left[{ }^{\circ} \mathrm{C}\right]$.

Carga térmica por ventilación aportada por el aire exterior $\left(Q_{a}\right)$ : En verano se supone al edificio cerrado para reducir pérdidas y ahorrar energía. Esto implica que es necesario ventilar una parte o la totalidad del aire interior, por lo que se supone que debería introducirse en el ambiente interior una importante masa de aire caliente y húmedo que el equipo de aire deberá acondicionar. Este aire de renovación y recirculado contiene humos, partículas en suspensión y olores que son necesarios eliminar.

Donde:

$$
Q_{A}=C A R \times(0,29 \times \Delta t+0,72 \times \Delta w) \quad \text { [Ecuación X - 27] }
$$

CAR: Cantidad de aire a renovar en $\mathrm{m}^{3} / \mathrm{h}$.pers. [CAR = cantidad personas $x$ caudal aire/persona]

$\Delta \mathrm{t}$ : diferencia entre temperatura exterior y temperatura interior $\left[{ }^{\circ} \mathrm{C}\right]$.

$\Delta \mathrm{w}$ : diferencia entre la humedad específica exterior e interior $[\mathrm{g} / \mathrm{kg}]$. 
Carga térmica solar $\left(Q_{s}\right)$ : Debido a las superficies vidriadas del local a analizar una parte de los aportes se deberá a la radiación del sol que al atravesar el cristal ingresa al local calentándolo. Cabe aclarar que para el caso de oficinas esta superficie tiene una influencia mayor sobre el total de la envolvente que en el caso de edificios de vivienda y por lo tanto también es mayor la influencia de la carga térmica solar sobre el total del edificio. Por su parte la radiación del sol varía con cada hora del día solar y también a lo largo de los meses del año. La expresión general para el cálculo de la carga debida al sol es:

Donde:

$$
Q_{S}=S . I_{S} \cdot F_{e s} \quad \text { [Ecuación X - 28] }
$$

Qs: ganancia solar [W].

S: superficie vidriada en $\left[\mathrm{m}^{2}\right]$.

$I_{S}$ : Intensidad de la radiación solar en $\left[\mathrm{W} / \mathrm{m}^{2}\right]$.

$\mathrm{F}_{\mathrm{es}}$ : Factor de exposición solar del vidrio o aventanamiento (adimensional 0 a 1).

Carga térmica por fuentes internas $\left(Q_{0}\right)$ : Es la suma del calor total por personas, más el calor sensible de la iluminación artificial, más el calor sensible de los artefactos de oficina (computadoras, impresoras, fotocopiadoras, etc.). En este caso también la influencia de estos factores cobra mayor importancia debida a que el factor de ocupación y de equipamiento eléctrico es mayor que en el caso de un edificio de viviendas. Por otra parte la actividad que se desarrolla en un edificio de oficinas requiere de un mayor nivel de iluminación que en el caso de un edificio de viviendas. La expresión general para el cálculo de la carga debida a fuentes internas es:

Donde:

$$
Q_{O}=Q_{\text {pers }}+Q_{\text {ilum }}+Q_{\text {equip }} \text { [Ecuación X - 29] }
$$

$Q_{0}$ : carga térmica por fuentes internas [W].

$Q_{\mathrm{PERS}}$ : aporte de calor interno por personas; sensible + latente [W].

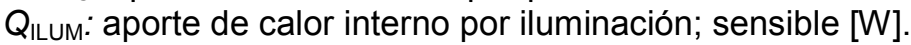

$Q_{\text {EQUIP: }}$ aporte de calor interno por equipamiento; sensible [W].

Otras ganancias internas de calor sensible: Existen otros aportes internos debidos a los conductos de inyección y retorno de aire acondicionado. Es usual que estos se establezcan como un valor estimado porcentual. Existe otra penalización a agregar debida a la calidad en la construcción de los conductos de distribución y retorno, y que en general se establece entre un $4 \%$ y un $10 \%$ de la suma de calor sensible debida a conducción y efecto solar.

\section{El Coeficiente de refrigeración por unidad de superficie $\left(S_{R}\right)$ :}

El valor del Coeficiente de refrigeración por unidad de superficie del edificio o local refrigerado, se calcula con la fórmula siguiente:

$$
\left.S_{R}=Q_{R} / A_{R} \quad \text { [Ecuación } X-30\right]
$$

Donde:

$Q_{R}$ : Carga térmica total de verano [W].

$A_{R}$ : Superficie refrigerada $\left[\mathrm{m}^{2}\right]$.

\section{El coeficiente volumétrico de refrigeración $\left(G_{R}\right)$ :}

El valor del coeficiente volumétrico de refrigeración del edificio o local refrigerado, se calcula con la fórmula siguiente:

Donde:

$$
\left.G_{R}=Q_{R} / V_{R} \quad \text { [Ecuación } X-31\right]
$$


$Q_{R}$ : Carga térmica total de verano $[\mathrm{W}]$.

$V_{R}$ : Volumen refrigerado $\left[\mathrm{m}^{3}\right]$.

\section{El modelo edilicio:}

El modelo de ahorro de energía en refrigeración para edificios de oficinas en altura es el mismo que para el caso de calefacción. El mismo parte de la repetición en altura de una planta tipo de $185 \mathrm{~m}^{2}$, con altura de local mínima media según Códigos de Edificación de $2,70 \mathrm{~m}$, y con un volumen variable entre $1.000 \mathrm{~m}^{3}$ (dos niveles) y $10.000 \mathrm{~m}^{3}$ (veinte niveles). Esto implica un volumen creciente a superficie de planta constante (Figura $X-6$ ), a partir del cual se obtienen las superficies de la envolvente discriminadas; muros, techos y superficies vidriadas.

El hecho de adoptar una planta de $185 \mathrm{~m}^{2}$ que se desarrolla en altura está relacionado con el relevamiento de casos de la realidad donde puede apreciarse cómo el avance de este tipo edilicio en las limitaciones de los solares urbanos es incentivado por la especulación inmobiliaria, tal como se menciona anteriormente.

Por otra parte en lo que respecta a la relación vidriado - opaco se prevé un máximo del $50 \%$ de superficie vidriada sobre el total de la envolvente vertical, el cual se distribuye según un criterio bioclimático (Czajkowski, J.; Corredera, C.; 2006) de la siguiente forma:

- No se admiten vidriados en techos.

- $40 \%$ del área vidriada se ubica al norte.

- 25\% del área vidriada se ubica al este.

- 25\% del área vidriada se ubica al oeste.

- 10\% del área vidriada se ubica al sur.

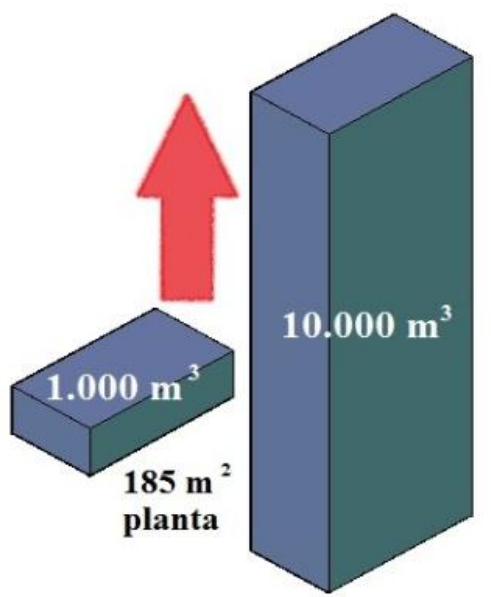

Figura X - 6: Modelo adoptado de volumen edilicio creciente.

En cuanto a las Renovaciones de Aire, igual que para el caso de calefacción, se adopta un valor de 0,7RA, que cumple con los requisitos mínimos de salubridad y confort (Ley 13.059 Provincia de Buenos Aires).

\section{Calidad térmica de la envolvente:}

Como se mencionó anteriormente la Norma IRAM 11.605 sugiere tres niveles de calidad térmica para muros y techos $-\mathrm{A}$, B y C-. Debido a que los valores de transmitancia térmica propuestos por el Nivel C son ineficientes en cuanto al ahorro de energía, dicho nivel fue descartado. Por consiguiente se tomó como nivel de calidad térmica para muros y techos un nivel intermedio entre los niveles A y B propuestos por la Norma IRAM 11.605.

Asimismo se propone el uso de una transmitancia térmica "K" variable en función de la variación de la Temperatura Exterior de Diseño "TDMX" de verano (IRAM 11.603). Esto implica 
una variación desde $\mathrm{K}_{\text {techos }}=0,335 \mathrm{~W} / \mathrm{m}^{2} . \mathrm{K}$ y $\mathrm{K}_{\text {muros }}=0,875 \mathrm{~W} / \mathrm{m}^{2} . \mathrm{K}$ para una $\mathrm{T}_{\mathrm{DMX}}=30^{\circ} \mathrm{C}$ hasta un $\mathrm{K}_{\text {techos }}=0,315 \mathrm{~W} / \mathrm{m}^{2} \cdot \mathrm{K}$ y $\mathrm{K}_{\text {muros }}=0,775 \mathrm{~W} / \mathrm{m}^{2} . \mathrm{K}$ para una $\mathrm{T}_{\mathrm{DMX}}=40^{\circ} \mathrm{C}$.

En cuanto al sistema de carpinterías se plantea la utilización de sistemas con DVH y Low-e. De la Tabla A.1 del Anexo A de la Norma IRAM 11.507-4 se obtuvo el valor de K=1,80W/m2K. La elección de este tipo de carpinterías busca reducir las ganancias de calor a través de las superficies vidriadas.

Como se mencionó anteriormente la verificación del modelo se hizo para el rango entre los $30^{\circ} \mathrm{C}$ y los $40^{\circ} \mathrm{C}$ de TDMX, para el día 15 de enero a las $13 \mathrm{hs}$.

\section{Sobre referencia climática:}

Tal como en el caso de edificios de vivienda, se utilizó el criterio adoptado en el trabajo realizado por el Grupo Eficiencia Energética Edilicia (GEEE) de la Cátedra de Instalaciones de la FAU - UNLP, en el cual se hizo un análisis comparativo del antecedente respecto de las necesidades de refrigeración en el territorio nacional. En aquel trabajo se concluyó que hay un rango que va de los 100 Grados Día de Refrigeración $\left(G_{R}\right)$ en el norte de la Patagonia (latitud $=40^{\circ}$ Sur) a los 1.000 Grados Día de Refrigeración $\left(G D_{R}\right)$ en la zona chaqueñoformoseña (latitud $=25^{\circ} \mathrm{Sur}$ ). Esto implica un rango de Temperaturas de Diseño Máximas que va desde los $30^{\circ} \mathrm{C}$ a los $40^{\circ} \mathrm{C}$.

Cabe destacar que mientras los Grados Día de Refrigeración $\left(G_{R}\right)$ funcionan como un indicador muy útil en la determinación de la Carga Térmica Anual en Refrigeración con fines de economía y gestión ambiental de la energía, no lo son tanto en cuanto a verificar la Calidad Térmica y el Diseño Ambiental de la envolvente; aunque estén relacionados. Razón por la cual se optó por utilizar la Temperatura de Diseño Exterior.

\section{Radiación solar:}

Como se concluyó en el antecedente, la radiación solar es un componente significativo en la carga térmica de un local o edificio y no es sencillo encontrar una correlación de fácil implementación ya que en la Argentina existen variaciones por latitud, altitud o amplitud térmica según el sitio. Motivo por el cual fue necesario adoptar un criterio que permita tratarla como un valor preestablecido, de manera que se pondere su influencia según las diferentes orientaciones del edificio, al tiempo que se contemple la variación en latitud y longitud.

Para este modelo se adoptaron los valores propuestos en el trabajo desarrollado por el Grupo Eficiencia Energética Edilicia (GEEE) de la Cátedra de Instalaciones de la FAU - UNLP, para las $13 \mathrm{hs}$. del día 15 de enero: Plano horizontal $736 \mathrm{~W} / \mathrm{m}^{2}$; Norte $370 \mathrm{~W} / \mathrm{m}^{2}$; Sur $268 \mathrm{~W} / \mathrm{m}^{2}$; Este $268 \mathrm{~W} / \mathrm{m}^{2}$; y 360 Oeste $\mathrm{W} / \mathrm{m}^{2}$. Se adoptó un factor de exposición solar $F_{E S}$ de 0,5 que implica la utilización de algún sistema o mecanismo que permita reducir la carga solar sobre las áreas vidriadas. Es un valor que puede alcanzarse fácilmente con la incorporación de parasoles.

El modelo propuesto no tiene en cuenta el aporte de calor solar por conducción en la envolvente opaca puesto que la verificación se realiza en estado estacionario y supone la incorporación de aislamiento térmico a esta parte de la envolvente edilicia.

\section{Carga térmica por iluminación artificial:}

En cuanto a las fuentes internas de energía debidas a la iluminación artificial se adoptó un nivel de iluminación de 400 lux propuestos por la Norma IRAM 11.659-1 para oficinas, que equivale a un factor de $16 \mathrm{~W} / \mathrm{m}^{2}$ para lámparas del tipo bajo consumo. Al respecto se prevé que las necesidades de iluminación se cubrirán en un $100 \%$ con lámparas de bajo consumo, despreciándose el uso de lámparas incandescentes o halógenas para satisfacer esta demanda.

\section{Carga térmica por fuentes internas:}


En el caso de la carga térmica por personas se adoptó una densidad de $8 \mathrm{~m}^{2} /$ persona con trabajo liviano (Norma IRAM 11.659-1) y $99 \mathrm{~W} /$ persona de calor total (sensible + latente). En cuanto al equipamiento se hizo un cálculo estimativo en función de la cantidad de personas (1 computadora por persona) y de la cantidad de plantas del edificio (1 impresora láser multifunción para oficinas por planta), lo que da un coeficiente de $28 \mathrm{~W} / \mathrm{m}^{2}$ de calor sensible. Por otra parte se desprecia la generación de calor latente por equipamiento. Para la carga de calor total por renovaciones de aire se usa una tasa de ventilación sanitaria de $15 \mathrm{~m}^{3} / \mathrm{h} /$ persona (Norma IRAM 11.659-1).

El Gráfico X - 22 muestra los valores de $G_{R}$ admisibles para el modelo propuesto; para el caso de la Ciudad de La Plata $\left(35^{\circ} \mathrm{C}\right)$ el $\mathrm{G}_{R}$ admisible varía de $38,46 \mathrm{~W} / \mathrm{m}^{3}$ para un edificio de $1.000 \mathrm{~m}^{3}$ a $31,20 \mathrm{~W} / \mathrm{m}^{3}$ para un edificio de $10.000 \mathrm{~m}^{3}$. Por su parte el Gráfico X - 23 muestra los valores de Carga Térmica de Refrigeración $\left(Q_{R}\right)$ para el modelo propuesto; con él se pretende determinar valores máximos admisibles. Por ejemplo, para un edificio de $10.000 \mathrm{~m}^{3}$ implantado en la Ciudad de La Plata $\left(35^{\circ} \mathrm{C}\right)$, el valor máximo de la Carga Térmica de Refrigeración sería de $312.009 \mathrm{~W}$, mientras que para un edificio de $1.000 \mathrm{~m}^{3}$, para la misma localización, el valor máximo admisible sería de $38.458 \mathrm{~W}$.

Por último el Gráfico X - 24 muestra los valores del Coeficiente de Refrigeración por unidad de superficie $\left(S_{R}\right)$ para el modelo propuesto; con él se pretende determinar valores máximos admisibles. Por ejemplo, para un edificio de $10.000 \mathrm{~m}^{3}$ implantado en la Ciudad de La Plata $\left(35^{\circ} \mathrm{C}\right)$ el valor máximo de la Carga Térmica de Refrigeración sería de $84,24 \mathrm{~W} / \mathrm{m}^{2}$ mientras que para un edificio de $1.000 \mathrm{~m}^{3}$ para esa misma localización sería de $103,84 \mathrm{~W} / \mathrm{m}^{2}$.

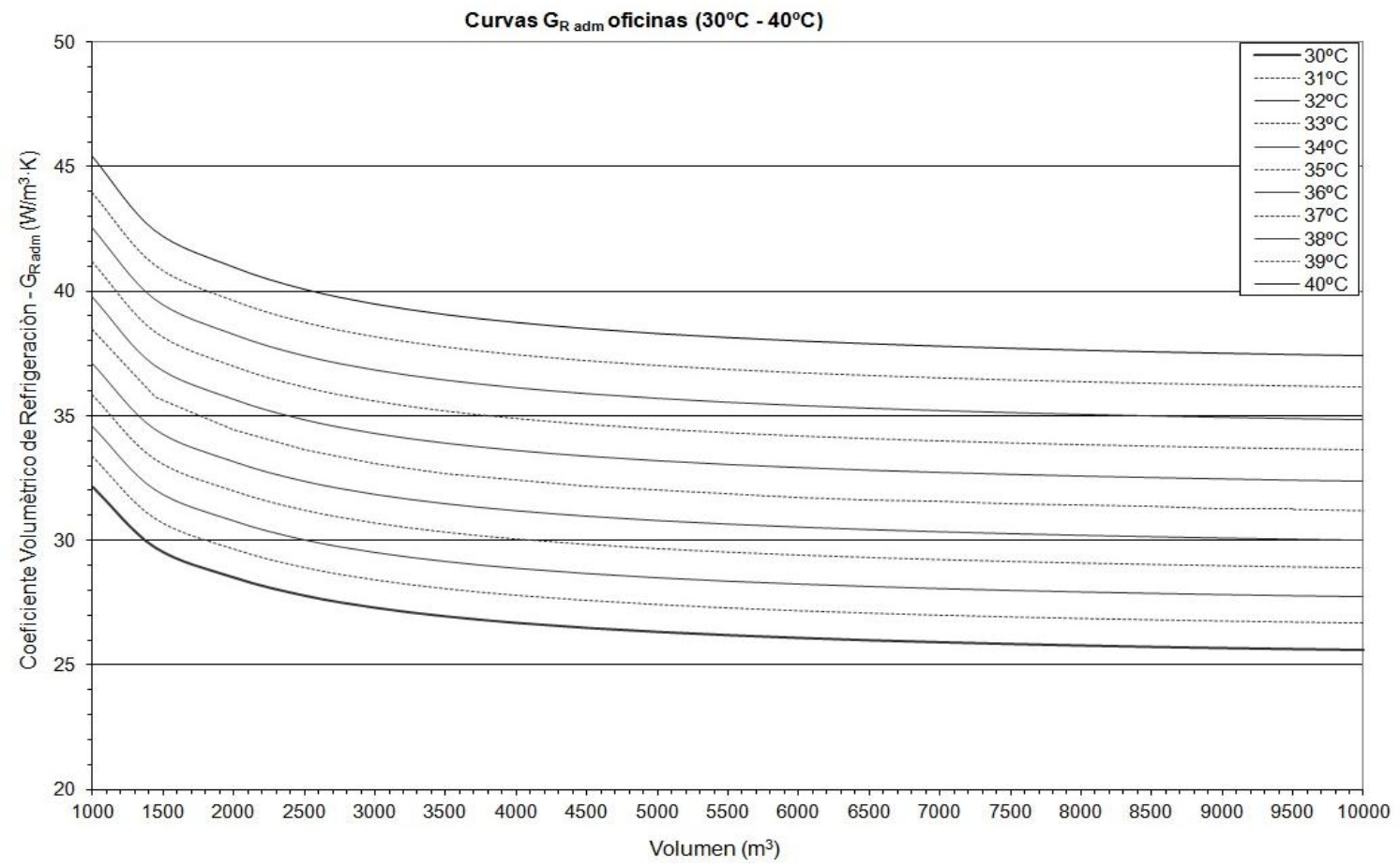

Gráfico X - 22: Valores admisibles para el Coeficiente Volumétrico de Refrigeración $-G_{R}$. 


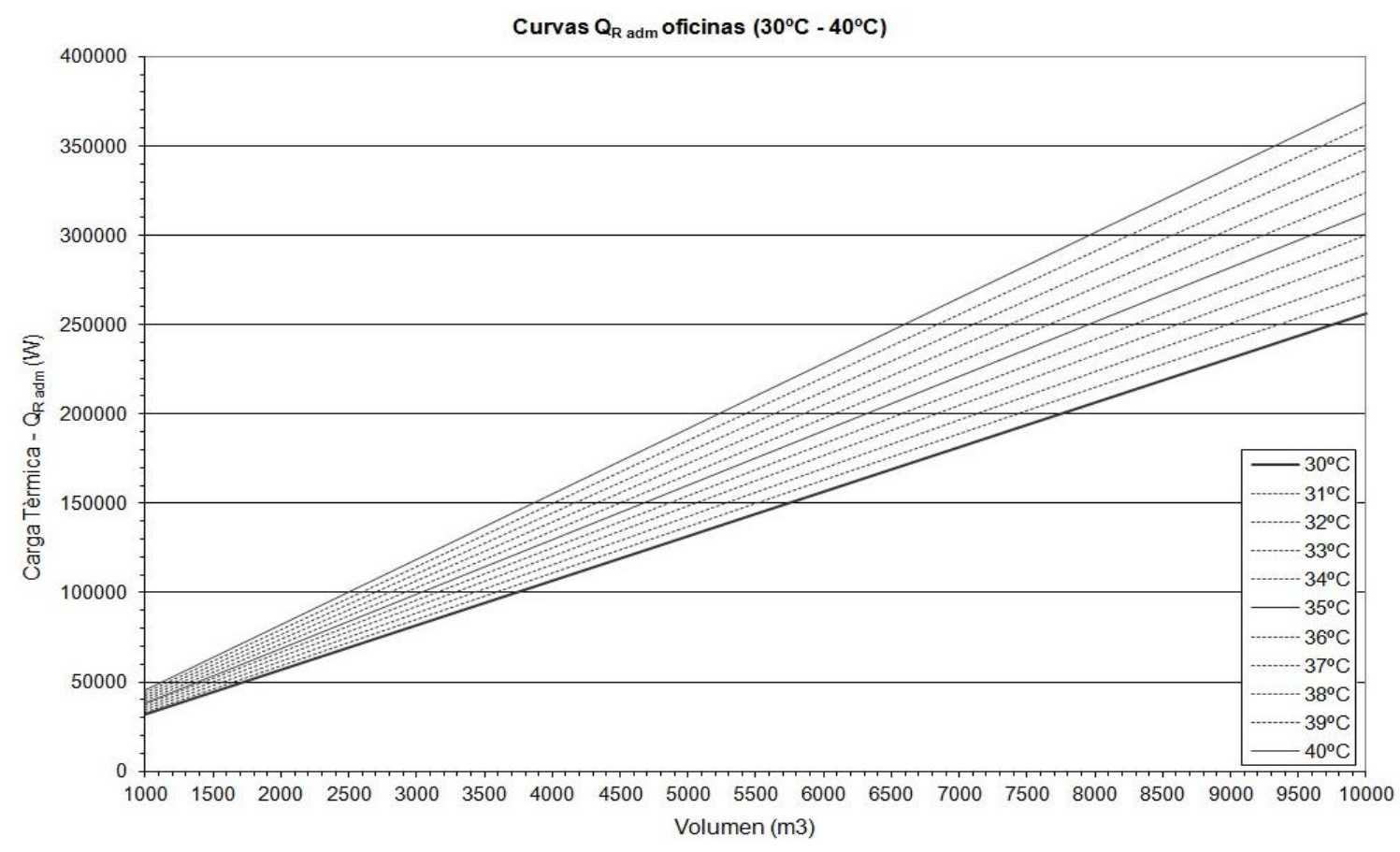

Gráfico X - 23: Valores de Carga Térmica en Refrigeración $-Q_{R}$.

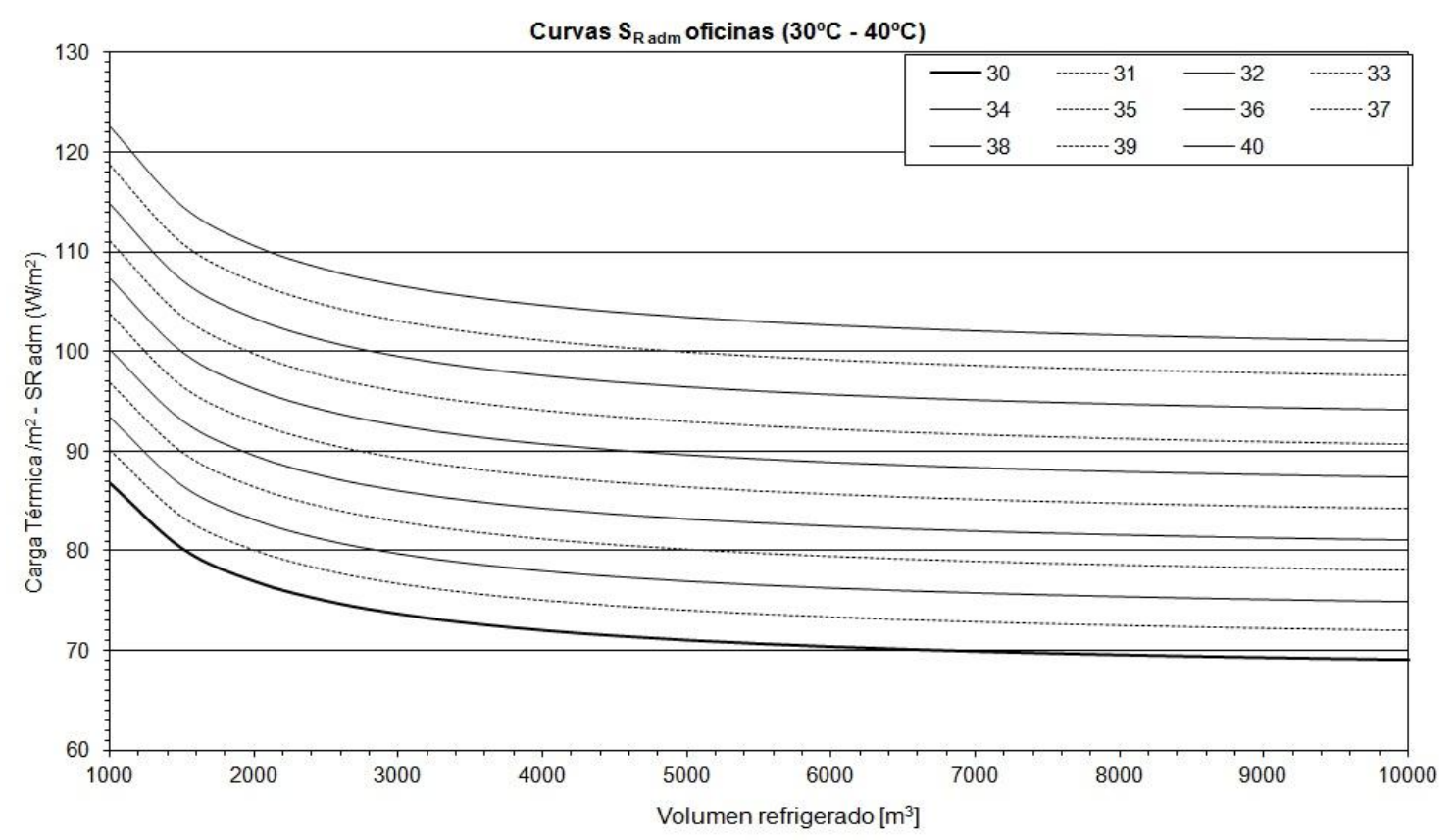

Gráfico X - 24: Valores de Carga Térmica en Refrigeración por unidad de superficie $-S_{R}$. 


\section{CAPÍTULO XI \\ ENERGÍAS RENOVABLES}

\subsection{Introducción}

En nuestro país el abastecimiento energético de los edificios que conforman los centros urbanos se realiza principalmente a través de fuentes de energías convencionales, basadas en la explotación de recursos fósiles, cada vez más escasos. Sin embargo la situación geográfica de Argentina es sumamente privilegiada para la utilización de la energía solar como fuente energética (Barros, V.; 2009).

En la actual política energética el actor preponderante es el Estado Nacional, ya sea por medio de inversiones de empresas públicas, como por medio de subsidios a empresas privadas. Actualmente no existe en Argentina una valoración ambiental y económica de largo plazo en las prioridades de inversión. La mayor parte de las inversiones estatales incrementan la dependencia en los combustibles fósiles o incluso en la energía nuclear, ubicando a las energías renovables en un rol marginal, desconociendo el potencial existente en el país y las tecnologías disponibles en la actualidad.

En los últimos años el Estado Nacional ha venido utilizando cada vez más subsidios para sostener precios y tarifas en el sector que no reflejan la realidad económica y ambiental de la actividad energética. Sin embargo la aplicación de subsidios en las tarifas ha tenido un efecto doblemente perjudicial; por un lado ha estado beneficiando a los sectores de mayor consumo mientras que por otro, ha incentivado el sobreconsumo, exacerbando el problema de escasez de oferta (Barros, V.; 2009).

La mejora de la envolvente térmica no es el único camino para alcanzar la reducción del consumo de fuentes de energías convencionales. En los países más avanzados la satisfacción de la demanda energética mediante la incorporación de fuentes de energías renovables lleva años de estudio y desarrollo. En el Capítulo IV de esta Tesis se hace referencia a distintas Normas y Directivas internacionales, las cuales establecen ciertos objetivos que los países firmantes se comprometen a cumplir. Los Códigos de Edificación de estos países incorporan cuestiones relacionadas a la utilización de energías renovables que garantizan el cumplimiento de las exigencias planteadas por dichas Directivas, tendientes al desarrollo de edificios de energía cero o casi nula.

En Argentina la situación difiere bastante de esta realidad. Tal como se comentó anteriormente, los programas de eficiencia energética son relativamente nuevos, comenzaron a desarrollarse en respuesta a la crisis energética actual pero sin planificación previa y pese a los intentos 
desde la Secretaría de Energía de la Nación aún no se ha generado una política eficaz para introducir masivamente las energías renovables en el país (Barros, V.; 2009).

Si bien en nuestro país existen distintos grupos que trabajan en la explotación de los recursos renovables y su aplicación en la construcción, la mayoría de ellos realiza sus trabajos de extensión mayormente en ámbitos rurales, no-urbanos, en los que el acceso a las redes de distribución de energía convencional es dificultoso. Algunos de ellos son el INENCO en Salta, el CRICYT en Mendoza, del grupo GERSolar en Luján, el IFIR en Rosario, la Fundación Bariloche, el Departamento de Energía Solar de la CNEA en Buenos Aires, etc.

Durante los años dedicados al avance de esta Tesis se ha tomado contacto con muchos de estos grupos a través de la participación como colaboradora en algunos proyectos de investigación, la realización de distintos cursos de postgrado e incluso mediante la participación en congresos que centran su discusión en el tema de las energías renovables y su aplicación al ámbito construido. Del mismo modo, durante la estancia de investigación en el Instituto de Ingeniería Energética de la Universidad Politécnica de Valencia se tuvo la posibilidad de estudiar la realidad de un país de avanzada en la incorporación de fuentes de energía renovables al ámbito urbano y de interactuar con profesionales de distintas disciplinas, de distintos países de la Unión Europea y del mundo.

La realidad de nuestro país dista bastante de la de los países más avanzados donde hay una fuerte iniciativa del Estado en el desarrollo de políticas de promoción de energías renovables. Como se ha expuesto en esta Tesis, si bien algunos Códigos de Edificación locales, como es el caso del Código de la Ciudad Autónoma de Buenos Aires, plantean la utilización de fuentes de energías renovables para el suministro de energía eléctrica o térmica; estos no abordan el tema en profundidad. Esto contribuye a que la implementación de este tipo de tecnologías se dé en casos aislados, como resultado del interés particular del propietario de la vivienda o edificio en el que se instalan (Juanicó, L. E.; González, A. D.; 2008).

En los países más desarrollados, el principal desafío para los responsables de la construcción del espacio urbano consiste en desarrollar edificios de energía cero o casi nula, que incorporen tecnologías sustentables para reducir la contaminación y los costes de mantenimiento. Actualmente tres cuartas partes de la energía diaria consumida en los edificios se deben principalmente a la luz eléctrica, calefacción y ventilación. La innovación en esos campos puede reducir radicalmente los costes de mantenimiento a largo plazo, así como la contaminación generada por los edificios (Martin Chivelet, N.; Fernández Sollá, I.; 2007).

La siguiente Tesis se centra particularmente en el estudio de generación eléctrica mediante paneles fotovoltaicos, colectores solares de aire para calefacción y colectores solares planos para satisfacer la demanda de agua caliente. Para estas tecnologías se estudió la aplicación a los modelos de edificios de viviendas y de oficinas planteados en el capítulo anterior.

\subsection{Energía solar fotovoltaica}

La generación eléctrica en base a fuentes renovables, distribuida e interconectada a la red pública eléctrica es, sin dudas, una alternativa con un gran potencial en el mediano y largo plazo. En particular, el uso de sistemas de generación por conversión fotovoltaica de la energía solar ha tenido un crecimiento explosivo durante los últimos años, principalmente debido a la instalación en diversos países desarrollados de sistemas integrados a la red eléctrica. La capacidad instalada se ha multiplicado por seis entre los años 2004 y 2008, llegando a superar los 22GW a fines de 2009 (Durán, J.; 2010).

Tal como se ha mencionado anteriormente en la Argentina, el uso de la energía solar fotovoltaica se ha limitado casi exclusivamente a aplicaciones en áreas rurales aisladas, alejadas de las redes de distribución. Se trata de aplicaciones que, en muchos casos, tienen gran relevancia social pero que prácticamente no contribuyen al reemplazo de combustibles fósiles en la matriz energética ni a la disminución de la contaminación ambiental asociada al 
quemado de éstos. Sin embargo, los centros urbanos concentran la casi totalidad de la demanda eléctrica del país y disponen de insolación satisfactoria que permite encarar un programa de penetración gradual de generación distribuida mediante sistemas fotovoltaicos (Durán, J.; 2010).

Un proyecto interesante que se está llevando a cabo en la región del AMBA es el PICTO-20100087, denominado "Interconexión de sistemas fotovoltaicos a la red eléctrica en ambientes urbanos" y dirigido por el Dr. Julio Durán, jefe del Departamento Energía Solar de la CNEA. EI objetivo principal de este proyecto es realizar un estudio integral, que contemple las cuestiones técnicas, económicas, legales y regulatorias, sobre la factibilidad de impulsar en áreas urbanas y periurbanas de nuestro país, en particular en el Área Metropolitana de Buenos Aires (AMBA), la instalación de sistemas fotovoltaicos distribuidos e interconectados a la red eléctrica. Como resultado de la participación como colaboradora en este proyecto se realizó un informe sobre las posibilidades de optimización del Código de Edificación Urbana de la Ciudad Autónoma de Buenos Aires, a fin de contemplar la protección de sistemas fotovoltaicos frente a sombras producidas por nuevas construcciones.

En el diseño de los sistemas fotovoltaicos integrados a edificios entran en juego varios factores como ser la generación fotovoltaica, la función y el diseño arquitectónico, el comportamiento térmico, la transmitancia luminosa de los módulos y el costo. Es importante alcanzar un equilibrio entre todos ellos, al mismo tiempo que se deben cumplir con las exigencias de seguridad que afectan a la instalación, tanto desde el punto de vista eléctrico como arquitectónico (Martin Chivelet, N.; Fernández Sollá, I.; 2007).

La buena integración arquitectónica de los módulos en los edificios es clave para el éxito del sistema. Sin embargo estos parámetros de diseño están determinados por otras variables que son las que hay que conocer y analizar para encontrar una solución óptima en cada caso; radiación solar local, latitud, uso del edificio, entorno, elección de la tecnología fotovoltaica, etc.

En los países desarrollados la gran mayoría de los sistemas fotovoltaicos integrados en edificios están conectados a la red eléctrica. El gran potencial de la integración arquitectónica en los edificios se encuentra en las zonas urbanas, donde se incentiva la conexión a la red de los sistemas fotovoltaicos mediante primas o subvenciones, y donde existen más posibilidades de integrar los módulos fotovoltaicos desde un punto de vista arquitectónico y estético (Martin Chivelet, N.; Fernández Sollá, I.; 2007).

Actualmente existen diversas posibilidades para adecuar el diseño de los módulos a las necesidades de cada aplicación arquitectónica; la variación en aspectos y tamaños es cada vez mayor. Algunas de las características que pueden variarse, dentro de ciertos parámetros, son las siguientes:

- Tamaño y forma del módulo.

- Estructura constructiva.

- Forma y tamaño de las células.

- Color de las células y de la cubierta posterior.

- Número de células y disposición por módulo.

Sin embargo, muchas de estas variaciones afectan el rendimiento eléctrico de los módulos y el costo de la instalación. Además la realidad de nuestro país indica que la utilización de sistemas con estas características más relacionadas a cuestiones estéticas que a cuestiones funcionales puede ser difícil de afrontar económicamente, impidiendo la amortización de la inversión inicial en el corto o mediano plazo (Grossi Gallegos, H. et Al.; 2010).

Cualquier superficie de la envolvente de un edificio que esté libre de sombras y bien orientada puede ser apta para albergar módulos fotovoltaicos. Desde el punto de vista de la generación de energía, la posición óptima para los sistemas fotovoltaicos conectados a red corresponde a la orientación norte (en latitudes Sur), con una inclinación de entre 5 y 10 grados por encima de 
la latitud local. Sin embargo, para los sistemas integrados en edificios no siempre es posible contar con estas condiciones pero sí es recomendable que los módulos reciban al menos un $80 \%$ de la irradiación máxima anual local (Grossi Gallegos, H. et Al.; 2010).

La modulación es importante en lo que respecta a la adaptación al diseño de la envolvente; el tamaño de la mayoría de los módulos no suele superar los $80 \times 160 \mathrm{~cm}$., aunque estas dimensiones pueden variar (Martin Chivelet, N.; Fernández Sollá, I.; 2007).

Como ya se ha mencionado anteriormente en nuestro país los pocos ejemplos de instalaciones fotovoltaicas aplicadas a construcciones distan bastante de los ejemplos de integración arquitectónica que pueden verse en los países más avanzados. En Argentina los módulos fotovoltaicos se diseñan mayormente con el único objetivo de generar electricidad, generalmente se ubican en las cubiertas de los edificios, totalmente ajenos al concepto de diseño arquitectónico. Esto contribuye a que se dupliquen los costos ya que generalmente se completa el revestimiento de la cubierta o la fachada y luego se monta el sistema fotovoltaico como una fachada superpuesta.

Convertir las superficies opacas del edificio (fachadas, cubiertas o parasoles) en productos generadores de electricidad, integrando en ellas sistemas fotovoltaicos, debería ser parte del mismo proceso de diseño del edificio. En términos constructivos esto significa que la fachada fotovoltaica integrada tiene que desempeñar el mismo papel que la fachada tradicional o los elementos de cubierta a los que sustituye. Entre estos requerimientos están el color, la imagen y el tamaño de los elementos de los cerramientos, la impermeabilidad, la estabilidad, la resistencia a las cargas de viento, fuego, durabilidad y mantenimiento, seguridad eléctrica durante la construcción y uso, y el costo (Martin Chivelet, N.; Fernández Sollá, l.; 2007).

Tampoco pueden dejarse de lado las exigencias en cuanto a la orientación e inclinación, evitación de sombras y aportación de calor y ventilación. Por lo tanto para poder dar respuesta tanto a los requerimientos constructivos como a los de producción de energía eléctrica es fundamental incorporar el sistema fotovoltaico desde el principio del proceso de diseño del edificio.

El arquitecto debe decidir el grado de exposición exterior del sistema fotovoltaico, determinando de este modo si se convierte en el elemento característico de la fachada o en una parte discreta de la misma. Sin embargo cabe aclarar que el hecho de que un sistema sea integrado no significa que tenga que alterar radicalmente la imagen del edificio. Existen distintas opciones que contribuyen a que un sistema fotovoltaico se integre en la fachada del edificio:

- Fachadas ventiladas: estos sistemas son muy adecuados para la integración fotovoltaica. La cámara posterior tiene como función reducir las temperaturas, por lo que contribuye a mantener un alto rendimiento además de proporcionar espacio para el cableado y las conexiones.

- Sistemas de muros cortinas: existen dos maneras de diseñar e instalar un muro cortina; el sistema de montantes y travesaños, montados en obra, y el sistema modular, prefabricado completamente en el taller. Si bien ambos tipos pueden incorporar paneles fotovoltaicos, los sistemas modulares son mejores desde el punto de vista constructivo porque la instalación y las conexiones se hacen en taller, bajo condiciones de calidad más controladas. Desde el punto de vista del rendimiento, el mayor problema de los muros cortina es la falta de ventilación posterior de los paneles fotovoltaicos, que puede causar una reducción de generación eléctrica. Una solución son las fachadas de doble piel.

- Sistemas de ventanas: en edificios con fachadas de materiales opacos, las ventanas son los únicos elementos de iluminación y ventilación natural. La integración fotovoltaica puede hacerse ocupando las partes fijas de la ventana con los paneles o sobre las partes opacas de la fachada conformando, en este último caso, una doble piel.

En la integración fotovoltaica es clave tener presente cual es la función de la fachada en un edificio, la cual proporciona una barrera entre el ambiente exterior (cambiante y agresivo) y el 
ambiente interior (estático y confortable). La piel del edificio necesita controlar el flujo de aire que la atraviesa, prevenir la entrada de agua y humedad, así como reducir la transmisión energética y acústica entre ambos ambientes. Además la fachada de un edificio debe dar respuesta a los requerimientos de seguridad contra intrusión e incendios. Por lo tanto la inclusión de un sistema fotovoltaico a la envolvente de un edificio no debería perturbar la función original de la fachada que conforma (Martin Chivelet, N.; Fernández Sollá, I.; 2007).

Si bien los elementos fundamentales de un sistema fotovoltaico son los módulos, existen otros componentes que completan el sistema y que es preciso conocer. Entre los principales componentes y características de los sistemas fotovoltaicos se pueden mencionar:

- Generador: suele estar constituido por más de un módulo fotovoltaico, aunque hay excepciones en algunas aplicaciones de baja potencia, como los sistemas de iluminación o de mobiliario urbano. Varios módulos asociados en serie y/o paralelo constituyen un arreglo fotovoltaico. Normalmente se procede asociando en serie (hilera) el número de módulos necesarios hasta conseguir el valor de tensión buscado y, posteriormente, asociando en paralelo tantas hileras de módulos como sean necesarias hasta alcanzar la intensidad deseada.

Otros elementos importantes del sistema generador son los encargados de las conexiones eléctricas y las protecciones; cableado, cajas de conexión, diodos de bloqueo, diodos de paso y fusibles. El rendimiento de un generador fotovoltaico es siempre inferior al de cada módulo individual que lo constituye debido a las pérdidas que se producen.

- Inversor: es un dispositivo electrónico de potencia que transforma en corriente alterna la corriente continua proveniente de los módulos. Esta corriente alterna puede inyectarse a la red eléctrica o consumirse directamente en el propio edificio. Existen diversos tipos de inversores, pero cualquiera de ellos debe cumplir con las normas de seguridad y protección a las personas, los equipos y la red eléctrica. Las principales características que definen el comportamiento de un inversor son:

- Rendimiento: es el cociente entre la potencia activa que suministra el inversor y la potencia continua que recibe. Los valores máximos del rendimiento se sitúan entre el 90 y el $95 \%$.

- Seguimiento del punto de máxima potencia: es la estrategia de control con la que el inversor intenta mantener el generador trabajando en el punto de máxima potencia. La existencia de sombras puede dificultar este seguimiento.

- Calidad de la onda: los valores de frecuencia y tensión deben mantenerse dentro ciertos límites para cumplir con las exigencias de la normativa existente.

- Parámetros de comportamiento: los factores de pérdidas que inciden en los parámetros de comportamiento de un sistema fotovoltaico dependen fundamentalmente del diseño. Desde el punto de vista de la generación eléctrica, el objetivo es reducir al mínimo los factores de pérdidas con el fin de alcanzar la máxima productividad final y el mayor rendimiento global del sistema. Existen pérdidas que el diseñador puede evitar y que pueden ser especialmente críticas en la integración de edificios. En cuanto a los parámetros de referencia se destacan los siguientes:

- Energía de referencia: irradiación solar recibida en el plano del panel fotovoltaico, dividida por la irradiancia de referencia de $1.000 \mathrm{~W} / \mathrm{m}^{2}$; se expresa en número de horas y se denomina "horas pico".

- Productividad del generador fotovoltaico durante un período de tiempo: energía útil generada durante ese tiempo por el sistema por unidad de potencia instalada; tiene en cuenta las pérdidas en el sistema completo.

- Rendimiento característico del sistema fotovoltaico: energía útil generada por un sistema fotovoltaico, dividida por la máxima teórica, esta última calculada teniendo en cuenta solamente la irradiancia recibida por el generador fotovoltaico y su potencia. 
En los sistemas fotovoltaicos integrados en edificios, el éxito de la aplicación a gran escala depende de la ausencia de defectos o fallos. Los fallos en los sistemas se pueden producir en las tres fases del proyecto; diseño, instalación y operación. El buen diseño de un sistema fotovoltaico contribuye enormemente a mejorar su rendimiento; si una instalación está diseñada y montada correctamente, y se realiza el mantenimiento adecuado, se pueden esperar rendimientos globales del sistema próximos al $80 \%$ y tiempos de vida útil de más de treinta años (Martin Chivelet, N.; Fernández Sollá, I.; 2007).

\subsubsection{Instalación solar fotovoltaica}

A partir de la formación adquirida en el VII Curso de Aprovechamiento Energético de la Radiación Solar del Grupo GEERSolar, en los cursos Solar I y Solar II de la Maestría en Energías Renovables de la UNSa, y la experiencia alcanzada durante la estancia de investigación en Valencia pudo realizarse el diseño del sistema fotovoltaico necesario para satisfacer parte de la demanda energética de los modelos edilicios propuestos en el capítulo anterior, tanto para edificios de viviendas como de oficinas.

\subsubsection{Instalación solar fotovoltaica en edificios de viviendas}

Tal como se mencionó anteriormente, para el diseño de la instalación fotovoltaica se continuó con el modelo edilicio de viviendas propuesto en el capítulo anterior en lo referente a cuestiones formales, relación de superficie vidriada - opaca, superficie habitable, nivel de iluminación y equipamiento eléctrico, etc. Sin embargo se estima que la instalación fotovoltaica sólo cubrirá la demanda de energía eléctrica para iluminación artificial, mientras que el consumo de energía eléctrico para abastecer la demanda del equipamiento será cubierto por la energía proveniente de la red.

En lo que respecta a la iluminación artificial, en este modelo, se adoptó un nivel de 250 lux, propuesto por la Norma IRAM 11.659-1 para viviendas. Se supone que las necesidades de iluminación se cubrirán en un $100 \%$ con este tipo de lámparas, lo que equivale a un factor de iluminación de $10 \mathrm{~W} / \mathrm{m}^{2}$.

Se plantea el diseño de la instalación para un edificio de planta baja y diez plantas tipo, con una superficie por planta de $185 \mathrm{~m}^{2}$. Esto da como resultado un edificio de $5.000 \mathrm{~m}^{3}$ y $1.850 \mathrm{~m}^{2}$ de superficie total sin contar la planta baja, que no es de interés al cálculo ya que no se considera superficie habitable. Se supone que los paneles fotovoltaicos se ubicarán principalmente sobre el frente del edificio, de orientación norte, con una inclinación de $90^{\circ}$. Del modelo descrito en el capítulo anterior se obtiene la superficie de fachada opaca por sobre la cual pueden colocarse los paneles. Siendo que para edificios de vivienda se planteó un máximo de superficie vidriada del $20 \%$ respecto del total de la envolvente vertical, y que el $50 \%$ de esa superficie vidriada se ubicaría sobre la fachada norte, esta fachada cuenta con $116 \mathrm{~m}^{2}$ libres para la disposición de paneles fotovoltaicos (Figuras XI - 1 y 2).

El Grupo IDEA (Investigación y Desarrollo en Energía Solar y Automática) de la Universidad de Jaén, España desarrolló una hoja de cálculo que permite estimar la radiación media mensual sobre superficies arbitrariamente orientadas e inclinadas, mediante el ingreso del valor de la irradiación diaria media mensual, en $\mathrm{Wh} / \mathrm{m}^{2}$. En esta hoja se ingresaron los valores de irradiación diaria media mensual extraídos del Atlas de Energía Solar de la República Argentina (Grossi Gallegos, H.; Righini, R.; 2007). En el punto 2.1. del Anexo II se muestran los resultados obtenidos para la ciudad de La Plata (Latitud $35^{\circ} \mathrm{S}$; Longitud $57^{\circ} \mathrm{O}$ ), para paneles con inclinación $0^{\circ}, 90^{\circ}$ y $45^{\circ}$ que para el caso de La Plata es la mejor inclinación.

La irradiación diaria media anual más alta se obtiene para el plano inclinado a $45^{\circ}$, luego con el plano horizontal $\left(0^{\circ}\right)$ y la más baja se obtiene para el plano vertical $\left(90^{\circ}\right)$ que es el ángulo con el que se propone orientar los paneles principalmente, puesto que es con el que se consigue una mejor integración arquitectónica. 
Al observar los valores mensuales de irradiación diaria media puede verse como para los meses más desfavorables (mayo - agosto) los valores más altos se registran para el plano inclinado a $45^{\circ}$, que es la mejor inclinación para la ciudad de La Plata. Luego, a diferencia de la irradiación diaria media anual, para estos meses los valores son más altos para el plano vertical que para el plano horizontal. Esto contribuye a revalidar la decisión de disponer los paneles principalmente en forma vertical, dado que este tipo de sistemas generalmente se dimensionan para los meses más desfavorables (invierno) en donde la demanda de energía eléctrica para iluminación artificial es mayor, y donde la disponibilidad energética (radiación solar) es menor.

Luego se hizo la verificación con el programa GEOSOL (Hernández, A.; 2003) para el día 21 de junio, que es el día más desfavorable del año. En el punto 2.2. del Anexo II se muestran los resultados obtenidos para la ciudad de La Plata (Latitud $35^{\circ} \mathrm{S}$; Longitud $57^{\circ} \mathrm{O}$ ), para paneles con inclinación $0^{\circ}, 45^{\circ}$ y $90^{\circ}$. Como puede verse en los resultados arrojados por el GEOSOL, los valores más altos de radiación global se registran para el plano inclinado a $45^{\circ}$, que es la mejor inclinación para la ciudad de La Plata y luego para el plano vertical, siendo el plano horizontal el que menos radiación global recibe en el día analizado.

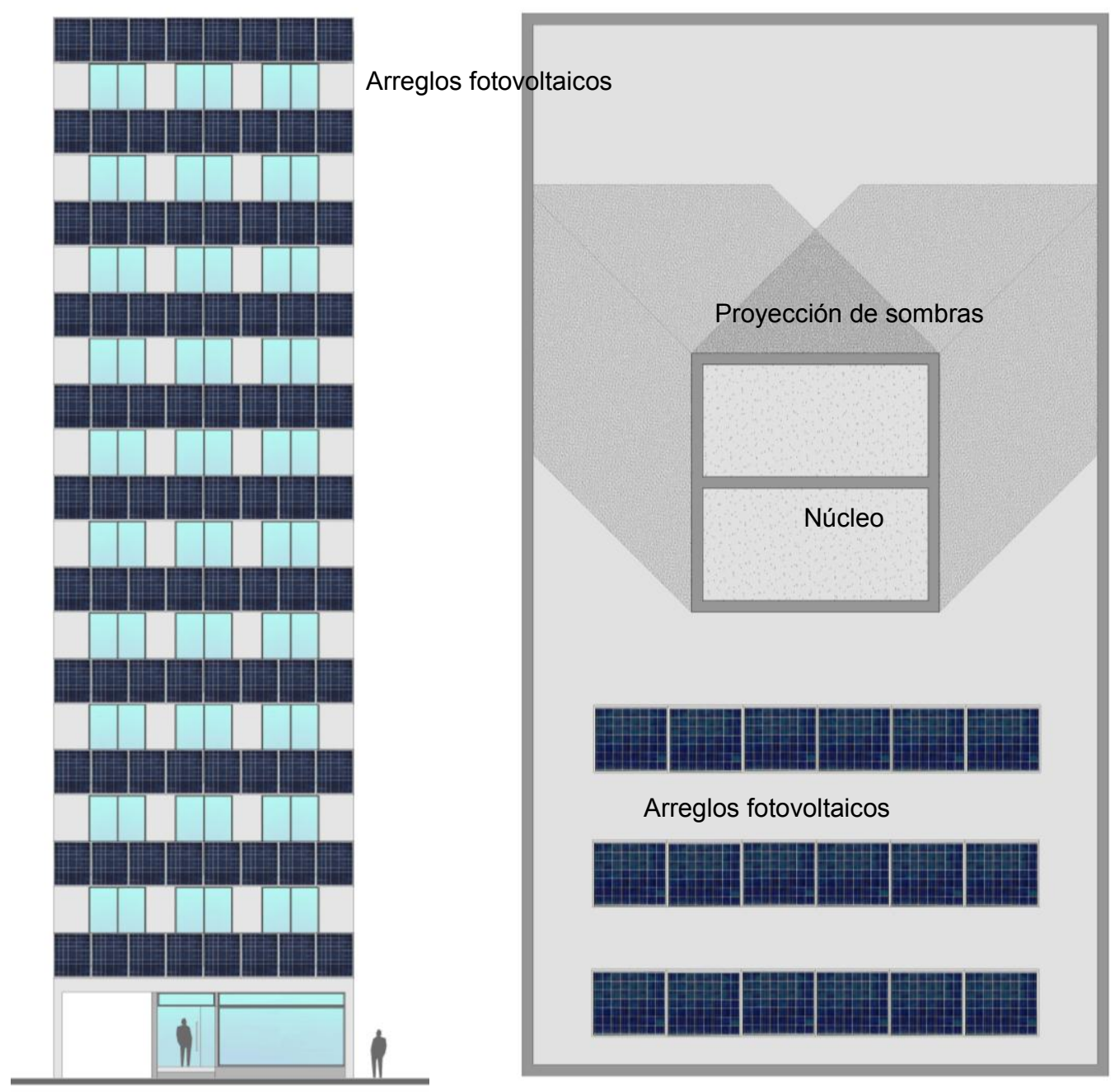

Figuras XI - 1 y 2: Esquema de ubicación de los paneles sobre la fachada norte y la azotea.

A partir de los datos obtenidos de estas tablas pudieron calcularse las Horas Solares Pico para la ciudad de La Plata, para el plano vertical y para el plano inclinado a $45^{\circ}$. Los cálculos se hicieron para el mes de junio que es, como se mencionó anteriormente, el mes más desfavorable. Las horas pico se calculan suponiendo que la radiación que llega es constante e igual a $1.000 \mathrm{~W} / \mathrm{m}^{2}$. De esta manera la cantidad de horas pico diarias multiplicadas por $1.000 \mathrm{~W} / \mathrm{m}^{2}$ proporcionan la energía total recibida por metro cuadrado diariamente [Ecuación XI 
- 1]. El resultado para el mes de junio para la ciudad de La Plata fue 1,912HSP para el plano vertical y $2,144 \mathrm{HSP}$ para el plano inclinado a $45^{\circ}$.

$$
\text { HPS } * 1000 W / m^{2}=H t \quad \text { [Ecuación XI - 1] }
$$

El hecho de usar $1.000 \mathrm{~W} / \mathrm{m}^{2}$ como radiación de referencia para el cálculo de horas pico se debe a que ese es el nivel de radiación con que se determinan las características de los paneles empleados por los fabricantes (Grossi Gallegos, H. et Al.; 2010).

Como se mencionó anteriormente se adopta una demanda de energía eléctrica de $10 \mathrm{Wh} / \mathrm{m}^{2}$ para iluminación y una superficie habitable de $1.850 \mathrm{~m}^{2}\left(185 \mathrm{~m}^{2}\right.$ por planta). Se supone un promedio de uso de cinco horas diarias en las que están encendidos el $50 \%$ de los artefactos, por lo que la demanda total de energía eléctrica a cubrir por los paneles fotovoltaicos será de $46.250 \mathrm{~W}$. Luego se calculó la eficiencia del sistema, la cual depende de la eficiencia del regulador y del inversor [Ecuación XI - 2]. Se supone que el edificio estará conectado a la red eléctrica, por lo tanto no es necesario disponer de un sistema de baterías para almacenar energía, de otro modo la eficiencia de las baterías también influiría en la eficiencia del sistema. Por lo tanto la eficiencia del sistema arrojó un valor de 0,855.

$$
\text { Ef. Sist. }=\text { Ef. Reg. }{ }^{*} \text { Ef. Inv. } \quad \text { [Ecuación XI - 2] }
$$

Se seleccionó un panel fotovoltaico Kyocera KD315, el cual tiene una potencia pico de 315W y un costo de u\$s530 (Alter Systems). Con los datos extraídos de la ficha técnica (Anexo III 3.2.1.) del panel pudo calcularse la energía generada por cada módulo [Ecuación XI - 3] y luego el número de paneles necesarios para satisfacer la demanda total de energía [Ecuación $X I-4]$.

$$
\begin{aligned}
& \text { En. Gen. }=\text { Pot. Pico Panel }{ }^{*} H S P{ }^{*} \text { Ef. Sist. } \\
& \text { [Ecuación XI - 3] } \\
& \text { Núm. Paneles = Cons. En. }{ }^{*} \text { FS } /\left(P P P^{*} H S P^{*} E S\right) \\
& \text { [Ecuación XI - 4] }
\end{aligned}
$$

Donde:

Consumo Energético $=46.250 \mathrm{~W}$

Factor de Seguridad $=10 \%$

Potencia Pico del Panel $=315 \mathrm{~W}$

Horas Solares Pico $=1,912 \mathrm{H}\left(90^{\circ}\right)$ y $2,144 \mathrm{H}\left(45^{\circ}\right)$

Eficiencia del Sistema $=0,855$

Teniendo en cuenta la superficie de fachada norte libre de aventanamientos para albergar los paneles fotovoltaicos se decidió colocar ochenta y ocho paneles sobre esta fachada, con un ángulo de $90^{\circ}$ y dieciocho paneles sobre la azotea del edificio con un ángulo de $45^{\circ}$, que es la mejor inclinación para la ciudad de La Plata. Los ochenta y ocho paneles montados en forma vertical representan el $80 \%$ de la energía demandada para cubrir los requerimientos de energía eléctrica, mientras que los dieciocho paneles de la azotea representan el $20 \%$ restante. La figura XI - 3 muestra la disposición de los paneles en la fachada norte y en la azotea.

Luego se seleccionó un inversor de corriente PVPowered PVP5200SD y con las características de la ficha técnica (Anexo III - 3.2.2.) se estimó la cantidad de unidades necesarias [Ecuación $X I$ - 5]. Suponiendo que la máxima potencia simultánea demandada será de $46.250 \mathrm{~W}$, el resultado del cálculo arrojó un valor de diez inversores para el total de la instalación.

$$
N^{\circ} \text { Conv. }=\frac{\text { Máx. Pot. Simultánea Demandada }}{\text { Potencia Nominal Inversor }}+1 \quad \text { [Ecuación XI -5] }
$$

Posteriormente se realizó el análisis de costos. Se estima una vida útil de conjunto de 30 años, que es cuando la eficiencia de los paneles cae a niveles muy bajos. La inversión inicial ronda los u\$s90.500, considerando la instalación de los diez inversores de corriente (u\$s3.000 cada 
uno) y el montaje de la estructura (5\% del costo total). Por su parte se estima un costo anual de operación y mantenimiento del $2 \%$ del total, que da un valor aproximado de u\$s1.800 (Grossi Gallegos, H. et Al.; 2010).

Luego se estimó el costo promedio por unidad de energía consumida en un año. Suponiendo que el pago de la instalación se realizará en quince años, con una tasa de interés del 10\%, con la Ecuación XI - 6 puede calcularse el Factor de Recuperación del Capital (FRC).

Donde:

$$
F R C=\frac{i^{*}(1+i)^{n}}{(1+i)^{n}-1} \quad[\text { Ecuación } X I-6]
$$

FRC= Factor de Recuperación del Capital.

$\mathrm{n}=15$ años (periodo de recuperación).

$i=10 \%$ (tasa de interés anual).

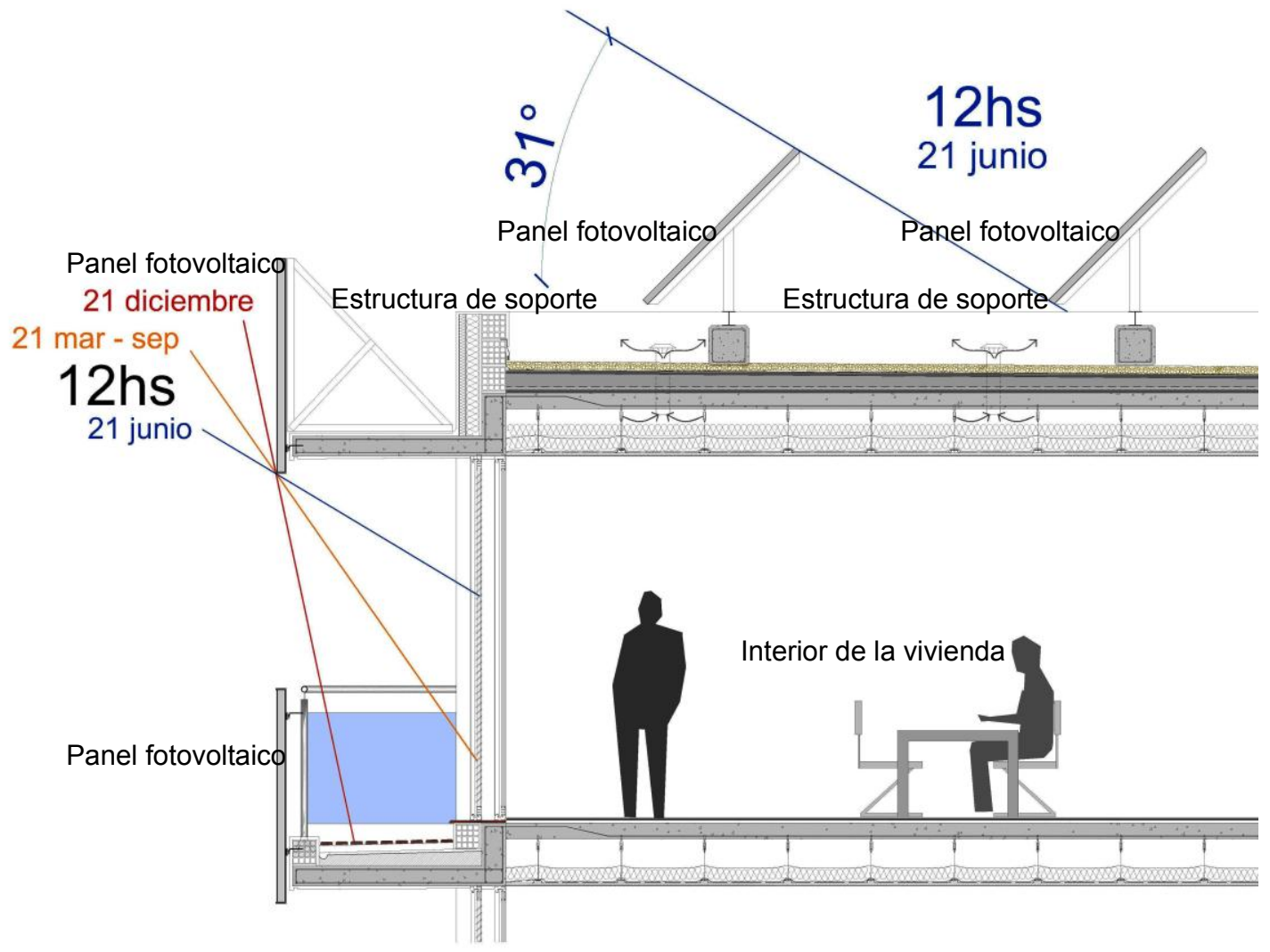

Figura XI - 3: Detalle de los paneles fotovoltaicos montados sobre la fachada norte y azotea.

Si a ese valor se lo multiplica por el Costo Inicial de la Inversión (CII) y se suma el Costo anual de Operación y Mantenimiento (COM) se obtiene el Costo Anual Equivalente (CAE), [Ecuación $\mathrm{XI}-7]$.

$$
C A E=C O M+C I{ }^{*} F R C \quad[\text { [Ecuación } X I-7]
$$

Esta ecuación arrojó un valor de u\$s13.700 para el Costo Anual Equivalente, que dividido por la energía consumida en un año $(16.880 \mathrm{kWh})$ da un costo promedio por unidad de energía de $0,811 \mathrm{u} \$ \mathrm{~s} / \mathrm{kWh}$, muy superior al $0,097 \mathrm{u} \$ \mathrm{~s} / \mathrm{kWh}$ que se le paga a la empresa distribuidora de energía eléctrica en La Plata, EDELAP.

Posteriormente se realizó la verificación con el RETScreen, un software de análisis de proyectos de energía limpia basado en Excel que ayuda a determinar la viabilidad técnica y financiera de proyectos potenciales de energía renovable, eficiencia energética y cogeneración. Los resultados arrojados por el programa no fueron satisfactorios, como se observa en el 
Gráfico XI - 1, el cual muestra el análisis financiero determinado por el programa. Según los datos arrojados por el RETScreen la realización de este proyecto no es rentable; esto se debe principalmente a que en nuestro país no existen incentivos por parte del Estado para promover la implementación de este tipo de tecnologías, pero también a que el costo de la energía suministrada por las empresas distribuidoras de energía eléctrica en Argentina es muy bajo. Al respecto, cabe destacar que se han considerado los costos de la energía eléctrica suministrada por la red sin tener en cuenta el subsidio otorgado por el Estado, que implicaría unos costos aún más bajos de energía eléctrica.

Como puede verse en este gráfico los costos de operación y mantenimiento anual del sistema son muy superiores a los costos anuales de energía eléctrica que tendría que afrontar el edificio de abastecer su demanda en forma exclusiva con energía eléctrica proveniente de la red de distribución.

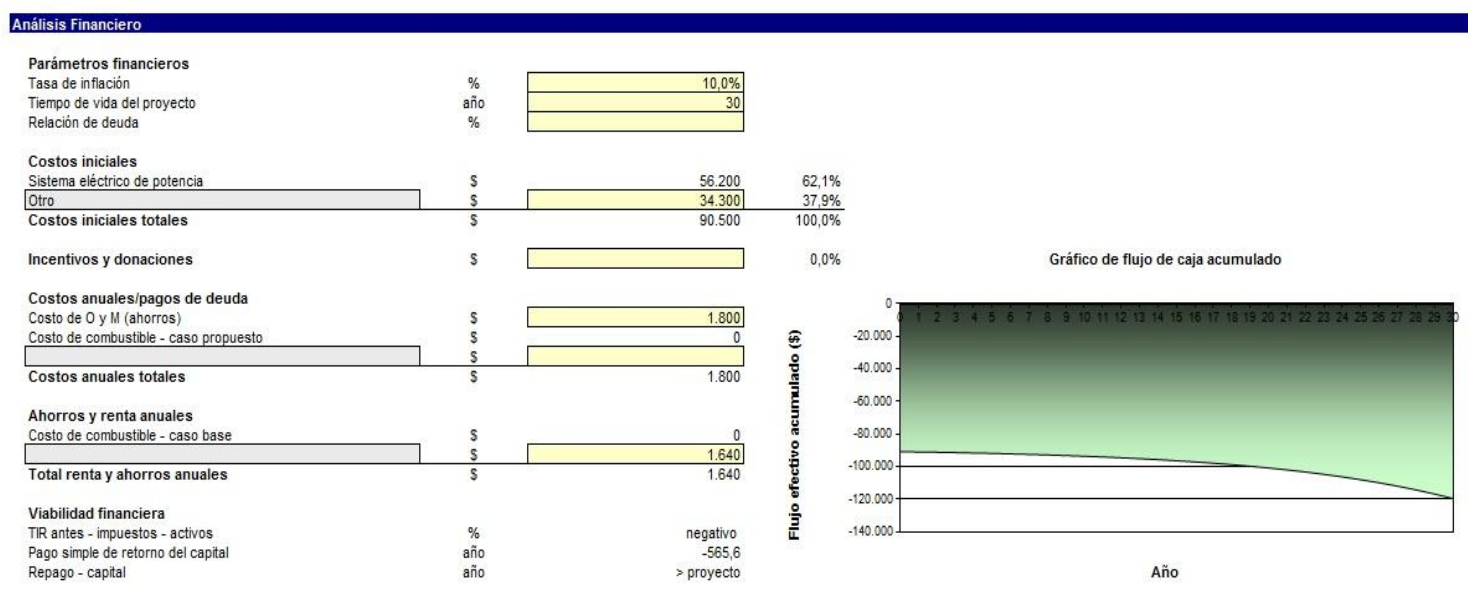

Gráfico XI - 1: Análisis financiero determinado por el RETScreen para el modelo de edificio de viviendas.

Sin embargo existe una alternativa que se implementa en muchos países y que es la venta de energía generada por el sistema fotovoltaico a la red de distribución. Esta alternativa todavía no se ha podido implementar en Argentina, principalmente porque la normativa actual no avala esta situación. Es por ello que, como ya se mencionó anteriormente, la mayoría de las construcciones que cuentan con sistema fotovoltaicos se encuentran en áreas rurales, alejadas de las redes de distribución.

EI RETScreen permite determinar la cantidad de energía que el sistema analizado puede exportar a la red. Si esta energía se vende a un precio de $0,087 \mathrm{u} \$ \mathrm{~s} / \mathrm{kWh}$, menor al costo de venta de la empresa distribuidora, el retorno de la inversión se haría a antes de los doce años, tal como lo muestra el Gráfico XI - 2.

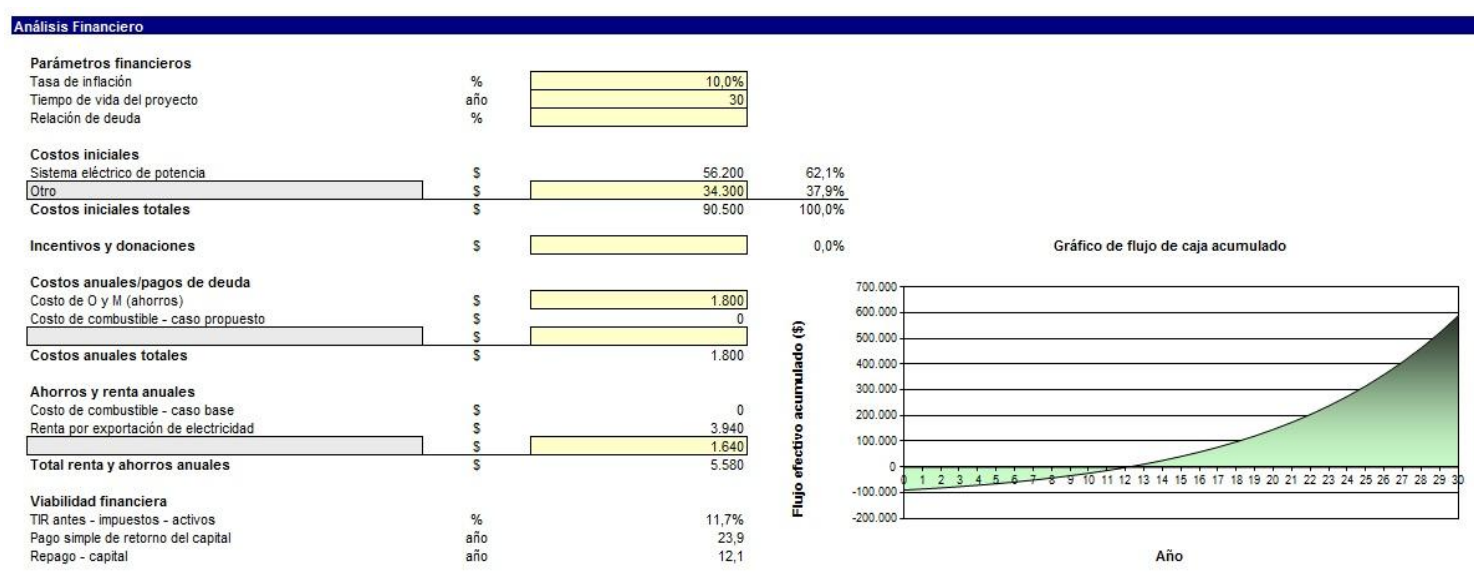

Gráfico XI -2: Análisis financiero determinado por el RETScreen para el modelo de edificio de viviendas Venta de energía a la red. 
Asimismo el RETScreen permite determinar la reducción de las emisiones de Gases de Efecto Invernadero (GEI) anual neta. Para el proyecto analizado el RETScreen determina una reducción anual neta de 13 toneladas de $\mathrm{CO}_{2}$. Este es un dato no menor ya que los Mecanismos de Desarrollo Limpio creados a partir del Protocolo de Kyoto (1997) permiten a empresas o entidades de países en desarrollo, como la Argentina, vender Certificados de Reducción de Emisiones (CERs) de Gases de Efecto Invernadero a compradores en países industrializados para compensar y equilibrar las medidas límites de GEI establecidas para ellos por el Protocolo. De este modo el cambio climático constituye una oportunidad para incorporar tecnologías limpias y reconvertir los negocios para hacerlos más sustentables, principalmente en los países en desarrollo como el nuestro, donde la implementación de estas tecnologías es incipiente. El mercado de Bonos de Carbono es uno de los instrumentos que impulsan esta reconversión a partir de la generación de "Bonos Verdes" entre los cuales, los Certificados de Reducción de Emisiones son los más conocidos. En los últimos años la oferta de CERs se ha concentrado principalmente en países como China, India, Brasil y México, sin embargo la Argentina tiene enormes oportunidades de posicionarse en el mercado de Bonos de Carbono. Es importante destacar que en el año 2008 el mercado regulado de bonos de carbono alcanzó los 120.000 millones de dólares (Secretaria de Ambiente y Desarrollo Sustentable de la Nación; 2010).

\subsubsection{Instalación solar fotovoltaica en edificios de oficinas}

Para el diseño de la instalación fotovoltaica se continuó con el modelo edilicio de oficinas propuesto en el capítulo anterior en lo que respecta a cuestiones formales, relación de superficie vidriada - opaca, superficie habitable, nivel de iluminación y equipamiento eléctrico, etc. Sin embargo se estima que la instalación fotovoltaica sólo cubrirá parte de la demanda de energía eléctrica para iluminación artificial ya que la superficie de fachada y azotea disponible no es suficiente para la colocación del número de paneles que permita cubrir la demanda total. Por su parte, se supone que el consumo de energía eléctrica para abastecer la demanda del equipamiento será cubierto por la energía proveniente de la red de distribución.

En lo que respecta a la iluminación artificial, en este modelo, se adoptó un nivel de 400 lux, propuesto por la Norma IRAM 11.659-1 para oficinas. Este nivel equivale a un factor de $16 \mathrm{~W} / \mathrm{m}^{2}$ para lámparas del tipo bajo consumo, donde además se supone que las necesidades de iluminación se cubrirán en un $100 \%$ con este tipo de lámparas.

Se plantea el diseño del sistema para un edificio de planta baja y diez plantas tipo, con una superficie por planta de $185 \mathrm{~m}^{2}$. Esto da como resultado un edificio de $5.000 \mathrm{~m}^{3}$ y $1.850 \mathrm{~m}^{2}$ de superficie total sin contar la planta baja, que no es de interés al diseño ya que no se considera ocupada por oficinas. Se supone que los paneles fotovoltaicos se ubicarán principalmente sobre el frente del edificio, de orientación norte, con una inclinación de $90^{\circ}$, conformando una fachada ventilada. Para edificios de oficinas se planteó un máximo de superficie vidriada del $50 \%$ respecto del total de la envolvente vertical donde el $50 \%$ de esa superficie vidriada se ubicaría sobre la fachada norte, de modo que se considera a esta fachada como totalmente vidriada. Sin embargo, como lo muestra la Figura XI - 4, los paneles fotovoltaicos se disponen de tal manera que no interrumpen las líneas de visuales.

Se tomaron los datos extraídos de las tablas realizadas por el Grupo IDEA y se corroboraron con el GEOSOL, tal como se procedió para el caso de edificios de vivienda. Luego, a partir de estos datos se calcularon las Horas Solares Pico para la ciudad de La Plata, para el plano vertical y para el plano inclinado a $45^{\circ}$. La cantidad de horas pico diarias multiplicadas por $1.000 \mathrm{~W} / \mathrm{m}^{2}$ dieron como resultado la energía total recibida por unidad de superficie por día [Ecuación XI - 8]. El resultado para el mes de junio para la ciudad de La Plata fue 1,912HSP para el plano vertical y $2,144 \mathrm{HSP}$ para el plano inclinado $45^{\circ}$, tal como se mencionó anteriormente.

$$
\text { HPS } \left.{ }^{*} 1.000 W / m^{2}=H t \quad \text { [Ecuación } X I-8\right]
$$


Como se mencionó anteriormente se adopta una demanda de energía eléctrica de $16 \mathrm{Wh} / \mathrm{m}^{2}$ para iluminación y una superficie habitable de $1.850 \mathrm{~m}^{2}\left(185 \mathrm{~m}^{2}\right.$ por planta). Se supone un promedio de uso de ocho horas diarias en las que están encendidos el $75 \%$ de los artefactos, por lo que la demanda total de energía eléctrica es de 177.600W. Esta demanda es casi cuatro veces superior a la demanda de energía para iluminación de edificios de viviendas y la superficie disponible tanto en la fachada norte como en la azotea del edificio no es suficiente para colocar la cantidad de paneles necesarios para cubrirla. Por este motivo se tomó la decisión de que solamente el $40 \%$ del total de dicha demanda será cubierto con paneles solares fotovoltaicos, es decir $71.000 \mathrm{~W}$.

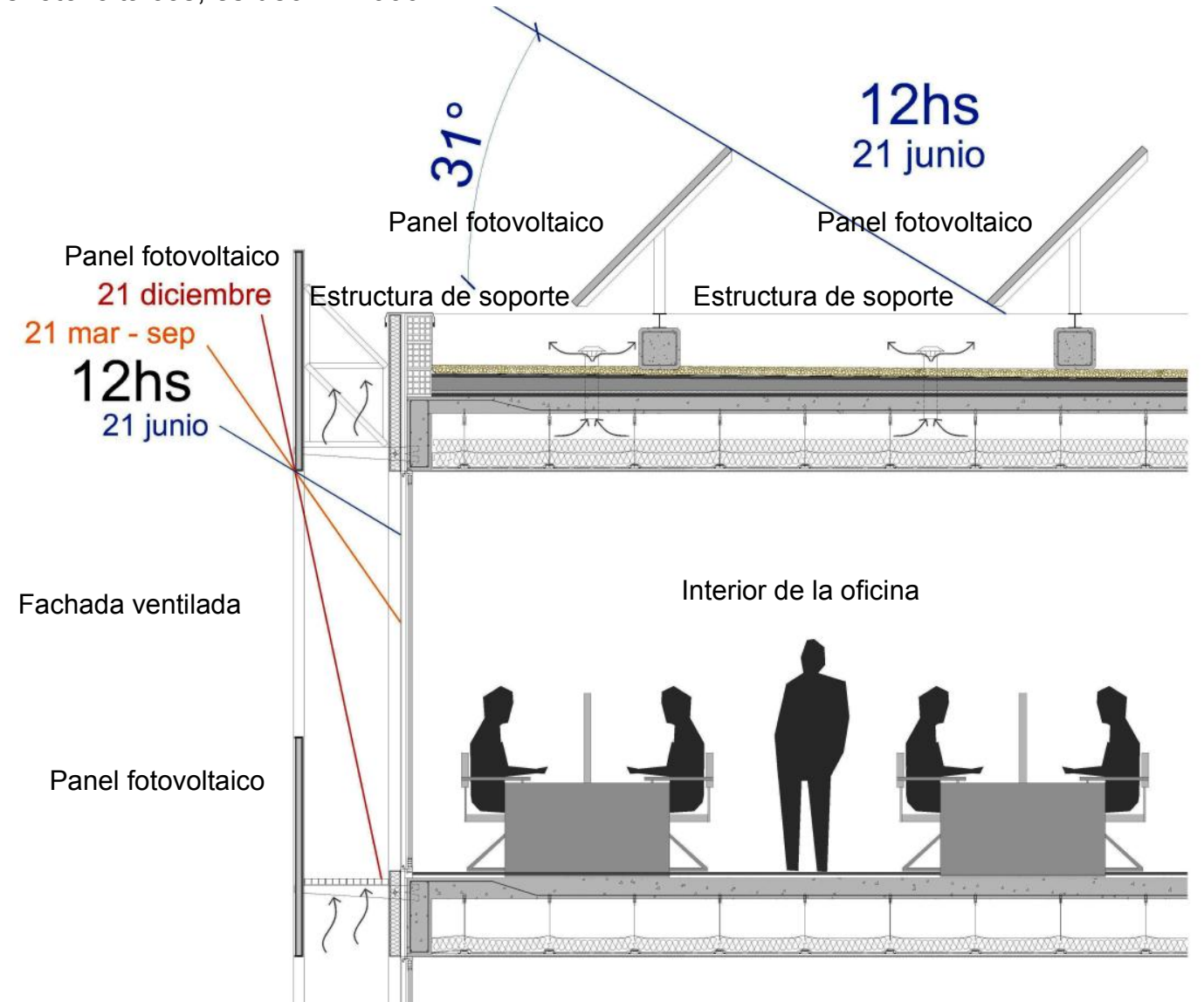

Figura XI -4: Detalle de la fachada ventilada conformada por los paneles fotovoltaicos.

Luego se calculó la eficiencia del sistema, la cual depende de la eficiencia del regulador y del inversor [Ecuación XI - 9]. Se supone que el edificio estará conectado a la red eléctrica, por lo tanto no es necesario disponer de un sistema de baterías para almacenar energía, de otro modo la eficiencia de las baterías también influiría en la eficiencia del sistema. De modo que la eficiencia del sistema arrojó un valor de 0,855.

$$
\text { Ef. Sist. }=\text { Ef. Reg. }{ }^{*} \text { Ef. Inv. } \quad \text { [Ecuación XI - 9] }
$$

Se seleccionó por un panel fotovoltaico Kyocera KD315, el cual tiene una potencia pico de $315 \mathrm{~W}$ y un costo de u\$s530 (Alter Systems). Con los datos extraídos de la ficha técnica del panel (Anexo III - 3.2.1.) pudo calcularse la energía generada por cada módulo [Ecuación XI 10] y luego el número de paneles necesarios para satisfacer la demanda de energía [Ecuación $X I-11]$.

$$
\text { En. Gen. }=\text { Pot. Pico Panel }{ }^{*} H S P{ }^{*} \text { Ef. Sist. [Ecuación XI - 10] }
$$

Núm. Paneles $=$ Cons. En. ${ }^{*} F S /\left(P P P^{*} H S P^{*} E S\right) \quad$ [Ecuación $\left.X I-11\right]$ 


\section{Donde:}

Consumo Energético $=71.000 \mathrm{~W}$ ( $40 \%$ de la demanda total).

Factor de Seguridad $=10 \%$.

Potencia Pico del Panel $=315 \mathrm{~W}$.

Horas Solares Pico $=1,912 \mathrm{H}\left(90^{\circ}\right)$ y $2,144 \mathrm{HSP}\left(45^{\circ}\right)$.

Eficiencia del Sistema $=0,855$.

Tal como se hizo para el caso de edificios de viviendas, se decidió que los paneles se dispondrían principalmente sobre la fachada norte del edificio. Sobre esta fachada se dispondrían ciento ocho paneles en forma vertical $\left(90^{\circ}\right)$, conformando una fachada ventilada sobre el curtain wall. Por su parte sobre la azotea del edificio habría espacio para albergar treinta y cuatro paneles más, con un ángulo de $45^{\circ}$, que es la mejor inclinación para la ciudad de La Plata. Los ciento ocho paneles montados en forma vertical permitirían cubrir el $74 \%$ de la energía demandada ( $40 \%$ de los requerimientos de energía eléctrica para iluminación del total del edificio), mientras que los treinta y cuatro paneles más con la inclinación de $45^{\circ}$ sobre la azotea del edificio permitirían cubrir el $26 \%$ restante (Figuras XI - 5 y 6 ).

Arreglos fotovoltaicos
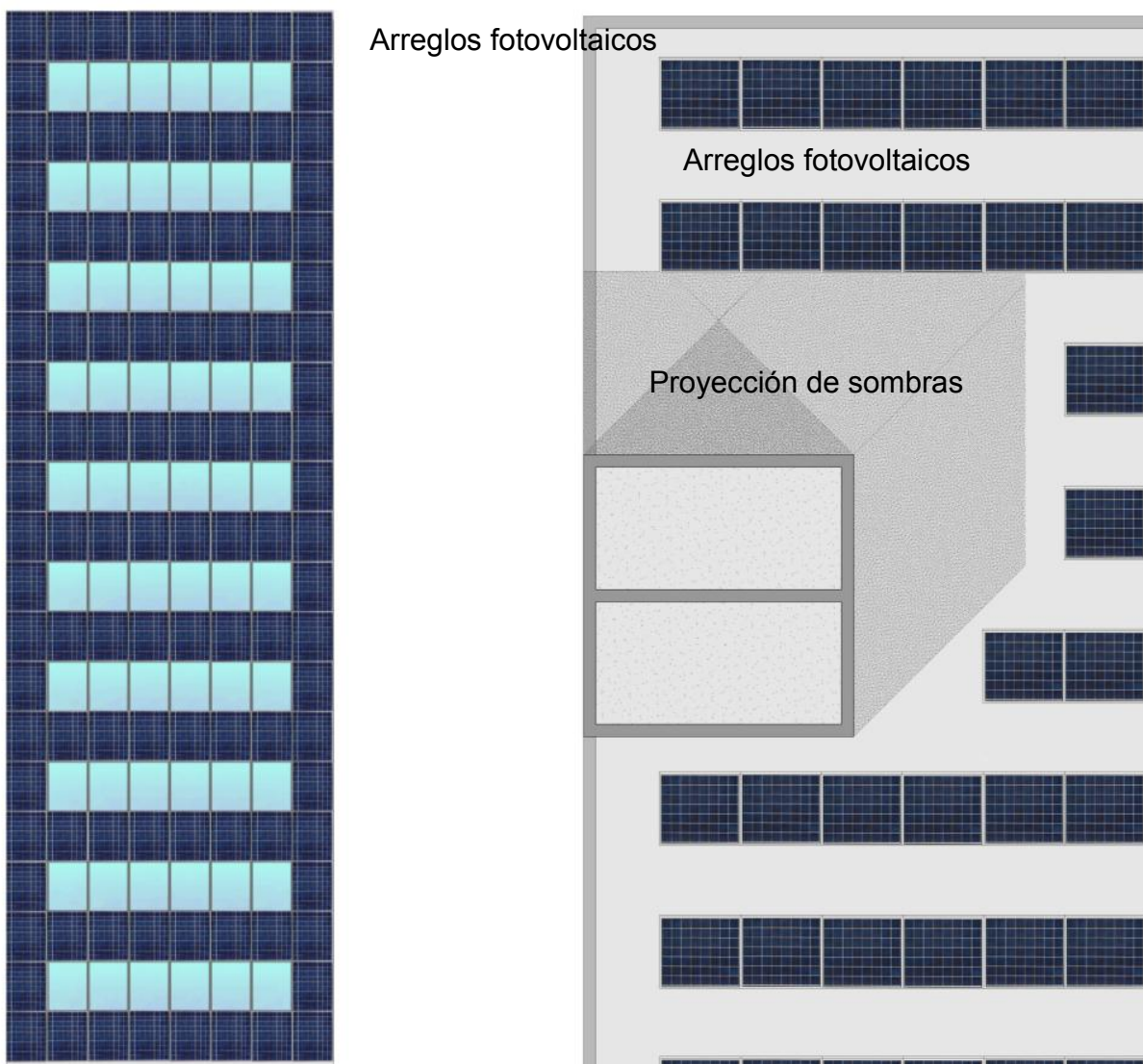

Arreglos fotovoltaicos

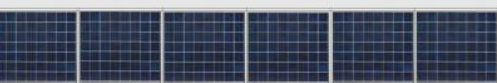

Proyección de sombras
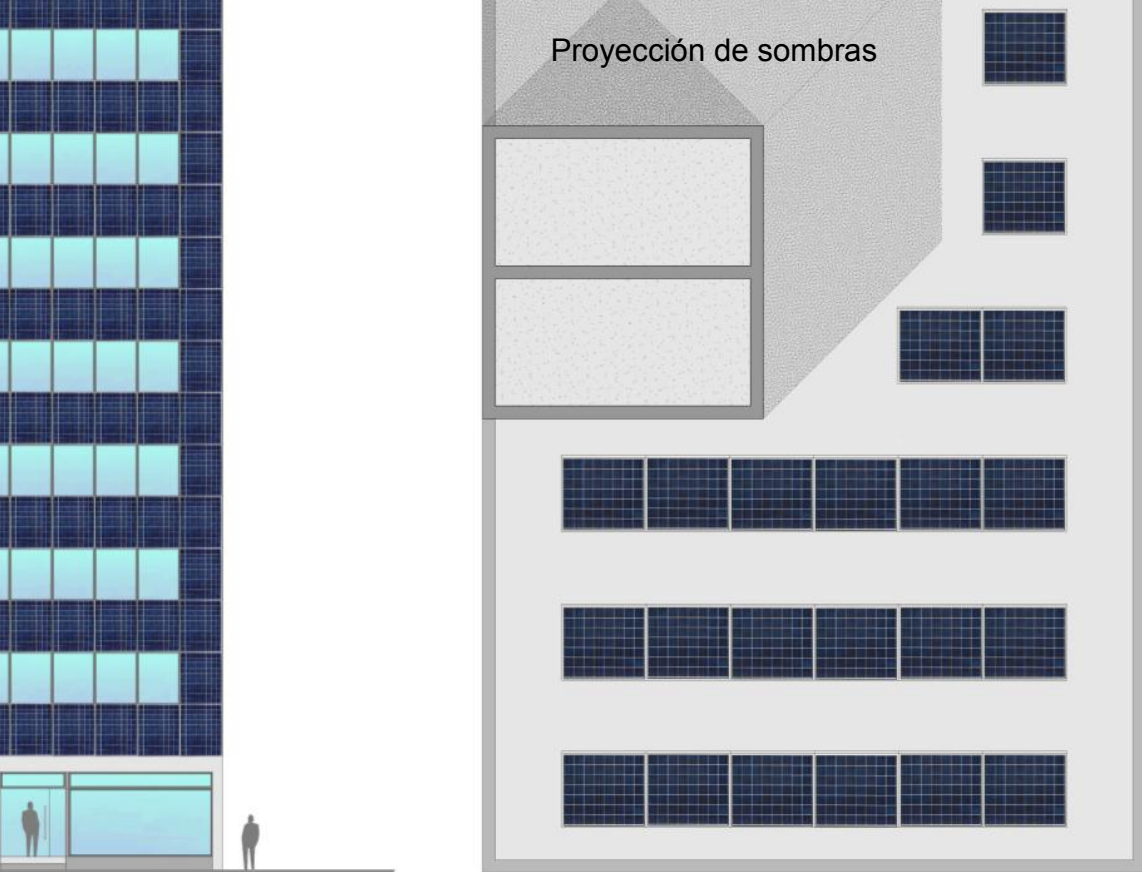

Figuras XI - 5 y 6: Esquema de ubicación de los paneles sobre la fachada norte y la azotea.

Luego se seleccionó un inversor de corriente PVPowered PVP5200SD y con las características de la ficha técnica (Anexo III - 3.2.2.) se estimó la cantidad de unidades necesarias [Ecuación $X I$ - 12]. Suponiendo que la máxima potencia simultánea demandada es $71.000 \mathrm{~W}$, el resultado del cálculo arrojó un valor de quince inversores para el total de la instalación. 


\section{$N^{\circ}$ Inv. $=\underline{\text { Máx. Pot. Simultánea Demandada }}+1 \quad$ [Ecuación XI-12] \\ Potencia Nominal Inversor}

Posteriormente se realizó el análisis de costos. Se estima una vida útil de conjunto de 30 años que es cuando la eficiencia de los paneles cae a niveles muy bajos. La inversión inicial ronda los u\$s126.300, considerando la instalación de los quince inversores de corriente (u\$s3.000 cada uno) y el montaje de la estructura ( $5 \%$ del costo total). Por su parte se estima un costo anual de operación y mantenimiento del $2 \%$, aproximadamente u $\$ \mathrm{~s} 2.500$.

Luego se estimó el costo promedio por unidad de energía. Suponiendo que el pago de la instalación se realizará en quince años, con una tasa de interés del 10\%, con la Ecuación XI 13 puede calcularse el Factor de Recuperación del Capital (FRC).

Donde:

$$
F R C=\frac{i^{*}(1+i)^{n}}{(1+i)^{n}-1} \quad[\text { Ecuación } X I-13]
$$

FRC $=$ Factor de Recuperación del Capital.

$\mathrm{n}=15$ años (periodo de recuperación).

$\mathrm{i}=10 \%$ (tasa de interés anual).

Si a ese valor se lo multiplica por el Costo Inicial de la Inversión (CII) y se suma el Costo Anual de Operación y Mantenimiento (COM) se obtiene el Costo Anual Equivalente (CAE), [Ecuación $X I-14]$.

$$
C A E=C O M+C I{ }^{*} F R C \quad[\text { Ecuación } X I-14]
$$

Esta ecuación arrojó un valor de u\$s19.100 para el Costo Anual Equivalente, que dividido por el $40 \%$ de la energía consumida en un año para 220 días hábiles $(15.628 \mathrm{kWh})$, da un costo promedio por unidad de energía de $1,222 \mathrm{u} \$ \mathrm{~s} / \mathrm{kWh}$, muy superior al $0,097 \mathrm{u} \$ \mathrm{~s} / \mathrm{kWh}$ que cobra la empresa distribuidora de energía en La Plata, EDELAP.

Posteriormente se realizó la verificación con el RETScreen. Los resultados arrojados por el programa no fueron satisfactorios, como se observa en el Gráfico XI - 3, el cual muestra el análisis financiero determinado por el programa. Según los datos arrojados por el RETScreen la realización de este proyecto no es rentable; esto se debe principalmente a que en nuestro país no existen incentivos por parte del Estado para promover la implementación de este tipo de tecnologías, pero también a que el costo de la energía suministrada por las empresas distribuidoras de energía eléctrica en Argentina es muy bajo. Al respecto, cabe destacar que se han considerado los costos de la energía eléctrica suministrada por la red sin tener en cuenta el subsidio otorgado por el Estado, que implicaría unos costos aún más bajos de energía eléctrica.

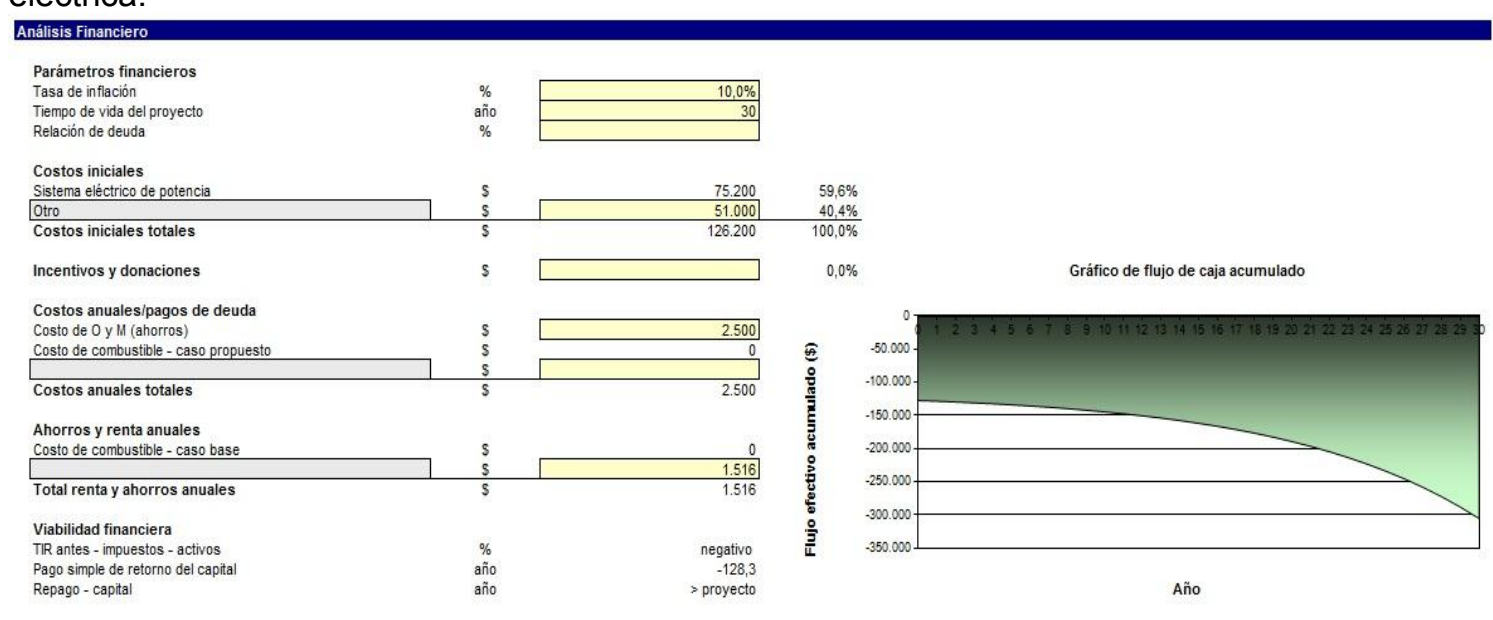

Gráfico XI - 3: Análisis financiero determinado por el RETScreen para el modelo de edificio de oficinas. 
Como puede verse en este gráfico los costos de operación y mantenimiento anual del sistema son muy superiores a los costos anuales de energía eléctrica que tendría que afrontar el edificio de no contar con el sistema fotovoltaico.

Sin embargo existe la alternativa de vender parte de la energía generada por el sistema fotovoltaico a la red de distribución. Tal como se comentó para el caso de edificios de vivienda, esta alternativa todavía no se ha podido implementar en Argentina, principalmente porque la normativa actual no avala esta situación. Es por ello que, como ya se mencionó anteriormente, la mayoría de las construcciones que cuentan con sistema fotovoltaicos se encuentran en áreas rurales, alejadas de las redes de distribución.

EI RETScreen permite determinar la cantidad de energía que el sistema analizado puede exportar a la red. Si esta energía se vende a un precio de $0,087 \mathrm{u} \$ \mathrm{~s} / \mathrm{kWh}$, menor al costo de venta de la empresa distribuidora, el retorno de la inversión se haría a antes de los diez años, tal como lo muestra el Gráfico XI - 4.

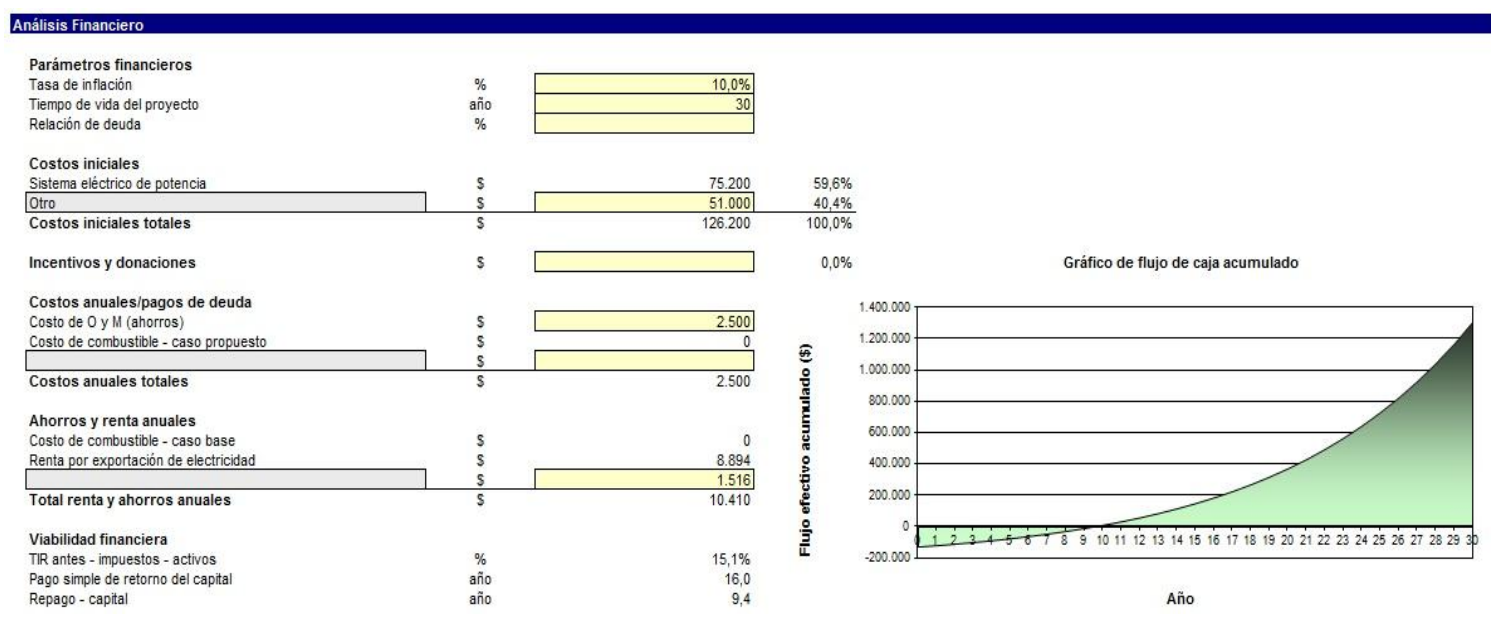

Gráfico XI - 4: Análisis financiero determinado por el RETScreen para el modelo de edificio de oficinas Venta de energía a la red.

Existe además otra opción que también se comentó en el caso de edificios de viviendas y que es la de vender Certificados de Reducción de Emisiones (CERs) de Gases de Efecto Invernadero a compradores en países industrializados. EI RETScreen permite determinar la reducción de las emisiones de Gases de Efecto Invernadero (GEI) anual neta, que para el proyecto analizado dicha reducción fue de 30 toneladas de $\mathrm{CO}_{2}$. Si bien en los últimos años la oferta de CERs se ha concentrado principalmente en países como China, India, Brasil y México, la Argentina tiene enormes oportunidades de posicionarse en el mercado de Bonos de Carbono. Es importante destacar que en el año 2008 el mercado regulado de bonos de carbono alcanzó los 120.000 millones de dólares (Secretaria de Ambiente y Desarrollo Sustentable de la Nación; 2010).

\subsection{Energía solar térmica}

Al igual que para el caso de los sistemas de energía fotovoltaica, en el diseño de los sistemas de energía solar térmica integrados en edificios entran en juego varios factores; la generación de calor, la función y el diseño arquitectónico, el comportamiento del sistema, el costo, etc. Es importante alcanzar un equilibrio entre todos ellos, al mismo tiempo que se debe cumplir con las exigencias de seguridad que afectan a la instalación, tanto desde el punto de vista de la generación de calor como de la integración arquitectónica (Grossi Gallegos, H. et Al.; 2010).

La buena integración arquitectónica de los módulos en los edificios es clave para el éxito del sistema. Sin embargo los parámetros de diseño están determinados por otras variables que 
hay que conocer y analizar para encontrar una solución adecuada a cada caso; radiación solar local, latitud, uso del edificio, entorno, elección de la tecnología fototérmica más apropiada, etc.

Sin embargo la integración arquitectónica de los sistemas de energía solar térmica parecería más difícil de alcanzar que para los sistemas de energía fotovoltaica, incluso en los países más desarrollados. Como se mencionó anteriormente, el gran potencial de la integración arquitectónica de los sistemas fotovoltaicos en los edificios se encuentra en las zonas urbanas de los países desarrollados principalmente, donde se incentiva la conexión a la red mediante primas o subvenciones. En las instalaciones de energía solar térmica no existe esta posibilidad, motivo por el cual deben evitarse los excesos de energía producidos por el sistema. Generalmente este tipo de sistemas se dimensionan para cubrir el $60 \%$ de la demanda en los meses más desfavorables, suponiendo que durante los meses de mayor radiación la instalación permitirá cubrir el total de la demanda. De este modo se evita el sobrecalentamiento de la instalación durante los meses de mayor radiación, que es cuando la demanda de energía es menor. Esta medida también contribuye a reducir los costos de inversión, de modo que puedan amortizarse a lo largo de la vida útil del sistema (CTE, España; 2009).

La inversión inicial de un sistema solar térmico es mayor a la de un sistema convencional. En teoría los costos de funcionamiento durante la vida útil de la instalación son inferiores a los costos de combustible o energía eléctrica, reparaciones, mantenimiento, etc., asociado a un sistema convencional. Sin embargo, el ahorro energético que produce un sistema de este tipo se materializa en ahorro económico. En los países más desarrollados donde el costo de la energía convencional es mucho más elevado que en nuestro país y donde existen subsidios para la instalación de este tipo de sistemas, la amortización puede oscilar entre los cinco y los doce años dependiendo del tamaño de la instalación, de las condiciones del sitio donde se instale, de las necesidades del usuario, etc. En nuestro país, en cambio, la instalación de este tipo de sistemas podría no ser rentable si se lo compara con una instalación convencional; esto debido a una falta de políticas por parte del Estado para la implementación de sistemas de energías renovables (Grossi Gallegos, H. et Al.; 2010).

La energía solar térmica consiste en el aprovechamiento de la energía procedente del sol para transferirla a un medio portador de calor, generalmente agua o aire. La principal aplicación térmica es la producción de Agua Caliente Sanitaria (ACS) para el sector doméstico y de servicios. El agua caliente sanitaria se usa a una temperatura de $45^{\circ} \mathrm{C}$, temperatura a la que se puede llegar fácilmente con captadores solares planos que pueden alcanzar hasta una temperatura media de $80^{\circ} \mathrm{C}$. En los países más desarrollados la normativa existente exige un porcentaje de cubrimiento del Agua Caliente Sanitaria anual del 60\%; el resto de las necesidades que no aportan los captadores se obtiene con un sistema auxiliar, a gas natural o a energía eléctrica (Grossi Gallegos, H. et Al.; 2010).

Los colectores solares planos de agua utilizan tanto la radiación directa como la difusa, no requieren de sistemas complejos de orientación y su mantenimiento es simple. Si bien su principal aplicación es la producción de agua caliente sanitaria para el sector doméstico y de servicios, también pueden utilizarse para calefacción de edificios, climatización de piscinas e incluso uso industrial. En términos generales una instalación solar para el calentamiento de agua está formada por varios sistemas;

- Sistema de captación: El sistema de captación está formado por captadores solares conectados entre sí. Su función es captar la energía solar para transformarla en energía térmica, aumentando la temperatura de fluido que circula por la instalación. El tipo de captador más extendido es el captador solar plano que consigue aumentos de temperatura de $60^{\circ} \mathrm{C}$ a un coste reducido. El captador plano está formado por una placa metálica negra (absorbedor) que se calienta con la exposición al sol. Por el interior de la caja se hace circular agua a través de un serpentín o un circuito de tubos de forma que el calor se transmite al fluido. El efecto que se produce es similar al de un invernadero, la radiación solar atraviesa la placa de vidrio y calienta la placa absorbedora. El vidrio deja pasar la radiación solar de onda corta pero no deja salir la radiación térmica que emite la placa absorbedora (de onda larga) y 
como consecuencia, esta placa se calienta y trasmite el calor al líquido que circula por los tubos.

Para las aplicaciones de calentamiento de agua de piscinas se pueden emplear captadores no vidriados. Estos están formados simplemente por una gran cantidad de pequeños tubos de metal o plástico dispuestos en serpentín por los que circula el agua. No necesitan caja ni cubierta de vidrio, por esta razón el aumento de la temperatura es bajo, en torno a los $30^{\circ} \mathrm{C}$. Las pérdidas de calor son grandes lo que limita su aplicación a otro tipo de instalaciones. Los tubos flexibles toleran bien el paso de aguas agresivas pero no resisten bien las tensiones mecánicas que se producen al congelarse el agua ni los rasguños superficiales. Son más económicos que los captadores planos.

También existen en el mercado captadores solares de vacío. Consisten en tubos de vidrio que recubren un tubo metálico que contiene el fluido de trabajo dejando entre ambos una cámara que actúa como aislante. Tienen un rendimiento elevado pero su costo también es elevado.

- Sistema de acumulación: Consiste en almacenar la energía térmica en un depósito de acumulación para su posterior utilización. En aplicaciones de agua caliente sanitaria o calefacción la demanda no siempre coincide con el momento en el que hay suficiente radiación, por lo tanto si se quiere aprovechar al máximo las horas de sol es necesario acumular la energía en aquellos momentos del día en que esto sea posible y utilizarla cuando se produzca la demanda. El sistema de acumulación está formado por uno o más depósitos de agua caliente. La dimensión de los depósitos de almacenamiento deberá ser proporcional al consumo estimado y debe cubrir la demanda de agua caliente de uno o dos días.

- Sistema de distribución: En este sistema se engloban todos los elementos destinados a la distribución y acondicionamiento del consumo; control, tuberías y conducciones, vasos de expansión, bombas, purgadores, válvulas, etc. También forman parte de este sistema los elementos de apoyo basados en energías convencionales (eléctricos, caldera de gas), necesarios para prevenir las posibles faltas derivadas de la falta de radiación y hacer frente a los picos de demanda o a un consumo superior al dimensionado.

Como se mencionó anteriormente, en la mayoría de los casos tanto en instalaciones de viviendas unifamiliares como en edificios de viviendas multifamiliares, las instalaciones solares se diseñan para proporcionar a las viviendas entre el $60 \%-70 \%$ del agua caliente demandada, aunque en zonas con gran insolación a lo largo de todo el año, el porcentaje de aporte suele ser superior. Pretender cubrir por encima de un $60 \%-70 \%$ anual requeriría colocar un campo solar muy grande, por lo que resultaría un costo sumamente elevado que no se llegaría a amortizar a lo largo de la vida útil del sistema, además de provocar en los meses de mayor radiación un excedente de producción que no se podría utilizar y que provocaría problemas de sobrecalentamiento en toda la instalación (CTE, España; 2009).

La energía solar térmica también puede utilizarse para calentar aire y utilizarse con fines industriales, por ejemplo para el secado de productos, o bien ser un complemento al sistema de calefacción de un edificio. Un ejemplo de colector solar de aire utilizado para calefaccionar edificios es el Muro Trombe. Este tipo de colector, integrado a la fachada norte del edificio, consiste en un muro de gran grosor e inercia térmica pintado de negro en su cara externa con orificios en su parte posterior e inferior y cerrado con cubiertas transparentes a unos diez o quince centímetros de la pared. El aire entra por el orificio interior, se calienta y vuelve al ambiente por el orificio superior. El muro a su vez actúa como acumulador devolviendo al ambiente parte del calor acumulado. El grosor del muro se calcula en función de la capacidad calorífica del material elegido buscando que la transferencia se realice preferentemente de noche. En verano se cierra el orificio superior del muro y se abre una salida al exterior en la cara norte del edificio, permitiendo que circule en el interior del local aire más fresco proveniente de la cara sur (Hernández, A.; 2010). 
Otro tipo de colector solar de aire lo constituyen los Loops Convectivos. Estos consisten en una caja, aislada térmicamente del exterior en su fondo y costados, que aloja en su interior una placa metálica negra (absorbedor), dejando un canal entre el aislante y la placa por donde circula el aire. Hacia el exterior, la caja se cierra con una doble cubierta de vidrio o policarbonato alveolar a fin de evitar que la chapa caliente se enfríe por acción del viento. Posee dos registros para la circulación del aire entre el colector y el edificio, uno en la parte superior de la caja y otro en la inferior. Una vez que el aire situado en el canal detrás de la placa absorbedora alcanza una temperatura suficientemente elevada, asciende naturalmente introduciéndose en el edificio por el registro superior mientras que el aire frío, situado sobre el piso de la vivienda, es succionado hacia el interior del canal a través del registro inferior. Durante la noche se evita que el aire frío procedente del colector ingrese al edificio a través del registro inferior, colocando una válvula de retención automática, mientras que durante el verano puede evitarse su funcionamiento con el simple sombreado del área colectora. Los loops convectivos son apropiados para la calefacción de locales de uso diurno (oficinas, bibliotecas, escuelas, comercios, etc.), ya que entregan el calor durante las horas de sol (Hernández, A.; 2010).

\subsubsection{Agua caliente sanitaria solar}

A partir de la formación adquirida en el VII Curso de Aprovechamiento Energético de la Radiación Solar del Grupo GEERSolar, en los cursos Solar I y Solar II de la Maestría en Energías Renovables de la UNSa, y la experiencia alcanzada durante la estancia de investigación en Valencia pudo hacerse el diseño de la instalación solar necesaria para satisfacer parte de la demanda de agua caliente sanitaria del modelo edilicio de viviendas propuesto en el Capítulo X. Cabe aclarar que no se realiza el diseño de esta instalación para el modelo de edificio de oficinas ya que muchos de los casos auditados de este tipo de edificios no cuentan con suministro de agua caliente sanitaria, y en general los que disponen de este suministro, se sirven de calentadores eléctricos para abastecer la demanda, que no es mucha.

\subsubsection{Agua caliente sanitaria solar en edificios de viviendas}

Para el diseño de la instalación solar necesaria para satisfacer parte de la demanda de agua caliente sanitaria para el modelo edilicio de viviendas propuesto se respetaron las cuestiones formales, relación de superficie vidriada - opaca, superficie habitable, nivel de iluminación y equipamiento eléctrico, etc. planteadas en el capítulo anterior. En función de la superficie de azotea libre de sombras disponible para la colocación de los colectores se estima que la instalación sólo cubrirá el $33 \%$ la demanda de agua caliente sanitaria, considerando para el dimensionamiento los datos de irradiación del mes más desfavorable (junio).

En lo que respecta a la demanda de agua caliente sanitaria, se estima un consumo de 40 litros por persona. Se plantea el cálculo para un edificio de planta baja y diez plantas tipo, con una superficie por planta de $185 \mathrm{~m}^{2}$. Esto da como resultado un edificio de $5.000 \mathrm{~m}^{3}$ y $1.850 \mathrm{~m}^{2}$ de superficie total sin contar la planta baja, que no es de interés al cálculo ya que no se considera superficie habitable. Se supone un factor de ocupación de $12 \mathrm{~m}^{2} /$ persona, lo que da como resultado un consumo total de 6.200 litros diarios. Sin embargo, tal como se mencionó anteriormente, en función de la superficie libre de sombras en la azotea del edificio, el sistema sólo cubrirá el $33 \%$ de la demanda, es decir 2.056 litros.

Los colectores solares se ubicarán en la azotea del edificio, con una inclinación de $45^{\circ}$, que como se mencionó anteriormente es la mejor inclinación para la ciudad de La Plata (Latitud $35^{\circ} \mathrm{S}$; Longitud $57^{\circ} \mathrm{O}$ ). De este modo se garantiza la mayor captación solar durante todo el año.

En la hoja de cálculo desarrollada por el Grupo IDEA (Investigación y Desarrollo en Energía Solar y Automática) de la Universidad de Jaén, España se ingresaron los valores de irradiación diaria media mensual extraídos del Atlas de Energía Solar de la República Argentina (Grossi Gallegos, Righini; 2007). La Tabla XI - 1 muestra los resultados obtenidos para la ciudad de La Plata, para colectores con inclinación $45^{\circ}$. 


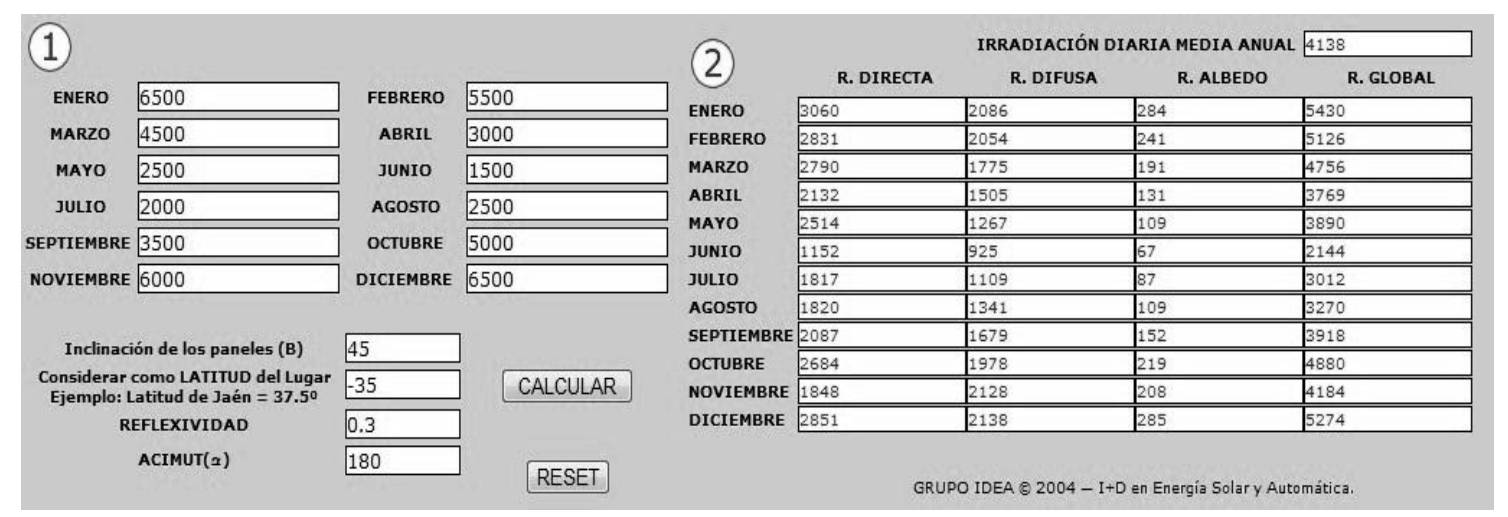

Tabla XI - 1: Radiación diaria media mensual para La Plata para una inclinación del plano $45^{\circ}$.

La irradiación media mensual para la ciudad de La Plata, para un plano inclinado a $45^{\circ}$ es de $2.144 \mathrm{Wh} / \mathrm{m}^{2}\left(1.843 \mathrm{kcal} / \mathrm{m}^{2}\right)$ para el mes de junio. Se eligió un colector solar plano de la marca Rheem; con los datos de la ficha técnica (Anexo III - 3.3.1.) pudo calcularse la eficiencia del colector [Ecuación XI -15].

$$
\eta=F R(\tau \alpha)-F R U L \frac{(T e-T a)}{\text { I plano }} \text { [Ecuación XI - 15] }
$$

Donde:

Coeficiente $F R(\tau \alpha)=0,76$.

Coeficiente $F R U L=5,93 \mathrm{~W} / \mathrm{m}^{2} \cdot{ }^{\circ} \mathrm{C}$.

Temperatura de Entrada $(\mathrm{Te})=15^{\circ} \mathrm{C}$.

Temperatura Ambiente (Ta) $=10^{\circ} \mathrm{C}$.

I plano $=2.144 \mathrm{Wh} / \mathrm{m}^{2}$.

El rendimiento del colector seleccionado para las condiciones descritas anteriormente es de 0,746. Luego con la Ecuación XI - 16, y en función de la superficie de azotea libre de sombras, pudo determinarse la superficie total de captación necesaria para cubrir el $33 \%$ de la demanda de agua caliente sanitaria (2.056 litros).

$$
\text { Sup. total captación }=\frac{\text { Consumo }(\text { Tac }- \text { Te })}{\text { I plano }{ }^{*} \eta} \quad \text { [Ecuación XI - 16] }
$$

Donde:

Consumo $=2.056$ litros (33\% demanda).

Temperatura de Acumulación $(T a c)=60^{\circ} \mathrm{C}$.

Temperatura de Entrada $(\mathrm{Te})=15^{\circ} \mathrm{C}$.

I plano= $1.843 \mathrm{kcal} / \mathrm{m}^{2}$.

La superficie de captación necesaria es de $67,32 \mathrm{~m}^{2}$ y el área neta de captación del colector seleccionado es $1,87 \mathrm{~m}^{2}$. Por lo tanto, según las medidas del colector extraídas de la ficha técnica, la inclinación que deben tener los mismos para que no se arrojen sombras y la superficie de la azotea libre de obstáculos y sombras, podrían instalarse treinta y seis colectores, que como se mencionó anteriormente servirían para satisfacer el $33 \%$ de la demanda de agua caliente sanitaria. La Figura XI - 7 muestra la disposición de los mismos en los espacios de la azotea libre de sombras. 


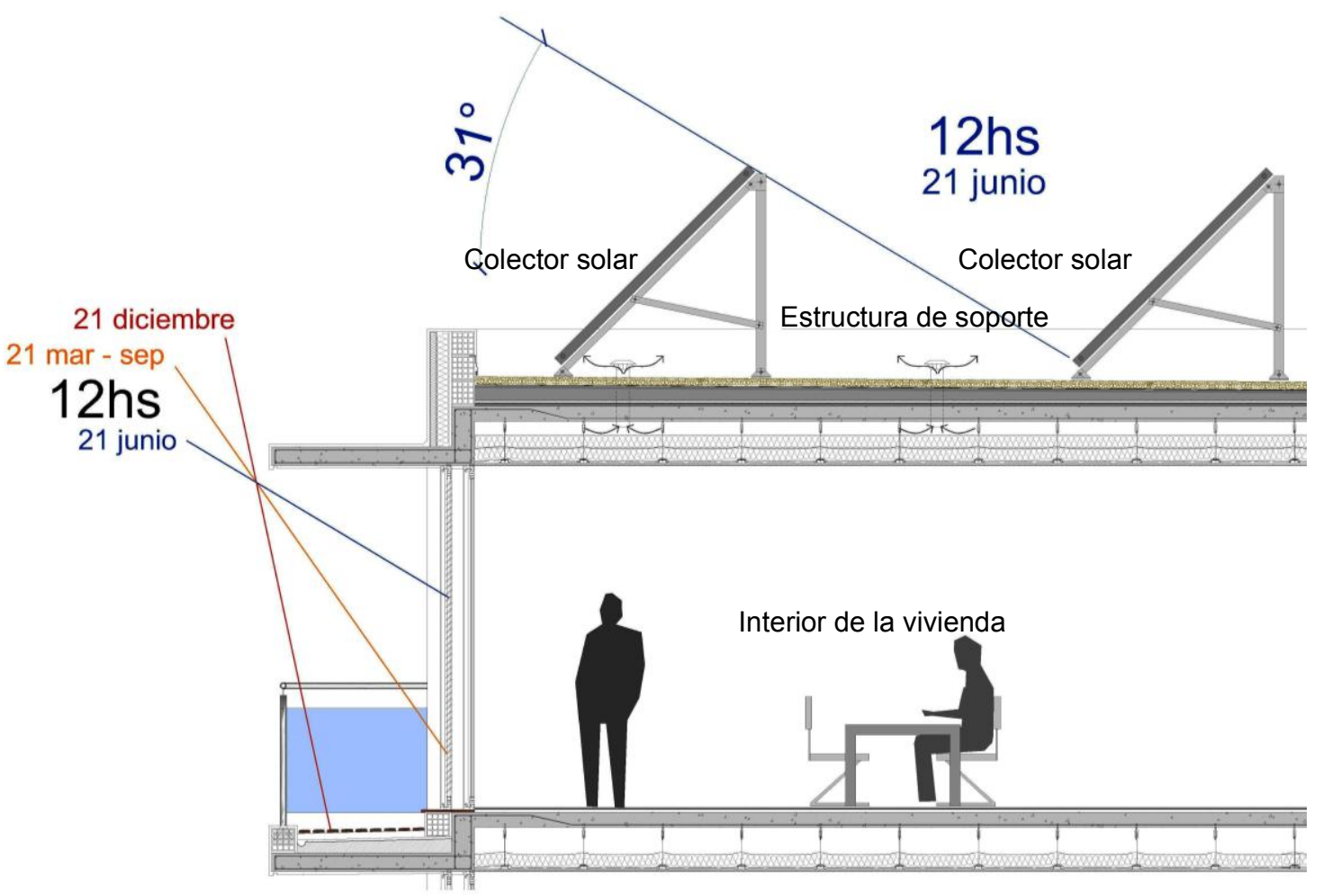

Figura XI - 7: Disposición de los colectores en la azotea.

Posteriormente se realizó el análisis de costos. Se estima una vida útil de conjunto de 25 años que es cuando la eficiencia de los colectores cae a niveles muy bajos. El costo de cada colector es de u\$s500 (Alter Systems). La inversión inicial ronda los u\$s20.700, considerando el montaje de la estructura y las cañerías para hacer la conexión a los sistemas auxiliares $(15 \%$ del costo total). Por su parte se estima un costo anual de operación y mantenimiento del $5 \%$, aproximadamente u\$s1.035. Al respecto cabe destacar que no se han considerado los costos del sistema auxiliar.

Tal como para el caso de la energía fotovoltaica, luego se estimó el costo promedio por unidad de energía consumida en un año. Suponiendo que el pago de la instalación se realizará en quince años, con una tasa de interés del 10\%, con la Ecuación XI - 17 puede calcularse el Factor de Recuperación del Capital (FRC).

$$
F R C=\frac{i^{*}(1+i)^{n}}{(1+i)^{n}-1} \quad[\text { Ecuación } X I-17]
$$

Donde:

FRC= Factor de Recuperación del Capital.

$\mathrm{n}=15$ años (periodo de recuperación).

i= 10 (tasa de interés anual).

Si a ese valor se lo multiplica por el Costo Inicial de la Inversión (CII) y se suma el Costo Anual de Operación y Mantenimiento (COM) se obtiene el Costo Anual Equivalente (CAE), Ecuación $\mathrm{XI}-18$.

$$
\left.C A E=C O M+C I{ }^{*} F R C \quad \text { [Ecuación } X I-18\right]
$$

Esta ecuación arrojó un valor de u\$s3.747 para el Costo Anual Equivalente, que dividido por el porcentaje de la energía consumida en un año que será abastecida por el sistema $\left(5.080 \mathrm{~m}^{3}\right)$ suponiendo un indicador de consumo de gas natural promedio por unidad de superficie y por día de $0,0228 \mathrm{~m}^{3} / \mathrm{m}^{2} /$ día para agua caliente, tomado del Capítulo X- da un costo promedio de 
energía equivalente a $0,737 \mathrm{u} \$ \mathrm{~s} / \mathrm{m}^{3}$, muy superior al $0,046 \mathrm{u} \$ \mathrm{~s} / \mathrm{m}^{3}$ que cobra la empresa distribuidora de gas natural en La Plata, Camuzzi Gas Pampeana.

Posteriormente se realizó la verificación con el RETScreen. Los resultados arrojados por el programa no fueron satisfactorios, como se observa en el Gráfico XI - 5, el cual muestra el análisis financiero determinado por el programa. La realización de este proyecto no es rentable; esto se debe principalmente a que en nuestro país no existen incentivos por parte del Estado para promover la implementación de este tipo de tecnologías, pero también a que el costo de la energía suministrada por la red en Argentina es muy bajo.

Como puede verse en este gráfico los costos de operación y mantenimiento anual del sistema son muy superiores a los costos anuales de gas natural que tendría que afrontar el edificio de no contar con los colectores solares. A diferencia de lo que ocurre con los sistemas de generación fotovoltaica, en los sistemas de energía solar térmica no es posible vender los excedentes de energía a la red de distribución, de modo que esta no es una alternativa válida para contribuir a que la inversión sea rentable. Una posibilidad es, como se mencionó anteriormente, que el Estado otorgue subsidios para la implementación de estos sistemas y no como ocurre actualmente que se subsidia el consumo de gas natural.

Sin embargo también existe la opción de vender Certificados de Reducción de Emisiones (CERs) de Gases de Efecto Invernadero a compradores en países industrializados, tal como se mencionó para el caso de la energía fotovoltaica. El RETScreen permite determinar la reducción de las emisiones de Gases de Efecto Invernadero (GEI) anual neta, que para el proyecto analizado dicha reducción fue de 6,3 toneladas de $\mathrm{CO}_{2}$. Como se ha mencionado anteriormente, en el año 2008 el mercado regulado de bonos de carbono, en el cual la Argentina tiene enormes oportunidades de posicionarse, alcanzó los 120.000 millones de dólares (Secretaria de Ambiente y Desarrollo Sustentable de la Nación; 2010).

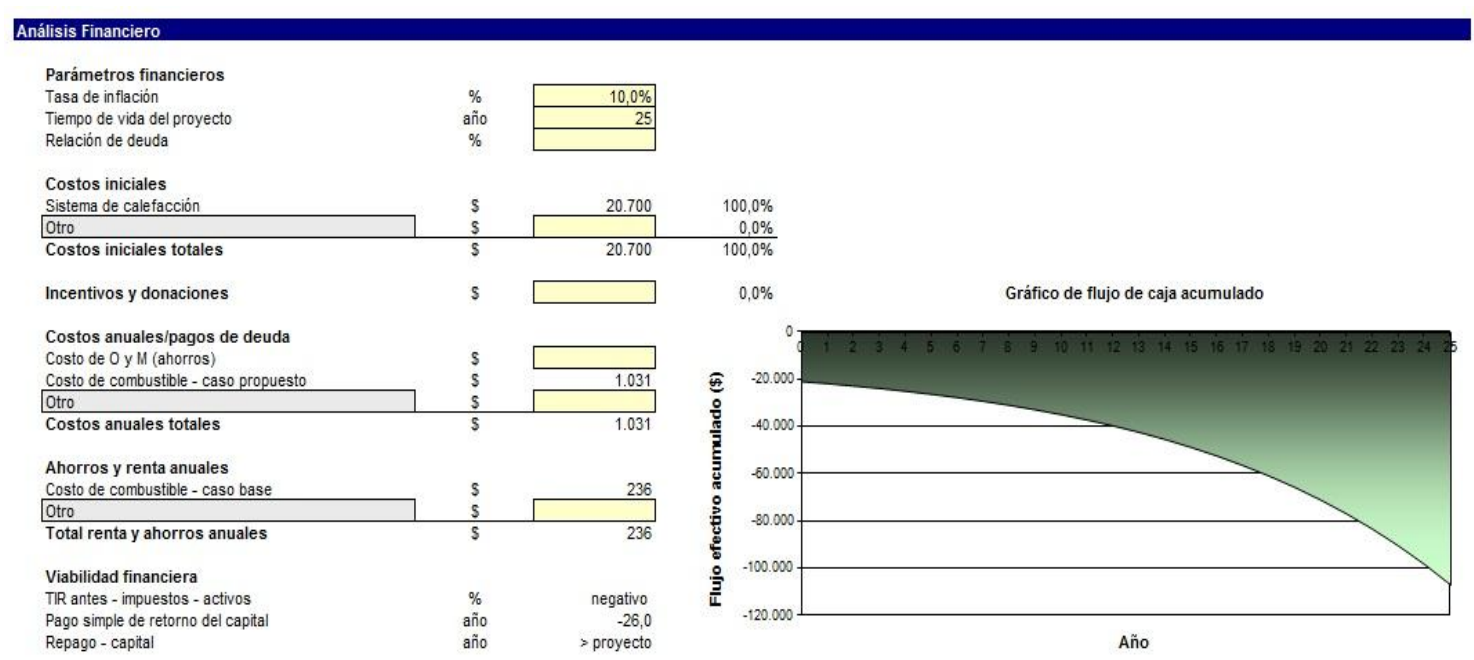

Gráfico XI - 5: Análisis financiero determinado por el RETScreen

\subsubsection{Calefacción solar}

A partir de la formación adquirida en el VII Curso de Aprovechamiento Energético de la Radiación Solar del Grupo GEERSolar, en los cursos Solar I y Solar II de la Maestría en Energías Renovables de la UNSa, y la experiencia alcanzada durante la estancia de investigación en Valencia pudo hacerse el diseño de la instalación solar necesaria para satisfacer parte de la demanda de calefacción de los modelos edilicios de viviendas y oficinas propuestos en el Capítulo X.

\subsubsection{Calefacción solar en edificios de vivienda}


Para el diseño de la instalación solar necesaria para satisfacer parte de la demanda de calefacción para el modelo edilicio de viviendas propuesto se respetaron las cuestiones formales, relación de superficie vidriada - opaca, superficie habitable, nivel de iluminación y equipamiento eléctrico, etc. planteadas en el capítulo anterior.

Se planteó el diseño de la instalación para un edificio de planta baja y diez plantas tipo, con una superficie por planta de $185 \mathrm{~m}^{2}$. Esto dio como resultado un edificio de $5.000 \mathrm{~m}^{3}$ y $1.850 \mathrm{~m}^{2}$ de superficie total sin contar la planta baja, que no es de interés al cálculo ya que no se considera superficie habitable.

Del Capítulo $X$ se obtuvo la carga térmica anual de calefacción, que para este modelo, es de 91.692kWh, suponiendo que el mismo se implanta en la ciudad de La Plata. Al multiplicar este valor por 18,4 se obtiene la demanda de calefacción por día [Ecuación XI - 19] que es igual a 1.687.133 W/día (Czajkowski, J.; 2001).

$$
Q_{\text {cal dia }}=Q_{\text {cal }}{ }^{*} 18,4 \quad[\text { Ecuación } X I-19]
$$

Donde:

$Q_{\text {cal dia }}=$ demanda de calefacción por día [W/día]

$\mathrm{Q}_{\mathrm{cal}}=$ demanda de calefacción anual [kWh/año]

Se propone que los colectores solares se ubicarán sobre el frente del edificio, de orientación norte, con una inclinación de $90^{\circ}$; de modo de lograr una mejor integración arquitectónica.

Como se mencionó anteriormente, el Grupo IDEA (Investigación y Desarrollo en Energía Solar y Automática) de la Universidad de Jaén, España desarrolló una hoja de cálculo que permite estimar la radiación media mensual sobre superficies arbitrariamente orientadas e inclinadas, mediante el ingreso del valor de la irradiación diaria media mensual, en $\mathrm{Wh} / \mathrm{m}^{2}$. En esta hoja se ingresaron los valores de irradiación diaria media mensual extraídos del Atlas de Energía Solar de la República Argentina (Grossi Gallegos, H.; Righini, R.; 2007). La Tabla XI - 2 muestra los resultados obtenidos para la ciudad de La Plata, para colectores con inclinación $90^{\circ}$.

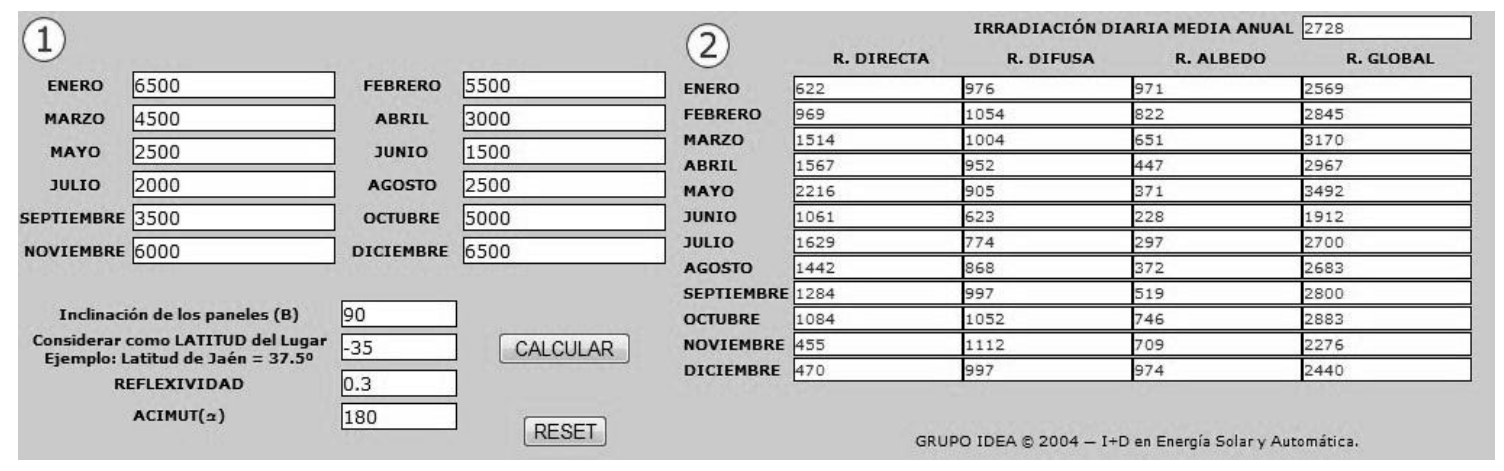

Tabla XI - 2: Radiación diaria media mensual para La Plata para un plano con inclinación a 90.

La irradiación media mensual para la ciudad de La Plata, para un plano inclinado a $90^{\circ}$ es de $1.912 \mathrm{Wh} / \mathrm{m}^{2}\left(1.644 \mathrm{kcal} / \mathrm{m}^{2}\right)$ para el mes de junio. Se optó por la utilización de colectores solares de la marca Grammer Solar, que tienen un área total de $2 \mathrm{~m}^{2}$. Se piensa su ubicación en los espacios libres de ventanas, sobre la fachada principal, de orientación norte, contribuyendo de este modo a que los mismos reciban la influencia del sol durante el invierno y permanezcan en sombra en el verano (Figura XI - 8). 


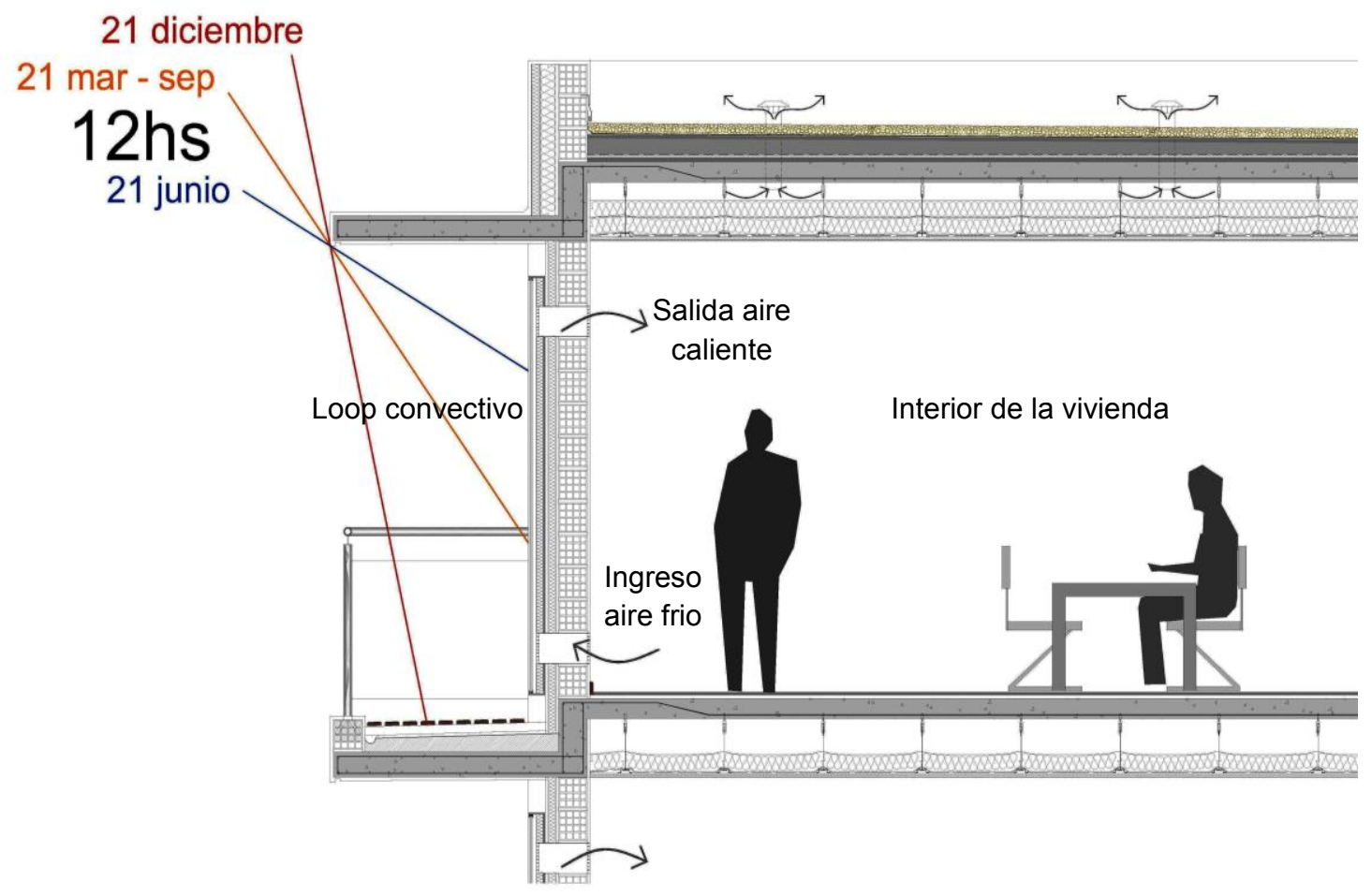

Figura XI - 8: Detalle de la ubicación de los colectores sobre la fachada norte.

En función del área del colector y de la superficie de fachada libre de aventanamientos se propone colocar treinta colectores sobre la fachada norte. De la ficha técnica del colector (Anexo III - 3.3.2.) se obtienen los datos para poder calcular el rendimiento del mismo [Ecuación XI - 20].

$$
\eta=F R(\tau \alpha)-F R U L \frac{(T e-T a)}{I \text { plano }} \quad[\text { Ecuación XI - 20] }
$$

Donde:

Coeficiente $F R(\tau \alpha)=0,62$

Coeficiente $F R U L=4,52 \mathrm{~W} / \mathrm{m}^{2} \cdot{ }^{\circ} \mathrm{C}$

Temperatura de Entrada $(T e)=15^{\circ} \mathrm{C}$

Temperatura Ambiente $(\mathrm{Ta})=10^{\circ} \mathrm{C}$

I plano $=1.912 \mathrm{Wh} / \mathrm{m}^{2}$

El rendimiento del colector seleccionado para las condiciones descritas anteriormente es de 0,608 . La superficie total de captación será de $55,5 \mathrm{~m}^{2}$, que resulta de multiplicar el área neta del colector $\left(1,85 \mathrm{~m}^{2}\right)$ por el número de colectores que se disponen sobre la fachada principal. Luego, con la Ecuación XI - 21, fue posible determinar qué porcentaje de la demanda cubrirá el sistema.

$$
\text { Sup. total captación } \left.=\frac{\text { Demanda Total de Calefacción }}{I \text { plano }{ }^{*} \eta} \quad \text { [Ecuación } X I-21\right]
$$

Donde:

Sup. total de captación $=55,5 \mathrm{~m}^{2}$

I plano= $1.644 \mathrm{kcal} / \mathrm{m}^{2}$

$\eta=0,608$ 
Esta ecuación arrojó como resultado que los treinta colectores permitirían cubrir $55.475 \mathrm{~W}$, lo que representa el $3,5 \%$ de la demanda total.

Posteriormente se realizó el análisis de costos. Se estima una vida útil de conjunto de 25 años que es cuando la eficiencia de los colectores cae a niveles muy bajos. El costo de cada colector es de u\$s150 (Alter Systems). La inversión inicial ronda los u\$s4.725, considerando el montaje de la estructura ( $5 \%$ del costo total). Por su parte se estima un costo anual de operación y mantenimiento del $2 \%$, aproximadamente u\$s 95 .

Luego se estimó el costo promedio por unidad de energía consumida en un año. Suponiendo que el pago de la instalación se realizará en dos años, con una tasa de interés del $10 \%$, puede calcularse el Factor de Recuperación del Capital (FRC) [Ecuación XI - 22].

Donde:

$$
F R C=\frac{i^{*}(1+i)^{n}}{(1+i)^{n}-1} \quad[\text { Ecuación } X I-22]
$$

FRC = Factor de Recuperación del Capital.

$\mathrm{n}=2$ años (periodo de recuperación).

$\mathrm{i}=10 \%$ (tasa de interés anual).

Si a ese valor se lo multiplica por el Costo Inicial de la Inversión (CII) y se suma el Costo Anual de Operación y Mantenimiento (COM) se obtiene el Costo Anual Equivalente (CAE), [Ecuación $\mathrm{XI}$ - 23].

$$
C A E=C O M+C I I^{*} F R C \quad[\text { Ecuación } X I-23]
$$

Esta ecuación arrojó un valor de u\$s2.817 para el Costo Anual Equivalente, que dividido por la energía consumida en un año que será abastecida por el sistema $\left(1.271,49 \mathrm{~m}^{3}\right)$-suponiendo un indicador de consumo de gas natural promedio por unidad de superficie y por día de $0,0538 \mathrm{~m}^{3} / \mathrm{m}^{2} /$ día para calefacción, tomado del Capítulo X- da un costo promedio por unidad de energía equivalente a $2,21 \mathrm{u} \$ \mathrm{~s} / \mathrm{m}^{3}$, muy superior al $0,046 \mathrm{u} \$ \mathrm{~s} / \mathrm{m}^{3}$ que cobra la empresa distribuidora de gas natural en La Plata, Camuzzi Gas Pampeana.

Posteriormente se realizó la verificación con el RETScreen. Los resultados arrojados por el programa no fueron satisfactorios, como se observa en Gráfico XI - 6, el cual muestra el análisis financiero determinado por el programa. La realización de este proyecto no es rentable; esto se debe principalmente a que el costo de la energía suministrada por la red en Argentina es muy bajo. Como puede verse en este gráfico los costos de operación y mantenimiento anual del sistema son muy superiores a los costos anuales de gas natural que tendría que afrontar el edificio de no contar con los colectores solares.

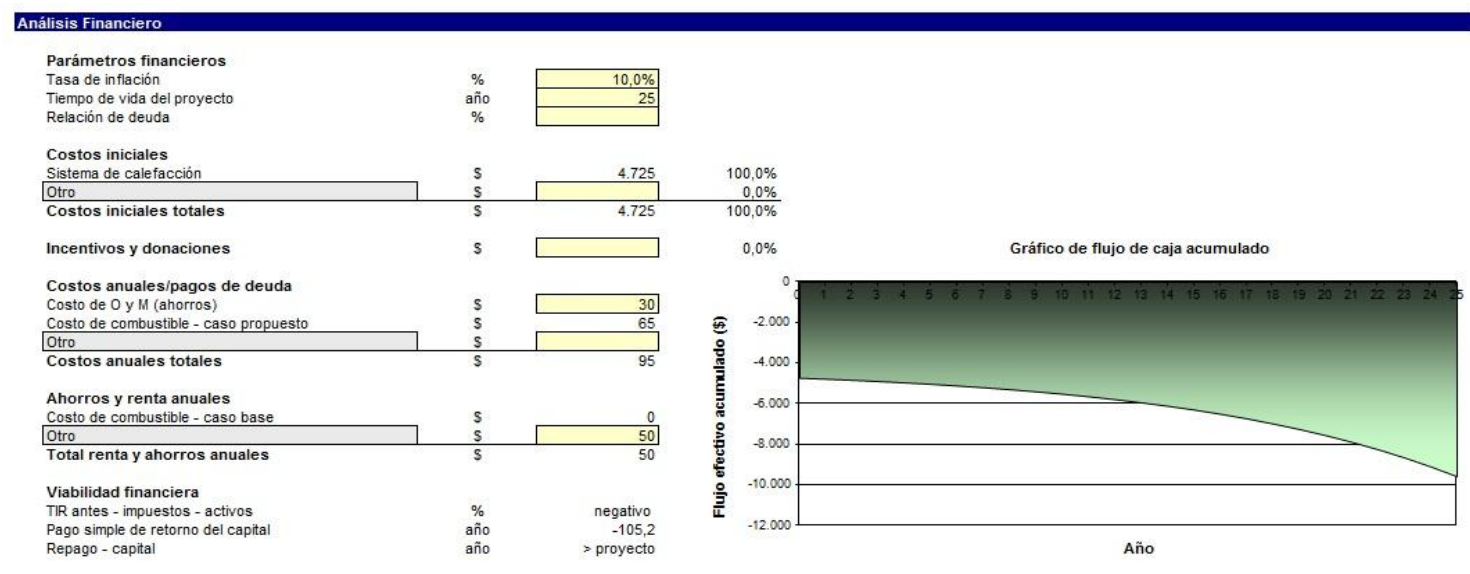

Gráfico XI - 6: Análisis financiero determinado por el RETScreen para colectores solares. 
Como ya se ha mencionado anteriormente en los sistemas de energía solar térmica no es posible vender los excedentes de energía a la red de distribución. Para que la inversión sea rentable debería existir la posibilidad de que el Estado otorgue subsidios para la implementación de estos sistemas y no como ocurre actualmente que se subsidia el consumo de gas natural.

Por otra parte existe la opción de vender Certificados de Reducción de Emisiones (CERs) de Gases de Efecto Invernadero a compradores en países industrializados, tal como se mencionó para el caso de la energía fotovoltaica. EI RETScreen permite determinar la reducción de las emisiones de Gases de Efecto Invernadero (GEI) anual neta, que para el proyecto analizado fue de 2,7 toneladas de $\mathrm{CO}_{2}$. Como se ha mencionado anteriormente, en el año 2008 el mercado regulado de bonos de carbono alcanzó los 120.000 millones de dólares (Secretaria de Ambiente y Desarrollo Sustentable de la Nación; 2010).

\subsubsection{Calefacción solar en edificios de oficinas}

Para el diseño de la instalación solar necesaria para satisfacer parte de la demanda de calefacción para el modelo edilicio de oficinas propuesto se respetaron las cuestiones formales, relación de superficie vidriada - opaca, superficie habitable, nivel de iluminación y equipamiento eléctrico, etc. planteadas en el capítulo anterior.

Se plantea el diseño de la instalación para un edificio de planta baja y diez plantas tipo, con una superficie por planta de $185 \mathrm{~m}^{2}$. Esto da como resultado un edificio de $5.000 \mathrm{~m}^{3}$ y $1.850 \mathrm{~m}^{2}$ de superficie total sin contar la planta baja, que no es de interés al cálculo ya que no se considera ocupada por oficinas.

Del Capítulo $X$ se obtiene la carga térmica anual de calefacción, que para este modelo, es de 97.966kWh, suponiendo que el mismo se implanta en la ciudad de La Plata. Al multiplicar este valor por 18,4 se obtiene la demanda de calefacción por día [Ecuación XI - 24] que es igual a 1.802.574 W/día. (Czajkowski, J.; 2001).

$$
\left.Q_{\text {cal dia }}=Q_{\text {cal }}{ }^{*} 18,4 \quad \text { [Ecuación } X I-24\right]
$$

Donde:

$Q_{\text {cal dia }}=$ demanda de calefacción por día [W/día]

$\mathrm{Q}_{\mathrm{cal}}=$ demanda de calefacción anual [kWh/año]

Se propone que los colectores solares se ubicarán sobre el frente del edificio, de orientación norte, con una inclinación de $90^{\circ}$; intercalando paneles vidriados con colectores planos, de modo de lograr una mejor integración arquitectónica.

Como se mencionó anteriormente, el Grupo IDEA (Investigación y Desarrollo en Energía Solar y Automática) de la Universidad de Jaén, España desarrolló una hoja de cálculo que permite estimar la radiación media mensual sobre superficies arbitrariamente orientadas e inclinadas, mediante el ingreso del valor de la irradiación diaria media mensual, en $\mathrm{Wh} / \mathrm{m}^{2}$. En esta hoja se ingresaron los valores de irradiación diaria media mensual extraídos del Atlas de Energía Solar de la República Argentina (Grossi Gallegos, H.; Righini, R.; 2007). La Tabla XI - 3 muestra los resultados obtenidos para la ciudad de La Plata, para colectores con inclinación $90^{\circ}$. 


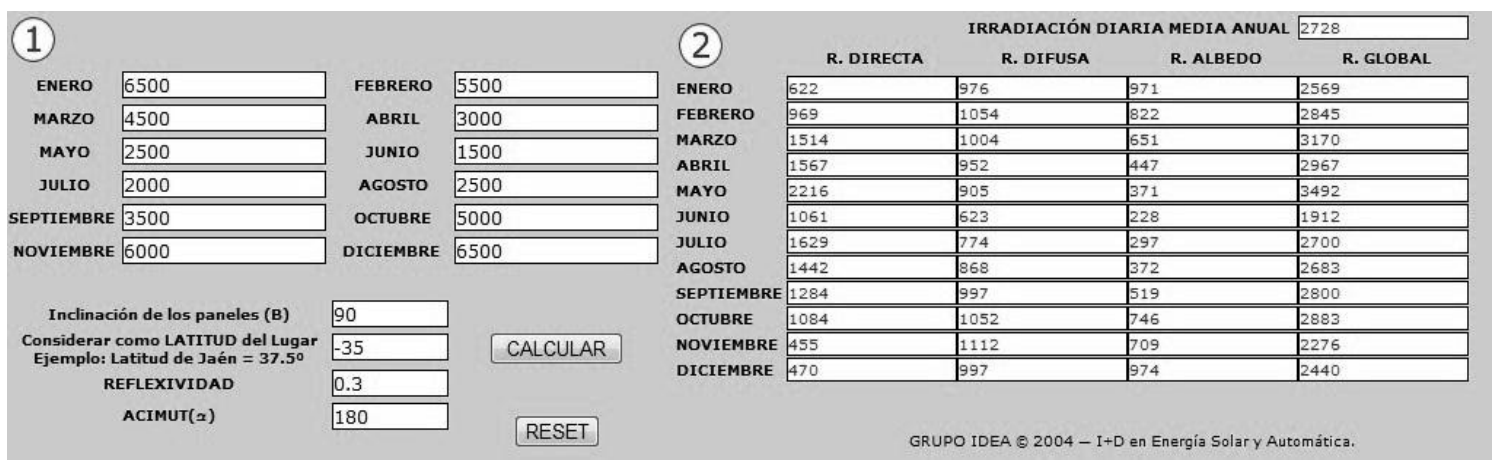

Tabla XI - 3: Radiación diaria media mensual para La Plata para plano inclinado a $90^{\circ}$.

La irradiación media mensual para la ciudad de La Plata, para un plano inclinado a $90^{\circ}$ es de $1.912 \mathrm{Wh} / \mathrm{m}^{2}\left(1.644 \mathrm{kcal} / \mathrm{m}^{2}\right)$ para el mes de junio. Se optó por colectores solares de la marca Grammer Solar, que tienen un área total de $2 \mathrm{~m}^{2}$. Se piensa su ubicación entre la línea de ventanas, sobre la fachada principal, de orientación norte, contribuyendo de este modo a que los mismos reciban la influencia del sol durante el invierno y permanezcan en sombra en el verano (Figura XI - 9).

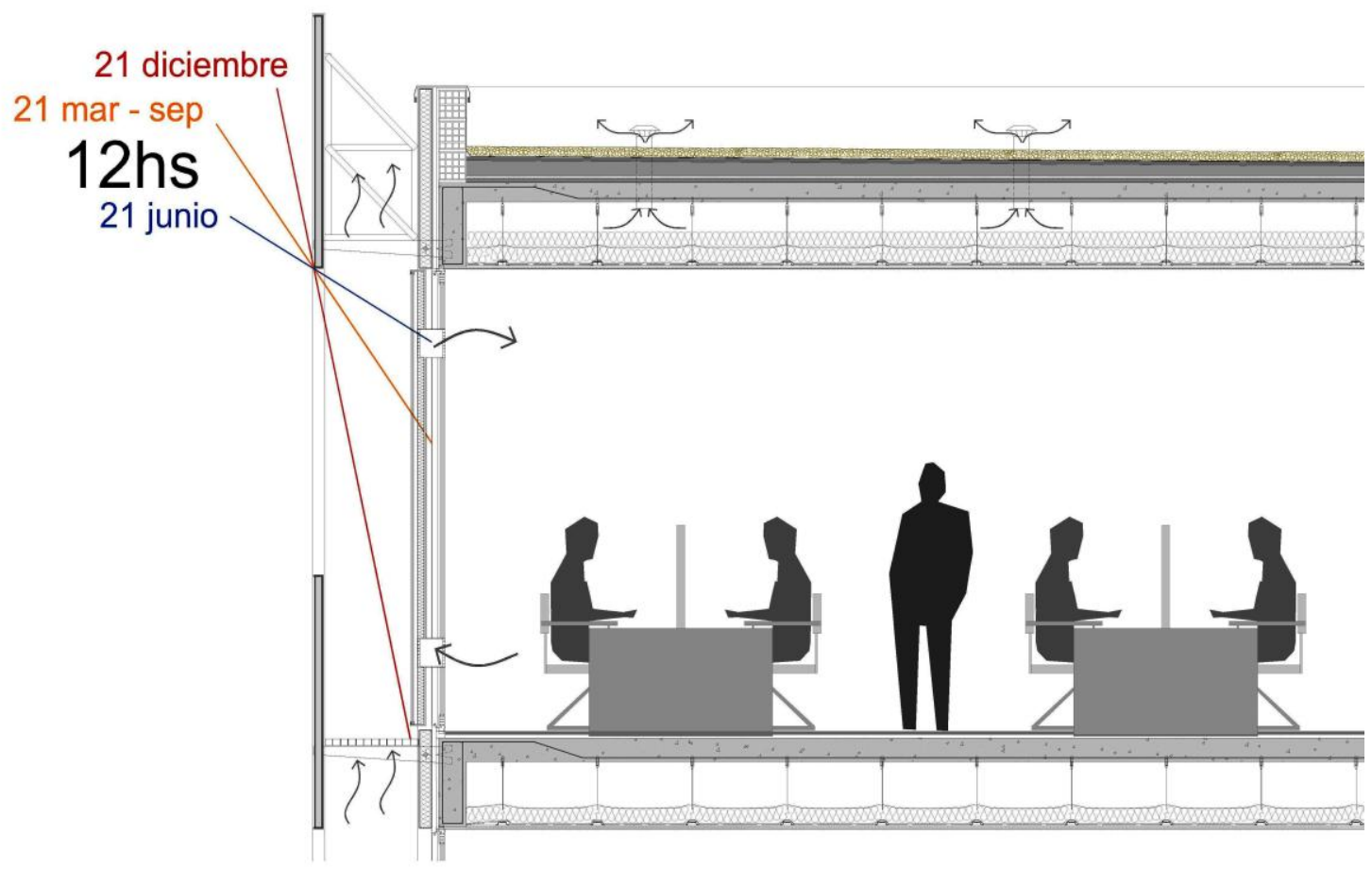

Figura XI - 9: Detalle de ubicación de los colectores solares sobre la fachada norte.

En función del área del colector y de la superficie de fachada libre de aventanamientos se propone colocar treinta colectores sobre la fachada norte. De la ficha técnica del colector (Anexo III - 3.3.2.) se obtienen los datos para poder calcular el rendimiento del mismo [Ecuación XI - 25].

$$
\eta=F R(\tau \alpha)-F R U L \frac{(T e-T a)}{I \text { plano }}[\text { Ecuación XI - 25] }
$$

Donde:

Coeficiente $F R(\tau \alpha)=0,62$

Coeficiente FR UL=4,52 W/m ${ }^{2} \cdot{ }^{\circ} \mathrm{C}$ 
Temperatura de Entrada $(T e)=15^{\circ} \mathrm{C}$

Temperatura Ambiente $(\mathrm{Ta})=10^{\circ} \mathrm{C}$

I plano $=1.912 \mathrm{Wh} / \mathrm{m}^{2}$

El rendimiento del colector seleccionado para las condiciones descritas anteriormente es de 0,608 . La superficie total de captación será de $55,5 \mathrm{~m}^{2}$, que resulta de multiplicar el área neta del colector $\left(1,85 \mathrm{~m}^{2}\right)$ por el número de colectores que se disponen sobre la fachada principal. Luego, con la Ecuación XI - 26, fue posible determinar qué porcentaje de la demanda cubrirá el sistema.

$$
\text { Sup. total captación }=\frac{\text { Demanda Total de Calefacción }}{\text { I plano }{ }^{*} \eta} \text { [Ecuación XI - 26] }
$$

Donde:

Sup. total de captación $=55,5 \mathrm{~m}^{2}$.

I plano $=1.644 \mathrm{kcal} / \mathrm{m}^{2}$

$\eta=0,608$.

Esta ecuación arrojó como resultado que los treinta colectores permitirían cubrir $55.475 \mathrm{~W}$, lo que representa el $3 \%$ de la demanda total.

Posteriormente se realizó el análisis de costos. Se estima una vida útil de conjunto de 25 años que es cuando la eficiencia de los colectores cae a niveles muy bajos. El costo de cada colector es de u\$s150 (Alter Systems). La inversión inicial ronda los u\$s4.725, considerando el montaje de la estructura ( $5 \%$ del costo total). Por su parte se estima un costo anual de operación y mantenimiento del $2 \%$, aproximadamente u\$s 95 .

Luego se estimó el costo promedio por unidad de energía consumida en un año. Suponiendo que el pago de la instalación se realizará en dos años, con una tasa de interés del 10\%, con la Ecuación XI - 27 puede calcularse el Factor de Recuperación del Capital (FRC).

$$
F R C=\frac{i^{*}(1+i)^{n}}{(1+i)^{n}-1} \quad[\text { Ecuación } \mathrm{XI}-27]
$$

Donde:

FRC = Factor de Recuperación del Capital

$\mathrm{n}=2$ años (periodo de recuperación)

$\mathrm{i}=10$ (tasa de interés anual)

Si a ese valor se lo multiplica por el Costo Inicial de la Inversión (CII) y se suma el Costo Anual de Operación y Mantenimiento (COM) se obtiene el Costo Anual Equivalente (CAE), Ecuación $\mathrm{XI}-28$.

$$
C A E=C O M+C I I^{*} F R C \quad[\text { Ecuación } X I-28]
$$

Esta ecuación arrojó un valor de u\$s2.817 para el Costo Anual Equivalente, que dividido por la energía consumida en un año que será abastecida por el sistema $\left(850,81 \mathrm{~m}^{3}\right)$-suponiendo un indicador de consumo de gas natural promedio por unidad de superficie y por día de $0,042 \mathrm{~m}^{3} / \mathrm{m}^{2} /$ día para calefacción, tomado del Capítulo X- da un costo promedio por unidad de energía equivalente a $3,31 \mathrm{u} \$ \mathrm{~s} / \mathrm{m}^{3}$, muy superior al $0,046 \mathrm{u} \$ \mathrm{~s} / \mathrm{m}^{3}$ que cobra la empresa distribuidora de gas natural en La Plata, Camuzzi Gas Pampeana.

Posteriormente se realizó la verificación con el RETScreen. Los resultados arrojados por el programa no fueron satisfactorios, como se observa en el Gráfico XI - 7, el cual muestra el análisis financiero determinado por el programa. La realización de este proyecto no es rentable; esto se debe principalmente a que en nuestro país no existen incentivos por parte del Estado 
para promover la implementación de este tipo de tecnologías, pero también a que el costo de la energía suministrada por la red en Argentina es muy bajo.

Como puede verse en este gráfico los costos de operación y mantenimiento anual del sistema son muy superiores a los costos anuales de gas natural que tendría que afrontar el edificio de no contar con los colectores solares. Como ya se ha mencionado anteriormente en los sistemas de energía solar térmica no es posible vender los excedentes de energía a la red de distribución. Para que la inversión sea rentable debería existir la posibilidad de que el Estado otorgue subsidios para la implementación de estos sistemas y no como ocurre actualmente que se subsidia el consumo de gas natural.

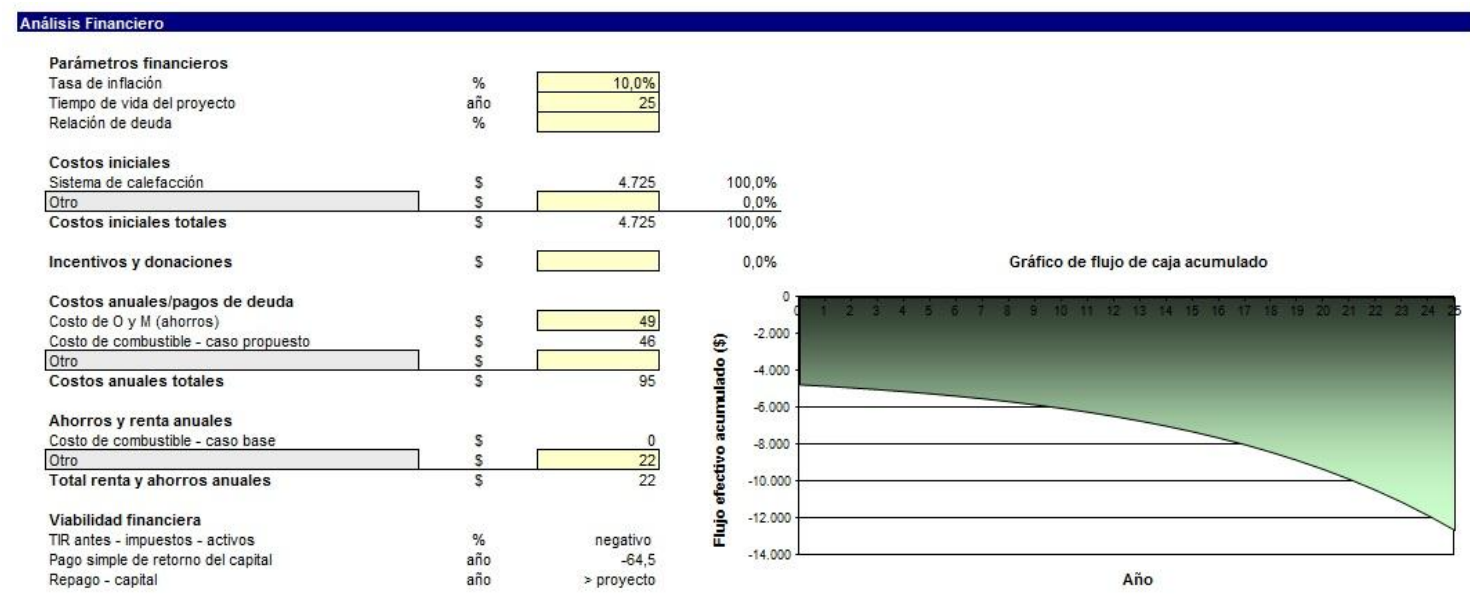

Gráfico XI - 7: Análisis financiero determinado por el RETScreen para colectores solares.

Por otra parte existe la opción de vender Certificados de Reducción de Emisiones (CERs) de Gases de Efecto Invernadero a compradores en países industrializados, tal como se mencionó para el caso de la energía fotovoltaica. EI RETScreen permite determinar la reducción de las emisiones de Gases de Efecto Invernadero (GEI) anual neta, que para el proyecto analizado dicha reducción fue de 1,8 toneladas de $\mathrm{CO}_{2}$. Como se ha mencionado anteriormente la Argentina tiene enormes oportunidades de posicionarse en el mercado de Bonos de Carbono (Secretaria de Ambiente y Desarrollo Sustentable de la Nación; 2010). 


\section{CONCLUSIONES}

Los edificios de propiedad horizontal en altura son los actores predominantes de cualquier ciudad del mundo. En la configuración de los mismos entran en juego una serie de elementos que están directamente relacionados con el contexto histórico, sociocultural, económico y político del país en el cual se desarrollan. En nuestro país, la especulación en el uso del suelo y la incesante búsqueda por reducir los costos de construcción han contribuido al detrimento de la calidad higrotérmica de la envolvente edilicia en los últimos años, priorizando la rentabilidad por sobre el confort interior de los edificios.

La baja calidad higrotérmica de la envolvente edilicia hace que sea necesario un gran consumo de energía, proveniente principalmente de fuentes no renovables, para que la temperatura de los espacios interiores alcance valores razonables. Sin embargo, en la mayoría de los casos, pese al derroche energético, los ambientes no alcanzan las condiciones de confort.

En invierno el mayor consumo de energía para calefaccionar los espacios interiores se debe principalmente a las pérdidas de calor a través de la envolvente y a la sensación de disconfort que se produce frente a las bajas temperaturas de los paramentos que se encuentran en contacto con el exterior. La falta de aislamiento térmico en estas caras hace que exista una gran diferencia entre la temperatura superficial interior de los cerramientos y la temperatura interior del local que conforman.

En verano a las cargas por ocupación, equipamiento eléctrico e iluminación propias de cualquier espacio habitado se suman otras debidas a la incidencia de la radiación solar y del aire exterior. Asimismo es importante destacar que en las ciudades, producto del efecto de isla de calor, la temperatura del aire exterior es más alta que en las zonas circundantes, no urbanizadas, y por lo tanto la situación es más grave. La baja calidad de la envolvente edilicia contribuye a que el sobrecalentamiento que se produce en la cara externa de los cerramientos se trasmita casi instantáneamente al espacio interior, debiendo solventar este problema mediante el funcionamiento de los equipos de aire acondicionado, favoreciendo el mayor gasto energético.

La inclusión en los Códigos de Edificación de cuestiones relativas al ahorro energético y la eficiencia energética es esencial para revertir la situación actual que atraviesa nuestro país. Frente al problema de la escasez de recursos el Estado debería actuar de manera responsable, estableciendo limitaciones al consumo y a la demanda energética según el tipo edilicio. Debería dejar de subsidiarse el consumo de energía proveniente de fuentes no renovables y comenzar a subsidiar la implementación de tecnologías de energías limpias y de materiales que contribuyan al ahorro y la eficiencia energética. Dentro de los Códigos de 
Edificación deberían establecerse el rendimiento y la eficiencia energética de las instalaciones e incluir la obligatoriedad de implementación de energías limpias para satisfacer parte de la demanda de al menos, agua caliente y energía eléctrica. Tal como ocurre en los países más avanzados estas exigencias deben estar acompañadas de ejemplos de cálculos, tablas de referencias climáticas, valores admisibles para cálculos de coeficientes de transmitancia térmica, etc.

Las Normas IRAM en su serie 11.6XX y la Norma IRAM 11.900 tratan sobre habitabilidad higrotérmica y eficiencia energética. Sin embargo actualmente sólo en Rosario y en la provincia de Buenos Aires, con la implementación de la Ley 13.059/03 y su Decreto Reglamentario 1.030 , se exige su cumplimiento obligatorio. El mayor problema radica en que, pese a haber sido concebidas para viviendas de interés social, estos valores de referencia se han extrapolado a todo edificio de ocupación humana, lo cual constituye un grave error. Si se toman como referencia los sistemas de certificación edilicia reconocidos a nivel mundial (LEED, BREEAM, Passivhaus) puede observarse que cada uno cuenta con un sistema de evaluación diferente de acuerdo a la complejidad y al uso del edificio a certificar, e incluso también del clima en el cual se inserta. Esta cuestión está directamente relacionada con el concepto de Benchmarking, por el cual se mide el rendimiento de un sistema, en este caso de un edificio, en comparación con otro de referencia.

Esta Tesis busca subsanar este error, generando un antecedente que continúe con la metodología utilizada en las Normas IRAM pero que pueda aplicarse a edificios de propiedad horizontal en altura, que permita tender a un desarrollo urbano-edilicio sustentable en el contexto de Argentina. Luego deberían buscarse valores de referencia para los distintos tipos edilicios.

En el Capítulo V - Estudio de casos, se realizó un estudio comparativo entre casos seleccionados de distintas revistas técnicas y la muestra de un trabajo previo realizado en lo que en aquel entonces constituía el Grupo de Eficiencia Energética Edilicia de la Cátedra №2 de Instalaciones de la FAU - UNLP. Para realizar este estudio se tuvieron en cuenta los aspectos dimensionales (superficie, volumen, compacidad, factor de forma), los aspectos térmicos (coeficiente $G$ ) y los aspectos energéticos de cada edificio (carga térmica), de ambas muestras. Dicho estudio permitió determinar la ecuación para el cálculo de la demanda anual de energía en calefacción a partir del volumen calefaccionado con un coeficiente de determinación $\left(R^{2}\right)$ alto para ambos casos.

También permitió comprobar que en los últimos años, como consecuencia del crecimiento de la ineficiencia energética en la construcción hubo un crecimiento en la demanda de energía en calefacción para el tipo edilicio estudiado.

Al analizar los diferentes edificios que componían la muestra se observó que ningún caso cumplía con las Normas IRAM, que de hecho sólo son de cumplimiento obligatorio en la Provincia de Buenos Aires (Ley 13.059/03) y en la Ciudad de Rosario. La correlación entre el volumen calefaccionado y el $G_{\text {cal }}$ era en general baja, lo que demostraba la ausencia de regulación acerca de la calidad energética edilicia en los Códigos de Edificación.

A partir del análisis particularizado de cada uno de los edificios auditados, distinguiendo los casos según el destino (viviendas u oficinas), pudieron determinarse las características constructivas del grupo de edificios seleccionados. Tal como se comenta en el cuerpo de la Tesis esta decisión de dividir los casos de estudio según el destino encuentra su fundamento en la técnica del Benchmarking. Siendo que para un mismo tipo edilicio, la variable función impacta en la intensidad de uso en lo que respecta al grado de ocupación, potencia de iluminación, potencia de equipamiento eléctrico, etc., es claro que para un mejor análisis debían distinguirse los casos según el destino. Al respecto cabe destacar que se trataba en todos los casos de ejemplos representativos de la realidad constructiva actual en el AMBA (Rosenfeld, E. et Al.; 1986, 1988, 1989; Veigas, G. et Al.; 2007; Evans, J. M.; 2012) e incluso en el país (Gonzalo, G.; 1999 - Baso, M. et Al.; 2001).

En general las características constructivas de los edificios analizados resultaron similares, con estructura portante de hormigón armado y cerramientos exteriores materializados con muros de

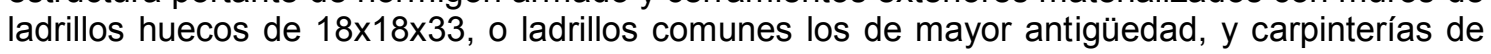


simple vidriado, sin aislamiento higrotérmico adicional. Los coeficientes de transmitancia térmica de los diferentes elementos de las envolventes térmicas rondaron los siguientes valores:

- Pisos / Techos: $\mathrm{k}=1,58 \mathrm{~W} / \mathrm{m}^{2} \cdot \mathrm{K}$

- Muros exteriores: $\mathrm{k}=1,83 \mathrm{~W} / \mathrm{m}^{2} \cdot \mathrm{K}\left(1,68<\mathrm{K}_{\mathrm{m} \text { ext }}<2,38\right)$

- Muros medianeros: $\mathrm{k}=1,83 \mathrm{~W} / \mathrm{m}^{2} \cdot \mathrm{K}\left(1,68<\mathrm{K}_{\mathrm{m} \text { med }}<2,38\right)$

- Muros interiores: $\mathrm{k}=2,36 \mathrm{~W} / \mathrm{m}^{2} \cdot \mathrm{K}\left(2,18<\mathrm{K}_{\mathrm{m} \mathrm{int}}<2,98\right)$

- Superficies vidriadas: $k=5,80 \mathrm{~W} / \mathrm{m}^{2} \cdot \mathrm{K}$

Estos valores resultaron altos comparándolos con los valores propuestos por los estándares de países desarrollados e incluso también con valores medios propuestos en las Normas Nacionales. La baja calidad de la envolvente higrotérmica en todos los casos demostró la falta de preocupación, y en muchos casos de información, por parte de los responsables de la construcción en materia de confort interior y ahorro energético.

Para la propuesta de mejora que seguía los criterios del DAC, para la zona del Área Metropolitana de Buenos Aires, los coeficientes de transmitancia térmica rondaron los siguientes valores:

- Pisos / Techos: $\mathrm{k}=0,57 \mathrm{~W} / \mathrm{m}^{2} \cdot \mathrm{K}$

- Muros exteriores: $\mathrm{k}=0,68 \mathrm{~W} / \mathrm{m}^{2} \cdot \mathrm{K}\left(0,63<\mathrm{K}_{\mathrm{m} \text { ext }}<0,69\right)$

- Muros medianeros: $\mathrm{k}=0,68 \mathrm{~W} / \mathrm{m}^{2} \cdot \mathrm{K}\left(0,63<\mathrm{K}_{\mathrm{m} \text { med }}<0,69\right)$

- Muros interiores: $\mathrm{k}=0,74 \mathrm{~W} / \mathrm{m}^{2} \cdot \mathrm{K}\left(0,67<\mathrm{K}_{\mathrm{m} \text { int }}<0,77\right)$

- Superficies vidriadas: $k=2,86 \mathrm{~W} / \mathrm{m}^{2} \cdot \mathrm{K}$ (viviendas)

- Superficies vidriadas: $\mathrm{k}=1,80 \mathrm{~W} / \mathrm{m}^{2} \cdot \mathrm{K}$ (oficinas)

Para alcanzar estos valores se necesitaron $5 \mathrm{~cm}$. de lana de vidrio en la cámara de aire entre el cielorraso suspendido y la losa de hormigón armado en pisos y techos $(10 \mathrm{~cm}$. en la losa del último nivel), $2,5 \mathrm{~cm}$. de poliuretano proyectado en la cara interior de los muros de cerramiento interior y carpinterías con DVH y con DHV + Low-e. Con estos niveles de aislamiento térmico (valor intermedio entre el Nivel A y el Nivel B propuestos por la Norma IRAM 11.605) pudo alcanzarse en la mayoría de los casos una reducción de aproximadamente un $60 \%$ del consumo de gas natural para calefacción y hasta un $50 \%$ de la carga térmica de invierno. Con estas mejoras los coeficientes $G_{\text {cal }}$ de los distintos edificios se ubicaron por debajo de la línea del $G_{a d m}$.

Al realizar la verificación de la Norma IRAM 11.900 por la cual se establece la Etiqueta de Eficiencia Energética de Calefacción para edificios y la clasificación según la transmitancia térmica de la envolvente pudo comprobarse la baja calidad higrotérmica de la envolvente edilicia de los edificios analizados. Todos los casos se situaron en la categoría $\mathrm{H}$, de menor eficiencia.

Siendo que los casos auditados son representativos del modo en que se construye en nuestro país, en la actualidad, esta situación confirmó la falta de cumplimiento de las Normas Nacionales. Al aplicar los conceptos del Diseño Ambientalmente Consciente a los componentes de la envolvente térmica de los distintos casos estudiados pudo alcanzarse el Nivel $D$ e incluso en algún caso el Nivel C.

Se trata de una mejora notable de la envolvente térmica si se considera que, para los casos analizados tal como están construidos en la actualidad, los valores de la variación media ponderada entre la temperatura de la superficie interior y la temperatura interior de diseño $\left(\tau_{m}\right)$ se encontraban muy por encima del valor mínimo que plantea la clase más baja $\left(\mathrm{H}: \tau_{\mathrm{m}}>4^{\circ} \mathrm{C}\right)$. La caída de temperatura entre la superficie de la envolvente y el interior de los edificios resultó en promedio de $8^{\circ} \mathrm{C}$ y en algunos casos alcanzó los $9^{\circ} \mathrm{C}$. Suponiendo una temperatura interior de $20^{\circ} \mathrm{C}$, estos valores se encuentran muy por debajo de los límites establecidos por las normas de países más desarrollados. Tal es el caso de las Normas Passivhaus para climas templados, según las cuales las temperaturas superficiales interiores de la envolvente térmica durante invierno deben ser mayores a $17^{\circ} \mathrm{C}$. Por su parte la transmitancia térmica media 
ponderada de los elementos que componen la envolvente edilicia en todos los casos promedió los $2,29 \mathrm{~W} / \mathrm{m}^{2} \cdot \mathrm{K}$.

Al aplicar los conceptos del Diseño Ambientalmente Consciente pudo alcanzarse la clase D, con una variación media ponderada entre la temperatura de la superficie interior y la temperatura interior de diseño $\left(\tau_{m}\right)$ próxima a los $2^{\circ} \mathrm{C}\left(6^{\circ} \mathrm{C}\right.$ menos que para los casos base, tal como están construidos en la actualidad). Suponiendo una temperatura interior de $20^{\circ} \mathrm{C}$, estos valores resultaron dentro de los límites establecidos por las normas Passivhaus. Por su parte la transmitancia térmica media ponderada de los elementos que componen la envolvente edilicia rondó los $0,7 \mathrm{~W} / \mathrm{m}^{2} \cdot \mathrm{K}$, muy inferior a los $2,29 \mathrm{~W} / \mathrm{m}^{2} \cdot \mathrm{K}$ promedio para los edificios tal como están construidos en la actualidad.

En lo que respecta al confort higrotérmico de las unidades auditadas pudo observarse que, durante el período analizado, la mayor parte del día, gran parte de los ambientes analizados se encontraba fuera de los límites de confort, incluso cuando recurrían a climatización mecánica. Esto permitió confirmar la baja calidad de la envolvente térmica de los edificios analizados. Según el Climograma de Givoni, para alcanzar los límites de confort, los edificios deberían incorporar en su diseño ventilación cruzada, inercia térmica y ventilación selectiva, y sistemas solares pasivos. Al respecto cabe destacar que si bien es mejor incorporar estos elementos desde el inicio del proceso de diseño, en los edificios ya construidos pueden implementarse mejoras que contribuyan a optimizar el confort higrotérmico interior y favorecer en gran medida a generar un ahorro energético. En el año 2011 se presentó en Bélgica, en PLEA XXVII, un artículo que planteaba el retrofit de un edificio de vivienda auditado durante la campaña de medición del año 2009. Asimismo, en los Capítulos X y XI se demostró que esto es posible de ser realizado en nuestro país con costos relativamente accesibles y con la posibilidad de retorno de la inversión en el corto plazo siempre y cuando exista un cambio en la política energética argentina.

Entre los múltiples datos interesantes que pudieron obtenerse a partir del estudio particularizado de los edificios auditados se obtuvieron las ecuaciones para determinar la demanda anual de energía en calefacción a partir del volumen calefaccionado tanto para los edificios según el modo en que se construye en la actualidad en nuestro país como para la propuesta de mejora que sigue los criterios del Diseño Ambientalmente Consciente. El coeficiente de determinación $\left(R^{2}\right)$ resultó alto para ambos casos. Las ecuaciones resultantes fueron las siguientes:

Situación actual:

$$
\mathrm{Q}_{\mathrm{cal}}=39,655 \times \text { volumen }+79.056(\mathrm{KWh} / \mathrm{año})\left[R^{2}=0,99\right]
$$

Propuesta de mejora:

$$
\mathrm{Q}_{\text {cal }}=10,035 \mathrm{x} \text { volumen }+149.776(\mathrm{KWh} / \mathrm{año})\left[R^{2}=0,89\right]
$$

También pudo verificarse que ninguno de los edificios auditados cumplía con la Norma IRAM 11.604 sobre eficiencia energética en calefacción. En todos los casos el valor del coeficiente $\mathrm{G}_{\mathrm{cal}}$ resultó superior a los valores admisibles, demostrando la ausencia de regulación acerca de la calidad energética edilicia en los Códigos de Edificación.

Por otra parte las auditorías energéticas permitieron realizar una discriminación del consumo de gas natural para consumo base (agua caliente y cocción) y para calefacción, para los edificios de viviendas. En los edificios de oficinas auditados no se registró consumo de gas natural para agua caliente. Según el estudio presentado por ENARGAS en el año 2008, para el caso de edificios de vivienda aproximadamente el $60 \%$ del consumo anual de gas natural corresponde a calefacción y el $40 \%$ restante corresponde al consumo base. Cabe destacar que se trata de consumos promedio a nivel nacional.

De los resultados obtenidos de las auditorías surgió que para el caso de viviendas el $53 \%$ del consumo de gas natural anual correspondía a calefacción y el $47 \%$ restante correspondía al consumo base para agua caliente y cocción. Al respecto cabe aclarar que se trata de consumos promedio para la región del AMBA. Esto dio un indicador de consumo de gas natural 
promedio por unidad de superficie y por día de $0,538 \mathrm{~m}^{3} / \mathrm{m}^{2} /$ día para calefacción y 0,228 $\mathrm{m}^{3} / \mathrm{m}^{2} /$ día para agua caliente y cocción.

Los datos extraídos de las auditorías energéticas fueron corroborados con los resultados del AuditCAD para los distintos casos analizados. Pudo estimarse la demanda de gas natural para calefacción por unidad de superficie, por día para los edificios de vivienda y de oficinas en sus dos versiones; tal como están construidos en la actualidad y según los criterios del Diseño Ambientalmente Consciente. Para los edificios tal como están construidos en la actualidad el AuditCAD arrojó un valor de $0,531 \mathrm{~m}^{3} / \mathrm{m}^{2} /$ día de gas natural para calefacción de edificios de viviendas (muy aproximado al valor medido) y $0,420 \mathrm{~m}^{3} / \mathrm{m}^{2} /$ día para edificios de oficinas. Para la opción que sigue los criterios del DAC el AuditCAD arrojó un valor de $0,112 \mathrm{~m}^{3} / \mathrm{m}^{2} /$ día de gas natural para calefacción de edificios de viviendas y $0,204 \mathrm{~m}^{3} / \mathrm{m}^{2} /$ día para edificios de oficinas. Como puede verse en estas cifras la reducción de la demanda de gas natural para calefacción al aplicar los criterios del DAC se volvió más importante para los casos de vivienda que para los casos de oficinas; se trató de una reducción del $78,90 \%$ contra una del $51,43 \%$.

Del mismo modo que para la condición de invierno se realizó el balance térmico de verano para cada uno de los edificios auditados. De este modo fue posible determinar la carga térmica total de verano para cada edificio analizado en sus dos versiones; tal como están construidos en la actualidad y según los criterios del DAC. En la mayoría de los casos el $G_{R}$ de los edificios

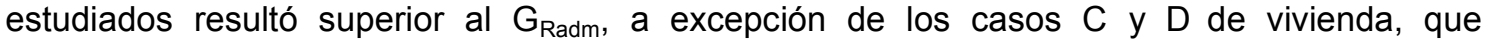
correspondían a los de mayor volumen.

Se observó que, incluso al incorporar los criterios del DAC al total de la envolvente, en la mayoría de los casos para los edificios de oficinas el $G_{R}$ era superior al $G_{R}$ adm. Esto se debió a que en el caso de edificios de oficinas la relación de superficie vidriado - opaco es mucho mayor a la de edificios de viviendas y a que, como ya se mencionó anteriormente, en este tipo de edificios hay una mayor concentración de personas y el uso de artefactos eléctricos y de iluminación es mucho más intensivo. De este modo se confirmó que deberían considerarse valores diferenciados de $G_{R}$ adm para el caso de edificios de oficinas.

En lo que respecta a la carga térmica de verano pudo observarse cómo al aplicar los conceptos del Diseño Ambientalmente Consciente a la envolvente edilicia, la disminución de la carga térmica de verano se volvía más importante a medida que se incrementaba el volumen de los edificios. Las líneas de tendencia diferían según si la envolvente contemplaba los criterios del DAC o no. Las expresiones resultantes, por su parte, permitieron conocer la demanda anual de energía para refrigeración a partir del volumen acondicionado térmicamente con un alto valor de confianza $\left(R^{2}\right)$ para ambos casos.

Situación actual:

Propuesta de mejora:

$$
\mathrm{Q}_{\mathrm{R}}=0,0265 \mathrm{x} \text { volumen }+73,753(\mathrm{~kW}) \quad\left[R^{2}=0,9803\right]
$$

$$
Q_{R}=0,022 \times \text { volumen }+57,507(\mathrm{~kW})\left[R^{2}=0,9831\right]
$$

Cabe destacar que al momento de realizar la discriminación del consumo de energía eléctrica de todas las unidades fue muy difícil poder discriminar los usos. Esto se debió principalmente a la gran variación entre los consumos de energía eléctrica de cada una de las unidades, incluso en el período invernal. Durante las auditorías energéticas se tomaron los consumos de energía eléctrica de todas las unidades y se pudo conocer detalladamente el equipamiento eléctrico, de iluminación y de acondicionamiento térmico de cada una de las unidades a las que pudo accederse. Se tomó nota de las potencias de los equipos de las unidades a las que se tuvo acceso, sin embargo fue muy difícil poder obtener una respuesta certera acerca de las horas de funcionamiento del equipamiento a partir de las encuestas realizadas y de las opiniones de los ocupantes.

Para los edificios de viviendas auditados, para el periodo invernal el consumo diario promedio de energía eléctrica por unidad de superficie fue de $0,102 \mathrm{kWh} / \mathrm{m}^{2} /$ día mientras que para el periodo estival fue de $0,089 \mathrm{kWh} / \mathrm{m}^{2} /$ día. Si bien fue muy difícil realizar la discriminación de dicho consumo, pudo inferirse el uso de equipos de aire acondicionado para refrigeración e 
incluso también para calefacción. Para edificios de vivienda podría hablarse de un consumo base (iluminación artificial y equipamiento eléctrico) que ronda los $0,075 \mathrm{kWh} / \mathrm{m}^{2} / \mathrm{día}$ y un consumo destinado al funcionamiento de los equipos de aire acondicionado que ronda los $0,20 \mathrm{kWh} / \mathrm{m}^{2} /$ día. Sin embargo cabe aclarar que esto es sólo un valor aproximado ya que la variación en el uso de energía eléctrica para el acondicionamiento del aire interior depende del equipo utilizado y del uso que se haga del mismo.

Para los edificios de oficinas auditados, para el periodo invernal el consumo diario promedio de energía eléctrica por unidad de superficie fue de $0,119 \mathrm{kWh} / \mathrm{m}^{2} /$ día mientras que para el periodo estival fue de $0,123 \mathrm{kWh} / \mathrm{m}^{2} / \mathrm{día}$. Al igual que en el caso anterior pudo inferirse el uso de equipos de aire acondicionado para refrigeración e incluso también para calefacción. Podría hablarse de un consumo base (iluminación artificial y equipamiento eléctrico) que ronda los $0,05 \mathrm{kWh} / \mathrm{m}^{2} /$ día para las oficinas que no cumplen jornada completa de trabajo -lo que se deduce de las encuestas realizadas- y $0,15 \mathrm{kWh} / \mathrm{m}^{2} /$ día para aquellas que sí lo hacen, y un consumo destinado al funcionamiento de los equipos de aire acondicionado que ronda los $0,25 \mathrm{kWh} / \mathrm{m}^{2} / \mathrm{día}$.

En el Capítulo IX se mostraron los datos arrojados por la simulación energética con el Software Energy PLUS. Tal como se comentó en dicho capítulo, siguiendo las recomendaciones del Apéndice $\mathrm{G}$ de la Norma ASHRAE 90.1 y con el fin de simplificar la simulación, se construyeron dos modelos edilicios de base, uno de viviendas y otro de oficinas. Para la construcción de estos modelos se tomaron las principales características de los edificios auditados: constructivas, relación de superficies vidriadas - opacas, factor de forma, factor de ocupación, nivel de iluminación y de equipamiento eléctrico, horarios de ocupación y uso de los sistemas de acondicionamiento de aire, equipamiento eléctrico, iluminación, etc. Luego sobre estos modelos de base se construyeron los modelos de referencia, a los cuales se aplicaron las propuestas de mejora que se comentaron en el Capítulo VIII. El archivo de clima utilizado correspondía a la ciudad de Buenos Aires.

Para el modelo base de viviendas la demanda anual de energía para refrigeración fue de 89,47 $\mathrm{kWh} / \mathrm{m}^{2} / a n ̃ o$. Por su parte, para el modelo de referencia con $\mathrm{DVH}$, la demanda anual de

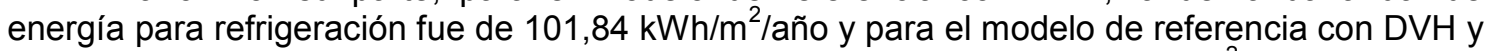
Low-e, la demanda anual de energía para refrigeración fue de $73,11 \mathrm{kWh} / \mathrm{m}^{2} / a n ̃ o$. En lo que respecta a las demandas de energía para calefacción para el Modelo de Base y los Modelos de Referencia (con DVH y con DVH + Low-e), se pudo observar que en este caso ambos Modelos de Referencia experimentaron una reducción de la demanda con respecto al Modelo de Base. Para el modelo base la demanda anual de energía para calefacción fue de $1,05 \mathrm{kWh} / \mathrm{m}^{2} / a n ̃ o$ mientras que para el modelo de referencia con $\mathrm{DVH}$, la demanda anual de energía para

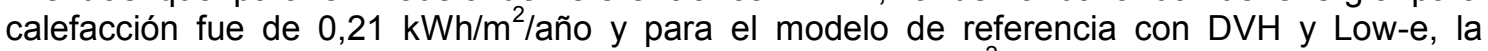
demanda anual de energía para calefacción fue de $0,47 \mathrm{kWh} / \mathrm{m}^{2} / a n ̃ o$.

Según los resultados arrojados por la simulación, para el modelo base de viviendas la demanda de energía para refrigeración representó más del $50 \%$ del total de la demanda de energía anual del modelo mientras que la demanda de energía para calefacción apenas superó el $2 \%$, ubicándose por debajo de la demanda de energía para el funcionamiento del equipamiento eléctrico e iluminación.

Cabe destacar que al simular el modelo de referencia los resultados arrojados por el Energy PLUS mostraron un aumento de la demanda de energía eléctrica para refrigeración de aproximadamente un 14\%. Este aumento de la demanda de energía eléctrica para refrigeración como consecuencia de la mejora de la envolvente térmica se debió principalmente a que las ganancias de calor por fuentes internas y la radiación solar encontraron una mayor resistencia para disiparse hacia el exterior, contribuyendo al sobrecalentamiento de los espacios interiores. Como consecuencia de esto se propuso un modelo alternativo al cual se le cambiaron los sistemas de aventanamientos por otros más eficientes con DVH y Low-e, disminuyendo de este modo las ganancias por radiación. Para este modelo de referencia la demanda de energía eléctrica para refrigeración se redujo aproximadamente un $19 \%$ con respecto al modelo de base.

Por su parte, en lo que respecta a la demanda de energía para calefacción el modelo de referencia con DVH mostró una reducción del $77 \%$ mientras que para el modelo de referencia 
al que se incorporaron las carpinterías con vidrios de baja emisividad, la reducción fue del $54 \%$. Sin embargo como la mayor demanda de energía se debía a refrigeración (representaba el $50 \%$ de la demanda total contra un $2 \%$ que representaba la demanda para calefacción) se determinó como la mejor opción ya que es la que más contribuía al ahorro energético.

Estas mejoras significaron una reducción de aproximadamente el 10,05\% del consumo total de energía del modelo de referencia con DVH y Low-e en comparación con el modelo de base. Según el sistema de Certificación LEED para nuevas construcciones y grandes reformas, una reducción del $10 \%$ de la demanda total de energía permitiría sumar dos puntos para el caso de edificios a rehabilitar, mientras que para el caso de nuevos edificios es necesario alcanzar una reducción del $12 \%$ de la demanda total de energía para poder sumar un punto de los 110 puntos que admite el sistema (100 de base, 6 por innovación en el diseño y 4 por prioridades regionales). Al respecto es importante destacar que con 40-49 puntos puede alcanzarse la certificación, con 50-59 puntos puede alcanzarse el nivel Plata, con 60-79 puntos puede alcanzarse el nivel Oro y con más de 80 puntos puede alcanzarse el nivel Platino (LEED,; 2009).

En lo que respecta al modelo de oficinas, para el modelo base la demanda anual de energía para refrigeración fue de $83,88 \mathrm{kWh} / \mathrm{m}^{2} / a n ̃ o$. Por su parte, para el modelo de referencia con DVH y Low-e, la demanda anual de energía para refrigeración fue de $63,46 \mathrm{kWh} / \mathrm{m}^{2} / a n ̃ o$. En lo que respecta a calefacción, para el modelo base la demanda anual de energía fue de 1,20 $\mathrm{kWh} / \mathrm{m}^{2} / a n ̃ o$. Por su parte, para el modelo de referencia con DVH y Low-e, la demanda anual de energía para refrigeración fue de $0,52 \mathrm{kWh} / \mathrm{m}^{2} / a n ̃ o$.

Según los resultados arrojados por el Energy PLUS la demanda de energía para refrigeración representó más del $50 \%$ del total de la demanda de energía anual del modelo mientras que la demanda de energía para calefacción apenas superó el 1\%, ubicándose por debajo de la demanda de energía para el funcionamiento del equipamiento eléctrico e iluminación.

Según los resultados arrojados por el Energy PLUS, las mejoras de la envolvente térmica favorecieron una reducción del $23,5 \%$ de la demanda de energía eléctrica para refrigeración y una reducción del $61,2 \%$ para calefacción.

Estas mejoras significaron una reducción de aproximadamente el $12,36 \%$ del consumo total de energía del modelo de referencia con DVH y Low-e en comparación con el modelo de base. Tal como se mencionó anteriormente, según el sistema de Certificación LEED para nuevas construcciones y grandes reformas, una reducción del 10\% de la demanda total de energía permitiría sumar dos puntos para el caso de edificios a rehabilitar, mientras que para el caso de nuevos edificios es necesario alcanzar una reducción del $12 \%$ de la demanda total de energía para poder sumar un punto de los 110 puntos que admite el sistema (100 de base, 6 por innovación en el diseño y 4 por prioridades regionales).

Finalmente en el Capítulo $X$ se presentaron los modelos de ahorro de energía para edificios de propiedad horizontal en altura destinados a viviendas y oficinas, modelos que fueron presentados al Subcomité de Acondicionamiento Térmico del Instituto Argentino de Normalización y Certificación, donde actualmente se está discutiendo la propuesta llevada por el LAyHS para la modificación de la Norma IRAM 11.604 "Aislamiento térmico de edificios. Verificación de sus condiciones higrotérmicas. Coeficiente volumétrico $\mathrm{G}$ de pérdidas de calor. Cálculo y valores límites".

En lo que respecta a los modelos de ahorro de energía para calefacción, la propuesta siguió los lineamientos de cálculo y dio continuidad al modelo de ahorro de energía en calefacción propuesto por la actual Norma IRAM 11.604 pero se plantearon mejoras en la construcción del modelo edilicio de referencia.

El modelo edilicio de referencia de la actual Norma IRAM 11.604 parte de un cubo que crece a altura constante de $2,70 \mathrm{~m}$, y que va desde $105^{3} \mathrm{~m}^{3}$ a $10.000 \mathrm{~m}^{3}$. A partir del estudio de dicha Norma se concluyó que este modelo edilicio de referencia devenía en un aumento en las pérdidas a través de las superficies horizontales (pisos y techos) que se apartaba de la realidad a medida que el volumen del edificio crecía. Si bien actualmente la Norma plantea que la premisa básica es dar libertad al diseñador al momento de materializar el edificio, a partir del 
estudio de casos de la realidad se concluyó que el modelo propuesto por la actual Norma IRAM 11.604 no era representativo de todos los edificios construidos en el país.

Tal como se mencionó anteriormente la Norma IRAM 11.604, aún vigente, fue concebida para regular la calidad térmica de edificios destinados a viviendas de interés social. Sin embargo, con la aplicación de la Ley 13.059/03 de la Provincia de Buenos Aires, se volvió obligatoria a todo edificio para habitación humana. Esto significó serios problemas en su aplicación como consecuencia de que en realidad no fue concebida para "todo uso". Desde agosto del 2012, fecha en que se llevó la propuesta elaborada en el LAyHS a los integrantes del Subcomité de Acondicionamiento Térmico de IRAM se está discutiendo la misma, sin lograr aún el consenso necesario para su aprobación.

La propuesta presentada al Subcomité de Acondicionamiento Térmico de Edificios de IRAM plantea el desarrollo de curvas de referencias para los distintos tipos edilicios (bloque, torre, etc.), distinguiendo además según la función; viviendas, escuelas, oficinas, hospitales, etc. Resultado de esta Tesis son los modelos de ahorro de energía propuestos para edificios de propiedad horizontal en altura, destinados a viviendas y oficinas.

La propuesta presentada al Subcomité de Acondicionamiento Térmico de Edificios de IRAM plantea la mejora de la envolvente térmica del modelo edilicio de referencia de la actual Norma IRAM 11.604, la cual plantea la utilización del Nivel C de la Norma IRAM 11.605 en cuanto a la transmitancia térmica de muros y techos. Cabe destacar que los valores de transmitancia térmica propuestos por el Nivel $\mathrm{C}$ son ineficientes en cuanto al ahorro de energía ya que dicho nivel fue elaborado para ser implementado en viviendas de interés social y solamente previene el riesgo de condensación superficial.

Tal como se comenta en el cuerpo de la Tesis el modelo propuesto utiliza un valor intermedio entre el Nivel A y el Nivel B de la Norma IRAM 11.605 para muros y techos (Czajkowski, J.; Gómez, A.; 2009). Siguiendo este criterio se adoptaron valores de $K_{\max }$ admisibles para la condición de invierno, para muros y techos, los cuales varían en función de los valores de Temperatura Mínima Exterior de Diseño (TDMN) $\left[{ }^{\circ} \mathrm{C}\right]$ en un rango que va desde $-15^{\circ} \mathrm{C}$ a $0^{\circ} \mathrm{C}$. En cuanto al sistema de carpinterías se planteó la utilización de sistemas con DVH. De la Tabla A.1 del Anexo A de la Norma IRAM $11.507-4$ se obtuvo el valor de $k=2,86 \mathrm{~W} / \mathrm{m}^{2} \mathrm{~K}$ para ventanas simples con perfilería de aluminio y ruptor de puente térmico. Con la implementación de este tipo de carpinterías se buscaba reducir las pérdidas de calor a través de las superficies vidriadas.

Asimismo la propuesta presentada al Subcomité de Acondicionamiento Térmico de Edificios plantea un nuevo límite inferior de $500^{\circ} \mathrm{D}_{\text {cal }} 18^{\circ} \mathrm{C}$ para las curvas del Coeficiente Volumétrico de Pérdidas $\left(\mathrm{G}_{\text {cal }}\right)$, por debajo de los $900^{\circ} \mathrm{D}_{\text {cal }} 18^{\circ} \mathrm{C}$ que propone la Norma actual. Esto permite la inclusión de zonas Templadas - Cálidas que no son contempladas en la actual Norma IRAM 11.604, y que también requieren de calefacción en el periodo invernal.

Como resultado los valores de $\mathrm{G}_{\mathrm{cal}}$ admisibles para el modelo de viviendas de propiedad horizontal en altura propuesto resultaron inferiores a los valores planteados por la Norma IRAM 11.604; se trató de una reducción de aproximadamente un 45\%. Esta reducción en los valores admisibles del $G_{\text {cal }}$ se debió en parte a la mayor exigencia en cuanto a la calidad de la envolvente térmica del edificio y a la reducción del número de renovaciones de aire.

Como consecuencia de estas mejoras también se redujeron los límites para la Carga Térmica de Calefacción y para el Coeficiente de Calefacción por Unidad de Superficie.

Por su parte los valores de $\mathrm{G}_{\mathrm{cal}}$ admisibles para el modelo de oficinas de propiedad horizontal en altura propuesto resultaron inferiores a los valores planteados por la Norma IRAM 11.604; se trató de una reducción de aproximadamente un 35\%. Esta reducción en los valores admisibles del $G_{\text {cal }}$ se debió en parte a la mayor exigencia en cuanto a la calidad de la envolvente térmica del edificio y a la reducción del número de renovaciones de aire. Como consecuencia de estas mejoras también se redujeron los límites para la Carga Térmica de Calefacción y para el Coeficiente de Calefacción por Unidad de Superficie. 
El modelo de ahorro de energía en refrigeración para edificios de propiedad horizontal en altura (viviendas y oficinas) adoptó la metodología utilizada por el Grupo de Eficiencia Energética Edilicia (GEEE) de la Cátedra de Instalaciones de la FAU - UNLP en el año 2006, la cual se convirtió en la parte 2 de la Norma IRAM 11.659 en 2007. De la parte 1 de dicha Norma se tomaron los datos para determinar la carga térmica de refrigeración del edificio.

Dicho modelo continuó con los valores propuestos por el modelo de ahorro de energía en calefacción; se respetaron los aspectos dimensionales (superficie y volumen a climatizar, factor de forma, relación superficie vidriado-opaco) y las características de la envolvente pero se incorporó la problemática de las ganancias internas, aspecto importante en el estudio del comportamiento higrotérmico para la condición de verano, especialmente para el caso de edificios de oficinas donde el uso del equipamiento eléctrico, la iluminación artificial y la ocupación es mucho más intensivo que en un edificio de viviendas.

Resultado del modelo fueron las nuevas curvas para el Coeficiente Volumétrico de Refrigeración $\left(G_{R}\right)$, los nuevos valores de Carga Térmica en Refrigeración $\left(Q_{R}\right)$ y para el Coeficiente de Refrigeración por Unidad de Superficie $\left(S_{R}\right)$.

Los valores de $G_{R}$ admisibles para el modelo de viviendas de propiedad horizontal en altura propuesto resultaron inferiores a los valores planteados por la Norma IRAM 11.659-2; se trató de una reducción de aproximadamente un $43 \%$. Esta reducción en los valores admisibles del $G_{R}$ se debió en parte a la mayor exigencia en cuanto a la calidad de la envolvente térmica del edificio, a la mayor eficiencia en el uso de iluminación (sólo bajo consumo) y a la reducción del número de renovaciones de aire.

Como consecuencia de estas mejoras también se redujeron los límites para la Carga Térmica de Refrigeración y para el Coeficiente de Refrigeración por Unidad de Superficie.

Por su parte los valores de $G_{R}$ admisibles para el modelo de oficinas de propiedad horizontal en altura propuesto fueron inferiores a los valores planteados por la Norma IRAM 11.659-2; se trató de una reducción de aproximadamente un $10 \%$. Tal como en el caso del modelo de viviendas, esta reducción en los valores admisibles del $G_{R}$ se debió en parte a la mayor exigencia en cuanto a la calidad de la envolvente térmica del edificio, a la mayor eficiencia en el uso de iluminación (sólo bajo consumo) y a la reducción del número de renovaciones de aire.

Como consecuencia de estas mejoras también se redujeron los límites para la Carga Térmica de Refrigeración y para el Coeficiente de Refrigeración por Unidad de Superficie.

Asimismo cabe destacar que la notable diferencia en la disminución de los valores entre los modelos de viviendas y oficinas se debió a que, como ya se mencionó anteriormente, las cargas internas en los edificios de oficinas tienen una incidencia mucho mayor en el Balance Energético que en el caso de los edificios de viviendas, debido a la mayor concentración de personas y al uso intensivo que se hace del equipamiento eléctrico y de la iluminación artificial principalmente.

Finalmente, sobre los modelos de ahorro de energía planteados, se estudió la factibilidad de incorporación de tecnologías de energías limpias para generación de electricidad, calefacción $\mathrm{y}$, en el modelo de viviendas, agua caliente solar.

Tal como se menciona en el cuerpo de la Tesis, la mejora de la envolvente térmica no es el único camino para alcanzar la reducción del consumo de fuentes de energías convencionales. En los países más avanzados la satisfacción de la demanda energética mediante la incorporación de fuentes de energías renovables lleva años de estudio y desarrollo. En Argentina la situación difiere bastante; los programas de eficiencia energética son relativamente nuevos, comenzaron a desarrollarse en respuesta a la crisis energética actual pero sin planificación previa y pese a los intentos desde la Secretaría de Energía de la Nación aún no se ha generado una política eficaz para introducir masivamente las energías renovables (Barros, V.; 2009). 
Entre los años 2010 al 2014 se tuvo la posibilidad de trabajar como colaboradora en el proyecto PICTO-2010-0087, "Interconexión de sistemas fotovoltaicos a la red eléctrica en ambientes urbanos", dirigido por el Dr. Julio Durán, jefe del Departamento Energía Solar de la CNEA. EI objetivo principal del proyecto fue realizar un estudio integral, que contemple las cuestiones técnicas, económicas, legales y regulatorias, sobre la factibilidad de impulsar en áreas urbanas y periurbanas de nuestro país, en particular en el Área Metropolitana de Buenos Aires (AMBA), la instalación de sistemas fotovoltaicos distribuidos e interconectados a la red eléctrica.

Tal como se comenta en este proyecto, la generación eléctrica en base a fuentes renovables, distribuida e interconectada a la red pública eléctrica es una alternativa con un gran potencial en el mediano y largo plazo. En la Argentina, el uso de la energía solar fotovoltaica se ha limitado casi exclusivamente a aplicaciones en áreas rurales aisladas, alejadas de las redes de distribución. Se trata de aplicaciones que, en muchos casos, tienen gran relevancia social pero que prácticamente no contribuyen al reemplazo de combustibles fósiles en la matriz energética ni a la disminución de la contaminación ambiental asociada al quemado de éstos. Por el contrario, los centros urbanos concentran casi la totalidad de la demanda eléctrica del país y disponen de insolación satisfactoria que permite encarar un programa de penetración gradual de generación distribuida mediante sistemas fotovoltaicos (Durán, J.; 2010).

La situación es similar para el caso de las tecnologías de captación y producción de energía solar térmica, principalmente de agua caliente solar. En nuestro país, la mayoría de las instalaciones de este tipo se han aplicado en viviendas sociales, con proyectos financiados por el Estado o, lo que constituye el otro extremo, en viviendas con un alto poder adquisitivo, ubicadas en barrios privados. En todos los casos se trata de ejemplos aislados. Por su parte, en los centros urbanos, donde se concentra casi la totalidad de la demanda y donde podrían aprovecharse las superficies libres de sombras de los edificios para colocar las instalaciones, prácticamente no se encuentran ejemplos de este tipo. Esto se debe principalmente a que en nuestro país no existe una regulación al respecto, a excepción de la Ciudad de Rosario, la cual cuenta desde julio de 2011 con una Ordenanza Solar Térmica.

Cabe destacar que si bien estos sistemas no son posibles de ser conectados a la red de distribución, igualmente contribuyen enormemente a reducir el consumo de fuentes de energía no renovables, principalmente de gas para agua caliente.

En los países más avanzados la implementación de tecnologías limpias para generación de energía eléctrica y agua caliente solar se encuentra regulada dentro de los códigos de edificación, haciendo obligatoria su incorporación para edificios nuevos o con grandes áreas a rehabilitar. En estos países el Estado incentiva la incorporación de estos sistemas en los edificios que conforman los centros urbanos mediante la implementación de subsidios.

En el Capítulo XI quedó demostrado que la implementación de este tipo de tecnologías no sólo es posible en nuestro país sino que es económicamente viable, siempre y cuando cambie la actual política energética.

Para el modelo de edificios de viviendas fue posible determinar que, de ser factible la implementación de sistemas de generación de energía fotovoltaica en la superficie libre de fachada y de cubierta se podría cubrir la demanda total de energía necesaria para iluminación. Para el modelo de edificios de oficinas, en cambio, la superficie libre de fachada y de cubierta permitiría cubrir el $40 \%$ de la demanda total de energía necesaria para iluminación, suponiendo siempre la localización del modelo en la Ciudad de La Plata.

Al realizar la verificación con el RETScreen, el programa determinó que estos proyectos no serían rentables en la situación actual que atraviesa el país ya que los costos de operación y mantenimiento anual del sistema, en ambos casos, resultarían muy superiores a los costos anuales de energía eléctrica que tendrían que afrontar los modelos en caso de abastecer su demanda en forma exclusiva con energía eléctrica proveniente de la red de distribución. Esto se debe principalmente a la falta de incentivos por parte del Estado para la implementación de este tipo de sistemas y a que el costo de la energía suministrada por las empresas 
distribuidoras de energía eléctrica en Argentina es muy bajo ya que se encuentra subsidiado por el Estado Nacional.

Sin embargo, si se considera la posibilidad de vender la energía generada por el sistema fotovoltaico a la red de distribución, la situación sería diferente. Por ejemplo para el modelo de edificios de viviendas, si la energía excedente se vendiera a un precio de $0,087 \mathrm{u} \$ \mathrm{~s} / \mathrm{kWh}$, menor al costo de venta de la empresa distribuidora, el retorno de la inversión se haría antes de los doce años. Para el modelo de edificios de oficinas el retorno sería a los diez años. Al respecto cabe destacar que en otras localidades, con mayor índice de radiación solar media global, podrían alcanzarse mayores rendimientos de la instalación, y por lo tanto mayores ganancias.

Si bien esta alternativa todavía no se ha podido implementar aún en Argentina, principalmente porque la legislación actual no avala esta situación, desde los distintos grupos de investigación especializados en el tema se están realizando grandes esfuerzos por generar antecedentes, tal es el caso del mencionado Proyecto PICTO-2010-0087, "Interconexión de sistemas fotovoltaicos a la red eléctrica en ambientes urbanos".

En lo que respecta a los sistemas de generación de energía solar térmica, para el modelo de edificios de viviendas fue posible determinar que, de ser factible su implementación en la superficie libre de fachada y de cubierta se podría cubrir el $33 \%$ de la demanda de energía total necesaria para agua caliente, considerando para el dimensionamiento los datos de irradiación del mes más desfavorable (junio). Si bien este porcentaje es menor al $60 \%$ que se pide a los edificios nuevos en los países más desarrollados cabe destacar que en otras localidades del país con mayor índice de radiación solar media global podrían alcanzarse valores mayores, incluso superiores al límite del $60 \%$ que determinan los códigos de edificación de los países más desarrollados.

Al realizar la verificación con el RETScreen, el programa determinó que este proyecto no sería rentable en la situación actual que atraviesa el país ya que los costos de operación y mantenimiento anual del sistema son muy superiores a los costos anuales de gas natural que tendría que afrontar el modelo de no contar con los colectores solares. La solución a este problema es que el Estado otorgue subsidios para la implementación de estos sistemas y no como ocurre actualmente que se subsidia el consumo de gas natural.

Sin embargo también existe la opción de vender Certificados de Reducción de Emisiones (CERs) de Gases de Efecto Invernadero a compradores en países industrializados, tal como se mencionó para el caso de la energía fotovoltaica. El RETScreen permite determinar la reducción de las emisiones de Gases de Efecto Invernadero (GEI) anual neta, que para el proyecto analizado fue de 6,3 toneladas de $\mathrm{CO}_{2}$.

También fue posible determinar qué porcentaje de la demanda de calefacción podría ser cubierta mediante la incorporación de loops convectivos, integrados en la fachada de los modelos tanto de viviendas como de oficinas.

Para el modelo de edificio de viviendas implantado en la Ciudad de La Plata, se determinó que la incorporación de loops convectivos en la fachada permitiría cubrir apenas el $3,5 \%$ de la demanda total de energía para calefacción. Por su parte, para el modelo de edificio de oficinas la incorporación de loops convectivos en la fachada permitiría cubrir el 3\% de la demanda total de energía para calefacción. Es importante destacar que para otras localidades con mayor índice de radiación media global podrían alcanzarse valores más altos. Al respecto no cabe más que mencionar el trabajo que vienen haciendo desde hace varios años en el INENCO UNSa para la integración de sistemas de energía solar térmica en edificios del Noroeste argentino.

Al realizar la verificación con el RETScreen, el programa determinó que los proyectos propuestos tampoco serían rentables en la situación actual que atraviesa el país ya que los costos de operación y mantenimiento anual de los sistemas son muy superiores a los costos anuales de gas natural que tendrían que afrontar los modelos de no contar con los colectores 
solares. Los subsidios al consumo de electricidad y gas natural implementados actualmente por el Gobierno Nacional constituyen una traba importante, dificultando la inserción masiva de las tecnologías limpias por falta de competitividad económica.

EI RETScreen determinó que para los proyectos analizados la reducción fue de 2,7 toneladas de $\mathrm{CO}_{2}$ para el modelo de viviendas y de 1,8 toneladas de $\mathrm{CO}_{2}$ para el modelo de oficinas. Estas podrían venderse como Certificados de Reducción de Emisiones (CERs) de Gases de Efecto Invernadero a compradores en países industrializados, y favorecer de este modo a la rentabilidad de los proyectos de energía limpia.

Finalmente es importante destacar que la eficiencia energética, el uso racional de la energía y la implementación de energías limpias en el diseño de los edificios constituyen una pequeña parte de lo que se conoce en la actualidad como arquitectura sustentable, entendida como el modo de concebir el diseño arquitectónico de modo tal que su inserción minimice el impacto sobre el medioambiente. Durante los años dedicados al avance de esta Tesis se han estudiado diferentes sistemas de certificación cuya aplicación favorece el desarrollo proyectos sustentables. En ellos se abordan cuestiones más amplias, relacionadas con la eficacia y moderación en el uso de materiales de construcción, la minimización del balance energético global del edificio, abarcando las fases de diseño, construcción, utilización y final de su vida útil, etc. Considero que esta es una línea interesante para continuar con el trabajo iniciado en el año 2008. 


\section{BIBLIOGRAFÍA}

\section{INTRODUCCIÓN}

BRUNDTLAND, G. H. Nuestro futuro común. Comisión Mundial sobre Medio Ambiente y Desarrollo, Naciones Unidas. Estocolmo, Suecia. 1987. Disponible en: <http://www.un.org/es/comun/docs/?symbol=A/42/427>

CÁMARA DE DIPUTADOS Y SENADO DE LA PROVINCIA DE BUENOS AIRES. Ley 13.059 de Acondicionamiento Térmico de Edificios. Gobierno de la Provincia de Buenos Aires. La Plata, Argentina. 2003. Disponible en: <http://www.gob.gba.gov.ar/legislacion/legislacion/l13059.html>

CZAJKOWSKI, J. D. Tesis Doctoral. Análisis y modelización energético-ambiental de la edilicia urbana basado en técnicas de auditoría y procedimientos estadísticos multivariados. Desarrollo de herramientas de diagnóstico y simulación. Facultad de Ingeniería, Universidad Nacional de La Plata, Argentina. 2009. Disponible en: <http://sedici.unlp.edu.ar/handle/10915/1371>

DEPARTAMENTO DE INFRAESTRUCTURA DE LA PROVINCIA DE BUENOS AIRES. Decreto Reglamentario 1.030 de la Ley 13.059 provincial de Acondicionamiento Térmico de Edificios. Gobierno de la Provincia de Buenos Aires. La Plata, Argentina. 2010. Disponible en: $<$ http://www.gob.gba.gov.ar/legislacion/legislacion/10-1030.htm/>

EDWARDS, B. Guía básica de la sostenibilidad. Gustavo Gili, SL. Barcelona, España. 2008. ISBN 9788425222085.

HERNÁNDEZ PEZZI, C. Un Vitruvio ecológico: principios y prácticas del proyecto arquitectónico sostenible. Editorial Gustavo Gili. Barcelona, España. 2007. ISBN 9788425221552.

IRAM. Norma 11.601. Aislamiento térmico de edificios. Métodos de cálculo. Propiedades térmicas de los componentes y elementos de construcción en régimen estacionario. Instituto Argentino de Normalización y Certificación. Buenos Aires, Argentina. 2002.

IRAM. Norma 11.603. Acondicionamiento térmico de edificios. Clasificación bioambiental de la República Argentina. Instituto Argentino de Normalización y Certificación. Buenos Aires, Argentina. 2011.

IRAM. Norma 11.604. Aislamiento térmico de edificios. Verificación de sus condiciones higrotérmicas. Ahorro de energía en calefacción. Coeficiente volumétrico $G$ de pérdidas de 
calor. Cálculo y valores límites. Instituto Argentino de Normalización y Certificación. Buenos Aires, Argentina. 2001.

IRAM. Norma 11.605. Acondicionamiento térmico de edificios. Condiciones de habitabilidad en edificios. Valores máximos de transmitancia térmica en cerramientos opacos. Instituto Argentino de Normalización y Certificación. Buenos Aires, Argentina. 2002.

IRAM. Norma 11.659-2. Aislamiento térmico de edificios. Verificación de sus condiciones higrotérmicas. Ahorro de energía en refrigeración. Parte 2: Viviendas. Instituto Argentino de Normalización y Certificación. Buenos Aires, Argentina. 2007.

IRAM. Norma 11.900. Etiqueta de Eficiencia Energética de Calefacción para Edificios. Clasificación según la transmitancia térmica de la envolvente. Instituto Argentino de Normalización y Certificación. Buenos Aires, Argentina. 2010.

SARQUIS, J. El medioambiente como material proyectual. $2^{\circ}$ Seminario Internacional "Medioambiente, Ahorro Energético e Innovación Tecnológica en Arquitectura". Sociedad Central de Arquitectos. Buenos Aires, Argentina. 2009.

SECRETARIA DE ENERGIA. Informe de Auditoría de "Gestión del Programa de Políticas Energéticas. Ministerio de Planificación Federal Inversión Pública y Servicios. Buenos Aires, Argentina. 2008.2 Disponible en: <http://www.agn.gov.ar/informes/informesPDF2008/2008_199.pdf>

SORIA LÓPEZ, F. J. Arquitectura y naturaleza a finales del siglo XX 1980-2000. Una aproximación dialógica para el diseño sostenible en arquitectura. Universidad Politécnica de Catalunya. Departamento de Proyectos Arquitectónicos. Barcelona, España. 2004. Disponible en: <http://www.tdx.cat/handle/10803/6799>

VEGARA, A.; DE LAS RIVAS, J. Territorios inteligentes. La ciudad sostenible. Fundación Metrópoli. Madrid. 2004. ISBN 9788460926986.

\section{CAPÍTULO I - CAMBIO CLIMÁTICO}

BARROS, V. [R]evolución energética. Un futuro energético sustentable para la Argentina. European Renewable Energy Council. Greenpeace. Ciudad Autónoma de Buenos Aires, Argentina. 2009.2 Disponible en: <http://www.greenpeace.org/argentina/Global/argentina/report/2009/11/r-evoluci-n-energeticaun-fu.pdf>

BOYADIJÁN, C. La futura energía argentina llegará desde la roca y la arena. Los enormes hallazgos de petróleo y gas "no tradicionales" en el país se han convertido en nuevo imán para las petroleras. Artículo Diario Clarín. Buenos Aires, Argentina. 2011. Disponible en:

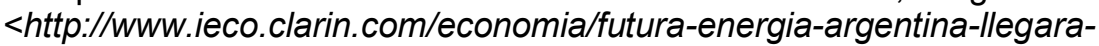

arena_0_590341165.html>

CARDINALI, L.M. Análisis comparativo. La generación eléctrica y el desarrollo social. Revista HYDRIA. Año 8. Número 39. Papel Tinta. Ciudad Autónoma de Buenos Aires, Argentina. 2012. ISSSN 1669-5119.

DE SCHILLER, S. Creatividad + responsabilidad $x$ sustentabilidad. $2^{\circ}$ Seminario Internacional "Medioambiente, Ahorro Energético e Innovación Tecnológica en Arquitectura". Sociedad Central de Arquitectos. Buenos Aires. 2009.

DIRECTIVA 2002/91/CE relativa a la eficiencia energética de los edificios. Parlamento Europeo y Consejo de la Unión Europea. Bruselas, Bélgica. 2002. Disponible en: <http://eurlex.europa.eu/LexUriServ/LexUriServ.do?uri=OJ:L:2003:001:0065:0065:ES:PDF> 
EDWARDS, B. Green buildings pay. Spon Press. Londres, Inglaterra. 2005. ISBN 9780415262712.

EDWARDS, B. Guía básica de la sostenibilidad. Gustavo Gili, SL. Barcelona, España. 2008. ISBN 9788425222085.

GOULDING, J.; LEWIS J.O.; STEEMERS, T.C. Energy conscious design: a primer for architects. Comisión de las Comunidades Europeas. 1996. ISBN 0713469196.

GOULDING, J.; LEWIS, J. O. European directory of sustainable and energy-efficient building. James and James. Londres, 1999. ISBN 1873936931.

HERNÁNDEZ, A. Calefacción solar pasiva. Información obtenida del curso Solar II. Maestría en Energías renovables. Facultad de Ciencias Exactas. Universidad Nacional de Salta. Salta, Argentina. 2010.

INTERNATIONA ENERGY AGENCY. Energy Policies of IEA Countries. IEA. París, Francia. $2011 . \quad$ Disponible en: <http://www.iea.org/publications/freepublications/publication/Denmark2011_unsecured.pdf>

INTERGOVERNMENTAL PANEL ON CLIMATE CHANGE. Tercer informe de evaluación del Intergovernmental Panel on Climate Change. Cambio Climático. Ginebra, Suiza, 2001. ISBN 052180770-0.

IRAM. Norma 11.900. Etiqueta de Eficiencia Energética de Calefacción para Edificios. Clasificación según la transmitancia térmica de la envolvente. Instituto Argentino de Normalización y Certificación. Buenos Aires, Argentina. 2010.

JUANICÓ, L.E.; GONZALEZ, A.D. Savings on natural gas consumption by doubling thermal efficiencies of balanced-flue space heaters. Energy and Buildings. Volumen 40. Elsevier. 2008. (pp 1479-1486). ISSN 03787788.

ORGANIZACIÓN DE LAS NACIONES UNIDAS. Declaración de Río sobre el Medio Ambiente y el Desarrollo. Rio de Janeiro, Brasil. 1992. Disponible en: $<$ <ttp://www.un.org/spanish/esa/sustdev/documents/declaracionrio.htm>

ORGANIZACIÓN DE LAS NACIONES UNIDAS. Protocolo de Kyoto de la Convención Marco de las Naciones Unidas sobre el Cambio Climático. Disponible en: $<$ <ttp://unfccc.int/resource/docs/convkp/kpspan.pdf>

ORGANIZACIÓN DE LAS NACIONES UNIDAS. Informe mundial sobre asentamientos humanos. Un hábitat por un mejor futuro urbano. ONU. Nueva York, Estados Unidos. 2009. Disponible en: <http://www.unhabitat.org/documents/GRHS09/K0952834s.pdf>

ORGANIZACIÓN PARA LA COOPERACIÓN Y EL DESARROLLO ECONÓMICOS. Hacia el Crecimiento Verde. Un resumen para los diseñadores de políticas. OCDE. París, Francia. 2011. Disponible en: <http://www.oecd.org/greengrowth/49709364.pdf>

LERNER, J. Orientación de la planificación urbana para la sostenibilidad en Curitiba, Brasil. Instituto de Pesquisa y Planejamento Urbano de Curitiba, Brasil. 1965. Disponible en $<h t t p: / / w w w . i p p u c . o r g . b r / d e f a u l t . p h p>$

MINISTERIO DE ECONOMÍA Y FINANZAS PÚBLICAS. Ley 26.190. Régimen de Fomento Nacional para el uso de fuentes renovables de energía destinada a la producción de energía eléctrica. Senado y Cámara de Diputados de la Nación. Buenos Aires, Argentina. 2006. Disponible en: <http://infoleg.mecon.gov.ar/infolegInternet/anexos/120000124999/123565/norma.htm> 
ROAF, S.; et al. Adapting buildings and cities for climate change. A $21^{\text {st }}$ century survival guide. Architectural Press. Londres, Inglaterra. 2005. ISBN 0-7506-5911-4.

ROCA, M.A. De la ciudad contemporánea a la arquitectura del territorio. EUDECOR SRL. Córdoba, Argentina 2003. ISBN 987-9094-39-5.

ROGERS, R. Towards an urban renaissance. E \& FN Spon. Londres, Inglaterra. 1999. ISBN10: 185112165X.

ROGERS, R.; Ciudades para un pequeño planeta. Editorial Gustavo Gili. Barcelona, España. 2000. ISBN 84-252-1764-4.

SECRETARÍA DE ENERGÍA DE LA NACIÓN. Plan Federal de Transporte de Energía Eléctrica I. Ministerio de Planificación Federal, Inversión Pública y Servicios. Secretaría de Energía. Comité de Administración. Fondo Fiduciario para el Transporte Eléctrico Federal. Buenos Aires, Argentina. 2000. Disponible en: <http://www.cfee.gov.ar/planfederal.php?screen_check=done\&Width=1366>

SECRETARÍA DE ENERGÍA DE LA NACIÓN. Programa Nacional de Uso Racional y Eficiente de la Energía (PRONUREE). Ministerio de Planificación Federal, Inversión Pública y Servicios. Secretaría de Energía. Buenos Aires, Argentina. 2007. Disponible en: <http://energia3.mecon.gov.ar/contenidos/verpagina.php?idpagina=3102>

TESKE, S.; et al. [R]evolución energética. Un futuro energético sustentable para la Argentina. European Renewable Energy Council. Greenpeace. Ciudad Autónoma de Buenos Aires, Argentina. 2009.2 Disponible en: <http://www.greenpeace.org/argentina/Global/argentina/report/2009/11/r-evoluci-n-energeticaun-fu.pdf>

WURGAFT, R. Un viaje por Vaca Muerta, el yacimiento de la discordia. Artículo del diario El Mundo. Madrid, España. 2012.2 Disponible en: <http://www.elmundo.es/america/2012/04/21/argentina/1335022561.html>

ZHOU, N.;LIN, J. The reality and future scenarios of commercial building genergy consumption in China. Energy and Buildings. Volumen 40 (pp 2121-2127). Elsevier. Londres, Inglaterra. 2008. ISSN 0378-7788.

\section{CAPÍTULO II - CONTEXTO URBANO}

BENÉVOLO, L. La proyectación de la ciudad moderna. Editorial Gustavo Gili Barcelona, España. 2000. ISBN 9788425218385.

BENÉVOLO, L. Historia de la arquitectura moderna. Editorial Gustavo Gili Barcelona, España. 2000. ISBN 9788425217937.

BENÉVOLO, L. Diseño de la ciudad. Editorial Gustavo Gili Barcelona, España. 2000. ISBN 9788425217937.

BOHIGAS, O. et Al. Barcelona. Arquitectura y Ciudad. 1980 -1992. Editorial Gustavo Gili. Barcelona, España. 1990. ISBN 8425214548.

BRITO, G.A.; MAUR, I. La primera modernidad arquitectónica en América Latina. Capítulo "Buenos Aires 1920 - 1940. Una modernidad silenciosa". Universidad Autónoma Metropolitana de México. Instituto Francés para América Latina. 1993. ISBN 9706202544.

CALVINO, I. Las ciudades invisibles. Editorial Siruela. Madrid, España. 2010. ISBN 9788478444151. 
FRAMPTON, K. Estudio sobre arquitectura tectónica; poética de la construcción en la arquitectura de los siglos XIX y XX. Editorial AKAL. Madrid, España. 1999. ISBN 9788446011873.

FRAMPTON, K. Historia crítica de la arquitectura moderna. Editorial Gustavo Gili. Barcelona, España. 2010. ISBN 9788425222740.

GOBIERNO DE LA CIUDAD AUTÓNOMA DE BUENOS AIRES. Plan urbano ambiental para la Ciudad Autónoma de Buenos Aires. Disponible en <http://www.buenosaires.gob.ar/areas/planeamiento_obras/copua/plan_urbano_ambiental.php>

GORELIK, A. La Grilla y el Parque. Espacio Público y Cultura Urbana en Buenos Aires, 1887 1936. Universidad Nacional de Quilmes Editorial. Bernal, Argentina. 2010. ISBN 9789879173275.

GRAVAGNUOLO, B. Historia del urbanismo en Europa (1750 - 1960). Editorial Akal, S.A. Madrid, España. 1998. ISBN 8446006278.

GUTIÉRREZ, R. Arquitectura y urbanismo en Iberoamérica. Ediciones Cátedra, S.A. Madrid, España. 1983. ISBN 8437604427.

GUTIÉRREZ, R. Buenos Aires; evolución histórica. Editorial Escala. Buenos Aires, Argentina. 1992. ISBN 9589082661.

JAJAMOVICH, G.; Arquitectos Proyectistas y Transición Democrática. El concurso de las "20 Ideas para Buenos Aires". Revista Anales del Instituto de Arte Americano e Investigaciones Estéticas "Mario J. Buschiazzo" \#41. Sociedad Central de Arquitectos. Buenos Aires, Argentina. 2011.

LE CORBUSIER. Hacia una arquitectura. Ediciones Apóstrofe. Colección Poseidón. Barcelona, España. 1998. ISBN 8445502778.

LIERNUR, J. F.; SILVESTRI, G. El umbral de la metrópolis. Transformaciones técnicas y cultura en la modernización de Buenos Aires (1870-1930). Editorial Sudamericana. Buenos Aires, Argentina. 1993. ISBN 9500708906.

LIERNUR, J. F. Arquitectura en la Argentina del siglo XX, la construcción de la modernidad. Fondo Nacional de las Artes (FNA). Buenos Aires, Argentina. 2008. ISBN 9876410008.

LOMBARDO, J. D. La construcción de la ciudad. El caso de la Región Metropolitana de Buenos Aires. Editorial Nobuko. Buenos Aires, Argentina. 2007. ISBN 9789875841109.

MARTORELL, J. et Al. La Villa Olímpica de Barcelona. Arquitectura. Parques. Puerto Deportivo. Editorial Gustavo Gili. Barcelona, España. 1991. ISBN 8425214858.

MERRO JOHNSTON, D. Tesis Doctoral. El autor y el intérprete. Le Corbusier y Amancio Williams en la casa Curutchet. Universidad Politécnica de Madrid, Escuela Técnica Superior de Arquitectura. Madrid, España. 2009. Disponible en <http://oa.upm.es/1729>

ROCA, M.A. De la ciudad contemporánea a la arquitectura del territorio. Editorial EUDECOR SRL. Córdoba, Argentina. 2003. ISBN 9879094395.

TAFURI, M. De la vanguardia a la metrópoli; crítica radical a la arquitectura. Editorial Gustavo Gili. Barcelona, España. 1972. ISBN 9788425204821.

\section{CAPÍTULO III - EL TIPO EDILICIO}


BODIO, I.; BARTOLINI, E. Medianería. Manual Práctico. Derechos reales, propiedad horizontal (Ley 13.512) Prehorizontalidad (Ley 19.724). Editorial Nobuko. Buenos Aires, Argentina. 2010. ISBN 9789875842656.

CUTRUNEO, J. P. Hacia el edificio de renta. La transformación de la vivienda en altura en manos de los arquitectos (Rosario, 1920-1948). DEARQ - Revista de Arquitectura de la Universidad de los Andes. Número 10. Bogotá, Colombia. 2012. Páginas 152 - 161. ISNN 2011-3188.

DUPRÉ, J. Rascacielos. Entrevista con Philip Johnson. Editorial Konemann. Colonia, Alemania. 1999. ISBN 3829032846.

LIERNUR, J. F.; SILVESTRI, G. El umbral de la metrópolis. Transformaciones técnicas y cultura en la modernización de Buenos Aires (1870-1930). Editorial Sudamericana. Buenos Aires, Argentina. 1993. ISBN 9500708906.

LIERNUR, J. F.; ALIATA, F. Diccionario de arquitectura en la Argentina. Editorial Grupo Clarín. Buenos Aires, Argentina. 2004. ISBN 9507824227.

LIERNUR, J. F. Arquitectura en la Argentina del siglo XX, la construcción de la modernidad. Fondo Nacional de las Artes (FNA). Buenos Aires, Argentina. 2008. ISBN 9876410008.

TAFURI, M. De la vanguardia a la metrópoli; crítica radical a la arquitectura. Editorial Gustavo Gili. Barcelona, España. 1972. ISBN 9788425204821.

ZIMMERMAN, C. Mies van der Rohe. 1886-1969. la estructura del espacio. Editorial Taschen. Köln, Alemania. 2006. ISBN97838228285588.

GONZÁLEZ MONTANER, B. Vanguardias argentinas. Editorial Grupo Clarín. Buenos Aires, Argentina. 2010. ISBN 9507826807.

\section{CAPÍTULO IV - NORMATIVA Y LEGISLACIÓN APLICADA A EDIFICIOS}

AENOR. Norma UNE EN ISO 6946. Componentes y elementos para la edificación. Resistencia Térmica y transmitancia térmica. Método de cálculo. Asociación Española de Normalización y Certificación. Madrid, España. 2007.

AENOR. Norma UNE-EN ISO 10077-1. Comportamiento térmico de ventanas, puertas y persianas. Cálculo de la transmitancia térmica. Parte 1: Generalidades. (ISO 10077-1:2006). Asociación Española de Normalización y Certificación. Madrid, España. 2010.

AGENCIA ESTATAL. Boletín Oficial del Estado (BOE). Ley 38/1999, de Ordenación de la Edificación. Jefatura del Estado. Gobierno de España. Madrid, España. 1999.

ANSI/ASHRAE. Standard 189.1-2009. Design of High-Performance Green Buildings (ANSI Approved; USGBC and IES Co-sponsored). American Society of Heating, Refrigerating and AirConditioning Engineers, Inc. Washington, Estados Unidos. 2009.

ANSI/ASHRAE. Standard 55-2010. Thermal Environmental Conditions for Human Occupancy. American Society of Heating, Refrigerating and Air-Conditioning Engineers, Inc. Washington, Estados Unidos. 2010.

ANSI/ASHRAE/IES. Standard 90.1 - 2010. Energy Standard for Buildings Except Low-Rise Residential Buildings. American Society of Heating, Refrigerating and Air-Conditioning Engineers, Inc. Washington, Estados Unidos. 2010. 
Building Research Establishment. BRE Environmental Assessment Method (BREEAM). Disponible en <http://web.archive.org>

CÁMARA DE DIPUTADOS DE LA PROVINCIA DE BUENOS AIRES. Ley 13.059. Sala de sesiones de la Honorable Legislatura de la provincia de Buenos Aires. La Plata, Argentina. 2003.

CZAJKOWSKI, J. D.; CORREDERA, C. Ahorro de energía en refrigeración de edificios para viviendas y propuestas de indicadores de eficiencia y valores admisibles. Revista Avances en Energías Renovables y Ambientales Nº10. La Plata, Argentina. 2006. ISSN 03295184.

CZAJKOWSKI, J. D. Tesis Doctoral. Análisis y modelización energético-ambiental de la edilicia urbana basado en técnicas de auditoría y procedimientos estadísticos multivariados. Desarrollo de herramientas de diagnóstico y simulación. Capítulo 1: Descripción del problema y marco teórico. Universidad Nacional de La Plata. Facultad de Ingeniería. La Plata, Argentina. 2009. Disponible en <http://sedici.un/p.edu.ar/handle/10915/1371>

GOBIERNO DE ESPAÑA. Ministerio de Fomento. Código Técnico de la Edificación (CTE España). Disponible en <http://www.codigotecnico.org/web/>

GOBIERNO DE LA CIUDAD DE BUENOS AIRES. Código de la Edificación de la Ciudad Autónoma de Buenos Aires. Buenos Aires, Argentina. Disponible en $<h t t p: / / w w w . a g c o n t r o l . g o b . a r / p d f / c o d i g o-e d i f i c a c i o n-C A B A . p d f>$

HASELBACH, L. The Engineering Guide to LEED - New Construction. Sustainable Construction for Engineers. Editorial MC Graw Hill. Nueva York, Estados Unidos. 2008. ISBN 9780071489935.

IDAE. Directiva 2002/91/CE del Parlamento Europeo y del Consejo, relativa a la eficiencia energética de los edificios. Instituto para la Diversificación y Ahorro de la Energía. Diario Oficial de las Comunidades Europeas. Bruselas, Bélgica. 2002.

IDAE. Directiva 2009/18/CE del Parlamento Europeo y del Consejo, relativa al fomento del uso de energía procedente de fuentes renovables y por la que se modifican y se derogan las Directivas 2001/77/CE y 2003/30/CE. Instituto para la Diversificación y Ahorro de la Energía. Diario Oficial de las Comunidades Europeas. Estrasburgo, Francia. 2009.

IDAE. Directiva 2010/31/UE del Parlamento Europeo y del Consejo, relativa a la eficiencia energética de los edificios. Instituto para la Diversificación y Ahorro de la Energía.Diario Oficial de las Comunidades Europeas. Estrasburgo, Francia. 2010.

IRAM. Norma 11.601. Aislamiento térmico de edificios. Métodos de cálculo. Propiedades térmicas de los componentes y elementos de construcción en régimen estacionario. Instituto Argentino de Normalización y Certificación. Buenos Aires, Argentina. 2002.

IRAM. Norma 11.603. Acondicionamiento térmico de edificios. Clasificación bioambiental de la República Argentina. Instituto Argentino de Normalización y Certificación. Buenos Aires, Argentina. 2011.

IRAM. Norma 11.604. Aislamiento térmico de edificios. Verificación de sus condiciones higrotérmicas. Ahorro de energía en calefacción. Coeficiente volumétrico $G$ de pérdidas de calor. Cálculo y valores límites. Instituto Argentino de Normalización y Certificación. Buenos Aires, Argentina. 2001.

IRAM. Norma 11.605. Acondicionamiento térmico de edificios. Condiciones de habitabilidad en edificios. Valores máximos de transmitancia térmica en cerramientos opacos. Instituto Argentino de Normalización y Certificación. Buenos Aires, Argentina. 2002. 
IRAM. Norma 11.659-1. Aislamiento térmico de edificios. Verificación de sus condiciones higrotérmicas. Ahorro de energía en refrigeración. Parte 1: Vocabulario, definiciones, tablas y datos para determinar la carga térmica de refrigeración. Instituto Argentino de Normalización y Certificación. Buenos Aires, Argentina. 2004.

IRAM. Norma 11.659-2. Aislamiento térmico de edificios. Verificación de sus condiciones higrotérmicas. Ahorro de energía en refrigeración. Parte 2: Edificios de Viviendas. Instituto Argentino de Normalización y Certificación. Buenos Aires, Argentina. 2007.

IRAM. Norma 11.900. Etiqueta de Eficiencia Energética de Calefacción para Edificios. Clasificación según la transmitancia térmica de la envolvente. Instituto Argentino de Normalización y Certificación. Buenos Aires, Argentina. 2010.

MINISTERIO DE VIVIENDA. Real Decreto 1371/2007. Aprobación del documento básico "DBHR Protección frente al ruido" del CTE - España y modificación el Real Decreto 314/2006, de 17 de marzo, por el que se aprueba el CTE - España. Boletín Oficial del Estado. Madrid, España. 2006.

MINISTERIO DE VIVIENDA. Real Decreto 314/2006. Aprobación del Código Técnico de la Edificación (CTE - España). Boletín Oficial del Estado. Madrid, España. 2006.

MUNICIPALIDAD DE LA PLATA. Ordenanza $N^{\circ}$ 10681. Código de edificación para el Partido de La Plata. La Plata, Argentina. 2010.

PEP. Estándar Passivhaus España. Plataforma Edificación Passivhaus. Disponible en $<h t t p: / / w w w . p l a t a f o r m a-p e p . o r g>$

PHI. Passivhaus Standard. Passivhaus Institute. Disponible en <http://www.passiv.de>

U.S. GREEN BUILDING COUNCIL. Leadership in Energy \& Environmental Design (LEED). Disponible en <http://www.usgbc.org/leed>

\section{CAPÍTULO V - ESTUDIO DE CASOS}

CÁMARA DE DIPUTADOS Y SENADO DE LA PROVINCIA DE BUENOS AIRES. Ley 13.059 de Acondicionamiento Térmico de Edificios. Gobierno de la Provincia de Buenos Aires. La Plata, Argentina. 2003. Disponible en <http://www.gob.gba.gov.ar/legislacion/legislacion/l13059. htm/ >

CORREDERA, C.; CZAJKOWSKI, J. Evolución en el diseño de torres de oficinas en la Argentina desde un enfoque ambiental. ENCAC-COTEDI (VII Encuentro Nacional sobre Confort en el Ambiente Construido - III Conferencia Latinoamericana sobre Confort y Comportamiento Térmico de Edificaciones). Brasil, Curitiba. 2003.

CZAJKOWSKI, J.; ROSENFELD, E. Resultados del análisis energético y de habitabilidad higrotérmica de las tipologías del sector residencial urbano del Área Metropolitana Buenos Aires. Actas del XIV ASADES. Páginas 131 - 136. Mendoza, Argentina. 1990. ISSN 03295184.

CZAJKOWSKI, J. Desarrollo del programa AuditCAD para el análisis de edificios a partir de auditorías ambientales. Revista Avances en energías renovables y ambientales Volumen 3. Año 1999. ISSN 03295184.

CZAJKOWSKI, J. Psiconf 1.0 - Programa para el cálculo y graficación en modelo bioclimático de

Givoni de datos provenientes de microadquisidores de datos Hobo, termohigrómetros digitales, termómetros de máxima y mínima e higrómetros analógicos. La Plata, Argentina. 2006. 
CZAJKOWSKI, J. D. Análisis y modelización energético-ambiental de la edilicia urbana basado en técnicas de auditoría y procedimientos estadísticos multivariados. Desarrollo de herramientas de diagnóstico y simulación. Capítulo 6: Estudio de casos. Universidad Nacional de La Plata. Facultad de Ingeniería. La Plata, Argentina. 2009. Disponible en <http://sedici.unlp.edu.ar/handle/10915/1371>

DEPARTAMENTO DE INFRAESTRUCTURA DE LA PROVINCIA DE BUENOS AIRES. Decreto Reglamentario 1.030 de la Ley 13.059 provincial de Acondicionamiento Térmico de Edificios. Gobierno de la Provincia de Buenos Aires. La Plata, Argentina. 2010. Disponible en $<$ http://www.gob.gba.gov.ar/legislacion/legislacion/10-1030.html>

GONZALO, G. Determinación de índices de consumo de energía para distintas funciones edilicias en el área de San Miguel de Tucumán. Revista Avances en energías renovables y ambientales Volumen 3. Año 1999. ISSN 03295184.

IRAM. Norma 11.603. Acondicionamiento térmico de edificios. Clasificación bioambiental de la República Argentina. Instituto Argentino de Normalización y Certificación. Buenos Aires, Argentina. 2011.

IRAM. Norma 11.604. Aislamiento térmico de edificios. Verificación de sus condiciones higrotérmicas. Ahorro de energía en calefacción. Coeficiente volumétrico $G$ de pérdidas de calor. Cálculo y valores límites. Instituto Argentino de Normalización y Certificación. Buenos Aires, Argentina. 2001.

MCKNIGHT, T.; HESS, D. Climate Zones and Types. Physical Geography: A Landscape Appreciation. Editorial Prentice Hall. Nueva Jersey, Estados Unidos. 2000. ISBN 0130202630.

ROSENFELD ET AL. Eficiencia energética y URE en los sectores residencial-terciarios metropolitanos. Revista Avances en energías renovables y ambientales Volumen 3. Año 1999. ISSN 03295184.

ROSENFELD ET AL. Hacia un modelo de confort integral. Auditorías ambientales en viviendas. Revista Avances en energías renovables y ambientales Volumen 3. Año 1999. ISSN 03295184.

VEIGAS ET AL. Comportamiento térmico-energético de tipologías representativas pertenecientes a mosaicos urbanos de la Ciudad de La Plata. Revista Avances en energías renovables y ambientales Volumen 11. Año 2007. ISSN 03295184.

\section{CAPÍTULO VI - AUDITORIA ENERGÉTICA}

AENOR. Norma UNE-EN ISO 7726. Ergonomía de los ambientes térmicos Instrumentos de medida de las magnitudes físicas (ISO 7726:1998). Asociación Española de Normalización y Certificación. Madrid, España. 1998.

ALCÁZAR ORTEGA, M. Auditoria Energética. Máster en Tecnología para el Desarrollo Sostenible. Apuntes de clase. Escuela Técnica Superior de Ingenieros Industriales. Universidad Politécnica de Valencia, España. 2011.

ÁLVAREZ BEL, C. Mercados Energéticos. Máster en Tecnología para el Desarrollo Sostenible. Apuntes de clase. Escuela Técnica Superior de Ingenieros Industriales. Universidad Politécnica de Valencia, España. 2011.

AYUNTAMIENTO DE BARCELONA. Agencia Regional de la Energía de Barcelona. Disponible en <http://www.barcelonaenergia.com/>

AYUNTAMIENTO DE MADRID. Agencia Regional de la Energía de Madrid. Disponible en $<$ http://www.madrid.es/portales/munimadrid/es/Inicio/Ayuntamiento/Medio-Ambiente/Educacionambiental/Energia-y-cambio-climatico/Agencia-de-la-Energia-de-Madrid> 
AYUNTAMIENTO DE VALENCIA. Agencia Valenciana de la Energía. Disponible en $<h t t p: / / w w w . a v e n . e s />$

CAMUZZI GAS PAMPEANA. Datos de los consumos de gas natural y costo unitario. Disponible en $<$ http://www.camuzzigas.com/>

CÁMARA DE DIPUTADOS Y SENADO DE LA PROVINCIA DE BUENOS AIRES. Ley 13.059 de Acondicionamiento Térmico de Edificios. Gobierno de la Provincia de Buenos Aires. La Plata, Argentina. 2003. Disponible en <http://www.gob.gba.gov.ar/legislacion/legislacion/l13059.html>

CZAJKOWSKI, J. Desarrollo del programa AuditCAD para el análisis de edificios a partir de auditorías ambientales. Revista Avances en energías renovables y ambientales Volumen 3. Año 1999. ISSN 03295184.

CZAJKOWSKI, J. Psiconf 1.0 - Programa para el cálculo y graficación en modelo bioclimático de Givoni de datos provenientes de microadquisidores de datos Hobo, termohigrómetros digitales, termómetros de máxima y mínima e higrómetros analógicos. La Plata, Argentina. 2006.

CZAJKOWSKI, J. Tesis Doctoral. Análisis y modelización energético-ambiental de la edilicia urbana basado en técnicas de auditoría y procedimientos estadísticos multivariados. Desarrollo de herramientas de diagnóstico y simulación. Capítulo 8: Modelo de ahorro de energía y estándares de calidad edilicia en calefacción y Refrigeración. Universidad Nacional de La Plata. Facultad de Ingeniería. La Plata, Argentina. 2009. Disponible en $<$ http://sedici.unlp.edu.ar/handle/10915/1371>

DEPARTAMENTO DE INFRAESTRUCTURA DE LA PROVINCIA DE BUENOS AIRES. Decreto Reglamentario 1.030 de la Ley 13.059 provincial de Acondicionamiento Térmico de Edificios. Gobierno de la Provincia de Buenos Aires. La Plata, Argentina. 2010. Disponible en $<$ http://www.gob.gba.gov.ar/legislacion/legislacion/10-1030.htm/>

EDELAP. Empresa Distribuidora La Plata S.A. Datos de los consumos de energía eléctrica y costo unitario Disponible en <http://www.edelap.com.ar/>

IDAE. Plan de ahorro y eficiencia energética 2011 - 2020. $2^{\circ}$ Plan de acción nacional de eficiencia energética en España 2011-2020. Instituto para la Diversificación y Ahorro de Energía. Madrid, España. 2011.2 Disponible en $<$ http://www.idae.es/index.php/mod.documentos/mem.descarga?file=/documentos_11905_PAE E_2011_2020._A2011_A_a1e6383b.pdf>

IRAM. Norma 11.604. Aislamiento térmico de edificios. Verificación de sus condiciones higrotérmicas. Ahorro de energía en calefacción. Coeficiente volumétrico $G$ de pérdidas de calor. Cálculo y valores límites. Instituto Argentino de Normalización y Certificación. Buenos Aires, Argentina. 2001.

IRAM. Norma 11.659-1. Aislamiento térmico de edificios. Verificación de sus condiciones higrotérmicas. Ahorro de energía en refrigeración. Parte 1: Parte 1: Vocabulario, definiciones, tablas y datos para determinar la carga térmica de refrigeración Instituto Argentino de Normalización y Certificación. Buenos Aires, Argentina. 2007.

IRAM. Norma 11.659-2. Aislamiento térmico de edificios. Verificación de sus condiciones higrotérmicas. Ahorro de energía en refrigeración. Parte 2: Edificios para Viviendas. Instituto Argentino de Normalización y Certificación. Buenos Aires, Argentina. 2007.

NATURAL RESOURCES CANADA. RETScreen. Software de gestión energética. Disponible en $<h t t p: / / w w w . r e t s c r e e n . n e t / e s / h o m e . p h p>$ 
OLGYAY, V. Arquitectura y clima. Manual de diseño bioclimático para arquitectos y urbanistas. Editorial Gustavo Gili. Barcelona, Madrid. 2008. ISBN 9788425214882.

ONSET. HOBOWare Pro Data Logger Software. Disponible en $<h t t p: / / w w w . o n s e t c o m p . c o m /$ products/software>

ROSENFELD ET AL. Eficiencia energética y URE en los sectores residencial-terciarios metropolitanos. Revista Avances en energías renovables y ambientales Volumen 3. Año 1999. ISSN 03295184.

ROSENFELD ET AL. Hacia un modelo de confort integral. Auditorías ambientales en viviendas. Revista Avances en energías renovables y ambientales Volumen 3. Año 1999. ISSN 03295184.

SECRETARÍA DE ENERGÍA DE LA NACIÓN. Información del mercado de hidrocarburos. Disponible en <http://energia3. mecon.gov.ar/contenidos/verpagina. php?idpagina=3443>

SECRETARÍA DE ENERGÍA DE LA NACIÓN. Información del mercado eléctrico. Disponible en <http://energia3.mecon.gov.ar/contenidos/verpagina.php?idpagina=3444>

U.S. DEPARTMENT OF ENERGY. EnergyPLUS. Energy Simulation Software. Energy Efficiency and Renewable Energy. Disponible en <http://apps1.eere.energy.gov/buildings/energyplus/>

VEIGAS ET AL. Comportamiento térmico-energético de tipologías representativas pertenecientes a mosaicos urbanos de la Ciudad de La Plata. Revista Avances en energías renovables y ambientales Volumen 11. Año 2007. ISSN 03295184.

\section{CAPÍTULO VII - COMPORTAMIENTO HIGROTÉRMICO}

CZAJKOWSKI, J. Psiconf 1.0 - Programa para el cálculo y graficación en modelo bioclimático de Givoni de datos provenientes de microadquisidores de datos Hobo, termohigrómetros digitales, termómetros de máxima y mínima e higrómetros analógicos. La Plata, Argentina. 2006.

OLGYAY, V. Arquitectura y clima. Manual de diseño bioclimático para arquitectos y urbanistas. Editorial Gustavo Gili. Barcelona, Madrid. 2008. ISBN 9788425214882.

ONSET. HOBOWare Pro Data Logger Software. Disponible en $<h t t p: / / w w w . o n s e t c o m p . c o m / p r o d u c t s /$ software>

IRAM. Norma 11.507-4. Carpintería de obra. Ventanas exteriores. Requisitos básicos y clasificación. Aislamiento térmico. Instituto Argentino de Normalización y Certificación. Buenos Aires, Argentina. 2010.

IRAM. Norma 11.601. Aislamiento térmico de edificios. Métodos de cálculo. Propiedades térmicas de los componentes y elementos de construcción en régimen estacionario. Instituto Argentino de Normalización y Certificación. Buenos Aires, Argentina. 2002.

IRAM. Norma 11.603. Acondicionamiento térmico de edificios. Clasificación bioambiental de la República Argentina. Instituto Argentino de Normalización y Certificación. Buenos Aires, Argentina. 2011.

IRAM. Norma 11.604. Aislamiento térmico de edificios. Verificación de sus condiciones higrotérmicas. Ahorro de energía en calefacción. Coeficiente volumétrico $G$ de pérdidas de calor. Cálculo y valores límites. Instituto Argentino de Normalización y Certificación. Buenos Aires, Argentina. 2001. 
IRAM. Norma 11.605. Acondicionamiento térmico de edificios. Condiciones de habitabilidad en edificios. Valores máximos de transmitancia térmica en cerramientos opacos. Instituto Argentino de Normalización y Certificación. Buenos Aires, Argentina. 2002.

IRAM. Norma 11.659-1. Aislamiento térmico de edificios. Verificación de sus condiciones higrotérmicas. Ahorro de energía en refrigeración. Parte 1: Parte 1: Vocabulario, definiciones, tablas y datos para determinar la carga térmica de refrigeración Instituto Argentino de Normalización y Certificación. Buenos Aires, Argentina. 2007.

IRAM. Norma 11.659-2. Aislamiento térmico de edificios. Verificación de sus condiciones higrotérmicas. Ahorro de energía en refrigeración. Parte 2: Edificios para Viviendas. Instituto Argentino de Normalización y Certificación. Buenos Aires, Argentina. 2007.

\section{CAPÍTULO VIII - DEMANDA DE ENERGÍA PARA CALEFACCIÓN - ETIQUETADO DE EFICIENCIA ENERGÉTICA EN CALEFACCIÓN}

CZAJKOWSKI, J. Desarrollo del programa AuditCAD para el análisis de edificios a partir de auditorías ambientales. Revista Avances en energías renovables y ambientales Volumen 3. Año 1999. ISSN 0329-5184.

CZAJKOWSKI, J. Tesis Doctoral. Análisis y modelización energético-ambiental de la edilicia urbana basado en técnicas de auditoría y procedimientos estadísticos multivariados. Desarrollo de herramientas de diagnóstico y simulación. Capítulo 7: Sistematización, análisis e interpretación de datos. Universidad Nacional de La Plata. Facultad de Ingeniería. La Plata, Argentina. 2009. Disponible en <http://sedici.un/p.edu.ar/handle/10915/1371>

IRAM. Norma 11.603. Acondicionamiento térmico de edificios. Clasificación bioambiental de la República Argentina. Instituto Argentino de Normalización y Certificación. Buenos Aires, Argentina. 2011.

IRAM. Norma 11.604. Aislamiento térmico de edificios. Verificación de sus condiciones higrotérmicas. Ahorro de energía en calefacción. Coeficiente volumétrico $G$ de pérdidas de calor. Cálculo y valores límites. Instituto Argentino de Normalización y Certificación. Buenos Aires, Argentina. 2001.

IRAM. Norma 11.605. Acondicionamiento térmico de edificios. Condiciones de habitabilidad en edificios. Valores máximos de transmitancia térmica en cerramientos opacos. Instituto Argentino de Normalización y Certificación. Buenos Aires, Argentina. 2002.

IRAM. Norma 11.900. Etiqueta de Eficiencia Energética de Calefacción para Edificios. Clasificación según la transmitancia térmica de la envolvente. Instituto Argentino de Normalización y Certificación. Buenos Aires, Argentina. 2010.

\section{CAPÍTULO IX - SIMULACIÓN CON ENERGY PLUS}

ANSI/ASHRAE. Standard 189.1-2009. Design of High-Performance Green Buildings (ANSI Approved; USGBC and IES Co-sponsored). American Society of Heating, Refrigerating and AirConditioning Engineers, Inc. Washington, Estados Unidos. 2009.

ANSI/ASHRAE. Standard 55-2010. Thermal Environmental Conditions for Human Occupancy. American Society of Heating, Refrigerating and Air-Conditioning Engineers, Inc. Washington, Estados Unidos. 2010. 
ANSI/ASHRAE/IES. Standard 90.1 - 2010. Energy Standard for Buildings Except Low-Rise Residential Buildings. American Society of Heating, Refrigerating and Air-Conditioning Engineers, Inc. Washington, Estados Unidos. 2010.
ENERGYPLUS
Energy Simulation
Software.
Disponible
en

<http://apps1.eere.energy.gov/buildings/energyplus/>

IRAM. Norma 11.507-4. Carpintería de obra. Ventanas exteriores. Requisitos básicos y clasificación. Aislamiento térmico. Instituto Argentino de Normalización y Certificación. Buenos Aires, Argentina. 2010.

IRAM. Norma 11.601. Aislamiento térmico de edificios. Métodos de cálculo. Propiedades térmicas de los componentes y elementos de construcción en régimen estacionario. Instituto Argentino de Normalización y Certificación. Buenos Aires, Argentina. 2002.

IRAM. Norma 11.603. Acondicionamiento térmico de edificios. Clasificación bioambiental de la República Argentina. Instituto Argentino de Normalización y Certificación. Buenos Aires, Argentina. 2011.

IRAM. Norma 11.604. Aislamiento térmico de edificios. Verificación de sus condiciones higrotérmicas. Ahorro de energía en calefacción. Coeficiente volumétrico $G$ de pérdidas de calor. Cálculo y valores límites. Instituto Argentino de Normalización y Certificación. Buenos Aires, Argentina. 2001.

IRAM. Norma 11.605. Acondicionamiento térmico de edificios. Condiciones de habitabilidad en edificios. Valores máximos de transmitancia térmica en cerramientos opacos. Instituto Argentino de Normalización y Certificación. Buenos Aires, Argentina. 2002.

IRAM. Norma 11.659-1. Aislamiento térmico de edificios. Verificación de sus condiciones higrotérmicas. Ahorro de energía en refrigeración. Parte 1: Parte 1: Vocabulario, definiciones, tablas y datos para determinar la carga térmica de refrigeración Instituto Argentino de Normalización y Certificación. Buenos Aires, Argentina. 2007.

IRAM. Norma 11.659-2. Aislamiento térmico de edificios. Verificación de sus condiciones higrotérmicas. Ahorro de energía en refrigeración. Parte 2: Edificios para Viviendas. Instituto Argentino de Normalización y Certificación. Buenos Aires, Argentina. 2007.

IRAM. Norma 11.900. Etiqueta de Eficiencia Energética de Calefacción para Edificios. Clasificación según la transmitancia térmica de la envolvente. Instituto Argentino de Normalización y Certificación. Buenos Aires, Argentina. 2010.

\section{CAPÍTULO X - MODELO DE AHORRO DE ENERGÍA}

ASHRAE. Advanced energy design guide for small office buildings. Achieving $30 \%$ energy savings over ANSI/ASHRAE/IESNA Standard 90.1-1999. American Society of Heating, Refrigerating an Air-conditioning Engineers. American Institute of Architects. Illuminating Engineering Society of North America.New Buildings Institute. U.S. Department of Energy. Atlanta, Estados Unidos. 2004. ISBN 1931862559.

ASHRAE. Advanced energy design guide for small retail buildings. Achieving $30 \%$ energy savings towards a net zero energy building. American Society of Heating, Refrigerating an Airconditioning Engineers. American Institute of Architects. Illuminating Engineering Society of North America. U.S. Green Building Council. U.S. Department of Energy. Atlanta, Estados Unidos. 2006. ISBN 1933742062.

ASHRAE. Advanced energy design guide for small warehouses and self-storage buildings. Achieving $30 \%$ energy savings towards a net zero energy building. American Society of Heating, Refrigerating an Air-conditioning Engineers. American Institute of Architects. 
Illuminating Engineering Society of North America. U.S. Green Building Council. U.S. Department of Energy. Atlanta, Estados Unidos. 2008. ISBN 9871933742229.

BLANCA GIMÉNEZ, V. Técnicas de Acondicionamiento pasivo y activo en la edificación. Máster en Arquitectura Avanzada, Paisaje, Urbano y Diseño. Apuntes de clase. Escuela Técnica Superior de Arquitetctura. Universidad Politécnica de Valencia. Valencia, España. 2011.

CÁMARA DE DIPUTADOS Y SENADO DE LA PROVINCIA DE BUENOS AIRES. Ley 13.059 de Acondicionamiento Térmico de Edificios. Gobierno de la Provincia de Buenos Aires. La Plata, Argentina. 2003. Disponible en <http://www.gob.gba.gov.ar/legislacion/legislacion/l13059.html>

CZAJKOWSKI, J.; GÓMEZ, A. Diseño bioclimático y economía energética edilicia. Fundamentos y métodos. Editorial UNLP, Colección Cátedra. La Plata, Argentina. 1994.

CZAJKOWSKI, J. Modelo de ahorro de energía en refrigeración aplicable a edificios del sector terciario: viviendas, administración, oficinas, comercios, educación y salud. Parte 2: Procedimiento de cálculo. Caso viviendas. Informe. 25 páginas. La Plata, Argentina. 2004.

CZAJKOWSKI, J.; CORREDERA, C. Ahorro de energía en refrigeración de edificios para viviendas y propuestas de indicadores de eficiencia y valores admisibles. Revista Avances en energías renovables y ambientales Nº10. La Plata, Argentina. 2006. ISSN 0329-5184.

CZAJKOWSKI, J. Tesis Doctoral. Análisis y modelización energético-ambiental de la edilicia urbana basado en técnicas de auditoría y procedimientos estadísticos multivariados. Desarrollo de herramientas de diagnóstico y simulación. Capítulo 8: Modelo de ahorro de energía y estándares de calidad edilicia en calefacción y Refrigeración. Universidad Nacional de La Plata. Facultad de Ingeniería. La Plata, Argentina. 2009. Disponible en $<$ http://sedici.unlp.edu.ar/handle/10915/1371>

CZAJKOWSKI, J.; GÓMEZ, A. Herramientas para arquitectos 2009. Tomo 03: Arquitectura Sustentable. Editorial Clarín. Buenos Aires, Argentina. 2009. ISBN 9789870706038.

CZAJKOWSKI, J.; GÓMEZ, A. Cuadernos de Arquitectura Sustentable. Artículos Seleccionados 2011. Editorial Dunken. Buenos Aires, Argentina. 2011. ISBN: 97895034080.

DEPARTAMENTO DE INFRAESTRUCTURA DE LA PROVINCIA DE BUENOS AIRES. Decreto Reglamentario 1.030 de la Ley 13.059 provincial de Acondicionamiento Térmico de Edificios. Gobierno de la Provincia de Buenos Aires. La Plata, Argentina. 2010. Disponible en $<$ http://www.gob.gba.gov.ar/legislacion/legis/acion/10-1030.htm/>

ENARGAS. NAG-215. Rejillas de ventilación permanente para instalaciones internas de gas. Ente Nacional Regulador del Gas. Buenos Aires, Argentina. 2008. Disponible en <http://www.enargas.gov.ar/_blank.php?iFrame=/MarcoLegal/Normas/Nag215.pdf>

FILIPPIN, C. Uso eficiente de la energía en edificios. Editorial ARMERINDIA. Santa Rosa, Argentina. 2005. ISBN 9879521331.

GARCÍA CAVERO, I. et Al. Guías de Sostenibilidad en la edificación residencial. Calidad del ambiente interior. Foro para la edificación sostenible. Generalitat Valenciana. Valencia, España. 2009. Disponible en <http://www.upv.es/contenidos/CAMUNISO/info/U0551273.pdf>

IDAE. Guía de la Edificación Sostenible: calidad energética y medioambiental en la edificación. Institut Cerdá. Ministerio de Fomento. Madrid, España. 1999. ISBN 8486850916.

IRAM. Norma 11.507-4. Carpintería de obra. Ventanas exteriores. Requisitos básicos y clasificación. Aislamiento térmico. Instituto Argentino de Normalización y Certificación. Buenos Aires, Argentina. 2010. 
IRAM. Norma 11.601. Aislamiento térmico de edificios. Métodos de cálculo. Propiedades térmicas de los componentes y elementos de construcción en régimen estacionario. Instituto Argentino de Normalización y Certificación. Buenos Aires, Argentina. 2002.

IRAM. Norma 11.603. Acondicionamiento térmico de edificios. Clasificación bioambiental de la República Argentina. Instituto Argentino de Normalización y Certificación. Buenos Aires, Argentina. 2011.

IRAM. Norma 11.604. Aislamiento térmico de edificios. Verificación de sus condiciones higrotérmicas. Ahorro de energía en calefacción. Coeficiente volumétrico $G$ de pérdidas de calor. Cálculo y valores límites. Instituto Argentino de Normalización y Certificación. Buenos Aires, Argentina. 2001.

IRAM. Norma 11.605. Acondicionamiento térmico de edificios. Condiciones de habitabilidad en edificios. Valores máximos de transmitancia térmica en cerramientos opacos. Instituto Argentino de Normalización y Certificación. Buenos Aires, Argentina. 2002.

IRAM. Norma 11.659-1. Aislamiento térmico de edificios. Verificación de sus condiciones higrotérmicas. Ahorro de energía en refrigeración. Parte 1: Parte 1: Vocabulario, definiciones, tablas y datos para determinar la carga térmica de refrigeración Instituto Argentino de Normalización y Certificación. Buenos Aires, Argentina. 2007.

IRAM. Norma 11.659-2. Aislamiento térmico de edificios. Verificación de sus condiciones higrotérmicas. Ahorro de energía en refrigeración. Parte 2: Edificios para Viviendas. Instituto Argentino de Normalización y Certificación. Buenos Aires, Argentina. 2007.

IRAM. Norma 11.900. Etiqueta de Eficiencia Energética de Calefacción para Edificios. Clasificación según la transmitancia térmica de la envolvente. Instituto Argentino de Normalización y Certificación. Buenos Aires, Argentina. 2010.

OLGYAY, V. Arquitectura y clima. Manual de diseño bioclimático para arquitectos y urbanistas. Editorial Gustavo Gili. Barcelona, Madrid. 2008. ISBN 9788425214882.

ONSET. HOBOWare Pro Data Logger Software. Disponible en $<h t t p: / / w w w . o n s e t c o m p . c o m /$ products/software>

ORGANIZACIÓN DE LAS NACIONES UNIDAS. Protocolo de Kyoto de la Convención Marco de las Naciones Unidas sobre el Cambio Climático. Disponible en: <http://unfccc.int/resource/docs/convkp/kpspan.pdf>

SECRETARIA DE AMBIENTE Y DESARROLLO SUSTENTABLE DE LA NACIÓN. EI mercado de bonos de carbono, después de Copenhague. Jefatura de Gabinete de Ministros. Presidencia de la Nación. Buenos Aires, Argentina. 2010. Disponible en $<$ http://www.ambiente.gob.ar/?idarticulo=9199>

SERRANO LANZAROTE, B. Sostenibilidad en la arquitectura y los modelos urbanos. Máster en Arquitectura Avanzada, Paisaje, Urbano y Diseño. Apuntes de Clase. Escuela Técnica Superior de Arquitectura. Universidad Politécnica de Valencia. Valencia, España. 2011.

U.S. DEPARTMENT OF ENERGY. EnergyPLUS. Energy Simulation Software. Energy Efficiency and Renewable Energy. Disponible en $<$ http://apps1.eere.energy.gov/buildings/energyplus/>

\section{CAPÍTULO XI - ENERGÍAS RENOVABLES}


AGUILERA TEJERO, J. Orientsol 1.0, Programa para el cálculo de la radiación en superficies orientadas. Grupo I + D en Energía Solar y Automática (IDEA). Universidad de Jaén. Jaén, España. 2011.

ALCÁZAR ORTEGA, M. Auditoria Energética. Máster en Tecnología para el Desarrollo Sostenible. Apuntes de clase. Escuela Técnica Superior de Ingenieros Industriales. Universidad Politécnica de Valencia, España. 2011.

ÁLVAREZ BEL, C. Mercados Energéticos. Máster en Tecnología para el Desarrollo Sostenible. Apuntes de clase. Escuela Técnica Superior de Ingenieros Industriales - Universidad Politécnica de Valencia, España. 2011.

ASADES. Avances en Energías Renovables y Medio Ambiente. Volúmenes 1- 16. Asociación Argentina de Energías Renovables y Ambiente. Salta, Argentina. 1997-2009. ISSN 03295184. Disponible en <http://www.asades.org.ar/averma.php>.

BARROS, V. [R]evolución energética. Un futuro energético sustentable para la Argentina. EREC. Greenpeace. Ciudad Autónoma de Buenos Aires, Argentina. 2009.

BLANCA GIMÉNEZ, V. Técnicas de Acondicionamiento pasivo y activo en la edificación. Apuntes de clase. Máster en Arquitectura Avanzada, Paisaje, Urbano y Diseño. Universidad Politécnica de Valencia. Valencia, España. 2011.

BOLES, M.; CENGEL, Y. Thermodynamics: an Engineering Approach. Editorial Mc Graw Hill. México D.F.; México. 2008. ISBN 97873277134

CZAJKOWSKI, J. GÓMEZ, A. Instalaciones II. Guía de trabajos prácticos. Cátedra de Instalaciones. Facultad de Arquitectura y Urbanismo. Universidad Nacional de La Plata. La Plata, Argentina. Disponible en <http://www.arquinstal.com.ar/apuntesn2.html>

DUFFIE, J.; BECKMAN, W. Solar Engineering of Thermal Processes. Editorial Wiley Interscience. Nueva York, Estados Unidos. 2006. ISBN 0471223719.

DURÁN, J. Proyecto PICTO-2010-0087 "Interconexión de Sistemas Fotovoltaicos a la Red Eléctrica en Ambientes Urbanos". Universidad Nacional de San Martín (UNSAM). FONCYT. Proyectos de Investigación Científica y Tecnológica Orientados. Buenos Aires, Argentina. 2010.

EDWARDS, B. Green buildings pay. Spon Press. Londres, Inglaterra. 2003. ISBN 9780415262712.

EDWARDS, B. Guía básica de la sostenibilidad. Gustavo Gili, SL. Barcelona, España. 2008. ISBN 9788425222085.

FRANCO, J. et Al. Energía Solar II. Apuntes de clase. Maestría en Energías Renovables. Facultad de Ciencias Exactas. Universidad Nacional de Salta. Salta, Argentina. 2009.

FLORES LARSEN, S.; LESINO, G. Modelo térmico del programa SIMEDIF de simulación de edificios. INENCO, UNSA - CONICET. Avances en Energías Renovables y Medio Ambiente. Vol. 9, pp. 15 - 24. Argentina. 2001. ISSN 03295184.

GRAMMER SOLAR. Colectores solares de aire. Catálogo de productos y ejemplos de aplicación. Disponible en <http://www.grammer-solar.com/cms/es/airesolar.html>

GROSSI GALLEGOS H. Notas sobre radiación solar. Departamento de Ciencias Básicas. Universidad Nacional de Luján. Buenos Aires, Argentina. 2005. ISBN 9879285190.

GROSSI GALLEGOS, H.; RIGHINI, R. Atlas de energía solar de la República Argentina. Universidad Nacional de Luján. Secretaría de Ciencia y Tecnología. Buenos Aires, Argentina. 2007. ISBN 9789879285367. 
GROSSI GALLEGOS, H. et Al. VII Curso de aprovechamiento energético de la radiación solar. Apuntes de clase. Grupo de Estudios de la Radiación Solar (GERSolar). Instituto de Ecología y Desarrollo Sustentable (INEDES). División Física, Departamento de Ciencias Básicas. Universidad Nacional de Luján. Buenos Aires, Argentina. 2010.

IRAM. Norma 11.659-1. Aislamiento térmico de edificios. Verificación de sus condiciones higrotérmicas. Ahorro de energía en refrigeración. Parte 1: Vocabulario, definiciones, tablas y datos para determinar la carga térmica de refrigeración. Instituto Argentino de Normalización y Certificación. Buenos Aires, Argentina. 2004.

HAL, V. Microeconomía intermedia: un enfoque actual. Editorial Antoni Bosch. Barcelona, España 1999. ISBN 9788495348579.

HERNÁNDEZ, A. GEOSOL: Una herramienta computacional para el cálculo de coordenadas solares y la estimación de irradiación solar horaria. INENCO UNAS - CONICET. Avances en Energías Renovables y Medio Ambiente. Vol. 7, № 2. Argentina. 2003. ISSN 03295184.

HERNÁNDEZ, A. Calefacción solar pasiva. Energía Solar II. Apuntes de clase. Maestría en Energías renovables. Facultad de Ciencias Exactas. Universidad Nacional de Salta. Salta, Argentina. 2010.

HERNÁNDEZ, A. Método de pre-diseño térmico de edificios con aprovechamiento solar. Energía Solar II. Apuntes de clase. Maestría en Energías renovables. Facultad de Ciencias Exactas. Universidad Nacional de Salta. Salta, Argentina. 2010.

INCROPERA, F.; DE WITT, D. Fundamentos de transferencia de calor. School of Mechanical Engineering. Purdue University. Editorial Prentice Hall. México D.F., México. 1999. ISBN 9701701704.

JUANICÓ, L.E.; GONZALEZ, A.D. Savings on natural gas consumption by doubling thermal efficiencies of balanced-flue space heaters. Energy and Buildings. Volumen 40. Elsevier. 2008. (pp 1479-1486). ISSN 03787788.

KYOCERA. Paneles fotovoltaicos. Catálogo de productos y aplicaciones. Disponible en $<$ http://www.kyocerasolar.es/index/products.html>

LESINO, G. et Al. Energía Solar I. Apuntes de Clase. Maestría en Energías Renovables. Facultad de Ciencias Exactas. Universidad Nacional de Salta. Salta, Argentina. 2009.

MARTIN CHIVELET, N. ; FERNÁNDEZ SOLÁ, I. Integración de la energía solar fotovoltaica en edificios. Editorial Progensa - Promotora general de estudios S.A. Sevilla, España. 2011. ISBN 9788495693686.

MINISTERIO DE VIVIENDA. Real Decreto 314/2006. Aprobación del Código Técnico de la Edificación (CTE - España). Boletín Oficial del Estado. Madrid, España. 2006.

PASSAMAI, V. Termodinámica Básica. Universidad Nacional de Salta, Facultad de Ciencias Exactas. Salta, Argentina. 2009. ISBN 9875420182.

RHEEM. Calefones solares. Catálogo de productos y herramientas para el dimensionamiento de la instalación. Disponible en <http://www.rheem.com/products/solar_water_heating/>

SARAVIA, L. et Al. Energética General y Medioambiente. Apuntes de clase. Maestría en Energías Renovables. Facultad de Ciencias Exactas. Universidad Nacional de Salta. Salta, Argentina. 2009.

SECRETARÍA DE ESTADO DE ENERGÍA. Certificación eficiencia energética: Programa CALENER. Ministerio de Industria, Energía y Turismo. Gobierno de España. Disponible en 
<http://www.minetur.gob.es/energia/desarrollo/eficienciaenergetica/certificacionenergetica/progr amacalener/paginas/documentosreconocidos.aspx>

SERRANO LANZAROTE, B. Sostenibilidad en la arquitectura y los modelos urbanos. Apuntes de clase. Máster en Arquitectura Avanzada, Paisaje, Urbano y Diseño. Universidad Politécnica de Valencia. Valencia, España. 2011.

SOLARTRONIC. Módulos solares - energía. Catálogo de productos eléctricos solares 2010. Disponible en <http://www.solartronic.com/download/Catalogo_Solartronic.pdf> 


\section{ANEXO I \\ ENCUESTAS}

\subsection{Introducción}

En el siguiente Anexo se muestran los modelos de encuestas que se llevaron a cabo en los edificios de viviendas y oficinas auditados durante las respectivas campañas de medición que comprendieron los años 2009, 2010 y 2011.

Tal como se menciona en el Capítulo VI, con las encuestas pudieron obtenerse datos precisos acerca del e dificio ( año d e c onstrucción, u bicación, c aracterísticas c onstructivas, et c.), per o también datos relevantes de los ocupantes y de la percepción que estos tenían respecto del confort de las unidades funcionales. Se obtuvieron datos acerca de la composición del grupo que oc upaba I a un idad $f$ uncional a uditada, $f$ actor de oc upación $s$ egún $b$ andas hor arias (distinguiendo días hábiles y $f$ ines $d$ es emana), equipamiento d e $c$ alefacción, acondicionamiento térmico, equipamiento el éctrico y de i luminación ar tificial, movilidad de los ocupantes, há bitos de c alefacción, v entilación, i luminación, us o de a gua c aliente, etc. D el mismo modo s e ob tuvieron dat os r elacionados $\mathrm{c}$ on la o pinión de los us uarios r especto del comportamiento de la unidad funcional en invierno y verano, de la luminosidad, y del consumo anual de energía eléctrica y de gas natural, para lo cual se tomaron lecturas de las boletas de gas natural y energía eléctrica de cada una de las unidades auditadas. 


\subsection{Modelo de Encuesta para Edificios de Viviendas}

\section{A $\quad$ IDENTIFICACION}

\begin{tabular}{|l|l|l|}
\hline A.1 & Encuesta $\mathrm{N}^{\circ}$ & \\
\hline A.2 & Fecha & \\
\hline A.3 & Encuestador & \\
\hline A.4 & Respondente & \\
\hline A.5 & Razón de no respuesta & \\
\hline A.6 & Nombre y Apellido del Titular & \\
\hline
\end{tabular}

\section{\begin{tabular}{|l|l|l|l|l}
\hline B & LOCALIZACION \\
\hline
\end{tabular}}

\begin{tabular}{|l|l|l|}
\hline B.1 & Domicilio & \\
\hline B.2 & Localidad / C.P. & \\
\hline B.3 & Teléfono & \\
\cline { 2 - 3 }
\end{tabular}

\section{\begin{tabular}{|l|l}
\hline C & CARACTERISTICAS DE LA VIVIENDA \\
\hline
\end{tabular}}

\begin{tabular}{|l|l|l|}
\hline C.1 & Tipología & \\
\hline C.2 & Sup. cubierta interior $\left(\mathrm{m}^{2}\right)$ & \\
\hline C.3 & Año de construcción & \\
\hline C.4 & Año de cocupación & \\
\hline C.5 & ¿Amplió la vivienda? ¿Cuándo? & \\
\hline C.6 & Cant. de pisos del edificio & \\
\hline C.7 & Número de piso & \\
\hline C.8 & $\begin{array}{l}\text { Cantidad de habitaciones } \\
\text { (sin contar baño y cocina) }\end{array}$ & \\
\hline C.9 & Cant. de ocupantes & \\
\hline C.10 & Local de comercio (tipo) & \\
\hline C.11 & Local / taller de trabajo (tipo) & \\
\hline
\end{tabular}

\section{\begin{tabular}{|l|l}
\hline D & DATOS DE LOS COMPONENTES DEL HOGAR \\
\hline
\end{tabular}}

No incluir pensionistas; personal doméstico sin cama adentro; miembros de la familia que duerman menos de tres noches por semana en la vivienda (salvo que aporten la mayor parte del ingreso familiar o poseen un trabajo "itinerante"); miembros ausentes desde hace más de seis meses, o que fijaron o piensan fijar residencia en otra vivienda.

\begin{tabular}{|c|c|c|c|c|c|c|c|}
\hline \multirow[t]{3}{*}{$\mathrm{N}^{\circ}$} & \multirow{3}{*}{$\begin{array}{l}\text { PARENTESCO } \\
\begin{array}{l}\text { a. Relación con el jefe del } \\
\text { hogar }\end{array}\end{array}$} & \multirow{3}{*}{$\begin{array}{l}\text { SEXO } \\
\text { b. }\end{array}$} & \multirow{3}{*}{\begin{tabular}{|l} 
EDAD \\
c. Años \\
cumplidos
\end{tabular}} & \multicolumn{2}{|c|}{ EDUCACION FORMAL } & \multirow{2}{*}{\multicolumn{2}{|c|}{\begin{tabular}{|l} 
OCUPACION \\
f. Trabaja \\
\end{tabular}}} \\
\hline & & & & \multirow{2}{*}{$\begin{array}{l}\text { d. Nivel más alto } \\
\text { alcanzado }\end{array}$} & \multirow{2}{*}{$\begin{array}{l}\text { e. ¿Completó } \\
\text { ese nivel? }\end{array}$} & & \\
\hline & & & & & & $\mathrm{Si}$ & No \\
\hline 1 & & & & & & & \\
\hline 2 & & & & & & & \\
\hline 3 & & & & & & & \\
\hline 4 & & & & & & & \\
\hline 5 & & & & & & & \\
\hline 6 & & & & & & & \\
\hline 7 & & & & & & & \\
\hline 8 & & & & & & & \\
\hline & $\begin{array}{l}\text { 1. Jefe/a } \\
\text { 2. Cónyugue/pareja } \\
\text { 3. Hijo/hijastro/a } \\
\text { 4. Yerno/Nuera } \\
\text { 5. Hermano/a } \\
\text { 6. Nieto/a } \\
\text { 7. Cuñado/a } \\
\text { 8. Padre/madre/suegro/a } \\
\text { 9. Otro familiar } \\
\text { 10. Otro no familiar }\end{array}$ & $\begin{array}{l}\text { 1. Varón } \\
\text { 2. Mujer }\end{array}$ & & $\begin{array}{l}\text { 1. Jardín o preescolar } \\
\text { 2. EGB/Primario } \\
\text { 3. Polimodal/Secundario } \\
\text { 4. Terciario o superior } \\
\text { 5. Universitario } \\
\text { 6. Posgrado } \\
\text { 9. Otros }\end{array}$ & $\begin{array}{l}\text { 1. Si } \\
\text { 2. No }\end{array}$ & $\begin{array}{l}\text { 1. Informal } \\
\text { 2. Formal }\end{array}$ & $\begin{array}{l}\text { 1. Estudiante } \\
\text { 2. Jubilado/ } \\
\text { Pensionado } \\
\text { 3. Desocupado }\end{array}$ \\
\hline
\end{tabular}


Lunes a Viernes (cant. Personas)

\begin{tabular}{|l|l|l|l|l|l|l|l|l|l|l|l|l|l|l|l|l|l|l|l|l|l|l|l|l|l|l|l|l|}
\hline Horas del día & 1 & 2 & 3 & 4 & 5 & 6 & 7 & 8 & 9 & 10 & 11 & 12 & 13 & 14 & 15 & 16 & 17 & 18 & 19 & 20 & 21 & 22 & 23 & 24 \\
\hline E.1 & Comedor & & & & & & & & & & & & & & & & & & & & & & & & \\
\hline E.2 & Estar & & & & & & & & & & & & & & & & & & & & & & & & \\
\hline E.3 & Dormitorio 1 & & & & & & & & & & & & & & & & & & & & & & & & \\
\hline E.4 & Dormitorio 2 & & & & & & & & & & & & & & & & & & & & & & & & \\
\hline E.5 & Dormitorio 3 & & & & & & & & & & & & & & & & & & & & & & & & \\
\hline E.6 & Otro & & & & & & & & & & & & & & & & & & & & & & & & \\
\hline E.7 & Otro & & & & & & & & & & & & & & & & & & & & & & & \\
\hline E.8 & Otro \\
\hline
\end{tabular}

Sábados y Domingos (cant. Personas)

\begin{tabular}{|l|l|l|l|l|l|l|l|l|l|l|l|l|l|l|l|l|l|l|l|l|l|l|l|l|l|l|}
\hline Horas del día & 1 & 2 & 3 & 4 & 5 & 6 & 7 & 8 & 9 & 10 & 11 & 12 & 13 & 14 & 15 & 16 & 17 & 18 & 19 & 20 & 21 & 22 & 23 & 24 \\
\hline E.11 & Comedor & & & & & & & & & & & & & & & & & & & & & & & & \\
\hline E.12 & Estar & & & & & & & & & & & & & & & & & & & & & & & & \\
\hline E.13 & Dormitorio 1 & & & & & & & & & & & & & & & & & & & & & & & & \\
\hline E.14 & Dormitorio 2 & & & & & & & & & & & & & & & & & & & & & & & & \\
\hline E.15 & Dormitorio 3 & & & & & & & & & & & & & & & & & & & & & & & & \\
\hline E.16 & Otro & & & & & & & & & & & & & & & & & & & & & & & & \\
\hline E.17 & Otro & & & & & & & & & & & & & & & & & & & & & & & \\
\hline E.18 & Otro \\
\hline
\end{tabular}

EQUIPAMIENTO ENERGETICO

\section{\begin{tabular}{l|l}
\hline F & EQUIPAMIENTO DEL HOGAR: CALEFACCION \\
\hline
\end{tabular}}

\section{\begin{tabular}{|l|l|l}
\hline F.1 & GAS NATURAL \\
\hline
\end{tabular}}

\begin{tabular}{|c|c|c|c|c|c|c|}
\hline \multirow{2}{*}{ Tipo } & \multirow{2}{*}{ Cantidad } & \multirow{2}{*}{ Capacidad (cal) } & \multicolumn{3}{|c|}{ Hs/Día } & \multirow{2}{*}{ Mes/Año } \\
\hline & & & $\mathrm{Mx}$ & $\mathrm{Mn}$ & $\bar{P}$ & \\
\hline$a$ & & & & & & \\
\hline $\mathrm{b}$ & & & & & & \\
\hline c & & & & & & \\
\hline d & & & & & & \\
\hline
\end{tabular}

1. Infrarrojo s/tiraje// 2. Catalítica// 3. Tiro Nat.// 4: Tiro Bal.// 5. Con Termoregulador// 6. Cal. Central// 7. Otro

A. gas Natural// B. Gas Envasado

\begin{tabular}{|l|l|l}
\hline F.2 & ELECTRICO \\
\hline
\end{tabular}

\begin{tabular}{|l|l|l|l|l|l|}
\hline \multirow{2}{*}{ Tipo } & \multirow{2}{*}{ Cantidad } & \multirow{2}{*}{ Potencia (W) } & \multicolumn{2}{|c|}{ Hs/Día Mes/Año } \\
\cline { 4 - 5 } & & & Mx & \\
\hline a & & & & & \\
\hline b & & & & & \\
\hline c & & & & & \\
\hline d & & & & & \\
\hline
\end{tabular}

1. Calentador Eléctrico// 2. Estufa Eléctrica// 3. Caloventor Eléctrico// 4. Otro

\begin{tabular}{|l|l}
\hline $\mathbf{G}$ & EQUIPAMIENTO DE LAVADO DE ROPA \\
\hline
\end{tabular}

\begin{tabular}{|l|l|l|l|l|}
\hline Tipo & Cantidad & Potencia (W) & Hs/Día Inv & Mes/Año Ver \\
\hline G.1 & & & & \\
\hline G.2 & & & & \\
\hline
\end{tabular}

1. Lavarropas Automático// 2. Lavarropas Semiautomático// 3. Lavarropas Común// 4. Otro 


\section{\begin{tabular}{|l|l|}
\hline H & EQUIPAMIENTO DE COCCION \\
\hline
\end{tabular}}

\begin{tabular}{|l|l|l|l|}
\hline Tipo & Cantidad & Hs/Día Inv & Hs/Día Ver \\
\hline H.1 & & & \\
\hline H.2 & & & \\
\hline H.3 & & & \\
\hline H.4 & & & \\
\hline
\end{tabular}

1. Cocina 3 Hornallas// 2. Cocina 4 Hornallas// 3. Anafe// 4. Horno// 5. Cocina Economica (indicar combustible)

\section{\begin{tabular}{|l|l}
\hline I & EQUIPAMIENTO DE PRODUCCION DE FRIO \\
\hline
\end{tabular}}

\begin{tabular}{|l|l|l|l|}
\hline Tipo & Modelo & Cantidad & Potencia (W) \\
\hline 1.1 & & & \\
\hline 1.2 & & & \\
\hline 1.3 & & & \\
\hline 1.4 & & & \\
\hline
\end{tabular}

1. Heladera común// 2. Heladera con Freezer// 3. Freezer// 4. Otro

\section{\begin{tabular}{l|l}
$\mathrm{J}$ & ELECTRODOMESTICOS Y OTROS EQUIPAMIENTOS \\
\hline
\end{tabular}}

\begin{tabular}{|c|c|c|c|c|c|}
\hline Tipo & Modelo & Cantidad & Potencia (W) & Uso Inv. & Uso Ver. \\
\hline J.1 & Extractor o purif. & & & & \\
\hline $\mathrm{J} .2$ & Ventilador/Turbo & & & & \\
\hline J.3 & Vent. De techo & & & & \\
\hline \begin{tabular}{|l|}
$J .4$ \\
\end{tabular} & T.V. Color & & & & \\
\hline $\mathrm{J} .5$ & T.V. ByN & & & & \\
\hline J.6 & Video Casetera & & & & \\
\hline \begin{tabular}{|l|}
$J .7$ \\
\end{tabular} & Lustradora & & & & \\
\hline $\mathrm{J} .8$ & Aspiradora & & & & \\
\hline J.9 & Batidora & & & & \\
\hline \begin{tabular}{|l|}
$J .10$ \\
\end{tabular} & Luicuadora & & & & \\
\hline J.11 & Microprocesadora & & & & \\
\hline $\mathrm{J} .12$ & Secador de cabello & & & & \\
\hline J.13 & Plancha & & & & \\
\hline \begin{tabular}{|l|}
$J .14$ \\
\end{tabular} & Secarropas & & & & \\
\hline \begin{tabular}{|l}
.15 \\
\end{tabular} & Centrifugadora & & & & \\
\hline J.16 & Radio grabador & & & & \\
\hline \begin{tabular}{|l|}
$J .17$ \\
\end{tabular} & Equipo de audio & & & & \\
\hline $\mathrm{J} .18$ & Horno eléctrico & & & & \\
\hline J.19 & Microondas & & & & \\
\hline $\mathrm{J} .20$ & Lavavajilla & & & & \\
\hline J.21 & Tostadora & & & & \\
\hline $\mathrm{J} .22$ & Máq. de coser eléc. & & & & \\
\hline $\mathrm{J} .23$ & Computadora & & & & \\
\hline $\mathrm{J} .24$ & Cortadora de césp. & & & & \\
\hline $\mathrm{J} .25$ & Bombeador de ag. & & & & \\
\hline $\mathrm{J.26}$ & Motor Taller Dom. & & & & \\
\hline $\mathrm{J} .27$ & Grupo Electrógeno & & & & \\
\hline$J .28$ & Otro & & & & \\
\hline 5.29 & Otro & & & & \\
\hline J.30 & Otro & & & & \\
\hline J.31 & Otro & & & & \\
\hline J.32 & Otro & & & & \\
\hline J.33 & Otro & & & & \\
\hline J.34 & Otro & & & & \\
\hline J.35 & Otro & & & & \\
\hline$J .36$ & Otro & & & & \\
\hline J.37 & Otro & & & & \\
\hline J.38 & Otro & & & & \\
\hline
\end{tabular}




\section{\begin{tabular}{|l|l}
\hline$K$ & MOVILIDAD DEL GRUPO FAMILIAR \\
\hline
\end{tabular}}

\begin{tabular}{|l|l|}
\hline K.1 & VEHICULOS (de la familia y de trabajo) \\
\hline
\end{tabular}

\begin{tabular}{|r|l|l|l|l|l|}
\hline $\mathrm{N}^{\circ}$ & a. Tipo & b. Cantidad & c. Modelo & d. Combustible & e. Lts./semana \\
\hline 1 & & & & & \\
\hline 3 & & & & & \\
\hline 4 & & & & & \\
\hline
\end{tabular}

\begin{tabular}{|c|c|c|c|}
\hline $\begin{array}{l}\text { 1. Moto } \\
\text { 2. Automóvil } \\
\text { 3. Camioneta } \\
\text { 4. Bicicleta } \\
\text { 5. Otro }\end{array}$ & Indicar año & $\begin{array}{l}\text { 1. Nafta súper } \\
\text { 2. Nafta común } \\
\text { 3. Gas oil } \\
\text { 4. Otro }\end{array}$ & $\begin{array}{l}\text { Si el vehículo tiene } \\
\text { diferentes usos indicar } \\
\text { por separado }\end{array}$ \\
\hline
\end{tabular}

\begin{tabular}{|l|l|}
\hline K.2 & TRANSPORTE PUBLICO \\
\hline
\end{tabular}

\begin{tabular}{|r|l|l|l|l|l|}
\hline $\mathrm{N}^{\circ}$ & a. Tipo & b. Veces/día & c. Distancia a la parada & d. Viaje & e. Motivo \\
\hline 1 & & & & & \\
\hline 2 & & & & & \\
\hline 4 & & & & & \\
\hline
\end{tabular}

\begin{tabular}{|l|l|l|l|l|}
\hline 1. Colectivo & & & 1. Local & 1. Trabajo \\
2. Taxi & & 2. Interurbano & 2. Estudio \\
3. Larga Distancia & & 3ecreación \\
3. Remis & & & & \\
4. Ff.CC. & & & \\
5. Otro & & & \\
\hline
\end{tabular}

\section{\begin{tabular}{|l|l|}
\hline$L$ & HABITOS DE COCCION \\
\hline
\end{tabular}}

\begin{tabular}{|l|l|}
\hline L.1 & USO DE HORNALLAS \\
\hline
\end{tabular}

\begin{tabular}{|c|c|c|c|c|c|}
\hline & romidn & & & & \\
\hline & Comiaa & Cantidad & Tiempo & Cantidad & Tiempo \\
\hline$a$ & Desayuno & & & & \\
\hline $\mathrm{b}$ & Almuerzo & & & & \\
\hline c & Merienda & & & & \\
\hline d & Cena & & & & \\
\hline L.2. & ¿USA HOR & RA CALEFACC & & & \\
\hline$a$ & ¿Cuántas? & & & & \\
\hline $\mathrm{b}$ & ¿Cuánto ti & & & & \\
\hline L.3. & ¿CUANTAS & R SEMANA CC & MIDA HECHA? & & \\
\hline L. 4 & USO DEL H & & & & \\
\hline $\mathrm{a}$ & PARA COC & & & & \\
\hline a.1 & Cantidad & & & & \\
\hline a.2 & Tiempo & & & & \\
\hline $\mathrm{b}$ & PARA CALE & & & & \\
\hline b.1 & Cantidad & & & & \\
\hline b. 2 & Tiempo & & & & \\
\hline
\end{tabular}


\begin{tabular}{|l|l|l}
\hline M & HABITOS DE USO DE AGUA CALIENTE \\
\hline
\end{tabular}

\begin{tabular}{|l|l|l|}
\hline M.1 & BAÑOS DE INMERSION (Veces/ Semana/ Mes /Año) \\
\hline M.2 & LAVADOS DE ROPA CON AGUA CALIENTE \\
\hline a & Veces/ Semana & \\
\hline b & Meses/Año & \\
\hline c & Temperatura del agua & \\
\hline M.3 & LAVADOS DE PLATOS CON AGUA CALIENTE \\
\hline a & Veces/ Semana & \\
\hline b & Meses/ Año & \\
\hline c & Temperatura del agua & \\
\hline M.4 & OBSERVACIONES \\
\hline a & ¿Acostumbra lavar la ropa en lavaderos automáticos? \\
\hline
\end{tabular}

1. Agua Fría// 2. Agua Caliente de Calefón// 3. Agua Calentada por el Lavarropas

\section{\begin{tabular}{|l|l|l|}
\hline$N$ & HABITOS DE USO DE ELECTRICIDAD: ILUMINACION \\
\hline
\end{tabular}}

\begin{tabular}{|l|l|l|}
\hline N.1 & DURANTE EL DIA USA ILUMINACION PARA: \\
\hline
\end{tabular}

\begin{tabular}{|l|l|l|l|l|l|l|l|l|l|l|l|l|l|}
\hline a & Estar & & Baño & & Com. & & Estudio & & Trabajo & & Dorm. & & Otros \\
\hline
\end{tabular}

\begin{tabular}{|l|l}
\hline N.2 & ¿POR QUE USA LAMPARAS INCANDESCENTES/ FLUORESCENTES/ OTRAS? \\
\hline
\end{tabular}

\begin{tabular}{|l|l|l|l|l|l|l|l|l|l|}
\hline a & Estetica & & Costo del equip. & & Consumo eléct. & & Por Desconocimiento & & Otros \\
\hline
\end{tabular}

\begin{tabular}{|l|l|l|l}
\hline N.3 & CANTIDAD DE LAMPARAS \\
\hline
\end{tabular}

\begin{tabular}{|c|c|c|c|c|c|c|c|}
\hline & \multirow{2}{*}{ Ambiente } & \multicolumn{3}{|c|}{ Lámparas } & \multirow{2}{*}{ Potencia (W) } & \multirow{2}{*}{ Hs/ Día Inv. } & \multirow{2}{*}{ Hs/Día Ver. } \\
\hline & & Tipo & Cant. & Prende & & & \\
\hline$a$ & Living/Comedor & & & & & & \\
\hline $\mathrm{b}$ & Cocina & & & & & & \\
\hline C & Baño & & & & & & \\
\hline $\mathrm{d}$ & Dormitorio 1 & & & & & & \\
\hline $\mathrm{e}$ & Dormitorio 2 & & & & & & \\
\hline$f$ & Dormitorio 3 & & & & & & \\
\hline $\mathrm{g}$ & Otro & & & & & & \\
\hline h & Otro & & & & & & \\
\hline$i$ & Otro & & & & & & \\
\hline$j$ & Exterior & & & & & & \\
\hline
\end{tabular}

Tipo: A. Incandescente// B. Fluorescente// C. Bajo Consumo// D. Halógena// E. Dicroica// F. Otro (especificar)

\section{O OPINION: LUMINOSIDAD DE LA VIV. (Luz Natural)}

\begin{tabular}{|l|l|l|l|l|l|l|l|l|l|l|l|l|l|l|}
\hline 0.1 & Estar & & Cocina & & Com. & & Dorm. 1 & & Dorm. 2 & & Dorm. 3 & & Otro & \\
\hline
\end{tabular}

1. Muy Luminoso// 2. Más luminoso que oscuro// 3. Más oscuro que luminoso// 4. Muy oscuro 


\section{\begin{tabular}{|l|l|}
\hline P & OPINION: COMPORTAMIENTO DE LA VIV. EN INVIERNO \\
\hline
\end{tabular}}

\begin{tabular}{|c|c|c|c|c|}
\hline \multirow{2}{*}{$\begin{array}{l}\text { P.1 } \\
\mathrm{a}\end{array}$} & \multicolumn{4}{|c|}{ ¿PARA USTED LA VIVIENDA ES?: } \\
\hline & Muy fría & Más fría que calurosa & Más cálida que fría & Muy cálida \\
\hline$b$ & \multicolumn{4}{|c|}{ ¿Por qué le parece que es asi? } \\
\hline P.2 & \multicolumn{4}{|c|}{ ¿COLOCO BURLETES O PREOTECCION EN PUERTAS Y VENTANAS? } \\
\hline $\mathrm{a}$ & En todas & \multicolumn{2}{|c|}{ En algunas (¿cuántas?) } & En ninguna \\
\hline P.3 & \multicolumn{4}{|c|}{ ¿VENTILA LA VIVIENDA EN INVIERNO? } \\
\hline $\mathrm{a}$ & \multicolumn{4}{|l|}{ Indicar horario } \\
\hline P.4 & \multicolumn{4}{|c|}{ ¿ACOSTUMBRA DEJAR ABIERTA UNA VENTANA, BANDEROLA O VENTILUZ? } \\
\hline $\mathrm{a}$ & Siempre & Casi Siempre & A veces & Nunca \\
\hline P.5 & \multicolumn{4}{|c|}{ ¿A QUE HORA ENCIENDE Y APAGA LA CALEFACCION? } \\
\hline $\mathrm{a}$ & \multicolumn{4}{|l|}{ Indicar horario } \\
\hline P.6 & \multicolumn{4}{|c|}{ ¿ACOSTUMBRA DEJAR LA CALEFACCION ENCENDIDA DE NOCHE? } \\
\hline $\mathrm{a}$ & Siempre & A veces & No, por economía & No, por seguridad \\
\hline P.7 & \multicolumn{4}{|c|}{ ¿LA DEJA ENCENDIDA CUANDO SALE? } \\
\hline $\mathrm{a}$ & Siempre & A veces (¿cuántas?) & No, por economía & No, por seguridad \\
\hline
\end{tabular}

\section{Q OPINION: COMPORTAMIENTO DE LA VIV. EN VERANO}

\section{\begin{tabular}{|l|l}
\hline Q.1 & ¿PARA USTED LA VIVIENDA ES?: \\
\hline
\end{tabular}}

\begin{tabular}{|l|l|l|l|l|l|l|l|}
\hline $\mathrm{a}$ & Muy fresca & Más fresca que calurosa & & Más calurosa que fresca & & Muy calurosa & \\
\hline $\mathrm{b}$ & ¿Por qué le parece que es asi? & & & & \\
\hline
\end{tabular}

\begin{tabular}{l|l}
\hline Q.2 & ¿EN QUE EPOCA REFRIGERA LA VIVIENDA? \\
\hline
\end{tabular}

\begin{tabular}{|l|l|l|}
\hline a & Indicar meses \\
\hline
\end{tabular}

\begin{tabular}{|l|l}
\hline Q.3 & ¿ACOSTUMBRA VENTILAR CON ALGUN METODO NATURAL? \\
\hline
\end{tabular}

\begin{tabular}{|l|l|}
\hline $\mathrm{b}$ & Indicar método de refrescamiento natural \\
\hline
\end{tabular}

\begin{tabular}{|l|l}
\hline Q.4 & HORAS POR DIA QUE PRENDE LA REFRIGERACION \\
\hline
\end{tabular}

\begin{tabular}{l|l|l}
\hline a & Indicar horario \\
\hline
\end{tabular}

\begin{tabular}{|l|l|}
\hline Q.5 & ¿ACOSTUMBRA DEJARLA ENCENDIDA DE NOCHE? \\
\hline
\end{tabular}

\begin{tabular}{|l|l|l|l|l|l|l|l|l|}
\hline a & Siempre & & A veces & & No, por economía & & No, por seguridad & \\
\hline
\end{tabular}

\section{\begin{tabular}{|l|l|}
\hline$R$ & CONSUMO ANUAL DE COMBUSTIBLE \\
\hline
\end{tabular}}

\begin{tabular}{|l|l|}
\hline R.1 & ELECTRICIDAD \\
\hline
\end{tabular}

\begin{tabular}{|l|l|l}
\hline a & $N^{\circ}$ de Usuario \\
\hline$b$
\end{tabular}

\begin{tabular}{|l|c|c|c|c|c|c|c|c|c|c|c|c|c|c|}
\hline b & Bim. 1 & $\$$ & Bim. 2 & $\$$ & Bim. 3 & $\$$ & Bim. 4 & $\$$ & Bim. 5 & $\$$ & Bim. 6 & \$ & TOTAL & $\$$ \\
\hline b.1 & & & & & & & & & & & & & & \\
\hline
\end{tabular}

\begin{tabular}{|l|l}
\hline R.2 & GAS NATURAL \\
\hline
\end{tabular}

\begin{tabular}{|l|l|}
\hline a & $N^{\circ}$ de Usuario \\
\hline
\end{tabular}

\begin{tabular}{|l|c|c|c|c|c|c|c|c|c|c|c|c|c|c|}
\hline b & Bim. 1 & $\$$ & Bim. 2 & $\$$ & Bim. 3 & $\$$ & Bim. 4 & $\$$ & Bim. 5 & $\$$ & Bim. 6 & \$ & TOTAL & $\$$ \\
\hline b.1 & & & & & & & & & & & & & & \\
\hline
\end{tabular}

1. Gas Env. 10Kg.// 2. Gas Env. 15Kg.// 3. Gas Env. 45Kg.// 4. Kerosene// 5. Fuel oil// 6. Alcohol// 7. Leña

8. Carbón// 9. Otro 


\section{\begin{tabular}{|l|l|}
\hline$S$ & PLANTA ESQUEMATICA DE LA VIVIENDA (Escala 1:100) \\
\hline
\end{tabular}}

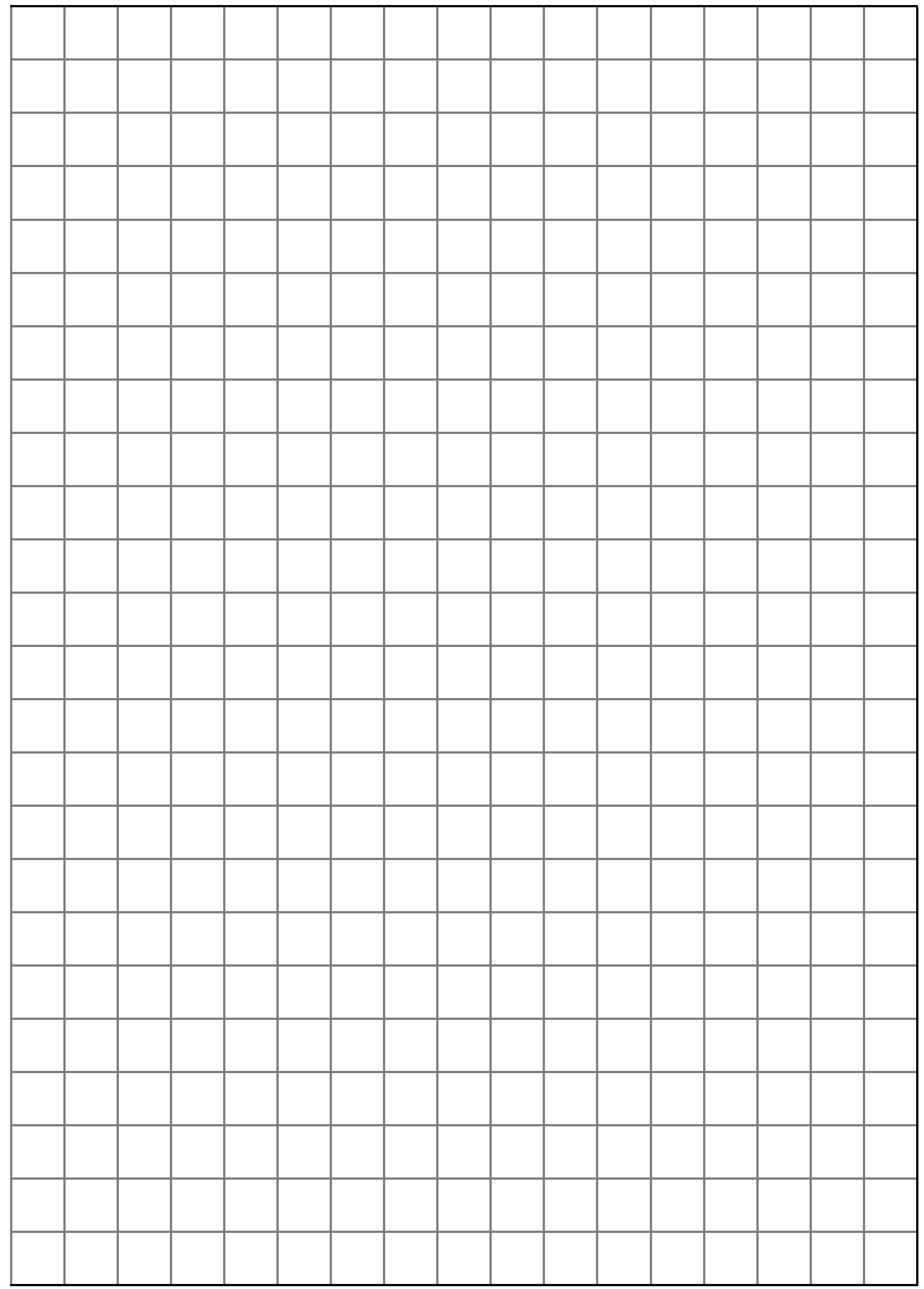

\begin{tabular}{l|l}
\hline S.1 & OBSERVACIONES \\
\hline
\end{tabular}

Encuesta PICT_06 / 956 - LAyHS - FAU - UNLP / CONICET 


\section{\begin{tabular}{|l|l}
\hline$T$ & CARACTERISTICAS CONSTRUCTIVAS \\
\hline
\end{tabular}}

\begin{tabular}{|l|l}
\hline T.1 & CUBIERTAS (materiales constructivos) \\
\hline
\end{tabular}

\begin{tabular}{|c|c|c|c|}
\hline $\mathrm{a}$ & Tejas/ Aisl. Térm./ Ent. Mad. a la vista & TI & Idem j/ Terminación aluminio \\
\hline $\mathrm{b}$ & Tejas/Ent. Mad./ Cielorraso suspendido & $\mathrm{m}$ & Idem j/ Terminación azotea \\
\hline c & Tejas/ Ent. Mad./ Aisl. Térm./ Ciel. Susp. & n & Losa ceràmica idem j \\
\hline d & Chapa metálica (idem a) & o & Losa ceràmica idem $\mathrm{k}$ \\
\hline $\mathrm{e}$ & Chapa metálica (idem b) & $p$ & Losa ceràmica idem I \\
\hline$f$ & Chapa metálica (idem c) & q & Losa ceràmica idem $\mathrm{m}$ \\
\hline g & Chapa metálica/ Cielorraso susp. & $\mathrm{r}$ & Chapa metàlica/ Aisl. Tèrm./ Chapadur \\
\hline $\mathrm{h}$ & Asbesto cemento autoportante visto & $\mathrm{s}$ & Entrepiso de madera machiembrada \\
\hline $\mathrm{i}$ & Idem 9/ Cielorraso suspendido & $\mathrm{t}$ & Losa cerámica/ Atico/ Chapa \\
\hline j & Losa $\mathrm{H}^{\circ} \mathrm{A}^{\circ} /$ Contr. $\mathrm{H}^{\circ} \mathrm{P} /$ Terminación negro & u & Otros (especificar) \\
\hline $\mathrm{k}$ & Idem j/ Terminaciòn blanco & $\mathrm{v}$ & Otros (especificar) \\
\hline
\end{tabular}

\begin{tabular}{l|l}
\hline T.2 & MUROS EXTERIORES (materiales constructivos) \\
\hline
\end{tabular}

\begin{tabular}{|c|c|c|c|}
\hline$a$ & Lad. Com./ 15cm./ Rev. Ambas caras & $f$ & Idem d/ Espesor $24 \mathrm{~cm}$. \\
\hline $\mathrm{b}$ & Idem a/ Espesor $20 \mathrm{~cm}$. & $g$ & Bloque Ho/ Rev. Ambas caras \\
\hline C & Idem a/ Espesor $30 \mathrm{~cm}$. & $h$ & Bloque $\mathrm{H}$ o sin revocar \\
\hline$d$ & Lad. Cer. Hueco/ 15cm./ Term. Idem a & i & Lad. Hueco/ Esp. 10cm/ Rev. Ambas caras \\
\hline e & Idem d/ Espesor $21 \mathrm{~cm}$. & j & Otros (especificar) \\
\hline
\end{tabular}

\begin{tabular}{l|l}
\hline T.3 & SOLADOS (materiales constructivos) \\
\hline
\end{tabular}

\begin{tabular}{|l|l|l|l|l|}
\hline a & Sin cám. de aire (baldosas, contr., T.N.) & & b & Con cám. De aire ( mach., aire, T.N.) \\
\hline
\end{tabular}

\begin{tabular}{|l|l|l|l|}
\hline T.4 & CALIDAD DE EDIFICACION \\
\hline
\end{tabular}

\begin{tabular}{|l|l|l|l|}
\hline $\mathrm{a}$ & Opinión del Usuario & $\mathrm{b}$ & Opiniòn del encuestador \\
\hline
\end{tabular}

1. Lujosa// 2. Muy Buena// 3. Buena// 4. Económica

\begin{tabular}{|l|l}
\hline T.5 & MUROS EXTERIORES (materiales constructivos) \\
\hline
\end{tabular}

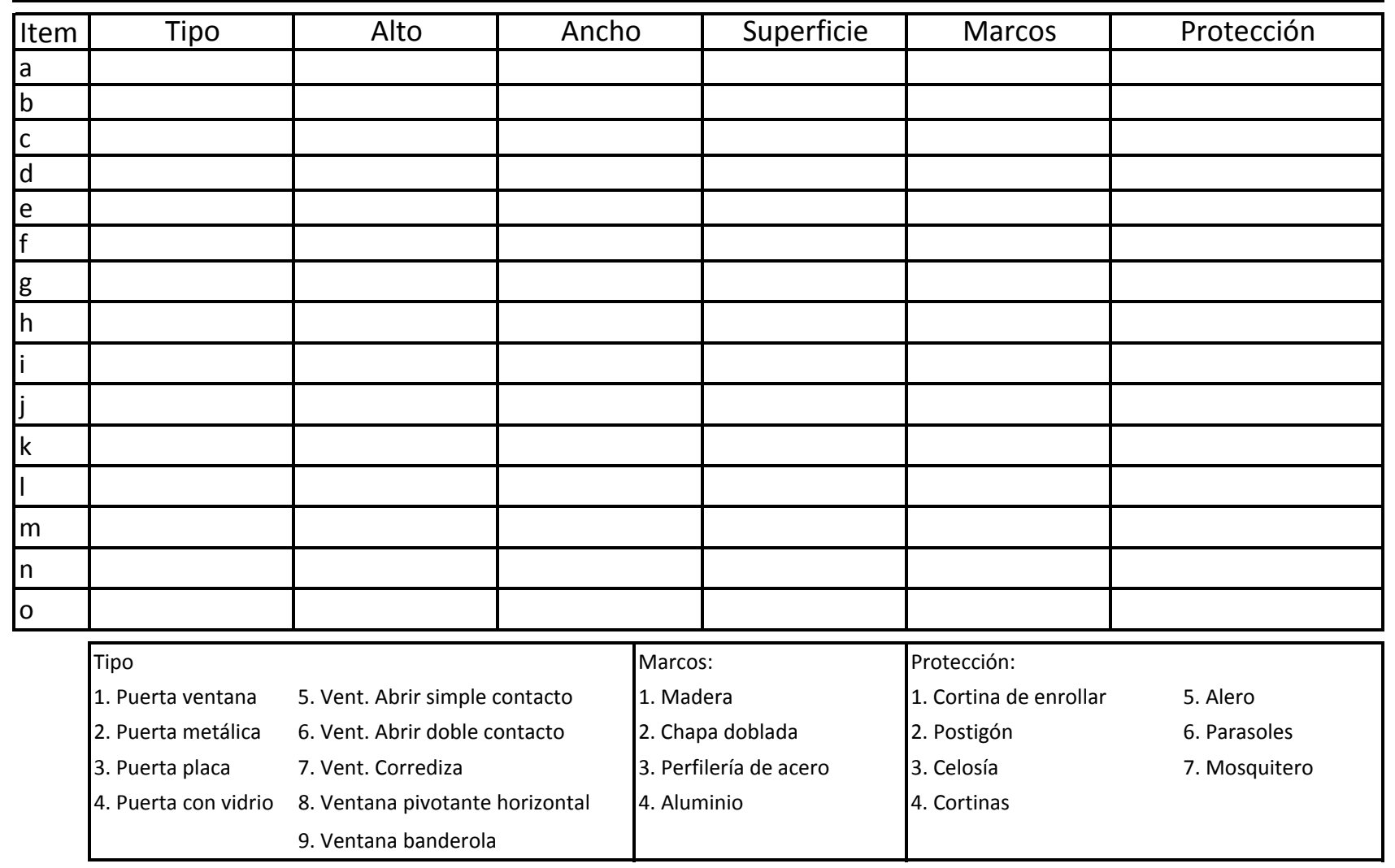




\section{\begin{tabular}{|l|l|}
\hline $\mathrm{U}$ & REGISTRO DE MEDICIONES \\
\hline
\end{tabular}}

\begin{tabular}{|l|l|l|l|l|l|}
\hline U.1 & ENCUESTA & \\
\hline $\mathrm{a}$ & Encuesta № & c & Tipología & \\
\hline $\mathrm{b}$ & Auditor & e & Dirección & \\
\hline $\mathrm{d}$ & Nombre & g & Localidad & \\
\hline $\mathrm{f}$ & Teléfono & & & \\
\hline
\end{tabular}

\begin{tabular}{|l|l|}
\hline U.2 & CONSUMO DE ENERGIA \\
\hline
\end{tabular}

\begin{tabular}{|l|l|}
\hline a & ELECTRICIDAD \\
\hline
\end{tabular}

\begin{tabular}{|l|c|c|c|c|}
\hline Consumo & Día & Hora & Registro & Observaciones / № de Medidor \\
\hline Inicial & & & & \\
\hline Final & & & & \\
\hline b & & & \\
\hline
\end{tabular}

\begin{tabular}{|l|l}
\hline $\mathrm{b}$ & GAS NATURAL \\
\hline
\end{tabular}

\begin{tabular}{|l|l|l|l|l|l|l|l|}
\hline Consumo & \multicolumn{3}{|c|}{ Día } & \multicolumn{2}{c|}{ Hora } & Registro & Observaciones / № de Medidor \\
\hline Inicial & & & & & & & \\
\hline Final & & & & & & & \\
\hline
\end{tabular}

\begin{tabular}{|l|l|}
\hline U.3 & HOBOS \\
\hline
\end{tabular}

\begin{tabular}{|l|l|l|l|l|l|l|}
\hline Nombre & Ubicación & Período & Archivo (*.dtf) & Mínima & Máxima & Media \\
\hline & & & & & & \\
\hline & & & & & & \\
\hline \\
\hline
\end{tabular}

\begin{tabular}{|l|l|}
\hline U.4 & OBSERVACIONES \\
& \\
& \\
\hline
\end{tabular}




\subsection{Modelo de encuesta para edificios de oficinas}

\section{\begin{tabular}{|l|l|}
\hline A & IDENTIFICACION \\
\hline
\end{tabular}}

\begin{tabular}{|l|l|l|}
\hline A.1 & Encuesta $\mathrm{N}^{\circ}$ & \\
\hline A.2 & Fecha & \\
\hline A.3 & Encuestador & \\
\hline A.4 & Respondente & \\
\hline A.5 & Razón de no respuesta & \\
\hline A.6 & Nombre y Apellido del Jefe & \\
\hline
\end{tabular}

\section{\begin{tabular}{|l|l|}
\hline$B$ & LOCALIZACION \\
\hline
\end{tabular}}

\begin{tabular}{|l|l|l|}
\hline B.1 & Domicilio & \\
\hline B.2 & Localidad / C.P. & \\
\hline B.3 & Teléfono & \\
\cline { 2 - 3 }
\end{tabular}

\section{\begin{tabular}{|l|l}
\hline$C$ & CARACTERISTICAS DE LA OFICINA \\
\hline
\end{tabular}}

\begin{tabular}{|l|l|l|}
\hline C.1 & Tipología & \\
\hline C.2 & Sup. cubierta interior $\left(\mathrm{m}^{2}\right)$ & \\
\hline C.3 & Año de construcción & \\
\hline C.4 & Año de cocupación & \\
\hline C.5 & ¿Amplió la oficina? ¿Cuándo? & \\
\hline C.6 & Cant. de pisos del edificio & \\
\hline C.7 & Número de piso & \\
\hline C.8 & $\begin{array}{l}\text { Cantidad de ambientes } \\
\text { (sin contar baño y office) }\end{array}$ & \\
\hline C.9 & Cant. de ocupantes & \\
\hline
\end{tabular}

\section{\begin{tabular}{|l|l}
\hline$D$ & DATOS DE LOS COMPONENTES DE LA OFICINA
\end{tabular}}

\begin{tabular}{|c|c|c|c|c|c|}
\hline $\mathrm{N}^{\circ}$ & CARGO & SEXO & EDAD & EDUCACION FORMAL & \\
\hline & a. & b. & c. Años cumplidos & d. Nivel más alto alcanzado & $\begin{array}{l}\text { e. ¿Completó ese } \\
\text { nivel? }\end{array}$ \\
\hline & & & & & \\
\hline & & & & & \\
\hline & & & & & \\
\hline & & & & & \\
\hline & & & & & \\
\hline & & & & & \\
\hline & & & & & \\
\hline & & & & & \\
\hline & \begin{tabular}{|l|} 
1. Jefe/a \\
2. Empleado \\
3. Secretario \\
4. Encargado \\
5. Otro
\end{tabular} & $\begin{array}{l}\text { 1. Varón } \\
\text { 2. Mujer }\end{array}$ & & \begin{tabular}{|l} 
1. EGB/Primario \\
2. Polimodal/Secundario \\
3. Terciario o superior \\
4. Universitario \\
5. Posgrado \\
6. Otros
\end{tabular} & $\begin{array}{l}\text { 1. Si } \\
\text { 2. No }\end{array}$ \\
\hline
\end{tabular}


Lunes a Viernes (cant. Personas)

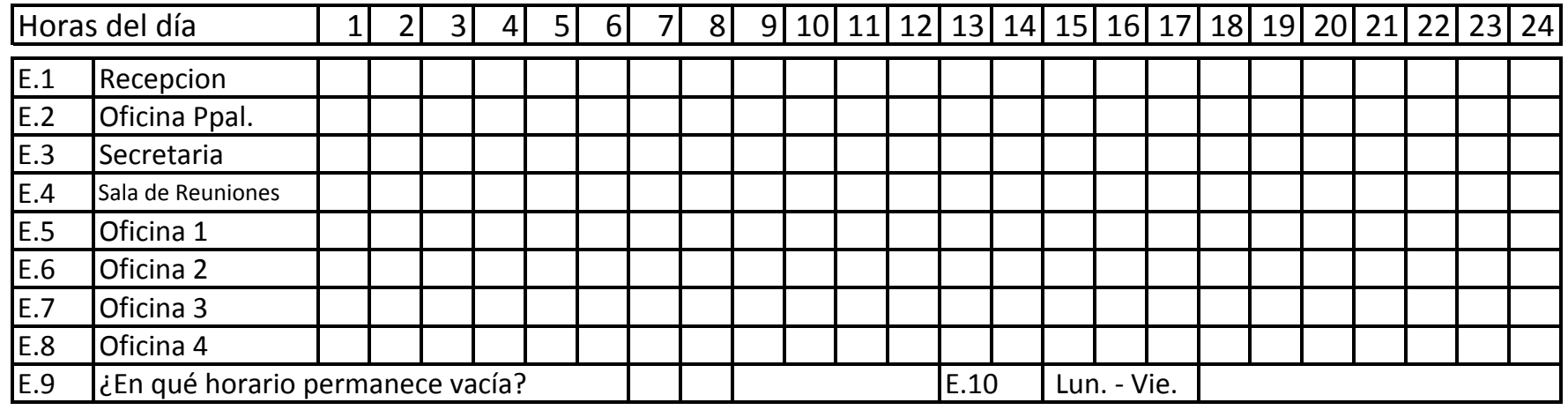

Sábados (cant. Personas)

\begin{tabular}{|l|l|l|l|l|l|l|l|l|l|l|l|l|l|l|l|l|l|l|l|l|l|l|l|l|}
\hline Horas del día & 1 & 2 & 3 & 4 & 5 & 6 & 7 & 8 & 9 & 10 & 11 & 12 & 13 & 14 & 15 & 16 & 17 & 18 & 19 & 20 & 21 & 22 & 23 & 24 \\
\hline
\end{tabular}

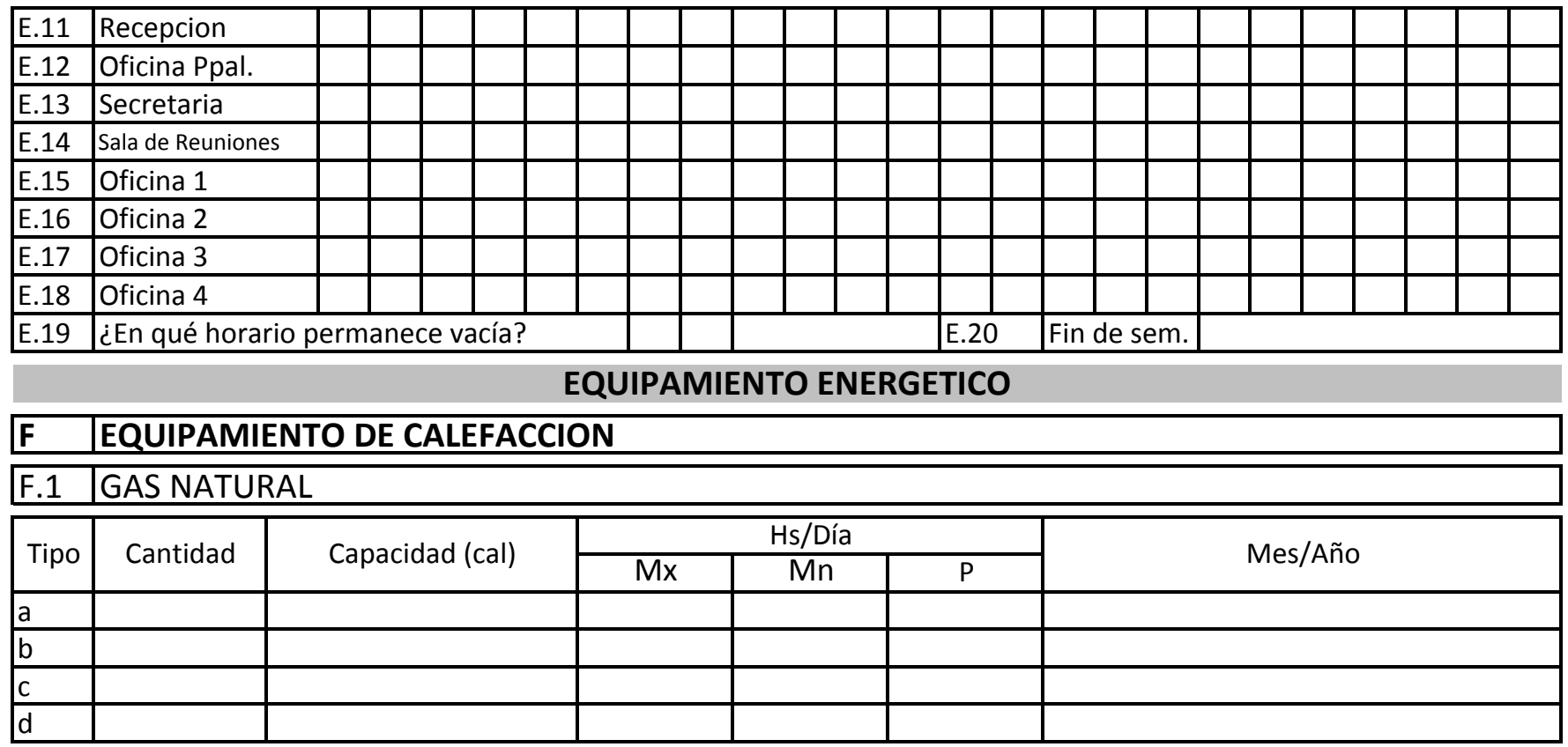

1. Infrarrojo s/tiraje// 2. Catalítica// 3. Tiro Nat.// 4: Tiro Bal.// 5. Con Termoregulador// 6. Cal. Central// 7. Otro

\section{\begin{tabular}{|l|l|}
\hline F.2 & ELECTRICO \\
\hline
\end{tabular}}

\begin{tabular}{|l|l|l|l|l|l|}
\hline \multirow{2}{*}{ Tipo } & \multirow{2}{*}{ Cantidad } & \multirow{2}{*}{ Potencia (W) } & \multicolumn{2}{|c|}{ Hs/Día Mes/Año } \\
\cline { 4 - 5 } & & & Mx & & \\
\hline a & & & & & \\
\hline b & & & & & \\
\hline c & & & & & \\
\hline d & & & & & \\
\hline
\end{tabular}

1. Calentador Eléctrico// 2. Estufa Eléctrica// 3. Caloventor Eléctrico// 4. Otro 


\section{\begin{tabular}{|l|l|}
\hline G & EQUIPAMIENTO DE COCCION \\
\hline
\end{tabular}}

\begin{tabular}{|l|l|l|l|}
\hline Tipo & Cantidad & Hs/Día Inv & Hs/Día Ver \\
\hline G.1 & & & \\
\hline G.2 & & & \\
\hline G.3 & & & \\
\hline G.4 & & & \\
\hline
\end{tabular}

1. Cocina 3 Hornallas// 2. Cocina 4 Hornallas// 3. Anafe

\section{\begin{tabular}{|l|l}
\hline $\mathrm{H}$ & EQUIPAMIENTO DE PRODUCCION DE FRIO \\
\hline
\end{tabular}}

\begin{tabular}{|l|l|l|l|}
\hline Tipo & Modelo & Cantidad & Potencia (W) \\
\hline H.1 & & & \\
\hline H.2 & & & \\
\hline H.3 & & & \\
\hline H.4 & & & \\
\hline
\end{tabular}

1. Heladera común// 2. Heladera con Freezer

\section{\begin{tabular}{|l|l|}
\hline$I$ & OTROS EQUIPAMIENTOS \\
\hline
\end{tabular}}

\begin{tabular}{|c|c|c|c|c|c|}
\hline Tipo & Modelo & Cantidad & Potencia (W) & Uso Inv. & Uso Ver. \\
\hline 1.1 & Aire Acondicionado & & & & \\
\hline 1.2 & Aspiradora & & & & \\
\hline 1.3 & Cafetera & & & & \\
\hline 1.4 & PC Escritorio & & & & \\
\hline 1.5 & Notebook & & & & \\
\hline 1.6 & Equipo de Audio & & & & \\
\hline 1.7 & Fotocopiadora & & & & \\
\hline 1.8 & Horno Electrico & & & & \\
\hline 1.9 & Impresora tinta & & & & \\
\hline 1.10 & Impresora laser & & & & \\
\hline 1.11 & Proyector & & & & \\
\hline 1.12 & Ventilador Turbo & & & & \\
\hline 1.13 & Ventilador Techo & & & & \\
\hline 1.14 & Otro & & & & \\
\hline 1.15 & Otro & & & & \\
\hline I.16 & Otro & & & & \\
\hline I.17 & Otro & & & & \\
\hline I.18 & Otro & & & & \\
\hline 1.19 & Otro & & & & \\
\hline 1.20 & Otro & & & & \\
\hline 1.21 & Otro & & & & \\
\hline 1.22 & Otro & & & & \\
\hline 1.23 & Otro & & & & \\
\hline 1.24 & Otro & & & & \\
\hline 1.25 & Otro & & & & \\
\hline 1.26 & Otro & & & & \\
\hline 1.27 & Otro & & & & \\
\hline 1.28 & Otro & & & & \\
\hline 1.29 & Otro & & & & \\
\hline 1.30 & Otro & & & & \\
\hline 1.31 & Otro & & & & \\
\hline 1.32 & Otro & & & & \\
\hline 1.33 & Otro & & & & \\
\hline 1.34 & Otro & & & & \\
\hline 1.35 & Otro & & & & \\
\hline 1.36 & Otro & & & & \\
\hline
\end{tabular}




\section{\begin{tabular}{|l|l|}
\hline $\mathrm{J}$ & MOVILIDAD \\
\hline
\end{tabular}}

\begin{tabular}{|l|l|l|}
\hline$J .1$ & VEHICULOS \\
\hline
\end{tabular}

\begin{tabular}{|c|c|c|c|c|c|}
\hline $\mathrm{N}^{\circ}$ & a. Tipo & b. Cantidad & c. Modelo & d. Combustible & e. Lts./semana \\
\hline 1 & & & & & \\
\hline 2 & & & & & \\
\hline 3 & & & & & \\
\hline 4 & & & & & \\
\hline & $\begin{array}{l}\text { 1. Moto } \\
\text { 2. Automóvil } \\
\text { 3. Camioneta } \\
\text { 4. Bicicleta } \\
\text { 5. Otro }\end{array}$ & & Indicar año & $\begin{array}{l}\text { 1. Nafta súper } \\
\text { 2. Nafta común } \\
\text { 3. Gas oil } \\
\text { 4. Otro }\end{array}$ & \\
\hline
\end{tabular}

\begin{tabular}{|l|l|}
\hline J.2 & TRANSPORTE PUBLICO \\
\hline
\end{tabular}

\begin{tabular}{|r|l|l|l|l|}
\hline $\mathrm{N}^{\circ}$ & a. Tipo & b. Veces/día & c. Distancia a la parada & d. Viaje \\
\hline 1 & & & & \\
\hline 2 & & & & \\
\hline 3 & & & & \\
\hline 4 & & & & \\
\hline
\end{tabular}

\begin{tabular}{|l|l|l|l|}
\hline 1. Colectivo & & & 1. Local \\
2. Taxi & & & 2. Interurbano \\
3. Remisse & & & 3. Larga Distancia \\
4. F.CC. & & \\
5. Otro & & \\
\hline
\end{tabular}

\section{\begin{tabular}{|l|l}
\hline$K$ & USO DE HORNALLAS \\
\hline
\end{tabular}}

\begin{tabular}{|l|l|l|l|}
\hline K.1 & COCCION \\
\hline
\end{tabular}

\begin{tabular}{|c|c|c|c|c|c|}
\hline & \multirow{2}{*}{ Comida } & \multicolumn{2}{|c|}{ Lunes a viernes } & \multicolumn{2}{|c|}{ Fines de Semana } \\
\hline & & Cantidad & Tiempo & Cantidad & Tiempo \\
\hline $\mathrm{a}$ & Desayuno & & & & \\
\hline $\mathrm{b}$ & Almuerzo & & & & \\
\hline c & Merienda & & & & \\
\hline K.2 & \multicolumn{5}{|c|}{ ¿USA HORNALLAS PARA CALEFACCION? } \\
\hline$a$ & \multicolumn{3}{|l|}{ ¿Cuántas? } & & \\
\hline $\mathrm{b}$ & \multicolumn{3}{|l|}{ ¿Cuánto tiempo? } & & \\
\hline K.3 & \multicolumn{5}{|c|}{ ¿CUANTAS VECES POR SEMANA CONSUME COMIDA HECHA? } \\
\hline
\end{tabular}




\section{\begin{tabular}{|l|l|l|l}
\hline L & HABITOS DE USO DE AGUA CALIENTE \\
\hline
\end{tabular}}

\begin{tabular}{|l|l}
\hline L.3 & LAVADOS DE VAJILLA CON AGUA CALIENTE \\
\hline
\end{tabular}

\begin{tabular}{|l|l|l|}
\hline $\mathrm{a}$ & Veces/ Semana & \\
\hline $\mathrm{b}$ & Meses/Año & \\
\hline $\mathrm{c}$ & Temperatura del agua & \\
\hline
\end{tabular}

1. Agua Fría// 2. Agua Caliente Termotanque Eléctrico// 3. Agua Caliente Termotanque a Gas

\section{\begin{tabular}{|l|l}
\hline$M$ & HABITOS DE USO DE ELECTRICIDAD: ILUMINACION \\
\hline
\end{tabular}}

\begin{tabular}{|l|l}
\hline M.1 & DURANTE EL DIA USA ILUMINACION PARA: \\
\hline
\end{tabular}

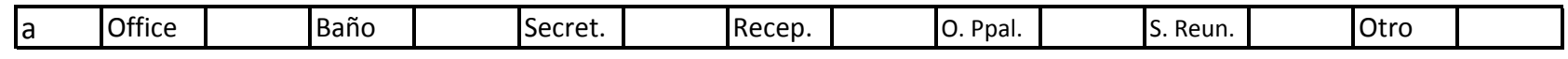

\begin{tabular}{|l|l}
\hline M.2 & ¿POR QUE USA LAMPARAS INCANDESCENTES/ FLUORESCENTES/ OTRAS? \\
\hline
\end{tabular}

\begin{tabular}{|c|c|}
\hline$a$ & $T_{E S}$ \\
\hline
\end{tabular}

\section{\begin{tabular}{|l|l|}
\hline M.3 & CANTIDAD DE LAMPARAS \\
\hline
\end{tabular}}

\begin{tabular}{|l|l|l|l|l|l|l|l|}
\hline \multirow{2}{*}{ Ambiente } & \multicolumn{3}{|c|}{ Lámparas } & Potencia (W) & Hs/ Día Inv. & Hs/Día Ver. \\
\hline & Tipo & Cant. & Prende & & \\
\hline a & Office & & & & & & \\
\hline b & Baño & & & & & & \\
\hline c & Secretaria & & & & & & \\
\hline d & Recepción & & & & & & \\
\hline e & O. Ppal. & & & & & & \\
\hline$f$ & S. Reuniones & & & & & & \\
\hline g & Otro & & & & & & \\
\hline h & Otro & & & & & & \\
\hline i & Otro & & & & & & \\
\hline$j$ & Otro & & & & & & \\
\hline
\end{tabular}

Tipo: A. Incandescente// B. Fluorescente// C. Bajo Consumo// D. Halógena// E. Dicroica// F. Otro (especificar)

\section{\begin{tabular}{|l|l|l}
$\mathrm{N}$ & OPINION: LUMINOSIDAD DE LA OFICINA (Luz Natural) \\
\hline
\end{tabular}}

\begin{tabular}{|c|c|c|c|c|c|c|c|}
\hline \multicolumn{2}{|r|}{ Office } & Baño & Secret. & Recep. & o. Ppal. & S. Reun. & Otro \\
\hline
\end{tabular}

1. Muy Luminoso// 2. Más luminoso que oscuro// 3. Más oscuro que luminoso// 4. Muy oscuro 


\section{O OPINION: COMPORTAMIENTO DE LA OFICINA EN INVIERNO}

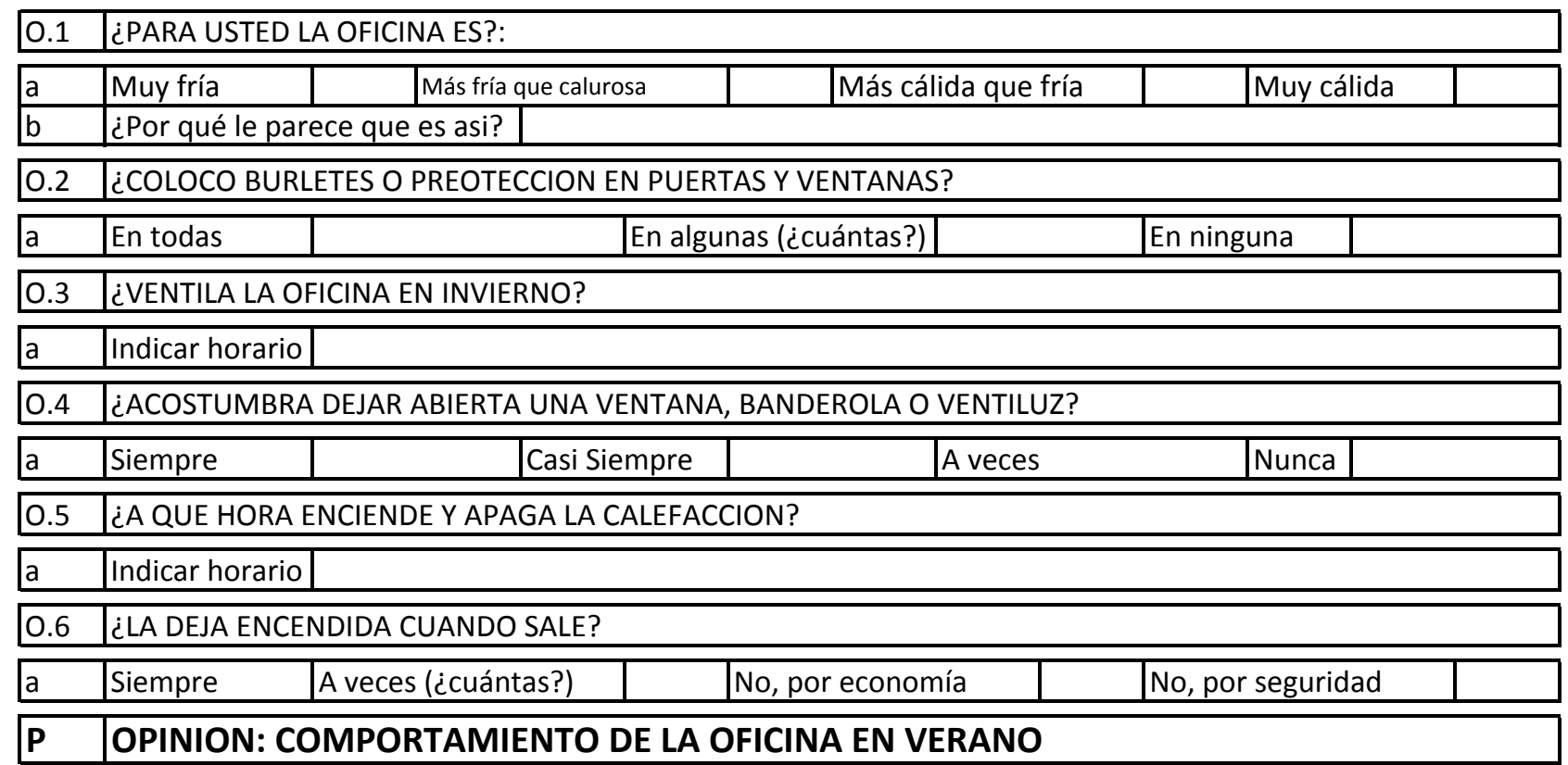

\begin{tabular}{|l|l|l}
\hline P.1 & ¿PARA USTED LA OFICINA ES?: \\
\hline
\end{tabular}

\begin{tabular}{|l|l|l|l|l|l|l|}
\hline $\mathrm{a}$ & Muy fresca & Más fresca que calurosa & Más calurosa que fresca & & Muy calurosa & \\
\hline $\mathrm{b}$ & ¿Por qué le parece que es asi? & & & \\
\hline
\end{tabular}

\begin{tabular}{|l|l}
\hline P.2 & ¿EN QUE EPOCA REFRIGERA LA OFICINA? \\
\hline
\end{tabular}

\begin{tabular}{|l|l|l|}
\hline a & Indicar meses \\
\hline
\end{tabular}

\begin{tabular}{|l|l}
\hline P.3 & ¿ACOSTUMBRA VENTILAR CON ALGUN METODO NATURAL? \\
\hline
\end{tabular}

\begin{tabular}{|l|l|l|}
\hline $\mathrm{b}$ & Indicar método de refrescamiento natural \\
\hline
\end{tabular}

\begin{tabular}{|l|l|}
\hline P.4 & HORAS POR DIA QUE PRENDE LA REFRIGERACION \\
\hline
\end{tabular}

\begin{tabular}{l|l|l}
\hline a & Indicar horario \\
\hline
\end{tabular}

Q CONSUMO ANUAL DE COMBUSTIBLE

\begin{tabular}{|l|l|l|l|l|l|l|l|}
\hline Q.1 & \multicolumn{1}{|l|}{ ELECTRICIDAD } \\
\hline a & \multicolumn{2}{|l|}{$\mathrm{N}^{\circ}$ de Usuario } & & \\
\hline b & Bimestre 1 & Bimestre 2 & Bimestre 3 & Bimestre 4 & Bimestre 5 & Bimestre 6 & TOTAL \\
\hline b.1 & & & & & & & \\
\hline Q.2 & GAS NATURAL & & & & \\
\hline a & $N^{\circ}$ de Usuario & & & & & \\
\hline b & Bimestre 1 & Bimestre 2 & Bimestre 3 & Bimestre 4 & Bimestre 5 & Bimestre 6 & TOTAL \\
\hline b.1 & & & & & & & \\
\hline
\end{tabular}


\begin{tabular}{|l|l|}
\hline$R$ & PLANTA ESQUEMATICA DE LA OFICINA (Escala 1:100) \\
\hline
\end{tabular}

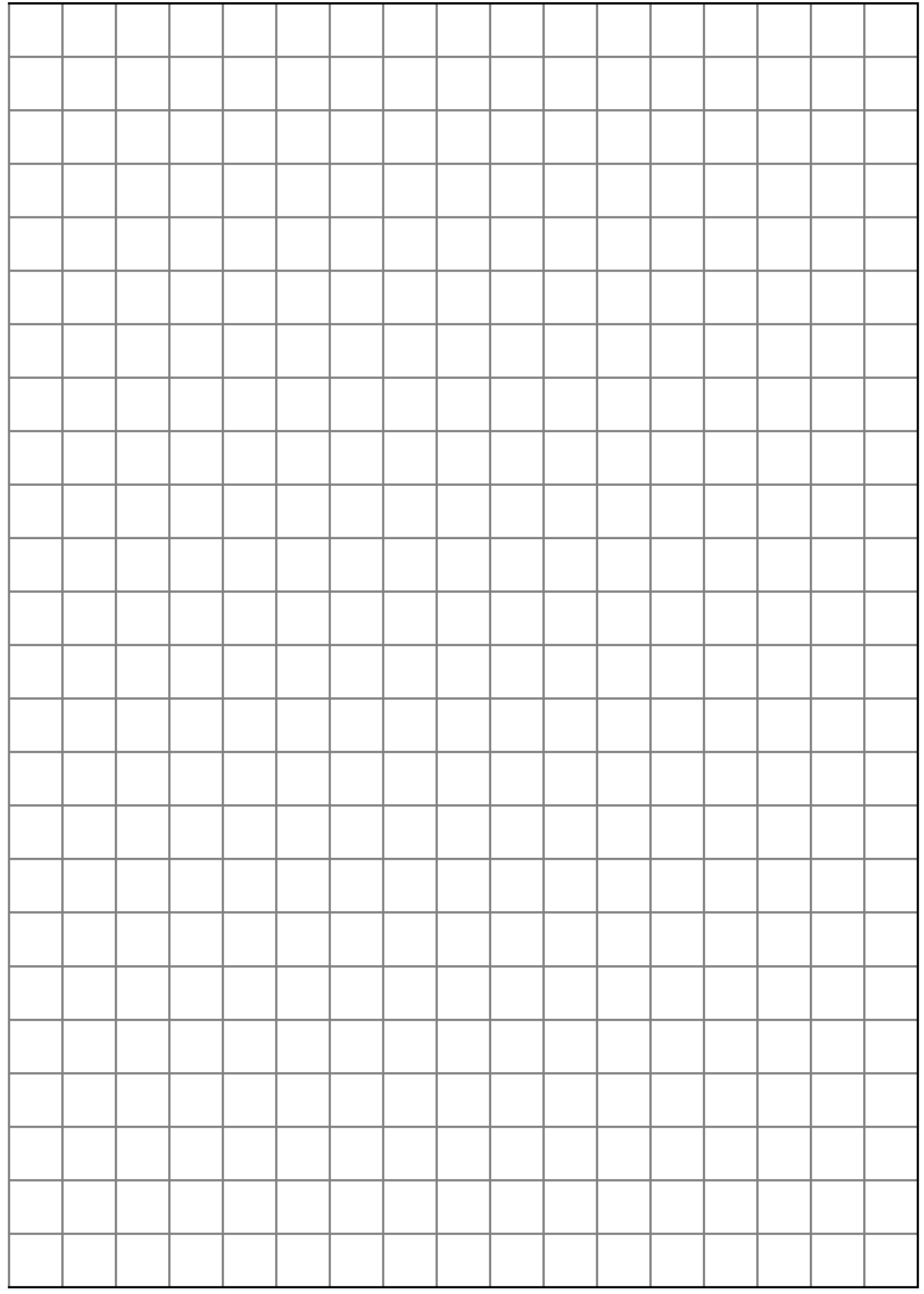

\begin{tabular}{l|l}
\hline R.1 & OBSERVACIONES \\
\hline
\end{tabular}

Encuesta PICT_06 / 956 - LAyHS - FAU - UNLP / CONICET 


\section{\begin{tabular}{|l|l}
\hline$S$ & CARACTERISTICAS CONSTRUCTIVAS \\
\hline
\end{tabular}}

\begin{tabular}{|l|l|l}
\hline S.1 & CUBIERTAS (materiales constructivos) \\
\hline
\end{tabular}

\begin{tabular}{|l|l|l|l|l|l|}
\hline $\mathrm{a}$ & Tejas/ Aisl. Térm./ Ent. Mad. a la vista & & $\mathrm{I}$ & Idem j/ Terminación aluminio & \\
\hline $\mathrm{b}$ & Tejas/ Ent. Mad./ Cielorraso suspendido & & $\mathrm{m}$ & Idem j/ Terminación azotea & \\
\hline $\mathrm{c}$ & Tejas/ Ent. Mad./ Aisl. Térm./ Ciel. Susp. & & $\mathrm{n}$ & Losa cerámica (idem j) & \\
\hline $\mathrm{d}$ & Chapa metálica (idem a) & $\mathrm{n}$ & Losa cerámica (idem $\mathrm{k}$ ) & \\
\hline $\mathrm{e}$ & Chapa metálica (idem b) & $\mathrm{o}$ & Losa cerámica (idem I) & \\
\hline $\mathrm{f}$ & Chapa metálica (idem c) & $\mathrm{p}$ & Losa cerámica (idem m) & \\
\hline $\mathrm{g}$ & Chapa metálica/ Cielorraso susp. & $\mathrm{q}$ & Chapa metálica/ Aisl. Term./ Chapadur & \\
\hline $\mathrm{h}$ & Asbesto cemento autoportante visto & & $\mathrm{r}$ & Entrepiso de madera machiembrada & \\
\hline $\mathrm{i}$ & Idem h/ Cielorraso suspendido & $\mathrm{s}$ & Losa cerámica/ Atico/ Chapa & \\
\hline $\mathrm{j}$ & Losa $\mathrm{H}^{\circ} \mathrm{A}^{\circ}$ Contr. $\mathrm{H}^{\circ} \mathrm{P} /$ Terminación negro & & $\mathrm{t}$ & Otros (especificar) & \\
\hline $\mathrm{k}$ & Idem $\mathrm{j} /$ Terminaciòn blanco & $\mathrm{u}$ & Otros (especificar) & \\
\hline
\end{tabular}

\begin{tabular}{|l|l}
\hline S.2 & MUROS EXTERIORES (materiales constructivos) \\
\hline
\end{tabular}

\begin{tabular}{|l|l|l|l|l|l|}
\hline $\mathrm{a}$ & Lad. Com./ 15cm./ Rev. Ambas caras & & $\mathrm{f}$ & Idem d/ Espesor 24cm. & \\
\hline $\mathrm{b}$ & Idem a/ Espesor $20 \mathrm{~cm}$. & & $\mathrm{g}$ & Bloque Ho/ Rev. Ambas caras & \\
\hline $\mathrm{c}$ & Idem a/ Espesor $30 \mathrm{~cm}$. & & $\mathrm{h}$ & Bloque Ho sin revocar & \\
\hline $\mathrm{d}$ & Lad. Cer. Hueco/ Esp. $15 \mathrm{~cm} . /$ Term. Idem 1 & & $\mathrm{i}$ & Lad. Hueco/ Esp. 10cm/ Rev. Ambas caras & \\
\hline $\mathrm{e}$ & Idem d / Espesor $21 \mathrm{~cm}$. & $\mathrm{j}$ & Otros (especificar) & \\
\hline
\end{tabular}

\begin{tabular}{|l|l}
\hline S.3 & SOLADOS (materiales constructivos) \\
\hline
\end{tabular}

\begin{tabular}{|l|l|l|l|l|}
\hline a & Sin cám. de aire (baldosas, contr., T.N.) & & b & Con cám. de aire ( mach., aire, T.N.) \\
\hline
\end{tabular}

\begin{tabular}{|l|l|l|l|l|l|}
\hline S.4 & CALIDAD DE EDIFICACION & & b & Opiniòn del encuestador & \\
\hline a & Opinión del Usuario & & \\
\hline
\end{tabular}

1. Lujosa// 2. Muy Buena// 3. Buena// 4. Económica

\begin{tabular}{|l|l}
\hline S.5 & MUROS EXTERIORES (materiales constructivos)
\end{tabular}

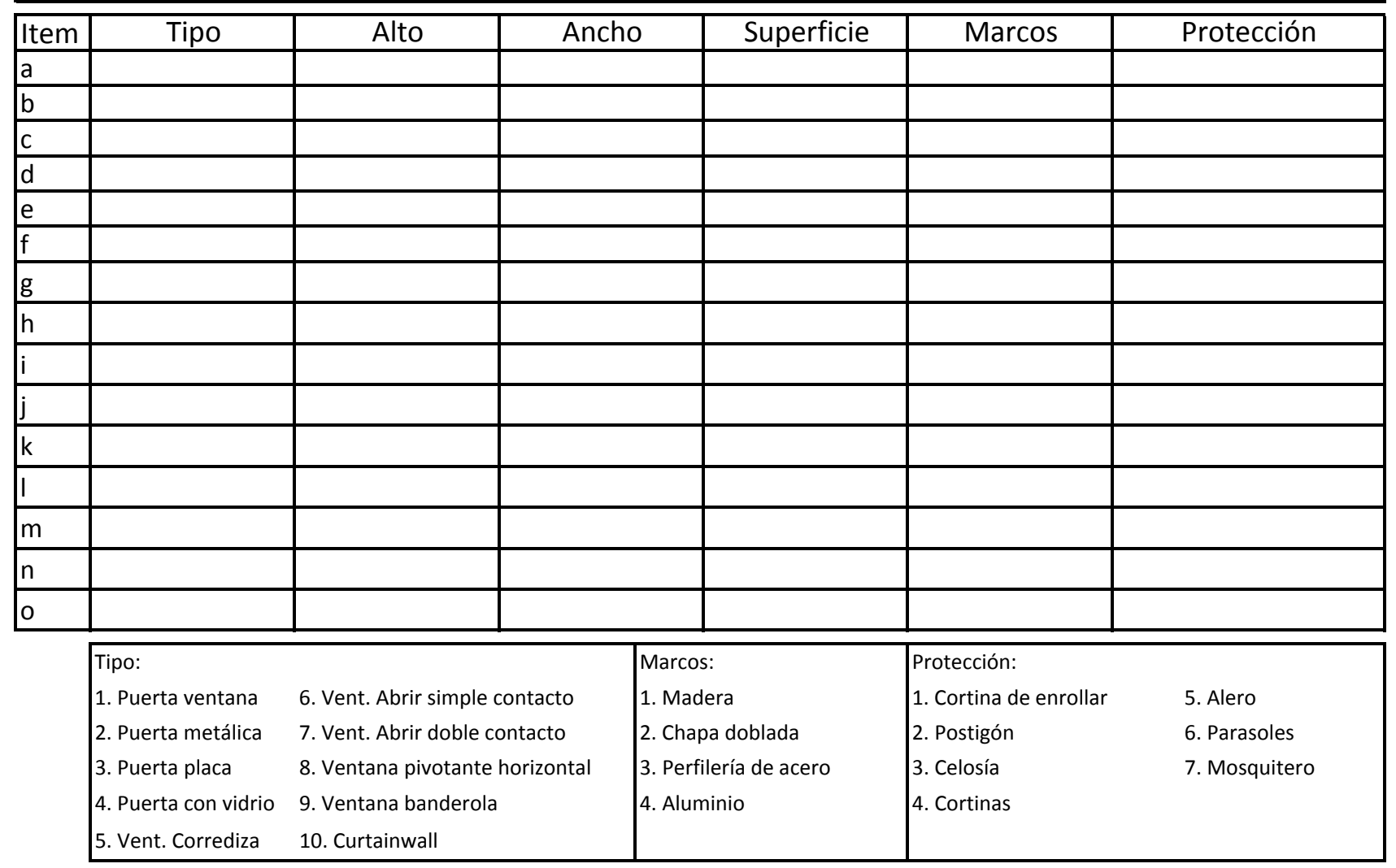




\section{\begin{tabular}{|l|l|}
\hline$T$ & REGISTRO DE MEDICIONES \\
\hline
\end{tabular}}

\begin{tabular}{l|l}
\hline T.1 & ENCUESTA \\
\hline
\end{tabular}

\begin{tabular}{|l|l|l|l|l|l|}
\hline a & Encuesta № & c & Tipología & \\
\hline b & Auditor & & e & Dirección & \\
\hline d & Nombre & & g & Localidad & \\
\hline f & Teléfono & & \\
\hline
\end{tabular}

\begin{tabular}{|l|l}
\hline T.2 & CONSUMO DE ENERGIA \\
\hline
\end{tabular}

\begin{tabular}{|l|l|}
\hline a & ELECTRICIDAD \\
\hline
\end{tabular}

\begin{tabular}{|l|l|l|l|l|}
\hline Consumo & Día & Hora & Registro & Observaciones / № de Medidor \\
\hline Inicial & & & & \\
\hline Final & & & & \\
\hline
\end{tabular}

\begin{tabular}{|l|l|}
\hline $\mathrm{b}$ & GAS NATURAL \\
\hline
\end{tabular}

\begin{tabular}{|l|l|l|l|l|}
\hline Consumo & Día & Hora & Registro & Observaciones / № de Medidor \\
\hline Inicial & & & & \\
\hline Final & & & & \\
\hline
\end{tabular}

\begin{tabular}{|l|l}
\hline T.3 & HOBOS \\
\hline
\end{tabular}

\begin{tabular}{|l|l|l|l|l|l|l|}
\hline Nombre & Ubicación & Período & Archivo (*.dt) & Mínima & Máxima & Media \\
\hline & & & & & & \\
\hline & & & & & & \\
\hline \\
\hline
\end{tabular}

\begin{tabular}{|l|l|}
\hline T.4 & OBSERVACIONES \\
& \\
\hline
\end{tabular}




\section{ANEXO II \\ RADIACIÓN MEDIA MENSUAL}

\subsection{Resultados de irradiación media mensual para La Plata}

A continuación se muestran los resultados arrojados por el Orientsol 1.0, desarrollado por el Grupo IDEA - Universidad de Jaén, España.

\subsubsection{Plano horizontal $\left(0^{\circ}\right)$}

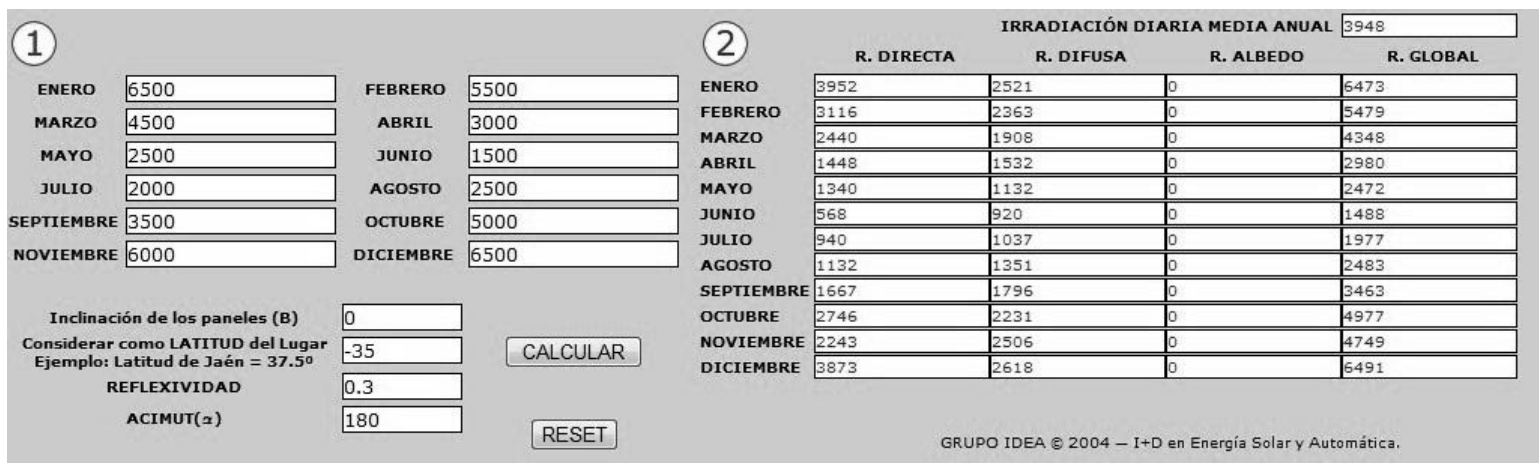

\subsubsection{Plano con inclinación óptima $\left(45^{\circ}\right)$}

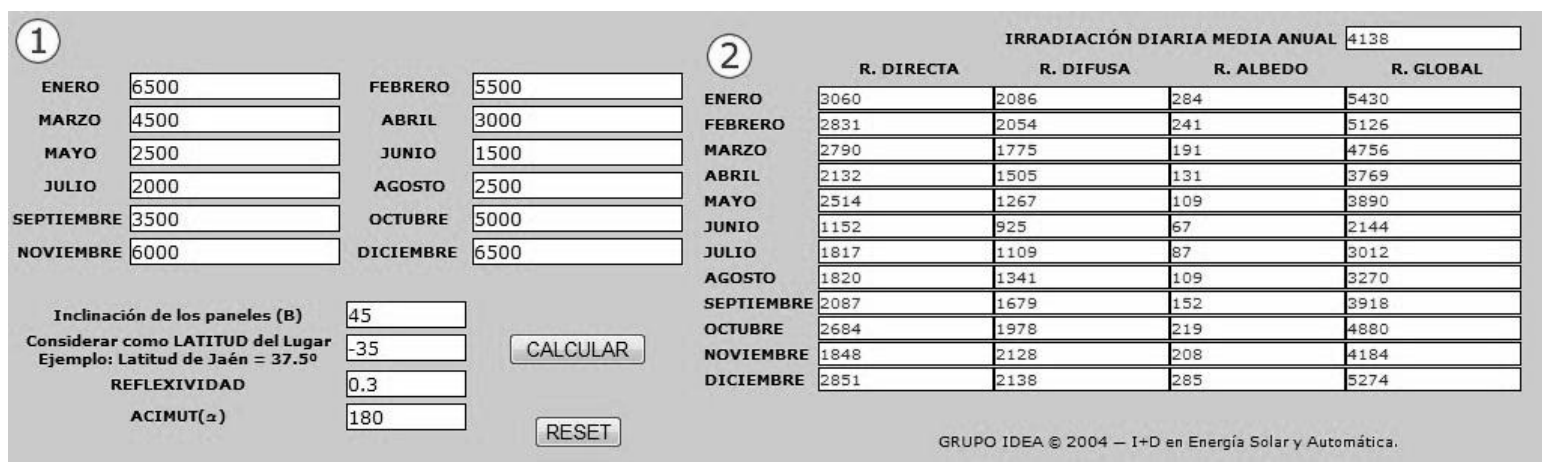


2.1.3. Plano vertical $\left(90^{\circ}\right)$

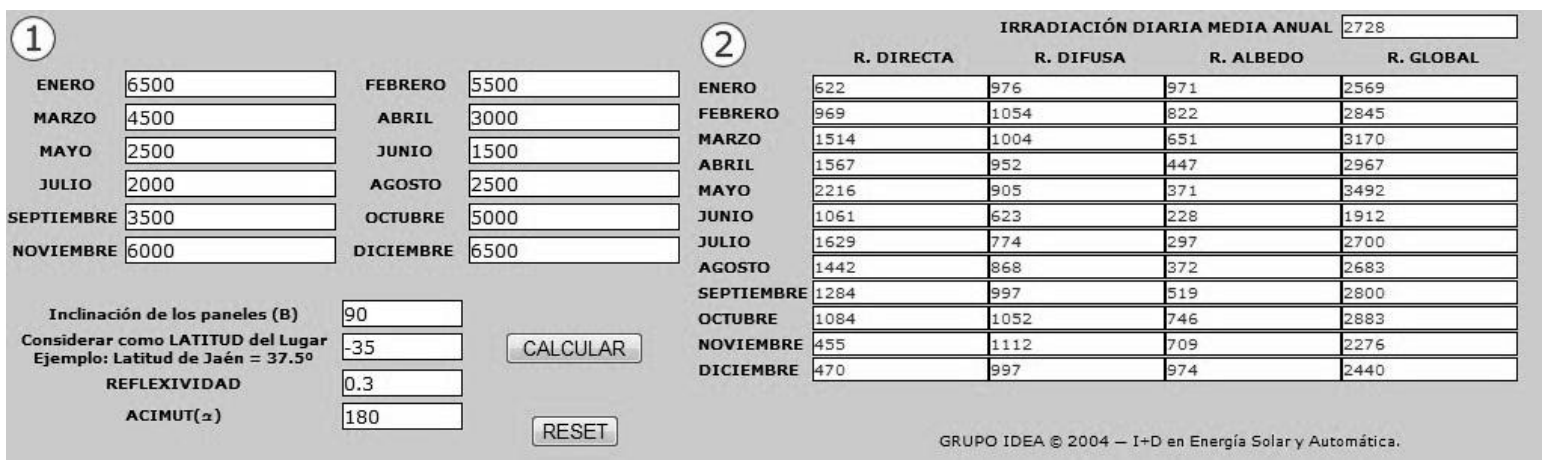

\subsection{Verificación con el programa SIMUSOL (Hernández, A.; 2003)}

\subsubsection{Plano horizontal $\left(0^{\circ}\right)$}

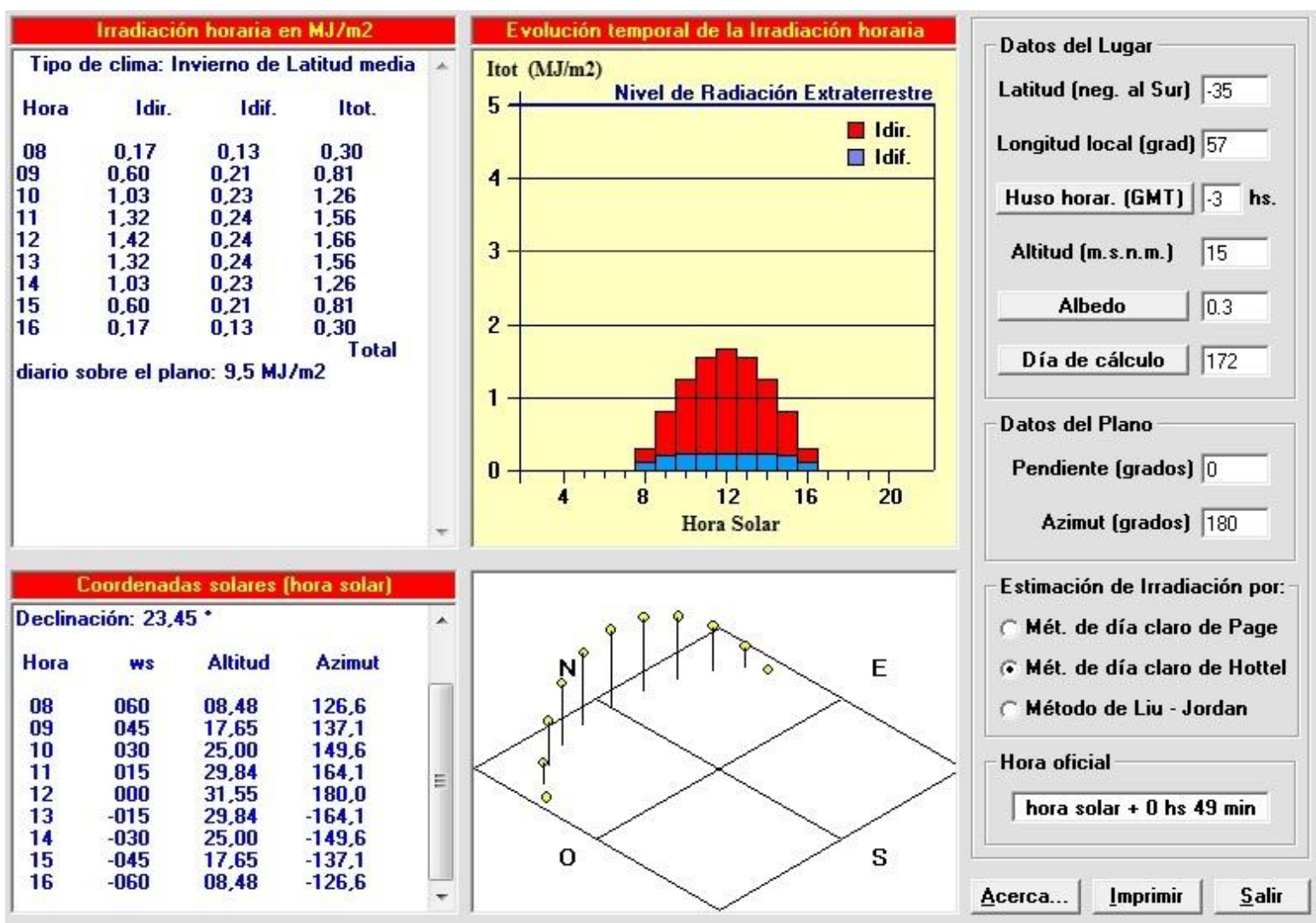


2.2.2. Plano con inclinación óptima $\left(45^{\circ}\right)$

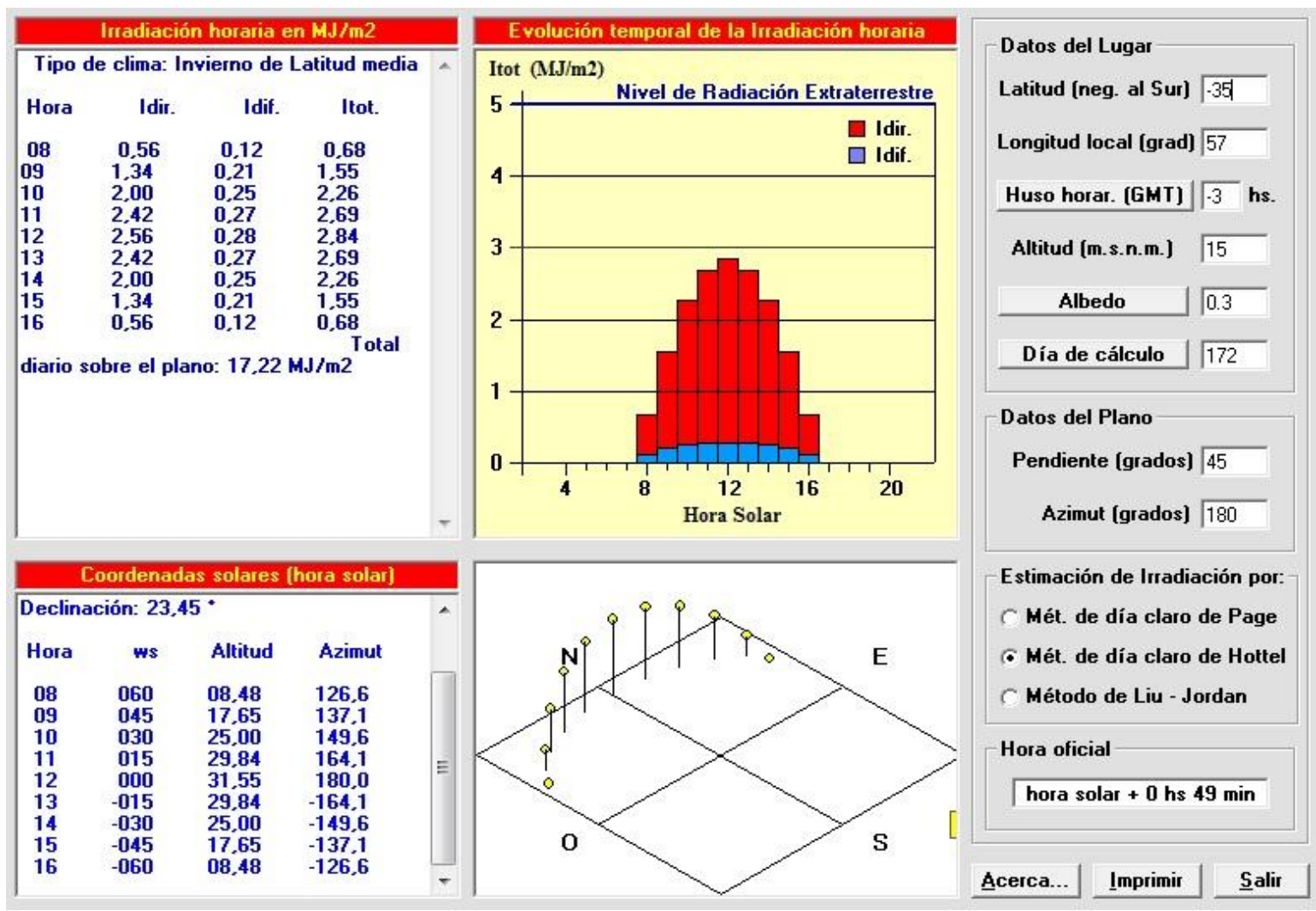

\subsubsection{Plano vertical $\left(90^{\circ}\right)$}

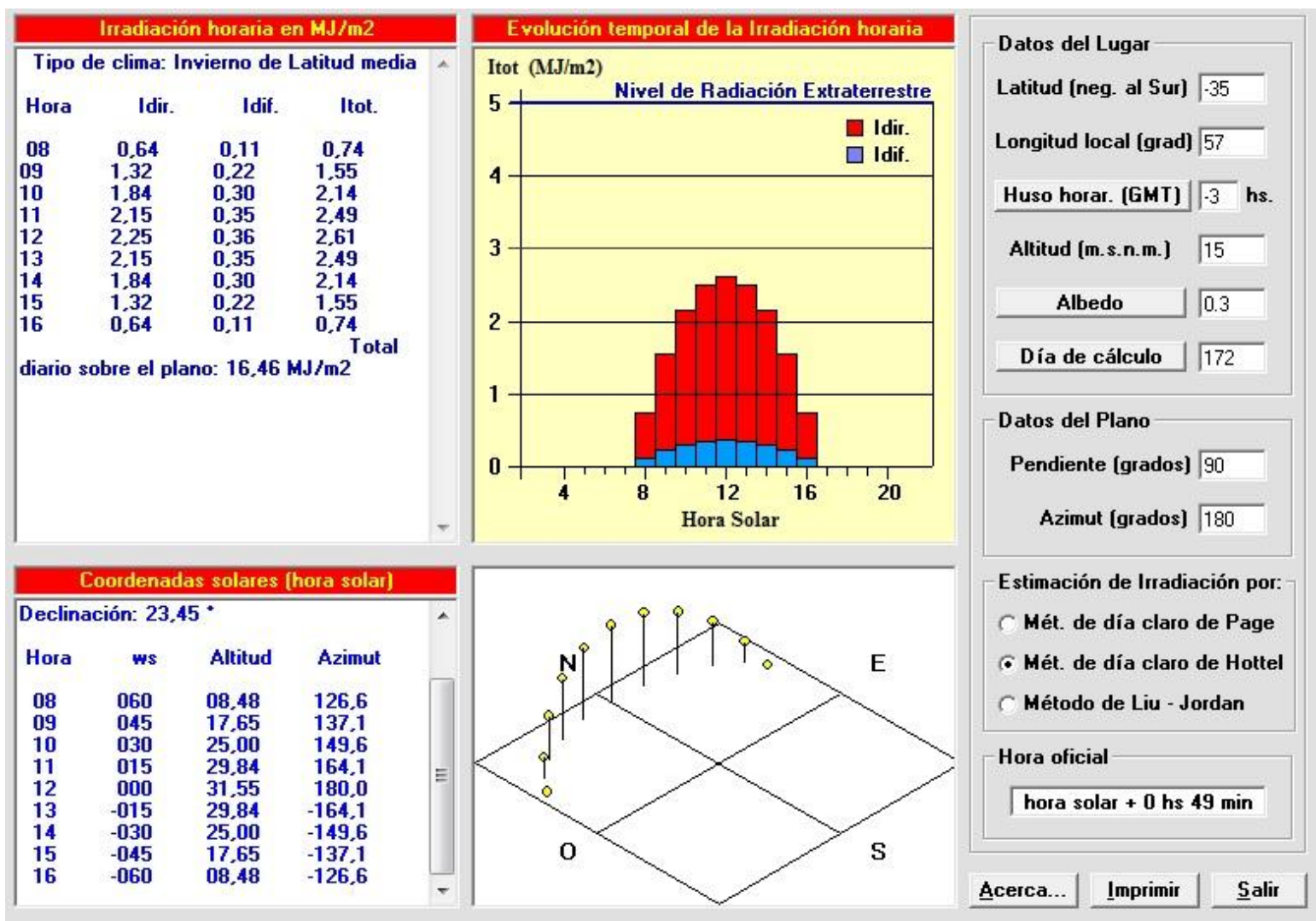




\section{ANEXO III TECNOLOGÍAS DE ENERGÍAS RENOVABLES}

\subsection{Introducción}

En el siguiente Anexo se muestran las fichas técnicas y extractos de los manuales técnicos de las tecnologías de energías limpias adoptadas en el Capítulo IX.

3.2. Generación de energía eléctrica

3.2.1. Panel Fotovoltaico Kyocera KD315

3.2.2. Inversor de Corriente PV Powered PV5200SD

3.3. Generación de energía fototérmica

3.3.1. Colector solar de agua Rheem

3.3.2. Colector solar de aire Grammer Solar 


\section{TSKYOCERZ}

\section{KD 315-80 F Series}

Preliminary

\section{CUTTING EDGE TECHNOLOGY}

As a pioneer with over 35 years in the solar energy industry, Kyocera demonstrates leadership in the development of solar energy products. Kyocera's Kaizen Philosophy, commitment to continuous improvement, is shown by repeatedly achieving world record cell efficiencies.

\section{QUALITY BUILT IN}

- UV stabilized, aesthetically pleasing black anodized frame

- Supported by major mounting structure manufacturers

- Easily accessible grounding points on all four corners for fast installation

- Proven junction box technology with 12 AWG PV wire to work with transformerless inverters

- Quality locking MC4 plug-in connectors to provide safe and quick connections

\section{RELIABLE}

- Proven superior field performance

- Tight power tolerance

- Only module manufacturer to pass rigorous long-term testing performed by TüV Rheinland

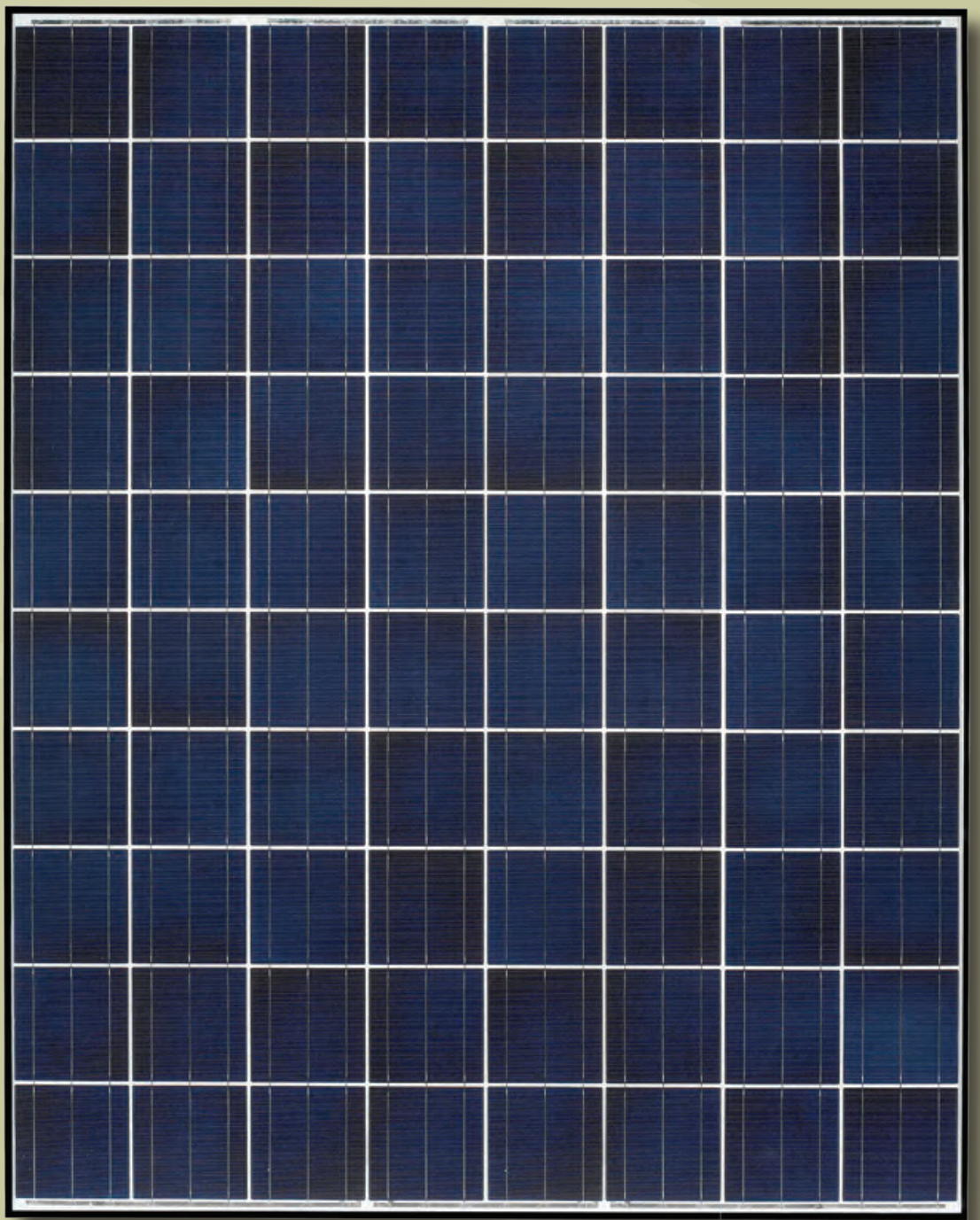

QUALIFICATIONS AND CERTIFICATIONS

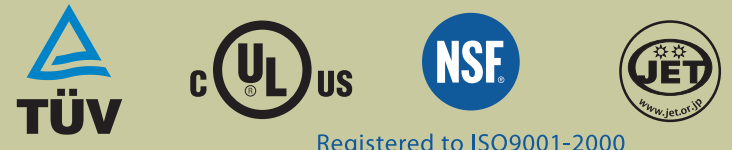

NEC 2008 Compliant, UL 1703, ISO 9001, and ISO 14001 UL Fire Safety Class C, CEC, FSEC

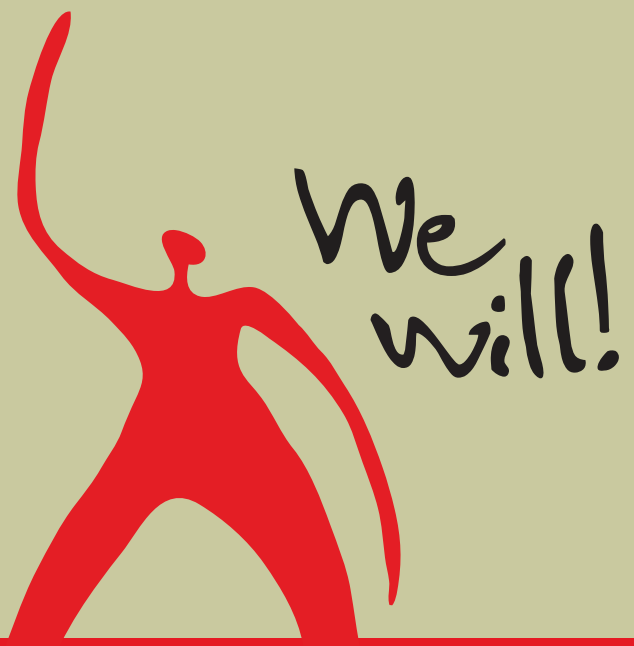




\section{ELECTRICAL SPECIFICATIONS}

\begin{tabular}{|c|c|c|}
\hline \multicolumn{3}{|c|}{$\begin{array}{l}\text { Standard Test Conditions (STC) } \\
\text { STC }=1000 \mathrm{~W}^{\prime} \mathrm{M}^{2} \text { irradiance, } 25^{\circ} \mathrm{C} \text { module }\end{array}$} \\
\hline \multicolumn{3}{|c|}{$\begin{array}{l}\text { KD315GX-LFB } \\
\text { (Preliminary) }\end{array}$} \\
\hline$P_{m p}$ & 315 & W \\
\hline$V_{m p}$ & 39.8 & V \\
\hline$I_{m p}$ & 7.92 & A \\
\hline$V_{o c}$ & 49.2 & V \\
\hline$I_{s c}$ & 8.50 & A \\
\hline$P_{\text {tolerance }}$ & $+5 /-3$ & $\%$ \\
\hline
\end{tabular}

Nominal Operating Cell Temperature Conditions (NOCT) NOCT $=800 \mathrm{~W} / \mathrm{M}^{2}$ irradiance, $20^{\circ} \mathrm{C}$ ambient temperature, AM 1.5 spectrum*

$T$
$P$
$V$
$I$
$V$

$\mathrm{T}_{\text {NOCT }}$

45

$\mathbf{P}_{\max }$

226

$\mathrm{V}_{\mathrm{mp}}$

35.8

6.34

$V_{\text {oc }}$

$\mathrm{I}_{\mathrm{sc}}$

45.0

6.88

\section{Temperature Coefficients}

$P_{\max }$

$-0.51$

$-0.52$

$\mathrm{V}_{\mathrm{mp}}$

$\mathrm{I}_{\mathrm{mp}}$

$\mathrm{V}_{\text {oc }}$

0.0064

$-0.36$

$\mathrm{I}_{\mathrm{sc}}$

0.061

Operating

Temp

-40 to +90

$\% /{ }^{\circ} \mathrm{C}$

\section{System Design}

Series Fuse Rating

Maximum DC System Voltage (UL)

$600 \mathrm{~V}$

Hailstone Impact

1 in $(25 \mathrm{~mm}) @ 51 \mathrm{mph}(23 \mathrm{~m} / \mathrm{s})$

Subject to simulator measurement uncertainty of $+/-3 \%$.

KYOCERA reserves the right to modify these specifications without notice.

\section{MODULE CHARACTERISTICS}

\begin{tabular}{ll}
$\begin{array}{l}\text { Dimensions: } \\
\text { length/width/height }\end{array}$ & $\begin{array}{l}65.43 \mathrm{in} / 51.97 \mathrm{in} / 1.8 \mathrm{in} \\
(1662 \mathrm{~mm} / 1320 \mathrm{~mm} / 46 \mathrm{~mm})\end{array}$ \\
\hline Weight: & $60.6 \mathrm{lbs}(27.5 \mathrm{~kg})$ \\
\hline
\end{tabular}

\section{PACKAGING SPECIFICATIONS}

\begin{tabular}{ll} 
Modules per pallet: & 20 \\
\hline Pallets per 53' container: & 22 \\
\hline Pallet box dimensions: & $66 \mathrm{in} / 53 \mathrm{in} / 47 \mathrm{in}$ \\
length/width/height & $(1675 \mathrm{~mm} / 1330 \mathrm{~mm} / 1190 \mathrm{~mm})$ \\
\hline Pallet box weight: & $1323 \mathrm{lbs}(600 \mathrm{~kg})$ \\
\hline
\end{tabular}

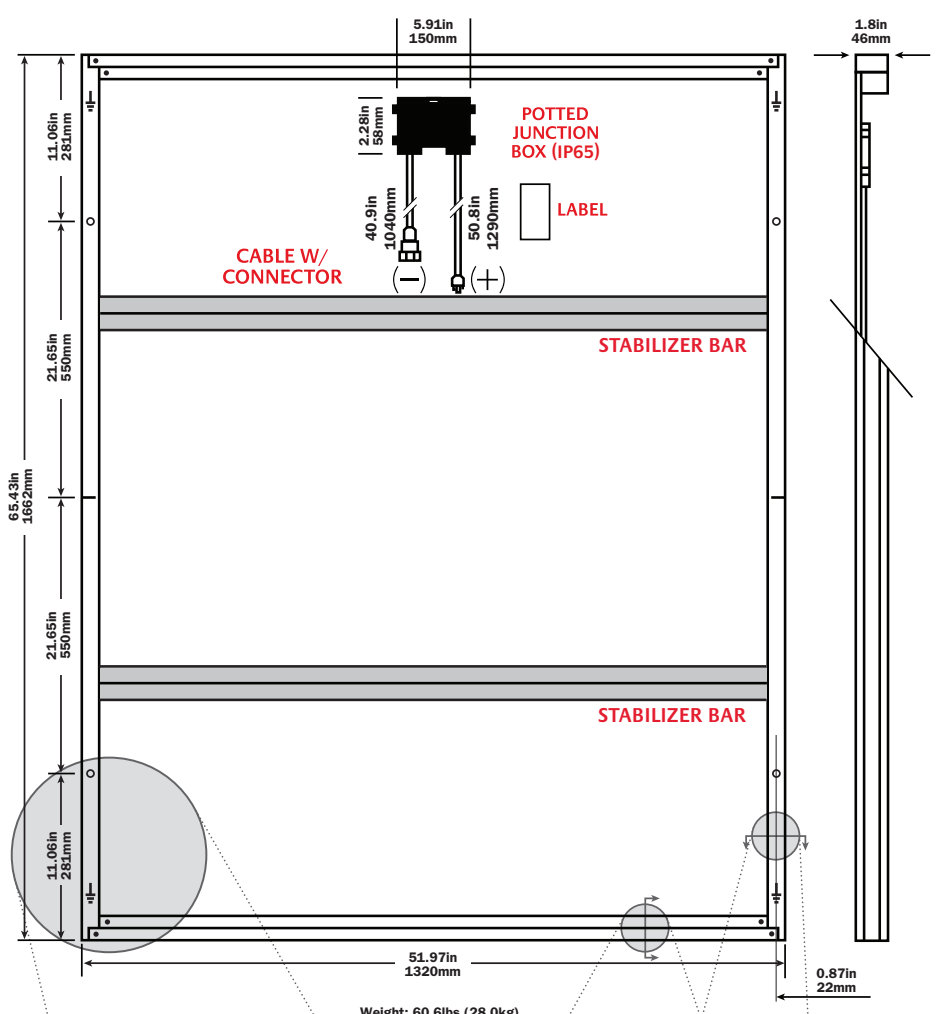

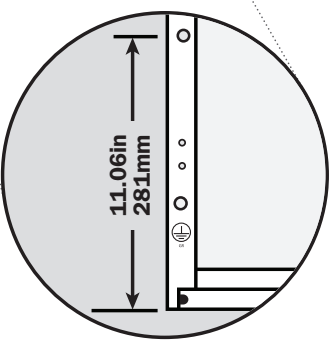

Expanded View of Grounding Holes

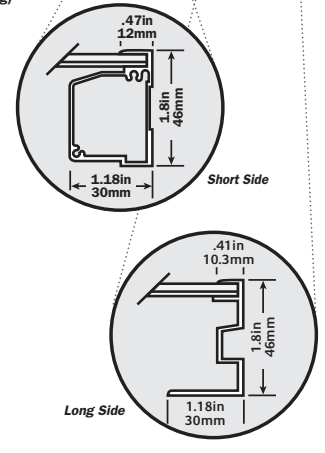

Frame Cross Section Diagrams
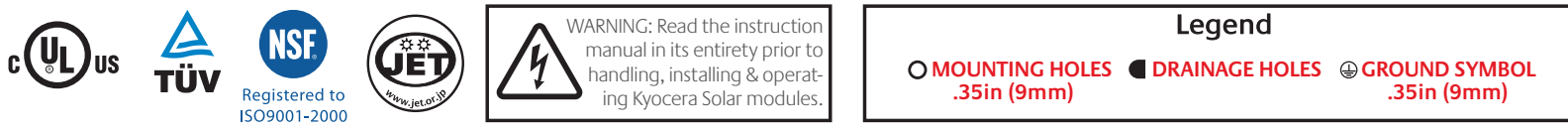

NEC 2008 COMPLIANT Is09001-2000 


\section{PV Powered" String Inverters}
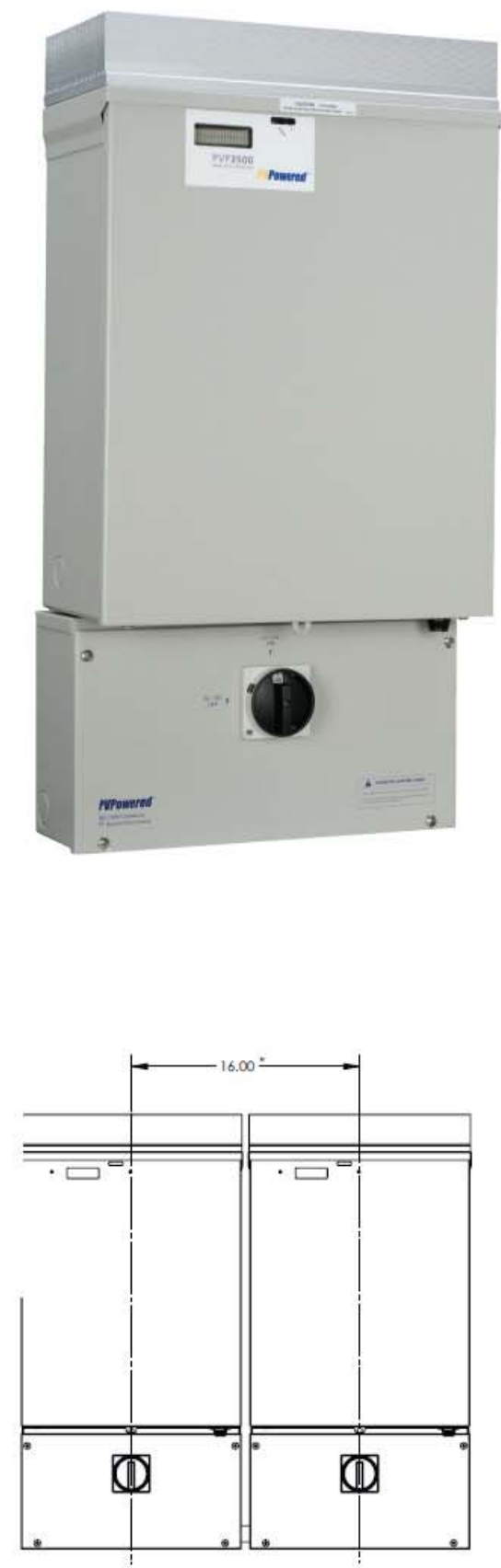

Example of Side-by-side Mounting on Standard Stud Spacing

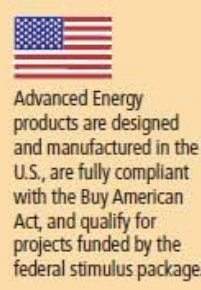

\section{Proven Reliability - With Integrated AC and DC PV System Disconnect Listed to the UL 98 Standard}

\begin{abstract}
PV Powered String Inverters continue to deliver industry-leading reliability and technical innovations that lower the total cost of PV systems installation. Advanced Energy is now the only manufacturer of a string inverter-integrated AC/DC PV System Disconnect that is listed to the UL 98 Standard. The UL 98 Standard, called "Enclosed and Dead-front Switches," ensures the integrated PV Powered disconnect meets all installation and inspection requirements of a PV System Disconnect.
\end{abstract}

\begin{abstract}
Housed within an NEC Compliant wire raceway, the innovative disconnect consists of one enclosure with generous working room for installation. In addition to providing for a single point of connection from the utility service and PV array, the wire raceway's optimized knockout locations also provide options for side, bottom and back entry with minimized conduit bending. The wire raceway enables flush side-by-side mounting, eliminating the need for extra equipment and resulting in a cleaner, less expensive installation.
\end{abstract}

The PV Powered string inverters are backed by the industry's first nation-wide ten year warranty and equipment replacement program. Optional performance monitoring is available which includes low cost, secure web-based access to inverter status and performance history.

\section{FEATURES}

\section{Industry-Leading Reliability}

- Endurance tested to 20 year operating life

- Lowest part counts and fewest interconnects eliminate common failure points

- Field-proven technology with thousands of units installed nationwide

Integrated AC and DC PV System Disconnect

- Listed to UL 98 Standard for use with PV Powered UL 1741 Listed string inverters

- Robust testing of switch mechanism to UL 98 Standard

- Single AC/DC switch visible and lockable in the OFF position

- NEC Compliant internal wire raceway enables side-by-side mounting

- Direct-to-wall surface enclosure design allows for easy access and installation

\section{Easy Installation}

- Factory integrated inverter and PV System Disconnect eliminates the need for extra equipment

- Integrated disconnect reduces conduit connection points saving installation time and material cost

- Field-configurable positive ground applications with simple jumper selection

- Optimally placed knockouts for a variety of conduit routing options

\section{Installer-Focused Support}

- No special purchase requirements to get the best technical support in the industry

- Live technical phone support

- Economical performance monitoring options 


\section{I M E N S I O N S}

PVP2000 to PVP3500
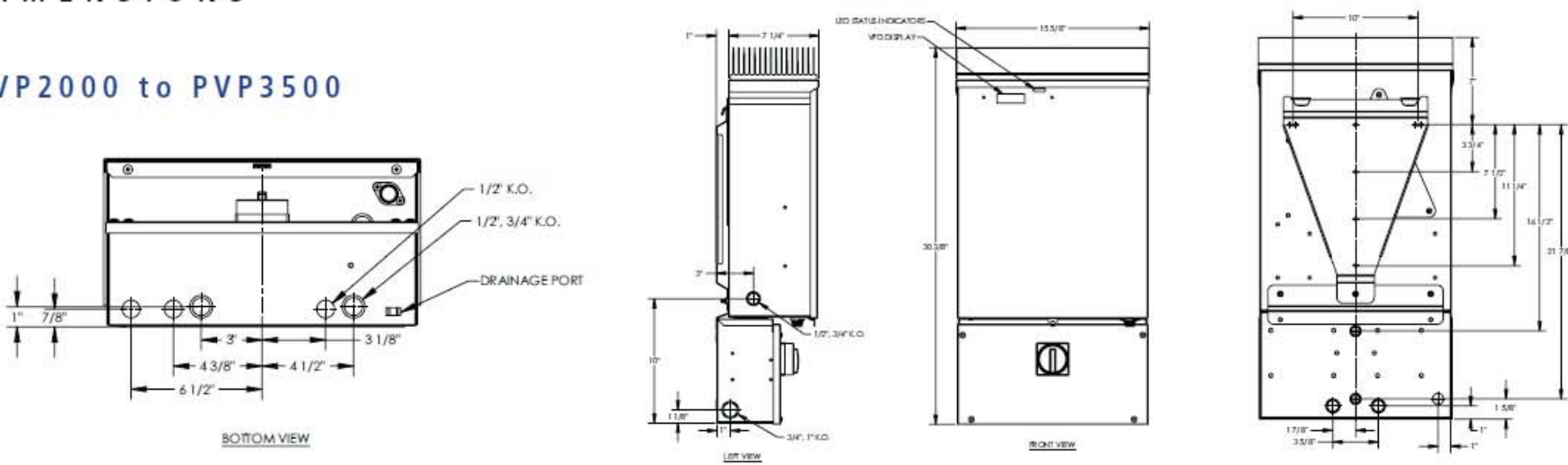

PVP4600, PVP4800, PVP5200

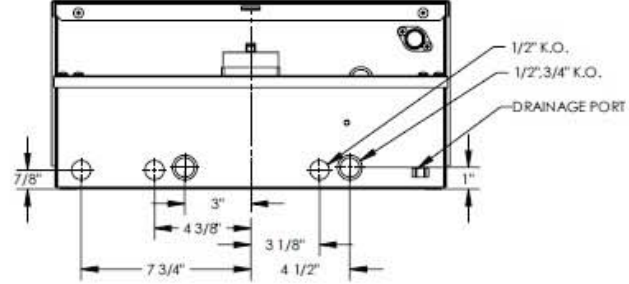

BOTIOM VIEW
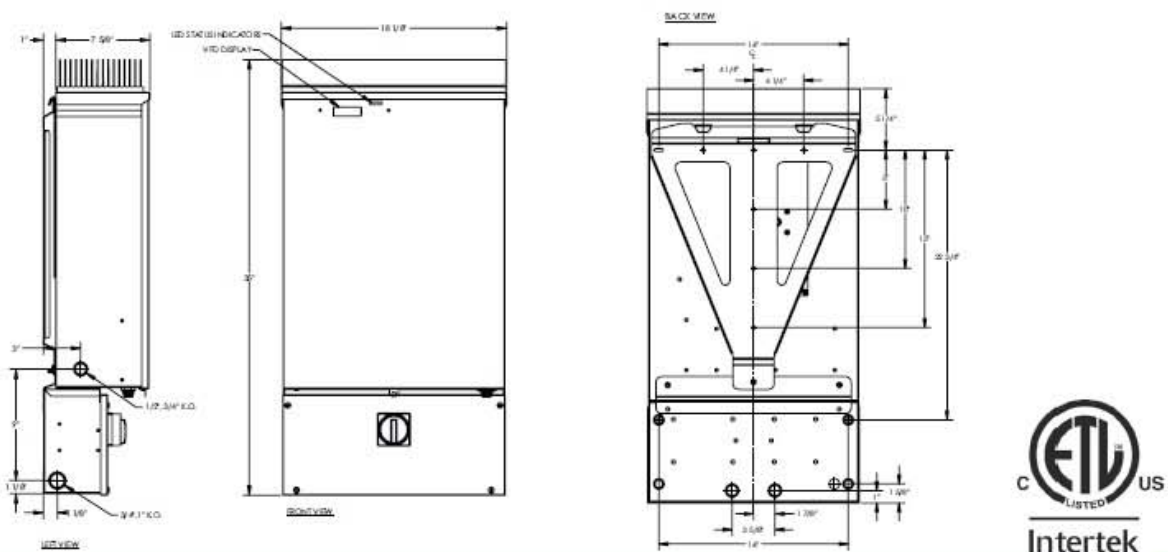

ELECTRICAL SPECIFICATIONS

\section{MODEL}

Continuous Output Power (watts)

Weighted CEC Efficiency (\%)

Maximum DC Input Voltage (VOC)

DC Voltage Operating Range (V)

DC Minimum Start Voltage (V)

DC Maximum Current (A)

AC Rated Output Current (A)

AC Nominal Voltage (V)

AC Output Voltage Range (V)

AC Frequency Range $(\mathrm{Hz})$

\begin{tabular}{cccccccc} 
PVP2000 & PVP2500 & PVP2800 & PVP3000 & PVP3500 & PVP4600 & PVP4800 & PVP5200 \\
\hline 2000 & 2500 & 2800 & 3000 & 3500 & 4600 & 4800 & 5200 \\
92 & 94.5 & 92 & 93.5 & 95.5 & 95.5 & 96 & 96 \\
500 & 500 & 500 & 500 & 500 & 500 & 500 & 500 \\
$115-450$ & $140-450$ & $180-450$ & $170-450$ & $200-450$ & $205-450$ & $200-450$ & $240-450$ \\
\hline 130 & 155 & 195 & 185 & 215 & 220 & 215 & 255 \\
18.5 & 19 & 16.5 & 19 & 18.5 & 24 & 25.5 & 23 \\
8.5 & 10.5 & 13.5 & 12.5 & 15 & 22.5 & 20.5 & 22 \\
\hline 240 & 240 & 208 & 240 & 240 & 208 & 240 & 240 \\
\hline $211-264$ & $211-264$ & $183-229$ & $211-264$ & $211-264$ & $183-229$ & $211-264$ & $211-264$ \\
\hline $59.3-60.5$ & $59.3-60.5$ & $59.3-60.5$ & $59.3-60.5$ & $59.3-60.5$ & $59.3-60.5$ & $59.3-60.5$ & $59.3-60.5$
\end{tabular}

MECHANICALSPECIFICATIONS

\section{MODEL}

\section{$\begin{array}{llllllll}\text { PVP2000 } & \text { PVP2500 PVP2800 } & \text { PVP3000 } & \text { PVP3500 } & \text { PVP4600 } & \text { PVP4800 } & \text { PVP5200 }\end{array}$}

Inverter with Factory-Integrated AC and DC PV System Disconnect

NEMA 3R Steel Enclosure, Wall Mounted with Bracket Included

Temperature

Weight (lbs) with Disconnect

$-25^{\circ} \mathrm{C}$ to $40^{\circ} \mathrm{C}$

Inverter with Disconnect Dimensions

A GENCY APPROVALS

\begin{tabular}{|c|c|c|c|c|c|c|c|}
\hline 92.5 & 106.5 & 106.5 & 106.5 & 120.5 & 162 & 162 & 162 \\
\hline $\begin{array}{c}303 / 8^{\prime \prime} \mathrm{H} \\
\times 155 / 8^{\prime \prime} \mathrm{W} \\
\times 81 / 4^{\prime \prime} \mathrm{D}\end{array}$ & $\begin{array}{c}303 / 8^{\prime \prime} \mathrm{H} \\
\times 155 / 8^{\prime \prime} \mathrm{W} \\
\times 81 / 4^{\prime \prime} \mathrm{D}\end{array}$ & $\begin{array}{c}303 / 8^{\prime \prime} \mathrm{H} \\
\times 155 / 8^{\prime \prime} \mathrm{W} \\
\mathrm{X} 81 / 4^{\prime \prime} \mathrm{D}\end{array}$ & $\begin{array}{c}303 / 8^{\prime \prime} \mathrm{H} \\
\times 155 / 8^{\prime \prime} \mathrm{W} \\
\mathrm{X} 81 / 4^{\prime \prime} \mathrm{D}\end{array}$ & $\begin{array}{c}303 / 8^{\prime \prime} \mathrm{H} \\
\times 155 / 8^{\prime \prime} \mathrm{W} \\
\text { X } 81 / 4^{\prime \prime} \mathrm{D}\end{array}$ & $\begin{array}{c}35^{\prime \prime} \mathrm{H} \\
\times 181 / 8^{\prime \prime} \mathrm{W} \\
\times 85 / 8^{\prime \prime} \mathrm{D}\end{array}$ & $\begin{array}{c}35^{\prime \prime} \mathrm{H} \\
\times 181 / 8^{\prime \prime} \mathrm{W} \\
\mathrm{X} 85 / 8^{\prime \prime} \mathrm{D}\end{array}$ & $\begin{array}{l}H \\
{ }^{\prime \prime} \\
\end{array}$ \\
\hline
\end{tabular}


RHEEM DOMESTIC HOT WATER

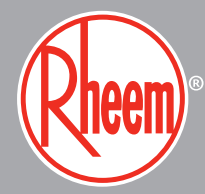

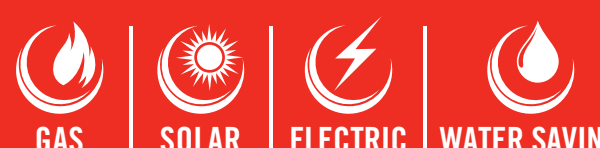

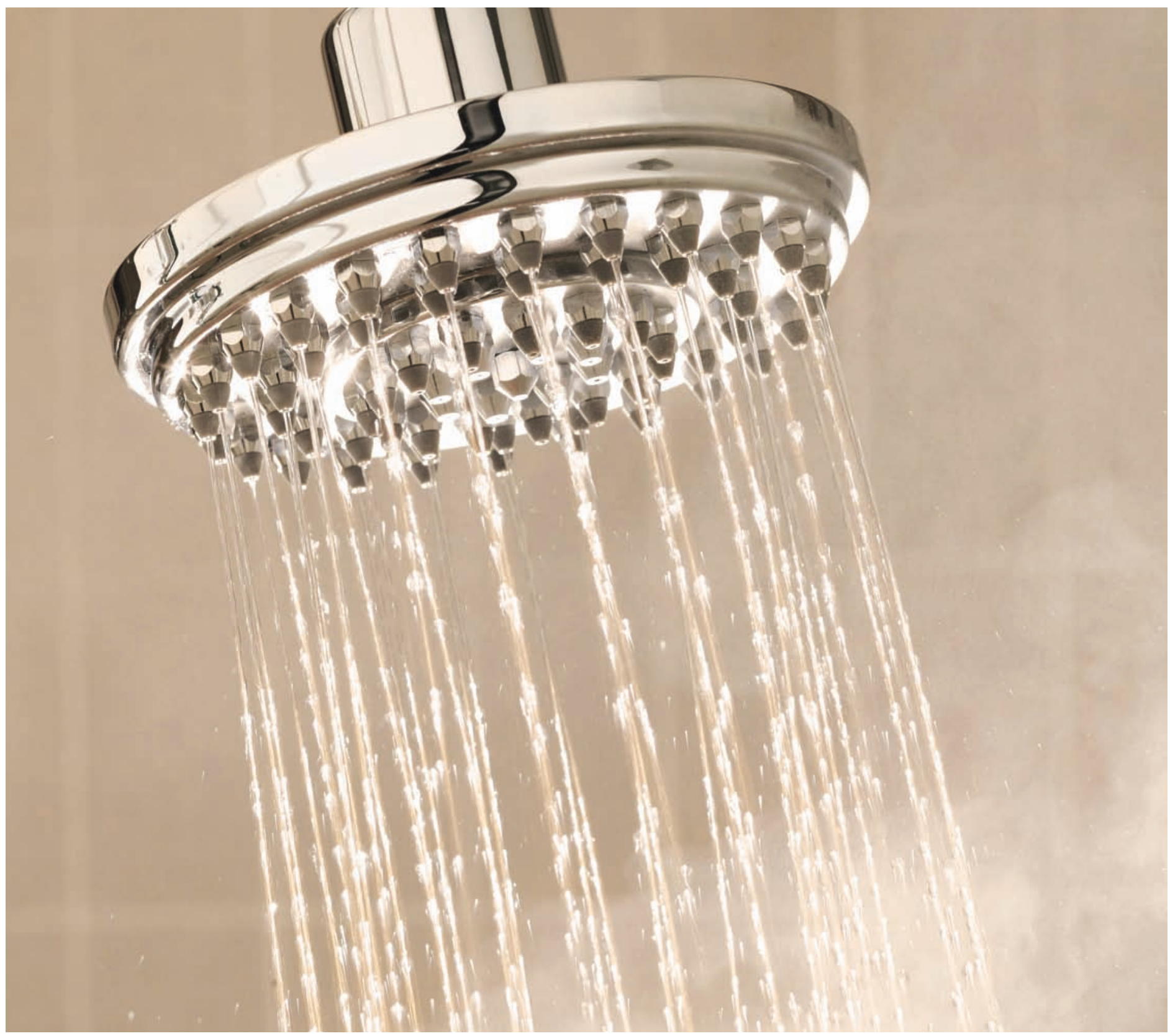

AUSTRALIA'S FAVOURITE NAME IN HOT WATER 


\section{CONTENTS}

4. Rheem Solar Hot Water

6. Rheem Heat Pump Hot Water

8. Rheem Electric Storage Hot Water

10. Rheem Gas Storage Hot Water

12. Rheem Continuous Flow Gas Hot Water

13. Rheem Water Star Water Saving System

14. Product Data 


\section{RHEEM IS AUSTRALIA'S FAVOURITE NAME IN HOT WATER AND THE NAME AUSTRALIANS HAVE TRUSTED FOR GENERATIONS}

\section{YOU'LL BE RIGHT WITH RHEEM}

No.1 with Australian families. Rheem is Australia's favourite hot water system... and it's been that way since 1939, when Rheem started making water heaters in Australia. Generations of Australian families have relied on Rheem for water that is steady, hot and strong!

\section{RHEEM IS EVERYWHERE}

There is an unequalled network of experienced Rheem service agents across the country. No matter where you are in Australia there is expert advice available to ensure that you get the Rheem solution that is right for you.

WE HAVE THE RIGHT RHEEM FOR YOU Rheem has the most extensive range of hot water systems available in Australia. Solar, gas or electric storage.

Continuous flow or heat pump. Energy efficient. Rheem has a range of capacities and sizes just right for every situation.

Solar, gas or electric. Continuous flow, heat pump or storage. Rheem has a range of hot water solutions for every situation.

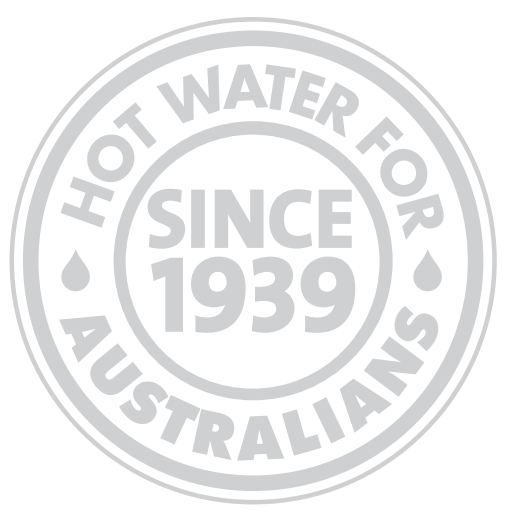

CHOOSING THE RIGHT CAPACITY RHEEM FOR YOUR HOME

Many households change over time, so it's important to choose the right capacity to meet your needs both now and as your family grows.

Factors to consider in determining your hot water needs:

- Number of bathrooms or people using hot water at once.

- Adults and children in the home (teenagers will use more hot water than young children).

- Dishwashers or washing machines connected, that use hot water at the same time.

- Will a large bathtub or spa-bath be filled using hot water? Your hot water system needs will be influenced by the water conditions, climate and water pressure in your region. 


\section{RHEEM SOLAR HOT WATER}

\section{SOLAR THAT SAVES}

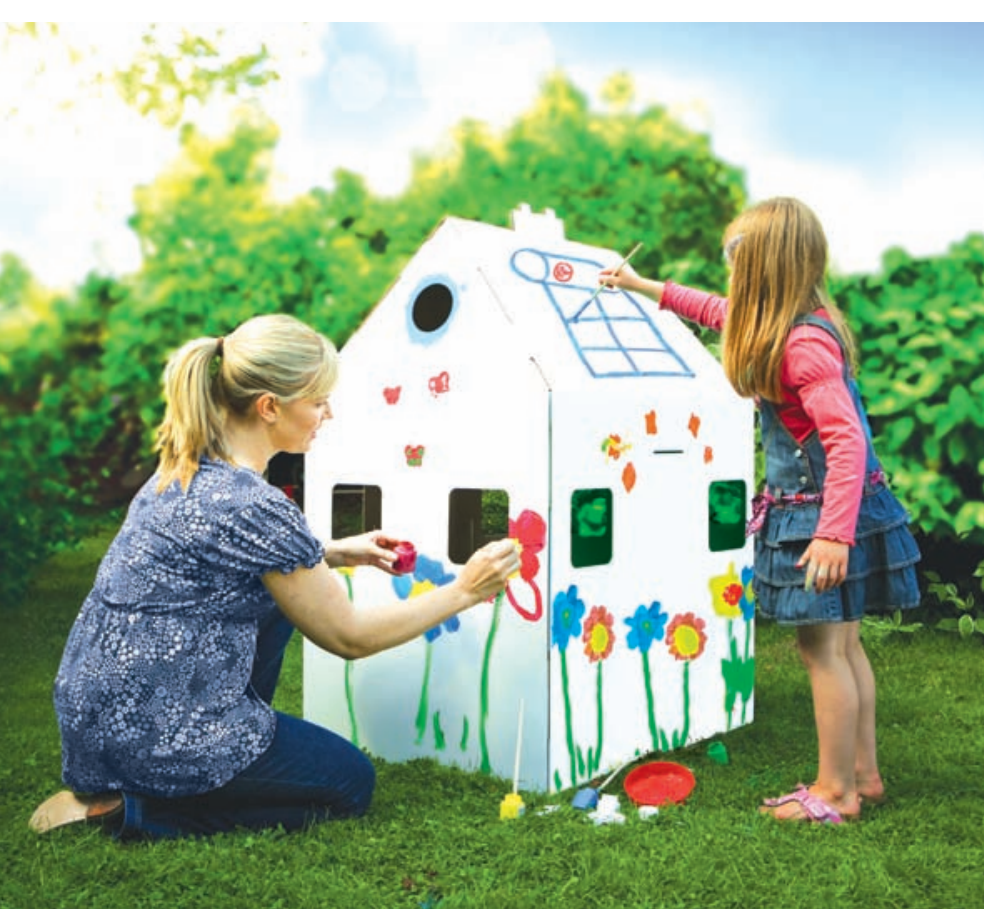

Solar water heaters come in both roof and ground mounted systems to suit various applications with a choice of either electric or gas back-up boosters for days when the sun doesn't shine. There are even models suited to particularly cold areas, which mean every family can enjoy the benefits a solar water heater has to offer.

\section{RBare SOLARSAVERS}

\section{SMALL-SCALE TECHNOLOGY CERTIFICATES}

Small-scale Technology Certificates (STCS) are a financial incentive to encourage the installation of solar water heaters provided under a Federal Government operated scheme.

This map shows the climate Zones within Australia which will define the number of STCs allocated to an approved solar water heater.

To claim your STC entitlement, simply complete the STC Assignment form.

\section{WHY RHEEM SOLAR}

Energy efficient - uses up to $70 \%$ less energy than an electric water heater, saving you money. ${ }^{1}$

Reduces carbon emissions - solar systems save up to 3.3 tonnes of greenhouse gas emissions every year. ${ }^{4}$ Minimise reliance on fossil fuels and protect yourself against future energy cost increases - take advantage of Australia's abundant supply of sunlight, and reduce your reliance on expensive, non-renewable gas and electricity. ${ }^{5}$ Complete range - the Rheem solar range includes both split, ground mounted systems and complete roof mounted models in a variety of capacities from 160 - 410 Litres. All weather protection - Rheem Premier ${ }^{\circledR}$ Loline series feature unique, drain-back heat exchange technology, that prevents the solar system from freezing, or overheating during weather extremes.

Booster options - Rheem solar systems are available with electric or gas boosting, providing hot water during cloudy weather, or at night.

Eligible for rebates \& incentives - STC and State Government rebates are available for installing solar water heating. ${ }^{6}$

Visit www.rheemsolarsavers.com.au to find out how many STCs apply to Rheem Solar water heaters by zone and to download the STC Assignment form.

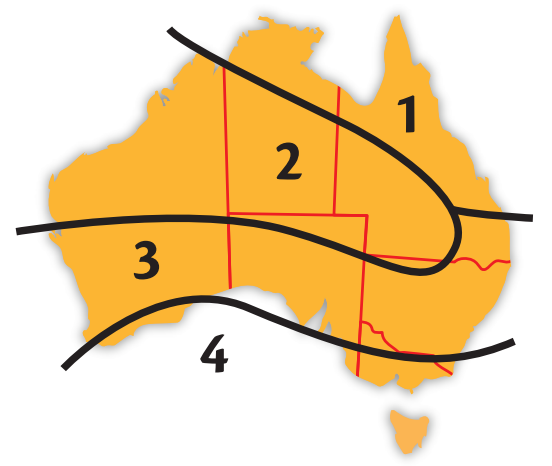




\section{HOW SOLAR WORKS}

Solar water heaters work by absorbing energy from

the sun's rays in the roof mounted solar collectors and transferring this to heat water stored in the tank. Ground mounted systems rely on inbuilt pumps to push the water through the system, whereas roof mounted systems rely on a natural 'thermosiphon' effect. Typically water passes through channels in the solar collector where the water is heated. As the water moves out of the collector and into the tank, the tank gradually gets hotter until the water reaches its maximum stored temperature.

3. As the water rises

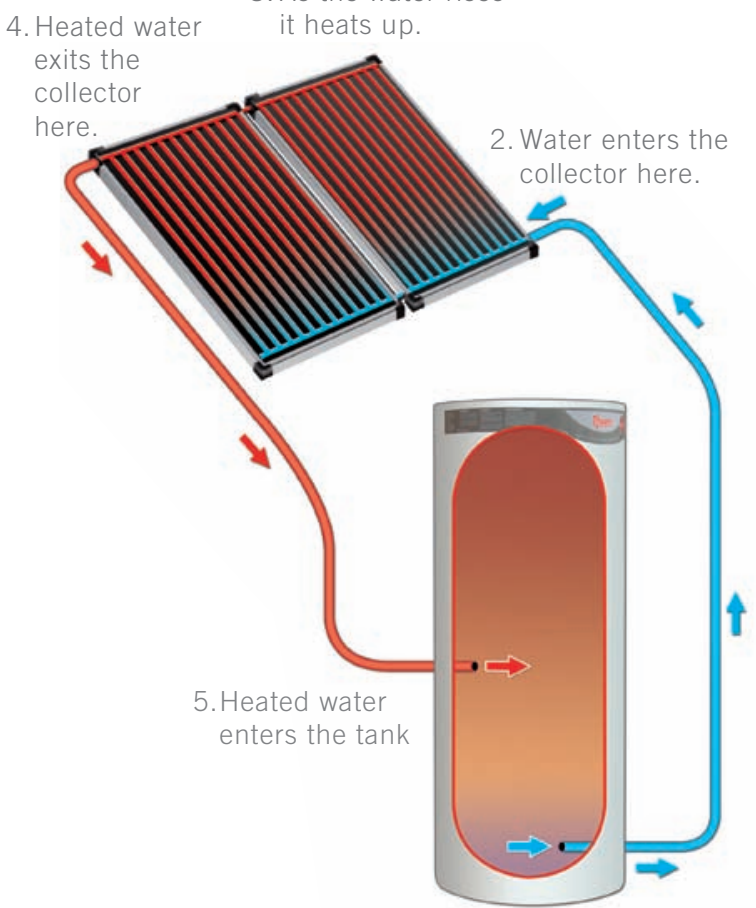

1.Water is pumped up to the solar collector.

\section{THE RIGHT RHEEM FOR YOU}

\section{GROUND MOUNTED SYSTEMS}

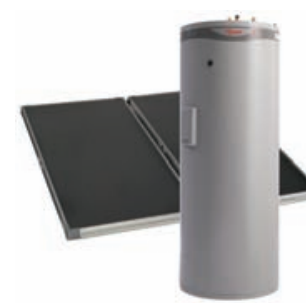

Model Number: 591270/2T

\section{Premier $^{\circledR}$ Loline}

- Indirect design with complete frost protection - ideal for even the coldest of climates.

- Features drain-back heat exchange technology, assuring you of reliable solar performance in any weather extreme.

- Electric boost and integrated or remote Gas boost models available.

- The split design reduces the structural load on your roof.

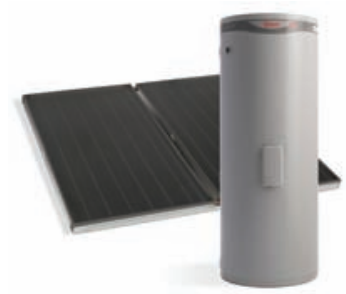

Loline

- The multi-riser solar collectors efficiently absorb energy from the sun.

- Economical to buy.

- Automatic, electronic controls maximise solar gain.

Model Number: 511340/2HBT

\section{ROOF MOUNTED SYSTEMS}

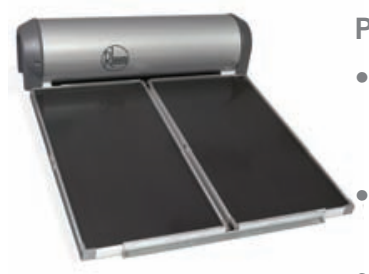

Premier $^{\circledR}$ Hiline

- Features an indirect heat exchange design, ensuring reliable operation in any climate.

Lightweight and durable stainless steel tank cylinder.

Model Number

- Space saving roof mounted installation.

- Suitable for use with most water quality types.

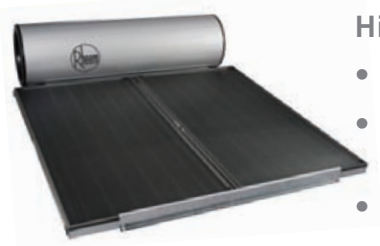

Hiline $^{\circledR}$

- Ideally suited to warmer climates.

- Does not require pumps and controllers.

- Relies on water moving through the solar collectors and into the

Model Number: tank using energy absorbed from 52S300/2NPT the sun. 


\section{HOW A HEAT PUMP WORKS}

Rheem Heat Pumps deliver hot water by efficiently utilising a free and abundant source of energy - the heat that is in the air around us. Refrigerant vapour compression technology enables the heat pump to intensify this heat, which is used to produce hot water. Rheem Heat Pumps are more efficient during warmer months, and will operate for less hours during the day than in colder months of the year. See illustration below.

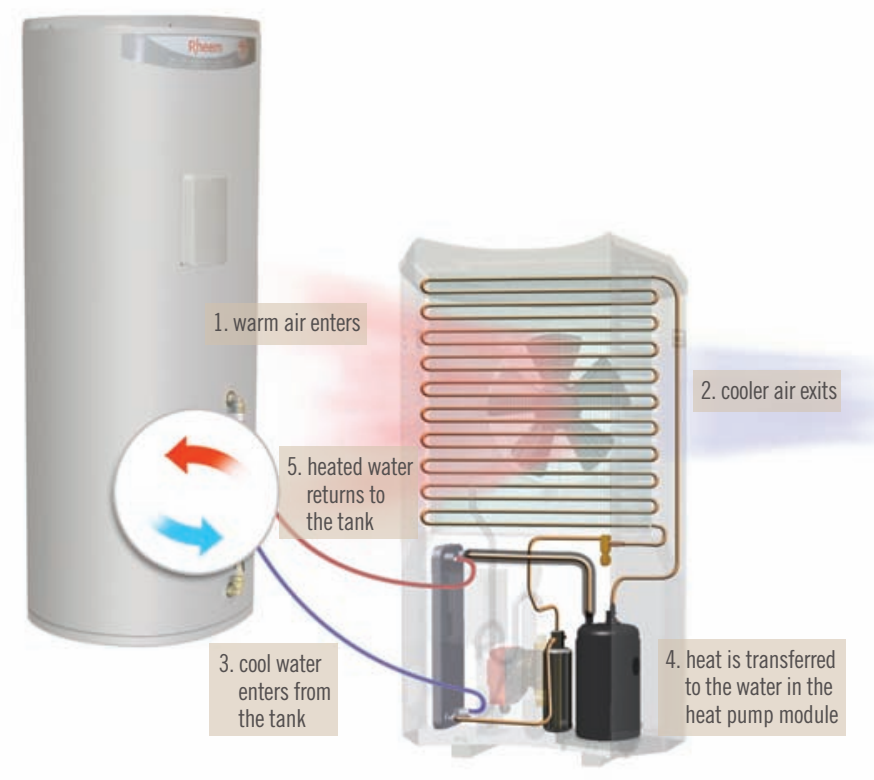

When power is available, the Heat Pump heating cycle will continue until the tank is full of hot water.

\section{THE RIGHT RHEEM FOR YOU}
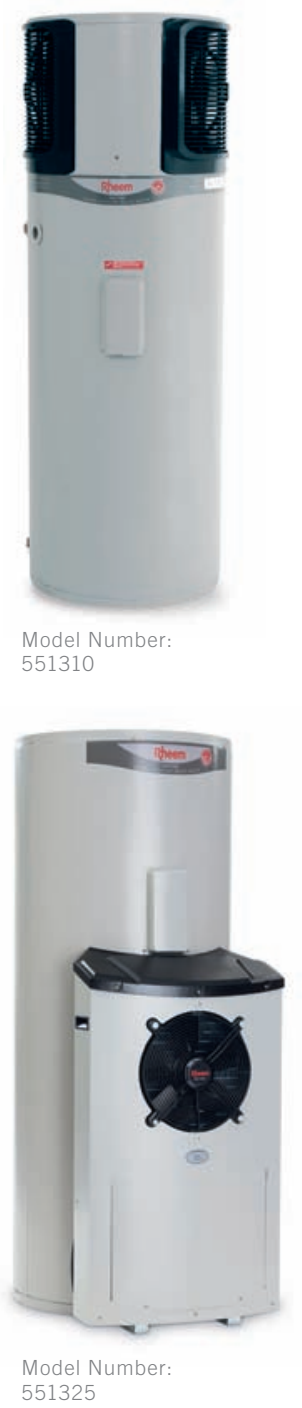

\section{MPi-Series}

- Heat Pump module is located well below the fence line, which keeps noise away from windows.

- Whisper technology enables quieter operation.

- Two piece interconnecting design allows for easy one-man installation.

- Most economical to buy and install.

- Ideal upgrade for an electric storage water heater, featuring common connections.

- Available in RheemPlus ${ }^{\circledR}$ $50^{\circ} \mathrm{C}$ temperature models.

- Suitable for warm and tropical climates.

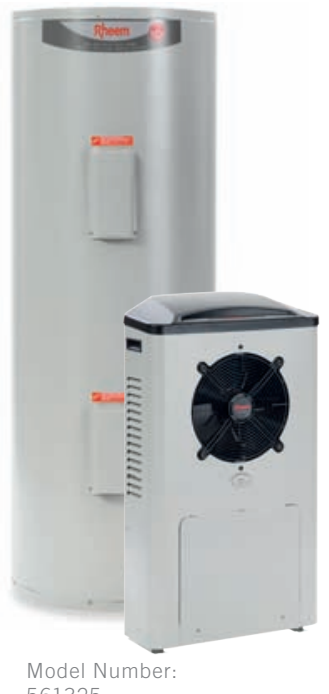

\section{MPs-Series}

- The tank and module can be separated by up to 4 metres, allowing you to install the tank inside a garage or laundry space.

- The Heat Pump module suits wall or slab mounting to make the best use of available space.

- $\mathrm{H}^{2} \mathrm{O}$ connections are environmentally responsible, as there is no risk of refrigerant escaping from them.

- Suitable for warm and tropical climates. 


\section{CHOOSING THE RIGHT CAPACITY RHEEM FOR YOUR HOME}

Many households change over time, so it's important to choose the right capacity to meet your needs both now and as your family grows.

Factors to consider in determining your hot water needs:

- Number of bathrooms or people using hot water at once.

- Adults and children in the home (teenagers will use more hot water than young children).

- Dishwashers or washing machines connected, that use hot water at the same time.

- Will a large bathtub or spa-bath be filled using hot water? Your needs may also depend on the climate and water pressure.

RHEEM OPTIMA ${ }^{\circledR}$

\begin{tabular}{|l|ccc|}
\hline Model (Litres) & 250 & 315 & 400 \\
\hline $\begin{array}{l}\mathrm{PPH}^{*}-\text { Off peak tariff } \\
\text { Single / Twin element }\end{array}$ & $1-3 / 2-3$ & $2-4 / 3-4$ & $4-6 / 4-7$ \\
\hline $\begin{array}{l}\mathrm{PPH}^{*} \text { - Continuous tariff } \\
\text { Single / Twin element }\end{array}$ & $3-5$ & $4-6$ & $5-9$ \\
\hline
\end{tabular}

RHEEMGLAS $^{\circledast}$ AND RHEEMPLUS $^{\circledast}$

\begin{tabular}{|c|c|c|c|c|}
\hline $\begin{array}{l}\text { Model (Litres) } \\
\text { Single element }\end{array}$ & 25 & 50 & 80 & 125 \\
\hline $\mathrm{PPH}^{*}$ - Off-peak tariff & - & - & - & - \\
\hline $\mathrm{PPH}^{*}$ - Continuous tariff & - & 1 & $1-2$ & $2-3$ \\
\hline $\begin{array}{l}\text { Model (Litres) } \\
\text { Single element }\end{array}$ & 160 & 250 & 315 & 400 \\
\hline $\mathrm{PPH}^{*}$ - Off-peak tariff & - & $1-3$ & $2-4$ & $4-6$ \\
\hline $\mathrm{PPH}^{*}$ - Continuous tariff & $2-4$ & $3-5$ & $4-6$ & $5-9$ \\
\hline $\begin{array}{l}\text { Model (Litres) } \\
\text { Twin element }\end{array}$ & 160 & 250 & 315 & 400 \\
\hline $\mathrm{PPH}^{*}$ - Off-peak tariff & $1-3$ & $2-3$ & $3-4$ & $4-7$ \\
\hline $\mathrm{PPH}^{*}$ - Continuous tariff & $2-4$ & $3-5$ & $4-6$ & $5-9$ \\
\hline
\end{tabular}

* People per household

\section{THE RIGHT RHEEM FOR YOU}

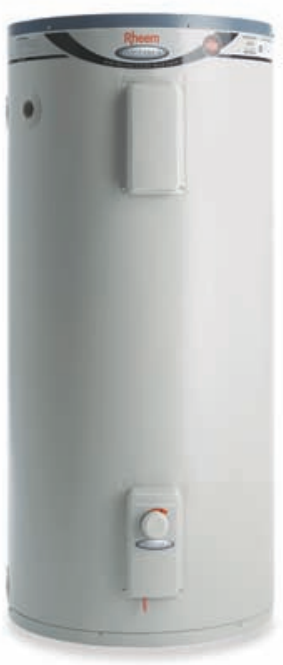

\section{RHEEM OPTIMA ${ }^{\circledR}$ ELECTRIC}

- Mains pressure at multiple taps

- 10 year warranty ${ }^{14}$

- Available in 250L, 315L \& 400L capacities

- Designed for economical Off-peak energy tariffs

- Twin element daytime boost models available

- User adjustable thermostat 462 Series

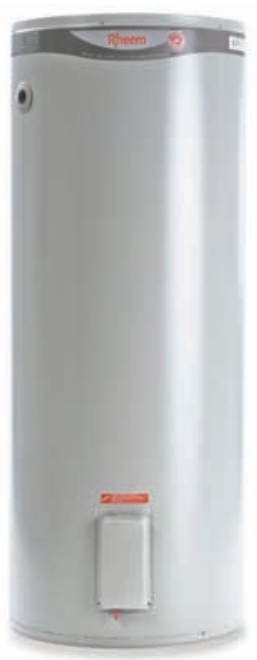

Model Number 111 Series

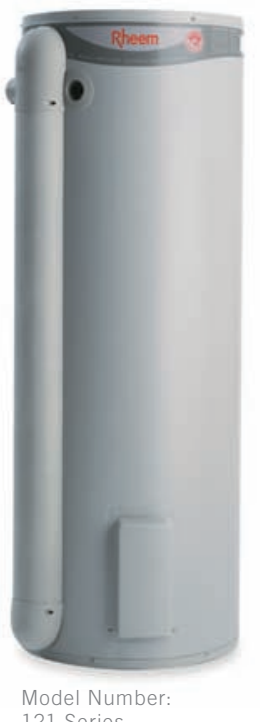

\section{RHEEMPLUS $^{\circledR}$ ELECTRIC}

- Mains pressure at multiple taps

- 7 year warranty ${ }^{13}$

- $50^{\circ} \mathrm{C}$ maximum

temperature delivery ${ }^{15}$

- Single element

- Left hand connection

- Available in $125 \mathrm{~L}, 160 \mathrm{~L}, 250 \mathrm{~L}$ \& 315L capacities 


\section{RHEEM GAS STORAGE HOT WATER}

\section{MAINS PRESSURE HOT WATER WHEN YOU NEED IT}

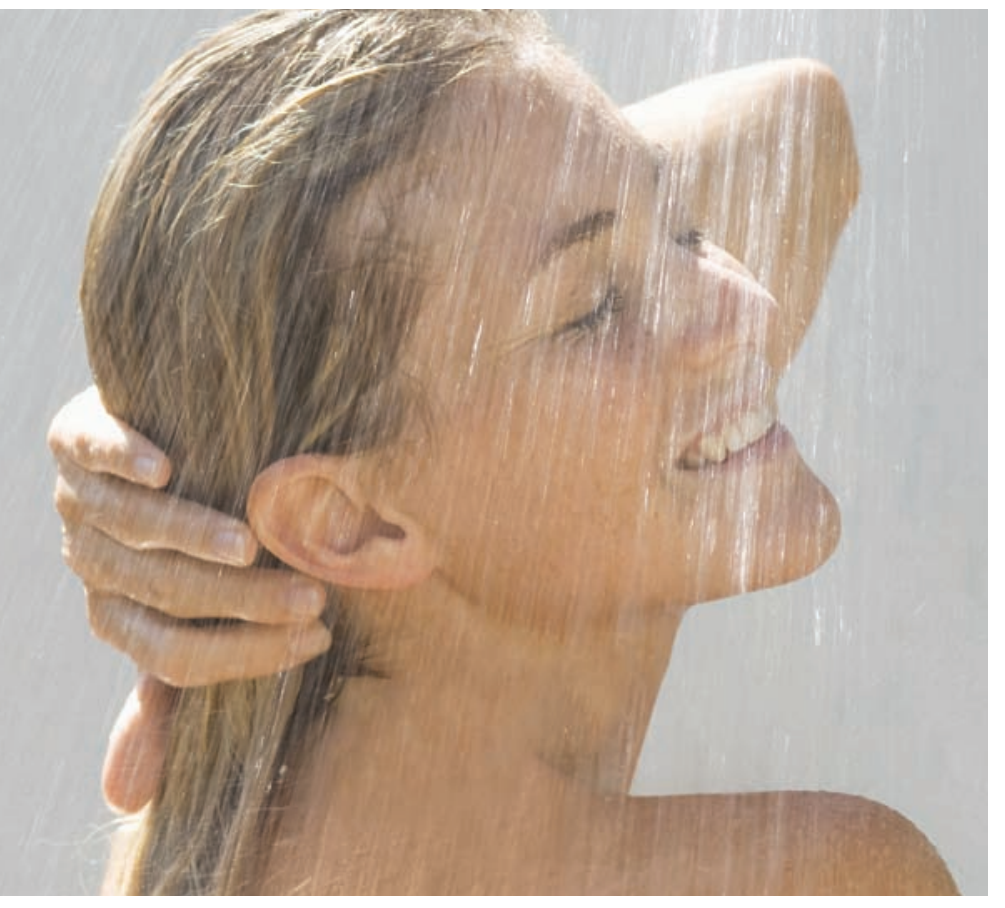

Mains pressure gas storage water heaters deliver hot water instantly, as they keep a generous quantity stored hot and ready for your use. As they are at mains pressure, you can be sure of a strong flow of hot water, and the ability to service multiple showers or hot water needs at once. A choice of 4 and 5 Star models, in a range of capacities means there is a model for every budget and family. And should you ever run short, Rheem's high recovery models will have you back in hot water fast.

\section{Star energy efficient} Rheem Gas Storage water heaters are good for the environment.

\section{FACTORS TO CONSIDER:}

Purchase, Installation and Running costs:

- Gas Storage systems are a relatively inexpensive solution to your hot water needs. There is a Rheem model to suit just about every budget. If replacing an existing gas unit, there is probably a Rheem model which can simply be installed in the same space.

- Higher efficiency Gas Storage water heaters cost less to run. As a guide, every extra energy-rating star represents approx $7 \%$ less gas usage, which means savings in energy bills.

\section{Capacity:}

- Gas Storage heaters are rated by their storage capacity and also their "recovery rate". This is the quantity that can be fully reheated in one hour; the higher this rate the faster you can be back in hot water.

\begin{tabular}{|c|c|c|c|}
\hline RHEEM STELLAR ${ }^{\circledR}$ & 330 & & 360 \\
\hline \multicolumn{4}{|l|}{ Number of People } \\
\hline Moderate Climate & $2-5$ & \multicolumn{2}{|r|}{$3-6$} \\
\hline Cool Climate & $2-4$ & \multicolumn{2}{|r|}{$3-5$} \\
\hline RHEEM 5 STAR & 265 & \multicolumn{2}{|r|}{295} \\
\hline \multicolumn{4}{|l|}{ Number of People } \\
\hline Moderate Climate & $2-4$ & \multicolumn{2}{|r|}{$3-5$} \\
\hline Cool Climate & $2-3$ & \multicolumn{2}{|r|}{$3-4$} \\
\hline RHEEM 4 STAR $^{+}$ & 90 & 135 & 170 \\
\hline \multicolumn{4}{|l|}{ Number of People } \\
\hline Moderate Climate & $1-3$ & $2-4$ & $3-5$ \\
\hline Cool Climate & $1-2$ & $2-3$ & $3-4$ \\
\hline RHEEM 3 STAR & 90 & 135 & 170 \\
\hline \multicolumn{4}{|l|}{ Number of People } \\
\hline Moderate Climate & $1-3$ & $2-4$ & $3-5$ \\
\hline Cool Climate & $1-2$ & $2-3$ & $3-4$ \\
\hline RHEEM INDOOR* & 135 & & 170 \\
\hline \multicolumn{4}{|l|}{ Number of People } \\
\hline Moderate Climate & $2-4$ & & $3-5$ \\
\hline Cool Climate & $2-3$ & & $3-4$ \\
\hline
\end{tabular}




\section{WHY RHEEM GAS STORAGE?}

5 Star energy rating models save you money and are good for the environment.

Designed for Australia's tough conditions, using 70 years of experience in Australia.

5,7 or $\mathbf{1 0}$ year warranty models available. ${ }^{17,} 18,19$

Capacities to suit most family sizes and hot water requirement, starting from 90 Litres.

Fast hot water recovery of up to 200 Litres per hour available. ${ }^{16}$

High recovery Rheem Stellar models for high-demand installations.

Mains pressure water delivery for steady, hot and strong hot water.

Indoor models also available (3 star energy rating).

The ability to service multiple uses at once without losing hot water pressure.

Full technical support through Rheem's National Service Network.

Available to suit Natural Gas or Propane.

\section{THE RIGHT RHEEM FOR YOU}

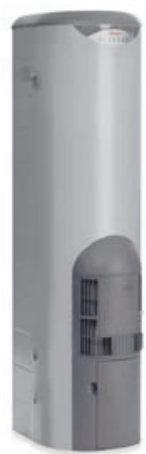

Model Number: 850 Series

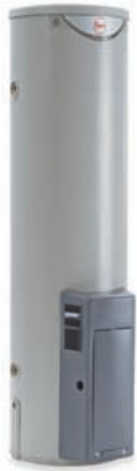

Model Number: 350/354 Series

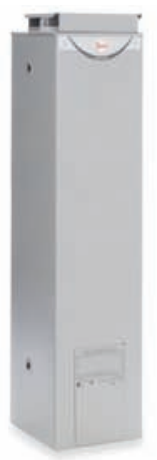

Model Number: 347 Series

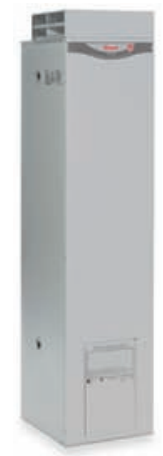

Model Number: 311 Series

\section{RHEEM STELLAR ${ }^{\circledR}$}

- 5 Star energy efficiency

- High recovery $200 \mathrm{~L} /$ hour of hot water ${ }^{16}$

- Mains pressure at multiple taps

- 330L or 360L first hour capacity of hot water ${ }^{16}$

- 10 year warranty ${ }^{19}$

- Modern design that complements any home

\section{RHEEM 5 STAR}

- 5 Star energy efficiency

- Mains pressure at multiple taps

- Strong recovery

- 272L or 302L first hour capacity of hot water ${ }^{16}$

- 5 year warranty ${ }^{17}$

\section{RHEEMPLUS $^{\circledR}$}

- Available in RheemPlus ${ }^{\circledR} 50^{\circ} \mathrm{C}$ temperature models

- No tempering valve required

- Adjustable to deliver higher temperatures (complying with AS 3498)

\section{RHEEM 4 STAR}

- 90L, 135L and 170 L capacities

- 4 Star energy efficiency

- Mains pressure

- Hi-temp thermostat, so you need less hot water ${ }^{\dagger}$

- 7 year warranty ${ }^{18}$

Based on the most common temperature $43^{\circ} \mathrm{C}$ showe through a 9 litre/minute showerhead mixing with cold water at $10^{\circ} \mathrm{C}$ Rheem 4 star 347 Series with thermostat set at $73^{\circ} \mathrm{C}$ delivers $15-20 \%$ more continual shower time than the Rheem 3 Star 311 Series with thermostat time than the Rheem 3 Star 311 Series with thermostat set at $65^{\circ} \mathrm{C}$

\section{RHEEM 3 STAR}

- 90L, 135L and 170L capacities

- Mains pressure

- 5 year warranty ${ }^{17}$

- Indoor models available (not shown)

- 3 Star energy efficiency

* Not available in NSW 


\section{RHEEM CONTINUDUS FLOW GAS HOT WATER}

\section{CONTINUOUS HOT WATER WHEN YOU NEED IT}

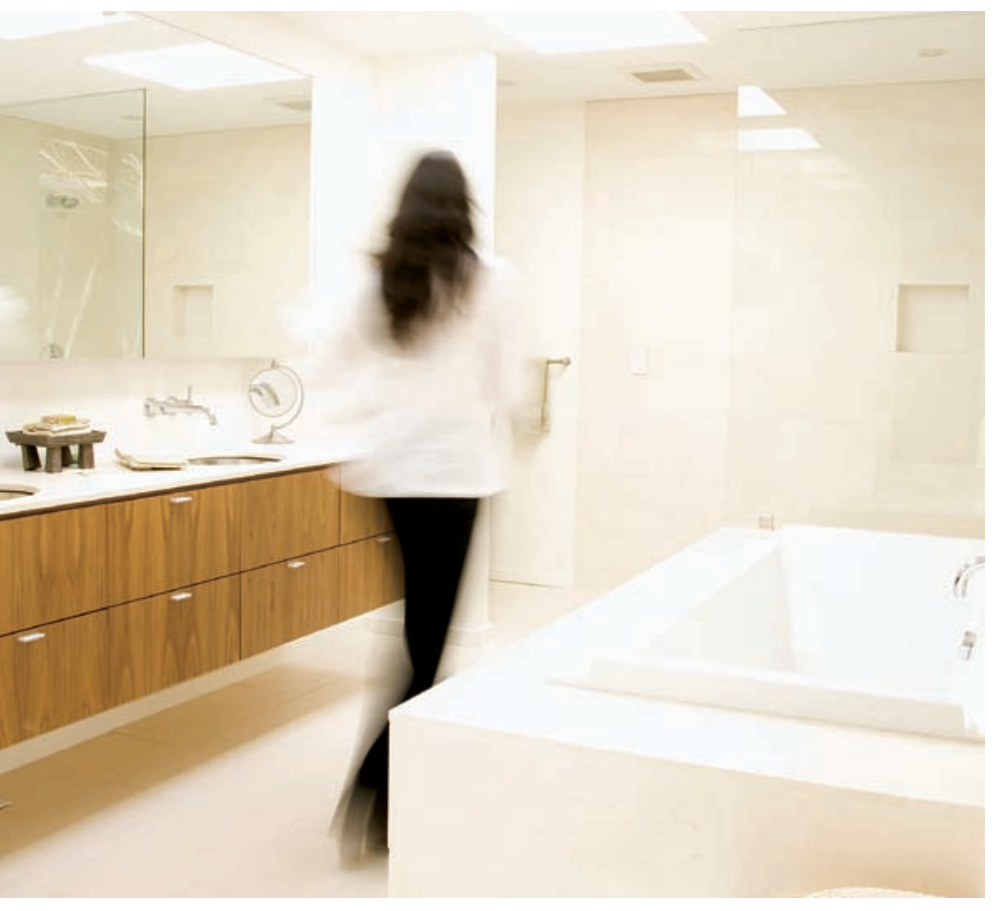

Continuous Flow gas water heaters deliver hot water that will never run out because they heat water when you need it, for as long as you need it. Continuous Flow water heaters work differently from storage water heaters, only heating on demand rather than heating and storing water until needed. 5 Star and better energy efficient Rheem Continuous Flow heaters are good for the environment. Mounted to the wall and taking up less space, they are ideal for a compact home site or apartment.

$5^{+}$Star energy efficient Rheem Continuous Flow for hot water that never runs out.
WITH RHEEM YOU'RE IN CONTROL

Rheem delivers added safety by putting you in control of the hot water in your home.

Rheem Standard and Deluxe Electronic Temperature Controllers are optional on all models, allowing you to choose the exact temperature you need and to guard against scalding. Rheem Bathroom Controllers can be set up to $50^{\circ} \mathrm{C}$. Deluxe Controllers also offer a "bath fill" mode, to turn off the water flow once the bath is filled.

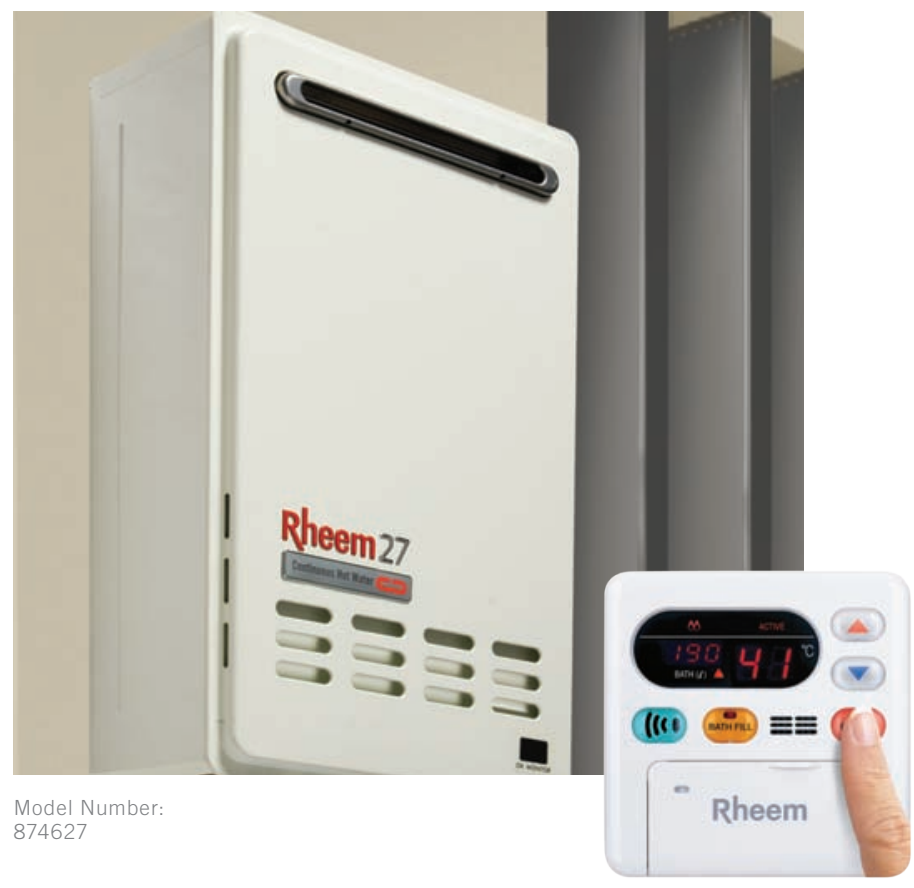




\section{WHY RHEEM CONTINUOUS FLOW?}

Sizes to suit every home, apartment or family $12 \mathrm{~L}, 16 \mathrm{~L}, 18 \mathrm{~L}, 20 \mathrm{~L}, 24 \mathrm{~L}$ and $27 \mathrm{~L} /$ minute capacities. ${ }^{20}$ 5 Star and better energy rating to save money and the environment.

\section{Designed for Australia's tough conditions, combining} international expertise with over 70 years of experience in Australia.

\section{0 year warranty. ${ }^{22}$}

Flamesafe ${ }^{\circledR}$ overheat protection, which automatically shuts down your heater should it overheat.

Rheem EZ LINK ${ }^{\circledR}$ delivers up to $54 \mathrm{~L} /$ minute by linking 2 Rheem units to act as one, thereby doubling capacity. ${ }^{20}$

Rheem Q Factor ${ }^{\mathrm{TM}}$ for rapid hot water every time, without the fluctuation when multiple taps demand hot water, which can occur with some Continuous Flow units.

Family safety with electronic control for accurate and reliable water temperature, reducing the risk of scalding.

Electronic Remote Temperature Controllers for accurate setting of the ideal and safest temperature.

Solar ready Rheem $70^{\circ} \mathrm{C}$ capable models are compatible with solar systems without the need for special fittings. ${ }^{25}$

Factory pre-set $50^{\circ} \mathrm{C}$ models available, requiring no tempering valve. ${ }^{21}$

Full technical support through Rheem's National Service Network.

Compact size for flexibility in design to suit every installation.

Available to suit either Natural Gas or Propane Indoor 27L model available, with matched flue system.

\section{DESIGNED TO DISAPPEAR}

Your Rheem Continuous Flow water heater can be neatly hidden away to save even more space:

Pipe covers in matching colour will conceal all pipework. Recess boxes will set your Rheem into the wall.

\section{RHEEM WATER STAR ${ }^{\circledR}$ \\ WATER SAVING SYSTEM}

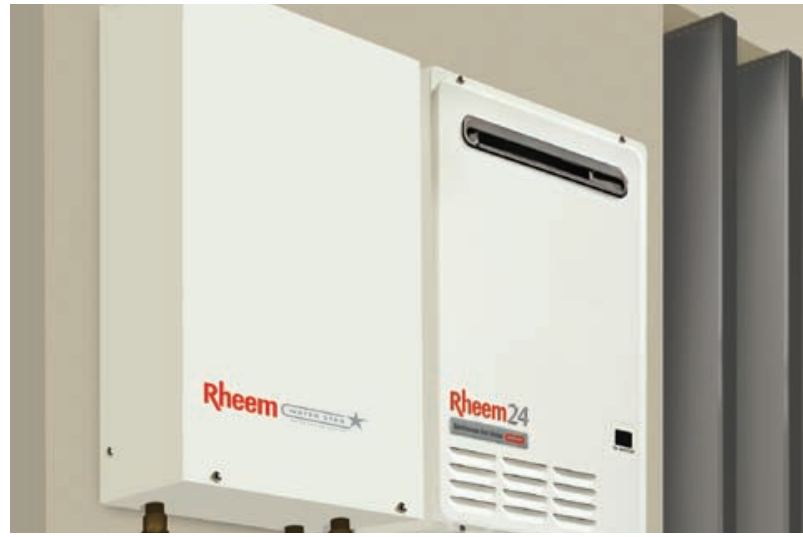

Rheem Water Star is a water-saving device suitable for use with all brands of continuous flow water heaters. It is an easy way to have faster hot water, minimise water wastage and reduce energy usage in the home.

Continuous Flow water heaters can waste water waiting for the heating mechanism to reach full temperature.

Independent research shows a Continuous Flow water heater in a typical home can on average waste between 1.2 and $2.5 \mathrm{~L}$ of water when the hot water tap is turned on which equates to $135 \mathrm{~L}$ per day. ${ }^{24}$

By capturing cold/warm water for re-heating later, while releasing already-hot water for instant use Rheem Water Star ensures hot water flows immediately, saving water and energy.

Rheem Water Star is easily installed and comes with a 5 year warranty. ${ }^{23}$ There is no extra electrical wiring, it has its own plug-in point for the water heater and is the same size as a Continuous flow water heater. Rheem Water Star cannot be installed with a $50^{\circ} \mathrm{C}$ Continuous Flow Water Heater or with remote temperature controllers.

A tempering valve may be required to be fitted in accordance with AS/NZS 3500:4 


\section{RHEEM SOLAR \\ HOT WATER PRDDUCT DATA}

\section{RHEEM PREMIER ${ }^{\circledR}$ HILINE SOLAR HOT WATER HEATER}

GAS BOOSTED

$\begin{array}{lr}\text { MODEL } & \\ \text { Storage Capacity } & \text { L } \\ \text { Solar Collectors } & \text { S20 } \\ \text { Booster Type } & \\ \text { Boost Capacity } & \mathrm{L} \\ \text { People Per Household } & \\ \text { Dimensions \& Specifications } & \\ \text { Height (A) } & \mathrm{mm} \\ \text { Width (B) } & \mathrm{mm} \\ \text { Depth (C) } & \mathrm{mm} \\ \text { Weight Empty - Tank } & \mathrm{kg} \\ \text { Weight Full - Tank } & \mathrm{kg} \\ \text { Weight Empty - Solar Collectors } & \mathrm{kg} \\ \text { Weight Full - Solar Collectors } & \mathrm{kg}\end{array}$

$52 \mathrm{H} 180 \mathrm{~K} / 1 \mathrm{~S}-\mathrm{G}$

180

Gas-Remote

27L/min

1-3

2490

1495

561
48

48
237

48

52

$52 \mathrm{H} 300 \mathrm{~K} / 2 \mathrm{~S}-\mathrm{G}$
300
2
Gas - Remote
$27 \mathrm{~L} / \mathrm{min}$
$2-5$

2490
2180
561
68
386
96
104

ELECTRIC BOOSTED

$\begin{array}{cc}52 \mathrm{H} 180 \mathrm{~K} / 1 \mathrm{~S} & 52 \mathrm{H} 300 \mathrm{~K} / 2 \mathrm{~S} \\ 180 & 300 \\ 1 & 2 \\ \text { Electric } & \text { Electric } \\ 90 & 15 \mathrm{O} \\ 1-2 & 2-5 \\ & \\ 2490 & 2490 \\ 1495 & 2198 \\ 561 & 561 \\ 48 & 68 \\ 237 & 386 \\ 48 & 96 \\ 52 & 104\end{array}$

\section{RHEEM HILINE ${ }^{\circledR}$ SOLAR HOT WATER HEATER}

GAS BOOSTED

MODEL

Storage Capacity

Solar Collectors

Booster Type

Boost Capacity

People Per Household

Dimensions \& Specifications

Height (A)

Width (B)

Depth (C)

Weight Empty - Tank
Weight Fuli - Tank

Weight Empty - Solar Collectors

Weight Full - Solar Collectors

L
NPT20
L

$\mathrm{mm}$
$\mathrm{mm}$
$\mathrm{mm}$
$\mathrm{kg}$
$\mathrm{kg}$
$\mathrm{kg}$
$\mathrm{kg}$

52S160/1NPT-G

Gas - Remote

24L/min

1-3

2490

1070

540
70

230

36

38

$52 \mathrm{S300/2NPT-G}$
300
2
Gas - Remote
$24 \mathrm{~L} / \mathrm{min}$
$2-5$
2490
1865
540
100
400
72
75

ELECTRIC BOOSTED

$\begin{array}{cc}52 \mathrm{~S} 160 / 1 \mathrm{NPT} & 52 \mathrm{~S} 300 / 2 \mathrm{NPT} \\ 160 & 300 \\ 1 & 2 \\ \text { Electric } & \text { Electric } \\ 80 & 160 \\ 1-2 & 2-5 \\ 2490 & 2490 \\ 1070 & 1865 \\ 540 & 540 \\ 70 & 100 \\ 230 & 400 \\ 36 & 72 \\ 38 & 75\end{array}$

\section{RHEEM PREMIER ${ }^{\circledR}$ LOLINE SOLAR HOT WATER HEATER}

\section{GAS BOOSTED}

\section{MODEL}

Storage Capacity

Solar Collectors

Booster Type

Boost Capacity

People Per Household

Dimensions \& Specifications

Height (A)

Width (B)

Depth (C)

Cold In (D)

Weight Empty - Tank

Weight Full - Tank

Weight Empty - Solar Collectors

Weight Full - Solar Collectors

$\begin{array}{cccc} & 596270 / 1 \mathrm{~S} & 596270 / 2 \mathrm{~S} & 590270 / 1 \mathrm{~S}-\mathrm{G} \\ \mathrm{L} & 596270 / 1 \mathrm{~T} & 596270 / 2 \mathrm{~T} & 590270 / 1 \mathrm{~T}-\mathrm{G} \\ & 270 & 270 & 270 \\ & 1 & 2 & 1 \\ \mathrm{~L} & \begin{array}{c}\text { Gas }- \text { Integrated } \\ 27 \mathrm{~L} / \mathrm{min}\end{array} & \begin{array}{c}\text { Gas }- \text { Integrated } \\ 27 \mathrm{~L} / \mathrm{min}\end{array} & \begin{array}{c}\text { Gas }- \text { Remote } \\ 27 \mathrm{~L} / \mathrm{min}\end{array} \\ & 2-5 & 2-5 & 2-5 \\ \mathrm{~mm} & 1775 & 1775 & 1775 \\ \mathrm{~mm} & 648 & 648 & 648 \\ \mathrm{~mm} & 890 & 890 & 682 \\ \mathrm{~mm} & 377 & 377 & 377 \\ \mathrm{~mm} & 1078 & 1078 & 1078 \\ \mathrm{~kg} & 141 & 141 & 145 \\ \mathrm{~kg} & 411 & 411 & 415 \\ \mathrm{~kg} & 48 & 96 & 48 \\ \mathrm{~kg} & 52 & 104 & 52\end{array}$

\section{ELECTRIC BOOSTED}

$590270 / 2 \mathrm{~S}-\mathrm{G}$
$590270 / 2 \mathrm{~T}-\mathrm{G}$
270
2
Gas - Remote
$27 \mathrm{~L} / \mathrm{min}$
$2-5$

1775
648
682
377
1078
145
415
96
104

$\begin{array}{cc}591270 / 2 S & 591270 / 3 S \\ 591270 / 2 T & 591270 / 3 T \\ 270 & 270 \\ 2 & 3 \\ \text { Electric } & \text { Electric } \\ 125 & 125 \\ 1-3 & 2-4 \\ & \\ 1775 & 1775 \\ 648 & 648 \\ 682 & 682 \\ 377 & 377 \\ 1078 & 1078 \\ 146 & 146 \\ 416 & 416 \\ 96 & 144 \\ 104 & 156\end{array}$

\section{RHEEM LOLINE SOLAR HOT WATER HEATER}

GAS BOOSTED

ELECTRIC BOOSTED

\section{MODEL}

Storage Capacity

Solar Collectors

Booster Type

Boost Capacity

People Per Household

Dimensions \& Specifications

Height (A)

Width (B)

Depth (C)
Cold In (D)

Hot Out (E)

Weight Empty - Tank
Weight Full - Tank

Weight Empty - Solar Collectors

Weight Full - Solar Collectors

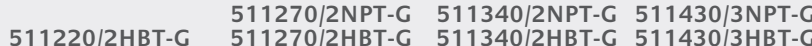

220

Gas - Integrated

$$
20
$$

$$
270
$$

Gas - Remote

\section{5}

592
670

670
102

1113

94
314

314
72

76

$\begin{array}{cc}325 & 410 \\ 2 & 3 \\ \begin{array}{c}\text { Gas }- \text { Remote } \\ 24 L / m i n\end{array} & \begin{array}{c}\text { Gas }- \text { Remote } \\ 24 L / m i n\end{array} \\ 2-6 & 3-7 \\ 1640 & 1840 \\ 640 & 690 \\ 680 & 730 \\ 73 & 81 \\ 1357 & 1519 \\ 87 & 111 \\ 412 & 521 \\ 72 & 108 \\ 76 & 113\end{array}$

511270/2NPT 511340/2NPT 511430/3NPT $511270 / 2 \mathrm{HBT} 511340 / 2 \mathrm{HBT} 511430 / 3 \mathrm{HBT}$

270
2
Electric
160
$1-3$
1395
640
680
73
1117
71
341
72
76

$\begin{array}{cc}325 & 410 \\ 2 & 3 \\ \text { Electric } & \text { Electric } \\ 200 & 285 \\ 2-4 & 3-6 \\ & \\ 1640 & 1840 \\ 640 & 690 \\ 680 & 730 \\ 73 & 81 \\ 1357 & 1519 \\ 87 & 111 \\ 412 & 521 \\ 72 & 108 \\ 76 & 113\end{array}$

HBT Collectors are only available for installation in zones $3 \& 4$. 

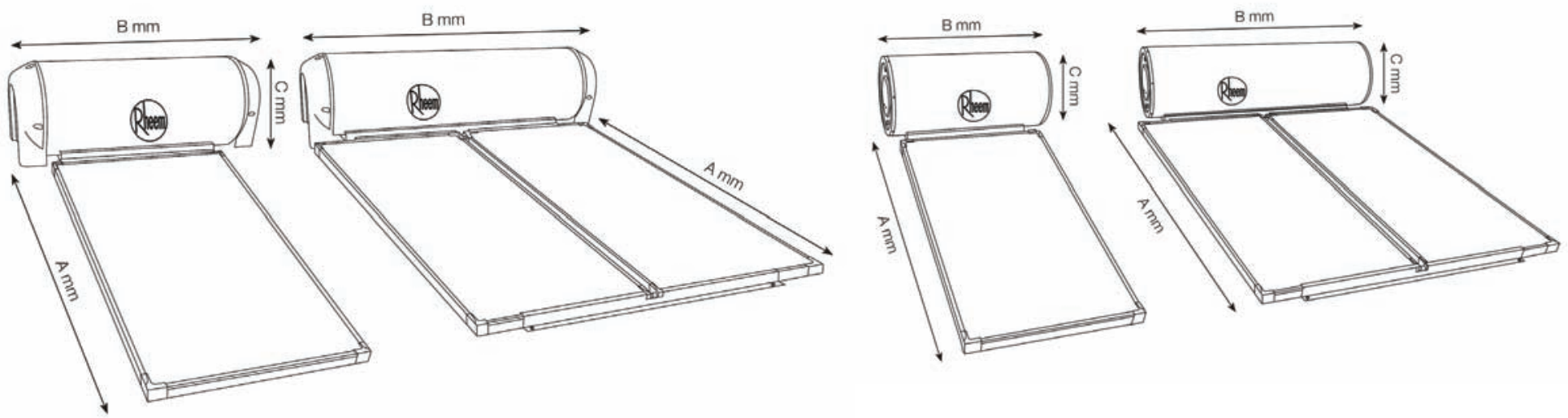

RHEEM PREMIER ${ }^{\circledR}$ LOLINE SOLAR HOT WATER HEATER
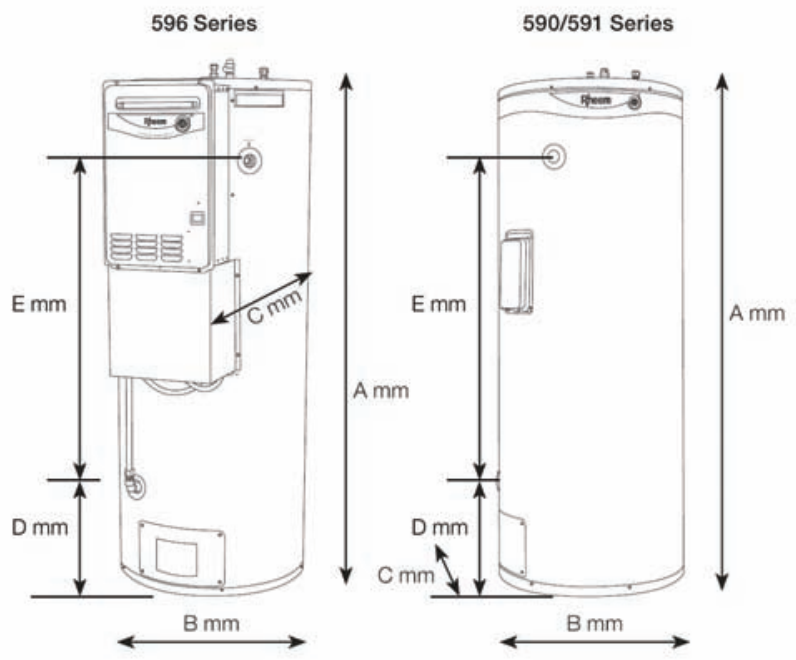

RHEEM LOLINE SOLAR HOT WATER HEATER
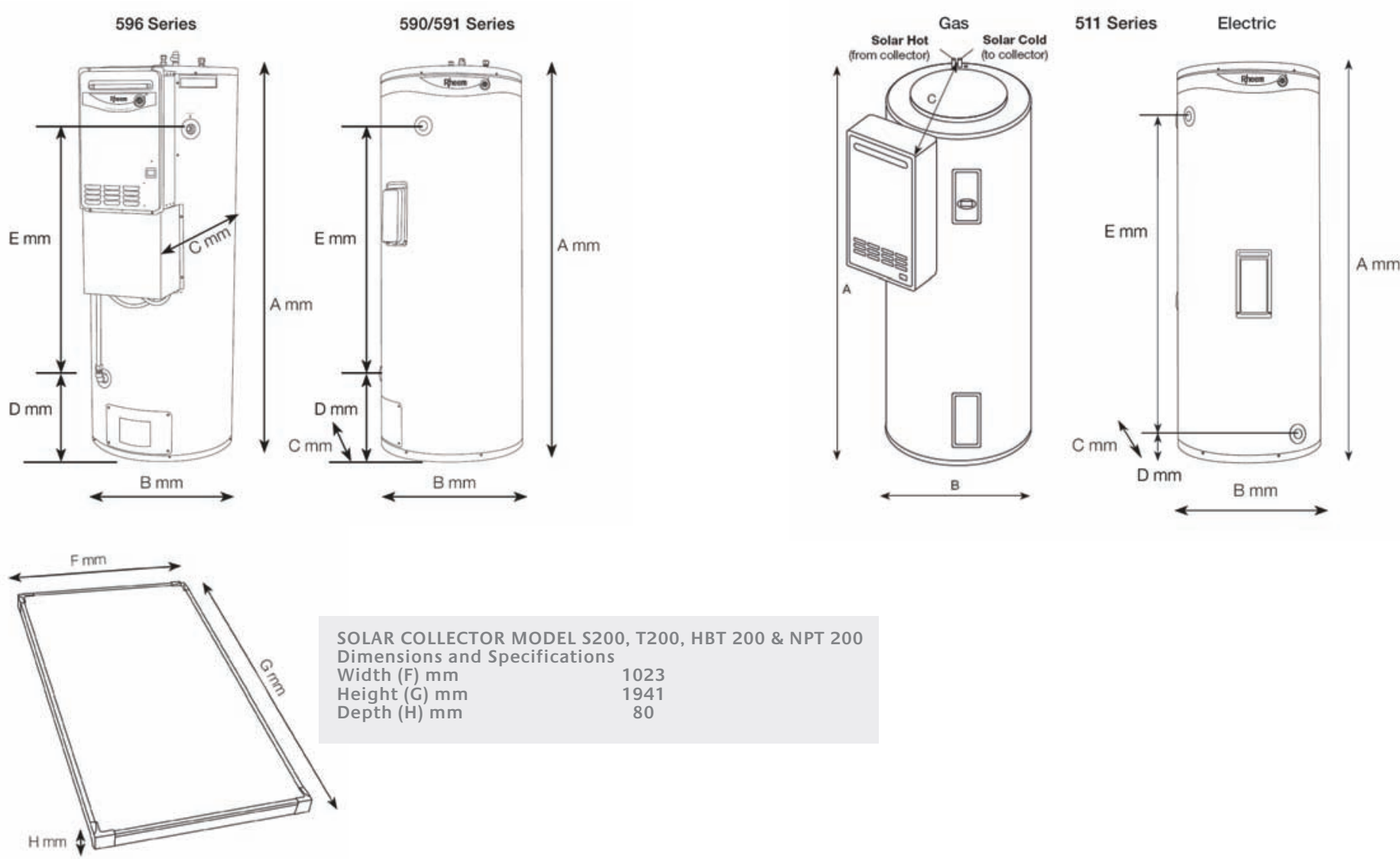

Warranty, terms and conditions

1. Energy reduction of up to $70 \%$ based on Australian Government Approved TRNSYS simulation modelling and apply when replacing an electric water heater with a Rheem Solar water heater in Zone 3.

2. Rheem Premier ${ }^{\circledast}$ Loline / Loline / Hiline ${ }^{\circledR} 5$ year cylinder, heat exchanger and solar panels, 3 year labour on cylinder and heat exchanger, 1 year parts including labour. Applies to domestic installations only. Conditions apply, see the Rheem warranty set out in the product's Owner's Guide or view it at www.rheem.com.au/warranty

3. Rheem Premier ${ }^{\circledR}$ Hiline 6 year cylinder, 5 year solar panels, 1 year labour on cylinder, 1 year parts including labour. Conditions apply, see the Rheem warranty set out in the product's Owner's Guide or view it at www.rheem.com.au/warranty

4. Greenhouse gas emission savings based upon installing a 511340/2NPT Solar Hot Water heater, when replacing an electric water heater.

5. Any financial savings will vary depending upon type of Rheem Solar system installed, orientation and inclination of the solar collectors, type of water heater being replaced, hot water consumption and fuel tariff. Maximum financial savings off your hot water bill are achievable when replacing an electric water heater on continuous tariff.

6. Eligibility criteria apply. Rebates and incentive schemes are subject to change or cancellation without notice.

7. 591270 should be used with T200 solar panels in Victoria and South Australia.

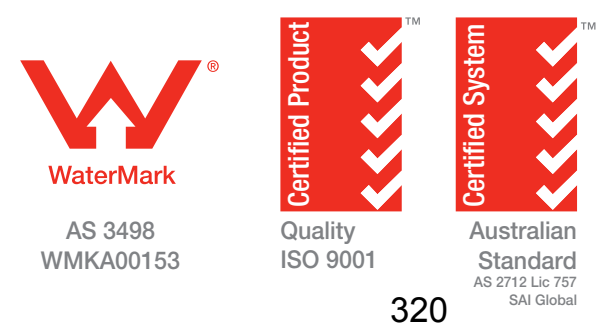




\section{RHEEM HEAT PUMP HOT WATER PRDDUCT DATA}

\begin{tabular}{|c|c|c|c|c|}
\hline & HDi-310 & MPi-325 & MPi-410 & MPs-325 \\
\hline $\begin{array}{l}\text { Product Code } \\
\text { Number of People (Moderate Climate) }\end{array}$ & $\begin{array}{c}551310 \\
3-6\end{array}$ & $\begin{array}{c}551325 \\
2-5\end{array}$ & $\begin{array}{c}551410 \\
2-6\end{array}$ & $\begin{array}{c}561325 \\
2-4\end{array}$ \\
\hline $\begin{array}{l}\text { Dimensions } \\
\text { Height }(\mathrm{mm})\end{array}$ & & & & \\
\hline Module: D & N/A & 1018 & 1018 & 1034 \\
\hline Tank: A & 1870 & 1631 & 1842 & 1630 \\
\hline \multicolumn{5}{|l|}{ Width (mm) } \\
\hline Module: E & N/A & N/A & N/A & 575 \\
\hline Tank: B & 670 & 863 & 931 & 640 \\
\hline \multicolumn{5}{|l|}{ Depth (mm) } \\
\hline Module: F & N/A & N/A & N/A & 332 \\
\hline Tank: C & 679 & 638 & 686 & N/A \\
\hline \multicolumn{5}{|l|}{ Weight } \\
\hline Heat Pump module (kg) & 48 & 48 & 48 & 50 \\
\hline Tank (kg) & 87 & 88 & 118 & 88 \\
\hline \multicolumn{5}{|l|}{ Technical } \\
\hline Capacity (L) & 310 & 325 & 410 & 325 \\
\hline Power input (Watts) & 1300 & 800 & 800 & 800 \\
\hline Refrigerant & $\mathrm{R} 134 \mathrm{a}$ & $\mathrm{R} 134 \mathrm{a}$ & $\mathrm{R} 134 \mathrm{a}$ & $\mathrm{R} 134 \mathrm{a}$ \\
\hline Element Sizes (kW) & 2.4 or 3.6 & $1.8,2.4$ or 3.6 & 2.4 or 3.6 & 2.4 or 3.6 \\
\hline Boost Capacity (L) & 220 & 180 & 200 & 180 \\
\hline \multicolumn{5}{|l|}{ Water Connections \& Settings } \\
\hline Inlet (RP) & $3 / 4 / 20$ & $3 / 4 / 20$ & $3 / 4 / 20$ & $3 / 4 / 20$ \\
\hline Outlet (RP) & $3 / 4 / 20$ & $3 / 4 / 20$ & $3 / 4 / 20$ & $3 / 4 / 20$ \\
\hline Tank Relief Valve Setting (kPa) & 1000 & 1000 & 1000 & 1000 \\
\hline ECV Setting (kPa) & 850 & 850 & 850 & 850 \\
\hline \multicolumn{5}{|l|}{ Maximum Mains Pressure } \\
\hline With ECV (kPa) & 680 & 680 & 680 & 680 \\
\hline Without ECV (kPa) & 800 & 800 & 800 & 800 \\
\hline Min. Water Supply Pressure (kPa) & 200 & 200 & 200 & 200 \\
\hline
\end{tabular}

MPi-410 only recommended for Nth NSW \& QLD.

HDi-310

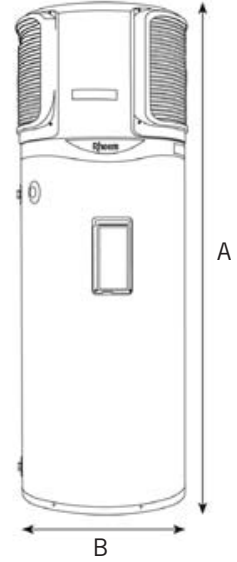

MPi Series

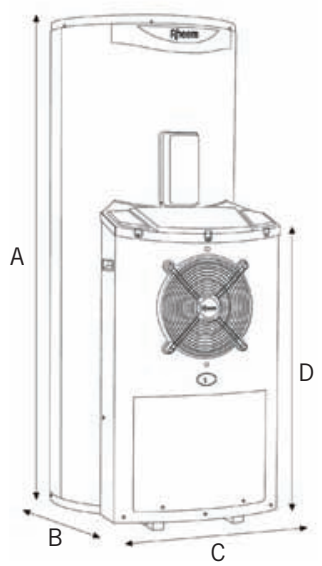

MPs-325

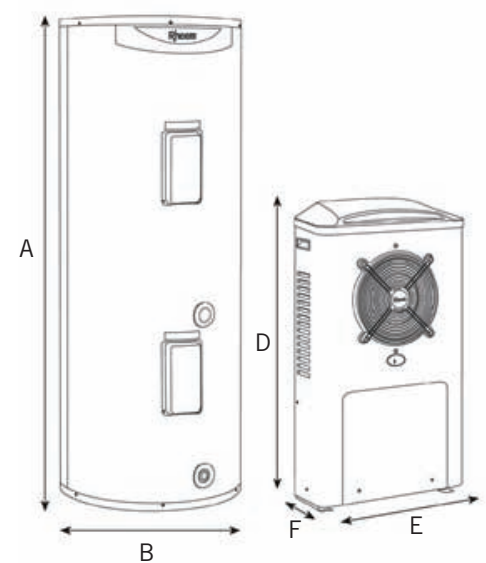

Warranty, terms and conditions

8. The impact on an electricity account will depend on the tariff arrangement of the water heater being replaced and where you live. These Rheem Heat Pump water heaters (model dependant) are recommended for connection to either 24 hour continuous tariff or extended off peak (min 16 hours/day). Before purchase consult your energy provider for more information on cost comparisons.

9. Heat Pump warranty conditions. 5 year cylinder warranty, 3 year labour on cylinder, 2 year on sealed system including labour, 1 year on all other parts and labour. Applies to domestic installations only. Amended warranty may apply where a government rebate has been received for the solar water heater. Phone 131031 for details. Conditions apply, see the Rheem warranty set out in the product's Owner's Guide or view it at www.rheem.com.au/warranty

10. Energy and greenhouse gas emissions reduction of up to $65 \%$ based on Australian Government Approved TRNSYS simulation modelling and apply when replacing an electric water heater with a Rheem Heat Pump water heater in Zone 3.

11. Assumes consumer eligibility for rebates. Eligibility criteria apply. Rebates and incentive schemes are subject to change or cancellation without notice.

12. Any financial savings will vary depending upon type of Rheem Heat Pump installed, type of water heater being replaced, hot water consumption and fuel tariff.

Maximum financial savings off your hot water bill are achievable when replacing an electric water heater on continuous tariff.

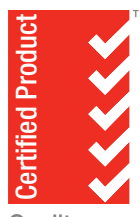

Quality ISO 9001

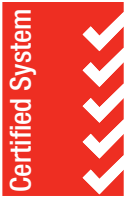

Australian

Standard

Standard
AS 2712 Lic 757 


\section{RHEEM ELECTRIC STORAGE HOT WATER PRDDUCT DATA}

\begin{tabular}{|c|c|c|c|c|c|c|c|c|c|c|}
\hline & & \multirow[t]{2}{*}{ Warranty } & \multicolumn{8}{|c|}{ Model } \\
\hline & & & 25 & 50 & 80 & 125 & 160 & 250 & 315 & 400 \\
\hline $\begin{array}{l}\text { Rheemglas }{ }^{\circledast} \text { Single Element } \\
\text { Rheemglas } \\
\text { Rheem Opin Element } \\
\text { Rhema Optima Single Element } \\
\text { Rheem Optima } \\
\text { RheemPlus }^{\circledR} \text { Single Element }\end{array}$ & & $\begin{array}{l}7 \text { years } \\
7 \text { years } \\
10 \text { years } \\
10 \text { years } \\
7 \text { years }\end{array}$ & $\begin{array}{l}111025 \\
- \\
- \\
- \\
-\end{array}$ & $\begin{array}{l}191050 \\
- \\
- \\
- \\
-\end{array}$ & $\begin{array}{l}111080 \\
- \\
- \\
- \\
-\end{array}$ & $\begin{array}{l}111125 \\
- \\
- \\
- \\
121125\end{array}$ & $\begin{array}{c}111160 \\
162160 \\
- \\
- \\
121160\end{array}$ & $\begin{array}{l}111250 \\
162250 \\
411250 \\
462250 \\
121250\end{array}$ & $\begin{array}{l}111315 \\
162315 \\
411315 \\
462315 \\
121315\end{array}$ & $\begin{array}{l}111400 \\
162400 \\
411400 \\
462400 \\
-\end{array}$ \\
\hline $\begin{array}{l}\text { Hot Water Delivery } \\
\text { Storage Capacity } \\
\text { Boost Capacity Twin Element }\end{array}$ & & $\begin{array}{l}\text { Litres } \\
\text { Litres } \\
\quad-\end{array}$ & $\begin{array}{l}20 \\
25 \\
-\end{array}$ & $\begin{array}{l}50 \\
53 \\
-\end{array}$ & $\begin{array}{l}80 \\
90 \\
-\end{array}$ & $\begin{array}{l}125 \\
135 \\
-\end{array}$ & $\begin{array}{l}160 \\
165 \\
45\end{array}$ & $\begin{array}{l}250 \\
270 \\
50\end{array}$ & $\begin{array}{c}315 \\
324 \\
50\end{array}$ & $\begin{array}{l}400 \\
412 \\
90\end{array}$ \\
\hline $\begin{array}{l}\text { Dimensions } \\
\text { Approx. Weight Empty }\end{array}$ & $\begin{array}{l}A \\
B \\
C \\
D \\
E \\
F \\
G \\
H \\
J \\
K \\
L\end{array}$ & $\begin{array}{l}\mathrm{mm} \\
\mathrm{mm} \\
\mathrm{mm} \\
\mathrm{mm} \\
\mathrm{mm} \\
\mathrm{mm} \\
\mathrm{mm} \\
\mathrm{deg} \\
\mathrm{deg} \\
\mathrm{mm} \\
\mathrm{mm} \\
\mathrm{Kg}\end{array}$ & $\begin{array}{l}390 \\
385 \\
420 \\
130 \\
116 \\
75 \\
- \\
26 \\
65 \\
- \\
- \\
18\end{array}$ & $\begin{array}{l}695 \\
393 \\
429 \\
397 \\
142 \\
80 \\
- \\
26 \\
59 \\
- \\
- \\
23\end{array}$ & $\begin{array}{l}940 \\
480 \\
515 \\
702 \\
64 \\
84 \\
- \\
23 \\
58 \\
- \\
- \\
34\end{array}$ & $\begin{array}{c}1340 \\
480 \\
515 \\
1102 \\
64 \\
84 \\
- \\
23 \\
58 \\
545 \\
183 \\
49\end{array}$ & $\begin{array}{c}1610 \\
480 \\
515 \\
1332 \\
104 \\
84 \\
1085 \\
23 \\
58 \\
545 \\
183 \\
57\end{array}$ & $\begin{array}{l}1395 \\
640 \\
700 \\
1117 \\
73 \\
128 \\
1005 \\
32 \\
88 \\
705 \\
262 \\
74\end{array}$ & $\begin{array}{l}1640 \\
640 \\
700 \\
1317 \\
113 \\
128 \\
1255 \\
32 \\
88 \\
705 \\
262 \\
89\end{array}$ & $\begin{array}{c}1840 \\
690 \\
755 \\
1479 \\
121 \\
129 \\
1346 \\
30 \\
83 \\
- \\
112\end{array}$ \\
\hline
\end{tabular}

$111,411,162,462$ and 121 models have left hand connections.

191 models have left and right hand connections and are available in 050 Litre delivery capacity only.

Rheemglas single element models with right hand connections only are available in 80 and 125 Litre delivery capacities and have a 171 prefix.

Technical data is subject to change.
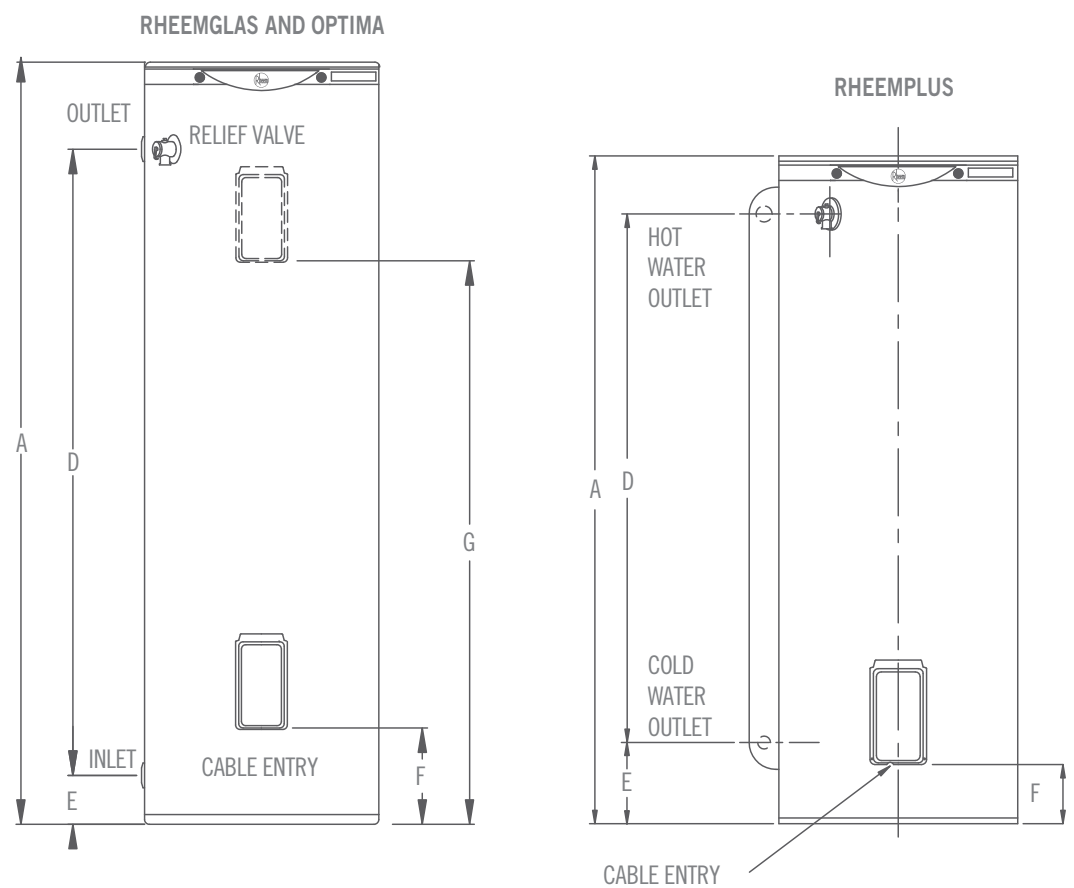

\begin{tabular}{|c|c|c|c|c|}
\hline \multicolumn{5}{|l|}{ RHEEM OPTIMA ${ }^{\circledR}$} \\
\hline Model (Litres) & 250 & \multicolumn{2}{|c|}{315} & 400 \\
\hline $\begin{array}{l}\text { PPH }^{*} \text { - Off peak tariff } \\
\text { Single / Twin }\end{array}$ & $1-3 / 2-3$ & \multicolumn{2}{|c|}{$2-4 / 3-4$} & $4-6 / 4-7$ \\
\hline $\begin{array}{l}\mathrm{PPH}^{*} \text { - Continuous tariff } \\
\text { Single / Twin }\end{array}$ & $3-5$ & \multicolumn{2}{|c|}{$4-6$} & $5-9$ \\
\hline \multicolumn{5}{|l|}{ RHEEMGLAS $^{\circledR}$ AND RHEEMPLUS ${ }^{\circledR}$} \\
\hline $\begin{array}{l}\text { Model (Litres) } \\
\text { single element }\end{array}$ & 25 & 50 & 80 & 125 \\
\hline $\mathrm{PPH}^{*}$ - Off-peak tariff & - & $\cdot$ & - & - \\
\hline $\mathrm{PPH}^{*}$ - Continuous tariff & - & 1 & $1-2$ & $2-3$ \\
\hline $\begin{array}{l}\text { Model (Litres) } \\
\text { single element }\end{array}$ & 160 & 250 & 315 & 400 \\
\hline $\mathrm{PPH}^{*}$ - Off-peak tariff & - & $1-3$ & $2-4$ & 4-6 \\
\hline $\mathrm{PPH}^{*}$ - Continuous tariff & $2-4$ & $3-5$ & $4-6$ & $5-9$ \\
\hline $\begin{array}{l}\text { Model (Litres) } \\
\text { twin element }\end{array}$ & 160 & 250 & 315 & 400 \\
\hline $\mathrm{PPH}^{*}$ - Off-peak tariff & $1-3$ & $2-3$ & $3-4$ & $4-7$ \\
\hline $\mathrm{PPH}^{*}$ - Continuous tariff & $2-4$ & $3-5$ & 4-6 & $5-9$ \\
\hline
\end{tabular}
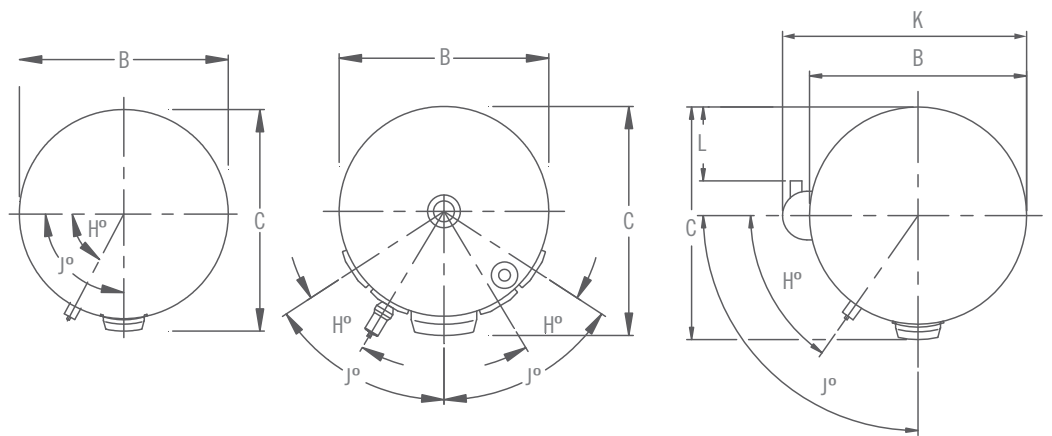

Warranty, terms and conditions

13. Warranty: 7 year cylinder warranty, 3 year labour warranty on the cylinder, 1 year parts and labour warranty on all other components for domestic (non-commercial) installations. 7 year warranty appplies to product manufactured after 1/1/2012. Conditions apply, see the Rheem warranty set out in the product's Owner's Guide or view it at www.rheem.com.au/warranty

14. Warranty: 10 year cylinder warranty, 5 year labour warranty on the cylinder, 1 year parts and labour warranty on all other components for domestic (non-commercial) installations.

Conditions apply, see the Rheem warranty set out in the product's Owner's Guide or view it at www.rheem.com.au/warranty

$15.50^{\circ} \mathrm{C}$ factory pre-set models supply hot water at a maximum $50^{\circ} \mathrm{C}$ at all outlets in accordance with AS 3498. Some applications may require tempering, refer to AS 3500:4.

LEFT HAND CONNECTIONS

DUAL HANDED CONNECTIONS 


\section{RHEEM GAS STORAGE HOT WATER PRDDUCT DATA}

\begin{tabular}{|c|c|c|c|c|c|c|c|c|c|c|c|c|}
\hline & \multicolumn{3}{|c|}{ Rheem 3 Star\# } & \multicolumn{3}{|c|}{ Rheem 4 Star } & \multicolumn{2}{|c|}{ Rheem 5 Star } & \multicolumn{2}{|c|}{ Rheem Stellar® } & \multicolumn{2}{|c|}{ Rheem Indoor* } \\
\hline & 90 & 135 & 170 & 90 & 135 & 170 & 265 & 295 & 330 & 360 & 135 & 170 \\
\hline Model Number & 311090NO/PO & 311135No/P0 & 311170NO/P0 & 347090NO/PO & 347135No/P0 & 347170NO/PO & $350265 \mathrm{NO} / \mathrm{PO}$ & 350295NO/PO & 850330NO/PO & 850360NO/PO & $300135 \mathrm{~N} 0 / \mathrm{PO}$ & $300170 \mathrm{~N} 0 / \mathrm{PO}$ \\
\hline RheemPlus ${ }^{\circledR}$ & - & - & - & - & - & - & $354265 \mathrm{NO} / \mathrm{PO}$ & 354295NO/PO & - & - & - & - \\
\hline $\begin{array}{l}\text { Number of People: } \\
\text { Moderate Climate } \\
\text { Cool Climate }\end{array}$ & $\begin{array}{l}1-3 \\
1-2\end{array}$ & $\begin{array}{l}2-4 \\
2-3\end{array}$ & $\begin{array}{l}3-5 \\
3-4\end{array}$ & $\begin{array}{l}1-3 \\
1-2\end{array}$ & $\begin{array}{l}2-4 \\
2-3\end{array}$ & $\begin{array}{l}3-5 \\
3-4\end{array}$ & $\begin{array}{l}2-4 \\
2-3\end{array}$ & $\begin{array}{l}3-5 \\
3-4\end{array}$ & $\begin{array}{l}2-5 \\
2-4\end{array}$ & $\begin{array}{l}3-6 \\
3-5\end{array}$ & $\begin{array}{l}2-4 \\
2-3\end{array}$ & $\begin{array}{l}3-5 \\
3-4\end{array}$ \\
\hline $\begin{array}{l}\text { Warranty (years) } 17,18,19 \\
\text { Gas Type } \\
\text { GAS Energy Rating } \\
\text { Storage Capacity (Litres) } \\
\text { Recovery Rate (L/Hour@45ㄷ) Natural Gas } \\
\text { First Hour Capacity (Litres) } \\
\text { Hourly Gas Consumption (MJ/Hr)Nat/Prop }\end{array}$ & $\begin{array}{c}5 \\
\\
3.4 \\
85 \\
125 \\
210 \\
30 / 30\end{array}$ & $\begin{array}{c}5 \\
\text { atural Gas/Propan } \\
3.2 \\
130 \\
150 \\
280 \\
35 / 35\end{array}$ & $\begin{array}{c}5 \\
3.2 \\
160 \\
170 \\
330 \\
40 / 40\end{array}$ & $\begin{array}{c}7 \\
4.1 \\
90 \\
100 \\
190 \\
25 / 25\end{array}$ & $\begin{array}{c}7 \\
\text { tural Gas/Propan } \\
4.3 \\
135 \\
117 \\
252 \\
27 / 26\end{array}$ & $\begin{array}{c}7 \\
4.0 \\
170 \\
117 \\
287 \\
27 / 26\end{array}$ & $\begin{array}{l}5 \\
\text { Natural Gas } \\
5.3 \\
130 \\
142 \\
272 \\
30 / 30\end{array}$ & $\begin{array}{c}5 \\
\text { s/Propane } \\
5.3 \\
160 \\
142 \\
302 \\
30 / 30\end{array}$ & $\begin{array}{l}10 \\
\text { Natural Ga } \\
5.2 \\
130 \\
200 \\
330 \\
42 / 42\end{array}$ & $\begin{array}{r}10 \\
\text { s/Propane } \\
5.0 \\
160 \\
200 \\
360 \\
42 / 42\end{array}$ & $\begin{array}{l}5 \\
\text { Natural Ga } \\
3.4 \\
135 \\
120 \\
255 \\
30 / 30\end{array}$ & $\begin{array}{c}5 \\
\text { as/Propane } \\
3.2 \\
170 \\
126 \\
296 \\
30 / 30\end{array}$ \\
\hline $\begin{array}{c}\text { Dimensions mm } \\
\text { A } \\
B \\
\text { C } \\
\text { D } \\
\text { E } \\
\text { F } \\
\text { G } \\
\text { H (RheemPlus }{ }^{\circledR} \text { Only) } \\
\text { J (RheemPlus }{ }^{\circledR} \text { Only) } \\
\text { K } \\
\text { L } \\
\text { M } \\
\text { N } \\
\text { Weight Empty (kg) }\end{array}$ & $\begin{array}{l}1198 \\
422 \\
502 \\
588 \\
328 \\
298 \\
1078 \\
\\
473 \\
208 \\
\\
52\end{array}$ & $\begin{array}{c}1598 \\
422 \\
502 \\
988 \\
328 \\
298 \\
1478 \\
\\
\\
473 \\
208 \\
\\
68\end{array}$ & $\begin{array}{l}1898 \\
422 \\
502 \\
1213 \\
403 \\
298 \\
1778 \\
\\
\\
473 \\
208 \\
\\
79\end{array}$ & $\begin{array}{c}1158 \\
422 \\
502 \\
588 \\
328 \\
298 \\
1078 \\
\\
473 \\
208 \\
\\
48\end{array}$ & $\begin{array}{l}1558 \\
422 \\
502 \\
988 \\
328 \\
298 \\
1478 \\
\\
\\
473 \\
208 \\
\\
59\end{array}$ & $\begin{array}{c}1858 \\
422 \\
502 \\
1213 \\
403 \\
298 \\
1778 \\
\\
\\
473 \\
208 \\
\\
69\end{array}$ & $\begin{array}{l}1622 \\
485 \\
556 \\
988 \\
328 \\
298 \\
600 \\
545 \\
182 \\
520 \\
240 \\
297 \\
97 \\
75\end{array}$ & $\begin{array}{c}1922 \\
485 \\
556 \\
1213 \\
409 \\
298 \\
600 \\
545 \\
182 \\
520 \\
240 \\
297 \\
97 \\
85\end{array}$ & $\begin{array}{l}1600 \\
485 \\
558 \\
988 \\
328 \\
298 \\
770 \\
\\
\\
520 \\
252 \\
299 \\
93 \\
70\end{array}$ & $\begin{array}{l}1900 \\
485 \\
558 \\
1213 \\
409 \\
298 \\
770 \\
\\
\\
520 \\
252 \\
299 \\
93 \\
80\end{array}$ & $\begin{array}{l}1615 \\
425 \\
500 \\
988 \\
328 \\
297 \\
1490 \\
\\
490 \\
213 \\
\\
54\end{array}$ & $\begin{array}{c}1915 \\
425 \\
500 \\
1213 \\
403 \\
297 \\
1790 \\
\\
\\
490 \\
213 \\
\\
63\end{array}$ \\
\hline $\begin{array}{l}\text { Relief Valve Setting (KPa) } \\
\text { Expansion Control Valve Setting (KPa) } \\
\text { Max Water Supply Pressure: } \\
\text { with ECV (KPa) } \\
\text { without ECV (kPa) } \\
\text { Water Connections } \\
\text { Water Connections (RheemPlus) } \\
\text { Gas Connection }\end{array}$ & & $\begin{array}{c}1400 \\
1200 \\
960 \\
1120 \\
\operatorname{RP} 3 / 4 / 20 \\
\operatorname{RP} 1 / 2 / 15\end{array}$ & & & $\begin{array}{c}1400 \\
1200 \\
960 \\
1120 \\
\operatorname{RP} 3 / 4 / 20 \\
\operatorname{RP} 1 / 2 / 15\end{array}$ & & $\begin{array}{r}96 \\
112 \\
\operatorname{RP} 3 / 4 \\
\text { G3/4 } \\
\operatorname{RP} 1 / 2\end{array}$ & & $\begin{array}{r}11 \\
\text { RP } 3 \text {, }\end{array}$ & 20 & & $\begin{array}{l}00 \\
00 \\
60 \\
20 \\
4 / 20\end{array}$ \\
\hline
\end{tabular}
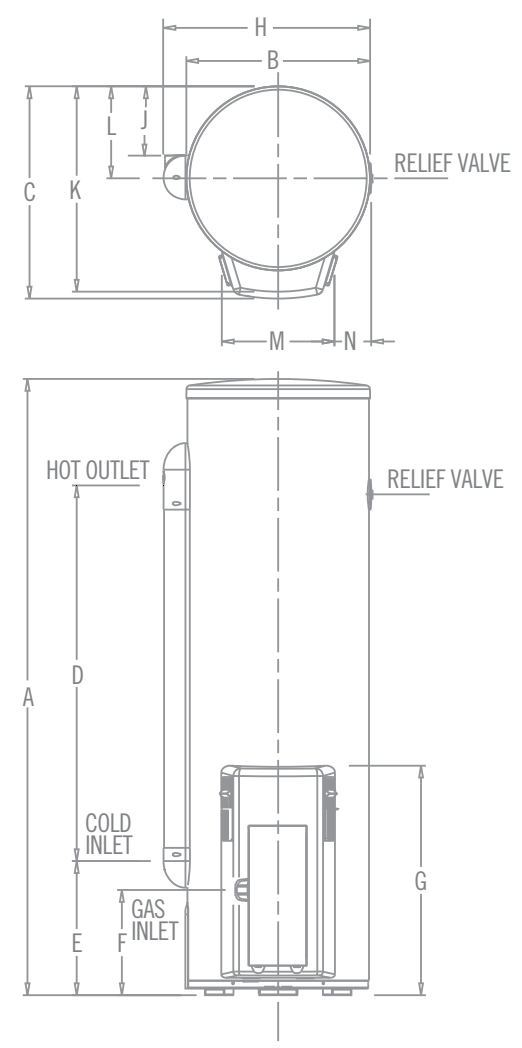

\section{GLOSSARY OF TERMS}

Recovery rate - the volume of water a heater can reheat in one hour. Measured as the volume of completely cold water (should the water heater be run completely out) that can be heated to $45^{\circ} \mathrm{C}$ over the cold water temperature.

First Hour Capacity - a measure of water heater capacity that combines both the stored hot wate volume \& the hourly recoveny rate (eg. if a water heater has storage capacity of $130 \mathrm{~L}$ and a recover rate of $200 \mathrm{~L} /$ hour, its First Hour Capacity is $330 \mathrm{~L}$ ).

\section{Warranty, terms and conditions}

16. Based on $45^{\circ} \mathrm{C}$ temperature rise.

17. 5 year cylinder warranty, 3 year labour on cylinder, 1 year parts and labour warranty on all other components for domestic (non-commercial) installations. Conditions apply, see the Rheem warranty set out in the product's Owner's Guide or view it at www.rheem.com.au/warranty

18. 7 year cylinder warranty, 3 year labour on cylinder, 1 year parts and labour on all other components for domestic (non-commercial) installations. Conditions apply, see the Rheem warranty set out in the product's Owner's Guide or view it at www.rheem.com.au/warranty

19. 10 year cylinder and SuperFlue warranty, 5 year labour on cylinder and SuperFlue, 1 year parts and labour warranty on all other components for domestic (non-commercial) installations. Conditions apply, see the Rheem warranty set out in the product's Owner's Guide or view it at www.rheem.com.au/warranty Some applications require a tempering valve in accordance with AS/NZS 3500:4

" Not available in NSW 


\section{RHEEM CONTINUDUS FLOW HOT WATER PRDDUCT DATA}

\begin{tabular}{|c|c|c|c|c|c|c|c|}
\hline & Rheem 12 & Rheem 16 & Rheem 18 & Rheem 20 & Rheem 24 & Rheem 27 & Rheem Water Star \\
\hline $\begin{array}{l}\text { Model Number } \\
\text { Maximum Temperature }{ }^{\circ} \mathrm{C}\end{array}$ & \begin{tabular}{c|c}
$876012 N F / P F$ & $874012 N F / P F$ \\
50 & 60
\end{tabular} & \begin{tabular}{c|c} 
876M16NF/PF & $874 M 16 N F / P F$ \\
50 & 60
\end{tabular} & $\begin{array}{cc}\text { 876018NF/PF } & \text { 874018NF/PF } \\
50 & 60\end{array}$ & $\begin{array}{cc}\text { 876020NF/PF } & 874020 \mathrm{NF} / \mathrm{PF} \\
50 & 60\end{array}$ & \begin{tabular}{c|c} 
875024NF/PF & 871024NF/PF \\
875M24NF/PF & $871 \mathrm{M} 24 N F / P F$ \\
50 & 60
\end{tabular} & \begin{tabular}{c|c}
$876627 N F / P F$ & $874627 N F / P F$ \\
50 & 60
\end{tabular} & W8100401 \\
\hline $\begin{array}{l}\text { Number of Bathrooms } \\
\text { Gas Type } \\
\text { GAS Energy Rating } \\
\text { Flow Rate L/Min at } 25^{\circ} \mathrm{C} \text { Rise } \\
\text { Minimum Operating Flow Rate } \\
\text { Nominal Gas Consumption }\end{array}$ & $\begin{array}{c}1-1.5 \\
\text { Natural Gas/Propane } \\
5.9 \text { Stars } \\
12 / \mathrm{Min} \\
2.7 \mathrm{~L} / \mathrm{Min} \\
94 \mathrm{MJ} / \mathrm{Hr}\end{array}$ & $\begin{array}{c}1-1.5 \\
\text { Natural Gas/Propane } \\
5.3 \text { Stars } \\
16 \mathrm{~L} / \mathrm{Min} \\
2.7 \mathrm{~L} / \mathrm{Min} \\
126 \mathrm{MJ} / \mathrm{Hr}\end{array}$ & $\begin{array}{c}1-1.5 \\
\text { Natural Gas/Propane } \\
5.3 \text { Stars } \\
18 \mathrm{~L} / \mathrm{Min} \\
2.7 \mathrm{~L} / \mathrm{Min} \\
140 \mathrm{MJ} / \mathrm{Hr}\end{array}$ & $\begin{array}{c}1.5-2 \\
\text { Natural Gas/Propane } \\
5.0 \text { Stars } \\
\text { 20L/Min } \\
2.7 \mathrm{~L} / \mathrm{Min} \\
153 \mathrm{MJ} / \mathrm{Hr}\end{array}$ & $\begin{array}{c}2-2.5 \\
\text { Natural Gas/Propane } \\
5.1 \text { Stars } \\
24 \mathrm{~L} / \mathrm{Min} \\
2.7 \mathrm{~L} / \mathrm{Min} \\
188 \mathrm{MJ} / \mathrm{Hr}\end{array}$ & $\begin{array}{c}2.5-3 \\
\text { Natural Gas/Propane } \\
6.1 \text { Stars } \\
27 \mathrm{~L} / \mathrm{Min} \\
2.0 \mathrm{~L} / \mathrm{Min} \\
205 \mathrm{MJ} / \mathrm{Hr}\end{array}$ & $\begin{array}{l}- \\
- \\
- \\
- \\
-\end{array}$ \\
\hline $\begin{array}{l}\text { Dimensions } \\
\text { A - Height mm } \\
\text { B - Width mm } \\
\text { C - Depth mm } \\
\text { Depth - from wall to Hot Water Outlet } \\
\text { Depth - from wall to Cold Water Inlet } \\
\text { Depth - from wall to Gas Inlet }\end{array}$ & $\begin{array}{l}520 \\
350 \\
160 \\
51 \\
43 \\
45\end{array}$ & $\begin{array}{c}520 \\
350 \\
160 \\
51 \\
43 \\
45\end{array}$ & $\begin{array}{c}520 \\
350 \\
160 \\
51 \\
43 \\
45\end{array}$ & $\begin{array}{l}520 \\
350 \\
160 \\
51 \\
43 \\
45\end{array}$ & $\begin{array}{c}565 \\
350 \\
205 \\
127 \\
53 \\
103\end{array}$ & $\begin{array}{c}600 \\
350 \\
215 \\
84 \\
64 \\
97\end{array}$ & $\begin{array}{l}565 \\
350 \\
190 \\
- \\
- \\
-\end{array}$ \\
\hline $\begin{array}{l}\text { Weight (empty) } \\
\text { Max. Water Supply Pressure } \\
\text { Min. Water Supply Pressure } \\
\text { Cold Water Connection } \\
\text { Hot Water Connection } \\
\text { Gas Connection }\end{array}$ & $\begin{array}{c}18 \mathrm{~kg} \\
1000 \mathrm{kPa} \\
140 \mathrm{kPa} \\
\mathrm{R}^{3 / 4} / 20 \\
\mathrm{R}^{3 / 4} / 20 \\
\mathrm{R} 3 / 4 / 20\end{array}$ & $\begin{array}{c}18 \mathrm{~kg} \\
1000 \mathrm{kPa} \\
140 \mathrm{kPa} \\
\mathrm{R}_{3 / 4} / 20 \\
\mathrm{R}_{3 / 4} / 20 \\
\mathrm{R} 3 / 4 / 20\end{array}$ & $\begin{array}{c}18 \mathrm{~kg} \\
1000 \mathrm{kPa} \\
140 \mathrm{kPa} \\
\mathrm{R}^{3 / 4} / 20 \\
\mathrm{R}^{3 / 4} / 20 \\
\mathrm{R}^{3 / 4} / 20\end{array}$ & $\begin{array}{c}18 \mathrm{~kg} \\
1000 \mathrm{kPa} \\
140 \mathrm{kPa} \\
\mathrm{R} 3 / 4 / 20 \\
\mathrm{R}^{3 / 4} / 20 \\
\mathrm{R} 3 / 4 / 20\end{array}$ & $\begin{array}{c}21 \mathrm{~kg} \\
1000 \mathrm{kPa} \\
140 \mathrm{kPa} \\
\mathrm{R} 3 / 4 / 20 \\
\mathrm{R} 3 / 4 / 20 \\
\mathrm{R} 3 / 4 / 20\end{array}$ & $\begin{array}{c}24 \mathrm{~kg} \\
1000 \mathrm{kPa} \\
140 \mathrm{kPa} \\
\mathrm{R}^{3 / 4} / 20 \\
\mathrm{R}^{3 / 4} / 20 \\
\mathrm{R}^{3 / 4} / 20\end{array}$ & $\begin{array}{c}12.5 \mathrm{Kg} \\
800 \mathrm{kPa} \\
- \\
\mathrm{R}^{3 / 4} / 20 \\
\mathrm{R}^{3 / 4} / 20 \\
-\end{array}$ \\
\hline $\begin{array}{l}\text { Temperature Controllers } \\
\text { Kitchen } \\
\text { Bathroom } 1 \\
\text { Bathroom } 2\end{array}$ & $\begin{array}{l}299850 \\
299851 \\
299852\end{array}$ & $\begin{array}{l}299850 \\
299851 \\
299852\end{array}$ & $\begin{array}{l}299850 \\
299851 \\
299852\end{array}$ & $\begin{array}{l}299850 \\
299851 \\
299852\end{array}$ & $\begin{array}{l}299850 \\
299851 \\
299852\end{array}$ & $\begin{array}{l}299850 \\
299851 \\
299852\end{array}$ & $\begin{array}{l}- \\
- \\
-\end{array}$ \\
\hline $\begin{array}{l}\text { Deluxe Temperature } \\
\text { Controllers } \\
\text { Kitchen } \\
\text { Bathroom } 1 \\
\text { Bathroom } 2\end{array}$ & $\begin{array}{l}29958 \\
299859 \\
299860\end{array}$ & $\begin{array}{l}299858 \\
299859 \\
299860\end{array}$ & $\begin{array}{l}299858 \\
299859 \\
299860\end{array}$ & $\begin{array}{l}299858 \\
299859 \\
299860\end{array}$ & $\begin{array}{l}299858 \\
299859 \\
299860\end{array}$ & $\begin{array}{l}299858 \\
299859 \\
299860\end{array}$ & $\begin{array}{l}- \\
- \\
-\end{array}$ \\
\hline $\begin{array}{l}\text { Accessories } \\
\text { Pipe Cover } \\
\text { Recess Box } \\
\text { Rheem EZ Link Kit } \\
\text { Wall Mount Security Kit } \\
\text { Security Cage } \\
\text { Power }\end{array}$ & $\begin{array}{l}299841 \\
299842 \\
290141 \\
299868 \\
299867 \\
-\end{array}$ & $\begin{array}{l}299841 \\
299842 \\
290141 \\
299868 \\
299867 \\
-\end{array}$ & $\begin{array}{l}299841 \\
299842 \\
290141 \\
299868 \\
299867 \\
-\end{array}$ & $\begin{array}{l}299841 \\
299842 \\
290141 \\
299868 \\
299867 \\
-\end{array}$ & $\begin{array}{c}299848 \\
299842 \\
\text { N/A } \\
299868 \\
299867 \\
-\end{array}$ & $\begin{array}{l}299830 \\
299831 \\
290141 \\
299868 \\
299867 \\
-\end{array}$ & $\begin{array}{c}- \\
- \\
- \\
- \\
- \\
240 V \text { AC }\end{array}$ \\
\hline
\end{tabular}
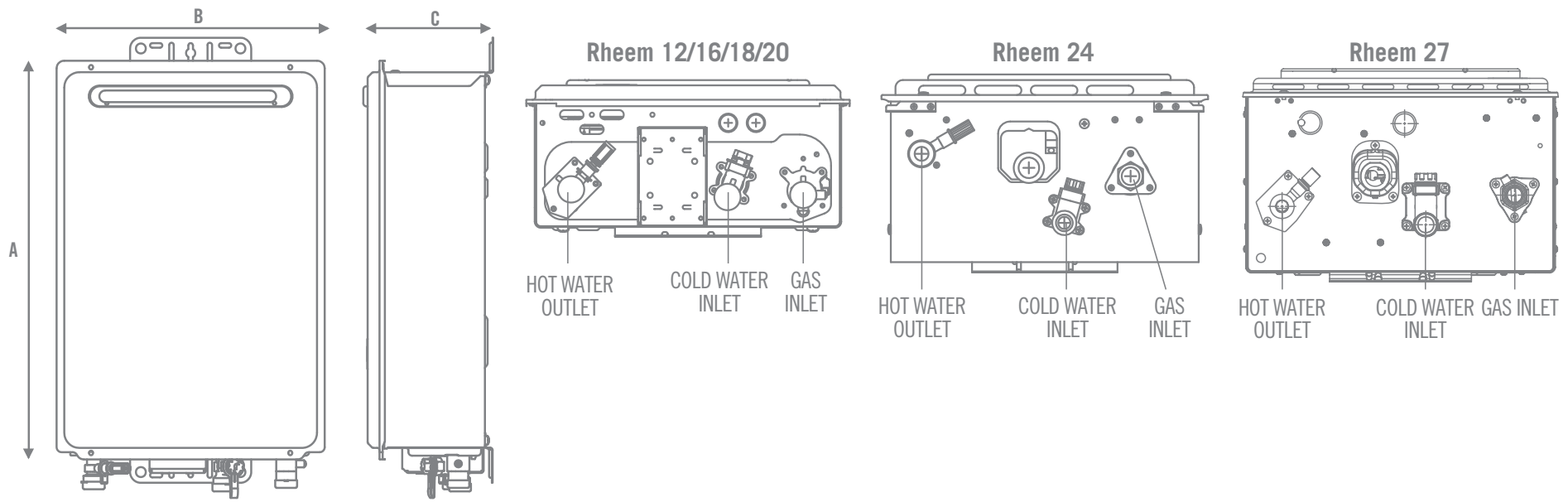

GLOSSARY OF TERMS

Flamesafe ${ }^{\circledR}$ - a unique Rheem safety protection feature that automatically shuts down

the continuous flow water heater should a fault develop.

Q Factor ${ }^{\mathrm{TM}}$ - a unique Rheem feature that keeps the heater in readiness so hot water

delivery is as fast as possible, and at consistent temperature.

Warranty, terms and conditions

20. Guide only, subject to ambient water temperature and pressure, correct pipe sizing and appliance flow rates.

$21.50^{\circ} \mathrm{C}$ factory pre-set models supply hot water at a maximum $50^{\circ} \mathrm{C}$ at all outlets in accordance with AS3498. Some applications may require tempering, refer to $\mathrm{AS} 3500: 4.60^{\circ} \mathrm{C}$ models must have a tempering valve installed in accordance with AS 3500:4.

22. Warranty Conditions: 10 Years parts and 3 Years labour on Heat Exchanger, 3 Years parts \& labour on other components, when installed in a domestic dwelling. For all other installations, the warranty period is

1 Year parts and labour on Heat Exchanger and other components. Conditions apply, see the Rheem warranty set out in the product's Owner's Guide or view it at www.rheem.com.au/warranty
23. Rheem Water Star warranty: 5 year supply on cylinder, 3 year supply \& labour on cylinder, 1 year full parts \& labour. Conditions apply, see the Rheem warranty set out in the product's Owner's Guide or view it at www.rheem.com.au/warranty

24. Average wastage incurred at water heater outlet per demand until water reaches within $5^{\circ} \mathrm{C}$ of $60^{\circ} \mathrm{C}$ set temperature, based on 19 demands per day, with the water heater cold each time tap is turned on and 200L/day average hot water consumption. Source: WELS Water Wastage of Instantaneous Gas Water Heaters - 2008. C Commonwealth of Australia 2008

25. Applies to $70^{\circ} \mathrm{C}$ capable models when set to $70^{\circ} \mathrm{C}$
324

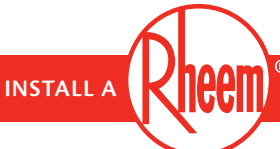




\section{CONTACT US}

Rheem Australia Pty Ltd

ABN 21098823511

\section{Head Office}

1 Alan Street,

Rydalmere NSW 2116

Australia

PO Box 6,

Rydalmere NSW 2116

Australia

National Sales Phone: 132552

National Service Phone: 131031

www.rheem.com.au

( 8 Registered Trademark of Rheem Australia Pty Ltd

TM Trademark of Rheem Australia Pty Ltd 


\section{TWINSOLAR - SLK TOPSOLAR MANUAL TÉCNICO}

Instrucciones de montaje Información técnica

Manual de uso y mantenimiento
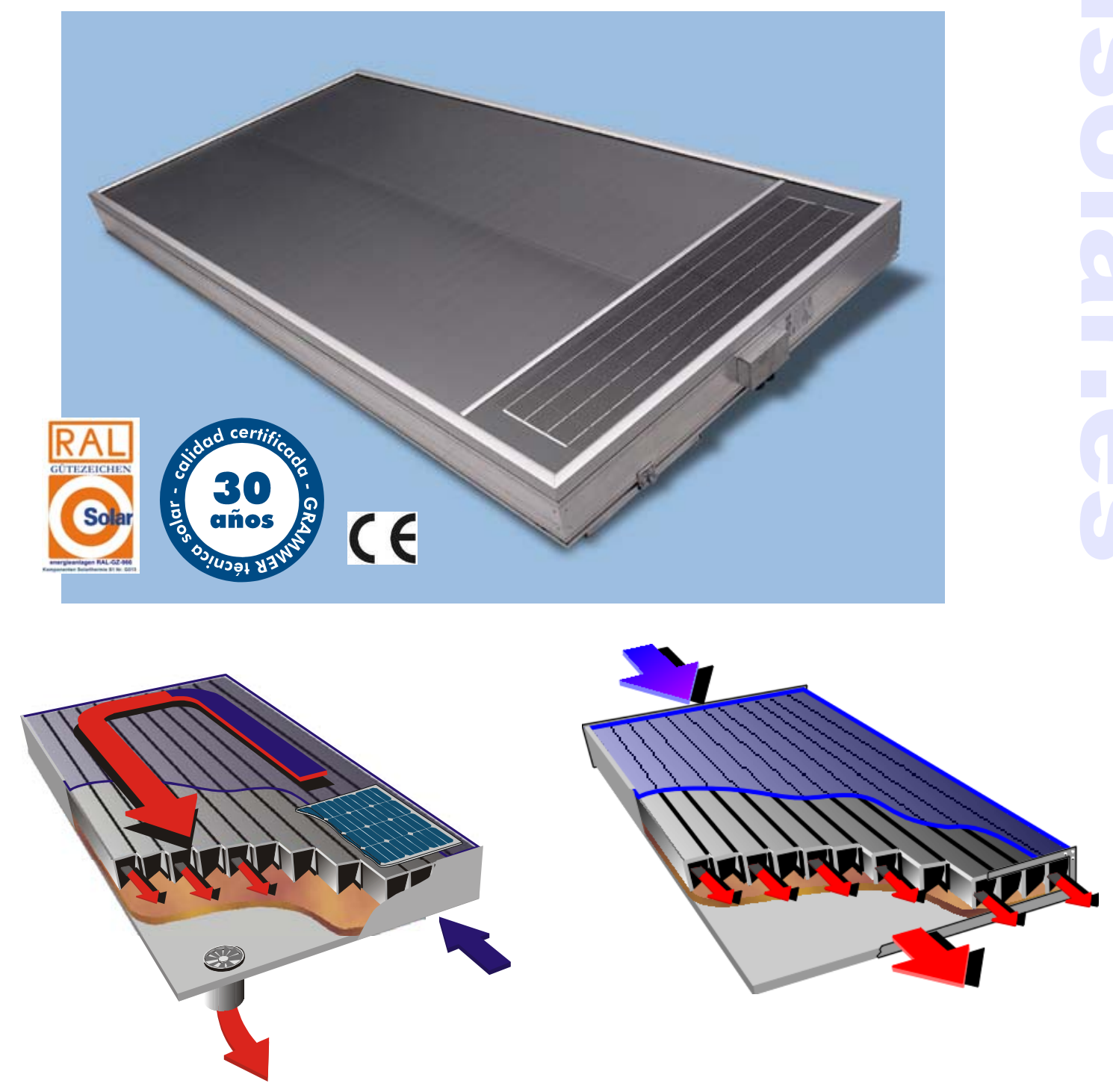


\section{Índice}

\section{Página}

3 ¿Qué rendimiento tiene el Grammer TWINSOLAR?

4 Dimensionamiento - Tamaño ideal del colector

5 Grammer TWINSOLAR - Calidad comprobada

6 Datos técnicos

7 Paquetes de accesorios - Descripción general

8 Instrucciones de planificación para el TWINSOLAR

11 Instrucciones de montaje y de mantenimiento

11 Control - Ventilador

14 Control TWINSOLAR 2.0

15 Control TWINSOLAR $4.0-12.5$

17 TWINSOLAR - Kit de conmutación Confort

18 Medición de temperatura - Disposición de sondas

18 Funcionamiento con el kit de ventilación de verano

19 Lista de chequeo - Corrección de fallos

20 Montaje del colector

27 Montaje en fachada

28 Montaje sobre tejado plano

29 Instrucciones generales de mantenimiento

29 Avisos generales de seguridad

32 Anexo 1: Esquemas CAD de los colectores TWINSOLAR 2.0 - 12.5

33 Anexo 2: Colector: Ficha técnica del fabricante 


\section{GRAMMER TWINSOLAR-TOPSOLAR}

\section{Calefactar y ventilar con energía solar}

GRAMMER TWINSOLAR es un sistema con colector de aire caliente para calefactar y ventilar con energía solar, sin conexión a la red general eléctrica.

EI TWINSOLAR es muy seguro en su funcionamiento y casi no necesita ningún mantenimiento, puesto que su medio caloportador es el aire. El módulo fotovoltaico, integrado en el colector, garantiza un funcionamiento independiente de la red eléctrica.

La estructura del TopSolar, la alternativa conectada a red,es análoga a la del TwinSolar, pero sin módulo fotovoltaico.

Con TWINSOLAR y TOPSOLAR Ud. adquiere una tecnología de colector muy probada y con 30 años de experiencia en la producción de colectores de aire caliente.

\section{1 ¿Qué rendimiento tiene el Grammer TWINSOLAR y TOPSOLAR?}

EI GRAMMER TWINSOLAR empieza a trabajar con muy poca irradiación, es decir con el cielo nublado, y transporta aire fresco y caliente al interior del edificio.

La intensidad máxima del sol asciende a $1000 \mathrm{~W}$ por $\mathrm{m}^{2}$ de superficie del colector,

independientemente de la estación del año. Con esta irradiancia el aumento de temperatura llega hasta $40 \%$, siendo la potencia útil de $700 \mathrm{~W} / \mathrm{m}^{2}$.

Este rendimiento máximo se puede alcanzar sobre todo durante los días despejados de invierno. EI TWINSOLAR convierte el $70 \%$ de la energía solar incidente en energía térmica y la transporta al interior del edificio.

El rendimiento y el salto térmico mostrado son análogos para el Topsolar.

Flujo volumétrico GRAMMER TWINSOLAR SLK

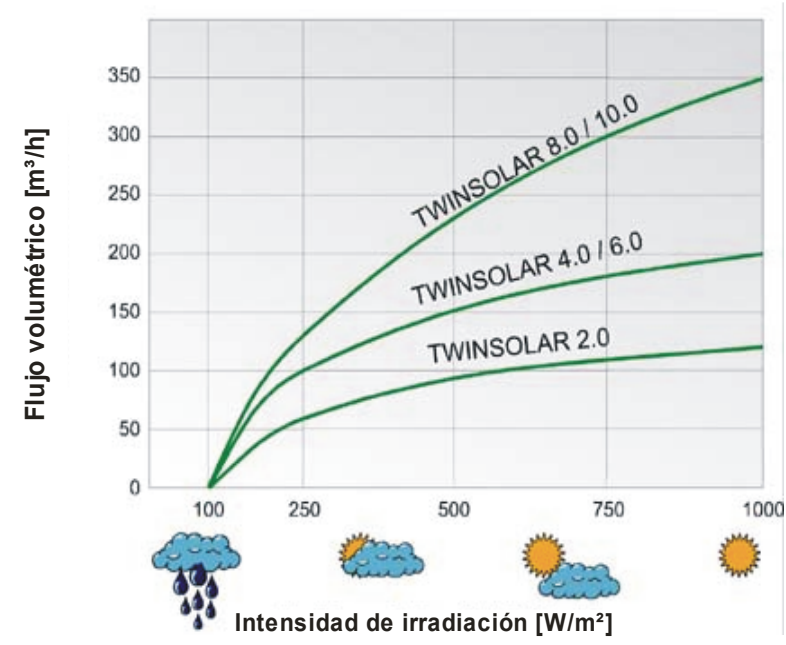

Promedio de aumento de temperatura en situaciones de diferentes irradiaciones solares (temperatura exterior $0^{\circ} \mathrm{C}$, funcionamiento en régimen de aire fresco)

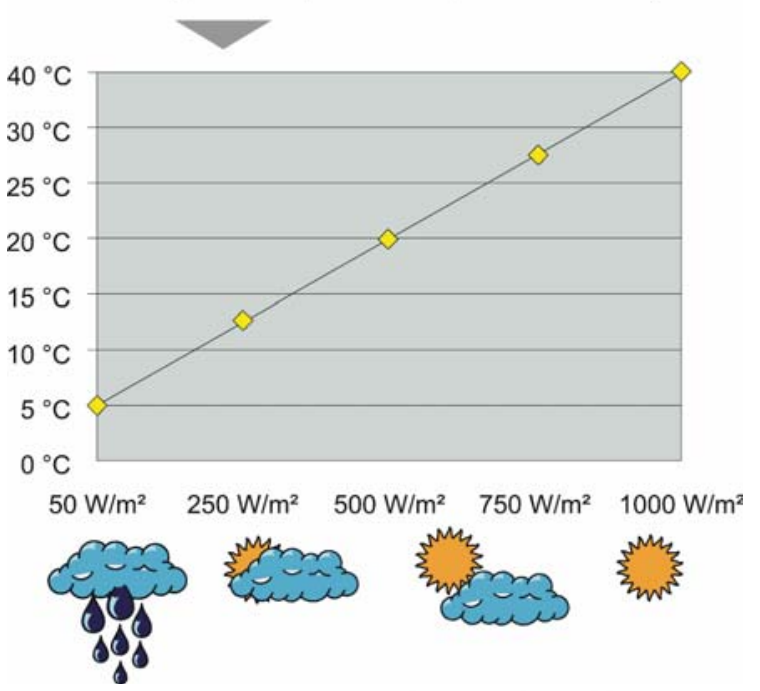

¿Qué rendimiento tiene un TWIN- / TOPSOLAR ?

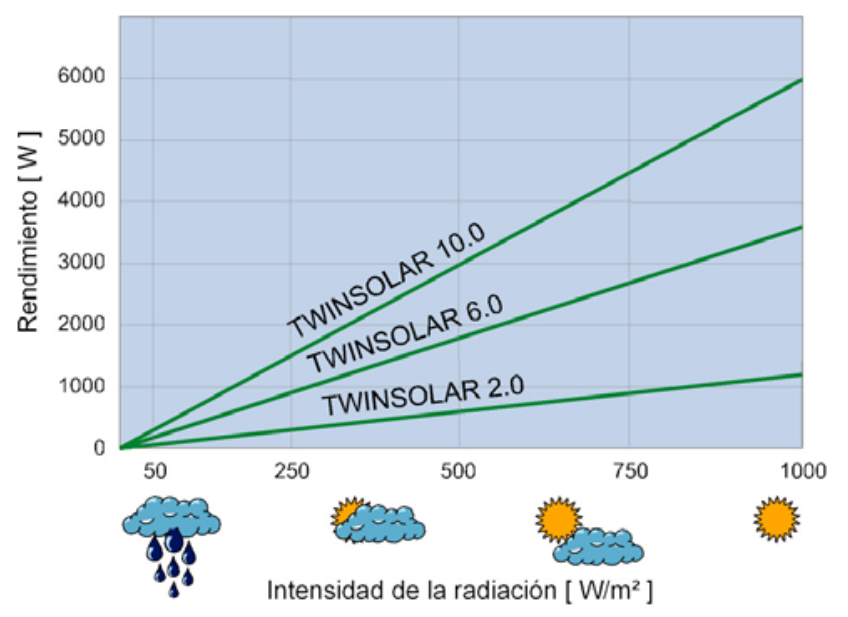




\section{Dimensionamiento- Tamaño ideal del colector}

La dimensión de la instalación del TWINSOLAR y del TOPSOLAR depende en gran medida de la superficie proyectada para calentar.

El gráfico siguiente servirá de orientación para el dimensionamiento del colector.

\section{Rango de acción TWINSOLAR / TOPSOLAR}

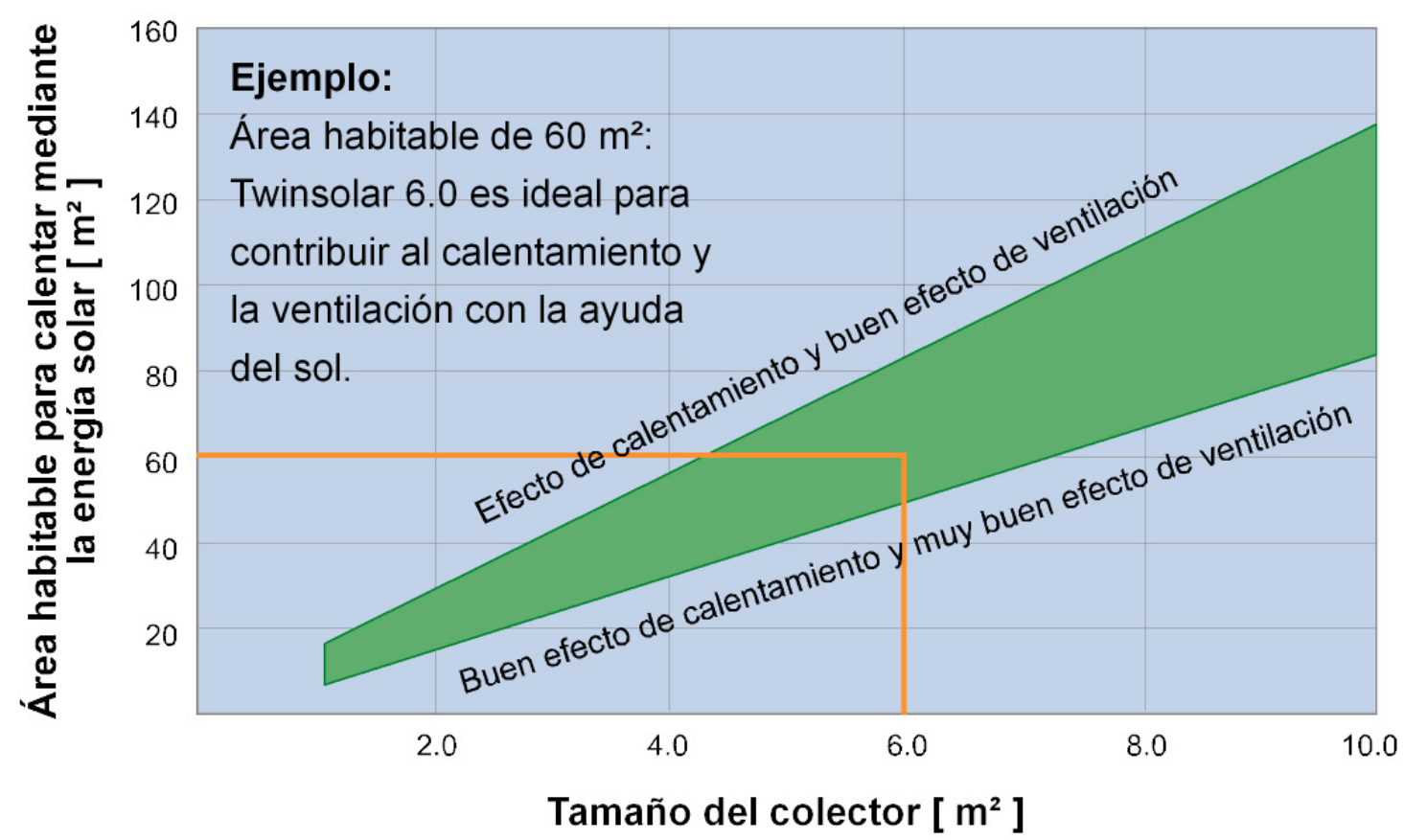

Dimensionamiento del colector - valor orientativo para edificios con nivel de aislamiento medio

\section{$10 \mathrm{~m}^{2}$ superficie vivienda <-> $1 \mathrm{~m}^{2}$ colector de aire caliente}

\section{Avisos:}

- ¡En el sur de Europa o en caso de edificios con nivel de aislamiento bueno se puede calefactar y ventilar con $1 \mathrm{~m}^{2}$ de superficie de colector hasta $15 \mathrm{~m}^{2}$ de superficie de vivienda!

- Los valores orientativos se refieren a un promedio de altura de las habitaciones de la vivienda de $2,5 \mathrm{~m}$.

- Para edificios de uso permanente (por ejemplo viviendas residenciales), con el software de simulación "Luftikuss" se puede efectuar un dimensionamiento incluyendo datos para el ahorro energético. Encontrará un versión demostrativa en el área de descargas de www.grammer-solar.de.
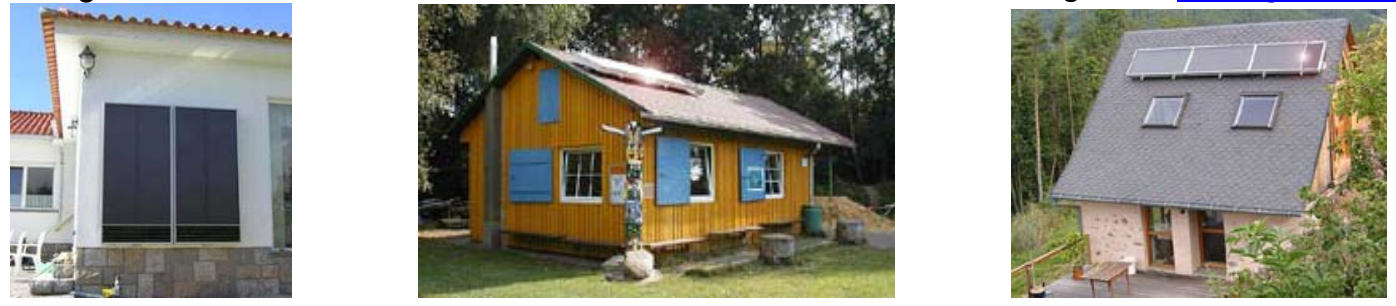


\subsection{Grammer TWINSOLAR-TOPSOLAR - Energía Solar pura...}

\section{Información / Datos técnicos}

El sistema Grammer TWINSOLAR le llega listo para funcionar. Además, es muy fácil de instalar.

Los módulos PV, integrados en la entrada de aire del colector solar de aire caliente, generan la corriente eléctrica necesaria para el ventilador; el absorbedor se encarga de calentar el aire y los tubos de aire lo conducen donde se necesite.

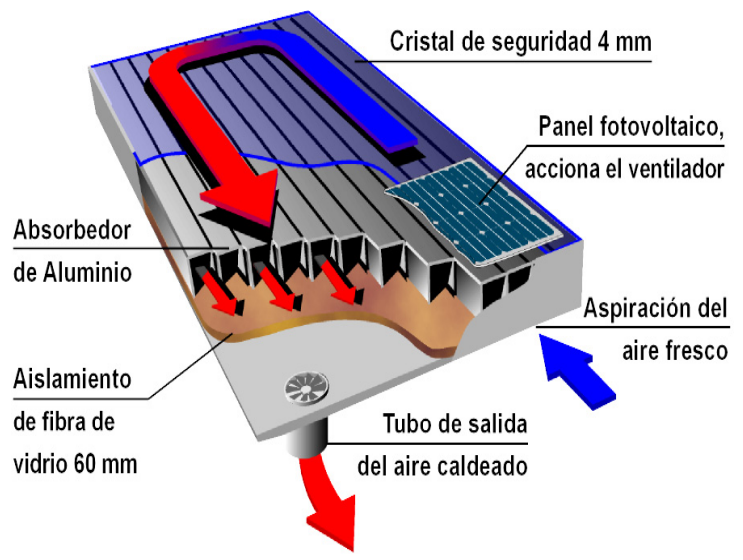

La regulación automática vigila que todos los componentes trabajen juntos en perfecta armonía - también cuando Ud. esté ausente.

\section{La entrega de los paquetes TWINSOLAR incluye:}

- Colector de aire caliente de alto rendimiento Grammer, modelo SLK

- Módulo PV y caja de conexión, integrados en el colector

- Ventilador incluyendo electrónica de adaptación

- Regulación TWINSOLAR Control (modelo TWIN 2.0 con termostato)

- Filtro de aire con marco extraíble, integrado en el colector
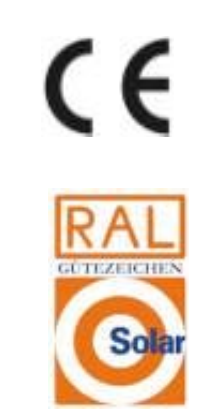

\section{TWINSOLAR - ¡Calidad comprobada!}

En 1998, dentro del marco del proyecto de investigación de la UE IEA-Task 19, se efectuó ensayos del Grammer colector de aire caliente con otros 6 colectores de aire caliente.

El Grammer colector de aire caliente consiguió los mejores resultados.

Fue la base en la que desarrollamos, en cooperación con el

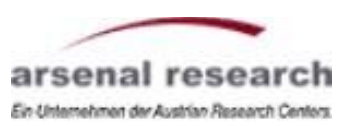

Instituto Fraunhofer para sistemas de energía solar - ISE, el nuevo colector solar de aire caliente SLK para instalaciones pequeñas.

Más de 30 años de experiencia en la producción de colectores solares de aire caliente.

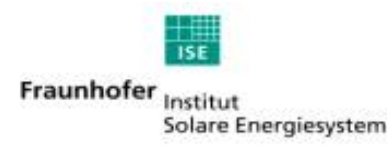

\section{Características TWINSOLAR SLK}

- Carcasa de aluminio robusta y de larga vida útil (¡resistente a ambientes salinos!)

- Vidrio de seguridad de $4 \mathrm{~mm}$, resistente al granizo

- Absorbedor de aluminio de larga vida útil

- Módulos PV de silicio monocristalino o bien policristalino, de alta calidad

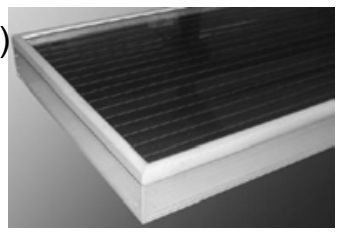

- Filtros de aire integrados impiden el ensuciamiento interno del colector

- Potencia nominal de aproximadamente $700 \mathrm{~W} / \mathrm{m}^{2}$ - rendimiento teórico $>80 \%$

- 10 años de garantía en la carcasa del colector - vida útil mínimo de 25 años 


\section{Datos técnicos del TWINSOLAR SLK}

(Datos técnicos TOPSOLAR: ver capítulo 2.1)

\begin{tabular}{|c|c|c|c|c|c|c|c|c|c|}
\hline & TWINSOLAR 1.3 & $\begin{array}{l}\text { TwinSolar } \\
2.0\end{array}$ & TwinSolar 4.0 & TwinSolar 6.0 & TwinSolar 8.0 & $\begin{array}{c}\text { TwinSolar } \\
10.0\end{array}$ & TwinSolar 4.5 & TwinSolar 8.5 & $\begin{array}{c}\text { TwinSolar } \\
12.5\end{array}$ \\
\hline Superficie colector bruta $\quad\left[\mathrm{m}^{2}\right]$ & 1,3 & 2,0 & 4,0 & 6,0 & 8,0 & 10,0 & 4,55 & 8,55 & 12,55 \\
\hline $\begin{array}{l}\text { Dimensiones colector: } \\
\text { [longitud } \mathrm{x} \text { anchura en } \mathrm{m} \text { ] }\end{array}$ & $1,45 \times 0,9$ & $2,0 \times 1,0$ & $4,0 \times 1$ & $6,0 \times 1$ & $8,0 \times 1$ & $10,0 \times 1$ & $2,25 \times 2,1$ & $4,25 \times 2,1$ & $6,25 \times 2,1$ \\
\hline Potencia térmica pico [W] & 700 & 1.200 & 2.400 & 3.600 & 4.800 & 6.000 & 2.700 & 5.100 & 7.500 \\
\hline Superficie apta a calefactar $\left[\mathrm{m}^{2}\right]$ & $10-20$ & $15-30$ & $40-50$ & $60-80$ & $80-100$ & $100-120$ & $40-60$ & $80-100$ & $120-150$ \\
\hline Potencia eléctrica módulo PV [W] & 11 & 26 & 54 & 54 & 108 & 108 & 54 & 108 & 108 \\
\hline Potencia nominal ventilador [W] & 4 & 18 & 50 & 50 & 100 & 100 & 50 & 100 & 100 \\
\hline Carcasa & aluminio & aluminio & aluminio & aluminio & aluminio & aluminio & aluminio & aluminio & aluminio \\
\hline Peso colector & 29 & 45 & 90 & 135 & 180 & 225 & 110 & 200 & 290 \\
\hline $\begin{array}{l}\text { Tipo ventilador - disposición } \\
\text { Ventiladores de alto rendimiento }\end{array}$ & $\begin{array}{l}\text { 4312NN axial } \\
\text { integrado }\end{array}$ & $\begin{array}{l}6224 N \text { Axi } \\
\text { axial } \\
\text { integrado }\end{array}$ & $\begin{array}{l}\text { G1G } 120 \\
\text { radial } \\
\text { externo }\end{array}$ & $\begin{array}{l}\text { G1G } 120 \\
\text { radial } \\
\text { externo }\end{array}$ & $\begin{array}{l}\text { G1G } 140 \\
\text { radial } \\
\text { externo }\end{array}$ & $\begin{array}{l}\text { G1G } 140 \\
\text { radial } \\
\text { externo }\end{array}$ & $\begin{array}{l}\text { G1G } 120 \\
\text { radial } \\
\text { externo }\end{array}$ & $\begin{array}{l}\text { G1G } 140 \\
\text { radial } \\
\text { externo }\end{array}$ & $\begin{array}{l}\text { G1G } 140 \\
\text { radial } \\
\text { externo }\end{array}$ \\
\hline $\begin{array}{l}\text { Potencia máxima de aireación, } \\
\text { soplando libremente } \quad\left[\mathrm{m}^{3} / \mathrm{h}\right]\end{array}$ & 80 & 120 & 200 & 200 & 350 & 350 & 200 & 350 & 350 \\
\hline Presión máxima externa $\quad[\mathrm{Pa}]$ & 25 & 30 & 80 & 80 & 130 & 130 & 80 & 130 & 130 \\
\hline Diámetro salida de aire $\quad[\mathrm{mm}]$ & 125 & 125 & 160 & 160 & 160 & 160 & 160 & 160 & 160 \\
\hline Control diferencial de temperatura & Termostato & Termostato & $\checkmark$ & $\checkmark$ & $\checkmark$ & $\checkmark$ & $\checkmark$ & $\checkmark$ & $\checkmark$ \\
\hline $\begin{array}{l}\text { TWINSOLAR Control con sonda } \\
\text { (modelo Pt 1000) }\end{array}$ & & - & $\checkmark$ & $\checkmark$ & $\checkmark$ & $\checkmark$ & $\checkmark$ & $\checkmark$ & $\checkmark$ \\
\hline
\end{tabular}

Encontrará en el anexo una ficha técnica con datos detallados del colector SLK e indicaciones en relación al instituto de ensayo.

\section{Pérdidas de presión en el colector Twin-TopSolar}
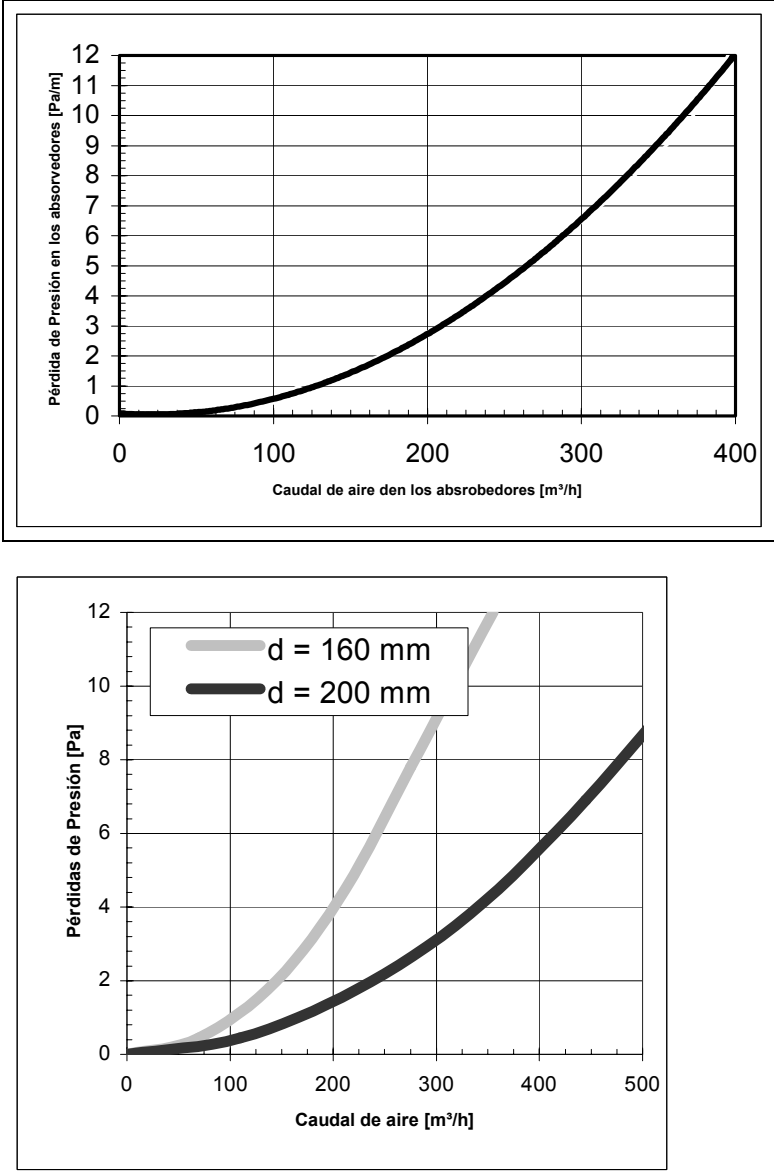

Diagrama 1:

Pérdidas de presión de cada serie de colectores en dependencia del volumen trasegado

Diagrama 2:

Pérdidas de presión en la entrada y salida del colector por los canales de conducción

Ejemplo:

TOPSOLAR 10 con conducciones $2 \mathrm{x}$

DN $160 \mathrm{~mm}$ y caudal de aire de $300 \mathrm{~m}^{3} / \mathrm{h}$

Diagrama 1)

$300 \mathrm{~m}^{3} / \mathrm{h}->6,5 \mathrm{~Pa} / \mathrm{m} 6,5$ * $10 \mathrm{~m}=65 \mathrm{~Pa}$

Diagrama 2)

DN $160 \mathrm{~mm}: 300 \mathrm{~m}^{3} / \mathrm{h}->9 \mathrm{~Pa}$

$2^{*} 9=18 \mathrm{~Pa}$

Suma $=83 \mathrm{~Pa}$ 


\subsection{Paquetes de accesorios}

\subsubsection{Paquetes para el montaje del colector}

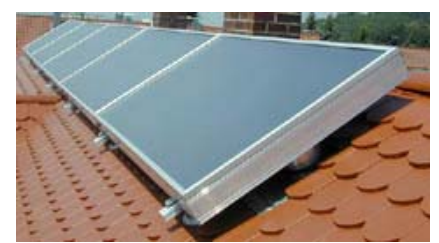

\section{Montaje en tejado inclinado}

+ Ganchos de anclaje de acero inoxidable para tejados de tejas

+ Carriles de montaje de aluminio, escuadras y tornillos

+ Kit para pasar el tejado: Chapa de plomo, junta de estanquidad, conexión para tubería

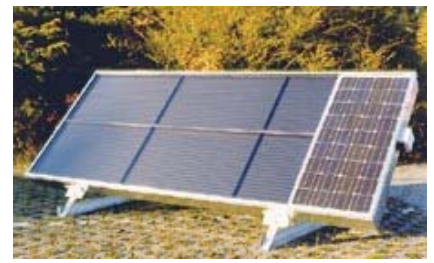

\section{Montaje sobre tejados planos}

+ Montaje con carriles de aluminio en triángulo con inclinación $45^{\circ}$

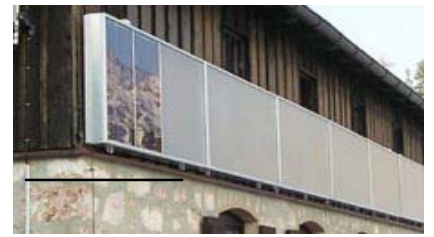

\section{Montaje en fachadas}

+ Perfiles de aluminio en $L$ (pretaladradas + material de fijación)

+ Conducto pasa-muros aislado

\subsubsection{Accesorios externos}

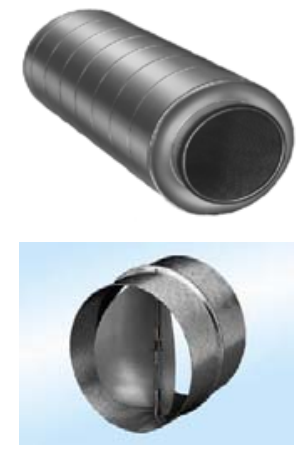

\section{Silenciador (SD)}

+ Amortiguador de alto rendimiento para la reducción del ruido del ventilador, se integra directamente después del ventilador en el propio conducto

Accesorio recomendado a partir del TWINSOLAR 4.0 y TOPSOLAR

\section{Válvula de retención}

+ Impide que entre de aire a través de la habitación, pasando por el sistema de ventilación, al colector

\section{i Accesorio recomendado ! \\ Válvula de disco de salida}

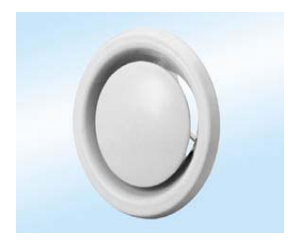

+ Difusor decorativo; fabricado en chapa de acero galvanizado, lacado en blanco

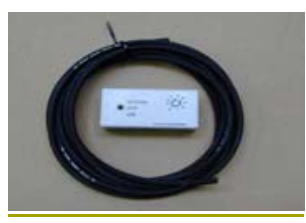

\section{Kit de conmutación Confort}

+ Uso externo de los módulos PV, integrados en el colector (Twin 2.0 - 10.0)

+ Componentes del kit: Conmutador, cable $5 \mathrm{~m}$ de $3 \times 15 \mathrm{~mm}^{2}$, resistente a la radiación UV

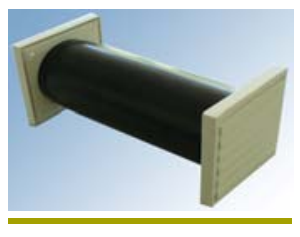

\section{Kit de ventilación de verano}

+ Uso de verano de los módulos PV, integrados en el colector, para la expulsión de aire

+ Componentes del kit: Ventilador de corriente continua (12 V, $5 \mathrm{~W})$ con pieza pasamuro, silenciador y válvula de disco termostática de salida 


\subsection{Instrucciones de planificación para el TWINSOLAR}

\subsubsection{Disposición de los colectores}
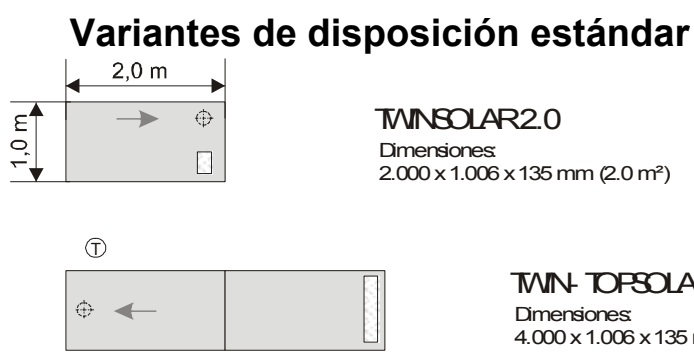

TNN- TOPSOLAR4.0

Dimensiones:

$4.000 \times 1.006 \times 135 \mathrm{~mm}\left(4,0 \mathrm{~m}^{2}\right)$
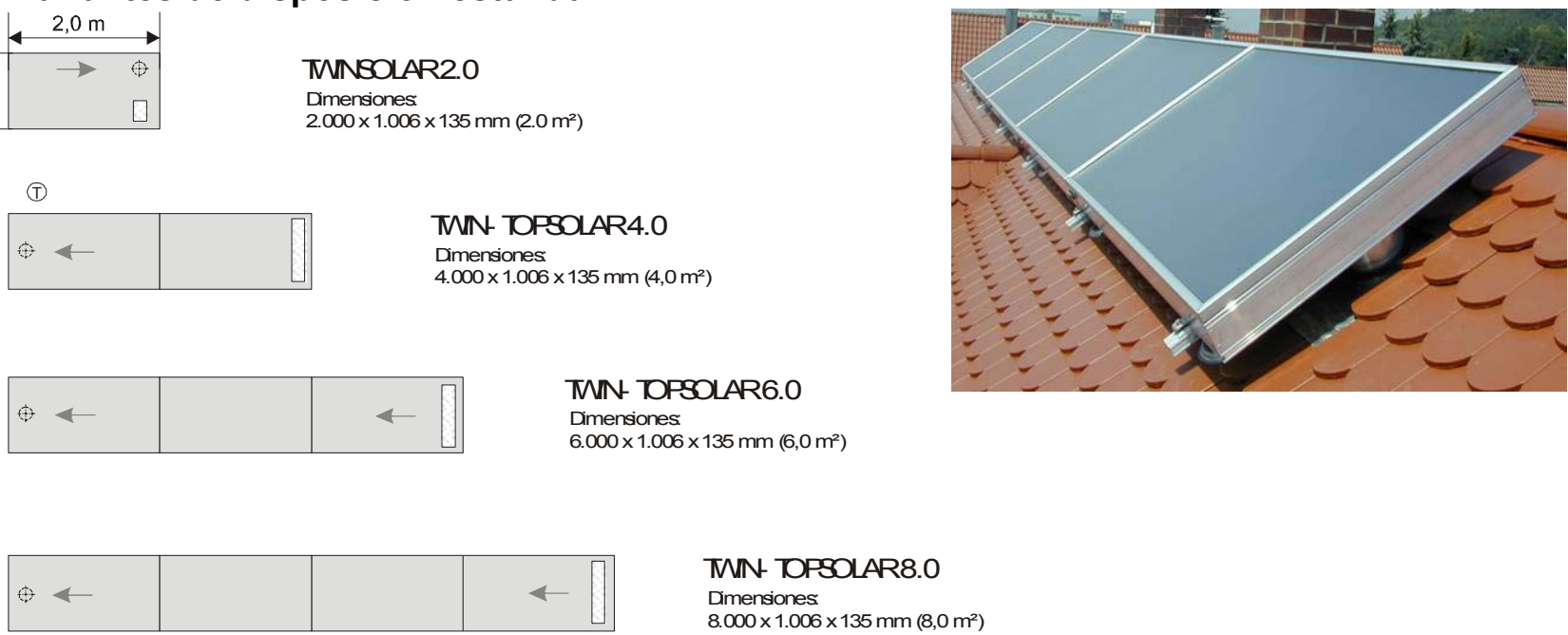

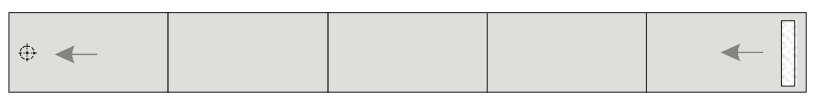

Variantes de disposición alternativa
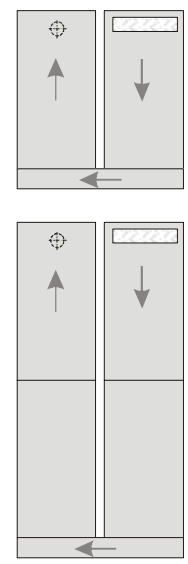

TWN- TOPSOLAR8.5

Dimensiones:

$2.21 \times 4,25 \times 135 \mathrm{~mm}\left(8.55 \mathrm{~m}^{2}\right)$
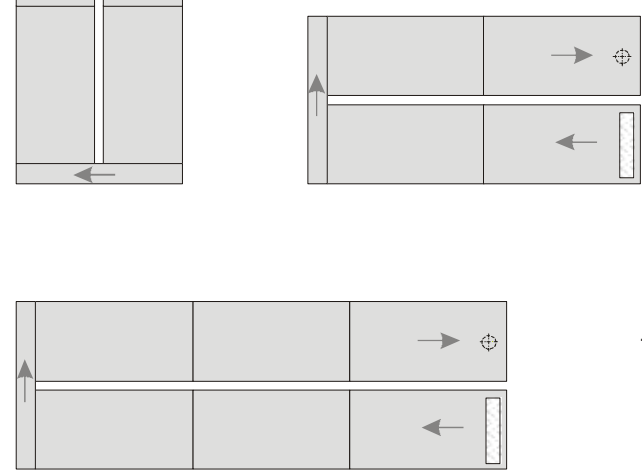

TNN TOPBOLAR12.5

Dimensiones:

$2.21 \times 6,25 \times 135 \mathrm{~mm}\left(12.55 \mathrm{~m}^{2}\right)$
TNN TOPSOLAR10.0

Dimensiones:

$10.000 \times 1.006 \times 135 \mathrm{~mm}\left(10,0 \mathrm{~m}^{2}\right)$

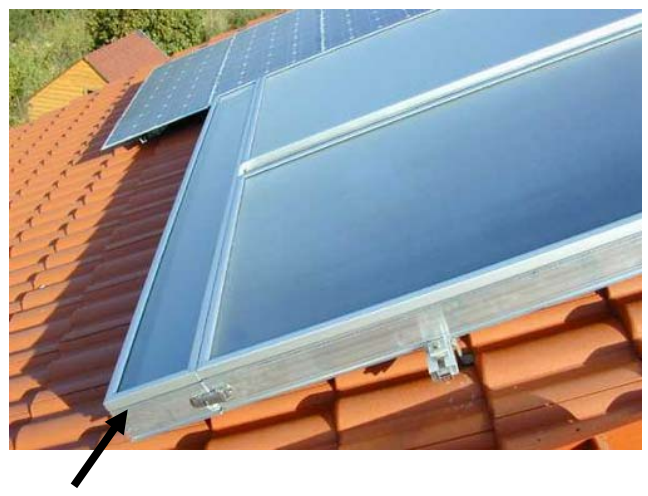

Colector de giro de aire

Las variantes alternativas de disposición se efectúan con un colector de giro, situado al final de dos filas de colectores en paralelo.

El colector de cambio de dirección tiene una superficie de $0,5 \mathrm{~m}^{2}$ y una estructura parecida al colector estándar SLK.

Dimensiones: $2,12 \times 0,25 \mathrm{~m}$

\section{Avisos:}

- Todos los colectores se puede montar en horizontal o vertical.

- Otras disposiciones y combinaciones de colectores hasta $18 \mathrm{~m}^{2}$ posibles bajo petición

- Esquemas detallados CAD encontrará en el capítulo 3 


\subsubsection{Opción funcionamiento con aire interior}

El modelo estándar de TWIN y del TOPSOLAR se suministra para el funcionamiento con aire fresco del exterior, es decir, aspira aire exterior a través de un filtro integrado en el colector.

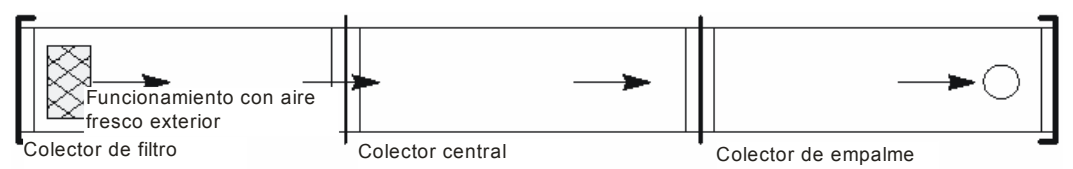

\section{Funcionamiento}

opcional para aire interior

Como alternativa al funcionamiento directo con aire del exterior, se puede aspirar también aire desde el interior del edificio (recirculación)o mezclado con aire fresco del exterior, pasándolo a través de una caja de filtro externa.

Puede ser útil en las aplicaciones siguientes:

1) Funcionamiento solamente para calefacción, no se necesita ventilación. El colector calienta aire recirculado del interior del edificio y lo vuelve a introducir al mismo.

2) Cambio confortable del filtro desde la buhardilla. En vez de cambiar el filtro en el tejado con las complicaciones que conlleva, el mantenimiento de la caja del filtro se puede efectuar de manera muy sencilla desde la buhardilla.

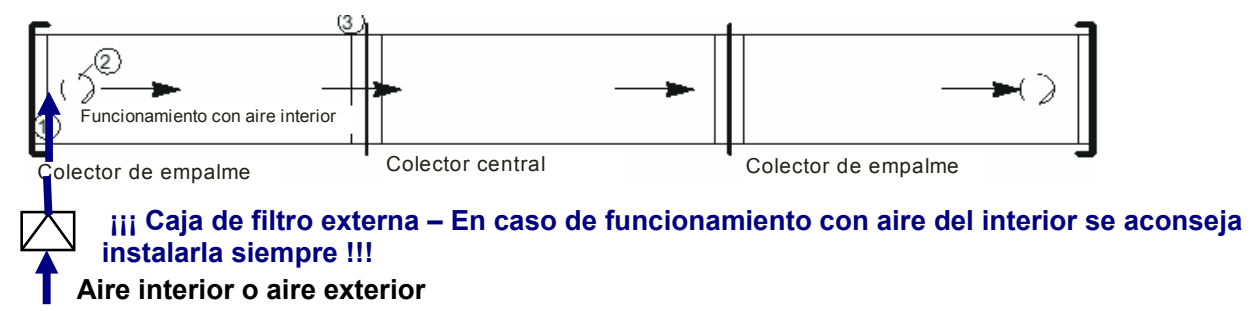

\subsubsection{Sistema de distribución de aire - Instrucciones de planificación}

- Usar tubería helicoidal de acero cincado con la medidas $125 \mathrm{~mm}$ y $160 \mathrm{~mm}$.

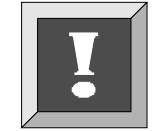

- No usar tubos de plástico (exhalación, problemas de malos olores).

- En el tramo de tubería entre el colector y la habitación se debe prever la instalación de una válvula de retención.

- El ventilador del TWINSOLAR 1.3 y 2.0 está integrado en el colector. A partir del modelo TWINSOLAR 4.0 se suministra ventilador radial externo dentro del paquete de entrega.

- En el tramo de la tubería de entrada de aire hay que prever intercalar después del ventilador un silenciador (a partir de TWIN 4.0).

- En caso de dos habitaciones conectadas por los tubos de ventilación, hay que prever instalar entre las dos habitaciones atenuadores de sonido.

- Hay que aislar térmicamente todos los tubos que lleven aire caliente.

- Se debe aislar tubos que lleven aire frío y vayan por habitaciones calientes - ipeligro de condensación!

- ¡Tramos de tubería lo más corto posible para reducir pérdidas de presión y de calor!

- Tener en cuenta pérdidas de presión admisibles (tabla en capítulo 1.2, "Datos técnicos") 
Reglas generales orientativas para no pasar los rangos de pérdida de presión

\begin{tabular}{|c|c|c|c|c|c|}
\hline Componentes & \begin{tabular}{|l|} 
TWIN 1.3 \\
TWIN 2.0 \\
\end{tabular} & $\begin{array}{l}\text { TWIN } 4.0 \\
\text { TOP } 4.0\end{array}$ & $\begin{array}{l}\text { TWIN } 6.0 \\
\text { TOP } 6.0\end{array}$ & $\begin{array}{l}\text { TWIN 8.0 } \\
\text { TOP 8.0 }\end{array}$ & $\begin{array}{l}\text { TWIN } 10.0 \\
\text { TOP } 10.0\end{array}$ \\
\hline Radio conexión de tubería de aire en el colector & $125 \mathrm{~mm}$ & $160 \mathrm{~mm}$ & $160 \mathrm{~mm}$ & $160 \mathrm{~mm}$ & $160 \mathrm{~mm}$ \\
\hline tubo DN $160 \mathrm{~mm} \quad[\mathrm{~m}]^{*}$ ) & & 10 & 10 & 10 & 10 \\
\hline$n^{\circ}$ max. tubo Rohr DN $125 \mathrm{~mm}[\mathrm{~m}]^{*}$ ) ( $n^{\circ}$ de tubos verticales ) & $4(3)$ & 8 & 8 & 10 & 10 \\
\hline $\mathrm{n}^{\circ}$ max. unidades codos ${ }^{*}$ ) & 2 & 8 & 8 & 8 & 8 \\
\hline max. unidades tes - derivaciones & & 1 & 2 & 3 & 4 \\
\hline$n^{\circ}$ max. válvulas de disco DN $125^{* *}$ ) & 1 & 2 & 3 & 4 & 5 \\
\hline $\begin{array}{l}\text { Cantidad de aire con pérdida externa de presión } \\
150 \mathrm{~Pa}\left[\mathrm{~m}^{3} / \mathrm{h}\right]\end{array}$ & $\left|\begin{array}{c}120 \text { con } 30 \\
\mathrm{~Pa} \\
80 \mathrm{con} 20 \\
\mathrm{~Pa}\end{array}\right|$ & 200 & 200 & 350 & 350 \\
\hline
\end{tabular}

*) $\mathrm{N}^{\circ}$ de unidades válido para el tramo más largo (más desfavorable)

**) Se puede sustituir 2 salidas DN125 por una salida DN160

**) Se puede sustituir 3 salidas DN125 por una salida DN200

\section{Conducción de aire del TWINSOLAR 2.0}

En este modelo, los ventiladores están dimensionados para tramos cortos de tubería. La longitud de la tubería para su instalación vertical está limitada (véase gráfico).El ventilador del TWINSOLAR 2.0 está integrado en el colector y acústicamente aislado. Habitualmente no se necesita un silenciador adicional.

\section{Detalles del colector}

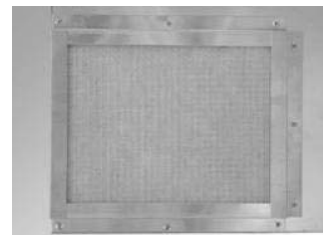

Imagen 1: Filtro en la parte trasera del colector

Extraer lateralmente desde la parte frontal del colector.

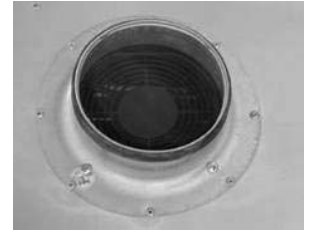

Imagen 2: Salida de aire Situada en la parte trasera del colector

DN $125 \mathrm{~mm}$ en caso del TWIN 2.0

DN $160 \mathrm{~mm}$ a partir de TWIN 4.0

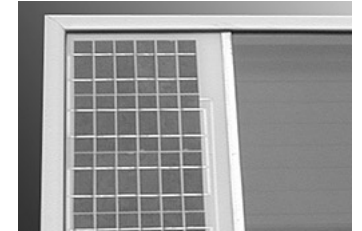

Imagen 3: Módulo fotovoltaico

El módulo fotovoltaico se sitúa en la zona vitrificada, concretamente en la zona de aspiración de aire frío.

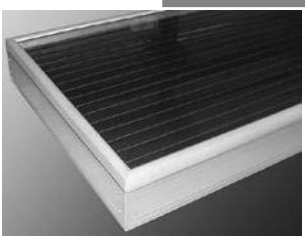

Imagen 4: Cubierta de vidrio

La cubierta de vidrio consiste de vidrio de seguridad, resistente al granizo.

Imagen de tubos y accesorios de la instalación:
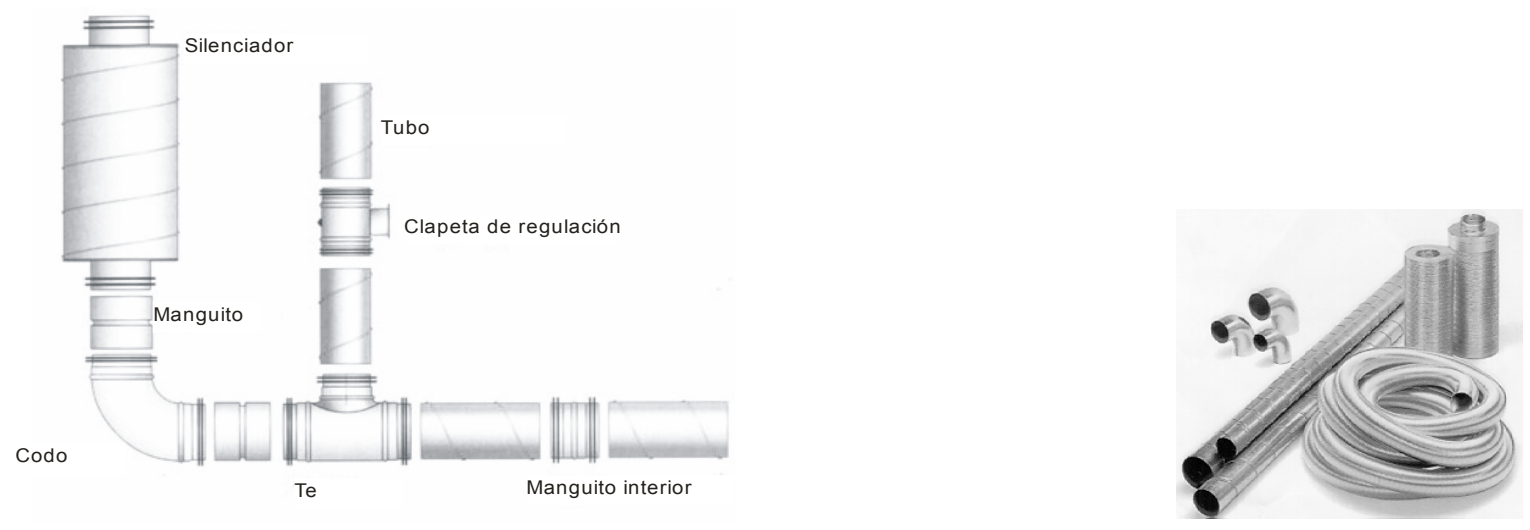

Nuestros socios más cerca de su residencia disponen de accesorios de ventilación!!! 


\subsection{Instrucciones de montaje - Instrucciones de mantenimiento}

\subsubsection{Avisos importantes TwinSolar y TopSolar}

- Hay que instalar los colectores TWINSOLAR en lugares sin sombra; sombras pequeñas reducen el rendimiento enormemente.

- Cambiar el filtro de aire cada año por lo menos una o dos veces.

- No instalar la aspiración de aire (colector que lleva el filtro) cerca de una chimenea o de una salida de aire.

- Hay que disponer de espacio suficiente para poder extraer lateralmente el filtro de aire desde la parte frontal del colector que lleva el filtro.

- Montar los ventiladores (a partir de TWINSOLAR 4.0 externo) en modo de amortiguado de vibraciones.

- Prever la instalación de un silenciador detrás del ventilador (véase gráfico abajo)

- A ser posible, hay que montar el módulo fotovoltaico en el sitio más bajo de la instalación para reducir su calentamiento en situaciones de paro de la instalación.

- Las instalaciones eléctricas tendrán que ser efectuadas por una empresa cualificada según VDE.

- Hay que revisar todas las uniones enroscadas una vez al año y, en su caso, reapretarlas.

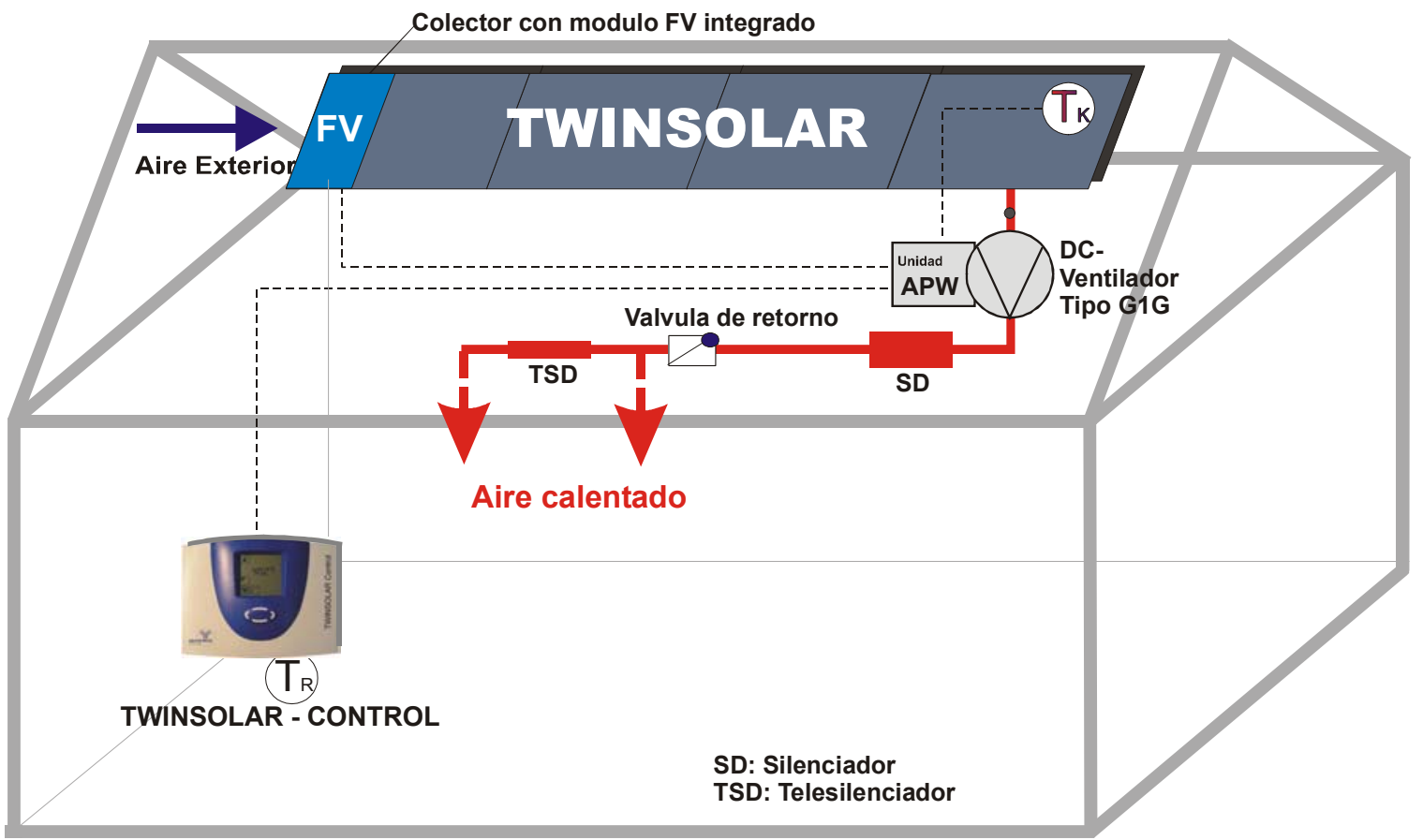

Gráfico 1: Sistema TWINSOLAR con ventilador externo (a partir de TWIN 4.0) y sistema solar sencillo de alimentación de aire

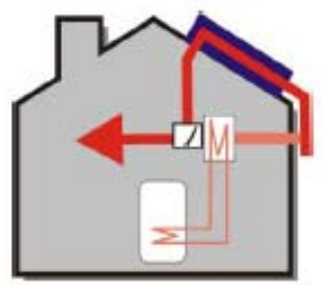

Sistema de aire caliente con ACS

Ventilación solar

Suelo/Pared radiante mediante energía solar 


\subsubsection{Orientación del colector}

Para conseguir un rendimiento óptimo, hay que orientar el colector siempre hacía el sur; sin embargo, desviaciones de hasta $45^{\circ}$ no reducen significantemente el rendimiento energético.

Hay que procurar montar el colector con una inclinación entre $45^{\circ}$ y $60^{\circ}$ en relación al plano horizontal, ya que el sistema del colector de aire caliente tiene su mejor rendimiento durante invierno y las estaciones de transición, cuando el sol tiene una altura relativamente baja.

¡En zonas con mucha nieve se recomienda la integración del sistema en la fachada!

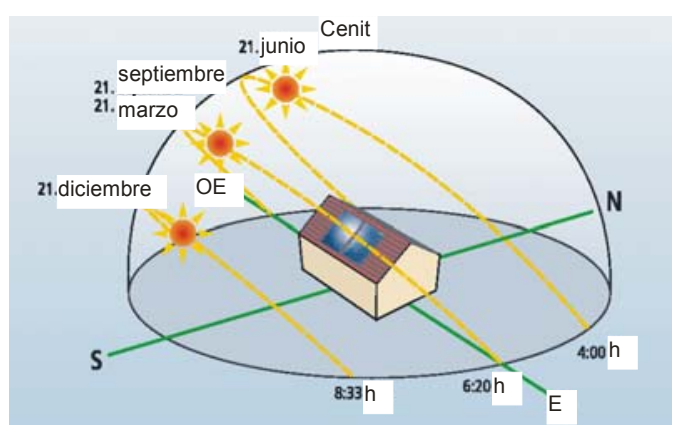

\subsubsection{Ventilador}

Imagen 1: Altura solar según las estaciones Fuente: DGS-Leitfaden Thermie

- Puesta en marcha: ¡Únicamente con el sistema de tubería conectado!

- Transmisión de vibraciones hacía la tubería: Hay que prever la instalación de manguitos flexibles (incluidos en la entrega), situados en dirección hacía la salida de aspiración y presión; véase imagen 3.

- Transmisión de vibraciones hacia el edificio: ¡Entre elsoporte del ventilador y estructura inferior hay que prever el montaje de una base de espuma dura; emplear tornillos con arandelas de goma!

- Sonidos de flujo: ¡Hay que instalar detrás del ventilador siempre un silenciador!

- Disposición de ventiladores: ¡Siempre montar en dirección de la aspiración, detrás de los colectores!

- ¡Nunca aislar los ventiladores: Peligro de sobrecalentamiento!

- ¡Los ventiladores no son impermeables ni aptos para la intemperie!

- En el modelo TWINSOLAR 1.3 y 2.0, el ventilador está integrado en el colector y listo para su uso.

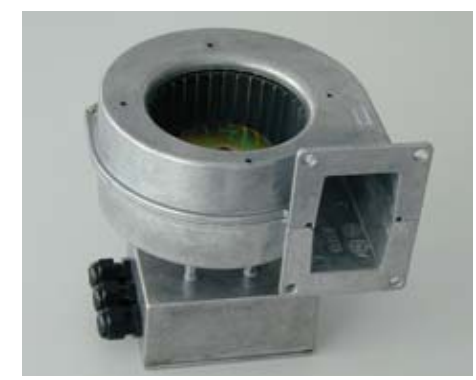

Imagen 2: Ventilador de corriente continua G1G (montaje externo detrás del colector).

Ventilador estándar a partir de TWINSOLAR 4.0

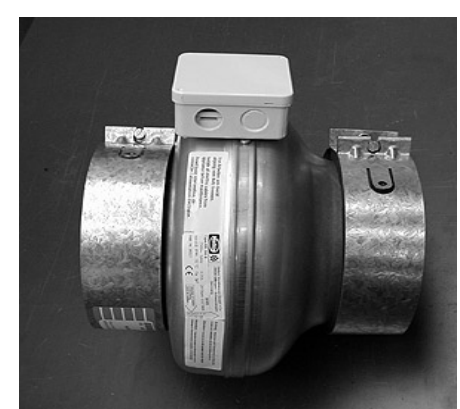

Imagen 3:

Ventilador estándar del sistema TopSolar-Sistema de aire solar

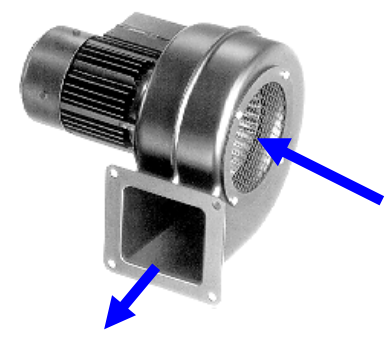

Imagen 4: Ventilador Radial con motor externo resistente a altas temperaturas (ACS) 


\subsection{Control - Ventilador}

Para conseguir el mejor aprovechamiento solar, el usuario debe tener en cuenta:

- El control solar supervisa y controla de forma automática el funcionamiento de los sistemas TWINSOLAR, en función de la radiación (o bien temperatura de colector) y la temperatura interior del edificio.

- Hay que fijar el valor máximo deseado para la temperatura interior en el regulador solar aproximadamente $2-3{ }^{\circ} \mathrm{C}$ encima del valor máximo de temperatura de la calefacción convencional (prioridad para la energía solar).

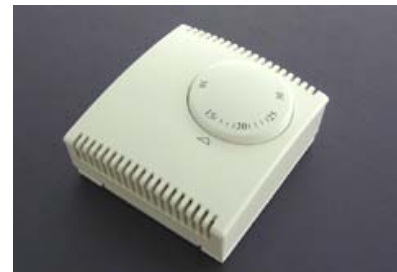

Imagen 1: TWINSOLAR 2.0

Termostato TEM $73 \mathrm{~A}$

Para determinar la temperatura máxima en el

TWINSOLAR 1.3 y en el 2.0 (incluido en la entrega).

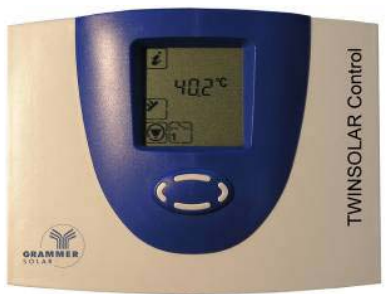

Imagen 2: TWINSOLAR 4.0 - 12.5

TWINSOLAR Control

Regulador de temperatura diferencial accionado por PV (incluido en la entrega).

\section{Conmutador de adaptación APW}

El conmutador de adaptación APW se encarga de optimizar el funcionamiento del módulo fotovoltaico para las diferentes condiciones de irradiación y garantiza la máxima producción solar. A partir del TWINSOLAR 4.0, este regulador estándar se encuentra integrado en la caja de conexión del ventilador (ver imagen 4)

El conmutador de adaptación en sistemas de TWINSOLAR coordina de manera óptima la curva característica del ventilador y del módulo fotovoltaico. De esta manera la instalación rinde al máximo en situaciones de irradiaciones variables.

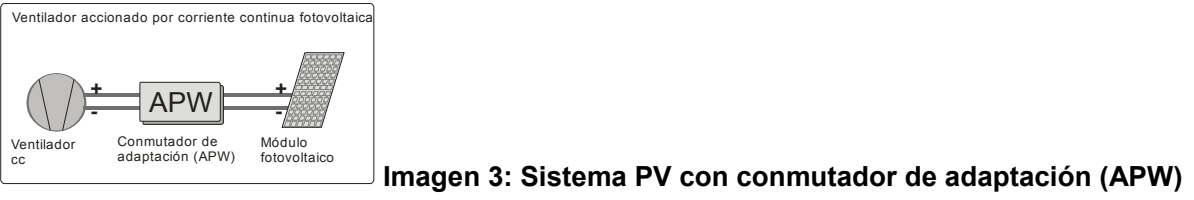

Principio de funcionamiento: El conmutador de adaptación mantiene constante la tensión de entrada del módulo fotovoltaico. Significa que las revoluciones del ventilador se adaptan automáticamente a la irradiación en cada momento. Así se consigue mantener la dispersión geométrica sin encender y apagar el ventilador permanentemente. Con la limitación de corriente se consigue un arranque suave del ventilador.

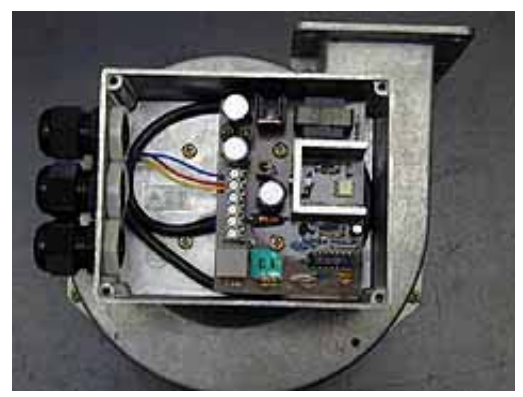

Imagen 4: Ventilador TWINSOLAR con APW integrado

A partir del TWINSOLAR 4.0, la electrónica de adaptación (APW), se produce en serie y está integrada en la caja de conexión del ventilador G1G, según se puede apreciar en la imagen.

\section{Garantía:}

No intente manipular el sistema del colector o la electrónica; en este caso perdería la garantía. Si el colector resulta defectuoso, dentro del plazo de garantía, lo arreglaremos o bien, en su caso, entregaremos un colector nuevo. 


\subsubsection{Control TwinSolar COMpacto 1.3 hasta 6.0}

El control de temperatura de todos los TWINSOLAR Compacto consiste en un interruptor de funcionamiento y un control mediante termostato TEM 73A.

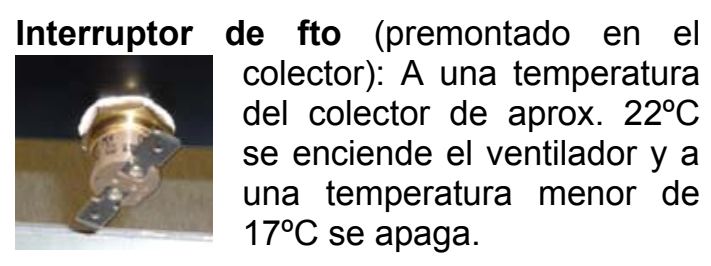

Termostato ambiente (accesorio):

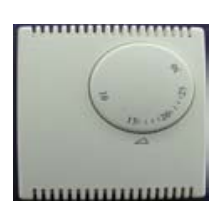

Al alcanzar la temperatura programada se apaga el ventilador.

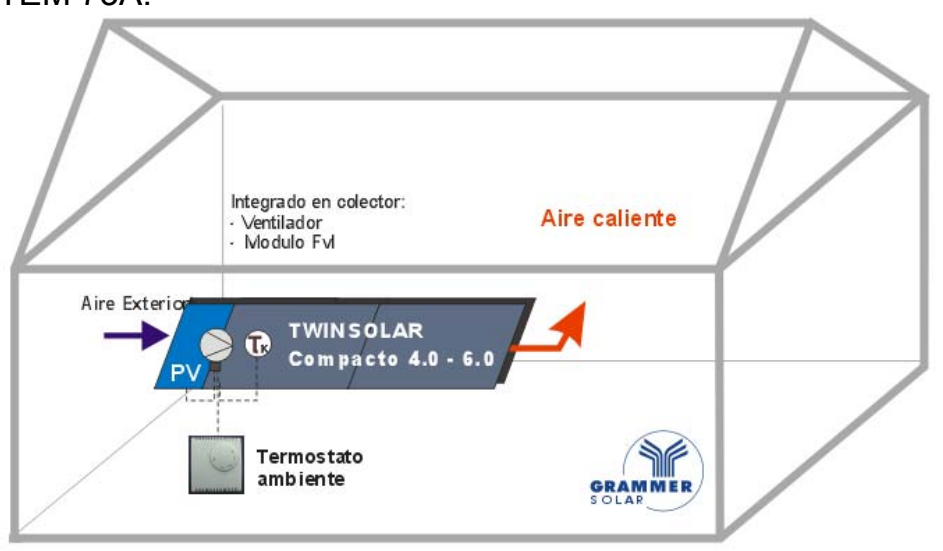

Conexión en el colector-accesible por la entrada del filtro

\begin{tabular}{|l|l|l|l|}
\hline $\begin{array}{l}\text { TWINSOLAR } \\
\text { Compacto }\end{array}$ & $\mathbf{1}$ (1.3 a partir de 2011) & TWINSOLAR 4.0, 4.5, 6.0 Compacto \\
\hline Interruptor de funcionamiento accesible en la salida del \\
colector:
\end{tabular}

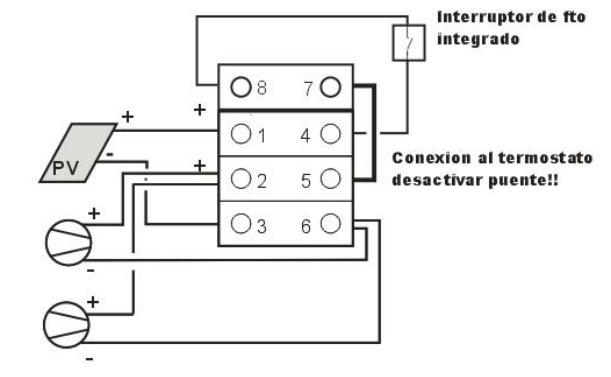

\section{Observación:}

- Desde Septiembre 2010, los colectores TWINSOLAR 2.0 se han suministrado con un interruptor de funcionamiento.

- A partir de mediados del 2011, el TWINSOLAR 1.3 será fabricado con este mismo interruptor.

- De manera opcional, se puede puentear o desactivar este interruptor. El ventilador funcionaría, siempre en dependencia de la radiación solar, pero incluso cuando la temperatura del mismo está por debajo de $22^{\circ} \mathrm{C}$. Este caso tiene sentido si la aplicación prioritaria del sistema es la de ventilar.

ADVERTENCIA: El ventilador se encuentra junto a la caja de conexiones y éste funciona en cuanto hay radiación solar suficiente en el módulo FV. Para trabajar con las conexiones se debe cubrir el módulo fotovoltaico 
A diferencia del sistema de control sencillo del TWINSOLAR Compacto, aquí tenemos un control TWINSOLAR de temperatura diferencial.

\section{Función:}

TWINSOLAR Control (imagen 2) controla y supervisa el funcionamiento de los sistemas TWINSOLAR. El regulador funciona gracias a la placa FV y trabaja cuando hay suficiente radiación. Sin o con poca radiación no funciona.

Este sencillo sistema de control compara las temperaturas del interior y del colector $y$ enciende $\mathrm{o}$ apaga el ventilador, dependiendo del resultado. (control por temperatura diferencial). Una vez alcanzada la temperatura deseada, el sistema se apaga.

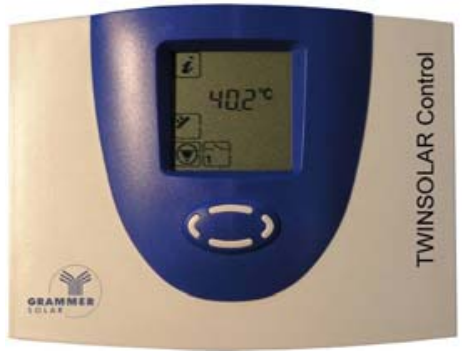

Imagen 2 TWINSOLAR Control

Funcionamiento manual

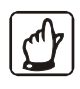

(jFuncionamiento a modo de prueba sin control de temperatura!)

Con el botón izquierdo se puede activar o desactivar el menú "Funcionamiento manual" (símbolo mano).

Con el botón derecho se puede activar manualmente el ventilador (¡sólo cuando haya potencia FV suficiente!).

Después de 8 horas o abandonando el funcionamiento manual, se pasa al funcionamiento automático.

\section{Instalación funcionando:}

Si el ventilador (pictograma) se mueve, la instalación está en funcionamiento.

\section{Desactivar la instalación}

Programar la max. Temperatura interior en $5{ }^{\circ} \mathrm{C}$.

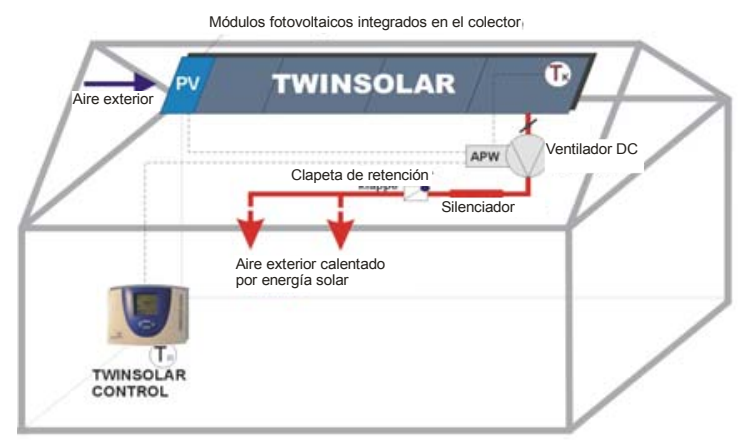

Imagen 1: Equema de funcionamiento - TWINSOLAR 4.0 - 12.5

PANTALLA VALORES DE MEDICIÓN - Menú de información $i$

En el menú de información, a través de los botones "arriba" y "abajo", se puede consultar los siguientes valores:

- Temperatura actual del colector

- Temperatura mínima y máxima del colector (valor diario)

- Temperatura del acumulador=temperatura del interior

- Temperatura interior mínima y máxima (valor diario)

¡El pictograma de ventilador móvil $@$ señaliza cuando el sistema está funcionando! ¡Cuando haya poca irradiación, el valor en la pantalla desaparece!

CONFIGURACIÓN- Programar

Con el botón izquierdo se puede activar o desactivar el menú "Programar".

Con los botones "Arriba" y "Abajo" se puede consultar los siguientes valores de configuración:

- $\max \left(\right.$ temperatura máxima) aprox. $23^{\circ} \mathrm{C}$

- $\quad$ dT máx. (diferencia de encendido): $6 \mathrm{~K}$

- $\quad$ dT min. (diferencia de apagado): $3 \mathrm{~K}$

En caso de cambios de valores, hay que confirmarlos y guardarlos con el botón derecho. 


\section{Esquema de conexión TWINSOLAR Control}

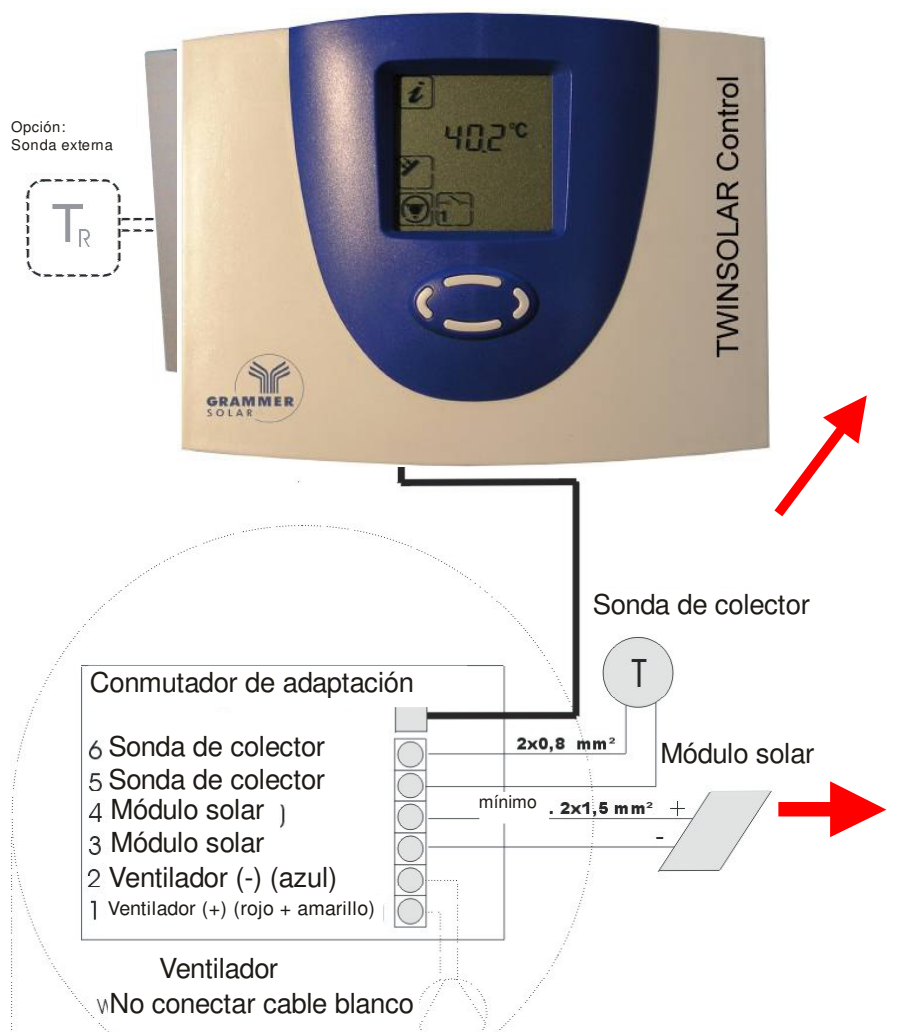

Avisos importantes:

> Verificar POLARIDAD de la conexión del módulo solar; véase imágenes 1 y 2.

$>$ No colocar TWINSOLAR Control cerca de fuentes de calor o expuesto a la radiación solar directa.

$>$ Si no se conecta el cable de comunicación o si el TWINSOLAR Control se encuentra desconectado, el ventilador funciona en dependencia de la irradiación (sin regulación de temperatura).

> Véase también los capítulos siguientes de este manual: Ventilador Capitulo 1.5.3 Lista de chequeo Corrección de fallos Capítulo 1.7

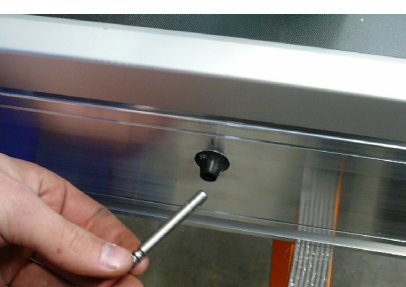

Imagen 1: montaje del sensor del colector

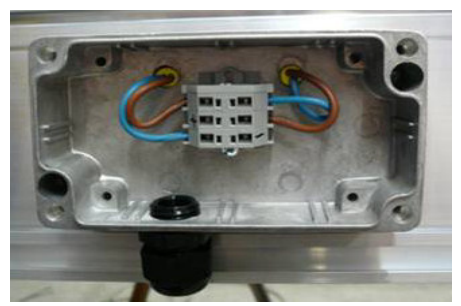

Imagen 2:Caja de conexión del módulo, en el colector

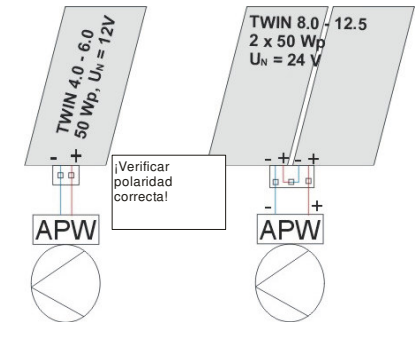

Imagen 3: Esquema de conexión del módulo para instalaciones con 1 ó 2 módulos

Imagen 3: Kit de ventilación en el paquete de colector TWINSOLAR

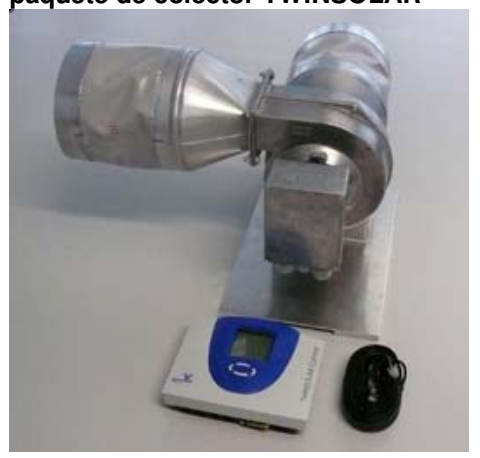

\section{Opciones:}

Como alternativa a la sonda integrada, se puede conectar una sonda externa al regulador; para efectuar el cambio, véase manual del regulador. La adaptación se encuentra en el Menú Ajuste Normal desde $0=$ interno hasta $1=e x t e r n o$. Esta adaptación es sólo posible dentro del primer minuto después de la conexión del regulador. En el bloque libre de conexión T2 se puede conectar un sensor externo (Pt1000). 


\subsubsection{TWINSOLAR - Kit de conmutación Confort}

\section{Accesorio opcional TWINSOLAR 1.3 - 12.0}

\section{FUNCIÓN:}

El kit de conmutación confort sirve para llevar la corriente de los módulos fotovoltaicos a consumidores externos.

Aparte de la posibilidad estándar de efectuar la conmutación directamente en el colector, se puede elegir también desde el interior de la vivienda entre funcionamiento para ventilación o consumidores externos (por ejemplo lámparas, radio etc.).

\section{INSTRUCCIONES DE USO}

Externo: La corriente de los módulos PV se puede usar externamente.

Off: $\quad$ Los módulos PV están

completamente desconectados sistema sin servicio.

On: Los módulos PV están conectados al ventilador - sistema de ventilación en función.

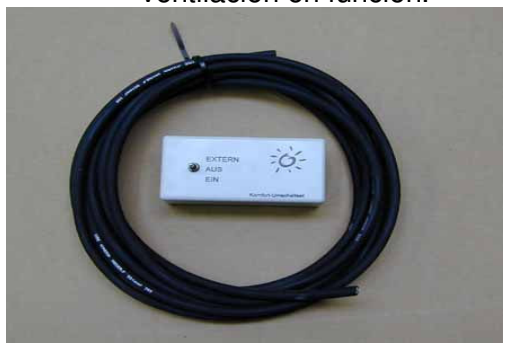

Imagen 1: Kit de conmutación con cable

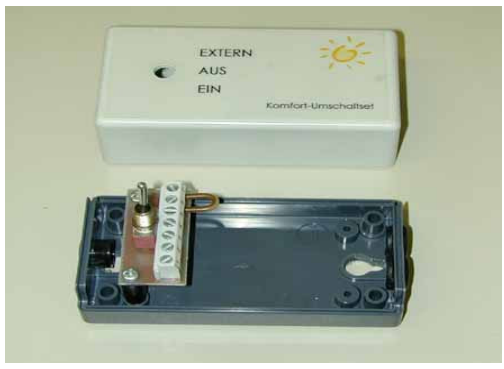

Imagen 2: Conmutador
Esquema de conexión TWINSOLAR 1.3/2.0 Serie $\underline{1-2007}$

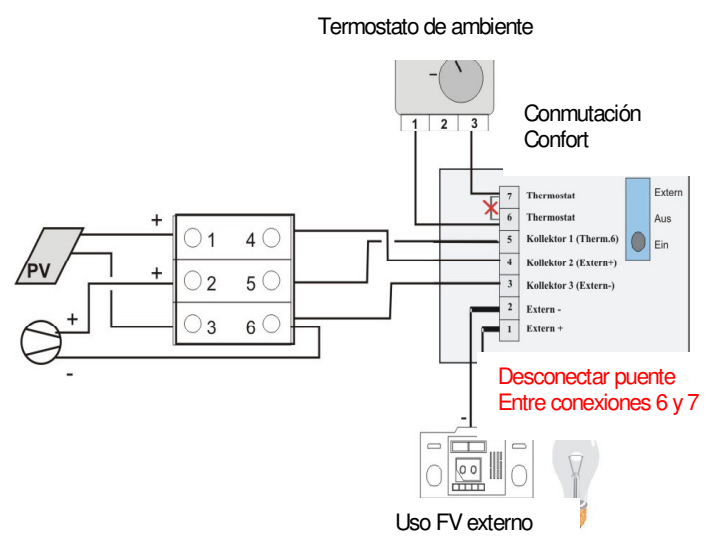

Esquema de conexión TWINSOLAR 2.0 Serie 102006-02-2007

Conmutar a modo Externo en la caja de conexiones!

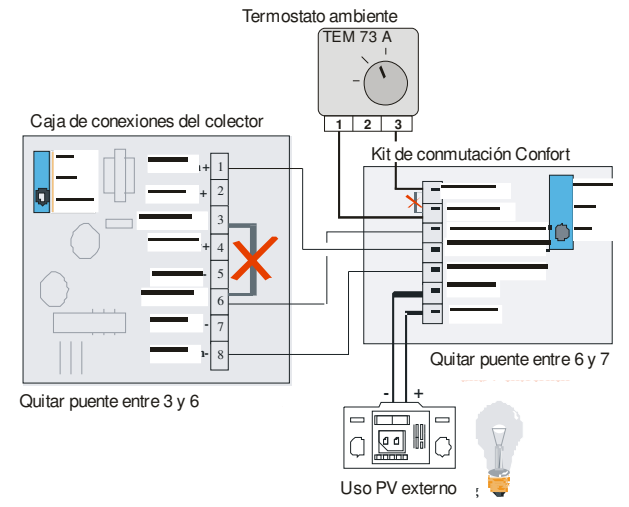

Esquema de conexión TWINSOLAR 4.0 y 10.0

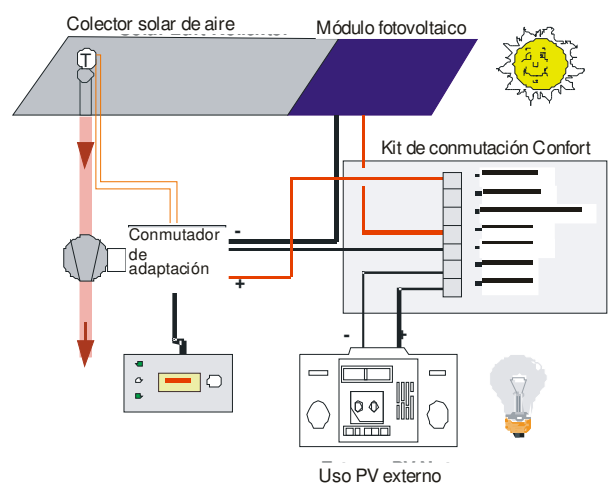




\subsubsection{Medición de la temperatura - Dispositivo de control para el interior de la vivienda - Termostato ambiente}

A partir TWINSOLAR 4.0: Una sonda para el interior de la vivienda (tipo PT1000) está integrada en el TWINSOLAR Control (imagen 1); sin embargo, alternativamente se puede conectar una sonda exterior al dispositivo de control para el interior de la vivienda (véase página 16). En el modelo TWINSOLAR 2.0, un termostato ambiente recoge la temperatura interior.

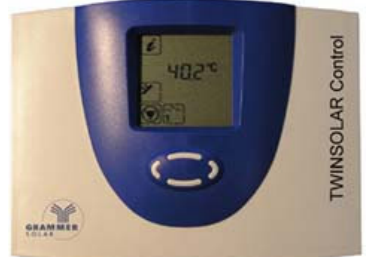

Imagen 1: TWINSOLAR Control
Tenga en cuenta estos avisos al disponer el dispositivo de control para el interior de la vivienda y el termostato ambiente:

- Evitar radiación directa

- Evitar influencia por otras fuentes de calor

- No disponer cerca de elementos de ventilación

El funcionamiento correcto de la sonda de temperatura puede ser comprobado a través de las siguientes tablas de resistencia y con la ayuda de un dispositivo de medición de resistencias:

\begin{tabular}{|c|c|c|c|}
\hline $\begin{array}{c}\text { Temperatura } \\
\text { en }{ }^{\circ} \mathbf{C}\end{array}$ & $\begin{array}{c}\text { Resistencia } \\
\text { en ohmios }\end{array}$ & $\begin{array}{c}\text { Temperatura } \\
\text { en }{ }^{\circ} \mathbf{C}\end{array}$ & $\begin{array}{c}\text { Resistencia } \\
\text { en ohmios }\end{array}$ \\
\hline $\mathbf{- 3 0}$ & 882 & $\mathbf{6 0}$ & 1232 \\
\hline $\mathbf{- 2 0}$ & 921 & $\mathbf{7 0}$ & 1271 \\
\hline $\mathbf{- 1 0}$ & 960 & $\mathbf{8 0}$ & 1309 \\
\hline $\mathbf{0}$ & 1000 & $\mathbf{9 0}$ & 1347 \\
\hline $\mathbf{1 0}$ & 1039 & $\mathbf{1 0 0}$ & 1385 \\
\hline $\mathbf{2 0}$ & 1077 & $\mathbf{1 2 0}$ & 1461 \\
\hline $\mathbf{3 0}$ & 1116 & & \\
\hline $\mathbf{4 0}$ & 1155 & & \\
\hline $\mathbf{5 0}$ & 1194 & & \\
\hline
\end{tabular}

\subsubsection{Funcionamiento con el kit de ventilación de verano y ventilador de pared}

En verano se puede usar los módulos PV integrados en el colector, en combinación con un ventilador empotrado en la pared (kit de ventilación de verano), para la ventilación de determinadas habitaciones.

Datos técnicos del ventilador empotrado:

Tensión nominal:

Potencia:

Cantidad máxima de aire :
12 voltios ( $7-14,5$ voltios),

5,6 vatios aprox. $80 \mathrm{~m}^{3} / \mathrm{h}$

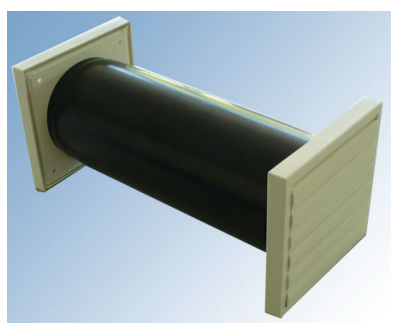

Imagen 2: Ventilador empotrado (kit de ventilación de verano)

\section{Conexión eléctrica:}

TWINSOLAR 1.3/2.0 - . Lea las indicaciones del capítulo 1.6.1 hasta 1.6.3. "Conexión uso externo".

TWINSOLAR 4.0 - 10.0 - Lea las indicaciones del capítulo 1.6.3 "Conexión uso externo". Para un buen funcionamiento se necesita un kit de conmutación Confort. En el modelo TWINSOLAR 10.0 (24 voltios tensión PV), hay que montar un estrangulador adicional (incluido en la entrega). 


\subsection{LISTA DE CHEQUEO - CORRECCIÓN DE FALLOS para TwinSolar}

\begin{tabular}{|c|c|}
\hline FALLO & Causa posible - Corrección \\
\hline \multirow{12}{*}{$\begin{array}{l}\text { Ventilador no } \\
\text { funciona }\end{array}$} & Módulos PV sombreados. ¡Poca sombra tiene mucho efecto! \\
\hline & Poca irradiación. \\
\hline & Electrónica de adaptación. Comprobar contacto de terminales - en su caso apretar. \\
\hline & Verificar polaridad de los módulos solares y el ventilador. \\
\hline & Comprobar cable que une el módulo solar con la electrónica de adaptación/ventilador. \\
\hline & $\begin{array}{l}\text { Caja de conexión del módulo en el colector. Comprobar contactos de terminales de conexión } \\
\text { - en su caso apretar. }\end{array}$ \\
\hline & Comprobar el cable de comunicación entre ventilador y regulador TWINSOLAR Control. \\
\hline & $\begin{array}{l}\text { Aviso: Si se desconecta el cable de comunicación o el regulador solar, el ventilador funciona } \\
\text { en dependencia de la irradiación (sin regulación de temperatura). }\end{array}$ \\
\hline & Comprobar que la tubería no esté obstruida. \\
\hline & TWINSOLAR 2.0 \\
\hline & $\begin{array}{l}\text { En funcionamiento con el kit de conmutación Confort: Comprobar que el interruptor dentro de } \\
\text { la caja de conexión del colector está en "Externo". }\end{array}$ \\
\hline & $\begin{array}{l}\text { Comprobar reparto de terminales en el termostato; tener en cuenta los puentes en caso de } \\
\text { funcionamiento sin termostato. }\end{array}$ \\
\hline \multirow{4}{*}{$\begin{array}{l}\text { Instalación no } \\
\text { funciona en modo } \\
\text { automático }\end{array}$} & $\begin{array}{l}\text { Comprobar que las sondas tengan contacto y se encuentren en sitios adecuados; véase } \\
\text { capítulo 1.6.5. }\end{array}$ \\
\hline & Comprobar temperatura diferencial fijada - puede ser demasiada alta. \\
\hline & $\begin{array}{l}\text { Comprobar valor fijado de la temperatura máxima - puede ser demasiado pequeño; en este } \\
\text { caso, la instalación no puede funcionar en régimen de calefacción. }\end{array}$ \\
\hline & $\begin{array}{l}\text { Módulo solar demasiado caliente. En caso de instalaciones de TWINSOLAR integradas en el } \\
\text { tejado, los módulos solares pueden calentarse mucho en verano; en consecuencia, el } \\
\text { arranque después de un período sin actividad puede ser lento. }\end{array}$ \\
\hline \multirow{2}{*}{$\begin{array}{l}\text { Instalación } \\
\text { funciona } \\
\text { permanentemente } \\
\text { y sin regulación }\end{array}$} & $\begin{array}{l}\text { En el menú de configuración, está puesta la función ON - cambiar a funcionamiento } \\
\text { automático. }\end{array}$ \\
\hline & Cable de comunicación de instalaciones TWINSOLAR no conectado; problema de contacto. \\
\hline \multirow{4}{*}{$\begin{array}{l}\text { Ventilador hace } \\
\text { demasiado ruido }\end{array}$} & Instalar silenciador. \\
\hline & Montar el ventilador de manera amortiguada de vibraciones. \\
\hline & Válvulas de aire excesivamente estranguladas - ruidos de silbido. \\
\hline & Comprobar topes mecánicos ajustables del motor. \\
\hline \multirow{2}{*}{$\begin{array}{l}\text { Valores de } \\
\text { temperatura } \\
\text { oscilantes en el } \\
\text { interfaz }\end{array}$} & $\begin{array}{l}\text { Si los cables de las sondas están muy largos y se encuentran al lado de cables que lleven } \\
\text { tensión, puede ocasionar interferencias. Solución: Usar cables protegidos o cambiar el } \\
\text { trazado de colocación. }\end{array}$ \\
\hline & $\begin{array}{l}\text { Situaciones de poca irradiación pueden ocasionar en las instalaciones TWINSOLAR cambios } \\
\text { de temperatura en el dispositivo de control para el interior de la vivienda. }\end{array}$ \\
\hline \multirow{3}{*}{ Poca potencia } & $\begin{array}{l}\text { Comprobar nivel de suciedad del filtro. ¡iiCambiar filtro por lo menos una o dos veces al } \\
\text { año!!! }\end{array}$ \\
\hline & Tubería obstruida - limpiarla en su caso. \\
\hline & $\begin{array}{l}\text { Comprobar sombreado de la instalación. Sombras en el módulo solar, aunque sean } \\
\text { pequeñas, pueden reducir considerablemente el rendimiento. }\end{array}$ \\
\hline
\end{tabular}




\subsection{Montaje del colector}

\subsubsection{Montaje en tejado inclinado}

En caso de montaje en tejados inclinados, el colector (por ejemplo el TWINSOLAR 2.0) o los colectores se fijan en la armadura de la cubierta a través de ganchos o anclajes de vigueta.

Los colectores constituyen para la cubierta una carga adicional. Hay que decidir en cada caso si hace falta efectuar un cálculo estático nuevo. Los colectores tienen un peso estático de 22 $\mathrm{kg} / \mathrm{m}^{2}$ de superficie del colector.

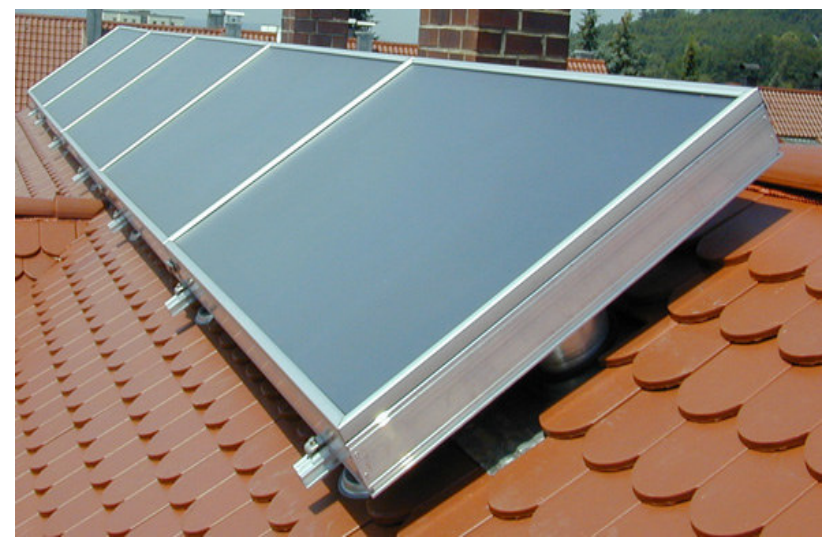

Montaje en tejado inclinado - Volumen de entrega del paquete estándar

Ejemplo: Paquete de montaje en tejado inclinado 4.0 - SLK.

El paquete para el montaje del colector sobre tejas tipo "Pfanne" incluye:

8 uds. ganchos para tejas tipo "Pfanne"

¡Lea también el capítulo de avisos generales para la seguridad!

16 uds. tornillos de madera M $8 \times 100+$ arandelas

4 uds. carriles de montaje de aluminio; longitud 1,15 m + tornillos

4 uds. escuadras en $Z+$ tornillos

4 uds. pinzas de fijación + tornillos

1 ud. chapa de plomo con banda impermeable DN 180/160

1 tubo DN $160 \mathrm{~mm}$, longitud $450 \mathrm{~mm}$, para pasar el tejado.

¡En zonas de mucha nieve hay que prever el montaje de más carriles de montaje y anclajes de tejado que los previstos en el paquete estándar! Para más informaciones y precios consultar.

\section{Pasos de montaje - Descripción breve}

1. Medir/fijar el campo de colectores en el tejado (véase esquemas de colectores en el anexo).

2. Fijar el punto de pasar el tejado (jtener en cuenta posibles viguetas!). Efectuar la perforación del tejado - cortar un agujero en la cubierta y ajustar la chapa de plomo de manera impermeable.

3. Colocar ganchos de anclaje y atornillarlos a la vigueta; en su caso equilibrar diferencias de altura con tablas de equilibrio.

4. Montar carriles de montaje sobre los ganchos.

5. Colocar sonda de colector y cable de conexión para PV y prepararlos para la conexión.

6. Pegar junta de conexión de los colectores.

7. Montar colectores.

8. Conectar colectores entre si con cierres de presión.

9. Pegar de una cara la junta para el cable de la sonda del colector (+ cable PV para TWINSOLAR).

10. Al terminar comprobar todos los tornillos. ¡Repetirlo cada año! 


\section{Montaje - Descripción detallada}

Paso 1 - Medir el tejado (esquemas CAD de los colectores: Véase a partir de página 32)

\section{Paso 2 - Perforación del tejado y conexión del colector}

Los materiales para pasar el tejado son: una chapa de plomo con banda lateral, junta y enganche para tubería (125 mm o $160 \mathrm{~mm}$ ).

La chapa de plomo es flexible y puede ser adaptada a muchos tipos de tejas.

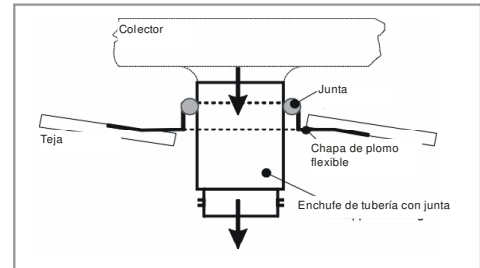

Los colectores de aire caliente Grammer tienen en la parte trasera del colector un enchufe para tubería redonda. Sobre este enchufe se coloca el manguito (incluido en la entrega) y se lo asegura, por ejemplo con una escuadra de soporte.

Si el tejado está aislado, hay que unir el tubo con la lámina de aislamiento mediante pegamento.
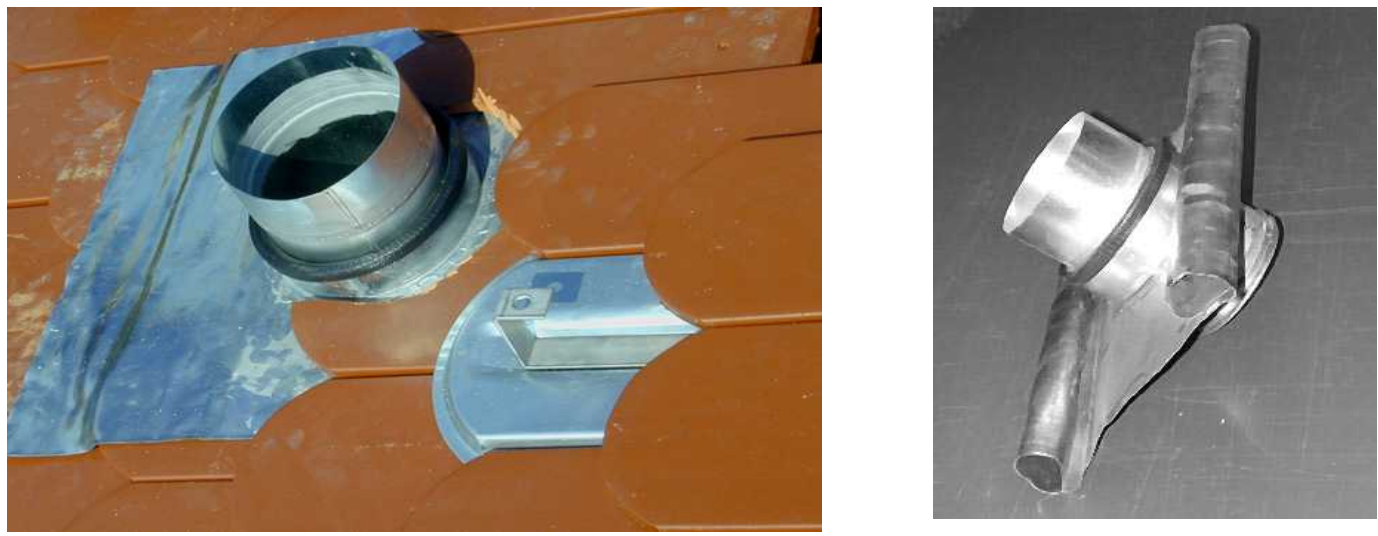

\section{Paso 3 - Colocar los ganchos}

Hay que colocar los ganchos en la zona de la vigueta y atornillarlos fijamente.

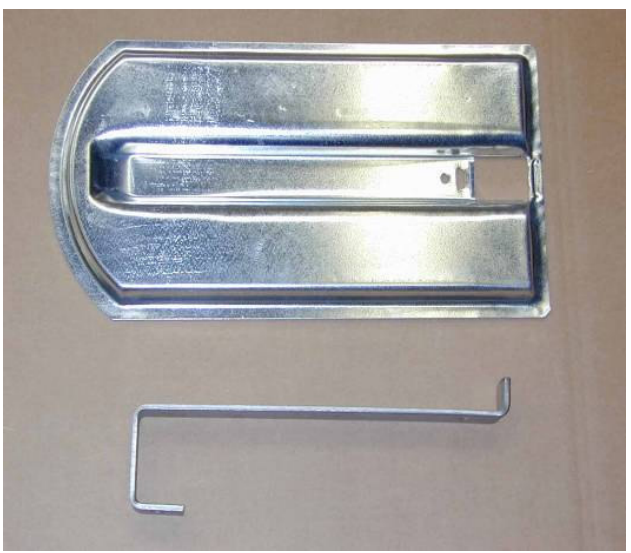

Gancho de anclaje para tejados tipo "Biberschwanz"

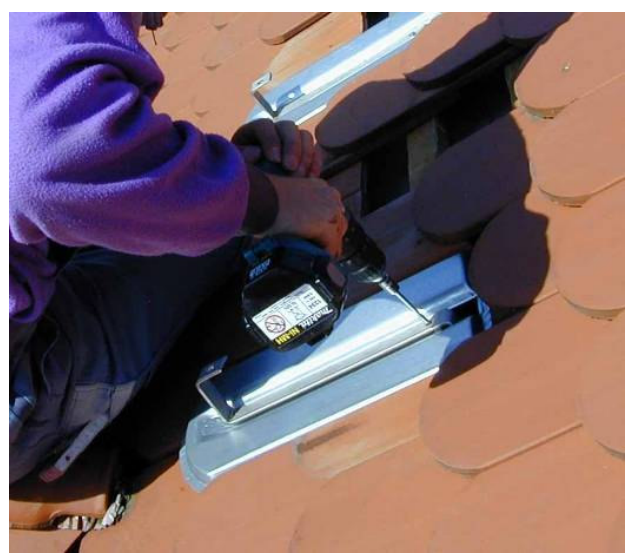

Fijación de un gancho de anclaje para tejados tipo "Biberschwanz" 


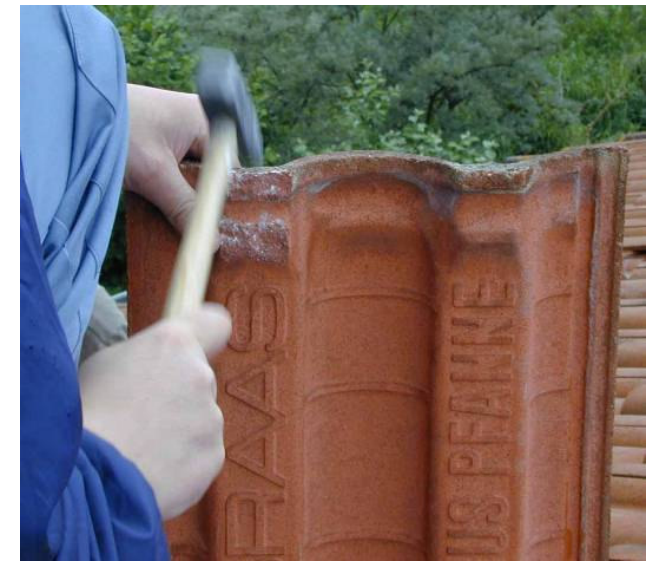

Liberar hueco para el gancho de anclaje

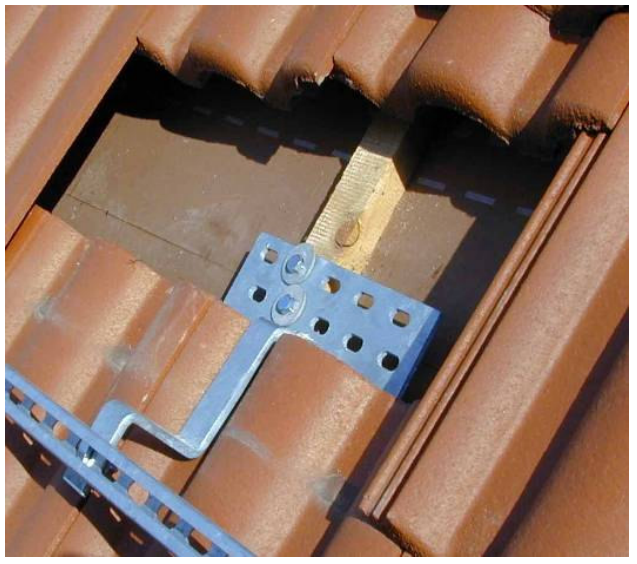

Gancho de anclaje puesto con carril transversal atornillado

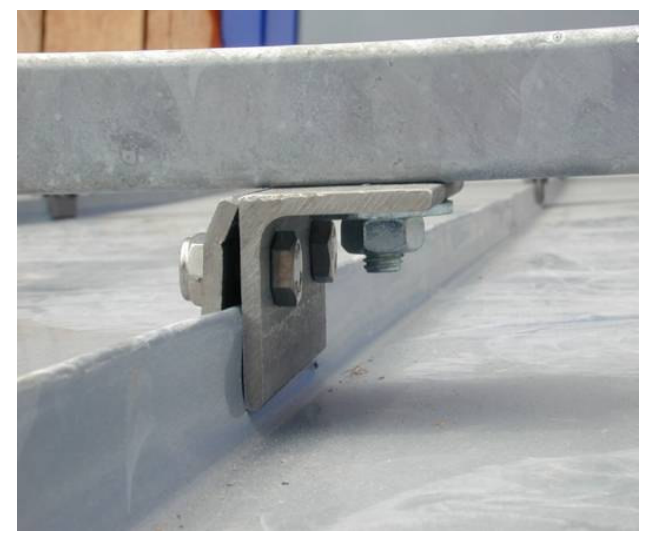

Montaje sobre tejado de chapa plegada en vertical

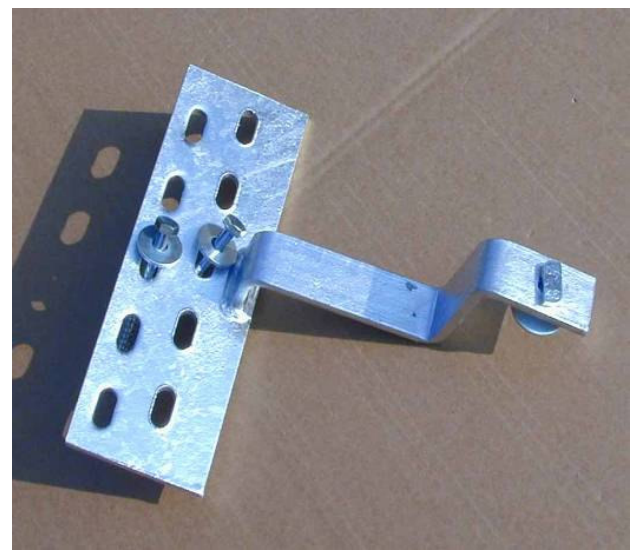

Ganchos de anclaje para tejas tipo "Pfanne" y tornillos de fijación

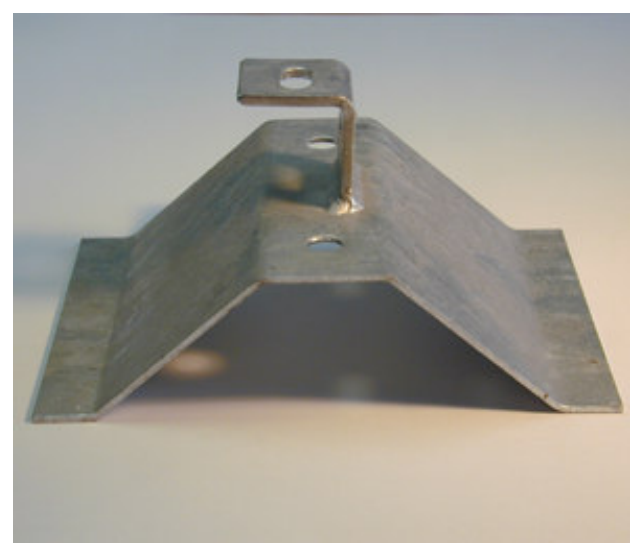

Gancho de anclaje para tejado metálico de minionda

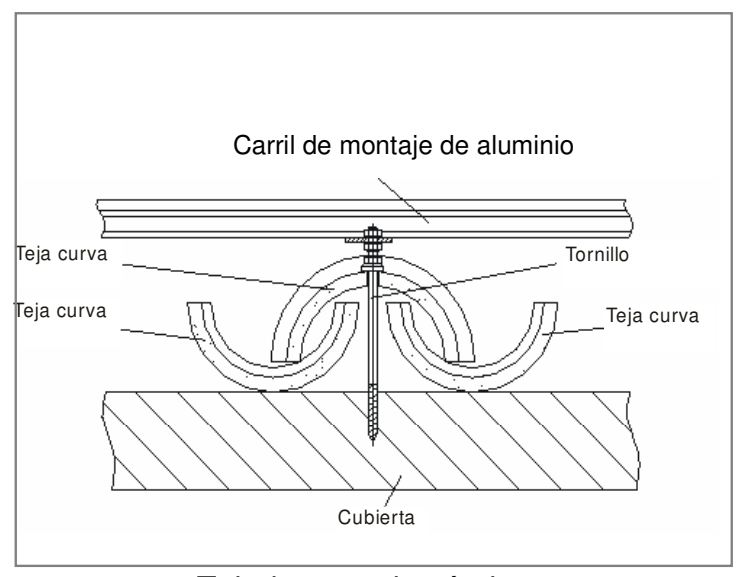

Tejado con tejas árabes

Paso 4 - Montar carriles de montaje sobre ganchos de anclaje 

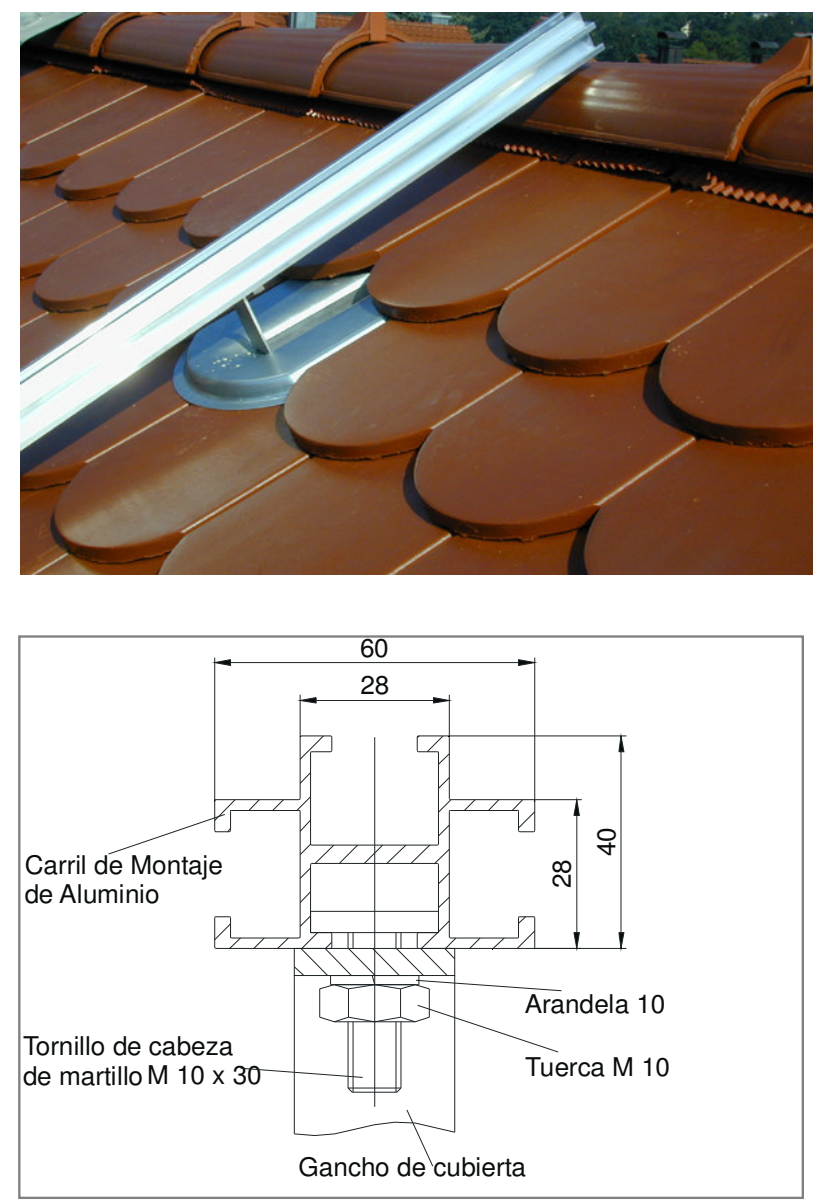

Paso 5 - Colocar cable de sonda del colector / cable de conexión PV y prepararlos para su conexión

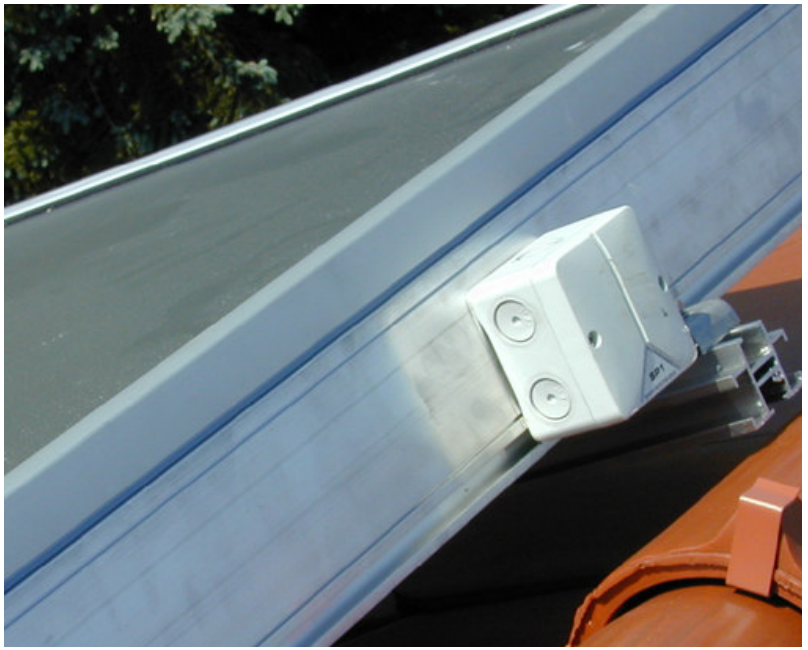

\section{Cajas de conexión}

$>$ En cada colector final se encuentra una caja de conexión para la conexión de la sonda. Se conecta la sonda al regulador con un cable bipolar (sección mínima 2 × 0,8 mm²).

$>$ Caja de conexión PV (solo colectores TWINSOLAR): Conectar los módulos PV al ventilador con un cable bipolar (sección mínima 2 x $\left.1,5 \mathrm{~mm}^{2}\right)$.

$>$ Tener en cuenta la ubicación de las cajas de conexión (medidas reflejadas en los esquemas de montaje de los colectores).

$>$ Pasar los cables por el tejado, en la zona de perforación del tejado.

Paso 6 - Conectar los colectores - Pegar el perfil de junta 


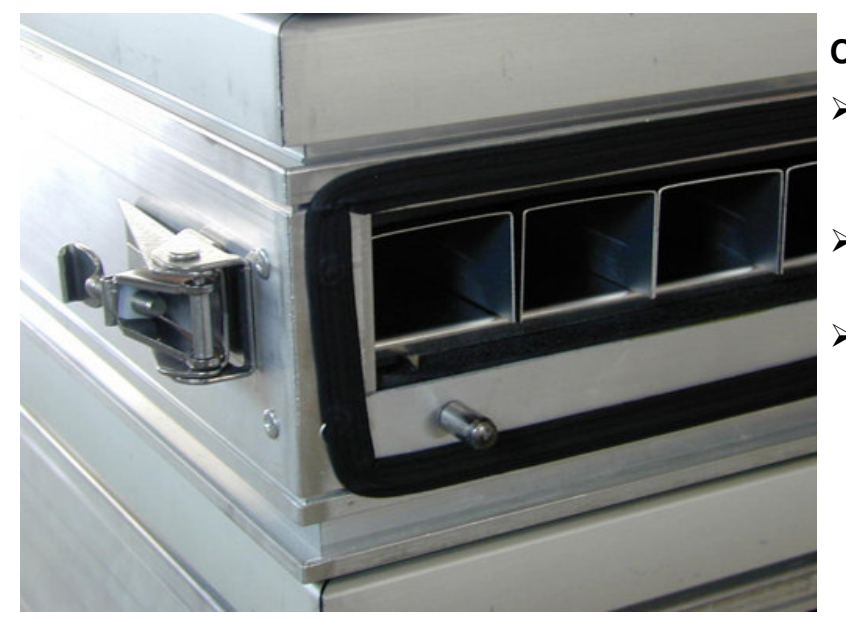

Conexión de los colectores - Superficie a sellar

$>$ Para sellar las conexiones entres los colectores, hay que pegar -antes de montar los colectores- una junta.

Juntas (autoadhesivas) están incluidas en la entrega.

¡Pegar las juntas solamente a uno de los dos colectores!

\section{Paso 7 - Montaje del colector}

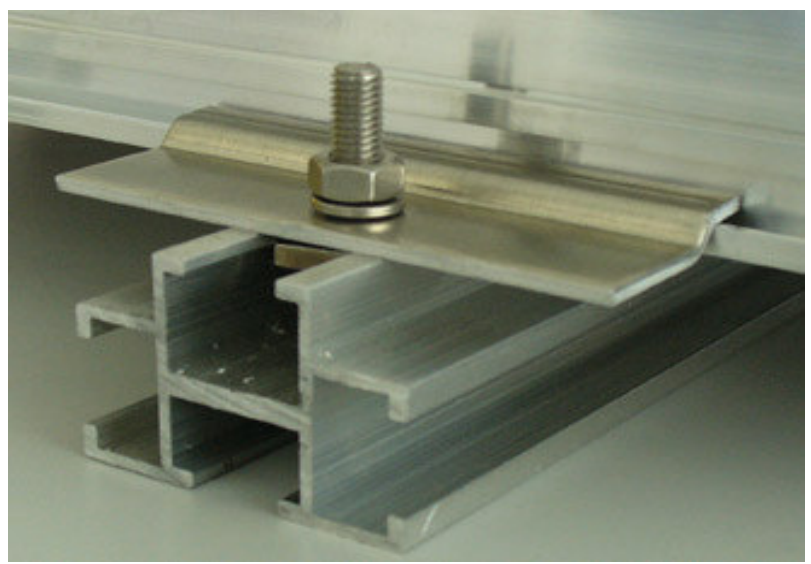

\section{Fijación del colector I}

> Fijar los colectores con escuadras en $Z$ en la parte trasera del colector.

> Hay que montar y orientar las escuadras en Z sobre los carriles de montaje antes de montar los colectores.
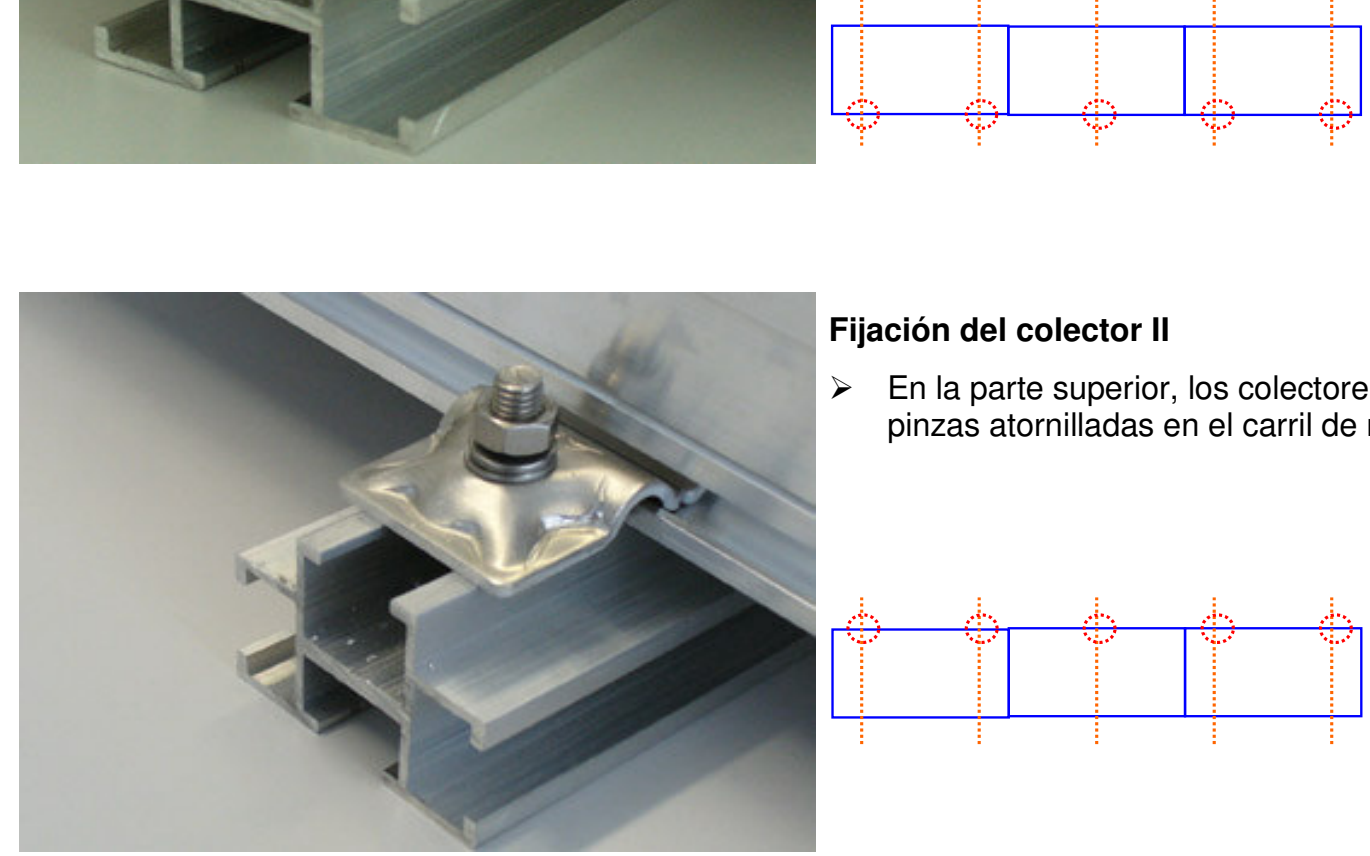

\section{Fijación del colector II}

> En la parte superior, los colectores se fijan con pinzas atornilladas en el carril de montaje.

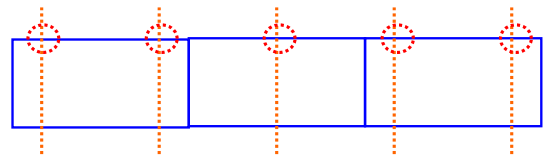




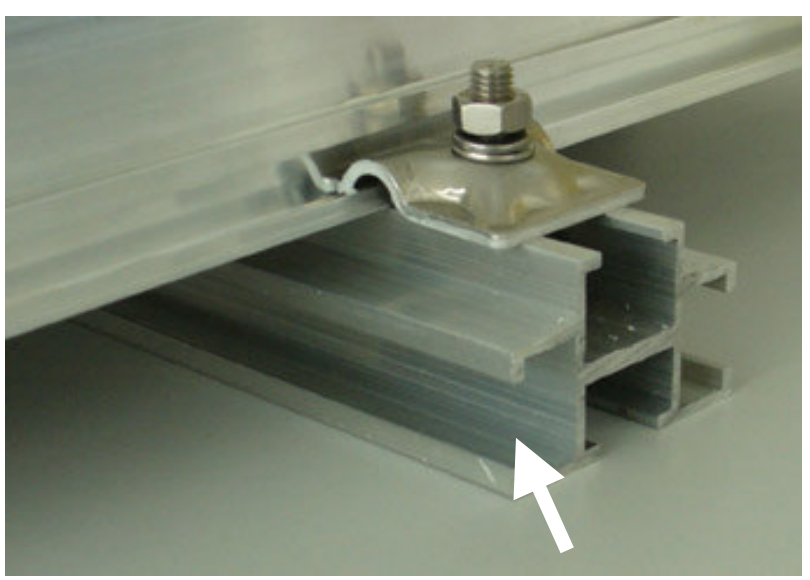

\section{Montaje vertical}

$>$ Con las pinzas de montaje se atornilla los colectores a los carriles de montaje.

$>$ Apoyo de montaje contra el deslizamiento.

\section{Paso 8 - Conexión de colectores entre si mediante cierres rápidos de presión}

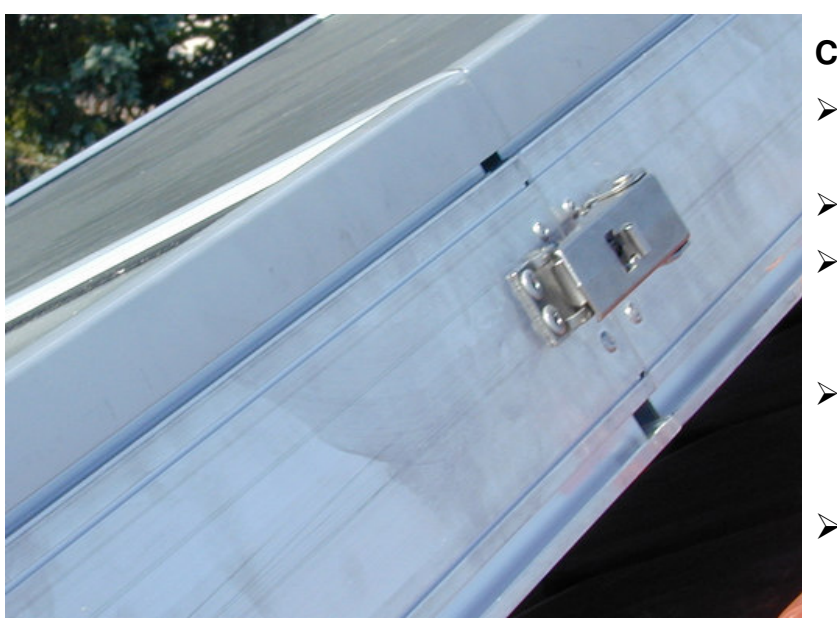

\section{Conexión de colectores}

Hay que conectar los colectores entre si mediante cierres rápidos de presión.

$>$ ¡Poner juntas a los espacios previstos!

Los pasadores de posicionamiento en los puntos de conexión facilitan la colocación de los colectores.

> Hay que ajustar los cierres de presión de tal forma que los colectores queden juntados a presión.

$>$ Hay que asegurar los cierres de presión con el cierre.

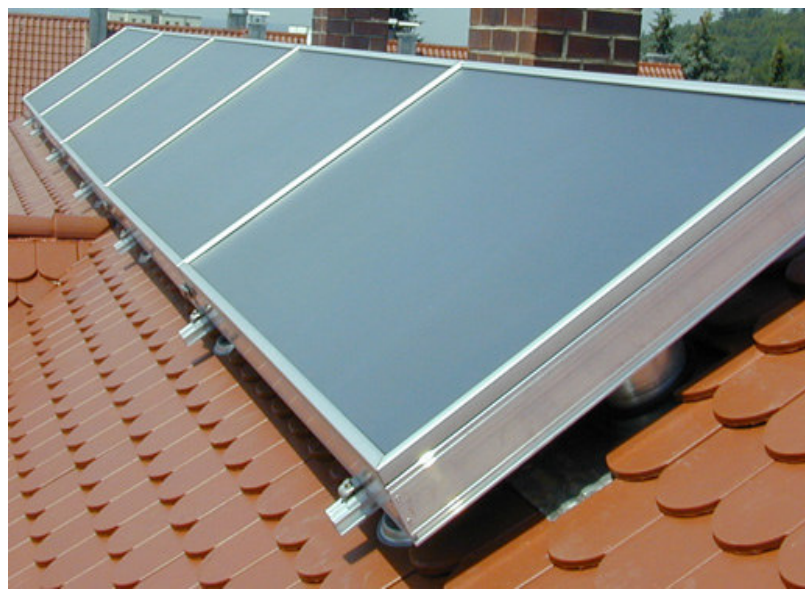

Disposición estándar para el montaje en tejados inclinados

Habitualmente se dispone los colectores de aire caliente en filas. 


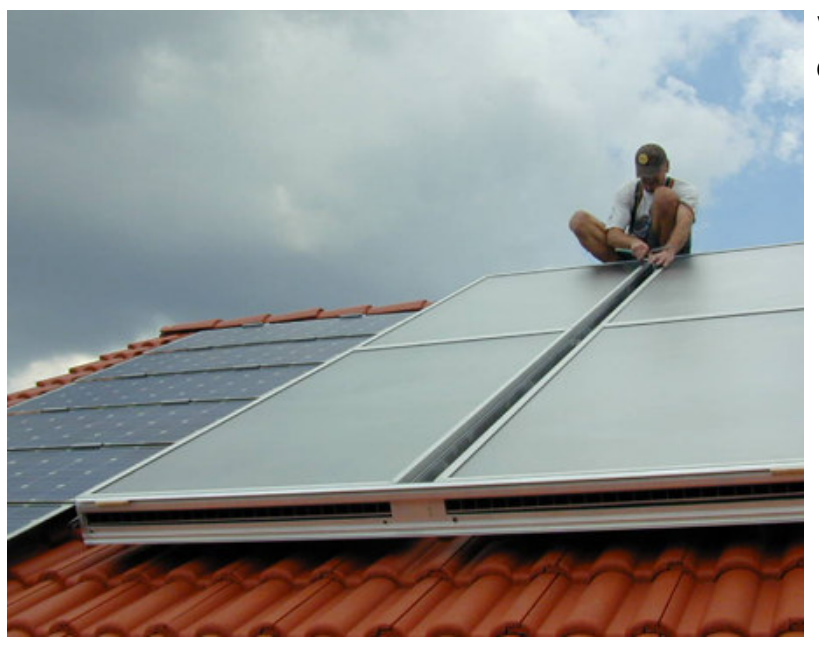

Variante alternativa de disposición - Montaje en paralelo

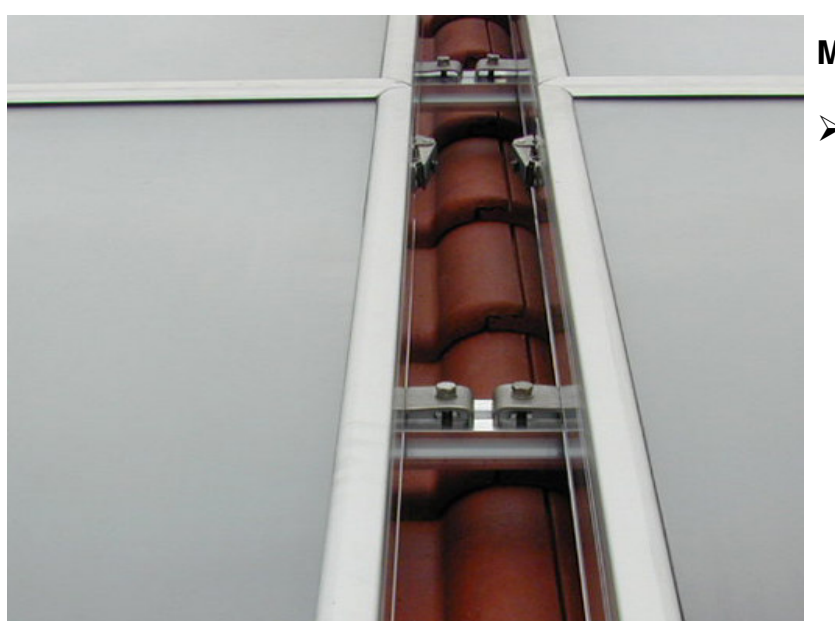

\section{Montaje en paralelo}

Se monta las filas de colectores en paralelo con una distancia de $110 \mathrm{~mm}$.

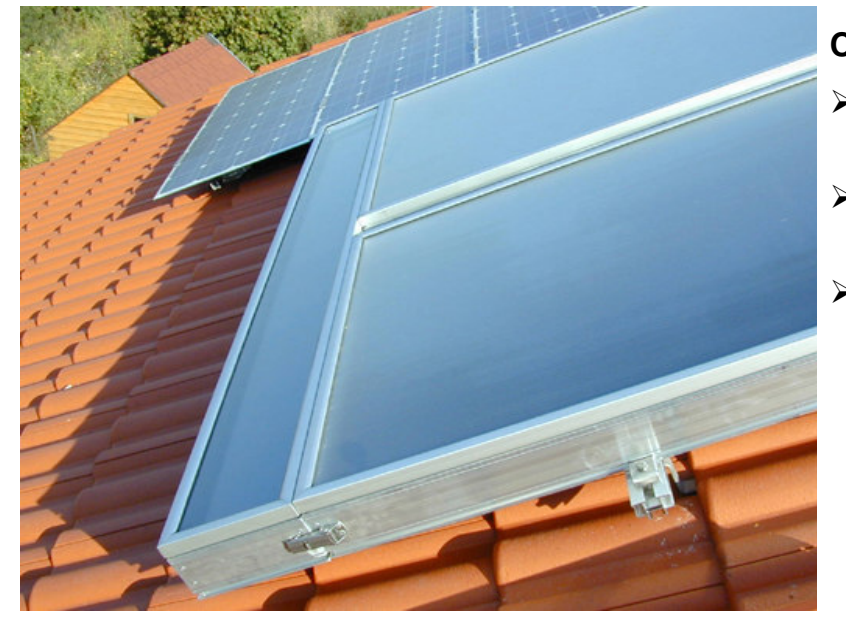

\section{Colector de giro}

El colector de giro se conecta con otros colectores mediante cierres de presión .

$>$ En las superficies previstas hay que pegar un perfil de junta (descripción véase paso 6).

$>$ En zonas de mucha nieve hay que afianzar el colector de giro con un carril de montaje adicional. 


\subsubsection{Montaje en fachada}

Ejemplo: Paquete de montaje en fachada TWINSOLAR 1.3 - 2.0

1 Ud. Pasamuros, diám. interior $125 \mathrm{~mm}$

4 Ud. Ángulo multi-función de aluminio

4 Ud. Tuerca M8, deslizable por la ranura del colector

4 Ud. Tornillo sin cabeza M8 x 25, V2A

4 Ud. Arandela, V2A

4 Ud. Anillo, V2A

4 Ud. Tuerca hexagonal M8, V2A

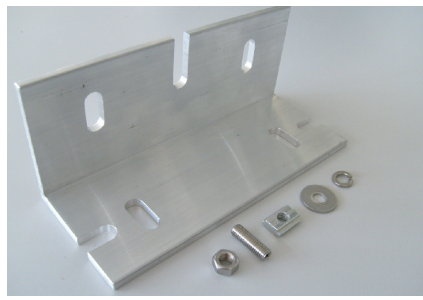

- El colector se monta en la fachada con los ángulos multi-función de aluminio premontados.

- ¡Hay que dejar una distancia mínima de $2 \mathrm{~cm}$ entre filtro, parte trasera del colector y la pared!

- Es necesario aislar el conducto del pasamuros para evitar problemas de condensaciones.

- Hay que efectuar todos los trabajos de atornillar y fijar con tacos con mucho cuidado - ipor la resistencia contra las cargas del viento!

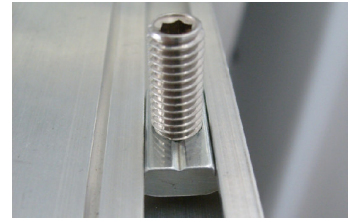

Fig. 1

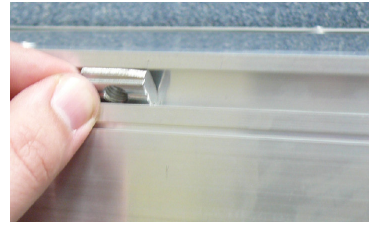

Fig. 2

Este nuevo sistema de montaje simplifica la instalación:

- La altura del colector es regulable gracias al tornillo sin cabeza deslizante por la ranura del colector.

- Salva irregularidades en la fachada con los orificios alargados de I apieza multi-función.

- Simplifica el almacenaje, al ser un sistema de montaje unificado para TWIN 1.3, 2.0 y paquetes SLK .

MONTAJE VERTICAL

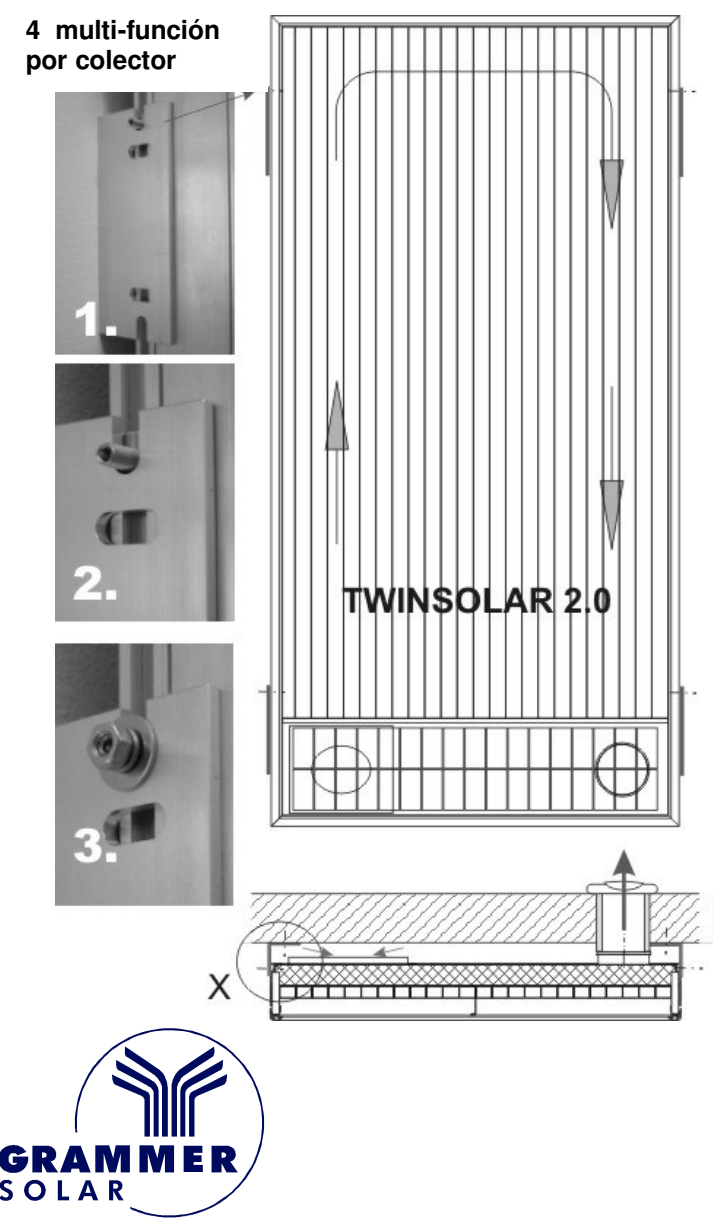

\section{MONTAJE HORIZONTAL}

A diferencia del montaje vertical, los ángulos multifunción se fijan a la pared con la superficie opuesta

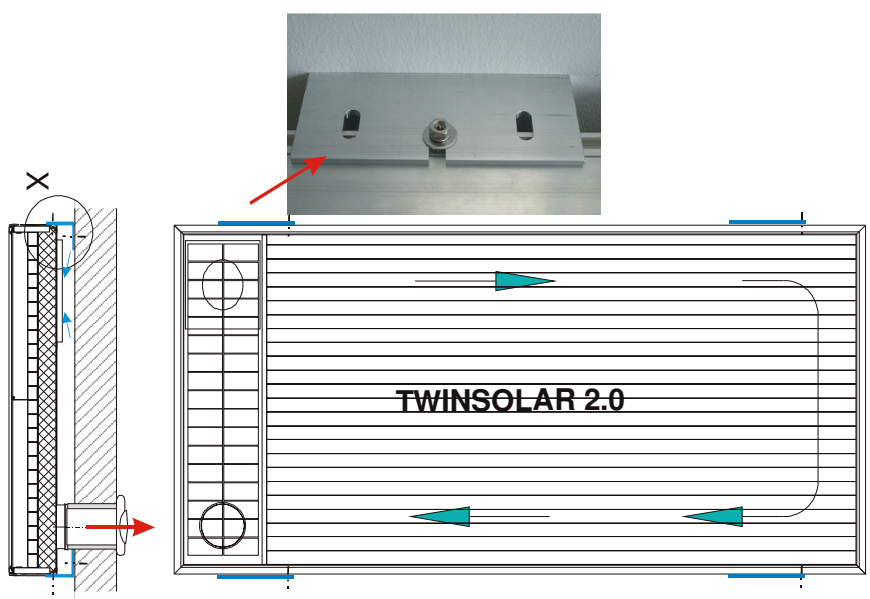

Lea los avisos de seguridad en capítulo10 


\subsubsection{Montaje sobre tejado plano}

El kit de montaje es apto para:

- Montaje sobre tejados planos

- Montaje en el suelo, por ejemplo en el jardín

- Montaje sobre fachada con inclinación de 45은

a la pared

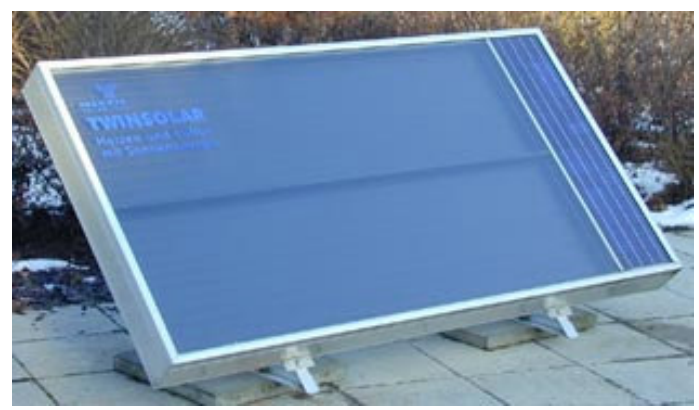

\section{Recomendaciones importantes:}

- Hay que colocar los colectores sobre los triángulos y atornillarlos con las pinzas de fijación.

- En caso de instalaciones sobre tejados planos puede hacer falta asegurar la instalación contra las cargas del viento (atornillar, poner peso, apuntalar). En condiciones favorables, la protección por el peso de la propia instalación es suficiente. Hay que efectuar un cálculo de carga del viento.

- Hay que efectuar todos los trabajos de atornillar y fijar con tacos con mucho cuidado - ¡por la resistencia contra las cargas de viento!

- Lea los avisos de seguridad en capítulo 10!

- En caso de tejados de láminas hay que pegar los carriles de soporte con cinta elastomérica celular 


\section{Variables del montaje en tejado plano}
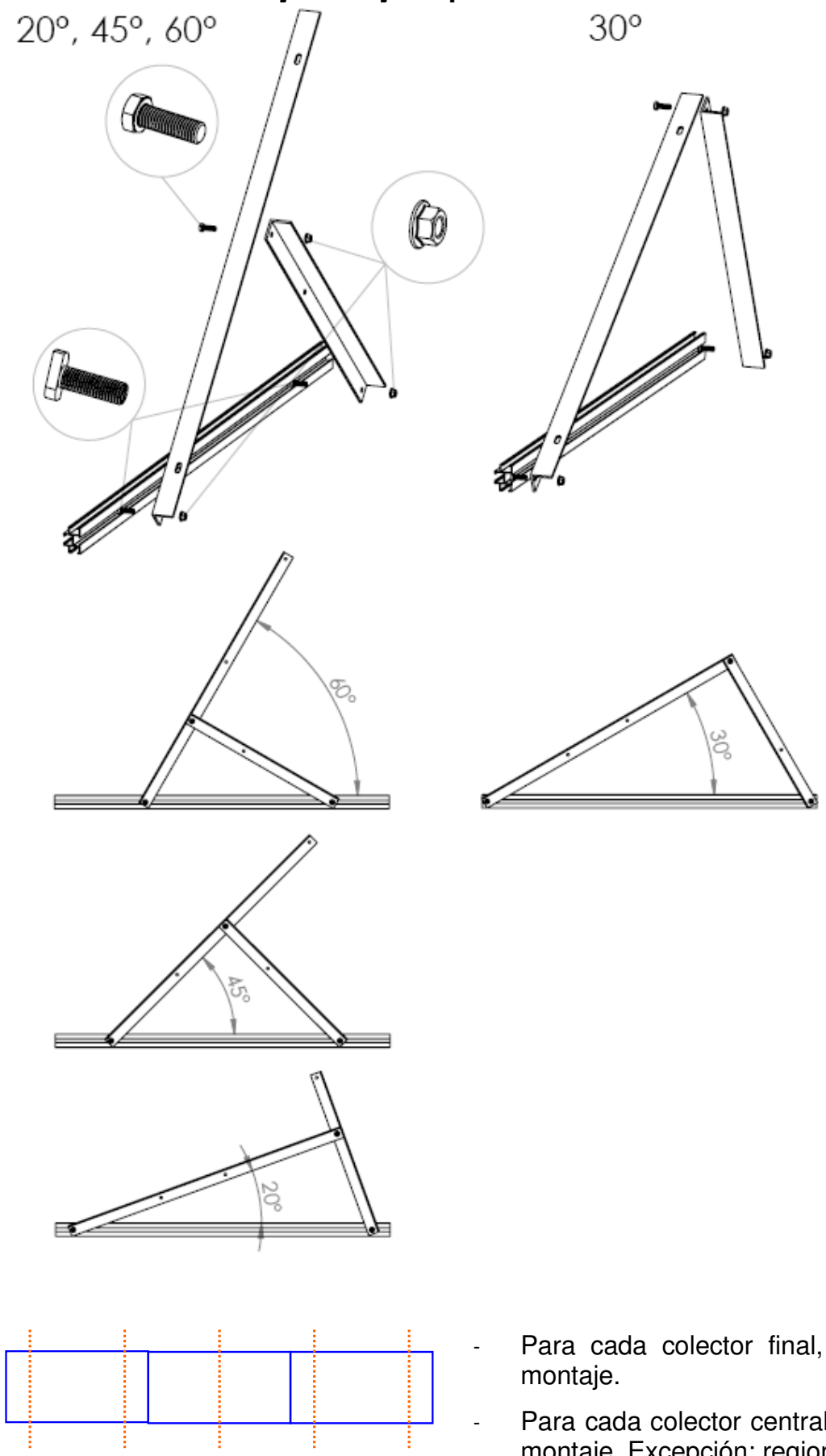

Para cada colector final, se utilizarán dos ángulos de montaje.

Para cada colector central, se utilizará sólo un ángulo de montaje. Excepción: regiones con mucha nieve!

\section{Recomendación:}

Las variables de montaje sobre superficie plana se pueden combinar con ángulos multifunción de montaje en fachada. De esta manera, se pueden realizar montajes en fachada con ángulo de inclinación.

\section{Herramientas necesarias:}

Llave inglesa M13, M17, Set de destornilladores, cinta métrica, lápiz marcador, martillo, taladro con kit de adaptación a tortillería, herramientas auxiliares para fijación durante el montaje. 


\subsection{Instrucciones generales de mantenimiento}

\subsubsection{GRAMMER Colector de aire caliente}

El colector de aire caliente GRAMMER no tiene partes móviles, con lo cual es seguro y libre de mantenimiento.

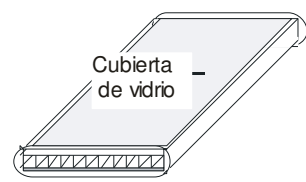

\subsubsection{Control de fijación de colectores y bastidores}

La instalación en el tejado está debidamente asegurada por la empresa instaladora; sin embargo, está expuesta a las fuerzas de viento. Para asegurar que todas las uniones roscadas estén en buen estado, conviene efectuar controles rutinarios, sobre todo después de tempestades.

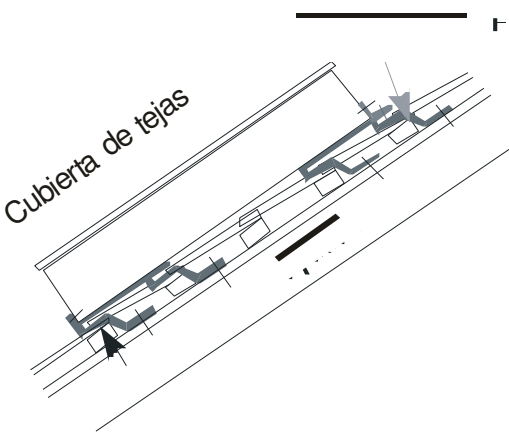

\subsubsection{Limpieza}

La experiencia muestra que normalmente los colectores son limpiados por la acción de la lluvia; sin embargo, en zonas muy contaminadas o con una carga fuerte de pólenes, unido con temporadas prolongadas de sequías, puede tener sentido limpiar la cubierta de vidrio con agua del grifo y esponja o una escoba para limpiar vehículos.

\subsubsection{Filtro de aire}

Los colectores están protegidos contra suciedades internas con filtros de aspiración integrados en el sistema, según categoría UE 4. Hay que cambiar los filtros según los intervalos habituales del lugar y según las instrucciones generales de mantenimiento; en los casos de funcionamiento con aire fresco exterior o aire mixto cada seis meses, en caso de funcionamiento con aire interior una vez al año, antes de empezar la temporada de calefacción (septiembre).

Para cambiar los filtros integrados en el colector, hay que desmontar la tapa final abriendo las pinzas atornilladas. Se extrae la caja del filtro para cambiar el filtro viejo por uno nuevo. Después se vuelve a introducir la caja del filtro dentro del colector y se fija la tapa final. El filtro viejo se extrae quitando los cierres de presión del marco. En caso de aspiración de aire interior hay que cambiar el filtro dentro de la caja del filtro (situada, por ejemplo, en la buhardilla).

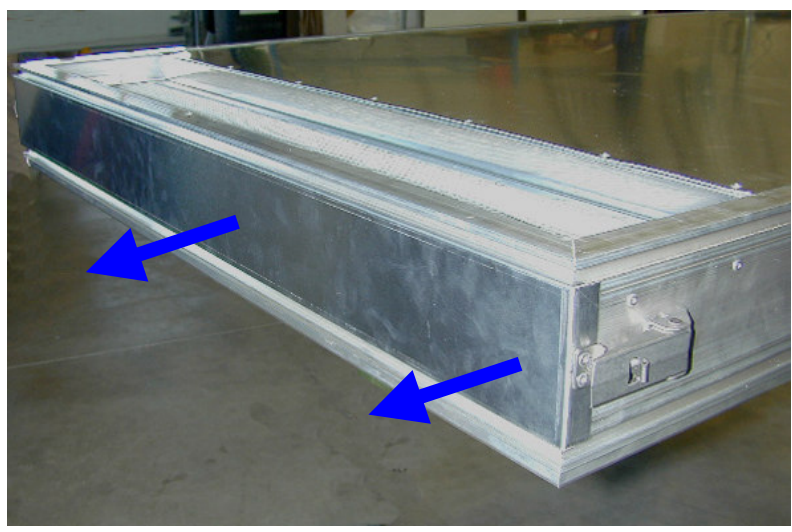

\section{CAMBIO DEL FILTRO \\ 1 - 2 veces cada año}

Los colectores de filtro aspiran el aire por la parte trasera del colector.

Hay que abrir los cierres de presión para abrir y quitar la cubierta del filtro.

Después se puede extraer y cambiar el filtro. 


\subsubsection{Aire como medio caloportador}

El aire no tiene cambios de fase (congelar o hervir) y por lo tanto no hace falta tomar ninguna medida de seguridad en este sentido.

Eventualmente se pueden producir condensaciones en la parte interior de la cubierta de vidrio, dependiendo de la humedad y las temperaturas exteriores, sobre todo después de intervalos prolongados de paro de la instalación. Estas condensaciones desaparecerán después de arrancar la instalación.

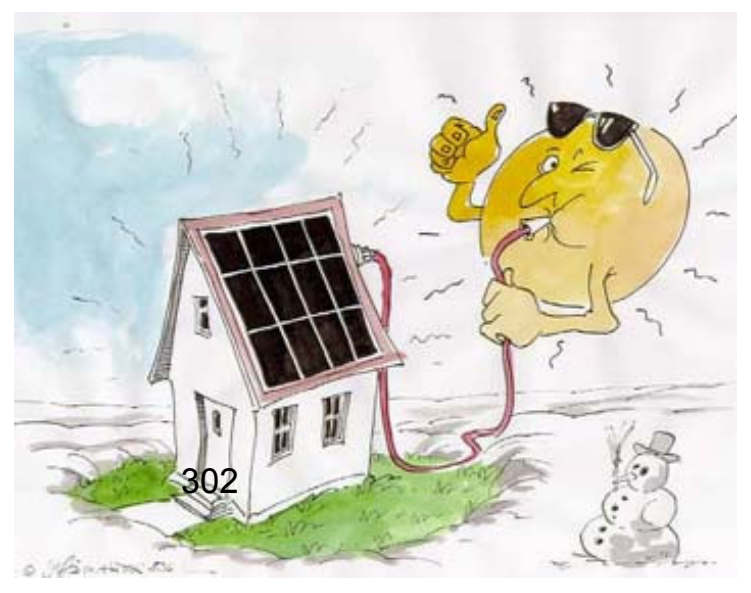

\subsection{Avisos generales de seguridad}

\subsubsection{El tiempo}

Efectúe labores de montaje solamente en días de buen tiempo. Sobre todo en caso de instalaciones integradas en el tejado hay procurar instalarlas en días sin lluvias para impedir que entre humedad en el edificio. Interrumpa la instalación cuando se avecinen vientos fuertes. En días de mucha irradiación hay que tener en cuenta el peligro de quemarse tocando partes metálicas. La temperatura en situaciones desfavorables puede llegar hasta $150^{\circ} \mathrm{C}$ (sobre todo en la zona del absorbedor).

\subsubsection{Escaleras}

Hay que apoyar escaleras en puntos seguros y con un ángulo de $65^{\circ}-75^{\circ}$. La escalera debe superar el borde de salida superior de la escalera en por lo menos 1 m. Hay que asegurarla contra deslizamiento, caída, hundimiento etc. Solamente use escaleras para superar una diferencia de altura máxima de $5 \mathrm{~m}$.

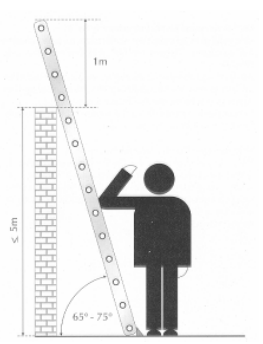

\subsubsection{Protección contra objetos que puedan caerse del tejado}

Hay que asegurar vías de tráfico y lugares de trabajo en la zona debajo de la obra contra el peligro de objetos que puedan caerse. Estas zonas hay que señalizarlas y cortar el acceso.

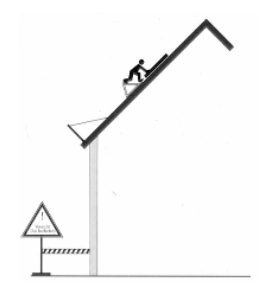




\subsubsection{Protección de operarios contra caídas del tejado}

A partir de una altura de $3 \mathrm{~m}$ y una inclinación del tejado entre $20^{\circ}$ y $60^{\circ}$, hay que instalar protecciones contra caídas (VBG, 37, artículo 8).

Una posibilidad para proteger a los operarios son andamios de retención para tejados. La distancia vertical entre lugar de trabajo y dispositivo de protección no debe superar $5 \mathrm{~m}$. Puede servir también como dispositivo de protección el apoyo superior del andamio.

En caso de inclinaciones del tejado superiores de 45을 hay que acondicionar lugares de trabajo especiales (por ejemplo silla de tejador, escaleras de tejador, construcciones especiales de tableros).

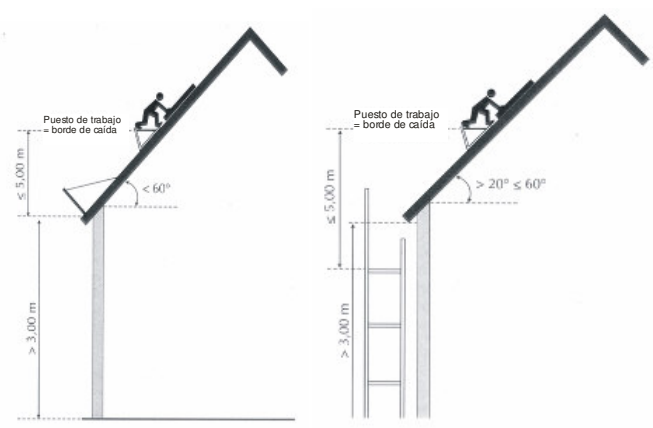

Otra alternativa son los muros de protección. Son necesarios a partir de una altura potencial de caída de $3 \mathrm{~m}$ y su distancia vertical entre lugar de trabajo y dispositivo de protección no debe superar $5 \mathrm{~m}$. Muros de protección tienen que superar los lugares de trabajo en por lo menos $2 \mathrm{~m}$ de altura.

Cuando no convenga montar andamios ni muros de protección, se puede emplear también arnés de seguridad. Colocar el gancho de seguridad, al ser posible, encima del usuario en un elemento sustentador del edificio. ¡No usar ganchos de escalera!

\subsubsection{Normas técnicas}

El montaje debe cumplir con las condiciones particulares del lugar, las normas locales y las normas de las buenas prácticas. Especialmente se destaca los siguientes:

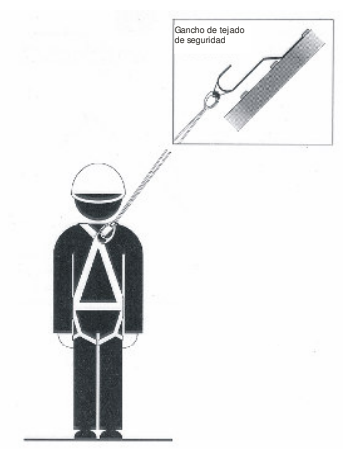

- Montaje en tejados

DIN 18338 Labores del tejador y de impermeabilización de tejados,

DIN 18339 Labores de fontanería,

DIN 18451 Labores de andamiaje

- Conexión de instalaciones solares térmicas

DIN 4757

- Conexión eléctrica

VDE 0100 Construcción de recursos eléctricos

VDE 0185 Generalidades sobre la construcción de instalaciones de protección contra rayos

VDE 0190 Equilibrio del potencial principal en instalaciones eléctricas

DIN 18382 Instalaciones de cableado eléctrico en edificios

¡Se ha de poner en funcionamiento el ventilador únicamente con el sistema de tubería conectado. En ningún caso introducir la mano con el ventilador en marcha! 


\section{TOPSOLAR}

\section{La alternativa conectada a red de TwinSolar}

Los TopSolar son sistemas de colectores de aire conectados a la red para calefacción y ventilación mediante energía solar que incluyen ventilador a $230 \mathrm{~V}$ y regulador.

El sistema es análogo al TWINSOLAR, aunque sin módulo fotovoltaico.

El paquete de montaje y la técnica de aire es idéntica a TWINSOLAR

\subsection{Información / Datos Técnicos}

\section{Paquete de entrega colector TOPSOLAR:}

Colectores de aire Grammer de alto rendimiento: Grammer Tipo SLK

Ventilador con manguitos - 230 Volt

Regulador Solar Delta Sol II - 230 Volt

Filtro de aire integrado en el colector con marco

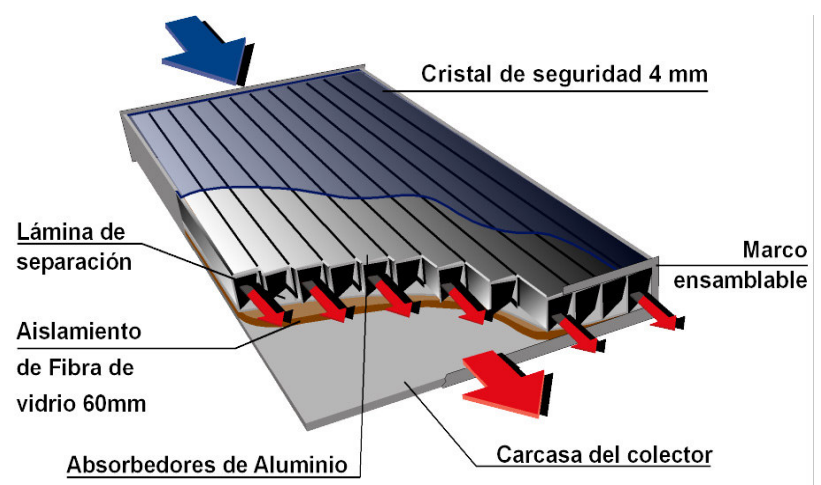
intercambiable

\begin{tabular}{|c|c|c|c|c|c|c|c|c|}
\hline & & TOPSOLAR 4.1 & TOPSOLAR 6.1 & $\begin{array}{c}\text { TOPSOLAR } \\
8.0\end{array}$ & $\begin{array}{c}\text { TOPSOLAR } \\
10.0\end{array}$ & $\begin{array}{c}\text { TOPSOLAR } \\
4.5\end{array}$ & TOPSOLAR $8 . !$ & $\begin{array}{c}\text { TOPSOLAR } \\
12.5\end{array}$ \\
\hline Superficie bruta & {$\left[\mathrm{m}^{2}\right]$} & 4,0 & 6,0 & 8,0 & 10,0 & 4,55 & 8,55 & 12,55 \\
\hline Dimensiones del colector LxB & {$[\mathrm{m}]$} & $4,0 \times 1,006$ & $6,0 \times 1,006$ & $8,0 \times 1,006$ & $10,0 \times 1,006$ & $2,25 \times 2,1$ & $4,25 \times 2,1$ & $6,25 \times 2,1$ \\
\hline Potencia térmica pico & {$[\mathrm{W}]$} & 2.400 & 3.600 & 4.800 & 6.000 & 2.700 & 5.100 & 7.500 \\
\hline Apropiado para calentar ${ }^{1)}\left[\mathrm{m}^{2}\right]$ & & $40-50$ & $60-80$ & $80-100$ & $100-120$ & $40-60$ & $80-100$ & $120-150$ \\
\hline Peso del colector & {$[\mathrm{kg}]$} & 90 & 135 & 180 & 225 & 110 & 200 & 290 \\
\hline Potencia nominal del ventilador & {$[\mathrm{W}]$} & 69 & 69 & 100 & 100 & 50 & 100 & 115 \\
\hline Tipo de ventilador-Disposición & & $\begin{array}{l}\text { HE-160B } \\
\text { Conectado } \\
\text { al conducto }\end{array}$ & $\begin{array}{l}\text { HE-160B } \\
\text { Conectado } \\
\text { al conducto }\end{array}$ & $\begin{array}{l}\text { HE-160C } \\
\text { Conectado } \\
\text { al conducto }\end{array}$ & $\begin{array}{l}\text { HE-160C } \\
\text { Conectado } \\
\text { al conducto }\end{array}$ & $\begin{array}{l}\text { HE-160B } \\
\text { Conectado } \\
\text { al conducto }\end{array}$ & $\begin{array}{l}\text { HE-160C } \\
\text { Conectado } \\
\text { al conducto }\end{array}$ & $\begin{array}{l}\text { HE-200B } \\
\text { Conectado } \\
\text { al conducto }\end{array}$ \\
\hline Caudal de aire para 150 Pa presión & {$\left[\mathrm{m}^{3} / \mathrm{h}\right]$} & 200 & 200 & 350 & 350 & 200 & 350 & 380 \\
\hline Diámetro conducción salida de aire & {$[\mathrm{mm}]$} & 160 & 160 & 160 & 160 & 160 & 160 & 160 \\
\hline Control de diferencia de temperatura & & Delta Sol II & Delta Sol II & Delta Sol II & Delta Sol II & Delta Sol II & Delta Sol II & Delta Sol II \\
\hline
\end{tabular}

En los Anexos, se adjunta hoja con los datos específicos del Colector -SLK así como las observaciones de los ensayos de prueba 


\section{Sistema de aire solar (Sistema Standard)}

El sistema de aire solar es una solución sencilla y eficiente para apoyar el sistema de calefacción y ventilación en viviendas ya existentes o de nueva construcción.

Aire fresco exterior o interior se calienta en el colector y fluye a través de una sistema sencillo de conducciones hacia el interior de la vivienda.

En viviendas con envolventes muy robustas se ha de tomar precauciones en las salidas de aire ( $p$ ej. WC-Extractor; Cocina-Campana extractora de humos)

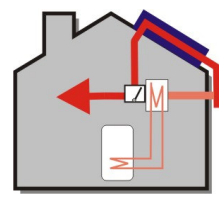

También se puede calentar agua en verano mediante la utilización de la SolarBox con

\section{Otras variantes del sistema}

\section{Ventilación Solar}

Los sistemas de aire solar pueden integrarse de manera sencilla en nuevos sistemas de ventilación o en los ya existentes A través del sistema de distribución de aire, el dispositivo de ventilación impulsa el calor solar a la vivienda. Cuando no se necesita calor en la vivienda, la SolarBox genera agua caliente.

\section{Calefacción radiante}

Gracias a la energía solar se calienta el aire en un sistema cerrado a través del colector y al final es irradiado por la pared.

De esta manera, la energía calorífica se transmite y almacena en este componente y se distribuye uniformemente en la vivienda como si fuera energía calorífica procedente de la radiación.

En ausencia de radiación solar, la pared radiante puede utilizarse con sistema de calefacción adicional.

Cuando no se necesita calor en la vivienda, la SolarBox genera agua caliente.

\section{SOLITH Almacenamiento de calor en pared}

Piedra caliza-Sistema Radiante

Para más información: Ver Prospecto Solith o ver www.ks-fasenstein.de intercambiador aire-agua integrado
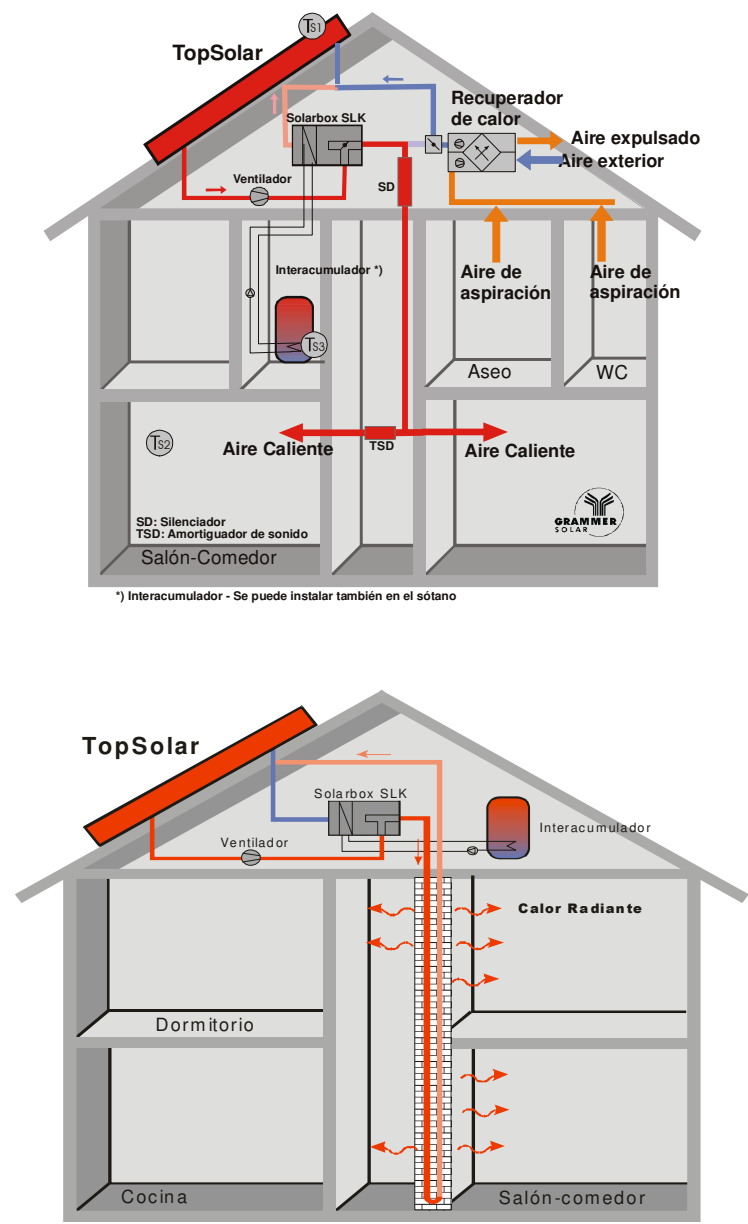


\subsection{Agua caliente sanitaria SolarBox}
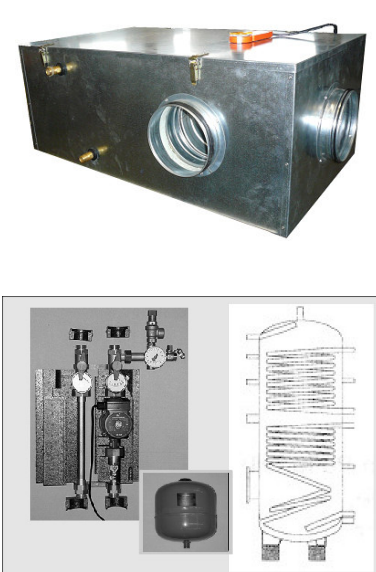

\section{Solar Box - Opcional: Calentar agua sanitaria}

Cada sistema TWIN y TOPSOLAR a partir de $8 \mathrm{~m}^{2}$ de superficie del colector pueden combinarse con sistemas de agua caliente o la SolarBox.

Todos los componentes necesarios son compactos,sencillos, de fácil acceso en las instalaciones así como con fácil mantenimiento y se encuentran integrados en una caja técnica.

Información de detalle: Ver instrucciones de montaje SolarBox (Descargar en www.grammer-solar.de)

\section{Sistema acumulador}

+ Grupo de bomba solar con armazón de seguridad

+ Volumen de depósito 12 Litros

+300 Litros Acumulador solar

+ regulador solar Tipo Delta Sol Pro + Sensor Pt+1000

Advertencia!: En regiones con peligro de heladas, utilizar mezcla de glycol en el circuito solar.

Esquema de funcionamiento para calentar agua con sistema solar de aire

El sistema de aire solar con agua caliente integrada se dimensiona habitualmente como se observa en el esquema siguiente

En la realización de la SolarBox, los componentes del intercambiador de calor aire-agua, la clapeta Bypass, las conexiones de aire y del regulador se encuentran fácilmente montadas en un caja técnica:

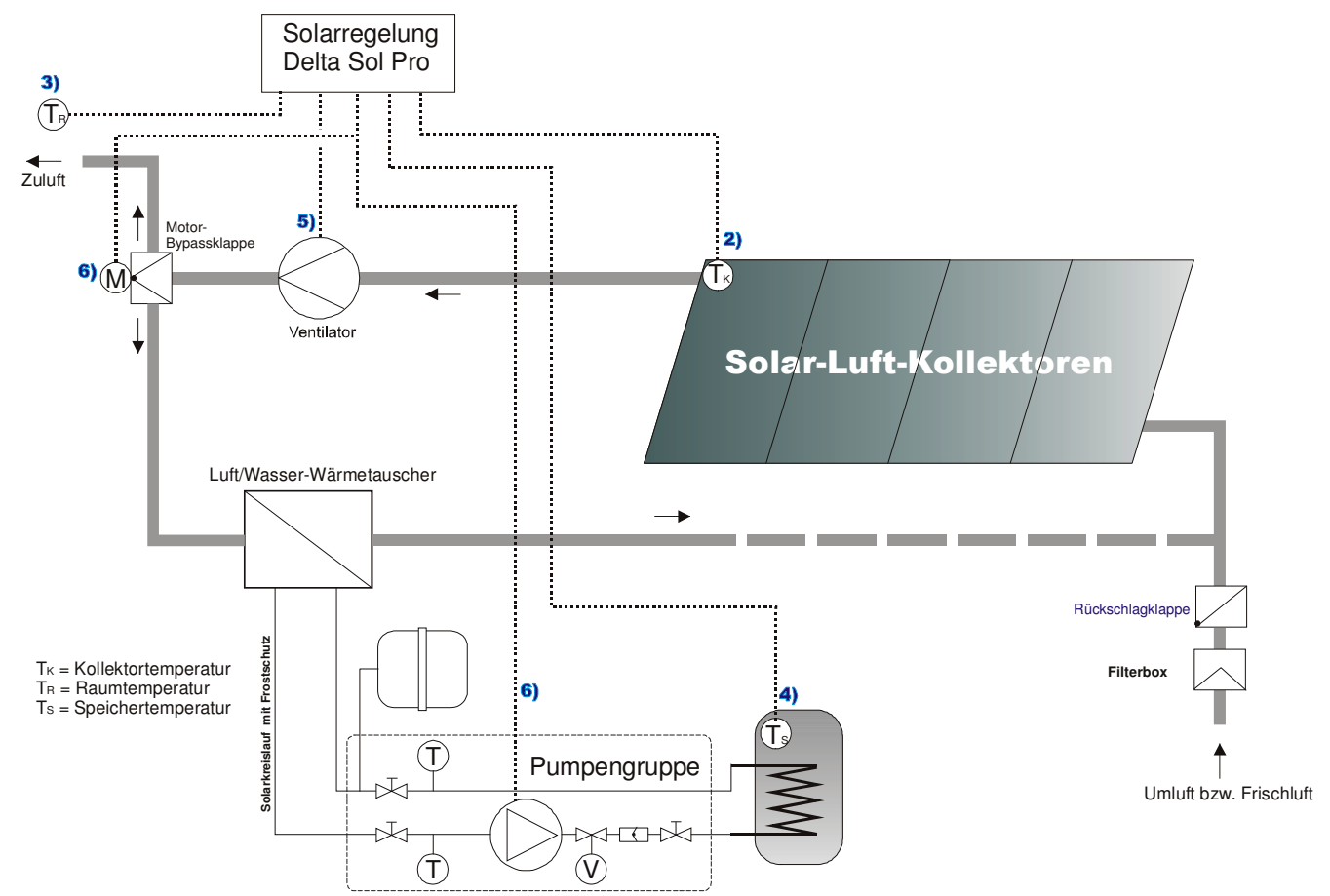




\subsection{Regulador}

\subsubsection{Instrucciones DeltaSol BS Plus}

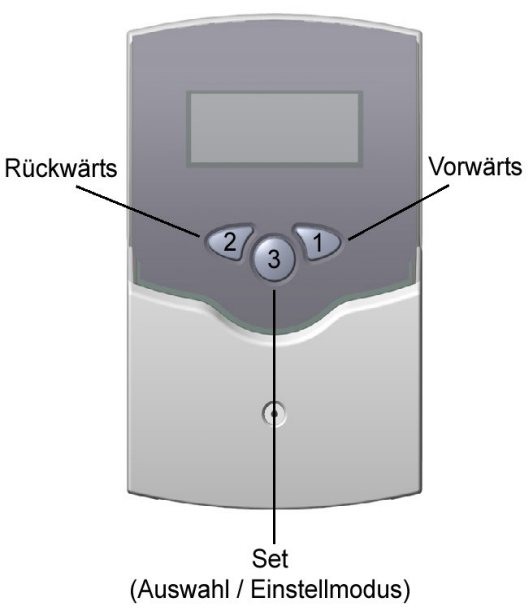

El regulador se parametriza a través del pulsador 3.

El pulsador 1 avanza en posiciones a través del menú o aumenta valores en el menú de valores de instalación. El pulsador 2 actúa a la inversa que el 1. Para instalación de valores y después de llegar al valor mostrado en pantalla, se debe mantener apretado durante 3 segundos el pulsador 1 . Aparecerá en pantalla SET parpadeante. Después, mediante el pulsador 3 se puede cambiar en el modo descrito.

- Elegir canal mediante pulsadores 1 y 2

- Mantener el pulsador 3 durante 3 segundos apretado, llegando a Modo-Set

- Con los pulsadores 1 y 2 , elegir el valor

Apretar el pulsador 3 , el display muestra el valor cambiado y guardado.

Para más información, consultar las instrucciones originales del regulador.. Los siguientes símbolos muestran diversos estados del sistema:

\begin{tabular}{|c|c|c|}
\hline Símbolo & normal & Parpadeante \\
\hline & Relé 1 activo & \\
\hline & Relé 2 activo & \\
\hline & $\begin{array}{l}\text { Límite máximo de acumulador activo / } \\
\text { Límite máximo de acumulador excedido }\end{array}$ & $\begin{array}{l}\text { Función de enfriamiento de colector } \\
\text { activo }\end{array}$ \\
\hline 䔳 & Opción anticongelante activo & $\begin{array}{l}\text { Límite mínimo de acumulador activo / } \\
\text { Función descongelante activo }\end{array}$ \\
\hline 1 & & $\begin{array}{l}\text { Kollektornotabschaltung aktiv oder } \\
\text { Speichernotabschaltung }\end{array}$ \\
\hline & & Defecto de sensor \\
\hline$\Lambda$ & & Funcionamiento manual activo \\
\hline SEI & & Modo de cambio de parámetros \\
\hline
\end{tabular}




\subsubsection{Regulador TopSolar - Sistema de aire solar}
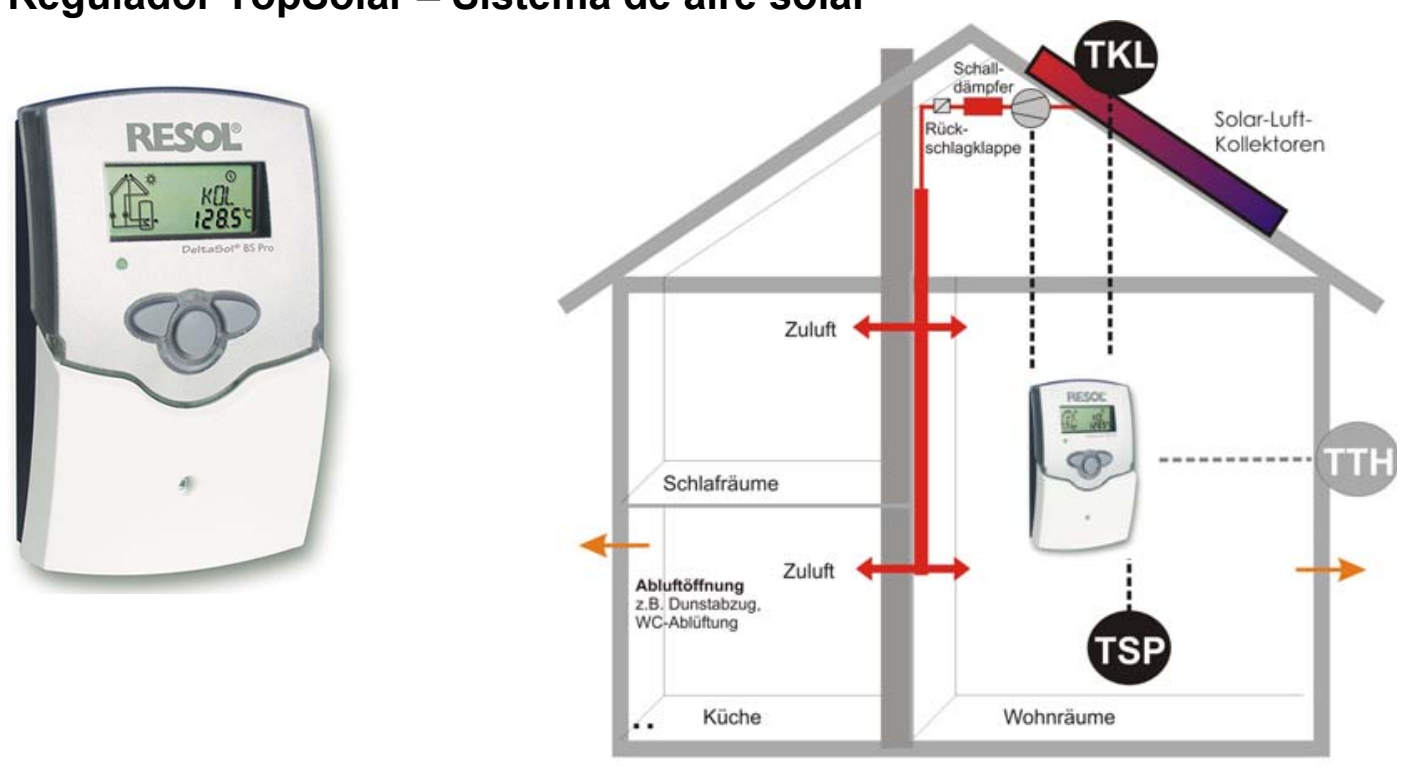

Función:

El regulador solar Delta BS Plus compara la temperatura del colector COL con la temperatura de referencia TST y actúa en dependencia de la temperatura requerida por la instalación S MX. Con un sensor de temperatura opcional S3 se puede mostrar una temperatura adicional (p.ej. la temperatura exterior)

\section{Datos y valores de instalación}

\begin{tabular}{|c|c|c|}
\hline Canal & Descripción & Valores de instalación (recomendados) \\
\hline $\mathrm{COL}$ & Temperatura del colector & * \\
\hline TST & Temperatura interior & * \\
\hline $\mathrm{n} \%$ & Velocidad relé \% & * \\
\hline h P & Horas de ejercicio del relé & * (se puede resetear) \\
\hline Time & Hora actual & ${ }^{*}$ (se puede reprogramar) \\
\hline Arr & Sistema & Instalación en taller (1) \\
\hline DT O & Diferencia de temperatura de conexión & $\begin{array}{l}\text { Instalación de fábrica }(6 \mathrm{~K}) \\
\text { (Para conductos gran longitud } 10 \mathrm{~K})\end{array}$ \\
\hline DT F & Diferencia de temperatura de desconexión & $\begin{array}{l}\text { Instalación de fábrica }(4 \mathrm{~K}) \\
\text { (Para conductos gran longitud } 8 \mathrm{~K} \text { ) }\end{array}$ \\
\hline DT S & Diferencia de temperatura nominal & Instalación de fábrica $(10 \mathrm{~K})$ \\
\hline RIS & Aumento & Instalación de fábrica $(2 \mathrm{~K})$ \\
\hline S MX & Temperatura máxima del acumulador & $\begin{array}{l}\approx 22^{\circ} \mathrm{C} \text { (aprox. } 2^{\circ} \mathrm{C} \text { sobre la temperatura programada } \\
\text { en el sistema de calefacción convencional !!) }\end{array}$ \\
\hline EM & Temperatura de seguridad del colector & $180^{\circ} \mathrm{C}$ \\
\hline OCX & Opción refrigeración del colector & Instalación de fábrica (OFF) \\
\hline OCN & Opción limitación mínima & Instalación de fábrica (OFF) \\
\hline OCF & Opción anticongelante de colector & Instalación de fábrica (OFF) \\
\hline OREC & Opción refrigeración de colector & Instalación de fábrica (OFF) \\
\hline O TC & Opción captador tubular & Instalación de fábrica (OFF) \\
\hline OHQM & Opción WMZ & Instalación de fábrica (OFF) \\
\hline $\mathrm{nMN}$ & Velocidad Mínima de relé 1 & $100 \%$ \\
\hline HND1 & Funcionamiento manual Relé 1 & Instalación de fábrica (Auto) \\
\hline HND2 & Funcionamiento manual Relé 2 & Instalación de fábrica (Auto) \\
\hline LANG & Selección del idioma & Elija "En" para códigos en inglés \\
\hline
\end{tabular}




\section{Conexión Eléctrica}

Para instalación eléctrica, puede verse el esquema eléctrico oportuno.

El montaje de la sonda del colector y de la sonda del interior, puede verse en capítulo 2.3.5.

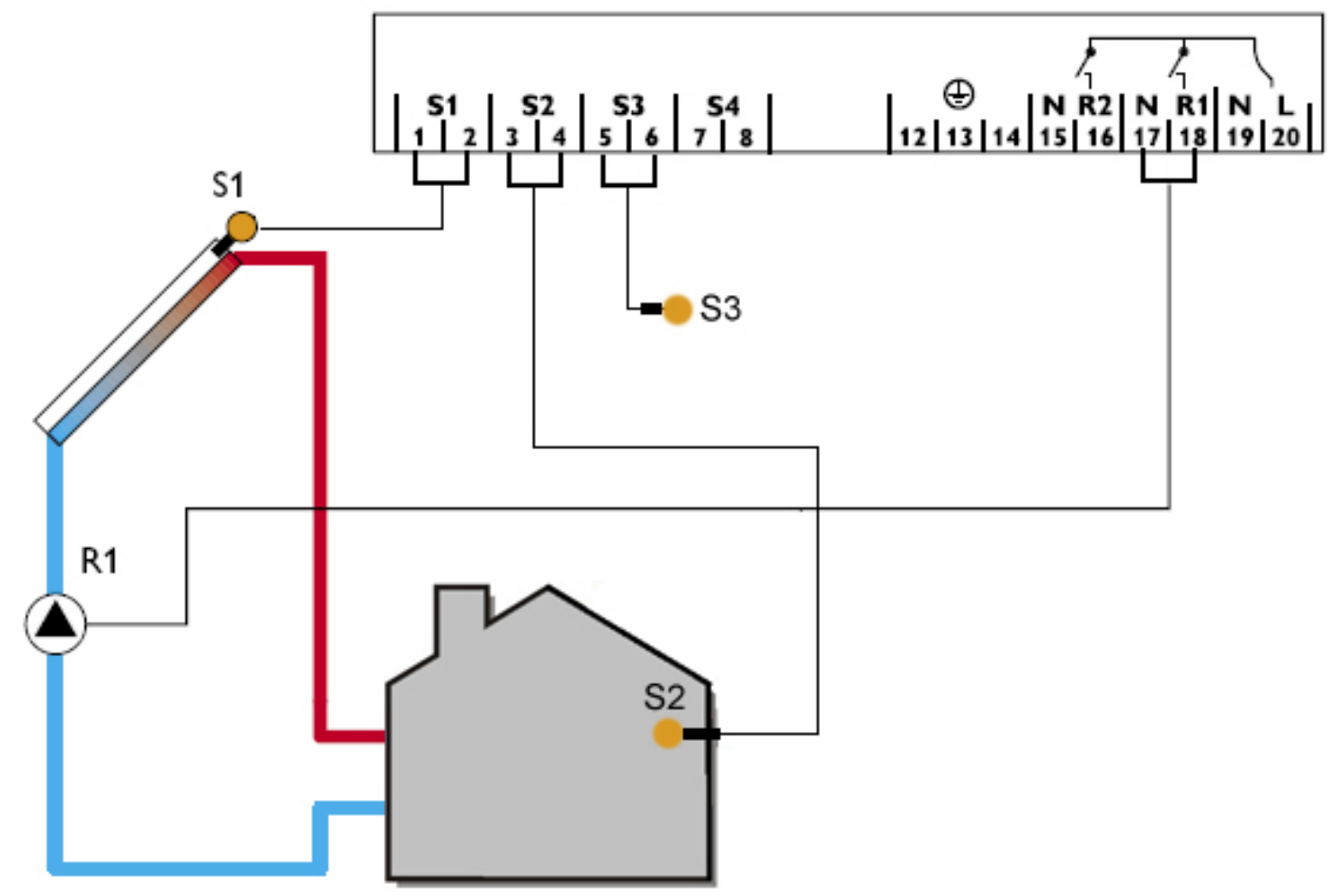

Cuando la temperatura del colector COL (S1) supera la diferencia de temperatura programada en el regulador como superior a la temperatura ambiente (interior) TST (S2), comienza a funcionar el ventilador (R1) e introducir aire caliente en el interior de la estancia hasta alcanzar la temperatura programada como la requerida en el interior de la casa siempre y cuando la diferencia de temperatura de desconexión sea superior en los grados programados en el regulador.

En la posición (S3) se puede instalar una sonda adicional (por ej. Temperatura ambiente) de medida.

\section{Tipos de funcionamiento}

Mediante los canales HND1 y HND2 se pueden seleccionar entre las diferentes formas de funcionamiento:

HND1=OFF: Relé 1 está apagado (desconexión manual)

HND1=Auto: Funcionamiento automático para las salidas de relés (INSTALACIÓN ESTÁNDAR)

HND1=On: Relé 1 está encendido (Funcionamiento prueba) 


\subsubsection{Sistema de regulación TopSolar-Agua caliente solar}
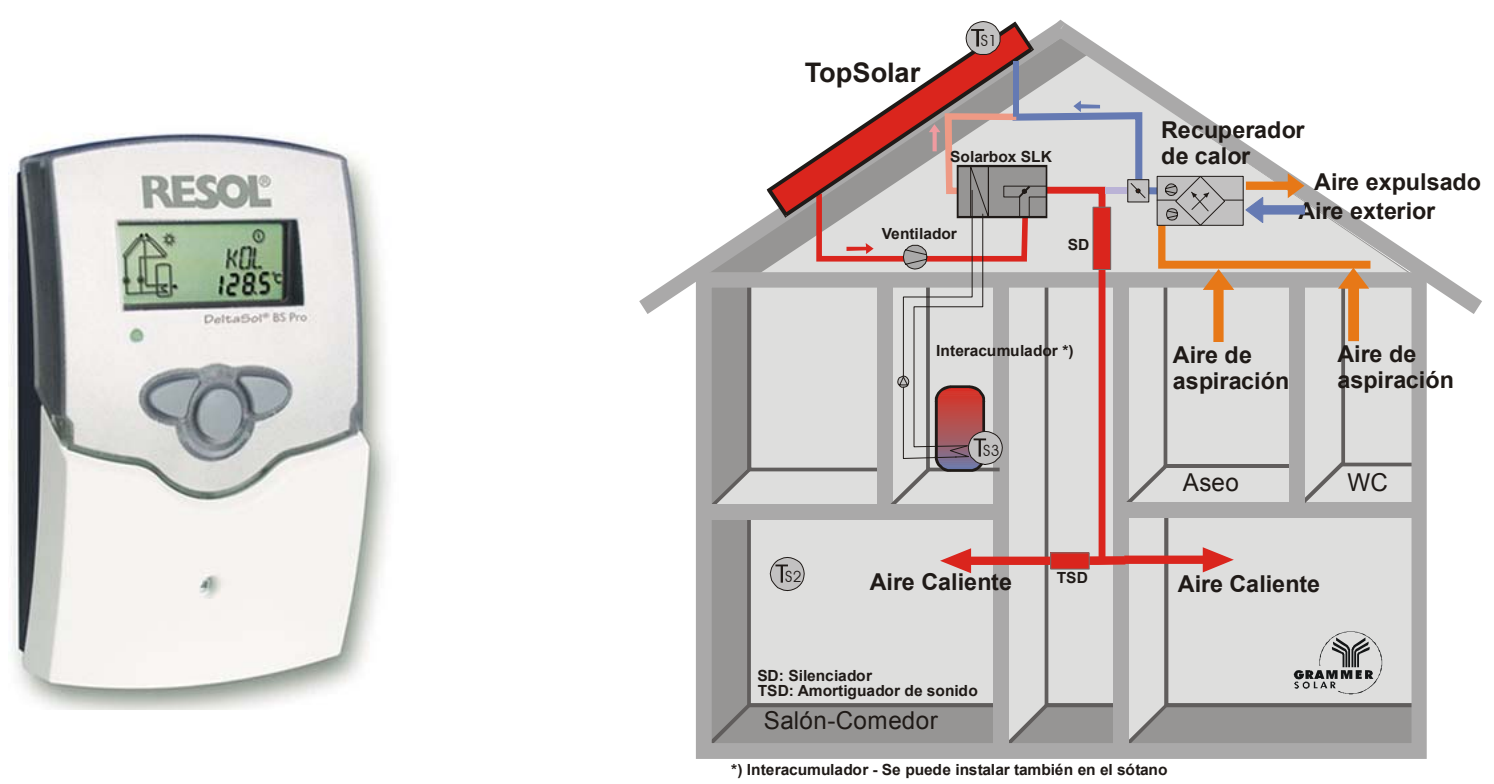

\section{Funcionamiento}

Cuando existe radiación (TS1>TS2) el sistema calienta el interior de la vivienda hasta alcanzar la temperatura requerida (TS2). Después, el regulador comprueba que existe energía suficiente para el calentamiento de agua (TS1>TS3) y si es así, la instalación calienta el agua hasta la temperatura deseada (TS3) o si la temperatura del colector es menor a la del acumulador de agua.

\section{Datos y valores de instalación}

\begin{tabular}{|c|c|c|}
\hline Canal & Descripción & $\begin{array}{l}\text { Funcionamiento con SolarBox -Valores de instalación } \\
\text { (recomendados) }\end{array}$ \\
\hline $\mathrm{COL}$ & Temperatura de colector & * \\
\hline TST1 & Temperatura ambiente interior 1 & * \\
\hline TST2 & Temperatura acumulador agua & * \\
\hline $\mathrm{n} \%$ & Número Rev. ventilador en \% & * \\
\hline $\mathrm{hP}$ & Horas de funcionamiento & ${ }^{*}$ (se puede resetear) \\
\hline Time & Hora actual & ${ }^{*}$ (se puede reprogramar) \\
\hline Arr & Tipo de sistema & 5 (importante!!!) \\
\hline DT10 & Diferencia de temperatura de conexión1 & Instalación de fábrica $(6 \mathrm{~K})$ \\
\hline DT1F & Diferencia de temperatura de desconexión 1 & Instalación de fábrica $(4 \mathrm{~K})$ \\
\hline DT1S & Diferencia de temperatura nominal 1 & Instalación de fábrica (10 K) \\
\hline RIS1 & Aumento 1 & Instalación de fábrica $(2 \mathrm{~K})$ \\
\hline S1MX & Temperatura máxima acu. 1 (max. Ambiente interior) & $\begin{array}{l}\approx 22^{\circ} \mathrm{C} \text { (aprox. } 2^{\circ} \mathrm{C} \text { sobre la temperatura programada en el } \\
\text { sistema de calefacción convencional !!) }\end{array}$ \\
\hline DT2O & Diferencia de temperatura de conexión 2 & $9,5 \mathrm{~K}$ \\
\hline DT2F & Diferencia de temperatura de desconexión 2 & $7 \mathrm{~K}$ \\
\hline DT2S & Diferencia de temperatura nominal 2 & Instalación de fábrica (10 K) \\
\hline RIS2 & Aumento 2 & Instalación de fábrica $(2 \mathrm{~K})$ \\
\hline S2MX & Temperatura máxima acu. 2 (max. agua) & Instalación de fábrica (60 k) \\
\hline EM & Temperatura máxima del colector & $180^{\circ} \mathrm{C}$ \\
\hline OCX & Opción refrigeración & Instalación de fábrica (OFF) \\
\hline $\mathrm{OCN}$ & Opción limitación mínima captador & Instalación de fábrica (OFF) \\
\hline OCF & Opción anticongelante & Instalación de fábrica (OFF) \\
\hline PRIO & Prioridad & Instalación de fábrica (1) \\
\hline tST & Tiempo de parada & Instalación de fábrica (2) \\
\hline tRun & Tiempo de circulación & Instalación de fábrica (15) \\
\hline OREC & Opción refrigeración acumulador & Instalación de fábrica (OFF) \\
\hline O TC & Opción captador tubular & Instalación de fábrica (OFF) \\
\hline OHQM & Opción WMZ & Instalación de fábrica (OFF) \\
\hline $\mathrm{nMN}$ & Velocidad mínima Relé 1 & $50 \%$ \\
\hline HND1 & Funcionamiento Relé 1 & Instalación de fábrica (Auto) \\
\hline HND2 & Funcionamiento Relé 2 & Instalación de fábrica (Auto) \\
\hline LANG & Selección del idioma & Elija "En" para códigos en inglés \\
\hline
\end{tabular}

* Estos valores son valores de medida y no se pueden programar 


\section{Esquema eléctrico SolarBox SLK}

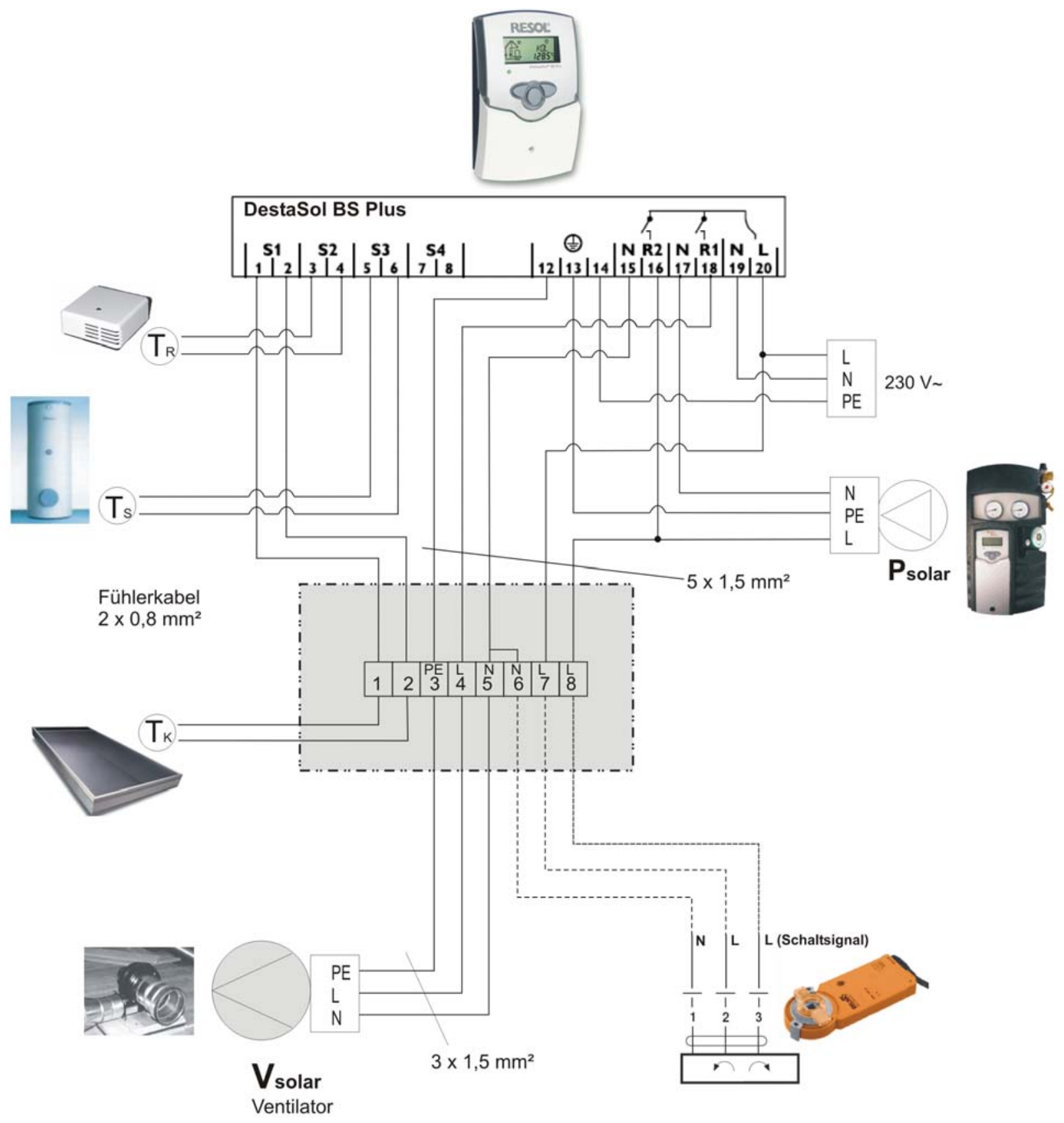




\subsubsection{Sistema de regulación TopSolar - Sistema radiante}
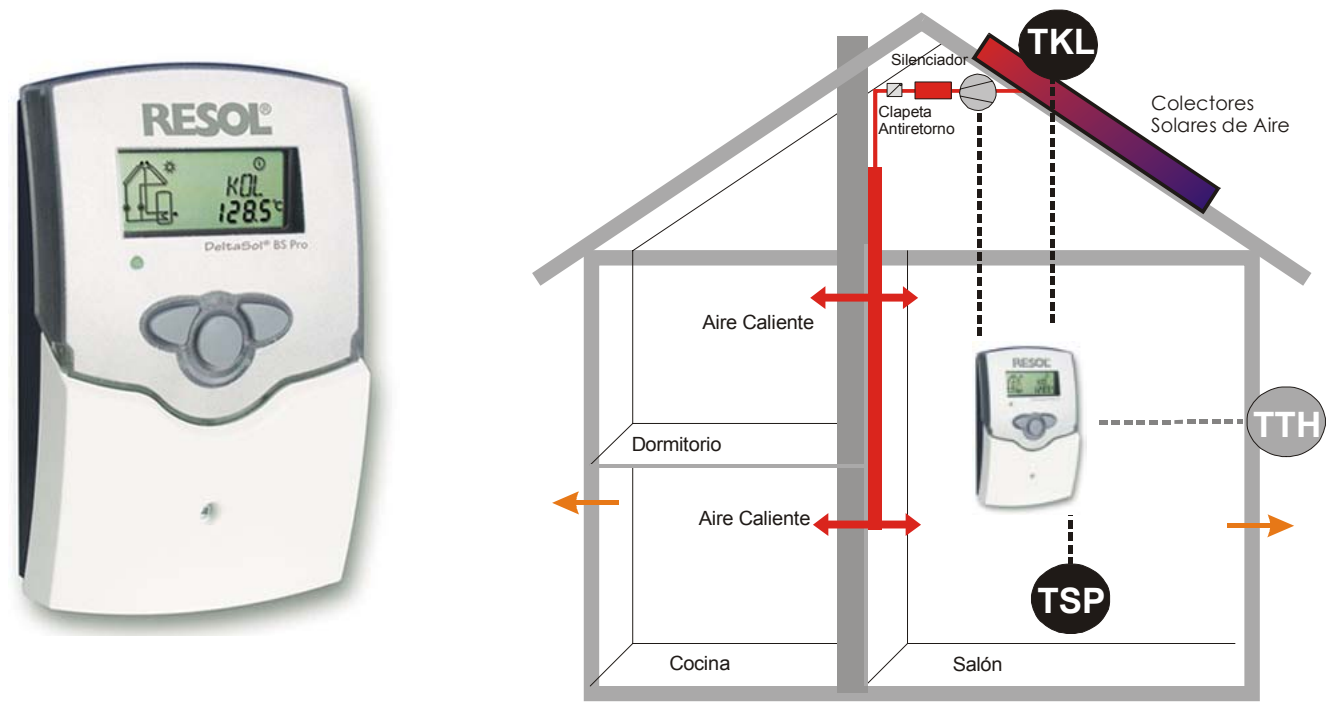

La Temperatura del colector (2) aparece en el regulador Delta BS Plus (1) Si la diferencia de temperatura es mayor a la temperatura de la pared (temperatura de acumulación) (3), se enciende el sistema y el ventilador (4) impulsa aire caliente al elemento radiante (pared) hasta que la temperatura de la habitación alcance la temperatura deseada. En la posición (5) se puede colocar un sensor de temperatura adicional para medir la temperatura exterior (También se dispone del funcionamiento opcional del termostato para esta temperatura)

Datos y valores de instalación

\begin{tabular}{|c|c|c|}
\hline Canal & Descripción & $\begin{array}{l}\text { Funcionamiento con SolarBox -Valores de instalación } \\
\text { (recomendados) }\end{array}$ \\
\hline COL & Temperatura del colector & * \\
\hline TST & Temperatura acumulador (Temperatura pared) & * \\
\hline $\mathrm{n} \%$ & Número Rev. ventilador en \% & * \\
\hline h P & Horas de funcionamiento & * (se puede resetear) \\
\hline Time & Hora actual & * (se puede reprogramar) \\
\hline Arr & Tipo de sistema & Instalación de fábrica (1) \\
\hline DT O & Diferencia de temperatura de conexión1 & Instalación de fábrica (6 K) \\
\hline DT F & Diferencia de temperatura de desconexión 1 & Instalación de fábrica (4 K) \\
\hline DT S & Diferencia de temperatura nominal 1 & Instalación de fábrica (10 K) \\
\hline RIS & Aumento & Instalación de fábrica (2 K) \\
\hline S MX & Temperatura máxima acum. (max. Temp. pared) & $\approx 30-35^{\circ} \mathrm{C}$ \\
\hline EM & Temperatura máxima del colector & $180^{\circ} \mathrm{C}$ \\
\hline OCX & Opción refrigeración & Instalación de fábrica (OFF) \\
\hline OCN & Opción limitación mínima captador & Instalación de fábrica (OFF) \\
\hline OCF & Opción anticongelante & Instalación de fábrica (OFF) \\
\hline OREC & Opción refrigeración acumulador & Instalación de fábrica (OFF) \\
\hline O TC & Opción captador tubular & Instalación de fábrica (OFF) \\
\hline OHQM & Opción WMZ & Instalación de fábrica (OFF) \\
\hline $\mathrm{nMN}$ & Velocidad mínima Relé 1 & $100 \%$ \\
\hline HND1 & Funcionamiento manual Relé 1 & Instalación de fábrica (Auto) \\
\hline HND2 & Funcionamiento manual Relé 2 & Instalación de fábrica (Auto) \\
\hline LANG & Selección del idioma & Elija "En" para códigos en inglés \\
\hline
\end{tabular}

* Estos valores son valores de medida y no se pueden programar

La temperatura máxima interior se debe programar por encima del termostato ambiente! 


\section{Conexión Eléctrica}

Para instalación eléctrica, puede verse el esquema eléctrico oportuno.

El montaje de la sonda del colector y de la sonda del interior, puede verse en capítulo 2.3.5.

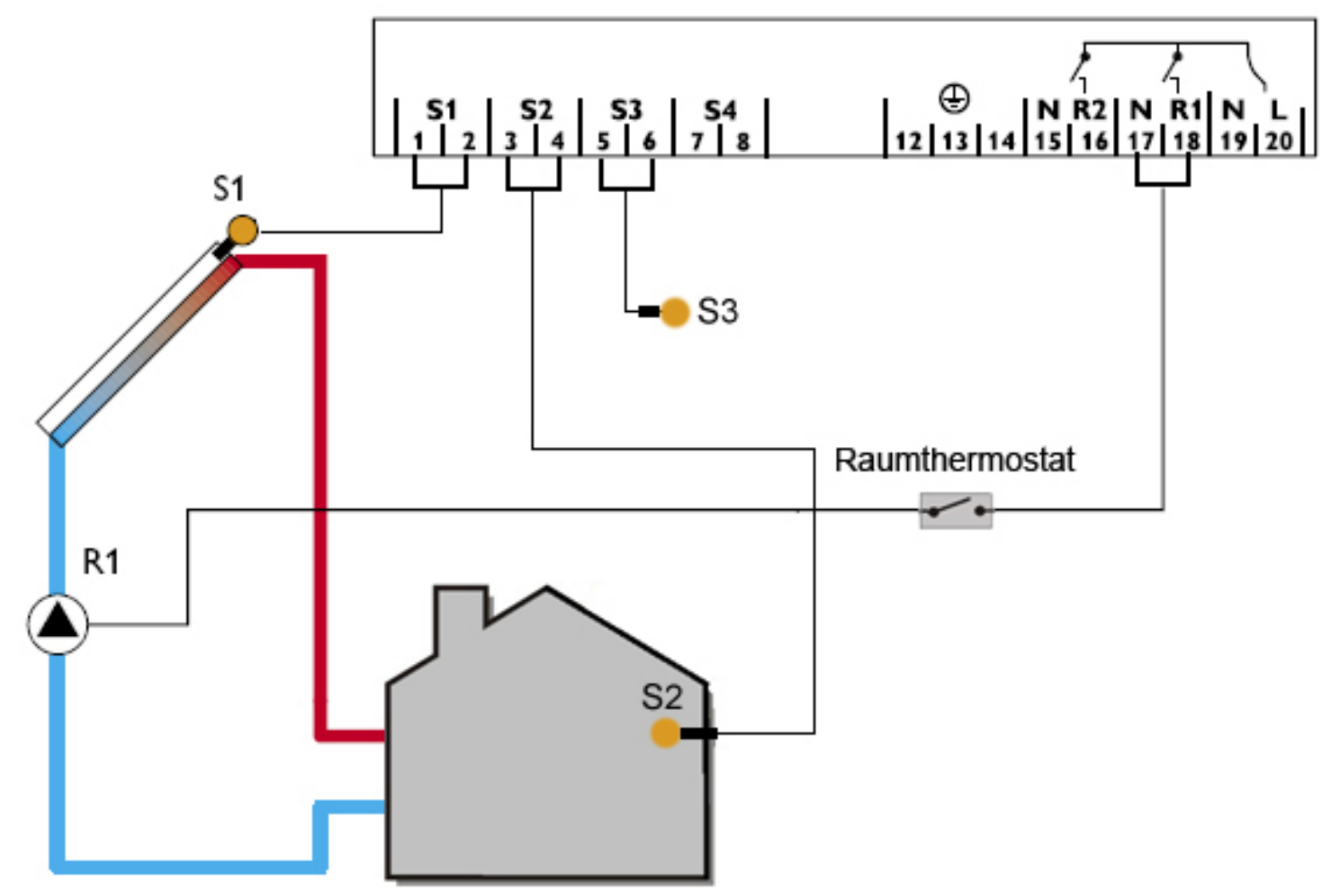

En un termostato externo se regula el ventilador del sistema. Cuando la habitación ha alcanzado la temperatura deseada, se aparaga el ventilador.

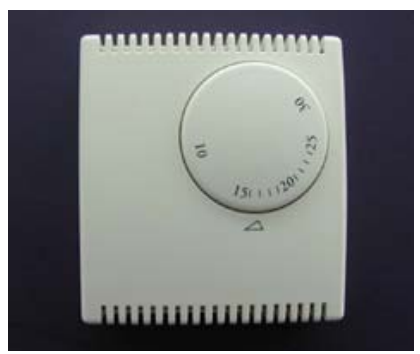

El termostato de la habitación debe sobrepasar aprox. $2^{\circ} \mathrm{C}$ al termostato de la calefacción convencional. 


\subsubsection{Sensor de temperatura - Disposición / Montaje}

Se tienen que tener en cuenta algunos criterios para realizar la colocación y montaje del sensor de temperatura ambiente (Imagen1)

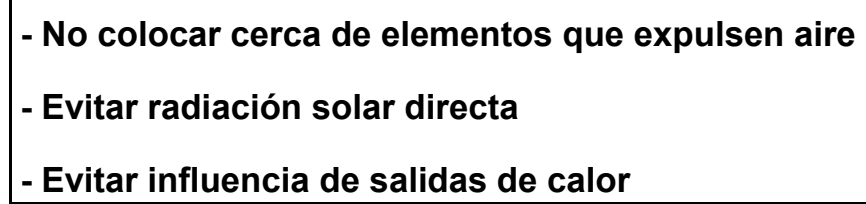

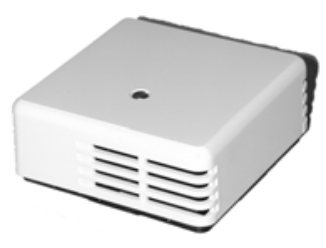

Imagen.1: Sensor de temp ambiente de Sensor

Tipo de sensor standar: Pt 1000

Montaje del sensor del colector(Imagen.2): El sensor (algo húmedo) se coloca en el orificio al final del colector hasta que llegue al tope (aprox. $20 \mathrm{~cm}$.) y después se conecta el cable al regulador solar.

Cable del sensor - Prolongación con $2 \times 0,75 \mathrm{~mm}^{2}$ hasta $50 \mathrm{~m}$ de longitud, o en otro caso $1,5 \mathrm{~mm}^{2}$. Es conveniente poner en el TOPSOLAR un sensor de resistencia Pt1000

Control de funciones Tipo de sensor standard Pt 1000: El valor de resistencia a $20^{\circ} \mathrm{C}$ asciende a aproximadamente $1078 \Omega$.

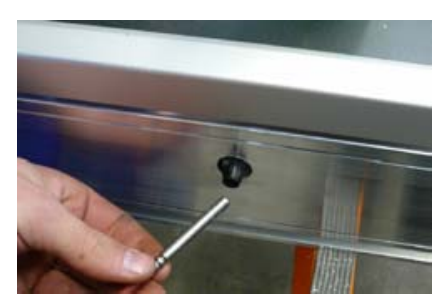

Imagen 2: Sensor del colector 


\subsection{CHECKLIST - Eliminación de fallos en TopSolar}

\begin{tabular}{|c|c|}
\hline Fallos & Posibles causas - Eliminación de errores \\
\hline \multirow{3}{*}{$\begin{array}{l}\text { El ventilador no } \\
\text { funciona }\end{array}$} & $\begin{array}{l}\text { Probablemente el interruptor de funcionamiento está apagado. Encenderlo o ponerlo en modo } \\
\text { automático Capítulo 2.3.2 }\end{array}$ \\
\hline & Interruptor atascado no hace buen contacto - quizá la fijación de tornillos \\
\hline & Conducción de aire-válvulas.en sección transversal abierta \\
\hline \multirow{3}{*}{$\begin{array}{l}\text { El sistema no } \\
\text { funciona en modo } \\
\text { automático }\end{array}$} & Contacto de las sondas, y comprobar colocación \\
\hline & Comprobar regulación diferencias de temperatura \\
\hline & $\begin{array}{l}\text { Comprobar REGULACIÓN DE MÁXIMA TEMPERATURA- quizá el valor se ha establecido } \\
\text { demasiado pequeño, de manera que imposibilita cualquier funcionamiento de calefacción }\end{array}$ \\
\hline $\begin{array}{l}\text { El sistema función de } \\
\text { manera discontinua }\end{array}$ & Sistema en funcionamiento en modo ON - Ponerlo en modo automático- Capítulo 2.3.2 \\
\hline \multirow{4}{*}{$\begin{array}{l}\text { El ventilador es muy } \\
\text { ruidoso }\end{array}$} & Preveer un silenciador \\
\hline & Montar amortiguador de vibraciones para el ventilador \\
\hline & Salida de aire estrangulada - Sonido de silbato \\
\hline & Comprobar el ajuste del tope mecánico del motor \\
\hline \multirow{2}{*}{$\begin{array}{l}\text { Válvula motorizada } \\
\text { no funciona }\end{array}$} & Cable enroscado N, L1 y L2 en el motor y/o cabel enroscado en el regulador \\
\hline & Comprobar el ajuste del tope mecánico del motor \\
\hline $\begin{array}{l}\text { Aviso de temperatura } \\
\text { oscilante }\end{array}$ & $\begin{array}{l}\text { Para cables muy largos del sensor, las tensiones inducidas son transmitidas y pueden obstaculizar la } \\
\text { conducción. Solución: cable protegido o elegir otra longitud de cable. }\end{array}$ \\
\hline \multirow{3}{*}{$\begin{array}{l}\text { Rendimiento muy } \\
\text { bajo }\end{array}$} & Comprobar la suciedad en el filtro, se debe de cambiar al menos 1 ó 2 veces al año!!! \\
\hline & $\begin{array}{l}\text { Se ha atascado la clapeta de retención. Comprobar, si los tornillos de montaje entorpecen la función } \\
\text { de la clapeta Comprobar sección transversal abierta }\end{array}$ \\
\hline & Sistema de conducción embozado. Comprobar sección transversal abierta \\
\hline
\end{tabular}




\section{O. CAD-Esquemas del Colector}

\section{TWINSOLAR 1.3}
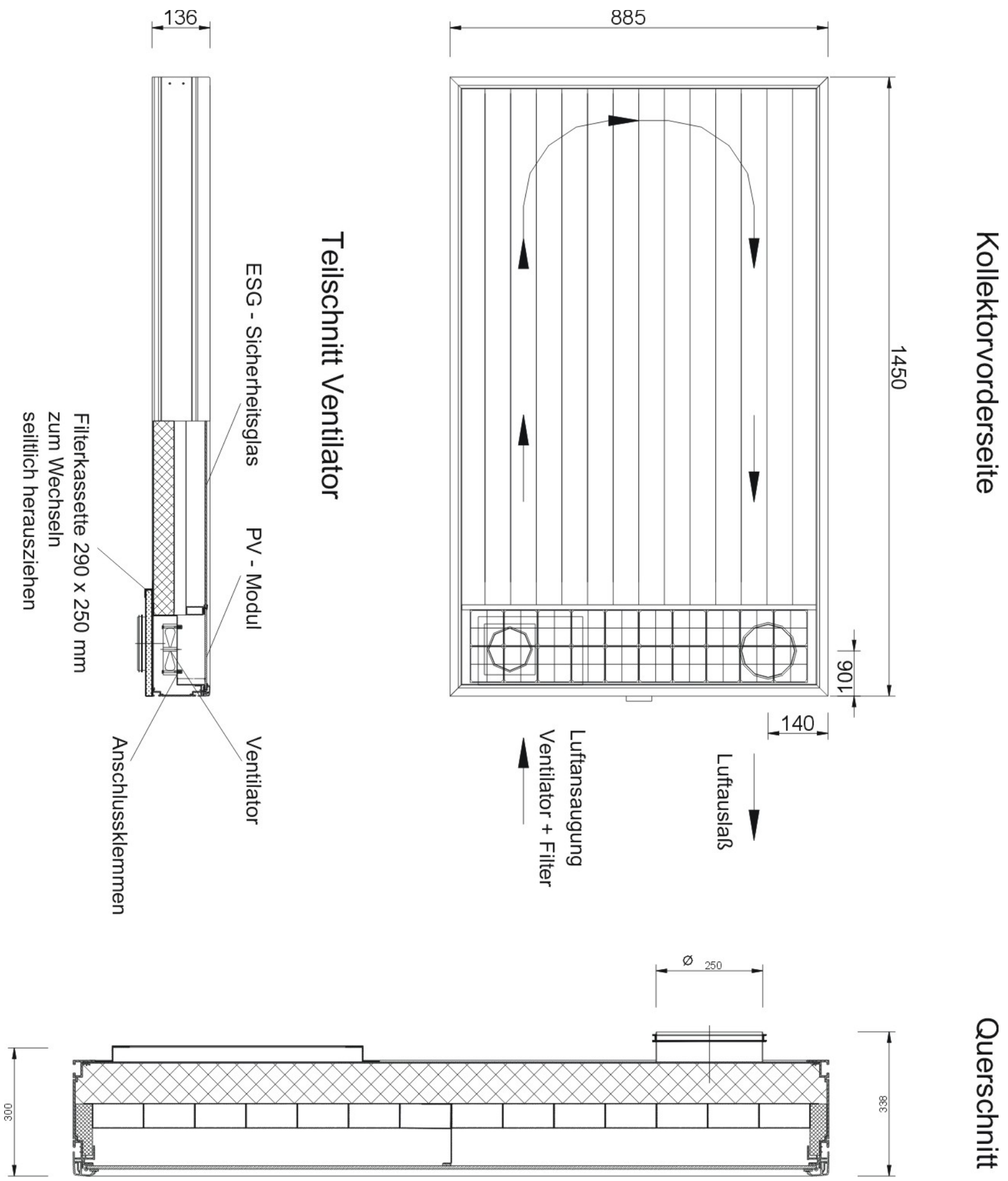
TWINSOLAR 2.0
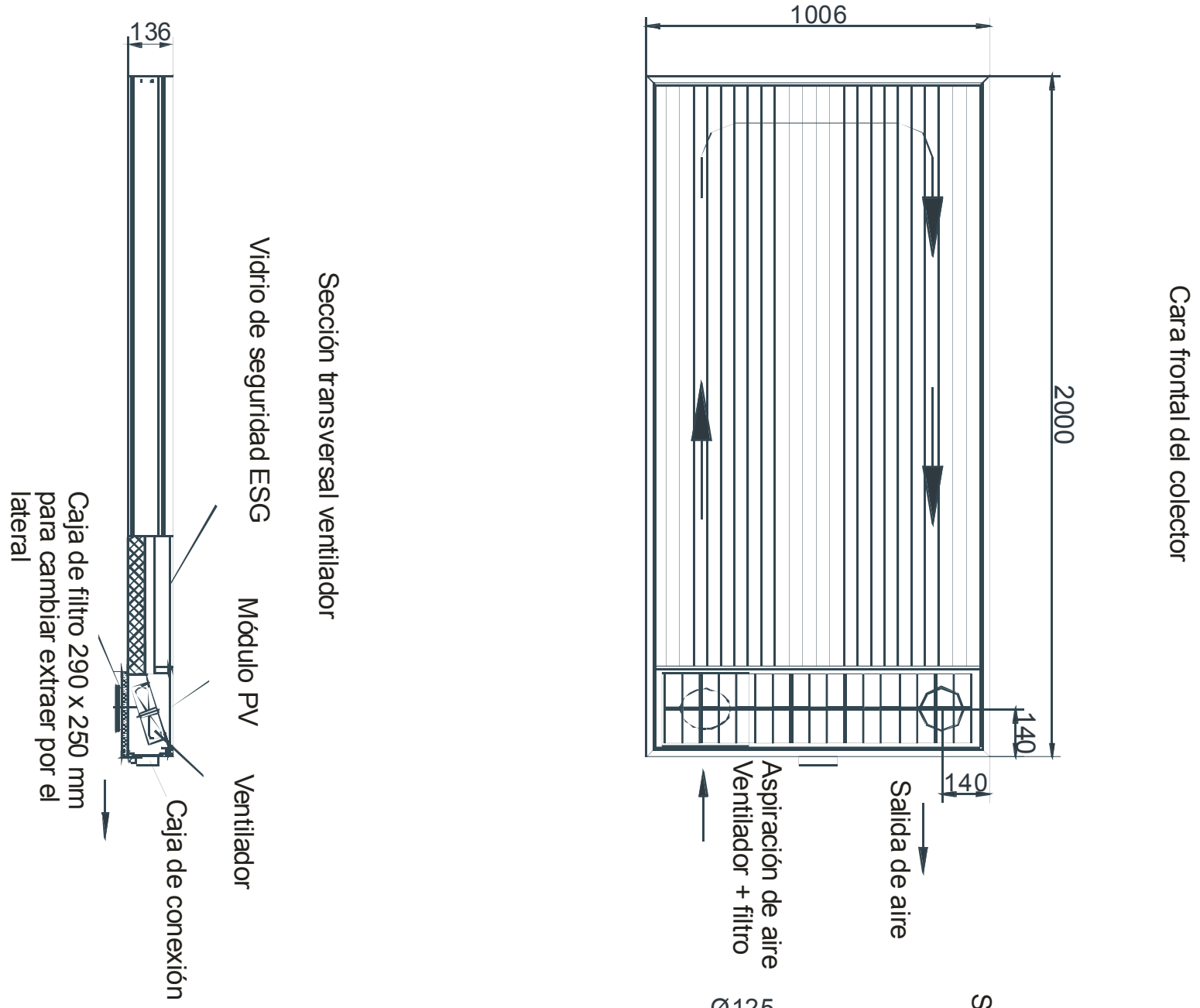

in 
TWINSOLAR 4.0

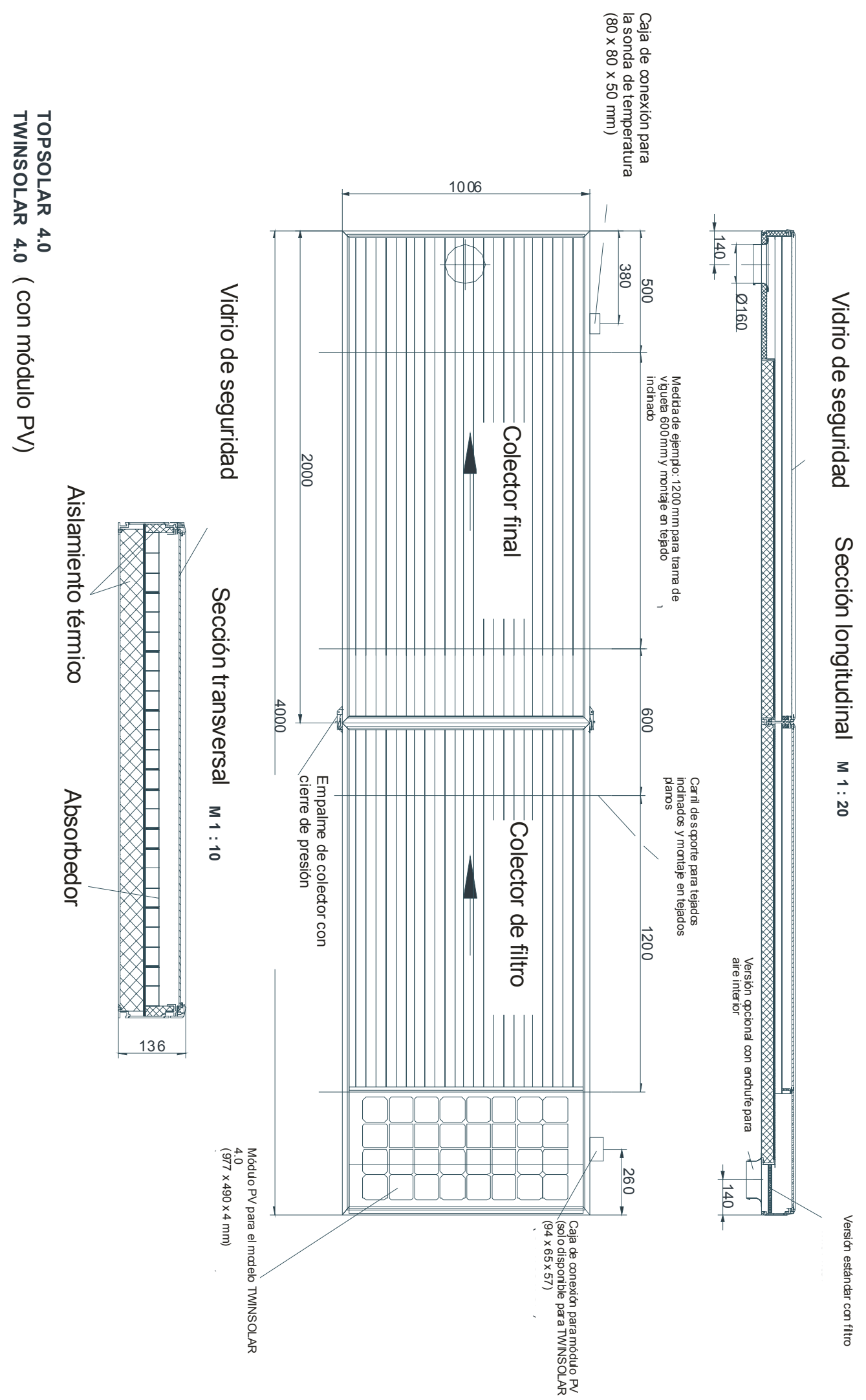


TWINSOLAR 6.0

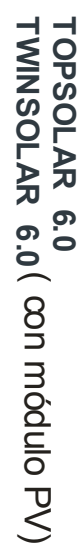

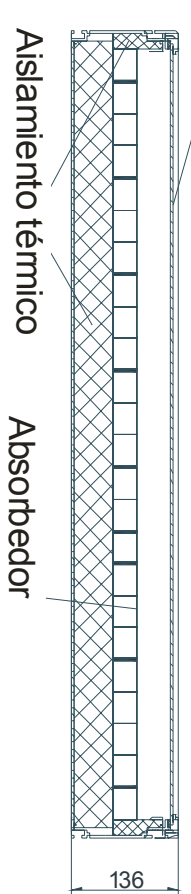

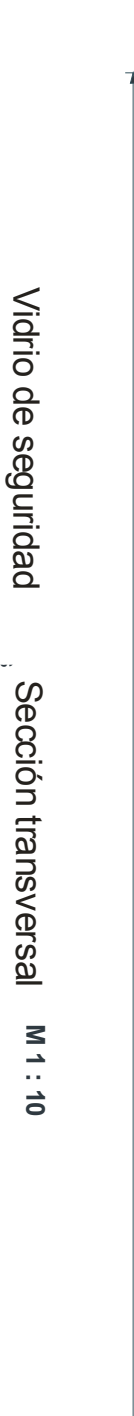

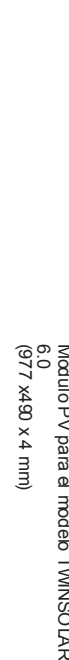

1006

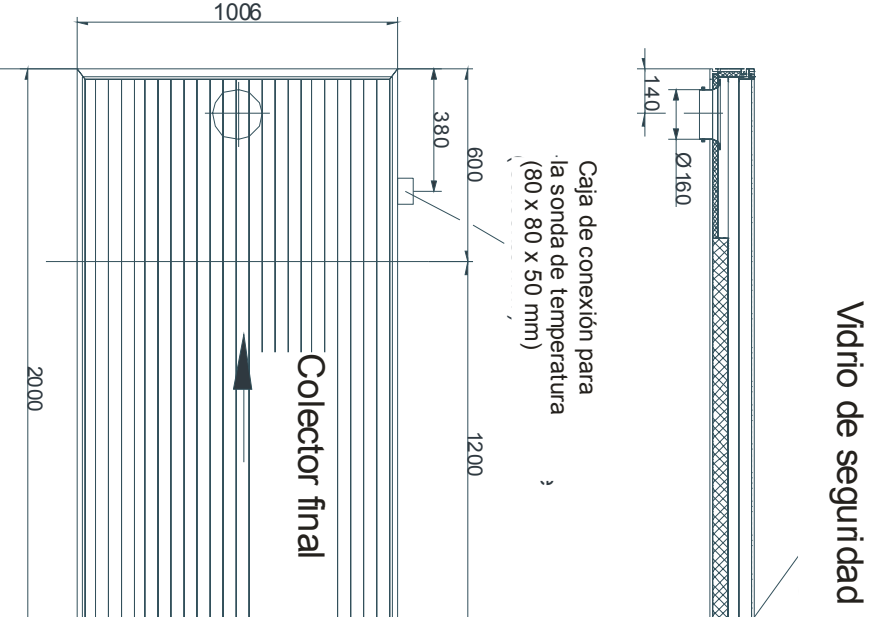

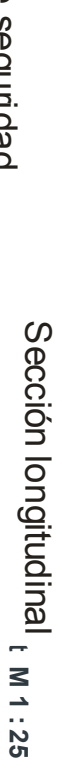

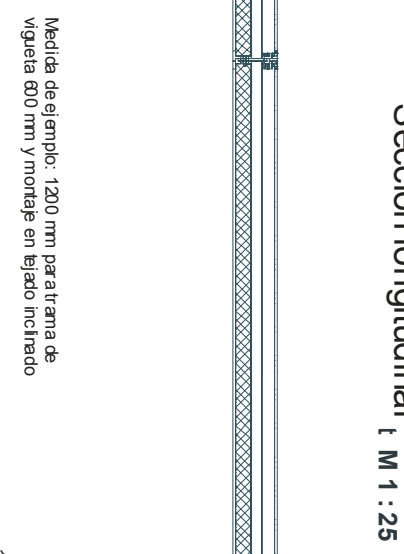

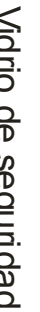


TWINSOLAR 8.0

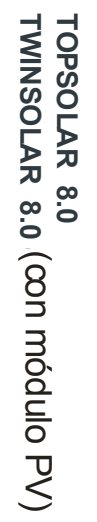

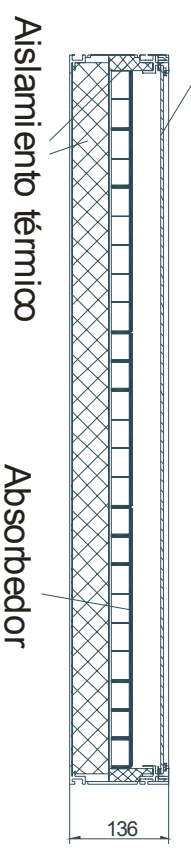

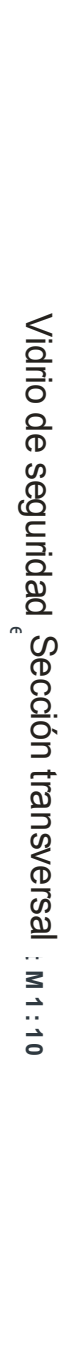

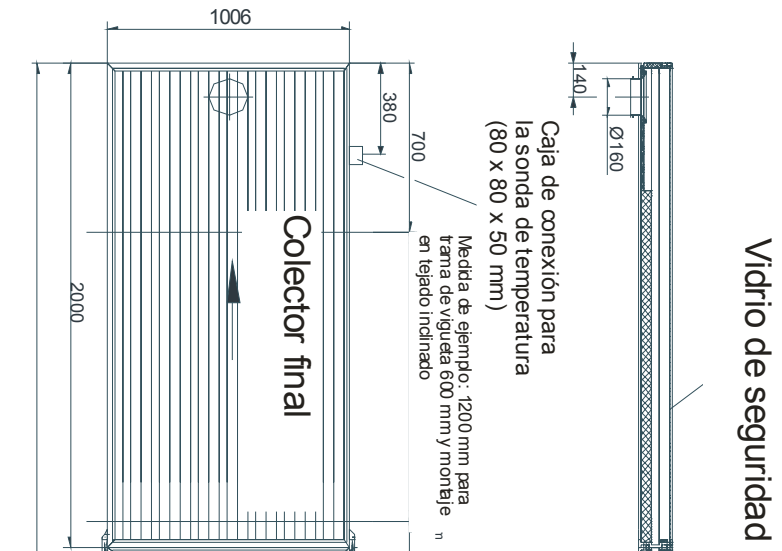

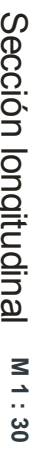




\section{TWINSOLAR 10.0}

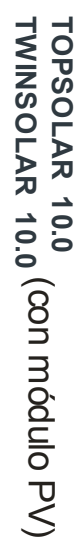
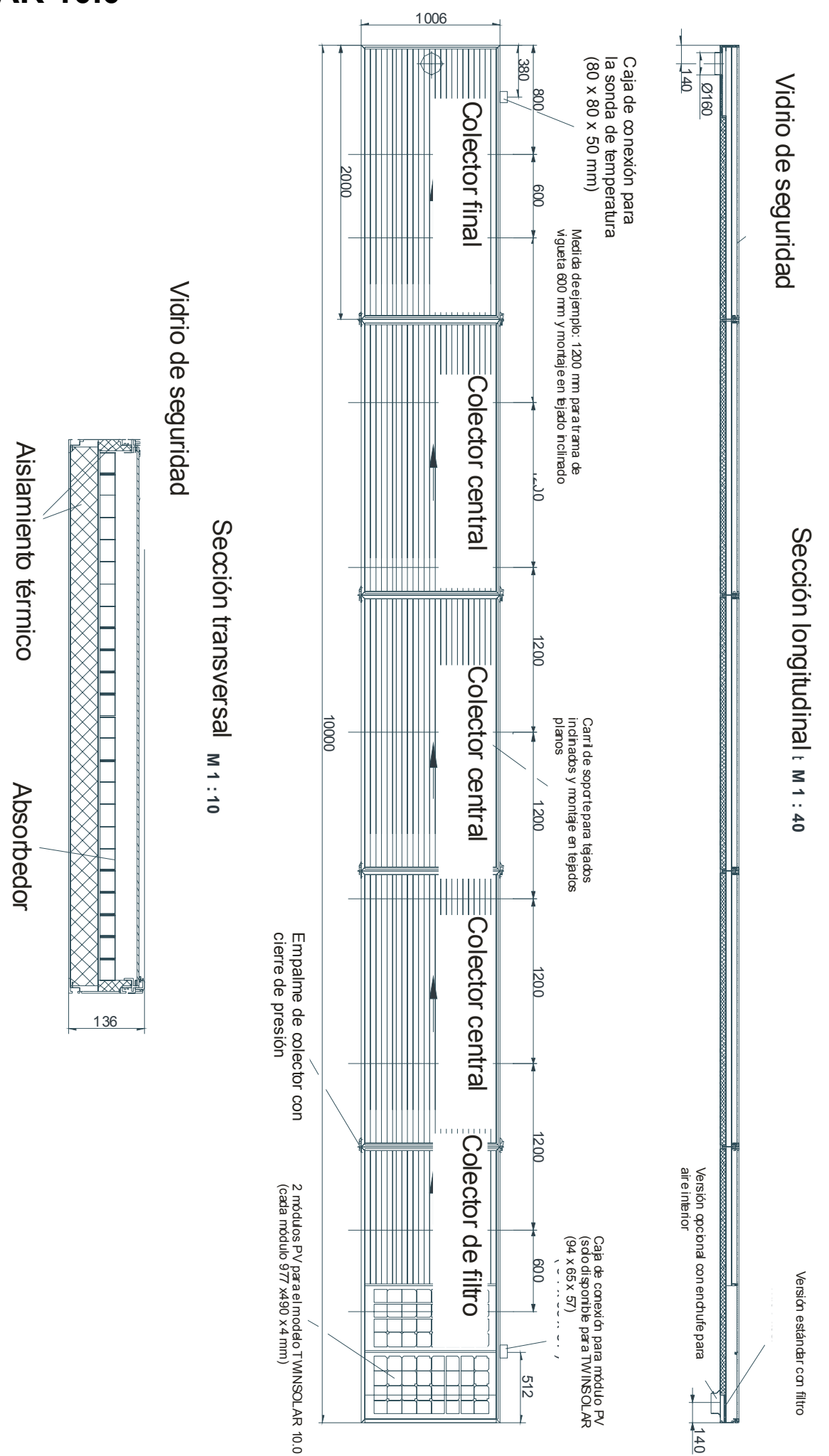
TWINSOLAR 4.5

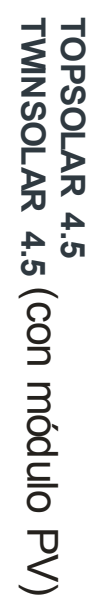

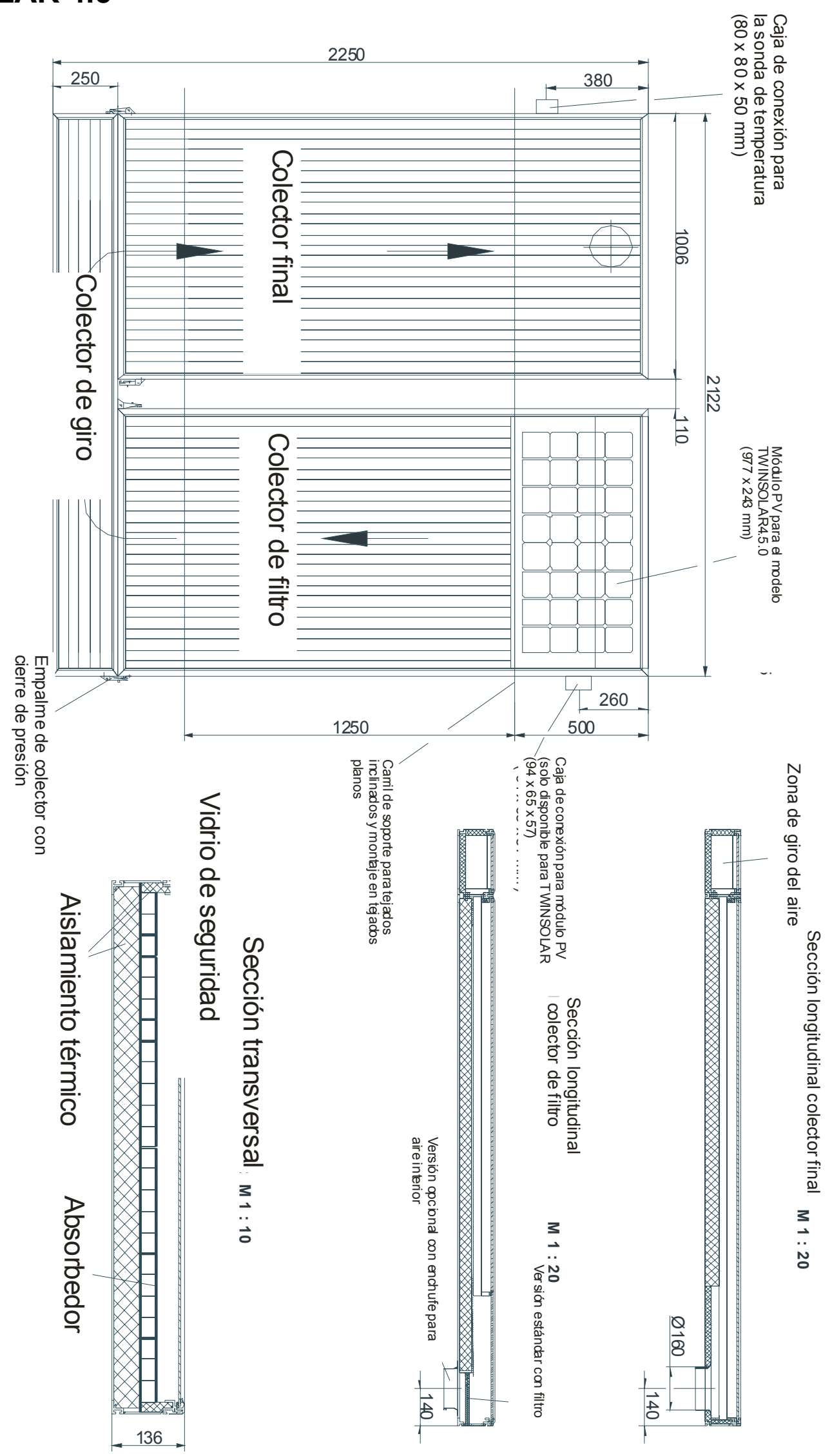


TWINSOLAR 8.5

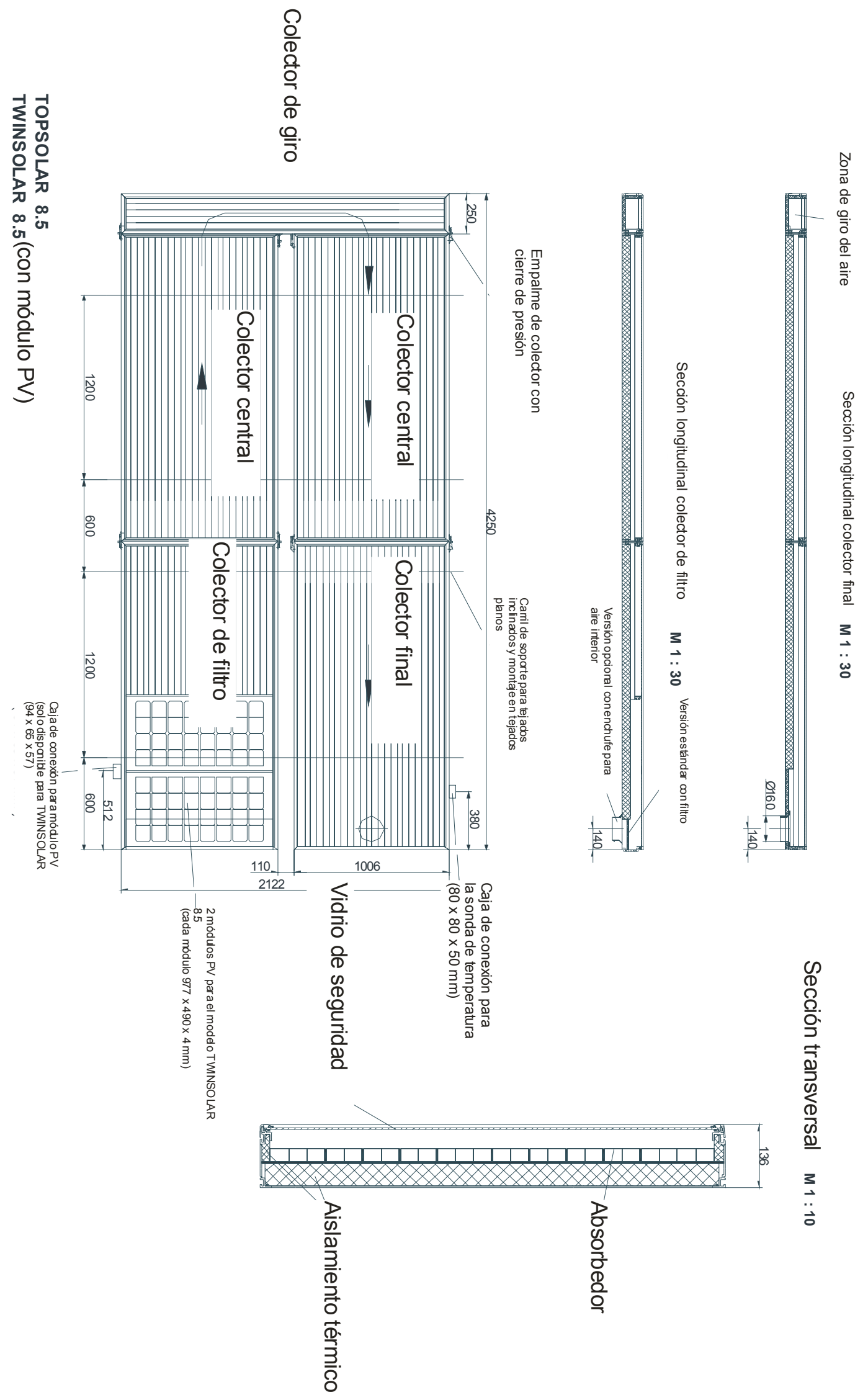


TWINSOLAR 12.5

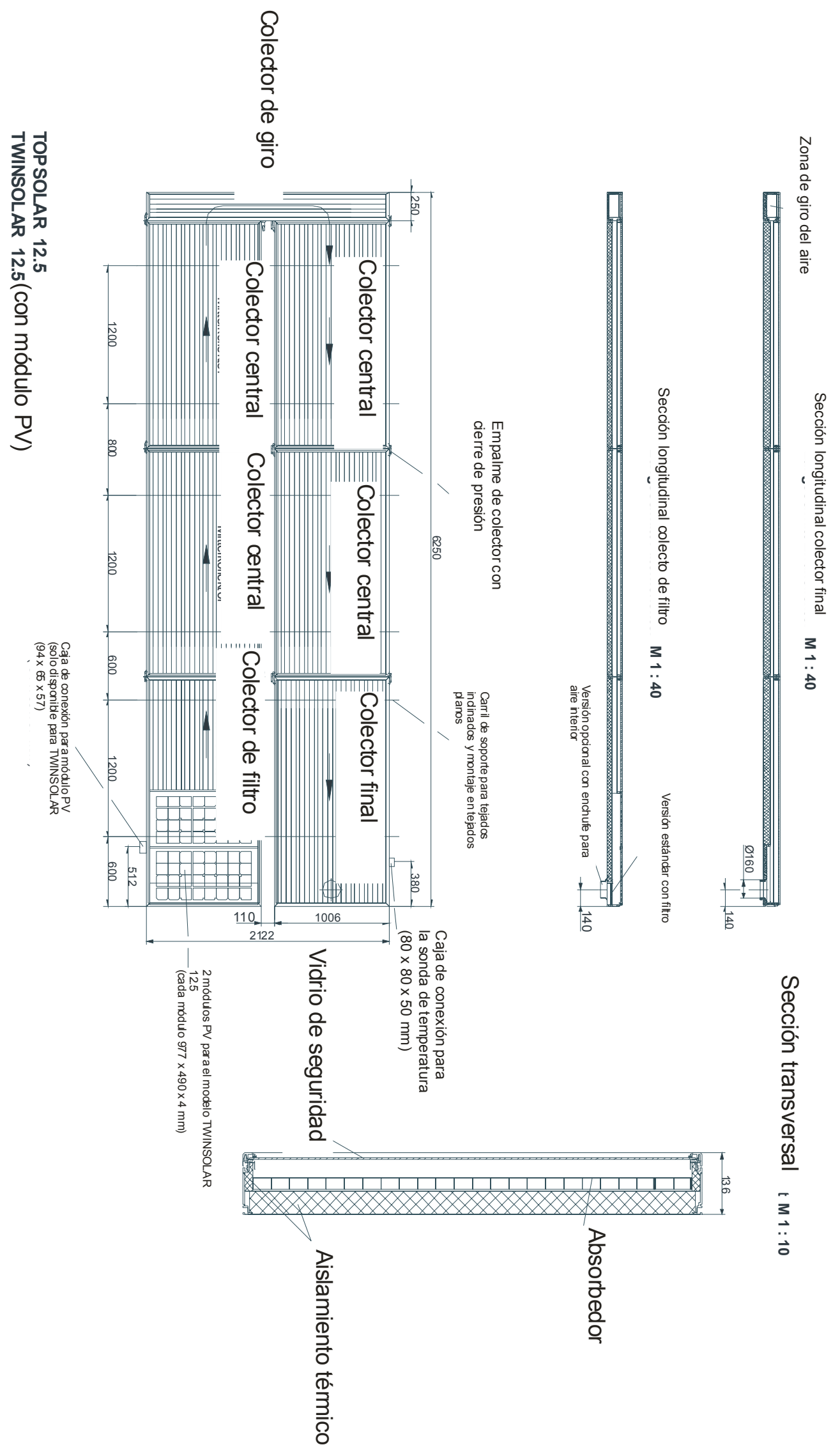


Ficha técnica del colector: Datos del fabricante

Datos relativo al tipo del colector y del instituto de ensayo

Tipo de colector / denominación

SLK - Colector solar de aire caliente

\begin{tabular}{|l|l}
\hline Sistema de construcción & Colector de aire caliente \\
\hline Fabricante & GRAMMER Solar GmbH \\
\hline Instituto de ensayo & ARSENAL RESEARCH A-Wien, ISE D-Freiburg \\
\hline Ensayo según norma & $\begin{array}{l}\text { No existe actualmente una norma específica para colectores de aire } \\
\text { caliente }\end{array}$ \\
\hline Informe de ensayo & SLK200305_01 (ISE), IEA-TASK 19 SOLAR AIR SYSTEMS \\
\hline
\end{tabular}

Valores característicos (todos los valores se refieren a la superficie de apertura)

\begin{tabular}{l|l|l|l|}
\hline Magnitud & Símbolo & Unidad & Valores típicos / ejemplos (referencia:
\end{tabular}

Factor de conversión; diferencia de temperatura $\left(t_{m}-t_{a}\right)=0$,

rendimiento óptico

Coeficiente de eficacia lineal, coeficiente de pérdida

Coeficiente de eficacia de segundo grado, coeficiente de pérdida

Factor de ángulo

Pérdida de presión

Rango de caudal recomendado

Capacidad térmica en función de la superficie (llena)

Carcasa

Dimensiones (longitud $\mathrm{x}$ anchura $\mathrm{x}$ altura)

Material

Masa total colector (llena)

\begin{tabular}{|c|c|c|}
\hline Símbolo & Unidad & $\begin{array}{c}\text { Valores típicos / ejemplos (referencia: } \\
\text { superficie de apertura) }\end{array}$ \\
\hline$\eta_{0}$ & - & 0,834 \\
\hline$a_{1}$ & $\mathrm{~W} /\left(\mathrm{m}^{2} \times \mathrm{K}\right)$ & 3,197 \\
\hline$a_{2}$ & $\mathrm{~W} /\left(\mathrm{m}^{2} \times \mathrm{K}^{2}\right)$ & 0,034 \\
\hline $\mathrm{K}_{\theta}\left(50^{\circ}\right)$ & - & 0,96 \\
\hline \multicolumn{3}{|c|}{$\Delta p=a_{1} \times m+a_{2} \times m^{2}$} \\
\hline & $\mathrm{m}^{3} /\left({\left.\mathrm{h} \times \mathrm{m}^{2}\right)}^{2}\right.$ & 30 hasta 60 \\
\hline c & $\mathrm{J} /\left(\mathrm{m}^{2} \times \mathrm{K}\right)$ & \\
\hline
\end{tabular}

\section{Absorbedor}

Material del absorbedor, grosor material, conexión al registro

de tubería

Material conductos de calor

Volumen medio caloportador

Cubierta transparente

Material, grosor, en su caso recubrimiento

Aislamiento térmico

Tipo, material

Conductividad térmica

Grosor

\section{Superficies de referencia}

Superficie bruta

Superficie de apertura

Superficie eficaz de absorción

Valores límite para el funcionamiento

Temperatura de paro

Presión admisible

Medio caloportador admisible

Instalación

Formas de instalar

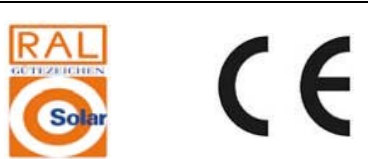

\begin{tabular}{|c|c|}
\hline en $\mathrm{mm}$ & \\
\hline $\mathrm{kg}$ & \\
\hline
\end{tabular}

$2000 \times 1006 \times 136$
aluminio
45

aluminio, $\mathrm{t}=0,6 \mathrm{~mm}$ sin registro de tubería

aluminio

(absorbedor=conducto de aire)

55 I (conducto de aire)

\section{ESG, 4mm, -}

Planchas, lana mineral

$$
0,040
$$

$50 \mathrm{~mm}$ (parte trasera),

$20 \mathrm{~mm}$ (lateral) 


\section{ANEXO IV GLOSARIO DE TÉRMINOS}

\subsection{Introducción}

El siguiente Glosario de términos intenta homogenizar y racionalizar la terminología específica utilizada en la presente Tesis Doctoral, que no corresponde al lenguaje común.

\subsection{Términos}

Acuerdo voluntario: Acuerdo entre una autoridad gubernamental y una (o varias) partes privadas, y compromiso unilateral reconocido por la autoridad pública, para lograr objetivos ambientales o para mejorar los resultados ambientales, más allá de la observancia.

Amplitud térmica: Diferencia entre las temperaturas media máxima y media mínima en un período establecido.

Auditoría energética: Estudio, inspección y análisis del consumo energético de un sistema para comprender su dinámica y buscar oportunidades de mejora del rendimiento energético. Los objetivos de una auditoría energética son analizar los flujos energéticos de la instalación auditada, establecer las estrategias de ahorro y eficiencia energética más adecuadas, evaluar y valorar los ahorros potenciales desde el punto de vista técnico, económico y medioambiental.

Benchmarking (punto de referencia): Técnica utilizada para medir el rendimiento de un sistema, en este caso del edificio, en comparación con otro de referencia. Se trata de indicar en qué situación se encuentra el consumidor dentro de su entorno de actividad, en este caso viviendas $u$ oficinas.

Biocombustible: Combustible producido a partir de material seco orgánico o aceites combustibles producidos por plantas. Entre los ejemplos de biocombustibles se encuentran el alcohol, el licor negro proveniente del proceso de fabricación de papel, la madera y el aceite de soja.

Biomasa: Masa total de organismos vivos en una zona o volumen determinado; a menudo se incluyen los restos de plantas que han muerto recientemente (biomasa muerta).

Bonos de carbono: Mecanismo internacional propuesto en el Protocolo de Kyoto para la reducción de emisiones de gases de efecto invernadero. El sistema ofrece incentivos 
económicos para que empresas privadas contribuyan a la mejora de la calidad ambiental y se consiga regular la emisión generada por sus procesos productivos, considerando el derecho a emitir $\mathrm{CO}_{2}$ como un bien canjeable y con un precio establecido en el mercado. La transacción de los bonos de carbono (un bono de carbono representa el derecho a emitir una tonelada de dióxido de carbono) permite mitigar la generación de gases invernadero, beneficiando a las empresas que no emiten o disminuyen la emisión y haciendo pagar a las que emiten más de lo permitido.

Cambio climático: Importante variación estadística en el estado medio del clima o en su variabilidad, que persiste durante un período prolongado (normalmente decenios o incluso más). El cambio climático se puede deber a procesos naturales internos o a cambios del forzamiento externo, o bien a cambios persistentes antropogénicos en la composición de la atmósfera o en el uso de las tierras. Se debe tener en cuenta que la Convención Marco de las Naciones Unidas sobre el Cambio Climático (CMCC), en su Artículo 1, define cambio climático como "un cambio de clima atribuido directa o indirectamente a la actividad humana que altera la composición de la atmósfera mundial y que se suma a la variabilidad natural del clima observada durante períodos de tiempo comparables". La CMCC distingue entre cambio climático atribuido a actividades humanas que alteran la composición atmosférica y variabilidad climática atribuida a causas naturales.

Cambio de combustible: Política diseñada para reducir las emisiones de dióxido de carbono, adoptando combustibles con menos contenido de carbono, como el paso de carbón a gas natural.

Cambio en el uso de las tierras: Un cambio en el uso o gestión de las tierras por los humanos, que puede llevar a un cambio en la cubierta de dichas tierras. La cubierta de las tierras y el cambio en el uso de las tierras pueden tener un impacto en el albedo, la evapotranspiración, y las fuentes y los sumideros de gases de efecto invernadero, u otras propiedades del sistema climático, y puede tener igualmente consecuencias en el clima, ya sea de manera local o mundial.

Capacidad de adaptación: Capacidad de un sistema para ajustarse al cambio climático (incluida la variabilidad climática y los cambios extremos) a fin de moderar los daños potenciales, aprovechar las consecuencias positivas, o soportar las consecuencias negativas.

Capacidad de mitigación: Estructuras y condiciones sociales, políticas y económicas que se requieren para una mitigación eficaz.

Carga térmica de calefacción (Q): Energía que debe suplir el equipo de calefacción para mantener constante la temperatura interior durante un período dado, sin considerar ganancias $[\mathrm{kWh}]$.

Célula fotovoltaica: Dispositivo electrónico que permite transformar la energía luminosa en energía eléctrica mediante el efecto fotoeléctrico, generando energía solar fotovoltaica. Cuando los electrones libres son capturados, el resultado es una corriente eléctrica que puede ser utilizada como electricidad.

Certificado de reducción de emisiones: Bonos de carbono emitidos por la Junta ejecutiva del Clean Development Mechanism (CDM) para reducir emisiones. Están verificados por el Ministerio de Medio Ambiente, siguiendo las directivas del Protocolo de Kyoto.

Clima: En sentido estricto, se suele definir el clima como "estado medio del tiempo" o, más rigurosamente, como una descripción estadística del tiempo en términos de valores medios y variabilidad de las cantidades pertinentes durante períodos que pueden ser de meses a miles 0 
millones de años. El período normal es de 30 años, según la definición de la Organización Meteorológica Mundial (OMM). Las cantidades aludidas son casi siempre variables de la superficie (por ejemplo, temperatura, precipitación o viento), aunque en un sentido más amplio el clima es una descripción (incluso una descripción estadística) del estado del sistema climático.

Coeficiente volumétrico de pérdida de calor (G): Flujo de calor que pierde un local calefaccionado por unidad de volumen y por unidad de diferencia de temperatura, en régimen estacionario $\left[\mathrm{W} / \mathrm{m}^{3} \cdot \mathrm{K}\right]$.

Combustibles fósiles: Combustibles basados en carbono de depósitos de carbono fósil, incluidos el petróleo, el gas natural y el carbón.

Comercio de derechos de emisiones: Enfoque basado en el mercado para lograr objetivos ambientales que permiten a los países que reduzcan las emisiones de gases de efecto invernadero por debajo de los niveles requeridos, utilizar o comercializar el remanente de derechos de emisión para compensar las emisiones en otra fuente dentro o fuera del país. En general, el comercio puede ocurrir entre empresas o a nivel nacional o internacional. El Segundo Informe de Evaluación del IPCC incorporó el empleo de permisos para sistemas de comercio nacional y cupos para el internacional.

Confort térmico: Condición ambiental que favorece el equilibrio térmico del cuerpo y ofrece sensación de neutralidad térmica.

Convención Marco de las Naciones Unidas sobre el Cambio Climático (CMCC): La Convención se adoptó el 9 de mayo de 1992 en Nueva York. Más de 150 países y la Comunidad Europea la firmaron en la Cumbre sobre la Tierra de 1992, celebrada en Río de Janeiro. Su objetivo es la estabilización de las concentraciones de gases de efecto invernadero en la atmósfera a un nivel que impida interferencias antropogénicas peligrosas en el sistema climático. Contiene compromisos para todas las Partes.

Costos de aplicación: Costos que conllevan las opciones de aplicación o mitigación. Estos costos están asociados con los cambios institucionales necesarios, los requisitos de información, el tamaño del mercado, las oportunidades para adquirir y aprender tecnologías, y los incentivos económicos necesarios (ayudas, subvenciones e impuestos).

Desarrollo sustentable: Desarrollo que atiende las necesidades actuales sin comprometer la capacidad de las generaciones futuras para satisfacer sus propias necesidades.

Dióxido de carbono $\left(\mathrm{CO}_{2}\right)$ : Gas que se produce de forma natural, y también como subproducto de la combustión de combustibles fósiles y biomasa, cambios en el uso de las tierras y otros procesos industriales. Es el principal gas de efecto invernadero antropogénico que afecta al equilibrio de radiación del planeta. Es el gas de referencia frente al que se miden otros gases de efecto invernadero.

Diseño ambientalmente consciente (DAC): Metodología de diseño que tiene por objeto producir una arquitectura que minimice el uso de recursos no renovables, utilice sistemas renovables para cubrir total o parcialmente sus necesidades y generar un bajo impacto ambiental en su ciclo de vida.

Edificio de propiedad horizontal: Tipo de edificio de vivienda en altura, ubicado en un lote urbano, dentro del amanzanamiento tradicional. Este uso de la frase es índice del condicionamiento que a partir de 1949, debido a la lógica de la venta por unidades, sufrió el diseño de tales edificaciones, y de las formas que asumió ese tipo de producción y de 
comercialización. Se convirtió en una tipología clásica de la vivienda de las áreas urbanas de densidad media y alta en Argentina.

Edificio tipo torre: Edificio de gran altura, de perímetro libre, desarrollado especialmente en la segunda mitad del Siglo XX. Las torres son respuestas desencadenadas a las demandas de máximo aprovechamiento del suelo, máxima eficiencia funcional y máxima ganancia, correspondientes al estadio maduro de las operaciones inmobiliarias modernas de tipo estándar.

Efecto invernadero: Los gases de efecto invernadero absorben la radiación infrarroja emitida por la superficie de la Tierra, por la propia atmósfera debido a los mismos gases y por las nubes. La radiación atmosférica se emite en todos los sentidos, incluso hacia la superficie terrestre. Los gases de efecto invernadero atrapan el calor dentro del sistema de la troposfera terrestre. A esto se le denomina efecto invernadero natural. La radiación atmosférica se vincula en gran medida a la temperatura del nivel al que se emite. En la troposfera, la temperatura disminuye generalmente con la altura. Un aumento en la concentración de gases de efecto invernadero produce un aumento de la opacidad infrarroja de la atmósfera, y por lo tanto, una radiación efectiva en el espacio desde una altitud mayor a una temperatura más baja. Esto causa un forzamiento radiativo, un desequilibrio que sólo puede ser compensado con un aumento de la temperatura del sistema superficie - troposfera, lo que se denomina efecto invernadero aumentado.

Eficiencia energética: Relación entre el producto de energía de un proceso de conversión o de un sistema y su insumo de energía.

Elevación del nivel del mar: Ascenso del nivel medio del océano. La elevación eustática del nivel del mar es un cambio en el nivel medio del mar producido por la alteración en el volumen mundial de los océanos. La elevación relativa del nivel del mar ocurre cuando existe una elevación neta del nivel del océano relacionado con movimientos locales de tierras.

Emisiones: En el contexto de cambio climático, se entiende por emisiones la liberación de gases de efecto invernadero y/o sus precursores y aerosoles en la atmósfera, en una zona y un período de tiempo específicos.

Emisiones de $\mathrm{CO}_{2}$ fósil: Emisiones de dióxido de carbono que resultan del consumo de combustibles de yacimientos de carbono fósil como el petróleo, gas natural y carbón.

Energía alternativa: Energía derivada de combustibles que no tienen un origen fósil.

Energía final: Energía suministrada que pone a disposición del consumidor, para que la convierta en energía útil (por ejemplo, electricidad en un tomacorriente).

Energía fotovoltaica: Electricidad renovable obtenida a partir de la radiación solar mediante un dispositivo semiconductor denominado célula fotovoltaica.

Energía fototérmica: Aprovechamiento de la energía del Sol para producir calor que puede aprovecharse para cocinar alimentos o para la producción de agua caliente destinada al consumo de agua doméstico, ya sea agua caliente sanitaria, calefacción, o para producción de energía mecánica y, a partir de ella, de energía eléctrica.

Energía primaria: Energía contenida en recursos naturales (carbón, petróleo crudo, luz solar, uranio) que no han sido objeto de ninguna conversión o transformación antropogénica. 
Energías renovables: Fuentes de energía que son sustentables, dentro un marco temporal breve si se compara con los ciclos naturales de la Tierra, e incluyen tecnologías no basadas en el carbono, como la solar, la hidrológica y la eólica, además de las tecnologías neutras en carbono, como la biomasa.

Envolvente: Cerramiento del edificio. Incluye tanto los opacos como los transparentes (techos, paredes, puertas, ventanas y similares). No incluye los pisos en contacto con el suelo pero sí aquellos sobre espacios exteriores (por ejemplo: pisos sobre plantas libres).

Equilibrio energético: El balance energético del sistema climático, sobre la base de una media en todo el planeta y sobre períodos prolongados, debe estar en equilibrio. Como el sistema climático recibe toda su energía del Sol, este equilibrio implica que, en todo el planeta, la cantidad de radiación solar entrante debe ser igual a la suma de la radiación solar reflejada saliente y la radiación infrarroja saliente emitida por el sistema climático.

Escenario climático: Diferencia entre un escenario climático y el clima actual. Representación estimada del clima futuro, basada en un conjunto internamente coherente de relaciones climatológicas, que se construye para ser utilizada de forma explícita en la investigación de las consecuencias potenciales del cambio climático antropogénico, y que sirve a menudo de insumo para las simulaciones de los impactos.

Escenario de emisiones: Representación plausible de la evolución futura de las emisiones de sustancias que son radiativamente activas (por ejemplo, gases de efecto invernadero), basada en un conjunto de hipótesis coherentes e internamente consistentes sobre las fuerzas impulsoras de este fenómeno (tales como el desarrollo demográfico y socioeconómico, el cambio tecnológico) y sus relaciones clave. Los escenarios de concentraciones, derivados a partir de los escenarios de emisiones, se utilizan como insumos en una simulación climática para calcular proyecciones climáticas.

Expansión térmica: En conexión con el nivel del mar, se refiere al aumento de volumen (y la disminución de densidad) que resulta del calentamiento del agua. El calentamiento del océano provoca una expansión del volumen del océano y, por lo tanto, una elevación del nivel del mar.

Fuente: Cualquier proceso, actividad o mecanismo que emite un gas de efecto invernadero, un aerosol, o un precursor de gases de efecto invernadero o aerosoles en la atmósfera.

Ganancias internas: Flujo de calor producido por las personas, equipamiento y artefactos en un local, excluyendo el flujo de calor de instalaciones de calefacción.

Gas de efecto invernadero (GEI): Gases integrantes de la atmósfera, de origen natural y antropogénico, que absorben y emiten radiación en determinadas longitudes de ondas del espectro de radiación infrarroja emitido por la superficie de la Tierra, la atmósfera, y las nubes. Esta propiedad causa el efecto invernadero. El vapor de agua $\left(\mathrm{H}_{2} \mathrm{O}\right)$, dióxido de carbono $\left(\mathrm{CO}_{2}\right)$, óxido nitroso $\left(\mathrm{N}_{2} \mathrm{O}\right)$, metano $\left(\mathrm{CH}_{4}\right)$, y ozono $\left(\mathrm{O}_{3}\right)$ son los principales gases de efecto invernadero en la atmósfera terrestre. Además existe en la atmósfera una serie de gases de efecto invernadero totalmente producidos por el hombre, como los halocarbonos y otras sustancias que contienen cloro y bromuro.

Grados días de calefacción $\left({ }^{\circ} \mathrm{D}\right)$ : Suma de las diferencias de temperaturas, entre una temperatura base y la media diaria, para los días en que la media diaria es menor que la temperatura base en un período establecido $\left[{ }^{\circ} \mathrm{C}\right]$. 
Grados días de refrigeración $\left({ }^{\circ} \mathrm{D}\right)$ : Suma de las diferencias de temperaturas, entre una temperatura base y la media diaria, para los días en que la media diaria es mayor que la temperatura base en un período establecido $\left[{ }^{\circ} \mathrm{C}\right]$.

Impactos climáticos: Consecuencias del cambio climático en sistemas humanos y naturales. Según la medida de la adaptación, se pueden distinguir impactos potenciales e impactos residuales.

Impactos potenciales: Todos los impactos que pueden suceder dado un cambio proyectado en el clima, sin tener en cuenta las medidas de adaptación.

Impactos residuales: Los impactos del cambio climático que pueden ocurrir después de la adaptación.

Impuesto sobre emisiones: Gravamen impuesto por un gobierno por cada unidad de emisiones de $\mathrm{CO}_{2}$ equivalente producidas por una fuente sujeta al impuesto. Como prácticamente todo el carbono de combustibles fósiles se emite como dióxido de carbono, un gravamen sobre el contenido de carbono de los combustibles de origen fósil es equivalente a un impuesto sobre emisiones provenientes de la combustión de combustibles fósiles. El impuesto sobre energía reduce la demanda de energía y, por lo tanto, reduce las emisiones de dióxido de carbono que resultan del consumo de combustibles fósiles. Lo impuestos ecológicos tienen por objeto influir en el comportamiento humano y fomentar de esta forma una vía que sea racional desde el punto de vista ecológico. El impuesto internacional sobre emisiones carbono - energía es un gravamen aplicado por un organismo internacional sobre fuentes específicas en los países participantes. Los ingresos se distribuyen o utilizan según como lo especifiquen los países participantes o el organismo internacional.

Índice de renovación de aire(n): Número de cambios de aire producidos en un volumen por unidad de tiempo $\left[\mathrm{h}^{3}\right]$.

Infiltración de aire: Media aritmética del caudal de aire que pasa a través de las juntas de un cerramiento móvil (aberturas), medido por unidad de longitud de la junta del cerramiento, y para condiciones establecidas de diferencia de presión de aire.

Intensidad energética: Relación entre el consumo de energía y su rendimiento físico o económico. A nivel nacional es la relación entre el consumo total de energía primaria nacional o el consumo de energía final y el Producto bruto interno.

Investigación, desarrollo y demostración: Investigación y desarrollo científico y/o tecnológico para nuevos procesos de producción o nuevos productos, junto con el análisis y las medidas que proporcionan información a los usuarios potenciales respecto a la aplicación de nuevos productos o procesos, pruebas demostrativas, y la posibilidad de aplicación de dichos procesos y productos a través de plantas piloto y otras aplicaciones pre-comerciales.

Isla de calor: Zona dentro de un área urbana caracterizada por una temperatura ambiente más alta que las zonas colindantes debido a una absorción de la energía solar por materiales como el asfalto.

Mecanismo para un desarrollo limpio: Definido en el Artículo 12 del Protocolo de Kyoto, intenta cumplir dos objetivos: 1) ayudar a los países en vías de desarrollo a lograr un desarrollo sustentable y contribuir al objetivo último de la Convención; y 2) ayudar a los países desarrollados a dar cumplimiento a sus compromisos cuantificados de limitación y reducción de emisiones. En el marco de proyectos del Mecanismo para un Desarrollo Limpio emprendidos por países en vías de desarrollo para limitar o reducir las emisiones de gases de efecto 
invernadero, se pueden otorgar al inversor (gobierno o industria) Unidades de Reducciones Certificadas de Emisiones, si esas reducciones están certificadas por entidades operativas designadas por la Conferencia de las Partes/ Reunión de las Partes. Una parte del producto de las actividades de proyectos certificadas se utiliza para cubrir gastos administrativos, y a ayudar a Partes que son países en desarrollo y son especialmente vulnerables a los efectos adversos del cambio climático, para que sufraguen los costos de adaptación.

Medidas reguladoras: Reglamentos o códigos aprobados por los gobiernos que ordenan especificaciones de productos o características del rendimiento de un proceso.

Microclima: Expresiones más localizadas del clima en que se ven modificadas las relaciones de las variables componentes del mismo, y cuyo conocimiento permite un mejor diseño.

Mitigación: Intervención antropogénica para reducir las fuentes o mejorar los sumideros de gases de efecto invernadero.

Modelo: En ciencias aplicadas se denomina modelo científico a una representación abstracta, conceptual, física, matemática, gráfica o visual de fenómenos, sistemas o procesos a fin de analizar, describir, explicar, simular esos fenómenos o procesos. Un modelo permite determinar un resultado final a partir de unos datos de entrada. Se considera que la creación de un modelo es una parte esencial de toda actividad científica.

Normas: Conjunto de reglas o códigos que da instrucciones o define el rendimiento de un producto (por ejemplo, niveles, dimensiones, características, métodos de prueba y reglas para su uso). Las normas internacionales sobre calidad de producto y/o tecnologías establecen unos requisitos mínimos para los productos y/o las tecnologías afectados en los países en donde se adoptan. Las normas reducen las emisiones de gases de efecto invernadero asociadas con la fabricación o empleo de los productos y/o la aplicación de la tecnología.

Predicción climática: Resultado de un intento de producir la descripción o la mejor estimación de la evolución real del clima en el futuro (a escalas temporales estacionales, interanuales o a largo plazo).

Producto bruto interno (PBI): Suma del valor añadido bruto, a precios de consumidor, de todos los productores residentes y no residentes en la economía, más los impuestos, y menos las subvenciones no incluidos en el valor de los productos en un país o zona geográfica durante un período determinado, normalmente de 1 año. Se calcula sin deducir de ello la depreciación de los activos fabricados y la degradación y eliminación de recursos naturales. El PIB es a menudo una medida, aunque incompleta, del bienestar.

Protocolo de Kyoto: El Protocolo de Kyoto a la Convención Marco de las Naciones Unidas sobre el Cambio Climático (CMCC) se adoptó en el tercer periodo de sesiones de la Conferencia de las Partes de la CMCC en 1997 en Kyoto, Japón. Contiene unos compromisos legales vinculantes, además de los incluidos en la CMCC. Los países del Anexo B del Protocolo (la mayoría de los países en la Organización de Cooperación y Desarrollo Económicos (OCDE), y los países con economías en transición) acordaron la reducción de sus emisiones antropogénicas de gases de efecto invernadero a al menos un $5 \%$ por debajo de los niveles en 1990 durante el período de compromiso de 2008 al 2012.

Radiación solar total $\left(I_{\mathbf{s}}\right)$ : Intensidad de la energía radiante recibida del sol sobre la unidad de superficie, la inclinación y orientación establecidas $\left[\mathrm{W} / \mathrm{m}^{2}\right]$.

Radiación solar directa $\left(\mathrm{I}_{\mathrm{D}}\right)$ : Radiación solar proveniente directamente del sol [W/m $\left.{ }^{2}\right]$. 
Radiación solar difusa $\left(\mathbf{I}_{\mathrm{d}}\right)$ : Radiación solar proveniente de la bóveda celeste $\left[\mathrm{W} / \mathrm{m}^{2}\right]$.

Recursos: Fenómenos con características geológicas y/o económicas menos ciertas, pero que son consideradas potencialmente recuperables con avances tecnológicos y económicos previstos.

Reservas: Fenómenos identificados y medidos como recuperables económica y técnicamente con los precios y tecnologías actuales.

Resistencia térmica (R): Inversa de la transmitancia térmica $\left[\mathrm{m}^{2} \cdot \mathrm{K} / \mathrm{W}\right]$.

Revolución Industrial: Período de rápido crecimiento industrial con amplias consecuencias sociales y económicas, que comenzó en Inglaterra durante la segunda mitad del Siglo XVIII y se extendió a Europa y a otros países, incluidos los Estados Unidos. La invención de la máquina de vapor impulsó en gran medida este desarrollo. La Revolución Industrial marca el principio de un fuerte aumento en el uso de combustibles fósiles y de las emisiones de dióxido de carbono fósil.

Sequía: Fenómeno que se produce cuando la precipitación ha estado muy por debajo de los niveles normalmente registrados, causando unos serios desequilibrios hidrológicos que afectan de manera adversa a los sistemas terrestres de producción de recursos.

Simulación energética de edificios: Modelización de un edificio y su entorno para analizar su comportamiento energético teórico. La simulación energética tiene en cuenta no sólo la geometría y materiales del edificio, sino también las condiciones climatológicas exteriores, y el uso del edificio (niveles de ocupación y horarios de funcionamiento, cargas interiores debidas al uso previsto, etc).

Sistema de certificación: Herramienta para medir, evaluar y ponderar el nivel de sustentabilidad de un edificio y su entorno, tanto en la fase de diseño como en las fases de ejecución, uso y mantenimiento, y aún después cuando el edificio es demolido; contemplando cuestiones relacionadas con el tratamiento de los desechos de la construcción y el reciclado de materiales. Si bien estos sistemas varían en las herramientas que proponen para el análisis de los edificios y del entorno, todos apuntan a conseguir una reducción en las emisiones de $\mathrm{CO}_{2}$ causadas por los edificios en sus distintas fases, contemplando las particularidades propias de cada una de las principales tipologías de uso existentes (vivienda, oficinas, edificación industrial, centros de salud, escuelas, etc.).

Subvención: Pago directo por un gobierno o una entidad, o una reducción de impuestos a dicha entidad, para la aplicación de una práctica que el gobierno desea fomentar. Las emisiones de gases de efecto invernadero se pueden reducir disminuyendo las subvenciones existentes que tienen como efecto el aumento de las emisiones (por ejemplo, las subvenciones para el uso de combustibles fósiles, o la aportación de subvenciones para prácticas que reducen emisiones (por ejemplo, el aislamiento de edificios o la plantación de árboles).

Sustentabilidad: La sustentabilidad de los sistemas depende de la posibilidad que tienen de abastecerse de recursos y de deshacerse de redes, y de controlar las pérdidas de calidad. En ecología, la sustentabilidad describe cómo los sistemas biológicos se mantienen diversos y productivos con el transcurso del tiempo. Se refiere al equilibrio de una especie con los recursos de su entorno. Por extensión se aplica a la explotación de un recurso por debajo del límite de renovación del mismo.

Tecnología: Una pieza de equipo o técnica para la realización de una actividad concreta. 
Temperatura de diseño: La temperatura del aire exterior definida para el día típico de diseño de la estación correspondiente, que se obtiene estadísticamente sobre la base de un período de diez años y que será superada en severidad en ocho días por año en promedio.

Temperatura de la superficie mundial: Media mundial con ponderación de la temperatura de la superficie marina de los océanos (es decir, la temperatura de la sub-superficie en los primeros metros del océano), y la temperatura del aire en la superficie terrestre a 1,5 m por encima del nivel del suelo.

Temperatura máxima de diseño (TDMAX): La temperatura de diseño obtenida para el verano y elaborada a partir de las temperaturas máximas correspondientes a los meses de diciembre, enero, febrero y marzo, y que será superada en severidad en ocho días por año en promedio $\left[{ }^{\circ} \mathrm{C}\right]$.

Temperatura mínima de diseño (TDMN): La temperatura de diseño obtenida para el invierno y elaborada a partir de las temperaturas mínimas correspondientes a los meses de mayo, junio, julio y agosto, y que será superada en severidad en ocho días por año en promedio $\left[{ }^{\circ} \mathrm{C}\right]$.

Transmitancia térmica (k): Cociente entre el flujo de calor en régimen estacionario y el área y la diferencia de temperatura entre los medios circundantes a cada lado del sistema $\left[\mathrm{W} / \mathrm{m}^{2} \cdot \mathrm{K}\right]$.

Transferencia de tecnología: Amplio conjunto de procesos que abarcan el intercambio de conocimiento, fondos y bienes entre las diferentes partes interesadas que conduce a la difusión de la tecnología para la adaptación o mitigación de un cambio climático. Como concepto genérico, el término se utiliza para englobar tanto la difusión de tecnologías como la cooperación tecnológica entre y dentro de los países.

Unidad de reducción de emisiones (ERU): Igual a 1 tonelada de emisiones de dióxido de carbono reducidas o secuestradas según la decisión de un proyecto de Aplicación conjunta calculado en base al Potencial de calentamiento mundial.

Urbanización: Transformación de la tierra, desde un estado natural o natural gestionado (como la agricultura) en ciudades; proceso impulsado por la migración neta desde zonas rurales a las ciudades por el que un porcentaje cada vez mayor de la población en cualquier nación o región pasa a vivir en asentamientos definidos como centros urbanos.

Variabilidad del clima: La variabilidad del clima se refiere a las variaciones en el estado medio y otros datos estadísticos (como las desviaciones típicas, la ocurrencia de fenómenos extremos, etc.) del clima en todas las escalas temporales y espaciales, más allá de fenómenos meteorológicos determinados. La variabilidad se puede deber a procesos internos naturales dentro del sistema climático (variabilidad interna), o a variaciones en los forzamientos externos antropogénicos (variabilidad externa).

Viento predominante: Dirección del viento de mayor frecuencia.

Yacimiento: Componente del sistema climático que tiene capacidad para almacenar, acumular o emitir una sustancia que es motivo de preocupación (como el carbono, un gas de efecto invernadero, o un precursor). Los océanos, tierras y bosques son ejemplos de yacimientos de carbono. La cantidad absoluta de sustancias preocupantes dentro de un yacimiento en un momento determinado se denomina reserva.

Zona bioambiental: Zona geográfica definida según parámetros meteorológicos referentes a la interacción del hombre, vivienda, clima, a la que corresponden requerimientos higrotérmicos específicos aplicables a los edificios para lograr confort térmico o uso racional de la energía. 


\subsection{Bibliografía}

AENOR. Norma UNE EN ISO 6946. Componentes y elementos para la edificación. Resistencia Térmica y transmitancia térmica. Método de cálculo. Asociación Española de Normalización y Certificación. Madrid, España. 2007.

ALCÁZAR ORTEGA, M. Auditoria Energética. Máster en Tecnología para el Desarrollo Sostenible. Apuntes de clase. Escuela Técnica Superior de Ingenieros Industriales. Universidad Politécnica de Valencia, España. 2011.

ÁLVAREZ BEL, C. Mercados Energéticos. Máster en Tecnología para el Desarrollo Sostenible. Apuntes de clase. Escuela Técnica Superior de Ingenieros Industriales. Universidad Politécnica de Valencia, España. 2011.

AYUNTAMIENTO DE BARCELONA. Agencia Regional de la Energía de Barcelona. Disponible en <http://www.barcelonaenergia.com/>

AYUNTAMIENTO DE MADRID. Agencia Regional de la Energía de Madrid. Disponible en <http://www.madrid.es/portales/munimadrid/es/Inicio/Ayuntamiento/Medio-Ambiente/Educacionambiental/Energia-y-cambio-climatico/Agencia-de-la-Energia-de-Madrid>

FRANCO, J. et Al. Energía Solar II. Apuntes de clase. Maestría en Energías Renovables. Facultad de Ciencias Exactas. Universidad Nacional de Salta. Salta, Argentina. 2009.

GOBIERNO DE ESPAÑA. Ministerio de Fomento. Código Técnico de la Edificación (CTE España). Disponible en <http://www.codigotecnico.org/web/>

GOBIERNO DE LA CIUDAD DE BUENOS AIRES. Código de la Edificación de la Ciudad Autónoma de Buenos Aires. Buenos Aires, Argentina. Disponible en $<h t t p: / / w w w . a g c o n t r o l . g o b . a r / p d f / c o d i g o-e d i f i c a c i o n-C A B A . p d f>$

GROSSI GALLEGOS H. Notas sobre radiación solar. Departamento de Ciencias Básicas. Universidad Nacional de Luján. Buenos Aires, Argentina. 2005. ISBN 9879285190.

GROSSI GALLEGOS, H. et Al. VII Curso de aprovechamiento energético de la radiación solar. Apuntes de clase. Grupo de Estudios de la Radiación Solar (GERSolar). Instituto de Ecología y Desarrollo Sustentable (INEDES). División Física, Departamento de Ciencias Básicas. Universidad Nacional de Luján. Buenos Aires, Argentina. 2010.

HASELBACH, L. The Engineering Guide to LEED - New Construction. Sustainable Construction for Engineers. Editorial MC Graw Hill. Nueva York, Estados Unidos. 2008. ISBN 9780071489935.

HERNÁNDEZ, A. Calefacción solar pasiva. Energía Solar II. Apuntes de clase. Maestría en Energías renovables. Facultad de Ciencias Exactas. Universidad Nacional de Salta. Salta, Argentina. 2010.

INTERGOVERNMENTAL PANEL ON CLIMATE CHANGE. Tercer informe de evaluación del Intergovernmental Panel on Climate Change. Cambio Climático. Ginebra, Suiza, 2001. ISBN 0$52180770-0$.

IRAM. Norma 11.601. Aislamiento térmico de edificios. Métodos de cálculo. Propiedades térmicas de los componentes y elementos de construcción en régimen estacionario. Instituto Argentino de Normalización y Certificación. Buenos Aires, Argentina. 2002.

IRAM. Norma 11.603. Acondicionamiento térmico de edificios. Clasificación bioambiental de la República Argentina. Instituto Argentino de Normalización y Certificación. Buenos Aires, Argentina. 2011. 
IRAM. Norma 11.604. Aislamiento térmico de edificios. Verificación de sus condiciones higrotérmicas. Ahorro de energía en calefacción. Coeficiente volumétrico $G$ de pérdidas de calor. Cálculo y valores límites. Instituto Argentino de Normalización y Certificación. Buenos Aires, Argentina. 2001

IRAM. Norma 11.605. Acondicionamiento térmico de edificios. Condiciones de habitabilidad en edificios. Valores máximos de transmitancia térmica en cerramientos opacos. Instituto Argentino de Normalización y Certificación. Buenos Aires, Argentina. 2002.

IRAM. Norma 11.659-1. Aislamiento térmico de edificios. Verificación de sus condiciones higrotérmicas. Ahorro de energía en refrigeración. Parte 1: Vocabulario, definiciones, tablas y datos para determinar la carga térmica de refrigeración. Instituto Argentino de Normalización y Certificación. Buenos Aires, Argentina. 2004.

IRAM. Norma 11.659-2. Aislamiento térmico de edificios. Verificación de sus condiciones higrotérmicas. Ahorro de energía en refrigeración. Parte 2: Edificios de Viviendas. Instituto Argentino de Normalización y Certificación. Buenos Aires, Argentina. 2007.

IRAM. Norma 11.900. Etiqueta de Eficiencia Energética de Calefacción para Edificios. Clasificación según la transmitancia térmica de la envolvente. Instituto Argentino de Normalización y Certificación. Buenos Aires, Argentina. 2010.

ORGANIZACIÓN DE LAS NACIONES UNIDAS. Protocolo de Kyoto de la Convención Marco de las Naciones Unidas sobre el Cambio Climático. Disponible en: <http://unfccc.int/resource/docs/convkp/kpspan.pdf>

ORGANIZACIÓN DE LAS NACIONES UNIDAS. Declaración de Río sobre el Medio Ambiente y el Desarrollo. Rio de Janeiro, Brasil. 1992. Disponible en: $<h t t p: / / w w w . u n . o r g / s p a n i s h / e s a / s u s t d e v / d o c u m e n t s / d e c l a r a c i o n r i o . h t m>$

LESINO, G. et Al. Energía Solar I. Apuntes de Clase. Maestría en Energías Renovables. Facultad de Ciencias Exactas. Universidad Nacional de Salta. Salta, Argentina. 2009.

MARTIN CHIVELET, N. ; FERNÁNDEZ SOLÁ, I. Integración de la energía solar fotovoltaica en edificios. Editorial Progensa - Promotora general de estudios S.A. Sevilla, España. 2011. ISBN 9788495693686.

SARAVIA, L. et Al. Energética General y Medioambiente. Apuntes de clase. Maestría en Energías Renovables. Facultad de Ciencias Exactas. Universidad Nacional de Salta. Salta, Argentina. 2009.

U.S. DEPARTMENT OF ENERGY. EnergyPLUS. Energy Simulation Software. Energy Efficiency and Renewable Energy. Disponible en <http://apps1.eere.energy.gov/buildings/energyplus/>

U.S. DEPARTMENT OF ENERGY. EnergyPLUS. Energy Simulation Software. Energy Efficiency and Renewable Energy. Disponible en <http://apps1.eere.energy.gov/buildings/energyplus/> 